\title{
INTERNATIONAL GONFERENGE ON EURASIAN ECONOMIES 2020
}




\title{
INTERNATIONAL CONFERENCE ON EURASIAN ECONOMIES 2020
}

\author{
Editors: \\ Selahattin Sarı \\ Alp H. Gencer
}

Copyright (C) 2020

Eurasian Economists Association

\begin{abstract}
ALL RIGHTS RESERVED.
This book contains material protected under International and Federal Copyright Laws and Treaties. Any unauthorized reprint or use of this material is prohibited. No part of this book may be reproduced or transmitted in any form or by any means, electronic or mechanical, including photocopying, recording, or by any information storage and retrieval system without express written permission from the publisher.
\end{abstract}

ISBN: 978-975-6319-55-0

e-ISBN: 978-975-6319-56-7

Beykent University Press Publication Number: 154

Typesetting: Hülya Üzümcü \& Alp H. Gencer

Print: Özlem Printing 


\title{
INTERNATIONAL CONFERENGE ON EURASIAN EGONOMIES 2020
}

\author{
Baku - Azerbaijan \\ Istanbul - Turkey \\ Bishkek - Kyrgyzstan \\ 2-4 September 2020
}




\section{FOREWORD}

We are proud to have completed the $12^{\text {th }}$ International Conference on Eurasian Economies on 2-4 September 2020, in cooperation of Odlar Yurdu University, Beykent University, Kyrgyzstan-Turkey Manas University, Doğuş University and Eurasian Economists Association.

Preparations for the conference typically take 10 months. It was decided in December 2019 that the conference would be held in Baku, and preparations in cooperation with Odlar Yurdu University were started accordingly. However, the Covid-19 pandemic that broke out in February 2020 and the ensuing travel restrictions made it clear that it would not be possible to have a live conference as in past years. Therefore, the organization committee settled on a hybrid live-online model: Three conference centers were established at Odlar Yurdu University, Beykent University, Kyrgyzstan-Turkey Manas University, and authors were given the opportunity to present either live at one of the centers or online, with interactive questions from the participants.

In the end, the conference attracted over 100 live and online attendees, many of whom were rectors, deans and non-presenting authors. Achieving such a broad attendance despite the adverse conditions of the pandemic shows the solid place the conference has established within the academic circles. We would like to express our gratitude to all participants who honored us with their trust and support in the conference organizing committee by participating in the conference.

In total, 115 abstracts were submitted to the conference from 14 countries and 53 universities. The spread of the pandemic, international travel restrictions and the start of quarantines affected the number of papers that could be presented at the conference. In total, 42 papers were selected by the scientific board to be presented at the conference and included in this proceedings book.

A considerable amount of time and effort is put into evaluating and formatting the papers for the book. Each paper undergoes a rigorous three-stage selection process. We would like to thank our reviewers, scientific and organization committee members who contributed their valuable time and support to evaluating every paper. Additionally, we would like to extend our gratitude to Dr. Alp Gencer, who designed our web platform with great patience, despite all the difficulties, and prepared the proceedings for publication, as well as Fatih Akkuş, who built and ran the online backbone of the conference.

We would like to extend our greatest appreciation to the Rector of Beykent University Prof. Dr. Murat Ferman, the Rector of Odlar Yurdu University, Prof. Dr. Ahmet Veliyev and Vice Rector Tarlan Abdullayev, who provided an amplitude of support from the planning stages to the finalization of the conference. As in the past conferences, the Chairman and members of the Board of Trustees of Beykent University did not spare any support. We would also like to thank Beykent University General Coordinator Dr. Murat Süslü, Beykent University Information Technology and Public Relations departments, Odlar Yurdu University Information Technology department and Prof. Dr. Jusup Pirimbaev from Kyrgyzstan-Turkey Manas University, who provided support with great devotion. The family of Prof. Dr. Mükerrem Hiç and Eurasian Economists Association continued their support by awarding best papers presented at the conference.

Finally, our greatest appreciation goes to all the academicians, researchers, and participants whose contributions have made this conference a success. We hope and believe that the International Eurasian Conference 2020 has made important contributions to the Eurasian region and scientific community at large.

We hope to see you at the $13^{\text {th }}$ International Conference on Eurasian Economies.

\section{Prof. Dr. Selahattin Sarı}

Conference Chairs 


\section{ÖNSÖZ}

Onikinci Uluslararas1 Avrasya Ekonomileri Konferans1, Azerbaycan Odlar Yurdu Üniversitesi, Beykent Üniversitesi, Kırgızistan-Türkiye Manas Üniversitesi, Doğuş Üniversitesi ve Avrasya Ekonomistler Derneği'nin ortak organizasyonuyla 2-4 Eylül 2020 tarihlerinde gerçekleştirilmiştir.

Konferans düzenleme çalışması yaklaşık 10 aylık bir süreyi kapsamaktadır. Bakü'de gerçekleştirilmesi planlanan konferas için 2019 yılının Aralık ayında Odlar Yurdu Üniversitesi ile birlikte çalışmalar başlatılmıştır. Ancak 2020 yılının Şubat ayında tüm ülkelerde Covid-19 pandemisinin ortaya çıkması ve beraberinde gelen seyahat kısıtlamaları, yüz-yüze katılımlı konferans düzenlenmesi imkanını ortadan kaldırmış ve 2020 konferansının hibrit olarak online ve küçük guruplar arasında yapılması benimsenmiştir. Odlar Yurdu Üniversitesi, Beykent Üniversitesi, ve Manas Üniversitesi'nde oluşturulan üç konferans merkezinde, bildiri sahiplerinin bu merkezlerden birisine gelerek bildirisini sunma imkanı sağlanmıştır. Böylece guruplar halinde üç merkezde bir biriyle anında bağlantılı olarak canlı ve dinleyicilerin de iştirak etme imkanı sağlanarak konferans gerçekleştirilmiştir.

Konferansa, Türkiye, Azerbaycan, Kırgızistan'dan Rektörler, Rektör Yardımcıları, Dekanlar, konferansta bildirisi olan ve olmayan çok sayıda öğretim üyesi, sektör temsilcileri ve dinleyici iştirak etmiş, konferans 100'ün üzerinde katılımcının iştiraki ile gerçekleşmiştir. Pandemi ortamına rağmen katılımın yüksekliği konferansa olan ilginin büyüklügünü göstermekte ve bilim dünyasındaki yerini ve önemini bir kez daha öne çıkarmaktadır. Konferans düzenleme komitesine olan güven ve desteklerini konferansa iştirakleriyle şereflendiren tüm katılımcılara öncelikle teşekkürlerimizi arz ediyoruz.

Özet gönderim aşamasında 14 ülkeden 53 üniversite ve kurumdan 115 başvuru olmuştur. Pandeminin yaygınlaşması, ülkelerin seyahatleri kısıtlaması, karantinaların başlaması konferansta sunulabilen bildiri sayısını etkilemiş̦tir. Başvurulardan 42 bildirinin konferansta sunulması hakem değerlendirmesine göre uygun bulunmuştur ve elinizde bulunan bu kitapta toplanmıştır.

Gerek bildirilerin değerlendirilmesi aşamasında, gerekse kitap haline getirilmesi aşamasında ciddi emek sarf edilmektedir. Her bildiri üç aşamalı hakem sürecinden geçmektedir. Bu değerlendirmelere zaman ayıran ve destek veren hakemlerimize, bilim kurulu üyelerimize, konferans hazırlıklarının başlamasından itibaren çok yoğun mesai harcayan organizasyon komitesindeki arkadaşlarımıza, web sayfası dizaynında ve uygulamasında sabırla işlemleri yerine getiren Dr. Alp Gencer'e ve konferansın online alt yapısını oluşturup işleten Fatih Akkuş'a teşekkürleri borç biliriz.

Uluslararas1 Avrasya Ekonomileri Konferansı'nın onikincisinin eksiksiz ve mükemmel olarak gerçekleştirilmesinde, planlama aşamasından konferansın sonlandırılmasına kadar her türlü desteği etkin bir şekilde veren Beykent Üniversitesi Rektörü Prof. Dr. Murat Ferman, Odlar Yurdu Üniversitesi Rektörü Prof. Dr. Ahmet Veliyev ve Rektör Yardımcısı Tarlan Abdullayev'e teşekkürlerimizi arz ediyoruz. Bu konferansta da Beykent Üniversitesi Mütevelli Heyet Başkan ve üyeleri, hiçbir desteği esirgememişlerdir. Beykent Üniversitesi Genel Sekreteri Dr. Murat Süslü başta olmak üzere; Bilgi İşlem Daire başkanlığı ile Halkla İlişkiler dairesinin tüm idari birimleri, Odlar Yurdu ve Manas Üniversitelerinin Bilgi İşlem daireleri çok büyük bir özveri ile destek vermişlerdir. Kendilerine sonsuz teşekkürler. Konferansın organizasyonunda birlikte hareket ettiğimiz Prof. Dr. Jusup Primbaev'in şahsında Kırgızistan-Türkiye Manas Üniversitesi'nin temsilcilerine ve bu konferansta da sağladıkları ödül desteği ile konferansı destekleyen Prof. Dr. Mükerrem Hiç ailesi ve Avrasya Ekonomistler Derneği'nin tüm yöneticilerine teşekkürler.

En büyük teşekkürümüz elbette ki konferansın oluşmasını sağlayan ve teşvikleriyle bizleri cesaretlendiren akademisyen, araştırmacı ve katılımcılaradır. Uluslararası Avrasya Ekonomileri Konferansının onikincisinin başta Avrasya ülkeleri olmak üzere bilim dünyasına katkı sağlayacağı inanç ve dileği Organizasyon Heyeti adına teşekkür ve saygılarımızı sunuyoruz.

13. Uluslararası Avrasya Ekonomileri Konferansı'nda buluşmak üzere.

Prof. Dr. Selahattin Sarı

Konferans Organizasyon Komitesi Başkanı 


\section{ADVISORY BOARD}

- Prof. Dr. Ali Murat Ferman (Rector, Beykent University, Turkey)

- Prof. Dr. Ahmed Veliyev (Rector, Odlar Yurdu University, Azerbaijan)

- Prof. Dr. Alparslan Ceylan (Rector, Kyrgyz-Turkish Manas University, Kyrgyzstan)

- Prof. Dr. Turgut Özkan (Rector, Doğuş University, Turkey)

\section{ORGANIZING COMMITTEE}

- Prof. Dr. Selahattin Sarı (Beykent University, Turkey)

- Prof. Dr. Jusup Pirimbaev (Kyrgyz-Turkish Manas University, Kyrgyzstan)

- Prof. Dr. E. Ayşen Hiç Gencer (Beykent University, Turkey)

- Assoc. Prof. Dr. Sitkı Sönmezer (Beykent University, Turkey)

- Prof. Dr. İlyas Sözen (Dokuz Eylül University, Turkey)

- Prof. Dr. Erdoğan Taşkın (Beykent University, Turkey)

- Assoc. Prof. Dr. Ainura Turdalieva (Kyrgyz-Turkish Manas University, Kyrgyzstan)

- Asst. Prof. Dr. Junus Ganiev (Kyrgyz-Turkish Manas University, Kyrgyzstan)

- Dr. Hasan Boztoprak (Beykent University, Turkey)

- Zeynep Emir (Beykent University, Turkey)

- Dr. Qabil Qafarov (Odlar Yurdu University, Azerbaijan)

- Assoc. Prof. Dr. Valiyeva Samira (Odlar Yurdu University, Azerbaijan)

- Ph.D. Candidate Ashraf Hassanov (Odlar Yurdu University, Azerbaijan)

- Ph.D. Candidate Mayil Orucov (Odlar Yurdu University, Azerbaijan)

- Ph.D. Candidate Fidan Askerova (Odlar Yurdu University, Azerbaijan)

- Assoc. Prof. Dr. Ramin İsmayilov (Odlar Yurdu University, Azerbaijan)

- Mr. Vidadi Fatullayev (Odlar Yurdu University, Azerbaijan)

\section{WEB \& PRINT DESIGN}

- Dr. Alp Gencer (Germany)

- Ms. Hülya Üzümcü (Turkey)

- Mr. Alpin Gencer (Germany) 


\section{SCIENTIFIC BOARD}

- Prof. Dr. Tarlan Abdullayev (Odlar Yurdu University, Azerbaijan)

- Prof. Dr. Aziz Alakbarov (Odlar Yurdu University, Azerbaijan)

- Prof. Dr. Neşe Algan (Çukurova University, Turkey)

- Prof. Dr. Ahmet Ay (Selçuk University, Turkey)

- Prof. Dr. Harun Bal (Çukurova University, Turkey)

- Prof. Dr. Mehmet Balcilar (Eastern Mediterranean University, TR of Northern Cyprus)

- Prof. Dr. Viktor Barhatov (Chelyabinsk State University, Russia)

- Prof. Dr. Tansu Barker (Brock University, Canada)

- Prof. Dr. Mustafa Besim (Eastern Mediterranean University, TR of Northern Cyprus)

- Prof. Dr. Ersan Bocutoğlu (Avrasya University, Turkey)

- Prof. Dr. Cihan Çobanoğlu (University of South Florida, United States of America)

- Prof. Dr. Mustafa Kemal Değer (Karadeniz Technical University, Turkey)

- Prof. Dr. Ljubomir Drakulevski (Ss. Cyril and Methodius University, Macedonia)

- Prof. Dr. Hüseyin Avni Egeli (Dokuz Eylül University, Turkey)

- Prof. Dr. Ömer Selçuk Emsen (Atatürk University, Turkey)

- Prof. Dr. Cevat Gerni (Beykent University, Turkey)

- Prof. Dr. Ahmet İncekara (İstanbul University, Turkey)

- Prof. Dr. Mustafa İsmihan (Eastern Mediterranean University, TR of Northern Cyprus)

- Prof. Dr. Danijela Jacimovic (University of Montenegro, Montenegro)

- Prof. Dr. Gani Kaliev (Academy of Agricultural Sciences, Kazakhstan)

- Prof. Dr. Zeynep Karaçor (Selçuk University, Turkey)

- Prof. Dr. S. Ridvan Karluk (Anadolu University, Turkey)

- Prof. Dr. Nuriddin Kayumov (Tajikistan Academy of Sciences, Tajikistan)

- Prof. Dr. Obidjon Khamidov (Tashkent State University of Economics, Uzbekistan)

- Prof. Dr. Merim Koichueva (National Academy of Sciences, Kyrgyzstan)

- Prof. Dr. Recep Kök (Dokuz Eylül University, Turkey)

- Assoc. Prof. Dr. Igor Kokh (Kazan Federal University, Russia)

- Prof. Dr. Makhfirat Kosimova (Tashkent State University of Economics, Uzbekistan)

- Prof. Dr. Turar Koychuev (National Academy of Sciences, Kyrgyzstan)

- Prof. Dr. Nosir Makhmudov (Tashkent State University of Economics, Uzbekistan)

- Prof. Dr. Sherzod Mustafaqulov (Tashkent State University of Economics, Uzbekistan)

- Prof. Dr. Fevzi Okumuş (University of Central Florida, United States of America)

- Prof. Dr. Zekai Özdemir (Istanbul University, Turkey)

- Prof. Dr. Tatiana Pyshkina (Academy of Economic Studies of Moldova (ASEM), Moldova)

- Prof. Dr. Farhad Rahmanov (Azerbaijan State Economy University, Azerbaijan)

- Prof. Dr. Alisher Rasulev (Institute of Economics, Uzbekistan)

- Prof. Dr. Orazaly Sabden (Institute of Economics, Kazakhstan)

- Prof. Dr. Mehmet Sarışık (Sakarya Applied Sciences University, Turkey)

- Prof. Dr. Haldun Soydal (Selçuk University, Turkey)

- Prof. Dr. Euphrasia Susy Suhendra (Gunadarma University, Indonesia)

- Prof. Dr. Ferenec Szavai (Kaposvar University, Hungary)

- Prof. Dr. Erdoğan Taşkın (Beykent University, Turkey)

- Prof. Dr. Muammer Tekeoğlu (Çukurova University, Turkey)

- Prof. Dr. Mustafa Topaloğlu (Özyeğin University, Turkey)

- Prof. Dr. Khodjamahmad Umarov (Tajik National University, Tajikistan)

- Prof. Dr. Bahadir Umurzakov (G.V. Plekhanov Russian University of Economics in Tashkent, Uzbekistan)

- Dr. Munir Valiyev (Odlar Yurdu University, Azerbaijan) 


\section{Contents}

Opening Session

Session Chair: Prof. Dr. Selahattin Sart

\#2467: COVID-19 Recession: The Global Economy in Crisis

- Prof. Dr. Mehmet Balcilar (Eastern Mediterranean University, TR of Northern Cyprus) *

\#2466: Çalışma Hayatına Etkisi Açısından Covid-19 Salgını

- Prof. Dr. Nükhet Hotar (Dokuz Eylül University, Turkey) *

SESSION 1A: Sectoral Analysis

Session Chair: Assoc. Prof. Dr. Sitkı Sönmezer

\#2360: Financial Evaluation of Drug Addiction Rehabilitation Services with Respect to the Health Economics 16

- Asst. Prof. Dr. Osman Altay (Beykent University, Turkey) *

- Ph.D. Candidate Hatice Mutlu (Üsküdar University, Turkey)

\#2465: Determinants of Capital Structure in the Construction Companies across Europe and Central Asia Region

- Asst. Prof. Dr. Hakan Bal (Beykent University, Turkey) *

SESSION 2A: Büyüme

Session Chair: Assoc. Prof. Dr. Volkan Öngel

\#2362: Geçiş Ekonomilerinde Kamu Harcamaları ve Ekonomik Büyüme İlişkisi

- Asst. Prof. Dr. Mustafa Batuhan Tufaner (Beykent University, Turkey) *

\#2370: OECD Ülkelerinde Sağlık Harcamaları-Ekonomik Büyüme İlişkisi

- Asst. Prof. Dr. Mustafa Batuhan Tufaner (Beykent University, Turkey)

- Fatma Dizge (Beykent University, Turkey)

- Zeynep Emir (Beykent University, Turkey) *

\#2367: Akademisyenlerin Bakış Açısıyla Türkiye'nin Orta Gelir Tuzağından Çıkamamasında Verimsiz Kamu Harcamalarının Rolü

- Prof. Dr. Menşure Kolçak (Atatürk University, Turkey)

- Dr. Halil İbrahim Şen (Ministry of Industry and Technology, Turkey) *

\#2428: Stratejik Kaynak Petrol ve Terör İlişkisi

- Prof. Dr. Kamil Uslu (Doğuş University, Turkey) *

SESSION 3A: Mikroekonomi ve Finans

\section{Session Chair: Prof. Dr. Erdoğan Taşkın}

\#2353: Sosyal Medya Tüketici Algıları Demografik Özellikler Bağlamında 70

- Dr. Muhammed Fatih Cevher (Munzur University, Turkey)

- Prof. Dr. Erdoğan Taşkın (Beykent University, Turkey) *

\#2372: Sağlıkta Uluslararası Akreditasyon ve Türkiye'de Sağlıkta Kalite Standartları

- Dr. Seniha Avcil (Memorial Şişli Hospital, Turkey) *

\#2395: Belirsizlik ve Borsalar Arasında Bulaşma Etkileri: S\&P'den BİST100’e .85

- Prof. Dr. Mine Gerni (Marmara University, Turkey)

- Dr. Hatıra Sadeghzadeh Emsen (, Turkey)

- Asst. Prof. Dr. Ziya Çağlar Yurttançıkmaz (Atatürk University, Turkey)

- Prof. Dr. Ömer Selçuk Emsen (Atatürk University, Turkey) * 
\#2427: Euro/Dolar Paritesinin Üst Orta Gelirli Ülkelerin İhracatları Üzerindeki Etkisi: Bir Panel Veri Analizi .93

- Ph.D. Candidate Remzi Can Yilmaz (Beykent University, Turkey)

- Ph.D. Candidate Ferhat Orman (Beykent University, Turkey) *

- Asst. Prof. Dr. Murat Süslü (Beykent University, Turkey)

\section{SESSION 4A: Makroekonomi}

\section{Session Chair: Prof. Dr. Dilek Yllmazcan}

\#2418: Yolsuzluk ve Makroekonomi Üzerindeki Etkileri ..

- Prof. Dr. Dilek Yilmazcan (Maltepe University, Turkey) *

- Hasan Basri Cifci (Maltepe University, Turkey)

\#2393: Askeri Harcamalar ile İcatçıllk ve Teknolojik Mal İhracatı Arasındaki İlişkiler

- Prof. Dr. Cevat Gerni (Beykent University, Turkey)

- Prof. Dr. Selahattin Sarı (Beykent University, Turkey)

- Asst. Prof. Dr. Ziya Çağlar Yurttançıkmaz (Atatürk University, Turkey)

- Prof. Dr. Ömer Selçuk Emsen (Atatürk University, Turkey) *

\#2384: Türkiye ve Azerbaycan Ekonomilerinin Makroekonomik Değişkenler Açısından İncelenmesi

- Assoc. Prof. Dr. Volkan Öngel (Beykent University, Turkey)

- Ph.D. Candidate Hasan Sadık Tatlı (Beykent University, Turkey)

- Ph.D. Candidate Gözde Bozkurt (Beykent University, Turkey) *

\#2379: Teknoloji Transferi ve Ekonomik Büyüme Üzerine Panel Veri Analizi: Avrasya Ekonomileri Örneği ..124

- Ph.D. Candidate Tuğçe Acar (Beykent University, Turkey) *

- Asst. Prof. Dr. İsmail Erkan Çelik (Beykent University, Turkey)

SESSION 5A: Orta Asya Ekonomileri

Session Chair: Assoc. Prof. Dr. Ainura Turdalieva

\#2359: İktisadi Büyüme ve Sefalet Endeksi Arasındaki İlişki: Geçiş Ülkeleri Örneği

- Prof. Dr. Ebru Çağlayan Akay (Marmara University, Turkey)

- Asst. Prof. Dr. Zamira Oskonbaeva (Kyrgyz-Turkish Manas University, Kyrgyzstan) *

\#2380: Avrasya Ekonomik Birliği Ülkelerinde Döviz Kuru ve Diş Rezervler İlişkisi

- Asst. Prof. Dr. Junus Ganiev (Kyrgyz-Turkish Manas University, Kyrgyzstan) *

- Prof. Dr. Jusup Pirimbaev (Kyrgyz-Turkish Manas University, Kyrgyzstan)

- Asst. Prof. Dr. Damira Baigonushova (Kyrgyz-Turkish Manas University, Kyrgyzstan)

\#2365: Bişkek Halkının E-Devlet Hizmetlerine Hazırlık Düzeyleri

- Asst. Prof. Dr. Azamat Maksüdünov (Kyrgyz-Turkish Manas University, Kyrgyzstan) *

\#2382: Kırgızistan'da Yerel Yönetimlerin Vergilendirmedeki Özerkliği

- Asst. Prof. Dr. Dastan Aseinov (Kyrgyz-Turkish Manas University, Kyrgyzstan) *

SESSION 6A: Hukuk

Session Chair: Prof. Dr. Mustafa Topaloğlu

\#2381: Türk Hukukunda ve Uluslararası Antlaşmalarda Hasarın İntikali

- Almıla Özkan (Bilkent University, Turkey) *

- Ayşe Sena Aksakallı (Bilkent University, Turkey)

\#2408: Banka Kredi Yapılandırmalarında Kefilin Durumu

- Prof. Dr. Mustafa Topaloğlu (Özyeğin University, Turkey) *

\#2371: İdari Yaptırımlar, Lehe Kanun Uygulaması ve Yargıya Güven

- Assoc. Prof. Dr. Gürsel Özkan (Turkish State Council, Turkey) * 
SESSION 1B: Management

Session Chair: Prof. Dr. Korkmaz Imanov

\#2453: Formation of Integrated Structures in Industrial Manufacturing Enterprises and their Regional Analysis

- Ph.D. Candidate Tural Suleymanli (Odlar Yurdu University, Azerbaijan) *

\#2458: The Process of Developing an Integrated Model of Catering Services Efficiency

- Ph.D. Candidate İlhama İskandarova (Odlar Yurdu University, Azerbaijan) *

\#2457: Methods of Segmentation and Positioning in the Product Market with Access to a New Foreign Market

- Ph.D. Candidate Rana Mikailova (UNEC- Azerbaijan State University of Economics, Azerbaijan) *

SESSION 2B: Finance

Session Chair: Prof. Dr. E. Ayşen Hiç Gencer

\#2375: Cryptocurrencies, Blockchain Technology and Sustainability

- Dr. Burcu Sakız (Istanbul Aydın University, Turkey) *

- Prof. Dr. E. Ayşen Hiç Gencer (Beykent University, Turkey)

\#2363: Footprint of Inexhaustible Energy Usage and Financial Development on Carbon Outrush of Eurasian

Countries

- Ph.D. Candidate Daberechi Chikezie Ekwueme (Eastern Mediterranean University, TR of Northern Cyprus) *

\#2402: How Do the Volume and Maturity of Debt Relate to Investment Efficiency? The Case of Asia

- Ehsan Poursoleiman (Urmia University, Iran) *

- Dr. Gholamreza Mansourfar (Urmia University, Iran)

- Assoc. Prof. Dr. Sazali Abidin (Lincoln University, New Zealand)

SESSION 3B: Макроэкономика

Session Chair: Prof. Dr. Damira Japarova

\#2366: Медицинский Туризм в Кыргызской Республике: Возможности и Перспективы

- Prof. Dr. Anara Kamalova (Kyrgyz National University, Kyrgyzstan) *

\#2378: Диагностика Финансирования Системы Здравоохранения в Кыргызской Республике и ее

Модернизация

- Prof. Dr. Damira Japarova (Kyrgyz-Turkish Manas University, Kyrgyzstan) *

\#2396: Проблемы Эффективной Трансформации и Перспективы Развития Аграрного Сектора

Кыргызстана в ЕАЭС

- Prof. Dr. Dzhumabek Dzhailov (Ministry of Agriculture, Kyrgyzstan) *

SESSION 4B: экономика развития

Session Chair: Prof. Dr. Jusup Pirimbaev

\#2383: Евразия Экономикалык Биримдигине Мүчө Өлкөлөрдө Тышкы Карыздын Туруктуулугу

- Asst. Prof. Dr. Junus Ganiev (Kyrgyz-Turkish Manas University, Kyrgyzstan)

- Asst. Prof. Dr. Damira Baigonushova (Kyrgyz-Turkish Manas University, Kyrgyzstan) *

\#2397: Потенциал Развития Торгово-Экономического Сотрудничества Кыргызстана в Условиях

Углубления Интеграции

- Asst. Prof. Dr. Asel Dzhailova (State Service for Regulation and Supervision of the Financial Market, Kyrgyzstan) *

- Prof. Dr. Arzybek Kozhoshev (State Service for Regulation and Supervision of the Financial Market,

Kyrgyzstan) 
\#2454: Развитие Торговых Отношений Кыргызской Республики с Турцией

- Assoc. Prof. Dr. Khicheza Fynchina (Kyrgyz-Russian Slavic University, Kyrgyzstan) *

\#2357: Анализ Инновационного Потенциала в Управлении Здравоохранением Азербайджана

- Prof. Dr. Farhad Rahmanov (Azerbaijan State Economy University, Azerbaijan) *

- Assoc. Prof. Dr. Elchin Suleymanov (Baku Engineering University, Azerbaijan)

SESSION 5B: Regional iqtisadiyyatlar

Session Chair: Assoc. Prof. Dr. Ramin Ismayilov

\#2358: Azerbaycan’da Kamu Hizmet Kalitesinin Artırılmasında E-Devlet Innovativ Teknoloji Kullanımının

Geliş̧imi .280

- Prof. Dr. Farhad Rahmanov (Azerbaijan State Economy University, Azerbaijan)

- Assoc. Prof. Dr. Elchin Suleymanov (Baku Engineering University, Azerbaijan) *

- Khayala Ibrahimova (UNEC- Azerbaijan State University of Economics, Azerbaijan)

\#2435: Azerbaycan'ın Uluslararası Ticaret İlişkileri

- Assoc. Prof. Dr. Ramin İsmayilov (Odlar Yurdu University, Azerbaijan) *

\#2451: Müəssisələrin Menecmentində Aparılan İslahatlar Sistemində Marketinqin Effektivliyinin və Səmərəliliyinin Qiymətləndirilməsi

- Ph.D. Candidate Cinara Kocarieva (Odlar Yurdu University, Azerbaijan) *

SESSION 6B: Microeconomics

Session Chair: Prof. Dr. Aziz Alakbarov

\#2445: Problems of Innovative Management Strategies in Manufacturing

- Ph.D. Candidate Elvin Balakishiev (Odlar Yurdu University, Azerbaijan) *

\#2452: Diagnostics of Hotel Business: Features and Specifics

- Ph.D. Candidate Ilkin Gahramanov (Odlar Yurdu University, Azerbaijan) *

\#2456: Determination of Correct Lighting Based on Fuzzy Logic Model to Reduce Electricity in the Workplace

- Ph.D. Candidate Rahib Imamguluyev (Odlar Yurdu University, Azerbaijan) *

\footnotetext{
* Presenting author
} 


\title{
COVID-19 Recession: The Global Economy in Crises
}

\author{
Prof. Dr. Mehmet Balc1lar (Eastern Mediterranean University, TR of Northern Cyprus)
}

\begin{abstract}
In January 2020, the International Monetary Fund (IMF) predicted that the world economy would grow by $3.3 \%$ in 2020. However, in its latest forecasts, in April, it predicts a contraction of 3.0\%, without growth prospects and with numerous risks. The World bank even forecasts a 3.6\% contraction in 2020 . These forecasts are already seen as overestimates. Most baseline forecast envisions the deepest global recession since World War II. This study analyzes various economics impacts of the COVID-19 on a global scale. If the global recession expected due to the effects of the coronavirus (COVID-19) would lead to a decline in growth rate of global gross domestic product (GDP) between $2.0 \%$ and $10 \%$ in all countries in 2020, the number of unemployed people in the net food importer countries would increase between 14.4 million and 80.3 million; the biggest part of the increase would occur in low-income countries. As the pandemic has shown its most severe impact on the largest world economies, the study considers the developments in United States, Euro Area, Japan and China. The recessions in these parts of the world spreads to the other countries and one should primarily consider these regions. Next, we consider the trends in global trades, financial markets, and commodity markets. In association with the four regions of the global economy and trends in global trade, financial markets and commodity markets we consider recent developments in emerging markets.
\end{abstract}

\section{The following is a transcript of the keynote speech given by Prof. Dr. Mehmet Balcular.}

Dear colleagues, organizers and participants, I would like to welcome you to the 12th International Conference on Eurasian Economies. As the keynote speakers, I will be addressing today one of the hottest issues affecting the global economy the COVID-19 recession, or the pandemic recession. Currently, calling the situation, I believe, with a more proper name, would be the COVID-19 recession because there has been another pandemic recession during the Spanish fully at the end of the First World War. Firstly, I will try to draw your attention on the extent of the recession. We do observe frequent recessions in a capitalist economic system. Indeed, about every 4 to 7 years, it is expected to face a session in market economies. But, the COVID-19 recession is quite unique. Not because it is a pandemic recession it is because one of the deepest recessions we have experiencing since World War II.

I am going to be giving you a picture of this recession with its most attention taking features. Also, summarize the lessons we should be drawing from this recession for the future because it is a recession affecting the lives of the whole citizens of the world. My presentation will be concentrating on the economic aspects, but there are other aspects that cannot go unnoticed. The first question is what type of recession we are facing. It is one of the kinds that is called the sudden stop. Actually, this is not a typical sudden stop, it is more radical as it is caused by the COVID-19 pandemic. during the initiation of the pandemic in 1918-1920, the Spanish flue, many countries introduced lockdowns, the lockdown was initiated were first signals of the recession, that supply side effects were actually large during the shutdown. The supply side has been one of the initial reasons for the pandemic recession. Now, we understand that the recession is long here. And, it is a global recession. It is, at the moment, not questionable that we are going to have a global recession, but the question is, how deep it will be. Also, we are currently not sure how long the recession will last.

Recessions usually last for few quarters to, say two to six quarters on average. There has been a longer recession certainly in since in 1870 s which I going to mention later on. There is a lot of ambiguity about the current COVID19 recession, because it may be a long recession. The cumulative loss certainly is going to be quite big, if the recession turns out to be a prolonged one. Currently, United States economy on an annualized basis, has about $32 \%$ negative growth, that means a recession of $32 \%$ annual rate a in between April and June of 2020, that is the second quarter. The United States economy has been actually contracting by about $8 \%$ quarterly. The United Kingdom has been contracting about 20\%. Most of European economies were also contracting, about at $10 \%$ in Germany, a big recession. In the second quarter of 2020, supply, demand, trade and finance are severely disrupted globally. This is one big face of the recession. This is another dominantly supply side or supply shock recession, which is not mainly caused by demand. But demand side also contributed. It is much broader than we understand, it is both disruption of the demand and supply and this is also a one big side of this recession. The recession is hitting all countries globally. It is more sever in countries where the pandemic is actually more severe; those countries who are facing severe pandemic positive cases like the United States, like United Kingdom, Italy, Spain, Spain, and Brazil. The recessions in these countries are different than the others. There is a heavy disruption in global trade, tourism, commodity exports and external financing. And the countries that are heavily relying on these are hit by the recession deeper than the other countries, so, we can understand which countries are going to be the worst during this time, like Italy, Spain, Turkey and Greece are heavily hit because these countries do depend significantly on tourism and external financing. Indeed, there is a long-term implication of this recession.

Usually, in a market economy, when the recession is over the expansion picks up, and expect that the unemployment will decline and we will just put back the recession as history. The COVID-19 recession has 
significant implication for human capital development, because we have suspension of schooling and we have also a big detrition in the primary health care access. The damage to the healthcare system will take a long time to recover. Also, universities are not operating in a regular fashion. Schooling all over the world has been now largely interrupted, which will have long term human capital development implications and the reduction in the growth rates and the healthcare and economic consequences of the pandemic is going to be worse in the medium term for countries where there is widespread informality, what I mean by this is the informal economy where most of the activities are not actually formal or recorded. One of those countries is Turkey with an estimate about informal economy something about from 20 to $30 \%$. Why this is important, because the government cannot extend help or financing to informal sectors, because it is on records, as those people are put unemployed in the informal sector, they are not helped because they are not on the records. As they are not officially employed, they do not receive any benefits. So, in those countries like Turkey, where informal sector is big, actually, the effect is bigger than we understand. Indeed, at least 20 to $30 \%$ of those people who are initially became unemployed are the informal ones, because the government has been placing restrictions on firing. Therefore, most of the companies could not fire anybody because of the ban on firing, but those who are working informally became unemployment from the first day ahead. This trend will continue, not only in Turkey. Most of the emerging markets and the developing economies (EMDEs) has big informal sectors. One reason that the recession looks lighter in countries like Turkey is because these countries do have a large informal sector like. For instance, India, alike China, might have an economy with 20 to $30 \%$ of GDP generated by informal sectors.

The advanced economies are anticipated to contract about 7\% in 2020. Emerging markets and developing economies are expected to shrink by about $2.5 \%$. This is a big change because as a group, emerging market and developing economies did not contract in the last sixty years. That is, for six decades there was not negative or zero growth in emerging and developing countries as a group. First time in 60 years, these economies are going to be hit by a $2.5 \%$ contraction in the GDP adding this the informal sector shut downs makes the contraction even higher. That is, actually net contraction is something around $3.5 \%$ to $4 \%$ by the inclusion of informal sectors in these economies. Per capita income all over the world in 2020, given the lift of restrictions mobility and ending the lockdowns, is estimated to shrink about 3.6\% to 5\%. I am going to take the smaller figures to be optimistic. When the things turn out to be worse than what we expect, we can look into the worst-case scenarios. With a $3.6 \%$ contraction in the per capita income, millions of people will be put into extreme poverty conditions.

Because of the already high poverty rates in the low-income countries, millions of people will be experiencing extreme poverty. Millions of people will be living with an income of less than $\$ 1$ a day, which is the definition of extreme poverty by the United Nations. Let me consider, first, what has happened to per capita GDP and GDP worldwide. In my presentation, I am going to be going back to $1870 \mathrm{~s}$. So, we will be considering recessions in the last 150 years, seeing what has happened during this whole period in terms of depth and length of recessions. If you look at the right-hand side of Figure 1, which plots the index of per capita global GDP taking 1870 as 100 . And, the left-hand side is the index of global GDP taking 1870 as 100.

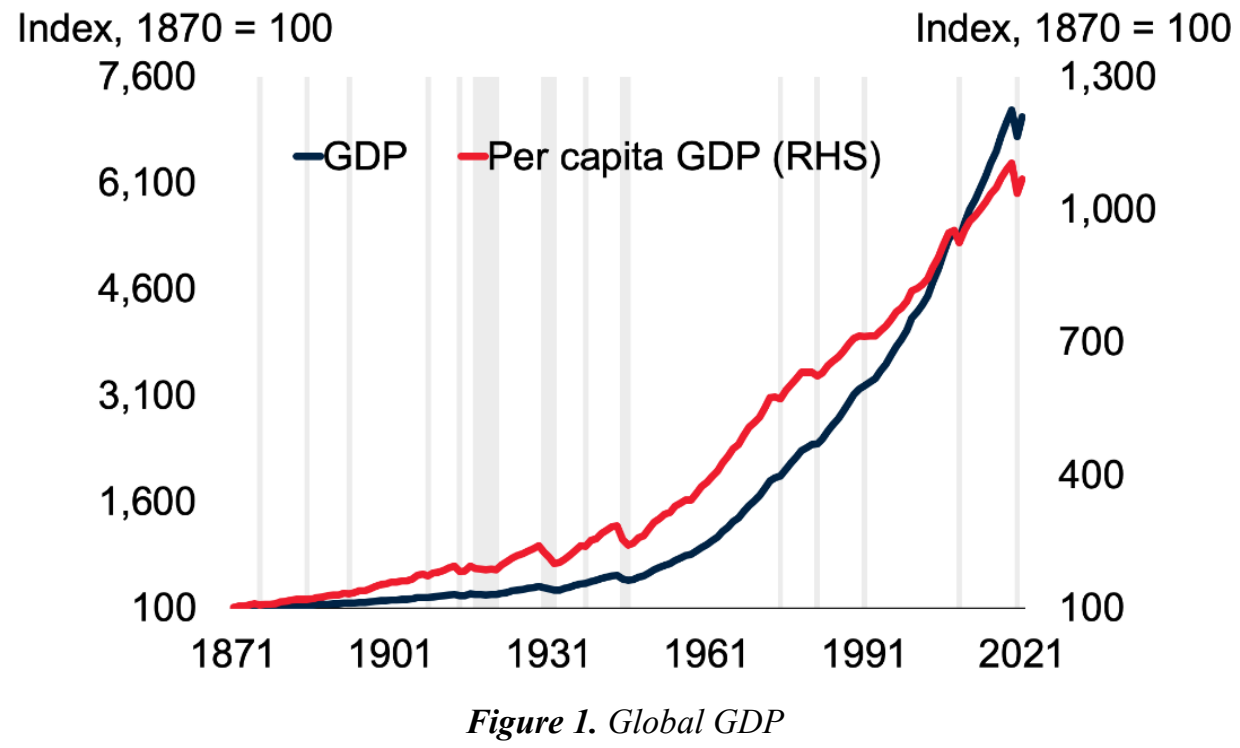

Since 1870, we have experienced a big welfare increase, and the global GDP increased from 100 to 7600 while the global per capita GDP increased from 100 to 1300. If we follow the per capita GDP line in here, or the GDP line, we will see that the COVID-19 recession created one of the largest crashes in both GDP and per capita GDP. It also looks like the recovery from this one might take long time. We have a similar recession, the Great Crash of 1930 and then the World War II, which may help to explain the case today. The recovery from the Great Crash actually, if you look at the trend line, took about 10 years or so. The World War II, on the other hand, to be restored 
back to the original trend path took about 10 years or so. We are, at the moment, not very sure when the full recovery from the COVID-19 recession will happen, because it is too early to make a judgement or make forecast on the numbers. But, the full recovery from the pandemic recession and restoring the pre pandemic trend growth may take anything from 3 to years to 10 years.

Let us look at GDP growth rates since 1870 in Figure 2. Looking 150 years back, we see that the first deepest recession is the one called the long recession, which was initiated in the United States but it was a global recession. The gray regions in this figure are the ones that were global recessions, by global I mean, it is not only the advanced economies, but also a large number of countries were affected from the recession. So, since 1870, if you count, we had 13 global recession and the COVID-19 is the 14th one. On average, our long experience about the global recession is that they come about every 10 years, but some of them are quite mild, something around zero to minus $1 \%$ GDP growth. A few of them are big, and these are the First World War, and then the first pandemic recession following that, which is the Spanish flu, then we have the Great Crash, then the Second World War, a global recession with the largest negative growth in the history. Next, we have the subprime crisis in 2007-2008. The last is the COVID-19 recession. We are hoping in 2021, the recovery from the recession will start, most estimates are so. My estimate is that, we are going to have about 3\% GDP growth in 2021 . Hopefully, this will be the reality. So, in any case, we are living the second largest global recession since the World War II, the one in subprime crisis was even milder than this one. Our estimate is about in this one is about something like $6 \%$, negative growth in 2020. Then recovery is started to pick up in 2021.

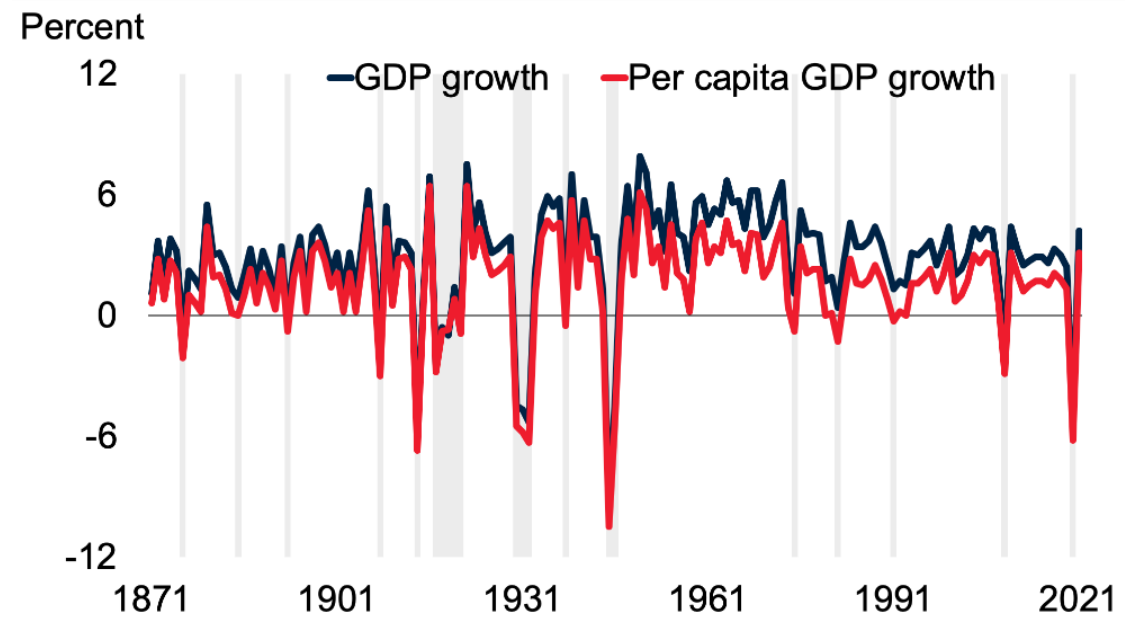

Figure 2. Global GDP Growth

Now, let me consider the growth rates in global recession periods and let us see what is expected with the COVID-19 recession compared those hundred in the last 150 years of global recessions. Considering the biggest ones with more than $3 \%$ cumulative GDP contraction, if you see the first one, we had about minus $6.7 \%$, negative growth. Then, right after the First World War, this is the actually Spanish Flu period, the Spanish fully flu starts in 1918 and goes up 1920. There were already some recessionary signals before the Spanish Flu, but the Spanish Flu is mixed with the 1917 recession and ended up with 4.4\% decline. So, we can call this one, the first pandemic recession and the second one is the 2020 COVID-19 recession. Adding up the cumulative declines over the recession period, the Great Crash ended up with cumulative 17.6\% decline the global GDP. The Second World War follows with minus $15.4 \%$ cumulative change in GDP. If you look at the Great Recession, following the subprime financial crisis, it is depth was about half of what we are experiencing now. The minus $6.2 \%$ GDP decline is the most optimistic estimate for 2020. It may be something around this minus $6.2 \%$. It may go up to minus $9 \%$. We are not yet through the pandemic yet. We will go to the third and the fourth quarter of 2020 with a recessionary state. So, if you compare this one, which now even the young economists in our session already know, with the history of the Great Recession of 2007-2009 with 2.9\% decline. This figure is about half of what we are experiencing now. In the Great Recession period with $2.9 \%$ negative growth, the emerging and developing economies had a positive growth. This time, it is more extensive than the Great Recession, as the emerging and developing economies as group will have a negative GDP growth. 


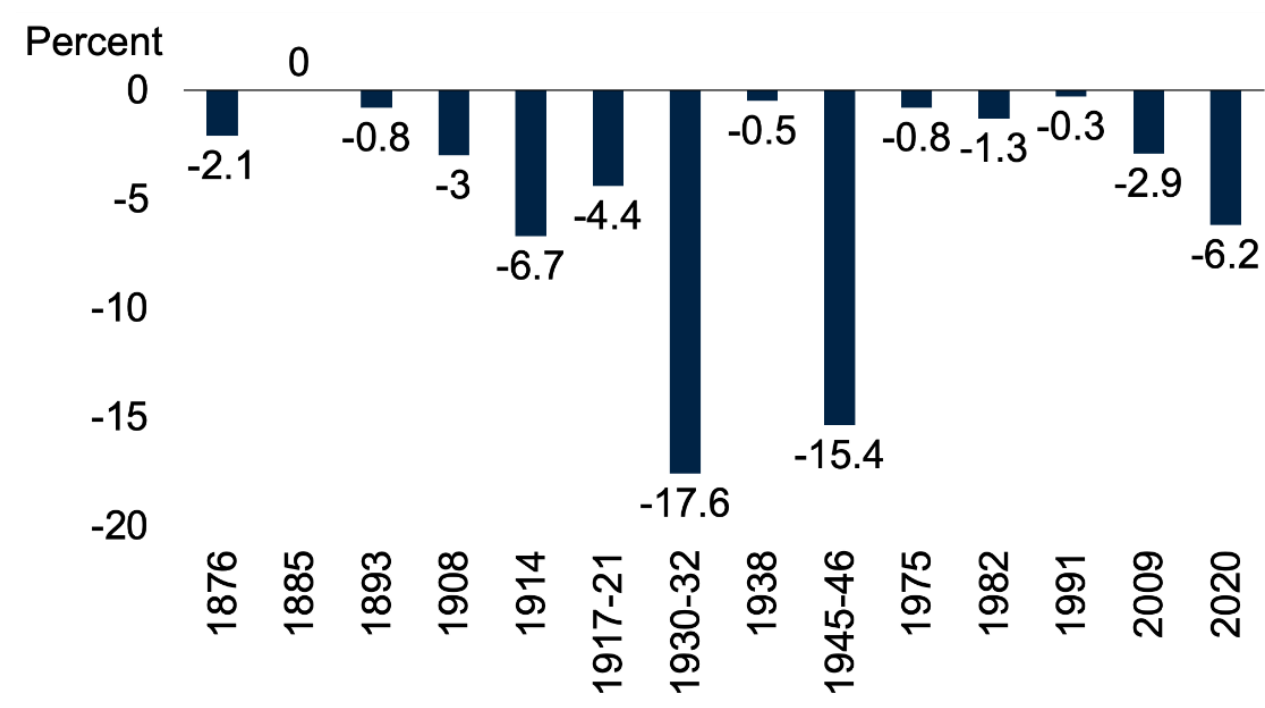

Figure 3. Cumulative Global GDP Decline during Global Recessions

As the figures show, we are living in a very deep recession period now. We have to see that the extent of this recession is much beyond what we initially anticipated.

Another important aspect recession that I am going to look at is how global is the recession. Let us count the number of countries in the world, I mean, affected by the global recessions and recessions of the history, and calculate the percentage of countries that are affected by the recession. This percentage is given in Figure 4. So, this is a measure of how global the recession is. Let us start from the first pandemic recession that was a global, as it was a pandemic and quite global, and the First World War. These ones affected about $70 \%$ of the whole economies, the Great Crash effect about $80 \%$ of the world economies. The Great recession of 2007-2009, only had an about $60 \%$ of the world economies affected. Now, the COVID-19 recession is affecting $90 \%$ of the world economies. So, extent of the COVID-19 recession is the biggest in the last century and a half. In the last 150 years, we did not have such an extensive recession in the world. This means much larger proportion of the world population will be affected from this recession. Almost no country is free of the COVID-19 recession. It looks like all countries are going to feel the influence of the recession, covering almost the whole world population.

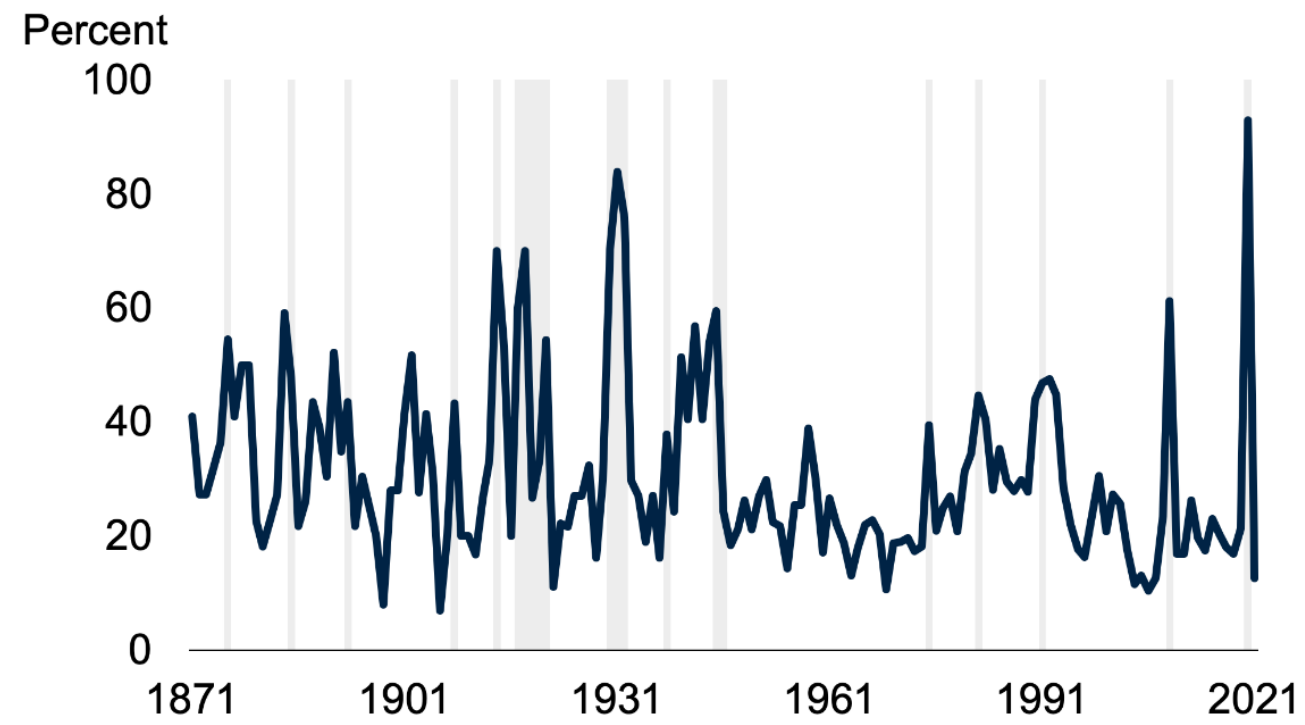

Figure 4. Number of Economies in Recession (\%)

Our universe 7.8 billion people and $90 \%$ of the economies such a large number of people living in are affected from the recession. It is not difficult to imagine how many of people and families will be suffering from this recession. It is the most extensive recession of the last 150 year in terms of the coverage of the world economies.

Let me also illustrate the deepness of the COVID-19 recession in comparison to recent history. How deep is the COVID-19 recession in comparison to other recessions since 1970 is illustrated in Figure 5. The figure uses an index of GDP taking a value of 100 in period t-1 for a recession that started in period t. In the figure two earlier recessions we consider are the recession of 1975, which was caused by oil shock and the 1982 recession, which was partly due to oil price hike, but it was also initiated by the Iranian Revolution. However, the 1982 recession 
was indeed a monetary recession. Most of the central banks in the world were afraid of inflationary pressures, and they were actually pressing the pedal on the money supply. This caused a deep recession in most of the advanced economies and many of the emerging markets are affected. Next, I will put the 1991 recession on the figure. I will compare the GDP index of last two deep recessions as lines in the figure. The gray area represents the region covered by the minimum and maximum of the 1975, 1982 and 1991. And the blue line represents the GDP index during the Great Recession following the subprime crisis period. This recession was actually globally felt in 2009 . That is why I call this one as 2009 recession. And, the red line represents GDP index of the COVID-19 recession. So, the $\mathrm{t}$ is the recession year, that means it is 2020 for the COVID-19 recession and 2009 for the Great Recession.

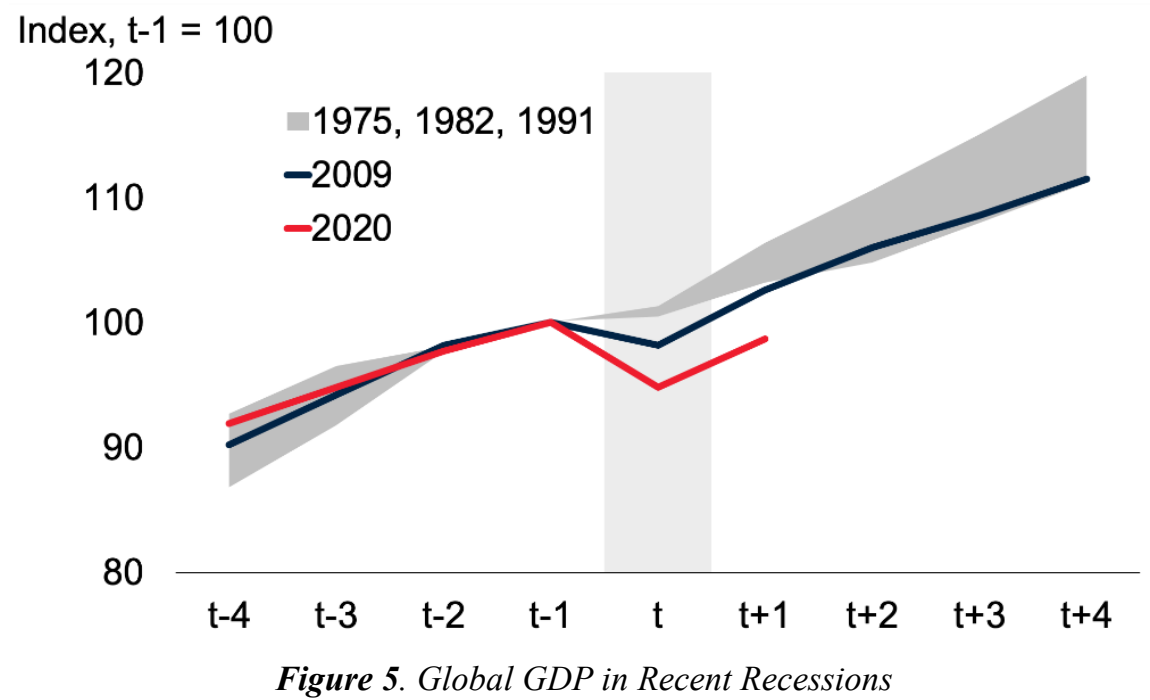

We will consider a period covering four years before and four years before around the recession year $t$. For instance, for the 2020 COVID-19 recession, a period from 2016-four years before the recession start year-to 2024-four years after the recession start year will give us a sense of how deep the recession that we are living at the moment, and also how long the recovery will take. So now let's look at the numbers. Since I cannot compare the numerical values, I am going to use the GDP index that takes a value of 100 in year $\mathrm{t}-1$. So, all the recession GDP indexes are equal at time $\mathrm{t}-1$. So, if the index is 90 in a period, that is a $10 \%$ decline in the GDP compared to the year before the recession. At the moment, for the COVID-19 recession, the index in around 94, meaning a $6 \%$ negative growth in the COVID-19 recession. Let us look at the path of the line and see how it compares with the great recession of 2009. This will help us to judge how long it will take to recover from recession as deep as you this one. Currently, given the path of the line the recovery to the level before the recession is going to take something around 10 years or so. So, it will be $t$ a deep and long recession. We should understand that we are living the deepest recession since 1970. If you consider the global economy, we are hit by the most extensive and the deepest recession of the last 50 years.

Per capita GDP figures are more important than the GDP as it will adjust the GDP for the population. It is also extensively used as a measure of personal welfare then the GDP. The per capita figures are also more relevant to part of the world population that will be affected by the recession. The global per capita GDP path in comparison to recessions after 1970 is given in Figure 6. Again, the figure show the recession is the deepest of the recessions of the last 50 years. We also note that the recovery will probably be faster for the per capita GDP than the GDP level itself because we are expecting the emerging and developing countries, which are more dynamic in terms of their economies and young population, will probably recover faster. And those advanced economies, which were already experiencing slow growth in the last decade, are likely to recover later than the emerging markets and developing economies. 


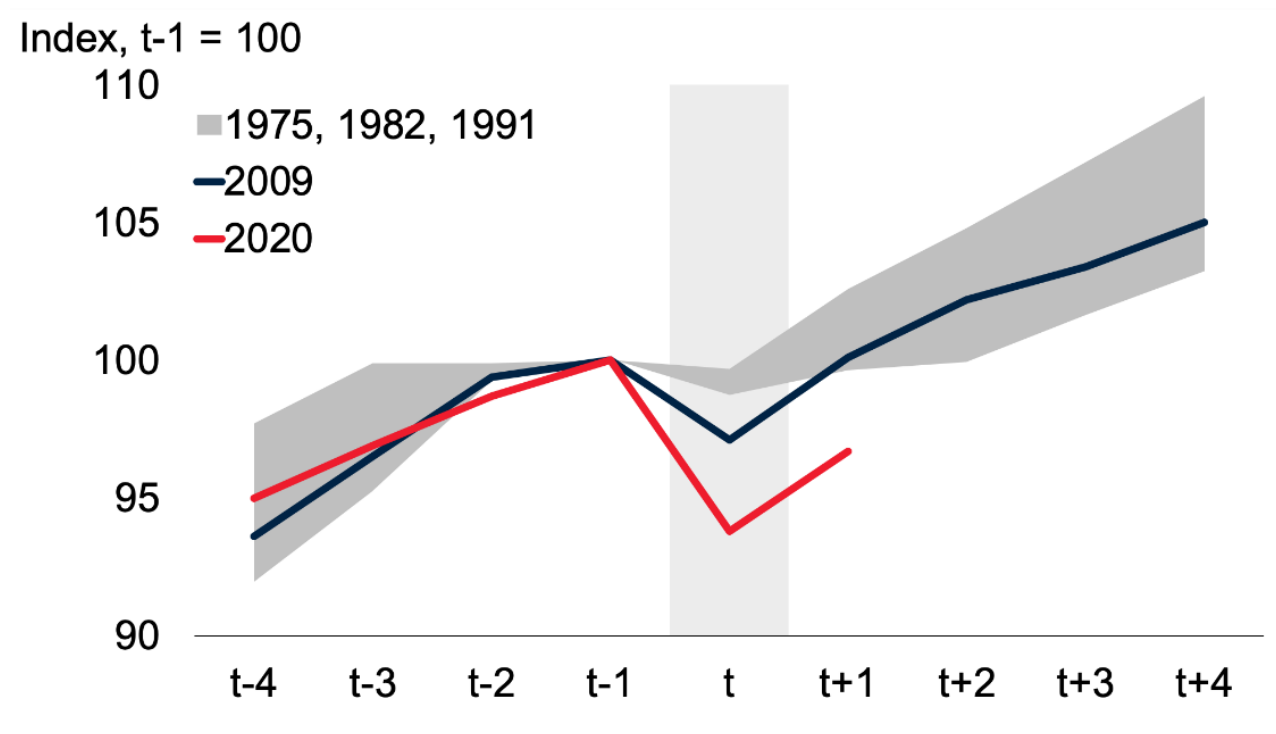

Figure 6. Per capita Global GDP in Recent Recessions

This point is well illustrated by the consensus forecast of GDP growth for the period February 2020-June 2020 given in Figure 7.

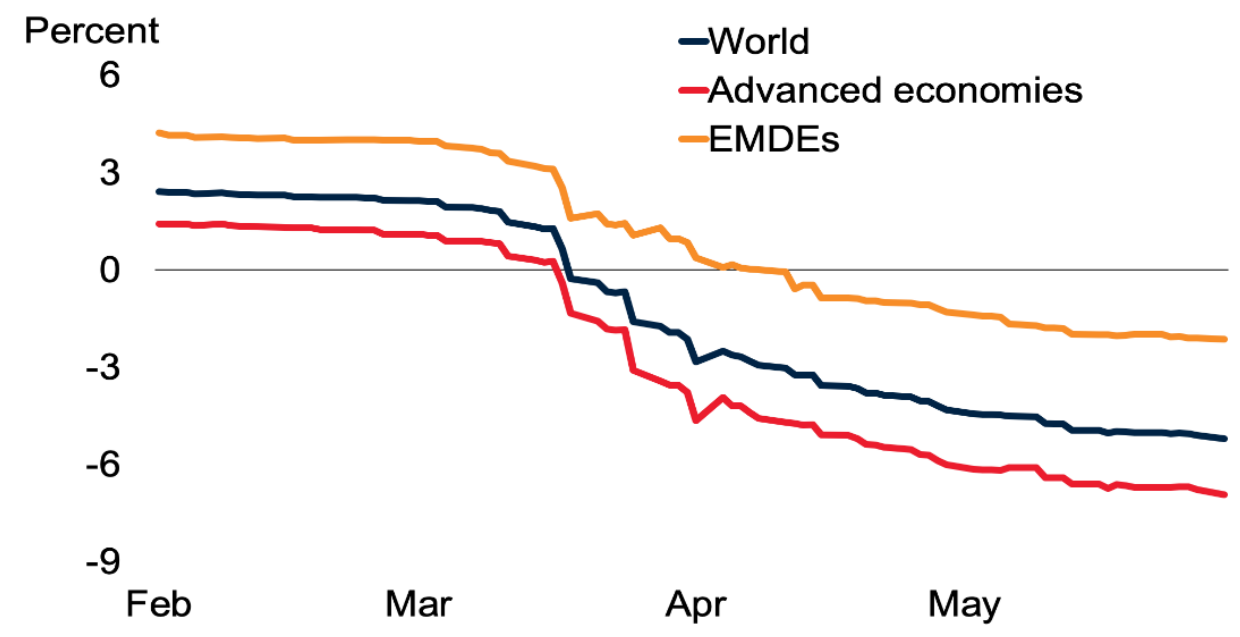

Figure 7. Consensus Forecasts of GDP Growth for February-June 2020

Let us know look at the e initiation of this recession. Let us go back and consider the GDP growth rates in Figures 2 and 5. As we see from this figure, the GDP growth rates suddenly makes a sharp decline in the second quarter of 2020. So, the recession initially came as a supply shock. The recession started initially as a sudden stop of the production because of lockdowns and restrictions on trade and shipments of goods across the countries. This sudden stop-initiated supply shock arose mainly because of lockdowns, as there was interruption in the supply chain and the world trade. There was also interruption in financial flows. Most countries who are dependent on external financing experienced actually a difficulty to finance their debt and imports.

Now let us look at the retail sales, which gives us an idea about the demand. Figure 8 presents the retail sales index during the major global recessions since 1970. The demand did not initially contract much because consumers were not sure on how long and how extensive the COVID-19 pandemic would be. However, the retail sales made a sharp decline in the second quarter of 2020, a large negative demand shock. So, the weak demand is likely to continue because the pandemic progressed fast and affected most of the world. A lot of uncertainties remain about the evolution of the COVID-19, so, the demand may stay quite weak even until the second quarter of 2021. Thus, the COVID-19 recession has unique feature, as initial negative supply shock further reinforced by the demand shock that followed it. 


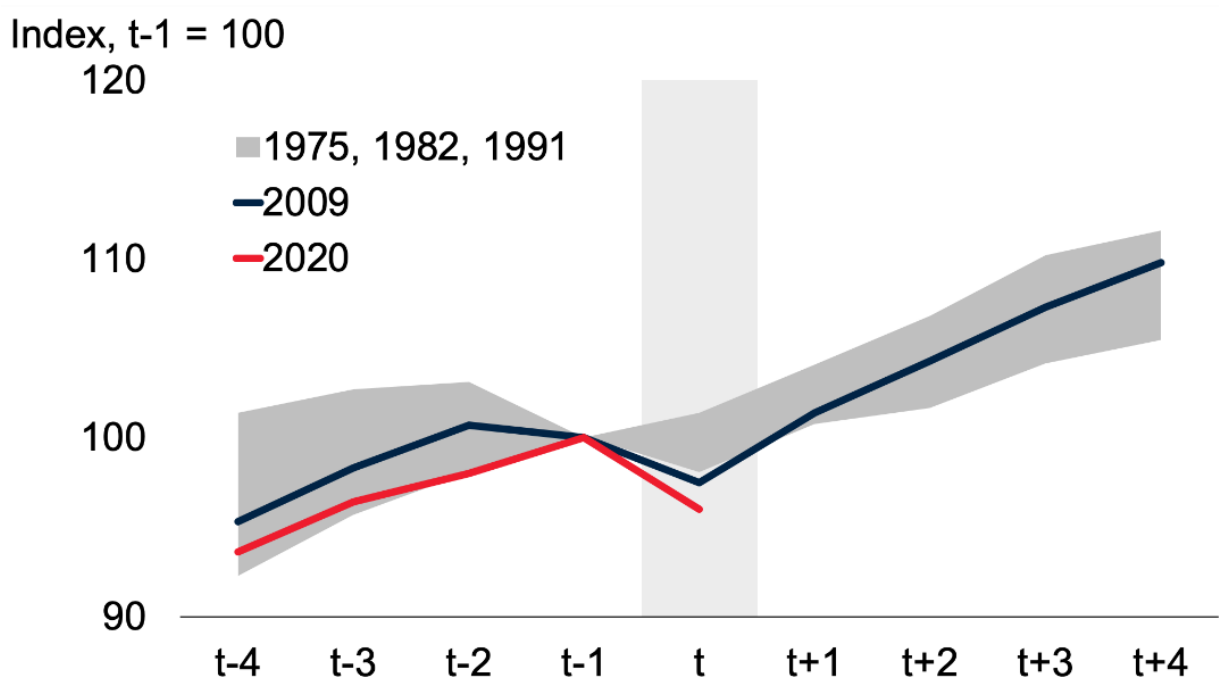

Figure 8. Global Retail Sales Index in Recessions

A question yet remains to answer: Why is the COVID-19 pandemic recession so different than the others? First and foremost, the recession was initiated by a supply shock, because of the lockdowns, interruptions in the supply chain and the trade flows. Second, high unemployment leaded to significant declines in personal income which triggered a demand shock. But, is all we can say? can economists say anything else other than supply and demand shock? Do we know what are the root causes of the weak demand and supply shocks? We tend to link everything to supply and demand. Do we have a better story to explain the causes of the weak demand? I will quote an important statement from Keynes: "Many candid persons, when confronted with the results of Probability, feel a strong sense of the uncertainty of the logical basis upon which it seems to rest." (Keynes J. M. 1921, A Treatise on Probability. London: MacMillan).

This is something about the core causes of many events in economics. So, he links behavior of economic actors to the relevant key "probabilities", which inherently contain uncertainty. I am one of the researchers who have been giving a lot place to uncertainty in many of my papers, I probably have more than 50 work somehow related to uncertainty, all published in the last 10 years. I believe most of the core causes in economics is linked to uncertainty. There are three core decision makers and three core decisions in economics: (1) Firms make decisions to maximize profits, thus, firms make decisions on whole future path of profits not only today. So, the whole future flows of revenue and cost are relevant, when firms are making a decision on maximizing profits. (2) Consumers make decisions on maximizing utility. But, they consider the whole future lifetime utility, not only today's utility. For instance, when a consumer considers a decision on buying a house or placing some money into his saving account, she does not consider only the next year, but she considers her whole lifetime, maybe even beyond lifetime. So, the whole future flows of income and consumption are relevant in consumer decisions. We should approach the many decisions we study in economics from this perspective lifetime perspective. We should look into how firms and consumers make decisions in real world, not how textbook consumers and firms make decision. Consumers and firms make decisions by considering the whole future relevant to them. But, future is unknown and characterized by uncertainty. Uncertainty radically affects all decisions. In the face of the COVID-19 recession, in order answer the questions such as why investment is cut so badly, why consumers are so reluctant to spend, and why consumers do panic buying, we need to consider the most relevant characteristics of future, which is uncertainty. The future of the COVID-19 pandemic is so uncertain that firms and consumers are pushed into a state of waiting, cutting all spending. Thus, the root cause of the recession being so deep is the uncertainty that has been introduced by the COVID-19 pandemic. In order to bring some evidence on my case I present the world index of uncertainty in Figure 9. 


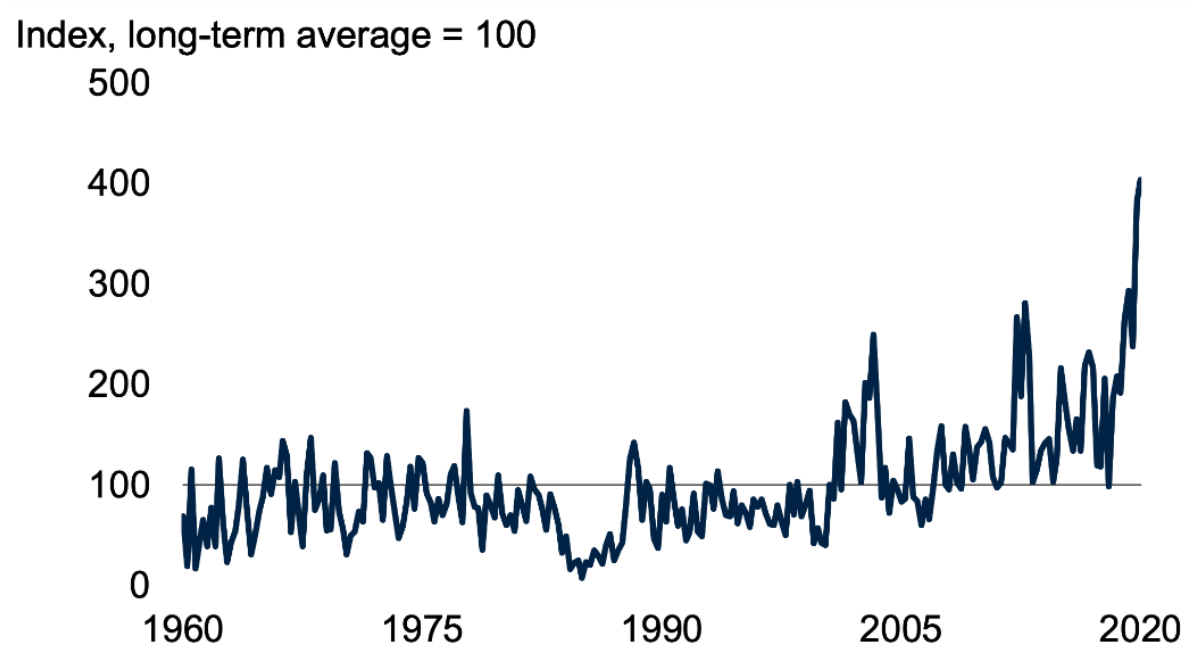

Figure 9. Global Index of Uncertainty

The index is normalized such that the long-run average id 100. The average uncertainty 100 is exceeded significantly during 2003, 2012, and 2020, with peak values 250,280 , and 403 , respectively. Thus, the global uncertainty index is now during this pandemic is four times larger than the long-run average, and it is about 1.5 times larger than the 2012 peak, which is the second largest peak. This figure shows so radically that we are in an era of the greatest uncertainty of the last 70 years. It is this uncertainty that characterizes the COVID-19 uncertainty. 


\title{
Covid-19 and its Effects on Work Life Çalışma Hayatına Etkisi Açısından Covid-19 Salgını
}

\author{
Prof. Dr. Nükhet Hotar (Dokuz Eylül University, Turkey)
}

\begin{abstract}
Covid-19 which emerged in Wuhan province of China, evolved into a global pandemic within a short time has had social and economic effects besides its influence on public health. Research has shown that during the pandemic, besides health sector, manufacturing, tourism and education sectors have been affected adversely. In addition to its sectoral repercussions, the changes it has caused on working life should also be taken into consideration. In parallel with the practices in many other countries, our country has taken measures in order to slow down the spread of the virus and the to minimize the number of employees in the same working place such as distance working and rotated working in public and private sectors and etc. Due to physical isolation requirements during the pandemic period, individuals have got to know new practices and concepts such as virtual shopping, distance education and have tried to adapt themselves to them. Individuals who actively take part in working life have also been encountered with concepts such as distance working and rotated working. All foundation and enterprises have strived for taking the measures of hygiene stipulated by the public authority while trying to ensure the adaptation process takes place with efficiency and without loss of workforce. In both public and private sectors, online meetings, conferences and activities etc. and non-spatial life style and working system have become a part of individuals' lives. This study is aimed at coming up with a future projection by handling the effects of COVID-19 pandemic has caused on working life.
\end{abstract}

\section{Giriș}

Modern dünyanın kaderi, insanlığın sebep olduğu savaş ve felaketler kadar teknolojik buluşlar, yenilikçi yaklaşımlar ve ölümcül salgınların ortaya çıkmasına da bağlanmıştır. Mesafelerin ortadan kalktığı ve uluslararası ilişkilerin küreselleşme kavramı ile şekillendiği günümüz toplumlarında; son derece basit gözüken ancak sonuçları itibariyle insan hayatını doğrudan tehdit eden salgın hastalıklar ve doğal afetler, sosyal ve iktisadi hayatın dinamiklerini etkilemeye başlamıştır. Bu gerçeklik, devletleri ve kamu iradesini çözüm odaklı arayışlara iterken; birey ve toplum hayatının hemen her alanında bir takım düzenlemeleri zorunlu kılmıştır.

Çin'in Wuhan kentinde 2019 yılında başladığı değerlendirilen ve Dünya Sağlık Örgütü (DSÖ) tarafindan pandemi olarak tanımlanan COVID-19 da bu bağlamda beraberinde getirdiği olumsuzluklarıyla birlikte yeni normalin alt eşiğini oluşturmuştur. Ülkelerin sosyal güvenlik sistemini, çalışma hayatını, ithalat ve ihracata dayalı global ekonomilerini derinden sarsan bu virüs, çalışma hayatına ilişkin zorunlu düzenlemelerin de ortaya çıkmasına sebep olmuştur.

İnsanlık, tarihsel süreç içinde birçok salgınla mücadele etmiş; geleceğe ilişkin planlarını yeniden yapmak zorunda kalmıştır. Ortaçağ'da veba salgınlarıyla ortaya çıkan ağır tablo, sosyal, siyasal ve ekonomik açıdan Avrupa'yı etkilemiş; dönemin hiyerarşik yapısı içinde sınıfsal farklılıkların önemsizleşmesi ve enfeksiyonun sadece doğaüstü bir lanetten ibaret olmadığı sonucunu ortaya çıkarmıştır. Bu durum bir anlamda mutlakiyetçi anlayışın güç kaybetmesine de sebep olmuştur. Günümüzde ise çevre ve iklim değişikliği gibi insan hayatını doğrudan ilgilendiren konular, afet ve salgınlarla birlikte medeniyetleri tehdit eder hala gelmiştir. Covid-19 salgını ise bilinenlerin de ötesine geçerek modern tıp uygulamaları ile pratiklerinin getirdiği çözümlerine rağmen coğrafi sınırları hızlı şekilde aşmış ve dünyayı derinden sarsan bir gerçeğe dönüşmüştür.

Sosyal politikalar açısından bakıldığında ise pandemi ile birlikte sosyal güvenlik çatısı altında tanımlanan birçok hizmet ve faaliyet üzerinde ciddi bir yük oluşmuş; hasta ve hasta yakınlarına yönelik kamu hizmetleri kimi ülkelerde yetersiz kalmıştır. Çalışma hayatıyla yakından ilgili olan bu durum, toplumsal ihtiyaç ve sorunlara çözüm bulunması noktasında tıkanmaların yaşanmasını sebep olmuştur. Pandemiye bağlı zorunlu nedenlerle iş gücü piyasasında yaşanan daralma, özellikle özel sektörde ücretli çalışanların maaş kaygısını tetiklemiş; yatırımcıları endişelendirmiş; demografik olarak dezavantajlı grupta bulunanları çaresizliğe itmiştir. Birçok ülkede yaşanan bu tablo, günümüz medeniyetinin ihya ettiği sosyal ilişkiler ve işbirlikleri alanındaki çözülmenin aslında doğal faktörlerle çok hızlı olabileceğini göstermiştir. Bunun yanı sıra çalışma hayatında işsizliğin bertaraf edilmesi, emek sermaye ilişkisinin hakkaniyetli şekilde kurgulanması, emekli-çalışan arasındaki sosyal dengenin güçlendirilmesi, beklenti olmaktan çıkarak ivedi bir hedefe dönüşmüştür.

Salgının kendini göstermeye başladığı günden itibaren Türkiye, devletin aldığı tedbirler ve toplumsal dayanışmaya dayalı yapısı itibariyle sorunları çözme mücadelesini kararlılıkla sürdürmüştür. Sosyal politikalar konusunda son yıllarda birçok önemli aşamayı başarıyla geçen Türkiye'nin afetler karşısında risk ve tehditlere karşı hazırlıklı olması; özellikle sağlık hizmetleri konusundaki uluslararası nitelikteki altyapısı, sürecin kontrollü geçmesini sağlamıştır. Burada, sosyal adalet mekanizmasının geliştirilmesine yönelik fikir ve eylemlerin Türkiye'nin geleceğinde barış ve huzur ikliminin tesis edilmesi amacı güttüğünü söylemek mümkündür. 
Dolayısıyla bu yaklaşımın salgının getirdiği zorunlulukları, zihinsel noktada bir ölçüde bertaraf ettiği değerlendirmesinde bulunulabilir.

\section{Covid-19 Salgını ve Türkiye}

Türkiye Cumhuriyeti Sağlık Bakanı Dr. Fahrettin Koca'nın Türkiye'de ilk Covid-19 vakasının 10 Mart 2020 tarihinde yurtdışından dönen bir vatandaşta görüldüğ̈̈n̈̈ açıklamasıyla birlikte2, salgın kavramı resmi olarak telaffuz edilmiştir. Bu açıklamadan sonra, 12 Mart 2020'de, Türkiye Cumhuriyeti Cumhurbaşkanı Recep Tayyip Erdoğan başkanlığında toplanan Cumhurbaşkanlığı Kabinesi ve devletin üst düzey bürokratları, durum değerlendirmesi yaparak; Türkiye'nin salgınla mücadeledeki ilk adımlarını kararlaştırmıştır. Bu toplantı, kamu iradesinin konuya yönelik refleksinin ne kadar hızlı olduğunu ortaya çıkarması açısından önem taşımaktadır. Düzenlenen bu toplantının ardından Cumhurbaşkanı Erdoğan'ın talimatıyla bir takım önlemlerin alındığını vurgulayan Cumhurbaşkanlığı Sözcüsü İbrahim Kalın, temel ve yükseköğretime bir süre ara verildiğini; spor müsabakalarının seyircisiz oynanacağını; kamu görevlilerinin yurtdışına izinle çıkabileceğini açıklamıştır. $3 \mathrm{Bu}$ kapsamda Milli Eğitim Bakanlığı da ülke çapında temel eğitim düzeyinde faaliyet gösteren kurumların bir haftalığına kapatıldığını; eğitim faaliyetlerinin uzaktan eğitim metoduyla devam edileceğini belirtmiştir.

Salgınla mücadele dönemini başlatan bu kararlar, aslında devletin virüs ile teması engelleyecek ve bulaş riskini azaltacak ivedi önlemleri, öncelikle çocuk ve gençler için aldığının net göstergesi olmuştur. Zihinsel ve bedensel olarak gelişim çağında olan ve toplumun geleceğini inşa edecek bireylerin korunmaya alınması, devlet erkinin ana gayesini göstermesi açısından son derece anlamlıdır. Birey ve toplum sağlığına ilişkin beklenti, ilk etapta iktisadi hayata yönelik taleplerin önüne geçmiştir.

Sağlık Bakanlığı bünyesinde oluşturulan Koronavirüs Bilim Kurulu’nun (KBK) salgının yayılmasının önlenmesine ilişkin tavsiyesi doğrultusunda; Cumhurbaşkanı Erdoğan'ın talimatıyla Cumhurbaşkanlığı İdari İşler Başkanlığı Personel ve Prensipler Genel Müdürlüğü, 13 Mart 2020 tarihli bir yazı yayınlayarak idari izine tabi olan kamu çalışanlarına ilişkin bir düzenleme getirmiştir. Sürecin ivedi şekilde kontrol altına alınmasını içeren bu yazı ile öncelikle yurtdışında bulunan kamu görevlilerinin yurda dönüş itibariyle 14 gün boyunca evde tecrit oldukları; sürenin mesai günlerine tekabül eden kısımlarında idari izinli sayılmaları kararlaştırılmıştır. Hemen akabinde ise hamilelerin, yasal süt izni kullananların, engelli çalışanların, yönetici pozisyonlarındakiler hariç 60 yaş ve üzerinde olanlar ile Sağlık Bakanlığı'nın belirlediği dezavantajlı grupların 16 Mart 2020 tarihinden itibaren on iki gün idari izinli sayılmaları kararlaştırılmıştır.

Yine asgari seviyede personel bulundurulması kaydıyla kamu kurum ve kuruluşlarının başta okul öncesi ve ilköğretimde çocuğu bulunan kadın çalışanların yıllık izin taleplerinin karşılanması, yıllık izin hakkı bulunmayanlar için mazeret izinlerinin kullandırılması Cumhurbaşkanlığı tarafından uygun görülmüştür. Buradaki karar, virüs karşısında hassas, kritik ya da özel durumu bulunan personelin izinli sayılmasına yönelik çıkartılmış olsa da; risklerin bulaş yoluyla kamu kurumlarına yayılmasının önlenmesi ve risk grubunda bulunanların can güvenliğinin temin edilmesi de hedeflenmiştir.

Bu noktada; kadın çalışanlara kolaylık sağlanması, yukarıda özetle bahsedilen önceliğin tamamlanması ve anneçocuk bağının kopmasını engellemeye yönelik olduğu aşikârdır. Dolayısıyla devletin küçük çocuğu olan çalışan annelerden beklentisini, sorumlu olduğu iş ve işlemlerden ziyade salgın süresince ebeveynlik vazifesini kaygı duymadan yerine getirmesine yönelik olduğu şekliyle değerlendirilebilir. Benzer şekilde; engelli ve ileri yaş grubundaki vatandaşların bu bağlamda korumaya alınması; üretim ve hizmet esaslı bir talebin kamusal öncelik olmadığı yönünde düşünülebilir.

Hastalığın yayılımını önlemek amacıyla KBK'nın tavsiyesi doğrultusunda ulusal ve uluslararası organizasyonların; her türlü bilimsel, kültürel, sanatsal ve benzeri toplantıların bir süre ertelendiğine ilişkin Cumhurbaşkanlığı Genelgesinin (2020/3) Resmi Gazete'nin 20 Mart 2020 tarih ve 31074 sayısında yayınlanması ile yeni bir süreç başlatılmıştır. Aynı gün Sağlık Bakanlığı Sağlık Hizmetleri Genel Müdürlüğü tarafından yayınlanan kararda;

"Sağlık kurumlarına müracaat eden hastaların, COVID-19 tanısı kesinleşinceye kadar Sağlık Bakanlığı hastaneleri, Devlet ve Vakıf Üniversitesi hastaneleri ile tüm özel sağlık kuruluşlarınca kabul ve tedavi süreçlerinin yapılması zorunludur. Bünyesinde Enfeksiyon Hastalıkları ve Klinik Mikrobiyoloji, Göğüs hastalıkları, İç Hastalıkları uzmanı hekimlerden en az ikisinin bulunduğu ve 3. seviye erişkin yoğun bakım yatağı bulunan hastaneler Pandemi Hastanesi olarak” kabul edildiği açıklanmıştır.

Bakanlığın bu tedbiri hayata geçirmesindeki amaç, hasta ve hasta yakınlarının mağdur olmasının engellenmesi; sağlık kuruluşlarındaki yoğunluk ile sağlık personelinin üzerindeki yükün azaltılması olmuştur. Kamu ve vakıf üniversitelerine bağlı hastanelerin de bu sürece dahil edilmesi, olası vaka artış hızına bağlı olarak sağlıkta seferberlik hali olarak düşünülebilir. 


\section{Kamuya Özel Düzenlemeler}

Resmi Gazete'de 22 Mart 2020 tarihi ve 31076 (Mükerrer) sayılı Cumhurbaşkanlığı Genelgesi’nin (2020/4) yayınlanmasıyla birlikte ise kamu çalışma hayatında bir takım düzenlemelere gidilmiştir. COVID-19 Kapsamında Kamu Çalışanlarına Yönelik İlave Tedbirler5 konulu genelge uyarınca; “...salgınla mücadeleyi ve salgının etkilerinin azaltılmasına yönelik faaliyetleri zafiyete uğratmayacak ve kamu hizmetlerini aksatmayacak şekilde, ihtiyacı karşılayacak kadar asgari sayıda personelin bulundurulması şartıyla çalıştırılma biçimine bakılmaksızın kamu kurum ve kuruluşlarında çalışanlara uzaktan çalışma, dönüşümlü çalışma gibi esnek çalışma yöntemleri uygulanabilir” hükmü getirilmiştir.

Genelge uyarınca “dönüşümlü çalışanlar fiilen göreve gelmedikleri süre zarfında idari izin sayılır. Bu genelge kapsamında esnek çalışma yöntemlerinden faydalanan çalışanlar ile idari izinli sayılanlar bu sürede istihdamlarına esas görevlerini fiilen yerine getirmiş sayılırlar. Uzaktan veya dönüşümlü çalışanlar ile görev yerinde çalışanlar hizmetin yürütülmesi sorumluluğu açısından eşittir. Uzaktan veya dönüşümlü çalışanlar ile idari izinli sayılanların mali ve sosyal hak ve yardımları ile diğer özlük hakları saklıdır” denilmiştir.

Türk kamu yönetiminde süreklilik, esasa itibardır. Buradaki amaç, vatandaşın kamu hizmetlerinden istifadesinin aksatılmadan sürdürülmesinin sağlanması; bu şekliyle ortaya çıkacak olumsuz tablonun önlenmesidir. Salgının boyutu dikkate alındığında; ulusal düzeyde bir hareket planının oluşturulması ve ilk etapta çalışma hayatına ilişkin düzenlemelere gidilmesi, son derece stratejik bir yaklaşımdır.

Kamu kurum ve kuruluşlarında 2020 yılının ilk çeyreğinde- yani salgının başladığı dönem itibariyle- kadrolu personel, sözleşmeli personel, sürekli işçi ve geçici işçi statüsünde toplam 4 milyon 6996 bin kişinin istihdam edildiği düşünüldüğünde alınan ilk kararın ne kadar hayati önem taşıdığı da ortaya çıkmaktadır.

$\mathrm{Bu}$ genelgenin salgınla mücadele olgusunun dışında çalışma hayatına ilişkin getirdiği temelde üç husus bulunmaktadır. Bunlardan birincisi yöntem bazında bir takım değişiklik ve düzenlemelerdir. Kamudaki iş ve işlemlerin aksamadan sürdürülmesi, Türk devlet bürokrasisinde çalışma saatleri ve çalışma yeri ile ilgili kesin ve kati kurallara tabi olmasını gerektirmektedir. Ancak salgının başlaması ve ortaya çıkan olağanüstü şartlar, burada bir takım kuralların esnetilmesini zorunlu kılmıştır. Burada; uzaktan, dönüşümlü ya da esnek çalışma olarak adlandırılan metodlar ön plana çıkmıştır.

Kamu otoritesinin buradaki gayesi, bürokrasiye dayalı yapının çalışma prensiplerine uygun olarak; sürecin sağlıklı işleyebileceği bir formül bulmak olmuştur. Burada dikkat edilmesi gereken diğer bir husus, salgın boyunca sadece işin yapılması değil; aynı zamanda personelin korunmasına yönelik sürecin şekillendirilmesidir. Bu salgın, Türk kamu yönetimde bazı değişiklikleri; çalışma usul ve esasları bağlamında yeni yaklaşımların oluşabileceği öngörüsünü gündeme getirmiştir. Burada ortaya çıkan olgu, teknolojik altyapının dahil olduğu süreçlerin çalışma hayatına ilişkin düzenlemelerde kendini göstermesidir ki; ‘yerinde bulunma zorunluluğu’ ilk defa kamu sektöründe fiziki mekanın kısmen ortadan kalkabileceğine işaret etmektedir. Bu yaklaşım, ilgili idarenin pratik veya mecburi uygulamalarının ötesinde kamu çalışma hayatına yeni bir perspektif getireceğinin işareti olarak yorumlanabilir.

Genelgenin getirdiği diğer bir nokta ise çalışanların bir takım kaygıları önlemeye yönelik olmuştur. Buradaki amaç, çalışanın moral ve motivasyonunun bozmadan çalışmalarını uzaktan da olsa yürütmesi ve bu süre zarfında idari izinli sayılmasıdır. Yine, kamuda idari izine ilişkin gerekçeler açık ve net şekilde tarif edilmiş olup; bugüne kadar salgınla ilgili doğrudan ve bu ölçüde bir kapsamı içermemiştir. Genelge, uygulamaya ilişkin aşamaları merkezi ve taşra teşkilatının ilgili yapılarına bırakmış olsa da; idari izin konusunda herhangi bir esnekliğe izin verilmediği görülmüştür. Bu durum, Anayasa'da ve ilgili mevzuatta güvence altına alınan mali ve sosyal haklar açısından da büyük önem taşımaktadır.

Son olarak bu genelge, uzaktan çalışma yöntemi ile görev yerinde çalışanlar arasında hizmetin yürütülmesi noktasında sorumluluğu eşit olarak vermiştir.

Kamu sektörünün bu kadar hızlı bir biçimde kararlar alması, özellikle uzaktan çalışma gibi daha önceden denenmemiş yöntemlere başvurması ve bunu başarılı bir biçimde yürütülebilmiş olması, özel sektöre de örnek olmuş, özel sektörün, özellikle beyaz yakalı olarak tabir edilen çalışma kolunun da hızla bu önlemleri almasına katkı sağlamıştır.

Kamu sektörünün dışında; özel sektör de alınan önlem ve tedbirlere uygun olarak işletmeleri ve işyerlerinde de bir takım düzenlemelere gitmiştir. Cumhurbaşkanlığı'nın talimatlarına uygun olarak Hazine ve Maliye Bakanlığı, Ticaret Bakanlığı, Aile, Çalışma ve Sosyal Hizmetler Bakanlığı'nın aldığı kararlar, salgının çalışma hayatında olası etkilerini azaltmayı hedeflemiştir. Burada Kısa Çalışma Ödeneğinin süresinin uzatılmasından İş Kanunu'na eklenen geçici maddeyle her türlü iş veya hizmet sözleşmesinin 3 ay süreyle feshedilemeyeceği kuralının getirilmesi, özellikle çalışanlar açısından bir koruma kalkanı oluşturmuştur.

Sokağa çıkma yasağı ile birlikte, ülke genelinde, bölgesel ve belli lokasyonlarda sosyal izolasyon kurallarının başlatılması, özellikle küçük işletmeler, KOBİ statüsünde bulunan firmalar, esnaf ve zanaatkarlar üzerinde ödeme ve borç baskısını gündeme getirmiştir. Hizmet ve perakende sektörünü doğrudan etkileyen bu durum karşısında devletin aldığı kararlar, öncelikle işletmelerin mevcut durumlarını korumaya yönelik olmasını hedeflemişstir. 
Böylece firmaların vergi borçlarının ertelemeye başlandığı bir süreç yaşanmış; covid-19 salgını nedeniyle zarar gören esnaf sanatkârlara düşük faizli borç kullandırılması piyasanın pozitif anlamda regüle edilmesini sağlamıştır.

Kısıtlamalar ve sokağa çıkma yasağının başlamasıyla birlikte; özel sektörde üretimin yavaşlamaması adına dönüşümlü çalışma uygulamasına geçilmiş; fabrikaların kapasiteleri revize edilmiştir. Zaruri şartlara ve daralan piyasalara rağmen, döviz kuruna yönelik talep kontrol altına alınmaya çalışılıışıtır. İleri yaş grubunda yer alan çalışanlar; emekli halde olup çalışmak zorunda kalanlar için sokağa çıkma yasağı, sosyal hizmetler bağlamında diğer bir konu başlığını teşkil etmiştir. Devletin buradaki formülü ise yerel yönetimler aracıllğ̆ıla doğrudan vatandaşa yönelik destekleyici çalışmalar olmuştur.

Türkiye genelinde vaka sayılarındaki azalışa bağlı olarak 4 Mayıs 2020'de7 bir açıklama yapan Cumhurbaşkanı Erdoğan'ın normalleşme sürecine kademeli olarak geçileceğini vurgulaması, salgınla mücadelenin kontrollü şekilde devam edeceğinin göstergesi olmuştur. Nitekim, hazırlanan planın ardından 1 Haziran 2020 itibariyle 'Yeni Normal' olarak adlandırılan döneme geçilmiş; şehir giriş çıkışlarına koyulan kısıtlamalar kaldırılmış; sosyal izolasyon uygulamasına son verilmiş; kapalı olan esnaf ve AVM'lerin belli şartlar dâhilinde açılmasına izin verilmiştir.

'Yeni normalin' çalı̧̧ma hayatına getirdiği bir diğer konu ise, Sağlık Bakanlığı tarafından hazırlanan Hayat Eve Sığar (HES) uygulaması olmuştur. Kamu binaları başta olmak üzere toplu kullanım alanlarında HES kodu zorunluluğu getiren bu uygulama, salgının yayılmasını engellemek ve bulaş riskini düşürmek olmuştur. Yine ‘maske, mesafe ve hijyen' konusunda kamuoyu algısının geliştirilmesine yönelik çalışmalar yürütülmüştür.

\section{Salgının Çalışma Hayatına Etkisi}

Covid-19 salgınının ortaya çıkardığı riskler, Amerika Birleşik Devletleri (ABD), Çin Halk Cumhuriyeti, Almanya ve Avrupa Birliği (AB) ülkeleri gibi küreselleşmiş ekonomiler için de çıkış yolu bulunması gereken bir sağllk tehditi olmuştur. Burada söz konusu olan sadece ülke ekonomilerinin orta ve uzun vadeli yatırım planların bozulmasının değil; salgının toplumsal çıkmazlara veya kaosa sürükleyecek sonuçların engellenmesidir. Burada iş gücü piyasalarındaki dengenin gözetilmesi; teşvik ve desteklerin sürdürülerek uzlaşı ortamının sağlanması; sağlık hizmetlerinden eşit ve adil şekilde yararlanması ön plana çıkmaktadır.

ABD'de 2008-2009 yllında kendini gösteren Mortage krizi, o dönemde küresel bir felakete dönüşerek piyasaların resesyona girme tehlikesine sebebiyet verse de, kaynağı itibariyle kontrol edilebilme gerçeğini saklı tutmuştur. Dönemin ABD hükümetinin bankalara yönelik aldığı tedbirler, konut kredisi satışlarında yaşanan sıkıntıyı bir nebze hafifletmiş; Türkiye'nin de dahil olduğu bir çok ülke, bu alanda bir takım düzenlemeleri gerçekleştirmiştir. Covid-19 salgını ise zaten hassas olan uluslararası piyasaların, aynı anda ve birkaç ay içinde dengesini bozmuştur. Dolayısıyla Covid krizini ne Mortage ne de 1929'daki Büyük Buhran ile kıyaslamak doğru olmayacaktır. Bu salgının gündelik ve basit stratejiler üretilerek üstesinden gelinebilecek bir sorun olarak algilanmamalidır.

Sonuçta bu salgınla mücadeledeki beklentiler, sadece arz-talep dengesine ya da finans kaynaklarına bağlı bir denge arayışı değildir. Burada; salt üretim kabiliyetinin yüksek olması ve çalışma hayatına ilişkin veriler bir anlam ifade etmeyecektir çünkü salgınla gelen değişkenlerin sayısı oldukça fazladır. Bu nedenle iş gücü piyasası, ihracat ve ithalat dengesi ya da pazar gücü açısından durum, kendi içinde birkaç ülkenin belirleyeceği bir gerçeklik olmaktan çıkmıştır. Bunun temel sebebi ise iktisadi hayata ilişkin bütün gerçekliğin özünde insan hayatıyla bağlantılı olmasıdır.

Sosyal politikaların belirlenmesinde çağdaş devlet için sorumluluk ilkesi, vatandaşının refah ve mutluluğunun temin edilmesiyle başlar. Dolayısıyla sosyal adaletin ve barışın sağlanması, gelir dağılımının dengelenmesi, istihdam kayıplarının engellenmesi ve benzeri kavramlar, salgınla mücadelede yeniden ele alınması gereken konular olarak karşımıza çıkmaktadır. Gelişmişlik düzeyi ne olursa olsun; salgın sorunsalını basit ve kısa vadeli çözümlerle geçiştirmek sonuç vermeyecektir. Buradaki temel neden, sektörlerden bağımsız olarak, insan gücü ve bilgisine dayalı iktisadi bütün faaliyetlerin kesintiye uğramasıdır. Endüstri 4.0 ve geleceğinin tartışıldığı günümüz dünyasında, geleneksel yaklaşımların yeni gerçekliğe dönüşümünü sağlamak zaman alacaktır ki; bunun için iyimser ve öngörülebilir süre belki de 10 yıldır.

Covid-19'un teşhis, tanı ve tedavisine yönelik; belki de başka enfeksiyon hastalıkların önlenmesine ilişsin çözümlerin bulunamayışı, çalışma hayatı için de bir takım bilinmezlikleri gündeme getirmektedir. Dolayısıyla insanın yer aldığı bütün iş ve işlemlerde, sadece ölçek ekonomisinin kurallarına göre süreç işletilemeyecektir. Bu durum, bütün dünya ülkeleri için geçerlidir. Kaldı ki, insandan bağımsız ama teknolojiye bağımlı bütün süreçler de, salgının etkilerine açıktır. Çünkü, nihai ürün ve hizmetin kullanımı, fayda esasına dayanır. Burada faydayı elde etme imkanı bulamayan bir sosyal yapıda, teknolojinin avantajlarından söz edilemez. Örneğin emeklilik sistemini, sanayide devrimlerin olması; nesnelerin internetinin kullanılması; kuantum mekaniğine yönelik teknolojileri tasarlanması gibi gelişmeler temel düzeyde desteklemeyecektir. 
Dolayısıyla sosyal, kültürel ve iktisadi alanda yaşanan şok etkisini, birey ve toplum hayatını olumlu yönde absorbe edecek bir finans kaynağı olmadığından; sosyal politikalarda ulusal, bölgesel ve yerel formüllerin bulunmas1 gerekecektir.

Türkiye, salgınla mücadele kapsamında iki önemli noktaya dikkat etmiştir. Bunlardan birincisi daha önce özetle anlatılan kararların alınması ve uygulanmasıdır. Buradaki hareket noktası genel itibariyle birey ve toplum sağlı̆̆ını korunmasının öncelenmesi olmuştur. İkinci nokta ise ekonominin sürdürülebilir bir eksende kalmasının sağlanmasıdır ki; çalışma hayatına ilişkin bütün düzenlemeler, ulusal düzeyde oluşturulan teşvik ya da telafi mekanizmaları burada kendine yer bulmuştur. Ortada zorlayıcı bir sebep olduğundan devletin en üst düzeyde gösterdiği kararlılık; motivasyon zemininin oluşturulması açısından dikkat çekicidir. Mevzuat değişikliğine gitmenin sorunlara çözüm olamayacağını bilen Türkiye'de, "Yeni Dengeleme-Yeni Normal-Yeni Ekonomi" başlıklı Yeni Ekonomi Paketi'nin açıklanmasının sebebini de bu bağlamda değerlendirmek gerekir. Yine ekonomide yılın üçüncü çeyreğinden itibaren toparlanma olacağına ve büyüme oranlarının pozitife döneceğine ilişkin işaretleri, işgücü piyasasının morali yükseltilmesi açısından düşünmek yerinde olacaktır.

Türkiye'nin salgınla mücadelede odak noktasına üretim ve yatırım kavramlarını koymasının; toplumsal uzlaşının hedefine ise birliktelik duygusunu yerleştirmesinin asıl sebepleri de bunlardır. Cumhurbaşkanlığ tarafından başlatılan 'Biz bize yeteriz Türkiyem' kampanyası, aslında bu gerçekliğe bir vurgudur.

\subsection{Kurum Kültürünün Yeniden İnşası}

Küresel Covid-19'un süre gelen bir takım alışkanlıkları, alınan önlemlerle birlikte değişime zorlayacağı ortadır. Türkiye'de kamuya açık alanlarda, hastanelerde, sağlık kuruluşlarında, temel ve yükseköğretim faaliyetleri gösteren kurumlarda gerekli planlamalar yapılmış; tedbirler hayata geçirilmiştir. Kamu çalışanlarının özlük hakları korunarak, çalışma yöntemleri değiştirilmiştir. Özel sektörde faaliyet gösteren firma ve işletmeler de, ilgili mevzuata uygun önlemleri hayata geçirmiş; başta Oda, Borsa ve Birlikler ile meslek örgütleri bu konuda yönlendirici olmuştur. Virüs bulaş riskini düşürecek bu uygulamalar, çalışma hayatının kontrollü şekilde sürdürülmesine; çalışanların sağlığının korunmasına yöneliktir. Salgının firmalar ve işletmeler üzerinde uzun vadeli etkilerine ilişkin bir öngörüde bulunmak gerekirse; öncelikle kurum kültürünün oluşturulması ve tanımlanmasında bazı değişikliklerin olacağı ortadadır. Bugüne kadar farklı pratiklere ve gerekçelere dayanmış olsa da her kurum, hedef ve beklentileri doğrultusunda yönetimsel kabiliyetlerine, maddi imkanlarına ve mevcut çalışanlarının profiline uygun bir kültür geliştirmiştir.

Burada söz konusu olan sadece kendisine bağl1 rasyonel gerçeklikler değil; bulunduğu veya iş yaptığı sektörün dinamikleri belirleyici olmuştur. Halbuki bu salgın, iş akış planlamasından üretim metodlarına kadar birçok noktada değişikliği zorunlu kılmaktadır. Mesai saati düzenlemesinden çalışma ortamının salgın şartlarına uygun hale getirilmesine; üretim araçlarından hammadde temini süreçlerine kadar birçok konuda firmalar, yapacakları düzenlemeleri risk faktörünü dikkate alarak gerçekleştirmek zorunda kalacaktır. Elbette, devletin denetim mekanizmalarında değişikliğe gitmesi de doğal bir sonuç olacaktır. Yeni normal olarak adlandırılan bu geçiş döneminin akabinde ise bazı fiziki düzenlemeler kalıcı hale gelecek; kurum kültürünün bileşenleri farklılaşmayla birlikte yeniden tanımlanacaktır. Belirsizliklere ve salgın gibi tehditlere hazırlıklı olan işletmeler, rekabette öne geçecekken, çalışanların da kuruma olan aidiyet duygusunu güçlendirecektir. Kurum kültüründe ve stratejilerin belirlenmesinde bu risklere adapte olma becerisi, başarıyı da beraberinde getirecektir.

\subsection{Sosyal Politikalar Özelinde Salgın Gerçeği}

Covid-19 salgını, bireysel ve toplumsal duyarlılığı zorunlu kılmaktadır. Devletin aldığı kararların amacına ulaşması, vatandaşların sorumluluk duygusu içinde hareket etmesine; bilinçli davranmasına ve tehlikenin farkına varmasına doğrudan bağlıdır. Kontrollü sosyal hayata geçildiği bir dönemde, uzun vadeli mücadelenin başarılı olması bu konudaki beklentilerin karşılanmasıyla da ilişkilidir. Başta bakanlıklar olmak üzere kamu kurumlarının yürüttüğü bilgilendirme faaliyetleri kadar, sivil toplum kuruluşları, meslek örgütleri ve kamusal sorumluluğu bulunan yapıların da ortak paydada buluşmasını zorunlu kılmaktadır. Sosyal politikaların geliştirilmesinde son yıllarda önemli adımlar atan; sağlık hizmetlerinin ve sosyal adaletin yaygınlaştırılmasında başarılı sonuçlar elde eden Türkiye'de, salgın tehlikesinin bertaraf edilmesi ve ortadan kaldırılmasına yönelik uygulamalara karşı bir direnişin bulunmaması da bu noktada umut verici bir gelişmedir.

ABD ve İngiltere gibi ülkelerde, salgının başladığı günden bu yana, direş gösteren cemiyetlerin olduğu; sağlık sistemlerinin ciddi şekilde sorgulanmaya başladığı görülmektedir. Öyle ki, İngiltere Başbakanı'nın salgınla ilgili yaptığı ilk açıklamalar aslında konuyla ilgili duyarlılı̆̆ın henüz yönetimsel noktada idrak edilemediğinin göstergesi olmuş; eleştirilerin hedefi sosyal adalet kavramı üzerinde gelişmiştir. Yine gelişmişlik düzeyinin tanımında yer alan milli gelirden elde edilen payın adil şekilde dağıtılmadığına ilişkin tartışmalar, maddi gücü olan ve olmayanların sağlık hizmetinden eşit şekilde yararlanamadığı noktasında bazı ülkeleri ikilemde bıraktığ aşikardır.

Türkiye'nin, toplumsal yapısı ve kültürü itibariyle dayanışma ruhunu daha üst başlıkta yaşaması, İtalya ve İspanya gibi ülkelerdeki vahim tabloların oluşmasını engellemiştir. Salgın sürecindeki “Türkiye'nin bu kadar yüksek oranda nüfusa sahip olmasına karşın doğrulanmış vaka oranlarının daha az olmasındaki en büyük faktör, Covid-19 vakası ile temas ederek bulaşmayı en aza indirmek ve hastalığı kontrol altında tutmak için devlet 
idaresinin gerekli tedbirleri hızlı ve kararlı bir şekilde alması, aynı zamanda vatandaşlar tarafından da bu tedbirlere büyük oranda uyulmasıdır.".

\subsection{Eğitimde Hibrit Modele Doğru}

Türkiye'nin temel eğitim ve yükseköğretim kurumlarındaki faaliyetler genel itibariyle yüz yüze eğitim anlayışına dayalı bir yapıda oluşturulmuştur. Ancak salgınla birlikte bunun değişmesi gerekebileceği; yüz yüzü eğitim ile çevrim içi eğitimi barındıran hibrit bir modelin planlanmasının zorunluluğu ortaya çıkmıştır. Salgının başlamasıyla birlikte Türk eğitim sisteminin öncelikli amacı, sürecin aksamadan sürdürülmesine yönelik olmuştur. Devletin aldığı ilk kararların eğitim kurumlarını bağlaması, genç ve dinamik bir nüfusa sahip Türkiye için önem taşımaktadır. Bu alana yönelik planlamaların ölçme ve değerlendirme gibi temel konular üzerinde olduğu kadar; bu kurumlardaki çalışma hayatını yeniden dizayn etmeye yönelik eylemlerin de gözden geçirilmesi gerektiği düşünülmelidir.

Bu kapsamda önceliğin eğiticilerin eğitimine verilmesi gerektiği, bunun aynı zamanda öğrencilerin başarısını etkileyeceği unutulmamalıdır. Yine; günümüz iletişim teknolojileri dikkate alındığında, salgınla birlikte bunların doğru kullanımına ilişkin yöneylem araştırmaların yapılması, üniversiteler için akademik bir misyon olmalıdır. Gelişim çağında bulunan çocukların ve kariyer yolculuğunun başındaki gençlerin algısı, bu ve benzeri hastalıklar karşısında teknolojinin bilinçli şekilde kullanılmasına yönelik şekillenmelidir. Uzaktan ve yüz yüze eğitim, bir hibrit model olarak, Türkiye'nin uzun vadeli eğitim yatırımlarında belirleyici olması beklenmelidir.

Yine; ekonomik faaliyetlerin devamının sağlanmasında bir takım farklılaşmaların olacağı da ortadadır. Bu durum, sayısal ve işlevsel esnek üretim süreçlerinden ticari faaliyetlere kadar hemen her aşama için düşünülebilir. Buradaki esas konu, mevcut ekosistemin nasıl okunması gerektiğinin bilinmesidir. Bunu çözen girişimciler veya firmalar, salgının getirdiği maddi tehditleri fırsata dönüştürme eğilimi gösterdikleri ölçüde, başarıya ulaşabilecektir. Elektronik satışlarda yaşanan artışı ve buna bağlı olarak lojistik sektörünün refleksini bu bağlamda düşünmek mümkündür.

\section{Sonuc}

Covid-19 salgını, toplumun en temel ihtiyacının öncelikle sağlık hizmetleri olduğunu ortaya çıkarmıştır. Bunun yanı sıra; günümüz ekonomilerinin ne kadar hassas olduğunu; çalışma hayatına ilişkin bilgi ve tecrübelerin güncellenmesi gerektiğini de göstermiştir. Burada söz konusu olan refah ve mutluluğu toplumun her kesimi tarafından paylaşılması; iktisadi kalkınmanın özünü teşkil eden üretim ve iş gücü planlamasının doğru şekilde yapılmasidir.

Kuruluşunun 100. yıldönümünde dünyanın en büyük 10 ekonomisi arasında yer alma hedefini adım adım yaklaşan; teknoloji ve nitelikli iş gücü noktasında küresel güç olma öngörüsüne sahip Türkiye, salgınla mücadele konusunda da örnek bir gayret göstermiştir. Buradaki başarının temelinde, devletin son 15 yılda sağlık alanında yaptığı yatırımların ve özel sektöre yönelik teşvik ve destek mekanizmalarının rolü bulunmaktadır. Nitelikli sağlık çalışanlarının yetiştirilmesi, yatak sayısının artırılması, vatandaşın sağlık hizmetlerine hızlı ve ücretsiz şekilde ulaşabilmesi ve bürokrasinin azaltılması gibi faktörler, Türkiye'nin salgınla mücadele konusundaki artılarını teşkil etmiştir. Sosyal izolasyon ve karantina süreçlerinde etkin kararlar alan Türkiye, kriz yönetimi konusundaki beceresini de ortaya koymuştur.

Cumhurbaşkanlığı Hükümet Sisteminin salgın dönemindeki çalışma hayatına ve istihdama yönelik uygulamalarda hızlı ve doğru kararlar vermesi; bilimsel gerçeklikleri ve toplumsal beklentileri dikkate alması, sürecin kontrollü olarak ilerlemesini sağlamıştır. Bu noktada; Cumhurbaşkanı Recep Tayyip Erdoğan'ın aldığı kararların insan odaklı sosyal politikalara ve iktisadi yaklaşımlara önem verdiğinin göstergesi olarak düşünmek mümkündür. Demokratik toplum düzeni içinde hak arayışının koruma altına alındığı; yatırım ve girişimlerin önem kazandığı; işçi-işveren arasında anlamlı bağların kurulduğu bir dönemde, devletin salgının getirdiği olumsuzlukların iş hayatına minimum düzeyde yansıması adına adımlar atması istikrarlı ekonomi hedefiyle uyumludur. Dolayısıyla Türkiye, bu süreçte güvenli bir liman ve başarılı bir ülke olmuştur. Salgının çalışma hayatına getirdiği en önemli sonuç, geleneksel çalışma anlayışın önümüzdeki yıllarda mutlak değişime uğrayacağıdır.

Türkiye'de, pandemi ile birlikte uzaktan, esnek ve dönüşümlü çalışma kavramları literatüre girmiştir. Sosyal izolasyon ve sinırlamalar nedeniyle kitlesel faaliyetlerin görüldüğü eğitim sektörü ile iş dünyasında uzaktan erişime geçme süreci hızlanmış; alışkanlıklar değişmeye başlamıştır. Bu durum, iletişim teknolojilerinin kullanım alanlarını genişlettiği gibi yeni iş kollarının oluşmasına sebep olmuş; bireysel adaptasyon süreci ise demografik özelliklerden bağımsız olarak ilerlemeye başlamıştır. Bu süreçte, kamusal alandaki faaliyetlerde de bir takım yeni düzenlemelere gidilmiştir. Başta merkezi yönetim ve taşra teşkilatları ile üniversiteler burada etkin rol üstlenmiş; toplantıların, konferansların, söyleşilerin mekandan bağımsız olarak düzenlenmesi sağlanmıştır. Özel sektör de buna paralel olarak, işyerlerindeki benzer faaliyetlerini yeni çalışma sistemine uyumlu olacak şekilde tasarlanmaya başlamıştır. 
Elbette, teknolojinin kullanım alanının yaygınlaşması, bu alandaki öncü ve inovatif çalışmalara ilham olacağını öngörmek mümkündür. Yine; çalışma hayatında etki alanı artacak dijital teknolojilerin kullanımına yönelik, çalışanların niteliğinin artırılması gerekeceği de aşikardır. Bu bağlamda temel ve yükseköğretim kurumlarındaki eğitim ve öğretim müfredatının geliştirilmesi gerektiği ortadadır. Yine; hayat boyu öğrenme ilkesi, kapsamı itibariyle genişlemek zorundadır. Özellikle yetişkinlik evresinde, kişinin buna yönelik tutum ve davranışları, kariyer yolculuğunda belirleyici olacaktır. Salgın bu anlamda da sürekli eğitim kavramını sosyal hayatın vazgeçilmez bir unsuru haline dönüştürecek; bireysel yetkinliklerin artırılmasını da tetikleyecektir.

Pandeminin alışkanlıkların hızlı değişimine yönelik baskısı, bazı zorlukları da beraberinde getirmesi olasıdır. Kişinin benliği ve toplumun algısı, uzun süreçlerde şekillenebilen gerçekliklerdir. Bu noktada kamu yönetiminin sosyal ve iktisadi hayatın bileşenlerine yönelik ufuk açıcı yaklaşımları benimseyeceğini söylemek mümkündür. Çalışmada vurgulanan kurum kültürü kavramı, işletmeler, sermaye şirketleri ve küresel firmalar açısından uzaktan çalışma metodu ile içselleştirilecektir. Rekabette teknolojiyi kullanan firmaların elde ettikleri kazanımlar yadsınamaz bir gerçektir. Ancak yaşanan pandemi süreci uzaktan çalışma yöntemlerini başarılı bir şekilde kurum kültürünün içerisine adapte edebilen şirketlerin de bu süreçten kazanım ile çıkmalarına olanak sağlayacaktır. Bunu, olumsuzluklardan ders çıkarmak olarak değil; olumsuzlukları kazanımlara dönüştürmek olarak düşünmek gerekir.

Fiziki izolasyon ortamı, ihtiyaçların giderilmesi noktasında iş akış süreç ya da mekanizmalarını da etkilemiştir. Orta ve uzun vadede bazı iş kollarının yeniden tanımlanacağı; iş ve işlemlerin bir kısmının ortadan kalkabileceği ya da dönüşeceğini de söylemek mümkündür. Burada belirleyici olan sadece kamu otoritesi ve ilgili mevzuatlar olmayacaktır. Beklentinin karşılanması, iç/dış pazarın kendi dinamikleri içinde şekilleneceği için işletmeler bu alanda öncü olacaktır. Normalleşme sürecinde Sağlık Bakanlığı tarafından hazırlanan sektörel ve mesleki guruplara yönelik önlemler ise bu kapsamda iş gücü piyasaları tarafından kurum içi işleyiş esaslarına uygun olarak değerlendirilmelidir.

Kamu-özel sektör işbirliğinin önümüzdeki dönemde daha da gelişeceği ortadadır. Bu noktada ulusal ve uluslararası politikaların oluşturulmasında itici güç, eşgüdümlü hareket etmek olacaktır. Dünyanın bütün ülkelerinde ekonominin makro ve mikro ölçekli sorunları bulunmaktadır. Küresel salgın, bu sorunların gün yüzüne çıkmasına; dengelerin sanıldığı gibi kendini medeniyet eksenine koyan ülkelerin tekelinde olamayacağını göstermiştir. Dolayısıyla küresel felaketin insanlığı nereye götürebileceğinin doğru okunması şarttır.

Üretim güç ve kabiliyeti her ne olursa olsun her ülke, bu süreçle birlikte elindeki insan kaynağını iyi değerlendirmek zorundadır. Bu noktada akademi dünyasının bilimsel çalışmaları ve sahip olduğu nitelikler, büyük önem arz edecektir. Çünkü, bireye temel eğitimde nitelik kazandırmak sosyal hayatın; mesleki donanımı kazandırmak ise üniversitelerin meselesidir. Bu yüzden çalışma hayatına yönelik bütün girişimler, yükseköğretim kurumlarının dahil olduğu mekanizmalar tarafından yönlendirilmelidir. Oyunun kurallarının oyuncuya göre değiştiği çağ, salgınla birlikte sona erecektir. Yeni dönem, doğaya dönüş ve uyum sürecidir.

\section{Kaynakça}

- $\quad$ HOTAR, Nükhet; OMAY, Rabia Ece; BAYRAK, Serdar; KURUÜZÜM, Ziya ve ÜNAL, Belgin, "Pandeminin Toplumsal Yansımaları" İzmir İktisat Dergisi, C.35, S.2, ss.211-220 Türkiye, 2020

\section{Resmi Yayın}

- “COVID-19 Kapsamında Kamu Çalışanlarına Yönelik İlave Tedbirler”, 22 Mart 2020, Resmi Gazete, Erişim Adresi: https://www.resmigazete.gov.tr/eskiler/2020/03/20200322M1.pdf Erişim Tarihi:15.10.2020

- “Cumhurbaşkanı Erdoğan: Normal hayata dönüşü kademe kademe başlatacağız”, 04 Mayıs 2020, Anadolu Ajans1, Erişim Adresi: https://www.aa.com.tr/tr/turkiye/cumhurbaskani-erdogan-normal-hayata-donusukademe-kademe-baslatacagiz/1828617 Erişim Tarihi:20.10.2020

- “İbrahim Kalın 'koronavirüs' toplantısında alınan tedbirleri açıkladı”, Anadolu Ajansı, 12 Mart 2020, Erişim Adresi: https://www.aa.com.tr/tr/koronavirus/ibrahim-kalin-koronavirus-toplantisinda-alinan-tedbirleriacikladi/1763918 Erişim Tarihi:13.10.2020

- “Kamu sektörü istihdamına ilişkin veriler”, 10 Ağustos 2020, TÜİK, Erişim Adresi: https://data.tuik.gov.tr/tr/main-category-sub-categories-sub-components2/\# Erişim Tarihi:17.10.2020

- “Pandemi Hastaneleri”, 20 Mart 2020, Sağlık Bakanlığı, Erişim Adresi: https://hasta.saglik.gov.tr/Eklenti/36907/0/pandemi-hastaneleripdf.pdf Erişim Tarihi:15.10.2020

- “Sağlık Bakanı Koca açıkladı: Türkiye'de ilk Kovid-19 vakası tespit edildi”, Milliyet Gazetesi, 11 Mart 2020, Erişim Adresi: https://www.milliyet.com.tr/gundem/saglik-bakani-koca-acikladi-turkiyede-ilk-kovid19-vakasi-tespit-edildi-6163101a Erişim Tarihi:10.10.2020 


\title{
Financial Evaluation of Drug Addiction Rehabilitation Services with Respect to the Health Economics
}

\author{
Asst. Prof. Dr. Osman Altay (Beykent University, Turkey) \\ Ph.D. Candidate Hatice Mutlu (Üsküdar University, Turkey)
}

\begin{abstract}
Healthcare interventions are concern of government policies, health service providers, civil society organizations and public. These interventions are mainly criticized with respect to their cost effectiveness. However, economic, social and health benefits of drug addiction rehabilitation services are not well understood and they remain relatively subsidized in comparison to other aspects of healthcare interventions. But, notwithstanding this, drug addiction rehabilitation services are generally financed with public funds in Turkey as like many other countries and this situation become subject to questioning when fiscal policies and cost effectiveness of these services are considered.

Based on this circumstances there is a great need for scientifically sound and practical financial and economic evaluation of substance abuse treatment services. In Turkey, recent legislative developments on substance abuse treatment services provide a baseline for structural evaluation of financial and economic feasibility of these services. In spite of ongoing methodological and empirical developments in economic evaluation of the primary health services, similar studies regarding addiction treatments are very rare in the literature. Correspondingly, methodological guidelines in this area are also very limited.

This study addresses these gaps by presenting a financial and economic evaluation of drug addiction rehabilitation services in Turkey considering urgent need of intervention in this area. Evaluation of these services is based on the basic requirements of a drug addiction rehabilitation center, which is determined by the related legislation in Turkey, and the evaluation was conducted according to the methodological principles presented by EMCDDA, European Monitoring Centre for Drugs and Drug Addictions.
\end{abstract}

\section{Introduction}

Having gradually increased in recent years, drug misuse and drug/substance addiction have become one of the most serious social problems. In addition to its effects on individuals, drug addiction exerts impacts on every segment of society and poses a problem at the international level. Moreover, it affects not only users but also their families and social circles, consequently the whole society. Therefore, the fight against addiction needs to be carried out systematically and at societal rather than individual level.

The United Nations Office on Drug and Crime (UNODC) delivers a World Drug Report biyearly, and one report states that 271 million people around the world used drugs in 2017, which accounts for $5.5 \%$ of the world population aged 15-64. The rate is 3.1 for Turkey (TUBIM 2018). The 2017 report sets forth also that, among the users, 35 million people suffer from drug use disorders; of them, only one in seven gets treatment and in 2017, the global drug-related death toll was 585 thousand (UNODC, 2019).

Turkey experienced a two-fold increase in drug use from 2002 to 2011. Accordingly, drug-related deaths doubled through 2009-2013, and drug law offenses escalated by 50\% through 2011-2013 (TUBİM, 2014). That brought with its healthcare costs, drug-related crimes, and deaths.

Compiled by the EMCDDA, the 2019 European Drug Report exhibits that the amount of heroin seized in Turkey in one year is surpassingly higher than that seized in all the European countries. It is also reported that drug law offenses in Turkey rose by $45 \%$ in 2017 , and most of the offenses were caused by drug use and possession. According to the data in the report, there occurred an upward trend in the number and rate of drug overdose deaths in Turkey. 105 people died of drug use in 2011. The number increased to 920 in 2016 and reached 941 in 2017. Besides, most of the decedents were male and the average age was 32 (EMCDDA, 2019).

In Turkey, drug users getting treatment are mostly male. The Republic of Turkey Ministry of Health offers detoxification services to drug addicts at Alcohol and Drug Treatment Centers (These centers are called as AMATEM in Turkish as an abbreviation). Detoxification-oriented inpatient treatment options grow in parallel with the increased number of AMATEMs.

Figures regarding treatment services at the substance addiction facilities between 2014-2016 are indicated at the following table. 


\begin{tabular}{|r|r|r|r|}
\hline YEAR & OUTPATIENCE & INPATIENCE & TOTAL \\
\hline 2014 & 237.335 & 10.167 & 247.502 \\
\hline 2015 & 181.622 & 12.327 & 193.949 \\
\hline 2016 & 226.118 & 13.006 & 239.124 \\
\hline
\end{tabular}

Table 1: Number of Substance Addiction Outpatient \& Inpatient Treatment in Turkey between 2014- 2016 (Ulu 2018)

Looking at their profile, the drug addict population in our country is young, has a high unemployment rate and low education level, and lives with their family. $47 \%$ of those seeking treatment are aged 15-24, and age at first use is 20 on average. $66 \%$ of the treatment-seekers are unemployed and earn less than 500 TL monthly. $70 \%$ of the addicted individuals have a high school or lower degree; \%96 live with their families, and 38\% started doing drugs because of their families and social circles (TUBIM, 2014).

The magnitude of the risk and harms it produces establish the significance of the fight against drugs. It is a fact that detoxification forms an indispensable part both in the fight against drugs and the treatment of addicts. On the other hand, the need for capacity increase in detoxification services as well as for developing rehabilitation services for relapse prevention is a generally accepted issue.

In its fight against non-communicable diseases, the World Health Organization emphasizes that the world faces new challenges in view of the health and demographic trends, and the number of individuals with noncommunicable diseases is on the rise the same way as the outcomes they produce (WHO, 2018). Accordingly, it becomes more vital to invest in rehabilitation as it does not only decrease mortality and morbidity but also improves functionality, thus welfare. Economic and social consequences of meeting that investment need will contribute to social welfare, too.

It is accepted that illicit drug use worsens the global disease burden (Rehm J, et al, 2017; Degenhardt L, Hall W., 2012) Chronicle problems include communicable diseases induced by addiction and drugs whereas there are well-documented acute harms such as overdose.

Understanding the costs of drug-related actions stands as an essential dimension of policy-making and evaluation. On the other hand, we have poor and heterogeneous information on drug-related public expenditures in Europe, at both the local and national levels. According to estimates submitted to EMCDDA in the last decade, expenditures made on demand reduction efforts using the total medication budget represent $21 \%$ to $75 \%$ of the drug-related public expenditures and vary considerably among countries. It is estimated that, in the European Union, 1.1103 million people (1.5 million when Norway and Turkey included) got treatment for illicit drug use. Individual application is seen as the ideal and widespread way of starting the drug treatment process. In Europe, most of those in replacement therapy are over 35 years of age and have been under treatment for more than 2 years. The replacement therapy, usually combined with psychosocial interventions, is the most common treatment for opioid addiction. The evidence available supports this combined approach, which produces positive outcomes in terms of retention, illicit opioid use rate, reported risk behaviors, as well as drug-related harms and death rates (EMCDDA, 2019).

Drug treatment and other relevant healthcare costs make up the biggest part of the estimated expenditures on demand reduction initiatives. National differences come into view partly because of diverse policies and service options. In addition, various estimation methodologies used, along with the diversity of the drug problems and of public service provision, produce a serious impact on the outcomes.

Reducing overdose-induced disease and death rates forms a serious public health challenge in Europe. Extensive public health reflex in this field aims to reduce vulnerability among drug users by removing obstacles, making the services accessible and encouraging users to take fewer risks.

The scope of treatment for drug-related problems was extended in mid-90s, which is one of the reasons why the number increased. Again, there arose an intensified pressure on service providers to offer more effective services

The literature is poor when it comes to drug treatment expenditures. In the past 10 years, 18 European countries reported comprehensive estimates of expenditures by central governments including drug treatment costs. The said reports show that total drug-related public expenditures account for $0.01-0.5 \%$ of GDP. The share of health expenditures in total drug-related public expenditures varies from $\% 15$ to 53\% (EMCDDA, 2017).

\section{Setting a Methodology for Cost-Effectiveness Analysis}

Since drug addiction is a public health issue with social and economic aspects, making cost-effective policies and taking cost-effective actions grow in importance in consideration of the needs and circumstances relating to drug addiction rehabilitation services. The European Union Drugs Strategy 2013-2020 and Action Plan 2017-2020 were prepared by taking this fact into account. In line with the requirements set forth in those strategies, EMCDDA makes efforts to develop analytic tools for evaluating the effectiveness of drug policies and actions, and thereby to contribute to the estimation of expenditures borne by EU countries when fighting against drug addiction. The 
insufficient data on the issue along with the uncertainty in the transfer of funds for drug treatment pose an obstacle to the effective allocation of sources.

It is not easy to analyze public expenditures on drug treatment because the data on related expenditures is not satisfactory for EU countries and Turkey. Therefore, by using conventional cost analysis methods, this study seeks to determine the cost of rehabilitation work to be carried out at a rehabilitation center that will be founded in compliance with standards established by the Regulation on Addiction Counseling, Detoxification and Rehabilitation Centers. It does also take into account the scope of approach in the "Drug Treatment Expenditure: a methodological overview" in which the EMCDDA compiled drug rehabilitation efforts from different countries and evaluated methodologies used in them with a unique approach. For the purposes of this study, the possible fiscal burden on public finance is estimated by subjecting the defined unit costs to a projection using the available data and countries' data in the EMCDDA publications. The said financial burden was evaluated together with the external benefits of the rehabilitation services. Rehabilitation services create benefits for addicted individuals; expenditures induced by individuals' dependence go down and social welfare improves with their participation in the labor force. Therefore, such benefits should also be taken into account in the evaluation.

It should be emphasized that medical treatment services and rehabilitation services are two different processes in the treatment of drug addicts. The medical treatment refers rather to detoxification of a given addict within the rehabilitation process. Following the medical treatment, individuals need to be cleaned from psychological, social and environmental impacts of addiction. Otherwise, the relapse risk increases for addicts who have not been empowered against such impacts, which stands as a cost-increasing element (EMCDDA, 2017). Individuals who return to the same social environment without getting any support after medical treatment go back to the addiction cycle inevitably. The current situation lower treatment success rates whereas the addicts resuming the medical treatment over and over put great pressure on AMATEMs (Alkol ve Madde Tedavi Merkezi - Alcohol and substance addiction treatment center) and CEMATEMs (Çocuk ve Ergen Madde Bağımlılı̆̆ Tedavi Merkezleri Substance addiction treatment center for children and adults). Treatment success rates are likely to go up substantially with the foundation of rehabilitation centers.

Addicts' taking up drugs after medical treatment, recurrence, in other words, is named "relapse" in the literature. The relapse rate is $60 \%$ in our country against $30 \%$ in developed countries. This study analyses the costeffectiveness to be created if the relapse rate would be reduced to $45 \%$ through rehabilitation services to be offered after detoxification.

Although not included in this study's scope, expenditures to be borne for the inclusion of addicts into rehabilitation process may achieve savings on the following cost items in terms of public finance:

- Treatment of other health problems caused by drug use (Communicable diseases; HIV, Hepatitis, etc., problems with kidneys, lungs or other visceral organs, and mental problems, etc.)

- Costs relating to law enforcement and legal procedures.

Some literature works assert that each penny spent within an integrated ecosystem uniting medical treatment, rehabilitation and social cohesion returns the system 15-20 times more benefits. In reference to the data published by Public Health England, every pound invested in drug treatment has a social return of 21 pounds over a 10-year period whereas the ratio is 1:26 for alcohol treatment (Public Health England 2012).

Health economists have employed various economic evaluation methods and techniques to evaluate healthcare service programs, services or interventions. The primarily used one is the economic cost analysis. Economic cost analysis tries to estimate the opportunity cost of a program from a societal point of view. The opportunity cost grounds itself on market prices of all the sources used for the provision of a given program (French, M. T., Salomé, H. J., Sindelar, J. L., \& McLellan, A. T., 2002).

In that regard, the ruling economic evaluation method is the benefit-cost analysis (Cartwright, 1998; French, 2002; Alexandre et al., 2012; French et al., 2000). This technique creates a monetary measurement comparing a program's opportunity cost to its economic benefit. The results are called benefit-cost ratio or net benefit (benefitcost) estimate. If the benefit-cost ratio is above 1 or net benefit estimate is positive, the intervention in question is cost wise beneficial. This study adopted that approach in running the analysis.

Today, 40 alcohol and drug addiction centers operate in Turkey under the Ministry of Health (AMATEM ÇEMATEM) These centers provide both inpatient and outpatient treatment, and minor and adult inpatients are treated in separate centers. Very often news about the insufficient capacity of AMATEMs and CEMATEMs come to public agenda (Drug Related News n.d.) High relapse rates are considered one of the reasons why those centers fail to meet the demand that exceeds their capacities. Forming a basis for this study, the Regulation on Addiction Counseling, Detoxification, and Rehabilitation Centers, issued on March 10, 2019, aims to carry into effect arrangements for establishing and operating centers where drug addicts will get inpatient and outpatient pharmacological treatment in addition to psycho-social therapy and rehabilitation (T.C. Resmi Gazete 2019). Therefore, present 40 centers, which provide detox-oriented pharmacological therapy, need to be turned into ones that rehabilitate addicted individuals with pscyhosocial support, with a view to reintroducing them to the social 
life. In that regard and in the first stage, it is planned and advised by experts that each AMATEM and CEMATEM work in close cooperation with a rehabilitation center. For this reason, this study will make analysis over the costs to be induced with the establishment of 40 rehab centers across Turkey.

Before making the cost analysis, this study examined the cost analyses that works of national and international literature made on healthcare services and methodologies. Then, it analyzed the cost of rehabilitation services to be provided for drug addiction (alcohol and substance) in Turkey within the scope of the regulation that sets out the rules for the field.

Healthcare costs can be classified into the following main categories (axes); however, it has been established that developing a methodology based on a single axis will not be possible because each will have a scope and functionality with differing extents.

Axes:

1 - Healthcare Functions

2 - Healthcare Providers

3 - Funding Schemes

Drug treatment expenditures can be estimated, sorted and categorized by healthcare service functions (axis 1), healthcare service providers (axis 2) or healthcare service financing plans (axis 3). Classifying healthcare expenditures according to healthcare service functions may follow treatment provision modalities such as withdrawal, rehabilitation, and pharmacotherapy, etc. Thereby, expenditures in each category can be calculated. As an alternative, healthcare expenditures can be calculated according to providers, which can be hospitals, inpatient and outpatient service providers, etc. Categorization by practitioner type is helpful for thinking through the types of expenditure data because in many instances the type of expenditure data is linked to the type of practitioner (EMCDDA, 2017).

The regulation already sets forth what qualifications' practitioners must have at which providers, as well as cost items and categories for Turkey. Therefore, this study has made a cost analysis on rehabilitation-oriented services bearing in mind the minimum conditions established by the regulation.

\section{Evaluating the Cost of Rehabilitation Services in Turkey within the Limits of Legislative Regulations}

There are three main international conventions on drug policies: the Single Convention on Narcotic Drugs of 1961, 1971 Convention on Psychotropic Substances, and the United Nations Convention Against Illicit Traffic in Narcotic Drugs and Psychotropic Substances of 1988. Those conventions have contexts guiding and regulating states' policies in fighting the supply of addictive substances. The conventions were concluded with the goal of a drug-free world and they set an overall framework for nation-states' drug policies.

The spread of drug use across the world in recent years provoked discussions on the efficiency of present conventions and the policies derived from them. It came to be debated that current conventions and national policies needed to be revised with a wide range of strategic practices and approaches. Prominent approach generating from such discussion argues that it will be more efficient if drug policies are shaped with a local-tointernational approach rather than international-to-local. So, encouragement is offered to studies and models that will mobilize the current dynamics with this approach.

In addition to the national anti-drug policies and common legal regulations, the Regulation on Addiction Counseling, Detoxification, and Rehabilitation Centers, promulgated on March 10, 2019, is the most significant legal foundation regulating the rehabilitation services in Turkey. It was put into effect for the purposes of eliminating uncertainties in the field and delivering evidence-based services to the target group.

When making a rehabilitation cost evaluation one may benefit from inputs such as the minimum conditions to be fulfilled by a center that will be founded to provide rehabilitation services in compliance with the arrangements established by the regulation in terms of set-up, operation and treatment processes. The cost elements in the regulation were checked to determine the cost elements to be covered in this evaluation. So, the cost items may be divided as set-up and operating costs, as is the case in other investments. The set-up and operating cost items of a rehabilitation center for 20 patients, meeting the minimum criteria in the regulation, may be identified under the following categories: 


\begin{tabular}{|c|c|}
\hline Setup Cost Items: & Operating Cost Items: \\
\hline - Land Cost & - $\quad$ Salaries (Gross Wages) \\
\hline - $\quad$ Construction Cost & - Operating expenses: \\
\hline $\begin{array}{l}\text { - Equipment and Furnishing } \\
\text { (IT Infrastructure, Furniture, Whiteware, } \\
\text { Fittings, etc. included) }\end{array}$ & $\begin{array}{ll}\circ & \text { Electricity, Water, Gas } \\
\circ & \text { Transportation } \\
\circ & \text { Kitchen/Food }\end{array}$ \\
\hline - $\quad$ Staff Training & $\begin{array}{ll}\circ & \text { Cleaning } \\
\circ & \text { Stationery } \\
\circ & \text { Maintenance \& Repair, Amortization } \\
\circ & \text { Uniforms, } \\
\circ & \text { Continuing training for the staff, } \\
\circ & \text { Central Administration Costs (Supervision Costs) } \\
\circ & \text { Control Costs }\end{array}$ \\
\hline
\end{tabular}

Table 2: Setup and Operating Cost Items of a Rehabilitation Center for 20 Patients

A center with an inpatient capacity for 20 must recruit following staff in minimum: specialized physician (1), specialized clinical psychologist (1), psychologist (2), social worker (2), occupational therapist (3), secretary (2), security staff (6), and nurse. The table below shows the annual staffing cost for a center with 20-patient capacity; the salaries were calculated based on those of civil servants with the same posts.

\begin{tabular}{|l|r|r|r|r|}
\hline \multicolumn{1}{|c|}{ TITLE } & $\begin{array}{c}\text { Number } \\
\text { of Staff }\end{array}$ & $\begin{array}{c}\text { Net Minimum } \\
\text { Wage (Monthly, } \\
\text { per person) }\end{array}$ & $\begin{array}{c}\text { Average Gross } \\
\text { Wage (Monthly, } \\
\text { per person) }\end{array}$ & $\begin{array}{c}\text { Annual Gross } \\
\text { Wage (All } \\
\text { posts) }\end{array}$ \\
\hline Specialized Physician & 1 & $6,882.45$ & $7,974.18$ & $95,690.16$ \\
\hline Specialized Clinical Psychologist & 1 & $4,749.85$ & $5,628.61$ & $67,543.32$ \\
\hline Psychologist & 1 & $4,744.3$ & $5,622.02$ & $67,464.24$ \\
\hline Nurse & 1 & $4,668.16$ & $5,511.25$ & $66,135.00$ \\
\hline Social Worker & 2 & $4,744.30$ & $5,622.02$ & $134,928.48$ \\
\hline Occupational Therapist & 3 & $3,963.52$ & $4,671.1$ & $168,159.60$ \\
\hline Secretary & 2 & $4,048.93$ & $4,771.97$ & $114,527.28$ \\
\hline Security Staff & 6 & $3,106.85$ & $3,893.44$ & $280,327.68$ \\
\hline \multicolumn{3}{|r|}{} & \multicolumn{3}{|c|}{ TOTAL } & $\mathbf{9 9 4 , 7 7 5 . 7 6}$ \\
\hline
\end{tabular}

Table 3: Annual Minimum Staffing Cost of a Rehabilitation Centre with 20 Employees (TRY) Source: Memurlarnet / https://www.memurlar.net/maasrobot/

Other than the staffing cost, the table below shows approximate estimates of set-up and operating costs calculated by comparison to current market rates.

\begin{tabular}{|l|r|}
\hline INVESTMENT COST ITEMS & AMOUNT (TRY) \\
\hline Land Cost & $1,000,000$ \\
\hline Construction Cost & $2,625,000$ \\
\hline $\begin{array}{l}\text { Equipment and Furnishing (IT Infrastructure, Furniture, Whiteware, Fittings, etc. } \\
\text { included) }\end{array}$ & 178,692 \\
\hline Staff Training & 82,300 \\
\hline Vehicle for Transportation & 130,000 \\
\hline \multicolumn{2}{|c|}{ TOTAL } \\
\hline
\end{tabular}

Table 4: Investment Cost Items of a Rehabilitation Center

\begin{tabular}{|l|r|}
\hline OPERATING COST ITEMS (ANNUAL) & AMOUNT (TRY) \\
\hline Salaries (severance pay included) & $1,126,775.8$ \\
\hline Operating expenses: & 51,000 \\
\hline Electricity, Water, Gas, Telephone, Internet services & 25,000 \\
\hline Transportation & 405,150 \\
\hline Kitchen/Food & 24,500 \\
\hline Consumables (Cleaning materials, stationery, uniforms, etc.) & 30,000 \\
\hline Maintenance \& Repair and Insurance & 10,000 \\
\hline Central Administration Costs (Central Control, Supervision and Management Costs) & 10,000 \\
\hline Unforeseen Expenses & $\mathbf{1 , 6 8 2 , 4 2 5 . 7 6}$ \\
\hline
\end{tabular}

Table 5: Operating Cost Items of a Rehabilitation Center 
For a rehabilitation center with 20-patient capacity, cost induced by one consulee/addict is 230,47 TL per day on the assumption that the center operates in full capacity year-round. This amount approximates to 247,72 , which is the procedure score used for (F-10-19) mental and behavioral disorders caused by psychoactive substance use (excluding F-15-17 code groups) under Group 5-Psychiatric patients' daily treatment as stated in the Health Application Communiqué (SUT), Appendix-2/C, Diagnostic Procedure Score List. This proximity reinforces the rationality and significance of the modeling and estimation methods employed in this study.

Payback period must also be addressed in the modeling by reflecting the set-up costs of the centers to their service life. Again on the assumption that a center with a capacity of 20-patient operates in full capacity over years, the return on a center's investment cost is calculated as stated below if we are to compute centers' investment payback period by using the amount to be saved for each patient due to the difference between break-even level of 230.47 TL needed to cover the operating costs and the basis point of 247.72 designated in the SUT;

$247.72-230.47=17.25 \times(20 \times 365=7300)=125,925$

Investment Cost Total / Annual SUT income net of operating costs= Investment payback period 4,015,992 / 125,925 = 31.89 YEARS.

Meanwhile, 247,72 procedure score is equivalent of same amount of Turkish Lira at the time when it was first introduced in 2018. Since then regular increase is not applied to this amount although procedural points of many other treatment expenditures are subject to incremental change with respect to increase in economic indicators such as inflation.

Even if investment into rehabilitation centers, within this perspective, may not be seen reasonable with respect to investment efficiency, every penny spent on rehabilitation achieve 21 -fold return over a 10 -year period, as stated previously above. In that regard, it can be concluded that governing power should support this field or augment particularly services focused on this field.

Besides, if we consider that each year number of substance addiction inpatient detoxification treatment to be served to 15.000 people in a year and each patient is subject to AMATEMS' 21 days of detoxification program then it counts $15,000 \mathrm{X} 21=315,000$ days of inpatient treatment in for a year. If we multiply this number by the daily SUT basis point of 247,72 we reach 78,031,800 TRY of yearly inpatient detoxification cost, as an assumption.

However, psychological and social rehabilitation of drug addiction needs generally more time than 21 days, three months at least according to the observations results. Therefore, a risky group of detoxification inpatients should be sent to the rehabilitation centers. If we assume that half of them transferred to the rehabilitation centers, then the number of rehabilitation inpatients would be 7,500 or 8,000 in round with respect to the 15,000 of inpatient detoxification inpatient as it is indicated above. Regarding 3 months of rehabilitation period for each patient then it makes $8,000 \mathrm{X} 90$ days $=720,000$ rehabilitation service days each year and the yearly costs may be calculated as $720,000 X 230,47=165,938,400$ TRY.

Aligned with present AMATEMs and CEMATEMs, rehabilitation services may start by establishing 40 centers across Turkey. But 40 centers for 20 people each would have 292,000 days of yearly impatience capacity, but the capacity required for 8,000 patients for three months of rehabilitation is 720,000 as indicated above. Therefore, number of rehabilitation centers must be increased gradually.

However, with respect to the ratio of drug treatment has a social return of 21 pounds over a 10 -year period, then $165,938,400$ TRY cost of 8,000 patient rehabilitation in a year will provide saving of 3,484,706,400 TRY.

\section{Conclusion and Suggestions}

Healthcare services differ from other sectors for their societal features and appeal to the whole society. And they seek to enhance and improve health conditions across society. As those services are considered full or partial public goods, state interventions are intensive in the field. Although the state intervenes in many service sectors the most interventions take place in the healthcare services sector and this is how the healthcare services market is shaped.

In this framework, addiction is not only a physiological disease but also a brain disease; and it is directly related to sociological and environmental impacts. On the other hand, it is an urgent issue for Turkey to develop a system that is focused on medical and psychotherapeutic treatment within a functional harmony. With the development of the system, an integrated mechanism should be established to provide psychological and social support services. Because the individuals who return to the same social environment without getting any support after medical treatment go back to the addiction cycle inevitably. The current situation lower treatment success rates whereas the addicts resuming the medical treatment over and over put great pressure on AMATEM and CEMATEMS. Treatment success rates are likely to go up substantially with the foundation of rehabilitation centers.

One of the reasons for state intervention in the healthcare sector is that market failures occur detracting the sector away from Pareto efficiency when the sector does not produce health-related goods and services effectively. The state remains the most influential actor in the healthcare sector for a justification that forms the foundation of the market failure theory, one of the most significant financial theories. 
In consideration of the findings in this study and the societal and economic dimension of healthcare services, there is obviously an urgent need to disseminate rehabilitation services for drug addicts by or under the control of public authorities.

\section{References}

- Alexandre, Pierre \& Beulaygue, Isabelle \& French, Michael \& McCollister, Kathryn \& Popovici, Ioana \& Sayed, Bisma, 2012. "The Economic Cost of Substance Abuse Treatment in the State of Florida". Evaluation Review. 36. 167-85. 10.1177/0193841X12450164.

- AMATEM - ÇEMATEM, (n.d.). Retrieved from https://alo191uyusturucu.saglik.gov.tr/TR,15589/amatem--cematem.html

- Cartwright, W S, 1998. "Cost-benefit and Cost-effectiveness Analysis of Drug Abuse Treatment Services". Evaluation Review, 22. Retrieved from http://www.biomedsearch.com/nih/Cost-benefit-cost-effectivenessanalysis/10186896.html

- Degenhardt, Louisa \& Hall, Wayne. 2012. "Extent of Illicit Drug use and Dependence, and Their Contribution to the Global Burden of Disease." Lancet. 379. 55-70. 10.1016/S0140-6736(11)61138-0.

- Drug Related News. (n.d.) Retrieved from https://alo191uyusturucu.saglik.gov.tr/TR,25452/haberler.html

- EMCDDA, 2017. "Drug Treatment Expenditure: A Methodological Overview, EMCDDA Insights", Publications Office of the European Union, Luxembourg. Retrieved from

- EMCDDA, 2019. “Turkey Drug Report.” Retrieved from http://www.emcdda.europa.eu/countries/drugreports/2019/turkey/drug-induced-deaths_en

- EMCDDA. 2019. "European Drug Report.” Retrieved from http://www.emcdda.europa.eu/edr2019_en

- French M.T., 2002. "Economic Evaluation of Alcohol Treatment Services." Recent Developments in Alcoholism (Services Research in the Era of Managed Care), vol 15. Springer, Boston, MA

- French MT, Salomé HJ, Krupski A, McKay JR, Donovan DM, McLellan AT, Durell J., 2000. "Benefit-Cost Analysis of Residential and Outpatient Addiction Treatment in the State of Washington." Evaluation Review. 2000;24(6):609-34. PubMed Retrieved from https://www.ncbi.nlm.nih.gov/pubmed/11151519

- French, M. T., Salomé, H. J., Sindelar, J. L., \& McLellan, A. T., 2002. "Benefit-cost Analysis of Addiction Treatment: Methodological Guidelines and Empirical Application Using the DATCAP and ASI." Health Services Research, 37(2), 433-455. doi:10.1111/1475-6773.031 Retrieved from https://www.ncbi.nlm.nih.gov/pmc/articles/PMC1430361/

- French, M., 1995. "Economic Evaluation of Drug Abuse Treatment Programs: Methodology and Findings." American Journal of Drug and Alcohol Abuse, 21(1), 111-135. https://doi.org/10.3109/00952999509095233

- Public Health England, 2012. "Alcohol and Drug Prevention, Treatment and Recovery: Why Invest?" Retrieved from https://www.gov.uk/government/publications/alcohol-and-drug-prevention-treatment-andrecovery-why-invest/alcohol-and-drug-prevention-treatment-and-recovery-why-invest

- Rehm J, Gmel GE Sr, Gmel G, et al., 2017. "The Relationship Between Different Dimensions of Alcohol Use and the Burden of Disease-an Update. "PubMed - NCBI. Retrieved from https://www.ncbi.nlm.nih.gov/pubmed/28220587

- Salomé H.J., French M.T., 2002 Using Cost and Financing Instruments for Economic Evaluation of Substance Abuse Treatment Services. In: Alcoholism. Recent Developments in Alcoholism (Services Research in the Era of Managed Care), vol 15. Springer, Boston, MA

- T.C. Resmi Gazete, 2019. "Bağimlilik Danişma, Arindirma Ve Rehabilitasyon Merkezleri Hakkinda Yönetmelik." Retrieved from https://www.resmigazete.gov.tr/eskiler/2019/03/20190310-2.htm

- TUBIM - Turkish National Monitoring Centre for Drugs and Drugs Addiction, 2018. "Türkiye'de Genel Nüfusta Tütün, Alkol ve Madde Kullanımına Yönelik Tutum ve Davranış Araştırması Raporu.” Retrieved from http://www.narkotik.pol.tr/turkiyede-genel-nufusta-tutun-alkol-ve-madde-kullanimina-yonelik-tutumve-davranis-arastirmasi-raporu-yayimlanmistir

- TUBIM - Turkish National Monitoring Centre for Drugs and Drugs Addiction, 2014. Retrieved from http://www.narkotik.pol.tr/kurumlar/narkotik.pol.tr/Arsiv/TUBIM/Documents/TURKIYE\%20UYUSTURU CU\%20RAPORU\%202014.pdf

- $\quad$ Ulu, Ö., 2018. “Türkiye'de ve Dünyada Uyuş̧urucu İle Mücadele.” 1st ed. TİAV Türk İdari Araştırmalar Vakfi İktisadi İşletmesi. p. 330

- UNODC, 2019. “World Drug Report.” Retrieved from https://wdr.unodc.org/wdr2019/

- WHO, 2018. "Noncommunicable Diseases." Retrieved from https://www.who.int/news-room/factsheets/detail/noncommunicable-diseas 


\title{
Determinants of Capital Structure in the Construction Companies across Europe and Central Asia Region
}

\author{
Asst. Prof. Dr. Hakan Bal (Beykent University, Turkey)
}

\begin{abstract}
This study examines the effects of asset tangibility, profitability, size and liquidity on capital structure (debt leverage) across the construction companies operating in in Europe and Central Asia region using the data between 1993 and 2019. The study documents that the capital structure and other financial ratios under study differ across countries, even in the same industry. Book leverage is found to be significantly negatively related to asset tangibility, profitability and liquidity in accordance with pecking order theory. In particular, fixed ratio has a negative effect on debt ratio in Russia and Romania, but no effect in other countries under study. The effect of size disappears when time dummy variables are introduced.
\end{abstract}

\section{Introduction}

How and when firms choose external financing, or choose capital structure, is a heavily researched topic. Since the discovery of the irrelevance of the capital structure on the firm value under perfect markets and absence of taxes, researchers have investigated factors which may affect the capital structure decision.

Static tradeoff theory argues there are costs and benefits of debt. In particular, costs of debt include the direct and indirect costs of bankruptcy, while the benefits include tax deductibility of interest expenses. By analyzing the benefits and costs, firms choose an optimal leverage and try to maintain this ratio in their balance sheet. Assuming insiders know more about the company than outsiders, pecking order theory argues firms prefer internal financing, and when external financing is required, they choose debt over equity without any target or optimal leverage. The two theories may give different predictions, which may yield testable hypotheses. For example highly profitable firms would not need external financing, so would not raise debt according to pecking order theory. However, according to tradeoff theory, for highly profitable firms, bankruptcy costs are lower, so they would have an incentive to issue debt. Empirical studies find support for target leverage (Bradley, etal, 1984) and also support for pecking order; a negative relation of profitability with market debt ratio (debt/market value of equity) (Titman and Wessels, 1988).

Especially the studies on developing countries, the results of the studies have been less conclusive. The results typically change with sectors and time period under investigation. Mismeasured variables pose a threat to the validity of tests, the role of other stakeholders and supply side of capital should be investigated more (Graham and Leary, 2011).

Construction sector is a particular sector, which requires large initial capital outlays, project life times and cash payments are typically long term. This study examines the effects of asset tangibility, profitability, size and liquidity on debt ratio for construction companies in Europe and Central Asia Region which mostly comprises of developing countries. Asset tangibility, profitability and liquidity are found to be negatively associated with higher leverage consistent with pecking order theory. Moreover, the negative relation between debt ratio and asset tangibility comes from the companies in Russia and Romania.

The paper is organized as follows. Section 2 reviews the literature, Section 3 discusses the model and hypotheses, Section 4 presents the data and descriptive statistics and Section 5 presents and discusses the results.

\section{Literature Review}

Under perfect capital markets and absence of taxes, it has been shown that debt ratio does not change the value of the company (Modigliani and Miller, 1958). Static tradeoff theory emerged in which costs of debt, such as bankruptcy, are balanced against benefits, such as tax shields associated interest payments provide, in order to obtain an optimal debt structure (Kim, 1978) (Lee and Barker, 1977). In pecking order theory, firms prefer internal financing to external financing, and in the latter, prefer issuing debt to equity, due to the information asymmetry between owners and the market (Myers, 1984). Agency cost theory posits that firms may increase their debt to reduce the free cash flow by increasing interest expense to alleviate the agency problem between owners and managers (Jensen and Meckling, 1976). According to market timing theory, firms sell shares when they believe the stock price is high, and engage in share buybacks when the stock price is low, and the effects of these actions have persistent effects on the capital structure (Baker and Wurgler, 2002).

There is an extended literature on testing these theories empirically, with some shortcomings withstanding (Graham and Leary, 2011). Based on the data between 1996 and 2004 on 15 EU countries on construction sector, firm size is positively related to debt and market leverage. Asset utilization, profitability and risk (profit variability) are negatively related, while liquidity and asset tangibility are not significantly related. Growth opportunities are negatively related to book leverage but positively with market leverage (Feidakis and Rovolis, 2007). 
In UK companies between 1984 and 1996, profitability, liquidity and growth opportunities are found to be negatively related to debt ratio, while size has no effect (Ozkan, 2001). Using the data on UK companies between 1989 and 1996, it is found that property asset intensity, development activities are positively, and trading activities and size are negatively related to book leverage (Ooi, 1999).

Using the cross sectional data from France, Germany, Japan, the UK, and the US of 1992 or 1993, it has been found that asset tangibility has a positive and profitability has a negative effect on leverage across all countries. The effect of size is positive for US, UK and Japan but insignificant in Germany and France (Wald, 1999).

Cross industry studies, especially on construction sector, on capital structure are less numerous. In a cross industry study based on US construction companies, market-to-book ratio, profitability and firm age are found to be negatively related to leverage (measured as long term debt to assets), and firm size is positively related to leverage (Talberg, et.al., 2008).

There are also studies on construction sector in developing markets. Construction sector differs from other sectors in that the projects undertaken are usually long term and require significant capital outlays.

The evidence on the effects of firm variables on leverage is largely inconclusive in developing markets. Based on the data between 2000 and 2010 of construction companies in South Korea, firm size has a positive effect while profitability and asset tangibility negatively affects book leverage (Yoo, et.al., 2014). In Malaysia, based on the data between 2001 and 2007, firm sales (proxy for size), asset tangibility and growth opportunities have positive effect on leverage, while profitability has a negative effect on leverage (Baharuddin, et.al.,2011). Another study in Malaysia using the data between 2005 and 2009 found profitability is positively related and asset growth is negatively related to leverage (Ramezanalivaloujerdi, et.al., 2015). Between 2002 and 2011, on book leverage, firm size has a negative effect in Russia, positive effect in India. Asset tangibility and firm size positively affects leverage in India, while growth opportunities has a negative effect. In China, asset tangibility is found to have a positive effect. The size and significance of these effects depend on the debt level of companies (Silva, et.al., 2016). Based on the construction company data in Indonesian Stock Exchange between 2009 and 2014, profitability increases the debt ratio (Gunardi, 2020). Asset tangibility is significantly negatively correlated with book leverage on Omani listed construction companies (Al Ani and Al Amri, 2005). Profitability, liquidity and asset tangibility are negatively, size and asset turnover are positively related to debt ratio in Romanian construction companies (Serghiescu and Văidean, 2014). A study based on Slovenian firms between 1999 and 2006 finds asset tangibility and profitability are negatively related to book leverage, while size is positively related (Črnigoj and Mramor, 2009).

\section{Model and Methodology}

A fixed effect panel data model was employed as follows.

$$
\begin{aligned}
& \text { Book Leverage }_{i t}=\beta_{1} \text { LogFixedAssetRati o }_{\text {it }}+\beta_{2} \text { EBITTA }_{\text {it }}+\beta_{3} \text { LogAssets } \\
& +\beta_{4} \text { LogLiquidity }+u_{i}+v_{t}+\varepsilon_{i t}
\end{aligned}
$$

Depending on the postestimation tests performed, random effects and OLS were also employed where the associated diagnostic tests of corresponding models failed.

The variables are book leverage (debt ratio=total liabilities/total assets), asset tangibility (fixed asset ratio=plant property and equipment over total assets), profitability ratio (EBIT over TA), size (log(assets)), liquidity (current ratio) and operating leverage (percentage change in EBIT over percentage change in sales). All of the variables were computed using only balance sheet and income statement data. Fixed asset ratio, assets as well as liquidity was transformed by log function, which will be explained in the later section.

From a tradeoff theory standpoint, fixed asset ratio is expected to positively affect leverage, as companies with more fixed assets may find it easier to access debt. On the other hand, companies with higher fixed asset ratio have lower cash, and thus lower agency costs. Therefore, they have less incentive to issue debt, from an agency cost perspective. From a pecking order viewpoint, companies with more fixed assets than intangible assets may have less information asymmetry between the owners and market, and may use more equity.

Highly profitable (EBIT/TA ratio) companies, according to tradeoff theory, will have more incentive to keep higher levels of debt to utilize tax shields. Also, from the agency cost theory perspective, these companies have more excess cash and has more incentive to reduce the excess cash through higher debt. From the pecking order viewpoint, these companies have lower motives to seek external financing so their debt ratio would be lower.

According to tradeoff theory, larger (more assets) companies have more debt since these firms are typically more diversified, so the bankruptcy risk is smaller, reducing the cost of debt. Since these companies are monitored more by the market participants and regulatory authorities, there exists less information asymmetry between the owners and managers. So, according to agency cost theory, they have less incentive to issue debt.

Companies with higher liquidity (current ratio) may have lower probability of bankruptcy or even may use working capital to secure financing, thus lowering the cost of debt. So they have more incentive to take on debt 
according to tradeoff theory. From an agency cost perspective, these companies have more cash. So, to solve the agency problem between owners and managers, they have an incentive to take on more debt. From a pecking order standpoint, they have more internal resources and thus have less incentive to seek outside resources, and thus have lower debt.

\section{Data}

Corporate financial data of construction companies (listed and delisted) with assets more than 3 million USD in Europe and Central Asia region was downloaded from EMIS Database. The data for which any of the variables under study is missing was dropped. The final dataset contains 2607 company-year observations of 184 companies from 16 countries from 1993 to 2019 . The data is winsorized at $1 \%$ from both sides.

Table 1 shows the means of variables by country, and number of companies in each country. Financial ratios differ across countries even if they are all in construction sector. Comparing Romanian construction companies with other studies leverage is higher, fixed asset ratio is smaller, size is smaller (Serghiescu, L. and Văidean, 2014). Book leverage is larger than reported in another study focusing on Russia, however this study focuses on construction companies (Silva, et.al., 2016). The data on Poland are similar to another study which focuses on all sectors.

\begin{tabular}{|c|c|c|c|c|c|c|c|c|c|}
\hline & $\begin{array}{l}\text { No of } \\
\text { comp. }\end{array}$ & No of obs & Min year & Max year & $\begin{array}{l}\text { Avg Debt } \\
\text { to asset } \\
\text { ratio }\end{array}$ & $\begin{array}{c}\text { Avg } \\
\text { Fixed } \\
\text { Asset } \\
\text { Ratio }\end{array}$ & $\begin{array}{c}\text { Avg } \\
\text { Current } \\
\text { Ratio }\end{array}$ & $\begin{array}{c}\text { Avg } \\
\text { EBIT/TA } \\
\text { ratio }\end{array}$ & $\begin{array}{c}\text { Log } \\
\text { (Asts) }\end{array}$ \\
\hline Bulgaria & 4 & 63 & 2001 & 2019 & 0.37 & 0.15 & 3.79 & 0.03 & 9.76 \\
\hline Croatia & 6 & 97 & 1999 & 2019 & 0.65 & 0.35 & 1.08 & -0.00 & 11.06 \\
\hline Estonia & 2 & 6 & 2008 & 2016 & 0.19 & 0.01 & 13.93 & 0.02 & 11.02 \\
\hline Kazakhstan & 1 & 9 & 2010 & 2018 & 0.20 & 0.75 & 1.97 & 0.10 & 14.72 \\
\hline Latvia & 1 & 9 & 2007 & 2015 & 0.40 & 0.19 & 0.70 & 0.18 & 10.15 \\
\hline Lithuania & 1 & 4 & 2006 & 2010 & 0.01 & 0.00 & 1.79 & 0.11 & 11.25 \\
\hline Moldova & 1 & 2 & 2017 & 2018 & 0.46 & 0.54 & 1.06 & 0.00 & 8.66 \\
\hline Montenegro & 1 & 2 & 2017 & 2018 & 0.08 & 0.32 & 8.39 & -0.01 & 10.18 \\
\hline North Macedonia & 4 & 41 & 2006 & 2019 & 0.49 & 0.25 & 1.28 & 0.01 & 10.73 \\
\hline Poland & 81 & 1326 & 1993 & 2019 & 0.46 & 0.12 & 3.16 & 0.04 & 10.36 \\
\hline Romania & 13 & 165 & 2005 & 2019 & 0.54 & 0.44 & 2.59 & 0.02 & 9.19 \\
\hline Russia & 37 & 474 & 2001 & 2019 & 0.67 & 0.13 & 1.85 & 0.05 & 11.39 \\
\hline Serbia & 2 & 25 & 2005 & 2018 & 0.54 & 0.30 & 1.32 & 0.07 & 9.04 \\
\hline Slovakia & 8 & 149 & 1995 & 2019 & 0.45 & 0.33 & 2.55 & 0.04 & 9.73 \\
\hline Turkey & 9 & 88 & 2005 & 2019 & 0.48 & 0.19 & 2.04 & 0.04 & 11.49 \\
\hline Ukraine & 13 & 147 & 2001 & 2019 & 0.74 & 0.18 & 2.38 & 0.02 & 10.51 \\
\hline $\mathrm{N}$ & 184 & 2607 & 1993 & 2019 & & & & & \\
\hline
\end{tabular}

Table 1. Descriptive Statistics by Countries Source: Author's Own Calculations.

Table 2 shows the correlations between the variables. Debt to asset ratio is negatively correlated with fixed asset ratio (asset tangibility), current ratio (liquidity), and EBIT/TA ratio (profitability), in accordance with pecking order, but positively related to assets (size), in accordance with tradeoff theory. Other studies with developing markets found similar correlations with respect to profitability and size of Oman companies (Al Ani and Al Amri, 2015), and size, fixed asset ratios, profitability and liquidity of South Korean companies (Choi, et.al., 2014). Companies with higher fixed assets tend to have lower liquidity (current ratio), lower profitability (EBIT/TA) and be smaller in size.

\begin{tabular}{llllll}
\hline & $\begin{array}{l}\text { Debt to asset } \\
\text { ratio }\end{array}$ & Fixed asset ratio & Current ratio & $\begin{array}{l}\text { EBIT/TA } \\
\text { ratio }\end{array}$ & $\begin{array}{l}\text { Log } \\
\text { (asset) }\end{array}$ \\
\hline Debt to asset ratio & 1.00 & & & & \\
Fixed asset ratio & $-0.03^{*}$ & 1.00 & & & \\
Current ratio & $-0.42^{* * *}$ & $-0.17^{* * *}$ & 1.00 & & \\
EBIT/TA ratio & $-0.04^{*}$ & $-0.06^{* * *}$ & $-0.07 * * *$ & 1.00 & 1.00 \\
Log(asset) & $0.20^{* * *}$ & $-0.26^{* * *}$ & $-0.04 * *$ & -0.01 & \\
\hline$t$ statistics in parentheses $* p<0.1, * * p<0.05, * * * p<0.01$ & & &
\end{tabular}

Table 2. Correlations of Variables Source: Author's Own Calculations.

Table 3 shows the descriptive statistics of the variables under study. Debt to asset (leverage) ratios are similar to other studies in developing countries; 0.60 in construction sectors in South Korea (Choi, et.al., 2014), 0.59-0.63 in Slovenia (Črnigoj and Mramor, 2009). The variables fixed asset ratio and current ratio has been transformed by 
natural log, as they exhibit a high degree of skewness. The transformed variables show better properties in terms of range and skewness.

\begin{tabular}{|c|c|c|c|c|c|c|c|c|}
\hline & $\mathrm{N}$ & Mean & St.Dev. & Min & $25 \%$ & $\begin{array}{c}50 \% \\
\text { (Median) } \\
\end{array}$ & $75 \%$ & Max \\
\hline Debt to asset ratio & 2607 & 0.52 & 0.26 & 0.01 & 0.33 & 0.54 & 0.72 & 0.98 \\
\hline Fixed asset ratio & 2607 & 0.18 & 0.21 & 0.00 & 0.01 & 0.10 & 0.27 & 0.82 \\
\hline $\begin{array}{l}\log (\text { Fixed asset } \\
\text { ratio) }\end{array}$ & 2607 & 0.15 & 0.16 & 0.00 & 0.01 & 0.10 & 0.24 & 0.60 \\
\hline EBIT/TA ratio & 2607 & 0.04 & 0.09 & -0.26 & -0.00 & 0.03 & 0.08 & 0.37 \\
\hline $\log ($ asset $)$ & 2607 & 10.50 & 1.74 & 6.66 & 9.21 & 10.49 & 11.68 & 15.00 \\
\hline Current ratio & 2607 & 2.67 & 4.64 & 0.04 & 1.02 & 1.39 & 2.34 & 32.32 \\
\hline $\log ($ Current ratio) & 2607 & 1.03 & 0.60 & 0.04 & 0.70 & 0.87 & 1.21 & 3.51 \\
\hline Observations & 2607 & & & & & & & \\
\hline
\end{tabular}

Table 3. Descriptive Statistics Source: Author's Own Calculations.

\section{Results}

Table 4 shows the results of the regressions. Columns (1) to (3) show results without time dummy variables, and columns (4) to (6) show results with time dummy variables. Based on the diagnostic tests shown, model (6) passes the diagnostic tests. Other regressions results are displayed, since by using fixed effects in (6) cross country variation in leverages would be omitted, and the results are the same without the fixed effects.

In all specifications, debt ratio is negatively related to fixed asset ratio (asset tangibility), EBIT/TA ratio (profitability) and log of current ratio (liquidity), but positively related to size. The results are consistent with the findings in the literature for construction companies (Yoo, et.al., 2014) and Slovenia (Črnigoj and Mramor, 2009), but not studies on Malaysia (Baharuddin, et.al.,2011) (Ramezanalivaloujerdi, et.al., 2015), India and China (Silva, et.al., 2016).

These results are largely consistent with Pecking Order framework, except size. Similar conclusion are reached by a study on Polish companies (Mazur, 2007). In Table 4, in the regression with time dummies (6) size loses significance, and time effects are significant. This shows it is important to add time covariates into leverage regressions (Feidakis and Rovolis, 2007) (Gunardi, et.al.,2020).

\begin{tabular}{|c|c|c|c|c|c|c|}
\hline $\begin{array}{l}\text { Dependent variable } \\
\text { Debt to asset ratio }\end{array}$ & (1) & $(2)$ & (3) & (4) & $(5)$ & $(6)$ \\
\hline \multirow[t]{2}{*}{ Log(Fixed asset ratio) } & $-0.17 * * *$ & $-0.14 * *$ & $-0.14 * *$ & $-0.19 * * *$ & $-0.16 * *$ & $-0.16 * *$ \\
\hline & $(0.03)$ & $(0.06)$ & $(0.07)$ & $(0.03)$ & $(0.06)$ & $(0.07)$ \\
\hline \multirow[t]{2}{*}{ EBIT/TA ratio } & $-0.12 * * *$ & $-0.23 * * *$ & $-0.24 * * *$ & $-0.12 * *$ & $-0.23 * * *$ & $-0.25 * * *$ \\
\hline & $(0.05)$ & $(0.06)$ & $(0.06)$ & $(0.05)$ & $(0.06)$ & $(0.07)$ \\
\hline \multirow[t]{2}{*}{ Log(Asset) } & $0.02 * * *$ & $0.02 * *$ & $0.01 *$ & $0.02 * * *$ & $0.02 * *$ & 0.02 \\
\hline & $(0.00)$ & $(0.01)$ & $(0.01)$ & $(0.00)$ & $(0.01)$ & $(0.01)$ \\
\hline \multirow[t]{2}{*}{ Log(Current ratio) } & $-0.24 * * *$ & $-0.17 * * *$ & $-0.16^{* * *}$ & $-0.25 * * *$ & $-0.17 * * *$ & $-0.16^{* * *}$ \\
\hline & $(0.01)$ & $(0.02)$ & $(0.02)$ & $(0.01)$ & $(0.02)$ & $(0.02)$ \\
\hline Company effects & No & Yes (re) & Yes (fe) & No & Yes (re) & Yes (fe) \\
\hline Time dummy vars & No & No & No & Yes & Yes & Yes \\
\hline Observations & 2607 & 2607 & 2607 & 2607 & 2607 & 2607 \\
\hline$R^{2}$ & 0.35 & & 0.20 & 0.37 & & 0.21 \\
\hline Adjusted $R^{2}$ & 0.35 & & 0.20 & 0.36 & & 0.20 \\
\hline $\mathrm{F}$ & $351.59 * * *$ & & 25.11 & 49.88 & & \\
\hline $\mathrm{N}$ (groups) & & 184 & 184 & & 184 & 184 \\
\hline Hausmann test stat & & & $46.33 * * *$ & & & $108.71 * * *$ \\
\hline (df) & & & (4) & & & (30) \\
\hline Wald test for heterosce. & & & $1.6 \mathrm{e}+33 * * *$ & & & $1.0 \mathrm{e}+33 * * *$ \\
\hline (df) & & & (184) & & & (184) \\
\hline $\begin{array}{l}\text { Breusch Pagan LM test for } \\
\text { random effects }\end{array}$ & & $2463.84 * * *$ & & & $2194.96 * * *$ & \\
\hline Joint test for time effects & & & & $2.60 * * *$ & $263.04 * * *$ & $7.45 * * *$ \\
\hline$(\mathrm{df} 1, \mathrm{df} 2)$ or $(\mathrm{df})$ & & & & $(26,2576)$ & (26) & $(26,183)$ \\
\hline
\end{tabular}

Robust standard errors in parentheses $* p<0.1$, ** $p<0.05, * * * p<0.01$

Table 4. Regression Results of Debt to Assets Ratio Source: Author's Own Calculations

Table 5 shows the separate regression results for the largest countries in the sample. For each country different methods were used as suggested by the diagnostic tests. In particular, as the number of groups in countries drop, it became harder to estimate time dummy variables under heteroscedasticity. 
In Table 5, Russia and Romania are the countries where fixed asset ratio negatively affects the debt ratio, while in other countries the effect is statistically insignificant. This is consistent with the OLS regressions of the Romania study (Serghiescu and Văidean, 2014), but not with the study on Russia (Silva, et.al., 2016). This may be due to Russian and Romanian construction companies utilizing more fixed assets (median fixed asset ratios are 9\% and $44 \%$ respectively) compared to other countries like Poland (4\%).

Profitability (EBIT/TA ratio) loses significance in Russia, Romania and Turkey. Also, liquidity (current ratio) is negatively related to debt ratio in all countries except Romania. These two results may be due to reduced sample size.

\begin{tabular}{|c|c|c|c|c|c|}
\hline $\begin{array}{l}\text { Dependent variable } \\
\text { Debt to asset ratio }\end{array}$ & $\begin{array}{l}\text { Poland } \\
\text { (1) }\end{array}$ & $\begin{array}{l}\text { Russia } \\
\text { (2) }\end{array}$ & $\begin{array}{l}\text { Romania } \\
\text { (3) }\end{array}$ & $\begin{array}{l}\text { Turkey } \\
\text { (4) }\end{array}$ & $\begin{array}{l}\text { Others } \\
(5)\end{array}$ \\
\hline $\log$ (Fixed asset ratio) & $\begin{array}{c}0.04 \\
(0.09)\end{array}$ & $\begin{array}{c}-0.34 * * * \\
(0.12)\end{array}$ & $\begin{array}{c}-0.58 * * * \\
(0.16)\end{array}$ & $\begin{array}{l}-0.18 \\
(0.14)\end{array}$ & $\begin{array}{l}-0.23 \\
(0.22)\end{array}$ \\
\hline EBIT/TA ratio & $\begin{array}{c}-0.18 * * \\
(0.08)\end{array}$ & $\begin{array}{l}-0.19 \\
(0.13)\end{array}$ & $\begin{array}{l}-0.30 \\
(0.25)\end{array}$ & $\begin{array}{l}0.04 \\
(0.09)\end{array}$ & $\begin{array}{l}-0.39 * \\
(0.23)\end{array}$ \\
\hline Log(Asset) & $\begin{array}{c}0.02 \\
(0.01)\end{array}$ & $\begin{array}{c}0.02 \\
(0.02)\end{array}$ & $\begin{array}{l}-0.10 \\
(0.07)\end{array}$ & $\begin{array}{c}0.03 * * \\
(0.01)\end{array}$ & $\begin{array}{c}0.01 \\
(0.02)\end{array}$ \\
\hline Log(Current ratio) & $\begin{array}{c}-0.16^{* * * *} \\
(0.02)\end{array}$ & $\begin{array}{c}-0.21 * * * \\
(0.05)\end{array}$ & $\begin{array}{l}-0.10 \\
(0.06)\end{array}$ & $\begin{array}{c}-0.35 * * * \\
(0.09)\end{array}$ & $\begin{array}{c}-0.08 * * * \\
(0.03)\end{array}$ \\
\hline Company effects & Yes (fe) & Yes (re) & Yes (re) & No & Yes (fe) \\
\hline Time fixed effects & No & No & No & No & No \\
\hline Observations & 1326 & 474 & 165 & 88 & 466 \\
\hline$R^{2}$ & 0.25 & 0.28 & 0.18 & 0.29 & 0.19 \\
\hline Adjusted $R^{2}$ & 0.25 & 0.28 & 0.16 & 0.25 & 0.18 \\
\hline $\mathrm{F}$ & 16.84 & 15.81 & 10.02 & 21.25 & 5.40 \\
\hline $\mathrm{N}$ groups & 81 & 37 & 13 & 9 & 41 \\
\hline
\end{tabular}

Table 5. Regression Results of Debt to Assets Ratio by Countries Source: Author's Own Calculations.

\section{Conclusion}

In this study, the effects of asset tangibility (fixed asset ratio), profitability (EBIT to total assets), size (assets) and liquidity (current ratio) on capital structure are examined for the listed and delisted construction companies in European and Central Asian region.

Debt ratio is significantly negatively related to asset tangibility, profitability and liquidity. The significance of size drops when time dummies are introduced, which shows the importance of adding time varying covariates. The results provide support for pecking order theory of capital structure.

Country-wise regressions show that negative effect of asset tangibility arise from Russia and Romania, while it is not present in Poland and other countries.

\section{References}

- $\quad \mathrm{Al}$ Ani and Al Amri, 2015. "The determinants of capital structure: an empirical study of Omani listed industrial companies", Business: Theory and Practice, 16(2), p.159.

- Baharuddin, Khamis, Mahmood and Dollah, 2011. "Determinants of capital structure for listed construction companies in Malaysia", Journal of Applied Finance and Banking, 1(2), p.115.

- Baker and Wurgler, 2002. "Market timing and capital structure", The Journal of Finance, 57(1), p.1.

- Bradley, Jarrell and Kim, 1984. "On the existence of an optimal capital structure: Theory and evidence", The Journal of Finance, 39(3), p.857.

- Choi, Yoo, Kim and Kim, 2014. "Capital structure determinants among construction companies in South Korea: A quantile regression approach”, Journal of Asian Architecture and Building Engineering, 13(1), p.93.

- Črnigoj and Mramor, 2009. "Determinants of capital structure in emerging European economies: Evidence from Slovenian firms", Emerging Markets Finance and Trade, 45(1), p.72.

- Feidakis and Rovolis, 2007. "Capital structure choice in European Union: evidence from the construction industry”, Applied Financial Economics, 17(12), p.989.

- Graham and Leary, 2011. "A Review of Empirical Capital Structure Research and Directions for the Future”, Annual Review of Financial Economics, 3(1), p.309.

- Gunardi, Firmansyah, Widyaningsih, and Rossi, 2020. "Capital Structure Determinants of Construction Firms: Does Firm Size Moderate the Results?”, Montenegrin Journal of Economics, 16(2), p.93. 
- Jensen and Meckling, 1976. "Theory of the firm: Managerial behavior, agency costs and ownership structure", Journal of Financial Economics, 3(4), p.305.

- Kim, 1978. "A mean-variance theory of optimal capital structure and corporate debt capacity", The Journal of Finance, 33(1), p.45.

- Lee and Barker, 1977. "Bankruptcy costs and the firm's optimal debt capacity: a positive theory of capital structure", Southern Economic Journal, p.1453.

- Mazur, 2007. "The determinants of capital structure choice: evidence from Polish companies", International Advances in Economic Research, 13(4), p.495.

- Miller, 1977. "Debt and taxes", The Journal of Finance, 32(2), p.261.

- Modigliani and Miller, 1958. "The cost of capital, corporation finance and the theory of investment", The American Economic Review, 48(3), p.261.

- Myers, 1984. “The Capital Structure Puzzle” The Journal of Finance, 39(3), p.574.

- Ooi, 1999. “The determinants of capital structure Evidence on UK property companies”, Journal of Property Investment and Finance, 17(5), p.464.

- Ozkan, 2001. "Determinants of capital structure and adjustment to long run target: evidence from UK company panel data", Journal of Business Finance \& Accounting, 28(1-2), p.175.

- Ramezanalivaloujerdi, Rasiah and Narayanasamy, 2015. "Corporate capital structure and performance of listed construction companies in Malaysia from 2005-2009”, International Business Management, 9(3), p.191.

- Serghiescu and Văidean, 2014. "Determinant factors of the capital structure of a firm-an empirical analysis", Procedia Economics and Finance, 15, p.1447.

- Silva, Santos, Perobelli and Nakamura, 2016. "Capital structure of Brazil, Russia, India and China by economic crisis", RAM. Revista de Administração Mackenzie, 17(3), p.105.

- Talberg, Winge, Frydenberg and Westgaard, 2008. "Capital structure across industries", International Journal of the Economics of Business, 15(2), p.181.

- Titman and Wessels, 1988. "The determinants of capital structure choice”, The Journal of Finance, 43(1), p.1.

- Wald, 1999. "How firm characteristics affect capital structure: an international comparison", Journal of Financial research, 22(2), p.161. 


\title{
Geçiş Ekonomilerinde Kamu Harcamaları ve Ekonomik Büyüme İlişkisi
}

\section{The Relationship between Public Expenditures and Economic Growth in Transition Economies}

\author{
Asst. Prof. Dr. Mustafa Batuhan Tufaner (Beykent University, Turkey)
}

\begin{abstract}
The effect of public expenditures on economic growth gained importance, especially after the First World War. In this study, the effect of public expenditures on economic growth was analyzed using data from the 1996-2017 period for 12 Transition Economies (Azerbaijan, Belarus, Armenia, Georgia, Kazakhstan, Kyrgyzstan, Moldova, Russia, Tajikistan, Turkmenistan, Ukraine, and Uzbekistan) in the transition period. In this context, the relationship between public expenditures and economic growth is investigated by applying unit root test, short and long term cointegration tests and causality tests. According to the results of the analysis, there is a long-term negative cointegration relationship between public expenditures and economic growth. However, there is a two-way causal relationship between public expenditures and economic growth.
\end{abstract}

\section{Giriş}

Kamu kesiminin ekonomik faaliyetlerdeki yeri ve önemi iktisat literatüründe uzun yıllardan beri tartışma konusu olmuştur. $\mathrm{Bu}$ tartışmaların odak noktasını, kamu harcamalarının ekonomik büyüme üzerindeki etkinliği oluşturmaktadır. Kamu harcamaları ile ekonomik büyüme arasındaki ilişkinin tarihsel sürecine bakıldığında, 1917 yılındaki Rus Devrimi'nin ve 1929 yılında yaşanan Büyük Buhran'ın dönüm noktaları olduğu ifade edilebilmektedir. Özellikle, Büyük Buhran döneminde Klasik iktisadi paradigmanın bu krize çözüm bulamaması bu çıkış noktasının temel nedenini oluşturmaktadır.

Kamu harcamaları ile ekonomik büyüme arasındaki ilişki 19. yüzyıldan beri tartışılagelen bir konudur. Kamu harcamaları ile ekonomik büyüme arasındaki ilişki, Wagner ve Keynes tarafından geliştirilen iki farklı teorik çerçeveye dayanmaktadır. Wagner ekonomik büyümenin kamu harcamalarının nedeni olduğunu ileri sürerken; Keynes ise kamu harcamalarının ekonomik büyümenin nedeni olduğunu ileri sürmektedir.

Özellikle geçiş sürecindeki ekonomilerde kamu harcamaları, milli gelirin büyük bir kısmını oluşturmaktadır. Geçiş ekonomilerinde kamu harcamalarının ekonomik büyümeye etkisi konusunda literatürde fazla çalışma bulunmamaktadır. Bu bağlamda, geçiş ekonomilerinde kamu harcamalarının ekonomik büyüme üzerindeki etkisinin ortaya konulması hem teorik hem de ampirik açıdan büyük önem taşımaktadır. Bu amaçla, çalışmada 12 geçiş ekonomisinde kamu harcamalarının ekonomik büyüme üzerindeki etkisi araştırılmaktadır. Bu doğrultuda, çalışmanın nispeten kapalı ekonomiler olarak tanımlanan geçiş ekonomilerinin iktisadi gelişim sürecinin incelenmesine yönelik literatüre katkı yapması düşünülmektedir.

Çalışmanın ilk kısmında, kamu harcamaları ile ekonomik büyüme arasındaki ilişkiyi ele alan çalışmalara yönelik ampirik literatür ele alınmaktadır. İlerleyen kısımda, kamu harcamaları ile ekonomik büyüme arasındaki ilişkiyi açıklayan teorik çerçeve sunulmaktadır. Takip eden kısımda, kamu harcamaları ile ekonomik büyüme arasındaki ilişkinin ampirik analizi yer almaktadır. Bu bağlamda, 12 geçiş ekonomisi 1996-2017 dönemi için panel veri analiziyle incelenmektedir.

\section{Teorik Çerçeve}

Kamu harcamaları ile ekonomik büyüme arasındaki ilişki, iktisat literatürünün temel yapı taşlarından birini oluşturmaktadır. Temelde, kamu harcamalarının artması ekonomik büyümeyi arttırsa da, bu etki azalabilmekte hatta ekonomik büyümeyi azaltabilmektedir. Kamunun ekonomik faaliyetlerde yer almaması durumunda üretim düzeyi nispeten düşüktür. $\mathrm{Bu}$ durumda kamunun payının artması, ekonomik faaliyetlerin yükselmesini sağlamaktadır. Ancak, vergi oranlarının artması ve buna bağlı olarak kamu harcamalarının azalan getirisi üretim düzeyini ve etkinliği azaltabilmektedir.

Kamu harcamalarının etkinliği ve üretim düzeyi üzerindeki etkisi, ülkelerin sosyal, ekonomik ve hukuki yapısına göre değişebilmektedir. Uzun bürokratik süreçler veya yüksek kamu borcu faizleri, kamusal harcamaların etkinliğini azaltmakta ve üretim seviyesini düşürmektedir. Kamu harcamaları ile ekonomik büyüme arasındaki ilişkiyi belirleyen üç temel faktör bulunmaktadır. Bunlar; ülkelerin gelişmişlik düzeyleri, kamu harcamalarının türü ve kamu harcamalarının finansman yöntemleridir. Az gelişmiş ülkelerde kamu harcamalarının artması ekonomik büyümeyi pozitif yönde etkilerken, gelişmiş ülkelerde ise negatif yönde etkileyecektir. Kamunun beşeri sermaye yatırımlarına yönelmesi ekonomik büyümeyi teşvik ederken, kamusal tüketim harcamalarının artması ise ekonomik büyümeyi düşürecektir. Benzer biçimde, kamusal harcamaların merkez bankası kaynakları veya iç 
borçlanma yöntemleriyle finanse edilmesi ekonomik büyüme üzerinde negatif bir etkiye sahip olacaktır (Uzay; 2002; 162).

Kamu harcamalarının ekonomik büyüme üzerinde olumlu etkileri kadar olumsuz etkileri de bulunabilmektedir. Özel sektörün yetersiz kaldığı alanlarda faaliyet göstermek suretiyle talebin arttırılması, altyapı hizmetlerinin sağlanması, özel yatırımların teşvik edilmesi ve rekabet yaratarak karşılaştırmalı üstünlük oluşturulması kamu harcamalarının olumlu etkileri arasında gösterilebilmektedir. Kamusal harcamaların en büyük olumsuz etkisi ise, özel sektör yatırımlarının dışlanmasıdır. Bunun yanı sıra; azalan getiri, piyasa şartlarına kısa sürede uyum sağlanamaması ve kamusal harcamaların verimliliğinin düşük olması kamusal harcamaların diğer olumsuz etkileri arasında gösterilebilmektedir.

\section{Literatür}

Kamu harcamaları ile ekonomik büyüme arasındaki ilişki çeşitli teorik ve ampirik çalışmalarla incelenmiştir. Çalı̧̧maların bir kısmı kamusal harcamaların ekonomik büyüme üzerinde pozitif etkisi olduğunu ileri sürerken, bir kısmı ise negatif bir etkisi olduğunu ortaya koymaktadır. Bu çalışmalarda farklı ülke gruplarının, araştırma yöntemlerinin ve ampirik metotların uygulanması farklı sonuçlar ortaya çıkarabilmektedir. Dolayısıyla, bu çalışmaların kendi koşulları içerisinde değerlendirilmesi ve sonuçlarının buna göre yorumlanması önem taşımaktadır.

\begin{tabular}{|c|c|c|c|c|}
\hline Yazar & Yıl Aralığı & Ülke & Yöntem & Sonuç \\
\hline Landau (1986) & $1960-1980$ & $\begin{array}{l}65 \text { Gelişmekte } \\
\text { Olan Ülke }\end{array}$ & Panel regresyon & $\begin{array}{l}\text { Kamu harcamaları ile ekonomik } \\
\text { büyüme arasında negatif bir ilişki } \\
\text { bulunmaktadır. }\end{array}$ \\
\hline Romer (1989) & $1960-1985$ & 112 Ülke & Panel regresyon & $\begin{array}{l}\text { Toplam kamu harcamaları } \\
\text { ekonomik büyümeyi arttırırken, } \\
\text { kamusal yatırım harcamaları ise } \\
\text { ekonomik büyümeyi } \\
\text { azaltmaktadır. }\end{array}$ \\
\hline Barro (1991) & $1960-1985$ & 98 Ülke & Panel regresyon & $\begin{array}{l}\text { Kamu harcamalarının GSYH } \\
\text { içindeki payının artması } \\
\text { ekonomik büyümeyi negatif } \\
\text { yönde etkilerken, kamusal yatırım } \\
\text { harcamalarının artması ise } \\
\text { ekonomik büyümeyi pozitif } \\
\text { yönde etkilemektedir. }\end{array}$ \\
\hline $\begin{array}{l}\text { Oktayer ve } \\
\text { Susam (2008) }\end{array}$ & $1970-2005$ & Türkiye & En Küçük Kareler & $\begin{array}{l}\text { Toplam kamu harcamaları, cari } \\
\text { kamu harcamaları ve yatırım } \\
\text { kamu harcamaları toplam üretimi } \\
\text { arttırmaktadır. }\end{array}$ \\
\hline Ăgayev (2012) & $1995-2009$ & $\begin{array}{l}10 \text { Eski SSCB } \\
\text { Ülkesi }\end{array}$ & $\begin{array}{l}\text { Panel eşbütünleşme } \\
\text { ve nedensellik }\end{array}$ & $\begin{array}{l}\text { Kamu harcamaları ve gelir } \\
\text { düzeyinin eşbütünleşik olduğunu } \\
\text { bulmuştur. Ayrıca, ekonomik } \\
\text { büyümeden kamu harcamalarına } \\
\text { doğru tek yönlü bir nedensellik } \\
\text { ilişkisi tespit edilmiştir. }\end{array}$ \\
\hline $\begin{array}{l}\text { Esen ve Bayrak } \\
\text { (2015) }\end{array}$ & $1990-2012$ & $\begin{array}{l}5 \text { Türk } \\
\text { Cumhuriyeti }\end{array}$ & $\begin{array}{l}\text { Panel eşbütünleşme } \\
\text { ve nedensellik }\end{array}$ & $\begin{array}{l}\text { Kamu harcamaları ile ekonomik } \\
\text { büyüme arasında uzun dönemde } \\
\text { pozitif bir ilişki bulunmaktadır. }\end{array}$ \\
\hline $\begin{array}{l}\text { Balıkçıoğlu } \\
\text { (2016) }\end{array}$ & $1992-2014$ & $\begin{array}{l}12 \text { Geçiş } \\
\text { Ekonomisi }\end{array}$ & Dinamik panel & $\begin{array}{l}\text { Kamu harcamalarından ekonomik } \\
\text { büyümeye doğru bir ilişkiye } \\
\text { rastlanamamıştır. }\end{array}$ \\
\hline $\begin{array}{l}\text { Şanlısoy ve } \\
\text { Ekinci (2019) }\end{array}$ & 1991-2015 & Kazakistan & NARDL & $\begin{array}{l}\text { Kamu harcamalarının artması } \\
\text { ekonomik büyümeyi arttırırken, } \\
\text { kamu harcamalarının azalması ise } \\
\text { ekonomik büyümeyi } \\
\text { etkilememektedir. }\end{array}$ \\
\hline
\end{tabular}

Tablo 1. Kamu Harcamaları ve Ekonomik Büyüme İlişkisini Araştıran Çalışmalar 
Tablodan görüldüğü üzere, kamu harcamaları ile ekonomik büyüme arasındaki ilişkiyi inceleyen çalışmaların sonuçları ülkelere, yıl aralığına ve ampirik yöntemlere göre değişebilmektedir. Çalışmaların bir kısmı kamu harcamalarının ekonomik büyümenin itici gücü olduğunu savunurken, bir kısmı ise ekonomik büyümeyi olumsuz etkileyen bir yük olduğunu savunmaktadır. Dolayısıyla, bu iki değişken arasındaki ilişki için genel geçer bir sonuca ulaşılamamaktadır.

\section{Ampirik Analiz}

Çalışmada kamu harcamaları ile ekonomik büyüme arasındaki ilişki seçilmiş geçiş ekonomileri (Azerbaycan, Beyaz Rusya, Ermenistan, Gürcistan, Kazakistan, Kırgızistan, Moldova, Rusya, Tacikistan, Türkmenistan ve Ukrayna) ve 1996-2017 dönemi için incelenmektedir. Kamu harcamaları için “kamu harcamalarının GSYH'ya oranı”, ekonomik büyüme için ise "GSYH büyüme oranı” değişkenleri kullanılmıştır. Veriler Dünya Bankası/Dünya Kalkınma Göstergeleri veri setinden elde edilmiştir. Çalışmada kullanılan model şu şekildedir;

$$
\mathrm{GSYH}_{\mathrm{it}}=\beta_{0}+\beta_{1 \mathrm{i}} \mathrm{KAMU}_{\mathrm{it}}+\varepsilon_{\mathrm{it}}
$$

Modelde yer alan GSYH gayri safi yurtiçi hasılanın yıllık büyümesini, KAMU ise kamu harcamalarının GSYH'ya oranını ifade etmektedir. $\varepsilon_{\text {it }}$ hata terimini temsil ederken, i modeldeki yatay kesit birimleri, $t$ ise her birime ait zaman boyutunu ifade etmektedir. Panel veri analizinde, öncelikle seriler arasında birimler arası korelasyon olup olmadığ 1 araştırılmaktadır. Birimler arası korelasyonun olmadığı durumda birinci nesil panel veri testleri kullanılırken, birimler arası korelasyon olması durumunda ise ikinci nesil panel veri testleri kullanılmaktadır. Panel veri analizinde birimler arası korelasyonu tespit etmek için Breusch-Pagan (1980) LM testi, Pesaran (2004) CD testi ve Pesaran, Ullah ve Yamagata'nın (2008) NLM testi kullanılmıştır. Modelde, T>N olduğundan Breusch-Pagan LM testi ve Pesaran, Ullah ve Yamagata NLM testinin kullanılması uygundur. Birimler arası korelasyon testlerinde sifir hipotezi birimler arası korelasyon yoktur, alternatif hipotez ise birimler arası korelasyon vardır şeklinde kurulmaktadır.

\begin{tabular}{|l|l|}
\hline Test & İstatistik \\
\hline Breusch-Pagan LM & $168.9 * * *$ \\
\hline NLM & $22.5 * * *$ \\
\hline Pesaran CD & $7.859 * * *$ \\
\hline
\end{tabular}

Not: ***, \%1 anlamlılık düzeyini ifade etmektedir.

Tablo 2. Birimlerarası Korelasyon Testi Sonuçları

\subsection{Birim Kök Testi}

Serilerde birimler arası korelasyon bulunduğundan ikinci nesil panel birim kök testlerinin yapılması gerekmektedir. Bu nedenle, $\mathrm{T}>\mathrm{N}$ koşulu bulunan ve ikinci nesil panel birim kök testleri içerişinde yer alan MADF (Çok Değişkenli Genişletilmiş Dickey Fuller) panel birim kök testi kullanılmıştır. Taylor ve Sarno'nun (1998) önerdiği MADF testinin sıfir hipotezi serinin birim kök içerdiği, alternatif hipotezi ise serinin birim kök içermediği yani durağan olduğu şeklinde kurulmaktadır. MADF test istatistik değeri kritik değerden küçükse serinin durağan olduğu kabul edilmektedir. Dolayısıyla, yapılan birim kök testi sonucunda, her iki serinin de düzeyde durağan olduğu anlaşılmıştır.

\begin{tabular}{|l|l|}
\hline Değișken & MADF İstatistiği \\
\hline GSYH & $560.070^{* *}$ \\
\hline KAMU & $894.648^{* *}$ \\
\hline
\end{tabular}

Not: Gecikme uzunluğu 1 olarak belirlenmiştir. **, \%5 anlamlılı düzeyini ifade etmektedir.

\section{Tablo 3. Birim Kök Testi Sonuçları}

\subsection{Eşbütünleşme Testi}

Kamu harcamaları ile ekonomik büyüme arasındaki uzun dönem ilişkisinin varlığını sınamak için eşbütünleşme analizinin yapılması gerekmektedir. Serilerin birimler arası korelasyon içermesi nedeniyle ikinci nesil panel eşbütünleşme testleri arasında yer alan Westerlund (2007) panel eşbütünleşme testi kullanılmaktadır. $G_{t}$ ve $G_{a}$ grup ortalaması varyans oranı istatistiklerini, $\mathrm{P}_{\mathrm{t}}$ ve $\mathrm{P}_{\mathrm{a}}$ ise panel varyans oranı istatistiklerini temsil etmektedir. Tüm testler için $\mathrm{H}_{0}$ hipotezinin reddedilmesi, eşbütünleşme ilişkisinin reddedilmesi anlamına gelmektedir. Aşağıdaki tabloda yer alan tüm istatistiklere göre $\mathrm{H}_{0}$ hipotezi reddedildiğinden kamu harcamaları ile ekonomik büyüme arasında eşbütünleşme ilişkisinin mevcut olduğu görülmektedir.

\begin{tabular}{|l|l|}
\hline İstatistik & Değer \\
\hline $\mathrm{G}_{\mathrm{t}}$ & $-3.294 * *$ \\
\hline $\mathrm{G}_{\mathrm{a}}$ & $-17.310^{* * *}$ \\
\hline $\mathrm{P}_{\mathrm{t}}$ & $-14.447 * *$ \\
\hline $\mathrm{P}_{\mathrm{a}}$ & $-15.607 * * *$ \\
\hline
\end{tabular}

Not: Gecikme uzunluğu 0-1 aralığında alınmıştır. Bootstrap sayısı 100 olarak belirlenmiştir.

*** ve ** siraslyla \%1 ve \%5 anlamlillk düzeyini ifade etmektedir.

Tablo 4. Eşbütünleşme Testi Sonuçları 


\subsection{Uzun Dönem Eşbütünleșme Testi}

Panel eşbütünleşme testinde kamu harcamaları ile ekonomik büyüme arasındaki uzun dönem ilişkisinin tespit edilmesinin ardından, panel uzun dönem katsayılarının tahmin edilmesi gerekmektedir. Bu amaçla, değişkenlerin yatay kesit ortalamalardan fark alınarak dönüştürüldüğü Pedroni (2001) DOLSMG (Ortalama Grup Dinamik En Küçük Kareler) tahmincisi ile test edilmiştir. Bulunan $t$ istatistik değerinin $t$ tablo değerinden büyük olması durumunda $\mathrm{H}_{0}$ hipotezi reddedilmektedir. Test sonuçlarına göre, uzun dönem parametresinin (-0.2143) t istatistiği anlamlıdır. Dolayısıyla, uzun dönemde kamu harcamalarında meydana gelen bir birimlik artışın ekonomik büyümeyi 0.21 birim azalttığı ifade edilebilmektedir.

\begin{tabular}{|l|l|l|}
\hline Değișken & Katsayı & t-istatistiğ \\
\hline KAMU & -0.2143 & $-3.848^{* *}$ \\
\hline
\end{tabular}

Not: Gecikme uzunluğu 1 olarak belirlenmiştir. **, \%5 anlamlllık düzeyini ifade etmektedir.

Tablo 5. Uzun Dönem Eşbütünleşme Testi Sonuçları

\subsection{Nedensellik Testi}

Eşbütünleşme testinin ardından, modeldeki değişkenler arasında bir nedensellik ilişkisinin olup olmadığına bakılmaktadır. Değişkenler arasındaki nedensellik ilişkisini test etmek için Dumitrescu-Hurlin (2012) panel nedensellik testi kullanılmıştır. Test sonuçlarına göre, değişkenler arasında nedensellik ilişkisi olmadığını ifade eden sıfır hipotezleri reddedilmiş ve en az bir birimde kamu harcamaları ile ekonomik büyüme arasında karşılıklı bir nedensellik ilişkisinin olduğu anlaşılmıştır.

\begin{tabular}{|l|l|l|}
\hline Gecikme sayısı $=1$ & W istatistiği & Z istatistiğ \\
\hline KAMU $>$ GSYH & 2.5061 & $2.7289^{* * *}$ \\
\hline GSYH $>$ KAMU & 3.1202 & $3.9423^{* * *}$ \\
\hline
\end{tabular}

Not: Optimal gecikme uzunluğu Akaike bilgi kriterine göre 1 olarak seçilmiştir.

Tablo 6. Nedensellik Testi Sonuçları

\section{Sonuç}

Kamu kesiminin ekonomik faaliyetlerdeki yeri ve önemi iktisat literatüründe uzun yıllardır tartışılmaktadır. 1929 yılında meydana gelen Büyük Buhran'a kadar Klasik paradigmanın minimal devlet anlayışı hakimken, bu paradigmanın Büyük Buhran'a kapsamlı bir çözüm önerisi getirememesi bu görüşün sorgulanmasına yol açmıştır. Krize çözüm önerisi getiren Keynesyen anlayış, kamu harcamalarının arttırılması vasıtasıyla kamu kesiminin ekonomik faaliyetlerdeki rolünün arttırılmasını önermiştir.

Kamu harcamaları; rekabet yaratmak, altyapı hizmetleri sağlamak, ulusal güvenliği temin etmek ve sosyal dengeyi oluşturmak suretiyle ekonomik büyümeyi olumlu yönde etkilerken; özel sektörü dışlama etkisi, uzun bürokratik süreçler, azalan getiri ve piyasa şartlarına geç uyum sağlanması gibi nedenlerle ekonomik büyümeyi olumsuz yönde etkileyebilmektedir. Bu bağlamda çalışmanın amacı, kamu harcamaları ile ekonomik büyüme arasındaki ilişkiyi araştırmaktır. Çalışmada, devlet güdümlü planlı ekonomiden serbest piyasa ekonomisine geçiş yapan 12 geçiş ekonomisi 1996-2017 dönemini için ampirik olarak analiz edilmiştir. Bu çerçevede, panel veri analizine ilişkin birim kök testi, kısa ve uzun dönem eşbütünleşme testi ve nedensellik testi uygulanmıştır.

Yapılan birim kök testine göre, serilerin düzey değerde durağan olduğu görülmüştür. Ardından, Westerlund panel eşbütünleşme testi yapılmış ve kamu harcamaları ile ekonomik büyüme arasında bir ilişki olduğu tespit edilmiştir. Uzun dönem ilişkinin tespit edilmesi için DOLSMG (Ortalama Grup Dinamik En Küçük Kareler) tahmincisi kullanılmış ve uzun dönemde kamu harcamalarında meydana gelen bir birimlik artışın ekonomik büyümeyi 0.21 birim azalttığı görülmüştür. Bununla birlikte, nedensellik testi sonuçları kamu harcamaları ile ekonomik büyüme arasında karşılıklı bir nedensellik ilişkisinin olduğu tespit edilmiştir. Bunun en önemli nedenleri arasında, rekabetin tam olarak sağlanamaması, özel sektör yatırımlarının dışlanması ve kaynakların verimli ve etkin bir şekilde kullanılamaması gösterilebilmektedir.

\section{Kaynakça}

- $\quad$ Ağayev, 2012. "Kamu Harcamaları ve Ekonomik Büyüme İlişkisi: Eski Sovyetler Birliği Ülkelerinde Wagner Yasası Analizi”, Eskişehir Osmangazi Üniversitesi İİBF Dergisi, Cilt. 7, No. 2, ss. 7-27.

- Balıç̧ığlu, 2016. "Fiscal Policy and Growth: Comparative Analysis of Russia and the other Post Soviet Union Countries", Journal of Business, Economics and Finance, Cilt. 5, No. 1, ss. 98-107.

- Barro, 1991. "Economic Growth in a Cross Section of Countries", The Quarterly Journal of Economics, Cilt. 106, No. 2, ss. 407-443.

- Breusch ve Pagan, 1980. “The Lagrange Multiplier Test and Its Applications to Model Specification in Econometrics, Review of Economic Studies, No. 47, ss. 239-253.

- Dumitrescu ve Hurlin, 2012. "Testing for Granger Non-Causality in Heterogenous Panels", Economic Modelling, Cilt. 29, Say1. 4, ss. 1450-1460. 
- Esen ve Bayrak, 2015. "Kamu Harcamaları ve Ekonomik Büyüme İlişkisi: Geçiș Sürecindeki Türk Cumhuriyetleri Üzerine Bir Uygulama”, Bilig, No. 73, ss. 231-248.

- Landau, 1986. "Government and Economic Growth in the Less Developed Countries: An Empirical Study for 1960-1980”, Economic Development and Cultural Change, No: 35, ss. 35-75.

- Oktayer ve Susam, 2008. "Kamu Harcamalar1-Ekonomik Büyüme İlişkisi: 1970-2005 Yılları Türkiye Örneği”, Atatürk Üniversitesi İktisadi ve İdari Bilimler Dergisi, Cilt. 22, Sayı. 1, ss. 145-164.

- Pedroni, 2001. "Purchasing Power Parity Tests in Cointegrated Panels", The Review of Economics and Statistics, Cilt. 83, Sayı. 4, ss. 727-731.

- Pesaran, 2004. "General Diagnostic Tests for Cross Section Dependence in Panels”, Cambridge Working Paper, Sayı. 0435.

- Pesaran, Ullah ve Yamagata, 2008. "A Bias-Adjusted LM Test of Error Cross Section Independence”, Econometrics Journal, No. 11, ss. 105-127.

- $\quad$ Romer, 1989. "Human Capital and Growth: Theory and Evidence”, National Bureau of Economic Research Working Paper, No. 3173, Cambridge.

- Şanlısoy ve Ekinci, 2019. “Wagner Yasasının Testi: Kazakistan Ekonomisi Bulguları”, Avrasya Uluslararası Araştırmalar Dergisi”, Cilt. 7, No. 19, ss. 428-451.

- Taylor ve Sarno, 1998. "The Behavior of Real Exchange Rates During the Post-Bretton Woods Period", Journal of International Economics, Cilt. 46, Sayı. 2, ss. 281-312.

- Uzay, 2002. "Kamu Büyüklüğü ve Ekonomik Büyüme Üzerindeki Etkileri: Türkiye Örneği (1970-1999)", Erciyes Üniversitesi İktisadi ve İdari Bilimler Fakültesi Dergisi, Say1. 19, ss. 151-172.

- Westerlund, 2007. "Testing for Error Correction in Panel Data”, Oxford Bulletin of Economics and Statistics, No. 69, ss. 709-748. 


\title{
OECD Ülkelerinde Sağlık Harcamaları-Ekonomik Büyüme İlişkisi
}

\section{Health Expenditure-Economic Growth Relationship in OECD Countries}

\author{
Asst. Prof. Dr. Mustafa Batuhan Tufaner (Beykent University, Turkey) \\ Fatma Dizge (Beykent University, Turkey) \\ Zeynep Emir (Beykent University, Turkey)
}

\begin{abstract}
Capital accumulation is one of the most important components of economic growth. Health expenditure is also one of the ways to increase capital accumulation and thus economic growth. Therefore, the relationship between health expenditure and economic growth is of great importance especially for developing countries. In this context, the relationship between health expenditures and economic growth was investigated for the period 2000-2016 and for 36 OECD countries. For this purpose, firstly unit root tests were performed in the study and then panel cointegration and panel causality tests were applied to determine the relationship between the two variables.
\end{abstract}

Since there was a cross-sectional dependence in the variables, second-generation panel tests were used. As a result of the cointegration test, it is understood that there is no cointegration relationship between health expenditures and economic growth. The panel causality test revealed that there was no causality from health expenditures to economic growth, but there was a causality relationship from economic growth to health expenditures. Findings from the study show that health expenditure does not affect economic growth, but economic growth increases health expenditure in the short term. Therefore, it can be stated that developing countries have the advantage of time to increase the quality of health services.

\section{Giriş}

Sağlık, beşeri sermayenin en önemli unsurlarından birini oluşturmaktadır. Bireylerin eğitim süreçlerinde ve iş hayatlarında hem fiziksel hem de zihinsel olarak sağlıklı olmaları, bireylerin motivasyonlarını ve üretim verimliliğini arttırmaktadır. Dolayısıyla, bireylerin tam bir iyilik halinde olmaları, beşeri sermayenin etkinliğini arttırarak ülkelerin ekonomik büyümelerine katkı sağlayabilmektedir.

Çalışmanın amacı, sağlık harcamaları ile ekonomik büyüme arasındaki ilişkiyi araştırmaktır. Bu kapsamda, 36 OECD ülkesi 2000-2016 dönemi için panel veri yöntemiyle analiz edilmektedir. Çalışmada ilk olarak, literatür taraması yapılarak sağlık harcamaları ile ekonomik büyüme arasındaki ilişkiyi ele alan çalışmalara yer verilmiştir. Takip eden bölümün ilk kısmında, serilerde birimlerarası korelasyon olup olmadığını sınamak için Pesaran CD testi yapılmıştır. Ardından, serilerin durağanlığını sınamak amacıyla ikinci nesil panel birim kök testlerinden Levin-Lin \& Chu, Im-Pesaran \& Shin ve CIPS testleri uygulanmıştır. Değişkenler arasındaki eşbütünleşme ilişkisinin tahmini için ikinci nesil panel eşbütünleşme testleri arasında yer alan Westerlund panel eşbütünleşme testi kullanılmıştır. Analizin son aşamasında ise, sağlık harcamaları ile ekonomik büyüme arasındaki nedensellik ilişkisi panel Granger nedensellik testiyle incelenmiştir.

\section{Literatür}

Uluslararası literatüre bakıldığında, ekonomik büyümede sağlık harcamalarının etkisinin çokça merak edilen ve araştırılan bir konu olduğu gözlemlenmektedir. Konu ile ilgili yapılan Türkiye'de ve uluslararası alanda yapılan çalışmalar incelendiğinde iki farklı sonucun elde edildiği ortaya çıkmaktadır. Bunlardan birincisi ekonomik büyümenin sağlık harcamalarını pozitif yönde etkilediği ortaya çıkmıştır. İkincisinin ise negatif yönde etkisi olduğu ve yok denecek kadar az bir orana sahip olduğu ortaya çıkmıştır.

Erdil ve Yetkiner (2004)'in 1990-2000 yılları arasında yapmış oldukları çalışmalarda sağlık harcamaları ile ekonominin büyüme oranı arasındaki nedensellik ilişkileri incelediğinde; ekonomik büyümeden sağlık harcamalarına "düşük ve orta" gelirli ülkelerde, sağlık harcamalarından ekonomik büyümeye ise "yüksek" gelirli ülkelerde bir nedenselliğe rastlandığı görülmüştür (Kamacı ve Uğurlu Yazıc1, 2017;61).

Çetin ve Ecevit (2010), 15 OECD ülkesinin içinde bulunduğu 1990-2006 yılları arasında yapmış oldukları çalışmalarında ampirik analizler yapmışlardır. Bu analizler sonucunda sağlık harcamaları ile ekonomik büyüme arasında zayıf pozitif bir ilişki saptamış oldukları ve bu ilişkinin istatistikî olarak anlamlı olmadığını ifade etmişlerdir. 
Ulusal alanda yapılan ampirik çalışmalardan 12'si incelendiğinde bunlardan iki tanesinin arasında anlamlı bir bağlantıya rastlanmadığı bununla birlikte bir çalışmada ise negatif bağlantıya rastlanmıştır. Yapılan diğer çalışmalarda ise değişkenler arasında pozitif bir etki olduğu görülmüştür.

\begin{tabular}{|c|c|c|c|}
\hline Yazar(lar) & Dönem & Yöntem & Bulgular \\
\hline Kar ve Ağır (2006) & 1926-1994 & $\begin{array}{l}\text { Johansen Eşbütünleşme ve } \\
\text { Nedensellik Testi }\end{array}$ & GSYH $\rightarrow$ sağlık harcamaları \\
\hline Kiymaz vd. (2006) & 1984-1998 & Eşbütünleşme analizi & GSYH $\rightarrow$ sağlık harcamaları \\
\hline Taban (2006) & $1990-2003$ & Nedensellik & GSYH $\leftrightarrow$ sağlık göstergeleri \\
\hline $\begin{array}{l}\text { Yumuşak ve Yıldırım } \\
(2009)\end{array}$ & $1980-2005$ & Zaman serisi analizi & $\begin{array}{l}\text { Doğuşta yaşam } \\
\text { beklentisi } \rightarrow \mathrm{GSYH}\end{array}$ \\
\hline Arısoy vd. (2010) & $1960-2005$ & Zaman serisi analizi & Pozitif ilişki \\
\hline Bozkurt (2010) & $1980-2005$ & $\begin{array}{l}\text { Engle-Granger, Johansen } \\
\text { Kointegrasyon ve Stock Watson }\end{array}$ & Sağlık $\rightarrow$ GSYH \\
\hline Tan vd. (2010) & $1969-2003$ & Zaman serisi analizi & İlişki yok \\
\hline $\begin{array}{l}\text { Tiraşoğlu ve Yıldırım } \\
\text { (2012) }\end{array}$ & $2006-2012$ & $\begin{array}{l}\text { Lee ve Strazicich } \\
\text { (2004) birim kök testi ve tek } \\
\text { kırılmalı Gregory ve Hansen (1996) } \\
\text { eș bütünleşme testi }\end{array}$ & Uzun dönemli bir ilişki \\
\hline Ay vd. (2013) & $1968-2006$ & Eşbütünleşme testi & Pozitif ilişki \\
\hline Akar (2014) & $2004-2013$ & Zaman serisi analizi & Uzun dönemli bir ilişki \\
\hline Şimşir vd. (2015) & $1975-2012$ & ARDL sinır testi & Negatif ilişki \\
\hline Uçan ve Atay (2016) & 2006-2014 & ARDL Test & Pozitif ilişki \\
\hline
\end{tabular}

Tablo 1. Sağllk Harcamaları ve Ekonomik Büyüme İlişkisini Araştıran Ulusal Çalı̧̧malar

Uluslararası yapılan çalışmalardan 12'si incelendiğinde bunlardan iki tanesinin arasında anlamlı bir bağlantıya rastlanmadığı gözlemlenmiştir. Diğer 10 çalışmada ise değişkenler arasında pozitif bir etki olduğu ve bu etkinin sonuçlarının olumlu olduğu görülmüştür.

\begin{tabular}{|l|l|l|l|l|}
\hline Yazar(lar) & Dönem & \multicolumn{1}{|c|}{ Ülke(ler) } & Yöntem & Bulgular \\
\hline Bhargava vd. (2000) & $1965-1990$ & $\begin{array}{l}\text { Gelişmiş ve } \\
\text { gelişmekte olan } \\
\text { ülkeler }\end{array}$ & Panel veri analizi & Pozitif zayıf ilişki \\
\hline $\begin{array}{l}\text { Gerdtham ve Jönsson } \\
\text { (2000) }\end{array}$ & $1960-1997$ & 22 OECD ülkesi & Panel veri analizi & Eşbütünleşik ilişki \\
\hline Bloom vd. (2004) & $1960-1990$ & 104 ülke & Panel veri analizi & Pozitif ilişsi \\
\hline Chakraborty (2004) & $1970-1990$ & 95 ülke & EKK & Pozitif ilişki \\
\hline $\begin{array}{l}\text { Dreger ve Reimers } \\
\text { (2005) }\end{array}$ & $1975-2001$ & 21 OECD ülkesi & Panel veri analizi & Uzun dönemli ilişki \\
\hline Chang ve Ying (2006) & $1980-1998$ & 15 OECD ülkesi & Panel veri analizi & Pozitif ve anlamlı bir ilişki \\
\hline Akram (2009) & $1972-2006$ & Pakistan & Zaman serisi analizi & Kısa dönemde ilişi yok \\
\hline Çetin ve Ecevit (2010) & $1990-2006$ & 15 OECD ülkesi & Panel veri analizi & İlişki yok \\
\hline Narayan vd. (2010) & $1974-2007$ & 5 Asya ülkesi & Panel veri & Pozitif etki \\
\hline Elmi ve Sadeghi (2012) & $1990-2009$ & $\begin{array}{l}\text { Gelişmekte olan } \\
\text { ülkeler }\end{array}$ & $\begin{array}{l}\text { Panel Eşbütünleşme } \\
\text { ve VECM }\end{array}$ & GSYH↔sağlık harcamaları \\
\hline $\begin{array}{l}\text { Selim, Uysal ve Eryiğit } \\
\text { (2014) }\end{array}$ & $2001-2011$ & $\begin{array}{l}\text { 27 AB ülkesi ve } \\
\text { Türkiye }\end{array}$ & $\begin{array}{l}\text { Panel Eşbütünleşme } \\
\text { ve VECM }\end{array}$ & Kisa dönemde pozitif ilişki \\
\hline $\begin{array}{l}\text { Hayaloğlu ve Bal } \\
\text { (2015) }\end{array}$ & $2000-2013$ & $\begin{array}{l}54 \text { Üst orta } \\
\text { gelirli ülke }\end{array}$ & Panel veri analizi & Pozitif ilişki \\
\hline
\end{tabular}

Tablo 2. Sağlık Harcamaları ve Ekonomik Büyüme İliş̧kisini Araştıran Uluslararası Çalışmalar

Ekonomik kalkınma ve büyümede beşeri sermayenin verimliliği büyük öneme sahiptir. Bununla birlikte beşeri sermayeyi geliştirmek ve verimliliğini sürdürebilme amacıyla sağlık harcamalarına düşen payın arttırılması gerekmektedir. Sağlık harcamalarına düşen payın arttırılması, ülkelerde ekonomik kalkınma ve büyümeyi sağlayacaktır. bu bağlamda GSYH ve sağlık harcamalarının birbiriyle ilişkisi literatürde önemli bir yere sahiptir (Akar, 2014:320-321). 
Yardımcığlu (2012), 1975-2008 yılları arasında 25 OECD ülkesini kapsayan çalışmasında sağlık harcamaları ile ekonomik büyüme birbiriyle ilişkisini incelediği çalışmasında eşbütünleşme ve nedensellik analizleri yaptığ görülmektedir. Bu çalışmalar sonucunda sağlık harcamaları ile ekonomik büyüme arasında uzun dönemde pozitif ve anlamlı bir ilişki olduğunu ifade edilmiştir.

Bloom ve Canning (2000), sağlık harcamalarının ekonomik büyüme üzerinde refah ve pozitif büyümeye etkiye sahip olduğunu ifade etmişlerdir. Pozitif etkinin özelliklerini ise;

- Bireylerin sağlıklı olması beşeri sermayeyi olumlu etkiler.

- Bireylerin sağlıklı olması iş gücü verimini arttırır.

- Yaşam süresinin artması ile fiziksel yatırım oranlarının artmasını olumlu etkiler.

Bunun yanı sıra, sağlık harcamalarının artması, ortalama yaşam sürelerinin artmasını sağlamakta ve bu bağlamda uzun dönem büyümeyi pozitif etkilemektedir (Akar, 2014:313-314).

Kwak (2009)'ın 1990-2000 yılları arasında OECD ülkeleri ve gelişmekte olan ülkelerin de içinde bulunduğu 84 ülkeyi kapsayan çalışmasında, sağlık harcamalarının 'devlet' ve 'özel sağlık' harcamalarının ayrılması ile ekonomik büyümenin sağlık harcamasındaki etkisini incelemiştir. Bu doğrultuda kamu sağlık harcamalarının, özel sağlık harcamalarından ekonomik büyümeyi daha az etkilediği görülmüştür.

Sağın ve Karasaç (2018), 2000-2014 yılları arasında 34 OECD ülkesini kapsayan sağlık harcamalarının ekonomik büyüme üzerine etkisini inceleyen çalışmalarında iki değişken arasında anlamlı bir ilişkinin olduğunu tespit etmişlerdir ve bu çalışmalarında sonuç olarak ekonomilerde beşeri sermayenin artması ile ekonomik kalkınmanın sağlayacağını ifade etmişlerdir.

Ekonomik büyüme ile beşeri sermayenin unsuru olan sağlık düzeyinin birbiriyle yakın ilişkisi bulunmaktadır. Bu bağlamda sağlıklı bir toplum ile beşeri sermayeyi arttırmak etkili bir yoldur. Bireylerin eğitimde psikolojik ve fiziksel olarak güçlü olmaları beden sağlıklarının ve psikolojik olarak sağlıklı olmaları ile ilgilidir. Sonuç olarak ülkeler beşeri sermayenin artmasını sağlamak için toplumun sağlıklarını yükseltmesi ve geliştirmesi ön koşul olmaktadır (Karagül, 2002; 71).

\section{Veri, Yöntem ve Bulgular}

Çalışmada, sağlık harcamaları ile ekonomik büyüme arasındaki ilişki 2000-2016 dönemi ve 36 OECD ülkesi için incelenmektedir. Sağlık harcamalarının GSYH’ya oranı (\%) ve GSYH büyüme oranı (\%) verileri Dünya Bankası'ndan (Dünya Kalkınma Göstergeleri) elde edilmiştir.

SH: Sağlık harcamalarının GSYH'ya oranı (\%)

GSYH: GSYH büyüme oranı (\%)

Ekonomik ilişkilerin tahmini, zaman boyutuna sahip kesitsel verilerden oluşan panel veri modelleriyle gerçekleştirilmektedir. Analizde, öncelikle değişkenlerin durağanlığını sınamak amacıyla birim kök testleri uygulanmıştır. Ardından, değişkenler arasındaki uzun dönemli ilişkinin tahmini için eş bütünleşme testi yapılmıştır. Son olarak ise, değişkenler arasında bir nedensellik ilişkisinin olup olmadığını araştırmak için Granger nedensellik ilişkisi araştırılmıştır. Analizde kullanılacak testlerin seçimi için öncelikle birimler arası korelasyonun varlığının test edilmesi gerekmektedir.

\begin{tabular}{|l|l|l|l|l|}
\hline Değişken & CD-Testi & P-değeri & Korelasyon & Abs (korelasyon) \\
\hline SH & 50.39 & 0.000 & 0.487 & 0.593 \\
\hline GSYH & 62.58 & 0.000 & 0.605 & 0.606 \\
\hline
\end{tabular}

Tablo 3. Birimlerarası Korelasyon Testi Sonuçları

Pesaran CD (2004) testi sonuçlarına göre, her iki değişken için de $\mathrm{H}_{0}$ hipotezi reddedilmekte ve birimler arası korelasyonun mevcut olduğu anlaşılmaktadır. Korelasyon katsayısı ise sağlık harcamaları için 0.487 ve ekonomik büyüme için ise $0.605^{\prime}$ tir.

\subsection{Birim Kök Testi}

Panel birim kök testleri, birimler arası korelasyonu dikkate alan ve almayan testler olarak ikiye ayrılmaktadır. Birinci nesil birim kök testleri birimler arası korelasyonu dikkate almadığından, birimler arası korelasyonun mevcut olduğu durumlarda ikinci nesil panel birim kök testlerinin kullanılması daha uygun olmaktadır. Bu doğrultuda, değişkenlerin durağanlığını sınamak için ikinci nesil testler içerisinde yer alan Levin-Lin \& Chu, ImPesaran \& Shin ve CIPS panel birim kök testleri kullanılmaktadır. Test sonuçları aşağıdaki tabloda görülebilmektedir;

\begin{tabular}{|l|l|l|l|}
\hline Değișken & Levin-Lin \& Chu t* & Im-Pesaran \& Shin W-t bar & CIPS \\
\hline SH & $-3.0880 * * *$ & 0.2771 & -1.786 \\
\hline GSYH & $-11.1957 * * *$ & -8.0835 & -2.915 \\
\hline$\Delta$ SH & $-16.5936 * * *$ & $-13.7565 * * *$ & $-3.451 * * *$ \\
\hline$\Delta$ GSYH & $-25.2971 * * *$ & $-20.9737 * * *$ & $-4.580 * * *$ \\
\hline
\end{tabular}


Not: ***, \%1 anlamlılı düzeyini ifade etmektedir. $\square$, değişkenlerin birinci dereceden farkını göstermektedir.

\section{Tablo 4. Birim Kök Testi Sonuçlart}

Yukarıdaki tabloya bakıldığında, birimler arası korelasyonu dikkate alan ikinci nesil panel birim kök testleri uygulandığında değişkenlerin düzeyde durağan olmadığı anlaşılmaktadır. Değişkenleri durağan hale getirmek için seriler dönüştürülmüş ve birinci dereceden farkları alınmıştır. Değişkenlerin birinci dereceden farkları alındığında durağan hale geldikleri görülmektedir.

\subsection{Eşbütünleşme Testi}

Panel verilerde yer alan değişkenlerin düzeyde durağan olmaması durumunda, değişkenler arasındaki uzun dönem ilişkisi panel eş bütünleşme testleriyle analiz edilebilmektedir. Panel eş bütünleşme testleri de panel birim kök testleri gibi, değişkenlerin birimler arası korelasyona sahip olup olmamasına göre ikiye ayrılmaktadır. Birimler arası korelasyonun mevcut olmadığı durumlarda birinci nesil panel eş bütünleşme testleri kullanılırken, birimler arası korelasyonun mevcut olduğu durumlarda ise ikinci nesil panel eş bütünleşme testlerinin kullanılması uygun olmaktadir.

Westerlund (2007), panellerde uzun dönem ilişkisini tespit etmek için hata düzeltme modelini esas alan dört farklı panel eş bütünleşme testi önermiştir. Testlerin temeli, her birimin kendi hata düzeltmesine sahip olup olmadığına karar vermesine dayanmaktadır. Dolayısıyla, "hata düzeltme yoktur" şeklinde kurulan $\mathrm{H}_{0}$ hipotezi reddedildiğinde, "eş bütünleşme yoktur" hipotezi de reddedilmektedir. Buna göre, hata düzeltme modeli;

$$
\Delta Y_{i t}=\delta_{i}^{\prime} d_{t}+\alpha_{i}\left(Y_{i t-1}-\beta^{\prime}{ }_{i} X_{i t-l}\right)+\sum_{j=1}^{p_{i}} \quad{ }_{i j} \Delta Y_{i t-j}+\sum_{j=0}^{p_{i}} \quad{ }_{i j} \Delta X_{i t-j}+e_{i t} \text { şeklinde kurulmaktadır. }
$$

$G_{a}$ ve $G_{t}$ istatistikleri, grupların ortalama istatistikleridir. $P_{a}$ ve $P_{t}$ istatistikleri ise, panelin tamamına ait bilgilerin hesaplanmasıyla elde edilmektedir. Birimler arası korelasyonun mevcut olması durumunda, Westerlund testinin bootstrap versiyonunu esas alan kritik değerler (düzeltilmiş p-değerleri) önerilmektedir.

\begin{tabular}{|l|l|l|l|l|}
\hline İstatistik & Değer & Z-değeri & P-değeri & Düzeltilmiş p-değeri \\
\hline $\mathrm{G}_{\mathrm{t}}$ & -2.305 & -3.456 & 0.000 & 0.530 \\
\hline $\mathrm{G}_{\mathrm{a}}$ & -5.280 & 2.128 & 0.983 & 0.950 \\
\hline $\mathrm{P}_{\mathrm{t}}$ & -12.265 & -3.374 & 0.000 & 0.920 \\
\hline $\mathrm{P}_{\mathrm{a}}$ & -3.606 & 0.980 & 0.837 & 0.970 \\
\hline
\end{tabular}

Tablo 5. Eşbütünleşme Testi Sonuçlarl

Yukarıdaki tabloda yer alan p-değerleri, birimler arası korelasyonun olmadığı durumdaki eşbütünleşme sonuçlarını göstermektedir. Birimler arası korelasyonun mevcut olduğu durumlarda ise düzeltilmiş p-değerleri dikkate alınmaktadır. $\mathrm{Bu}$ noktadan hareketle, $\mathrm{G}_{t}, \mathrm{G}_{\mathrm{a}}, \mathrm{P}_{\mathrm{t}}$ ve $\mathrm{P}_{\mathrm{a}}$ istatistiklerine bakıldığında $\mathrm{H}_{0}$ hipotezleri reddedilemediğinden eşbütünleşme ilişkisi olmadığı sonucuna ulaşılmaktadır.

\subsection{Nedensellik Testi}

Değişkenler arasındaki nedensellik ilişkileri, tek yönlü olabileceği gibi karşılıklı da olabilmektedir. Bu noktada, nedenselliğin varlığı ve yönü, nedensellik testleriyle araştırılabilmektedir. Çalışmada, değişkenler arasındaki nedensellik ilişkisinin tespit edilmesi için Panel Granger nedensellik testi kullanılmıştır;

$Y_{i t}=\alpha_{i}+\sum_{k=1}^{K} \quad{ }_{k} Y_{i t-k}+\sum_{k=1}^{K} \quad{ }_{k} X_{i t-k}+\varepsilon_{i t}$

Model için kurulan temel hipotez, $\mathrm{X}$ değişkeninden $\mathrm{Y}$ değişkenine doğru nedensellik olmadığı şeklindedir. Kurulan ikinci eşitlikte de, Y değişkeninden X değişkenine doğru bir nedensellik olup olmadığı test edilmektedir.

\begin{tabular}{|l|c|l|l|}
\hline Ho Hipotezi & Ki-Kare & df & Olasılık > Ki-Kare \\
\hline GSYH, SH'nın Granger nedeni değildir. & 10.204 & 2 & $0.006^{* *}$ \\
\hline SH, GSYH'nın Granger nedeni değildir. & 5.293 & 2 & 0.071 \\
\hline
\end{tabular}

Not: **, \%5 anlamlılık düzeyini ifade etmektedir.

\section{Tablo 6. Nedensellik Testi Sonuçları}

Panel nedensellik için yapılan Wald testi sonuçlarına göre, ekonomik büyümeden sağlık harcamalarına doğru bir nedensellik ilişkisi olduğu saptanmıştır. Ancak, sağlık harcamalarından ekonomik büyümeye doğru bir nedensellik ilişkisi bulunamamıştır. Dolayısıyla, ekonomik büyümenin sağlık harcamalarını belirlediği ifade edilebilmektedir.

\section{Sonuç}

Sermaye birikimi, ekonomik büyümenin en önemli bileşenlerinden birini oluşturmaktadır. Sağlık harcamaları da sermaye birikimini ve dolayısıyla ekonomik büyümeyi arttırmanın yollarından biridir. Dolayısıyla, sağlık harcamaları ile ekonomik büyüme arasındaki ilişki, özellikle gelişmekte olan ülkeler açısından büyük önem taşımaktadır. Bu bağlamda, çalışmada sağlık harcamaları ile ekonomik büyüme arasındaki ilişki 2000-2016 
dönemi ve 36 OECD ülkesi için araştırılmıştır. Yapılan birim kök testlerinin ardından, iki değişken arasındaki ilişkinin belirlenmesi için panel eşbütünleşme ve panel nedensellik testleri uygulanmıştır.

Analizde birimler arası korelasyona rastlandığı için ikinci nesil panel testleri kullanılmıştır. Birim kök testlerine göre, değişkenlerin düzeyde durağan olmadığ 1 ve birinci dereceden farkları alındığında durağan hale geldiği görülmüş̧ür. Ardından, yapılan eşbütünleşme testi sonucunda sağlı harcamaları ile ekonomik büyüme arasında bir eşbütünleşme ilişkisinin olmadığı anlaşılmıştır. Panel nedensellik testi ise, sağlık harcamalarından ekonomik büyümeye doğru bir nedensellik olmadığı ancak, ekonomik büyümeden sağlık harcamalarına doğru bir nedensellik ilişkisi olduğunu ortaya koymuştur.

Çalışmadan elde edilen bulgular, sağlık harcamalarının ekonomik büyümeyi etkilemediğini ancak, ekonomik büyümenin sağlık harcamalarını kısa vadede arttırdığını göstermektedir. Bir diğer ifadeyle, OECD ülkelerinin sağladıkları ekonomik büyümeyi kısa vadede sağlık harcamalarına yönlendirdikleri anlaşılmaktadır. Dolayısıyla, gelişmekte olan ülkelerin sağllk hizmetlerinin kalitesini arttırmak için zaman avantajına sahip olduğu ifade edilebilmektedir.

\section{Kaynakça}

- Akar, 2014. "Türkiye'de Sağlık Harcamaları, Sağlık Harcamalarının Nisbi Fiyatı ve Ekonomik Büyüme Arasındaki İlişkinin İncelenmesi”, Celal Bayar Üniversitesi İ.I.B.F Yönetim ve Ekonomi, Cilt. 21, Sayı. 1, ss. 311-322.

- Akram, 2009. "Short Run and Long Run Dynamics of Impact of Health Status on Economic Growth Evidence from Pakistan", MPRA Papers, Sayı. 15454.

- Arısoy vd., 2010. "Sosyal Harcamalar ve İktisadi Büyüme İlişkisi: Türkiye Ekonomisinde 1960-2005 Dönemine Yönelik Bir Dinamik Analiz", Maliye Dergisi, Sayı. 158, ss. 398-421.

- Ay vd., 2013. "Sağlık Göstergeleri ile Ekonomik Büyüme Arasındaki İlişki: Türkiye Örneğì", Niğde Üniversitesi IIIBF Dergisi, Cilt. 6, Sayı. 1, ss. 163- 172.

- Bloom ve Canning, 2000. "The Health and Wealth of Nations", Science, Cilt. 287, Sayı. 5456, ss. 12071209.

- Bloom vd., 2004. "The effect of health on economic growth: A production function approach", World Development, Cilt. 32, Sayı. 1, ss. 1-13.

- Bozkurt, 2010. “Eğitim, Sağlık ve İktisadi Büyüme Arasındaki İlişkiler: Türkiye İçin Bir Analiz”, Bilgi Ekonomisi ve Yönetim Dergisi, Cilt. 5, Sayı. 1, ss. 7-27.

- Braghava, 2010. "Sağlık Harcamalarının Ekonomik Büyüme Üzerindeki Etkisi: OECD Ülkeleri Üzerine Bir Panel Regresyon Analizi”, Doğuş Üniversitesi Dergisi, Cilt. 11, Sayı. 2, ss. 166-182.

- Chang ve Ying, 2006. "Economic Growth, Human Capital İnvestment, and Health Expenditure: A Study of OECD Countries", Hitotsubashi Journal of Economics, Cilt. 47, Sayı. 1, ss. 1-16.

- Chakraborty, 2004. "Endogenous Lifetime and Economic Growth", Journal of Economic Theory, Cilt. 116, Say1. 1, ss. 119-137.

- Çetin ve Ecevit, 2010. "Sağlık Harcamalarının Ekonomik Büyüme Üzerindeki Etkisi: OECD Ülkeleri Üzerine Bir Panel Regresyon Analizi”, Doğuş Üniversitesi Dergisi, Cilt. 11, Sayı. 2, ss. 166-182.

- Dreger ve Reimers, 2005. "Health Care Expenditures in OECD Countries: A Panel Unit Root and Cointegration Analysis", IZA Discussion Paper, Sayı. 1469.

- Elmi ve Sadeghi, 2012. "Health Care Expenditures and Economic Growth in Developing Countries: Panel Co-Integration and Causality", Middle-East Journal of Scientific Research, Cilt.12, Say1. 1, ss. 88-91.

- Erdil ve Yetkiner, 2004. "A panel Data Approach for Income-health Causality”, RePEc.

- Gerdtham ve Jönsson, 2000. "International Comparisons of Health Expenditure: Theory, Data and Econometric Analysis", Chapter 1 in Handbook of Health Economic, Cilt. 1, ss. 11-53.

- Hayaloğlu ve Bal, 2015. "Üst Orta Gelirli Ülkelerde Sağlık Harcamaları ve Ekonomik Büyüme İlişkisi”, İşletme ve İktisat Çalışmaları Dergisi, Cilt. 3. Sayı. 2, ss. 35-44.

- Im, Pesaran ve Shin, 2003. "Testing for Unit Roots in Heterogenous Panels”, Journal of Econometrics, Say1. 115 , ss. 53-74.

- Kamacı ve Uğurlu Yazıcı, 2017. “OECD Ülkelerinde Sağlık Harcamalarının Ekonomik Büyüme Üzerindeki Etkisinin Ekonometrik Analizi”, Sakarya Iktisat Dergisi, Cilt. 6, Say1, 2, ss. 52-69.

- Kar ve Ağır, 2006. "Türkiye'de Beşeri Sermaye ve Ekonomik Büyüme İlişkisi: Eşbütünleşme Yaklaşımı ile Nedensellik Testi, 1926-1994”, Sosyal Ekonomik Araştırmalar Dergisi, Cilt. 6, Sayı. 11, ss. 50-68.

- Karagül, 2002. Beşeri Sermayenin İktisadi Gelişmedeki Rolü ve Türkiye Boyutu, Afyon Kocatepe Üniversitesi Yayını No. 37, Ankara. 
- Kiymaz vd., 2006. "Tests of Stationarity and Cointegration of Health Care Expenditure and Gross Domestic Product”, The European Journal of Health Economics, Cilt. 7, Say1. 4, ss. 285-289.

- Kwak, 2009. "The Relative Role of Public and Private Health Expenditure for Economic Growth: A Solow Growth Model Expansion", Senior Honor Thesis.

- Levin, Lin ve Chu, 2002. "Unit Root Tests in Panel Data: Asymptotic and Finite-Sample Properties", Journal of Econometrics, Say1. 108, ss. 1-24.

- Narayan vd., 2010. "Investigating The Relationship between Health and Economic Growth: Empirical Evidence from A Panel of 5 Asian Countries", Journal of Asian Economics, Cilt. 21, ss. 401-411.

- Pesaran, 2004. "General Diagnostic Tests for Cross Section Dependence in Panels", Cambridge Working Paper, Sayı. 0435.

- Pesaran, 2007. “A Simple Panel Unit Root Test in the Presence of Cross Section Dependence”, Journal of Applied Econometrics, Cilt. 22, Say1. 2, ss. 265-312.

- Sağın ve Karasaç, 2018. “OECD Ekonomilerinde Sağlık Harcamalarının Ekonomik Büyüme Üzerine Etkisi”, Kırklareli Üniversitesi I.İ.B.F Dergisi, Cilt. 7, Sayı. 1, ss. 72-86.

- Selim, Uysal ve Eryiğit, 2014. “Türkiye’de Sağlık Harcamalarının Ekonomik Büyüme Üzerindeki Etkisinin Ekonometrik Analizi”, Niğde Üniversitesi İİ.B.F Dergisi, Cilt. 7, Say1. 3, ss. 13-24.

- Ş̧imşir vd., 2015. “Türkiye'de Sağlık ve Ekonomik Büyüme İlişkisi: ARDL Sınır Testi Yaklaşımı”, Finans Politik \& Ekonomik Yorumlar, Cilt. 52, Sayı. 604, ss. 43-54.

- Taban, 2006. “Türkiye'de Sağlık ve Ekonomik Büyüme Arasındaki Nedensellik İlişkisi”, Sosyoekonomii, Cilt. 4, Say1. 4, ss. 31-46.

- Tan vd., 2010. "Kamu yatırımları ve ekonomik büyüme ilişkisine bir bakış: Türkiye 1969-2003”, Dokuz Eylül Üniversitesi I.İ.B.F Dergisi, Cilt. 25, Sayı. 1, ss.25-39.

- Tıraşoğlu ve Yıldırım, 2012. "Yapısal Kırılma Durumunda Sağlık Harcamaları Ve Ekonomik Büyüme İlişkisi: Türkiye Üzerine Bir Uygulama”, Ejovoc, Cilt. 2, Sayı. 2, ss. 111-117.

- Uçan ve Atay, 2016. “Türkiye’de Sağlık Harcamaları ve Ekonomik Büyüme Arasındaki İlişki Üzerine Bir İnceleme”, Niğde Üniversitesi İ.̇.B.F Dergisi, Cilt. 9, Sayı. 3, ss. 215-222.

- Yardımcıoğlu, 2012. “OECD Ülkelerinde Sağlık ve Ekonomik Büyüme İlişkisinin Ekonometrik Bir İncelemesi” Eskişehir Osmangazi Üniversitesi Sosyal Bilimler Dergisi, Cilt. 13, Say1. 2, ss. 27-47.

- Yumuşak ve Yıldırım, 2009. "Sağlık Harcamaları İktisadi Büyüme İlişkisi Üzerine Ekonometrik Bir İnceleme”, Bilgi Ekonomisi ve Yönetim Dergisi, Cilt. 4, Say1. 1, ss. 57-70.

- Westerlund, 2007. "Testing for Error Correction in Panel Data", Oxford Bulletin of Economics and Statistics, Say1. 69, ss. 709-748. 


\title{
Akademisyenlerin Bakış Açısıyla Türkiye'nin Orta Gelir Tuzağından Çıkamamasında Verimsiz Kamu Harcamalarının Rolü
}

\section{The Role of Inefficient Government Expenditures in Turkey's Failure to Escape the Middle Income Trap from the Perspective of Academics}

\author{
Prof. Dr. Menşure Kolçak (Atatürk University, Turkey) \\ Dr. Halil İbrahim Şen (Ministry of Industry and Technology, Turkey)
}

\begin{abstract}
According to the middle income trap, economies that can come up to a certain point by imitation or capacity at hand are clogging at some point. A new paradigm is needed to continue progress. In the literature studies, it is seen that public initiative is very decisive in the fight against middle income trap. Especially in Far East Countries, the effect of public sector in getting rid of middle income trap is remarkable. It is tried to explain in a hierarchy the issues that are effective in avoiding the middle income trap. Analytical Hierarchy Process (AHP) method was preferred due to the suitability of the study. With the AHP method, it is tried to understand the point of view of the academicians who examine theoretically. According to the study, academician evaluators considered political reasons as more important.
\end{abstract}

\section{Giriş}

Ülkelerin ekonomik anlamda sınıflandırılmasında kullanılan en önemli kriterlerden biri kişi başı gayri safi yurt içi hâsıla tutarıdır. Bu sınıfların sınırları ise Dünya Bankası'nın çalışması sonucunda elde edilen değerlerle belirlenmiştir. Bu sınıflandırmada Türkiye'nin de içinde bulunduğu orta gelirli ülkeler $1025 \$-12.376$ \$arasında kişi başı milli gelire sahip olan ülkelerdir (Dünya Bankası, 2018). Bu grupta bulunan ekonomilerden ekonomik başarı anlamında beklenen şey, makul bir süre sonunda bir üst grup olan yüksek gelirli ekonomilere katılmalarıdır. Bu bekleme süresinin uzunluğu ile ilgili çeşitli çalışmalarla ortaya konan bir takım süreler olsa da literatürde kesin kabul görmüş bir tanım bulunmamaktadır. Orta gelir grubunda bulunan ve ekonomik büyüme anlamında yerinde sayan ekonomilerin durumunu anlatmak için kullanılan terim "Orta Gelir Tuzağıdır” (Yeldan vd., 2012).

Türkiye'nin durumunu netleştirmek için Türkiye ekonomisine ait kişi başı gayri safi yurt içi hâsıla değişimlerine bakmak gerekmektedir. Türkiye'nin, 2007-2015 yılları arasındaki kişi başı gayri safi yurt içi hâsıla açısından neredeyse hiçbir ilerleme sağlayamadığı anlaşılmaktadır. 2007 yılında 9.247 \$ ile başlayan periyot yaklaşık 9 yıllık sürenin sonunda 10 \$ artışla 9.257 \$'a ulaşmıştır. 2008-2009 finans krizi nedeniyle 8.500 \$ civarına gerileyen kişi başı GSYH değeri krizi izleyen yıllarda hızla toparlanarak kriz öncesi seviyenin de üzerine çıkmış ancak yine azalarak yükselişini kaybetmiştir.

“Orta gelir tuzağından kurtulamamada verimsiz kamu harcamalarının etkisi ne kadardır?” sorusu çalışmanın konusunu oluşturmaktadır. Çalışmaya ışık tutması ve Türkiye'nin diğer ülkeler ile karşılaştırılması açısından aşağıdaki veriler Türkiye'nin orta gelir tuzağından kurtulmak için daha fazla çaba sarf etmesi gerektiğini göstermektedir:

- 1960-2002 döneminde kişi başına GSYH'deki yılık ortalama artış oranı Türkiye, Brezilya ve Kore'de sıralı olarak \%2,5, \%2,1 ve \%6,5 olarak gerçekleşmiştir. Böylece Kore, 1960 yılında Türkiye ve Brezilya'nın ancak yarısı kadar kişi başı GSYH değerine sahipken 2002 yılında iki ülkenin sırasıyla 2,4 ve 2,8 katı kişi başına üretim seviyesine ulaşmıştır (Taymaz ve Suiçmez, 2005).

- 1990'ların başında Türkiye'nin kişi başı milli geliri Polonya’nın kişi başı milli gelirinden \%64 daha fazla iken 2015 yılında Türkiye'nin kişi başına geliri Polonya'nın kişi başına milli gelirinin \% 73'üne kadar azalmıştır (Sak, 2016).

Bu örneklerin daha da artırılması mümkün ancak özellikle başlangıçta Türkiye ile benzer noktalarda bulunan ya da imkân olarak Türkiye'den herhangi bir fazlası bulunmayan ülkeler seçilerek değişik alanlarla ilgili fark gösterilmeye çalışılmıştır. Çalışmada, Türkiye ekonomisinin gelişmiş ülkeler ile arasındaki fark araştırılmıştır. Buradan bulunan sonuçlar ve yapılan araştırmalar neticesinde orta gelir tuzağından çıkma çabalarının önündeki engeller belirlenmiş ve AHP ağacı oluşturulmuştur. Analitik Hiyerarşi Prosesi yöntemi ile analiz edilecek veriler AHP matrisleri ile ilgililerinden alınmıştır. Elde edilen bu veriler ile Analitik Hiyerarşi Prosesi yönteminde analizin temelini oluşturacak olan karar ağacı meydana getirilmiştir. Akademisyenlerden elde edilen bu veriler yöntemin usullerine uygun şekilde değerlendirmeye tabi tutulmuştur. 


\section{Türkiye Ekonomisinde Verimlilik}

Verimlilik değerleri göreceli olarak yüksek olan ülkelerin bunu birkaç stratejik faktör ile başardığı görülmektedir. Genel olarak gelişmiş ekonomiler bugünkü değerlerini teknoloji yoğun üretimi ve katma değeri yüksek olan ürünlere yoğunlaşması ile yakalamış gözükmektedir. Ekonomik büyüme, temel olarak iki sebeple gerçekleşir ki bunlardan ilki girdiyi artırarak bu sayede çıktıyı çoğaltmaktır. İkincisi ise Schumpeter'in belirttiği gibi teknolojik ilerleme ve değişimler sonucu artan verimlilikle ortaya çıkan büyümedir (Taymaz ve Suiçmez, 2005). Teknolojik ilerleme ile verimlilik artışının bahsedilebileceği baş sektör sanayi sektörüdür. Ekonomide tarımın oranının düşmesi ve özellikle sanayinin payının yükselmesi emek verimliliğin artmasına katkı sunmuştur.

Türkiye ekonomisinin verimlilik incelemesinde her sektör ayrı ayrı araştırılmıştır. Ekonomi genel hatlarıyla;

- Sanayi sektörü,

- Hizmetler sektörü,

- Tarım sektörü ve

- $\quad$ Enerji sektörü olarak 4 gruba ayrılmıştır.

\subsection{Sanayi Sektörü}

Dünyada endüstri devriminin başlangıç noktası olarak 1781 yılındaki buhar makinesinin keşfi görülmektedir. Türkiye'de ise sanayileşmenin başlangıcı olarak 1800'lü yılların başlangıcı alınabilir. Bu yıllarda Osmanlı İmparatorluğu bir atılım gerçekleştirmiş ve birçok sanayi mektebi ile sanayi atölyeleri faaliyete geçirilmiştir (Doğan, 2013). Sanayi sektörü tüm ekonomiler için en çok önem verilen alan olmuştur. Kalkınma iktisadı teorilerinde bir ekonominin gelişmesi ve ülkenin kalkınması için en kritik husus olarak sanayi görülmektedir (Kocabaş 2010). Sanayi sektörüne atfedilen bu önemin en büyük nedeni tarım ve hizmet sektörüne nazaran çok daha yüksek bir verimliliğe sahip olmasıdır. Sanayi sektörünün yüksek verimliliğe sahip olmasının yanında en büyük katkısı, yeni teknolojilerin geliştirilmesi ve diğer sektörlere de bu gelişmelerin dolaylı olarak büyük etki etmesidir (Taymaz ve Suiçmez, 2005).

Bilim, Sanayi ve Teknoloji Bakanlığı'nın yayınladığı verimlilik endekslerine göre sanayi sektöründe verimlilik, 2010-2015 yılları arasındaki 5 yıllık süreçte yerinde saymaktadır (BSTB, Verimlilik Endeksi, 2016).

\begin{tabular}{|l|l|l|l|}
\hline & Aralık 2011 & Eylül 2015 & Değișim (\%) \\
\hline Toplam Sanayi & $\mathbf{1 0 3 , 3 8}$ & $\mathbf{1 0 2 , 5 8}$ & $\mathbf{- 0 , 7 8}$ \\
\hline Madencilik & 102,03 & 108,52 & 6,36 \\
\hline İmalat & 103,45 & 102,22 & $-1,19$ \\
\hline Elektrik, Gaz, Buhar ve İklimlendirme & 113,53 & 129,83 & 14,35 \\
\hline Aramalı Üretim & 102,56 & 96,74 & $-5,68$ \\
\hline Dayanıklı Tüketim Malları Üretimi & 105,71 & 103,97 & $-1,64$ \\
\hline Dayanıksız Tüketim Malları Üretimi & 99,89 & 105,75 & 5,86 \\
\hline Enerji Üretimi & 109,45 & 124,88 & 14,10 \\
\hline Yatırım Malı Üretimi & 108,71 & 106,51 & $-2,02$ \\
\hline
\end{tabular}

Tablo 1. Çalışan Kişi Başına Üretim Endeksi Kaynak: BSTB, Verimlilik Endeksi, 2016

Tablo 1'de gösterildiği gibi çalışan başına üretim endeksinin değeri 2011 y1lında gerçekleşen değerin \%0,78 gerisindedir. Dayanıksız tüketim malları üretiminde ise $\% 5,86^{\prime}$ lık bir verimlilik artışı yaşanmıştır. Bu durum Türkiye ekonomisinin beklenen dönüşümden uzak olduğunu ve ekonominin emek yoğun alanlara sıkıştığını göstermektedir (Özkul, 2016).

\subsection{Hizmetler Sektörü}

Hizmetler sektörü 20. yy’ın ikinci yarısından sonra özellikle gelişmiş ekonomilerde artan bir öneme sahip olmuştur. Sanayi toplumlarının hizmet ekonomisine/toplumuna dönüşmesi bir kaç aşamada gerçekleşir:

- Sanayi hareketleri arttıkça ulaşım hizmetleri ile kamusal bir takım hizmetler artış gösterir,

- Nüfus artışının da etkisi ile ürünlerin ticareti noktasında bankacılık ve sigortacılık faaliyetleri artış gösterir,

- Milli gelirin yükselmesi ile gıda harcamaları aynı oranda artmadığı için bu harcamaların gelir içindeki payı azalır. Buna karşın lüks mal ve hizmetlere yapılan harcamaların miktarı dolayısıyla da oranı yükselir.

- Tüm bunlar neticesinde hizmetler zincirinin son halkası olan otel, seyahat, eğlence gibi hizmetler gelişmiş olur (Dura, 1990).

Hizmetler sektörünün artan bu önemine binaen bugün hem gelişmiş hem de gelişmekte olan ekonomiler önemli yatırımlarını daha ziyade hizmetler sektörüne yapmakta ve dünya hizmet ticaretinden mümkün olan en yüksek payı almayı hedeflemektedir (Özsağır ve Akın, 2012). Hizmetler sektörü özellikle Türkiye için ödemeler dengesinde açıkların kapatılmasındaki en kritik sektördür.

Hizmet sektörü ile ilgili ölçülebilecek somut bir verimlilik değeri olmadığı için daha çok yardımcı olabilecek diğer endeks ve değerler kullanılır. Bunun sebebi hizmet sektöründeki çıktının değerinin tam olarak tanımlanamaması veya ölçülememesidir (Yurtsuzoğlu ve Kılıçaslan, 2017). Ulusal düzeyde ölçüm yapmak isteyen 
merkez ya da kurumlar hizmet sektörü için daha ziyade çalışan kişi başına katma değer ya da çalışılan saat başına katma değer gibi istatistikleri kullanmaktadırlar. Bunun nedeni iş gücü girdisinin net olarak bilinebilmesidir (Balkan, 2010). Hizmet sektöründe giren ve çıkan ürünlerdeki değişkenlik diğer sektörlere göre oldukça fazladır (Yurtsuzoğlu ve Kılıçaslan, 2017). Hizmet sektörü ile ilgili Türkiye'deki en net gösterge hizmet sektörü güven endeksidir. $\mathrm{Bu}$ endeks son üç aylık dönemdeki iş durumu, hizmetlere olan taleple ilgili eldeki sonuçlar ve hizmetlere olan taleple ilgili beklentiler sonucunda oluşturulmaktadır (TÜİK-Sektörel Güven Endeksleri, 2017).

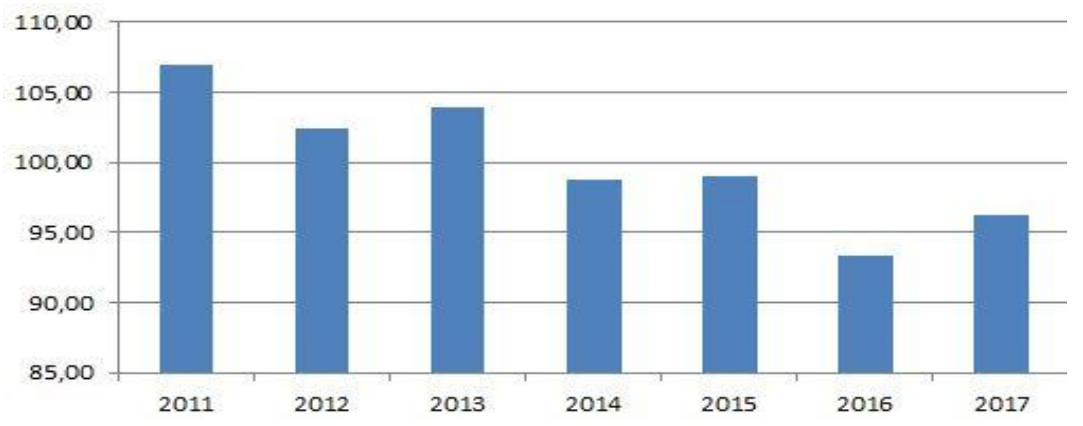

Şekil 1. Hizmet Sektörü Güven Endeksi Kaynak: TüIK Hizmet Sektörü Güven Endeksi Verilerinden Oluşturulmuştur, 2018

Şekil 1 hizmet sektöründe iş durumu ve beklentilerin genel olarak düşüş eğiliminde olduğunu göstermektedir. Son 6 yıllık sürede 2016 yılı itibari ile dip noktayı gören değer, 2017 yılı itibari ile yükselmeye başlasa da hala eski değerlerine ulaşamamıştır.

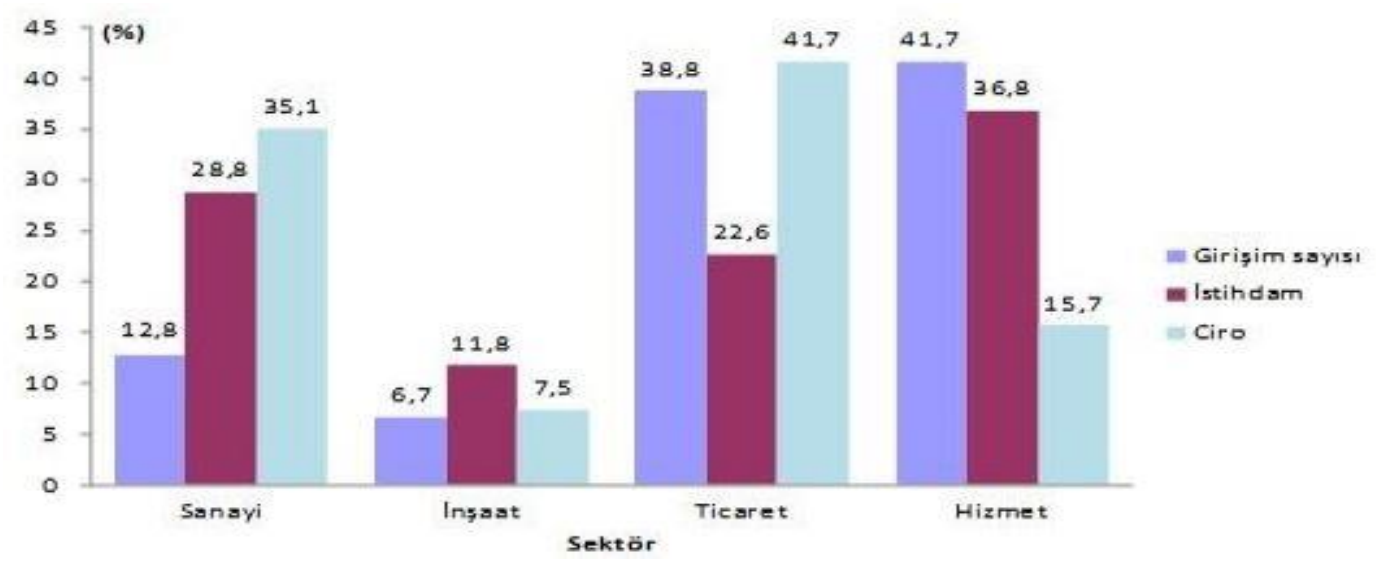

Şekil 2. Girişim Sayısı, Istihdam ve Cironun Sektörlere Göre Dă̆llımı-2015 Kaynak: TÜIK, Yıllık Sanayi ve Hizmet Istatistikleri, 2015

Şekil 2'ye göre 2015 yılında faal olan girişimcilerin \% 41,7'si hizmet sektöründe yer almaktadır. Bu oran istihdam sağlama noktasında \% 36,8'e toplam ciro içindeki payda ise \%15,7'ye düşmektedir. Bu veriler ile ciro noktasında hizmet sektörünün beklentiden uzak olduğu söylenebilir. Hizmet sektörünün içinde ciro yapma açısından en yüksek payı ise ulaştırma ve depolama işleri almaktadır. Oransal olarak aldıkları pay sırasıyla \%36,8 ve \% 14,4’tür (TÜİK, Yıllık Sanayi ve Hizmet İstatistikleri, 2015).

\subsection{Tarım Sektörü}

Tarım; insanların hayatını sürdürebilmesi, kalkınmaya ve istihdama olan katkısı, harici sektörlere sağladı $\breve{g} 1$ hammadde ile sermaye ve en önemlisi de ekolojik dengeye olan etkisi ile vazgeçilmez olan sektördür (Doğan vd., 2015). Tarım sektörünün gelişimi tam olarak iktisadi bir araştırma konusu olup tarımı; "eldeki kısıtlı imkânları en verimli şekilde kullanarak bitkisel ve hayvansal varlıkların üretim yeteneklerinden istifade etmek" şeklinde tanımlamak mümkündür (Gürler, 2008).

Türkiye tarım politikasını 2000'li yıllarda daha çok IMF yönlendirmesi ile bir revizyona sokmuş, aşağıda sıralanan birçok değişikliği bu dönemde hayata geçirmiştir (Günaydın, 2006):

- Destekleme politikası Dünya Bankası'nın önerdiği gibi daha çok küçük üreticiyi öne alan ve alana dayalı doğrudan gelir desteği şekline dönüşmüş,

- $\quad$ Tütün, şeker ve hububat gibi ürünlerin zamanla destek alımlarının dışında bırakılması ve fiyatların dünyaya uygun hale getirilmesi benimsenmiş,

- Çiftçilere verilen kredi desteğinin adım adım kaldırılması kararlaştırılmıştır. 


\begin{tabular}{|c|c|c|c|c|c|}
\hline Ülke & $\begin{array}{l}\text { İstihdam-Tarım } \\
(\%)\end{array}$ & $\begin{array}{l}\text { Toplam } \\
\text { Üretim } \\
\text { (Milyar \$) }\end{array}$ & $\begin{array}{l}\text { Tarımda } \\
\text { Çalışan } \\
\text { (Bin Kişi) }\end{array}$ & $\begin{array}{l}\text { Çalışan Başına } \\
\text { Düşen Tarımsal } \\
\text { Üretim (\$) } \\
\end{array}$ & $\begin{array}{l}\text { 5,8 Milyon Kişinin Türkiye'de } \\
\text { Yaptığı Üretim Diğer Ülkelerde } \\
\text { Kaç Kişi ile Yapılabilir (Bin Kişi) }\end{array}$ \\
\hline İngiltere & 1,2 & 14 & 360 & 38.836 & 1.596 \\
\hline Almanya & 1,5 & 26 & 593 & 43.874 & 1.413 \\
\hline $\mathrm{ABD}$ & 1,6 & 174 & 2.333 & 74.581 & 831 \\
\hline Kanada & 2,4 & 27 & 429 & 62.907 & 986 \\
\hline Hollanda & 2,5 & 15 & 213 & 70.423 & 880 \\
\hline Fransa & 2,9 & 46 & 787 & 58.455 & 1.061 \\
\hline Avusturya & 3,3 & 35 & 375 & 93.414 & 664 \\
\hline İtalya & 3,7 & 37 & 829 & 44.654 & 1.388 \\
\hline Japonya & 3,7 & 72 & 2.312 & 31.148 & 1.990 \\
\hline İspanya & 4,4 & 30 & 775 & 38.700 & 1.602 \\
\hline G. Kore & 6,6 & 27 & 1.646 & 16.402 & 3.780 \\
\hline Rusya & 9,7 & 68 & 7.046 & 9.650 & 6.425 \\
\hline Meksika & 13,4 & 40 & 6.735 & 5.940 & 10.439 \\
\hline Brezilya & 15,3 & 101 & 14.920 & 6.769 & 9,159 \\
\hline TÜRKİYE & 23,6 & 61 & 5.796 & 10.524 & ------------ \\
\hline Çin & 34,8 & 830 & 261.762 & 3.171 & 19.553 \\
\hline Endonezya & 35,1 & 127 & 38.797 & 3.273 & 18.940 \\
\hline Hindistan & 47,2 & 302 & 220.837 & 1.368 & 45.337 \\
\hline
\end{tabular}

Tablo 2. Tarım Ekonomisinin Ülkeler Arası Karşılaştırması Kaynak: Dünya Bankası Tarım İstatistikleri, Derleyen Çağdaş Şirin - Bloomberg Ekonomi Servisi, 2013

Tablo 2 tarımsal üretimin ülkemiz ekonomisinde ve diğer ülke ekonomilerinde ne anlama geldiğini göstermektedir. Tabloda özellikle gelişmiş ülkelerde tarımın istihdamdaki payının oldukça düşük olduğu görülmektedir. Bunun yanında çalışan başına düşen tarımsal üretim değerinde ise gelişmiş ülkelerin oldukça pozitif ayrıştığı anlaşılmaktadır. Çalışan başına üretim değeri Türkiye ile kıyasla;

- ABD'de yaklaşık olarak 7 katı,

- Ingiltere'de yaklaşık 4 katı,

- Hollanda'da yine yaklaşık 7 katı ve

- Kanada için yaklașık olarak 6 katıdır.

Türkiye bu tabloda bulunan gelişmiş ve gelişme yolunda olan 18 ülke içinde tarımsal üretim verimliliğinde 12 . sıradadır. Türkiye bu ülkelerden orta sıralarda bulunan İtalya'nın ulaştığı verimlilik rakamlarını yakalayabilse toplam tarımsal üretimini 61 milyar \$'dan yaklaşık olarak 260 milyar \$'a çıkarabilecektir. ABD ve Hollanda gibi ilk sıralarda bulunan ülkelerin verimlilik değerlerinin yakalanması durumunda ise bu değer yaklaşık olarak 420 milyar \$'dir.

Türkiye'nin tarımda gelişmiş ülkelerin sahip olduğu verimliliği yakalayamamasının birçok nedeni bulunmaktadır. En önemlilerinden biri ise tarımda makineleşme problemidir. 2015 yılı itibari ile Türkiye'deki 130 milyar TL tutarındaki makine-ekipman yatırımının yalnızca 7,3 milyar TL'si tarım alanındadır. Dünya tarım makineleri ihracatı yaklaşık olarak 53 milyar \$ civarında bulunurken Türkiye'nin bu pastadan aldığı pay sadece 850 milyon TL yani yaklaşık \%1,6'dır (Donat, 2017). Bu pazardaki liderler ise ABD, Almanya ve İtalya olup bu ülkeler aynı zamanda Tablo 1.6'da verimliliği en yüksek olan ülkelerdendir.

\subsection{Enerji Sektörü}

Enerji, insan hayatının sürdürülebilmesi için en önemli unsurlardan biridir. Özellikle 1970'lerde patlak veren petrol krizi ile enerjinin ülke ekonomisi için ne kadar önemli olduğu net olarak görülmüştür (Aktaş ve Alioğlu, 2012). Enerjiye olan ihtiyaç her geçen gün daha da artmaktadır. Geçtiğimiz 50 yıllık sürede dünya nüfusu yalnızca 2 kat artmasına rağmen enerjiye olan ihtiyaç yaklaşık 6 kat artmıştır (Satman, 2006).

Türkiye, ortaya çıkacak olan bu büyük açığı kapatabilmek için son yıllarda enerji sektöründe köklü değişikliklere gitmiştir. Özellikle rekabetin artması amacıyla özel sektör mümkün olduğu kadar sektöre dâhil edilmiştir. 2002 yılında elektrik üretimi noktasında \%32'lik paya sahip olan özel sektör 2017 yılında bu payını yaklaşık olarak \%75'e çıkarmıştır (T.C. Başbakanlık Yatırım, Destek ve Tanıtım Ajansı, 2017). Özel sektörün piyasaya daha fazla katılması sayesinde bugün itibari ile yaklaşık $80 \mathrm{GW}$ olan elektrik üretim kapasitesinin 2023 yılı itibari ile 120 GW büyüklüğüne erişmesi beklenmektedir (YDTA, 2017).

Verimliliğin çok önemli bir parametre olduğu enerji üretim sektöründe son yıllarda benimsenen kavram "yenilenebilir enerjidir". Yenilenebilir enerji kaynakları vasıtasıyla yapılan elektrik üretimi ile mümkün olan en az şekilde zararlı gaz salınımı yapılmakta, daha verimli ve daha uzun ömürlü enerji üretim kaynaklarına sahip olunmaktadır. Genel ifadeyle, yenilenebilir enerji kaynağı; enerji kaynağından alınan enerjiye eşit oranda veya kaynağın tükenme hızından daha çabuk bir şekilde kendini yenileyebilmesi şeklinde tanımlanabilir (YEGM, 
2015). Türkiye gibi enerji açığı bulunan ülkelerin enerji politikalarını kurgularken en önemli kriterler ilk yatırım maliyetleri, işletme maliyetleri ve elde edilecek olan çıktıdır (Kaya ve Koç, 2015).

\begin{tabular}{|c|c|c|c|}
\hline Santral Tipi & $\begin{array}{c}\text { İlk Yatırım } \\
\text { Maliyeti }(\$ / \mathbf{k W})\end{array}$ & $\begin{array}{c}\text { Sabit İşletme Maliyeti } \\
\text { (\$/kW-Yıl) }\end{array}$ & $\begin{array}{l}\text { Değişken İşletme } \\
\text { Maliyeti (\$/MWh) }\end{array}$ \\
\hline Deniz Üstü Rüzgâr Santrali & 6230 & 74 & - \\
\hline Nükleer Santral & 5530 & 93,28 & 2,14 \\
\hline Jeotermal Enerji Santrali & 4362 & 100 & - \\
\hline Biyokütle Enerji Santrali & 4114 & 105,63 & 5,26 \\
\hline Güneș Enerji Santrali & 3873 & 24,69 & - \\
\hline Kömür Yakıtlı Linyit Santral & 3246 & 37,8 & 4,47 \\
\hline Hidroelektrik Santral & 2936 & 14,13 & - \\
\hline Rüzgâr Santrali (Kara) & 2213 & 39,55 & - \\
\hline Doğalgaz Yakıtlı Linyit Santral & 917 & 13,17 & 3,6 \\
\hline
\end{tabular}

Tablo 3. Enerji Santrali Maliyetleri Kaynak: Kaya ve Koç, 2015: 65

Tablo 3'ten anlaşıldığı gibi ilk yatırım maliyeti en düşük tesisler sırasıyla doğalgaz yakıtlı linyit santraller, karada kullanılan rüzgar santralleri ve hidroelektrik santrallerdir. Yatırım kaynakları Türkiye gibi sınırlı olan bir ekonomide öncelik, ilk yatırım maliyetleri en düşük tesislere verilerek en az maliyetle enerji ihtiyacını gidermek bir enerji politikası olarak belirlenmiştir.

Santrallerde üretilen enerjinin birim maliyetlerine bakıldığında, en yüksek birim maliyetin güneş enerji santralinde (2014 yılı 18-26,5 cent/kWh), en düşük birim maliyetinin ise rüzgâr enerji santralinde (2014 yılı 3,716,2 cent/kWh) olduğu görülmektedir (Kaya ve Koç, 2015). Bu verilerle yapılan değerlendirmede gerek ilk yatırım maliyetinin düşüklüğü gerekse birim maliyetinin azlığı nedeniyle karada kurulu rüzgâr santralleri enerji ihtiyacını karşılamada bugünkü değerler itibari ile en verimli kaynaktır.

\section{Yöntem}

Yapılan literatür çalışması, inceleme ve araştırmalarla beraber ekonomik gözlemler sonucu orta gelir tuzağında bulunulmasına sebebiyet veren etkenler geniş bir çerçevede ele alınmış ve basamak basamak değerlendirilmiştir. Değerlendirme sonucu yapının Şekil 3'teki ağaç yapısı şeklinde olması kararlaştırılmıştır.

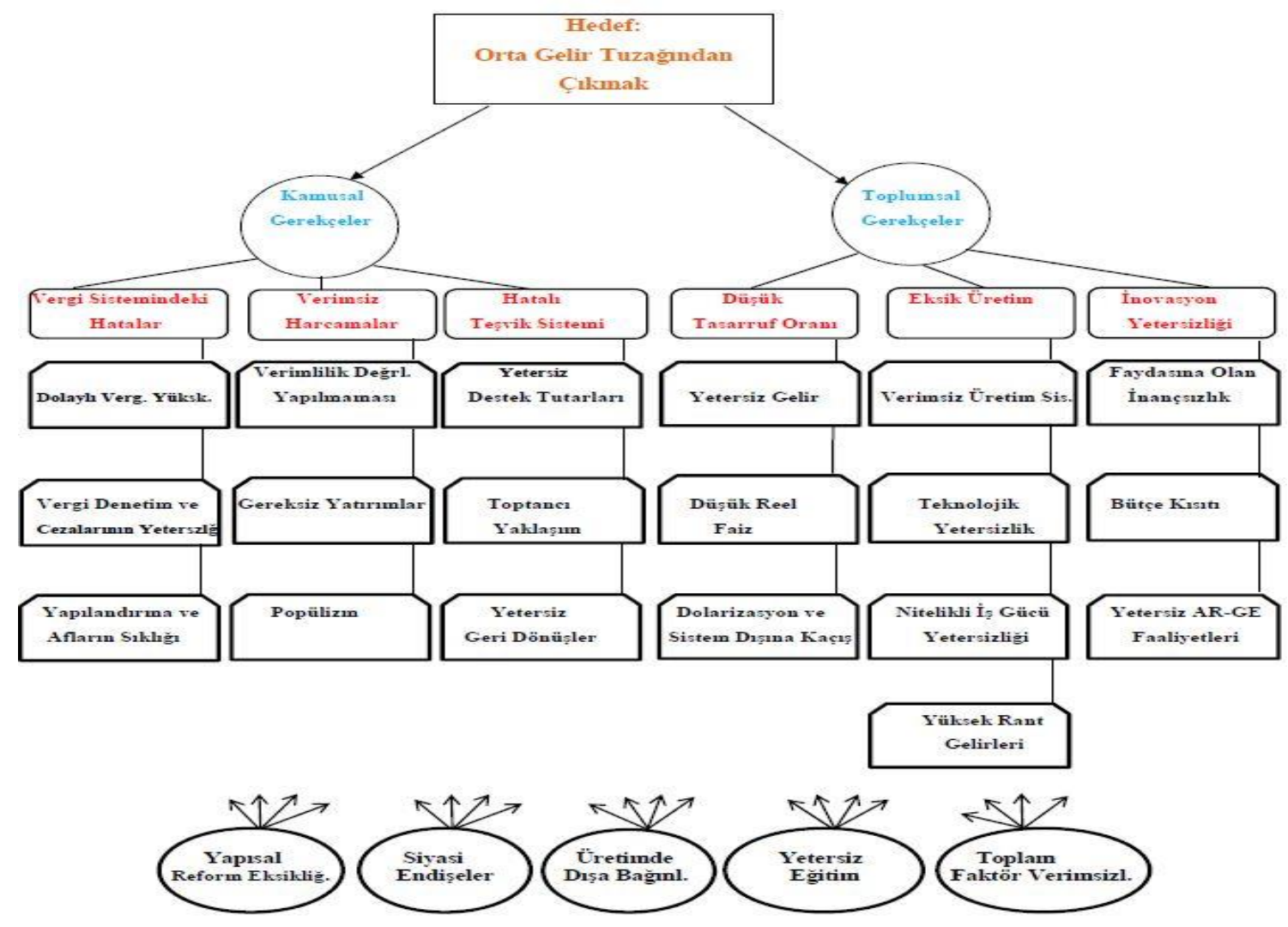

Şekil 3. AHP Hiyerarşik Yapısı 
AHP yöntemi kullanılarak gerçekleştirilecek olan analizde hiyerarşi ağacının netleştirilmesi analizin en önemli ve temel aşamasıdır. Ağaç yapısı oluşturulurken; gerek yapılan literatür araştırmalarından, gerek uzman görüşlerinden gerekse gözlemlenen ekonomik gelişmelerden yola çıkılarak seçenekler belirlenmiş ve geniş çaplı bir inceleme için bu seçeneklerden aynı şeyi anlatanlar hariç neredeyse tamamı ağacın yapısına eklenmiştir.

Ağacın yapısının geniş çerçevede belli olmasından sonra belirlenen kriterlerin alt kriterleri incelenmeye başlanmıştır. Nihai olarak ise orta gelir tuzağından çıkılamamasında tüm bu kriterleri etkileyen gerekçeler ağacın en altında sıralanmıştır. Bu gerekçeler belirlenirken de yine çalışmada bugüne kadar elde edilen bilgi ve bulgular ile yapılan araştırmalardan faydalanılmıştır.

Bu bilgiler 1şı̆̆ında belirlenen tüm bu ağaç yapısı iki ana başlık altında hiyerarşik bir düzene göre sıralanmıştır. Bir ekonomik sistemin iki temel unsuru, iki yön vereni olarak kamu ve toplum belirlenmiştir. Kamu, yetkisi ve güce ile aldığı kararlar ve çizdiği politikalar aracılığıyla ekonomiye yön verebilirken toplum hem en büyük tüketici grubunu oluşturan hem de üretimi üstlenen ve kararları ile sisteme etki edebilen birimdir. Böylece ana gerekçeler bu iki çatı altında toplanmıştır.

\subsection{Kamusal Gerekçeler}

Bir ekonomide ekonominin yönünü belirleyecek ve politikaları oluşturacak olan güç kamudur. Elinde olan güç ile piyasayı yönlendirebilecek ya da alınan kararların uygulanması noktasında gerekli zorlamayı yapabilecektir. Daha önce çalışması yapılan her dört sektör için de kamunun çizeceği yol haritası varılacak noktayı önemli ölçüde değiştirebilmektedir. Yani bu güç, yönlendirici olmakta ne ölçüde etkili olabiliyorsa yapacağı hataların sonuçları da ekonomi üzerinde aynı şekilde etkili olabilmektedir. Kamu imkânlarının orta gelir tuzağı ile mücadelede ne denli bir etkiye sahip olduğunu görmek için incelenecek çok önemli örnekler vardır. Bunlardan en önemlileri Güney Kore ve Japonya ekonomileridir. Üretim yapısının ve ihracatının içeriğini ve kalitesini değiştirmeye karar veren Kore devleti 1988-2008 yılları arasında ileri teknoloji ürünlerin ihracattaki payını \%15'lerden \%35'lere çıkarmıştır (Dünya Bankası-Dünya Gelişim Göstergelerinden elde edilmiştir). Güney Kore hükümetinin öncülüğünde 1962 yılında başlayan ekonomik planlama ile 1960-1989 döneminde ülkede kişi başı gelir 79\$'dan 5199\$'a ve ihracat 33 milyon \$'dan yaklaşık 62 milyar \$'a yükselirken işsizlik oranı \%12'lerden \%3'lere düşmüştür (Çakmak, 2016). Japon hükümetinin İkinci Dünya Savaşının hemen ardından neredeyse bitmiş bir ekonomiyi düzeltmek adına kurduğu Japon Prodüktivite Merkezi ülkenin ileride yaşayacağı kalkınmanın temellerini atmıştır (Yener, 2015). Kamu idaresi öncülüğünde yapılan çalışmalar ile Japonya, verimlilik konulu çalışmaların ve verimlilik düşüncesinin merkezi haline gelmiştir. Bu fikri değişim ile ortaya Japon Modeli denilen ekonomik model çıkmıştır (Murat, 1992). Japonya bugün yaklaşık 5 trilyon \$'lık GSYH değeri ABD ve Çin'in ardından dünyanın en büyük üçüncü ekonomisidir (TEB, 2018; Trading Economics, 2018). Japon hükümeti tarafından 1955-1970 yılları arasında temeli atılan sistemin etkileri hızlı şekilde görülmüş ve Japon ekonomisi tarihin en hızlı ekonomik sıçramalarından birini gerçekleştirmiştir.

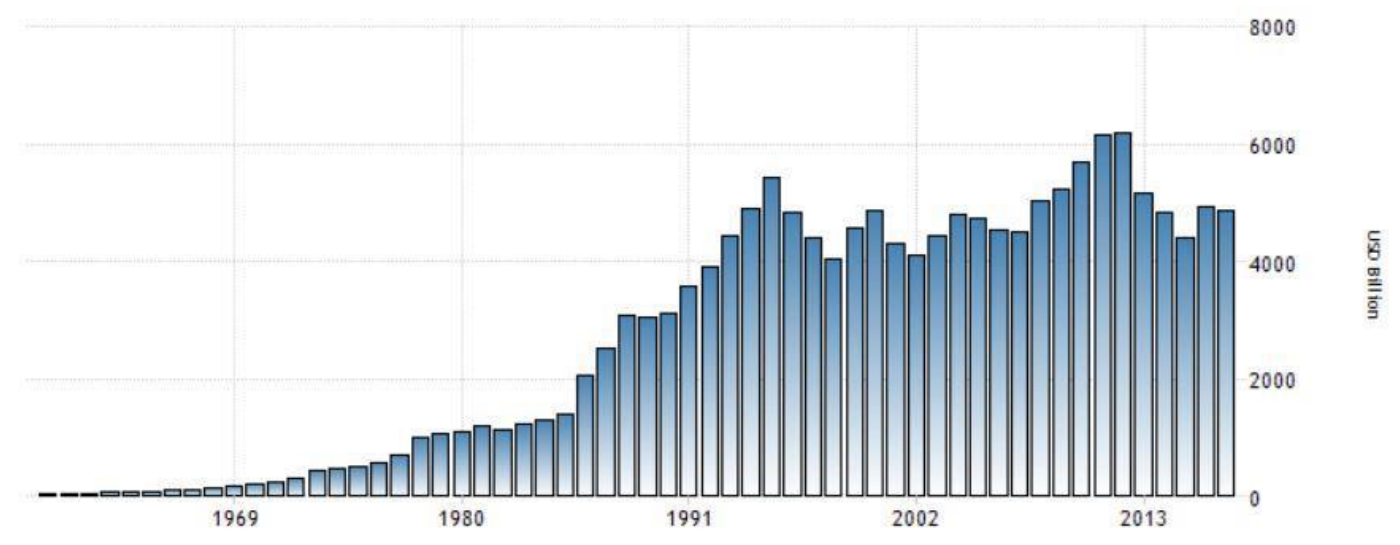

Şekil 4. Japon GSYH Değişimi Kaynak: Trading Economics, 2018

Özellikle 1980-2000 yılları arasında GSYH değeri büyüklüğü yaklaşık 4 katına ulaşmıştır. Sonradan yine Japon Durgunluğu olarak adlandırılan bir durgunluk süreci içerisine girilse de Japon ekonomisini savaşın yıkıntıları arasından dünyanın üçüncü büyük ekonomisi haline getiren etken, kamu öncülüğünde hazırlanan ve uygulanan plandır. Bu doğrultuda özellikle verimliliği incelenen dört ana sektör üzerinde kamunun etkisi en belirgin güçtür. Bu gücün doğru ya da yanlış kullanımına göre bir ekonomi orta gelir tuzağından kolayca kurutulabilirken uzun yıllar bu tuzakta da kalabilir. Türkiye'nin orta gelir tuzağından kurtulma çabasında engel teşkil eden kamusal gerekçeler; vergi sistemindeki hatalar, verimsiz harcamalar ve hatalı teşvik sistemi ile onların da altında bulunan 9 alt başlik ile incelenmiştir.

\subsection{Toplumsal Gerekçeler}

Ekonomik sistemin en önemli unsurlarından bir tanesi, tüketimin ve üretimin en büyük paydaşı olan toplumdur. Davranışları ve tercihleri, ekonomik gidişatın en belirgin etkileyenleridir. Parayı tutma ve harcama alışkanlıkları, 
üretime olan katılma hevesleri, bilgi ve birikimleri ile onu üretime aktarma yetenekleri ekonomi üzerinde kalıcı izler birakabilmektedir.

Çok yüksek insani gelişmeye sahip ülkeler ile KB GSYH değeri bakımından ülkeler sıralamasında ilk sıralarda bulunan ülkelerin \%76 oranında aynı ülkeler olması toplumun ekonomi için anlamını daha net ortaya koymaktadır. Türkiye'nin orta gelir tuzağından kurtulma çabasında engel teşkil eden toplumsal gerekçeler; düşük tasarruf oranı, eksik üretim ve inovasyon yetersizliği başlıkları ile onların da altında bulunan 10 alt başlık ile incelenmiştir.

\section{Analiz}

AHP yönteminde, genel olarak belirli kriterler dâhilinde seçilen uzman kişilerden oluşan ve sayıları 7-12 arasında değişen uzman gruplar ile çalışılmıştır. Yapısı belirlenen ağaç uzman grubun değerlendirmesine sunulup;

- Uzman grubun bir araya gelerek ortaklaşa tek bir matris oluşturması ya da

- Ayrı ayrı kendi değerlendirmelerini yapan uzmanların matrislerinin geometrik ortalaması alınarak sadece bir matris tablosuna dönüştürülmesi yoluyla yöntem uygulanmıştır.

Albayrak (2004) tarafından yapılan çalışmada piyasadaki en büyük bankalardan seçilmiş olanlarının performans ölçümleri AHP yoluyla gerçekleştirilmiştir. Bunun için profesyonellerden ve müşterilerden oluşan 12 kişiyi geçmeyen bir uzman grup belirlenmiş ve analiz bu kişilerin değerlendirmeleri üzerinden yapılmıştır.

Bu çalışmada ise çok daha büyük bir yapı benimsenmiş ve elde edilecek sonuçların gerçeğe en yakın sonuçlar olması amaçlanmıştır. Bu doğrultuda analiz konusunda fikirlerinin alınacağı ilk ekip için Türkiye'deki devlet üniversitelerinin İktisadi ve İdari Bilimler Fakülteleri bir evren olarak alınmıştır. Yüksek Öğretim Kurumu (YÖK) internet sitesinde yapılan araştırma ile 96 adet devlet üniversitesinde İIBF bulunduğu anlaşılmıştır (YÖK, 2018). $\mathrm{Bu}$ üniversitelerin iktisat bölüm başkanları ile telefon ve e-mail ile iletişim sağlanarak kendilerinden ya da görevlendirecekleri bir akademisyenden matrisleri doldurmaları talep edilmiştir. 61 üniversiteden geri dönüş alınmış ancak bunların 48 tanesi tutarlılık analizi sonucunda kullanılabilir bulunmuştur. Bu sayıda bir örneklem ile AHP yöntemini uygulamak literatürde bugüne kadar uygulanmamış büyüklükte bir çalışmadır. Bu matrislerin bir kısmı grup değerlendirmesi şeklinde alınırken diğerleri de ferdi olarak alınmıştır. Nihayetinde çalışma için toplam 48 üniversiteden sağlıklı geri dönüş sağlanabilmiş ve çalışma, alınan bu verilerin üzerinden gerçekleştirilmiştir.

Çalışma kapsamında oluşturulan AHP ağacı, yönteme uygun şekilde analiz edilmiştir. Bu analizler esnasında bazı tabloların tutarlılık oranlarında beklenenden daha yüksek değerler çıkmıştır. Karşılaşılan bu durumlar eğer bireysel olarak doldurulan AHP matrisleri tablosundan kaynaklamışsa değerleri giren ilgili kişi ile görüşülmüş ve tutarsızlıktan bahsedilerek tutarsızlığın olduğu matrisin yeniden değerlendirilmesi istenmiştir. Bu durum tüm değerlendiriciler için aynı şekilde gerektiği kadar tekrar edilmiş ve bireysel olarak doldurulan tüm matrisler tutarsızlık analizi açısından sorunsuz hale getirilmiştir. Elde edilen bu matrisler yine yöntemde bahsedildiği şekilde geometrik ortalamalarının alınması usulü ile tek bir matrise dönüştürülmeye çalışılmıştır. Bu şekilde oluşturulan nihai matrisler de tekrar tutarsızlık analizine tabi tutulmuş ve yine bazı matrislerde beklenenden fazla tutarsızlık oranı ile karşılaşılmıştır. Bu durumda değerlendirmede bulunan değerlendiriciler ile görüşülmüş ve bu durumdan haberdar edilmişlerdir. Ortaya çıkan bir tutarsızlık durumundan bahsedilmiş ve kendi kanıları ile ilgili herhangi bir değişiklikte bulunup bulunmayacakları öğrenilmiş ve ağaçta bulunan tüm detaylar tekrar açıklanmıştır. Detaylı bilgilendirmeden sonra kanısını değiştirmek istemeyen değerlendiricilerin fikirleri aynen korunurken değişiklik talebinde bulunanların fikirleri matriste güncellenerek tutarsızlık analizleri tekrar yapılmıştır. Bu durum, katlanılabilen en yüksek tutarsızlık oranı olan 0,10 değerinin nihai matrisler tablosunda bulunan hiçbir matriste de aşılmamasına kadar devam etmiş ve elde edilen nihai matrisler de yöntemde belirlenen tüm koşulları sağlar hale gelmiştir.

Elde edilen verilerin tutarlılığı hususunda yöntemin belirlediği sınırların dışına çıkılmadığı anlaşıldıktan sonra bu veriler nihai analize tabi tutulmuştur. Yapılan analizlerde Türkiye'nin orta gelir tuzağından çıkamamasında birinci seviye etkenler olarak kamusal ve toplumsal gerekçeler karşılaştırılmış ve bu durum üzerinde akademisyen değerlendiricilere göre;

- Kamusal gerekçelerin \%79,

- Toplumsal gerekçelerin ise \%21 etkisinin olduğu görülmüştür.

Tüm bu temel gerekçeler 19 alt kriter baz alınarak karşılıklı değerlendirmeye tabi tutulmuştur Türkiye'nin orta gelir tuzağından kurtulamamasını 5 ana ayak üzerinde açıklayan çalışma sonucunda etki ağırlığı sırasıyla;

- \%41 ile siyasi endişeler,

- \%20,2 ile yapısal reform eksikliği,

- \%15 ile kalitesiz eğitim,

- \%12,6 toplam faktör verimsizliği ve

- \%11,2 ile üretimde dışa bağımlılık hususları Türkiye'nin orta gelir tuzağından çıkamama nedenlerini açıklamaktadır. 


\section{Kaynakça}

- Aktaş, E., Alioğlu, O., (2012), “Türkiye’de Enerji Sektörü Analizi: Marmara Bölgesi Termik Santraller Örneği”, Ç.Ü. SBE Dergisi, Cilt:21, Sayı:1, s.281-298

- Albayrak, Y.E., "Hizmet Sektöründe Performans Odaklı Çok Amaçlı Karar Verme: Banka Performans Ölçümünde Analitik Hiyerarşi Süreci Uygulaması”, İ.T.Ü. Fen Bilimleri Enstitüsü Doktora Tezi, İstanbul:2004, s.48.

- Balkan, D.(2010). "Hizmet Sektörü ve Hizmet Sektöründe Verimlilik Ölçümü”. Anahtar Dergisi, MPM Aylık Yayın Organı: Verimlilik, 22(260), 44-45.

- Bilim, Sanayi ve Teknoloji Bakanlığı Verimlilik Endeksi, 2016

- Çakmak, U., (2016), “Güney Kore’nin Ekonomik Kalkınmasının Temel Dinamikleri” (1960-1990), Süleyman Demirel Üniversitesi İ̈BF Dergisi, C:21, S:1, s. 151-171

- Doğan, M., (2013), “Türkiye Sanayileşme Sürecine Genel Bir Bakış”, Marmara Coğrafya Dergisi, Sayı:28, s. 211-231

- Doğan, Z., Arslan, S., Berkman, A. N., (2015), “Türkiye'de Tarım Sektörünün İktisadi Gelişimi ve Sorunları: Tarihsel Bir Bakış", Niğde Üniversitesi İ̈BF Dergisi

- Donat, İ., (2017), Tarım Makineleri Sektörünün Karnesi, http://www.bloomberght.com/yorum/irfandonat/2054148-tarim-makineleri-sektorunun-karnesi, Erişim Tarihi: 18.01.2018

- Dura, C. (1990). Bilgi Toplumu, Kültür Bakanlığı Yayınları, Ankara

- Dünya Bankasi, (2018), World Bank Country and Lending Groups, https://datahelpdesk.worldbank.org/knowledgebase/articles/906519-world-bank-country-and-lendinggroups), Erişim Tarihi: 09.08.2019

- Günaydın, G. (2006), “Türkiye Tarım Sektörü”, Tarım ve Mühendislik Dergisi, Sayı 76-77,

- Gürler, A. Z., (2008), Tarım Ekonomisi, Ankara, Nobel Yayın ve Dağıtım.

- Kaya, K., Koç, E., (2015), "Enerji Üretim Santralleri Maliyet Analizi”, Makine Mühendisleri Odası - MMO Mühendis ve Makine Dergisi, Cilt:56, Say1:660, s.61-68, , https://www.mmo.org.tr/sites/default/files/14c4511b3c98f14_ek.pdf, Erişim Tarihi: 20.01.2018

- Kocabaş, (2010), "Teknolojinin İşgücü ve Üretim Üzerindekileri Etkileri (Türkiye'de İmalat Sanayinin İncelenmesi)", Çukurova Üniversitesi SBE İktisat Ana Bilim Dalı, Yüksek Lisans Tezi

- Murat, S., (1992), "Sosyal Siyaset Konferansları”, İstanbul Üniversitesi Yayınları, 37-38. Kitap, Yayın No: 3662

- Özkul, İ., (2016), "Sanayide Verimlilik 5 Yıldır Yerinde Sayıyor”, Dünya Gazetesi, Köşe Yazısı (https://www.dunya.com/kose-yazisi/sanayide-verimlilik-5-yildir-yerinde-sayiyor/27476 ) - Erişim Tarihi: 20.12.2017

- Özsağır ve Akın, (2012), "Hizmetler Sektörü İçinde Hizmet Ticaretinin Yeri ve Karşılaştırmalı Bir Analizi”, Elektronik Sosyal Bilimler Dergisi, Cilt.11, Say1.41, s. 311-331

- Sak, G., "Türkiye Yan Yan Giderken Polonya Düz Yolda İlerliyor”, Türkiye Ekonomi Politikaları Araştırma Vakfi-TEPAV, Ankara, http://www.tepav.org.tr/tr/blog/s/5740/Turkiye+yan+yan+giderken_+Polonya+duz+yolda+ilerliyor, (Erişim Tarihi:07.08.2017)

- Satman, A.,(2006), “Dünyada Enerji Kaynakları”, Türkiye'de Enerji ve Kalkınma, Tasarım Yayınları 24: Enerji 1, İstanbul.

- T.C. Başbakanlık Yatırım, Destek ve Tanıtım Ajansı, 2017

- Taymaz, E. ve Suiçmez, H., (2005), “Türkiye'de Verimlilik, Büyüme ve Kriz”, Turkish Economic Association, Ankara, s. 12

- TÜiK, Sektörel Güven Endeksleri, 2017

- Yeldan, E., Taşçı, K., Voyvoda, E., ve Özsan, M.E., (2012), "Orta Gelir Tuzağından Çıkış: Hangi Türkiye?” Cilt 1: Makro/Bölgesel/Sektörel Analiz, TÜRKONFED Türk Girişim ve İş Dünyası Konfederasyonu, İstanbul

- Yener, E., (2015), "Verimlilik Stratejileri: Başarılı Örnekler ve Türkiye için Öneriler”, Anahtar DergisiBilim, Sanayi ve Teknoloji Bakanlığı (https://anahtar.sanayi.gov.tr/tr/news/verimlilik- $\quad$ stratejileribasarili-ornekler-ve-turkiye-icin-oneriler/1993 ), Erişim Tarihi: 24.11.2017

- Yenilenebilir Enerji Genel Müdürlüğü, (2015)

- Yurtsuzoğlu ve Kılıçaslan, (2017), “Türkiye Hizmet Sektöründe Yapısal Değişim ve Verimlilik”, Ege Akademik Bakış Dergisi, Cilt.17, Sayı.2, s.215-228 


\title{
Stratejik Kaynak Petrol ve Terör İlişkisi Strategic Resource Oil and Terror Relationship
}

\author{
Prof. Dr. Kamil Uslu (Doğuş University, Turkey)
}

\begin{abstract}
The September 11 events provided an opportunity for the US administration, initiating strong policies to better understand the region. It also reminded the world of America's political-military control capacity. The terrorist attacks on September 11 were not a real surprise. Indeed, 9/11 looked like the wild fantasies they needed to justify a new military role developed by American strategic analysts and military and intelligence planners. Terrorism is intended to intimidate or coerce individuals, societies or governments by a person or an organized group with the threat of threat or use of force. Terrorism is an illegal act, usually for ideological or political reasons. Oil is not an object, but also contains many positives and negatives. Turkey is a neighbor with its geopolitical position as the world's proven oil and natural gas reserves, with three-quarters of the country. It takes part in many important projects, including a natural "Energy Center" between the energy-rich Caspian, Central Asian, Middle Eastern countries and consumer markets in Europe. It supports these projects. As long as the strategic resource, oil and scarce brand are available, terrorism will not end. political instability in the oil belt of countries in the immediate vicinity of Turkey brings many disadvantages. This situation also adversely affect the Turkish economy, itself nonthreatening terrorism and conflict of interest due to the large states to support terrorism in Turkey has led to more cautious.
\end{abstract}

\section{Giriş}

Stratejik bir kaynak olan petrol, insanlığın hizmetine çağlar öncesinden girmiştir. Zamanla günümüzün modern ekonomilerin vazgeçilmez kaynağı haline gelmiştir. Petrolün yakın ikamesi olmaması stratejik yapısını devam ettirirken, ülkelerin sosyal, makroekonomik ve politik yapılarında önemli bir yere sahiptir. Petrolün kısa geçmişine baktığımızda petrol, eski çağlardan beri var olan bir maddedir. "Eski Orta Doğu'da bitümen ticari meta olarak satılıyor ve inşaatlarda harç olarak kullanılıyordu. Filistin'deki Eriha kenti ve Mezopotamya'daki Babil'in duvarları bu harçla yapılmıştır. Büyük olasılıkla Hz. Nuh'un gemisi ve Hz. Musa'nın sepeti, su geçirmemesininsin nedeni de bitümenle kalafat edilmişler. Nihayet petrol, Bakü ve Pennsylvania'da petrol keşfedildiğinden sonra, reel politikanın ve endüstrilerin vazgeçilemez ekonomik kaynağı haline dönüştürmüştür.

Günümüzde, finansal ve ticari yönlere odaklanarak petrol endüstrisi, dünyanın en büyük ve en önemli küresel endüstrilerinden haline gelerek, bu endüstrilerinin analizleri yapılabilmektedir. Ne yazık ki, petrol kaynağı stratejik hale gelmesiyle, dünya üzerindeki savaşların, işgal, sömürü ve terörist faaliyetlerin de bir sonucu olmuştur. Sektörün küresel ekonomide ne kadar önemli olduğu ve endüstrinin günlük hayatımızın pek çok yöne dokunduğu düşünüldüğünde, zaman zaman bu alanda bilgi eksikliğimiz bizleri şaşırtabilmektedir.

1967 yılında Arap - İsrail Savaşı sonrasında, Arap ülkeleri kendi aralarında Arap Petrol İhraç Eden Ülkeler Teşkilatı (APİEÜT), 1973 yılında Kuveyt'te kurmuşlardır. APİEÜT, İsrail'i destekleyen, ABD, İngiltere, Batı Almanya gibi ülkelere petrol ambargo koymuştur. Ayrıca, Teşkilat, petrol arzını da azaltmıştır. Bununla beraber, Batılı Ülkelerde petrol girdi maliyetleri artmıştır. Özellikle ABD'de Dolar devalüe edilmiş ve Bretton Woods Sistemi çökmüştür. Bu olayların sonucunda; ABD de petrol maliyetlerini azalmak için Stratejik Petrol Rezervi (SPR), 1975'te kurulmuştur. Bununla beraber, ABD, 1 milyar varil ham petrole petrol depolama kapasitesini kurarak, petrol arzındaki kesintilerden korumak için önlemler almıştır.

Arap - İsrail Savaşı sonra, Arap ülkelerinde Batı Ülkelerine karşı, radikal terör örgütler faaliyete geçmiştir. Terörizm sadece Arap ülkelerinin bir ürünü değildir. Batı toplumlarında hala var olan bir olgudur. Terörist gruplar, ülkelerindeki, gelir ve sosyal adaletsizliğe karşı direnişe başlamışlardır. Aslında, terör örgütleri tarihin her döneminde vardır. Çünkü terörizm, insanlık için en kötü fiili bir durumdur. Şüphesiz terör olayları, tarihsel, dini çatışmalarla vurgulanan, kültürel ve sosyal bir savaşı işaret etmektedir. Batı ve gelişmiş dünya, belki de şu anda yok olan, ama hala devam eden sömürü üstünlüğünü, oluşma tehlikesini sözde olumlu bir şekilde göz ardı edebilmiștir.

Terörizm, değişimi etkilemek veya varsayılanı taciz etmek için bir araç olarak yeni bir düşman değildir. Terörizm, petrol endüstrisinde de yeni değildir. Stratejik kaynak petrol, kıt kanyak olduğu sürece, terörizm de bitmeyecektir. Türkiye'nin yakın çevresinde bulunan petrol kuşağı ülkelerdeki siyasi istikrarsızlıklar birçok olumsuzlukları da beraberinde getirmektedir. Türk ekonomisini de olumsuzlardan etkilenmektedir. Türkiye çevresindeki terörizm ve yerli işbirlikçileriyle tehdit edilmektedir. Radikal terörizm, tarihsel terör olaylarının genel olarak okunması, 9/11 başlamıştır. El Kaide'nin 11 Eylül 2001'de New York'taki Dünya Ticaret Merkezi'ne ve ABD’nin Savunma Bakanlığına (Pentagon) düzenlediği terör saldırılarında hayatlarını kaybedenler ile öne çıkmaktadır. Irak'ta kendine göre İslami dinci hareketler, Yasser Arafat, El-Kaide veya Usame bin Ladin de dâhil olmak üzere genel terörizm konularının türevleridir. 
Terörizmi İslam'la anılması, İslam inancına tamamen terstir. İslam inancı, insanı hayatın merkezine koyar. Onu yüceltir ve yaşatmaya çalışır. Bugün İslam adını kullanarak oluşturulan terör olayları, bu olayları çıkaranların kendi menfaat ve çıkarları içindir. Çalışmanın amacı; Stratejik kaynak petrolün, terörizmle ilişkisini ortaya koymaktır. Burada terörizmin tarihi geçmişini, petrol terörizmi ilişkisini, petrolün kısa tarihi geçmişini, Ortadoğu'nun stratejik önemi ve zengin petrol rezervlerine sahip olma çatışmalarını incelemeye çalışılmıştır. Türkiye'nin yakın çevresinde bulunan petrol kuşağı ülkelerdeki siyasi istikrarsızlıklar birçok olumsuzlukları da beraberinde getirmektedir. Türk ekonomisini de olumsuzlardan etkilenmektedir. Türkiye'nin güneyindeki terörizm tehdit edilmektedir. Büyük devletlerin, petrol kaynağına doğrudan veya dolaylı ulaşması için, teröristleri kullanmaktadır. $A B D$ ve Rusya gibi ülkeler, Suriye'deki Petrol alanlarına sahip olmak için IŞiD, PKK/ PYD'yi kullanmaktır. Kıt kaynak çıkar çatışmasından dolayı, teröre destek vermeleri Türkiye'yi bölgede daha dikkatli olmaya yöneltmiştir.

\section{Sömürgecilik ve Ekonomik Kaynak İlişkisi}

Sömürgecilikle emperyalizmin arasında kesin bir ayırım yapılamamaktadır. Sömürgecilik; 18. - 19. Yüzyıllarda yaygın olarak kullanılmıştır. Sömürge ülkelerinin çeşitli amaçları vardır. Kısaca; güçlü devletlerin stratejik kaynaklara ulaşması, kontrol altına alması ya da nüfus yoğunluğu ile yetersiz topraklarını genişletmesi ya da dini yayılma amacıyla olmuştur. 20. ve 21. Yüzyılda emperyalizm deyimi kullanılmaktadır. Emperyalizm: "Bir devletin, diğer bir devlet üzerinde, ister maddi, ister manevi kontrolü ile nüfus kurması veya üstünlük sağlamasıdır " (Armaoğlu, 1984). Sömürgeciliğin başladığı dönemlerde ekonomik kıt kaynak elde etmek için bir nevi terör faaliyeti olarak nitelendirilebilir.

Avrupa'yı 1890'lardan sonra, sebep ekonomiktir. Sanayinin gelişmesiyle elde edilen üretim fazlasını hızla diğer ülkelere gönderebilme telaşı ile artan sanayi üretiminin ham maddeye olan ihtiyacı başlamıştır. Diğer bir değişle, sanayileşmiş ülkelerin sürekli artan ekonomik kaynak ihtiyacı, yerli kaynaklardan sağlanamayınca başka ülkelerin kaynaklarına yöneltmişlerdir. Bu dönemde endüstrinin enerji ihtiyacı çoğunlukla kömüre dayanmaktadır.

"Dünya ticaretinin 1870 de 58 Milyar Frank iken,1913 yılında 200 milyar Frank’tır. 1800 yılında Avrupa kömür üretimi sadece 15 ton iken, 1900 yılında, 700 milyon tona ulaşmıştır.1913 yılında ise, 1,2 milyar tondur. 1890 y1lında petrol üretimi 10 milyon ton,1900 de 20 milyon ton, 1910 yılında.44 milyon ton,1913 yllında 52 milyon tona ulaşmıştır. Endüstrinin gelişmesiyle birlikte, Petrol üretimindeki artış, sömürgecilik bakımından yeni mücadelelere yol açmıştır." 1900'lü yıllardan günümüze kadar, petrol ülkelerin ekonomilerinde artan bir hızla yerini alabilmekte ve stratejik kaynak olarak yerini korumaktadır. Yakın geçmişimizde de savaşların sebebi olmuş ve olmaya da devam edebilecektir. Bundan dolayı da terörizmin doğrudan veya dolaylı kaynağı olmuştur.

\section{Terör Tanımı ve Terörün Geçmişi}

Terörizm, değişimi etkilemek veya varsayılanı taciz etmek için düşman bir araçtır. Terörizm petrol endüstrisinde de yeni bir şey dediğidir. Batıll teorisyenler terörizmi; fiziksel güçle, özellikle de suikastla ilişkilendirme eğilimindedir. Terörizm, siyasi amaçların peşinde koşarken şiddet ve gözdağı kullanmaktan ibarettir. "Terör" kelimesinden gelen "terörizm", Fransız Devrimi sırasında uygun bir şekilde adlandırılan terör döneminde ortaya çıkmış gibi görünüyor. Girondin'lerin düşüşünden Robespierre'nin düşüşüne kadar devrimci hükümet tarafından kararlaştırılan istisna halidir (Rockmore, 2011).

Terörizmin tanımlanması çok zordur. Virginia Held, "terörizm" in "genellikle saldırıya uğrayanların ötesine korku yayan politik şiddet" ve "belki de her şeyden daha fazla yayılması" olarak iki farklı tanım sunuyor. Küçük ölçekli savaş̧ andırıyor" ve "ya korku yaymak ya da savaşçı olmayanlara zarar vermek amacıyla" uygulanan siyasi şiddet olarak gösteriyor. Her iki tanım da, meşru bir askeri hedefi hedefleyen bir savaş eyleminin terörizm olarak kabul edildiğini ima ederek, savaş ve terörizmi birlikte yönetiyor gibi görünmektedir. Çünkü Troçki'nin "kızıl terör", "savaş" savunmasında işaret ettiği gibi....gözdağı üzerine kurulmuştur (Rockmore, 2011).

Siyasi terörizm bir savaş biçimidir. Direnişçilerin mücadele tarzı koşullar tarafindan belirlenir ve mümkün olduğunda çeşitli stratejiler benimser. Ayaklanmanın en kolay şekli terörizmdir. Terörizmin benzersiz özelliklerini, diğer şiddet içeren çatışma biçimleriyle teröristlerin hedeflerini gerçekleştirmeyi umdukları ana stratejik fikir olarak tanımlanabilir. Terörizm, grupların devlete karşı şiddet içeren eylemleri anlamına gelir. Diğer bir tanım da, bir devletin kendi vatandaşlarına yönelik baskısıdır. Terörizm, diğer devletlere karşı savaşan devlet eylemleri olarak da tanımlanabilir. Tanımlarda terörizmin amacına göre de değişir. Terörizmin tanımı için gerekli olan temel varsayımların anlambilimin genel kabul görmemiş olması, örneğin ABD'nin 1985'te Roma ve Viyana havalimanlarına Libya destekli saldırıların terör eylemleriydi ve mantıksal olarak kanıtlanmasının hiçbir yolu olmayışıdır (Merari, 2007).

Fiziksel şiddet olarak anlaşılan terörizmin çok eski bir geçmişi vardır. Bilinen erken bir örnek, Peloponnes Savaşları sırasında Melians'ın Atina'nın sindirilmesi ve nihayetindeki toplu katliamdır. Çok daha sonra terörizm, suikastla sıkı bir şekilde ilişkilendirilmiştir. Görünüşe göre "suikastçı" terimi, üyelerinin sekizinci ila on dördüncü yüzyıllarda aktif olduklarına inanılan ve bu konuda uzmanlaşmış Nizari alt kesiminden bir grup, İsmali Müslüman 
olan Haşşaşin (veya Haşşaşiyin olarak da bilinen) Haşşaşiyin ‘den geliyor. Haşşaşiyin’ler Abbasi seçkinlerine suikastler düzenlemişlerdir (Rockmore, 2011).

Terörizm, geçmişte, Batı ülkelerinin değişmez hayatlarının bir parçası olmuştur. "Bu tür olaylar arasında St. Bartholomew Günü 1572'de binlerce Fransız Protestan katliamı, Hollanda'da İspanyol birlikleri tarafindan işlenen zulüm ve belki de en kötü şöhretli olayı, Katolikliğin var olduğunu düşünen Guy Fawkes'in, İngiltere'de zulüm görmesidir. Bunun üzerine Guy Fawkes'in içinde bulunduğu Barut Komplosu ile 5 Kasım 1605'te Parlamentoyu havaya uçurmaya çalışmıştır” (Rockmore, 2011).

Terörizm yine geçmişte Rus hayatının uzun zamandır bir parçası olmuştur. Rus nihilistleri (Hayatın anlamsız olduğuna inanan ve tüm dini ve ahlaki ilkeleri reddeden kişi veya kişiler),1866'da Çar II. Aleksandr'a suikast düzenlemeye çalışmışlardır. Stalin, Rusya'da şov denemeleri sonucunda; kitlesel açlık, kronikleştirilen zorunlu çalıştırmaya dayanan bir dizi hapishane ve toplama kampları da dâhil olmak üzere, rezil bir terör saltanatı sürmüştür. Rus terörizminin en son örneği, Çeçenlere karşı devam eden ve binlerce ölümle sonuçlanan savaştır (Rockmore, 2011).

Terörizm, "Amerikan tarihinde önemli bir rol oynar. Ku Klux Klan,(KKK) İç Savaş'tan sonra Beyazların üstünlüğ̈nnü güçlendirerek yeniden yapılanmaya karşı koymak için ortaya çıkmıştır. Nispeten yakın zamana kadar, beyazların siyahlara karşı yönettiği önemli bir terör kaynağıydı. 1868'de sadece Georgia'da KKK tarafindan zincirleme ile 336 cinayet veya cinayete teşebbüs vakası vardır. Terörizm, Amerikan tarihinde önemli bir rol oynar. Ku Klux Klan, İç Savaş'tan sonra Beyazların üstünlüğünü güçlendirerek Yeniden Yapılanmaya karşı koymak için ortaya çıkmıştır. Nispeten yakın zamana kadar, beyazların siyahlara karşı yönelttiği önemli bir terör kaynağıydı.1886'da McCormick'teki bir grev sirasında Chicago'daki Reaper fabrikasında, Haymarket Ayaklanmaları sırasında bir bomba patladı, altı polis öldü ve yaklaşı 60 polis yaralandı. Sekiz kişi hakkında dava açıldı ve dördü bu olay nedeniyle asılmıştır.

Terörizm uzun zamandır Amerikan başkanlık siyasetinin bir parçası olmuştur. Amerikan tarihindeki kabaca her onuncu başkan suikasta kurban gitmiştir. Başkan Abraham Lincoln, 1865'te John Wilkes Booth tarafindan vurularak öldürüldü ve daha sonra kaçışı sırasında vuruldu. Başkan James Garfield, 1881'de Charles Guiteau tarafından öldürüldü. 1901'de Başkan William McKinley, Leon Czolgosz tarafindan öldürüldü, daha sonra suçundan dolayı elektrikli sandalyede idam edildi. Başkan John F. Kennedy, 1963 yılında Lee Harvey Oswald tarafından öldürüldü. Daha sonra Oswald'ı bir gece kulübü sahibi olan Jack Ruby tarafından öldürüldü." (Rockmore, 2011). ABD'de tarihinde ki terörizm daha çok başkanlık seçimleri ve çıkar çevreleri ile Beyaz- Zenci çatışmasında Beyazların zencileri öldürmeleriyle yapılmıştır.

1941'de Pearl Harbor'a yapılan Japon saldırısı, belki de Amerika Birleşik Devletleri'nde can kaybı açısından 11 Eylül'e benzeyen tek olay, burada açıklama gerektirmeyecek kadar iyi bilinmektedir. Yine de 11 Eylül'den farklı olarak, Pearl Harbor'a saldırı kıta ABD'sinde gerçekleşmediğinden, etkisi belki de daha az şiddetli hissedildi. 1954'te, dört Porto Rikolu milliyetçisi Kadınlar Galerisi'nden ateş açıldı ve ABD Temsilciler Meclisinden, beş temsilciyi yaraladı. Amerika'nın terörizme odaklanmasına katkıda bulunan son olaylar arasında 1993'teki Dünya Ticaret Merkezi bombalaması, 1998 ABD büyükelçiliği bombalamaları, İsrail'deki intihar bombalamaları ve 1998'de Libya'nın destekli terör örgütü, ABD havayollarına ait uçağa bomba koyması ve İskoçya'daki Lockerbie de uçak havada iken patlamıştır. 11 Eylül'den sonra önemli uluslararası terör olayları Bali'de gece kulübü bombalaması, Madrid de tren garının bombalaması ve Londra metrosundaki bombalı terör olayları buna dâhildir (Rockmore, 2011).

1990'da Sovyetler Birliği'nin çöküşü ve dağılmasının ardından gelen, genel liberal siyasi coşku yaşanmıştır. Birçokları yanlış bir şekilde ABD'nin bundan böyle politikalarını, isteklerini ve arzularını dünyanın geri kalanına dikte edebileceğine inanıyordu. Sovyetler Birliği'nin çöküşünün ardından birçok cumhuriyetler bağımsızlığını ilan emişlerdir. Burada İki önemli stratejik ülke öne çıkmaktadır. Bunlar; Azerbaycan ve Çeçenistan'dır. Bunun nedeni; her iki ülke petrol bakımından zengin ülkelerdir.

Çeçenistan, “ petrol yataklarına ilişkin ilk raporlar köylülerin yağ olarak kullandığı yeraltından fişkıran tuhaf siyah madde akıntıları şeklinde not eden gezginlerin yazılarından oluşuyor. 19. yüzyılın sonlarında Rusya'nın Çeçenistan'ı ilhak etmesinden sonra, evlerde küçük çaplı petrol üretimi başlamış ve 1893'te ilk ticari petrol kuyusu Grozni'nin Starye Promisla kenar mahallesinde açılmıştır.

Çeçenistan'ının petrol yatakları 5-6 metre gibi yeryüzüne yakın derinliklerde bulunduğundan petrol sık sık fışkırarak dışarı çıkıyor ve toprağa sızarak kirlenmeye sebep olmuştur. Çeçenistan'ın bazı bölgelerinde toprağın üst katmanı petrole doymuş durumda; Bazı yerlerde petrol ürünleri yaklaşık 2 metre kadar yüzeye sızmış ve 250 metre derinliklerdeki yeraltı suyu normalden 15 kat daha fazla petrol ürünleri bileşenleri içeriyor. Sovyetlerin iktidara gelmesinden önce Çeçenistan'ının petrol yatakları Belçikalı, İngiliz, Rus, Çeçen ve Azeri şirketleri tarafindan işletiliyordu. Bolşeviklerin petrol endüstrisini millileştirmelerinden sonra üretim hacmini 20. yüzyllın başında yakalanan seviyeye çıkarmak 15 yılı almıştır. İkinci Dünya Savaşı'nın başında Çeçen-İnguş Cumhuriyeti y1llık yaklaşık 4 milyon ton yüksek kalitede ham petrol üretiyordu ve bu durum Hitler'in Grozni ve Bakü petrol rezervlerini kontrolünü ele geçirmeye sevk etti.” (Vaçagayev, 2008). 
Sovyetler Birliğinin dağılmasından sonra diğer Cumhuriyetler gibi Çeçenistan da Bağımsızlığını ilan etti.” 27 Ekim 1991 tarihinde Çeçenler bağımsızlıklarını ilan etmiş ve Dudayev'i bağımsız Çeçenistan'ın ilk başkanı olarak seçmiştir. Dudayev, 1 Kasım 1991'de resmi olarak Çeçenistan'ın egemenliğini ilan etti ve bu şekilde Çeçenistan, hem Rusya'dan hem de SSCB'den ayrılmıştır. Rusya, bağımsız Çeçenistan'ı tanımamış, bu hareketin Rusya Federasyonu'nun toprak bütünlüğünü tehdit eden bir davranış olduğunu ve Çeçenistan'ın Rusya'nın parçası olduğunu belirtmiştir. 7 Kasım 1991 tarihinde R.F. Başkanı Yeltsin, "anayasal düzeni” korumak gerekçesi ile Çeçenistan'da olağanüstü hal ilan etmiş ve Dudayev hakkında tutuklama kararı çıkarttırmış ayrıca, aynı gün Rus birlikleri Grozni'ye göndermiştir. Dudayev ise hapishaneleri boşaltarak eli silah tutan herkesi silahlandırarak karşılık verdi. Dudayev'in başarılı harekâtı Rus birliklerinin geri çekilmesine neden olmuştur." (Avc1, https://www.dunyabulteni.net/tarih-dosyasi/dudayev-i-nasil-oldurduler-h40525.html (21. 07. 2020). 21 Nisan 1996 yılında Cohar Dudayev Rus savaş uçağından atılan füze ile öldürüldü. Çeçen bağımsızlığının önderi, kaynak düşüncesi Şeyh Şamil'den kaynaklanan devlet adamı Çeçenlerin bağımsızlığı için şehit olmuştur. Assıl neden Çeçenistan'ının zengin petrol bölgesi olasıdır. Putin bunu bir terör faaliyeti olarak görmesidir (Avc1, https://www.dunyabulteni.net/tarih-dosyasi/dudayev-i-nasil-oldurduler-h40525.html (21. 07. 2020). II. Çeçen Savaşı'na baktığımızda, ilk olarak hiçbir üçüncü taraf açıklanmadan Rusların II. Çeçen Savaşı sonunda Çeçenleri tamamen yendiğini Putin'in zaferini ilan ettiğini görüyoruz. İkinci olarak, ABD'ye 11 Eylül 2001 saldırısından sonra Rusya'nın Çeçenleri özgürlük savaşçısından tamamen terörist olarak nitelendirmesini görüyoruz (Avc1, https://www.dunyabulteni.net/tarih-dosyasi/dudayev-i-nasil-oldurduler-h40525.html (21. 07. 2020).

SSCB'nin dağılımından sonra, Azerbaycan, 18 Ekim 1991de ikinci defa bağımsızlığını ilan etmiştir. Federasyonu yetkilileri, eski komünist yöneticiler bunu istemiyorlardı. Bir bahane buldular. "Kara Ocak" katliamı Ermenistan Sovyet Sosyalist Cumhuriyeti'ne tepki gösteren, Azerbaycanlıların "Ermeniler Dışarı" sloganları eşliğinde yaptıkları yürüyüşle başlamıştır. Ermeniler ise bu olaydan sonra Ermenistan Karabağ'da yaşayan çok sayıda Azerbaycanlıyı sürgüne göndermiş, bunların çoğu Bakü’ye yerleştirilmiştir. 1990 yılının başlarında, Ermenilerin artan toprak taleplerine ve Sovyet yönetimine tepkilerini göstermek isteyen binlerce Azerbaycanlı, Bakü'nün Azadlık Meydanı'na akın etti ve uzun süreli mitinglere başladı. Mitingleri dağıtmak amacıyla 20 Ocak'ta Bakü'nün çeşitli bölgelerine giren 26 bin kişilik Sovyet ordusu, aralarında kadın ve çocukların da bulunduğu 147 sivili katletti, yüzlerce kişiyi yaraladı http://www.gazetevatan.com/20-ocak-1990-yanvar-azerikatliami-kara-ocak-olayi-nedir-kim-y-1296627-gundem/ (21,07.2020). Bu Rusların Azerbaycan'da yaptığı devlet terörüdür. Esas amaç, Azerbaycan petrolleridir.

Son aylarda,17 Temmuz 2020’de Rus destekli Ermeni silahlı kuvvetleri, Tovuz ilini hedef almıştır. Bunun sebebi, Tovuz' ilinden Türkiye ve Azerbaycan'ın ortaklaşa gerçekleştirdiği Bakü-Tiflis-Kars demir yolu, BaküTiflis-Ceyhan petrol boru ve TANAP'ın başlangıcı olan Güney Kafkasya doğal gaz boru hatları geçtiği bölgedir. Ermenistan'ının amacı, Tovuz'un bazı stratejik noktaları ele geçirmek ve Azerbaycan'ı Türkiye ile birleştiren tek kara yolu, iki ülkenin ortak enerji ve ulaştırma hatları sabote etmektir. Bu aslında bir Stratejik kaynak olan petrol ve doğal gaza yönelik askeri nitelikli devlet terörüdür. Ermenistan'1 destekleyen Rusya, Batı ülkeleri ve İran'dır. Azerbaycan bu saldırıya cevap vermiştir. Bunlara ilaveten Uygur Türk'lerine Çin'in uyguladığı asimilasyon terörünün asl1, Uygur Özerk Bölgesindeki zengin petrol ve yeraltı zenginliğinden başka bir şey değildir.

\section{Bir Ayaklanma Stratejisi Olarak Terörizm}

Uygulamalara bakıldığında, teröristlerin operasyonel envanteri oldukça sınırlı olasına rağmen, çok üzücüdür. Teröristler halka açık yerlere patlayıcı yükler yerleştirirler, siyasi muhaliflere suikast düzenlerler, halka küçük silahlarla patlayıcılarla saldırılar düzenlerler. Binaları kendileri için adam kaçırarak veya rehin alarak, barikat kullanırlar. Çoğu durumda, yetenekleri oldukça zayıf görünümlüdür. Örneğin, Alman Kızıl Ordu Fraksiyonu (yaygın olarak Baader Meinhof çetesi olarak bilinir) gibi kötü şöhretli bir grubu düşünün. Varlığı boyunca herhangi bir dönemde, birkaç kamu görevlisine ve işadamına suikast düzenleyebilen, ikisini kaçıran ve bir barikat rehine olayını düzenleyen otuzdan az aktif üyesi vardı (Merari, 2007). Federal hükümet yaptığı operasyonlarla bu çeteyi çökertmiştir.

Aynı muamma, İrlanda Cumhuriyet Ordusu (IRA) gibi çok daha büyük kuruluşlar için de geçerlidir; bu, 1990'lardaki bir İngiliz tahminine göre, 200-400 erkek ve kadının tahmini aktif üyeliğine ve çok daha geniş bir destekçiye sahipti. Büyük Britanya'ya karşı savaşı kazanabilirler mi? Kazanması da mümkün değildir. Sağc1 isyancıların, "kargaşa stratejisi" veya "gerilim stratejisi" tipiktir. İsyancılar, halkın bu tür koşullar altında, "zayıf" liberal hükümetin yerini güçlü bir rejim almasını talep edeceğini ummuşlardır. Teröristler, kendilerini sözde kabul ettirebilmeleri için bir düzensizlik ve güvensizlik atmosferi yaratmak için halka açık yerlerde rastgele bombalamalara saldırırlar. Böylece, İtalyan Neofaşist Ordine Nero (Kara Düzen) grubu 5 Ağustos 1974'te bir trene bomba yerleştirerek keyfi olarak 12 yolcuyu öldürdü ve 48 kişiyi yaraladı. Bir başka aşırı sağ İtalyan grubu olan Silahlı Devrimci Çekirdek, Bolonya tren istasyonu Ağustos 1980'de 84 kişinin ölümüne ve 200 kişinin yaralanmasina neden oldu (Merari, 2007).

Yukarıda anlatılan terör olaylarını Batı Ülkelerinde çoğaltmak mümkündür. Bu terör olaylarının birçoğunu Türkiye'ye yönelik de görebilirsiniz. Özellikle Ermeni Asala Örgütünün Türkiye'nin yurtdışı temsilciliklerinde 
görevli ve büyükelçi ve diplomatları hedef almış ve şehit etmişlerdir. Geçmişte bu terör örgütünü destekleyen ülkeler vardı, bu gün de var. Bunlar açıktan olmasa da gizliden desteklediği bilinmektedir. Türkiye'ye yönelik teröristleri destekleyen ülkeler; ABD, Rusya, Fransa, Ermenistan, Yunanistan, Suriye, İran gibi ülkelerdir. Asala'nın çökertilmesiyle adı geçen bu ülkeler, şimdi özellikle ABD, PPK ve PYD gibi terör örgütlerini Türkiye'ye karşı desteklemektedirler.

Alberto Abadie, terör riskini, veri kümesindeki değişkenlerin tanımlarını ve tanımlayıcı istatistikleri kullanmıştır. Kullanılan terör riskinin ölçüsü; Dünya Pazar Araştırma Merkezi'nin Küresel Terörizm Endeksi (World Market Research Center's Global Terrorism Index (WMRC-GTI). WMRC-GTI, küresel olarak riski ölçmek için ilk girişim gibi görünüyor. Abadie, 2003-2004 yılları arasında 186 ülkede terörist saldırılarından ve bu ülkelerin yurtdışındaki çıkarlarına karşı terör riskini değerlendirmiştir. WMRC-GTI, beş faktör almıştır. Bunlar; terörizmin motivasyonu, varlığı, ölçeği, etkinliği ve önlenmesini olarak sıralamıştır. WMRC-GTI'nın potansiyel aralığ 10-100'dür ve daha yüksek değerler terörizme daha yüksek etkiyi temsil etmektedir. Yoksulluğu ölçmek için, kişi başına ülke GSYH'sine iliş̧in verileri kullanan Abadie, bazı regresyonlarda kişi başına GSYİH yerine Birleşmiş Milletler İnsani Gelişme Endeksi'ni (HDI) veya ülke Gini Endeksi'ni kullanmıştır. Gini Endeksi, bir ülkenin sakinlerinin refahını üç farklı boyutta ölçer. Bunlar: sağlık, eğitim ve gelirdir. Abadie, dünya çapında terörist risk üzerine yeni bir veri seti kullanarak, terörizm ve ekonomik değişkenler arasında anlamlı bir ilişki bulamamıştır. Çalışmada ters nedenselliği düzeltmek için kullanılan enstrümantal değişken tahminleri aynı niteliksel sonuçları üretmektedir (Abadie, 2006). Tahminler, siyasi özgürlüğün terörizm üzerinde monoton olmayan bir etkiye sahip olduğunu göstermektedir. Gelir seviyesi yüksek ve özgür olan ülkelerde terörün olması daha düşüktür.

\section{Petrol ve Terörizm}

Terör eylemleri tarihin her döneminde söylemek mümkündür. Tarihsel terör olaylarının genel olarak okunması, El-Kaide'ye bağlı teröristler tarafindan kaçırılan, ABD İç Hat yolcu uçakların 11 Eylül 2001 (9/11) tarihinde, iki farklı hedefe intihar saldırısı düzenlemesiyle gerçekleşen koordineli dört saldırıdır. Saldırılar sonucunda 19 hava korsanı dâhil 2.996 kişi hayatını kaybederken, 10 milyar \$'ın üstünde maddi hasar meydana gelmiştir. Ülkeler, Yasser Arafat, El-Kaide veya Usame bin Ladin de dâhil olmak üzere genel terörizm konularının ve türevlerinin, uzun süren tartışmalarını önlemek için vicdani çaba sarf etmişlerdir (Adams, 2003).

Enerjinin endüstriye ve dünyanın enerji refahına etkisi güçlü ve kalıcı olmak zorundadır. Enerji, sadece günlük hayatımızın ekonomik ve sosyal normlarındaki derin değiş̧iklikler değildir. Daha da önemlisi, enerji kaynakları, öfkeyle ortaya çıkan terörizm türü arasındaki yakın bağlantıdır. Dünyanın en büyük petrol üreticisi, petrol ve doğal gaz rezervlerine ev sahipliği yapan Suudi Arabistan, II Eylül terörist saldırılarında belirlenen 19 korsanının çoğunun kökenidir. Gerisi Mısır'dır. Aynı zamanda bu ülkeler, Batı'ya dost bir ulus olarak kabul ediliyorlar. Geçmişe bakılırsa, merak edilmeyen bir şeydi. Hiçbiri ABD'nin - Irak, Libya veya Filistinlilerin muhtemelen ve resmi olarak imkânsız düşmanlarından gelmiyordu (Adams, 2003).

Gerçek İslami din anlayışında terör yoktur. Sadece, terörü kendi amaçları için yorumlayan uygulayan marjinal unsurlar vardır. Bu gibi istenmeyen olaylar her toplumda görülebilir. Maalesef bu olayların hepsinin en kötü olasılığı, tarihsel ve dini çatı̧̧malarla vurgulanan sosyal bir savaşa işaret etmesidir. Batı ve gelişmiş dünya, belki de şu anda yok olan ama hala devam eden sömürgeci üstünlük kompleksleri veya hassasiyet eksikliğinden dolayı, terörü, demleme tehlikesini olumlu bir şekilde göz ardı etmeleridir. Belki de dersleri tarihe karşı çok saygısızlıktan dolayı, ABD gibi karmaşık, genç ve canlı bir ulusun ayırt edici bir özelliğidir.

Petrolün taşınmasında; bazı suyolları, boğazlar, kanallar, petrol endüstrisinde ve ticaretinde terörizmin tehdidi altındadır. Bu jeopolitik kırılganlıklardan, faydanın Jeopolitik boğulma noktaları olarak adlandırılan, korkutucu bir olasılık altındadır. Bu korkutucu bir olasılığın coğrafi alanları: Hürmüz Boğazı, Malaca Boğazı, İstanbul ve Çanakkale Boğazı, dünya petrol ticaretinin çok büyük bir bölümünün geçtiği olağanüstü dar ve oldukça yoğun deniz yollarıdır (Adams, 2003). Özellikle ihraç edilen Rus petrolünün geçtiği İstanbul ve Çanakkale Boğazlarının, en dar noktasında yarım milden az geniştir. Bu suyollarının herhangi birinde büyük bir sabotaj dünya ekonomisine zarar verebilir.

Ancak, yukarıdaki bu olasılıklar tek endişe kaynağı değildir. Pratik olarak tüm büyük petrol üreten ülkelerde, sosyal, ekonomik veya politik olarak hoşnutsuz gruplar vardır. Bunun iki nedeni olabilir. Birincisi; çoğu petrol üreten ülkelerde demokrasi yoktur ve despot bir yönetim vardır. Elde edilen petrol gelirlerinin çoğunu yönetim, kendi zenginliklerine aktarırlar. Ülkede yaşayan çoğunluk fakir ve yoksul toplumlardan oluşmaktadır. Sosyal ve ekonomik hayat, daha da kötüleştirmekte olduğundan, petrol şirketlerini, petrol tesislerini ve çalışanlar çok cazip terörist hedefler haline getirmektedir. Íkincisi; petrol arz güvenliğine yönelik, dış kaynaklı terörist faaliyetlerdir. Teröristlerin, belli bir çıkar karşılığında, petrol tesislerini hedef alabilir. Bu da şok etkisiyle petrol fiyatlarının yükselmesine, neden olabilen, terörist faaliyetlerdir.

Petrol zengini ülkeler, aynı zamanda Batılı kapitalist ülkelerin ihracatında büyük bir paya sahiptir. Batılı Kapitalist ülkeler, petrol zengin olan ülkelerin, elde ettikleri petrol gelirlerini alma peşindedir. İkame üretim sektörü olmayan bu ülkelerin yönetimlerini tehdit ederek kendilerinden, mal ve hizmet alımlarını teşvik ederek 
bağımlı hale getirmektedirler. Çoğu petrol ihraç eden ülkelerin yönetimleri Krallık, Emirlik ya da Batılı güç hegemonyasının altındadır. Bu ülkelerde demokrasi yoktur. Kral ya da Emir'leri elde etmeleri, demokrasiye göre daha kolaydır. Bu da dolalı bir terördür.

2015-2019 döneminde dünyanın en büyük beş silah ihracatçısı sırasıyla ABD, Rusya, Fransa, Almanya ve Çin olurken, en büyük beş ithalatçısı Suudi Arabistan, Hindistan, Mısır, Avustralya ve Çin olmuştur. Suudi Arabistan (SA) 2010-2014 döneminde \%5,6'lık pay ile küresel silah ithalatında 2'nci sırada yer almıştır. SA, 2015-2019 döneminde silah alımlarını \%130 artırarak \%12'lik pay ile büyük silah ithalatçısıdır. ABD, Suudi Arabistan silah ithalatının \%73'ünü tek başına karşılamaktadır (https://www.defenceturk.net/2019-uluslararasi-silah-transferleriithalatci-ulkeler (05.06.2020). Ancak, SA, reel olarak ne kadar dolar askeri malzeme ithalat yaptığ belli değildir.

Diğer bir ülke Katar'dır. Katar silah ithalatında \%634'lük büyüme sağlamıştır. Katar'ın silah ithalatında 2015 2019 döneminde 2010-2014 dönemine göre \%631 gibi devasa bir büyüme gerçekleştirmiştir. Katar bu büyüme ile küresel silah ithalatındaki \%0,5'lik payını \%3,4'e taşımıştır. Katar gerek fiziki gerek demografik boyutuna oranla fazla silahlanan bir ülke durumundadır. Bu durum, Körfez Krizi'nden önce de süregeliyordu. Ancak, Katar, kriz ile birlikte özellikle hava kuvvetlerine oldukça fazla sayıda savaş uçağı sipariş etmiştir. Katar'ın silah ithalatında birinci sırada \%50'lik pay ile ABD yer alırken, sırasıla; Fransa \%34 ile ikinci, Almanya ise \%9,2'lik oranla üçüncü sırada yer almaktadır (https://www.defenceturk.net/2019-uluslararasi-silah-transferleri-ithalatci-ulkeler (05.06.2020).

BAE: 2015-2019 dönemleri arasında, silah ithalatının payı \% 3,4 olmuştur. En çok silah ithalatı \% 68 ile ABD, \%11 ile Fransa ve \% 3,4 ile de Hollanda yer almaktadır. Aynı dönemde Irak’ın silah ithalatının payı \% 3,4 olmuştur. ve en çok silah ithalatı \% 45 ile ABD , \% 34 ile Rusya ve \%8.6 ile de Güney Kore yer almıştır (https://www.defenceturk.net/2019-uluslararasi-silah-transferleri-ithalatci-ulkeler (05.06.2020). Özellikle Körfez ülkelerinde suni düşmanlıklar oluşturularak, birbirlerine karşı aşırı silahlanma yarışına gitmişlerdir (https://www.defenceturk.net/2019-uluslararasi-silah-transferleri-ithalatci-ulkeler (05.06.2020).

\section{Petrol Terörü}

Konuya şöyle bir soru ile başlanabilir;. “Neden Petrol Terörü ve Neden Önemsemeliyiz?” Nerede olursanız olun etrafınıza bakınız. İstanbul, New York, Washington, Londra, Tokyo, Pekin... ev, hafta sonu daireniz, tatil, gece geç saatlerde ofiste, çevrenizi tararken, görünümünüzdeki bu öğeleri zihinsel olarak not ediniz. Görüş alanınızdaki her şeyde bir petrol bağlantısı görüyorsanız, tebrikler - normalsiniz. Ancak, önemsiz istisnalar dışında, görebileceğiniz veya dokunabileceğiniz her şey sadece petrol veya gazın keşfi ve üretiminin bir sonucudur. Sonuç olarak, günlük deneyimlendiği hayat, yeniden yapılanmayı gerektirebilecektir.

\begin{tabular}{|l|l|l|}
\hline $\begin{array}{l}\text { Açık Petrol } \\
\text { Uygulamaları }\end{array}$ & $\begin{array}{l}\text { Otomobiller için benzin, Uçak yakıtı Ev 1sıtması için doğal gaz, } 18 \text { tekerlekli çekiciler, } \\
\text { traktör römorkları için dizel... }\end{array}$ \\
\hline & 1. Otomobil / kamyon lastikleri & 17. Bilgisayarlar ve aksesuarlar \\
& 2. Tüm kauçuk ürünler & 18. Golf topları \\
& 3. Alkolsüz içecekler & 19. Asfalt yollar ve garajlar \\
& 4. Prezervatifler & 20. Su hortumları (çim, araba) \\
& 5. Ampuller & 21. Buz sandıkları \\
& 6. Tarımsal gübreler & 22. Kadın abiye \\
& 7. Kasetler, CD'ler, DVD'ler & 23. Steril cerrahi eldivenler \\
Daha Az Belirgin & 8. Şişe su kapları & 24. Kalp izleme ekipmanları \\
Uygulamalar & 9. Pasaport kapakları & 25. İlaç üretimi \\
& 10. Bayan çanta & 26. Genomik araştırmaları \\
& 11. İç çamaşırı elastik & 27. Plastik defter bölücüler \\
& 12. Diş macunu & 28. Tuvalet kâğıdı \\
& 13. Saç spreyi & 29. Saat kordonu \\
& 14. Deodorant & 30. İnşaat projeleri \\
& 15. Kadın hijyen ürünleri & 31. (hidro, nükleer, elektrik, \\
& 16. Ayakkabı (koşu, golf, tenis) & 32. Otomobil üretimi) \\
\hline
\end{tabular}

Tablo 1. Çeşitli Petrol Uygulamaları Kaynak: Neal Adams, Terrorism \& Oil, a.g.e., s.2

"Petrol”, aşağıdaki öğeleri tanımlayan toplu bir terim olarak şekilde kullanılmaktadır: •likit petrol, • doğal gaz, - gres, • benzin, • petrokimya. Ancak, yukarıdaki Tablo 1'den de görebileceğimiz gibi petrol, halkın hemen tanıyabileceğinden çok daha fazla işlevi olan bir kaynaktır. Petrol ürünleri üç ana kategoriye ayrılır: nakliye yakıtı, 1sıtma ve üretim yakıtı ve hammaddeler.

“Isıtma ve Enerji Üretimi. Damıtılmış yağlar ve artık yağlar evleri ve işletmeleri ısıtmak, ayrıca elektrik üretmek ve üretim için güç sağlayacak yakıt. Isıtma ve enerji üretimi rafine edilmiş petrol kullanımının yaklaşık $\%$ 26'sını oluşturmaktadır. 
Petrokimyasallar ve Hammaddeler. Kalan petrol ürünü kullanımından, rafine edilmiş petrolün yaklaşık \% 13'ü üretimde hammaddeler için kullanılmaktadır. Bunların çoğu, kozmetik, deterjan, ilaç, gübre, böcek ilacı, plastik, sentetik elyaf ve yüzlerce diğer ürün de dâhil olmak üzere binlerce ürünün imalatında kullanılan petrokimya haline gelmektedir. Petrol arıtma işleminin diğer yan ürünleri, mumlar ve mobilya cilası gibi çeşitli ürünlerde kullanılan asfalt, yol yapım malzemesi ve balmumudur" (Adams, 2003). Yukarıda sıralanalar petrol türevi olup, üretim ve sanayide büyük girdi kaynağıdır. Terör stratejik kaynağı hedef alarak petrol arz güvenliğini de tehdit etmektedir.

\section{Strateji Tanımı ve Petrol İçin Önemi}

Stratejiler konusu ve amacına göre belirlenir. Tanımlamaları da buna göre yapılır. "Strateji kelime anlamıyla "sevketme, yöneltme, gönderme, götürme ve gütme” demektir. Kelime ilk olarak askeri alanda kullanılmıştır. Bir savaşta kazanmak için yapılacak askeri harekâtın planlanması ve yürütülmesi bilimidir. 20. Yüzyılın başında askeri bir kavram olarak Türkçemize giren strateji kelimesi, düşmanın ne yapabileceği ve ya ne yapamayacağını belirleyerek buna göre genel bir plan yapmak, kendi güçlerini yerleştirerek gerektiğinde harekete geçirmek demektir.

Strateji, çok yönlü amaçlara ulaşmak üzere kaynakların üstüne önemle gitmek ve harekete geçmek için yapılmış genel programlardır. Bir organizasyonun amaç programları, bunlardaki değişiklikler, kaynakların bu amaçlara erişmek için kullanılması, kâr yönetimi politikaları, temel uzun dönemli amaçların belirlenmesi, faaliyetlerin bunlara adapte edilmesi ve gerekli kaynakların dağıtılması, işte tüm bu süreç ve faaliyetler işletmenin stratejisini oluşturur."(http://www.ozyazilim.com/ozgur/marmara/uluslararasi/stratejikplan.htm (20.7.2020).

Genel olarak işletmelerde Strateji; yöneticilerin rakiplerine göre şirketlerinin performansını artırmak için yaptıkları bir dizi eylemdir. Bir şirketin stratejisi üstün performansla sonuçlanırsa, rekabet avantajına sahip olduğu söylenebilir. Yöneticilerin şirketlerinin performansını rakiplerine göre artırmak için yaptıkları bir dizi eylemlerdir. Terörizm: Tehdit veya güç kullanımı tehdidi ile bir kişi veya örgütlü bir grup tarafından, bireyleri, toplumları veya hükümetleri korkutma veya zorlama niyeti, genellikle ideolojik veya politik nedenlerle yapılan yasadış1 hareketlerdir.

İşletmelerde biçimsel stratejik planlama sürecinin beş ana adımı vardır. Bunlar; "(1) Kurumsal misyonu ve önemli kurumsal hedefleri seçin.(2) Fırsatları ve tehditleri belirlemek için kuruluşun dış rekabet ortamını analiz edin. (3) Kuruluşun güçlü ve zayıf yönlerini belirlemek için kuruluşun dâhili çalışma ortamını analiz edin.(4) Dış firsatlardan yararlanmak ve diş tehditlere karşı koymak için kuruluşun güçlü yönlerini temel alan ve zayıf yönlerini düzelten stratejiler seçin. Bu stratejiler, şirketin misyonu ve ana hedefleriyle tutarlı olmalıdır. Organizasyon. Uyumlu olmalı ve uygulanabilir bir iş modeli oluşturmalıdırlar.(5) Stratejileri uygulayın” (Charles ve Jones, 2012).

Shell, petrol için 1980'lerden beri senaryo planlamasını yapmaktadır. Shell, gelecekteki petrol taleplerini karşılamak ve ilgili stratejik planlamasını iyileştirmek için iki ana senaryo kullanmaktadır. Birinci senaryo; petrol için. "Her Zamanki Dinamikler" olarak adlandırılan karbon yakıtlarından, doğal gaz yoluyla yenilenebilir enerjiye kademeli bir geçiş sağlanması. İkinci senaryo, "Gelecek Çă̆ın Ruhu", teknolojik bir gelişmenin yeni enerji kaynaklarına hızlı bir geçişe yol açması olasılığına bakıyor. Shell bunları sağlayacak yatırımlar yapmaktadır (Charles ve Jones, 2012). Yukarıda stratejik planlama sürecinin beş ana adımında görüldüğü gibi, petrol üreticisi ülkeler, stratejik petrolün dış tehditlere karşı koymak için ne tehdit bulunabilir. Bunun için marjinal terör örgütleri açık veya gizliden desteklenmektedirler. $\mathrm{Bu}$ günlerde Suriye’nin kuzeyindeki terör örgütünü ABD’nin desteklemesi kendi planını bir parçasıdır. Burada ülkelerin müttefiki olması, güçlü lehine çalışır. Bu da stratejik kaynak petrol için önemlidir.

\section{Stratejik Petrol}

Stratejik petrol, ilk defa Batı dünyası ve ABD’de kullanılmıştır. 3 Haziran 1967 yılında Arap - İsrail Savaşı sonrasında Arap ülkeleri kendi aralarında Arap Petrol İhraç Eden Ülkeler Örgütü (APİEÜÖ), 1973 y1lında Kuveyt'te Kuruldu. Kurulmasıyla birlikte, İsrail'i destekleyen, ABD, İngiltere, Batı Almanya gibi ülkelere ambargo koymuştur. Ayrıca, Teşkilat, petrol arzını da azaltmıştır. Bununla beraber, Batılı Ülkelerde petrol girdi maliyetleri artmıştır. Özellikle ABD'de Dolar devalüe edilmiş ve Bretton Woods Sistemi çökmüştür. APIÜÖ, petrol ambargosunu genişletmiştir. ABD'nin yanında, Hollanda, Kanada'ya petrol ambargosu uygulayarak üretimi düşürdü. Bir miktar Arap ham petrolü Amerika Birleşik Devletleri'ne ulaşırken, ithal edilen ham petrolün fiyatı 1973 'ün son çeyreğinde kabaca varil başına; 4 \$ / varilden (varil) 1974'te 12.50 \$ / varile ortalama fiyatına yükseldi (Bamberger, 2010). Petrol tüketen (ithal eden) ülkelerin, yükselen petrol fiyatları bir anda piyasalarında maliyet şoklarına neden oluşmuştur. Petrol ithalatçısı ülkeler, fiyat artışları karşısında, stratejik petrol stokların varlığı, piyasaların krize tepkisinin büyüklüğünü azaltmaya yardımcı olabilecek, tedbirleri gecikmeli olarak uygulamaya çalışmışlarsa da, petrol arz şokun sayesinde iç fiyatların genel seviyesini de artmıştır.

11 Eylül olayları, ABD yönetimine bir fırsat sağlamıştır. ABD,11 Eylül saldırısını daha iyi kavramaya yönelik güçlü politikalar başlattı. Aynı zamanda Amerika'nın politik-askeri kontrol kapasitesini dünyaya hatırlatmıştır. 11 Eylül'deki terörist saldırılar gerçekte bir sürpriz değildi. Gerçekten de 11 Eylül, Amerikan stratejik analistleri ile 
askeri ve istihbarat planlamacıları tarafından geliştirilen yeni bir askeri rolü haklı çıkarmak için ihtiyaç duydukları vahşi fantezilere geliştirdiler. Soğuk Savaş sonrası dünya, 1990'larda, Sovyet sonrası yeni tehditlerden kaynaklanan en kötü senaryoları hayal etmek için büyük çaba harcandığını söylemek mümkündür. ABD güvenlik planlamacıları, kimyasal savaştan, biyolojik silahlara ve kaçırılan araçlardan, kamyon bombalarına, 11 Eylül hizmetlerini sıkıştıracak, elektriği veya telekomünikasyonunu kesecek, hava trafik kontrolünü bozacak siber terörizme kadar her türlü "kötü" yeni olası tehdidi ortaya çıkarmıştır. Hatta bir CyberTerrorist'in yeni nesil hava trafik kontrol sistemlerine saldıracağı ve iki büyük sivil uçağın çarpışacağı iddia edilmiştir. Bu gerçekçi bir senaryodur. Çünkü CyberTerrorist, uçağın kokpit sensörlerini de kırabilecek bilgiye sahiptirler (Fouskas ve Gökay, 2005).

"W. Bush'un 24 Eylül 2001'de terörizmle mücadele için kampanyada başlatmıştır. Bunun için; teröristlerin küresel eylemlerini desteklemek için kullanılabilecek fonların, hem toplanmasını hem de hareketini bastırma çabası da dâhil olmak üzere geleneksel olmayan yöntemlere, kurumlara ve kaynaklara başvuran uzun süreli bir mücadele olacaktır. Terörle savaşı kazanmak için diplomasi, istihbarat, yasa uygulama aracı, her türlü mali etki ve kaynağı emrimize yönlendireceğiz. Teröristleri paradan mahrum bırakacağız, onları birbirlerine karşı çevireceğiz, güvenli saklandıkları yerlerden çıkaracağız ve adalet önüne çıkaracağı”" (Biersteker ve Eckert, 2008). Bu stratejinin altında yatan mantık, derinden devlet merkezli bir mantıktır. Devletler, stratejinin merkezinde yer alır ve kendi topraklarından kaynaklanan eylemlerden sorumlu tutulmalıdır. Devletlerin, istihbarat toplamayı, kanun yaptırımını güçlendirerek ve terörizmin finansmanına karşı yeni mali kontroller getirerek küresel terörizmin zorluklarıyla başa çıkma konusundaki zorlayıcı kapasitelerini artırmaları beklenmektedir.

Kâbus senaryolarında, terörizme destek olacak "kitle imha silahları" ile "haydut devletler" fikri, ABD'nin çıkarlarını tüm bu yeni ve çoğunlukla hayali tehditlere karşı savunmak için, 1990'larda yeni yüksek teknolojili savaş teknikleri geliştirilmiş ve uygulanmıştır. Ancak, savaşın artık politik olarak kabul edilebilir olmaması anlaşılmıştır. Vietnam'ın hayaleti hala hayatta olduğuna göre, Amerikan bombaları, uçakları, uyduları ve tanklardaki üstünlüğünün ABD kayıplarını sınırlamak için kullanılması gerektiği ortaya çıkmıştır. ABD’nin askeri performansın doğrudan bir düşmana saldırmak için yoğun teknoloji kullanımına yönelmiştir. Bu teknolojik uygulama; Kuzey Irak'taki Kürt gruplarını, Kosova'daki KLA ve Afganistan'daki Kuzey İttifakı gibi bir grubun desteklenmesi, çatışmanın yükünü ortadan kaldırmak için de kullanmıştır. 1991 yılında Basra Körfezi Savaşı'nda, 1999'da Kosova'da ve 2001-2002'de Afganistan'da gerçekleşen hızlı zaferlerin hepsi, kullanılan silah teknolojisi sayesinde gerçekleştirilmiştir (Fouskas ve Gökay, 2005).

\section{Stratejik Petrolün Durumu}

Petrol, hidrojen ve karbondan oluşan ve içerisinde az miktarda nitrojen, oksijen ve kükürt bulunan çok karmaşık bir bileşimdir. Normal şartlarda gaz, sıvı ve katı halde bulunabilir. Gaz halindeki petrol, imal edilmiş gazdan ayırt etmek için genelde doğal gaz olarak adlandırılır. Ham petrol ve doğal gazın ana bileşenleri hidrojen ve karbon olduğu için bunlar "Hidrokarbon" olarak da isimlendirilirler (Enerji Bakanlığı, 2010).

Türkiye, jeopolitik konumu itibariyle dünya ispatlanmış petrol ve doğal gaz rezervlerinin dörtte üçüne sahip bölge ülkeleriyle komşu olup, enerji zengini Hazar, Orta Asya, Orta Doğu ülkeleri ile Avrupa'daki tüketici pazarları arasında doğal bir "Enerji Merkezi" olmak üzere pek çok önemli projede yer almakta ve söz konusu projelere destek vermektedir. 2030 yılına kadar \%40 oranında artması beklenen dünya birincil enerji talebinin önemli bir bölümünün içinde bulunduğumuz bölgenin kaynaklarından karşılanması öngörülmektedir (Enerji Bakanlığı, 2010).

Türkiye,2018 yılında 21 milyon ton olarak gerçekleştirilen ham petrol ithalatımızın yanı sıra 17,7 milyon ton petrol ürünü ithal edilmiştir. Buna karşın 8,9 milyon ton petrol ürünü ihraç edilmiştir. Her geçen gün artan petrol ve doğal gaz ihtiyacının mümkün olduğunca yerli kaynaklardan karşılanması yönündeki faaliyetler kapsamında, ülkemizin yeterince aranmamış basenlerinde ve özellikle Karadeniz ve Akdeniz'deki deniz alanlarında yapılan çalışmalar büyük bir ivme kazanmıştır. Son yıllarda deniz sondaj teknolojisindeki gelişmelerin, su derinliklerinin fazla (1.000-2.000 m) olduğu alanlarda arama ve üretim imkânlarını ortaya çıkarması ile denizlerimizde hidrokarbon aramacılığının yapısı hızla oluşturulmuştur. Bu kapsamda, gerek satın alma gerekse yerli imalat yoluyla iki adet sismik arama ile iki adet sondaj gemisi temin edilmiştir (Enerji Bakanlı̆̆ 1,2010 ).

\section{Petrolün Kısa Ekonomi Politik Tarihi ve Ortadoğu}

Zamanımızın iki önemli sorusunun kesiştiği noktada, yani Dünya gezegeninin küresel barışı ve sürdürülebilirliği, son zamanlarda insanlığın malzemesi ve zihnine zarar veren tüm metaların ötesinde bir metadır. Bu meta, gerçekleri ve kurgusal izlenimi, bugün kamuoyu üzerinde sonuç veren bir etkiye sahip olan petrolden başka bir şey değildir.

Petrol, eski çağlardan beri var olan bir maddedir. "Eski Orta Doğu'da bitümen ticari meta olarak satılıyor ve inşaatlarda harç olarak kullanılıyordu. Filistin'deki Eriha kenti ve Mezopotamya'daki Babil'in duvarları bu harçla yapılmıştır. Büyük olasılıkla Hz. Nuh’un gemisi ve Hz. Musa'nın sepeti, su geçirmemesininsin nedeni de 
bitümenle kalafat edilmişti. M.S. Birinci Yüzyılda yaşamış Romalı naturlist, Phiny'nin eczacıılık alanında da kullanıldığını söylemiştir. Nihayet, Edwin L. Drake (Albay) 1859'da Pennsylvania'da petrol keşfedildiğinde" (Yergin, 2003), merkantilizmin ekonomik değeri, petrolü değil, altın ve gümüşü içeriyordu.

Petrol bir nesne değil, aynı zamanda birçok olumlu ve olumsuzlukları da bünyesinde taşır. Bunlar bir yörünge etrafinda; eksiler, olaylar, eylemler ve reaksiyonlar, anlaşmazlıklar, çürütmeler, eşitsizlikler, sapmalar, gibidir. Her şeyden önce, tarihsel zaman ve toplumsal süreçte çelişkiler, çatışmalar, kaynaşmış ve yapışıktır. Uluslararasıı ekonomik ilişkilerde tam gelişmiş kartelleşme petrolün erken gelişiminde görülebilir. Petrol Karteli (1928-72) ile rekabetçi bir küreselleşmeye herhangi bir ulus-devletin sınırlarının ötesinde üçüncü geçen yüzyılın çeyreğidir. Bu, tüm zaman ve amaçla, yeni kolonizmde, ağartılmış ve geçmiş zamanda tarih haline gelmeden önce Pax Americana'nın (ABD veya İngiltere tarafindan denetlenen göreceli uluslararası barış durumu) şizofrenik değerlendirme tablosu tarafından taşınan ve aktarılan eski sömürgeciliğin öyküsüdür. Bu bir tarihin sonu ve yeni bir tarihin başlangıcıdır. Bu bağlamda, 1970'lerin başlarında petrolü (ve bir bütün olarak enerjiyi) dönüştüren petrol krizi, bugün küresel yönetimin ve ekonomisindeki imajı sayesinde kendi başına uygun bir tarihi yere sahiptir (Bina, 2013).

Petrolün evrimi yüzyıllık bir gelişmede bir seyir izledi (1870-1970). Sonuçta, bütünü kucaklamak için küreselleşme, dünyaya ve bilinenlere yol gösterme dönemi olarak gelişti. Böylece petrol için yirminci yüzyılda topallayan kapitalizmden büyüme ve olgunluk yaşında kartelde koltuk değneği, sosyal bir ilişki olarak gezegen boyunca kendine tam bir daire çizmiştir (Bina, 2013).

Bakü, Bibi-Haybat'da 1846 petrol keşfedilmiştir. Daha sonraki 1859 Albay Drake'in Pennsylvania'daki grevi, petrolün uluslararası evrimi oldu. Batı ve Doğu'daki Kafkaslar, İngiliz sömürgeciliği nedeniyle o zamandan bu yana odak noktasını olmuştur. Orta Doğu. Petrolün evrimsel gelişimi ve belirginliği bu nedenle bu bölgeye geçiş hikâyenin önemli bir parçasıdır. Dünya çapında petrolün evriminde ve kartelleşmesinde ilk aşama olmuştur. Başka bir deyişle, D'Arcy'nin 1901'de İran'daki petrol imtiyazı, 1908'de Mescid Süleyman'ın (güneybatı İran) petrolünün ve daha sonraki Britanya'nın sömürgesi, ekonomik ve politik hâkimiyetinin keşfedilmesine yol açmıştır. Bu, ABD gibi yükselen güçlerin, 1970'lerin başında petrolün küreselleşmesine kadar Orta Doğu'nun kıymetli ama değiş̧en kumlarında dayanak kazandığı bir temel taşıydı. Petrolün evrimi, 1950-72 geçiş dönemi olarak tanımladığımız ikinci bir aşamadan geçti. Sonunda 1973-74 petrol krizi yoluyla petrolün tam teşekküllü bir küreselleşmeye ve küreselleşmesine yol açan bir geçiş olmuştur. 1973-74 petrol krizinin rolü ve kartelleşmedeki sonucunda petrolün küreselleşmesi, rekabetçi bir evrim mekanizmasını göstermiştir. Çeşitli petrol üreten bölgelerin eşit olmayan maliyetlerine (ve verimliliklerine) karşı dünya çapında fiyatlandırmaktadır. Uluslararası ilişkilerde ortodoks düşünceye göre; 1970'lerin "saldırgan OPEC" bir imaja sahipti. OPEC karşısında, ABD, büyük tankerler ile yerli ve diğer petrol üreten bölgelerdeki petrol taşımadığının bölünmezi olmuştur. Bu kural. "Ulusdevlet" ve "anarşiı" olarak sembolize edilen kurgusal yapılarda, uluslararası siyasete "gerçekçi" yaklaşım olarak adlandırıldı. Yeni bir giysi ile eski bir sömürge tarzında kontrolü tercih etmek, "Neo-muhafazakârlar" düşünürlerin çoğu, OPEC'i ne kartel ne de tekel olduğunu kabul etmiyordu. OPEC, petrol kârlarına rağmen aşırı rekabetçi ve küreselleşmiş petrol varlığının eşlik ettiği sermayenin yoğunlaşma (ve merkezileştirme) deşifre etmek için rantı, kârdan ayırt edememiştirler (Bina, 2013).

\section{Petrol Krizinin Bağımlılık Teorisi}

Bağımlılık Teorisi “1960’larda Latin Amerika'da ortaya çıkmıştır. Doğu ülkelerinin geri kalmışlığını, bu ülkelerin batılı ülkelerin geçirdiği tarihsel aşamalardan geçmemesi nedeniyle ve bilimsel-teknolojik gelişmelerden yoksun olmasıyla açıklamaya çalışan modernleşme teorisine tepki olarak doğmuştur. Samir Amin, Immanuel Wallerstein, Fernando Cardoso, Andre Gunder Frank gibi birçok akademisyen bu teorinin önemli isimleri olmuşlardır. Bağımlılık Teorisi, esas olarak ekonomik bir teoridir. Samir Amin'e göre sorununun temeli merkez ülkelere olan bağımlılıktır.

Bağımlılık Teorisi, uluslararası ilişkiler alanında da kullanılmış ve gelişmiş ülkelere ekonomik ve diğer yönlerden bağımlı olan gelişmekte olan, az gelişmiş ülkelerin dış politikalarının bağımsız olamayacağı varsayımı üzerinden geliştirilmiştir. Buna göre, gelişmiş ülkelerin gelişmemiş ülkeler üzerinde yoğun siyasi kontrolleri mevcuttur. Gelişmiş ülkeler bu kontrolü siyasi isteklerini açıktan bildirerek yapmazlar, ancak ekonomik baskılar uygulayarak gerçekleştirebilirler." (http://www.tuicakademi.org/bagimlilik-teorisi/ ( 08,06.2020).

Petrol Krizinin Bağımlılık Teorisine uyarlaması:1973-74 petrol krizinin bağımlılık teorileri derinden genel olarak bağımlılık teorisine dayanır. Bu bölüm ne iddia ediyor ne de bu teori ile ilgili tüm konuları incelemeyi düşünmüyor (Prebisch 1950, Frank 1969'a, 1969'b, 1972; Emmanuel 1972; Amin 1974; Girvan 1976; Hafta 1981 'b; bkz. Brenner 1977, Haftalar 1981'b bir eleştiri; daha fazla araştırma için bkz. Latin Amerika Perspektifleri 1976, 1977, 1979, 1981). Buradaki görev daha çok belirli analizi ile ilgili olduğu için bağımlılık metodolojisinin iddiaları petrol krizidir. Böylece, başlangıç olarak Girvan'ın (1975),1973-74 petrol krizinin değerlendirilmesi ile birlikte Tanzer (1974) ve Stork (1975) gibi yazarlar bağımlılık teorisi açısından konuya katkı sağlamışlardır. Bu yazarların çoğu tarafından dile getirilen en büyük tartışma yukarıda da belirtildiği gibi, Batı'nın sanayileşmiş ülkelerine karşı kendi kaderini tayin ve egemenlik elde etmek için bir "OPEC saldırısı" olduğunu varsaymaktadır 
(Bina, 2013). Ancak, bu "saldırgan” 1n, bir yanda Emperyalist ülkeler ile diğer yanda Üçüncü Dünya ülkeleri arasında var olan uzun süreli hâkimiyet ilişkilerine bir tepki olduğu söylenmesi gerekir.

\section{Ortadoğu Petrol Üretiminde Stratejik Dönemler Politik Oluşumu}

Ortadoğu petrol üretimi yukarıda anlatıldığı gibi çok eski yıllara dayanır. Petrolün o günkü ekonomik ihtiyacı ile bugünkü petrole olan ihtiyaç arasında çok büyük farklar var. Bugün petrol, dünyanın en önemli stratejik kaynağı haline dönüşmüştür.

“Ortadoğu'daki petrol üretiminin tarihini üç ayrı döneme ayırmak mümkündür. Birincisi: sömürge / petrol imtiyazları dönemi, İkincisi : (1901-50), kapitalist gelişime geçiş aşaması ve Üçüncüsü; (1950-72) ve modern kapitalist üretimin kriz sonrası dönemi.

- Sömürge / imtiyazlar dönemi; uluslararası petrol şirketlerinin ham petrolün keşfi ve üretimi için imtiyazlı haklar elde ederek tüm Ortadoğu bölgesini kendi aralarına böldüğü dönemdir. Bu imtiyazlara maruz kalan alanlar, neredeyse bir yüzyıla kadar süren sözleşmelerle, çoğu zaman ilgili ülkelerin yönetimindeydi. Sosyal ilişkilerin varlığı, toprakta özel mülkiyetin olmaması ve uluslararası sermayenin siyasi hâkimiyeti, bu dönemin temel özelliğidir.

- $\quad$ İkinci dönem, Orta Doğu petrol endüstrisinde kapitalist üretimin daha da gelişmesi ile ilişkilidir. Bu dönemin ayırt edici özellikleri, İran'da petrolün millileştirilmesi (ve 1953 CIA darbesi ile geri dönüşü) ve müteakip, OPEC'2e üye olan ülkelerin petrolü millileştirilmesi, ekonomik ve politik egemenlik altında kapitalist sosyal ilişkilerin gelişmesi, petrol endüstrisinde sermayenin uluslararası aşma sürecini hızlanmıştır.

- Son olarak, üçüncü dönemin başlaması, değer oluşumu ve petrol endüstrisinde fiyat oluşumu ile tarihinde ilk kez, sanayi tüm küresel yapıda genişleyen modern bir uluslararası boyut kazanmıştır.

Orta Doğu Petrol tarihine bakıldığında; İngiltere, Osmanlı’ya karșı Arap ayaklanmasını garantiledikten sonra, Fransa ile gizli görüşmeyle başlamıştır. Amaç, Asya'daki Osmanlı topraklarının paylaşılması konusunu görüşmek için Fransa'nın Beyrut eski konsolosu, François Georges Picot'a bir temsilci göndermesini istemiştir. İngiltere'nin Araplar 'la gizlice anlaşmasından memnun olmayan Fransa, Beyrut eski konsolosu François Georges Pilot'u özel temsilci olarak yolladı. İngiltere de Dışişleri Bakanlığı müsteşarı Sir Mark Sykes’1 görevlendirmiştir" (İslam Ansiklopedisi, 2010). Bu gizli anlaşmada Çarlık Rusya'sı da var. Ekim 1917'de Çarlık Rusya Bolşeviklerin iktidarı ele geçirmeleri ile bu Anlaşmayı açıklamışlardır. 16 Mayıs 1916'da (Sykes-Picot) İngiliz-Fransız Gizli Anlaşması Anlaşmanın tek amacı, Ortadoğu’daki zenginliklerin üzerine konmaları ve Osmanlıyı parçalamaktır. Bu Anlaşma ile ortaya irili ufaklı mandater krallıklar çıkmıştır. Bugün irili ufaklı devletler mevcudiyetini devam ettirmektedir. Irak ve Suriye bugün oldubittilerle karşı karşıyadır. Tek sebep,1916 şartlarında bölgede ABD'nin olmamasıdır. Güçlü ABD şimdi bunu firsat bilmektedir. ABD, Irak petrollerine savaş tazminatı olarak konmuştur. Irak’taki askeri gücü ile Suriye'deki petrol alanlarını kontrol ve işgal etmek için bölgedeki marjinal terör örgütlerini kullanmaktadır. Bu doğrudan terörizmi destekleme anlamına gelmektedir.

Suudi Arabistan, Mayıs 1927'de ise İngiltere ile yapılan antlaşmayla Suudiler bağımsızlıklarını ilan ettiler ve Abdülaziz bin Suud, tüm Hicaz'a hâkim oldu. 1932'de resmen kurulan bu devlet bugün Suudi Arabistan Krallığ1 adıyla varlığını sürdürmektedir (https://gezimanya.com/suudi-arabistan/suudi-arabistanin-kisa-tarihi (20.05.2020). Prens Faysal'ın Moskova'yı ziyaret ettiği 1932'den bu yana iki ülke arasındaki ilk üst düzey temas oldu. 1926'da Sovyetler Birliği ironik bir şekilde krallıkla diplomatik ilişkiler kuran ilk ülke olmuştur (Bahgat, 2004). Bununla birlikte, Sovyet-Suudi ilişkisi karşılıklı şüphe ve karşıtlık ile karakterize edildi. İkinci Dünya Savaşı arifesinde Sovyetler diplomatlarını Riyad'dan geri çekti. Soğuk savaş sırasında Suudiler muhafazakâr Arap ülkelerini Orta Doğu'nun Sovyet nüfuzuna karşı direnmeye yönlendirdiler. Ayrıca Riyad ve Moskova, Doğu Afrika ve Afganistan'da vekâletle savaştılar. Sovyetler sosyalist rejimleri destekledi ve Suudiler muhafazakâr hareketleri finanse etmiştir (https://gezimanya.com/suudi-arabistan/suudi-arabistanin-kisa-tarihi (20.05.2020).

Ağustos 1990'da Irak'ın Kuveyt'i işgali, Sovyet-Suudi ilişkisinde yeni bir sayfa açtı. Diplomatik ilişkilere devam edildi, ancak, soğuk kalmıştır. 11 Eylül'de ABD'deki terörist saldırıları izleyen stratejik değişiklikler, Moskova ve Riyad için ortak bir zemin oluşturmuştur. Amerikan petrol şirketleri. Geçtiğimiz yarım yüzyılın çoğunda, Washington Riyad'ı güvenilir bir petrol arzı kaynağı olarak görmüştür (Bahgat, 2004). Büyüyen ABD-Rusya işbirliğine rağmen, Suudi Arabistan Kanada, Meksika ve Venezuela ile birlikte ABD'ye büyük bir petrol ihracatçısı olma özelliğini korumuştur.

"Rus-Suudi diyalogunun enerjinin jeopolitiği üzerindeki etkilerini tam olarak değerlendirmek biraz zaman alacaktır. Ancak, yine de ön sonuçlar çıkarılabilir. İk olarak, Rusya ve Suudi Arabistan arasındaki iletişim hatlarının en üst düzeyde açılması, iki ülkenin siyasi çıkarlarına hizmet edecektir. Moskova, Sovyet döneminde Orta Doğu'daki etkisini yeniden kazanmaya heveslidir. Dahası, Suudi Arabistan ile yakın ilişkiler Rusya'nın İslam dünyasındaki duruşunu iyileştirecektir. 
İkincisi, Rusya-Suudi zirvesinin önemli bir sonucu, terörizme karşı çabalarını koordine etmek için bir çalışma grubu kurma anlaşmasıydı. Çünkü Rusya'ya ait petrol boru hatları Çeçenistan'dan geçmektedir. Çeçenler, Çeçenistan'da üretilen petrol kendilerine ait olduğunu ve Çeçenistan'dan geçen petrol boru hattından yararlanmak istemişlerdir. Rusya, Çeçen isteklerini reddedince, Çeçen direniş̧̧iler boru hatlarına saldırdılar ve Çeçenistan da bir iç çatışma başlamıştır. Rus yetkililer, Çeçen direnişçilere Suudi Arabistan yardım ettiği düşüncesiyle Suudilerle görüş̧meler başlamıştır. Suudi yetkililer, teröristleri desteklemediklerini Rus yetkililere aktarmıştır (Bu durum yukarıda açıklanmıştır)." (Bahgat, 2004).

Petrol kaçakçılığı, hırsızlık, gasp, Irak'ta ve 2011 den sonra Suriye'de oluşan otorite boşluğu, Iş̧iD'in milyarlarca Dolar Petrolden kazanç sağlamıştır. Bu terör örgütleri dış destek almadan hayatlarını devam ettirmeleri mümkün değildir. ABD istihbarat yetkilileri ve özel uzmanlara göre; bir zamanlar zengin İran Körfezinde, paraya güvenen İslam Devleti militanları, petrol kaçakçılı̆̆ı, insan kaçakçılığı, hırsızlık ve gasptan günde 3 milyon dolardan fazla kazanç elde ederek, kendi kendini devam ettiren, yıkan, finansal bir güç haline gelmiştir (https://www.cnbc.com/2014/09/14/oil-smuggling-theft-extortion-how-isis-earns-3m-a-day.html $\quad$ (0.05.2020). Analistler, İslam Devleti grubunun Suriye ve Irak'ın büyük bölümlerini ele geçirdiğini ve her iki ülkede de 11 petrol sahasını kontrol ettiğini söylüyorlar. Savaştığı aynı hükümetlerin bazılarına kaçakçılık ağları aracılığıyla petrol ve diğer malları satıyor. Kürt kontrolündeki kuzey Irak’tan, Türkiye ve Ürdün'e petrol satmışladır.

Uluslararası terörizm kendi başına bir hareket edemediğine göre, mutlaka uluslararası bir desteği olduğu bilinmektedir. Uluslararası çıkar çevreleri bazen bu terör gruplarını taşeron olarak kullanırlar. Uluslararası terörizmin belirleyicileri, iç terörizmin belirleyicileri hakkında bilgilendirici olmak zorunda değildir. Günümüz ulus ötesi terörizminin çoğu, zengin ülkelere yönelik şikâyetlerden kaynaklanıyor gibi görünmektedir. Bazı durumlarda terörist gruplar, uluslararası tanıtım kazanmak için zengin ülkelerin mülklerine veya vatandaşlarına saldırmaya karar verebilirler. Ulusaşırı terörizm zengin ülkeleri ağırlıklı olarak etkileyebilir. Aynı şey iç terörizm için de geçerli değildir (Abadie, 2006).

Terör, petrol finansmanıyla bağlantılı olduğu üç mekanizmayı tanımlamaktadır. Bunlar: finansman, hedefleme ve motive etmedir. Petrol üreten ülkeler, daha fazla etkiye neden olmak ve güçlü ülkelerin denizaşırı menfaatlerine zarar vermek için petrol tesislerine teröristleri saldırmaktadır. Aynı zamanda petrolün yerel halklar arasında sık sık mağduriyet ürettiği için terörizme yatkındırlar. Bundan dolayı, petrol geliri ile terörizm arasında güçlü bir ilişki bulmaktadır. Petrol üreten ülkelerin terörizme daha fazla destek olma eğilimi vardır (Chia-yi Lee, 2016).

\section{Terörist Saldırılar ve Siyasi Şiddet: Petrolün Etkilenmesi}

Genel olarak baktığımızda, siyasi şiddetin yükselişte olduğu bir dünyada yaşıyoruz. Terörizm ve Siyasi Şiddet haritasına göre, 2016 terörist saldırıların sayısında yüzde 14,2'lik bir artış olmuştur. Bu saldırıların çoğu, dünya çapında terörizmin en fazla hedef aldığı petrol ve gaz endüstrisidir. Küresel GSYH'nin yaklaşık yüzde 4,5-6,5'ini oluşturan petrol, bu kadar değerli bir meta olduğu için giderek artan bir saldırı altındadır (The One Brief, 2017). Büyük bir petrol ve gaz sektörü olan ülkelerin ekonomileri için, terör olayları birden fazla sektörde önemli aksamalara yol açarken, maliyetleri artırıp ekonomik büyümeyi aşağı çekmektedir. Bu tür iki ülke, Nijerya ve Kolombiya, 2016 yılında sektöre yönelik tüm saldırıların yüzde 74'ünün hedefi olmuştur. Küresel ve politik belirsizlik konusunda yeni bir döneme girerken, terörist saldırıların dünyanın en değerli mallarından biri üzerindeki potansiyel etkisini anlamak zorunludur (The One Brief, 2017).

\section{Petrol Endüstrisi Saldırılarının Küresel Etkisi}

Petrol boru hatları gibi uzak altyapıya yönelik terörist saldırılara karşı savunmak zordur. Siyasi rejimler tarafindan giderek artan bir şekilde ekonomileri, hükümetlerin otoritesini zayıflatma ve yerel şikâyetleri kullanma firsatı görülmektedir. 2016 yılında petrol ve doğal gaz altyapısına yönelik terörist saldırılar, ticari çıkarlara yönelik tüm terörist saldırıların neredeyse yüzde 42'sini oluşturmuştur. Yerel ekonomik faaliyetlerdeki aksamaların kümülatif (birikmiş) etkinin nasıl önemli bir etkiye sahip olabileceğini kanıtlamıştır (The One Brief, 2017).

Petrol üreten ülkede azalan yerel desteğin bir sonucu olarak, ülkelerde faaliyet gösteren kuruluşlar ve dış yatırımcılar arasındaki sözleşmeleri etkileyebilir. Yatırımlarını bu şekilde tehlikeye atılması tehdidi, ilk başta gelen yabancı yatırımı da caydırabilir. Başka bir yerde daha güvenli yatırımlar yapabilir. Terör tehdit düzeyi yüksek bir ülkelere de yatırım yapmazlar. Bundan dolayı, petrol üreten ülkeler, küresel ekonomik ve finansal ağlardan uzaklaştıracak bir kısır döngü yaratabilir.

Petrol endüstrisini hedef alan terörist ve milis saldırıları, yüksek düzeyde hasara yol açabilecek diğer savunmasız altyapılara yönelmeleri muhtemeldir. 2017 itibariyle, gelişmekte olan ülkelerde terörizm, yüzde 50,3'ünün siyasi şiddet nedeniyle ihmal edilebilir veya düşük riskli olduğu söylenebilir (The One Brief, 2017). Diğer tüm ülkelerin neredeyse yarısı siyasi şiddet tehlikesinden ile ciddi risk almaktadır. Sadece terörist saldırıların karmaşık, belirsiz dünyasını anlayarak firmalar, saldırıların, petrol tedarik zincirlerini nasıl etkileyebileceğini ve buna göre tedbirleri nasıl alabileceğini düşünürler. Tehditler her zaman açık olmayabilir - Nijerya, Kolombiya ve daha az ölçüde Venezüella petrol endüstrileri terörizmden en çok etkilenen üç ülkedir. Kuzey Afrika ve Orta Doğu üreticileri, ülke 
düzeyinde terörizmden daha geniş etkilere sahip olmakla birlikte, petrol ve gaz altyapısını daha az sıklıkla hedef almaktadır. Bu riskler, bir ülkenin iç politik ve ekonomik durumundaki değişikliklerle hızla değişiklikler göstermektedir. Ülkelerin, bu tür risk ve tehditleri hem yerel, hem de küresel doğasını değerlendirilebilir, öngörülebilir ve hafifletilebilir (The One Brief, 2017). Petrol ve doğal gaz boru hatları enerji sektörü için daha fazla risk oluşturmaktadır.

\section{Küreselleşmenin Petrol ve Terör İlişkisi}

Amerikan neo-liberal politik düşüncesinde tüm dünyaya ülkelerini hegemonya altına alma temalıdır. Dünya egemenliğe ulaşmanın temelinde, ekonomik kıt kaynaklara sahip olma düşüncesidir. Bu düşüncenin farklı yolları vardır. Bazıları belirli bir dinin yayılmasını, askeri fetihler veya siyasi hegemonyayı içerebilir. Ancak, günümüzde en etkili yol, kapitalizmin devam eden ekonomik genişlemesidir. Bunun son şekli şimdi küreselleşme altında giderek artan bir sıklıkta tartışılmasıdır.

II. Dünya Savaşı'ndan sonra petrol alanındaki gelişmelere petrol çağı da denilebilir. Petrol bu dönemde önemli bir cazibe kazanırken, küreselleşme de hız kazandığını söylemek mümkündür. Geçmişte yaşayan atalarımız, küreselleşmenin tüm boyutlarındaki yükselişinden ve petrolün baskın enerji biçimi olarak ortaya çıkmasına şaşırabilirlerdi.

Küreselleşme ile ekonomik büyüme ve buna bağlı olarak petrol talebi arasında bir bağlantı vardır. Küreselleşme, ekonomik büyümeye ve petrol talebine katkıda bulunmuştur. Bunun nedeni, küreselleşmenin, ulaşım ve iletişim üzerindeki etkisiyle petrol talebini de artırmıştır. Küresel iletişim, stratejik kaynak olan petrol üreten ülkelerde ve bölgelerde çatışma ve çıkarları da canlandırmıştır.

Küreselleşme ile Orta Doğu petrolü arasındaki bağ, petrol parası ve petrol ekonomileriyle desteklenen statüko ile küreselleşmenin baskılarının neden olduğu değişism arasındaki gerilimin ötesine uzanmaktadır. Bunun nedeni; mevcut statükonun bozulmaması için, El Kaide'nin düşüncesi, Arap devletlerinin, ABD’ye ve Batı'nın laik rejimlere karşı olan etkisini Orta doğunun petrol sorunu olarak yaymaktı. Küreselleşme bu şikâyetlerin küresel kitleye sunulduğu, iletildiği, güçlendirildiği ve iletildiği daha geniş küresel bağlamdır. Petrol sorunları bu tür küresel tüketim için çok uygundur. Küresel iletişim ve medya yoluyla, El Kaide'nin davasını ortaya çıkarmasına yardımcı olacak, korku yaratacak ve El Kaide'nin daha büyük algılanan bir tehdidini üreten bir şekilde çerçevelenmişlerdir.

\section{Küreselleşme, Petrol ve Güç Elitleri}

Günümüzde iki konunun birleşiminden daha önemli bir konu yok gibi görünmektedir. Bunlar; çokuluslu şirketler ve küresel para politikacılarıdır. Bunlar, ülkelerin politika kararlarını satın alıp, iyi çalışan kamu yönetişimi süreçlerini yok ederler. Enerji de büyük petrol tekelleri tarafından yönlendirilen, yirminci yüzyılın "petrol yüzyılı" boyunca alışkın olduğu güç ve kâr seviyesini korumak için tüm finansal gücü ile savaşmaktadır. Bu yönden, ABD’nin Irak’’n işgali, sömürgeleştirilmesi girişimi tamamen ilgili değilse de 225 milyar varile kadar olası petrol rezervine el konulması, kesinlikle stratejinin önemli bir parçasıdır. Bu strateji 2001 Baharında ABD yönetimi tarafindan, on dört haftalık enerji görev gücü sırasında tartışılmış ve planlanmıştır (Standlea, 2006).

Petrol arama ve üretiminin neredeyse katlanarak büyümesi, Orta Doğu'dan Afrika'ya, Güneydoğu Asya'dan Güney Amerika'ya kadar gelişmekte olan ülkelerde paralel dramatik çatışmalara neden oluyor. Petrol üretiminin azalması ve uzman enerji analistlerine göre, petrol ve gazdan elde edilen enerji yakında yılda yüzde 2 oranında azalmaya başlayacaktır. Bu da endüstriyel topluma büyük, doğrudan ekonomik ve sosyal kanamalara neden olabilecektir. Petrol ve doğal gazdaki düşülüşle beraber, petrol şirketleri de dünyayı umutsuzca yeni ve ekonomik olarak uygun üretim ve nakliye firsatları aramaya yönetmiştir. Genişletilmiş araştırma, yerel ve / veya yerli halkla artan sayıda çatışmalara neden olmaktadır (Standlea, 2006). Potansiyel olarak en ölümcül fikir birliği varsayımı şudur: Bin Ladin ve El Kaide daha çok öldürdükleri için toplumda savaşı kaybediyor. Bu infazlardan en çok Müslümanlar kaybediyor beyanı" demektir.

\section{Terör Suçu İşletmeleri}

Terörizm son birkaç on y1l içinde sürekli olarak gangsterleşti. Bu, bir modadan sonra, 21. yüzy1lda terörist grupların uyumluluğunu gösteren bir başarı hikâyesidir. Gizli operasyonların ödenmesi, silah ve patlayıcıların satın alınması da dâhil olmak üzere bugün terörist operasyonların finansmanı, sadece yasadışı operasyonların tatmin edebileceği işlem türlerini gerektirmektedir. Bu nedenle, terörist suç teşebbüslerinin evrimi sadece birçok terörist grubun hayatta kalmasını ve genişlemesini sağlamakla kalmamış, aynı zamanda onlara ek esneklik ve hareketlilik sağlamıştır (Thachuk ve Lal, 2018).

Günümüz küresel gelişimin dinamik işletim ortamında dönüştürülmüş terör tehdidiyle başa çıkmak, aşırılık yanlısı grupların neden organize suçlara yöneldiklerini, gelişen suçlu işletmelerine nasıl giriştiklerini ve yeni tehditle mücadele etmek için politika yapıcıların neler yapabileceğini anlamayı gerektirir. 


\section{Teröristlerin Çok Para İhtiyaçları}

Terör örgütleri (İşletmeler); ticaret, finans, telekomünikasyon ve teknolojideki gelişmeler, artan küresel ticaretin uğursuzluğundan yararlanmasını ve kaçakçılık, kredi kartı sahtekârlığı, ticarete dayalı kara para aklama ve hatta siber suçlarla daha fazla ilgilenmelerini sağladı. Çok sayıda grup için,11 Eylül sonrası dünyaya terörist komplo kurmak, gizli bir verimlilikle gizlice çalışmak anlamına geliyordu; organize suçun mükemmelleştiği gizli operasyonel yöntemlerde deneyimlediler.

"Başlangıçta, El Kaide gibi aşırılık yanlısı örgütler hem kısa hem de uzun vadeli operasyonları finanse etmek için güvenilir alternatif gelir kaynakları aramaya başladılar. Sonuç olarak, pek çok aşırılık yanlısı ilk önce "geleneksel” suç örgütleriyle "bağ” veya yakınsama ilişkileri yoluyla suç teşebbüsüne girmeye başladı. Başlangıçta bu, uyuşturucu laboratuvarlarının korunmasını, hava sahalarının güvenliğinin sağlanmasını veya sahte kimlik belgeleri üretmek için taklitçilere ödeme yapılmasını içeriyordu. Zamanla, kendi yasadışı girişimleri yoluyla daha fazla para kazanabileceklerini fark ederek, bazı terör örgütleri ceza almaya başladı yeterlilikler ve yakında gasp, kredi kartı sahtekârlığı, banka soygunları ve diğer sokak suçları. Oradan silah, uyuşturucu ve insan ticareti üzerine mezun oldular; kaçak mal kaçakçılı̆̆ı; fidye için adam kaçırma ve diğer suçlar geleneksel olarak organize suçun tasavvuru sayılmaktadır” (Thachuk ve Lal, 2018).

Terörizm insanlığa karşı çirkin bir veba ve insan medeniyetinin yirminci yüzyılında hala böyle barbarca ve iğrenç suç eylemlerine tanık olmamız utanç verici. Teröre karşı tek bir yanıt vardır: Bu, tamamen, tamamen ve her şekilde gerekli olmak üzere Dünya'nın yüzünden yok edilmeli ve silinmelidir. Terörizmi ve onu savunan ideolojiyi reddetmek için yasalar BM'nin tüm üyeleri tarafından yürürlüğe konmalı ve uygulanmalıdır. Terörizmin finansmanı ortadan kaldırılmalı ve terörist ideolojiye, gruplara veya eylemlere fon sağlayanlar, insanlığa karşı suç işleyen suçlular olarak destekledikleri teröristlerle birlikte yasaların en geniş ölçüde kovuşturulmalıdır. Bu çirkin olayın insan topluluklarında bir daha asla kaymaması için terörizmin kökenleri ve nedenleri de ele alınmalıdır (Dawoody, 2016).

Üzücü bir şekilde ve çeşitli nedenlerle Orta Doğu, geçtiğimiz on yıllarda dünyanın diğer yerlerinden daha fazla terörizmin merkezi olmuştur. Böyle bir lanetin nedenlerinden bazıları, bölgenin kültürüne ve tarihine dayanan organiktir bir ilişki vardır. Terörizm, dünyadaki çeşitli siyasi güçlerin manipüle edilmesiyle dışsaldır. Bu durum, genellikle kendi bencil ve dar çıkarları için sebep üretme şeklindedir. Terörizmin, sebep veya oluş şekli ne olursa olsun, masumları, kurbanları bu tür acımasız barbar eylemler yaparlar. Hatta devlete altyapıya, topluluklara, antik çağlara, dini duygulara ve değerlere büyük zararlar verirler.

Orta Doğu bölgesindeki bazı ülkelerde uygulanan polisiye rejimleri, muhalefeti susturmak ve zalim rejimlere uygulamak için korku, gözdağı verme, hapis, etnik temizlik, adam kaçırma, işkence, kitlesel sınır dışı etme, sansür ve telkin kullanmıştır. Devlet dışı aktörler giderek daha görünür hale 1970'lerde oyuna girmeye başlamıştır. Soğuk Savaş döneminde, Sovyetlerin Afganistan'ı istilası ve Sovyetlerin Afganistan'dan çekilmesinin sertleştiği Batı destekli İslamcı terör gruplarını (kutsal fiht veya Mücahid olarak tanımlandıkları zaman) üretme fırsatını vermiştir. El Kaide, Taliban, İslami Cihad ve diğerleri gibi gruplar (Dawoody, 2016).

\section{Serbest petrolden 'özgürlük petrolüne': terör, savaş ve Basra Körfezi'ndeki ABD jeopolitiği}

Petrolün bulunmasından beri bir asır geçmiştir. Petrol ile dünya yeni ve stratejik bir kaynağa ulaşmış oldu. Petrol rezervlerine erişim ve ilgi, Petrol üreten bir ülkenin güvenliği için kritik hale gelmiştir. Dünya atlardan, arabalara geçerken, petrol küresel ekonominin yakıtı haline gelmiştir. Petrol aynı zamanda bir ülkenin savaş makinesinin (askeri nakliye ve savaş kabiliyeti sağlayan gemiler, tanklar, kamyonlar ve uçaklar) enerjisi oldu. Petrole erişim 20. yüzyıl savaşlarında ve bugünün dünyasında, Basra Körfezi'nin çatışmadan uzak tutulması küresel ekonomi için hayati önem taşımaktadır. Tüm ülkelerin ekonomik altyapısı büyük ölçüde petrole ve giderek doğal gaza bağımlıdır. Bu bağımlılık gelecek yüzyılda gelişecek olsa da, petrol yıllar boyunca baskın enerji kaynağı olmaya devam edebilecektir.

Petrol, yabancı çıkarların, bölgesel ve iç güç dengesinin ve Basra Körfezi'ndeki bölgesel çatışmaların ardında önemli bir itici güç olmuştur. '11 Eylül' terör saldırıları sonucunda petrol ve ABD'nin güvenlik gündemi önemli ölçüde değişti. Bir tarafta, ABD askeri müdahalesine karşı çıkanlar, 'terörle savaşın' bu bölgede yenilenen bir 'emperyalist petrol kapma' için daha uygun bir koruma sağladığını iddia etmiştir. Diğer yandan petrol ve terörizm arasındaki bağlantılar, petrol üreten ülkelerde yönetişim sorunlarına da işaret etmiştir. 'Teröre karşı savaş' petrol destekli diktatörlere karşı bir 'kurtuluş savaşı' olarak ortaya çıktı. Bu yönden, ABD dış politikasını, dünya piyasası için petrole ücretsiz erişim sağlamak, petrolün 'özgürlük' sağladığından emin olmak olarak değiştirmiştir (Le Billon ve El Khatib, 2004).

Teröristler, sadece petrol üretim yerlerine ve boru hatlarına saldırmadılar. Boğazlarda ve denizlerde petrol taşıyan tankerlere de yönelik saldırılar olmuştur. Ocak 2000 yılında denizde El Kaide'nin Yemen'deki saldırganları vasıtasıyla, patlayıcı yüklü bir tekneyi tankere çarpmasını denediler. Füze atmaya çalışmış ve ilk saldırı başarısızlıktan sonra, ikincisinde El Kaide intihar bombacıları patlayıcılarla dolu bir sürat teknesinde 2 Ekim'de2002'de Cole'u 17 denizciyi öldürerek tankerde delik açmışlardır. Ekim 2002'de, patlayıcı yüklü bir tekne Fransız petrol tankeri Limburg'u Yemen sahilinden vurulmuştur. Şubat 2004'te, güney Filipinler merkezli Abu 
Sayyaf en az 100 kişiyi öldüren büyük bir feribotta patlama sorumluluğunu üstlenmiştir. Örneğin Haziran 2002'de Fas Hükümeti, Cebelitarık Boğazı'ndan geçen İngiliz ve ABD tankerlerine baskın düzenleyeceğinden şüphelenilen bir grup El Kaide saldırganını tutuklamıştır (Luft ve Kori, 2004).

Birçok deniz taşımacılık şirketi, korsanlık olaylarını bildirememektedir. Sebebi risk yükseleceğinden sigorta risk primleri de yükselmektedir. Uzun süren, zaman alan soruşturmalara yönlendirme korkusundan dolayı, korsanlığın kesin boyutu bilinmemektedir. Daha operasyonel odaklı bir işbirliği aracı şu anda Asya ülkeleri arasında tartışılan Bölgesel Deniz Güvenliği Girişimi' dir. Bu girişim, Malacca Boğazı ve Singapur Boğazı'ndaki deniz aşırı korsanlık ve terörizm tehdidinde olduğundan önlemlerin alınması ile ilgilidir (Luft ve Kori, 2004).

Yukarıda bu önlemlerin alınması Doğu Asya'ya bağlı Orta Doğu petrolünün nakliye mesafesinden sadece 600 mil, aynı zamanda petrol nakliyecilerin Malacca Boğazı'nı güvenle geçilmesini sağlanmış olacaktır. Aynı şekilde Hürmüz Boğazı üzerindeki baskıyı azaltmak için İsrail'i dolaşan petrol boru hattı genişletilebilir. Karadeniz'den gelen Rus petrolü, Akdeniz kıyısında İsrail'in Ashqelon limanında boru hattına giriyor. Buradan petrolün Asya'ya gönderildiği Kızıldeniz'deki Elat'a akabilir. Bu rota Akdeniz ve Asya arasında çok daha kısa bir bağlantı sağlayan güvenli bir yol olabilecektir (Barnes, 2005).

En önemlisi, dünyadaki enerji arzının terörist bir hedef olarak kalması muhtemel olduğundan, risk sadece okyanus yollarının güvenliğini iyileştirmekle kalmayıp, aynı zamanda ülkelerin iç petrol borularına yapılacak bir saldırının önlemlerini gerekmektedir. Petrol enerji kaynağı, İthal enerjiden çok, alternatif yerli enerjiden türetilen yeni nesil enerji ile değiştirerek sağlanabilir. Böyle bir değişim, özgür dünya için enerji bağımsızlığını azaltabilecektir. Kısa zamanda petrolün dünya çapında taşınması ihtiyacını en aza indirecek durum görülmemektedir. Ham, petrolün üretim yerinden tüketim noktalarına varabilmesinde alternatif maliyet olan petrol deniz taşımacılığı önemini koruyabilmektedir. Alınacak arz güvenliği sayesinde, dünya denizlerindeki teröristlerden kaynaklanan, enerji arzının yıkıcı bir şekilde bozulmasına karşı savunmasızlığını da azaltabilecektir.

Petrolün bu kadar önemli bir enerji kaynağı haline gelmesinin ham petrolün taşınmasıdır. Boru hatları, gemiler ve mavnalar ham petrol için en yaygın ulaşım platformları olmasına rağmen, dünyanın bazı bölgelerinde demiryolları ve tankerler de kullanılmaktadır. Denizcilik endüstrisi çok parçalı ve petrol tankerleri çoğunlukla uluslararası sularda seyahat etmektedir. Son yıllarda gemi inşasındaki yeni teknolojiler gemilerin daha büyük ve daha güvenli olmasını sağlamıştır (Inkpen ve Moffett, 2011).

Alaska, Çad ve Kamerun, Rusya ve diğer ülkelerdeki boru hatları ile petrolü çok uzak bölgelerden pazarlara taşınmasına izin vermiştir. Boru hatlarının inşası ve yönetimi jeopolitik entrikalarla doludur (kamusal baskı, çıkarlar ve güvenlik gibi...). Bu da boru hattı geliştirme sürecinin yıllar hatta on yıllar sürdüğü anlamına gelmektedir. Ulusal sınırları geçen boru hatları müzakere etmek ve inşa etmek son derece karmaşıktır. Bölgelerinden geçen boru hatlarına sahip ülkelerin, pazarlık olarak kullandıkları bilinmektedir. Teröristler genellikle boru hatlarını sabote ederler. Nijerya ve Irak gibi bazı ülkelerde boru hatlarından petrol hırsızlığı ve ilgili çevre ve güvenlik sorunları günlük olaylar haline gelmektedir (Inkpen ve Moffett, 2011).

Tarihi bakımdan petrol üretiminde iki merkez dikkati çekmektedir. Bunlar; Pennsylvania ve Bakü'dür. Bu merkezlerin ilk yıllarda, petrol endüstrisi bireysel girişimcilerin mülk sahiplerinden petrol çıkarma ve geliştirme hakları kazanmasıdır. Mülk sahipleri özel ve kamu toprak sahiplerinin bir karışımı şeklinde idi. Girişimciler, petrole erişim hakları elde edildikten sonra, gelirin çoğunu toplayarak, petrolü geliştirip ürettiler. Hızlı başarıları, büyümeleri ve güçleri hükümetlerin müdahalesine yol açtı. John D. Rockefeller ve Standard Oil tarafından rafinaj ve nakliye sırasında elde edilen tekel gücü sonunda, Standart Petrol Güveninin zorla dağılmasına yol açtı (şekil 1 ve 2). Bakü, Azerbaycan'da hükümet Nobels ve Rothschilds gibi küçük bir petrol girişimcisi yaptırdı. Girişimcilerin oluşturduğu büyük petrol karlılığı üzerine, hükümetlerinin petrolün toplumsal ve ekonomik etkisinin agresif bir şekilde düzenlenmesine yol açmıştır (Inkpen ve Moffett, 2011). 


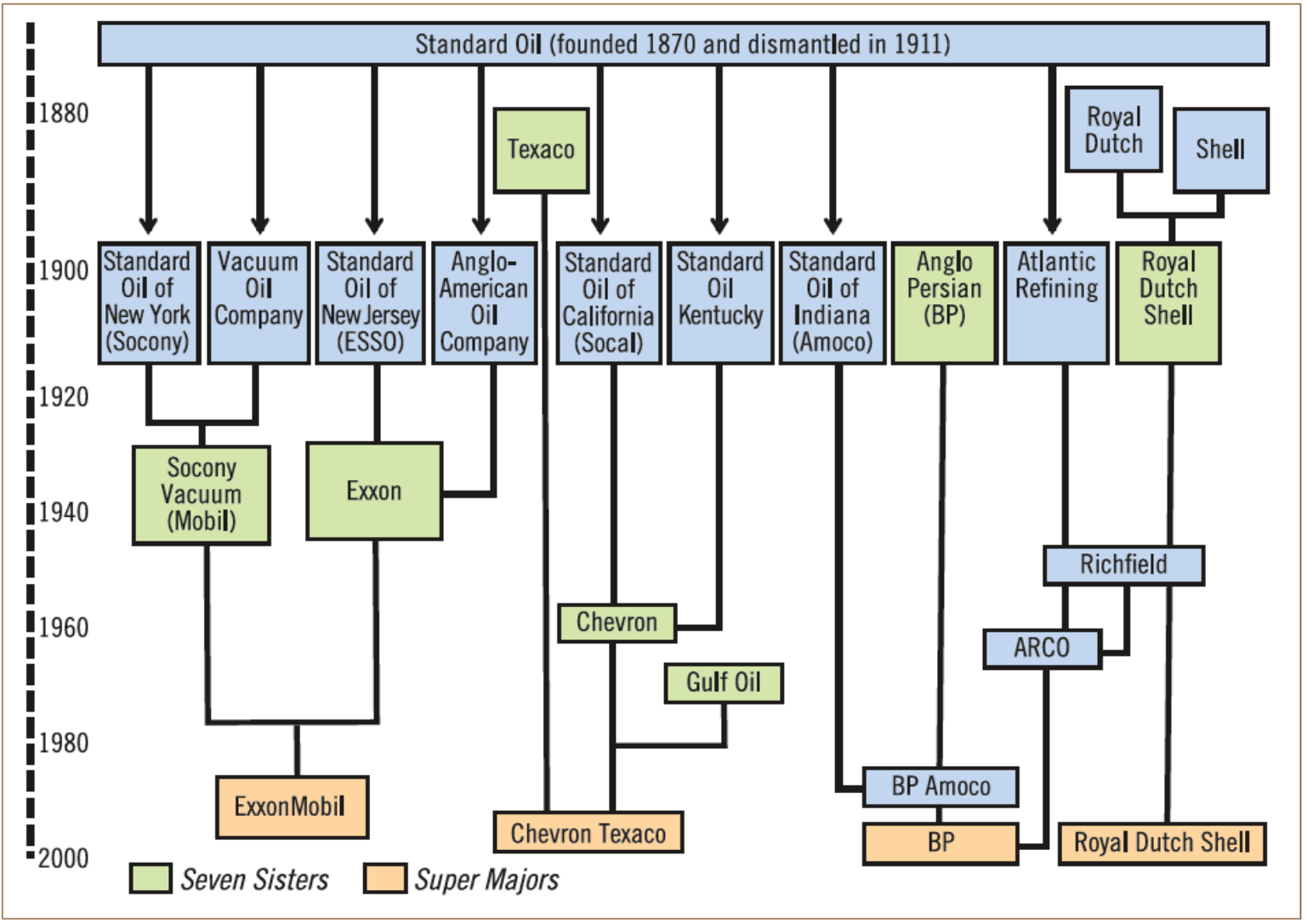

Şekil 1. Uluslararası Petrol Şirketlerinin (IOC) Bugüne Evrimi Kaynak: Deutschebank, 2008. Andrew Inkpen, Michael H. Moffett (Naklen) ,a.g.e.,s.53

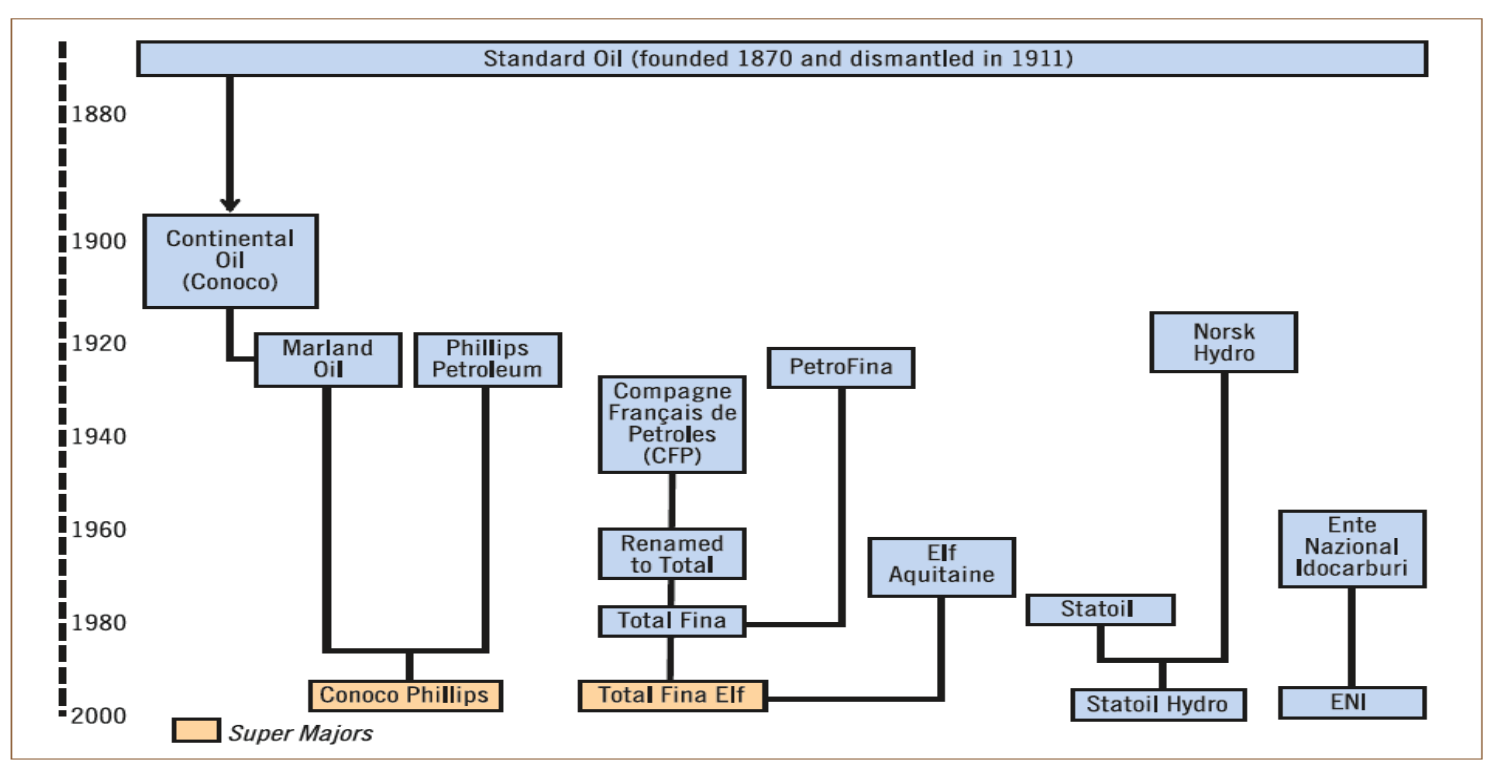

Şekil 2. Günümüz IOC'lerinin Evrimi (International Oil Company,IOC) (şekil 1'den devam) Kaynak: Deutschebank, 2008. Andrew Inkpen, Michael H. Moffett (Naklen) ,a.g.e.,s.54

\section{Ortadoğu Petrolünün Stratejik Önemi}

Orta Doğu toprakları inanç dünyası dışında ve petrol bulunmadan önce her hangi bir özelliği yoktu. Petrol bulunduktan sonra önemi artmıştır. Coğrafi konumu yönünden, ayrı bir öneme sahiptir. Petrol ve coğrafi konum birleşince stratejik bir önemi ortaya çıkmıştır. Özellikle bölgenin, Birinci Dünya savaşından sonra önemini gittikçe artırmıştır. Bölge, ABD için, yeni bir kritik karar alanı olmuş ve bunun nedeni de büyük petrol kaynağı olmasıdır (Eller, 1956). 
Birinci Dünya Savaşı sonrası modern Ortadoğu'nun yaratılmasından sonra hükümet sistemlerinin evrimi hem iç hem de dış pek çok zorluğa tanık olmuştur. Yönetim ve hükümet sistemleriyle Batılı ilişkiler şeffaflıklarına, açıklıklarına, hesap verebilirliklerine, verimliliklerine, meşruiyetlerine, temsillerine ve kamu hizmetlerine dayanmıyordu. Aksine, bölge, Batı çıkarları, istikrar ve güvenlik için kamu hizmeti ilkelerini feda ediyorlardı. Bu nedenle polis devleti, yolsuzluk, kayırmacılık, sansür, siyasi baskı, altyapının bozulması, eksiklikle donatılmış, hükümetlerin en belirgin yönleri haline gelmiştir. Hizmet, modası geçmiş düzenlemeler ve büyük ölçüde etkisiz bürokratik sistem, zayıf planlama, yetersiz ekonomik yatırımlar, artan yoksulluklar, işsizlik ve devlete aşırı güven kaybı şeklinde olmuştur (Eller, 1956).

\section{Türkiye'nin Çevresindeki Terör Örgütleri}

Türkiye'nin güneyinde, ABD'nin Irak'ın işgalinden sonra, bölgede bir otorite boşluğu olmuştur. Otorite boşluğunu kendilerinin illegal olarak kurdurdukları CIA destekli marjinal terör örgütü vasıtasıyla, hem Türkiye'ye hem de Suriye'ye yönelik terörist faaliyetlerde bulunmaktadırlar. “7 Nisan 2017 'de ABD, Başkan Trump'ın talimatıyla sabaha karşı Suriye'nin Humus kenti yakınlarındaki El Şayrat üssünü vurmuştur. Gerekçe olarak, Suriye hükümetinin İdlib'te kimyasal saldırı düzenlediği iddiaları üzerine yapılan operasyonda 59 Tomahawk füzesi kullanmıştır. Başkan Trump, bu operasyonun ABD'nin "hayati ulusal güvenlik çıkarlarına uygun" olduğunu açıkladı" (https://www.bbc.com/turkce/live/39525615 (08.06.2020). Bu durum bölgeye yönelik stratejik bir enerji tehdidinden başka bir şey değildir. Suriye ve Irak, ABD’nin sınır komşusu, ticaretine karşı misilleme, uluslararası politik tercihlerine karşı bir davranış içerisinde olmamıştır. Aslında, Irak ve Suriye'deki zengin petrol rezervlerinden pay almaktan başka bir şey değildir. Bu durum, Suriye'yi yalnızlaştırma politikası ile daha çok Rusya'ya yakınlaştırmıştır. Aynı durumu Rusya Dışişleri Bakanı Lavrov ABD’nin Suriye'ye saldırısını; "tamamen uydurulmuş bir bahaneyle yapılmış saldırgan bir eylem" olarak tanımlamıştır." (https://www.bbc.com/turkce/live/39525615 (08.06.2020).

\begin{tabular}{|l|l|l|l|l|}
\hline TARİH & ÖRGÜTÜN ADI & YÖNETİCİİ & $\begin{array}{l}\text { BAĞLI OLDUĞU } \\
\text { ÖRGÜT }\end{array}$ & $\begin{array}{l}\text { BULUNDUĞU } \\
\text { ÜLKE }\end{array}$ \\
\hline 1999 & $\begin{array}{l}\text { Cemaat el Tevhid vel } \\
\text { Cihad }\end{array}$ & Ebu Musab Ez Zerkavi & El Kaide & Afganistan-Irak \\
\hline Ekim 2004 & $\begin{array}{l}\text { Tanzim Kaidat el cihat fi } \\
\text { Bilad el Rafidayn }\end{array}$ & Ebu Musab Ez Zerkavi & El Kaide & Irak \\
\hline Ocak 2006 & Mücahidin Şura Konseyi & Ebu Musab Ez Zerkavi & El Kaide & Irak \\
\hline Haziran 2006 & Mücahidin Şura Konseyi & Ebu Musab Ez Zerkavi & El Kaide & Irak \\
\hline Ekim 2006 & Irak Sözde İslam Devleti & $\begin{array}{l}\text { Ebu Hamza el Muhacir- } \\
\text { Ebu Ömer El Bağdadi }\end{array}$ & El Kaide & Irak \\
\hline 2010 & Irak Sözde İslam Devleti & Ebubekir el Bağdadi & El Kaide & Irak \\
\hline 2013 & $\begin{array}{l}\text { Irak ve Şam Sözde İslam } \\
\text { Devleti }\end{array}$ & Ebubekir el Bağdadi & & Irak ve Suriye \\
\hline Temmuz 2014 & Sözde İslam Devleti & Ebubekir el Bağdadi & & - \\
\hline
\end{tabular}

Tablo 2. Ortadoğu'da Terör Örgütünün Ortaya Çıkış Süreci Kaynak: Türkiye'nin DEAŞ İle Mücadelesi, T.C. İç Işleri Bakanlığ

Yukarıdaki Tablo 2 de görüleceği gibi, Türkiye'nin güneyinde ter alan Irak ve Suriye'de kurulan ve faaliyette bulunan İslami terör örgütlerinin kuruluşları görülmektedir. İslami terör örgütlerinin kuruluşu 1999 - 2014 yılları arasındadır. Çok üzücü olan bir durum da, İslam’ın terörle ilişkilendirilmesidir. İslam’ın terörle ilişkisi olmadığı gibi, böyle bir din anlayışı da yoktur. Maalesef bazı örgütlerinin adı İslam’ın ileri gelen kişilerin isimleriyle anılmasıdır. Örnek olarak, Fatimiyyun (Afganlardan) ve Zeynebiyyun (Pakistanlılardan) gibi isimler, Hz. Ali'nin kızı Zeynep bint Ali gibi. Aşağıda bu durum ayrıca anlatılacaktır.

“YPG/PKK'nın işgal ettiği Suriye'nin El Ömer, Tanek ve Rimeylan bölgelerinde çıkan petrolü, Rusya'nın korumasında Esed rejimine taşıdığı iddia edildi. kirli ortaklığın en açık göstergesi olarak, Bölgedeki PKK-Esed rejimi ve Rusya koalisyonunun ispatı olan yerel kaynakların görüntülediği olayda, PKK işgalindeki bölgedeki petrol, havadan ve karadan Rusya'nın desteğiyle Esed rejimine taşınmaktadır. Kara yolundan tankerlerle taşınan petrol, havadan ise Rus askeri helikopterleriyle korunuyor. Referans medya isimli haber sitesinin yayımladığ 1 görüntülerde, bölgedeki petrol trafiğinin ve kirli ortaklığın geldiği boyut gözler önüne seriliyor.

Rusya, Suriye'deki askeri varlığını genişletirken bir yandan da özellikle Tel Rıfat bölgesindeki örgüt mensuplarıyla Rus askeri polisi arasında iş birliğinin devam etmektedir. Askeri uzmanlar, Rusya'nın günden güne Suriye'de askeri varlığını özellikle petrol sahalarına yönelik hâkimiyet noktasında artırmaktadır. Bölge uzmanları, Rusya-YPG/PKK işbirliğinde petrol taşınan bölgenin Suriye'deki en büyük barajın bulunduğu Tabka bölgesi olduğunu hatırlatarak, bölgenin stratejik bir önemde olduğunun altını çiziyor. Ayrıca Tabka'da stratejik bir hava üssü bulunuyor. BBC, Ekim 2019'da ABD askerlerinin bölgeden çekilmesinin ardından Tabka'daki hava üssüne, Rus Mu-35 ve Mi-8 tipi askeri helikopterlerin iniş yaptığı görüntülerin ortaya çıktığını bildirmişti.” (QHA, 2020). 
“İran'ın bölgede kullandığı devlet dışı aktörler, 1979 sonrası süreçte mezhepsel dayanışma üzerinden rejimin ihracı politikasına katkıda bulunmaları için aktif hale getirilmiş ve endoktrinasyona tabi tutulmuştur. Tahran'dan sağlanan propaganda ve askeri lojistik destekle adeta canlanarak ve etkinleşerek bölge ülkelerinin siyasetinde önemli güç unsurları haline gelmişlerdir. Mollalar, bağlantılı oldukları diğer ülkelerdeki paydaşlarını siyasal anlamda uyandırarak mobilize etmeye, böylece hedef ülkelerin iç işlerini yönlendirmeye başlamışlardır. Bu devlet dışı aktörler, 1979 sonrası süreçte mezhepsel dayanışma üzerinden rejimin ihracı politikasına katkıda bulunmaları için aktif hale getirilmiş ve endoktrinasyona tabi tutulmuşlardır. Özellikle İran-Irak savaşının yaşandığı sekiz yıllık dönemde (1980-1988) Bahreyn'den Lübnan'a, Kuveyt'ten Irak'a kadar pek çok ülkede İran destekli terör gruplarının saldırıları, bombalamaları, uçak kaçırma ve suikast eylemleri görü̈lmüşsür. İran destekli terör grupları, özellikle Obama'nın başkanlığı döneminde, İran ile ABD'nin işbirliği çerçevesinde, DEAŞ'a karşı mücadeleyi sebep olarak göstererek, Suriye'den Irak'a, Yemen'den Lübnan'a kadar her yerde hâkimiyetlerini pekiştirdiler.

Iran'ın en önemli devlet dışı aktörü Lübnan'daki Hizbullah örgütüdür. Hizbullah bir anlamda Iran'ın ilk göz ăgrısıdır; diğer örgütler için de adeta örnek konumdadır. Ülkedeki (Lübnan) Şii kesimi politize eden Hizbullah, Iran'ın çıkarları için Lübnan'da devlet içinde devlet olmuş; kuruluş amacını "Ísrail'e karşı direniş cephesi", olarak belirtse de, Suriye iç savaşının başlamasılyla birlikte, Esed rejiminin muhafizlı̆̆ını üstlenmiş ve Suriye muhalefetini de en önemli tehdit/hedef olarak görmüşür.

Hizbullah Suriye muhalefetiyle girdiği savaş üzerinden, bir anlamda dolayl olarak neredeyse dokuz yıldır Türkiye'yi de hedef almakta. Irak'taki Şii gençliği de Haşdi Şabi, Ketaib Hizbullah, Bedir Örgütü, Asaib ehl el Hak gibi Irak merkezli örgütlerin içinde radikalleştirip bu militanları Suriye'de Esed rejiminin saflarında savaştırmaktadır. Hizbullah, bahse konu devlet dışı terör örgütleri vasıtasıla, Suriye'de kalıcı olmayı da hedeflemektedir. Bu politikanın ilk örneği daha önce Lübnan'da uygulanmış ve İran açısından epey başarılı olmuştur. Hizbullah'ın bu başarısı bugün Suriye'de, Irak'ta ve Yemen'de pratiğe dökülmeye ve İran'ın bu ülkelerdeki kalıcı nüfuzu paramiliter aktörler aracılığıyla yerleştirilmeye çalışılmaktadır.” (AA, 2020. https://www.aa.com.tr/tr/analiz/iran-destekli-terorist-gruplarin-suriye-deki-varligi-/1732926 (08.06.2020).

“İran'ın devlet dışı aktörlerden ve yabancı terörist savaşçılardan yararlanması artık bir devlet politikası haline gelmiştir ve İran elindeki her imkânı da bu amaca hizmet etmesi için kullanmaktan geri durmamıştır. İran otoriterleri İan'a göçmen olarak gelen Afgan ve Pakistanlı Şii kökenli göçmenlerden ve ucuz işgücünden yararlanıp bunlardan Fatimiyyun (Afganlardan) ve Zeynebiyyun (Pakistanlılardan) tugayları adını verdikleri paramiliter örgütler kurarak Suriye'deki muhalefete karşı savaştırmaktalar. Özetle İran, kendisine sığınan ucuz iş gücü ve göçmenlerden dahi yabancı terörist savaşçı meydana getirecek ölçüde gözünü karartmıştır.” (AA, 2020. https:/www.aa.com.tr/tr/analiz/iran-destekli-terorist-gruplarin-suriye-deki-varligi-/1732926 (08.06.2020).

“Suriye'de Hizbullah militanlarından sonra ikinci büyük yabancı savaşçı güç olan Fatimiyyun birliklerinde 10 bin ila 12 bin arası Hazara kökenli Afgan bulunuyor. Amacını Hz. Ali’nin kızı Zeynep bint Ali'nin türbesini muhafaza etmek olarak tanımlayan Zeynebiyyun Tugayı da 2 bin kişilik Pakistan kökenli yabancı terörist savaşçıdan oluşuyor ve Suriye'deki savaşta İran tarafindan kullanılıyor. Her iki terörist örgüt de 2019 y1lında ABD Hazine Bakanlığı tarafından terör örgütleri listesine alınmıştır. İlginç bir şekilde bu örgütlere, İslam tarihinde çok önemli bir yeri olan Ehl-i Beyt'e mensup fertlerin isimleri verilmektedir. Afganlardan oluşturulan örgüte Hz. Fatıma'nın isminden, Pakistanlılara Hz. Ali'nin kız Zeynep'ten mülhem isimler verilirken; yine Hz. Hüseyin'in kızı Rukiye'nin ve Hz. Ali'nin Ümmü'l-Benîn'den olan oğlu Ebu Fadl Abbas'ın isimleri de diğer paramiliter gruplara verilerek Seyyide Rukiye ve Ebu Fadl Abbas Tugayları oluşmuştur." (AA, 2020. https:/www.aa.com.tr/tr/analiz/iran-destekli-terorist-gruplarin-suriye-deki-varligi-/1732926 (08.06.2020).

Yukarıda belirtilen bu tugaylar Suriye'deki varlıklarını Şam’da bulunan Seyyide Zeynep türbesini korumak şeklinde tanımlıyorlar. Türbenin kutsallığıyla Şam'ın müdafaasını birbirine eşitleyerek Esed rejiminin korunmasını kutsal bir amaca hizmet olarak gösteriyorlar. İran bu şekilde, başka ülkelerin vatandaşlarını da Suriye'deki savaşın bir parçası haline getirerek, bu insanları kutsal bir amaç için mücadele ettiklerine inandırıyor. Afganistan parlamentosunda milletvekili olan Belkıs Ruşen, Afganistan'da Tacik ve Hazara liderlerin Kasım Süleymani'nin ölümü nedeniyle İran'a başsağlığı mesajları yayınlamalarına karşı çıkarak Süleymani'nin 5 bin 500 Afgan gencinin Suriye'de ölmesinin sorumlusu ve Afganistan'da en çok cinayet işleyen kişi olduğunu iddia etmiştir. Ruşen ayrıca İran'ın, Afgan göçmenlerin inançlarını kötüye kullanarak bir lokma ekmek için Suriye'ye savaşa gönderdiğini de ifade etti. Öte yandan Tahran yönetimi, Afganistanlı ve Pakistanlı bu yabancı milislere ve ailelerine daimî oturum veya vatandaşlık vereceği taahhüdünde bulunarak, bunu İran meclisine yasa tasarısı olarak da sunmuş durumda. Bu tasarıya göre, Suriye'de savaşan ve ölen milislerin ailelerine vatandaşlık verilecek ve ölenlerin naaşları da İranlı şehitlerin mezarlıklarına defnedilecektir. Bu konuda dini lider Hamaney de kanun tasarısının takipçisi olduğunu birkaç kez dile getirmiştir.

İran destekli terör grupları, özellikle Obama'nın başkanlığı döneminde, İran ile ABD'nin işbirliği çerçevesinde, DEAŞ'a karşı mücadeleyi sebep olarak göstererek, Suriye'den Irak'a, Yemen'den Lübnan'a kadar her yerde hâkimiyetlerini pekiştirmişlerdir. Bugün Yemen'deki Ensarullah bile Hizbullah'tan eğitim alıyor, silahlarını İran veriyor ve Hizbullah'la aynı sloganları kullanıyor. Bölgenin Obama ve Demokratlar 
döneminde tam anlamıyla İran'a bırakılması, bugün bir anlamda ABD'nin Suriye'deki çıkarlarına füze olarak geri dönmektedir.

3 Ocak 2020 Öldürülen, Kudüs Gücü Komutanı Kasım Süleymani’nin adının İdlib'deki muhaliflere rejim tarafından atılan roketlere yazılması ve sanki onun intikamını alıyormuşçasına bir mesaj verildiğinin gösterilmesi, Esed rejimi saflarındaki İran destekli terör gruplarının ne kadar etkin ve güçlü olduklarını gözler önüne seriyor. İdlib'deki muhalifleri terörist olarak niteleyen güçler ve odaklar, Suriye'de çoğunluğu temsil eden muhalifleri acımasızca katleden bu paramiliter çeteler, hakkında ağılarını dahi açmıyorlar. Bu durum akla, Türk askerlerine ateş açabilme cüretini gösteren rejim güçlerinin içinde bu türden İran destekli terör gruplarının olup olmadığ 1 sorusunu da getiriyor. İran'ın Kudüs Gücü birliklerinin veya bahse konu paramiliter gruplarının Suriye'deki rejimin ordusunun içindeki güçlerinin ne düzeyde olduğu ve rejim ordusunu ne ölçüde yönlendirdikleri de bilinmeye muhtaç meselelerdir." (AA, 2020. https://www.aa.com.tr/tr/analiz/iran-destekli-terorist-gruplarinsuriye-deki-varligi-/1732926 (08.06.2020).

Suriye'de İran destekli terörist gruplara bakıldığında;" Lübnan Hizbullahı, Suriye Hizbullahı, Bedir Tugayları, Fatimiyyun Tugay, Zeynebiyyun Tugayı, Ammar bin Yasir Tugayı, Imam Hasan Tugayl, Seyyide Rukiye Tugayı, Irak Hizbullahı, Seyyid eş-Şüheda Tugayları, Şehit Muhammed Bakır es-Sadr Tugayl, Asaib ehl el Hak örgütü, el Hamad Tugayı, Seddu Şuheda Taburları, Hizbullah Nuceba Hareketi, el Vaat es-Sadık Birliği, Esedullah Galip Tugayı, Ensarü'l-Akide Birlikleri, Haddamü'l Akile, el Hüseyin Tugayl, Nafiz Esadullah Birlikleri, Ketaib İmam Ali, Ebu Fazıl Taburu, Ceyş eş-Şa'bi, Ebu Fadl Abbas Tugayı, Kuvvet er-Rida, el Galibiyyun, Zülfikar Tugayı, Kuteyb Seyyit Şüheda gibi yirmiden fazla paramiliter grup olduğunu görürüz. Bunların hemen hemen hepsinin flama ve bayrakları birbirlerine benzerdir ve genellikle Hz. Peygamber'in Ehl-i Beyt'ine mensup bir zatın ismini taşıdıkları görülür. İddialara göre, 150-200 bin milis 500 dolar ve civarı maaşlar karşılığında, İran'ın desteği altında, bölgede savaşmaktadır. Bu miktar Afgan Hazara ve Pakistanlı gruplarda daha da düşmektedir. Bu grupların Suriye içinde nerelere konuşlandığına baktığımızda, İmam Muhammed Bakır esSadr Tugayının orta ve doğu Suriye'de, Ebu Fadl Abbas Tugayının Şam'da, Suriye Hizbullah'ının da Halep ve İdlib başta olmak üzere kuzeybatı Suriye'de aktif olduğunu görüyoruz." (AA, 2020. https://www.aa.com.tr/tr/analiz/iran-destekli-terorist-gruplarin-suriye-deki-varligi-/1732926 (08.06.2020). Paramiliter bu grupların İslam düşüncesiyle de bir ilişkileri yoktur.

“ABD Hazine Bakanlığı'nın değerlendirmelerine göre; İran’ın Hizbullah’a yıllık maddi yardımı 700 milyon doları bulmakta. Bunu diğer örgütlere de genişlettiğimizde miktar daha da katlanmaktadır. İran bu paramiliter örgütleri destekleyip Orta Doğu'da aşırı harcamalar yaparken, diğer yandan kendi halkının ihtiyaçlarını karşılayamamakta, ekonomisi gittikçe kötüleşmekte, teröre verdiği destekten dolayı son dönemde iyice ağırlaşan ambargo şartları İran halkının sokaklara dökülmesine ve rejimi hedef almasına neden olmaktadır. İran'ın Orta Doğu'nun çeşitli ülkelerinden toplayarak endokrine ve mobilize ettiği bu milis güçlerini finanse etme politikası, içerdeki rejimi bölgeye yayma stratejisi ve Arap dünyasında kendi aleyhine bu faaliyetlerinden dolayı doğurduğu orantısız öfke, hiç beklenmedik bir şekilde rejimin içerden çöküşüne neden olabilecek hatalardır. Bölgede radikalleşmeyi sürekli körükleyen, başka ülkelerin iç işlerine müdahale eden, terör eylemlerini finanse eden bir İran hem bölge ülkeleri hem de Batı bloğu tarafından daha fazla izolasyonla karşı karşıya kalacaktır. Ayrıca Türkiye ile örtülü bir savaşı Suriye üzerinden sürdürmeye devam etmeleri, Türk askerine ve Türkiye tarafından desteklenen muhaliflere imzalı roketler firlatmaları, Türkiye'nin nasıl bir örtülü tehditle karşı karşıya olduğunu da göstermektedir.” (AA, 2020. https://www.aa.com.tr/tr/analiz/iran-destekli-terorist-gruplarin-suriye-deki-varligi/1732926 (08.06.2020).

- ABD Dışişleri Bakanlığı'nın 2019 Yılı Terörizm Ülke Raporunda, Türkiye'nin DEAŞ’la mücadelesi ve Yabancı Terörist Savaşçıların (YTS) hareketlerinin önlenmesi konusundaki çabaları yansıtılmakta, PKK'nın içeride ve dışarıda ülkemizin çıkarlarına yönelik terörist saldırılarının devam ettiği vurgulanmaktadır. Esasen Türkiye, güvenlik güçleri DEAŞ’la göğüs gögüse mücadele veren yegâne ülkedir. Ayrıca, YTS hareketlerinin önlenmesinde sorumluluklarını yerine getirerek, uluslararası toplumun güvenliğine ciddi katkı sağlamaktadır. Diğer taraftan, Türkiye terör örgütleriyle mücadelede sınırları ötesinde gerçekleştirdiği operasyonlarda sivil can kayıplarının oluşmaması için her zaman azami tedbirleri almaktadır MFA, 2020. http://www.mfa.gov.tr/sc_-56_-abd-disisleri-nin-terorizm-raporu-hk-sc.tr.mfa (25.06.2020).

Raporda, ülkemizin YPG'yi, PKK'nın Suriye'deki kolu olarak değerlendirdiği belirtilerek, YPG'nin PKK ile aynı terör örgütü olduğunun üstü örtülmeye çalışılmaktadır. Bu yaklaşım YPG'nin terörist kimliğinin açıkça vurgulanmasından kaçınılması anlamına gelmekte, dahası ABD’nin bu terör örgütüyle işbirliğini teyit etmektedir. Öte yandan, PKK ve YPG'nin aynı örgüt olduğuna ilişkin ABD'li yetkililerin, askerlerin ve kurumların açıklamaları da ortadadır. ABD'nin bir terör örgütüyle mücadele ederken başka bir terör örgütüyle işbirliği yapmasının doğru olmadığını artık anlaması gerekmektedir • MFA, 2020. http://www.mfa.gov.tr/sc_-56_-abddisisleri-nin-terorizm-raporu-hk-sc.tr.mfa (25.06.2020). ABD, petrol menfaati olunca müttefiklik ilişkisi maalesef çalışmamaktadır.

Son aylarda Suriye'nin kuzeyinde, Kürtlerin denetimindeki bölgede bulunan bir petrol sahasıyla ilgili olarak, Suriye Demokratik Güçleri PYD (SDG) ile bir Amerikan şirketi arasında varılan anlaşmaya Türkiye ve Suriye sert tepki göstermiştir. Türkiye Dışişleri Bakanlığı, "terör örgütü" ve "PKK'nın uzantısı" olarak nitelendirdiği Kürt 
silahlı gücü YPG'nin (Halk Savunma Birlikleri) öncülüğündeki SDG'nin, Delta Crescent adlı bir Amerikan şirketiyle anlaşmasının kabul edilemeyeceğini açıklamıştır • MFA, 2020. http://www.mfa.gov.tr/sc_-56_-abddisisleri-nin-terorizm-raporu-hk-sc.tr.mfa (25.06.2020).

- "Suriye'nin doğal kaynakları Suriye halkına aittir. ABD'nin uluslararası hukuku hiçe sayan, Suriye'nin toprak bütünlüğüne, birliğine ve egemenliğine kasteden ve terörizmin finansmanı kapsamına giren bu adıma destek vermesini esefle karşılıyoruz. Hiçbir meşru saikle gerekçelendirilemeyecek olan bu tasarruf asla kabul edilemez." BBC, https://www.bbc.com/turkce/live/39525615 (08.06.2020).

Suriye Dışişleri Bakanlığı'ndan yapılan açıklamada ise SDG ile yapılan petrol anlaşmasııın tarafı olan Amerikan şirketinin adı verilmedi. Amerikan Senatosu Dış İliş̧kiler Komisyonu'nda Senatör Lindsey Graham, SDG (PYD) ile bir Amerikan şirketi, Suriye'nin kuzeydoğusundaki petrol sahalarının modernizasyonu konusunda anlaşmaya varıldığını bildirmesi üzerine; "Bu durum iki kurumun da çöküşüne zemin hazırlar. ABD merkezli Delta Crescent Energy $\boldsymbol{L} \boldsymbol{L C}$ adlı şirketin, Suriye'nin kuzeydoğusunda petrol çıkarmak, işlemek ve ticaretini yapmak üzere YPG/PKK uzantısı SDG ile yaptığı anlaşma hukuken geçersiz. Uluslararası Adalet Divanı ve Amerikan iç hukukunda terör örgütlerini desteklemek ve onlarla anlaşma imzalamak suçtur. Söz konusu şirket ve imza atan taraflar yargılanacaktır. ABD hükümetine rağmen son söz Amerikan anayasasında olacaktır." https://www.aa.com.tr/tr/dunya/prof-dr-casin-abdli-sirketin-ypg-pkk-ile-yaptigi-petrol-anlasmasi-uluslararasihukuka-aykiri/1932320 (15.08.2020).

"Böylece ABD-İsrail ittifakı terör örgütü YPG/PKK aracıllğıyla bölgede hâkimiyetini artıracak. Plana göre günlük üretimin önce 60 bin varile, sonra kademeli olarak 380 bin varile çıkarılması hedefleniyor. Üretimin 60 bin varile çıkması halinde petrolün bugünkü piyasa değerinden günlük 3 milyon dolar, 380 bine çıktığı takdirde günlük 19 milyon dolar PKK'ya para aktarilacak. $\mathrm{Bu}$ da y1llı 7 milyar dolar yapiyor." https://www.aa.com.tr/tr/dunya/prof-dr-casin-abdli-sirketin-ypg-pkk-ile-yaptigi-petrol-anlasmasi-uluslararasihukuka-aykiri/1932320 (15.08.2020). "Bölgede bir terör devletini finanse edecek miktarda petrol mevcuttur." Türkiye sınırlarına yakın bölgede terörist yapıya izin veremeyeceği gibi Suriye'nin toprak bütünlüğüne de aykırıdır. Bu durum şunu kanıtlıyor: ABD terörist grupları petrol çıkarı için desteklemektedir.

\section{Sonuç}

Stratejik kaynak olan petrolün bulunmasından günümüze kadar çok kanlı savalar olmuştur. Bu savaşların sonunda, petrol çıkan ülkeleri kendi hükümranlık alanına almış, ya da ham petrol çıkan ülkeleri kendi kontrollerine almışlardır.1900'lü yılların hegoman ülkesi İngiltere, stratejik kaynağa ulaşması için çok gayret göstermiştir. Petrolü elde etmek için İngiliz başbakanı Winston Churchill, petrol için "Bir damla petrol, bir damla kandan daha değerlidir "sözü, günümüzde de geçerliliğini artırtarak korumaktadır. II. Dünya savaşından sonra, İngiltere hegomonik yapısı sona ermiş, yeni hegomonik ülke $\mathrm{ABD}$ olmuştur.

Petrol, eski çağlarda Bitümen olarak bilinen bir maddedir. Petrol ilk defa, 1846 da Bakü, Bibi-Haybat'da, daha sonraki 1859 Albay Drake'in Pennsylvania'da keşfedilmiştir. Petrol, Batı ve Doğu'daki Kafkaslar ana üretim merkezi haline gelmiştir. Orta Doğu. Petrolün evrimsel gelişimi ve belirginliği 1900 'lü yıllara rastlar. Dünya çapında petrolün evriminde ve kartelleşmesinde ilk aşama da başlamış olmuştur. Başka bir deyişle, D'Arcy'nin 1901'de İran'daki petrol imtiyazı, 1908'de Mescidi Süleyman'ın (güneybatı İran) petrolünün ve daha sonraki İngiltere'nin sömürgesi, ekonomik ve politik hâkimiyetinin keşfedilmesine yol açmıştır. Daha sonra, II. Dünya Savaşı'ndan sonrası, ABD'nin yükselen gücü, petrolün evrimi, 1950-72 geçiş dönemi olarak tanımlanan bir aşamaya geçmiş ve 1970 'lerin başında petrolün küreselleşmesinde önemli bir rol oynamıştır. Orta Doğu'nun kıymeti ise, değişen kumların altında petrolün varlı̆̆ının önemli bir dönüm noktası olmuştur. Sonunda 1973-74 petrol krizi yoluyla petrolün tam teşekküllü bir küreselleşmeye ve küreselleşmesine yol açan bir geçiş olmuştur. 1973-74 petrol krizinin rolü ve kartelleşmedeki sonucunda petrolün küreselleşmesi, rekabetçi bir evrim mekanizmasını göstermiştir. Çeşitli petrol üreten bölgelerin eşit olmayan maliyetlerine (ve verimliliklerine) karşı dünya çapında farklı fiyatlandırmalara neden olmuştur.

Petrol kaynakları bakımından zengin olan Orta Doğu coğrafyasına Osmanlı Devleti hâkimdi. 16 Mayıs 1916'da Sykes-Picot İngiliz-Fransız Gizli Anlaşması ile bu bölgedeki Osmanlı toprakları parçalanmış ve küçük büyük krallıklara ayrılmıştır. Bu krallıklar İngiliz ve Fransız Mandater yönetimine tabi tutulmuşlardır. Mandater yönetimle yönetilenlerden birisi de Suudi Arabistan'dır. Mandater yapıdaki ülkelerin toplamında Ortadoğu petrollerinin kabaca \% 62'sine sahiptir. Bu gün Ortadoğu'daki ülkelerin çoğu Batı ülkelerin ve özellikle ABD'nin kontrolü altındadır.

1967 yılında Arap - İsrail Savaşı sonrasında, Arap ülkeleri kendi aralarında Arap Petrol İhraç Eden Ülkeler Örgütü (APİË̈Ö), kurmuşlardır. APİË̈Ö, İsrail’’i destekleyen, ABD, İngiltere, Batı Almanya gibi ülkelere petrol ambargosu koymuştur. Ayrıca, Örgüt, petrol arzını da azaltmışıtır. Bununla beraber, Batılı Ülkelerde petrol girdi maliyetleri artmıştır. Özellikle ABD'de Dolar devalüe edilmiş ve Bretton Woods Sistemi çökmüştür. Bu olayların sonucunda; ABD de petrol maliyetlerini azalmak için Stratejik Petrol Rezervi (SPR), 1975'te kurulmuştur. ABD, 1 milyar varil ham petrole petrol depolama kapasitesini kurarak, petrol arzındaki kesintilerden korumak için stratejik önlemler almıştır. Petrol Krizinin ilgili ekonomik politik teoriler geliştirilmiştir. Bunlardan birisi de Petrol 
Krizinin Bağımlılık Teorisi'dir “1960'larda Latin Amerika'da ortaya çıkmıştır. Doğu ülkelerinin geri kalmışlı̆̆ını, bu ülkelerin batılı ülkelerin geçirdiği tarihsel aşamalardan geçmemesi nedeniyle ve bilimsel-teknolojik gelişmelerden yoksun olmasıyla açıklamaya çalışan modernleşme teorisine tepki olarak doğmuştur.

Terörizm tarihin her döneminde vardır. ABD Başkanlarının çoğu çıkar çatışmaları nedeni olan terörizmle öldürülmüştür. Terörizm I. Dünya Savaşının başlamasının da sebebi olmuştur. Terörün insan hayatınki her normalliği yok etme, insan dinamiklerini tam ve sarsılmaz korkuya boyun eğdirmeye dayalı açık bir tehlikedir. Böylesi bir terör örgütü, periyodik bombalar ve terör eylemleri devletlerin varoluşuna, insanların sosyal hayatlarına, mal ve can güvenliğine kastetmektedir. Bazı durumlarda devletler, açık ve gizli terör örgütlerine, parasal, politik ve silah yardımı da sağlayarak, terör örgütlerini kendi amaçları için kullanmaktadırlar. Bu durumda, teröre destek veren devletin amacı, diğer bir devletin yeraltı servetlerine ulaşmayı, ya da yönetim biçimlerini değiştirmek içindir. ABD'nin Kuzey Irak ve Suriye'deki PKK ve PYD'yi desteklemesi örnek olarak verilebilir. Terörizm, insanlık için çirkin bir vebadır. İnsan uygarlı̆̆ının yirmi birinci yüzyılda bu tür barbarca, iğrenç suç eylemlerine hala tanık olunması utanç vericidir. Terörizme verilecek tek bir yanıt vardır: Yok edilmeli ve yeryüzünden, tamamen ve her şekilde silinmelidir. Terörizmi destekleyen herkes ifşa edilmeli ve insan topluluğundan reddedilmelidir.

Uluslararası terörizm ve ülkelerdeki iç terörizm kendi başına bir hareket değildir. Mutlaka uluslararası bir desteği vardır. Uluslararası çıkar çevreleri bazen bu terör gruplarını taşeron olarak kullanırlar. Uluslararası terörizmin belirleyicileri, iç terörizmin belirleyicileri hakkında bilgilendirici olmak zorunda değiller. Günümüz ulus ötesi terörizminin çoğu, zengin ülkelere yönelik şikâyetlerden kaynaklanıyor gibi görünmektedir.

Petrol ve terörizm ilişkisi, 1967 Arap - İsrail çatışmasından sonra Ortadoğu'da görülmeye başlamıştı. Ortadoğu petrol zengini ülkelerin yönetimleri zengin, halkı ise sefalet içinde yaşamalarından kaynaklan sosyal huzursuzluklar terörizme davet çıkarmıştır. Ortadoğu'da Petrol ihraç eden Arap toplumu, daha demokratik bir yönetim ile refah toplumu oluşturmak için bir grup mücadele vermektedir. Bu grup, örgütlenmemiş, kendiliğinden ham, halka açık meydanlardaki barış̧̧ıl direnişleri ile medyada toplandılar. Bu hareket, Arap Baharı olarak bilinmeye başladı. Ne yazık ki bu ülkeler demokratik olmadığı için grubun yeniliği ve örgütsüz doğası nedeniyle, tam bir başarıya ulaşamamıştır. Başka bir grup, altıncı yüzyıl İslami Hilafetine ve Şeriat Hukukunun anayasallaşmasına dönebilecek bir yönetim değişikliği istemesidir. Bu tür bir kavram Ortadoğu'daki vatandaşların çoğunluğu tarafından paylaşılmadığından, çoğu (Müslümanlar dâhil) dini kişisel meseleler olarak görmüşler ve şiddet olarak görmemişlerdir. Bu görüşte olanlara karşı dini şiddet aracı olarak kullanan bir grup terörist eylemler şeklinde şiddete başvurarak gündem oluşturmuşlardır (İşiD gibi).İslam dini terörist bir din değildir. Uluslararası terörizmin stratejik kaynak petrol ile yakın ilişkilidir. Sovyetlerin dağıllmasından sonra Rusya- Çeçenistan savaşının nedeni 1990'da Çeçenistan'ın bağımsızlığını ilan etmesi, bunun Rusya tarafından kabul edilmemesi, I. Çeçenistan çatışmasına neden olmuştur. Sebebi de Çeçenistan'daki zengin petrol ve doğal rezervlerdi. Rusya'nın karşı çıkması ve II. Çeçen- Rus çatışmasında, Rus Yönetiminin çatışmada ağır silahlar kullanarak, Çeçen çatışmasını sonlandırmıştır. Bu gün bölge petrolü Rusya'nın kontrolündedir. Bir başka durum da 199016 Ocak'ta Rusya'nın Azerbaycan'a müdahalesi, ardından Ermenistan'ın Karabağ'ı işgal etmesi, Son aylarda Ermenistan'ın BTC petrol boru hattının geçtiği Tovuz Bölgesine saldırmasının ardında da stratejik kaynak petrol vardır. Bir başka oyun da Libya'da oynanmaktadır.

Stratejik kaynak petrolün küreselleşme ile Orta Doğu petrolü arasındaki bağ, petrol parası ve petrol ekonomileriyle desteklenen statüko ile küreselleşmenin baskılarının neden olduğu değişim arasındaki gerilimin ötesine uzanmaktadır. El Kaide'nin düşüncesi, mevcut statükonun bozulmaması için, Arap devletlerinin, ABD'ye ve Batı'nın laik rejimlere karşı olan etkisini Orta doğunun petrol sorunu olarak yaymaktı. Küreselleşme bu şikâyetlerin küresel kitleye sunulduğu, iletildiği, güçlendirildiği ve iletildiği daha geniş bir ağdır. Petrol sorunları bu tür küresel tüketim için çok uygundur. Küresel iletişim ve medya yoluyla, El Kaide'nin davasını ortaya çıkarmasına yardımcı olacak, korku yaratacak ve El Kaide'nin daha büyük algılanan bir tehdidini üreten bir almasına yardımcı olmuştur.

Esas petrol terörü, 9 Eylül 2001 de El Kaide'nin ABD New York'ta İkiz Kulelere terörist saldırısı ile daha çok gündeme gelmiştir. ABD yönetimi, teröristlerin küresel eylemlerini desteklemek için kullanılabilecek fonların, hem toplanması ve hareketini bastırma çabası da dâhil olmak üzere geleneksel olmayan yöntemlere, kurumlara ve kaynaklara başvuran uzun süreli bir mücadele olacağını açıklamışlardır. Terörle savaşı kazanmak için diplomasi, istihbarat, yasa uygulama aracı, her türlü mali etki ve kaynağ 1 emrimize yönlendireceğeyiz diyerek yeni bir dönemi başlatmışlardır. Bu stratejinin altında yatan mantık, devlet merkezli bir mantıktır. Devletler, stratejinin merkezinde yer alır ve kendi topraklarından kaynaklanan eylemlerden sorumlu tutulurlar. Devletlerin, istihbarat toplamayı, kanun yaptırımını güçlendirerek ve terörizmin finansmanına karşı yeni mali kontroller getirerek, küresel terörizmin zorluklarıyla başa çıkma konusundaki zorlayıcı kapasitelerini artırmaları gerekmektedir.

Teröristler, sadece petrol üretim yerlerine ve boru hatlarına saldırmazlar. Boğazlarda ve denizlerde petrol taşıyan tankerlere de yönelik saldırılar olmuştur. Örnek olarak; Ocak 2000 yılında denizde El Kaide'nin Yemen'deki saldırganları vasıtasıyla, patlayıcı yüklü bir tekneyi petrol tankerine çarpmasını denediler. Füze atmaya denediler ve ilk saldırı başarısızlıktan sonra, ikincisinde El Kaide intihar bombacıları patlayıcılarla dolu bir sürat teknesinde 2 Ekim'de2002'de Cole'u 17 denizciyi öldürerek petrol tankerde delik açmışlardır. Ekim 2002'de, patlayıcı yüklü 
bir Fransız petrol tankeri Limburg'u Yemen sahilinden vurulmuştur. Şubat 2004'te, güney Filipinler merkezli Abu Sayyaf en az 100 kişiyi öldüren büyük bir feribotta patlama sorumluluğunu üstlenmiştir. Buradan; Petrol tankerlerine saldıran teröristleri petrol ihraç eden ülkeler finanse ederek, petrol fiyatlarının armasını sağlarlar. Böylelikle terörizmin istekleri yerine getirilebilir. Diğer bir durum da, Petrol tanker şirketleri, riskli bölgelerde tanker sigortası büyük paralara neden olmaktadır. Petrol taşıma şirketleri çoğu zaman kendilerine olan terörist faaliyetleri açıklamazlar. Dolaylı olarak teröristlere finansal destek sağlayabilmektedirler.

Türkiye'nin güneyinde, ABD'nin Irak'ın işgalinden sonra, bölgede bir otorite boşluğu olmuştur. Otorite boşluğunu kendilerinin illegal olarak kurdurdukları CIA destekli marjinal terör örgütü vasıtasıyla, hem Türkiye'ye hem de Suriye'ye yönelik terörist faaliyetlerde bulunmaktadırlar. 7 Nisan 2017 'de ABD, Başkan Trump'ın talimatıyla sabaha karşı Suriye'nin Humus kenti yakınlarındaki El Şayrat üssünü vurmuştur. Gerekçe olarak, Suriye hükümetinin İdlib'te kimyasal saldırı düzenlediği iddiaları üzerine yapılan operasyonda 59 Tomahawk füzesi kullanmıştır. Asıl amaç, ABD petrol şirketlerin Suriye'nin kuzeyindeki zengin petrol alanlarına yerleşmektir. Bunun için terör örgütü olan PKK/ PYD'yi desteklemektedir. Elde edilen petrolden terör örgütlerine parasal destek sağlamaktır. Bu destek olunca terörizm bölgesel ve küresel olarak bitmeyecektir. Ne yazık ki Türkiye'nin güney sınırında varlığını sürdüren sözde İslami terör örgütleri bulunmaktadır. Bunların başında IŞİD, El - Kaide ve İran destekli para karşılığı çeşitli yerlerden gelen teröristler vardır. Bu terörist gruplar, İslam'ın önde gelen isimlerini, kurdukları terör örgütlerine vermektedirler. Bu durum, gerçek İslam dünyasında kabul görmedi. Nedeni "İslam'ın Terörle Hiç İlişkisi Yoktur. İslam Dini İnsanı Yaşatmak İçin Vardır”. Batı toplumları da İslam ülkelerine ve insanlarına kuşku ile bakmaktadır. Batı toplumunun tek kuşku duymadığı madde, Ortadoğu İslam ülkelerinde bulunan petrol ve onu elde etmeleridir. Bunun için bölgedeki terörist grupları açık ve gizliden desteklemektedirler.

\section{Kaynakça}

- AA, 2020. https://www.aa.com.tr/tr/analiz/iran-destekli-terorist-gruplarin-suriye-deki-varligi-/1732926 (08.06.2020)

- AA, 2020. https://www.aa.com.tr/tr/dunya/prof-dr-casin-abdli-sirketin-ypg-pkk-ile-yaptigi-petrol-anlasmasiuluslararasi-hukuka-aykiri/1932320 (15.08.2020)

- $\quad$ Adams, 2003. Terrorism, Terrorism \& Oil, South Sheridan Tulsa, Oklahoma.

- Avc1, Rusya için Çeçenistan neden bir sorun?, https://www.celikhanhaber.com/makale/rusya-icincecenistan-neden-bir-sorun--3476.html (20.07.2020)

- Abadie, 2013. "The Economics of National Security”, American Economic Review, Vol. 96, No. 2, s. 50.

- Armaoğlu, 1984. 20.Yüzyılsiyasi Tarihi1914-1980,Türkiye İş Bankası Kültür Yayınları, 2. Baskı, Genel Yayın No: 252,Tarih Dizisi 17.

- Bahgat, 2004. "Terrorism and Energy, Potential for a Strategic Realignment", World Affairs, Vol. 167, No. 2, s. 51 .

- $\quad$ Bamberger, 2010. The Strategic Petroleum Reserve: History, Perspectives, and Issues (Ed. Albert L. Strait Editor), New York.

- $\quad$ BBC, https://www.bbc.com/turkce/live/39525615 (08.06.2020)

- Biersteker ve Eckert, 2008. Countering the Financing of Terrorism, New York.

- $\quad$ Barnes, 2005. “Global Flows: Terror, Oil, and Strategic Philanthropy.” African Studies Review, 48 (1): 1-23.

- Bina, 2013. A Prelude to the Foundation of Political Economy: Oil, War and Global Polity. Palgrave Macmillan, New York.

- Charles ve Jones, 2012. Essentials of Strategic Management, (Third Edition), South-Western. USA.

- Chia-yi Lee, 2016. "Oil and Terrorism: Uncovering the Mechanisms”, Journal of Conflict Resolution, 62(2).

- CNBC, 2014. https://www.cnbc.com/2014/09/14/oil-smuggling-theft-extortion-how-isis-earns-3m-aday.html (0.05.2020)

- Dawoody, 2016. Eradicating Terrorism from the Middle East, Policy and Administrative Approaches. Springer International Publishing, Switzerland.

- Eller, 1956. "The Strategic Importance of Middle East Oil”, Journal of Petroleum Technology, Vol. 8, No, 5.

- Enerji Bakanlığ1, 2010. https://www.enerji.gov.tr/tr-TR/Sayfalar/Petrol

- Fouskas ve Gökay, 2005. The New American Imperialism. Praeger Security International Westport, Connecticut, London.

- Gezimanya, https://gezimanya.com/suudi-arabistan/suudi-arabistanin-kisa-tarihi (20.05.2020)

- Inkpen ve Moffett, 2011. The global oil \& gas industry : Management, Strategy, And Finance, Pennwell Corporation.

- İslam Ansiklopedisi, 2010. https://islamansiklopedisi.org.tr/sykes-picot-antlasmasi (06.06.2020) 
- Le Billon ve El Khatib, 2004. "From free oil to 'freedom oil': terrorism, war and US Geopolitics in the Persian Gulf, Geo Politic”. Journal Geopolitics, Vol. 9, No. 1.

- Luft ve Kori, 2004. "Terrorism Goes to Sea”, Foreign Affairs, Vol. 83, No. 6.

- Merari, 2007. Terrorism as a Strategy of Insurgency,(Ed: Gérard Chaliand and Arnaud Blin), The history of terrorism : from antiquity to al Qaeda, The Regents of the University of California.

- MFA, 2020. http://www.mfa.gov.tr/sc_-56_-abd-disisleri-nin-terorizm-raporu-hk-sc.tr.mfa (25.06.2020)

- QHA, 2020. https://qha.com.tr/haberler/guvenlik/kirli-ortaklik-teror-orgutu-ypg-pkk-rusya-nin-kontrolunderejime-petrol-tasiyor/203632/ (08.06.2020)

- $\quad$ Rockmore, 2011. Before And After 9/11, A Philosophical Examination of Globalization, Terror, and History, New York.

- Barnes, 2005. "Global Flows: Terror, Oil, and Strategic Philanthropy". African Studies Review, 48 (1): 123.

- $\quad$ Standlea, 2006. Oil, Globalization, and the War for the Arctic Refuge, State University of New York Press.

- T.C İç İşleri Bakanlığı, 2017. Türkiye’nin DEAŞ İle Mücadelesi. Ankara.

- $\quad$ Thachuk ve Lal, 2018. Terrorist Criminal Enterprises, Financing Terrorism through Organized Crime. Terrorist Criminal Enterprises içerisinde.

- Vaçagayev, 2008. http://ajanskafkas.com/arastirma-yazilari/cecen-petrolunun-kisa-tarihcesi/ (20.07.2020)

- Yergin, 2003. Petrol, Para ve Güç Çatışmasının Epik Övküsü. (Çev. Kamuran Tuncay), İş Bankası Kültür Yayınları,3. Baskı, İstanbul. 


\title{
Sosyal Medya Tüketici Algıları Demografik Özellikler Bağlamında
}

\section{Social Media Consumer Perceptions in the Context of Demographic Features}

\author{
Dr. Muhammed Fatih Cevher (Munzur University, Turkey) \\ Prof. Dr. Erdoğan Taşkın (Beykent University, Turkey)
}

\begin{abstract}
Consumer behavior, which is one of the focus issues of marketing, continues to be examined from different perspectives after changing technological developments. As marketing activities have been realized through social media platforms in recent years, it has also made it possible to examine the social media platforms and consumers as users. Influencer Marketing is an increasingly popular method of influencing consumers in social media with the help of influencers. It is important for businesses to send their messages about their brand or products to consumers and affect them. Consumers' evaluation of these messages is realized through their perceptions. The analysis of consumer perceptions in terms of demographic features in social media is also the focus of this study.
\end{abstract}

\section{Giriş}

Pazarlamanın odak konularından olan tüketici davranışları değişen teknolojik gelişmeler sonrası farklı bakış açılarıyla incelenmeye devam etmektedir. Pazarlama faaliyetlerinin son yıllarda sosyal medya platformları üzerinden gerçekleşmesi ile sosyal medya platformlarını ve kullanıcıları olan tüketicileri de incelemeyi ön plana çıkarmıştır. Sosyal medyadaki tüketicileri "Influencer Marketing" stratejisi ile etkileyici kişiler yardımıyla yönlendirmek gittikçe artan bir yöntem olmaktadır. İşletmelerin marka veya ürünleri ile ilgili mesajlarını tüketicilere göndermesi ve onları etkilemesi önemlidir. Tüketicilerin bu mesajları değerlendirmesi de algıları ile gerçekleşmektedir. Sosyal medyada tüketici algılarının demografik özellikler açısından analizi bu çalışmanın odak noktasidır.

Günümüz insanı zamanın büyük bir kısmını sosyal medya kullanarak geçirmektedir. Sosyal medya kullanım amaçları farklılık göstermektedir. Sosyal medya çağdaş tüketicilerin algı ve davranışlarını etkilemektedir. Özellikle sosyal medyanın pazarlama bağlamında tüketicilerin algı, davranış ve satın alma niyetlerini etkilemesi yönü ayrıntılı olarak bu çalışmada incelenmektedir. Sosyal medya içeriği oluşturup diğer kullanıcılar ile bu içeriği paylaşım olarak yapan kişilerin başka kullanıcıları da etkilediği görülmektedir. Bir alanda öne çıkan, diğer kullanıcılar tarafından dikkat çeken ve takip edilen kişiler, literatürde "influencer", "etkileyici" gibi kavramlar ile nitelendirildiği gibi bu kişiler "fenomen" kavramıyla da ifade edilmektedir (Yaylagül 2017).

Pazarlama açısından sosyal medya fenomenlerinin hazırladıkları içerikler ile diğer kullanıcıların ilgilerini çeken bu kişilerin nihai tüketicilerin algılarını da etkilediği görülmektedir (Marwick ve Boyd 2011).

Tüketicilerin sosyal medyada algıları çeşitli yönlerden etkilenmektedir. Sosyal konum, kişisel kullanım, imaj ve hedonik açılardan tüketici algıları farklılaşmaktadır. Ayrıca tüketici algıları demografik özellikler açısından incelendiğinde farklılıklar olabileceği düşünülmektedir. Temel anlamda tüketicilerin inançları incelendiğinde tüketici algılarının bilgi verme ve paylaşma, eğlence sunma, güvenilirlik, ekonomiye katkı, değer yozlaşması boyutlardan incelendiği görülmektedir (Wang, vd. 2009).

Pazarlama bağlamında sosyal medya, tüketici algılarının analizi, tüketici davranışlarının analizi ve tüketicilerin satın alma niyetlerini etkilemeleri açısından önemlidir.

\section{Tüketici Algısı}

Algılama insanların duyuları seçtiği, düzenlediği ve yorumladığı, yani duyu alıcılarının (gözler, kulaklar, burun, ağız ve gözler gibi) 1şık, renk, koku, doku ve ses gibi temel uyaranlara anında tepki vermesidir. Bir alıcıyı harekete geçirene uyaran denir. Algı çalışması, onlara anlam vermek için ham duyulara ne eklediğimiz kavramına odaklanmaktadır. Her birey, kendine özgü önyargıları, ihtiyaçları ve deneyimleriyle algılarını yorumlamaktadır (Madichie 2012).

Algılama süreci insanlara göre farklılaşmaktadır. Kişisel etkenler, değerler, dikkat ve insanların duyulara vermiş oldukları tepkiler algılama sürecini oluşturmaktadır (Kardes, vd. 2011).

Genel olarak algı, basit olarak tüketicinin karar vermesinde yardımcı olacak anlamlar üretmek için bilgi girdilerini seçme, düzenleme ve yorumlama sürecidir. Maruz kalma aşamasında ilk sezilen girdiler duyu organlarından alınır (Madichie 2012). 


\subsection{Sosyal Medyada Tüketici Algısı}

İnsanların kendilerine göre belirledikleri amaçları ve diğer insanlara yönelik hazırladıkları içeriklerin tümünü sosyal ağlar aracılığıyla gerçekleştirmesi sosyal medyayı oluşturmaktadır (Shing ve Stephanie 2017).

Başka bir ifade ile sosyal medya, insanların düşüncelerini paylaştığ 1 , başkalarının görüşlerini incelediği, tartışma ve sohbet ortamlarının bulunduğu, kişilerin birbirleri ile iletişim kurabildiği, ürün veya hizmetler hakkında bilgi edindiği, eğlenceli içeriklerin bulunduğu, fotoğraf, film ve seslerin paylaşılabildiği tüm siteleri de kapsayan internet tabanlı ortamlardan oluşmaktadır (Mangold ve Faulds, 2009).

\subsection{Bilgi Verme ve Paylaşma}

İnsanların sosyal medyada bilgi, deneyim ve yorumlarını paylaşması diğer kullanıcıların bu bilgilere kolay ve hızlı bir şekilde ulaşması bilgi verme ve paylaşma boyutunun temelini ortaya koymaktadır. Pazarlama faaliyetleri ile tüketicilerin bilgilendirilmesi, tüketicilerin farkında olması ve satın alma niyetlerinin oluşturulmasında etkili olmaktadır. Tüketicilerin bilgiye kolay ve hızlı yoldan ulaşabilme istekleri, tüketici algıları boyutlarından bilgi verme ve paylaşma boyutunun önemini artırmaktadır (Turgut 2016).

Aynı doğrultuda, bir üründen memnun olan tüketicilerin internet ve sosyal medya üzerinden ağızdan ağıza o ürün hakkında olumlu izlenimlerini paylaşmasının en etkili talep yaratma araçlarından biri olduğu saptanmıştır. Bilhassa turizm gibi tüketicinin yoğun kişisel deneyimine dayanan ürünler hakkındaki algı oluşumunda, eğitim düzeyi yüksek ve deneyimlerini internet üzerinden paylaşma alışkanlığı olan belirli turistlerin bu bölgenin pazarlanmasında etkin görevler yaptığı sonucuna varılmıştır (Artuner Özder 2020).

\subsection{Eğlence Sunma}

İnsanların duygusal açıdan doyuma ulaşması, kendilerini rahat hissetmesi, haz duyması ve mutlu olması eğlence diye nitelendirilmektedir. İnsanların eğlenceli bir durumda olması işletmecilere tüketicilerle bağ kurma anlamanda da faydalar sağlamaktadır. Sosyal medyanın özelliklerinden biri de insanlara eğlence duygusunu sunmasıdır. Sosyal medya kullanıcıları eğlence amacıyla da içerikleri oluşturma ve oluşturulmuş içerikleri diğer kullanıcılarla paylaşır. Bunun sonucunda tüketici algılarını olumlu olduğu yönde etkiler. Pazarlama açısından bu etki değerlendirildiğinde eğlence, işletme ve markalar için de tüketicilere ulaşma konusunda faydalıdır (Turgut 2016).

\subsection{Güvenilirlik}

İnsanlar arasında bir bilgi veya verinin paylaşılması ve alıcı tarafından kabul edilebilir, inandırıcı olarak algılanıp yorumlanması sonrasında da kabul edilmesi temel anlamda güvenirlik kavramını ifade etmektedir. İnsanların veriyi algılama sürecinde sahip oldukları bilgi, deneyim, durumların algılama sürecini etkilediği de görülmektedir. Algılama sürecinde insanlar tarafından yapılan değerlendirmeler sonucu veri olumlu olarak yorumlanırsa güvenilir olarak kabul edilir (Balcı 2014).

\subsection{Ekonomiye Katkı}

Pazarlama faaliyetlerinin tüketicilere ulaşması ve tüketici satın alma niyetlerinin olumlu yönde etkilenmesi sonucunda ürün ve hizmetlerin satılması olayı gerçekleşmektedir. Bu süreçte yapılan mübadele faaliyetleri ile ürünün üretiminden itibaren tüketicilere ulaştırılması ve sonrasında da parasal anlamda bir hareket gerçekleşmektedir (Taşkın 2009).

Sosyal ağlar da ekonomi açısından incelendiğinde ekonomik bir boyutu olduğu görülmektedir. Sosyal ağlar sayesinde kurulan bağlar, ağ ekonomisini ortaya çıkarmaktadır. Üretim sürecinde yaşanan değişiklikler, hız ve teknolojik boyuttaki farklılıklar; sosyal ağların ekonomiye katkı sunduğunu desteklemektedir (Kara 2013).

\subsection{Değer Yozlaşması}

Sosyal medya kullanımı ve sosyal medya içeriklerinin, insanların yaşamlarının bir parçası haline gelmesi sonucu insanların hayatlarını yorumlama ve bakış açılarındaki etkiler, değer olarak nitelendirilmektedir. Yapılan bu yorumlama ve bakış açıları ile oluşan değer, olumsuz olarak algılanırsa sahip olunan değerlerin de olumsuz yönde etkilendiği etkilenebileceği düşüncesini meydana getirmektedir (Wang vd. 2009).

\section{Araştırmanın Amacı}

Son yıllarda pazarlama faaliyetlerinin sosyal medya üzerinden yoğun bir şekilde gerçekleşmesi pazarlama faaliyetlerinde de değişikliğe sebep olmaktadır. İşletmelerin ürün ve markaları ile ilgili tüketicilere göndermek istedikleri bildirimler, sosyal medya üzerinden hızlı bir şekilde gerçekleşmektedir. İşletmeler tüketicileri bilgilendirmek, dikkatlerini çekmek, konumlandırma yapabilmek gibi birçok farklı amaçla sosyal medya üzerinden tüketici algılarına ulaşmaya ve etkilemeye çalışmaktadır.

Tüketici algılarının analizi ve tüketici algılarının demografik özelliklerden analiz edilmesi araştırmanın amacını oluşturmaktadır. 


\section{Veri Toplama ve Analiz Yöntemleri}

Araştırmaya konu olan veriler sosyal medyayı etkili olarak kullanan kişilerden oluşmaktadır. Marmara Bölgesinde yaşayan 18 yaşından büyük katılımcılara anket yöntemi uygulanmıştır. Anketin içeriğginde katılımcıların kişisel özellikleri incelenmektedir. Örneklem büyüklüğünde bu çalışmada 818 sayısına ulaşılmıştır. Örneklem analizinde kolayda örnekleme yöntemine başvurulmuştur. Ancak, elde edilen bulguların geneli temsil ettiğini iddia etmemek gerekir (Çinkay 2013; Altunışık vd. 2010).

\subsection{Güvenirlik Analizleri}

Güvenirlik, ölçeklerde bulunması gereken bir özellik olarak kabul edilmektedir. Aynı şartlar altında yapılan ölçümlerde tekrarlanan ölçümler olmak üzere ölçeğin kararlılık göstermesi güvenirlik olarak ifade edilmektedir. Ayrıca güvenirlik, ölçme aracı ve bunun ulaştığı sonuçlara yönelik bir özellik olarak da görülmektedir. Sadece ölçme aracına ilişkin bir durum olarak görülmemektedir (Ercan ve Kan 2004).

Tüketici algısı boyutunun Cronbach Alpha değeri ve madde sayıları Tablo-1 de gösterilmektedir. Güvenilirlik analizlerinde Cronbach Alpha sayısı güvenirlik analizlerinde sıkça karşılaşılan analizdir (Altunışık vd. 2005).

\begin{tabular}{|l|c|c|}
\hline Boyutlar & Cronbach $\boldsymbol{\alpha}$ Katsayısı & Madde Sayısı (N) \\
\hline Tüketici Algısı Boyutu &, 860 & 15 \\
\hline
\end{tabular}

Tablo-1: Çalışmanın Cronbach $\alpha$ Katsayı Değerleri

Araştırmada tüketici algısı ilgili maddelerin güvenirlik analizleri incelendiğinde Cronbach Alpha değerinin 0,860 olduğu görülmüş ve tüketici alg1sı boyutu güvenilir olarak kabul edilmiştir. Cronbach $\alpha$ katsayı değerlerinin 1 'e yakın olması güvenirlik seviyesinin iyi olduğunu ifade etmektedir (Can 2018).

\subsection{Faktör Analizleri}

Analiz edilen bir ölçeğin beklenilen değerleri ölçüp veya ölçemediği geçerlilik ile ilgilidir. Ölçümü yapılan ölçeğin özelliklerinin planlandığı şekilde ölçülebilmesi analiz edilen ölçeğin geçerli olduğunu göstermektedir (Çakmur 2012).

Çalışmada KMO değerinin 0.860 oranı ile çok iyi olduğu tespit edilmiştir. Bileşenlerin madde yükleri incelendiğinde yapılan faktör analiz sonuçlarına göre tüketici algısı boyutlarının her birinin madde yüklerinin 0,50' den büyük olduğu görülmüştür. KMO (Kaiser - Meyer - Olkin) Testi ile gözlenen korelasyon katsayıları ile kısmi korelasyon katsayılarının büyüklüğü kıyaslanmaktadır. KMO oranının 0,5' in üstü değerlerde olması gerektiği görülmektedir (Kalayc1 2014).

\section{Bulgular}

\begin{tabular}{|c|c|c|c|c|c|c|}
\hline $\begin{array}{c}\text { Tüketici AlgıSı } \\
\text { Soruları } \\
\end{array}$ & Cinsiyet & $\mathbf{N}$ & Ortalama & $\begin{array}{l}\text { Standart } \\
\text { Sapma }\end{array}$ & $\mathbf{F}$ & Sig \\
\hline \multirow{2}{*}{ TAB } & Erkek & 267 & 3,5031 &, 83689 & 30,122 & ,007 \\
\hline & Kadın & 551 & 3,6467 &, 65026 & & \\
\hline \multirow{2}{*}{ TAE } & Erkek & 267 & 3,7216 & ,65041 &, 023 &, 379 \\
\hline & Kadın & 551 & 3,6794 & ,64074 & & \\
\hline \multirow{2}{*}{ TAG } & Erkek & 267 & 2,8102 & ,76019 & ,299 & ,144 \\
\hline & Kadın & 551 & 2,7290 & ,73824 & & \\
\hline \multirow{2}{*}{ TAD } & Erkek & 267 & 3,4288 & ,82864 & ,687 & ,418 \\
\hline & Kadın & 551 & 3,4819 & 89931 & & \\
\hline \multirow{2}{*}{ TAEK } & Erkek & 267 & 2,8689 & ,97241 & 9,569 &, 146 \\
\hline & Kadın & 551 & 2,7731 & ,83724 & & \\
\hline
\end{tabular}

Tablo 2: Tüketici Algısına İlişkin Cinsiyete Göre T Testi

Tüketici algısının cinsiyete göre anlamlı bir farklılık gösterip göstermediğini belirlemek üzere yapılan $\mathrm{t}$ - testleri sonucunda Tablo 2'ye bakıldığında; tüketicilerin algısında cinsiyete göre anlamlı genelde bir fark oluşturmadığı sadece tüketici algılarından bilgi verme ve paylaşma" boyutunda cinsiyete göre anlamlı bir fark oluştuğu görülmektedir. 


\begin{tabular}{|l|l|r|r|r|r|r|}
\hline \multicolumn{2}{|c|}{ Yaş } & N & Ortalama & Standart Sapma & \multicolumn{1}{c|}{ F } & Sig \\
\hline \multirow{5}{*}{ TAE } & $18-24$ & 414 & 3,7657 &, 03034 & & \\
\cline { 2 - 7 } & $25-34$ & 316 & 3,6139 &, 03660 & & \\
\cline { 2 - 7 } & $35-44$ & 71 & 3,6620 &, 07401 & 3,808 &, 010 \\
\cline { 2 - 7 } & 45 ve üzeri & 17 & 3,5294 &, 24263 & & \\
\cline { 2 - 8 } & Total & 818 & 3,6932 &, 02251 & & \\
\hline
\end{tabular}

Tablo 3: Tüketici Algısına İlişkin Yaş Gruplarına Göre ANOVA Testi

Tüketicilerin algılarında yaş grupları arasında anlamlı bir fark olup, olmadığı yapılan ANOVA testi sonucunda Tablo.3' de görülmektedir. Tüketici algısı boyutlarından "Ekonomiye Katkı" boyutunda tüketicilerin algılarında yaş grupları açısından anlamlı bir fark olduğu ancak diğer boyutlarında görülmektedir.

\begin{tabular}{|c|c|c|c|c|c|c|}
\hline \multicolumn{2}{|c|}{ Öğrenim Düzeyleri } & $\mathbf{N}$ & Ortalama & Standart Sapma & $\mathbf{F}$ & Sig \\
\hline \multirow[t]{6}{*}{ TAB } & Lise ve alt1 & 184 & 3,5670 &, 64470 & & \\
\hline & Ön lisans & 223 & 3,7250 &, 66372 & & \\
\hline & Lisans & 283 & 3,5324 & ,76417 & 2,501 &, 041 \\
\hline & Yüksek Lisans & 90 & 3,5963 & ,81878 & & \\
\hline & Doktora & 38 & 3,5351 & , 72094 & & \\
\hline & Total & 818 & 3,5998 & ,71918 & & \\
\hline \multirow[t]{6}{*}{ TAG } & Lise ve alt1 & 184 & 2,6975 & .72321 & & \\
\hline & Ön lisans & 223 & 2,8625 & ,72976 & & \\
\hline & Lisans & 283 & 2,7126 &, 72760 & 2,691 & 030 \\
\hline & Yüksek Lisans & 90 & 2,8333 & 84837 & & \\
\hline & Doktora & 38 & 2,5439 & , 76099 & & \\
\hline & Total & 818 & 2,7555 & ,74599 & & \\
\hline
\end{tabular}

Tablo- 4: Tüketicilerin Öğrenim Düzeylerine Ait ANOVA Testi

Tüketicilerin öğrenim seviyelerine yönelik algıları incelendiğinde tüketici algılarından güvenirlik boyutunun tüketiciler arasında farklı yorumlandığı tespit edilmiştir. Öğrenim seviyeleri incelendiğinde farklılık gösteren öğrenim seviyeleri Anova testinin yanı sıra Post Hoc analiyle çoklu karşılaştırma testi tablosu hazırlanarak sunulmuştur.

\begin{tabular}{|c|c|c|c|c|}
\hline Bağımlı Değișken & (I) Öğrenim Düzeyiniz & (J) Öğrenim Düzeyiniz & Ortalama Fark (I-J) & Sig. \\
\hline \multirow{8}{*}{ TAB } & \multirow{4}{*}{ Lise ve alt } & Ön lisans &,$- 15793^{*}$ &, 027 \\
\hline & & Lisans &, 03464 &, 610 \\
\hline & & Yüksek Lisans &,- 02927 &, 751 \\
\hline & & Doktora &, 03194 &, 803 \\
\hline & \multirow[t]{4}{*}{ Ön lisans } & Lise ve alt1 & $15793^{*}$ &, 027 \\
\hline & & Lisans &, $19257^{*}$ &, 003 \\
\hline & & Yüksek Lisans &, 12867 &, 151 \\
\hline & & Doktora &, 18987 & ,131 \\
\hline \multirow[t]{20}{*}{ TAG } & \multirow[t]{4}{*}{ Lise ve alt 1} & Ön lisans &,$- 16502^{*}$ &, 026 \\
\hline & & Lisans &,- 01514 &, 830 \\
\hline & & Yüksek Lisans &,- 13587 &, 155 \\
\hline & & Doktora &, 15360 & 246 \\
\hline & \multirow[t]{4}{*}{ Ön lisans } & Lise ve alt1 &, $16502^{*}$ &, 026 \\
\hline & & Lisans &, $14988^{*}$ &, 025 \\
\hline & & Yüksek Lisans &, 02915 &, 753 \\
\hline & & Doktora & $.31862^{*}$ &, 015 \\
\hline & \multirow[t]{4}{*}{ Lisans } & Lise ve alt1 &, 01514 &, 830 \\
\hline & & Ön lisans &,$- 14988^{*}$ &, 025 \\
\hline & & Yüksek Lisans &,- 12073 &, 180 \\
\hline & & Doktora &, 16874 &, 189 \\
\hline & \multirow[t]{4}{*}{ Yüksek Lisans } & Lise ve alt1 &, 13587 &, 155 \\
\hline & & Ön lisans &,- 02915 &, 753 \\
\hline & & Lisans &, 12073 &, 180 \\
\hline & & Doktora &, $28947^{*}$ &, 044 \\
\hline & \multirow[t]{4}{*}{ Doktora } & Lise ve alt1 &,- 15360 & 246 \\
\hline & & Ön lisans &,$- 31862^{*}$ &, 015 \\
\hline & & Lisans &,- 16874 &, 189 \\
\hline & & Yüksek Lisans &,$- 28947^{*}$ &, 044 \\
\hline
\end{tabular}

Tablo- 5: Tüketicilerin Öğrenim Düzeylerine Ait Çoklu Karşılaştırma Testi 
Öğrenim düzeylerine göre tüketici algıları Tablo-5’te incelenmektedir. Tüketici algılarından "bilgi verme ve paylaşma" boyutu ile ilgili maddelerde "lise ve altı" ile "ön lisans" arasında anlamlı farklılıklar tespit edilmiştir. Tüketici algılarından "güvenirlik" boyutuyla ilgili maddeler de farklılık tespit edilmiş̧tir. Lise ve altı öğrenim düzeyindeki katılımcılar ile ön lisans öğrenim düzeyine sahip katılımcılar arasında, ön lisans öğrenime sahip katılımcılar ile lisans öğrenimine sahip katılımcılar arasında, yüksek lisans ve doktora öğrenim düzeyleri arasında da katılımcılar arasında anlamlı farklılıklar olduğu yapılan post hoc analizinde görülmektedir.

\section{Sonuç}

Sosyal medyada tüketicilerin algısı cinsiyete göre analiz edildiğinde erkek ve kadın cinsiyetlerinin tüketici algılarında anlamlı bir fark olmadığı ama bilgi verme ve paylaşma boyutunda anlamlı bir fark olduğu tespit edilmiştir. Yaş gruplarına göre yapılan tüketici algıları analizinde katılımcıların yaş gruplarının tüketici algılarında anlamla bir fark oluşturmadığı tespit edilmiş̧ir. Katılımcıların öğrenim düzeylerine yönelik kendilerinde oluşan algılar incelendiğinde güvenirlik boyutunda yorumlarda farklılık olduğu anlaşılmıştır. Pazarlamanın odak konularından olan tüketici davranışları konusunun analiz edilmesi, tüketici davranışlarının doğru bir şekilde izlenip yorumlaması hem pazarlama yöneticileri hem de işletmelerin amaçlarına erişmesi açısından büyük öneme sahiptir. Tüketicilerin sergilediği davranışların temelinde algılarının etkisi dikkat çekmektedir. Çalışmanın sonuçlarına göre de katılımcılar demografik özellikleri açısından incelendiğinde tüketici algılarında, cinsiyete, yaşa ve öğrenim düzeyine göre anlamlı düzeyde farkl1lıklar görülmektedir. Sosyal medyanın her geçen gün etkin olduğu pazarlamada işletmeler marka ve ürünleri ile ilgili mesajlarını tüketici algılarını iyice analiz ederek yönlendirdiğinde başarılı stratejiler geliştirmeleri mümkün hale gelecektir.

Bu çalışma: Muhammed Fatih CEVHER' in, Prof. Dr. Erdoğan TAŞKIN danışmanlığında Beykent Üniversitesi Sosyal Bilimler Enstitüsü İşletme Yönetimi Anabilim Dalı İşletme Yönetimi Bilim Dalında hazırlamış olduğu "Sosyal Medya Fenomenlerinin Tüketici Alglsı ve Satın Alma Niyeti Üzerine Etkisi" Doktora Tezinden hazırlanmıştır.

\section{Kaynakça}

- Altunışık, R. Coşkun R. Bayraktaroğlu, S. Yıldırım, E. 2005. Sosyal Bilimlerde Araştırma Yöntemleri. Sakarya Kitabevi. Adapazarı.

- Artuner Özder, C. G. 2020. Enotourisme: Le Nouvel Atout du Tourisme Expérientiel. Detay Yayınc1lık, Ankara.

- Balc1, Ş. ve Bekiroğlu, O. 2014. "Medyanın Kritik ve Süreğen Dönemeci: Üniversite Öğrencilerinin Gözünden Medya Haberlerinin Güvenilirliği”, Selçuk İletişim Dergisi, Cilt. 8, Sayı. 2, $193-217$.

- Can, A. 2018. SPSS İle Bilimsel Araştırma Sürecinde Nicel Veri Analizi. Pegem, 001-429.

- Çakmur, H. 2012. "Araştırmalarda Ölçme-Güvenilirlik-Geçerlilik”. TAF Preventive Medicine Bulletin, 11(3). 342.

- Çinkay B. 2013. Sosyal Medya Pazarlamasında Ünlü Onayların Tüketici Algısı ve Satın Alma Niyetine Etkisi. Kahramanmaraş Sütçü İmam Üniversitesi Sosyal Bilimler Enstitüsü İşletme Anabilim Dalı Yayınlanmış Doktora Tezi.

- Ercan, İ. ve İsmet, K. A. N. 2004. “Ölçeklerde Güvenirlik ve Geçerlik”. Uludağ Üniversitesi Tıp Fakültesi Dergisi, 30(3), 211-216.

- Kalaycı, Ş. 2014. SPSS Uygulamalı Çok Değişkenli İstatistik Teknikleri, 6. Baskı, Asil Yayın. Ankara.

- Kara, T. 2013. Sosyal Medya Endüstrisi. İstanbul: Beta Yayınc1lık.

- Kardes, F. R. Cline, T. W. and Cronley, M. L. 2011. Consumer Behavior: Science and Practice. Cengage Learning, Incorporated.

- Madichie N. 2012. Consumer Perception, Tata McGraw-Hill, Noida, India

- Mangold, W. G. and Faulds, D. J. 2009. "Social Media: The New Hybrid Element Of The Promotion Mix". Business Horizons, 52(4), 357-365.

- Marwick, A. Boyd, D. 2011. To See and Be Seen: Celebrity Practice on Twitter. Convergence, 17(2), 139158.

- $\quad$ Singh, S. ve Diamo, S. 2015. Social Media Marketing for Dummies. John Wiley and Sons.

- Taşkın, E. 2009. Pazarlama Esasları, Türkmen Kitapevi, İstanbul.

- Turgut, E. 2016. Sosyal Medya Reklamlarında Tüketici Algılamaları ile Satın Alma Niyeti ve Ağızdan Ağıza İletişim Arasındaki İlişski. Trakya Üniversitesi Sosyal Bilimler Enstitüsü İşletme Anabilim Dalı. Yayınlanmış Yüksek Lisans Tezi. 
- Wang, Y. Sun, S. Lei, W. Toncar, M. 2009. "Examining Beliefs and Attitudes Toward Online Advertising Among Chinese Consumers”. Direct Marketing: An International Journal, 3(1), 52-66.

- Yaylagül, Ş. 2017. "Sosyal Medya Fenomenlerine Bağlanmışlığın Belirlenmesi: Yükseköğretim Öğrencileri Üzerine Bir Uygulama”. Adnan Menderes Üniversitesi Sosyal Bilimler Enstitüsü Dergisi, 4(3), 222-223. 


\title{
Sağlıkta Uluslararası Akreditasyon ve Türkiye'de Sağlıkta Kalite Standartları
}

\section{International Accreditation in Health and Quality Standards in Health in Turkey}

\author{
Dr. Seniha Avcil (Memorial Şişli Hospital, Turkey)
}

\begin{abstract}
Accreditation studies in health started in the USA in the beginning of the 20th century, and in the beginning of the 21 st century, the World Health Organization (WHO) announced that it is necessary to determine the health care standards of member countries and to give importance to accreditation studies. Turkey in 2003, "Health Transformation Program" began apps. Within the scope of this program, "Quality Standards in Health " were determined in 2005. Refurbished versions of the standards set continue today, and the evaluation process according to the determined standards started in 2017 to cover all public and private health institutions. Health tourists; the diversity of health care, quality and prefer to receive health services from Turkey due to different advantages. The international accreditation of the health institution is a remarkable variable that influences the preference of health tourists. In this study, it is aimed to determine the opinions of the health institutions that have international accreditation and international health tourism authorization certificate regarding the comparison of the Quality Standards in Health (SKS) and evaluation process and the international accreditation evaluation process. It was designed in the research screening model and it was found appropriate to use qualitative methods. The research group consists of employees of health institutions that have international health tourism authorization certificate and international accreditation, among the organizations whose Quality Standards in Health (SKS) were evaluated in Istanbul in February 2020. The data were collected face to face by the researcher and recorded in the semistructured interview form.
\end{abstract}

\section{Giriş}

20. yüzyılın sonlarında gelişmiş ve gelişmekte olan ülkeler sağlık sektöründe kalitenin gelişmesine verdikleri önemi artırmışlardır (Montagu, 2003). Sağlık hizmeti sunan kurumların etkili, verimli ve kaliteli olması, yönetim süreci ile ilgili önemli bir performans göstergesi olarak kabul edilmiştir (Tabrizi, vd, 2011). Akreditasyon, sağlık hizmetlerinde kalitenin artırılması ve hizmet kalitesinin bir göstergesi olarak en önemli yöntem ve araçlardan biri olarak kabul edilmiştir (Braithwaite, vd, 2010).

\section{Literatür}

\subsection{Sağlıkta Akreditasyon Kavramı}

Akreditasyon kavramı, tarihsel süreçte geçirdiği evrelere göre farklı standart ve olgular üzerinde yoğunlaşması, farklı bakış açılarının oluşmasına ve birçok tanımının yapılmasına neden olmuştur (Avcı, 2018). Bununla birlikte yaygın olan yaklaşıma göre akreditasyon, kanıta dayanan klinik organizasyon uygulamalarını arttırma yoluna giderek sağlık hizmeti sunan kuruluşların, güvenlik ve kalitelerinin arttırılması amacıyla yapılan müdahalelerin tümü olarak tanımlanmaktadır (Hinchcliff, vd, 2013).

Dünya Sağlık Örgütü, standartlar kullanarak dış kalite değerlendirmesi yapan farklı kuruluşların kullandığı tanımların çakışması nedeniyle akreditasyon çalışmalarını kapsayan bir tanım geliştirmiş ve bunların tümüne birden "external quality assesment" (dış kalite değerlendirmesi) adını vermiştir (Montagu, 2003).

Sağlık hizmetleri alanındaki akreditasyon çalışmalarının, tıbbi uygulamalardaki birliği sağlamak, uygun olmayan bakımları ortadan kaldırmak, maliyetleri düşürmek ve ulusal standartlar oluşturmak gibi amaçları olduğu belirtilmektedir (Viswanathan ve Salmon, 2000). Bu tür standartların genellikle devlet kurumu ile ilişkisi olmayan ve uluslararası bağımsız bir kuruluş tarafından yürütülmesi esastır (Tabrizi, vd, 2011). Montagu akreditasyonu, ideal kalite standartlarına erişmek amacını taşıyan organizasyonları denetleme ve değerlendirme süreci olarak tanımlamaktadır (Montagu, 2003).

Akreditasyon çalışmaları dört temel unsurdan meydana gelmektedir. Bunlar; yazılı ve ilan edilmiş standartlara dayandırılması, değerlendirmelerin profesyonel ekipler tarafından yapılması, akreditasyon sürecinin bağımsız bir kuruluş ya da organ tarafından yürütülmesi, akreditasyon programının sağlık kuruluşunu gelişmeye teşvik etmesi beklenmektedir (Montagu, 2003). Bu dört temel unsur akreditasyon programlarının esasını teşkil etmektedir. Önceden ilan edilmiş ve yazılı hale getirilmiş standartların, profesyonel uzman ekipler tarafından bağımsız bir organizasyon aracılığıyla gelişime teşvik edilerek değerlendirilmesi akreditasyonun özünü oluşturmaktadır (Tapan, vd, 2010). Akreditasyonda sürekli gelişimin teşvik edilmesi akreditasyonun dinamik bir yapıya sahip olmasını sağlamaktadır. 


\subsection{Yazılı ve İlan Edilmiș Standartlar}

Akreditasyon programlarının özü ve esası belirlenmiş ve ilan edilmiş olan standartlardır. Standartlarında sağlaması gereken bazı şartlar bulunmaktadır. Buna göre iyi bir sağlık akreditasyon standartlarını şu özellikleri taşıyor olması gerekmektedir (Karaca, 2014; Scrivens, 1997).

- Standartlar akredite edilmesi talep olunan sağlık kuruluşu ile ilgili olmalıdır.

- İlgili personel ve profesyonel ekipler tarafından anlaşlır olmalıdır,

- Gerçekçi, optimal ve ideal sürede ulaşılabilir hedefler koymalıdır,

- Akredite edilmesi istenen sağlık kuruluşunu sürekli olarak gelişmeye teşvik edecek nitelikte olmalıdır,

- Standartlar ölçülebilir özellikte olmalıdır (Montagu, 2003; Saluvan, 2015)

Akreditasyon programı için belirlenmiş olan standartlar ölçülebilir verilere dayanmalıdır. Zira akredite çalışmaları sonucunda bir değerlendirmeye varılabilmesi için standardın sayısal verilerle ifade edilebiliyor olması gerekmektedir. Aksi halde soyut ve belirsiz değerlendirmeler akredite çalışmalarının konusunu oluşturmayacaktır (Shaw, vd, 2010).

Akreditasyon faaliyetlerinde standartlar belirlenir iken dikkat edilmesi gereken diğer önemli nokta ise standartların rasyonel ve optimum hedeflerden oluşması gerekliliğidir. Kimi zaman gerçeklikten kopuk ve ulaşılması mümkün olmayan hedefler belirlenmesi akredite edilmesi istenen sağlık kuruluşu için imkansız derecede zor hale gelmektedir (Kayral, vd, 2016). Sağlık kuruluşlarının belirlenene hedeflere erişme kapasiteleri farklılık arz etmektedir. Bu nedenle akreditasyon standartları belirlenirken sağlık kuruluşlarının imkan ve düzeyleri iyi tespit edilmeli, hedefler ilgili sağlık kuruluşlarının yakın gelecekte erişebilecekleri seviyelerde olmalıdır. $\mathrm{Bu}$ sayede akreditasyon değerlendirmeleri sağlık kuruluşlarını gelişmeye teşvik edecektir. Aksi halde iyi işleyen bir akredite çalışmasından bahsetmek mümkün olmayacaktır (Shaw, vd, 2010).

\subsection{Akreditasyon Çalış̧malarının Önemi ve Etkileri}

Akreditasyon aracılı̆gıyla benzer diğer kuruluşlar arasında kıyaslama yapılması mümkün hale gelmektedir. Yine benzer şekilde geri bildirim sayesinde sağlık kuruluşları kendilerini geliştirmeye firsat bulabilmektedir. Zira akreditasyon değerlendirmeleri sonucunda sağlık hizmeti veren kuruluşa bir rapor sunulmakta ve eksik yanları ortaya konulmaktadır (Montagu, 2003). Akreditasyon çalışmaları, sağlık kuruluşlarının daha yüksek kalitede hizmet sunabilmeleri ve kendilerini geliştirebilmelerine hizmet etmektedir. Buna göre akreditasyon sayesinde sağlık kurum ve kuruluşları mevcut kalite ve imkanlarını daha ileri düzeye çıkarabilecektir (Akyurt, 2007).

Devlet organından bağımsız olan ve tarafsız bir kuruluş aracılığıyla denetlenen hastaneler müşterilerine daha yüksek kalitede hizmet sunacaktır. Zira bağımsız organizasyonlar tarafından değerlendirmeye alınıyor olmak ilgili sağlık kuruluşunu gelişmeye zorlayacaktır (Karabulut, 2009) Akreditasyon esasında kalitenin bir nevi işaretidir. Dünya üzerinde faaliyet gösteren akreditasyon kuruluşlarının uygulamalarına ve amaçlarına bakıldığında görülecektir ki 'hasta beklentilerini karşılamak', 'kuruluşların performanslarını değerlendirmek' ve sağllk hizmetinin kalitesini arttırmak' akreditasyon çalışmalarının amaçları arasında gözlemlenmektedir (Etöz, 2008; Şencan, 2015).

Sağlık alanında yapılan akreditasyon çalışmalarının sonuçların uygulanan ülke veya bölgeye göre farklılıklar arz etmektedir. Ancak sağlık alanında yapılan akreditasyon uygulamalarının sonuçlarına bakıldığında genel bir benzerlik olduğu gözlemlenmektedir. Buna göre ülke ve uygulamaları değişse dahi akreditasyon çalışmalarından alınan sonuç ve faydalar benzerlik göstermektedir (Türkeli, 2015).

Akreditasyon çalışmalarının sağlık kuruluşlarına sağlayacağı faydaları şu şekilde sıralamak mümkündür (Kömürcü, vd, 2015; Montagu, 2003):

- Akredite olan bir hastane optimum hedeflere ve standartlara erişmeye çalışacağından dolayı hizmet ve organizasyon kalitesi artacaktır,

- Sağlık kuruluşunun marka değerini, tanınırlı̆̆ı ve bilinirliğini arttıracaktır,

- Geri ödeme programlarına katılmayı sağlayacaktır,

- Potansiyel müşteriler için onaylanmış servis sunucu imkanı sağlayacaktır,

- Kimi ülke sınırları içerisinde ve yasal mevzuatına göre fiilen tanınma lisansı sağlayacaktır,

- Ödeyici gruplarından daha yüksek oranlarda geri ödeme elde etmesini sağlayacaktır,

- Rakip sağlık kuruluşlarının seviyeleri hakkında bilgi elde edilmesini sağlayacaktır,

- Sağlık kuruluşları arasında karşılaşıırma ve kıyaslama yapma imkanı sağlayacaktır,

- Hastane yönetiminin ve bütünleşmesi çabalarının geliştirilmesini sağlayacaktır,

- Sağlık hizmetlerini daha etkili ve verimli kılarak oluşan genel maliyeti azaltacaktır,

- Sağlık kuruluşunda görev yapan sağlı personelinin ve diğer çalışanların eğitim ve mesleki gelişimlerini arttırmaya yarayacaktır,

- Sağlık kuruluşunun halk nezdindeki güvenlik algısı ve bakışını olumlu yönde etkileyecektir,

- Sağlık hizmetleri sırasında oluşabilecek olan hastalık, yaralanma ve enfeksiyon risklerini azaltacaktır (Aslanova, 2013; Sarp, 2018). 


\subsection{Sağlık Hizmetlerinde Akreditasyon Çalışmalarının Uluslararası Alanda Gelişimi}

Florence Nightingale, 1860 yılında hastane istatistiklerinin karşılaştırmalara izin verecek şekilde toplaması, toplanan verilerin değerlendirilmesi sağlık kurumları için kalite güvencesinin sağlanmasının başlangıcı olarak kabul edilmektedir (Erdoğan, 2003).

Ernest A. Codman, 1910 yılında Amerika'da ilk defa hasta güvenliği ve hasta kayıtlarının mevcut durumu eleştirilmiş, 1912 yılında Kuzey Amerika Klinik Cerrahlar Klinik Kongresi'nde hasta kayıtları düzenli tutulması sonucunda elde edilecek verilerin, hastanelerin etkililiği ve kalitesi hakkında bilgi vereceği gündeme getirmiştir. Amerikan Cerrah Koleji, 1913 yılında Codman'1, kolejin standardizasyon programını geliştirilmesi için görevlendirmiş, 1915 yılında ise hastane kayıtlarını denetlemiştir. Bu denetleme ilk kalite tanımlaması ve değerlendirilmesi olarak kabul edilir. 1919 yılında ise ilk hastane standartları raporunu sunmuştur. Bu rapor ise, hastanelerde akreditasyonunun başlangıcı olarak kabul edilmektedir (Facs, 1919; Erdoğan, 2003; Çavuş ve Gemici, 2013; Korkmaz, 2018). "The Minimum Standards For Hospital” adıyla yayınlanan bu raporda sağlık hizmetlerinin etkili ve verimli olması için asgari yapılması gerekenler; hasta kayıtlarının düzenli tutulması, doktorların düzenli toplantı yapması ve klinik deneyimlerini paylaşmaları gerektiği belirtilmiştir (Facs, 1919).

1951 yilında Hastanelerin Akreditasyonu Ortak Komisyonu (Joint Commission on Accreditation of Hospitals) (JCAH), American College of Physicians, The American Medical Association, The American Hospital Association, ve Canadian Medical Association kuruluşlarının katılımı ile oluşturulmuştur. 1988 yılında ise bütün sağlık kuruluşlarını kapsayacak şekilde genişletilmiş ve adı Joint Commission on Accreditation of Healthcare Organizations (JCAHO) olarak değiştirilmiştir. 2007 yılında ise adı kısaltılarak The Joint Commission (JCI) olarak anılmaya başlanmıştır (Jointcommission, 2016; Erdoğan, 2003; Akdu, 2009; Önal, 2015).

ABD'den sonra Kanada ve Avustralya'da akreditasyon çalışmalarına başlamış olup, diğer ülkelerdeki sağlık kurumlarında akreditasyon programlarının başlamasına öncülük etmişlerdir (Scrivens, 1997). Sağlık kurumlarında akreditasyon başlangıçta hastane odaklı, gönüllük esasına dayalı yürütülmüş, akredite olmak isteyen kurumlar faaliyetlerinin kendileri finanse etmiştir. 1960’lı yıllarda yaşam güvenliği, tıbbi kadro standartları ve kalite güvencesi, 1970'li yıllarda spesifik tanı ve prosedürler, 1980'li yıllarda maliyet kontrolü ve Toplam Kalite Yönetimi (TKY) felsefesine göre akreditasyon standartları şekillenmiştir (Scrivens, 1997; Erdoğan, 2003). TKY felsefesinde, hizmetlerden yararlanan kişilerin, aldıkları hizmetten memnun olmalarına odaklanmaktadır. Sağlık kurumlarında hastaların beklentilerinin ve haklarının tanımlanması, bütün gereksinimlerin (bilgi, insan kaynakları, yöntem, cihaz, malzeme, karar), organizasyon yapısının ve işleyişin doğru belirlenmesi esastır (Arısan ve Devebakan, 2016). TKY ile sağlık sektöründe hizmetler ve kalite, çıktı odaklı hale gelmiştir. Bu nedenle akreditasyon programları da sağlık hizmetlerinin organizasyonlarından çok çıktıları üzerinde yoğunlaşmıştır. 1986 yılında JCAHO, gelecek yıllar için sağlık hizmetlerinin, çıktı kalitesi üzerinden yapılacağını, bu nedenle denetim kriterlerinin ve ilkelerinin çıktılar üstünde yapılacak şekilde belirleneceğini ilan etmiştir (Scrivens, 1997). 1990'l1 yıllara gelindiğinde yasal düzenleyicinin gücü elinde tutabileceği sistemlerin oluşması, kurum, kuruluş ve gerçek kişiler için hesap verilebilirlik açısından akreditasyon programının geliştirilmesi ön plana çıkmıştır. 2000'li yıllarda Dünya Sağlık Örgütü (WHO) üye ülkelerin; sağlık politikaları belirlemelerini, sağlık hizmetleri için standartlar geliştirmelerini ve akreditasyon çalışmalarına önem vermeleri gerektiğini açıklamıştır (Karabulut, 2009).

Akreditasyon faaliyetleri kimi ülkelerde devlet organı tarafından zorunlu tutulur iken kimi ülke uygulamalarında gönüllülük esasına dayalı olarak yürütülmektedir. Bu durumda sağlık kuruluşlarını akredite olmaya iten teşvikler ve birtakım yaptırımlar devreye girmektedir. Polonya gönüllülük esasının kabul edildiği ülkelerden bir tanesidir. Ülke uygulamasına bakıldığında hastanelere akredite olmaları için herhangi bir zorunluluk şart koşulmamıştır. Ancak akredite olan sağlık kuruluşları genel bütçeden \% 3 ve \% 5 arasında daha fazla ödenek almışlardır. Bu şekilde hastaneler akredite olmaya teşvik edilmiştir (Shaw, vd, 2010). Sağlık kuruluşlarının akredite olmaları için teşvik uygulamasının görüldüğü diğer bir ülke Avustralya'dır. Buna göre Avustralya'da aile hekimleri için herhangi bir akredite şartı aranmamaktadır. Ancak akredite olan aile hekimlerine hükümet tarafından ikramiyeler verilmekte ve teşvik ödemeleri yapılmaktadır. Bu sayede Avustralya'da bulunan aile hekimlerinin yarısından fazlası akredite olmaktadır (Greenfield, vd, 2014).

Sağlık hizmetlerinin standartlarının belirlenmesi ve akreditasyon programları, günümüze gelince kadar farklı evrelerden geçmiştir. Sağlık hizmetlerinin geliştirilmesi için akreditasyon çalışmaları her dönem devam etmiştir (Shaw, vd, 2010). Günümüzde de sağlık kurumlarında akreditasyon çalışmaları gelişen bilim ve teknoloji ile birlikte değişmeye ve gelişmeye devam etmektedir.

\subsection{Türkiye'de Sağlık Hizmetleri ve Sağlık Standartlarının Gelişimi}

Ülkemizde Sağlık Bakanlığı 1920 yılında kurulmuş ve 1938 yılına kadar sağlık hizmetleri ile ilgili mevzuat çalışmalarına ağırlık verilmiş, halkın sürekli hizmet alması ve refahı hedeflenmiştir. Sağlık sisteminin örgütlenmesi ile ilgili bilinçli adımlar atılmıştır (Şahar, 2015). 1938-1960 tarihleri arasında bulaşıcı hastalıklar ile mücadele ve koruyucu sağlık hizmetleri önem kazanmıştır (Beştaş, 2006). 1945 yılında hastaneler belediye ve özel idarelerden alınarak devlet kontrolüne verilmiştir. 1946 yılında Birinci On Yıllık Sağlık Planı yapılması, yerel kurum ve kuruluşlar ile halk desteği ile sağlık bankası kurma girişimleri başlamış, Sosyal Sigortalar Kurumu (SSK) 
kurulmuştur (Sülkü, 2011). 1952 yılında çocuk sağlı̆̆ uluslararası kuruluşlardan destek alınarak, "Ana Çocuk Să̆lı̆̆ Tekamül Merkezi” açılmıştır. Çocuk ölümlerini önleme ve nüfus artışını destekleyecek politikaların uygulanmasına geçilmiştir (Akdağ, 2008). 1954 yılında SSK ve iktisadi devlet kuruluşları hastane işletmeye başlamışlardır (Tatar, 2011). 1961-1980 tarihleri arasında sosyalleşme anlayışı hakim olmuştur. Sağlık hizmetlerinin, ücretsiz, sürekli ve refahı yükseltmek amacıyla verilmesi amaçlanmıştır. 1980-2000 tarihleri arasında çeşitli reformlar ve dönüşüm programları ile sağlık hizmetlerinin yeniden yapılandırılma sürecini içermektedir. Bu dönemde halkın sunulan hizmetlerden eşit yararlanmasını sağlayacak yöntemler uygulanmaya çalışılmıştır. 1990'lı yıllarda yürütülen reform çalışmaları teorik çalışmalar olmasına rağmen, uygulamada karşılık bulması pek mümkün olmamıştır. 2000 yılında ise bilginin ve teknolojinin gelişimi küreselleşmeyi hızlandırmış ve ülkelerin belli standartlarda hizmet sunarak kalitenin ve verimliliğin artması hedeflenmiştir (Şahar, 2015).

2003 yılında sağlıkta dönüşüm kapsamında çalışmalar başlatılmış olup, 2005 yılında ilk kalite standartları belirlenmiştir. Belirlenen standartlar belirli aralıklarla görüş ve öneriler alınarak güncellenmeye devam etmektedir. 2015 yılında sağlık hizmetlerinde akrediteden sorumlu ve gerekli anlaşmaları yapma yetkisi verilen kamu tüzel kişiliğine sahip, özerk bir kuruluş olarak Türkiye Sağlık Hizmetleri Kalite ve Akreditasyon Enstitüsü (TÜSEB) açılmıştır. Türkiye Sağlıkta Kalite Sistemi (SKS); sağlık hizmet kalitesi ve klinik kalite olarak iki kategoride yapılmakta olup, sağlıta kalite değerlendirmeleri ile sağlık hizmet kalitesine karar verilmektedir. SKS değerlendirmeleri öz değerlendirme ile başlamış olup, 2010 yılında ülke genelinde tüm sağlık kurum ve kuruluşlarını kapsayacak şekilde yapılmış, 2017 yılından itibaren de Sağlık Bakanlığı tarafından yetkilendirilen SKS değerlendiricileri tarafından özel ve kamu tüm sağlık kuruluşlarında yapılmaktadır (Kalite.saglik, 2020). Her yıl yapılan SKS değerlendirme tarihleri Bakanlıkça değerlendirme öncesi ilan edilmekte ve SKS değerlendirme rehberine uygun yapılan değerlendirme sonucunda, 95 ve üstü puan alan kurum ve kuruluşlar öz değerlendirme sonuçlarını Bakanlığa takip eden yılın ilk yarısında iletirlerse o yıl değerlendirme yapılmaz ve mevcut kalite puanları geçerli olmaktadır. Kurum ve kuruluşun talep etmesi durumunda yeniden değerlendirme de yapılabilmektedir.

Değerlendirilen kriterlerin standartlara uygunluk değerlendirmesi belirlenen ölçütlerin karşılanma düzeyine karar verilerek yapılmaktadır. Ölçütler; Karşılanıyor, Kısmen Karşılanıyor, Karşılanmıyor olmak üzere üç kategoride değerlendirilir. Ölçüt ile ilgili yanlışlık ya da eksiklik olması durumunda uygunsuzluk tanılama kriterlerine (Sıkılık, etki alanı ve risk boyutu) göre incelenir. Standardın her bir ölçütünün karşılanma düzeyine göre standardın karşılanma düzeyi yine üç kategorili olarak sonuçlandırılır (Beylik, 2018).

Türkiye'de, sağlık sisteminin uluslararası kimliğe sahip olması için uluslararası ve ulusal kurum ve kuruluşlar ile işbirliği yaparak standartlar geliştirilmekte, sağlık sisteminin akreditasyon için uygun organizasyon yapısına ulaşmasına yönelik faaliyetleri devam etmektedir. Bu kapsamda yürürlükte olan kanun ve yönetmelikler incelendiğinde;

Ülkemizde sağlıkta uluslararası rekabet için "Uluslararası Să̆lık Turizmi ve Turistin Sağlı̆̆ Hakkında Yönetmelik” Sağlık Bakanlığı tarafından hazırlanan yönetmelik 13 Temmuz 2017 tarihinde 30123 sayılı Resmi Gazetede yayınlanmış olup amacı; "Uluslararası să̆lık turizmi ve turistin sağllğ kapsamında uluslararası sunulan sağlık hizmetlerinin asgari hizmet sunum standartlarının belirlenmesi, uluslararası sağlık turizmi hizmetlerinde faaliyet yürütecek sağllk kuruluşları ile arası kuruluşların yetkilendirilmesi ve bu faaliyetlerin denetlenmesi" belirlenmiştir (1.md).

Yönetmeliğin dayanakları incelendiğinde 1987 tarih ve 19461 sayılı Sağlık Hizmetleri Temel Kanunu'na 11 Ekim 2011 tarih 663/58. Md KHK ile eklenen "Bütün kamu ve özel sağllk kuruluşlarının tesis, hizmet, personel, kıstaslarını belirlemeye, sağlık kurum ve kuruluşlarını sınıflandırmaya ve sınıflarının değiştirilmesine, sağlık kuruluşlarının amaca uygun olarak teşkilatlanmalarına, sağlık hizmet zinciri oluşturulmasına, hizmet içi eğitim usul ve esasları ile sağllk kurum ve kuruluşlarının koordineli çalışma ve hizmet standartlarının tespiti ve denetimi ile bu Kanunla ilgili diğer hususlar Să̆llk ve Sosyal Yardım Bakanlı̆̆ınca, çıkarllacak yönetmelikle tespit edilir." (9.md/c).

Kanuna 02 Ocak 2014 tarih ve 6514/46md. ile eklenen “....Bakanlıkça belirlenen kayıtları uygun şekilde tutmayan veya bildirim zorunluluğunu yerine getirmeyen sağlık kurum ve kuruluşlarl iki defa uyarllır. Uyarıya uymayanlara bir önceki aya ait brüt hizmet gelirinin yüzde biri kadar idari para cezası verilir.” (Ek 11.md.) maddesi ile kalite standartlarının denetlenmesine yönelik kayıtların tutulma standartlarına uyma zorunluluğu getirildiği görülmektedir.

663 sayılı Sağlık Bakanlığına ve Bağlı Kuruluşlarının Teşkilat ve Görevleri Hakkında KHK'nın “Her türlü koruyucu, teşhis, tedavi ve rehabilite edici sağlık hizmetlerini planlamak, teknik düzenleme yapmak, standartları belirlemek ve bu hizmetler ile sunucularını sınıflandırmak, bununla ilgili iş ve işlemleri yaptırmak."(8.md/a), "Sağlık turizmi uygulamalarının geliştirilmesine yönelik düzenlemeler yapmak, ilgili kurumlarla koordinasyon sağlamak." (8.md/i), "Bakanlık ve bağlı kuruluşlar görev, yetki ve sorumluluk alanına giren ve önceden kanunla düzenlenmiş konularda idarî düzenlemeler yapabilir.” (40.md). Buna göre sağlıkta uluslararasılaşma ile ilgili yasal düzenlemelerin 2011 yılından itibaren başladığı görülmektedir. 
Uluslararası sağlık turizminin verilmesi için sağlık tesis yetkinlik kriterlerinin belirlenmesi aynı yönetmelikte belirtilmiştir. Buna göre, SKS değerlendirilmesinde asgari 85 puan alma şartı getirilmiştir. Standartları ve kalite göstergeleri belirlenmeyen kuruluşlar muaf tutulmuş, standart seti ve rehberi yayınlanan kuruluşlara ise belirlenen kriterleri sağlamaları için 6 ay süre verilmiştir. Uluslararası hasta kabul edebilecek kuruluşlar sağlık sistemi otomasyon sistemindeki yabancı hasta modülü üzerinden yapmaktadır (Ek-1.md). SKS değerlendirmelerinde yetkinlik kriterlerine uymayan kuruluşlara, kriterlere uymamanın tespiti durumunda 1.tespit, 2 . Tespit ve 3 . Tespit durumunda sırasıyla; ek süre verme, para cezası verme, uluslararası sağlık turizmi faaliyetinin süreli durdurulması, "Uluslararası Sağlık Yetki Belgesi”nin iptali, faaliyetlerinin durdurulmasına kadar giden aşamalı yaptırımlar uygulanmaktadır. Buna göre Türkiye'de uluslararası sağlık hizmeti vermek isteyen özel sağlık kuruluşlarının, SKS puanın asgari 85 olmak durumundadır.

\section{Araştırmanın Yöntemi}

\subsection{Araştırmanın Metodu ve Çalışma Grubu}

$\mathrm{Bu}$ araştırma, uluslararası akreditasyon ile Sağlıkta Kalite Standartları (SKS) değerlendirme sürecine ilişkin görüşlerin belirlenmesi amacıyla yapılmıştır. Araştırma tarama modelinde tasarlanmış, nitel yöntemlerden görüşme tekniği ile veriler toplanmıştır.

Bu kapsamda İstanbul ilinde Şubat 2020 tarihinde SKS değerlendirmesi yapılan sağlık kuruluşları arasından uluslararası akreditasyonu ve "Uluslararası Sağlık Yetki Belgesi” olan sağlık kuruluşlarına araştırma hakkında bilgi verilmiş, araştırmaya katılmayı kabul eden sağlık kuruluşlarının "Kalite Geliştirme Birimi” nin çalışanlarından gönüllü olanlar ile görüşme yapılmıştır. Görüşmelerde araştırmacı tarafından hazırlanan yarı yapılandırılmış görüşme formu kullanılmıştır. Görüşme formunda 5 madde katılımcıların demografik bilgileri ile, 3 madde sağlık kuruluşu ile, 11 madde ise SKS ve uluslararası akredite süreci ile ilgilidir.

Görüşmeler Mart 2020 tarihinde gerçekleştirilmiştir. Görüşme sürecinde ses kaydı alınmasına izin veren katılımcıların ses kaydı alınmış, ses kaydına izin vermeyen katılımcılar da ise görüşme esnasında forma işlenmiştir. Ses kaydına alınan görüşmeler araştırmacı tarafından yazılı hale getirilmiştir. Görüşmeleri yorumlamak için içerik analizi yapılmıştır.

Araştırma 2 sağlık kuruluşundan 8 gönüllü ile yapılmıştır. Katılımcıların yaş aralığ1 39-55 yaş aralığında, mesleki kıdemleri 17- 30 yıl aralığında değişmektedir.

\subsection{Araştırmanın Varsayımları ve Sınırlılıkları}

$\mathrm{Bu}$ çalışmada veri toplama aracı olarak kullanılan görüşme formunun çalışmanın amacına hizmet ettiği, katılımcıların görüşme formuna mevcut durum ile ilgili samimi görüşlerini bildirdikleri varsayılmaktadır.

Çalışma görüşme formu soruları ve katılımcıların verdikleri cevaplarla sınırlıdır

\section{Bulgular}

Sağlık kuruluşlarının kalite geliştirme biriminde çoğunlukla doktor ve hemşireler görev almaktadır, sadece bir kurumun kalite geliştirme biriminde endüstri mühendisi, sağlık kurumları yönetimi ve çevre mühendisi de bulunduğu belirtilmiştir. Birimde görevli sayısı 3-6 arasında değişmektedir. Sağlık kuruluşları uluslararası akreditasyonlarında JCI 2021-2022, LEED 2023 tarihlerine kadar akrediteleri devam etmektedir. Katılımcıların kurumları, SKS değerlendirmesine 3 kez katılmışlardır.

Uluslararası akredite süreci için yapılan hazırlıkları incelendiğinde; akreditasyon için gerekli standartlar ile mevcut durumun karşılaştırılmasının yapılarak eksiklerin giderildiği, çalışanların eğitimlerinin verildiği, performans değerlendirme ve izleme sürecinin yürütüldüğü, değerlendirme sonuçlarına göre düzenlemelere devam edildiği belirlenmiştir. Katılımcı görüşlerinden örnekler aşağıda verilmiştir.

"Standart eğitimler, standart çalışma gruplarının oluşturulması, standartları karşılamak için sistemlerin, dökümanların ve formların oluşturulması, yeni sistemler için çalışanların eğitimlerinin verilmesi, performans izlemesi, süreç denetimi ve iyileştirmesi” (Kadın, Yönetici, 53).

"Standartların gözden geçirilmesi, oluşturulan yeni standartların belirlenmesi, uygulanması ve çalışanların eğitim ve adaptasyonu” (Erkek, Doktor, 48).

"Akreditasyon öncesi dönemde hızlı bir şekilde geriye dönük bütün hasta dosyaları kontrol edilip, eksikler tamamlanmıştı. Alanların tertip düzeni JCI standartlarına göre ayarlandı.” (Kadın, Hemşire, 39).

SKS değerlendirme süreci için yapılan hazırlıklar ile ilgili uluslararası akreditasyon süreci ile benzer hazırlıkların yapıldığı belirlenmiştir. Katılımcı görüşlerinden örnekler aşağıda verilmiştir.

"JCI akredite bir kurum olduğumuz için akreditasyon standartlart ile benzer standartlar. Standart kapsamında bir fark olmamakla birlikte, değerlendirme süreci çalışanlar açısından hazırlıklı olmayı gerektiriyor ve daha çok süreçlere katılmalarını săglıyor.” (Kadın, Doktor, 49).

“SKS, JCI standartları ile örtüştüğü için hemen hemen aynı hazırlıklar yapıllyor.” (Kadın, Hemşire, 46). 
Uluslararası akredite sürecinin kuruma katkısı ile ilgili, hasta güvenliği ve bakım kalitesini artırdığı, çalışanların gelişimine, hizmet kalitesinin artmasında önemli bir rol üstlendiği belirlenmiştir. Katılımcı görüşlerinden örnekler aşağıda verilmiştir.

“Hasta güvenliği ve bakım kalitesinde artış” (Erkek, Yönetici, 55).

"Uluslararası gelişmelerin takip edilmesi, uygulanması, hasta güvenliği ve iş geliştirme, çalışan ĕgitimine katkısı ve kurumun verdiği hizmet kalitesi açısından büyün avantajlar sağlamaktadır” (Kadın, Hemşire, 46).

"Hasta bakım sürecini daha da kaliteli hale getirilmiştir. Bunun yanında hasta ve çalışan güvenliğini esas alan uygulamaları vardır. Bu uygulamalar ile kuruma büyük katkısı olmuştur.” (Erkek, Yönetici, 50).

SKS değerlendirme sürecinin kuruma katkısı ile ilgili özellikle çalışanların hazırlık olmasını gerektirmesi, sürece katılımın artmasına ve çalışan yeterliliğini artmasına katkı sağladı belirlenmiştir. Katılımcı görüşlerinden örnekler aşağıda verilmişstir.

"Çalışanların maksimum seviyede hazırlıklı olması gerektiği için verilen eğitim güncellemeleri ile eğitim açısından çalışanların yeterliliğini arttırmaktadır.” (Erkek, Uzman, 44).

"JCI akredite bir kurum olduğumuz için akreditasyon standartları ile benzer standartlar. Standart kapsamında bir fark olmamakla birlikte, değerlendirme süreci çalışanlar açısından hazırlıklı olmayı gerektiriyor ve daha çok süreçlere katılmalarını sağlıyor.” (Kadın, Yönetici, 53).

Uluslararası akredite sürecinde karşılaşılan güçlükler ile ilgili, çalışanların iyileştirmelere uyumunda zorluk, eğitimlerin öneminin algılanmaması güçlük olarak belirlenmiştir. Katılımcı görüşlerinden örnekler aşağıda verilmiştir.

"Güncellenen iyileştirmelerle ilgili çalışanların tamamının adaptasyonunda zorluk ve verilmek istenen eğitimin öneminin tam olarak anlaşılmaması.” (Kadın, Hemşire, 39).

"Tüm çalışanların katılım ve uyumunda güçlük yaşanması, bazı standartların öneminin yeteri kadar anlaşılamaması.” (Erkek, Uzman, 44).

“Özel hastanelerde biraz daha fazla personel olmasl gerektiğini düşünüyorum.” (Erkek, Yönetici, 50).

SKS değerlendirme sürecinde karşılaşılan güçlükler ile ilgili esneklik olmaması belirlenmiştir. Katılımcılar esnekliğin gerekçeleri olarak hastanelerin belirli alanlarda özelleşmesini, özel uygulamalarını ve çalışanların yeni olmasından kaynaklanan uyum sorunlarını belirtmişlerdir. Katılımcı görüşlerinden örnekler aşağıda verilmiştir.

“Her hastanenin özelleştiği çalışma alanları olabiliyor ,bu tip durumlarda daha toleranslı olabilir.” (Erkek, Doktor, 48).

“Kuruma özel bazı uygulamalarda esneklik sağlamıyor.” (Erkek, Yönetici, 50).

"Ĕ̈itimlerin oluşturulmasında çalışanların adaptasyonunda güçlükler yaşanabilmekte, çalışan sirkülasyonunda çalışanların işten ayrılmaları nedeniyle bazen sil baştan her şey yeni baştan güncellenerek çalışanlara öğretilmeye çalışıldı̆̆ından zaman ve adaptasyon açısından güçlükler yaşanabilmekte.” (Erkek, Yönetici, 55).

Uluslararası akredite sürecinde görev alan kişilerin yeterlikleri ile ilgili profesyonel, yeterlilikleri yüksek ve deneyimli değerlendiricilerin görev aldıklarını belirtmiş̧lerdir. Katılımcı görüşlerinden örnekler aşağıda verilmişstir.

“Alanında yetkin ve deneyimli kişilerle çalışmaktayız.” (Kadın, Yönetici, 53).

“Değerlendiriciler oldukça profesyonel ve işe hakimler.” (Erkek, Doktor, 48).

"Sıkıntı yaşamadım, iletişim dili İngilizce olduğu için problem olabilirdi.” (Kadın, Hemşire, 46).

SKS değerlendirme sürecinde görev alan kişilerin yeterlikleri ile ilgili üç SKS değerlendirmesini dikkate süreç ilerledikçe yetkinliklerinin artığını belirtmişlerdir. Katılımcı görüşlerinden örnekler aşağıda verilmiştir.

"Sürecin başında değerlendirme ekibi yetkin değildi fakat zaman içinde yetkinlik ve deneyimleri oldukça arttı." (Erkek, Yönetici, 55).

“Her değerlendirme de gelen ekip bir önceki ekipten daha yetkin oluyor.” (Kadın, Doktor, 49).

"Illk SKS denetiminde gelen denetçi, maddeleri çok iyi bilmediği içi kendimi anlatmakta sıkıntı yaşamıştık. " (Kadın, Hemşire, 46).

Uluslararası akreditasyonlar ve SKS değerlendirme sürecinin benzer biçimde gerçekleştiği, SKS Türkiye’ye özel standartlar oluştururken, uluslararası akreditasyonların ülkeye özgü mevzuatlar ile ilgili düzenlemelere karışmadığı belirtilmiştir. Katılımcı görüşlerinden örnekler aşağıda verilmiştir.

“Değerlendirme süreci benzer şekilde gerçekleştiriliyor.” (Erkek, Uzman, 44).

“Uluslararası Akreditasyonlar ile SKS değerlendirmesi birbirine çok benzer.” (Erkek, Yönetici, 50).

"SKS Türkiye'ye özel standartlar oluşturmakta, Uluslararası akreditasyonlar ise standart uygulamaları ülkelerin kendi yönetmeliklerine göre uygulamalarına olanak sağlamaktadır.” (Kadın, Yönetici, 53). 
Katılımcıların önerileri incelendiğinde çalışan eğitimine önem verilmesi gerektiği, eğitim kazanımlarının uygulamaya yansımasının ve sürekliliğinin önemli olduğu, ayrıca değerlendiricilerin alanda eğitim almış olmasının ve yeterliğin olmasına dikkat çekildiği belirlenmiştir. Katılımcı görüşlerinden örnekler aşağıda verilmiştir.

"Standartların gerçekten ne istediği ve yararlarının anlaşılarak tüm kurumlar, çalışanlar tarafindan bilinçli olarak uygulanması için çalı̧̧anların eğitimi önemli. Yetkin çalışanlar, okullardan mezun olmalı." (Kadın, Doktor, 49).

"Eğitim ve standartların çok iyi bir şekilde ne amaçla yapıldı̆̆ çallşanlara uygulanmak üzere benimsetilip eğitimleri verilmeli, yalnızca denetim zamanı değil tüm hizmet zamanlarında bu standartlar hasta güvenliği ve iş akışı kalitesi açısından çalışanlar tarafindan uygulanmalıdır. Bu alanda görev alan uzmanların, gerçekten bu eğitimi almış, yetkin uzmanlar tarafindan yapılması gereklidir." (Erkek, Uzman, 44).

\section{Sonuç}

Uluslararası akreditasyon ile SKS değerlendirme sürecine ilişkin görüşlerin belirlenmesi amacıyla yapılan araştırma sonucunda; uluslararası akreditasyonlardan JCI akreditasyonu ile SKS standartlarının ve değerlendirme sürecinin benzerlik gösterdiği, bu nedenle hazırlık sürecinde farklılık olmadığı, uluslararası akreditasyonlarda ulusal mevzuat boşluğunun olduğu, SKS değerlendirme sürecinin uygulanması ile sağlık kuruluşlarının ulusal mevzuat açısından da standartlara uygunluğunun denetlenmeye başlandığı belirlenmiştir. Uysal (2018), SKS'yi uluslararası gelişmeler ile birlikte ülkenin sağlık sisteminin önceliklerini ve yapısını bir bütün olarak değerlendirdiğini belirtmiştir.

SKS değerlendirme sürecinde, çalışanların katılımının arttığı ve yeterliklerinin gelişmesine katkı sağladığının düşünüldüğü belirlenmiştir. Uluslararası akreditasyonların gönüllük esasına dayalı olması, SKS'nin ise zorunlu olmasının çalışanların yeterliklerini geliştirmesine ve değerlendirme sürecine katılımına etkisi olduğu düşünülmektedir.

Uluslararası akreditasyon sürecinde karşılaşılan güçlükler çalışanların sürecin önemini içselleştirmesinde ve uyumu ile ilgili iken, SKS değerlendirmelerinde karşılaşılan güçlüklerin esneklik olmamasından ve insan kaynaklarının değişiminden olduğu belirlenmiştir. (Shaw, vd, 2010)'a göre kurumların mevcut durumlarına dikkat edilerek sürecin yönetilmesi önemlidir.

Katılımcılar uluslararası değerlendiricileri alanında yeterliği olan ve deneyimli olarak tanımlarken, SKS değerlendiricilerinin geçen süreçte yeterliklerini geliştirmeye devam ettiklerini belirtmişlerdir. Ayrıca katılımcı önerileri incelendiğinde değerlendiricilerin alan eğitimi almış ve yeterliği olan kişiler olmasının, standartların amacının, gerekçesinin anlaşılır ve uygulanabilir olması için eğitimlere önem verilmesi gerektiği belirtilmiştir.

Avc1l (2019a) JCI akreditasyonu olan özel hastanelerden, Avc1l (2019b), devlet hastanelerinden ve Avc1l (2020) üniversite hastanelerinden hizmet alan hasta ve hasta yakınları ile yaptığı çalışmalarda, hastanelerden hizmet alanların beklentilerinin karşılanmadığını belirtmiştir. Bu çalışmada, kalite geliştirme birimindeki görevliler uluslararası akreditasyon ile SKS değerlendirme sürecini, hizmet kalitesinin ve çalışan yeterliklerinin artmasında önemli görmektedir. Sağlık kurumlarının hizmet kalitesinin artması, teknolojik ve bilimsel gelişmelerin etkisi ile birlikte, hasta ve hasta yakınlarının beklentilerini etkilendiği, hizmet alanların beklentilerindeki değişimlerin ise hizmet kalitesinin sürekli gelişmesini sağlamaya yardımcı olduğu düşünülmektedir.

$\mathrm{Bu}$ çalışmadan elde edilen verilere göre, Türkiye'de SKS'nin belirlenmesi ve değerlendirilmesi, uluslararası akreditasyon sürecinde sağlanamayan ulusal mevzuata uygunluk değerlendirilmesinin yapılmasına katkı sağlamış, çalışanların yeterliklerini geliştirmeye ve katılımlarını artırmaya katkı sağladığını söyleyebiliriz. SKS değerlendirme sürecinde standartların gerekçesi, amacı ve uygulamasına yönelik eğitimlere önem verilmesi, değerlendiricilerin alan eğitimi almış, yeterlikleri olan kişilerden seçilmesinin önemli olduğu, ayrıca özel hastanelerin uzmanlaşma ve farklı uygulamaları ile ilgili gerekli değişikliklere gidilerek rekabet gücünün olumsuz etkilenmemesi sağlanmalıdır.

SKS ile ilgili yapılacak akademik çalışmalarda:

- SKS değerlendiricilerinin seçimi, eğitimi ve sürece ilişkin görüşlerinin incelenmesi,

- Özel sağllk kuruluşlarının rekabet gücünü olumlu ve olumsuz etkileyen, SKS boyutlarının belirlenmesi,

- SKS değerlendirmesi yüksek olan sağlık kuruluşlarının hizmet kalitesinin belirlenmesi,

Çalışmalarının SKS değerlendirme sürecine ve alanyazına katkı sağlayacağı düşünülmektedir.

\section{Kaynakça}

- Akdağ, R. 2008. Türkiye Sağlıkta Dönüşüm Programı İlerleme Raporu, https://sbu.saglik.gov.tr/Ekutuphane/kitaplar/turkiyeSDP.pdf Erişim Tarihi: 11.02.2020.

- Akdu, S.A. 2009. Sağlık Turizmi Kapsamında Medikal Turizm ve Türkiye'deki Uygulamalar Üzerine Bir Araştırma: İstanbul ve Ankara Örneği, Yayınlanmamış Yüksek Lisans Tezi, Gazi Üniversitesi, Eğitim Bilimleri Enstitüsü, Ankara. 
- Akyurt, N. 2007. Hastanelerde Akreditasyon Standartları: İstanbul'daki Özel Hastanelerin Radyoloji Yöneticilerinin Standartları Ne Ölçüde Yerine Getirildiği Konusundaki Görüşlerine İliş̧kin Bir Araştırma. Yayınlanmamış Doktora Tezi. İstanbul Üniversitesi, Sosyal Bilimler Enstitüsü, İstanbul.

- Arısan, Y. \& Devebakan, N. 2016. "Sağlık İşletmelerinde Çalışanların Sunulan Hizmetlere Yönelik Kalite Algısı: İzmir'de Bir Devlet Hastanesinde Araştırma.” Atatürk Üniversitesi İktisadi ve İdari Bilimler Dergisi, 30(3), pp.507-525.

- Aslanova, K. 2013. “Türkiye’de Sağl1k Turizmi ve Sağlık turizmi Hukuku.” Avrasya Uluslararası Araştırmalar Dergisi, 2(3), pp.129-145.

- Avcı, K. 2018. "Sağlık Hizmetlerinde kalite İyileştirme ve Türkiye Sağlık Hizmetleri Kalite ve Akreditasyon Enstitüsü." Sağllkta Kalite ve Akreditasyon Dergisi, 10(1), pp.1-5.

- Avc1l, S. 2019a, Türkiye’deki JCI Akreditasyonuna Sahip Özel Hastanelerin Hizmet Performansı, Yayınlanmamış Doktora Tezi, Beykent Üniversitesi Sosyal Bilimler Enstitüsü, İstanbul.

- Avc1l, S. 2019b, "Devlet Hastanelerinin Hizmet Performans1.” International Conference On Eurasian Economies 2019, 11-13 June, Famagusta, pp. 302-311.

- Avc1l, S. 2020c, “İstanbul'daki JCI Akreditasyonuna Sahip Özel Hastanelerin Hizmet Kalitesi.” Yönetim Bilimleri Dergisi, 18(36), pp.309-338.

- Beştaş, İ. 2006. “Sözlü Tarihin Tanıklığında Cumhuriyet Döneminde Buldan'da Verem Gerçeği ve Veremle Mücadele.” Buldan Sempozyumu Bildirileri (23-24 Kasım), pp.199-213.

- $\quad$ Braithwaite J, Greenfield D, Westbrook J, P. M., \& Westbrook M, G. R. 2010. "Health service accreditation as a predictor of clinical and organisational performance: a blinded, random, stratified study." Quality Safety Health Care, 19(1), pp.14-21.

- Çavuş, M. F., \& Gemici, E. 2013. "Sağlık Sektöründe Toplam Kalite Yönetimi.” Akademik Sosyal Araştırmalar Dergisi, 1(1), p.238-257.

- Erdoğan, Ö. N. 2003. "Sağlık Hizmetlerinde Akreditasyon Standartları.” Hacettepe Üniversitesi Eczacılık Fakültesi Dergisi, 23(2), pp.95-107.

- $\quad$ Etöz, S. D. 2008. Sağlık Hizmetlerinde Kalite Belgelendirme Sistemleri ve Akreditasyon. Yayınlanmamış Yüksek Lisans Tezi. Süleyman Demirel Üniversitesi, Sosyal Bilimler Enstitüsü, Isparta.

- Facs. 1919. The 1919 "Minimum Standard" document. https://www.facs.org/aboutacs/archives/pasthighlights/minimumhighlight Erişim Tarihi: 18.12.2019.

- Greenfield D, Civil M, Donnison A, H. A., \& Hinchcliff R, W. J. 2014. "A mechanism for revising accreditation standards: a study of the process, resources required and evaluation outcomes." BMC Health Services Research, 14(571), pp.2-6.

- Hinchcliff R, Greenfield D, Westbrook J, P. M., \& Mumford V, B. J. 2013. "Stakeholder perspectives on implementing accreditation programs: a qualitative study of enabling factors." BMC Health Services Research, 13(437), pp.2-9.

- Jointcommission. 2016. The Joint Commission: Over a century of quality and safety. https://www.jointcommission.org/assets/1/6/TJC-history-timeline_through_20161.PDF Erişim Tarihi: 22.12.2019.

- Kalite.saglik, 2020. Türkiye Sağlıkta Kalite Sistemi. https://kalite.saglik.gov.tr/TR,8785/turkiye-sagliktakalite-sistemi.html Erişim Tarihi: 16.02.2020.

- Karabulut, F. 2009. Sağlık İşletmelerinde Kalite ve Akreditasyon ISO/IEC 15189:2003 Uygulaması. Yayınlanmamış Yüksek Lisans Tezi, Dokuz Eylül Üniversitesi, Sosyal Bilimler Enstitüsü, İzmir.

- Karaca, Ş. B. 2014. Sağlık Hizmetlerinde Kalite Yönetimi ve Hasta Beklentileri Konusunda Bir Uygulama. Yayınlanmamış Yüksek Lisans Tezi. Adnan Menderes Üniversitesi, Sosyal Bilimler Enstitüsü, Aydin.

- Kayral, İ. H., Beylik, U., \& Orhan, F. 2016. "Hastane standartlarının çok boyutlu kalite analizi: Bir standart seti örneği.” Să̆llk Akademisyenleri Dergisi, 3(1), pp.6-16.

- Korkmaz, A. Ç. (2018). “Geçmişten Günümüze Hasta Güvenliği.” İnönü Üniversitesi Sağllk Hizmetleri Meslek Yüksekokulu Dergisi, 6(1), pp.10-19.

- Kömürcü, N., Durmaz, A., Bayram, N., Koyucu, R. G., \& Karaman, Ö. E. 2015. "Sağlık Hizmetlerinde Kalite Standartları ve Modelleri.” Sağllkta Performans ve Kalite Dergisi, 7(1), pp.95-114.

- Montagu, D. 2003. Accreditation and Other External Quality Assesment Systems For Healthcare. http:/www.heart-resources.org/wp-content/uploads/2012/10/Accreditation-and-other-external-qualityassessments.pdf Erişim Tarihi: 10.11.2019. 
- Önal, B. 2015. Sağlıkta Kalite ve Verimlilik. Bilim Sanayi ve Teknoloji Bakanlığı, Ankara.

- $\quad$ Sack, C., Lütkes, P., Günther, W., Erbel, R., Jöckel, K., \& Gerald, J. H. 2010. "Challenging the holy grail of hospital accreditation: A cross sectional study of inpatient satisfaction in the field of cardiology." BMC Health Services Research, 10(10), pp.2-7.

- Saluvan, M. 2015. Sağlık Hizmetlerinin Kalitesi ile Hastane Bilgi Sistemleri İlişkisi, Yayınlanmamış Doktora Tezi, Hacettepe Üniversitesi Sosyal Bilimler Enstitüsü, Ankara.

- Sarp, N. 2018. "Hasta Güvenliğinde Hastanın Rolü ve Katılımının Sağlanması.” Sağlıkta Kalite ve Akreditasyon Dergisi, 1(2), pp.22-29.

- Shaw, C.D., Kutryba, B., Braithwaite, J., Bedlicki, M., \& Warunek, A. 2010. "Sustainable healthcare accreditation: messages from Europe in 2009." International Journal for Quality in Health Care, 22(5), pp.341-350.

- Scrivens, E. 1997. "Putting continuous quality improvement into accreditation: improving approaches to quality assessment." Quality in Health Care, 6(4), pp.212-218.

- Sülkü, S. N. 2011. Türkiye'de Sağlıkta Dönüşüm Programı Öncesi ve Sonrasında Sağlık Hizmetlerinin Sunumu, Finansmanı ve Sağlık Harcamaları. T.C. Maliye Bakanlığı Strateji Geliştirme Başkanlığı SGB Yayın.

- Şahar, L. 2015. Sağlık Sektörü Hizmetlerinin Sunumunda Eksik Rekabet Koşulları. Yayınlanmamış Yüksek Lisans Tezi, Beykent Üniversitesi Sosyal Bilimler Enstitüsü, İstanbul.

- Şencan, İ. (2015). Sağlıkta Kalite Standartları Hastane. Sağlık Hizmetleri Genel Müdürlüğü, Sağlıkta Kalite ve Akreditasyon Daire Başkanlığı, Ankara.

- Tabrizi, J., Gharibi, F., \& Wilson, A. 2011. "Advantages and disadvantages of health care accreditation models." Health Promotion Perspectives, 1(1), pp.1-31.

- Tapan, B., Çapraz, N., \& Dinar, S. K. 2010. Sağlık Hizmetlerinde Kalite Yönetimi. https://studylibtr.com/doc/843966/sa\%C4\%9Flik-hi\%CC\%87zmetleri\%CC\%87nde-kali\%CC\%87tey\%C3\%B6neti\%CC\%87mi\%CC\%87-birkan-tapan---... Erişim Tarihi: 10.11.2019.

- Tatar, M. 2011. "Sağlık Hizmetlerinin Finansman Modelleri: Sosyal Sağlık Sigortasının Türkiye’de Gelişimi,” Sosyal Güvenlik Dergisi, 1(1), pp.103-133.

• Türkeli, S. 2015. “Standart Belge ile Farklılaşma Mümkün mü?” İstanbul Ticaret Üniversitesi Sosyal Bilimleri Dergisi, 14(27), pp.111-131.

- Uysal, B. 2018. "Sağlıkta Kalite Standartları ve Bilişsel Mahremiyet.” Selçuk Üniversitesi Sosyal ve Teknik Araştırmalar Dergisi, 16, pp.24-33.

- Viswanathan HN, S. J. 2000. “Accrediting organizations and quality improvement.” The American Journal of Managed Care, 6(10), pp.1117-1130. 


\title{
Belirsizlik ve Borsalar Arasında Bulaşma Etkileri: S\&P'den BİST100'e
}

\section{Transmission Effects between Uncertainty and Stocks: From S\&P to BIST100}

\author{
Prof. Dr. Mine Gerni (Marmara University, Turkey) \\ Dr. Hatıra Sadeghzadeh Emsen (, Turkey) \\ Asst. Prof. Dr. Ziya Çağlar Yurttançıkmaz (Atatürk University, Turkey) \\ Prof. Dr. Ömer Selçuk Emsen (Atatürk University, Turkey)
}

\begin{abstract}
The economic political uncertainty (EPU) index developed by Berg et al. (2013) and the global economic political uncertainty (GEPU) index developed by Davids et al. (2016) revealed the existence of their strong relations with macroeconomic indicators in the US economy in general. Parallel to this power exhibited by the index, the interest towards it has started to be evaluated in terms of other countries. In this context, while the existence of studies investigating the relations between the index and the Istanbul Stock Exchange index is noteworthy, it has been determined that some of these researches have relations, and some of them not. The existence of spillovers from strong exchanges to stock markets of developing countries is defined as spillover effects in the literature. From this point of view, it is worth examining the existence of the relationship in question with indirect effects rather than investigating direct relationships between the GEPU and BIST100. Therefore, this study aims to investigate the existence of spillover effects from GEPU to S\&P, from S\&P to the exchange rate and from the exchange rate to the BIST100 index, respectively. According to the results of VAR analysis using four variables, it has been found that there are spillover effects from GEPU to S\&P, from S \& P to exchange rate and from exchange rate to BIST100. Consequently, it is observed that the changes in GEPU index that reflect the developments in the US economy affect Turkey's stock market indirectly through spillover linkages.
\end{abstract}

\section{Giriş}

Belirsizlik veya muğlaklık kavramı riskten farklı olarak, olasılıkların kesin olarak bilinmediği durumu ifade eder. Bu noktada bilimsel veya objektif yöntemlerle gelecekte gerçekleşecek duruma ilişkin bir olasıllık dağılımı elde edilebiliyorsa, riskli ortamdan bahsedilir. Buna aksi durum söz konusu olmuşsa, objektif kıstaslardan ziyade sübjektif ölçütlere dayalı olarak ortaya çıkan durum belirsizlik olarak addedilmekte ve böylece belirsizlik ortamında karar alma sürecinin varlığı söz konusu olmaktadır (Altay, 2015: 45-46). Belirsizliği ölçmek üzere Baker vd. (2013) tarafından Ekonomik Belirsizlik Endeksi (EPU) geliştirilmiştir. Bu endeks, 1985'den başlayacak şekilde ABD özelinde 10 öncü konumdaki gazetelerden (USA Today, Miami Herald, Chicago Tribune, Washington Post, Los Angeles Times, Boston Globe, San Francisco Chronicle, Dallas Morning News, New York Times ve Wall Street Journal) elde edilen bilgilerden hareketle oluşturulmaktadır. Diğer bir ifadeyle endeks, ekonomi ve belirsizlik kavramları ile birlikte kongre, bütçe ve cari açık, merkez bankası, mevzuat, düzenleme veya Beyaz Saray ifadelerinin geçtiği makalelere dayandırılmaktadır. Temel alınan makalelerin bu bilgi verişlerindeki frekanslarından hareketle belirsizlik endeksi aylık olarak hazırlanmaktadır. Daha sonra, EPU endeksinden yola çıkarak Davids vd. (2016) tarafından Global Belirsizlik Endeksi (GEPU) geliştirilmiştir. Her iki endeks de 1900’lere kadar götürülmeye çalışıldığı gibi, başta G10 ülkeleri olmak üzere bazı ülkeler için de türetilmeye çalışılmış ve hâlihazırda ülke sayısı 24'e ulaştırılmıştır.

EPU endeksi ile GEPU endeksi temel alınarak daha çok ABD özelinde bir kısım makroekonomik değişkenler arasındaki güçlü ilişkilerin varlığını ortaya koyan çalışmalar (Baker vd., 2013 ve 2015; Davids vd., 2016) dikkat çekmeye başlamıştır. Bu çalışmada, EPU veya GEPU endeksinin ABD ekonomisinde ve özelde de borsa üzerine güçlü ilişkilerin varlığını ortaya koyan çalışmalardan hareketle, GEPU endeksinin BİST100 endeksi üzerine etkileri incelemeye değer kabul edilmiştir. Sadeghzadeh Emsen ve Aksu (2020) tarafindan ARDL ve NARDL analizleri kullanılarak yapılan bir çalışmada GEPU ile BİST100 arasındaki ilişkilerin varlığının sadece uzun vadede ve negatif şoklarda var olduğu tespit edilmiştir. Bu durum, ABD özelinde işleyen bir mekanizmanın ya da öncü göstergenin Türkiye ekonomisi özelinde işlerliğinin zayıf olduğuna işaret ederken, aslında literatürde GEPU'dan ABD borsasına ve oradan da Türkiye borsasına yansımalarının doğrudan değil, dolaylı yollardan ortaya çıktığına dair savlara dikkat çekmektedir. Genelde reel ekonomik boyutlarda ve özelde de borsa ve benzeri parasal olgulardan ortaya çıkan bulaşma etkilerinin dolaylı biçimde, ya "ülke içinde piyasalar" üzerinden ya da önemli ekonomik ilişkilerin var olduğu "ülkeler arasında" geliştiğine dair literatür de bu olguyu bulaşma, yayılma veya domino etkileri kavramları ile tanımlamaktadır. Dolayısıyla GEPU endeksinin ABD borsa endeksini etkilemesi doğal iken, Türkiye borsasını etkileme mekanizmasının da ancak dolaylı yollardan olacağı düşünülebilir. 
$\mathrm{Bu}$ çerçevede, ABD borsasındaki olumsuzluğun dünya ekonomisinde kötüye gidişe sinyal teşkil etiği varsayılırsa, bunun da ilk etapta ABD ekonomisi ile ilişkili olan diğer ülkelerin kurlarında oynaklığı artıracağı düşünülebilir. Kurlarda yaşanacak oynaklığın ise devamında o ülke borsasında oynaklığı tetiklemesi kuvvetle muhtemeldir. Krizlerin yayılma etkileri olarak nitelendirilecek bu durumun gelişmiş ülke ekonomileri arasında izlediği yolun benzeri bir yolu kurlar üzerinden dolaylı olarak izlediğine dair düşünce, çalışmanın temel hipotezini oluşturmaktadır. Dolayısıyla çalışmada bulaşma etkilerinin teorik perspektifi ile bulaşmanın reel ekonomi ve finansal ekonomideki yansımalarını ele alan literatür incelemeleri ikinci ve üçüncü kısımlarda yapılmıştır. Dördüncü kısımda ise konuyla ilgili ekonometrik analizlere gidilmiş ve sonuç kısmında hipotez ile ekonometrik bulgularda gerçekleşen bulgular tartıştırılmıştır.

\section{Bulaşma Etkileri Üzerine Literatür}

Literatürde bir ülkede ortaya çıkan kötüleşme veya iyileşmenin ticaret ortağı olduğu ülkede ortaya çıkardığ kötüleşme veya iyileşme şeklindeki yansımaları bulaşma etkisi olarak ifade edilir. Bulaşma etkisinin derinliğinin ise ülkeler arasındaki ticari ilişkilerin derinliğine bağlı olduğu ileri sürülmektedir (Andritzky vd., 2016: 2). Burada daha çok iyileşmeden ziyade kötü iklimin bulaşmada güçlü etkiler yarattığı söylenebilir. Dornbusch vd. (2000) de piyasa şokları veya dengesizliklerinin aktarımını bulaşma olarak tanımlamıştır. Bu aktarım sürecinin, oynaklığın krizdeki ülkenin finansal piyasalarından diğer ülkelerin finansal piyasalarına ulaştığında işlediği ifade edilmiştir.

Yayılmanın özellikle negatif olgularda ortaya çıkan mevcudiyeti kriz kavramı ile açıklanmaktadır. Diğer bir ifade ile kriz kavramı olağan süreçten olumsuz boyutta sapmalar olarak tanımlanır. Bu noktada ekonomik krizler de kendi içerisinde reel krizler, finansal krizler, bankacılık krizleri, döviz krizleri, borç krizleri gibi değişiklik türlerin varlığına işaret eder (Gerni vd., 2005).

Bulaşma etkisi süreci, bir ekonomide veya bölgede bir şokun fiyat hareketleri yoluyla diğerlerini etkilediği veya yayıldığı durum olarak açıklanabilir. Bu zincirleme tepkiler çoğunlukla piyasalar, ekonomiler, toplumlar veya politikalar arasındaki bağlantılardan dolayı ortaya çıkar. Bu noktada üç tür domino etkisinin varlığından söz edilir: (i) sosyo-politik, (ii) ekonomik ve (iii) finansal. Ancak, bunlar bireysel olarak ortaya çıkabileceği gibi, üçünden müteşekkil bir karşım şeklinde de ortaya çıkabilir ki, 6 Mayıs 2012'de Yunanistan seçimlerinin etkilerinin her üç boyutta AB'de de yansımamalarının olması buna örnek verilebilir (Emons, 2012).

OECD (2012) tarafından yapılan bankacılık krizinin yayılması tanımlamasında, uluslararası bankacılık yoluyla finansal bulaşma, yani bir ülkedeki banka bilançolarındaki bozulmanın doğrudan ilk finansal şoka maruz kalmayan ülkedeki müşterilere açtığı sınır ötesi kredilerini azaltarak tepki vermesi halinde yayılmanın ortaya çıkacağını ileri sürmüştür. Diğer bir ifadeyle, krizin baş gösterdiği ülke bankacılık sektörünün ilişki içerisinde olduğu diğer ülke şubesinin verdiği kredileri geri çağırması, kredilerin geri çağrıldığı ülkedeki diğer bankaları tetikleyen bir olgu olarak kabul edilmektedir. Burada 2008'de ABD bankacılık sektöründeki bir bankada başlayan iflasın diğer bankaları güç duruma düşürmesi ile ülke içinde ve hemen akabinde ABD bankacılık sisteminin güçlü ilişki içerisinde olduğu AB bankacılık sistemine yansımaları yayılmaya örnek olarak verilmektedir (bkz. Şekil 1).

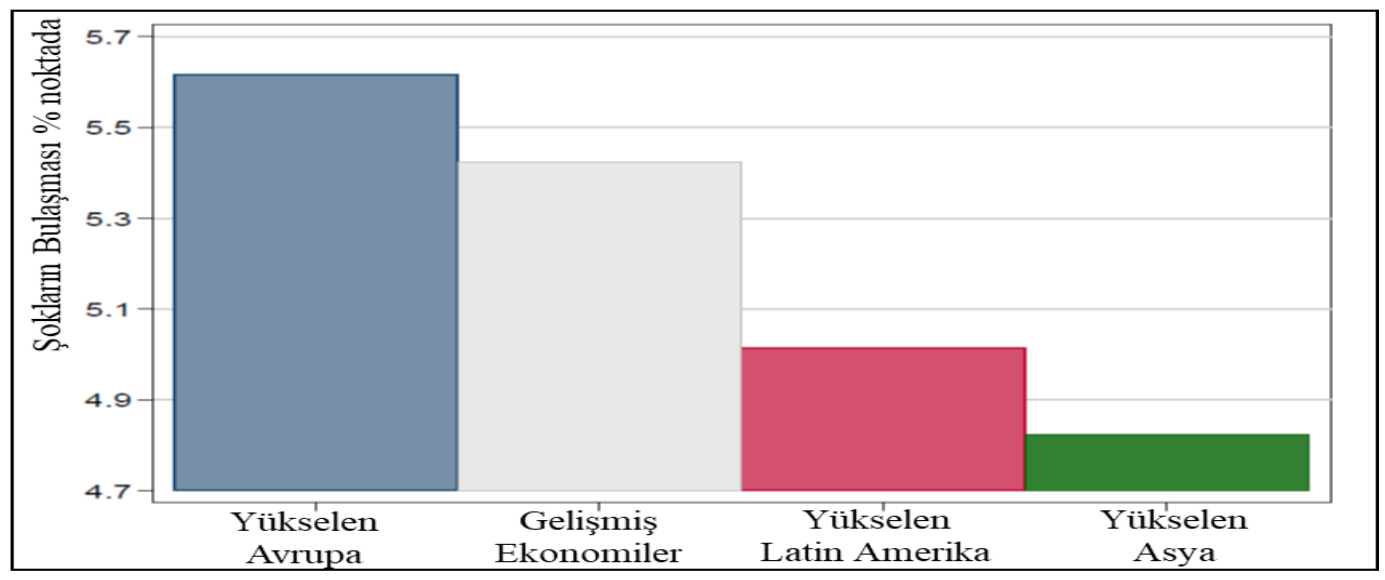

Şekil 1: 2008 ABD Özelinde Ortaya Çıkan Krizin Yayılması ve Etkileri Kaynak: Ahrend ve Goujard (2011) Dayalı Olarak OECD Hesaplamalarl

Contreras ve Fagiolo (2014) tarafından yapılan çalışmada, AB ülkeleri için girdi-çıktı tablolarından hareketle son yaşanan $A B D$ ve $A B$ menşeli ekonomik ve finansal krizlerde, şokların finansal yollarla ülkeler arasında ve endüstriyel sektörlerde kendini gösterdiği tespit edilmiştir. Bu durum krizlerin hem ülkeye özgü hem de ülkede sektöre özgü bulaşma etkilerinin varlığına işaret eder. Diğer bir ifadeyle, genel anlamda kriz literatüründe var olan bulaşmanın ilgili ülke ve sektörlerde değil, o ülke ve sektörün bağlantılı olduğu alanlara da yansıdığı ileri sürülmektedir. Bu yansımanın, ülke ve sektörün büyüklüğüyle ilişkili olduğu, yani ülke ve sektör ne kadar büyükse diğerlerine yansımasının da o kadar büyük olacağı ifade edilmektedir. 
Özetle, ülkeye özgü davranışlarının yanı sıra bir ülkede başlayan krizin diğer ülkelere yansıması yukarıda da belirtildiği gibi daha çok ticaret kanalları yoluyla olmaktadır. Bu noktada, gelişmiş ülkede başlayan bozulmaların gelişmekte olan ülkelere ulaşması ise reel ekonomide gecikmelerle mümkün olabilmektedir. Buna karşılık finansal piyasalardaki bozulmaların ülke borsaları üzerine yayılma etkilerinin varlığı özellikle bilişim teknolojilerindeki mükemmellik nedeniyle oldukça kısa sürelerde ortaya çıkabilmektedir.

Finansal piyasalarda küreselleşmenin en önemli artısı alternatif yatırım araçlarının çoğalmasına yardımcı olmasıdır. Ayrıca piyasalar arsındaki etkileşim kanallarının varlığı bu piyasalar arasında etkinliği artırıcı rol üstlenebilmektedir. En önemli bu iki avantaja karşılık, krizlerin gösterdiği yayılma etkileri dezavantajı borsalarda oynaklığı arttırması ve bunun diğer ülkelere sirayet etmesidir (Bayramoğlu ve Abasız, 2017: 184).

\section{Metodoloji ve Bulgular}

Finansal yayılma etkileri üzerine oldukça geniş bir literatür bulunmakta ve bu literatür içerisinde yerli araştırmalara ilişkin ayrıntılı bir inceleme de Değirmenci (2017) tarafından yapılmıştır. Konuyla ilgili yaygın literatürün korelasyon, eş-bütünleşme analizleri ve ARCH-GARCH modelleri ve türevleri kapsamında yapıldığına temas edilmiş ve genel anlamda yayılma etkilerinin varlığının yöntem, dönem ve ülke yapısına göre farklılık arz ettiğine vurgu yapılırken, ABD hisse senedi piyasasının diğer ülke piyasaları üzerinde en etkili hisse senedi piyasası olduğuna temas edilmiştir.

Krizin yayılma etkileri değerlendirildiğinde, dışa kapalı olan ya da dışa karşı tecrit politikalarına sevk edilmiş ülkelerde borsa endekslerinin çok fazla etkilenmemesi, krizin bulaşma boyutunda ekonomik anlamda dişa kapalılığın önemli bir avantaj sağladığına dikkat çekilmektedir. Krizden en fazla etkilenme doğal olarak dişa açık ve kırılganlığın yüksek olduğu ekonomilerde görülmüştür. 2008 krizinde en önemli kayıp yaşayan borsalar arsında Rusya (-\% 67.89), Macaristan (-\% 59.33 ve Arjantin (-\% 58.57) gelirken, İngiltere, ABD ve Almanya borsalarındaki kayıplar bu ülkelerin yarısı kadar olmuştur. Diğer taraftan İran (\%21.7) ve Kolombiya (\%6) borsalarında ise değerlenmeler dikkat çekmiştir (Emsen, 2009: 32).

Bu çalışmada, ABD ekonomisi özelinde güçlü bir sinyal teşkil eden GEPU endeksinin Türkiye ekonomisinde finansal açıdan güçlü bir bağlantı vermediğine dair Sadeghzadeh Emsen ve Aksu (2020) tarafindan yapılan araştırmadan yola çıkılarak, söz konusu ilişkilerin doğrudan değil, dolaylı yollardan işlediği kabulünden hareket edilmiştir. Bu çerçevede finansal krizlerin bulaşma etkilerinin gerek teorik, gerekse ampirik literatürde de belirtildiği şekliyle dolaylı yollardan ortaya çıkabileceğine dair sav araştırma konusu yapılmıştır. Dolayısıyla araştırmanın mantığı da 1997:01-2019:11 dönemi için GEPU'dan S\&P'ye, S\&P'den Türkiye'de reel kura, reel kurdan da BİST100'e etkiler doğuracak şekilde bir mekanizma inşa edilmesi ve bu mekanizmanın işlerliği şeklinde kurgulanmıştır. Burada sayılan değişkenler arasındaki etkileşimlerin silsilesinin bu şekilde olacağı düşünüldüğünde, buna uygun analiz yöntemi olarak vektör oto regressif(VAR) analizlerinin yapılması daha uygun görülmüştür. Çünkü VAR analizinde her bir değişken hem bağımlı değişken olarak diğerlerinden etkilenme hem de bağımsız değişken olarak da diğerlerini etkileme gücünü bünyesinde taşımaktadır.

Çalışmada değişkenlerin tümü logaritmik formda alınmış, BİST100 endeksi ise TL/\$ nominal kuru ile kısmen reelleştirilmeye çalışılmıştır. Değişkenlerin logaritmik formları, ilgili değişkenin kısaltmasının başına "L" harfi eklenerek sembolize edilmiş, bu çerçevede GEPU endeksi LGP, S\&P endeksi LSP, reel kur verisi LKUR ve BİST100 dolara çevrilmiş endeks değeri de LBIST şeklinde ifade edilmiştir. Aslında, VAR yaklaşımı için burada belirtilen akımın ya da ilişkilerin nedensellik testleri ile belirlenmesi yoluna gidilmesi gerekmektedir. Ancak, nedensellik sınamalarında BİST100'ün S\&P üzerine etkileri ortaya çıkabilmektedir ki, bu durum ekonomik rasyonalite ile uyumlu değildir. Zira S\&P üzerine LBIST'ın etkisinin olması hem çok zayıf ihtimaldir hem de böylesi bir etkinin varlığı ancak LBIST'ın ABD'deki herhangi bir değişskenin kukla değişkeniymiş gibi bir fonksiyon arz ettiğinden kaynaklandığını düşündürebilir. Dolayısıyla değişkenlerin en dışsaldan en içsele doğru sıralaması nedensellikle değil, ekonomi teorisinin önsel bakış açısıyla alınması yoluna gidilmiştir.

Çalışmada kullanılan veriler zaman serisi niteliğinde olduğundan dolayı serilerin durağanlığı önem arz etmektedir. Bilindiği üzere, durağan olmayan serilerle çalışıldığında analizlerde düzmece/sahte tahminci olasılığı ortaya çıkar ki, bu da sağlıklı bir tahminde bulunulmadığı anlamı taşır. Serilerin durağanlığı ADF birim kök testleri ile sınanmış ve test sonuçları Tablo 1'de verilmiştir.

\begin{tabular}{|l|c|c|c|c|}
\hline Değişkenler & \multicolumn{2}{|c|}{ Seviye } & \multicolumn{2}{c|}{ Birinci Fark Değeri } \\
\hline LGP & t-değeri & Olasılık değeri & t-değeri & Olasılık değeri \\
\hline LSP & $-3,281$ & 0,017 & - & - \\
\hline LKUR & $-0,470$ & 0,893 & $-15,624$ & 0,000 \\
\hline LBIST & $-3,256$ & 0,018 & - & - \\
\hline
\end{tabular}

Tablo 1: Değişkenlerin ADF Birim Kök Test Sonuçları

VAR analizlerinde kullanılacak veriler için yapılan durağanlık sınamalarında LGP ve LKUR serilerinin trend değerlerinde seviye değerlerinde durağan olduğu; LSP ve LBIST değişkenlerinin ise birinci farklarda durağan 
olduğu tespit edilmiştir. Birinci farklarda durağan olan bu iki değişken de farkları ifade etmek üzere başlarına "D" harfi eklenmiş ve değişkenler de DSP ve DBIST şeklinde gösterilmiştir.

DBIST üzerine domino etkileri bağlamında etkili olacağı düşünülen LGP ve DSP değişkenlerinin aynı zamanda hem piyasalar arası geçişkenlik için hem de ara değişken olarak LKUR'u da içerecek şekilde modellenmesi düşünüldüğünden, burada değiş̧enlerin gecikme uzunluklarının tespitine ihtiyaç vardır. Tablo 2'de gecikme uzunluklarının kriterlere göre belirlendiği sonuçlar verilmiştir.

\begin{tabular}{|c|c|c|c|c|c|c|}
\hline Lag & LogL & LR & FPE & AIC & SC & HQ \\
\hline 0 & 286.0939 & NA & $1.36 \mathrm{e}-06$ & -2.153388 & -2.098910 & -2.131492 \\
\hline 1 & 1226.176 & 1844.283 & $1.18 \mathrm{e}-09^{*}$ & $-9.20745^{*}$ & $-8.93505^{*}$ & $-9.09796^{*}$ \\
\hline 2 & 1235.249 & 17.52191 & $1.24 \mathrm{e}-09$ & -9.154569 & -8.664262 & -8.957504 \\
\hline 3 & 1249.100 & 26.32904 & $1.26 \mathrm{e}-09$ & -9.138171 & -8.429950 & -8.853521 \\
\hline 4 & 1256.052 & 13.00135 & $1.35 \mathrm{e}-09$ & -9.069100 & -8.142965 & -8.696866 \\
\hline 5 & 1266.376 & 18.99369 & $1.42 \mathrm{e}-09$ & -9.025775 & -7.881725 & -8.565956 \\
\hline 6 & 1275.484 & 16.47732 & $1.49 \mathrm{e}-09$ & -8.973162 & -7.611198 & -8.425759 \\
\hline 7 & 1285.765 & 18.28600 & $1.56 \mathrm{e}-09$ & -8.929505 & -7.349627 & -8.294518 \\
\hline 8 & 1299.447 & 23.91678 & $1.59 \mathrm{e}-09$ & -8.911808 & -7.114016 & -8.189236 \\
\hline 9 & 1308.168 & 14.97840 & $1.69 \mathrm{e}-09$ & -8.856241 & -6.840535 & -8.046085 \\
\hline 10 & 1316.910 & 14.74863 & $1.79 \mathrm{e}-09$ & -8.800840 & -6.567219 & -7.903099 \\
\hline 11 & 1324.155 & 12.00081 & $1.92 \mathrm{e}-09$ & -8.734005 & -6.282471 & -7.748680 \\
\hline 12 & 1342.949 & $30.55875^{*}$ & $1.89 \mathrm{e}-09$ & -8.755336 & -6.085888 & -7.682427 \\
\hline
\end{tabular}

Not: * işareti ilgili kriterce uygun gecikme uzunluğunu gösterir.

\section{Tablo 2: Gecikme Uzunluklarının Seçimi}

Gecikme uzunluğunun uzun olanı ile sapmasızlık; kısa olanında ise tutarlılık ön plana çıkmaktadır. Burada sadece LR'de 12 gecikme ve kalan FPE, AIC, SC ve HQ'de ise 1 gecikme uzunluğunun olduğu tespit edilmiş ve çoğunluk kuralından hareketle VAR tahminleri için 1 gecikme uzunluğunun alınması yoluna gidilmiştir. Böylece hem tutarlılık kriterine hem de finansal piyasalarda kısa dönemde ortaya çıkan etkilerin varlığına bağlı olarak gecikme uzunluğunun kısa olanı tercih edilmiştir.

Çalışmada 1980'de Sims tarafından geliştirilen yapısal olmayan VAR yöntemi kullanılmıştır. VAR modellemesinde her bir değişken kendi ve diğer değişkenlerin gecikmeli değerleriyle regresyona tabi tutularak değişkenler arasındaki tek yönlü ilişkiler değil, ileri geri bağlantılar ortaya çıkarılabilmektedir. Tablo 3'de VAR tahmin sonuçları verilmiştir.

\begin{tabular}{|c|c|c|c|c|}
\hline & LGP & DSP & LKUR & DBIST \\
\hline & 0.850337 & 0.014974 & 0.014417 & -0.004593 \\
LGP(-1) & $(0.03187)$ & $(0.00776)$ & $(0.00851)$ & $(0.02433)$ \\
& {$[26.6797]$} & {$[1.92916]$} & {$[1.69383]$} & {$[-0.18879]$} \\
\hline & -0.682533 & 0.044540 & -0.008196 & 0.389469 \\
DSP(-1) & $(0.28740)$ & $(0.06999)$ & $(0.07675)$ & $(0.21938)$ \\
& {$[-2.37484]$} & {$[0.63636]$} & {$[-0.10678]$} & {$[1.77528]$} \\
\hline & 0.050645 & -0.005909 & 0.981856 & 0.003164 \\
LKUR(-1) & $(0.01693)$ & $(0.00412)$ & $(0.00452)$ & $(0.01292)$ \\
& {$[2.99146]$} & {$[-1.43318]$} & {$[217.174]$} & {$[0.24485]$} \\
\hline & -0.083122 & 0.007077 & -0.026871 & -0.070717 \\
DBIST(-1) & $(0.09258)$ & $(0.02255)$ & $(0.02472)$ & $(0.07067)$ \\
& {$[-0.89783]$} & {$[0.31389]$} & {$[-1.08686]$} & {$[-1.00066]$} \\
\hline & 0.691895 & -0.063300 & -0.047052 & 0.019829 \\
& $(0.14623)$ & $(0.03561)$ & $(0.03905)$ & $(0.11162)$ \\
& {$[4.73160]$} & {$[-1.77751]$} & {$[-1.20491]$} & {$[0.17765]$} \\
\hline $\mathrm{R}^{2}$ & 0.835851 & 0.016675 & 0.996512 & 0.011783 \\
\hline Adj. R-squared & 0.833401 & 0.001999 & 0.996460 & -0.002966 \\
\hline F-statistic & 341.1662 & 1.136205 & 19139.68 & 0.798887 \\
\hline Akaike AIC & -0.587917 & -3.412915 & -3.228577 & -1.128021 \\
\hline Schwarz SC & -0.521809 & -3.346808 & -3.162469 & -1.061913 \\
\hline
\end{tabular}

Not: Standart hatalar parantez içinde ve t-değerleri ise kö̈şeli parantez içinde gösterilmişstir.

Tablo 3: VAR Tahmin Sonuçları

1 gecikmeli olarak yapılan tahminlere göre DBUSD değişseninin LGP'den negatif ve DSP ile LKUR'dan pozitif etkilendiği gözükmektedir. İstatistiki açıdan ise DBUSD üzerine orta düzeyde güçlü sinyal veren değişken DSP olmuştur. Bu sonuçlar bir bütün olarak değerlendirildiğinde, küresel belirsizlik endeksindeki iyileşmelerin DSP'yi 
olumlu ve anlamlı etkilediği gözükürken, DSP'deki olumlu iklimin de DBUSD’u olumlu yönde etkilediği gözükmektedir.

Varyans ayrımlaştırması ise modelin hareketli ortalama sunumundan hareketle varyans-kovaryans matrisini türetir. Varyans ayrımlaş̧ırması, her bir değiş̧kenin sistemdeki diğer değişkenlerin şoklarına ve kendi şoklarına isnat edilen değişmelerin her bir değişkenin kendi öngörüsündeki varyansının bir oranını gösterir. Aşağıdaki tablolarda değişkenlerin varyans ayrımlaştırma sonuçları verilmiştir.

\begin{tabular}{|c|c|c|c|c|c|}
\hline LGP/Dönem & S.E. & LGP & DSP & LKUR & DBIST \\
\hline 1 & 0.178714 & 100.0000 & 0.000000 & 0.000000 & 0.000000 \\
\hline 2 & 0.245165 & 97.84345 & 1.954006 & 0.091331 & 0.111211 \\
\hline 3 & 0.283929 & 96.92061 & 2.773890 & 0.162092 & 0.143404 \\
\hline 4 & 0.308714 & 96.40812 & 3.194155 & 0.238061 & 0.159666 \\
\hline 5 & 0.325375 & 96.05441 & 3.454661 & 0.321600 & 0.169331 \\
\hline 6 & 0.336935 & 95.77517 & 3.635980 & 0.413053 & 0.175793 \\
\hline 7 & 0.345142 & 95.53603 & 3.771753 & 0.511781 & 0.180431 \\
\hline 8 & 0.351085 & 95.32085 & 3.878432 & 0.616795 & 0.183926 \\
\hline 9 & 0.355466 & 95.12130 & 3.965076 & 0.726975 & 0.186647 \\
\hline 10 & 0.358755 & 94.93284 & 4.037149 & 0.841195 & 0.188820 \\
\hline
\end{tabular}

Tablo 4: LGP Değişkeninin Varyans Ayrımlaştırması

Tablo 4'deki sonuçlara göre, LGP'nin anlık değerinin yüksekliği bu değişkenin diğer üç değişkenden asla etkilenmediğine işaret ederken, 10 gecikmeye kadarki süreçte ancak \%94.9'a kadar kendi gecikmeli değerlerinden etkilendiği gözükmüş ve çok az da olsa DSP'nin etkilerinin olduğu belirlenmiştir.

\begin{tabular}{|c|c|c|c|c|c|}
\hline DSP/Dönem & S.E. & LGP & DSP & LKUR & DBIST \\
\hline 1 & 0.043523 & 7.922006 & 92.07799 & 0.000000 & 0.000000 \\
\hline 2 & 0.043636 & 8.052998 & 91.89567 & 0.025884 & 0.025448 \\
\hline 3 & 0.043706 & 8.339888 & 91.60684 & 0.027089 & 0.026186 \\
\hline 4 & 0.043759 & 8.551547 & 91.39381 & 0.028102 & 0.026542 \\
\hline 5 & 0.043795 & 8.698100 & 91.24628 & 0.028788 & 0.026828 \\
\hline 6 & 0.043821 & 8.799075 & 91.14461 & 0.029289 & 0.027024 \\
\hline 7 & 0.043838 & 8.868641 & 91.07455 & 0.029655 & 0.027158 \\
\hline 8 & 0.043851 & 8.916574 & 91.02625 & 0.029926 & 0.027250 \\
\hline 9 & 0.043859 & 8.949598 & 90.99296 & 0.030129 & 0.027313 \\
\hline 10 & 0.043865 & 8.972341 & 90.97002 & 0.030282 & 0.027356 \\
\hline
\end{tabular}

Tablo 5: DSP Değişkeninin Varyans Ayrımlaştırması

Tablo 5'deki sonuçlara göre, DSP değişkeninin de daha çok kendi gecikmelerinden etkilendiği ve bunu LGP'nin etkileme gücünün orta düzeyde olduğu gözükmektedir.

\begin{tabular}{|c|c|c|c|c|c|}
\hline LKUR/Dönem & S.E. & LGP & DSP & LKUR & DBIST \\
\hline 1 & 0.047725 & 3.267473 & 9.446266 & 87.28626 & 0.000000 \\
\hline 2 & 0.069035 & 4.668454 & 10.13610 & 85.04887 & 0.146577 \\
\hline 3 & 0.085175 & 5.914486 & 10.59814 & 83.30273 & 0.184642 \\
\hline 4 & 0.098705 & 7.061783 & 10.88311 & 81.84787 & 0.207235 \\
\hline 5 & 0.110558 & 8.123821 & 11.08622 & 80.56759 & 0.222365 \\
\hline 6 & 0.121201 & 9.102547 & 11.24066 & 79.42324 & 0.233551 \\
\hline 7 & 0.130909 & 10.00000 & 11.36276 & 78.39495 & 0.242280 \\
\hline 8 & 0.139856 & 10.81969 & 11.46179 & 77.46918 & 0.249335 \\
\hline 9 & 0.148164 & 11.56631 & 11.54359 & 76.63492 & 0.255177 \\
\hline 10 & 0.155923 & 12.24521 & 11.61215 & 75.88254 & 0.260101 \\
\hline
\end{tabular}

Tablo 6: LKUR Değişkeninin Varyans Ayrumlaştırması

Tablo 6'da verilen LKUR değişkeninin varyans ayrımlaştırması sonuçlarına göre, bu değişken üzerine en güçlü etkiye sahip olan değişken DSP'dir ve etkisi 0 gecikmede de, 10 gecikmede de $\% 10$ düzeyindedir. LKUR'u etkileyen ikinci değişken ise LGP değişkeni olup bu değişkenin etkileri 0 gecikmede \%3.3'lerden 10 gecikmede, DSP'nin etkisini de geçerek, \%12.2'lere kadar yükselmektedir. Buna karşıllk DBIST'in etkisi hemen hemen hiç yok denecek düzeydedir. 


\begin{tabular}{|c|c|c|c|c|c|}
\hline DBUSD/Dönem & S.E. & LGP & DSP & LKUR & DBIST \\
\hline 1 & 0.136419 & 7.759488 & 19.62058 & 20.63470 & 51.98523 \\
\hline 2 & 0.137223 & 7.712867 & 20.14938 & 20.50247 & 51.63529 \\
\hline 3 & 0.137226 & 7.712684 & 20.14856 & 20.50269 & 51.63606 \\
\hline 4 & 0.137227 & 7.713262 & 20.14842 & 20.50258 & 51.63574 \\
\hline 5 & 0.137227 & 7.713725 & 20.14834 & 20.50247 & 51.63546 \\
\hline 6 & 0.137227 & 7.714061 & 20.14829 & 20.50240 & 51.63525 \\
\hline 7 & 0.137227 & 7.714304 & 20.14825 & 20.50235 & 51.63510 \\
\hline 8 & 0.137228 & 7.714480 & 20.14822 & 20.50231 & 51.63499 \\
\hline 9 & 0.137228 & 7.714610 & 20.14820 & 20.50229 & 51.63490 \\
\hline 10 & 0.137228 & 7.714705 & 20.14818 & 20.50227 & 51.63484 \\
\hline
\end{tabular}

Tablo 7: DBIST Değişkeninin Varyans Ayrımlaştırması

Tablo 7'de verilen DBIST değişkenine ilişkin varyans ayrımlaştırması tahmin sonuçlarına göre, DBIST'in kendi gecikmelerinden etkileneme derecesi buradaki diğer üç değişkenin en düşüğü, \%51'ler konumundadır. DBIST'i etkileyen ikinci değişken \%20'ler ile LKUR, \%19'lar ile DSP ve \%7'ler ile LGP'dir. Burada en içsel değişken olarak sıralamada yer alan BİST100'ün dolar ile reelleştirilmiş değerinin iç ve dış olgulardan en fazla etkilenen değişken olduğu dikkat çekmektedir. Bu da hacim açısından derinliği olmayan borsanın etkileyen değil, etkilenen bir konumda olduğu ve etkilenme derecesinin de çalışmanın hipotezini teşkil eden mekanizmaya uygun bir şekilde oluştuğu gözükmektedir. Diğer bir ifadeyle, DBIST'nin LKUR'dan, LKUR'un DSP'den ve DSP'nin ise LGP'den etkilendiğine dair önsel beklentiler ampirik olarak da doğrulanmıştır. $\mathrm{Bu}$ sonuçlar bir bütün olarak değerlendirildiğinde, bulaşma/yayılma/domino etkileri olarak ifade edilen olgunun LGP'den DSP'ye, DSP'den LKUR'a ve LKUR'dan da DBIST'e doğru gerçekleştiği, yani bulaşma etkilerinin dolaylı olarak makro değişkenler kanalıyla ortaya çıktığı görülmektedir. Şekil 2'de ilgili etki-tepki fonksiyonları gösterilmiştir.
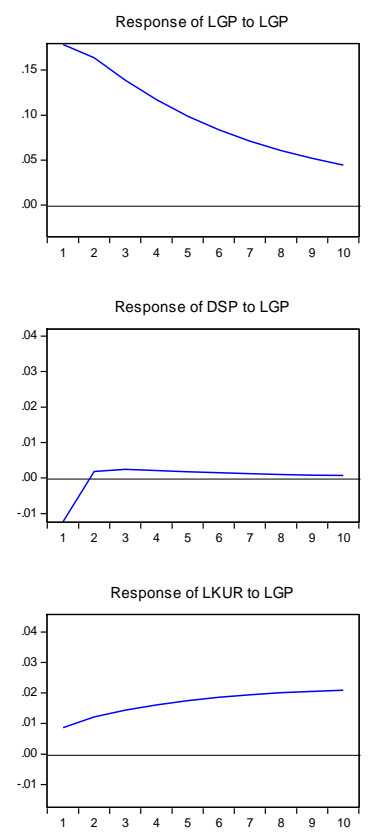

Response of DBIS to LGP

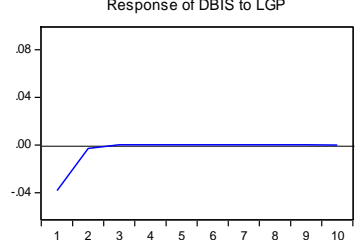

Response to Cholesky One S.D. (d.f. adjusted) Innov ations

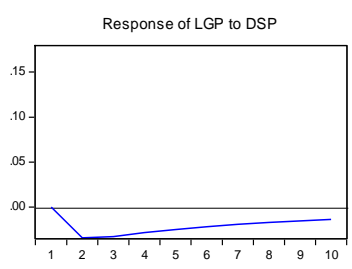

Response of DSP to DSP

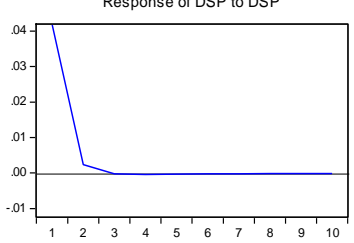

Response of LKUR to DSP

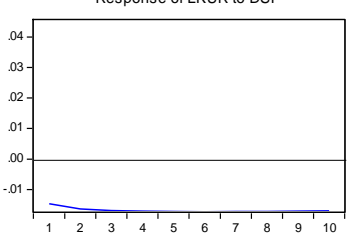

Response of DBIS to DSP

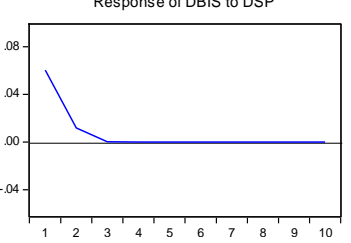

Response of LGP to LKUR

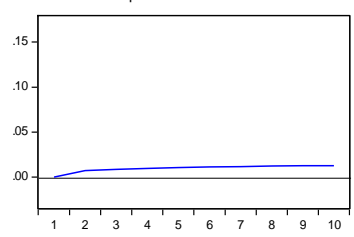

Response of DSP to LKUR

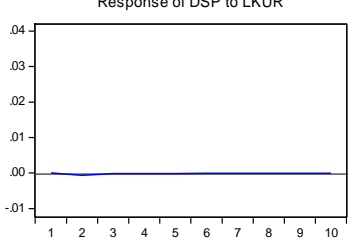

Response of LKUR to LKUR

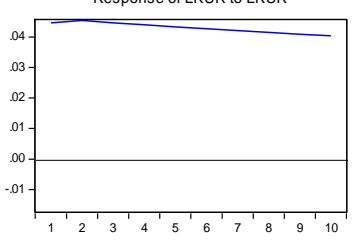

Response of DBIS to LKUR

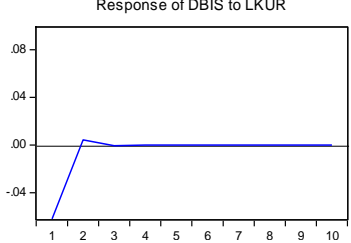

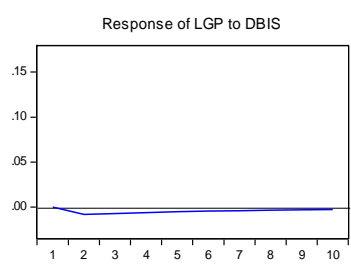

Response of DSP to DBIS

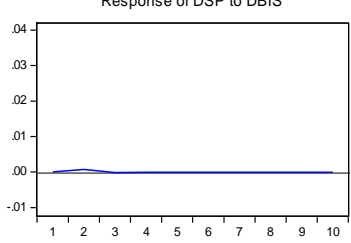

Response of LKUR to DBIS

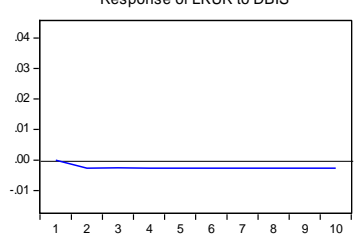

Response of DBIS to DBIS

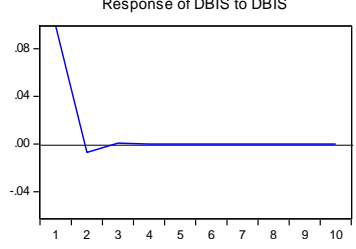

Şekil 2: Değişkenlerin Etki-Tepkileri

DBIST değişkeninin LGP'den 1. gecikmeden sonra negatif, DSP'den 1. gecikmeden sonra pozitif ve devamında sıfıra yakın tepki (yani tepkisiz), LKUR'dan ise 2. gecikmeden sonra negatif yönde etkilendiği gözükmüştür. DBIST'in 2. gecikmeye kadar azalarak devam eden pozitif etkilerinin 3. gecikmede negatife düştüğü ve devamında da tepkisizleştiği görülmektedir. 


\section{Genel Değerlendirme ve Sonuç}

Sosyo-ekonomik ortamda çeşitli nedenlerle her an belirsizlikler ortaya çıkabilmektedir. Belirsizlik ortamı ise riski yükselterek özellikle borsa gibi araçlara yönelimi caydırıcı etkiler yapabilmektedir. ABD özelinde geliştirilen EPU endeksi ile 24 ülkeye özgü olarak geliştirilen GEPU endeksinin ABD ekonomisinde genelde makroekonomik değişkenlerle ve özelde de borsa ile güçlü ilişkilerinin varlığı, endeksin bir öncü değişken olabilirliğine dikkatleri çekmeye başlamıştır. Bu çerçevede Türkiye borsası üzerine yapılan çalışmalarda, endeksin yayılma etkileri bağlamında güçlü sinyalci olmadığı gözükmüştür. Bu kapsamda iktisat literatüründe yayılma etkileri küresel güç konumundaki bir ekonomide meydana gelen olumsuz iklimin diğer ülkelere sirayet etmesi olgusu bulaşma, yayılma veya domino etkileri olarak tanımlanır olmuştur. Bulaşma etkilerinin hem coğrafi hem de ekonomik ilişkiler açısından yakınlık derecesi yüksek olan ekonomilerde ortaya çıktığı özellikle 1980'lerdeki kriz olguları ile yaygın kabul görmeye başlamıştır. Bulaşma etkilerini dikkate alan teorik ve ampirik literatür konuya ilginin artmasını beslerken, ampirik çalışmalarda olguyu teyit eden çalışmaların yanı sıra ülke, dönem ve metodolojiye bağlı olarak ilgi kuramayan çalışmalar da söz konusudur.

Türkiye ekonomisinde borsa üzerine belirsizlik endeksinin doğrudan etkilerinin yakalanamamasından hareketle, bu çalışmada, bulaşmanın dolaylı kanallar yoluyla olabileceğine dair hipotez inşası yoluna gidilmiştir. Buna göre GEPU'da meydana gelen olumsuzlaşmanın ABD borsasında olumsuzlaşmayı artırabileceği ve bunun da Türkiye ekonomisinde reel kurda kötüleşmeyi tetikleyeceği; kur kötüleşmesinin de Türkiye borsasında düşüşe yol açacağ şeklinde bir mekanizmanın varlığına dair hipotez analizlere tabi tutulmuştur. Bulaşma etkilerini en iyi şekliyle yansıtacağı düşünülen yöntem olarak VAR analizleri seçilmiştir. VAR analizlerinde reel BİST100 endeksi üzerine bulaşma etkilerinin dolaylı şekilde ortaya çıktığına dair hipotezin geçeli olduğu sonucuna varılmış, Türkiye borsası üzerine ABD'deki belirsizliğin doğrudan değil, ancak dolaylı bir şekilde hangi süreçle ortaya çıtığı belirlenmiştir. Dolayısıyla ABD'deki belirsizliğin sırasıyla ABD borsası, Türkiye reel kuru ve en nihayetinde Türkiye borsasına yansımaları olduğuna dair bu çalışmadaki ampirik bulgular dikkate alınırsa, ABD'deki olumsuzlukların Türkiye ekonomisine mutlaka yansımalarının gecikmeli de olsa ortaya çıkacağı öngörülebilir.

Bu araştırmadan hareketle, Türkiye ekonomisinin doğrudan ABD ekonomisi ile olan ilişkilerinden ziyade yakın ilişkiler içinde olduğu gelişmiş ve gelişmekte olan ülkelerle bulaşma etkilerinin ve buna ilaveten özellikle kırılganlık açısından Türkiye ekonomisi ile benzerlik arz eden ekonomilerin inceleme konusu yapılmasının daha anlamlı sonuçlar vereceği beklenebilir.

\section{Kaynakça}

- $\quad$ Altay, Erdinç (2015). “Knight Belirsizliği: Risk ve Muğlaklığın Borsa İstanbul Aşırı Getiri Oranları Üzerindeki Etkisi”, BDDK Bankacılık ve Finansal Piyasalar, 9 (2): 45-72.

- Andritzky, Jochen, Bernhard Kassner and Wolf Heinrich Reuter (2016), "Propagation of Changes in Demand through International Trade: Case Study China”, German Council of Economic Experts, Working Paper 10/2016, pp: 1-27.

- Bayramoğlu, Mehmet Fatih ve Tezcan Abasız (2017), “ Gelişmekte Olan Piyasa Endeksleri Arasında Volatilite Yayılım Etkisinin Analizi”, Muhasebe ve Finansman Dergisi, Nisan/2017: 183-199.

- Baker, Scott R., Nicholas Bloom and Steven J. Davis (2013). Measuring Economic Policy Uncertainty, (Erişim: Aralık 2019), https://www.policyuncertainty.com/media/EPU_BBD_2013.pdf

- Baker, Scott R., Nicholas Bloom and Steven J. Davis (2015). "Measuring Economic Policy Uncertainty”, NBER Working Paper 21633. (Erişim: Aralık 2018), https://www.nber.org/papers/w21633.pdf

- Contreras, Martha G. Alatriste and Giorgio Fagiolo (2014), "Propagation of Economic Shocks in InputOutput Networks: A Cross-Country Analysis”, Laboratory of Economics and Management (LEM) Working Paper Series (Erişim: Ocak 2020; https://arxiv.org/pdf/1401.4704.pdf).

- Davids, Steven J. (2016). “An Index of Global Economic Policy Uncertainty”, NBER Working Paper Series, Cambridge, MA 02138, pp: 1-16. (Erişim: Aralık 2019), https://www.nber.org/papers/w22740.pdf

- Dornbusch, Rudiger, Yung Chul Park and Stijn Claessens (2000), "Contagion: Understanding how it spreads". World Bank Research Observer, 15: 177-197.

- Değirmenci, Nurdan (2017), "Finansal Piyasalar Arasındaki Oynaklık Yayılımı: Literatür Araştırması”, The Journal of Academic Social Science, 47: 161-179.

- Emons, Ben (2012), “Financial Domino Effect”, McGraw Hill BusinessBlog, July 25, 2012. (Erişim: Ocak 2020; https://mcgrawhillprofessionalbusinessblog.com/2012/07/25/the-financial-domino-effect/).

- $\quad$ Emsen, Ö. Selçuk (2009), "Rol' Politiki Liberalizma i Keynsianstva v Konfutsianskom i Veblenistskom Obshchestvakh v Preodolenii Posledstviy Global'nogo Finansovogo Krizisa - Küresel Finansal Krizin Sonuçlarını Elimine Etmede Konfüçyen ve Veblenci Toplumlarda Liberal-Keynesyen Politikaların Rolü”, Bankovskiy Vestnik: Ejemesaçnıy Bankovskiy Jurnal, No: 2: 27-37. 
- Gerni, Cevat, Ö. Selçuk Emsen ve M. Kemal Değer (2005), “Erken Uyarı Sistemleri Yoluyla Türkiye’deki Ekonomik Krizlerin Analizi”, İstanbul Üniversitesi İktisat Fakültesi Ekonometri ve İstatistik Dergisi, Say1: 2, ss: 11-29.

- OECD (2012), "Financial Contagion in the Era of Globalised Banking?", OECD Economics Department Policy Notes, No. 14, June, pp: 1-10.

- Sadeghzadeh Emsen, Hatıra ve Lütfü Efe Aksu (2020), "Borsa İstanbul ve Belirsizlik Endeksi Arasındaki İlişkilerin Doğrusal Olup Olmadığına Dair İncelemeler (1998:01-2018:12)”, Atatürk Üniversitesi SBE Dergisi (Yayın Sürecinde). 


\title{
Euro/Dolar Paritesinin Üst Orta Gelirli Ülkelerin İhracatları Üzerindeki Etkisi: Bir Panel Veri Analizi The Effect of Euro/Dollar Parity on the Export of Upper Middle
Income Countries: A Panel Data Analysis
}

\author{
Ph.D. Candidate Remzi Can Y1lmaz (Beykent University, Turkey) \\ Ph.D. Candidate Ferhat Orman (Beykent University, Turkey) \\ Asst. Prof. Dr. Murat Süslü (Beykent University, Turkey)
}

\begin{abstract}
In this study, the hypothesis that the changes in Euro / Dollar parity affects the export amounts of the economies in real terms, whether the changes in the currencies of the two economies, which constitute almost half of the world economy in total, have a significant effect on the foreign trade balance of other countries; if it is, it is aimed to verify by what extent and in what direction it is. Nineteen upper middle income countries with the largest export volume were selected as the sample of the study. The 2000 - 2017 interval was analyzed with multi - panel regression analysis. As a result, the Euro / Dollar parity was statistically significant and the changes in the said variable affected the exports of the sample countries in the same direction. In addition to the Euro / Dollar parity, the gross domestic product, domestic loan amount and domestic savings ratio were also statistically significant and they changed the exports simultaneously with the changes that occurred in them. This result is mainly attributable to the exports of the upper middle income countries; and that the increase in Euro / Dollar parity has led to an increase in profit margins by lowering imported input costs and making exports more attractive.
\end{abstract}

\section{Giriș}

28 ülkeden meydana gelen, 509 milyonu aşkın bir nüfusa sahip olan ve kişi başı gayri safi yurtiçi hasılası yaklaşık 38.000 Amerikan Doları olan Avrupa Birliği, şüphesiz, dünyanın en büyük ekonomik pazarlarından ve güçlerinden biridir (Eurostat, 2018).

Dünya toplam gayri safi yurtiçi hasılasının \%21.8'ini oluşturan Avrupa Birliği Amerika Birleşik Devletleri’nin (\%24.6) ardından söz konusu sıralamada ikinci sırada yer almaktadır (Eurostat, 2018). Dünya mal ihracatının altıda birini gerçekleştiren Avrupa Birliği ülkeleri dünya mal ihracatının \%16.3'ünü, dünya mal ithalatının ise \%15'ini meydana getirmektedir. Mal ihracatı sıralamasında dünya birincisi, mal ithalatı sıralamasında ise ABD'nin (\%18.3) ardından dünya ikincisidir. ABD dünya mal ihracatında ise $\mathrm{AB}$ ve Çin Halk Cumhuriyeti'nin ardından üçüncü sırada yer almaktadır. Dünya hizmet ihracatında ve ithalatında ise sırasıyla \%24.7 ve \%21.1 paylarını alan Avrupa Birliği, dünya hizmet ticaretinde en büyük paya sahip olan ekonomik aktördür. ABD hizmet ticaretinde ise ikinci sirada yer almaktadır (Eurostat, 2018).

İşbu çalışma, Euro/Dolar paritesindeki artışların üst orta gelir ülkelerinin ihracatlarının üzerinde reel bir artışa yol açtığı hipotezini ampirik bir çalışmayla bilimsel bir temele dayandırmayı amaçlamaktadır.

Söz konusu şartlarda Euro/Dolar paritesindeki değişikliklerin dünya ekonomilerinin diş ticaret bilançolarını değiştirip değiştirmediği, eğer değiştiriyorsa ne yönde ve ne oranda bir değişime yol açtığının ortaya çıkarılması hipotezimizin sınanmasında yapılacak olandır. $\mathrm{Bu}$ şekilde ele alınan ekonomilerin diş ticaret döviz kompozisyonları da araştırılmış olacaktır.

Çalışmanın devamında ilk aşamada literatürdeki benzer çalışmalar üzerine bilgi verilecek, ardından veri seti ve metodoloji ele alınacak, kurulan model sonucu elde edilen bulgular ortaya koyulacak ve değerlendirilecektir. Son olarak sonuç bölümünde bulgular yorumlanacaktır.

\section{Literatür Taraması}

Berüment ve Dinçer (2005), Euro/Dolar paritesindeki oynamaların Türkiye ekonomisinin üretim seviyesi, reel döviz kuru ve dış ticaret dengesi üzerindeki etkisini araştırmışlardır. Çalışmada aylık veriler kullanılmış olup 1985:01-2003:07 dönemi ele alınmıştır. Söz konusu verilerle vektör otoregresif (VAR) modeli kurulmuş ve elde edilen bulgulara göre Euro/Dolar paritesindeki artışların uzun dönemde çıktıyı arttırdı̆̆ı, yerel para birimini değerlendirdiği ve dış ticaret dengesini iyileştirdiği ortaya çıkmıştır.

Yücel (2005), Euro/Dolar paritesindeki artışın Türkiye ekonomisinin üretim seviyesi, reel döviz kuru ve enflasyon seviyesi üzerindeki etkisini çeyreklik verilerle (1987: Q1 - 2004: Q4) kurduğu VAR modeliyle araştırmış ve söz konusu paritedeki artışın yerel para birimine değer kazandırdığını, enflasyon oranını düşürdüğünü ve üretim seviyesini yükselttiği sonucuna varmıştır. 
Kahyaoğlu ve Utkulu (2006) ise Euro/Dolar paritesindeki değişimin yerine söz konusu paritedeki volatilitenin Türkiye'nin Euro bölgesine ihracatı üzerindeki etkisini incelemişlerdir. Çalışmada ampirik yöntem olarak klasik ardışık bağımlı ve ardışık bağımlı şartlı varyans yaklaşımları tercih edilmiştir. İhracattaki ve Euro/Dolar paritesindeki oynaklıkların eşbütünleşik olup olmadıkları klasik ve parçalı olarak araştırılmıştır. Veriler aylık olup 1989-2004 dönemi ele alınmıştır. Elde edilen bulgulara göre paritedeki oynaklığın azalması ihracatı arttırmakta; azalması ise ihracatı azaltmaktadır.

Saatçioğlu ve Karaca (2010) Euro/Dolar paritesindeki değişmelerin Türkiye ihracatı üzerindeki etkisini ARDL modeli kurarak araştırmışlardır. Veriler çeyreklik olup 2002: Q1-2010: Q2 dönemleri ele alınmıştır. Elde edilen bulgulara göre Dolar/Euro paritesindeki değişiklikler Türkiye'nin ihracatını uzun ve kısa dönemde söz konusu paritedeki değişmeyle aynı yönde değiştirmektedir. Söz konusu etki kısa dönemde zayıf; uzun dönemde ise kısa dönemde nispeten güçlüdür.

Mohammad (2010) ise Euro/Dolar paritesindeki hareketlerin Pakistan ekonomisinin üretim düzeyi, fiyatlar genel seviyesi ve para arzı üzerindeki etkisini araştırmıştır. 1960-2004 dönemini yıllık verilerle ele alıp kurduğu VAR modeli sonucu elde ettiği sonuçlara göre Euro/Dolar paritesi ve ele aldığı değişkenler arası istatistiksel olarak anlamlı bir ilişki mevcut değildir.

Tunalı ve Manga (2017), Euro/Dolar paritesinin Türkiye'de konumlu serbest bölgelerin ihracatı üzerindeki etkisini araştırmışlardır. Çeyrek dönemlik verilerle (2002-2016) oluşturdukları ARDL modeli sonuçlarına göre Euro/Dolar paritesindeki değişim hem kısa hem uzun dönemde Türkiye'de konumlu serbest bölgelerin ihracatı üzerinde aynı yönde etkilidir.

\section{Veri ve Metodoloji}

Bu çalışmada Euro/Dolar paritesinin ihracat üzerindeki etkisi en büyük ihracat hacmine sahip on dokuz üst orta gelirli ülkenin verilerinden yararlanılarak panel veri analizi yöntemiyle test edilmiştir. Veriler yıllık olup 20002017 yılları aralığı çalışmanın gözlem aralığıdır. 342 gözlem sayısıdır.

$$
\mathrm{LNIHR}_{\text {it }}=\beta_{0}+\beta_{1} \mathrm{ED}_{\mathrm{it}}+\beta_{2} \mathrm{LNKREDI}_{\mathrm{it}}+\beta_{3} \mathrm{LNGSYH}_{\mathrm{it}}+\beta_{4} \mathrm{TASAR}_{\mathrm{it}}+\mathrm{e}_{\mathrm{it}}
$$

Yukarıda yer alan modelde $\mathrm{IHR}_{\text {it }}$ toplam ihracat, $\mathrm{ED}_{\mathrm{it}}$ Euro/Dolar paritesini, GSYH $\mathrm{H}_{\text {it }}$ gayri safi yurtiçi hasılayı,

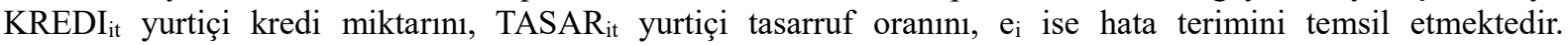
Değişkenlerin başında yer alan "LN" sembolü değişkenlerin doğal logaritmalarının alındığını belirtmektedir. Değişkenler arası esneklik ilişkisini bulabilmek için değişkenlerin doğal logaritmaları alınmıştır. ED değişkeninin veri seti Türkiye Cumhuriyet Merkez Bankası'nın (TCMB) Elektronik Veri Dağıtım Sistemi'nden (TCMBEVDS), geri kalan değişkenlerin veri setleri Dünya Bankası Veri Bankası'ndan alınmıştır.

$\beta_{1}$ parametresinin pozitif bir değer alması beklenmektedir. Söz konusu parametrenin pozitif ve anlamlı çıkması durumunda örneklem ülkelerinin ihracatlarının Euro/Dolar paritesindeki değişmelerle aynı yönlü etkilendiği ortaya çıkacak ve hipotezimiz onaylanacaktır. $\beta_{2}$ parametresinin de pozitif bir değer alması beklenmektedir. Yurtiçi kredi miktarındaki artışların yatırım harcamalarına dönüşmesi ve söz konusu yatırım harcamalarının belli bir kısmının ihracata konu olan malların üretim alanlarında gerçekleşeceğini ve toplam ihracatı arttırıcı bir etkide bulunacağı beklenmektedir. $\beta_{3}$ parametresinin de pozitif bir değer alması beklenmektedir. Bu senaryoda artan milli gelirle birlikte ekonomide bir toplam talep artışının gerçekleşmesi, bu durumda artan tüketim malları talebiyle birlikte firmaların artan toplam talebi karşılamak için yatırım harcamalarını da arttırmaları beklenmektedir. Hızlandıran etkisinin devreye girmesiyle milli gelirdeki artış yatırım harcamalarını da arttıracaktır. $\beta_{4}$ parametresinin pozitif değer alması beklenmektedir. Yurtiçi tasarruf oranının yükselmesi yurt dışı finansman kaynakları talebini düşürecek, bu durum yerli paranın değerlenmesini engelleyecektir. Bu senaryoda yerli parası değerlenmeyen ekonomiler dış ticarette rekabet üstünlüğüne sahip olacaklardır.

\section{Bulgular}

Çalışmada panel regresyon modeli kurulmuştur. Çalışmanın başında birim ve zaman etkilerinin olup olmadığı incelenmiştir. Birim ve zaman etkilerinin olmadığı durumda klasik model; birim ve/veya zaman etkilerinin bulunduğu durumda sabit ya da tesadüfi etkiler modellerinden kullanılması gerekmektedir. İlk aşamada zaman ve birim etkilerinin var olup olmadığına olabilirlik oranı testiyle bakılmıştır.

\begin{tabular}{|l|l|l|}
\hline Olabilirlik Oranı (LR) Testi & Chi' $^{\mathbf{2}(2)}$ & Prob. \\
\cline { 2 - 3 } & 734.26 & 0.0000 \\
\hline
\end{tabular}

Tablo 1: İki Yönlü Modelin Geçerliliğinin Sinanması

Sonuçlara göre birim ve zaman etkilerinin standart hatalarının en az birisinin 0'a eşit olduğu Ho hipotezi reddedilmiştir. Birim ve zaman etkilerinin tek tek sınanması gerekmektedir. 


\begin{tabular}{|l|l|l|l} 
F Testi & \multicolumn{1}{|c|}{ LR Testi } & \multicolumn{1}{|c|}{ LM Testi } & Score Testi \\
\hline $\mathbf{F}(\mathbf{1 8}, \mathbf{3 1 9})=\mathbf{1 8 7 . 8 2}$ & chibar2(01)=712.09 & chibar2(01)=2266.6 & chi2 $(1)=6.7 \mathrm{e}+05$ \\
Prob $=\mathbf{0 . 0 0 0}$ & Prob $=0.000$ & Prob $=0.000$ & Prob $=0.000$
\end{tabular}

Tablo 2: Birim Etkinin Sinanmast

Birim etkinin sınanmasında ilk olarak F testi uygulanmıştır. Tüm birim etkilerin sıfır olduğu $\mathrm{H}_{0}$ hipotezi $\left(\mathrm{H}_{0}\right.$ : $\mu_{\mathrm{i}}=0$ ) test edilmiş ve reddedilmiştir. Birim etki vardır.

İkinci olarak olabilirlik oranı (LR) testiyle birim etki sınanmıştır. Birim etkilerin standart hatalarının sıfıra eşit olduğu $\mathrm{H}_{0}\left(\mathrm{H}_{0}: \sigma_{\mathrm{i}}=0\right)$ hipotezi de reddedilmiştir.

Üçüncü test olarak Breusch-Pagan Lagrange Çarpanı Testi uygulanarak birim etkilerin varyanslarının sıfıra eşit olduğu $\mathrm{H}_{0}\left(\mathrm{H}_{0}: \sigma_{\mathrm{i}}^{2}=0\right)$ hipotezi sınanmıştır. $\mathrm{H}_{0}$ hipotezi reddedilmiştir ve klasik modelin uygun olmadığ bir kez daha görülmüştür. Birim etki mevcuttur.

Birim etki sınanmasında son olarak LR testinden türetilmiş olan Score testi uygulanmıştır. Birim etkilerin standart hatalarının sıfıra eşit olduğu $\mathrm{H}_{0}\left(\mathrm{H}_{0}: \sigma_{\mathrm{i}}=0\right)$ hipotezi test edilmiş ve reddedilmiştir. Birim etki vardır (Tatoğlu, 2018).

\begin{tabular}{|c|c|}
\hline F Testi & LR Testi \\
\hline $\mathrm{F}(17,321)=1.40$ & chibar2 $(01)=8.5 \mathrm{e}-13$ \\
Prob. $=0.1321$ & Prob. $=1.0000$ \\
\hline
\end{tabular}

\section{Tablo 3: Zaman Etkisinin Sinanmast}

Zaman etki sınamasında F Testi sonucunda zaman etkilerinin sıfıra eşit olduğu $\mathrm{H}_{0}$ hipotezi reddedilememekte ve zaman etkilerinin anlamsız olduğu görülmektedir.

Olabilirlik oranı (LR) testinde de zaman etkilerinin sıfira eşit olduğu $\mathrm{H}_{0}$ hipotezi reddedilememektedir. Dolayısıyla zaman etkileri yoktur.

Sonuç olarak birim etkinin varlığı kabul edilmiştir. Bu durumda sabit etkiler modelinin mi tesadüfi etkiler modelinin mi kullanılması gerektiğini anlamak için Hausman testi yapılacaktır.

\begin{tabular}{|l|}
\hline Hausman Testi \\
\hline chi2(4) $=10.51$ \\
Prob. $=0.0327$ \\
\hline
\end{tabular}

Tablo 4: Tahminci Seçimi

Hausman testinde parametreler arasındaki fark sistematik değildir veya bir diğer deyişle tesadüfi etkiler modeli uygundur şeklindeki $\mathrm{H}_{0}$ hipotezi test edilmiştir. Prob. değeri 0.05 'ten küçük çıkmıştır $(0,05>0.0327)$. $\mathrm{H}_{0}$ hipotezi reddedilmiş yani tesadüfi etkiler tahmincisinin tutarsız olduğuna ve sabit etkiler tahmincisinin geçerli olduğuna karar verilmiştir.

\begin{tabular}{|l|l|l|}
\hline Değiştirilmiş Wald Testi & DW - LBI Test & Pesaran Testi \\
\hline Chi2 $(19)=764.05$ & $\mathrm{DW}=.54715165$ & Yatay Kesit Bağımsızlı̆̆ $=3.955$ \\
Prob. $=0.0000$ & $\mathrm{LBI}=.70289685$ & Prob. $=0.0001$ \\
\hline
\end{tabular}

Tablo 5: Temel Varsayım Testleri

Değiştirilmiş Wald Testiyle $\mathrm{H}_{0}\left(\mathrm{H}_{0}\right.$ : birimler sabit varyansa sahiptir) hipotezi sınanmıştır. $\mathrm{H}_{0}$ hipotezi reddedilmiş, varyansın birimlere göre değiştiği anlaşılmış ve birimlere göre değişen varyans olduğu anlaşılmıştır.

Durbin Watson - Baltagi Wu LBI testi birinci dereceden otokorelasyonu sinamaktadır. Bu testte otokorelasyon katsayısının sıfıra eşit olduğu $\mathrm{H}_{0}$ hipotezi test edilmektedir. İki değer de kritik değer olan 2'den küçük olduğu için sabit etkiler modeli için otokorelasyonun ciddi olduğu anlaşılmıştır.

Birimler arası korelasyonun varlığının sınanması Pesaran testiyle yapılmıştır. Hata terimlerinin birimlere göre bağımsız olduğu temel varsayımlardan birisidir. Ancak yatay kesit birimler boyunca hataların eşzamanlı korelasyona sahip olmasıyla karşı karşıya kalınabilmektedir. Çıkan sonuca göre $\mathrm{H}_{0}$ yani birimler arasında korelasyon yoktur hipotezi reddedilmiştir. Birimler arası korelasyon mevcuttur.

Elde edilen sonuçlara göre modelde heteroskedastisite, otokorelasyon ve birimler arası korelasyon vardır. Bu durumda Driscoll - Kraay Standart Hatalar Tahmincisiyle sabit etkiler regresyonu tahmin edilmiştir (Tatoğlu, 2018).

$$
\operatorname{lnIHR} \mathrm{it}_{\mathrm{it}}=\beta_{0}+\beta_{1} \mathrm{ED}_{\mathrm{it}}+\beta_{2} \operatorname{lnKREDI} \mathrm{it}_{\mathrm{it}}+\beta_{3} \operatorname{lnGSYH}_{\mathrm{it}}+\beta_{4} \mathrm{TASAR}_{\mathrm{it}}+\mathrm{e}_{\mathrm{it}}
$$




\begin{tabular}{|c|c|c|c|}
\hline Değişken & Katsayı & Prob. & Standart Hata \\
\hline $\operatorname{ED}\left(\beta_{1}\right)$ & 0.3230718 & 0.000 & 0.0673976 \\
\hline $\operatorname{lnKREDI}\left(\beta_{2}\right)$ & 0.655421 & 0.018 & 0.249674 \\
\hline $\ln \operatorname{GSYH}\left(\boldsymbol{\beta}_{3}\right)$ & 0.7730718 & 0.000 & 0.435387 \\
\hline TASAR ( $\left.\boldsymbol{\beta}_{4}\right)$ & 0.0195189 & 0.000 & 0.001058 \\
\hline $\mathbf{C}\left(\boldsymbol{\beta}_{0}\right)$ & 2.09109 & 0.001 & 0.4994613 \\
\hline $\mathbf{R}^{2}$ (within) & 0.9632 & & \\
\hline
\end{tabular}

Tablo 6: Tahmin Edilen Modelin Regresyon Sonuçları

On dokuz üst orta gelirli ülke üzerine yapılan çalışma sonucunda Euro / Dolar paritesi $\left(\beta_{1}\right)$, yurtiçi kredi miktarı $\left(\beta_{2}\right)$, gayri safi yurtiçi hasıla $\left(\beta_{3}\right)$ ve yurtiçi tasarruf oranı $\left(\beta_{4}\right)$ parametreleri istatistiksel olarak anlamlı çıkmıştır.

\section{Araştırma Sonuçları}

Çalışmanın başında iki yönlü modelin geçerliliği olabilirlik oranı (LR) testiyle sınanmıştır. Çıkan sonucun ardından zaman ve/veya birim etkinin mevcut olduğu anlaşılmış ve birim etkinin varlığ test edilmiştir. Bunun için sırasıyla F testi, LM testi, LR testi ve Score testi yapılmıştır. Elde edilen bulgulara göre birim etkinin varlığı kabul edilmiştir.

İkinci aşamada zaman etkisinin varlığı test edilmiştir. F testi ve LR testi uygulanmış ve zaman etkilerinin anlamsız olduğu ortaya çıkmıştır.

Bir sonraki aşamada Hausman testi yapılmış ve sabit etkiler tahmincisinin etkin olduğu ortaya çıkmıştır.

Sabit etkiler modelinde varsayımdan sapmalar sınanmıştır. Otokorelasyon varlığı Durbin Watson - Baltagi Wu LBI testiyle sınanmıştır. İki değer de kritik değer olan 2'den küçük çıktığından dolayı otokorelasyonun önemli olduğu sonucuna varılmıştır. Birinci mertebeden otokorelasyon mevcuttur.

Bir diğer varsayımdan sapma olarak değişen varyans veya alt ana kütle hata terimlerinin varyanslarının sabit olmama durumu Değiştirilmiş Wald testiyle sınanmıştır. $\mathrm{H}_{0}$ hipotezi reddedilmiş ve varyansın birimlere göre değiştiği anlaşılmıştır.

Son olarak Pesaran testiyle birimler arası korelasyon test edilmiş ve birimler arası korelasyon olduğu sonucuna varılmıştır.

Modelde otokorelasyon, heteroskedastisite ve birimler arası korelasyon tespit edildiğinde dolayı Driscoll ve Kraay Tahmincisi ile regresyon analizi yapılmıştır. Sonuçlara göre parametrelerin tümü beklendiği gibi anlamlı ve pozitif değerli çıkmıştır. Euro/Dolar paritesindeki 0,01 birimlik artış ihracatı yüzde 0,32 oranında arttıracaktır. Bu sonuç ele alınan üst orta gelir ülkelerde, üretimde kullanılan girdilerin ithalatının ağırlıklı olarak dolar ile yapıldığını ancak ihracatın Euro ile yapıldığını göstermektedir.

Yurtiçi kredi miktarı değişkeni de beklendiği gibi pozitif değerli çıkmıştır. Yurtiçi kredi miktarındaki artışların bir kısmı yatırım harcamaları olarak gerçekleşmekte ve ihracata konu olan mal ve hizmetlerin üretimi artış göstermektedir. Sonuçlara göre yurtiçi kredi miktarındaki yüzde 1 oranındaki bir artış ihracatı yüzde 0.65 oranında arttıracaktır.

Milli gelir parametresi pozitif bir değer almıştır. Milli gelir artışı beraberinde harcamaların artışını, bir diğer deyişle, toplam talep artışını getirecek, artan tüketim malları talebiyle birlikte firmalar söz konusu talebi karşılamak için mevcut sermaye stokuna ilave yani yatırım yapacaklardır. Hızlandıran etkisinin devreye girmesiyle milli gelirdeki artış yatırım harcamalarını da arttıracaktır. Gayri safi yurtiçi hasılada meydana gelen yüzde 1'lik bir artışın ihracatı yüzde 0.77 oranında arttırması beklenmektedir.

Yurtiçi tasarruf oranındaki 0,01 birimlik artışın ihracatı yaklaşık yüzde 0,02 oranında arttırması beklenmektedir. Yabancı parayla borçlanmayan bir ekonomide yerli paranın döviz karşısında değerlenmesi mevcutsa hız kaybedecektir. Bu durumda ekonominin rekabet gücü de nispeten yüksek gerçekleşecektir.

\section{Sonuç}

1995 yılında kabul edilmiş olan Euro para birimi 1 Ocak 1999 yılında hesap para birimi olarak dünya finans piyasalarına tanıtılmıştır. 1 Euro 1,1743 ABD Doları olarak ECU (European Currency Unit)'nun yerini almıştır.

$\mathrm{Bu}$ çalışma, Euro/Dolar paritesindeki değişikliklerin ekonomilerin ihracat miktarlarını reel olarak etkilediği hipotezi sınanmıştır. Söz konusu hipotez, çalışmada, 2000 - 2017 yılları aralığı yıllık veriler ele alınarak sınanmıştır. Yapılan ekonometrik analizlerin sonucuna göre hipotezimizin doğruluğu onaylanmıştır. Euro/Dolar paritesindeki değişmeler ele alınan ekonomilerin ihracatını eş yönlü olarak etkilemektedir. Ek olarak çalışmanın diğer bağımsız değişkenlerini oluşturan gayri safi yurtiçi hasıla, yurtiçi kredi miktarı ve yurtiçi tasarruf oranı değişkenlerindeki değişiklikler de reel ihracatı aynı yönlü etkilemektedir.

Bulgular ele alındığında, günümüzde, üst orta gelirli ülkeler ihracatlarını ağırlıklı olarak Euro'yla yaparken ithalatlarını ABD Dolarıyla yaptıkları söylenebilmektedir. Araştırmamıza konu olan ülkelerin dış ticarette döviz 
kompozisyonları bu şekildedir. Euro/Dolar paritesindeki değişiklikler örneklem ülkelerin ithal girdi maliyetlerinin ihraç fiyatı içerisindeki payını azaltmaktadır. Bu durumda kar marjları yükselmekte ve ihracat yapmak daha cazip hale gelmektedir. Tersi durumda ithal girdi maliyetleri yükseldiği için kar marjları düşecek ve ihracat yapmak daha az cazip hale gelecektir.

Günümüzde yapılan tartışmalarda da sıklıkla karşımıza çıkan konumuz, zaman serileri analiziyle araştırılmış olsa da bahsi geçen çalışmalar tek bir ülke ekonomisi ele alınarak yapılmıştır. Bu yönüyle çalışmamız literatüre kayda değer bir katkı niteliğindedir. Diğer taraftan Euro para biriminin 1999 yılından beri dünya piyasalarında var olması gözlem aralığını önemli ölçüde sınırlamıştır. İlerleyen yıllarda, artan gözlem sayısıyla birlikte konunun tekrardan ele alınıp araştırılması mutlak surette faydalı olacaktır.

\section{Kaynakça}

- Berüment, H. \& Dinçer, N. (2005), '’Denomination Composition of Trade and Trade Balance: Evidence from Turkey”, Applied Economics, 37 (10): 1177-1191.

- Dünya Bankası, Veri Bankası. https://databank.worldbank.org/data/reports.aspx?source=worlddevelopment-indicators (Erişim: 10.03.2019).

- $\quad$ Eurostat, The Eu in The World, 2018 Edition, Statistical Books: 16-83. https://ec.europa.eu/eurostat/documents/3217494/9066251/KS-EX-18-001-EN-N.pdf/64b85130-5de2-4c9baa5a-8881bf6ca59b (Erişim: 10.03.2019)

- Kahyaoğlu, H. \& Utkulu, U. (2006), '’Euro-Dolar Paritesindeki Oynaklığı İhracat Üzerine Etkisi: Türkiye Örneği”, İktisat, İşletme ve Finans, 21 (242): 114-125.

- Mohammad, Sulaiman D. (2010), 'The Euro-Dollar Exchange Rates and Pakistan Macroeconomics Dynamics", European Journal of Scientific Research, 42 (1): 6-15.

- Saatçioğlu, C. \& Karaca, O. (2010), '’Dolar/Euro Paritesinin Türkiye'nin İhracatına Etkisi: Ekonometrik Bir Analiz”, Niğde Üniversitesi İ.İ.B.F. Dergisi, 3 (2): 106-118.

- Tatoğlu, F. Y. (2013), “Panel Veri Ekonometrisi: Stata Uygulamalı”,Beta Basım Yayın, İstanbul.

- Tunalı, H. \& Manga, S. (2017), '’Euro/Dolar Paritesinin Türkiye’de Konumlu Serbest Ticaret Bölgelerinin İhracatı Üzerindeki Etkisi: Ekonometrik Bir Analiz”, İktisat Politikası Araştırmaları Dergisi, 4 (2): 35-54.

- Yücel, M. E. (2005), '3+1 Essays on the Turkish Economy, The Institute of Economics and Social Sciences of Bilkent University, Unpublished Ph. D. Dissertation, Ankara. 


\title{
Yolsuzluk ve Makroekonomi Üzerindeki Etkileri Corruption and its Effects on Macroeconomy
}

\author{
Prof. Dr. Dilek Y1lmazcan (Maltepe University, Turkey) \\ Hasan Basri Cifci (Maltepe University, Turkey)
}

\begin{abstract}
This paper examines the issue of corruption and its effects on macroeconomy, especially on public expenditures, financing balance, investments, and savings. The issue is going to be discussed based on empirical evidence (such as CPI Reports and Indexes) regarding where and how the macroeconomic ingredients are sensitive to the corruption. The aim is to contribute unreconciled discussions from the perspective of economy of corruption. The corruption level is low in the developed countries where public spending or tax revenues are higher than national income; however, because of silent or weak structures of institutional control and fiscal transparency, the level of corruption is high in Turkey and Eurasian economies. Such difference has important macroeconomic impacts in those countries with higher levels of corruption. Public goods and services are inputs of private productive activities. States finance such inputs through taxes that are collected from taxpayers. If this financing process is influenced by corruption, efficiency of the public expenditures' decreases. And, that causes a sharp decrease in the total amount of invested capital since the growing level of corruption jeopardizes the risk of making an investment. And, increase in the level of corruption negatively affects the general level of prices and lowers income per capita. Thus, it seems that higher level of corruption is in a negative relationship with the level of public investments, public revenues, savings, quality of public goods and services, efficiency of public investments and public financing balance.
\end{abstract}

\section{Giriş}

Yolsuzluğun makroekonomi üzerindeki etkileri on yıllardır kamu maliyesinin önemli konuları içinde yer almaktadır. Yolsuzlukla makroekonomiyi oluşturan unsurlar arasındaki bağlantı farklı çalışmalarda birçok açıdan ele alınmıştır (örn. Rose-Ackerman, 2008; Tanzi, 1998; Tanzi ve Davoodi, 1997; Ulman ve Bujancă, 2014, Wei, 1999).

Son dönemde, ülke kaynaklarının etkin kullanımında yol gösterici bir gelişme, yolsuzluğun ekonomi üzerindeki etkilerinin azaltılmasını ve ekonomik ve siyasal sistemin yeniden yapılanmasını öngören "iyi yönetişim" (good governance) kavramıdır. Bu kavramın temel unsurları içinde yer alan saydamlık ve hesap verilebilirlik, devletin makroekonomik hedeflerine ulaşmak için hayata geçirdiği politikaları ve bu politikaların sonucunu görebilmek için gereken bilgiyi düzenli, anlaşılabilir, tutarlı ve güvenli bir şekilde kullanmayı gerektirir (Acar, 2007). Dolayısıyla, devletlerin makroekonomik hedeflerine ulaşması için, açık ve hesap verilebilir bir mali sistem kurarak yolsuzluğu azaltması bir ön şart niteliğindedir. Bunun yolu da yolsuzluğun makroekonomik etkilerini tespit etmekten ve olumsuz etkilerin gerçekleşmesine engel olmaktan geçer.

Öte yandan, yolsuzluğun tanımlanması ve önceden kestirilmesi çok kolay değildir. Üstelik, yolsuzluk farklı bağlamlarda farklı sebeplerden kaynaklanan ve farklı sonuçlara yol açan çok boyutlu bir yapıya sahiptir (Andvig, vd, 2001). Dolayısıyla, tüm bu boyutlarını kapsamlı olarak ele alan bir çalışma yapmaya ihtiyaç vardır. Bu başta, mali saydamlığın sağlanması için gereklidir. Bu çalışmanın amacı, yolsuzluğun makroekonomi üzerinde nerede, nasıl ve ne tarzda etki ettiğini inceleyerek tartışmalara yolsuzluk ekonomisi açısından katkıda bulunmaktır.

$\mathrm{Bu}$ çalışmada yolsuzluk ve yolsuzluğun yol açtığı makroekonomik sonuçlar ortaya konmaya çalışılacak, ülkelerin yolsuzluk endekslerinin gelişimi izlenecek ve çalışmada yolsuzluğun temel makroekonomik hedefler üzerinde ne gibi etkiler doğurduğu araştırılacaktır. Yolsuzluk bakımından en temiz ve en kirli ülkelerle birlikte, Türkiye'nin ve Avrasya ekonomilerinin yolsuzluk endekslerindeki konum ve süreçleri de ayrıca ortaya konacaktır.

\section{Yolsuzluk Kavramı}

Yolsuzluğun makroekonomik etkileri araştırılmadan önce kamu maliyesi literatüründe yolsuzluğun ne anlama geldiğini açıklamak yerinde olacaktır. Yolsuzluk konusu uzun zaman önce kamu maliyesi literatürüne girmiş ve pek çok tanımı yapılmıştır. Ancak, yolsuzluğun tanımını yapmak çok da kolay değildir, çünkü yolsuzluk teşkil eden fiiller gün 1 şığında değil, yasal olmayan bir şekilde ve gizli yapılmaktadır.

Yolsuzluk genellikle "kamu gücünün özel çıkar sağlamak için kötüye kullanılması” şeklinde tanımlanmaktadır. Bir başka tanımdaysa yolsuzluk "yakın ilişkiler kurarak kendisi ve yakınları için bu ilişkilerle bazı avantajlar sağlamaya yönelik kasıtlı ve uygunsuz olaylar” şeklinde ele alınmaktadır (Tanzi, 1998). Başka bir tanıma göreyse yolsuzluk "kamusal gücün veya kamu otoritesinin kamu yararı ya da kamusal çıkar dışında kullanılmasıdır" (Adaman, vd, 2001). 
Tanımlarda da açıkça ortaya konduğu üzere, yolsuzlukta, kamusal bir gücün özel çıkarlar için kötüye kullanılması ve devletin birtakım eylemler sonucu zarara uğratılması söz konusudur. Devlet, yolsuzluk sonucunda ekonomik, sosyal ve siyasi kayıplarla karşı karşıya kalmaktadır. Bu çalışmada, sosyal ve siyasi kayıplar konumuz dışında kaldığından, yalnızca yolsuzluğun ekonomik etkilerini inceleyecek ve kamu bütçesi açısından yolsuzluğun kamu harcamalarını nasıl etkilediğini ve sonuçlarını ele alacağız.

Yolsuzluk sonucu ortaya çıkan ekonomik, sosyal ve siyasi dinamiklerin aşağıdaki formülle ele alınması mümkündür (Çelen, 2007):

$$
C \text { (yolsuzluk) }=M \text { (tekel gücü) }+D \text { (takdir yetkisi) }-A \text { (hesap verilebilirlik) }
$$

Bu formüle göre, yolsuzluğun sabit olduğu bir durumda, tekel gücü ve takdir yetkisi ne kadar fazla olursa, hesap verilebilirlik düzeyi o kadar azalmaktadır. Bunun yanında, tekel gücü ve takdir yetkisi arttıkça ve hesap verilebilirlik azaldıkça yolsuzluk düzeyi artmaktadır. Bir ekonomide idari düzenlemeler ne kadar fazla olursa bürokrasinin gücü de o oranda artış göstermektedir. Bu gücün artması da yolsuzlukları beraberinde getirmektedir. Bürokratik yetkilerin tek elde toplanarak merkezileştirilmesi de yolsuzluk düzeyinin artmasına sebep olmaktadır (Ahlin, 2001). Yine 44 ülkenin ele alındığı ampirik bir çalışmada, hukuk düzeniyle bürokratik kalitenin yolsuzluk düzeyini artırıcı etki yapması sonucu istatistiksel olarak anlamlı bulunmaktadır (Tosun, 2003). Dolayısıyla, salt formülden yola çıkarak dahi söylenebilir ki, yolsuzluğun önlenmesi için tekel gücünün azaltılması, bürokratik işlemlerin kısaltılması ve kolaylaştırılması, takdir yetkilerinin belirli kurallara bağlanması ve tüm bunların yanında saydamlığın ve hesap verilebilirliğin artırılması gerekmektedir (Çelen, 2007).

Yolsuzluklar aşağıdaki şekilde sınıflandırılabilir (Tanzi, 1998):

a) Bürokratik veya siyasi yolsuzluklar

b) Maliyeti azaltma veya faydayı artırma

c) Rüşvet verme veya rüşvet alma alışkanlığı

d) Cebri veya müsamahalı davranma

e) Merkezi veya merkez diş1 yolsuzluklar

f) Önceden belirlenebilir veya keyfi yolsuzluklar

g) Para ödenen veya başka ödemeler yapılan yolsuzluklar

$\mathrm{Bu}$ sınıflandırmadan da anlaşıldığı üzere, farklı davranış biçimleriyle yolsuzluğa yol açılması mümkündür. Yukarıda sözü edilen tanımlara göre yolsuzluğun var olabilmesi için, önce bir devletin olması gerekmektedir. Nitekim, Nobel ödüllü yazar Gary Becker'ın da belirttiği gibi, devlet ortadan kaldırılırsa yolsuzluk da ortadan kalkacaktır.

Yolsuzluğa doğrudan yol açan konular şöyle sıralanabilir (Tanzi, 1998):

a) Düzenleme ve yetkiler

b) Vergileme

c) Harcama kararlar1

d) Piyasa fiyatlarının altında mal ve hizmet sunulması

e) Tarım topraklarının imara açılması

f) Hazine arazilerinin kullanılması

g) Yabancılara yatırım ayrıcalıklarının sağlanması

h) Özelleştirme ile kamu varlıklarının satılması

i) İhracat ve ithalata kota kolaylıklarının sağlanması

j) Siyasi partilerin finansmanı

Bu gibi konularda, kamu gücü kötüye kullanılarak bu gücü elinde tutan erke birtakım çıkarlar sağlanmaktadır. Görüldüğü üzere, kamusal karar alma mekanizmalarının neredeyse tamamında yolsuzluk sorunuyla karşılaşmak mümkündür (Andvig, vd, 2001).

Yolsuzluğa doğrudan yol açan bu faktörlerin yanında başka bazı faktörler de yolsuzluğa yol açabilmektedir (Tanzi, 1998):

a) Bürokrasinin ve bürokratların davranışları ve kalitesi

b) Kamu kesiminde ücretlerin düzeyi

c) Yasalarda yer alan cezaların caydırıcılığ

d) Kanun, kural ve yönetmeliklerin şeffaflığ 1

e) Siyasi kadroların dürüst ve şeffaf olmaları

$\mathrm{Bu}$ hususlar özellikle gelişmekte olan ülkelerde, demokrasinin iyi işlememesi, ücret yetersizliği ve hukuk sisteminin yeterince adil olmaması nedeniyle rüşveti ve yolsuzluğu daha da arttırmaktadır. Güçlü demokrasi kültürü olan ülkelerde yolsuzluk seviyesinin genellikle daha düşük olduğu görülmektedir (Rose-Ackerman, 2008).

Aşağıda inceleyeceğimiz Yolsuzluk Algı Endeksi (Corruption Perception Index) bakımından da ülkelerin konumlarına bakıldığında, kalkınmakta olan ülkelerde yolsuzluğun oldukça kötü bir seviyede olduğu görülmektedir. Bu çerçevede, öncelikle yolsuzluğun ölçülmesi hususunu inceleyip ardından özel bir ülke grubu olarak Avrasya ekonomilerinde yolsuzluğun düzeyini ayrı bir başlıkta ele alacağız. 


\section{Yolsuzluğun Ölçülmesi}

Uluslararası Şeffaflık Örgütü (Transparency International) ülkelerin yolsuzluk derecesini tespit etmek için yöntemler geliştirmekte ve bu doğrultuda endeksler oluşturmaktadır. Örgüt 1995 yılından beri Yolsuzluk Alg1 Endeksi’ni yayınlayarak, halkın yolsuzluk olmadığını düşündüğü ülkelerde dahi yolsuzluğun çok ciddi boyutlarda olduğunu ortaya koyan istatistikleri 180 ülkeyi kapsayacak şekilde dünyayla paylaşmaktadır.

Yolsuzluk Algı Endeksi, Dünya Bankası, Siyasi ve Ekonomik Risk Danışmanlığı (PERC), Dünya Ekonomi Forumu, Gallup International gibi uluslararası bağımsız araştırma grupları tarafından yapılan çalışmalar sonucunda hazırlanmakta ve her ülkenin endekse girebilmek için en az üç araştırma yapması gerekmektedir. Bu sonuçlar daha sonra Uluslararası Şeffaflık Örgütü tarafından açıklanmakta ve o ülkeye yapılacak yatırımları ve kamu harcamalarının etkinliğini önemli ölçüde etkilemektedir (Yılmazcan, 2001).

Yolsuzluk Algı Endeksi'nin yanında, Uluslararası Şeffaflık Örgütü kamusal süreçlerde verilen rüşvetleri de ölçebilmek adına 1999 yılında Rüşvet Verenler Endeksi (Bribe Payers Index) yayınlamaya başlamıştır. Bu endekste Uluslararası Şeffaflık Örgütü ve Gallup International birlikte çalışarak Dünya'da önde gelen ihracatçı ülkeleri sıralamış, ihracatçı ülkelerin iş alabilmek için rüşvete nasıl başvurduklarını açıklamışlardır. Bu endekslerde başta Çin olmak üzere, Güney Kore, Tayvan, İtalya ve Malezya gibi ülkelerin ihracat yaptıkları ülkelere rüşvet verme eğiliminde oldukları görülmektedir.

\subsection{Yolsuzluk Düzeyinin Belirlenmesi}

Bir toplumda yolsuzluk düzeyinin belirlenmesinde, o toplumda rüşveti talep eden bir kamu gücünün ve diğer tarafta da bu talebi karşılayacak bir kesimin olması gerekir. Yani, arz ve talep konusu yolsuzluğun belirlenmesinde önemli bir rol oynamaktadır. Denge yolsuzluk düzeyinin belirlenmesinde önemli bir unsur arz ve talep eğrilerinin esnekliğidir. Bu esneklik, rüşvet miktarındaki nispi değişmenin yolsuzluk talep ve arzındaki nispi değişmeye oranı olarak ifade edilebilir (Çelen, 2007).

Ülkelerin rüşvet düzeyindeki artış ve azalmalar yolsuzluğun arz ve talep eğrilerinde farklılaşmaya yol açacak ve esnekliğin yüksek olması halinde eğrileri yatay eksene yaklaştıracaktır. Böylece, rüşvet tutarındaki nispi değişiklik yolsuzluk talep edenlerin duyarlılığına göre etki edecek ve duyarlılık fazlaysa arz ve talep eğrileri yatay eksene doğru yaklaşacaktır. Dolayısıyla, yolsuzlukla mücadele ederken denge yolsuzluk düzeyinin de azalması mümkün gözükmektedir. Ancak bu mücadelenin yolsuzluğu belli bir düzeye indirebilmesi için bazı maliyetlere de katlanmak gerekmektedir. Örneğin, kamuda ücret artışı yoluyla yolsuzluğun azaltılması hedefleniyorsa kamu bütçesinin açık verme ihtimali vardır.

Yolsuzluk düzeyi ülkeden ülkeye değişiklik gösterdiğinden bu değişikliğin hangi nedenlerden kaynaklandığını da tespit etmek önem taşır. Ülkelerin rüşvet gibi konulara bakış açıları yasal ve kültürel olarak farklılık gösterebilir ve her ülkede farklı bir yaklaşım farklı bir yolsuzluk düzeyini beraberinde getirebilir (Gyimah-Brempong ve Gyimah-Brempong,, 2006). Dolayısıyla, yolsuzluk düzeyi her ülke bakımından o ülkeye has özellikler hesaba katılarak incelenmelidir.

\subsection{Yolsuzluk Bakımından En Temiz ve En Kirli Ülkeler}

Son yayınlanan Yolsuzluk Algı Endeksi 2019 yılına aittir. Bu endekse göre, yolsuzluk bakımından çok temiz ülkeler Tablo 1'deki gibidir:

\begin{tabular}{|c|c|c|}
\hline Puan & Ülke & Sıra \\
\hline 87 & Yeni Zelanda & 1 \\
\hline 87 & Danimarka & 1 \\
\hline 86 & Finlandiya & 3 \\
\hline 85 & İsviçre & 4 \\
\hline 85 & İsveç & 4 \\
\hline 85 & Singapur & 4 \\
\hline 84 & Norveç & 7 \\
\hline 82 & Hollanda & 8 \\
\hline 80 & Lüksemburg & 9 \\
\hline 80 & Almanya & 9 \\
\hline
\end{tabular}

Tablo 1. En Temiz Ülkeler Kaynak: Transparency International, Corruption Perception Index, 2019

Tablo 1'e göre, Singapur ve Yeni Zelanda dışında kalan ülkelerin tamamı Kuzey Avrupa ülkeleridir. Danimarka, Finlandiya ve Yeni Zelanda 1995'ten itibaren yayınlanan endekste hep listenin başında yer alan ülkelerden olmuştur. Bu ülkeler, kamu harcamalarının veya vergi gelirlerinin milli gelire oranla yüksek olduğu gelişmiş ülkelerdir. Dolayısıyla, tablodaki bu durum, ekonomide kamu kesiminin büyüklüğünün yolsuzluğa yol açacağ1 şeklindeki bir düşüncenin doğru olmadığını göstermektedir. Kamusal faaliyetlerdeki artışlar, yalnızca, yolsuzluğa uygun bir ortam yaratmaktadır.

2019 yılında endekse göre, yolsuzluk bakımından en kötü puanı alan ülkelerse Tablo 2'deki gibidir: 


\begin{tabular}{|c|c|c|}
\hline Puan & Ülke & Sira \\
\hline 18 & Libya & 168 \\
\hline 18 & Haiti & 168 \\
\hline 18 & Gine Bissau & 168 \\
\hline 18 & Kongo & 168 \\
\hline 17 & Kuzey Kore & 172 \\
\hline 16 & Venezuela & 173 \\
\hline 16 & Sudan & 173 \\
\hline 16 & Ekvator Ginesi & 173 \\
\hline 16 & Afganistan & 173 \\
\hline 15 & Yemen & 177 \\
\hline 13 & Suriye & 178 \\
\hline 12 & Güney Sudan & 179 \\
\hline 9 & Somali & 180 \\
\hline
\end{tabular}

Tablo 2. En Kirli Ülkeler Kaynak: Transparency International, Corruption Perception Index, 2019

Tablo 2'ye göre, yolsuzluğun en yüksek olduğu ülkeler Somali, Güney Sudan, Suriye, Yemen ve Venezuela gibi iç savaşın hâkim olduğu ve ABD tarafından bir şekilde düşman ilan edilmiş ülkelerdir. 180 ülke içinde bu ülkeler en alt siralarda yer almaktadır.

\subsection{Türkiye'nin Konumu}

Endekste Türkiye'nin yeri Tablo 3'teki gibidir:

\begin{tabular}{|c|c|c|}
\hline Puan & Ülke & Sıra \\
\hline 39 & Guyana & 85 \\
\hline 40 & Burkina Faso & 85 \\
\hline 39 & Türkiye & 91 \\
\hline 39 & Sırbistan & 91 \\
\hline 38 & Doğu Timor & 93 \\
\hline 38 & Sri Lanka & 93 \\
\hline 38 & Ekvador & 93 \\
\hline
\end{tabular}

Tablo 3. Türkiye ’nin Konumu Kaynak: Transparency International, Corruption Perception Index, 2019

Görüldüğü üzere, Türkiye maalesef Dünya’da yolsuzluk sıralamasında demokrasi kültürü zayıf yoksul ülkeler arasında konumlanmaktadır. 180 ülke arasından 91.sırada yer almak, Türkiye'nin sıralamada düşük olan ikinci yarıda kaldığını, ortalamanın altında bir puana sahip olduğunu göstermektedir. Bu sonuç Türkiye'de yolsuzluğun boyutlarının anlaşılmasına net bir biçimde yardım edecek boyuttadır. Türkiye'nin Dünya'daki algısı da ne yazık ki bu durumdan payını almaktadır.

2000'li yıllardan itibaren Türkiye 54-55.sıralarda yer almaktaydı. Bu sıralama bile Türkiye için çok ağır bir tablo teşkil etmekteydi. Yirmi yılda maalesef kırk sıra daha aşağılara düşülmüştür. Endeksin yayınlandığı ilk yıl olan 1995 yılında Türkiye 36.sırada yer alırken, 1997'de 54.sıraya düşmüştür (Lamsdorff, 2000). Bugün gelinen süreçteyse Tablo 3 'te görüldügüü üzere 91.siraya gerilemiştir.

Türkiye'nin, hâlâ devam eden büyük ekonomik gelişmelerin yaşandığı bir ülke olarak, güçlü kurumlara sahip olsa bile yeterli bir kontrol mekanizmasına sahip olmaması, yolsuzluğa açık bir ortamın oluşmasına sebep olmaktadır (Johnson, 2005). Sıralamada sürekli aşağılara düşülmesi, iş başına gelen hükümetlerin kamu harcamalarındaki tutumlarından ve özelleştirme süreçlerinde yapılan işlemlerden kaynaklanmaktadır. Siyasal yaşamın saydam ve temiz olmadığı ülkelerde, insanlar kamusal alanda bir mevkie geldiklerinde ve bir kamu gücüne sahip olduklarında bunu rahatlıkla kötüye kullanabilmekte ve zaman içinde elde ettikleri maddi çıkarlar sayesinde konumlarını daha da güçlendirmektedirler. Bu tarz kötüye kullanıma sadece yurt içinde yapılan işlemlerde değil, yurt dışı yatırımlarında, ihracat ve ithalat işlemlerinde, hatta ülkenin dış borç almasında bile rastlanmaktadır.

\subsection{Avrasya Ekonomilerinde Yolsuzluğun Değerlendirilmesi}

Avrasya ekonomileri dendiğinde Rusya, Belarus, Ukrayna, Moldova, Ermenistan, Gürcistan, Azerbaycan, Kazakistan, Özbekistan, Tacikistan, Türkmenistan ve Kırgızistan kastedilmektedir. Bu ülkelerin ortak yanı SSCB'nin dağılması sonucunda bağımsızlığını kazanan ülkelerin bir bölümünü oluşturmalarıdır. Letonya, Estonya ve Litvanya gibi Baltık ülkeleri dışında kalan ülkeler, uzun bir geçiş sürecinden sonra aralarında anlaşarak Avrasya Ekonomik Birliği'ni oluşturmuştur.

Geçiş ekonomileri olarak da adlandırılan bu ülkeler, SSCB dağıldıktan sonra piyasa ekonomilerine geçiş aşamasında oldukça zor bir süreçten geçmiştir. Ülkelerin piyasa ekonomisine yönlendirilmesi sürecinde devlet faaliyetlerinin kapsamı ve büyüklüğü değişime uğramıştır. Sadece kamusal mal ve hizmetlerin yapısı değil, 
devletin klasik fonksiyonlarının da değişmesi gündeme gelmiştir. Makroekonomik dengenin sağlanması, bütçeyle ilgili yeni kurumların oluşturulması ve gelir dağılımında adaletin sağlanması gibi makroekonomik hedefler yeniden belirlenmiştir (Gupta, vd, 2001).

$\mathrm{Bu}$ ekonomilerde yaşanan geçiş problemleri siyasi ve bürokratik süreçleri daha da zorlaştırmış ve saydamlığın olmaması sebebiyle rüşvet ve yolsuzluklar ciddi biçimde artırılmıştır. Yukarıda da belirttiğimiz üzere, bürokratik yetkilerin artması (Ahlin, 2001) ve bürokratik kalitenin düşmesi (Tosun, 2003) yolsuzluk düzeyinin artmasına sebep olmaktadir.

Avrasya ekonomilerinin Yolsuzluk Alg1 Endeksi'nde 1995 yılından sonraki performansına bakıldığında, yolsuzluğun fazla olduğu ve bazı ülkelerde puanların düşme eğilimi taşıdığı görülmektedir:

\begin{tabular}{|c|c|c|c|}
\hline Ülkeler & $\mathbf{1 9 9 8}$ & $\mathbf{2 0 0 0}$ & $\mathbf{2 0 0 5}$ \\
\hline Azerbaycan & - & 1.5 & 2.1 \\
\hline Belarus & 3.9 & 4.1 & 2.6 \\
\hline Ermenistan & - & 2.5 & 2.9 \\
\hline Gürcistan & - & - & 2.3 \\
\hline Kazakistan & - & 3 & 2.6 \\
\hline Kirgizistan & - & - & 2.3 \\
\hline Moldova & - & 2.6 & 2.9 \\
\hline Özbekistan & - & 2.4 & 2.2 \\
\hline Rusya & 2.4 & 2.1 & 2.4 \\
\hline Tacikistan & - & - & 2.1 \\
\hline Türkmenistan & - & - & 1.8 \\
\hline Ukrayna & - & 1.5 & 2.6 \\
\hline
\end{tabular}

Tablo 4. Avrasya Ekonomilerinin Performansı Kaynak: Transparency International, Corruption Perception Index, 1998-2005

Uluslararası Şeffaflık Örgütü başlangıçta yalnızca 54 ülkede çalışma yaparken, bugün bu ülkelerin sayısı 180’e ulaşmıştır. Ancak, Tablo 4'te de görüldüğü üzere, hesaplama biçimi değişmiş, başlangıçta daha az değişken kullanılırken ülke sayısının artmasıyla birlikte değişken ve yöntemler farklılaşmıştır. İlk yıllarda 10 puan üzerinden bir sıralama yapılır 1 puana yaklaşıldıkça yolsuzluğun fazla olduğu tespit edilirken, yeni endekslerde bu sıralama 100 puan üzerinden yapılmaktadır. Dolayısıyla, tablolar arasında farklılık vardır.

Tablo 4'e göre, Avrasya ekonomilerinin puanları karşılaştırıldığında puanlar 1.8 ile 2.9 arasında değişmektedir. Dolayısıyla Avrasya ekonomileri puanı en düşük ülkeler arasında yer almaktadır. Özellikle Türkmenistan en kötü üç ülkeden biri olarak karşımıza çıkmaktadır. Bu sıralama, Avrasya ekonomilerinde yolsuzluk algısının çok yüksek olduğunu gösterir. Bu ülkelerin aradan geçen 30 yıla karşılık iyi bir demokrasi kültürüne sahip olamaması bunun başlıca sebeplerindendir. Nitekim, yukarıda söylediğimiz üzere, güçlü demokrasi kültürü olan ülkelerde yolsuzluk seviyesinin genellikle daha düşük olduğu görülmektedir (Rose-Ackerman, 2008). Ülkelerin çoğunda doğal kaynakların bol olması ve bu kaynakların gelirinin doğrudan ülkeyi yönetenlerin elinde olması bu süreci zorlaştırmaktadır. Dolayısıyla, siyasi ve mali konularda saydamlık ve hesap verilebilirlik mümkün olmamaktadır. Kaynakların ve gelirin dağılımı ülkeyi yönetenlerin karar ve tasarruflarına bağlı olarak değişmektedir.

Yolsuzluğun boyutlarının yoğun olduğu ülkelerde ekonomik büyümeyi sağlamak da oldukça zordur. Ülkeler çok zengin bir petrol ve doğal gaz rezervine sahip olsa da yolsuzluk sağlıklı bir ekonomik gelişmeye ve adil bir gelir dağılımına engel teşkil etmektedir. Avrasya ekonomilerinde yapısal reformların büyüme üzerindeki etkisi, yolsuzluktan daha fazladır (Abed ve Davoodi, 2000). Dolayısıyla, ekonominin yapısal olarak yeniden tasarlanması yolsuzlukla mücadele noktasında iyi bir yardımcı olabilir. Nitekim, bu tarz ekonomilerde yolsuzluğun mali denge üzerindeki olumsuz etkisinin yapısal reformlar sonucunda ortadan kalktığı ampirik olarak ispatlanmıştır (Abed ve Davoodi, 2000).

\section{Yolsuzluğun Makroekonomik Etkileri}

\subsection{Yolsuzluğun Kamusal Harcamalar ve Finansman Dengesi Üzerindeki Etkisi}

Kamu kesiminde kamu harcamaları ile kamu gelirleri arasında bir denge oluşturmak ve kamu kesimi finansman açığı yaratmamak tüm yönetimlerin en önemli amaçlarından birisidir. Bu kısımda, yolsuzluğun hem kamu harcamalarıyla hem de kamu gelirleriyle ilişkisini değerlendireceğiz.

Yolsuzluğun kamu harcamalarını artırdığı genel kabul gören bir husustur (Tanzi ve Davoodi, 1997). Çünkü altyapı yatırımlarının, kamu ihalelerinin birtakım rüşvetlerle olması gerekenden çok daha fazlasına mal olduğu tahmin edilebilir bir gerçektir. Burada, söz konusu yolsuzluğun miktarı, kamunun o mal için ödediği miktarla o malın gerçek piyasa değeri arasındaki farkta gizlidir. Bu fark, satıcılar, bürokratlar, hatta devletin üst kademesinde yer alan yöneticiler tarafından paylaşılmaktadır. 
Eğer bahsettiğimiz fark özel sektöre aktarılıyorsa ve özel sektör bu miktarı başka üretken alanlarda kullanabiliyorsa, bunun büyüme üzerinde olumlu bir etkisi olabilir. Belirli bir miktarda yolsuzluğa izin verilmesi, yolsuzluğun üretimde verimliliğe dönüştürülmesi halinde ülkenin büyümesinde olumlu bir etki yaratabilir (Dimaria ve Le Van, 2002). Ancak, genellikle bu miktarın yurt dışındaki banka veya diğer finans kuruluşlarına aktarıldığı görülmektedir. Böylelikle, halkın ödediği vergiler özel kişilerin yurt dışı hesaplarına geçirilmektedir. Yukarıda ele aldığımız endeksler bakımından son yıllarda Türkiye'nin puanının çok düşük olmasının sebebi, bu tür davranışların sebep olduğu algı nedeniyledir.

Kamu harcamalarının fonksiyonel olarak sınıflandırılmasına bakıldığında, yapılan harcamaların eğitim, sağlık askeri harcamalar bakımından üç alanı da olumsuz etkilediği görülmektedir. Yolsuzluk nedeniyle hem harcama miktarı azalmakta hem de hizmetin kalitesi düşmektedir (Tanzi ve Davoodi, 1997; Tanzi, 1998; Wei, 1999). Buna karşılık, her harcama türünde aynı oranda azalma meydana gelmeyebilir. Teknolojik yeniliklerin yoğun olduğu oligopol piyasalarda ve gizlilik unsurunun ön planda olduğu hizmetlerde rüşvet ve yolsuzluk düzeyi de artış göstermektedir (Mauro, 1998).

Askeri harcamalarla yolsuzluk arasındaki ilişki çok daha yoğundur. Askeri harcamalarda belli bir oranda gizlilik olması, satın almalarda çok az sayıda yetkilinin karar vermesi, rüşveti veren ülkelerin de bu konuda sessiz kalması gibi hususlar yolsuzluğun düzeyini çok artırmaktadır (Jajkowicz ve Drobiszova, 2015). Örneğin, 1970'li yıllarda gerçekleşen ve 1976 yılında ortaya çıkartılan Lockheed uçak skandalı tüm dünyayı etkilemiş ve şirketin rüşvet alan ülkeleri ifşa etmesiyle yolsuzluğun boyutları gözler önüne serilmiştir. Türkiye'nin de kırk adet askeri uçak için şirketten rüşvet aldığı açıklanmasına rağmen, olay o dönemdeki hükümet tarafindan örtbas edilmiştir. Bu rüşvet olayında rüşveti alan ülkeler suçlu olduğu gibi, gelişmiş ülkelerin askeri malzeme satabilmek ve birbirleriyle rekabet edebilmek için bu yola başvurmaları da suçtur (Yılmazcan, 1997).

Gelişmekte olan ülkelerde yolsuzluk ve kamu harcamalarının dağılımı üzerine yapılan başka bir araştırmada, 64 ülkenin 1996-2001 yılları arasındaki durumu değerlendirilmiş ve kamudaki yolsuzluğun eğitim, sağlı ve sosyal alanlardaki harcamaların yapısında sapmalara ve bozulmalara yol açarken, enerji ve askeri harcamalarda artışa sebep olduğu görülmüştür (Delavallade, 2006).

Yolsuzlukla ilgili yapılan çalışmalarda, bazı ekonomistler yolsuzluğun ekonomik büyümeyi artırdığını iddia ederken, bir başka grubun büyümeyi azalttığını savunmaktadır Karagöz ve Karagöz, 2010). Buna karşılık, OECD ülkelerinde yolsuzluğun büyüme üzerinde olumsuz etkisi olduğu ampirik olarak ispatlanmıştır (Kotlánová ve Kotlan, 2013; Tanzi ve Davoodi, 1997). Dolayısıyla, yolsuzluğun tasarruflar ve buna bağlı olarak kamusal yatırımlar ve ekonomik büyüme üzerindeki etkisinin olumsuz olduğu anlaşılmaktadır. Yalnızca yolsuzluğun verimli harcamalara dönüştürülebilmesi halinde ekonomik büyüme üzerinde kısa vadeli bir artış söz konusu olabilmektedir (Dimaria ve Le Van, 2002).

\subsection{Yolsuzluğun Tasarruflar Üzerindeki Etkisi}

Yolsuzluk yalnızca kamu harcamaları üzerinde etki yaratmamakta, tasarruflar, yatırımlar, kamu ihaleleri, kamu harcamaları ve dolayısıyla iktisadi büyüme üzerinde de önemli sonuçlara yol açmaktadır. Özellikle tasarruf üzerindeki etkisi, fon maliyetini de etkilediğinden yatırım, istihdam ve büyümeyi de etkileyecektir.

Yolsuzluğun yüksek olduğu ülkelerde kamu gelirleri azalmakta, fert başına düşen milli gelir düşmekte ve gelir dağılımı bozulmaktadır (Wei, 1999). Yani yolsuzlukla fert başına düşen milli gelir arasında ters bir ilişki söz konusudur. 38 ülkede yapılan bir araştırmada da yolsuzlukla fert başına düşen milli gelir arasında da negatif bir ilişki olduğu görülmüştür (Gupta, vd, 1998).

Yolsuzluk Algı Endeksi’ne bakıldığında, bahsettiğimiz bu ilişkinin ne kadar güçlü olduğu ortaya çıkmaktadır. Somali veya Sudan gibi sıralamada en sonda yer alan ülkelerde gelir dağılımının da bozuk olduğunu söylemek mümkündür. $\mathrm{Bu}$ durum, yolsuzluğun hem sonucu olarak ortaya çıkmakta hem de yolsuzlukla mücadeleyi zorlaştırmaktadır. Nitekim, gelişmekte olan ülkelerde kaynak yetersizliğinin yolsuzlukla mücadeleyi zorlaştırdığı tespit edilmiştir (Koyuncu, 2002).

Yolsuzlukla tasarruflar arasındaki bu ters yönlü ilişki, ülkedeki fiyatların genel düzeyini de olumsuz etkilemekte, enflasyon oranının yükselmesine ve ekonomide reel faiz oranlarının artmasına sebep olmaktadır. Bu durumdan, kamu yatırımları ve kamu ihaleleri de olumsuz biçimde etkilenmektedir (Wei, 1999). Bu konuda yapılan ampirik çalışmalar da bu sonucu doğrulamaktadır (Swaleheen, 2008).

\subsection{Yolsuzluğun Yatırımlar Üzerindeki Etkisi}

Yolsuzluğun yatırımlar üzerindeki etkilerinin hesaplanabildiği çalışmalar oldukça sınırlıdır. Bu etkilerin ölçülebilmesindeki zorluklar az sayıda ampirik çalışma yapılmasına yol açmıştır. Az gelişmiş 33 ülkenin incelendiği bir araştırmada, yolsuzluk seviyesinin artmasının doğrudan yabancı yatırımları azalttığı ampirik olarak kanıtlanmıştır (Azam ve Ahmad, 2013).

Yatırımların veya kamu ihalelerinin ihale bedellerinin saptanmasında, ihaleye katılan şirketlerin tespitinde, tekliflerin değerlendirilmesinde yolsuzluğa yol açan çok sayıda ilişki ortaya çıkmaktadır. Çok daha ucuza ve daha kaliteli kamu yatırımları yapmak yerine, yolsuzluk sebebiyle büyük meblağlar ödenerek verimsiz yatırımlar 
yapılmaktadır (Tanzi ve Davoodi, 1997; Wei, 1999). Bu yatırımların konumu, maliyeti, gerekliliği de ayrıca tartışma konusudur (Commander, 1997).

Verimsiz ve pahalı yatırımlar sadece kamu harcamalarını arttırmakla kalmayıp özel sektörün yapacağı yatırımların da daha pahalı olmasına yol açmaktadır. Yolsuzluklardaki artışın kamu altyapı harcamalarını da azalttığı ampirik çalışmalarda ortaya konmuştur (Tanzi, 1998).

Yatırımların yolsuzluk sebebiyle olumsuz yönde etkilenmesi söz konusu olursa, bunun sonucunda büyüme düzeyi de düşecektir. Yolsuzluk miktarının artması, sermayenin dolaşımını ve yabancı yatırımları etkilediğinden, yatırımların ve büyümenin azalmasına sebep olur (Rose-Ackerman, 2008). Dolayısıyla, tıpkı yolsuzlukla tasarruflar arasında ters orantılı bir ilişki olması gibi, yolsuzlukla büyüme arasında da negatif bir ilişki söz konusu olur.

\section{Sonuç}

Devletin rolünün ve fonksiyonlarının kökenine inilerek irdelendiği ve kamu yönetiminin yeniden yapılandığ 1 günümüzde iyi yönetişim kavramının önemi artmıştır. İyi yönetişimin temel özellikleri katılımcı demokrasi, hukukun üstünlüğü, saydamlık, sorumluluk, uzlaşma arayışı, eşitlik, etkinlik, hesap verilebilirlik ve stratejik vizyondan oluşmaktadır (Acar, 2007). İyi yönetişimie planlama süreçlerinin saydam olmasının yanında, gerekli kontrolleri sağlamak üzere denge ve fren mekanizmalarının oluşturulması ve işletilmesi yolsuzluk miktarının azaltılmasında önemli bir role sahiptir (Ofosu-Amaah, vd, 1999).

Saydamlık hem mali saydamlığı, yani kamu kaynaklarının kim tarafından, nasıl ve hangi amaçla kullanıldığının bilinmesini, hem de performans saydamlığını, yani üretilen mal ve hizmetlerde en az maliyetle en uygun hedeflere ulaşılıp ulaşılmadığının değerlendirilebilmesi için lazım olan bilgilerin sunulmasını gerektirmektedir (Atiyas ve Sayın, 2000). Saydamlığın olmadığı bir ekonomide devlete duyulan güven azalmakta ve yolsuzluklar artmaktadır.

Devlet kamusal malları ve hizmetleri vergi mükelleflerinden topladığı vergiler başta olmak üzere kamu gelirleriyle finanse eder. Oysa, yolsuzluk, açıkladığımız üzere kamu gelirlerinde azalmaya sebep olur. Bunun yanında, kamusal mal ve hizmetlerin finansman süreci yolsuzluktan etkilenirse kamu harcamalarının verimliliği de azalır. Yani daha az gelirle daha verimsiz bir finansman söz konusu olur. Kamu sektöründe yolsuzluğun artması nedeniyle maliyet de artar ve bu durum kamu yatırımlarının seviyesini düşürür. Bunun yanında, yolsuzluk düzeyinin artması ülkedeki fiyatların genel düzeyini de olumsuz etkiler ve fert başına düşen milli geliri düşürür. Ayrıca artan yolsuzluk düzeyi, sermayenin dağılımı üzerinde etkili olacağı için yatırım yapma riskini artırır. Kısaca ifade etmek gerekirse, yolsuzlukla, tasarruflar, yatırımlar, kamu gelirleri, fert başına düşen milli gelir, kamusal yatırımlarında verimlilik, mal ve hizmetlerin niteliği ve finansman dengesi arasında negatif bir ilişki vardır.

Bunun yanında, Türkiye'nin Yolsuzluk Alg1 Endeksi'nde 180 ülke arasında 91.sırada yer alması oldukça üzücüdür. Bu durum son yıllarda daha da kötüye gitmektedir. Özelleştirmelerin şeffaflıktan uzak yapılması, köprü, tünel ve havalimanı gibi büyük altyapı yatırımlarının ihale yasalarından adeta kaçılarak yapılması, müteahhitlerin seçiminin bu yasalara uygun olmaması, Yap-İşlet-Devret gibi modellerde üstelik yabancı para cinsinden Hazine'yi zarara uğratabilecek talep garantilerine ve borç üstlenimlerine başvurulması ve hukuk sisteminin bu hususları çözümsüz bırakması gibi meseleler yolsuzluğa uygun bir ortam oluşmasına sebep olmakta ve vergilerin etkin olmayan bir şekilde kullanılmasını gündeme getirmektedir. Yolsuzluk iddiaları da bu doğrultuda artış göstermektedir.

Benzer şekilde, Avrasya ekonomilerinde de durum iç açıcı gözükmemektedir. Geçiş döneminde güçlü bir demokratik kültürün kurulamaması ve saydamlığın tesis edilememesi yolsuzluğa elverişli bir ortamın doğmasına sebep olmaktadir.

Siyasi otoritelerin tüm bu iddiaları ortadan kaldıracak şekilde, mali saydamlığı tam anlamıyla sağlaması ve yolsuzluğun bu çalışmada ortaya koyduğumuz makroekonomik etkileriyle mücadele etmesi beklenmektedir. Aksi takdirde, yolsuzluk önemli bir gündem oluşturmaya devam edecektir.

\section{Kaynakça}

- Abed ve Dovoodi, 2000. Corruption, Structural Reforms, and Economic Performance in the Transition Economies. IMF Working Paper.

- Acar, 2007. İyi Uygulama Örnekleri Çerçevesinde Kamu Yönetiminde Mali Saydamlık ve Kamuoyu Denetiminin Etkinleştirilmesi. Devlet Bütçe Uzmanlığ 1 Araştırma Raporu.

- Adaman, vd, 2001. Hanehalkı Gözünden Türkiye'de Yolsuzluğun Nedenleri ve Önlenmesine İlişkin Öneriler. Tesev, İstanbul.

- Ahlin, 2001. Corruption: Political Determinants and Macroeconomic Effects. Vanderbilt University Working Paper.

- Ajaz ve Ahmad, 2010. "The Effect of Corruption and Governance on Tax Revenues", The Pakistan Development Review, 49/4, p. 405

- Andvig, vd, 2001. Corruption A Review of Contemporary Research. Chr. Michelsen Institute Report. 
- Atiyas ve Sayın, 2000. “Devletin Mali ve Performans Saydamlı̆̆ı”, Kamu Maliyesinde Saydamlık. Tesev, İstanbul.

- Azam ve Ahmad, 2013. "The Effects of Corruption on Foreign Direct Investment Inflows: Some Empirical Evidence From Less Developed Countries”, Journal of Applied Sciences Research, 9(6), p. 3262.

- Commander, vd, 1997. The causes of government and the consequences for growth and well-being. World Bank Report.

- Çelen, 2007. Yolsuzluk Ekonomisi. Muh. Mali Müş. Od. Yay., İstanbul.

- Delavallade, 2006. "Corruption and Distribution of Public Spending in Devoloping Countries", Journal of Economics and Finance, 30(2), p. 222. Dimaria ve Le Van, 2002. "Optimal Growth, Debt, Corruption, and R\&D”, Macroeconomic Dynamics, 6, p. 597.

- Dimaria ve Le Van, 2002. “Optimal Growth, Debt, Corruption, and R\&D”, Macroeconomic Dynamics, 6, p. 597.

- Gupta, vd, 1998. Corruption and the Provision of Health Care and Education Services. IMF Working Paper.

- Gupta, vd, 2001. Transition Economies: How Appropriate Is the Size and Scope of Government?. IMF Working Paper.

- Gyimah-Brempong ve Gyimah-Brempong, 2006. "Corruption, Growth, and Income Distribution: Are there Regional Differences?”, Economics of Governance, 7, p. 245.

- Jajkowicz ve Drobiszova, 2015. "The Effect of Corruption on Government Expenditure Allocation in OECD Countries", Acta Universitatis Agriculture et Silviculturae Mendelianae Brunensis, 63(4), p. 1251.

- Johnson, 2005. Syndromes of Corruption. Cambridge University Press, Cambridge.

- Karagöz ve Karagöz, 2010. “Yolsuzluk, Ekonomik Büyüme ve Kamu Harcamaları”, Saylştay Dergisi, s. 5.

- Kotlánová ve Kotlán, 2013. Influence of Corruption on Economic Growth: A Dynamic Panel Analysis for OECD Countries.

- Koyuncu, 2002. Three Essays on Economics of Corruption. Unpublished PhD Dissertation.

- Lambsdorff, 2000. Transparency International CPI Framework Documents.

- Mauro, 1998. "Corruption and the Composition of Government Expenditure”, Journal of Public Economics, 69, p. 262.

- Ofosu-Amaah, vd, 1999. Combating Corruption: A Comparative Review of Selected Legal Aspects of State Practices and Major International Initiatives. World Bank.

- Rose-Ackerman, 2008. "Corruption and Government”, International Peacekeeping, 15/3, p. 328.

- Swaleheen, 2008. "Corruption and saving in a panel of countries”, Journal of Macroeconomics, 30, p. 1285.

- Tanzi, 1998. Corruption Around the World: Causes, Consequences, Scope, and Cures. IMF Working Paper.

- $\quad$ Tanzi ve Davoodi, 1997. Corruption, Public Investment, and Growth. IMF Working Paper.

- Tosun, 2013. "Yolsuzluğun Nedenleri Üzerine Ampirik Bir Çalışma", Akdeniz İ.̇.B.F. Dergisi, 5, s. 125.

- Transparency International, Corruption Perception Index, 1998, 2000, 2005 and 2019.

- Ulman ve Bujancă, 2014. "The Corruption Influence on the Macroeconomic Environment. Empirical Analysis on Countries Development Stages", IECS 2014.

- Vito, 1998. Corruption Around the World. IMF Working Paper.

- Wei, 1999. Corruption in Economic Development. World Bank Policy Research Working Paper.

- Yilmazcan, 1997. "Kamu Kesiminde Yolsuzlukla Mücadele”, Vergi Sorunlarl, s. 86.

- Yılmazcan, 2001. “Kamu Harcamalarında Yolsuzluk ve İsrafın Önlenmesinde Saydamlığın Rolü”, Sakarya Üniversitesi, Tebliğg. 


\title{
Askeri Harcamalar ile İcatçılık ve Teknolojik Mal İhracatı Arasındaki İlişkiler
}

\section{The Relationships between Military Expenditures and Innovations and Technological Goods Export}

\author{
Prof. Dr. Cevat Gerni (Beykent University, Turkey) \\ Prof. Dr. Selahattin Sarı (Beykent University, Turkey) \\ Asst. Prof. Dr. Ziya Çağlar Yurttançıkmaz (Atatürk University, Turkey) \\ Prof. Dr. Ömer Selçuk Emsen (Atatürk University, Turkey)
}

\begin{abstract}
Technological developments resulting from military expenditures increase competitiveness. This fact also increases exports based on military technology and foreign currency revenues. Indirectly, the increased competitiveness in the military sector contributes to the development of technologies that can be used in the civilian field after a while. It also contributes positively to the export revenues of the country by creating competitive power in the civilian sectors with the delayed effects of the superiority in the military field. Therefore, military expenditures, which are generally described as inefficient expenditures, are expected to both encourage innovation and, when used in civilian areas, stimulate, the high-tech exports. This study aims at investigating the relationships among military expenditures and inventiveness as a measure of efficiency of military expenditures, and high technology goods which are the reflection of efficiency in inventiveness. In the study covering 16 countries and the period of 1991-2018, panel regression estimates are made. As a result of the regression estimates, military expenditures seem to affect the patent positively, so findings support the first hypothesis. The effect of military expenditures on the medium and high technology goods exports is, contrary to the expectation, negative; which means the second hypothesis is not supported. This result might require studies covering much longer periods.
\end{abstract}

\section{Giriş}

Silahlanma ya da askeri harcamalarda bulunma zorunluluğunun ekonomilerde kaynak kullanımında etkinsizliği besleyerek sivil refaha gidecek kaynakların tüketilmesi anlamı taşıyacağı öne sürülmektedir. Doğu Bloku ya da Sovyet sisteminin çöküşünde de klasiklerin ileri sürdüğü gibi, askeri harcamaların etkinsiz olduğuna dair mekanizmanın işlediğine dikkat çekilmektedir. Buna göre 1990 öncesinde, iki kutuplu bir dünyada silahlanmaya kaynak aktarma zorunluluğunun yansıması, bir tür "uzay savaşları" veya "yıldız savaşları" projeleri ile kuvvetle muhtemel Doğu Blokunun kıt kaynaklarının doğrudan halkına refahı dışındaki alanlara kanalize etmesi olmuştur. Kaynakların etkin olmayan alanlarda kullanılması ve halkın ihtiyaçlarının yeterince karşılanamaması ise Doğu Blokunun çöküş sebepleri arasında gösterilmektedir.

Askeri harcamaların doğrudan ortaya çıkan olumsuz etkilerine karşılık; özellikle iç ve dış güvenlik ortamı yaratması ve böylece ortaya çıkması olası tehditleri caydırıcı rol üstlenerek ekonomik aktivitelerin yapılmasında güven tesis etmesi ile dolaylı olarak olumlu etkilerde bulunacağı yaygın kabullerdendir. Bu amaçları gerçekleştirme yeteneği ise devletin kapasitesini ifade etmektedir (Acemoğlu ve Robinson, 2020: 31) ve bu kapasite içerisinde askeri boyut da önemli bir yer tutmaktadır. Diğer taraftan kısa vadede doğrudan olumsuz etkilerde bulunarak kaynak dağılımını bozucu rolüne karşılık, uzun vadede askeri harcamaların özellikle yenilikçiliği besleyeceği ve bu yenilikçilik uygulamalarının da sivil endüstride kullanılabilirliğe yönelik "devşirme işlemleri”nin rekabet gücünde avantaj sağlayarak ülke gelişimine katkıda bulunduğu ileri sürülmektedir.

Kısaca askeri harcamalar konusundaki tartışmalarda bunun dolaylı ve uzun vadeli etkileri açısından modern savaş ve savaşın sanayi verimliliğine olumlu yansımaları dikkat çekici boyut kazanmıştır. Şöyle ki, ekonomik ve teknolojik aşçıdan düşünülürse, savaş yıllarında pek çok ilerlemeden bahsedilebilir. Otomobil ve kamyon üretiminde, hayvancılıkta, petrolün saflaştırılmasında ve kimyasal ürünlerde, elektrik, boya ilaçları ve çelik alaşım sanayilerinde, soğutma ve konservecilikte ve daha başka sanayi kollarındaki gelişmeler, savaş teknolojisinin sivil hayata yansımaları olarak sayılan gelişmelere örnek teşkil eder. Bu noktada ülke ekonomisi cephe hattının yarattığı karışıklıklardan uzaksa, gelişme ve ilerlemelerden ticari kazançlar sağlaması da daha kolay olmaktadır. Örneğin ABD, Kanada, Avusturalya, Güney Afrika, Hindistan ve Güney Amerika’nın büyük savaşın sürdüğü Avrupa'nın sınai hammadde ve yiyecek madde taleplerini karşılamaları, bu ülkelerde büyümenin ivmeli olmasına yol açmıştır (Kennedy, 1990: 328).

Askeri harcamaların ekonomik etkileri hususunda Klasik ve Keynesyenlerin bakış açılarında da önemli farklılıklar söz konudur. Askeri harcamaların bir maliye politikası aracı olarak kullanıldığı ve ekonomik büyüme üzerine olumlu etkilerinin olduğuna dair argüman Keynesçi nitelik taşımaktadır. Keynesçi görüş, askeri harcamalardaki artışın hükümet alımlarında bir artışa sebep olacağını ve bu durumun ekonomide toplam harcamaları artıracağını savunarak ekonomik büyümeyi de olumlu yönde etkileyeceğini ileri sürmektedir. Bu 
şekilde ortaya çıkan büyümede diğer gelişmeler askeri harcamaların olumlu etkilerini karmaşıklaştırsa bile, ortaya çıkması beklenen büyüme hükümetin satın alma çarpanının büyüklüğüne göre belirlenmektedir. Harcama artışını karşılamak için vergi artışına eşit bir artışın sağlanması durumunda büyümedeki net etki, harcama artışının fiili miktarına eşit olacaktır (Gerace, 2002; 2). Diğer taraftan geleneksel görüşe göre, ulusal savunmadaki kamu harcamaları bir firsat maliyeti taşımaktadır. Bu durum daha düşük çıktıya ve daha düşük ekonomik büyümeye neden olmaktadır. Temel görüş, ayrılan kaynağın sadece savaş hazırlıkları ve savaş için kullanıldığı, ancak bu kaynağın diğer alanlarda kullanılması halinde, ekonomik refah açısından daha faydalı olacağını ortaya koymaktadır. Ayrıca ekonomi için önemli olan insan sermayesinin sivil Ar-Ge yerine askeri hizmetlere ayrılmış olması ekonomik büyüme için bir engel olarak görülmektedir (Ma vd., 2015: 80).

Askeri amaçlar için yapılan Ar-Ge çalışmaları sivil uygulamalara sahip olduğu için sivil üretime örnek teşkil edebilir. Buna karşılık gelişmiş askeri teknolojinin temel sivil ihtiyaçlara katkıda bulunmasının çok daha az olduğu gelişmekte olan ülkelerde, askeri Ar-Ge'nin sivil sektördeki teknolojik yeniliklere büyük bir destek sağlama olasılığı ise düşüktür. Bununla birlikte, gelişmekte olan ülkelerdeki askeri harcamalar, sivil altyapı askeri kullanımları (örneğin yollar ve uydular) ve ordunun afet yardımındaki rolü gibi başka türden yayılma etkileri de söz konusudur (Enimola ve Akoko, 2008: 26; Kılıç vd., 2018). Özetle askeri harcamalar durgun bir ekonomide talebi canlandırır ve büyümeye yol açar, ancak kısıtlı bir ekonomide darboğazlar yaratabilir. Ancak, militarist bir ideolojinin geliştirilmesine yönelik faaliyetler ekonomik kalkınmayı yavaşlatmakla birlikte, milliyetçi tutumlar çabayı ve çıktıyı artırabilir ve ilaveten askeri ve militarist ideoloji işgücünü kontrol etmek için kullanılabilir. Diğer taraftan Melman (1970), ABD sanayi işletmelerinin savunma çıkarları tarafından kontrol edildiği ve "Pentagon Kapitalizmi” olarak adlandırdığı şeyin ayrıntılı analizlerini yaparak, ulusal ürün payını artırmak için güvenlik endişelerinin manipüle edildiğini belirtmiştir. Bu türden askeri-sanayi kompleksinin sivil sektör ve ekonomik büyüme üzerinde dişlama etkileri yaratmak suretiyle büyük olumsuz etkileri olduğuna işaret etmiştir (Melman, 1985).

Çalışmada, askeri harcamaların icatçılık ve buna bağlı olarak yüksek teknolojik mal ihracatına olumlu etkiler yarattığına dair hipotezin sınaması amaçlanmaktadır. Bu çerçevede takip eden ikinci kısımda Ar-Ge ve teknolojik mal ihracatı ele alınmıştır. Üçüncü kısımda askeri harcamalar lehinde ve aleyhinde argümanlar ışığında literatür incelemeleri yapılmıştır. Dördüncü kısımda askeri harcamaların patent ile orta ve yüksek teknolojik mal ihracatı üzerine etkileri panel veri analizleri ile inceleme konusu yapılmıştır. Sonuç kısmında da konu ile ilgili tartışmalar değerlendirilmiş ve politika çıkarımına gidilmiştir.

\section{Ar-Ge ve Teknolojik Mal İhracatı}

Beşeri ve fiziki bilgi birikiminin arttırılması ve bunun yeni uygulama alanlarında kullanımı için sistematik olarak yapılan çalışmalar Ar-Ge çalışmaları olarak adlandırılır (Frascati, 2002: 30). Ayrıca Ar-Ge çalışmaları ile yeni teknik bilgilerin ortaya çıkarılması veya mevcut üretim tekniklerinin iyileştirilmesi yoluyla üretiminin kalitesinin artırılması veya maliyetinin düşürülmesi ifade edilmektedir.

Ar-Ge harcamalarının temel amacı, devamlı değişen bir çevrede faaliyet gösteren özel ve kamu sektörünün, bu değişimleri yakalamalarını sağlamak, gelişmelerine ve büyümelerine yardım etmek ve devamlılığını sağlamaktır (Zerenler vd., 2007: 657-658). Bu kapsamda rekabet gücünü artırma, yeni ürün geliştirme, üretimde maliyetleri düşürme, kaliteyi artırma, ekonomik ve toplumsal fayda düzeyini yükseltme, kaynakların etkin ve verimli kullanımını sağlama, bilgi birikimini arttırma ve ulusal teknolojiler geliştirerek ekonomik kalkınma ve refahı artırmaktır (Eker, 2011: 24).

Savunma sanayi ise dünya genelinde Ar-Ge faaliyetlerine en çok kaynak ayrılan sektörlerden biridir. Adam Smith'e göre toplumun birinci öncelikteki ihtiyacı; milli savunma, adalet, diplomasi ve iç güvenlik hizmetleridir. İkinci derecedeki hizmetler arasında ise milli eğitim, sağlık, bayındırlık hizmetleri yer almaktadır. Milli savunma sistemlerinin geliştirilmesi, yenilikçi ürünler geliştirerek bu sektörde dünya genelinde daha geniş pazarlara erişim, siyasi ve ekonomik dengeler gibi stratejik hedefler dikkate alındığında, savunma sanayiinin önemi daha iyi anlaşılmaktadır. Bu nedenle dünya genelinde birçok ülkede kamu giderleri içerisinde en büyük payı savunma harcamaları oluşturmaktadır. Ülkeler savunma harcamaları yaparken, ya ülke dışındaki gelişmiş ülkelerden ihtiyaç duydukları silah sistemlerini satın alırlar ya da kendileri mevcut Ar-Ge altyapılarını kullanarak ihtiyaç duydukları silah sistemlerini üretmeye çalışırlar. Dışarıdan askeri silah sistemleri almanın alternatifi olan savunma sanayinde Ar-Ge harcamalarına kaynak ayırmak uzun vadede ülke için silah sanayinin gelişimine olanak tanır ve yayılma etkileri ile diğer üretim alanlarında da kullanılmasını besleyebilir. Dolaysıyla kamunun askeri alanda Ar-Ge teknolojilerinin geliştirilmesine verdiği destekler de pozitif dışsallık oluşturarak ekonominin tüm sektörlerini etkiler (Hareye, 2007: 1161). Ancak, askeri harcamaların sürekli pozitiflikler yaydığına ve özellikle büyümeye olumlu yansımaları olduğuna dair tez, konu ile ilgili 1978'de ilk çalışmayı yapan Benoit'in öncü çalışmasından bu yana halen daha kesin olarak ispatlanamamış, muğlak olarak kabul edilmektedir. Buna karşılık Jiang, ABD, Birleşik Krallık ve Almanya gibi ülkelerde askeri teknolojilerin \%15'inden daha azının yalnızca askeri amaçlı olduğunu ve \%80'inden fazlasının sivil amaçlı kullanıldığını ileri sürmektedir. Lu ise, sanal gerçeklik kulaklıklarının ilk olarak savaş uçağı için kasklarda kullanıldığına dikkat çekerek bunu geliştiren şirketin sanal 
gerçeklik, dronlar, robotik ve akıllı giyme gibi altı sivil endüstrinin gelişimine neden olduğuna işaret etmiştir. Askeri şirketler de avantajlı uzmanlıklarını tanıtmak ve çok sayıda yeni yüksek teknoloji endüstri geliştirmek için yerel yönetimlerle birlikte çalışmalarını teşvik etmektedirler (Broude vd., 2013).

Savunma sanayindeki Ar-Ge harcamaları ve sivil ekonominin büyümesi, dört ana konuyu takip eder (Dunne ve Braddon, 2008):

1) Yapılan temel ve askeri Ar-Ge'nin uygulamalı araştırmalara dayandırılması,

2) Teknoloji akışını savunma sanayinden sivil sektörlere evrilmesinin sağlanması,

3) Askeri harcamaların gecikmeli etkilerle de olsa sivil sanayi politikası aracı haline getirilmesi,

4) Savunmanın dönüşümüne paralel olarak sivil kullanım alanlarının belirlenmesi.

Askeri Ar-Ge harcamalarının yüksekliği ve ortaya çıkacak ürünlerin etkinliği özel firmalar için büyük riskler taşıdığından devlet desteği bu tür programlar için gereklidir. Sanayi politikasının uygulanmasında askeri harcamalar dolaylı olarak güçlü bir araç olmuştur. Seçerek savunmaya yönelik Ar-Ge ve hükümetler için çeşitli teknik alanlar, politika hedeflerini oluşturabilir. Havacıllk, elektronik ve bilgisayar gibi sektörler de savunma sanayi programları ile geliştirilmiş̧tir. Askeri teknolojinin bölünmesi ve sivil teknolojiye uyarlanmasında şu alternatif yöntemler bulunmaktadır:

1) Endüstri içi transfer: teknoloji transferinin askeri uçaklardan ticari uçaklara yönelik olması,

2) Sektörler arası transfer: lazer transferi silah sistemlerinden biyomedikal teknolojiye uyarlanması,

3) Firma içi transferler: firmanın kendi birimleri arasında ürün aktarma, Ar-Ge ve üretim fonksiyonları arasındaki teknoloji transferinde kolaylıklar ve geçişkenliklere dikkat edilmesi,

4) Firmalar arası transferler: bir firmadan diğerine çelik işleme teknoloji transferi yapılması.

Askeri harcamaların veya savaş ekonomisinin sivil sektörleri uyarmasına örnek duruma I. Dünya Savaşı verilebilir. I. Dünya Savaşı sonrası dönemde yukarıda sayılan sıkıştırma etkilerine karşı askeri gücü temin etme arayışları imalat sanayinin de temerküzünü tetikleyen unsurlardan olmuştur. Aşağıdaki tabloda 1913-1938 arası dönemde yıllık imalat sanayi üretim endeks değerleri verilmiştir (Kennedy, 1990: 348, 351).

\begin{tabular}{|c|c|c|c|c|c|c|c|c|}
\hline Y1llar & Dünya & ABD & Almanya & İngiltere & Fransa & SSCB & İtalya & Japonya \\
\hline 1913 & 100.0 & 100.0 & 100.0 & 100.0 & 100.0 & 100.0 & 100.0 & 100.0 \\
1920 & 93.2 & 9.2 & 59.0 & 92.6 & 70.4 & 12.8 & 95.2 & 176.0 \\
1925 & 120.7 & 120.7 & 94.9 & 86.3 & 114.3 & 70.2 & 156.8 & 221.8 \\
1929 & 153.3 & 153.3 & 117.3 & 100.3 & 142.7 & 181.4 & 181.0 & 324.0 \\
1930 & 137.5 & 13.5 & 101.6 & 91.3 & 139.9 & 235.5 & 164.0 & 294.9 \\
1931 & 122.5 & 122.5 & 85.1 & 82.4 & 122.6 & 293.9 & 145.1 & 288.1 \\
1932 & 108.4 & 108.4 & 70.2 & 82.5 & 105.4 & 326.1 & 123.3 & 309.1 \\
1933 & 121.7 & 121.7 & 79.4 & 83.3 & 119.8 & 363.2 & 133.2 & 360.7 \\
1935 & 154.5 & 154.5 & 116.7 & 107.9 & 111.4 & 533.7 & 162.2 & 457.8 \\
1937 & 195.8 & 185.8 & 138.1 & 127.8 & 123.8 & 722.2 & 194.5 & 551.0 \\
1938 & 182.7 & 182.7 & 149.3 & 117.6 & 114.6 & 857.3 & 195.2 & 552.0 \\
\hline
\end{tabular}

Tablo 1: 1913-1938 Ylllı Imalat Sanayi Üretim Endeksleri (1993=100) Kaynak: Milletler Cemiyeti, World Economic Survey, Genova, 1945: 134'den nakleden Kennedy, 1990: 351.

Askeri amaçlar için Ar-Ge çalışmalarının sivil uygulamaları bulunmaktadır veya ilerleyen süreçte ortaya çıkmaktadır. Bunlar içerisinde internet uygulaması Pentagon'un askeri amaçlarla hazırlamış olduğu bir haberleşme programıdır. Benzer şekilde askeri altyapı (yollar, havaalanları ve uydular) sivil kullanıma önemli bir destek sunmaktadır (Benoit, 1978: 277-8). Ayrıca askerlik hizmetinin becerilerin yayılmasına katkıda bulunduğu da önemli bir gerçektir. Weede (1992), askerlik hizmetinin bir tür okul ve beşeri sermaye oluşumu sağlayan birim olarak nitelendirmiştir (Dreze, 2006). Askeri amaçlı olarak geliştirilen ve sonrasında sivil kullanımda çığır açan temel teknolojik ürünlerden bazıları da şunlardır: www; World Wide Web, 1977 yılında ataları olan İleri Araştırma Projeleri Ajans Ağı (ARPANET) şeklinde hayata başlamıştır. GPS de II. Dünya Savaşı ve kısa bir süre sonra gelen uzay yarışından sonra, insanlığın atmosfere uydu göndermeye başlaması çok uzun sürmemiştir. 1990'larda bu uydulardan bazıları $\mathrm{ABD}$ hükümeti tarafindan sahip olunan ve işletilen uzay tabanlı bir radyo navigasyon sistemi için kullanılmıştır. Bu sistem, askerleri savaş alanında güvende tutmak için değil, aynı zamanda hedefleri belirlemek, haritalamayı geliştirmek, uçak yörüngelerini izlemek ve daha fazlası için de önemlidir. Teknoloji genişledikçe ve geliştikçe sivil dünyaya da taşınmıştır. Artık GPS özellikli akıllı telefonların icadı sayesinde cepte navigasyon da dahil olmak üzere günlük yaşamda kullanılmaktadır. Radar, günlük yaşamda benimsenen bir diğer teknolojidir. Radar geliştikçe, bilim insanları verileri incelemede ve ardından havayı tespit etmede kullanmıştır; yağmur, kar, dolu ve daha fazlası dahil olmak üzere hava tahminine yardımcı olmuştur. Dijital kamera teknolojisi başlangıçta düşman kurulumlarının yüksek çözünürlüklü havadan görüntülerini yakalamak için kullanıldıkları erken casus uydularda hayata geçmiştir. Teknoloji, özellikle Soğuk Savaş sırasında askeri alanda ilerlemiş ve 1970'lerde ilk bağımsız dijital kamera oluşmuştur. Bilgisayarlar için orijinal teknoloji, bugün olduğundan çok daha arkaik konumdaydı. Orijinal bilgisayarlar Nazi şifreleme makineleri tarafından gönderilen mesajları deşifre etmek için Colossus adlı elektronik dijital programlanabilir bir bilgisayar icat edilmiş ve bu teknoloji II. Dünya Savaşı 
sırasında daha hızlı gelişmiştir. Bilgisayarlar, Müttefiklerin savaşı kazanmasına ve modern dijital bilgisayarın çağına başlamalarına yardımcı olmanın küçük bir parçası olmuştur. Bunu izleyen yıllarda, bilgisayarlar cebe sığacak şekilde teknoloji büyük ölçüde gelişmiş ve küçülmüştür. Mucit Frank Whittle, 1920'lerin sonunda bir jet motoru tasarımı üzerinde çalışmalar yapmıştır. Ancak, II. Dünya Savaşı'nın son yıllarına kadar jet motoru teknolojisi yavaş ilerlemiştir. 1944'te dünyanın ilk jet avc1 uçağ 1 Messerschmitt Me262 şeklinde gökyüzüne çıkmıştır. Takip eden yıllarda, jet motoru teknolojisi gelişmeye devam etmiş ve şimdi göklerde ortak bir uçak vazifesi görmektedir. Ayrıca dondurarak kurutma işlemi başlangıçta 1906 yılında icat edilmiştir. Buradaki amaç kan serumunun dondurarak kurutulduğu zaman, taşıma sırasında bozulmasının önlenebilmesiydi. II. Dünya Savaşı sırasında daha fazla kullanıma alındı. Bu, yaralıların tıbbi tedavisine izin vermiş ve sayısız hayat kurtarmıştır. Takip eden yıllarda, dondurarak kurutma tekniği, gıda işleme ile ilaç, seramik ve sentetik üretimi ve çok daha fazlasına dönüşmüştür.

Savunma harcamalarının ekonomi üzerine etkilerini özetlenecek olursa, negatif ve pozitif yönlü etkiler şu şekilde sıralanabilir;

(i) Pozitif etkileri; Savunma harcamalarının pozitif dışsal etkileri ile faktör verimliliğinin artırılması mümkünüdür. Özellikle Ar-Ge faaliyetleri sonucunda ortaya çıkan yeni teknolojiler kısa sürede tüm topluma yayılacaktır. Nitekim elektronik ve ulaştırma alanlarındaki icatların neredeyse tamamı ilk defa askeri nedenlerle gerçekleştirilmiştir. Silah üretim teknolojisindeki gelişmeler, teknolojik geri beslemeler ve endüstriler arası bağlantılar ile sivil amaçlı üretimi desteklemektedir. Gelişmiş ülkelerde kimi zaman görülen efektif talep azlığ sonucunda ortaya çıkan üretimdeki düşüşler savunma harcamalarının iktisadi faaliyetleri teşvik edip üretimi canlandırması ile aşılabilmektedir. Savunma harcamaları durgunluk dönemlerinde artırılarak ve enflasyonist dönemlerde ise azaltılarak kamu maliyesi aracı olarak kullanılabilmektedir.

(ii) Negatif etkileri; Savunma harcamaları, kıt kaynakların doğrudan prodüktif yatırımlardan ve beşeri sermaye birikiminden uzaklaşmasına yol açar. Savunma harcamaları yüksek büyüme oranları içeren kalkınma projelerinde kullanılacak kaynakları başka alanlara kaydırmak suretiyle yüksek bir firsat maliyetine neden olabilirler. Nitekim ABD'de Japonya'ya oranla verimlilik düşüşünün nedenleri arasında yüksek savunma harcamalarının getirdiği yük sayılmaktadır. Eğer savunma harcamaları ağır bir sınai temeli gerektiren silah üretimini içeriyorsa, ithal ikameci sanayileşme stratejisi iyice güçlenir, bu da ihracatın teşvikini ve tarım gibi sektörlerin gelişimini engeller. Savunma harcamalarının finansmanının vergilerle yapılması ekonomide vergi yapısını bozabilir, tüketim ve/veya yatırım miktarını ve paralelinde büyüme oranını düşürebilir. Savunma alanında genellikle uzmanlar, bilim adamları ve mühendisler gibi nitelikli işgücü istihdam edilir. Bu ise, ekonominin diğer alanları için beşeri sermaye arzını azaltır. Savunma harcamaları içinde önemli bir kalem olan silahların bir kısmının yurtdışından ithal edilmesi, gelişmekte olan ülkelerin kıt döviz kaynakları üzerinde ciddi açıklar oluşturur. Savunma harcamaları grubu içinde yer alan ve verimliliğe olumlu katkısı olan Ar-Ge harcamalarının sivil harcamaların aleyhine olması, iktisadi büyüme üzerinde negatif etkiler ortaya çıkarır (Dunne ve Braddon, 2008).

\section{Literatür İncelemesi}

Sivil projelerde geliştirilen ticari teknolojiler zamana bağlı olarak askeri sektöre dönerken, askeri olmayan ticari teknolojilerdeki hızlı büyüme, sivil sektörü birkaç niş alanı dışındaki tüm alanlarda teknoloji lideri haline getirir (Brzoska, 2001). Bu durum dikkate alındığında, askeri teçhizat üreticileri de giderek askeri uygulamalara adapte olabilecekleri sivil teknolojiye yönelmektedir. Sivil ve askeri teknoloji arasındaki sınırlar daha az belirgindir. Sivilden askeri sektöre küresel olarak ticari Ar-Ge ve ilgili teknoloji transferi artık silah sistemi geliştirmede önemli bir güçtür ve bu durum hem savunma sanayinin hem de özellikle savunma elektroniği pazarını dönüştürmeye devam edeceği söylenebilir (Braddon vd, 2003).

Askeri teknolojilerin sivil teknolojilere geçişkenlik ve uyarlanma süreçleri daha çok teorik perspektifte ortaya koyulurken, askeri harcamaların Ar-Ge ve buna bağlı olarak patent ile yüksek teknolojik mal ihracatı üzerine etkileri konusunda yapılan çalışmalar, özellikle uzun dönemli etkileri araştırmadaki zorluklar nedeniyle oldukça kısırdır. Bunun yerine daha çok kısa dönemli ilişkileri dikkate alacak şekilde büyüme etkilerini araştıran çalışmaların yaygınlığı dikkat çekmektedir. Askeri harcamaların ekonomik büyüme üzerindeki etkileri konusundaki literatür ise bu harcamaların büyüme üzerine olumlu, olumsuz ve nötr etkiler yakalayan çalışmalar şeklinde sınıflandırılmaktadır. Bu çalışmalar arasında pozitif ilişki bulanlar arasında Benoit (1978), Değer ve Smith (1983), DeRouen (2000), Ateşoğlu (2002), Candar (2003), Galvin (2003), Erdoğdu (2006), Aizenman ve Glick (2006), Karagianni ve Pempetzoglu (2009), Chairil vd. (2013) örnek verilebilir. Negatif yönde ilişki yakalayan çalışmalar arasında Karagöl ve Palaz (2004), Chang vd. (2011), Dunne ve Tian (2013), Korkmaz (2015), Çetin ve Güzel (2019) sayılabilir. Üçüncü grupta ise askeri harcamalar ve ekonomik büyüme arasında ilişki olmadığını yönünde bulgular elde eden araştırmalar yer almaktadır. Bunlar arasında Kollias (1997), Gerace (2002), Durgun ve Timur (2017)'un çalışmaları sayılabilir.

Askeri harcamalar ile büyüme literatüründe konsensüsün sağlanamadığı, yani bir kısım çalışmalarda pozitif, bir kısmında negatif ve bir kısmında da ilişki yakalanamaması hem ülke, hem dönem, hem de yöntemdeki farklılıklardan kaynaklanabilmektedir. Çalışmanın temel motivasyonunu oluşturan askeri harcamaların Ar-Ge ve 
buna bağlı olarak patent yaratma etkileri ile yüksek teknolojik mala dönüşümünün yansıması olarak yüksek teknolojik ihracata etkileri üzerine literatür ise yok denecek kadardır. Konuyla ilgili olarak Leonard (1971) tarafından yapılan araştırma mikro bazda, yani işletme düzeyindedir. $\mathrm{Bu}$ araştırmada $\mathrm{ABD}$ araştırma yoğunluğunun, satış, varlık, net gelir ve diğer değişkenlerin neredeyse tamamını oluşturan 16 sektörde bunların büyüme ile pozitif korelasyon gösterdiğini ortaya koymuştur. Buna karşılık iki sanayi (uçak ile füze ve elektrikli ekipman) alanında Ar-Ge kaynaklarının savunma veya alan kullanımlarına aşırı tahsisi ile endüstriyel büyümenin yavaşladığı gösterilmiş̧tir. Yakovlev (2007) tarafından yapılan ve 28 ülke için 1965-2000 arası dönemi kapsayan panel veri analizlerinde Solow büyüme formu kullanarak askeri harcamalar ile net askeri mal ihracatının büyümeyi olumsuzlaştırdığı tespit etmiştir. Sezer (2018), 1988-2015 arası dönem için G-7 ve NIC ülkeleri için yüksek teknolojik mal ihracatında ve kişi başı gelirde askeri harcamaların etkilerini araştırdığı analizlerde çift taraflı logaritmik form kullanmıştır. G-7 ve NIC ülkeleri için askeri harcamalardaki \%1'lik artışların yüksek teknolojik mal ihracatına (sırasıyla $\% 0.71 \mathrm{ve} \% 1.7$ ) ve kişi başı gelire (sırasıyla $\% 0.98$ ve \%0.96) pozitif etkilerinin olduğunu tespit edilmiştir. Heo ve DeRouen Jr. (1998) Güney Doğu Asya'da 5 yükselen ekonomi üzerine askeri harcamalar, teknolojik değişme ve ekonomik büyüme ilişkilerini araştırdıkları çalışmalarında 1961-1990 arası dönemi incelemişlerdir. Bir üretim fonksiyonu mantığı ile yapılan araştırmada hem teknolojik sürecin hem de askeri harcamaların büyümeyi uyardığı tespit edilmiştir. Ward (2008) tarafından yapılan çalışma 25 gelişmiş ülke ve 1985-2005 dönemini kapsamıştır. Çalışmada kamu tarafından yürütülen Ar-Ge harcamalarının özel sektör Ar-Ge harcamaları üzerine dışlama etkisi yaptı̆̆ı ve verimliliği de azalttığı tespit edilmiştir. Askeri harcamaların teknoloji etkileri ve yayılımı üzerine Lee ve Sohn (2017) tarafından yapılan çalışmada ABD için 1976-2014 arası dönem verileri kullanılmıştır. Çalışmada askeri harcamalara bağlı olarak askeri teknolojideki iyileşmelerin sivil teknolojileri de uyardığı ve patenti artırıcı etkiler yaptığı tespit edilmiştir.

\section{Ekonometrik Bulgular}

Çalışmada genel anlamda askeri harcamaların verimsizliğine dair savların yaygınlığına karşılık, devletin küçük olması gerektiğini savunan liberallerin öncüsü A. Smith bile devlete biçilen fonksiyonlar arasında saydığı iç ve dış güvenlik unsurundan dolayı askeri harcamaların elzem olduğuna ve hatta dışa bağımlı olunmamasına işaret etmiştir. Askeri harcamaların dolaylı olarak ekonomik aktivite için uygun iklim yaratma fonksiyonuna ilaveten bu alanda zamana bağlı olarak rekabet gücü elde edilmesi ile birlikte ihracat kazançları sağlaması gibi fonksiyonlarıyla doğrudan ekonomiye olumlu yansımalar yaratabilmektedir. Buna ilaveten askeri alandaki yenilikçiliğin bir süre sonra sivil sektörlerde kullanılabilir hale gelmesi ve bunun da yine sivil ihracatı artırıcı etkiler doğurması kuvvetle muhtemeldir. Dolayısıyla askeri harcamalar Ar-Ge üstlenmesine bağlı olarak yenilikçiliği/inovasyonu artırırken, yenilikçiliğin de üretime dönüşmesi ile hem askeri ihracatta hem de bunun sivil sanayiye evrilmesiyle sivil ihracatta artışların ortaya çıkması beklenir.

$\mathrm{Bu}$ beklentinin ve dolayısıyla hipotezin sınanması amacıyla ulaşıllabilir veri setine sahip G20 ülkeleri ile Malezya'dan oluşan 16 ülkenin 1991-2018 arası dönem verileri analizlere tabi tutulmuştur. Askeri harcamalar SIPRI ve burada kullanılan diğer değişkenler de World Bank veri tabanından derlenmiştir. Bu bağlamda çalışma iki modelle sınanmaya çalışılmıştır. Modellerin matematiksel formu aşağıdaki gibidir:

$$
\begin{aligned}
& P T=f(M E) \\
& T X=f(M E)
\end{aligned}
$$

(1) ve (2) nolu matematiksel formlarda PT patent sayısını, TX teknolojik mal ihracatının toplam mal ve hizmet ihracatına oranını ve ME de askeri harcamaların GSYIH'ye oranını temsil etmektedir. Bu iki forma kontrol değişkenlerin de eklenmesiyle oluşturulan ekonometrik modeller de aşağıdaki gibidir:

$$
\begin{aligned}
& \mathrm{LPT}=\alpha_{0}+\beta_{0} \mathrm{ME}+\beta_{1} \mathrm{LPC}+\beta_{2} \mathrm{IHR}+\beta_{3} \mathrm{GCF} \\
& \mathrm{TX}=\alpha_{0}+\beta_{0} \mathrm{ME}+\beta_{1} \mathrm{LPC}+\beta_{2} \mathrm{NIHR}+\beta_{3} \mathrm{GCF}
\end{aligned}
$$

(3) ve (4) nolu modellerde LPT ve LPC sırasıyla patent sayısının ve kişi başı gelirin logaritmasını ifade etmektedir. Modellerde kullanılan IHR, toplam mal ve hizmet ihracatının GSYIH'ye oranını; NIHR, teknolojik mal hariç ihracatın GSYIH'ye oranını; TX, orta ve yüksek teknolojik mal ihracatının toplam mal ve hizmet ihracatına oranını ve GCF de sabit sermaye birikiminin GSYİH'ye oranın göstermektedir. Örnek büyüklüğü olarak ifade edilen $n=16$ ve zaman boyutunu temsilen $\mathrm{t}=28$ gözlemden oluşmaktadır. Burada $\mathrm{n}$ ve $\mathrm{t}$ boyutları nedeniyle tahminler de panel veri analizleri kapsamında yapılacaktır. Panel veride zaman boyutunun varlığı sahte regresyon sorunsalının olabileceğine işaret ettiğinden ilk etapta serilerin durağan olup olmadıkları araştırılmıştır. 


\begin{tabular}{|l|c|c|c|c|}
\hline Değişkenler & Levin, Lin \& Chu t & $\begin{array}{c}\text { Im, Pesaran and } \\
\text { Shin W-stat }\end{array}$ & $\begin{array}{c}\text { ADF - Fisher Chi- } \\
\text { square }\end{array}$ & $\begin{array}{c}\text { PP - Fisher Chi- } \\
\text { square }\end{array}$ \\
\hline LPT & $-3.51^{(\mathrm{a})}$ & $-1.77^{(\mathrm{b})}$ & $47.81^{(\mathrm{b})}$ & $50.78^{(\mathrm{b})}$ \\
\hline TX & $-2.36^{(\mathrm{a})}$ & -0.84 & 34.41 & $51.65^{(\mathrm{b})}$ \\
\hline ME & $-7.99^{(\mathrm{a})}$ & $-5.33^{(\mathrm{a})}$ & $92.48^{(\mathrm{a})}$ & $110.61^{(\mathrm{a})}$ \\
\hline LPC & $-5.84^{(\mathrm{a})}$ & 0.38 & 34.10 & $50.06^{(\mathrm{b})}$ \\
\hline IHR & $-1.94^{(\mathrm{b})}$ & $-2.29^{(\mathrm{a})}$ & $48.85^{(\mathrm{b})}$ & $54.88^{(\mathrm{a})}$ \\
\hline NIHR & $-1.88^{(\mathrm{b})}$ & $-2.94^{(\mathrm{a})}$ & $58.75^{(\mathrm{a})}$ & $67.61^{(\mathrm{a})}$ \\
\hline GFC & $-2.44^{(\mathrm{a})}$ & $-2.79^{(\mathrm{a})}$ & $53.25^{(\mathrm{a})}$ & $53.35^{(\mathrm{a})}$ \\
\hline
\end{tabular}

Not: (a) \%1, (b) \%5 ve (c) \%10 önem düzeyinde anlamlılı̆̆ göstermektedir. Bu değişkenlerden LPT, TX, ME, LPC ve GEFC sabitli; IHR ve NIHR ise sabitli-trendli formda birik kök sinamaları yapılmıştır

\section{Tablo 2: Değişkenlerin Seviye Değerlerinde Birim Kök Sınamaları}

Durağanlık sınaması sonuçlarına göre (3) ve (4) nolu modelleri oluşturan değişkenlerin tümünün seviye değerlerinde durağan olduğu gözükmektedir. Dolayısıyla seviye değerleri cinsinden yapılacak tahminlerin sahte regresyon içermeyeceği söylenebilir.

(3) nolu ekonometrik model kapsamında değişkenlerin korelasyon katsayıları Tablo 3'de verilmiştir.

\begin{tabular}{|c|c|c|c|c|c|}
\hline & LPT & ME & LPC & IHR & GCF \\
\hline LPT & 1.000 & & & & \\
\hline ME & 0.360 & 1.000 & & & \\
\hline LPC & 0.413 & 0.111 & 1.000 & & \\
\hline IHR & -0.289 & -0.158 & -0.056 & 1.000 & 1.000 \\
\hline GCF & -0.022 & 0.072 & -0.239 & 0.161 & \\
\hline
\end{tabular}

Tablo 3: (3) nolu Modele İlişkin Korelasyon Tablosu

LPT değişkenini üzerine açıklayıcı değişkenlerin korelasyon gücü dikkate alındığında, LPC ve ME değişkenlerinin orta düzeyde ve pozitif etkilerde bulunduğu; buna karşılık IHR ve GCF'nin ise negatif ve zayıf etkiler yarattığı gözükmektedir.

(3) nolu ekonometrik model kapsamında LPT değişkeni bağımlı değişken olmak üzere açıklayıcı değişkenlerin regresyon tahmin sonuçları Tablo 4'de verilmiştir. Burada (3) nolu model ME'nin sıfir gecikme, yani cari değerleri ile tahminine dayalı iken; gecikmelerle birlikte 5 adet daha ilave tahminde bulunulmuştur. Bu 5 tahmin, ME dışındaki diğer 3 değişken cari değerler ile tahmine koşturulmuş; buna karşılık ME değerleri bir gecikmeli, iki gecikmeli, üç gecikmeli, dört gecikmeli ve beş gecikmeli olacak şekilde ayrı ayrı tahminlemelerde kullanılmıştır. ME’nin gecikmelerinin alınarak regresyona koşturulmasında hem PT açısından hem de TX açısından bu değişkenin etkilerinin gecikmeli bir şekilde ortaya çıkacağına dair teorik ve ampirik literatür hareket noktasını oluşturmuştur.

\begin{tabular}{|l|c|c|c|c|c|c|}
\hline $\begin{array}{l}\text { Bağımsız } \\
\text { Değişkenler }\end{array}$ & $\begin{array}{c}\text { ME'nin sıfir } \\
\text { gecikmeli } \\
\text { tahmini }\end{array}$ & $\begin{array}{c}\text { ME'nin bir } \\
\text { gecikmeli } \\
\text { tahmini }\end{array}$ & $\begin{array}{c}\text { ME'nin iki } \\
\text { gecikmeli } \\
\text { tahmini }\end{array}$ & $\begin{array}{c}\text { ME'nin üç } \\
\text { gecikmeli } \\
\text { tahmini }\end{array}$ & $\begin{array}{c}\text { ME'nin dört } \\
\text { gecikmeli } \\
\text { tahmini }\end{array}$ & $\begin{array}{c}\text { ME'nin beş } \\
\text { gecikmeli } \\
\text { tahmini }\end{array}$ \\
\hline \multirow{2}{*}{ LPC } & 0.384 & 0.382 & 0.380 & 0.383 & 0.385 & 0.381 \\
& $(6.79)$ & $(6.66)$ & $(6.51)$ & $(6.40)$ & $(6.26)$ & $(6.07)$ \\
\hline \multirow{2}{*}{ IHR } & 0.615 & 0.604 & 0.599 & 0.586 & 0.573 & 0.563 \\
& $(9.66)$ & $(9.32)$ & $(9.07)$ & $(8.71)$ & $(8.32)$ & $(7.97)$ \\
\hline \multirow{2}{*}{ GFC } & -0.016 & -0.016 & -0.017 & -0.017 & -0.017 & -0.017 \\
& $(-5.95)$ & $(-6.04)$ & $(-6.14)$ & $(-6.20)$ & $(-6.15)$ & $(-6.10)$ \\
\hline \multirow{2}{*}{ C } & 0.025 & 0.027 & 0.027 & 0.028 & 0.028 & 0.029 \\
& $(2.20)$ & $(2.33)$ & $(2.29)$ & $(2.29)$ & $(2.21)$ & $(2.16)$ \\
\hline R & 2.803 & 2.894 & 2.970 & 3.100 & 3.244 & 3.351 \\
\hline F-istatistik & $(3.82)$ & $(3.88)$ & $(3.91)$ & $(4.00)$ & $(4.09)$ & $(4.11)$ \\
(prob) & 0.326 & 0.323 & 0.324 & 0.323 & 0.320 & 0.316 \\
\hline
\end{tabular}

Not: Parantez içerisindeki değerler t-değerlerini göstermektedir.

Tablo 4: (3) nolu Modele Illişkin Regresyon Tahmin Sonuçları

(3) nolu model kapsamında ve bu modelde yer alan ME'nin cari değeri, yani 0 gecikmeli değeri ile bu değişkenin 1'den 5'e kadar gecikmelerinin de regresyona koşturulduğu tahmin sonuçlarında askeri harcamaların, yani ME'nin LPT'yi pozitif ve istatistiki açıdan anlamlı bir şekilde etkilediği gözükmektedir. Kontrol değişkenler olarak modelde kullanılan LPC ve GCF'nin pozitif ve anlamlı; buna karşılık IHR değişkeninin etkisi ise negatif ve anlamlı bulunmuştur. Buradaki sonuç, literatürde Heo ve DeRouen Jr. (2018) ile Lee ve Sohn (2017) tarafindan 
yapılan çalışmalar ile uyumlu; Ward (2008)'ın çalışmasıyla zıt yönde bulgu vermiştir. Model bir bütün olarak değerlendirildiğinde, askeri harcamalar ile patent sayısı arasında pozitif ve anlamlı ilişkilerin varlığı, ele alınan ülke grubunda askeri harcamaların yenilikçiliği tetikleyen unsur olduğuna işaret etmektedir. Yine bu modelde kişi başı gelir ile sermaye birikiminin patenti uyarıcı etkiler yarattığı tespit edilirken, mal ve hizmet ihracatının GSYİH içerisindeki payındaki artışların patenti olumsuz yönde etkilediği gözükmektedir. Bu değişken dışındaki tüm değişkenlerin beklenti ile örtüşen bulguları söz konusu iken, ihracattaki artışların patenti olumsuz etkilemesi, kuvvetle muhtemel kesin rekabet gücünün olduğu alanlardaki dış satımın patenti etkilemekten uzak ve hatta negatif etkilediği gözükmektedir.

(4) nolu ekonometrik model kapsamında değişkenlerin korelasyon katsayıları ise Tablo 5'de verilmiştir.

\begin{tabular}{|c|c|c|c|c|c|}
\hline & TX & ME & LPC & NIHR & GCF \\
\hline TX & 1.000 & & & & \\
\hline ME & -0.111 & 1.000 & & & \\
\hline LPC & 0.427 & 0.111 & 1.000 & & \\
\hline NIHR & -0.311 & -0.087 & -0.257 & 1.000 & \\
\hline GCF & -0.070 & 0.072 & -0.239 & 0.159 & 1.000 \\
\hline
\end{tabular}

Tablo 5: (4) nolu Modele İlişkin Korelasyon Tablosu

TX değişkenini üzerine açıklayıcı değişkenlerin korelasyon gücü dikkate alındığında, LPC'nin orta düzeyde ve pozitif etkilerde bulunduğu; buna karşılık ME, NIHR ve GCF'nin ise negatif etkilerinin olduğu, ME ve GCF'nin zayıf ve NEXP'in ise orta düzeyde etkiler yarattığı gözükmektedir.

(4) nolu ekonometrik model kapsamında TX değişkeni bağımlı değişken olmak üzere açıklayıcı değişkenlerin regresyon tahmin sonuçları Tablo 6'da verilmiştir. Burada da (3) nolu modelde olduğu gibi (4) nolu modelde de ME'nin sıfir gecikme, yani cari değerleri ile tahminine dayalı iken; gecikmelerle birlikte 5 adet daha ilave tahminde bulunulmuştur.

\begin{tabular}{|l|c|c|c|c|c|c|}
\hline $\begin{array}{l}\text { Bağımsız } \\
\text { Değişkenler }\end{array}$ & $\begin{array}{c}\text { ME’nin sıfir } \\
\text { gecikmeli } \\
\text { tahmini }\end{array}$ & $\begin{array}{c}\text { ME'nin bir } \\
\text { gecikmeli } \\
\text { tahmini }\end{array}$ & $\begin{array}{c}\text { ME’nin iki } \\
\text { gecikmeli } \\
\text { tahmini }\end{array}$ & $\begin{array}{c}\text { ME’nin üç } \\
\text { gecikmeli } \\
\text { tahmini }\end{array}$ & $\begin{array}{c}\text { ME'nin dört } \\
\text { gecikmeli } \\
\text { tahmini }\end{array}$ & $\begin{array}{c}\text { ME’nin beş } \\
\text { gecikmeli } \\
\text { tahmini }\end{array}$ \\
\hline \multirow{2}{*}{ LE } & -3.134 & -2.971 & -2.825 & -2.622 & -2.426 & -2.295 \\
$(-4.42)$ & $(-4.13)$ & $(-3.85)$ & $(-3.46)$ & $(-3.12)$ & $(-2.88)$ \\
\hline \multirow{2}{*}{ NIHR } & 7.724 & 7.488 & 7.289 & 7.059 & 6.812 & 6.584 \\
& $(9.35)$ & $(8.90)$ & $(8.48)$ & $(8.03)$ & $(7.56)$ & $(7.14)$ \\
\hline \multirow{2}{*}{ GFC } & -0.493 & -0.499 & -0.500 & -0.499 & -0.495 & -0.496 \\
& $(-5.53)$ & $(-5.49)$ & $(-5.33)$ & $(-5.20)$ & $(-5.04)$ & $(-4.96)$ \\
\hline \multirow{2}{*}{ C } & 0.262 & 0.247 & 0.201 & 0.156 & 0.075 & -0.015 \\
& $(1.82)$ & $(1.66)$ & $(1.31)$ & $(0.98)$ & $(0.456)$ & $(-0.09)$ \\
\hline R & -14.300 & -11.661 & -8.762 & -5.750 & -1.790 & 2.382 \\
\hline F-istatistik & $(-1.48)$ & $(-1.18)$ & $(-0.87)$ & $(-0.55)$ & $(-0.169)$ & $(0.22)$ \\
(prob) & 0.262 & 0.255 & 0.245 & 0.235 & 0.224 & 0.218 \\
\hline
\end{tabular}

Not: Parantez içerisindeki değerler t-değerlerini göstermektedir.

\section{Tablo 6: (4) nolu Modele İlişkin Regresyon Tahmin Sonuçları}

(4) nolu model kapsamında ve bu modelde yer alan ME'nin cari değeri, yani 0 gecikmeli değeri ile bu değişkenin 1 'den 5'e kadar gecikmelerinin de regresyona koşturulduğu tahmin sonuçlarında askeri harcamaların, yani ME'nin TX'i negatif ve istatistiki açıdan anlamlı bir şekilde etkilediği gözükmektedir. Elde edilen bu bulgu, Yakovlev (2007) ile Sezer (2018) tarafından yapılan çalışmayla taban tabana zıttır. Ancak, gecikme değerleri negatif olsa da, gecikmelerdeki artışa bağlı olarak bu negatifliğin giderek küçüldüğü dikkat çekmektedir. Bu durum da kuvvetle muhtemel daha uzun gecikmelerde artıya dönüş yönünde bir trendin varlığına işaret etmektedir. Ancak, veri setinin daha fazla gecikmeyi modellemeye imkan vermemesi, bu türden ispatı yapmaktan uzak kalınmaya yol açtığı; dolayısıyla sadece 5 gecikmeye kadarki katsayıların trendinden hareketle böylesi bir çıkarımın yapıldığı söylenebilir. Diğer taraftan kontrol değişkenler olarak modelde kullanılan LPC ve GCF'nin pozitif etkilerine karşılık, GECF’nin etkisi istatistiki açıdan zayıf addedilebilir. IHR değişkeninin etkisi ise negatif ve anlamlı bulunmuştur. Ayrıca modelde NIHR ile ifade edilen orta ve yüksek teknolojik mal dışındaki mal ve hizmet ihracatının GSYİH'ye oranı da işaret açısından negatif ve istatistiki açıdan da anlamlı bulunmuştur ki, bu bulgu Yakovlev (2007) ile örtüşmektedir. Bu da ülkelerin karşılaştırmalı üstünlük yapısının orta ve yüksek teknolojik mallara yönelmesine paralel olarak diğer ihracat kalemlerinde rekabet güçlerinin ve böylece ihracatlarının azaldığına işaret etmektedir. Model bir bütün olarak değerlendirildiğinde, askeri harcamalar ile orta ve yüksek teknolojik mal ihracatı arasında negatif ve anlamlı ilişkilerin varlığı, ele alınan ülke grubunda askeri harcamaların 
orta ve yüksek teknolojik mal ihracatını tetiklemekten uzak kaldığını göstermektedir. Ancak, yenilikçiliği olumlu etkileyen askeri harcamaların bunun ticarileşmesine etkisi olmadığını söylemek, 5 gecikmeli modellerde katsayının giderek düşmesinden de anlaşılacağı gibi güçlü bir ifade olmaktan uzaktır. Diğer bir ifadeyle askeri harcamalara bağlı yenilikçiliğin ticarileşmeye dönüşüm süresinin oldukça uzun olduğuna dair bir bulgunun varlığından bahsedilebilir.

\section{Sonuç}

İktisat literatüründe askeri harcamaların verimsiz olduğunu savunan görüşlere karşılık, bu verimsizliğin hem uzun dönemde hem de dolaylı mekanizmalar yoluyla ekonomide pozitif ivme sağlayıcı rol üstlendiği de kabul görmektedir. Askeri harcamaların uzun dönemde ve dolaylı mekanizmalar yoluyla genel ekonomiye olumlu yansımaları arasında, askeri harcamaların iç ve dış güvenliği sağlayıcı fonksiyon üstlenerek sivil ekonomik aktiviteler için olumlu iklim yaratması başta gelmektedir. Diğer taraftan askeri harcamaların özellikle askeri teknolojiler bağlamında Ar-Ge'yi de içermesi ve bunun yenilikçiliği besleyen unsur olması, ülkeler için ilk etapta askeri teknolojiler alanında rekabet gücünün yükselmesi anlamı taşıdığı açıktır. Ayrıca askeri alandaki bu yenilikçiliğin de bir süre sonra sivil kullanıma evrilmesi söz konusu olabilmekte ve bu da orta ve yüksek teknolojik mal ihracatını ve buna bağlı olarak ulusal gelir artışlarını tetikleyebilmektedir.

Bu konu daha çok teorik düzeyde ele alınırken, ampirik literatürün oldukça kısır ve daha çok da saha araştırması niteliğinde, yani mikroekonomik boyutta kaldığı dikkat çekmektedir. Çalışmada uygun veri setine sahip G20 ülkelerinden 15'i ile Malezya olmak üzere 16 ülke üzerine 1991-2018 arası dönem için panel veri analizlerine gidilmiştir. İki modelin uygulandığı çalışmada, modellerden birisi askeri harcamaların patent ve ikincisi de orta ve yüksek teknolojik mal ihracatı üzerine etkisini ele almıştır. Elde edilen bulgularda, askeri harcamaların patent olgusunu pozitif ve istatistiki açıdan anlamlı yönde etkilediği gözlenirken, orta ve yüksek teknolojik mal ihracatını ise negatif ve istatistiki açıdan anlamlı etkilediği belirlemesi yapılmıştır. Elde edilen ilk bulgu çalışmada kurulan hipotezi teyit ederken, ikinci bulgu hipotez ile uyuşmaz nitelik taşımaktadır. Ancak, burada askeri harcamaların patent, yani yenilikçilik üzerine etkisi zaman açısından hemen hemen eşanlı ortaya çıktığı; buna karşılık askeri buluşların sivil alanlara dönüşümü için bir süre geçmesi gerektiğine dair bilgi teyit edilmiştir. Bunun üzerine modelde askeri harcamaların 5 gecikmeye kadar etkileri de araştırılmıştır. Elde edilen sonuçlarda yine negatif etkilerin olduğu gözlenirken, bu etkilerin her gecikmede katsayısının giderek düştüğü şeklinde bir trendin varlığı tespit edilmiştir. Dolayısıyla askeri harcamalardan patente ve patentten de mal üretimine, mal üretiminden dış satıma kadarki geçen zaman, askeri harcamaların ticarete konu olmasında "kuluçka evresi”nin varlığına işaret etmektedir. Bu kuluçka evresine bağlı olarak teknolojik mal ihracatçısı konumuna geçme durumunun varlığı da teknolojik olmayan mal ihracatındaki negatif parametre ile tespit edilmiştir.

Özetle, gelişmek için daha yüksek katma değerli mal satımında rekabet gücünün ele geçirilmesine bağlı olduğu gerçeği dikkate alınırsa, askeri harcamaların bu amaca hizmet etme fonksiyonu gördüğü açıktır. Bu nedenle hem askeri alanda dışa bağımlılığı azaltma hem de bu alandaki yenilikçiliğin sivil alanlarda rekabet gücü sağlayarak üst düzey gelir sınıfına geçme adına, ülkelerin askeri harcamalarda özellikle yenilikçilik boyutuna ağırlık vermesi gerektiği söylenebilir.

\section{Kaynakça}

- Acemoğlu, D. ve J. A. Robinson, Dar Koridor: Devletler, Toplumlar ve Özgürlüğün Geleceği, (Çev. Yüksel Taşkın), Doğan Kitap, İstanbul, 2020

- Aizenman, J. and R. Glick (2006), "Military Expenditure, Threats, and Growth”, Journal of International Trade and Economic Development, 15 (2): 129-155.

- Ateşoğlu, H. S. (2002), "Defense Spending Promotes Aggregate Output in The United States- Evidence From Cointegration Analysis", Defence and Peace Economics, 13 (1): 55-60.

- Benoit, E. (1978), “Growth and Defense in Developing Countries”, Economic Development and Cultural Change, 26 (2): 271-280.

- Broude, M., S. Deger and S. Sen (2013), "Defence, Innovation and Development: The Case of Israel”, Journal of Innovation Economics \& Management, 2 (12): 37-57. Heo, Uk and Karl DeRouen Jr. (1998), "Military Expenditures, Technological Change, and Economic Growth in the East Asian NICs", The Journal of Politicks, 60 (3): 830-846.

- Chairil, T., D. S. Sinaga and A. I Febrianti, (2013), "Relationship between Military Expenditure and Economic Growth in ASEAN: Evidence from Indonesia”, Journal of ASEAN Studies, 1 (2): 106-121.

- Chang, H-C, B-N. Huang and C. W. Yang (2011), "Military Expenditure and Economic Growth Across Different Groups: A Dynamic Panel Granger-Causality Approach", Economic Modelling, 28 (6): 2416 2423.

- C C Cetin, I. and S. Güzel (2019), "Military Expenditures and Economic Growth in Middle East and North African Countries", TESAM Akademi, 6 (1): 187-211. 
- DeRouen, K. J. (2000), “The Guns-Growth Relationship in Israel”, Journal of Peace Research, 37 (1): 6983.

- Dreze, J. (2006), Military Expenditure and Economic Growth, The Elgar Companion to Development Studies, Cheltenham: Edward Elgar, pp.377-382.

- Dunne, J. P. and D. Braddon, Economic Impact of Military R \& D, Brussels: Flemish Peace Institute, 2008.

- Dunne, J. P. and N. Tian (2013), "Military Expenditure, Economic Growth and Heterogeneity". (Erişim: Şubat 2020) http://saldru.com.uct.ac.za/bitstream/handle/11090/611/2013_95.pdf?sequence=1.

- Eker, S., KOBI'lerde Teknolojik Ar-Ge Çalışmalarının İstihdam Üzerine Etkileri: Tekmer'lerde Bir Uygulama, (Yüksek Lisans Tezi), Süleyman Demirel Üniversitesi, Sosyal Bilimler Enstitüsü, Isparta, 2011.

- Enimola, S. S. and A. Akoko (2008), "Defense Expenditure and Economic Growth: The Nigeria Experience 1977-2006", Department of Economics, Adekunle Ajasin University P.M.B 001.

- Erdoğdu, O. S. (2006), "Political Decisions, Defense and Growth”, MPRA, No:2520.

- Frascati, M., Propesey Standard Practice for Surveys on Research and Experimental Development (2002) OECD.

- Hartley, K. (2007). “The Arms Industry, Procurement and Industrial Policies”, Handbook of Defense Economics, Sandler T ve Hartley K. ed. Elsevier Pub., Amsterdam, Hollanda, Vol.II, bölüm 33, 1140-1174.

- Ward, J. W. (2008), Does Defense R\&D Boost or Bust Innovation? An Examination of Defense R\&D Budget and Patenting, A Thesis submitted to the Graduate School of Arts \& Sciences of Georgetown University, Washington, DC, 2008.

- Kennedy, P., Büyük Güçlerin Yükseliş ve Çöküşleri (1500'den 2000'e Ekonomik Değişme ve Askeri Çatışmalar), (Çev. Birtane Karanakçı), Türkiye İş Bankası Kütür Yayınları, Ankara, 1990.

- Kılıç, N. Ö., B. Açdoyuran, ve M. Beşer (2018) "G-8 Ülkelerinde Askeri Harcamalar ve Ekonomik Büyüme İlişkisi”, Girişimcilik ve Kalkınma Dergisi, 13 (2): 136-146.

- Kollias, C. (1997), "Defence Spending and Growth in Turkey 1954-1993: A Causal Analysis", Defence and Peace Economics, 8 (2): 189-204.

- Lee, Bo Kyeong and So Young Sohn (2017), "Exploring the Effect of Dual Use on the Value of Military Technology Patents Based on the Renewal Decision", Scientometrics, 112 (9): 1203-1227.

- Melman, Seymour, Pentagon Capitalism: The Political Economy of War, New York: McGraw-Hill, 1970.

- Melman, S. (1985), "Problems of Conversion from Military to Civilian Economy an Agenda of Topics, Questions and Hypotheses", Bulletin of Peace Proposals 16 (1): 11-19.

- Sezer, S. (2018), "The Relationship among Military Expenditure, High Technological Product Exports, and Economic Growth": An Econometric Analysis for Selected Economies, (Ed. Ramesh Chandra Das), Handbook of Research on Military Expenditure on Economic and Political Resources, IGI Global, Hershey PA, USA, 2018. (Erişim: Şubat 2020), https://books.google.com.tr/books?id=x9ZdDwAAQBAJ\&pg=PA67\&lpg=PA67\&dq=military+expenditure + and + high + tech + export\&source=bl\&ots=vJr1XbWCJG\&sig=ACfU3U3dswptTuw2P7h0KjSQ1QIPBXUH A\&hl=tr\&sa=X\&ved=2ahUKEwic7ciW6N_nAhVD6aQKHRaYAFoQ6AEwBXoECAoQAQ\#v=onepage\& $\mathrm{q}=$ military\%20expenditure\%20and\%20high\%20tech\%20export\&f=false

- Yakovlev, P. (2007), “Arms Trade, Military Spending, and Economic Growth”, Defense and Peace Economics, 18(4): 317-33.

- Yurttançıkmaz, Z. C.., A. Ali ve Ö. S. Emsen (2012), "Askeri Harcamalar ve Ambargonun Ekonomik Büyümeye Etkileri: İran Üzerine Bir Uygulama”, Atatürk Üniversitesi, İktisadi ve İdari Bilimler Fakültesi Dergisi, 26 (2): 171-190.

- Zerenler, M., N. Türker ve E. Şahin (2007), "Küresel Teknoloji Araştırma-Geliştirme (Ar-Ge) ve Yenilik İlişkisi”, Selçuk Üniversitesi SBE Dergisi, 17: 653-667. 


\title{
Türkiye ve Azerbaycan Ekonomilerinin Makroekonomik Değişkenler Açısından İncelenmesi
}

\section{Investigation of Turkey and Azerbaijan Economy Macroeconomic Variables}

\author{
Assoc. Prof. Dr. Volkan Öngel (Beykent University, Turkey) \\ Ph.D. Candidate Hasan Sadık Tatlı (Beykent University, Turkey) \\ Ph.D. Candidate Gözde Bozkurt (Beykent University, Turkey)
}

\begin{abstract}
The study aims to determine the presence or absence of causality relationship between economic growth, employment, inflation, exchange rate, import, export in Turkey, and Azerbaijan. In the study, the two countries' annual frequency data from 1992-2018 were analyzed with the Granger causality test. According to the study, the employment rate of GDP growth appears to be the one-way Granger cause for Turkey. Also, it has been determined that the import and exchange rate is caused to the employment rate. It was observed that GDP growth and export were active on inflation and were Granger cause to inflation. It is determined that GDP growth in Azerbaijan is Granger cause to exchange rate and employment. It is also observed that the exchange rate affects inflation. According to the findings, GDP growth has an impact on the employment rate in both countries. While GDP growth is found to be active over inflation in Turkey, it is seen to be valid on the exchange rate in Azerbaijan. Research differs from similar studies in the literature in terms of variables used and countries. The findings of the research have some limitations. The data frequency used in the research starts in 1992, depending on Azerbaijan gaining its independence in 1991. The data used in the research are on an annual basis. Also, local/regional and global crisis effects have been ignored for both countries.
\end{abstract}

\section{Giriş}

Makroekonomik politika yapıcıları açısından iç denge ve dıș dengenin aynı anda sağlanabildiği bir ekonomi en ideal durumu ifade eder. İç denge (internal balance), ekonominin yeterince düşük bir işsizlik ve enflasyon içinde olmasını ifade eden tam çalışma durumunu yansıtmaktadır. Dış denge ise ödemeler bilançosunda açık veya fazla bulunmaması durumudur. İç ve dıș dengelerin birlikte sağlanabilmesi ve güçlü bir ekonomik yapı içerisinde sürekli ve yüksek ekonomik büyümenin gerçekleştirilebilmesi ülkeler açısından büyük önem arz etmektir. Bu sebeple her iki denge için önemli olan, ekonomik büyüme, istihdam, enflasyon, döviz kuru, ithalat, ihracat arasındaki ilişkilerin doğru şekilde analiz edilmesi gerekmektedir.

Makroekonomik politikalardaki denge unsurları göz önüne alınarak çalışmanın amacı; Türkiye ve Azerbaycan için ekonomik büyüme, istihdam, enflasyon, döviz kuru, ithalat, ihracat arasında nedensellik ilişkisinin bulunup bulunmadığının tespit edilmesi olarak belirlenmiştir. Bu amaca bağlı olarak elde edilen sonuçlar Türkiye ve Azerbaycan için makroekonomik politika uygulayıcılarına yol gösterebilecektir. Bilindiği üzere; ekonomilerde bir hedef için kullanılan genişletici/daraltıcı bir politika diğer değişkenler üzerimde de etkili olabilmektedir. Bu sebeple değişkenler arasındaki nedenselliklerin tespiti politikaların doğru seçilebilmesi ve etkinliği açısından da önem arz etmektedir.

Çalışmada her iki ülke için 1992-2018 dönemini kapsayan yıllık frekansa sahip veriler üzerinden analiz yapılmaktadır. Verilerin ilgili dönem aralığında seçilmesinin en önemli nedeni Azerbaycan'ın 1991 yılında bağımsızlığını kazanmasıdır. Azerbaycan'ın 1991 yılında bağımsızlığını kazanmasından yaklaşık bir yıl sonra ise veri sunumu sağlanmıştır. Böylece her iki ülkenin sağlıklı olarak karşılaştırılabilmesi için Azerbaycan'daki veriler için başlangıç tarihi olan 1992 yılı ve her iki ülke için son tarih olan 2018 yılı veri aralığı olarak kabul edilmiştir. Ayrıca kullanılan verilerin frekansı yıllıktır. Makroekonomik değişkenlerin arasındaki nedensellik ilişkilerin analizinde Granger nedensellik testi kullanılmaktadır. Araştırmadaki ülke ekonomilerinin yapısal farklılıkları, ülke ekonomilerinin dayandığı dinamikler, incelenen dönemde yerel/bölgesel ve küresel ölçekte meydana gelen krizler çalışma kapsamında göz ardı edilmektedir. Yerli ve yabancı alanyazın incelendiğinde makroekonomik politikalar ve ekonomik göstergeler açısından Azerbaycan ve Türkiye'nin incelendiği araştırmanın olmadığı tespit edilmiştir. Bu açıdan araştırmada elde edilecek sonuçlar alanyazındaki benzer çalışmalardan ayrılmaktadır.

\section{Literatür Taraması}

Makroekonomik politika yapıcılar tarafından her ülkede gerçekleştirilmesi gereken dört temel makroekonomik hedeften bahsedilmektedir. Samuelson ve Nordhaus (1992)'a göre bu hedefler; a) Üretimin arttırılması, sürekli ve yüksek bir ekonomik büyüme sağlanması (GSYİH atışı); b) Yüksek istihdam ve düşük işsizliğin sağlanması; c) Fiyatlar genel düzeyinde istikrarın sağlanması; d) Ödemeler dengesinin istikrarının, dış ticaret ve cari işlemler 
dengelerinin ve döviz kuru istikrarının sağlanmasıdır. Hem Türkiye hem de Azerbaycan için söz konusu dört temel makroekonomik hedefe ulaşabilmek ve iç-dış dengeyi sağlayabilmek için bu unsurlara ilişkin iliş̧ilerin belirlenmesi önemlidir. Her iki ülke açısından bakıldığında farklı sebeplerle de olsa gayri safi yurtiçi hâsıla büyüme oranı, istihdam oranı, ithalat, ihracat, döviz kuru ve enflasyon arasındaki ilişkiler büyük önem taşımaktadır.

Göçer ve Gerede(2016)'nin çalışmasına göre; Türkiye ekonomisinin dört temel makroekonomik sorunla mücadele ettiği görülmektedir: yüksek cari açık, düşük ekonomik büyüme, yüksek enflasyon ve yüksek işsizlik. Ekonomik büyümeyi sağlamak ve istihdam yaratarak işsizliği azaltmak amacı ile genişletici para ve maliye politikaları uygulandığında cari açık ve enflasyonun yükseldiği; enflasyon ve cari açığa karşı politikalar uygulandığında ise ekonomik büyümenin, potansiyel büyümeden düşük kaldığı ve işsizlik sorununun derinleştiği görülmektedir. Bu durumun Türkiye ekonomisinin politika yapıcıları açısından bir açmaz yarattığı ve söz konusu paradoksu kırmanın mümkün olmadığı görülmüştür. Çalışmada 2000-2014 çeyreklik frekansta dönem aralığında Türkiye'de cari açı, ekonomik büyüme, enflasyon ve işsizlik arasındaki ilişkileri simetrik ve asimetrik saklı nedensellik testleriyle incelemiştir.

Azerbaycan'ın genel ekonomik yapısına bakıldığında; özellikle petrol ve türevleri ağırlıkta olmak üzere zengin doğal kaynaklara sahip olduğu, ülkenin hem ihracatı hem de GSYİH'sı içerisindeki doğal kaynak payının yüksek olduğu görülmektedir. Söz konusu durum, alanyazında "Hollanda Hastalığı" diye adlandırılan durum ile karş1 karşıya kalması riskini beraberinde getirmektedir. Bu durumda olan bir ekonomide, genel olarak ülkeye aşırı döviz girişi ve buna bağlı olarak reel döviz kurunun yükselmesi ile başlayan süreçte ülke zaman içerisinde dış ticarette rekabet gücünü kaybetmektedir. Süreç, makroekonomik göstergeler üzerinde olumsuz etkiler yaratabilmektedir. Böylece büyüme oranın düşmesi, dış ticaret dengesinin bozulması, işsizliğin artması, kaynakların etkin dağılımının sağlanamaması söz konusu olabilmektedir. Ülke ekonomisi doğal kaynaklarının dünya piyasalarındaki fiyatlarına daha duyarlı hale gelmekte ve dış bağımlılığı artmaktadır (Şanlısoy ve Ekinci, 2019). Gülmez ve Huseynli (2019), 1995-2017 yılı arası verileri kullanarak, Azerbaycan'ın enerji ihracatı (petrol, doğalgaz ve elektrik) ve ekonomik büyümesi arasındaki ilişkiyi araştırmışlardır. Çalışma sonuçlarına göre GSYİH ile petrol ve doğal gaz ihracatı arasında nedensellik ilişkisi bulunmuştur. Pearson korelasyon analizi sonucunda GSYİH ile elektrik ihracatı arasında negatif bir ilişki gözlemlenirken, petrol ihracatı ve doğal gaz ihracatı arasında pozitif bir ilişki gözlemlenmiştir.

Ekonomik büyüme ve işsizlik arasındaki ilişkiyi araştıran ampirik çalışmalarda bir fikir birliğine ulaşılamamıştır. Ceylan ve Şahin (2010) çalışmalarında eşbütünleşme analizi ile 1950-2007 dönemi için aradaki ilişkinin Türkiye açısından geçerli olduğunu (ekonomik büyüme arttıkça, işsizliğin azaldığı) bulurken; Yılmaz (2005) 1978-2004 dönemi için Granger ve Hsiao nedensellik analizini kullandığı çalışmasında söz konusu ilişkinin Türkiye için geçerli olmadığı sonucuna ulaşmıştır. Demirgil (2010)'in 1987Q2-2007Q3 dönemi için hareketli regresyon analizi kullanarak gerçekleştirdiği çalışmasının sonucunda da ilişkilerin Türkiye için geçerli olmadığı sonucuna ulaşılmıştır. Arı (2016) 1980-2014 dönemi için Bayer ve Hanck eşbütünleşme ve Hacker ve Hatemi-J nedensellik testlerini kullandığı çalışmasında büyüme oranı ve işsizlik oranı arasında uzun dönemde bir eşbütünleşme ilişkisinin ve nedenselliğin olmadığı sonucuna ulaşmıştır. Altuntepe ve Güner (2013) Türkiye için 1988-2011 yılları arası verileri kullanarak istihdam ve büyüme ilişkisini iki ayrı model üzerinden test ettikleri çalışmada, sadece hizmet sektöründe meydana gelen büyümenin istihdam artışına sebep olduğunu tarım ve sanayi sektörlerindeki büyümenin herhangi bir etkisi olmadığını belirlemişlerdir. Ayrıca hizmet sektöründeki istihdam artışı ile ekonomik büyüme arasında negatif ilişki tespit edilirken, tarımdaki artışın bir etkisi olmadığı, toplam istihdam artışının ise büyümeyi etkilediği sonucuna ulaşmışlardır. Yüceol (2006) ve Ceylan Ataman (2006) çalışmalarında Türkiye'de ekonomik büyümenin işsizliği azaltıcı bir etkisinin olmadığı sonuçlarına ulaşmışlardır. Granger nedensellik testi kullanarak Türkiye'de ekonomik büyüme ve istihdam arasındaki ilişkileri inceleyen çalışmalarda; Muratoğlu (2011), istihdam ve büyüme arasında kısa dönemde ilişki varken uzun dönemde ilişki olmadığı; Akan vd. (2008), ekonomik büyüme ve istihdamın doğru orantılı olduğu, Akçoraoğlu (2010), ekonomik büyüme ve istihdamın uzun dönemde doğru orantılı olduğu sonucuna ulaşmışlardır. Göktaş Yılmaz (2005) 19782004 dönemini kapsayan çalışmasında seriler arasında karşılıklı bir nedensellik ilişkisinin bulunmadığını, fakat işsizlikten büyümeye doğru tek yönlü bir nedensellik olduğu sonucuna ulaşmıştır.

Enflasyon-büyüme ilişkisini inceleyen çalışmalara bakıldığında; Karaca (2003), Türkiye'de 1987-2002 dönemine ait üç aylık veriler kullanarak gerçekleştirdiği çalışmada Granger nedensellik ve regresyon analizi kullanmıştır. Çalışma neticesinde enflasyondan büyümeye doğru tek yönlü bir nedensellik tespit etmiştir. Ayrıca, regresyon analizi sonuçlarında enflasyondaki 1 puanlık artışın, ekonomik büyümeyi 0.37 puan azalttığı sonucuna ulaşılmıştır. Karaçor vd. (2009), 1990-2005 dönemi üç aylık verilerini kullanarak eşbütünleşme ve nedensellik testleriyle yaptıkları çalışmalarında Türkiye'de enflasyon ile büyüme arasında negatif bir ilişkinin olduğu tespit etmişlerdir. Hasanov (2010) Azerbaycan'da enflasyon-büyüme ilişkisini 2000-2009 dönemi verilerini kullanarak incelemiştir. Çalışma sonucunda enflasyon için \%13 düzeyinde eşik tespit etmiş ve eşik seviyesinin aşılmasına bağlı olarak büyümenin yaklaşık olarak \%3 oranında düşeceği tespit edilmiştir. Aydın vd. (2016) çalışmalarında Azerbaycan, Kazakistan, Kırgızistan, Özbekistan ve Türkmenistan için panel eşik regresyon modelini kullanarak yaptıkları çalışmada enflasyon ve büyüme arasındaki ilişkinin doğrusal olmadığı sonucuna ulaşılmıştır. Enflasyon eşik değerini \% 7,97 olarak buldukları çalışmada, eşiğin aşılması durumunda ekonomik büyümenin olumsuz, 
altında kalınması durumunda olumlu etkileneceğini iddia etmişlerdir. Yapraklı (2007) çalışmasında Türkiye için enflasyonun ekonomik büyüme üzerinde olumsuz etkisi olduğu sonucuna ulaşırken, Artan (2008) enflasyonun uzun vadede ekonomik büyümeyi olumsuz etkilediğini tespit edilmiştir. Karabulut (2019) çalışmasında Türkiye ekonomisi için 2003:Q1-2018:Q1 döneminde ekonomik büyüme ve enflasyon arasındaki ilişki analiz edilmiştir. Yapılan Granger nedensellik testi sonucunda, yüzde 5 anlamlılık seviyesinde, GSYİH'nın enflasyonun nedeni olduğu sonucuna ulaşılmış ancak enflasyondan GSYİH'ya doğru bir nedensellik ilişkisi tespit edilememiştir.

Kostakoğlu ve Dibo (2011), tarafından yapılan araştırmada, Türkiye'nin cari açığı ile büyüme arasındaki ilişkiyi tespit edebilmek için 1991:Q1 ve 2010:Q2 dönemleri arasındaki verileri VAR analizi ile test etmişlerdir. Analizler sonucunda Türkiye için cari açıkla büyüme arasında ters yönlü ilişki tespit edilmiştir. Ağayev (2011) tarafinda yapılan araştırmada geçiş ekonomisindeki 12 ülkenin ihracat düzeyleri ile ekonomik büyümeleri arasındaki ilişki incelenmiştir. Verilerin analizi panel eşbütünleşme ve panel nedensellik analizleri ile yapılmıştır. Analizler sonucunda söz konusu ülkeler için ihracatın ekonomik büyümeye neden olmadığı sonucuna ulaşılmıştır. Nedesellik yönü ise ekonomik büyümeden ihracata doğrudur. Akçay ve Erataş (2012), tarafindan yapılan araştırmada Brezilya, Çin, Hindistan, Rusya ve Türkiye'nin 1993-2011 yılları arasındaki verileri ile cari açık ve enflasyon arasındaki ilişki incelenmiştir. Verilerin analiz yöntemi olarak panel nedensellik yöntemi kullanılmıştır. Araştırma sonucunda cari açık ile enflasyonun uzun dönemli ilişkisi olduğu ve cari açığın enflasyonu etkilediği sonucuna ulaşılmıştır. Korkmaz ve Aydın (2015) Türkiye'nin diş ticaret hareketliliği ile ekonomik büyümesi arasındaki ilişkilerin tespit edilmesi amacıyla yapmış oldukları çalışmada 2002-2014 dönemi incelenmiştir. Araştırmada veriler Granger nedensellik ile analiz edilmiştir. Araştırma sonucunda ithalat ile ekonomik büyüme arasındaki ilişkilerin çift yönlü olduğu sonucuna ulaşılmıştır.

Şerefli (2016) tarafından yapılan araştırmada, 1975-2014 yılları arasında, Türkiye'nin büyümesi ile dış ticaret işlemleri arasındaki ilişkilerin test edilmesi amaçlanmıştır. Araştırma sonucunda büyüme ile dış ticaret arasında anlamlı bir ilişki tespit edilememiştir. Gül ve Kamacı (2012) tarafından yapılan araştırmada gelişmiş ve gelişmekte olan ülkelerin ekonomik büyümeleri ile dış ticaret hacimleri arasındaki ilişkilerin tespit edilmesi amaçlanmıştır. Araştırma Pedroni Eşbütünleşme ve Granger Nedensellik Testleri kullanılmıştır. Araştırma sonucunda gelişmiş ve gelişmekte olan ülkelerin büyümenin ithalat ve ihracatı etkilediğine dair bir kanıt bulunamamıştır. Ancak, her iki gelişmişlik düzeyi için de ithalat ve ihracatın ekonomik büyüme üzerinde tek yönlü nedenselliğe sahip olduğu sonucuna ulaşılmıştır. Çelik vd. (2017) tarafından yapılan araştırmada, 2006-2014 yılları arasındaki verilerle geçiş ekonomisindeki 12 ülkenin döviz kuru ile ekonomik büyümeleri arasındaki ilişkiler incelenmiştir. Verilerin analizinde panel veri analizi kullanılmıştır. İncelenen dönem için reel döviz kuru atışına bağlı olarak ekonomik büyümenin de arttığı, fakat reel kurların hareketliliğinin ekonomik büyüme için ana değişken olmadığı sonucuna ulaşılmıştır. Ersungur vd. (2017) tarafından yapılan araştırmada, 1998-2014 yılları arasındaki veriler aracılığı ile Türkiye'nin ekonomik büyüme ve döviz kurlarının cari dengeye etkisi incelenmiştir. Araştırmadaki veriler eşbütünleşme ve VAR analizi ile test edilmiştir. Eşbütünleşme analizi sonucunda değişkenler arasında eşbütünleşme olduğu, VAR analizi sonucunda ise, GSYH ile cari işlemler dengesi arasında çift yönlü bir nedensellik ilişkisi olduğu tespit edilmiştir. Diğer değişkenler arasında nedensellik ilişkisine ulaşılamamıştır.

Şahin ve Konak (2019)'ın yaptığı çalışmada, enerji ithalat-ihracatının ve dış ticaretin ekonomik büyümeye etkisinin tespit edilmesi amaçlanmıştır. Araştırmada, Türkiye ve Azerbaycan'ın 1995-2016 dönemindeki GSMH, ihracat, ithalat, enerji ithalatı ve ihracatı verileri incelenmiştir. Analizler sonucunda; Türkiye ve Azerbaycan için kısa ve uzun dönemde değişkenler arasında ilişkiler olduğu sonucuna ulaşılmıştır. Ayrıca değişken setleri arasında tek ve çift yönlü ilişkiler olduğu görülmüştür. Genel olarak sonuçlar incelendiğinde, Türkiye ekonomisinin ihracat temelinde, Azerbaycan ekonomisinin ise ithalat temelinde büyüme odaklı olduğu tespit edilmiştir. Bozadalığlu ve Yılmaz (2017) tarafından yapılan araştırmada, Türkiye'nin döviz kuru ile enflasyon değerleri arasındaki ilişkiler 1994-2014 dönemi için VAR yöntemiyle incelemişlerdir. Araştırma sonucunda nominal döviz kurundaki artışın enflasyon üzerinde etkili olduğu sonucuna ulaşılmıştır.

Granger nedensellik analizinin kullanıldığ çalışmalarda; Mc Charty (1999) tarafından yapılan araştırmada döviz kurlarının fiyatlar üzerindeki etkisinin tespit edilmesi amaçlanmıştır. Araştırma sonucunda fiyatlardaki artış ve azalışların bir yıldan fazla sürede hissedildiği ancak etkilerin en çok ilk dört ayda ortaya çıktığı tespit etmiştir. TEFE'ye ve ÜFE'ye olan yansımalar incelendiğinde TEFE'nin yansımasının daha yüksek olduğunu belirtmektedir. Telatar ve Telatar (2003) tarafından yapılan araştırmada döviz kuru ile enflasyon değişkenleri arasındaki ilişkinin tespit edilmesi amaçlanmıştır. Araştırma sonucunda döviz kurundan enflasyona doğru tek yönlü bir nedensellik ilişkisinin olduğu tespit edilmiştir. Gül ve Ekinci (2006) tarafından yapılana araştırmada ise; nominal döviz kurları ile enflasyon arasında uzun dönemli bir ilişkinin olduğu ve döviz kurunun enflasyonu etkilediği sonucuna ulaşılmıştır. Ayvaz Güven ve Uysal (2013) tarafından yapılan çalışmada TÜFE ile reel efektif döviz kuru arasında çift yönlü bir ilişki olduğu tespit edilmiştir. 
Alanyazıdaki çalışmalar ve kavramlar arası ilişkilerden hareketle araştırmanın hipotezleri aşağıda verilmiştir.

$H_{0}$ :İncelenen makroekonomik değişkenler arasında granger nedensellik ilişkisi yoktur.

$H_{a}:$ İncelenen makroekonomik değişkenler arasında granger nedensellik ilişkisi vardır.

\section{Araştırma Metodu}

Çalışma amacına uygun olarak Granger nedensellik analizi kullanılması nedeniyle, ilgili yönteme dair ve zaman serilerinin incelendiği testlere dair bilgiler aşağıda verilmiş̧tir.

\subsection{Dickey-Fuller Birim Kök Testi (1979 \& 1981)}

Zaman serilerinde birim kökün varlığının tespit edilmesinde, Dickey ve Fuller (1979) tarafından tanıtılan test kullanılmaktadır.

$$
X_{t}=\rho X_{t-1}+\varepsilon_{t}
$$

Denklem 3.1.1, birinci dereceden otoregresif süreç tanımlanmaktadır. Denklemde yer alan $\varepsilon_{\mathrm{t}}$ saf hata terimi (white noise) olarak adlandırılmaktadır. Denkleme ait hipotezler aşağıda verilmiştir. Zaman serilerinin meydana gelme süreçlerinde birim kökün varlı̆̆ı sıfir hipotezi altında test edilmektedir. Serilerin sahip olduğu deterministik özelliklere göre kullanılan denklemler sırasıyla verilmiştir. Denklemlerde verilen ${ }^{\alpha}$ sabit terimi ve $\beta$ trendin yani serinin uzun dönem eğilimini ifade etmektedir.

$$
\begin{aligned}
& \Delta X_{t}=\rho X_{t-1}+\varepsilon_{t} \\
& \Delta X_{t}=\alpha+\rho X_{t-1}+\varepsilon_{t} \\
& \Delta X_{t}=\alpha+\beta T+\rho X_{t-1}+\varepsilon_{t}
\end{aligned}
$$

$\mathrm{Bu}$ testte, hata terimleri arasında otokorelasyon olması durumunda en küçük kareler tahmincileri etkinlik özelliğini kaybetmektedir. Bu nedenle Genişletilmiş Dickey-Fuller testinin (ADF) kullanılması önerilmiştir. İlgili denklemlerde otokorelasyon olması durumunda oluşturulan ADF test denklemleri sırasılyla verilmiş̧tir.

$$
\begin{aligned}
& \Delta Y_{t}=\rho Y_{t-1}+\sum_{i=1}^{k} \beta_{i} \Delta Y_{t-i} \varepsilon_{t} \\
& \Delta Y_{t}=\alpha+\rho Y_{t-1}+\sum_{i=1}^{k} \beta_{i} \Delta Y_{t-i}+\varepsilon_{t} \\
& \Delta Y_{t}=\alpha+\beta T+\rho Y_{t-1}+\sum_{i=1}^{k} \beta_{i} \Delta Y_{t-i}+\varepsilon_{t}
\end{aligned}
$$

ADF testinde de karar aşaması DF testi ile aynı ilerlemektedir. Denklemde yer alacak optimum gecikme sayısının belirlenmesinde ise çeşitli bilgi kriterlerinden yararlanılmaktadır (Dickey ve Fuller, 1979: 427-431). Sonrasında, Dickey ve Fuller (1981) kullanılan DF modelinin yaratma sürecinin de tespit edilmesine yönelik bir test geliştirmişlerdir. Bu testte, $F$-testi mantı̆ğ ile ilerlenmektedir. Testte temel hipotez incelenen serinin veri yaratma sürecinin stokatistik (DSP) olduğunu, alternatif hipotez ise deterministik (TSP) olduğunu ifade etmektedir (Dickey ve Fuller, 1981:1057- 1072). DF(81) testinde kullanılacak modelin doğru belirlenmesi gerektiğinden, uygulanırken en geniş modeli içeren testten başlayıp, daha dar tanımlı modele doğru inilmektedir. Serilere ait veri yaratma süreçlerinin doğru belirlenememesi durumunda sahte regresyon gibi ciddi bir problemle karşılaşılmaktadır.

\subsection{Granger Nedensellik Analizi}

Granger tarafından, $X$ ve $Y$ şeklinde iki zaman serisi olduğu varsayımı altında, " $Y$ serisine ait öngörünün başarısının, $X$ serisinin geçmiş değerlerinin kullanılmasına bağlı olması durumunda, $X$ serisinin $Y$ serisinin Granger nedeni” olduğu ifade edilmektedir. Bu test sonucunda bir tahmin değil, ilgili zaman serilerine ait nedensellik çıkarımının yapılabilmesi için serilerin öncelikle durağanlıklarının sağlanması gerekmektedir (Granger, 1988:554). Granger (1969) tarafindan önerilen testin uygulanmasında kullanılan denklemler verilmiştir. Denklemlerde yer alan " $k$ ", gecikme uzunluğunu ifade etmektedir.

$$
\begin{aligned}
& X_{t}=\alpha_{0}+\sum_{i=1}^{k} \alpha_{i} X_{t-i}+\sum_{i=1}^{k} \beta_{i} Y_{t-i}+u_{t} \\
& Y_{t}=\lambda_{0}+\sum_{i=1}^{k} \lambda_{i} Y_{t-i}+\sum_{i=1}^{k} \delta_{i} X_{t-i}+e_{t}
\end{aligned}
$$

Denklem 3.2.1 ve 3.2.2'ye ait optimal gecikme uzunluğunun belirlenmesinde, ilgili değişkenler arasında kurulan VAR modelinden yararlanılmaktadır. Uygun gecikmenin belirlenmesi aşamasında, denkleme öncelikle bağımlı değişken ve sonrasında bağımsız değişken dâhil edilmektedir. Denklem 3.2.1'de $X$ değişkeninden $Y$ değiş̧kenin 
doğru, denklem 3.2.2'de ise $Y$ değişkeninden $X$ değişkenine doğru nedensellik incelenmektedir. İlgili denklemlere ait hata kareler toplamlarının elde edilmesi sonucu, nedensellik analizinin karar aşamasında F-istatistiği kullanılmaktadır. Kısıtlı denklemin hata kareler toplamını $S S R_{R}$ ve kısıtsız modelin hata kareler toplamını $S S R_{U R}$ ile ifade etmek üzere test istatistiği denklem 3.2.3'te verilmiştir.

$$
F=\frac{\left(S S R_{R}-S S R_{U R}\right) / k}{S S R_{U R} /(n-2 k)}
$$

Denklem 3.2.3'te verilen test istatistiği, serbestlik derecesi $(k ; n-2 k)$ ve $\alpha$ anlamlılık düzeyi ile karşılaştırılmaktadır. İstatistiğin kritik değerden büyük elde edilmesi sonucu temel hipotez ret edilmektedir. Bu durumda örneğin, denklem 3.2.1'de verilen katsayıların istatistiksel olarak anlamlı elde edildiği ve $Y$ değişkeninden $X$ değişkenine doğru nedenselliğin olduğu sonucuna varılmaktadır (Granger, 1969:427-430).

\section{Bulgular}

Çalışma amacına uygun olarak Türkiye ve Azerbaycan ülkelerinin ekonomik büyümelerinin nedeni olabilecek makroekonomik göstergeler incelenmiştir. Bu kapsamda, gayri safi yurtiçi hâsıla büyüme oranı, istihdam oranı, ithalat, ihracat, döviz kuru ve enflasyon değişkenleri ele alınmıştır. Ele alınan değişkenler analiz esnasında doğal logaritması alınarak incelenmiştir. İlgili değişkenler 1992-2018 dönemini kapsayan yıllık frekansa sahiptir. Kullanılan bu veri seti Dünya Bankası veri tabanından (World Bank) elde edilmiştir.

Öncelikle ilgili zaman serilerinin durağanlıkları incelenmiştir. Durağanlık incelemesinde öncelikle Dickey ve Fuller (1981) tarafından geliştirilen test kullanılmış olup, test biçimi olarak düzey değerde olan değişkenlerde trend ve sabit terim kullanılmıştır. İlgili değişkenlerin veri yaratma süreçlerinin stokastik olduğunun tespit edilmesi sonucunda, Dickey ve Fuller (1979) tarafindan geliştirilen test uygulanarak serilerin durağanlık mertebeleri belirlenmiştir. Türkiye'ye ait bulgular Tablo.1'de ve Azerbaycan'a ait bulgular da Tablo.2'de verilmiştir.

\begin{tabular}{|c|c|c|c|c|c|}
\hline Değişkenler & DF & Olasılık Değeri (\%5) & Hipotez \& F & $\operatorname{arar}$ & Sonuç \\
\hline LGSYİH & -4.29 & 0.0000 & \multirow{6}{*}{$\begin{array}{l}H_{0}: \rho=0 \\
H_{a}: \rho<0\end{array}$} & $H_{0}$ red edilir. & LGSYİHI(1) \\
\hline LENFLASYON & -4.11 & 0.0040 & & $H_{0}$ red edilir. & LENFLASYONI(1) \\
\hline LİTHALAT & -4.38 & 0.0099 & & $H_{0}$ red edillir. & LİTHALATI $(0)$ \\
\hline LİHRACAT & -5.63 & 0.0006 & & $H_{0}$ red edillir. & LİHRACATI $(0)$ \\
\hline LDÖVIZKURU & -3.68 & 0.0425 & & $H_{0}$ red edillir. & $L D O ̈ V \mathrm{I} Z K U R U I(0)$ \\
\hline LİSTİHDAM & -5.31 & 0.0002 & & $H_{0}$ red edillir. & LISTTं $H D A M I(1)$ \\
\hline
\end{tabular}

Tablo.1: Seriler İçin Dickey-Fuller (1979) Test Sonuçlarl - Türkiye

Tablo.1'de verilen sonuçlara göre, ithalat, ihracat ve döviz kuru değişkenlerinin düzey halde durağan oldukları tespit edilirken, GSYİH büyümesi, enflasyon ve istihdam oranı değişkenlerinin birinci derece farklarının durağan olduğu görülmüştür.

\begin{tabular}{|c|c|c|c|c|c|}
\hline Değişkenler & $\mathrm{DF}$ & Olasılık Değeri (\%5) & Hipo & \& Karar & Sonuç \\
\hline LGSYİH & -6.80 & 0.0000 & \multirow{6}{*}{$\begin{array}{l}H_{0}: \rho=0 \\
H_{a}: \rho<0\end{array}$} & $H_{0}$ red edilir. & LGSYİHI(1) \\
\hline LENFLASYON & -4.23 & 0.0032 & & $H_{0}$ red edilir. & LENFLASYONI(1) \\
\hline LİTHALAT & -6.05 & 0.0000 & & $H_{0 \text { red edillir. }}$ & LíTHALATI(1) \\
\hline LİHRACAT & -4.83 & 0.0007 & & $H_{0}$ red edillir. & LİHRACATI(1) \\
\hline LDÖVİZKURU & -4.65 & 0.0001 & & $H_{0}$ red edillir. & LDÖVİZKURUI(2) \\
\hline LİSTİHDAM & -5.27 & 0.0000 & & $H_{0}$ red edillir. & $L \mathrm{I} S T \dot{\mathrm{I} H D A M I(2)}$ \\
\hline
\end{tabular}

Tablo.2: Seriler İçin Dickey-Fuller (1979) Test Sonuçlart - Azerbaycan

Tablo.2'de verilen sonuçlara göre, GSYİH büyümesi, enflasyon, ithalat ve ihracat ithalat, ihracat değişkenlerinin birinci derece farklarının durağan olduğu tespit edilirken, döviz kuru ve istihdam oranı değişkenlerinin ikinci derece farklarının durağan olduğu görülmüştür. Durağan olmayan, fakat aynı mertebeden durağan olan seriler arasındaki doğrusal bileşim sonucu nedensellik analizi bulgularının sahte olabilmesi durumu söz konusudur. Ancak elde edilen sonuçlar doğrultusunda, serilerin farklı mertebelerden durağan olmaları nedeniyle, aralarındaki eştümleşme ilişkisinin araştırılmadan nedensellik analizinin yapılması mümkündür. İlgili değişkenler arası nedensellik analizinde optimal gecikme uzunluğu 2 olarak Akaike bilgi kriterine belirlenmiş olup, sonucunda elde edilen bulgular Türkiye için Tablo.3'te ve Azerbaycan için Tablo.4'te verilmiştir. 


\begin{tabular}{|c|c|c|}
\hline Nedensellik Yönü & F-İstatistiği & Olasılık Değeri (\%5) \\
\hline$\Delta G S Y \dot{\mathrm{I}} H \rightarrow \Delta \dot{\mathrm{I} S T \dot{\mathrm{I}} H D A M}$ & 7.56 & 0.0227 \\
\hline$L \dot{\mathrm{I}} T H A L A T \rightarrow \Delta \dot{\mathrm{I} S T \dot{\mathrm{I}} H D A M}$ & 9.25 & 0.0098 \\
\hline$L D O ̈ V \dot{\mathrm{I} Z}$ KURU $\rightarrow \Delta \dot{\mathrm{I} S T \dot{\mathrm{I}} H D A M}$ & 6.65 & 0.0359 \\
\hline$\Delta G S Y \dot{\mathrm{I}} H \rightarrow \Delta E N F L A S Y O N$ & 7.88 & 0.0194 \\
\hline$L \dot{\mathrm{I}} H R A C A T \rightarrow \Delta E N F L A S Y O N$ & 6.25 & 0.0438 \\
\hline
\end{tabular}

Tablo.3: Nedensellik Analizi Sonuçları - Türkiye

Tablo.3'te verilen Granger nedensellik analizi sonucunda \%5 anlamlılık düzeyine göre, incelenen dönem aralığında Türkiye'de GSYİH büyümesinin istihdam oranının tek yönlü granger nedeni olduğu görülmektedir. Bunun yanı sıra, ithalat ve döviz kurunun da istihdam oranının nedeni olduğu, etkilediği tespit edilmiştir. GSYİH büyümesi ve ihracatın da enflasyon üzerinde etkili olduğu ve granger nedeni olduğu görülmüştür.

\begin{tabular}{|c|c|c|}
\hline Nedensellik Yönü & F-İstatistiği & Olasıllk Değeri (\%5) \\
\hline$\Delta^{2} D O ̈ V \dot{\mathrm{I} Z K U R U \rightarrow \Delta E N F L A S Y O N}$ & 6.16 & 0.0359 \\
\hline$\Delta G S Y \dot{\mathrm{I}} H \rightarrow \Delta^{2} D O ̈ V \dot{\mathrm{I} Z K U R U}$ & 6.57 & 0.0373 \\
\hline$\Delta G S Y \dot{\mathrm{I}} H \rightarrow \Delta^{2} \dot{\mathrm{I}} S T \dot{\mathrm{I}} H D A M$ & 5.41 & 0.0492 \\
\hline
\end{tabular}

Tablo.4: Nedensellik Analizi Sonuçlarl - Azerbaycan

Tablo.4'te verilen Granger nedensellik analizi sonucunda \%5 anlamlılık düzeyine göre, incelenen dönem aralığında Azerbaycan'da GSYİH büyümesinin döviz kuru ve istihdamın granger nedeni olduğu tespit edilmiştir. Bunun yanı sıra, döviz kurunun da enflasyon üzerinde etkisi olduğu görülmüştür. Elde edilen bulgular doğrultusunda, GSYİH büyümesinin her iki ülkede de istihdam oranı üzerinde etkili olduğu görülmektedir. Türkiye'de GSYİH büyümesi ayrıca enflasyon üzerinde etkili iken, Azerbaycan'da döviz kuru üzerinde etkili olduğu görülmektedir.

\section{Sonuç}

İdeal bir ülke ekonomisi için iç ve dış dengeyi sağlayacak makroekonomik göstergelerin incelenmesi sürdürülebilir ekonomik büyüme açasından önem arz etmektedir. Bu nedenle çalışmada, Türkiye ve Azerbaycan için 1992-2018 dönemini kapsayan her iki denge unsuruna ait önemli göstergeler olan ekonomik büyüme, istihdam, enflasyon, döviz kuru, ithalat ve ihracat arasındaki ilişkiler Granger nedensellik analizi ile incelenmiştir. Analiz sonucunda her iki ülke için de makroekonomik göstergeler arasındaki ilişsinin farklılık gösterdiği görülmüştür.

Türkiye'de ekonomik büyümeden enflasyona doğru tek yönlü nedensellik tespit edilmiştir. Literatürde yer alan çalışmalarda, örneğin Berber ve Artan (2004), Türkekul (2007), Turhan (2007), Çiftci (2015)'nin ampirik sonuçlarında genellikle bu durumun tam tersi ilişki yapısının ortaya koyulduğu sonuçlar yer almaktadır. Örneğin, beklenen sonuçtan farklı bir ilişki yapısının bulunması, incelenen dönem aralığındaki ekonomik yapıdan kaynaklanabileceği gibi, Türkiye’nin ekonomik olarak hızlı bir gelişim göstermesi ile de açıklamak mümkün gözükmektedir. Hızlı bir ekonomik büyüme, ekonominin ısınmasına ve beraberinde de enflasyonu getirmesine yol açabilmektedir. Mallik ve Chowdhury (2001)'nin de belirtmiş olduğu gibi Türkiye için incelenen dönemde elde edilen sonuç doğrultusunda, "bıçak sırtında" dengeye sahip bir ekonomik durum içerisinde olduğunu söylemek mümkündür. Elde edilen bu sonuca göre; en ufak bir sapmada yeni dengenin sağlanmasının zorluğu nedeniyle, enflasyon tuzağına düşülmeden hızlı bir büyüme gerçekleştirmenin zor olduğu çıkarımı yapılabilmektedir. Bunun yanı sıra, ihracattan enflasyona da tek yönlü bir ilişkinin varlığı tespit edilmiştir. Türkiye'nin ödemeler dengesinin iyileştirilmesi amacıyla ihracatın arttırılması ve buna bağlı olarak ekonomik büyüme ivmesinin hızlandırılması, ekonomik büyümeyi beraberinde getirmiş olsa da, enflasyon tuzağına düşülme riskini de ortaya çıkarmaktadır. Türkiye için ekonomik büyümeden istihdam göstergesine de tek yönlü ilişki olduğu tespit edilmiştir. Literatürdeki çalışmalar incelendiğinde, özellikle Türkiye'nin 2010-2011 döneminden itibaren yüksek büyüme dönemine girmesi sonucunda ekonomik büyümenin istihdam üzerinde etkin olduğu sonuçlarına ulaşıldığının görülmesi mümkündür. Bu sonuç doğrultusunda, Türkiye'nin emek piyasasındaki talep artışının büyüme-istihdam ilişkisinde olumlu olarak değerlendirilmesi mümkün gözükmektedir. Emek piyasasındaki taleplerin doğru değerlendirilmesi ve çözümlerin geliştirilmesi sonucunda bu durum sağlanabilir gözükmekle birlikte, ekonomik büyümenin aynı zamanda beraberinde enflasyonu da getirdiği sonucu, çalışmada elde edilen bulgular doğrultusunda göz ardı edilmemelidir. Türkiye'de ihracatın artışa geçmesi ve ekonomik büyümenin gelişim içerisinde olmasına rağmen, istihdamdaki talebin karşılanmasında yaşanan sorunun kaynağ 1 irdelendiğinde bu durumun nedeninin başka alanlarda aranması gerektiği sonucuna ulaşılmaktadır. Çalışmada elde edilen bulgular doğrultusunda bu durumu, ithalat ve döviz kurundan istihdama doğru tek yönlü nedensellik ilişkisiyle açıklamak mümkün gözükmektedir. Dış ticaret hacmindeki artış ya da azalışlar sonucu emek piyasasındaki imkânlar değişim göstermektedir. Özellikle 2002 ve 2003 yıllarındaki yüksek ekonomik büyümeye rağmen işsizliğin artma eğiliminde olması elde edilen sonuçları destekler niteliktedir (Yükseler, 2004:16). Ekonomik büyümenin aynı zamanda büyük ölçüde iç talepteki 
yüksek artıştan kaynaklanması ve artan iç talebe rağmen ithalatta ve beraberinde döviz kurunda da yüksek artışın yaşanması sonucu istihdam üzerindeki değişikliklerde belirleyici olması kaçınılmazdır. Elde edilen bu sonuçlar doğrultusunda, çalışmada vurgulanan ve çıkış noktası olan, makroekonomik göstergeler ile elde edilen iç ve diş dengenin bir ülkenin ekonomisindeki uyumun sağlanmasında önemli bir yere sahip olduğu gerçeği önem kazanmaktadır.

Azerbaycan'a ilişkin sonuçlar incelendiğinde, döviz kurundan enflasyona tek yönlü nedensellik ilişkisi olduğu tespit edilmiştir. Döviz kurlarında meydana gelen olası değişimler, ülkelerin hem hizmet ve sermaye akımlarını etkilerken hem de büyüme ve enflasyon gibi göstergeleri üzerinde de ciddi etkilere neden olabilmektedir. Azerbaycan'da 2014 yılında başlayan petrol fiyatlarındaki hızlı düşüş, ülkenin döviz gelirlerinin de azalmasına neden olmuştur. Ulusal paranın üzerindeki baskının azaltılması amacı ile 2015 yılında dalgalı kur sistemine geçiş yapılmasıyla birlikte, yüksek enflasyon oranlarını da arttırdığını ve daralmalara neden olduğunu ifade etmek mümkündür. Bu nedenle Azerbaycan ekonomisi için, düşük fiyat düzeyinin sağlanmasına katkısı büyük olan döviz kuru düzeyinde enflasyon tuzağına düşülmemesi açısından geliştirilecek politikaların önemli olduğu ifade edilebilir. Ayrıca, Azerbaycan ekonomisinde ekonomik büyümeden döviz kuruna tek yönlü nedensellik ilişkisi olduğu tespit edilmiştir. Azerbaycan'ın 2010 yılına kadar cari açık sorunuyla karşılaşmasının temelinde yatan nedenlerden birisi cari işlem fazlası probleminin petrol ve türevlerinin ihracatının yapılmasından kaynaklanmasıdır. Ekonominin petrol ürünlerine bağımlı olması ve Ar-Ge harcama paylarının düşük olması nedeniyle, ülke her ne kadar doğrudan yabancı yatırımlar açısından güçlü olsa da, petrol dışı mal ihracatında rekabet imkânlarını olumsuz etkilemektedir. Özellikle 2014 yılından sonra petrol fiyatlarında yaşanan düşüş sonucunda, petrol ihracatı yapan ülkelerin yabancı paralar karşısında kurları ciddi olarak etkilenmiştir. Azerbaycan'da bu dönemde, petrol fonunda ve döviz rezervlerinde önemli miktarda kayıp yaşamıştır. Bu nedenle elde edilen bulgu doğrultusunda ülke ekonomik büyümesinin döviz kuru açısından dengesinin sağlanmasında, hem uygulanan kur rejiminin hem de ekonomik gelişim politikalarının dikkatli belirlenmesinin gerekliliği ortaya konmaktadır. Bunun beraberinde, ülke ekonomik büyümesinden istihdama tek yönlü nedensellik ilişkisi olduğu tespit edilmiştir. Azerbaycan'a ait işsizlik rakamları incelendiğinde, özellikle 2006-2015 yılları arasında ciddi ölçüde azalma olduğu görülmektedir. Reel döviz kurunun yükselmesi, belirtilen dönemlerde Azerbaycan'ın ulusal parasının reel olarak değer yitirmesi sonucu işsizlik üzerinde de azaltıcı etkiye neden olmuştur. Elde edilen bu sonuçlar doğrultusunda, Türkiye ekonomisi için bahsedilen, makroekonomik göstergeler ile elde edilen iç ve diş dengenin bir ülkenin ekonomisindeki uyumun sağlanmasında önemli bir yere sahip olduğu gerçeği Azerbaycan için de söz konusudur. Sonuç olarak, yüksek istihdam ve ekonomik büyümenin amaçlanması durumunda izlenecek döviz kuru politikalarının önemi ortaya çıkmaktadır.

Sonuçlar genel olarak değerlendirildiğinde, ülke ekonomilerinin dayandığı dinamiklerin farklı olması ve küresel ölçekte meydana gelen krizlerin çalışma kapsamında olmaması nedeniyle, bu durumların da dahil edilmesi sonucu elde edilecek bulguların farklılaşabileceği ihtimali göz ardı edilmemelidir. Buna ek olarak, çalışmada sadece ilişkinin varlığının incelenmesi nedeniyle makroekonomik göstergeler arasındaki bu ilişkinin pozitif veya negatif yönlü etkisi hakkında yorum yapmak mümkün değildir. Fakat bu ampirik çalışmanın ileride yapılması hedeflenen diğer çalışmalara zemin hazırlayacağı düşünülmektedir. Makroekonomik politikalar ve ekonomik göstergeler açısından Azerbaycan ve Türkiye'nin incelendiği araştırmanın olmadığı tespit edilmesi nedeniyle araştırmada elde edilen sonuçlar alanyazındaki benzer çalışmalardan ayrılmaktadır.

\section{Kaynakça}

- $\quad$ Ağayev, 2011. "İhracat ve Ekonomik Büyüme İlişkisi: 12 Geçiş Ekonomisi Örneğinde Panel Eştümleşme ve Panel Nedensellik Analizleri”, Ege Akademik Bakış, 11, p.241-254.

- Akan, Arslan, Karatay, ve Druică, 2008. "Effects Economic Growth Creates on Employment in the Knowledge Society Process (1980-2007)”, BULETINUL Universităţii Petrol-Gaze din Ploieşti, LX 3, p.2330 ,

- $\quad$ Akçay ve Erataş, 2012. “Cari Açık ve Ekonomik Büyüme İlişkisinin Panel Nedensellik Analizi Ekseninde Değerlendirilmesi: BRICT”, UEK-TEK 2012, http://teacongress.org/ papers2012/AKCAY-ERATAS.pdf

- Akçoraoğlu, 2010. "Employment, Economic Growth and Labor Market Performance: The Case of Turkey", Ekonomik Yaklaşım, 21, p.101-114.

- Altuntepe ve Güner, 2013. "Türkiye'de İstihdam-Büyüme İlişkisinin Analizi (1988-2011)”, Uluslararası Alanya Issletme Fakültesi Dergisi, 5, p.73-84.

- Arı, 2016. "Türkiye'deki Ekonomik Büyüme ve İşsizlik İlişkisinin Analizi: Yeni Bir Eşbütünleşme Testi”, Siyaset, Ekonomi ve Yönetim Araştırmaları Dergisi, 4, p.57-67.

- Artan, 2008. “Türkiye'de Enflasyon, Enflasyon Belirsizliği ve Büyüme”, Uluslararası Íktisadi ve İdari Incelemeler Dergisi, 1, p.113-138.

- Aydin, Esen, ve Bayrak, 2016. "Inflation and Economic Growth: A Dynamic Panel Threshold Analysis for Turkish Republics In Transition Process”, Procedia-Social and Behavioral Sciences, 229, p.196-205. 
- Ayvaz Güven ve Uysal, 2013. “Türkiye'de Döviz Kurlarındaki Değişme İle Enflasyon Arasındaki İlişki (1983-2012)”, Akademik Araştırmalar ve Çalışmalar Dergisi, 5, p.41-156.

- Berber ve Artan, 2004. "Enflasyon ve Ekonomik Büyüme İlişkisi: Türkiye Örneği”, Turkish Economic Association, p.1-14.

- Bozdağlığlu ve Yılmaz, 2017. “Türkiye’de Enflasyon Ve Döviz Kuru İlişkisi: 1994-2014 Yılları Arası Bir İnceleme", BEU İzdüşüm Dergisi, 2, p.1-20.

- Ceylan Ataman, 2006. “Türkiye’de 2000-2005 Dönemi İşsizlik Üzerine Tartışmalar”, İktisat, İşletme ve Finans Dergisi, 21, p.93-107.

- Ceylan ve Şahin, 2010. “İşsizlik ve Ekonomik Büyüme İlişkisinde Asimetri”, Doğuş Üniversitesi Dergisi, 11, p.157-165.

- Çelik, Çelik ve Barak, 2017. "Geçiş Ekonomilerinde Reel Döviz Kuru Ve Ekonomik Büyüme İlişkisi”, Süleyman Demirel Üniversitesi İktisadi ve İdari Bilimler Fakültesi Dergisi, 22, p.877-890.

- Çiftci, 2015. “Türkiye’de Enflasyon ile Ekonomik Büyüme Arasındaki İlişki: Ampirik Bir Uygulama (19802014)", Selçuk Üniversitesi Sosyal Bilimler Üniversitesi. Konya: Yayınlanmamış Yüksek Lisans Tezi.

- Demirgil, 2010. “Okun Yasası'nın Türkiye İçin Geçerliliğine Dair Ampirik Bir Çalışma”, Alanya İşletme Fakültesi Dergisi, 2, p.139-151.

- Dickey ve Fuller, 1979. "Distribution of the Estimator for Autoregressive Time Series with a Unit Root", Journal of the American Statistical Association, 74. p.427-431.

- Dickey ve Fuller, 1981. "Likelihood Ratio Statistics for Autoregressive Time Series with a Unit Root", Econometrica, 49. p.1057-1072.

- Ersungur, Doru ve Aslan, 2017. “Türkiye’de Gsyh Ve Döviz Kuru Hareketlerinin Cari Denge Üzerindeki Etkisi: Var Analizi Yaklaşımı”, Atatürk Üniversitesi İktisadi ve İdari Bilimler Dergisi, 31, p.451-462.

- Göçer ve Gerede, 2016. "Cari Açık-Ekonomik Büyüme-Enflasyon ve İşsizlik Açmazında Türkiye: Yeni Nesil Bir Ekonometrik Analiz”, Anadolu Üniversitesi Sosyal Bilimler Dergisi 2016 Kasım Özel Sayısı, p.35-46.

- Göktaş Y1lmaz, 2005. "Türkiye Ekonomisinde Büyüme ile İşsizlik Oranları Arasındaki Nedensellik İlişkisi”, İstanbul Üniversitesi Iktisat Fakültesi Ekonometri ve Ístatistik Dergisi, 2, p.63-76. http://eidergisi.istanbul.edu.tr/sayi2/iueis2m4.pdf

- Granger, 1969. "Investigating Causal Relations by Econometric Models and Cross-Spectral Methods", Econometrica, 37, p.424-438.

- Granger, 1988. "Some Recent Developments in a Concept of Causality”, Journal of Econometrics. 39, p.199211.

- Gül ve Ekinci, 2006. “Türkiye'de Döviz Kuru ve Enflasyon Arasındaki Nedensellik İlişkisi: 1984-2003”, Dumlupınar Üniversitesi Sosyal Bilimler Dergisi, 16, p.165-189.

- Gül ve Kamac1, 2012. "Diş Ticaretin Büyüme Üzerine Etkileri: Bir Panel Veri Analizi”, Uluslararası Alanya Işletme Fakültesi Dergisi, 4, p.81-91.

- Gülmez ve Huseynli, 2019. “Enerji İhracatı ve Ekonomik Büyüme İlişkisi: Azerbaycan Örneği”, Uluslararası Ekonomik Araştırmalar Dergisi, 5, p.9-23.

- Hasanov, 2010. "Relationship Between Inflation and Economic Growth in Azerbaijani Economy. Is There Any Threshold Effect?", Asian Journal of Business and Management Sciences, 1, p.1-11.

- Karabulut, 2019. “Türkiye'de Ekonomik Büyüme ve Enflasyon İlişkisi”, Optimum Journal of Economics and Management Sciences, 6, p.171-184.

- Karaca, 2003. “Türkiye'de Enflasyon - Büyüme İlişkisi: Zaman Serisi Analizi”, Dogus Üniversitesi Dergisi, 4, p.247-255. http://journal.dogus.edu.tr/ index.php/duj/article/view/179/195

- Karaçor, Şaylan ve Üçler, 2009. "Türkiye Ekonomisinde Enflasyon ve Ekonomik Büyüme İlişkisi Üzerine Eşbütünleşme ve Nedensellik Analizi (1990-2005)", Niğde Üniversitesi IIBBF Dergisi, 2, p.60-74. http://iibfdergi.nigde.edu.tr/artic $\neg$ le/view/5000066524/5000061948

- Korkmaz ve Aydın, 2015. "Türkiye'de Dış Ticaret - Ekonomik Büyüme İlişkisi: Nedensellik Analizi”, Eskişehir Osmangazi Üniversitesi İ̈BF Dergisi, 10, p.47-76.

- Kostakoğlu ve Dibo, 2011. "Türkiye'de Cari Açık ve Ekonomik Büyüme İlişkisinin VAR Yöntemi ile Analizi”, Anadolu International Conference in Economics II, June 15-17, 2011. www.econanadolu.org/en/files.php?force\&file=2011/pdf/Kostakoglu_Dibo_TurkiyedeCari.pdf

- Mallik ve Chowdhury, 2001. "Inflation and Economic Growth: Evidence from four South Asian Countries", Asia-Pacific Development Journal, 8, p.123-135. 
- Mc Carthy, 1999. "Pass-Through of Exchange Rates and Import Prices to Domestic lnflation in Some Industrialized Economics”, BIS Working Papers, 79.

- Muratoğlu, 2011. "Büyüme İstihdam Arasındaki İlişki Türkiye Örneği”, International Conference On Eurasian Economies, p.167-173.

- Samuelson ve Nordhaus, 1992. "Economics", McGraw-Hill. 19th Edition.

- Şahin ve Konak, 2019. "Türkiye ve Azerbaycan Örnekleminde Büyümenin, Enerji ve Dış Ticaret Dinamikleri”, Insan ve Toplum Bilimleri Araştırmaları Dergisi, 8, p.1851-1874.

- Şanlısoy ve Ekinci, 2019. “Azerbaycan Ekonomisinin Hollanda Hastalığı Açısından Değerlendirilmesi”, Yönetim ve Ekonomi, 26, p.595-608.

- SŞerefli, 2016. "D1ş Ticaretin Ekonomik Büyüme Üzerine Etkisi: Türkiye Örneği”, Kastamonu Üniversitesi Íktisadi ve İdari Bilimler Fakültesi Dergisi, 13, p.136-143.

- Telatar ve Telatar, 2003. "The Relationship Between Inflation and Different Sources of Inflation Uncertainty in Turkey”, Applied Economic Letters, 10, p.431-435.

- Turhan, 2007. “Enflasyon ve Ekonomik Büyüme İlişkisi: Türkiye Örneği”, Kahramanmaraş: Yayınlanmamış Yüksek Lisans Tezi.

- Türkekul, 2007. “Türkiye'de Enflasyon-Büyüme İlişkisi: Tarım Sektörü İtibariyle Ekonometrik Bir Analiz”, Ege Üniversitesi Ziraat Fakültesi Dergisi, 44, p.163-175.

- Yaprakl1, 2007. "Enflasyon ve Ekonomik Büyüme Arasındaki İlişki: Türkiye İçin Eş- Bütünleşme ve Nedensellik Analizi”, Atatürk Üniversitesi Sosyal Bilimler Enstitüsü Dergisi, 10, p.287-301.

- Y Ylmaz, 2005. “Türkiye Ekonomisinde Büyüme ile İşsizlik Oranları Arasındaki Nedensellik İlişkisi”, İstanbul Üniversitesi İktisat Fakültesi, Ekonometri ve İstatistik Dergisi, 2, p.63-76.

- Yüceol, 2006. “Türkiye Ekonomisinde Büyüme ve İşsizlik İlişkisinin Dinamikleri”, İktisat, İşletme ve Finans Dergisi, 21, p.81-95.

- Yükseler, 2004. “2001-2003 Döneminde İşgücü Piyasasındaki Gelişmeler, İstihdam ve İşsizlik Sorunu”, T.C. Merkez Bankasl, 28 Nisan 2004 Raporu. 


\title{
Teknoloji Transferi ve Ekonomik Büyüme Üzerine Panel Veri Analizi: Avrasya Ekonomileri Örneği \\ Panel Data Analysis on Technology Transfer and Economic Growth: The Case of Eurasian Economies
}

\author{
Ph.D. Candidate Tuğçe Acar (Beykent University, Turkey) \\ Asst. Prof. Dr. İsmail Erkan Çelik (Beykent University, Turkey)
}

\begin{abstract}
Foreign Direct investments are interest to emerging countries as they may fuel growth. Countries compete with each other to attract new direct investment as they are permanent. This paper searches the relationship between technology transfer and economic growth in ten Eurasian countries via panel data analysis. For this purpose, gross domestic product, foreign direct investment, and current account balance are used as variables. The sample period is from 2000 to 2018. Dumitrescu and Hurlin panel causality test is used to because of heterogeneity The study provides evidence for a causal relationship from current account balances to GDP, and FDI to current account balance. Interestingly, the study provides evidence for no causal relationship from FDI to GDP but GDP levels affect FDI levels. Also, there is no found cointegration relationship between the variables.
\end{abstract}

\section{Giriş}

Yenilik ve teknoloji transferi günümüz dünya ekonomisinde ekonomik gelişmenin en temel itici gücüdür. Bu nedenle uygun bir ekonomi politikası, bu süreçlerin ülke genelinde güçlendirilmesine ve şirketler, devlet kurumları ve finansal kurumlar arasındaki bilgi ve teknoloji akışının kolaylaştırılmasına odaklanmalıdır. Teknoloji transferi en genel anlamıyla teknoloji sahibi ve teknoloji alıcısı arasında bir akış olarak tanımlanabilir. Hem kısa vadede hem de uzun vadede ekonomik büyüme ve gelişmeyi etkileyen önemli bir faktördür. Teknolojiye erişim ve bunun ekonomik süreçlerde kullanımı büyük ölçüde uluslararası iş bölümünde rekabetçi konuma yer vermektedir. Etkili bir teknoloji transferi ve ülke için iyi tanımlanmış bir inovasyon sistemi olmadan ülke ekonomisi için yapısal değişiklik neredeyse mümkün değildir. Bu iki faktör, ülke ekonomilerinin rekabetçiliğinde ve ekonomik başarısında mevcut sorunlara rağmen, iyileşme sağlayıcı bir potansiyel taşımaktadır. Öte yandan ekonomik seviye, teknoloji transfer yoğunluğunu belirleyen en önemli faktörlerden birisidir. Gerçekte, iş gücü faktörlerinin nitelik ve nicelik düzeyindeki çeşitlilik, potansiyel teknoloji akışı ile sıkı bir şekilde ilişkilendirilmektedir. Bu ilişkilendirmede karşımıza teknometri kavramı da çıkmaktadır. Teknometrinin odak noktası teknoloji ölçümüdür (Ramanathan 1988). Teknometri iki kavrayışa yönelik yaklaşım içerir. İlki teknolojiyi gerçekte daha iyi anlamayı sağlar. İkincisi ise teknoloji bileşenlerinin, gelişimi nasıl ve ne şekilde etkilediğini anlamaya yardımcı olur. $\mathrm{Bu}$ bileşenler ise Teknoloji Atlas Ekibi tarafından nesneye dayalı teknoloji, kişiye dayalı teknoloji, bilgi ve belgeye dayalı teknoloji ve kuruma dayalı teknoloji olarak sınıflandırılmıştır. Buradan teknolojinin sadece ürün teknolojisi olmadığı ve başka düzenleme çeşitlerini de içerdiği anlaşılmaktadır. Teknolojinin ele alınan kısmı ise daha çok bir üretim teknolojisi yani girdilerin çıktılara dönüştürülmesi süreci ile ilgilidir. Bu doğrultuda teknoloji transferine baktığımızda bu kavram hem dikey hem yatay karaktere sahip olabilir. Dikey teknoloji akışı, değer zincirinde katma değer yaratmanın belirli aşamalarında gerçekleşmektedir:

Ar-Ge $\rightarrow$ uygulama $\rightarrow$ üretim süreci $\rightarrow$ dağıtım $\rightarrow$ son alıcı

Yatay teknoloji transferi ise, benzer üretim aşamalarında tipik olan ekonomik ortamlarda şu şekilde gerçekleştirilir:

laboratuvar $\leftrightarrow$ laboratuvar; fabrika; fabrika; ülke $\leftrightarrow$ ülke

Teknoloji transferi ülkelerin ekonomik kalkınma ve teknoloji düzeylerinin farklılık göstermesi sebebiyle kademeli ve farklı şekillerde olmaktadır. Teknoloji transfer kanalları işgücü, teknoloji ve sermaye gibi üretim faktörlerini aktarmada temel rolü üstlenmektedir. Bununla birlikte üretim faktörleri arzının ülkeler ve bölgeler arasında farklılaşmasıyla ürün yaşam döngüsü teorisi, teknoloji açı̆̆ı teorisi ve üretim ölçeği teorisi gibi uluslararası ticaret ve sermaye akım teorilerinden bahsedilebilir. Teknoloji açığı teorisinde, ülkeler arasındaki ekonomik kalkınmadaki farklılıklar sayesinde dış ticaret mümkündür; üretim ölçeği teorisinde, yüksek uzmanlaşma ve üretilen birim başına maliyetlerin azalması nedeniyle kazanç ve rekabetçi pay mümkündür. R.Vernon'un ürün yaşam döngüsü teorisinde ise dış ticaretin nedenlerinin teknolojik avantajlar olduğu savunulmaktadır. Teorilerin ortak özelliği ülkeler arasında üretim faktörleri arzının mevcut farklılıkları sayesinde dış ticaretin mümkün olduğunu savunmalarıdır. Bununla birlikte teknik gelişme, ekonomik kalkınma ve ülkeler arasındaki teknoloji açığını azaltmada kilit faktördür ve teknoloji transferinin dinamikleri belirli bir firma yenilikçisinin stratejisine de bağlıdır. Bazı firmalar, teknolojiyi güvence altına almak için en güvenli çözüm olarak doğrudan yabancı yatırım yoluyla lisans alan teknolojiyi kullanarak genişlemeyi tercih etmektedir. Dolayısıyla inovasyon potansiyeli ve ekonomik kalkınma düzeyi teknoloji transfer yoğunluğunu belirleyen kilit faktördür. 
Bu doğrultuda çalışmanın amacı, Avrasya ekonomileri için teknoloji transfer göstergesi olarak ele alınan doğrudan yabancı yatırımlar, ekonomik büyüme ve ülkenin dış dünya dinamiklerine uyumunu gösteren cari işlemler dengesi arasında panel nedensellik ve eşbütünleşme analizlerini gerçekleştirerek elde edilen sonuçları değerlendirmektir. Ekonometrik analizlerde panel veri kullanımı, yatay kesit veya zaman boyutunun tek başına ele alınmasındansa hem birimlere hem de dönemlere göre inceleme yapma olanağı sunmasından dolayı çalışma alanını genişletmekte ve avantaj sağlamaktadır. Öte yandan çalışmalarda değişkenler arasındaki ilişskilerin yönünün ve ilişki olması durumunda bu ilişsinin uzun dönemli olup olmadığının bilinmesi de önemlidir. Burada da karşımıza nedensellik ve eşbütünleşme kavramları çıkmaktadır. Dolayısıyla analizde, yapılacak testlere karar verirken önemli bir gösterge olan yatay kesit bağımlılık sınaması, daha sonrasında sırasıyla birim kök, nedensellik ve eşbütünleşme analizleri gerçekleştirilmiştir. Bu bilgiler 1şı̆̆ında teknoloji transfer göstergesi ve büyüme değişkenleri arasında bir ilişki olup olmadığı, varsa söz konusu ilişkinin uzun dönemde de geçerliliğinin tespit edilip sonuçların yorumlanması ile literatüre katkı sağlanacağı düşünülmektedir.

\section{Literatür Özeti}

Bilginin büyümesi ve ekonomik küreselleşmenin geliştirilmesi ile teknoloji, stratejik kaynakların temel faktörü ve ulusal ve bölgesel kalkınma yetkinliği olarak büyük önem taşımaktadır. Bu önem etkisinde teknolojik gelişmeler ekonominin ileriye doğru gitmesinde önemli bir rol üstlenmektedir. Bu doğrultuda teknolojik gelişme ve büyüme ile ilgili çalışmalara yer verilmiştir.

Ekanayake (2011), 10 Latin Amerika ülkesi için 1975-2003 yılları arasındaki veri setine bilgi iletişim teknolojisi, doğrudan yabancı yatırımlar ve büyüme arasındaki ilişkiyi incelemek amacıyla zaman serisi analizi uygulamışlardır. Analizde 7 ülke için bilgi iletişim teknolojisi ve GSYH arasında, 6 ülke için doğrudan yabancı yatırımlar ve GSYH arasında ve 5 ülke için bilgi iletişim teknolojisi ile doğrudan yabancı yatırım arasında çift yönlü nedensellik olduğu sonucuna ulaşılmıştır.

Weng vd. (2012), Şangay üzerinde, 1991-2009 yıllarını baz alarak yaptıkları çalışmada, teknolojik gelişim ve ekonomik büyüme arasındaki ilişkiyi VAR analizi ile incelemişlerdir. Bunun için doğrudan yabancı yatırımlar, teknoloji pazarındaki ticaret hacmi, patent başvurusu ve ekonomik büyüme değişkenlerini ele almışlardır. Analiz sonucuna göre değişkenler arasında uzun dönemli denge ilişkisi saptanmıştır. Buna ek olarak sonuçlar, bilim ve teknoloji temsili olarak ele alınan doğrudan yabancı yatırımlar, patentler ve ticaret hacminin ekonomik büyüme ile pozitif korelasyon içerisinde olduğunu göstermiştir.

Hudea ve Stancu (2012), 1993-2009 yılları arasında 7 Doğu Avrupa ülkesi için doğrudan yabancı yatırımların büyüme üzerindeki etkisini tespit etmeye yönelik panel nedensellik ve eşbütünleşme analizi yapmışlardır. Elde edilen Granger nedensellik sonucuna göre doğrudan yabancı yatırımlar ve GSYH arasında çift yönlü bir nedensellik ve doğrudan yabancı yatırımlarla büyüme arasında uzun dönemli ilişki olduğu tespit edilmiştir.

Özcan ve Arı (2014), 190-2011 dönemini kapsayan 15 OECD ülkesi için panel veri analizi yapmışlardır. Elde edilen sonuçlara göre seçilen ülkelerden 7 tanesi için ARGE harcamalarının büyümeyi pozitif yönde etkilediği kalan 5 ülkede ise negatif etkilediği tespit edilmiştir. Tüm ülke paneli için ise ARGE harcamalarının reel kişi başı geliri arttırdığı yönünde sonuç bulunmuş, ARGE faaliyetlerine ayrılan payın artması gerektiği ifade edilmiştir.

Ustabaş ve Ersin (2016), 1989-2014 veri seti ile Türkiye ve Güney Kore için yüksek teknoloji ürün ihracatı ve ekonomik büyüme ilişkisini inceleyerek birim kök ve eşbütünleşme analizi uygulamışlardır. Sonuçlara göre değişkenler her iki ülke için eşbütünleşik bulunmuştur. Güney Kore için yüksek teknoloji ihracatının GSYİH üzerindeki olumlu etkisi uzun ve kısa vadede etkili iken, Türkiye için sadece kısa vadede olumlu etki yarattığ sonucu elde edilmiştir. Dolayısıyla Türkiye'nin teknoloji ihracatına yönelik beşeri sermaye ve Arge yatırımlarını arttırması gerektiği belirtilmiştir.

Kabaklarlı vd. (2018), 1989-2015 dönemi için seçilmiş 14 OECD ülke grubuna yönelik yüksek teknoloji ihracatı ve ekonomik büyüme arasındaki uzun dönemli ilişkiyi panel eşbütünleşme analizi ile incelemişlerdir. Bu amaçla yüksek teknoloji ürün ihracatı, GSYİH, doğrudan yabancı yatırımlar ve brüt sermaye oluşumu değişkenlerini ele almışlardır. Elde edilen sonuçlara göre yüksek teknoloji ürün ihracatı ve ekonomik büyüme arasında uzun vadeli ilişki tespit edilmiştir. Ayrıca sonuçlar, patent başvuruları ve doğrudan yabancı yatırımlardaki iyileşmenin seçilen ülkelerin yüksek teknoloji ihracatının yükselmesinde belirleyici bir rol oynadığını, büyüme oranının ve yatırımların ile yüksek teknoloji ürün ihracatında olumsuz bir rol oynadığını göstermiştir.

Şahin (2019), Türkiye için 1980-2016 veri setini kullanarak yüksek teknoloji ihracatı ve büyüme arasındaki ilişkiyi Granger nedensellik testi ile analiz etmiştir. Yüksek teknoloji ihracatının ekonomik büyümeyi etkilediği sonucuna ulaşılmış ve Türkiye ihracatında teknoloji üretimini teşvik edici yaklaşımlar sergilenmesi gerektiği belirtilmiştir.

Sultanuzzaman vd. (2019), 2000-2016 yılları arasında Genelleştirilmiş Momentler (GMM) yöntemi kullanarak ihracat ve teknolojinin gelişmekte olan Asya ülkelerinin ekonomik performansı üzerindeki etkisini incelemişlerdir. Slow ekonomik büyüme modelini takiben elde edilen sonuç ihracat ve gelişmekte olan Asya ekonomilerinin ekonomik büyümesi üzerinde olumlu ve anlamlı bir etkisini ortaya koymuştur. 


\section{Deneysel Çalışma}

\subsection{Veri Seti ve Model}

12 Avrasya Ekonomi ülkesi için 2000-2018 yılları arasındaki veri seti kullanılarak panel nedensellik ve panel eşbütünleşme yapılmıştır. Veri eksikliği göz önüne alınarak çalışmaya 10 ülke (Belarus, Rusya, Ermenistan, Azerbaycan, Gürcistan, Kıbrıs Cumhuriyeti, Kazakistan, Moldova, Tacikistan, Özbekistan) dahil edilebilmiştir. Çalışmada teknoloji transfer göstergesi olarak doğrudan yabancı yatırımlar ele alınmıştır. Çünkü doğrudan yabancı yatırım kavramı en genel itibari ile yatırımcının yerleşiği olduğu ekonomi dışındaki bir başka ekonomide söz sahibi olmasını ifade eder. Bir firmanın üretim merkezini bağlı olduğu ekonomi dışında bir ekonomiye taşıması aynı zamanda teknolojisini de o ekonomiye aktarması anlamına geldiğinden, söz konusu değişken teknoloji transfer göstergesi olarak ele alınabilir. Ayrıca bir ülkenin cari açığının artması o ülkeye olan güveni azaltmaktadır ve bu durum yatırımları azaltıcı etki yaratabilir. Dolayısıyla bu durum büyümeyi etkiler. Bu nedenle büyüme üzerinde etkili olan diğer bir değişken olarak cari işlemler dengesi değişkeni kullanılmıştır. Kullanılan büyüme verisi ise söz konusu ülkeye ait olan GSYH değeri olarak analize dahil edilmiş ve diğer değişkenlerle olan ölçek farklılığını gidermek adına bu değerin logaritması alınmıştır. Kurulan panel veri modeli ise aşağıdaki gibidir:

$$
L G S Y H_{i t}=\alpha_{i}+\beta_{i t} D Y Y_{i t}+\theta_{i t} C \dot{\mathrm{I}} D_{i t}+\varepsilon_{i t} \quad \mathrm{i}=1,2,3, \ldots . \mathrm{N} \quad \mathrm{t}=1,2,3, \ldots . \mathrm{T}
$$

Modelde bağımlı değişken büyümeyi göstermektedir ve GSYH'nın logaritma değeri olarak ele alınmıştır. Bağımsız değişkenler ise cari işlemler dengesi (CID) ve doğrudan yabancı yatırımlardır. DDY olarak gösterilmiştir.

\subsection{Ekonometrik Yöntem}

N sayıda birim ve her bir birime karşılık gelen T sayıda gözlemden oluşan veri türü panel veridir. Panel veriler kullanılarak oluşturulan modeller ise panel veri modelleri olarak ele alınmaktadır. Panel zaman serileri analizinde kullanılan test ve tahmin yöntemlerinin teorik temelleri hem panel veriye ait hem de zaman serileri analizine ait bilgiler barındırmaktadır. (Tatoğlu, 2018, s.1) Bu nedenle durağanlık kavramı burada da önem kazanmaktadır. Zaman serilerinde önemini koruyan ve en genel haliyle serinin ortalamasının, varyansının ve kovaryansının zamana bağlı olarak değişmemesini ifade eden bu kavram zayıf veya kovaryans durağanlık olarak ele alınmaktadır. Aynı zamanda serinin uzun dönemde belli bir değer etrafında dalgalanması anlamına da gelmektedir. Durağan olmayan serilerle analiz yapmak, zaman serilerinde olduğu gibi panel veriler için de sahte regresyon problemini ortaya çıkarmaktadır. Bu problem, serilerin sahip oldukları güçlü trend etkisi sebebiyle aralarınla güçlü bir ilişki varmış izlenimi yaratmaktadır. Bu da araştırmacıyı yanıltıcı sonuçlara götürmektedir. Bu nedenle analizde serinin durağanlık sınamasının yapılması ve serinin birim köke sahip olup olmadığının belirlenmesi önemli bir aşamadır. Öte yandan ekonometrik çalışmalar yapılırken değişkenler arasındaki ilişkinin bilinmesi gereklidir. Başka bir deyişle değişkenler arasında ilişki mevcutsa bu ilişkinin tek taraflı mı yoksa karşılıklı mı olduğu önem kazanmaktadır. Bu nedenle değişkenler arasındaki ilişkinin ve bunun uzun dönemde devam edip etmediğinin belirlenmesi adına nedensellik ve eşbütünleşme analizi yapılmıştır. Bu doğrultuda öncelikle analize durağanlık sınaması ile başlanmıştır. Panel zaman serileri analizinde birim kök testleri seride yatay kesit bağımlılık olup olmamasına göre birinci ve ikinci kuşak testler olarak ele alınmaktadır. Yatay kesit bağımlılık kavramı ise ele alınan panel veri modelinin her birimi için elde edilen regresyonlarda kalıntılar arasında ilişki olduğunu ifade eder. Dolayısıyla ilk önce yatay kesit bağımlılık sınaması yapılarak elde edilen sonuca göre durağanlık sınamasına geçilmesi analizin temelini oluşturacaktır. Yatay kesit bağımlılık sınaması için Pesaran'ın CD testi kullanılmıştır.

Pesaran CD (2004) Testi, Breusch ve Pagan (1980) testinin N büyük, T sonlu olması durumunda tutarlı̆̆ını kaybetmesi üzerine geliştirilmiştir. CD testinde ADF regresyon tahmini sonucu oluşan kalıntılardan hareket edilmektedir. Her birimin kendisi dışındaki diğer birimlerle tek tek korelasyonu hesaplanmaktadır. Değişkenlere ait tanımlayıcı istatistikler ve teste ait hipotezler ile test istatistiği aşağıdaki gibidir;

$$
\begin{aligned}
& H_{0}: \rho_{i j}=0 \\
& H_{1}: \rho_{i j} \neq 0
\end{aligned}
$$

olmak üzere test istatistiği dengeli panel veri seti için;

$$
C D=\sqrt{\frac{2 T}{N(N-1)}}\left(\sum_{i=1}^{N-1} \sum_{j=i+1}^{N} \hat{\rho}_{i j}\right)
$$

şeklinde ifade edilmektedir. Testin küçük örneklemlerde, $\mathrm{N}>\mathrm{T}$ durumunda, durağan olmama, yapısal kırılma ve heterojenlik durumlarında performansının iyi olduğu gösterilmiştir.

\begin{tabular}{|l|c|c|c|c|c|}
\hline Değişken & Gözlem Sayısı & Ortalama & Standart Sapma & Minimum & Maksimum \\
\hline LGSYH & 190 & 24.0327 & 1.728815 & 21.6721 & 28.174 \\
\hline DYY & 190 & 5.859632 & 7.049847 & -1.39 & 55.08 \\
\hline CID & 190 & -3.560368 & 9.559147 & -32.1 & 33.68 \\
\hline
\end{tabular}

Tablo 1: Tanımlayıcı Istatistikler 


\begin{tabular}{|c|c|c|}
\hline Değișken & İstatistik Değeri & Anlamlılık Değeri \\
\hline LGSYH & 28.21 & 0.000 \\
\hline DYY & 7.69 & 0.000 \\
\hline CíD & 2.41 & 0.016 \\
\hline
\end{tabular}

Tablo 2: Pesaran CD (2004) Testi

Yukarıda bulunan tabloda birimler arası korelasyon için Pesaran CD test istatistiği ve olasılık değerleri yer almaktadır. Elde edilen sonuçlara göre değişkenlerin hepsi için birimler arası korelasyon olmadığını ifade eden temel hipotezin reddedildiği ve birimler arası korelasyon olduğu görülmektedir.

Bu durumda da durağanlık sınaması için ikinci kuşak panel birim kök testlerinin kullanımı doğru olacaktır. Burada durağanlık sınaması için Pesaran (2007) birimler arası korelasyon durumunda bunu yok etmek için tahmin edilen ortak faktörlerden fark alma mantığına dayalı birim kök testi yerine, ADF regresyonunun gecikmeli yatay kesit ortalamaları ile genişletilmiş hali olan yeni bir yöntem önermiştir ve bu regresyonun birinci farkı birimler arası korelasyonu yok etmektedir. Bu nedenle de söz konusu test “ Yatay Kesit Genişletilmiş Dickey Fuller (CADF)" olarak isimlendirilir. Değişkenlerin durağanlık sınamalarına ilişkin test sonuçları ise aşağıdaki gibidir:

\begin{tabular}{|l|c|c|c|c|}
\hline \multicolumn{1}{|c|}{ Değişken } & Düzey & \multicolumn{2}{c|}{ Birinci Fark } \\
\hline & Z [t-bar] & Anlamlılık Değeri & Z [t-bar] & Anlamlılık Değeri \\
\hline LGSYH & 0.687 & 0.754 & -3.410 & 0.000 \\
\hline DYY & -1.209 & 0.109 & -3.335 & 0.000 \\
\hline ĊD & -0.040 & 0.484 & -3.195 & 0.001 \\
\hline
\end{tabular}

Tablo 3: Yatay Kesit Genişletilmiş Im, Pesaran ve Shin (CIPS) Panel Birim Kök Testi

Değişkenlere ait test istatistik ve anlamlılık değerleri incelendiğinde değişkenlerin düzeyde durağan olmadığ1, hepsinin birinci farkta durağan hale geldiği tespit edilmiştir. Değişkenler aynı mertebeden durağan olduğundan eşbütünleşme ilişkisi olup olmadı̆̆ı da incelenebilmektedir.

Öte yandan sabit ve eğim parametrelerinin birimlere göre homojen veya heterojen yapı göstermesi durumuna göre eşbütünleşme testleri ve tahmin yöntemleri belirlenmektedir. Dolayısıyla homojenlik sınaması da burada önem kazanmaktadır. Homojenlik sınaması için Swamy S testi kullanılmıştır. Swamy (1971) tarafından üretilen söz konusu test için test istatistiği şu şekildedir:

$$
\hat{S}=\chi_{k(N-1)}^{2}=\sum_{i=1}^{N}\left(\hat{\beta}_{i}-\bar{\beta}^{*}\right)^{\prime} \hat{V}_{i}^{-1}\left(\hat{\beta}_{i}-\bar{\beta}^{*}\right)
$$

Burada $\hat{\beta}_{i}$ birimlere göre regresyonlardan elde edilen OLS tahmincileri, $\bar{\beta}^{*}$ ağırlıklı WE tahmincisi ve $\hat{V}_{i}$ ise iki tahmincinin varyansı arasındaki farkı ifade etmektedir. Test istatistiği $k(N-1)$ serbestlik dereceli $\chi^{2}$ dağılımına sahiptir. Buna göre Swamy S test sonucu aşağıdaki gibidir:

\begin{tabular}{|l|l|}
\hline Test İstatistiği & Anlamlılık Değeri \\
\hline Chi2(81): 0.00023 & 0.0000 \\
\hline
\end{tabular}

Tablo 4: Swamy S Testi

Swamy S test sonucuna göre homojenliği ifade eden temel hipotez reddedilmiş ve parametrelerin heterojen olduğuna karar verilmiştir. Dolayısıyla nedensellik ve eşbütünleşme analizinde heterojenliği dikkate alan testlerin kullanılması daha doğru bir yaklaşım olacaktır.

Nedensellik analizine geçmeden önce uygun gecikme uzunluğunun belirlenmesi gerekmektedir.

\begin{tabular}{|c|c|c|c|c|c|c|}
\hline Lag & CD & J & J pvalue & MBIC & MAIC & MQIC \\
\hline 1 & .9152894 & 44.9794 & .1449502 & -112.7736 & -27.0206 & -61.40441 \\
\hline 2 & .9116327 & 31.35626 & .2567638 & -86.95846 & -22.64374 & -48.42935 \\
\hline 3 & .6170968 & 13.14838 & .7826837 & -65.7281 & -22.85162 & -40.04203 \\
\hline 4 & -26.34123 & 5.534909 & .7854118 & -33.90333 & -12.46509 & -21.06029 \\
\hline
\end{tabular}

Tablo 5: Gecikme Uzunluğunun Belirlenmesi

Değerler incelendiğinde $\mathrm{R}^{2}$ ilk gecikmede en yüksek değerdedir. Hansen'in J testine göre tüm gecikmelerde araç değişkenler geçerlidir. MBIC, MAIC ve MQIC model seçim kriterlerini minimum yapan değerin de birinci gecikme olduğu görülmektedir. Dolayısıyla uygun gecikme uzunluğu 1 olarak alınacaktır. Buna yönelik nedensellik ve birimler arası korelasyonun ve heterojenliğin varlığını kabul eden eşbütünleşme test sonuçları aşağıdaki gibidir: 


\begin{tabular}{|c|c|c|c|}
\hline $\mathbf{H}_{0}$ & Z-bar & Anlamlılık & Sonuç \\
\hline $\mathrm{DYY} \Rightarrow \mathrm{GSYH}$ & -1.4541 & 0.1459 & DYY, GSYH'nın Nedeni Değildir. \\
\hline $\mathrm{GSYH} \underset{?}{\Rightarrow} \mathrm{DYY}$ & 2.8764 & 0.0040 & GSYH, DYY'nın Nedenidir. \\
\hline $\mathrm{CID} \Rightarrow$ GSYH & 2.1589 & 0.0309 & CİD, GSYH'nın Nedenidir. \\
\hline$\underset{\text { GSYH } \Rightarrow \text { CID }}{\Rightarrow}$ & 0.0035 & 0.9972 & GSYH, CİD’nin Nedeni Değildir. \\
\hline $\mathrm{CID} \underset{?}{\Rightarrow} \mathrm{DYY}$ & -0.7727 & 0.4397 & CİD, DYY'ın Nedeni Değildir. \\
\hline $\mathrm{DYY} \Rightarrow \mathrm{CID}$ & 3.8045 & 0.0001 & DYY, CİD’nin Nedenidir. \\
\hline
\end{tabular}

Tablo 6: Dimitrechu \& Hurlin Nedensellik Testi

\begin{tabular}{|c|c|c|c|c|}
\hline İstatistik & Değer & Z Değeri & P Değeri & Robust P Değeri \\
\hline $\mathrm{Gt}$ & -1.102 & 0.844 & 0.801 & 0.900 \\
\hline $\mathrm{Ga}$ & -1.681 & 2.396 & 0.992 & 0.970 \\
\hline $\mathrm{Pt}$ & -4.130 & -0.878 & 0.190 & 0.890 \\
\hline $\mathrm{Pa}$ & -2.436 & 0.041 & 0.516 & 0.910 \\
\hline
\end{tabular}

Tablo 7: Westerlund Panel Eşbütünleşme Testi

Tabloda panel eşbütünleşme testi için Gt, Ga, Pt, Pa istatistikleri yer almaktadır. Birimler arası korelasyona karşı dirençli (robust) olasılık değerleri ve panel heterojen olduğundan Gt ve Ga istatistiklerine göre yorum yapmak doğru bir yaklaşım olacaktır. Sonuçlar incelendiğinde Gt ve Ga istatistiklerine göre değişkenler arasında bir eşbütünleşme ilişkisi tespit edilememiştir.

\section{Sonuç}

Ülkelerin sahip oldukları teknolojik güç ve yeniliğe yönelik atılan adımlar ekonomik büyümenin temel yapıtaşı haline gelmiştir. Günümüzde teknolojinin ilerleme hızı, ülkelerin yenilikçi yaklaşımları takip etmesini zorunlu hale getirmiştir. Teknolojik ilerleme aynı zamanda makro açıdan ekonomik büyümeyi ve refah seviyesinin artmasını sağlarken, mikro açıdan da firmaların piyasadaki kar paylarının ve küresel pazardaki paylarının artmasını sağlamaktadır. Dolayısıyla ülkelerin küresel dünya dinamiklerine ve dalgalanmalarına gösterdikleri uyum, teknolojik gelişmelere karşı adaptasyonda da oldukça etkili bir faktördür. Bu amaçla çalışmada veri setindeki eksiklikler dikkate alınarak 10 Avrasya ülkesine (Belarus, Rusya, Ermenistan, Azerbaycan, Gürcistan, Kıbrıs Cumhuriyeti, Kazakistan, Moldova, Tacikistan, Özbekistan) panel nedensellik ve eşbütünleşme analizi gerçekleştirilmiştir. Zaman aralığı olarak veri setinin niteliği doğrultusunda 2000-2018 yılları baz alınmıştır. Değişkenler ise teknoloji transfer göstergesi olarak ele alınan doğrudan yabancı yatırımlar, ekonomik büyüme ve ülkenin dış dünya dinamiklerine uyumunu gösteren cari işlemler dengesi olarak belirlenmiştir. Elde edilen nedensellik sonuçlarına göre büyümeden doğrudan yabancı yatırımlara doğru tek yönlü nedensellik ilişkisi tespit edilmiştir. Bu durum ise ekonomik büyümenin daha fazla yabancı yatırım çekmesine neden olmaktadır ve sonuç içsel büyüme teorilerindeki büyüme dinamiklerinin sistem içinde olduğu görüşünü desteklemektedir. Böylece ekonomik büyümenin kazandırdığı doğrudan yabancı yatırımlar, ev sahipliği yaptığı ülke ekonomilerine yeni teknolojilerle üretim kapasitesi ve istihdam açısından katkı sağlamaktadır.

Öte yandan cari işlemler dengesi ile büyüme arasında da cari işlemler dengesinden büyümeye doğru tek yönlü nedensellik tespit edilmiştir. Özellikle sermaye birikimi ve teknolojik ilerleme anlamında daha yüksek gelişme potansiyeline sahip olan ekonomik entegrasyonların varlığı daha yüksek oranlı cari işlemler açı̆̆ına neden olmaktadır (Duman, 2017). Cari işlemler açığı arttıkça büyüme oranı artmakta, cari fazla veya daha düşük cari işlemler açığı verilen yıllarda ise düşük büyüme oranları gerçekleşmektedir. Son olarak cari işlemler dengesi ve doğrudan yabancı yatırımlar arasında ise doğrudan yabancı yatırımlardan cari işlemler dengesine doğru tek yönlü ilişki tespit edilmiştir. Ülkeye yapılan doğrudan yabancı yatırımlar o ülkeye döviz girişi sağladığından ödemeler bilançosu dengesi olumlu yönde etkilenecektir. Doğrudan yabancı yatırım girişleri ise ödemeler bilançosunun finans hesabı içerisinde yer almaktadır. Cari işlemler hesabının açık vermesi durumunda bu açı öncelikle finans hesabından karşılanmaya çalışılır. Açığın kapatılmasını karşılayamayan finans hesabı olması durumunda ise portföy yatırımları veya gerekli görüldüğü durumda rezerv varlıklardan finanse edilir. Dolayısıyla doğrudan yabancı yatırımlar cari açığın finansmanı için en güvenilir kaynaklardan kabul edilmektedir. Değişkenler arasında uzun dönemli ilişki incelendiğinde ise yatay kesit bağımlılığı dikkate alan Westerlund eşbütünleşme testi sonucuna göre uzun dönemli bir ilişki olmadığg sonucuna varılmıştır. Bunun altında yatan sebep olarak ise incelenen dönem aralığının önemli ekonomik kriz dönemlerini kapsaması ve bu dönemlerin yarattığı yapısal kırılma, şok gibi etkenlerin uzun dönem ilişkisini etkilemiş olabileceği belirtilmiştir. 


\section{Kaynakça}

- Akhvlediani, T., Sledziewska, K. (2017). What Determines Export Performances in High-Tech Industries. Central European Economic Journal, s.37-50.

- Dimitrescu E.I., Hurlin,C. (2012). Testing for Granger Non-Causality in Heterogeneous Panels. Economic Modelling, 29(4), 1450-1460.

- Duman, K. Y. (2017). Türkiye'de Cari İşlemler Dengesi ve Ekonomik Büyüme Arasındaki İlişki. Finans, Ekonomi ve Sosyal Araştırmalar Dergisi, 2(4), s.231.

- Ekanayale, E. M. (2011). Information Technology and Economic Growth: A Casual Analysis. Southwestern Economic Review, s.75-88.

- Göçer,İ., Peker, O. (2014). Yabancı Doğrudan Yatırımların Cari İşlemler Dengesi Üzerindeki Etkileri: Türkiye, Çin, Hindistan Örnekleminde Çoklu Yapısal Kırılmalı Eşbütünleşme Analizi. BDDK Bankacılık ve Finansal Piyasalar, s.87-116.

- Hsiao, C. (2003). Analysis of Panel Data. Cambridge University Press: Cambridge.

- Hudea, O. S., Stancu, S. (2012). Foreign Direct Investment, Technology Transfer and Economic Growth: A Panel Approach. Romanian Journal of Economics Forecasting, s.85-102.

- Kabaklarlı, E., Duran, M. S., Üçler, T. Y. (2018). High Technology Export and Economic Growth: Panel Data Analysis for Selected OECD Countries. Forum Scientiae Oeconomia, 6(2), s.47-59.

- Özcan, B., Arı, A. (2014). Arge Harcamaları ve Ekonomik Büyüme İlişkisi : Panel Veri Analizi. Maliye Dergisi, s.39-55.

- Pesaran, M. H. (2004). General Diagnostic Tests for Cross- Section Dependence in Panels. Cambridge Working Papers in Economics, s.435.

- Pesaran, M. H. (2007). A Simple Panel Unit Root Test in the Presence of Cross-Section Dependence. Journal of Applied Econometrics, s.265-312.

- Pesaran, M. H. (2008). Testing Slope Homogeneity in Large Panels. Journal of Econometrics, s.50-93.

- Ramanathan, K. (1988). Measurement of Technology at the Firm Level. Sci Public Policy, s.230-248.

- Samuelson, P. A. (2001). Macroeconomics. New York: Mc Graw Hill.

- Sridharan, P., Vijayakumar, N., and RAO, C.S.K. (2009). Causal Relationship between Foreign Direct Investment and Growth: Evidence from BRICS Countries. International Business Research, 2(4), 198-203.

- Stock,James H., Waston, Mark W. . (2003). Introduction to Econometrics. Boston USA: Addison-Wesley.

- Sultanuzzaman, R. M. (2019). Effects of Export and Technology on Economic Growth: Selected Emerging Asian Economies. Economic Research, s.2515-2531.

- Swamy, P. (1970). Efficient Inference in a Random Coefficient Regression Model. Econometrica, s.311-323.

- Şahin, B. E. (2019). Impact of High Technology Export on Economic Growth : An Analysis on Turkey. Journal of Business, Economics and Finance, s.165-172.

- Tatoğlu, F. Y. (2013). İleri Panel Veri Analizi. İstanbul: Beta Basım Yayım Dağıtım A.Ş.

- Tatoğlu, F. Y. (2017). Panel Zaman Serileri Analizi. İstanbul: Beta Basım Yayım Dağıtım A.Ş.

- Team, T. A. (1987b). Components of Technology for Resources Transformation. Technol. Forecast. Soc., s.1935 .

- Ustabaş, A., Ersin, Ö. (2016). The Effect of R\&D and High Technology Export and Economic Growth: A Comparative Cointegration Analysis for Turkey and South Korea. International Conference on Eurasian Economies, s. 44-55.

- Vernon, R. (1966). International Investment and International Trade in Product Cycle. Quarterly Journal of Economics, s.190-207.

- Weng, L., Song, W., Sheng, S. (2012). Empirical Research on Scientific and Technical Innovation and Economic Growth in Shanghai. American Journal of Operations Research, s.82-90.

- Westerlund J., Persyn D. (2008). Error-Correction- Based Cointegration Tests for Panel Data. The Stata Journal, 8, 236-241.

- Westerlund, J. (2005). New Simple Tests for Panel Cointegration. Econometric Reviews, 24, 297-316.

- Westerlund, J. (2007). Testing for Error Correction in Panel Data. Oxford Bulletin of Economics and Statistics, 69, 709-748. 


\title{
İktisadi Büyüme ve Sefalet Endeksi Arasındaki İlişki: Geçiş Ülkeleri Örneği
}

\section{The Relationship between Economic Growth and Misery Index: Evidence from Transition Countries}

\author{
Prof. Dr. Ebru Çağlayan Akay (Marmara University, Turkey) \\ Asst. Prof. Dr. Zamira Oskonbaeva (Kyrgyz-Turkish Manas University, Kyrgyzstan)
}

\begin{abstract}
Unemployment and inflation, the main components of the misery index, continue to be vital macroeconomic problems, which draw researchers' attention both in developed and developing countries. The study investigates the interaction among economic growth and misery index in the selected transition countries using Panel ARDL. In the study, annual data for the period of 1996-2017 of selected 16 transition countries are used. The findings of the study show that there is a long-run relationship between the misery index and economic growth. In other words, it can be concluded that economic misery deteriorates economic growth. If the economy is to be sustainably improved, the misery index should be taken into account. The government needs a policy of decreasing inflation and unemployment, which is one of the fundamental macroeconomic policy priorities. This study may provide policy-makers with new insights to evaluate the role of economic misery in enhancing economic growth in transition countries.
\end{abstract}

\section{Giriș}

1990’lı yıllarda merkezi planlama sisteminden liberal ekonomik düzene geçiş yapan ülkeler yüksek enflasyon ve işsizlik sorunuyla karşı karşıya kalmışlardır. Yüksek enflasyon ve işsizlik gibi istikrarsız makroekonomik koşullar ülkelerin iktisadi büyüme performanslarını negatif etkilemişlerdir. Diğer bir deyişle söz konusu ülkelerin çoğunda küçülme, daralma olgusu gözlemlenmeye başlanmıştır.

Geçiş ülkelerinde sefalet endeksi ile iktisadi büyüme arasındaki etkileşimin boyutlarının daha yoğun hissedilmeye başlandığı söylenebilir. Sefalet endeksi olarak adlandırılan endeks iki bileşenden oluşmaktadır. Bir ülkedeki enflasyon ve işsizlik oranlarının toplamı sefalet endeksini vermektedir. Sefalet endeksi 1960'larda Arthur Okun tarafindan enflasyon ve işsizliğin sosyal maliyetlerinin açık bir göstergesi olarak ortaya atılmıştır (Lovell ve Tien, 2000). Daha sonra diğer makro iktisadi değişkenlerin de eklenmesi ile genişletilmeye başlanmıştır (Barro, 1999; Setterfield, 2009).

Makroekonomik sefalet endeksi veya iktisadi hoşnutsuzluk endeksi olarak da tanınan (Lovell ve Tien, 2000) bu endeksin daha yüksek oranlara ulaşmasının önemli ekonomik ve sosyal maliyetleri beraberinde getirdiği varsayılmaktadır. Yüksek endeks değeri bir ekonomi için depresif bir ekonomik iklimin söz konusu olduğunun göstergesidir (Akçay, 2018). Sefalet endeksi iktisadi hoşnutsuzluğun nesnel bir ölçüsü olarak da kullanılmaktadır (Barro ve Gordon, 1983; Blanchard ve Fisher 1989; MacRae, 1977; Nordhaus, 1989).

$\mathrm{Bu}$ çalışmanın amacı, seçilmiş geçiş ülkelerinde (Bulgaristan, Hırvatistan, Çek Cumhuriyeti, Estonya, Macaristan, Kazakistan, Kırgiz Cumhuriyeti, Letonya, Litvanya, Moldova, Polonya, Romanya, Rusya Federasyonu, Slovak, Slovenya, Ukrayna) iktisadi büyüme ile sefalet endeksi arasındaki ilişkiyi araştırmaktır. Bu amaç için 1996-2017 dönemi için 16 geçiş ülkesinin yıllık verileri, Panel ARDL modeli ile incelenmiştir.

Giriş bölümünü izleyen ikinci bölümde iktisadi büyüme ile sefalet endeksi arasındaki ilişkiyi inceleyen çalışmalar üzerinde durulmuştur. Üçüncü bölümde veri seti ve değişkenler tanıtılmıştır. Dördüncü bölümde ampirik uygulamada kullanılan metodoloji ve bulgulara yer verilmiştir. Çalışmamız sonuç bölümüyle sona ermektedir.

\section{Literatür}

1970’li yıllardan bu yana sefalet endeksinin diğer makro iktisadi değişkenlerle olası ilişkileri araştırmacıların ilgi odağını oluşturmuştur. Sefalet endeksinin suç oranları (Tang ve Lean, 2009; Munir vd., 2017; Ajide, 2019; Lorde vd., 2016; Nunley vd., 2011; Saboor vd., 2017; Sandoval, 2014 ), intihar oranı (Yang ve Lester, 1992), mutluluk ve yaşam tatminleri (Di Tella vd., 2001), yaşam beklentisi (Shahbaz vd., 2015; Alam vd., 2016), işgücü göçü (Akçay, 2018; Ali vd., 2015) hükümetlerin makroekonomik performansı (Adrangi ve Macri, 2019), gelir eşitsizliği (Sadeghi vd., 2014; Bayar ve Aytemiz, 2019), tüketici güveni (Lovell ve Tien, 2000), sağlık harcamaları (Wu vd., 2014) üzerindeki etkisi yoğun araştırılmıştır.

Literatürde daha çok sefalet endeksinin her bir öğesi ile büyüme arasındaki olası ilişki üzerine odaklanan çalışmalara rastlanmaktadır. Tang ve Lean (2009) çoklu doğrusallık sorunundan kaçınmak için işsizlik ve enflasyon değişkenlerini ayrı ayrı kullanmak yerine sefalet endeksinin kullanılmasını önermiştir. 
Sefalet endeksi ve büyüme arasındaki ilişkiyi ele alan çalışmaların sayısı pek fazla değildir. Yapılan çalışmalarda genellikle iki değişken arasındaki ilişkinin negatif yönde olduğu ileri sürülmektedir.

Dadgar ve Nazari (2018) ekonomik büyüme, iyi yönetişim ve sefalet endeksi arasındaki ilişkiyi İran örneğinde ele aldıkları çalışmalarında sefalet endeksi ile ekonomik büyüme arasında negatif yönlü bir ilişkinin söz konusu olduğunu vurgulamışlardır.

Wang vd., (2019) iktisadi büyüme, finansal gelişmişlik endeksi, sefalet endeksi arasındaki ilişkiyi Pakistan örneğinde ele aldıkları çalışmalarında sefalet endeksi ile ekonomik büyüme arasındaki ilişkinin yönü negatif yönde olduğunu ortaya koymuşlardır.

Yukarıdaki literatüre dayanarak sefalet endeksi ile büyüme arasındaki bağlantının seçilmiş geçiş ülkelerinde söz konusu olup olmadığını araştırmaya karar verilmiştir.

\section{Veri Seti ve Değișkenler}

Bu çalışmada seçilmiş 16 (Bulgaristan, Hırvatistan, Çek Cumhuriyeti, Estonya, Macaristan, Kazakistan, Kırgız Cumhuriyeti, Letonya, Litvanya, Moldova, Polonya, Romanya, Rusya Federasyonu, Slovak, Slovenya, Ukrayna) geçiş ülkelerinin 1996-2017 dönemine ait yıllık verileri kullanılmıştır. Tüm veriler Dünya Bankası veri tabanından temin edilmiştir. Değişkenlere ait bilgiler Tablo 1'de yer almaktadır.

\begin{tabular}{|c|c|c|}
\hline Değişken & Kisaltma & Tanımlama \\
\hline İktisadi büyüme & LGDP & $\begin{array}{l}2010 \text { sabit fiyatlarla (dolar cinsinden) kişi başına düşen } \\
\text { GSYİH }\end{array}$ \\
\hline Sefalet endeksi & LMISERY & Enflasyon+İşsizlik oranı \\
\hline İşçi transferleri & LREM & Dolar cinsinden \\
\hline Doğrudan yabancı yatırımlar & LFDI & $\begin{array}{l}\text { Doğrudan yabancı yatırım, net girişler (GSYİH'nin } \\
\text { yüzdesi) }\end{array}$ \\
\hline Dışa açıklık endeksi & LTRADE & İhracat ve ithalat toplamı (GSYİH'nin yüzdesi) \\
\hline
\end{tabular}

Tablo 1. Değişkenler

Ampirik uygulamada kullanacağımız model aşağıdaki gibidir:

$L G D P_{i t}=\alpha_{0}+\alpha_{1} L M I S E R Y_{i t}+\alpha_{2} R E M_{i t}+\alpha_{3} L F D I_{i t}++\alpha_{4} L T R A D E_{i t}+\varepsilon_{i t}$

Burada $L G D P_{i t}$ bağımlı değişken, $L M I S E R Y_{i t}, R E M_{i t}, L F D I_{i t} v e L T R A D E_{i t}$ açıklayıcı değişkenlerdir. $\varepsilon_{i t}$ hata terimi, i ve $t$ alt indisleri ise sirasıyla paneldeki ülkeleri ve zamanı temsil etmektedir.

\section{Metodoloji ve Bulgular}

Model tahminine geçmeden önce serilerin yatay kesit bağımlılık içerip içermedikleri incelenmelidir. Çünkü değişkenler arasındaki yatay kesit bağımlılığın göz önünde bulundurulmaması tahmin sonuçlarını büyük ölçüde etkilemektedir (Breusch ve Pagan, 1980; Pesaran, 2004). Bu amaç için Pesaran (2004) tarafindan ortaya atılan CD (Cross-Section Dependence) testi kullanılmıştır. Söz konusu testin üstün yönü serinin zaman boyutunun kesit boyutundan büyük $(\mathrm{T}>\mathrm{N})$ ve küçük $(\mathrm{T}<\mathrm{N})$ olduğu durumlarda da kullanılabilmesidir. Çalışmamızda $\mathrm{T}>\mathrm{N}$ olduğu için test istatistiği aşağıdaki gibi hesaplanmıştır:

$$
C D=\sqrt{\frac{1}{N(N-1)}} \sum_{i=j}^{N-1} \sum_{i=j+1}^{N}\left(T \hat{\rho}_{i j}^{2}-1\right) \square N(0,1)
$$

Burada $\rho_{i j}$ herbir denklemin en küçük kareler yöntemi ile tahmininden elde edilen artıklar arasındaki basit korelasyon katsayısını göstermektedir. Pesaran (2004) CD testi sonuçları Tablo 2'de özetlenmiştir.

\begin{tabular}{lcllll}
\hline Değişkenler & LGDP & LMISERY & LFDI & LTRADE & LREM \\
\hline Test istatistiğ $\mathrm{i}$ & 49,27 & 28,02 & 11,94 & 14,45 & 43,91 \\
\hline Olasıllk & 0,000 & 0,000 & 0,000 & 0,000 & 0,000 \\
\hline
\end{tabular}

Temel hipotez, H0: $i_{j}=$ cor(uit, ujt) $=0 i \neq j$ şeklindedir ve yatay kesit bağımlılık olmadlğını ifade etmektedir.

\section{Tablo 2. Yatay Kesit Bağımlılık Testi}

Tablo 2'de özetlenen sonuçlara göre tüm serilerde \% 1 anlamlılık düzeyinde yatay kesit bağımlılık vardır. Bu durumda ikinci nesil birim kök testlerinin uygulanması önerilmektedir. Buna göre serilerin birim kök içerip içermedikleri Pesaran (2007) tarafından önerilen CADF (Cross-Sectionally Augmented Dickey Fuller) testi ile incelenmiştir. Pesaran (2007) $\mathrm{CADF}$ testinin hem $\mathrm{T}>\mathrm{N}$ hem de $\mathrm{N}>\mathrm{T}$ durumlarında etkin bir şekilde kullanılabileceğini ileri sürmüştür. CADF regresyon denklemi

$$
\Delta Y_{i t}=\alpha_{i}+b_{i} Y_{i, t-1} c_{i} \dot{Y}_{t-1}+d_{i} \Delta \dot{Y}_{t}+\varepsilon_{i t}
$$


olarak gösterilebilmektedir. Burada $Y_{t}$, tüm yatay kesit gözlemlerin zamana göre ortalamasını ifade etmektedir. Otokorelasyon söz konusu olduğunda yukarıdaki denklem aşağıdaki gibi genişletilebilmektedir:

$\Delta Y_{i t}=\alpha_{i}+\rho_{i} Y_{i t-1}+d_{0} \dot{Y}_{t-1}+\sum_{j=0}^{p} d_{j+1} \Delta \dot{Y}_{t-j}+\sum_{k=1}^{p} c_{k} \Delta Y_{i, t-k}+\varepsilon_{i t}$

CADF regresyonu tahmin edildikten sonra CIPS istatistiği,

CIPS $=\frac{1}{N} \sum_{i=1}^{N} C A D F_{i}$

olarak elde edilecektir. Burada $C A D F_{i}$ gecikmeli değişkenlerin t-istatistiklerinin ortalamalarını ifade etmektedir. Tablo 3 'te Pesaran birim kök testi sonuçları özetlenmiştir.

\begin{tabular}{|c|c|c|c|}
\hline & t bar istatistiği & z bar istatistiği & Olasılık \\
\hline \multicolumn{4}{|c|}{ Düzey Seviyeleri (sabit+trend) } \\
\hline LGDP & $-2,599$ & $-1,242$ & 0,107 \\
\hline LMISERY & $-2,936^{*}$ & $-2,693 *$ & 0,004 \\
\hline LREM & $-2,810$ & $-2,152$ & 0,016 \\
\hline LFDI & $-3,268 *$ & $-4,121 *$ & 0,000 \\
\hline LTRADE & $-3,240 *$ & $-4,001 *$ & 0,000 \\
\hline \multicolumn{4}{|c|}{ İlk Farklar (sabit+trend) } \\
\hline$\Delta \mathrm{LGDP}$ & $-3,167 *$ & $-3,687^{*}$ & 0,000 \\
\hline$\triangle \mathrm{LREM}$ & $-2,767 *$ & $-4,194 *$ & 0,000 \\
\hline
\end{tabular}

Tablo 3. Pesaran Birim Kök Testi Sonuçları

Tablo 3'teki sonuçlara göre LGDP ve LREM değişkenleri hariç diğer değişkenlerin düzeyde durağan oldukları görülmektedir. LGDP ve LREM değişkenleri ise ilk farklarında durağan hale gelmişlerdir. Diğer bir deyişle serilerin farklı dereceden I(0) ve I(1) bütünlenen oldukları söylenebilir. Bu durumda seriler arasındaki uzun dönem ilişkisi Pesaran, Shin ve Smith (1999) tarafından geliştirilen panel otoregresif gecikmesi dağıtılmış (Autoregressive Distributed Lag, ARDL) modeli ile incelenecektir.

Çalışmada tahmin edilecek Panel ARDL modeli aşağıdaki gibidir:

$$
\Delta L G D P_{i t}=\sum_{j=1}^{p-1} \gamma_{j}^{i} \Delta L G D P_{i, t-j}+\sum_{j=0}^{q-1} \delta_{j}^{i} \Delta X_{i, t-j}+\theta^{i}\left[L G D P_{i, t-j}-\left(\beta_{0}^{i}+\beta_{1}^{i} X_{i, t-j}\right)\right]+\varepsilon_{i t}
$$

Burada $\mathrm{X}$ açıklayıcı değişkenleri, $\gamma$ ve $\delta$ kısa dönem katsayılarını, $\beta$ uzun dönem katsayılarını ve $\theta$ hata düzeltme terimini ifade etmektedir. Hata düzeltme teriminin (-) işaretli ve istatistiksel olarak anlamlı olması beklenmektedir. Hata düzeltme terimi, kısa dönemde meydana gelen sapmaların bir sonraki dönemde dengeye gelme hızını göstermektedir (Fosu ve Joseph, 2006).

Denklem (6) Havuzlanmış Ortalama Grup (Pooled Mean Group, PMG) ve Ortalama Grup (Mean Group, MG) tahmincileri yardımıyla tahmin edilmiştir. İki tahminci arasında seçim yapabilmek için Hausman testi kullanılmıştır. Temel hipotez havuzlanmış ortalama grup tahmincisinin tutarlı ve etkin olduğunu varsayarken, alternatif hipotez ortalama grup tahmincisinin tutarlı olduğunu ileri sürmektedir (Khan vd., 2019). Uzun dönem katsayılarının homojen olup olmadığını test eden Hausman testi sonuçları Tablo 4' te verilmiştir.

\begin{tabular}{lllll}
\hline Değişkenler & $\mathrm{b}(\mathrm{MG})$ & $\mathrm{B}(\mathrm{PMG})$ & $(\mathrm{b}-\mathrm{B})$ Fark & sqrt(diag(V_b-V_B $))$ S.E. \\
\hline LMISERY & $-0,4803$ & $-0,2266$ & $-0,2537$ & 0,4875 \\
LFDI & 0,2501 & 0,0773 & 0,1728 & 0,4703 \\
LTRADE & 0,1893 & 0,2505 & $-0,0612$ & 0,7368 \\
LREM & 0,1188 & 0,0763 & 0,0425 & 0,0719 \\
\hline
\end{tabular}

$c h i^{2}=1,68$ Prob $>$ chi $^{2}=0,7945$

Hausman test istatistigi: $H=(b-B)^{\prime}\left(V_{-} b-V_{-} B\right)^{-1}(b-B)$

\section{Tablo 4. Hausman Testi}

Elde edilen sonuçlara göre Hausman test istatistiği 1,68 değeri \%5 anlamlılık düzeyine göre istatistiksel olarak anlamsız bulunmuştur. Yani uzun dönemde katsayıların homojen olduğu kanısına varılabilir. Diğer bir deyişle temel hipotez altında etkin ve tutarlı olan PMG tahmincisi tercih edilmektedir. Buna göre havuzlanmış ortalama grup tahmincisi ile elde edilen tahmin sonuçları Tablo 5 'te yer almaktadır. 


\begin{tabular}{lcc}
\hline Değişkenler & Katsayılar & Standart hata \\
\hline Uzun Dönem Katsayılar & & \\
\hline LMISERY & $-0,2266^{*}$ & 0,0248 \\
LFDI & $0,0773^{*}$ & 0,0126 \\
LTRADE & $0,2505^{*}$ & 0,0456 \\
LREM & $0,0763^{*}$ & 0,0063 \\
\hline Kısa Dönem Katsayılar & & 0,0366 \\
\hline Hata Düzeltme Terimi & $-0,1921^{*}$ & 0,0087 \\
DLMISERY & $-0,0198^{* *}$ & 0,0037 \\
DLFDI & $-0,0020$ & 0,0255 \\
SLTRADE & 0,0376 & 0,0140 \\
$\Delta$ LREM & 0,0115 & 0,2582 \\
Sabit & $1,3935^{*}$ & \\
\hline
\end{tabular}

Log Likelihood=781,7856

Gözlem sayıs1=336

**, ve * sirastyla \%5, ve \%1 kritik değerlerine göre anlamlilı̆̆ göstermektedir.

Optimum gecikme uzunluğu Bayesian bilgi kriterine göre ARDL (1 11000 ) olarak belirlenmiştir.

\section{Tablo 5. Havuzlanmış Ortalama Grup Tahmin Sonuçları}

Havuzlanmış ortalama grup tahmin sonuçlarına göre tüm değişkenlerin uzun dönem katsayıları \%1 düzeyinde istatistiksel olarak anlamlı bulunmuştur. Elde edilen bulgulara göre sefalet endeksinde meydana gelen \% 1 'lik artış iktisadi büyümeyi \%0,22 oranında azaltmaktadır. Sefalet endeksi toplumdaki ekonomik kalkınmanın başlıca engelinin temel kaynağıdır (Asteriou ve Siriopoulos, 2000). Sefalet endeksinde bir azalma ve hükümetin etkililiğinde veya hukukun üstünlügünde herhangi bir artış, bölgede siyasi istikrar ile sonuçlanmaktadır (Agheli, 2017). Siyasi istikrarın ülkedeki üretim ve yatırımı artıırıı yönde etkilediği ileri sürülmektedir (Karahan ve Karagöl, 2014). Söz konusu endeksteki temel varsayım, artan işsizlik oranının ve nispeten yüksek enflasyonun ekonomik büyüme üzerinde olumsuz bir etki yarattığıdır. Ekonomik açıdan, enflasyondaki artı̧s ve yüksek işsizlik oranı tüketici harcamalarını düşürerek ekonomik yavaşlamaya sebep olabilir (Iqbal ve Nawaz, 2010). Böylece sefalet endeksinin iktisadi büyüme üzerindeki etkisinin negatif yönde olduğu sonucuna varılabilir.

Doğrudan yabancı yatırımlardaki (DYY) \%1'lik artış iktisadi büyümeyi \%0,07 oranında arttırmaktadır. DYY'ın brüt sabit sermaye oluşumuna katkıda bulunarak ekonomik büyümeyi doğrudan etkilediği varsayılmaktadır. Diğer yandan DYY'ın bilgi stokunu arttırarak ve alıcı ekonominin teknolojik büyümesini teşvik ederek dolaylı olarak ekonomik büyümeye katkıda bulunduğu ileri sürülmektedir (Borensztein vd., 1998; De Mello, 1999). Dolayısıyla DYY'n dışsallıklar (yani teknoloji ve bilgi yayılımları) sonucu ekonomik büyüme üzerinde kalıcı olumlu bir etkisinin olması beklenmektedir. Çalışmamızda DYY'ın büyümeyi artırdığına dair görüşü destekler nitelikte bulgulara ulaşı1mıştır.

Dışa açıklık endeksindeki \%1'lik artış ise iktisadi büyümeyi \%0,25 oranında yükselttiği gözlemlenmektedir. Dışa açıklık bir yandan yabancı yeniliklere erişim sağlayarak ekonomik büyümeyi desteklerken diğer yandan kıt kaynakların verimli bir şekilde tahsis edilmesini sağlayan pazar büyüklüğü ve rekabetin artmasına yol açmaktadır. Buna ilaveten sermaye girişlerini teşvik eden dişa dönük politikalar, özel sektörün gelişmesi ve iç ekonominin büyüme potansiyeline tam olarak katkıda bulunması için olanaklı ve destekleyici bir ortam yaratarak büyümeyi teşvik edebilir (Balassa, 1978; Kessides, 1991). Elde edilen bulgular ışığında dışa açıklık endeksinin büyümeyi pozitif yönde etkilediği söylenebilir.

İşçi transferlerindeki \%1'lik artışın ise büyümeyi \%0,07 oranında arttırdığı söylenebilir. İşçi transferlerinin sermaye birikim oranını doğrudan etkilediği bilinmektedir. Yerli hane halkları yatırım faaliyetlerini kısıtlayan finansal kısıtlamalarla karşılaştı̆̆ında, işçi dövizleri hane halklarının mali kısıtlamalarını azaltarak ve ekonominin yatırım düzeyini arttırarak ekonomik büyümeye katkıda bulunabilir (Barajas vd., 2009). Diğer yandan işçi transferlerinin çarpan yoluyla hane halklarının tüketim düzeyini etkileyerek büyümeye olumlu etki yapacağı ileri sürülmektedir (Stahl ve Arnold, 1986; Rahman, 2009; Acosta vd., 2007). Böylece işçi transferlerinin iktisadi büyüme üzerinde olumlu etkiler yaratacağı ortaya konulmaktadır.

Hata düzeltme parametresi ise $(-0,1921)$ negatif ve $\% 1$ düzeyinde istatistiksel olarak anlamlı bulunmuştur. $\mathrm{Bu}$ bir dönemde meydana gelen dengesizliklerin yaklaşı $\% 20$ 'si bir sonraki dönemde düzeleceğine işaret etmektedir. Sefalet endeksinin büyüme üzerindeki negatif yönlü etkisi kısa dönemde de anlamlı bulunmuştur. Diğer bir deyişle kısa dönemde sefalet endeksinde meydana gelen \% 1'lik artış iktisadi büyümeyi \% 0,01 oranında azaltmaktadır.

\section{Sonuç}

$\mathrm{Bu}$ çalışmada seçilmiş geçiş ülkelerinde sefalet endeksi ile iktisadi büyüme arasındaki ilişki incelenmiştir. Bu amaç doğrultusunda 16 geçiş ülkelerinin 1996-2017 dönemine ait yıllık verileri kullanılmıştır. Ampirik uygulamada Panel ARDL modeli kullanılmıştır. 
Elde edilen bulgulara göre ele alınan ülkelerde sefalet endeksi ile iktisadi büyüme arasında uzun dönem ilişki bulunmuştur. Tahmin sonuçları sefalet endeksi ile iktisadi büyüme arasında ilişkinin negatif yönde; dışa açıklık endeksi, doğrudan yabancı yatırımlar ve işçi transferlerinin büyüme üzerindeki etkisinin pozitif yönde olduğunu göstermektedir.

Ele alınan geçiş ülkelerinde sefalet endeksinin azaltılması ile iktisadi büyümenin arttırılabileceği sonucuna varılmıştır. Diğer bir deyişle sefalet endeksinde gözlemlenen olumlu bir gelişme ekonomik büyümeyi arttıracaktır. Genel olarak elde edilen bulgular 1şığında söz konusu ülkelerde sefalet endeksinin azaltılmasına ve doğrudan yabancı yatırımlar ile dış ticaretin arttırılmasına yönelik politikaların iktisadi büyüme üzerinde olumlu etkiler meydana getireceği söylenebilir.

\section{Kaynakça}

- Acosta, P., Fajnzylber, P., and Lopez, J. H. 2007. The Impact of Remittances on Poverty and Human Capital: Evidence from Latin American Household Surveys. (World Bank Policy Research Working Paper 4247). Washington, DC: The World Bank.

- Adrangi, B., and Macri, J. 2019. "Does the Misery Index Influence a US President's Political Re-Election Prospects?” Journal of Risk and Financial Management, 12, p. 22.

- Agheli, L. 2017. "Political Stability, Misery Index and Institutional Quality: Case Study of Middle East and North Africa". Ikonomchecki Izcledvaniya, 26, p. 30-46.

- Ajide Folorunsho, M. 2019. "Institutional Quality, Economic Misery and Crime Rate in Nigeria," Economics and Business, Sciendo, 33(1), p. 170-182.

- Akçay, S. 2018. "Remittances and Misery Index in Turkey: Is There a Link?” Applied Economics Letters, 25(13), p.895-899, DOI: 10.1080/13504851.2017.1380284.

- $\quad$ Alam, M.S., Shahbaz, M. and Paramati, S.R. 2016.”The Role of Financial Development and Economic Misery on Life Expectancy: Evidence from Post Financial Reforms in India”, Social Indicators Research, 128, p. 481-497 https://doi.org/10.1007/s11205-015-1040-4.

- $\quad$ Ali, A., N. Mujahid, and Rashid, Y. 2015. "Human Capital Outflow and Economic Misery: Fresh Evidence for Pakistan," Social Indicators Research, 124(3), p.747-764. doi:10.1007/s11205-014-0821-5.

- Asteriou, D., and Siriopoulos, C. 2000. "The Role of Political Instability in Stock Market Development and Economic Growth: The Case of Greece", Economic Notes, 29, p. 355-74.

- Balassa, B.1978. "Exports and Economic Growth: Further Evidence," Journal of Development Economics, 5(2), p.181-189.

- $\quad$ Barajas, A., R. Chami, C. Fullenkamp, M. Gapen, and Montiel, P. 2009. "Do Workers' Remittances Promote Economic Growth,’International Monetary Fund Working Paper, NoWP/09/153.

- Barro, R. J. 1999. “Reagan Vs. Clinton: Who’s the Economic Champ?” Business Week, February 22.

- Barro, R., and Gordon, D. 1983. “A Positive Theory of Monetary Policy in a Natural Rate Model," Journal of Political Economy, 91(4), p. 589-610.

- Bayar, Y., and Aytemiz, L. 2019. "The Misery Index, Corruption and Income Inequality in Latin American Countries: A Panel Cointegration and Causality Analysis", Scientific Annals of Economics and Business, 66(3), p. 309-319 DOI: 10.2478/saeb-2019-0024.

- Blanchard, O., and Fisher, S. 1989. Lectures on Macroeconomics. Cambridge: MIT Press.

- Borensztein, E., J. De Gregorio, and Lee, J.-W. 1998. "How Does Foreign Direct Investment Affect Economic Growth?” Journal of International Economics, 45(1), p. 115-35. doi:10.1016/S00221996(97)00033-0.

- $\quad$ Breusch, T. S., and Pagan, A. R. 1980. "The Lagrange Multiplier Test and its Applications to Model Specification in Econometrics", The Review of Economic Studies, 47(1), p. 239-253. http://dx.doi.org/10.2307/2297111.

- Dadgar, Y., and Nazari, R. 2018. "The Impact Of Economic Growth and Good Governance on Misery Index in Iranian Economy", European Journal of Law and Economics, 45, p. 175-93.

- De Mello, L. R. 1999. "Foreign Direct Investment-Led Growth: Evidence from Time Series and Panel Data”, Oxford Economic Papers, 51(1), p. 133-51. doi:10.1093/oep/51.1.133.

- $\quad$ Di Tella, R., R. MacCulloch, and Oswald, A. 2001. "Preferences of Inflation and Unemployment: Evidence from Surveys of Happiness," American Economic Review, 91(1), p. 335-341.

- Fosu, O. A. E., and Joseph, M. F. 2006. “Aggregate Import Demand and Expenditure Components in Ghana: An Econometric Analysis”, MPRA Paper No.599, August. 
- Iqbal, N., and Nawaz, S. 2010. "Fiscal Decentralization and Macroeconomic Stability: Theory and Evidence from Pakistan,” MPRA Paper, No. 27184, 1-18.

- Karahan, H., and Karagöl, Erdal T. 2014. "Ekonomik Performansın Temel Taşı: Siyasi İstikrar,” SETA Perspektif, 41, p. 1-5.

- $\quad$ Kessides, I. N. 1991. Lessons of Experience in Developing World. Oxford: Basil Blackwell.

- $\quad$ Khan, Z., Rabbi, F., Ahmad, M., and Siqun, Y. 2019. "Remittances Inflow and Private Investment: A Case Study of South Asian Economies via Panel Data Analysis", Economic Research-Ekonomska Istraživanja, 32(1), p. 2723-2742, DOI: 10.1080/1331677X.2019.1655464.

- Lorde, T., Jackman, M., Naitram, S. and Lowe, S. 2016. "Does Crime Depend on the "State" of Economic Misery?" Innternational Journal of Social Economics, 43(11), p. 1124-1134. https://doi.org/10.1108/IJSE03-2015-0047.

- Lovell, M., and Tien, P.-L. 2000. "Economic Discomfort and Consumer Sentiment.” Eastern Economic Journal, 26(1), p. 1-8.

- MacRae, D. 1977. “A Political Model of Business Cycle,” Journal of Political Economy, 85(2), p.239-263.

- Munir, S., Asghar, N., and Rehman, H. 2017. “An Analysis of the Interrelationship among Crime, and Institutional Quality: A Case Study of Pakistan”, Journal of Political Studies, 24(1), p.383-406.

- Nordhaus, W. 1989. “Alternative Approaches to the Political Business Cycle," Brookings Papers on Economic Activity, 2, p.1-68.

- $\quad$ Nunley J. M., Seals, R.A., and Zietzc, J. 2011. "Demographic Change, Macroeconomic Conditions, and the Murder Rate: The Case of the United States, 1934-2006”, The Journal of Socio-Economics, 40(6), p. 942948 .

- Pesaran, H. 2004. “General Diagnostic Tests for Cross Section Dependence in Panels”, Working Paper, No: 0435 University of Cambridge.

- Pesaran, M. H. 2007. "A Simple Panel Unit Root Test in the Presence of Cross-section Dependence," Journal of Applied Econometrics, 22, p. 265-312.

- $\quad$ Pesaran, M. H., Shin, Y., and Smith, R. P. 1999. "Pooled Mean Group Estimation of Dynamic Heterogeneous Panels", Journal of the American Statistical Association, 94(446), p. 621-634. doi: $10.2307 / 2670182$.

- Rahman, M. 2009. “Contributions of Exports, FDI, and Expatriates' Remittances to Real GDP of Bangladesh, India, Pakistan, and Sri Lanka”, Southwestern Economic Review, 36(1), p. 141-154.

- Saboor, A., Sadiq, S., Khan, A. U., and Hameed, G. 2017. "Dynamic Reflections of Crimes, Quasi Democracy and Misery Index in Pakistan”, Social Indicators Research, 133(1), p. 31-45.

- Sadeghi, S.K., Marvasti, M.B., and Karbor, R. 2014. "New Evidence of the Link Between Income Inequality and Misery Index. A Nonlinear Time Series”, International Journal of Sustainable Development and World Policy, Conscientia Beam 3(1), p. 25-30.

- Sandoval, L.E. 2014. "Demographic Change, Economic Conditions, and the Murder Rate: The Case of the Colombia 1990 to 2013”, Ecos de Economía, 18(39), p.97-111.

- $\quad$ Setterfield, M. 2009. “An Index of Macroeconomic Performance”, International Review of Applied Economics, 23, p. 625-649.

- $\quad$ Shahbaz, M., Loganathan, N., Mujahid, N., Ali, A., and Nawaz, A. 2015. "Determinants of Life Expectancy and its Prospects under the Role of Economic Misery: A Case of Pakistan”, MPRA Paper No. 67167. 1-28.

- Stahl, C. W., and Arnold, F. 1986. “Overseas Workers' Remittances in Asian Development”, International Migration Review, 20(4), p. 899-925. doi:10.2307/2545742.

- Tang, C. F., and Lean, H.H. 2009. "New Evidence from the Misery Index in the Crime Function", Economics Letters, 102, p. 112-15.

- Wang, N., Shah, M.H., Ali, K., Abbas, S. ve Ullah, S. 2019. "Financial Structure, Misery Index, and Economic Growth: Time Series Empirics from Pakistan”, Journal of Risk and Financial Management, 12 p. 100, doi:10.3390/jrfm12020100.

- World Bank Database, WDI (2020). www.worldbank.org

- Wu, P.C., S.Y. Liu and Pan, S.C. 2014. "Does Misery Index Matter for the Persistence of Health Spending? Evidence from OECD Countries", Social Indicators Research, 118, p. 893-910.

- Yang, B., Lester, D.1992. "The Misery Index and an Index of Misery”, Atlantic Economic Journal, 20(3), p. 98, https://doi.org/10.1007/BF02300179. 


\title{
Avrasya Ekonomik Birliği Ülkelerinde Döviz Kuru ve Dış Rezervler İlişkisi
}

\section{Relationship between Exchange Rate and Reserves in EAEU Countries}

\author{
Asst. Prof. Dr. Junus Ganiev (Kyrgyz-Turkish Manas University, Kyrgyzstan) \\ Prof. Dr. Jusup Pirimbaev (Kyrgyz-Turkish Manas University, Kyrgyzstan) \\ Asst. Prof. Dr. Damira Baigonushova (Kyrgyz-Turkish Manas University, Kyrgyzstan)
}

\begin{abstract}
The Eurasian Economic Union, which was officially established five years ago, faced many financial and economic problems in this period. After 2014, when sanctions against Russia began, all members' national currency suffered serious depreciation and central banks had to actively intervene in the foreign exchange market. In fact, Russia and Kazakhstan have changed regime and switched from the fixed to the flexible exchange rate system. Since the foreign exchange market has been more stable in recent years, central banks are trying to complete the reserves that had been lost that period. Therefore, with the change of foreign reserves, money supply is also changing. The aim of this study is to examine and compare the relationship between exchange rates, reserves and money supply in five EAEU countries. Quarterly data for the period 2010-2019 was used to achieve the goal. Toda-Yamamoto causality and ARDL cointegration approach were used as a method. It was concluded that more coordinated execution of monetary and exchange rate policies would be in favor of all members. However, the basic principle should be that all members benefit equally from the cooperation.
\end{abstract}

\section{Giriș}

Resmi olarak oluştuğuna beş sene olan Avrasya Ekonomik Birliği bu süre aralığında pek çok finansal ve ekonomik sorunlarla karşılaştı. Rusya'ya karşı yaptırımların başladığı 2014'ten sonra tüm üyelerin milli paraları ciddi değer kayıplarına uğradı ve merkez bankaları döviz piyasasına çok aktif müdahale etmek zorunda kaldı. Hatta Rusya ve Kazakistan rejim değişikliğine giderek sabit kur sisteminden esnek kur sistemine geçti. Son senelerde döviz piyasası daha istikrarlı olduğu için merkez bankaları bu sefer kaybettiği rezervleri tamamlamaya çalışıyorlardı. Fakat COVID-19 pandemisi dolayısıyla petrol fiyatlarının keskin düşüşü özellikle Rusya ve Kazakistan'ın döviz gelirlerini etkileyerek döviz piyasasında tekrar istikrarsızlıklara yol açmaktadır. Böyle bir ortamda bir taraftan diş rezervler değişirken, diğer taraftan para arzında değişmeler meydana gelmektedir. Bu da ekonomik istikrarı ve dolayısıyla büyümeyi olumsuz etkileyebilecektir. Ayrıca, Avrasya Ekonomik Birliği (AEB) ülkelerinin daha uzun bir pespektifte entegrasyonu derinleştirerek parasal birliğe gidilmesi düşünüldüğünden, döviz kuru politikasının ve genel olarak para politikasının uyumlu bir şekilde yürütülmesi önem arz etmektedir. Günümüzde sözkonusu Birliğe üye olan beş ülkenin döviz kuru ve para politikalarını ele alan çalışmalarda da bu ve benzeri sorunlara da özellikle dikkat çekilmektedir.

AEB ülkelerinde döviz kuru politikasına ilişkin temel sorunların arasında döviz kuru istikrarsızlığı önemli bir yere sahiptir, çünkü bu ekonomide beklentileri etkileyerek dolarizasyonu artırmaktadır. Diğer taraftan, ulusal paraların devalüasyonları Avrasya Ekonomik Birliği içerisinde dış ticaret dengesini bozmaktadır. Merkez bankaları politikalarında uyumlaştırmanın sağlanmaması üye ülkelerin iş çevrimlerinde dengesizliklere yol açmaktadır. Ortak ticari hedeflerin ve ortak dış ticaret mekanizmalarının olmaması üyeler arasındaki rekabeti artırmaktadır. Örneğin, Rusya ve Kazakistan ihracata dönük ülkeler iken, Ermenistan ve Kırgızistan ise ithalat odaklı ülkeler durumundadır (Andrienko ve İlyina, 2017: 26-27). Diğer bir ifadeyle, iç üretim yetersizliği dolayısıyla ithalata bağımlılı̆̆ı yüksek olan bu küçük ekonomiler ulusal paranın değerinin düşmemesine daha çok özen göstermektedirler. Amaca ulaşmada döviz rezervleri en önemli role sahiptir. Bununla beraber, rezervlerin uygun düzeyde bulundurulması da önemlidir, çünkü rezerv yetersizliği ülkenin dünya piyasasında ödeme gücünün azalmasına ve devletin para piyasasına müdahale imkanının kısıtlı olmasına neden olurken, rezerv fazlalığı ülke kaynaklarının önemli kısmının uzun süre atıl kalmasına yol açmaktadır (Esenalieva ve Balandina, 2017: 68). Her ülke bunun gibi hususları gözönünde bulundurarak kendisine uygun rezerv düzeyini belirlemektedir ve resmi olarak ekonomik birlikte bulunmalarına rağmen ekonomik hedefleri ve politikaları çoğu zaman birbiriyle uyuşmamaktadır.

Sandoyan ve diğerlerine (2016) göre, Ermenistan'ın 1 Ocak 2015'de Birliğe resmi olarak katılmasındaki temel faktör diğer üye ülkelere Ermenistan ihracatının gelişeceği ve özellikle Rus yatırımcılar için ülkenin yatırım cazibesinin artacağı beklentileri olmuştur. Fakat gerçekte Ermenistan'da para ve döviz kuru politikasının Avrasya Ekonomik Birliği üyeleriyle uyumlu bir şekilde uygulanmaması nedeniyle, ülkenin uluslararası ticaret ve yatırımlara ilişkin tüm temel göstergeleri kötüleşmiştir. Benzer durum belirli bir düzeyde Kırgızistan için de geçerlidir. 
Zaranskaya (2017) Belarus ülkesinde döviz kuru hedeflemesinin ülke ihracatının uluslararası pazarlarda rekabet gücünü sağlamak için oldukça etkili bir mekanizma olduğunu belirtmiştir. Ayrıca, döviz kuru politikasının, AEB ülkelerinin para piyasasının düzenlenmesinde en etkili araç haline gelmesi gerektiğini ve eşit rekabet koşullarının sağlanması için mekanizmaların koordinasyonuna ve döviz kuru oluşumuna yönelik ortak yaklaşımların oluşturulmasına ihtiyaç duyulduğunu ifade etmiştir. Voytekhovich (2015) ise parasal birliğin döviz kuru istikrarını sağlayarak Belarus Cumhuriyeti'nin diş ticaretini olumlu etkileyeceğini, fakat şu aşamada AEB üyelerinin ulusal paralarla dış ticareti artırarak ve ulusal paraların birbirine olan kurlarını döviz piyasasına yapılacak ortak müdahalelerle istikrarlı tutarak entegrasyon işbirliğini sürdürmesinin doğru olacağını, parasal birliğe gidilmesinin erken olacağını belirtmiştir.

Bununla beraber, mali sektörde ve onun bankacıllk ve sigortacılık gibi alt sistemlerinde birliğin sağlanması amacıyla tek bir finansal düzenleyicinin oluşturulması, 2025'de ise Avrasya Ekonomik Birliği Merkez Bankası'nın oluşturulması düşünülmüştür. Fakat tek bir finansal düzenleyicinin oluşturulması; finans sektöründe kanunların uyumsuzluğu ve tek bir para biriminin olmamasına ilave olarak, ekonomik yapılarda, sektörlerin gelişme düzeyinde ve ülkelerin sosyal ve ekonomik durumunda önemli farkların bulunmasından dolayı zorlaşmaktadır. Belirtmek gerekirse, AEB üyeleri arasında GSYİH farkı 250 kat, kişi başına GSYİH farkı yaklaşık 7 kat, rezerv hacmi farkı 250 kattan daha fazla ve cari işlemler hesabı fazlası sadece Rusya'da yer almaktadır (Golodova vd., 2019: 208). Özetlemek gerekirse, günümüzde AEB üyeleri arasında ticari ilişkilerde bazı önemli gelişmeler kaydedilmişken, diğer alanlarda uyumlu, ortak politika ve stratejiler uygulama imkanı bulunmamaktadır. Bu durum döviz kuru politikası ve genel olarak para politikası için de elbette geçerlidir.

Bu çalışmanın amacı AEB üyeleri olan beş ülkede döviz kuru, rezervler ve para arzı arasındaki ilişkiyi araştırmak ve mukayese etmektir. Ayrıca, analiz sonuçları 1şı̆̆ında daha uygun ve koordineli politika uygulanması konusunda öneriler sunmaktır.

\section{Literatür Taraması}

Bretton-Woods sisteminden sonra dünyadaki çoğu ülkelerin esnek kur sistemini benimsemeye başlaması nedeniyle döviz kuru oynaklığının uluslararası ticarete ve dış yatırımlara olan etkisi pek çok araştırmaya konu olmuştur. Döviz kuru oynaklığının dış ticareti olumsuz etkileyeceği yönünde genel bir kanaat oluşmasına rağmen, empirik çalışmaların her zaman bunu teyit etmediği, yani bazı çalışmaların döviz kuru oynaklığı ile dış ticaret arasında pozitif ilişki bulduğu ortaya çıkmıştır (Cote (1994) ve Ozturk (2006) tarafından bu konuda geniş bir literatür taraması yapılmıştır). Döviz kuru ile dış ticaret ilişkisi konusunda pek çok empirik çalışma yapılmışken, döviz kuru ile dış rezervler ve para arzı ilişkisi, yani merkez bankaların döviz kuru politikasının para piyasasına etkileri konusunda yapılan empirik çalışmalar nadirdir.

Teorik olarak bakıldığında, para arzının döviz kuru üzerindeki etkileri şu şekilde olabilmektedir: birincisi, kısa dönemde para arzının artması faizleri düşürerek ulusal para cinsinden aktiflerin getirisini azaltabilir; ikincisi de uzun dönemde, para arzının artması enflasyonu hızlandırarak satın alma gücü paritesine göre döviz kurunu artırabilir, yani ulusal paranın değerini düşürebilecektir (Yurdakul, 2016: 23-25). Aktiflerin getirisinin azalması sermaye çıkışına neden olarak döviz kuruna baskı oluşturacaktır.

Merkez bankası döviz rezervleri ile döviz kuru arasındaki ilişkide ekonomik beklenti şu şekilde olabilir. Merkez bankası piyasadan döviz satın alarak dış rezervlerini artırdığında piyasada döviz miktarı azalacaktır. Bundan dolayı kurlarda yükseliş beklenecektir. Tersine piyasaya döviz satarak rezervleri azaldığında piyasadaki döviz miktarı artarak kurlar düşmeye başlayacaktır (Şit ve Karadağ, 2019: 153). Diğer taraftan, döviz piyasasına yapılan müdahaleler, para arzının istikrarını sağlamak amacıyla açık piyasa işlemleri ile birlikte uygulanmadığı sürece ulusal para arzını da doğrudan etkilemektedir. Bu konuda bazı empirik çalışmalar şu şekildedir.

Hviding ve diğerleri (2004) dış rezervlerin reel döviz kuru oynaklığını azaltıp azaltmadığını araştırarak yükselen pazar ülkelerinde rezervlerin, reel efektif döviz kurunun kısa vadeli oynaklığı üzerinde negatif etkisinin olduğuna dair güçlü kanıtlar bulmuşlardır.

Afzal (2010) tarafından yapılan çalışmada Bangladeş, Hindistan, Pakistan, Filipinler, Sri Lanka ve Tayland'dan oluşan altı Asya ülkesinde döviz kuru ile dış rezervlerin ilişsisi nedensellik testi ile araştırılmıştır. Araştırma sonuçlarına göre, Pakistan, Sri Lanka ve Tayland'da rezervlerden döviz kuruna doğru; Filipinlerde ise tersine döviz kurundan rezervlere doğru tek taraflı nedensellik ilişkisi ortaya konmuştur. Bangladeş’te hiçbir nedensellik bulunmamışken, Hindistan'da sözkonusu iki değişken arasında çift yönlü bir ilişki bulunmuştur.

Tunay (2008) Türkiye'de merkez bankası müdahalelerinin döviz kuru oynaklığı üzerindeki etkilerini inceleyerek TCMB'nin döviz piyasalarına olan müdahalelerinin kurlardaki oynaklığı artırdığını ortaya koymuştur. Elde edilen bulgular ışı̆̆ında merkez bankasının döviz piyasasına müdahale etmekten kaçınması gerektiği, olası döviz şoklarının kalıcı olmayıp piyasa dinamikleriyle kısa sürede istikrar sağlanacağı belirtilmiştir.

Şit ve Karadağ (2019) tarafından Türkiye ekonomisi üzerine yapılan çalışmaya göre, Merkez Bankası döviz rezervleri ile döviz kuru arasında hem kısa, hem de uzun dönemde eşbütünleşme ilişkisi tespit edilmiştir. 
Yine Kartal ve diğerleri (2018) Türkiye'de döviz kurlarını etkileyen faktörleri belirlemek amacıyla para arzı, bütçe açığı, yabancı yatırımlar, işsizlik, iç borç, ithalat, ihracat, enflasyon ve cari açı gibi değişkenlerin döviz kuruna etkisini ele almışlardır. Çalışma sonucuna göre, para arzının; ABD Doları/TL kurunun belirlenmesinde ilk 5 değişkenin biri, Euro/TL kurunun belirlenmesinde ise ilk 3 değişkenin biri olduğu ortaya çıkmıştır.

Sekmen ve Ravanoğlu (2017) Kazakistan ekonomisi için döviz kuru, faiz haddi ve para arzı ilişkisini inceleyerek döviz kuru ile faiz haddi arasında çift yönlü bir nedensellik ilişkisi bulmuşlardır.

Empirik araştırmada kullanılacak veri ve yöntemler bunun gibi çalışmaları esas alarak belirlenmiştir.

\section{Veri, Yöntem ve Uygulama Sonuçları}

Çalışmada Avrasya Ekonomik Birliği'nin resmi sitesinden (http://www.eaeunion.org/) temin edilen 2010:012019:04 dönemine ait çeyreklik veriler $(n=40)$ kullanılmıştır. Ulusal paraların dolar kuru (ER), resmi rezervler (RES) ve para arzı (M0) arasındaki ilişkiler ARDL koentegrasyon yöntemi ve Toda-Yamamoto nedensellik testi yaklaşımıyla araştırılmıştır.

\begin{tabular}{|c|c|c|c|c|}
\hline \multirow{2}{*}{ Değişkenler } & \multicolumn{2}{|c|}{ Genişletilmiş Dickey-Fuller (ADF) } & \multicolumn{2}{|c|}{ Phillips-Perron (PP) } \\
\hline & Intercept & Trend and intercept & Intercept & Trend and intercept \\
\hline \multicolumn{5}{|c|}{$D \ddot{U} Z E Y$} \\
\hline ler_ar & -0.916033 & -1.443383 & -0.916033 & -1.758314 \\
\hline ler_be & -2.296452 & -0.947548 & -2.056457 & -1.181484 \\
\hline ler_kg & -0.993393 & -2.095122 & -0.898096 & -1.392823 \\
\hline ler_kz & -0.248434 & -2.825061 & -0.054101 & -1.869710 \\
\hline ler_ru & -0.835944 & -1.601641 & -0.845105 & -1.775162 \\
\hline $\operatorname{lm} 0$ ar & -1.138643 & -3.319709 & -1.273848 & -3.039554 \\
\hline $\operatorname{lm} 0$ be & -1.434532 & $-4.215440 *$ & -2.303606 & -2.514028 \\
\hline $\operatorname{lm} 0 \mathrm{~kg}$ & -0.349788 & $-3.998023 *$ & -1.088940 & -2.396542 \\
\hline $\operatorname{lm} 0 \mathrm{kz}$ & -1.259517 & -2.927052 & -1.262095 & -1.891083 \\
\hline $\operatorname{lm} 0$ ru & -1.021556 & -2.843491 & -2.559290 & $-4.275508 * *$ \\
\hline lres_ar & -1.451031 & -2.238512 & -1.320373 & -2.151171 \\
\hline lres_be & -1.865060 & -1.351933 & -1.177109 & -1.351933 \\
\hline lres kg & -1.668761 & -2.031825 & -1.602238 & -2.100786 \\
\hline lres kz & -2.570554 & -2.523770 & -2.621548 & -2.563647 \\
\hline lres_ru & -1.212201 & -0.874051 & -1.196680 & -0.826172 \\
\hline \multicolumn{5}{|c|}{ BIRINCCI FARK } \\
\hline dler ar & $-4.771632 * *$ & $-4.730310 * *$ & $-4.687898 * *$ & $-4.651176^{* *}$ \\
\hline dler_be & $-3.941495 * *$ & $-4.298437 * *$ & $-3.915817 * *$ & $-4.088429 *$ \\
\hline dler kg & -2.209428 & -2.194142 & $-4.728494 * *$ & $-4.675582 * *$ \\
\hline dler_kz & $-4.565453 * *$ & $-4.529578 * *$ & $-3.162675^{*}$ & -3.086559 \\
\hline dler_ru & $-6.015616^{* *}$ & $-5.936258 * *$ & $-6.016174^{* *}$ & $-5.936951 * *$ \\
\hline $\mathrm{d} \operatorname{lm} \overline{0}$ ar & -1.776392 & -1.733642 & $-12.07105^{* *}$ & $-11.81049 * *$ \\
\hline $\mathrm{d} \operatorname{lm} 0$ be & $-6.317664 * *$ & $-6.281006^{* *}$ & $-6.620251 * *$ & $-7.734825 * *$ \\
\hline $\mathrm{d} \operatorname{lm} 0 \ldots \mathrm{kg}$ & -2.630876 & -2.560143 & $-6.922276^{* *}$ & $-6.836423 * *$ \\
\hline $\mathrm{d} \operatorname{lm} 0 \mathrm{kz}$ & $-7.514660 * *$ & $-7.400083 * *$ & $-7.495991 * *$ & $-7.384709 * *$ \\
\hline $\mathrm{dlm} 0 \mathrm{ru}$ & -2.245561 & -2.236116 & $-9.391841 * *$ & $-9.691817 * *$ \\
\hline dlres_ar & $-5.945138 * *$ & $-6.118231 * *$ & $-6.133606 * *$ & $-7.554979 * *$ \\
\hline dlres be & $-4.649793 * *$ & $-4.626244 * *$ & $-4.516684 * *$ & $-4.484561 * *$ \\
\hline dlres kg & $-6.628911 * *$ & $-6.542421 * *$ & $-6.626792 * *$ & $-6.540767 * *$ \\
\hline dlres_kz & $-5.947566^{* *}$ & $-5.898211^{* *}$ & $-6.097969 * *$ & $-6.005548 * *$ \\
\hline dlres ru & $-3.861514 * *$ & $-3.957440^{*}$ & $-3.846819 * *$ & $-3.957440^{*}$ \\
\hline
\end{tabular}

Tablo 1. Birim Kök Testi Sonuçları Kaynak: Yazarlar tarafindan oluşturulmuştur.

Değişkenlerin varyansta durağan olmama durumunu önlemek amacıyla tüm değişkenlerin logaritmik halleri analize katılmıştır. Değişken isimlerinin başındaki "l” işareti bu durumu ifade etmektedir. Şunu da belirtmek gerekir ki, döviz kuru doğrudan fiyatlama yöntemine göre gösterildiği için, bu değişkendeki artış ulusal paranın dolara karşı değer kaybetmesini ve düşüş de değer kazanmasını ifade eder.

Merkez bankaların döviz piyasasına müdahale istatistiklerini kamuoyuna pek yansıtmaması nedeniyle, pek çok empirik çalışmalarda (örneğin, Taylor, 1982; Obstfeld, 1983; Gartner, 1991) bunun bir temsilcisi olarak diş rezervler kullanılmaktadır. Bu çalışmada da resmi müdahale istatistiklerinin tam olarak elde edilememesi nedeniyle temsilci olarak dış rezervler serisi alınmıştır. 
İlk olarak değişkenlere birim kök testi uygulanmıştır. Buna göre, değişkenlerin bazıları düzeyde, pek çoğu birinci farkta durağan bulunduğu için ve değişkenler arasındaki hem uzun hem kısa dönemli ilişkileri belirlemek amacıyla, yöntem olarak ARDL eşbütünleşme yaklaşımı uygun bulunmuştur. Uygun gecikme uzunluklarının belirlenmesinde Akaike kriteri (AIC) temel alınmış ve verilerin çeyreklik olduğunu da dikkate alarak maksimum uzunluk düzeyi olarak 4 dönem seçilmiştir. İlk olarak eşbütünleşmenin bulunup bulunmadığını tespit etmek amacıyla F-testi yapılmıştır ve tabloda sadece eşbütünleşme ilişkisi bulunanları sunulmuştur.

\begin{tabular}{|l|c|c|c|c|}
\hline Bağımlı Değişken & Bağımsız Değişkenler & F-istatistiği & Alt Sınır, I(0) & Üst Sınır, I(1) \\
\hline $\operatorname{lm} 0 \_a r$ & ler_ar, lres_ar & $6.140590^{*}$ & 4.133 & 5.260 \\
\hline ler_be & lm0_be, lres_be & $11.15362^{*}$ & 4.133 & 5.260 \\
\hline lres_kg & lm0_kg, ler_kg & $8.979378^{*}$ & 4.133 & 5.260 \\
\hline lm0_kz & ler_kz, lres_kz & 3.458491 & 4.133 & 5.260 \\
\hline lm0_ru & ler_ru, lres_ru & $5.901996^{*}$ & 4.133 & 5.260 \\
\hline
\end{tabular}

Not: Kritik değerler Narayan (2005)'den alınmıştır, $k=2$. *\%5 önem düzeyinde anlamlılı̆̆ı gösterir.

\section{Tablo 2. Eşbütünleşme İlişkisinin F-istatistiği}

Tablodan görüldüğü gibi, Ermenistan ve Rusya'da döviz kuru ile dış rezervlerin para arzını etkilediği; Belarus'ta para arzı ile rezervlerin döviz kurunu etkilediği; Kırgızistan'da para arzı ile döviz kurunun dış rezervleri etkilediği ve Kazakistan'da sözkonusu üç değişkenin arasında hiçbir eşbütünleşme ilişkisinin bulunmadığı ortaya çıkmıştır.

\begin{tabular}{|c|c|c|c|c|c|c|c|}
\hline \multicolumn{2}{|c|}{$\begin{array}{c}\operatorname{lm} 0 \text { ar } \\
\text { ARDL_(3,4,4) }\end{array}$} & \multicolumn{2}{|c|}{$\begin{array}{c}\text { ler_be } \\
\text { ARDL }(3,1,4)\end{array}$} & \multicolumn{2}{|c|}{$\begin{array}{c}\text { lres_kg } \\
\text { ARDL }(4,3,4)\end{array}$} & \multicolumn{2}{|c|}{$\begin{array}{c}\operatorname{lm} 0 \_r u \\
\text { ARDL }(4,4,2)\end{array}$} \\
\hline Değişken & Katsay1 & Değişken & Katsay 1 & Değişken & Katsay1 & Değişken & Katsay1 \\
\hline$\Delta \operatorname{lm} 0 \operatorname{ar}_{\mathrm{t}-1}$ & -0.213 & $\Delta$ ler be t $-1_{1}$ & 0.269 & $\Delta$ lres $\mathrm{kg}_{\mathrm{t}-1}$ & 0.078 & $\Delta \operatorname{lm} 0 \mathrm{ru}_{\mathrm{t}-1}$ & $-0.458 * *$ \\
\hline$\Delta \operatorname{lm} 0 \quad$ art $_{\mathrm{t}-2}$ & $0.338 *$ & $\Delta$ ler bet-2 & 0.226 & $\Delta$ lres $\mathrm{kg}_{\mathrm{t}-2}$ & 0.156 & $\Delta \operatorname{lm} 0$ rut$_{\mathrm{t}-2}$ & $-0.251 *$ \\
\hline$\Delta$ ler_ar & -0.953 & $\Delta \operatorname{lm} 0$ be & $-0.296^{*}$ & $\Delta$ lres_kg $\mathrm{kg}_{\mathrm{t}-3}$ & $0.303^{*}$ & $\Delta \operatorname{lm} 0 \_$rut-3 & $-0.394 * *$ \\
\hline$\Delta$ ler $\operatorname{ar}_{\mathrm{t}-1}$ & $-1.596^{*}$ & $\Delta$ lres be & 0.192 & $\Delta \operatorname{lm} 0 \mathrm{~kg}$ & $0.355 * *$ & $\Delta$ ler ru & 0.013 \\
\hline$\Delta$ ler art $_{\mathrm{t}-2}$ & 0.452 & $\Delta$ lres be t $-1_{1}$ & -0.026 & $\Delta \operatorname{lm} 0 \mathrm{~kg}_{\mathrm{t}-1}$ & -0.232 & $\Delta$ ler_rut t $_{\mathrm{t}}$ & 0.068 \\
\hline$\Delta$ ler_art-3 & 0.573 & $\Delta$ lres_bet-2 & -0.207 & $\Delta \operatorname{lm} 0 \_\mathrm{kg}_{\mathrm{t}-2}$ & $0.221^{*}$ & $\Delta$ ler_rut-2 & 0.097 \\
\hline$\Delta$ lres_ar & $0.336 * *$ & $\Delta$ lres_be $_{t-3}$ & $0.247 *$ & $\Delta$ ler_kg & $-0.559 *$ & $\Delta$ ler_rut-3 & $-0.152 *$ \\
\hline$\Delta$ lres_art-1 & 0.050 & $\mathrm{ECT}_{\mathrm{t}-1}$ & $-0.325 * *$ & $\Delta$ ler $k_{\text {t- } 1}$ & -0.358 & $\Delta$ lres ru & -0.194 \\
\hline$\Delta$ lres_art-2 & -0.245 & & & $\Delta$ ler_kg $\mathrm{kg}_{\mathrm{t}-2}$ & 0.643 & $\Delta$ lres_rut 1 & $0.590 * *$ \\
\hline$\Delta$ lres_art-3 & -0.221 & & & $\Delta$ ler_kg $\mathrm{kg}_{\mathrm{t}-3}$ & 0.287 & $\mathrm{ECT}_{\mathrm{t}-1}$ & $-0.149 *$ \\
\hline $\mathrm{ECT}_{\mathrm{t}-1}$ & $-0.613 * *$ & & & $\mathrm{ECT}_{\mathrm{t}-1}$ & $-1.085 * *$ & & \\
\hline \multicolumn{8}{|c|}{ Ek testler: } \\
\hline $\begin{array}{l}\text { Test } \\
\text { İstatistikleri }\end{array}$ & F-değeri & $\begin{array}{c}\text { Test } \\
\text { İstatistikleri }\end{array}$ & F-değeri & $\begin{array}{c}\text { Test } \\
\text { İstatistikleri }\end{array}$ & F-değeri & $\begin{array}{c}\text { Test } \\
\text { İstatistikleri }\end{array}$ & F-değeri \\
\hline $\begin{array}{l}\text { A: Serisel } \\
\text { korelasyon }\end{array}$ & $\begin{array}{l}0.164 \\
{[0.849]}\end{array}$ & $\begin{array}{l}\text { A: Serisel } \\
\text { korelasyon }\end{array}$ & $\begin{array}{l}1.539 \\
{[0.235]}\end{array}$ & $\begin{array}{l}\text { A: Serisel } \\
\text { korelasyon }\end{array}$ & $\begin{array}{l}0.294 \\
{[0.748]}\end{array}$ & $\begin{array}{l}\text { A: Serisel } \\
\text { korelasyon }\end{array}$ & $\begin{array}{l}1.297 \\
{[0.294]}\end{array}$ \\
\hline B: ARCH & $\begin{array}{l}1.418 \\
{[0.242]}\end{array}$ & B: ARCH & $\begin{array}{l}0.001 \\
{[0.964]}\end{array}$ & B: ARCH & $\begin{array}{l}0.494 \\
{[0.486]}\end{array}$ & B: ARCH & $\begin{array}{l}0.182 \\
{[0.672]}\end{array}$ \\
\hline $\begin{array}{l}\text { C: Normal } \\
\text { Dağılım } \\
\text { (Jarque- } \\
\text { Bera) }\end{array}$ & $\begin{array}{l}0.259 \\
{[0.878]}\end{array}$ & $\begin{array}{l}\text { C: Normal } \\
\text { Dağılım } \\
\text { (Jarque- } \\
\text { Bera) }\end{array}$ & $\begin{array}{l}4.798 \\
{[0.091]}\end{array}$ & $\begin{array}{l}\text { C: Normal } \\
\text { Dağ1lım } \\
\text { (Jarque- } \\
\text { Bera) }\end{array}$ & $\begin{array}{l}0.256 \\
{[0.879]}\end{array}$ & $\begin{array}{l}\text { C: Normal } \\
\text { Dağılım } \\
\text { (Jarque- } \\
\text { Bera) }\end{array}$ & $\begin{array}{l}0.811 \\
{[0.666]}\end{array}$ \\
\hline
\end{tabular}

Not: **\%1 ve *\%5 önem düzeyinde anlamlıl̆̆̆ gösterir. Köşeli parantez içerisinde olasıllk değerleri verilmiştir.

\section{Tablo 3. Hata Düzeltme Modelleri}

Tablo 3'de ARDL eşbütünleşme yaklaşımına göre oluşturulan hata düzeltme modelleri sunulmuştur. Tüm modellerin hata düzeltme katsayıları (ECT: error correction term) beklendiği gibi eksi işaretli ve anlamlı bulunmuştur. Katsayının büyüklüğüne göre, herhangi bir nedenle dengeden uzaklaşma olduğunda, Kırgızistan'da dış rezervlerin, Ermenistan'da para arzının dengeye dönme hızının gayet yüksek olacağı, Belarus'ta döviz kurunun ve Rusya'da para arzının dengeye dönme hızının mukayeseli olarak daha düşük olacağı söylenebilir.

Kısa dönem katsayıları genel olarak beklentilere uygun bulunmuştur. Kırgızistan'da döviz kurunun yükselmesi rezerv miktarını olumsuz etkilerken, Rusya ve Ermenistan'da para arzını azaltmaktadır. Hem Kırgızistan, hem Rusya'da para arzı ile rezervler arasında pozitif yönlü bir ilişki bulunmaktadır. İstisna olarak Belarus'da bazı çelişkili sonuçlar ortaya çıkmıştır. Fakat uzun dönem katsayılarının beklentilere uygun çıktığı tabloda görülmektedir. Buna göre, para arzındaki \%1'lik bir artış Belarus'da ulusal paranın \%0,92 değer kaybetmesine, rezervlerdeki \%1'lik bir artış ise yaklaşık aynı oranda değer kazanmasına yol açmaktadır. 


\begin{tabular}{|l|l|l|l|l|l|l|c|}
\hline \multicolumn{2}{|c|}{$\operatorname{lm} 0$ ar } & \multicolumn{2}{c|}{ ler_be } & \multicolumn{2}{c|}{ lres kg } & \multicolumn{2}{c|}{$\operatorname{lm} 0$ ru } \\
\hline Değişken & Katsay1 & \multicolumn{1}{|c|}{ Değişken } & Katsay1 & \multicolumn{1}{c|}{ Değişken } & Katsay1 & Değişken & Katsay1 \\
\hline ler_ar & $0.4167^{*}$ & lm0_be & $0.9266^{* *}$ & lm0_kg & $0.5115^{* *}$ & ler_ar & 0.2984 \\
\hline lres_ar & $1.1232^{* *}$ & lres_be & $-0.9260^{* *}$ & ler_kg & $-0.4857^{* *}$ & lres_ar & 0.2678 \\
\hline Sabit & $-5.0885^{* *}$ & Sabit & $8.7192^{* *}$ & Sabit & $7.4322^{* *}$ & Sabit & 4.5241 \\
\hline
\end{tabular}

Not: Parantez içerisinde t-istatistikleri verilmiştir. **\%1 ve *\%5 önem düzeyinde anlamlılı̆̆ gösterir.

\section{Tablo 4. Uzun Dönem Katsayıları}

Ermenistan'da incelenen dönemde döviz kuru, rezervler ve para arzında paralel artışların yaşandığı ortaya çıkmıştır. Para arzı artışı dış rezervlerdeki artıştan daha hızlı bir seyir izlemektedir. Aynı şekilde Kırgızistan ve Rusya'da da para arzı ile rezervler arasında pozitif yönlü ilişkiler görülmektedir. Yine beklentilere uygun olarak Kırgızistan'da döviz kuru artışlarının döviz rezervlerini azalttığı, ulusal paradaki \%1'lik bir değer kaybının döviz rezervlerinde \%0,48'lik bir azalmaya yol açtığı tespit edilmiştir. Ancak Rusya'da uzun dönemde tüm katsayılar istatistiki olarak anlamsız bulunmuştur.

\begin{tabular}{|c|c|c|}
\hline Sifir Hipotez & $\chi^{2}$ Test İstatistiği & Olasılık Değeri \\
\hline $\operatorname{lm} 0$ ar $\nRightarrow$ ler ar & 5.218109 & 0.1565 \\
\hline ler ar $\nRightarrow \operatorname{lm} 0$ ar & 2.315148 & 0.5096 \\
\hline lres ar $\nRightarrow \operatorname{lm} 0$ ar & $7.260221 *$ & 0.0641 \\
\hline $\operatorname{lm} 0$ ar $\nRightarrow$ lres ar & 6.105391 & 0.1066 \\
\hline $\operatorname{lm} 0$ be $\nRightarrow$ ler be & $9.665680 * * *$ & 0.0019 \\
\hline ler be $\nRightarrow \operatorname{lm} 0$ be & 0.440737 & 0.5068 \\
\hline lres be $\nRightarrow$ ler be & $5.453841 * *$ & 0.0195 \\
\hline ler be $\nRightarrow$ lres be & 2.492097 & 0.1144 \\
\hline lres $\mathrm{kg} \nRightarrow$ ler $\mathrm{kg}$ & 7.391380 & 0.1931 \\
\hline ler $\mathrm{kg} \nRightarrow$ lres $\mathrm{kg}$ & 7.250903 & 0.2026 \\
\hline lres $\mathrm{kg} \nRightarrow \operatorname{lm} 0 \mathrm{~kg}$ & 9.210197 & 0.1010 \\
\hline $\operatorname{lm} 0 \mathrm{~kg} \nRightarrow \operatorname{lres~} \mathrm{kg}$ & $13.22579 * *$ & 0.0214 \\
\hline $\operatorname{lm} 0 \mathrm{ru} \nRightarrow$ ler $\mathrm{ru}$ & $5.905527 * *$ & 0.0151 \\
\hline ler $\mathrm{ru} \nRightarrow \operatorname{lm} 0 \mathrm{ru}$ & 0.727106 & 0.3938 \\
\hline lres $\mathrm{ru} \nRightarrow \operatorname{lm} 0 \mathrm{ru}$ & $20.49082^{* * *}$ & 0.0000 \\
\hline $\operatorname{lm} 0$ ru $\nRightarrow$ lres ru & 0.197958 & 0.6564 \\
\hline
\end{tabular}

Not: ***, **, * strastyla \%1, \%5 ve \%10 anlamlllik düzeylerini ifade etmektedir.

Tablo 5. Toda-Yamamoto Nedensellik Testi Sonuçları Kaynak: Yazarlar tarafindan oluşturulmuştur.

Eşbütünleşme testi sonuçlarını pekiştirmek amacıyla sözkonusu değişkenler arasındaki ilişki Toda-Yamamoto nedensellik yaklaşımıyla da incelenmiştir. Test sonuçlarına göre, Ermenistan'da dış rezervlerden para arzına doğru, Belarus'da para arzından ve rezervlerden döviz kuruna doğru, Kırgızistan'da para arzından rezervlere doğru, Rusya'da para arzından döviz kuruna ve rezervlerden para arzına doğru istatistiki olarak anlamlı nedensellik ilişkileri tespit edilmiştir.

\section{Sonuç ve Öneriler}

Genel olarak elde edilen empirik sonuçlar beklentilere uygun çıkmıştır. Döviz kurunda bir artış olduğunda merkez bankası müdahalede bulunduğu için rezervlerde bir azalma, döviz kurunda bir düşüş olduğunda da tam tersine bir artma ortaya çıkmaktadır. Diğer taraftan, rezervlerle para arzı arasında hem merkez bankası bilançosunun bir gereği olarak, hem de onun yürüttüğü politikalar sonucunda pozitif bir ilişkinin bulunduğu görülmektedir. Örneğin, ulusal para değer kaybettiği dönemlerde merkez bankasının döviz piyasasına müdahalesi, yani piyasaya döviz satması sonucunda bir taraftan rezervler azalırken, diğer taraftan piyasadaki ulusal para miktarında bir azalma meydana gelmektedir.

ARDL eşbütünleşme testi sonuçlarına göre, Ermenistan ve Rusya'da döviz kuru ile dış rezervlerin para arzını etkilediği; Belarus'ta para arzı ile rezervlerin döviz kurunu etkilediği; Kırgızistan'da para arzı ile döviz kurunun dış rezervleri etkilediği ve Kazakistan'da sözkonusu üç değişkenin arasında hiçbir eşbütünleşme ilişkisinin bulunmadığı ortaya çıkmıştır. Kısa dönem katsayıları genel olarak beklentilere uygun bulunmuştur. Kırgızistan'da döviz kurunun yükselmesi rezerv miktarını olumsuz etkilerken, Rusya ve Ermenistan'da para arzını azaltmaktadır. Hem Kırgızistan, hem Rusya'da para arzı ile rezervler arasında pozitif yönlü bir ilişki bulunmaktadır.

Uzun dönem katsayılarına göre, para arzındaki \%1'lik bir artış Belarus'da ulusal paranın \%0,92 değer kaybetmesine, rezervlerdeki \%1'lik bir artış ise yaklaşık aynı oranda değer kazanmasına yol açmaktadır. Ermenistan'da incelenen dönemde döviz kuru, rezervler ve para arzında paralel artışların yaşandığı ortaya çıkmıştır. Para arzı artışı dış rezervlerdeki artıştan daha hızlı bir seyir izlemektedir. Aynı şekilde Kırgızistan ve Rusya'da da para arzı ile rezervler arasında pozitif yönlü ilişkiler görülmektedir. Yine beklentilere uygun olarak Kırgızistan'da döviz kuru artışlarının döviz rezervlerini azalttığı, ulusal paradaki \% 1 'lik bir değer kaybının döviz 
rezervlerinde \%0,48'lik bir azalmaya yol açtığı tespit edilmiştir. Ancak Rusya'da uzun dönemde tüm katsayılar istatistiki olarak anlamsız bulunmuştur.

Toda-Yamamoto nedensellik testine göre, Ermenistan'da dış rezervlerden para arzına doğru, Belarus'da para arzından ve rezervlerden döviz kuruna doğru, Kırgızistan'da para arzından rezervlere doğru, Rusya'da para arzından döviz kuruna ve rezervlerden para arzına doğru istatistiki olarak anlamlı nedensellik ilişkileri tespit edilmiştir.

AEB üyelerinin döviz ve para piyasasında uyumlu bir politika uygulamaması sonucunda bir taraftan döviz piyasasında istikrarsızlıklar yaşandığında ulusal paralara olan güven azalarak tüm ülkelerin rezerv kaynakları hızlı bir şekilde azalırken, diğer taraftan birbiriyle olan ticarette rekabeti kaybetmemek amaciyla devalüasyon yarışmaları ortaya çıkmaktadır. Örneğin, Rus rublesinin 2014'deki devalüasyonundan ve esnek kur sistemine geçişinden sonra 2015'de Kazak tengesinin de esnek kur sistemine geçerek yaklaşık iki kat değer kaybetmesinin temel nedeni üreticilerin rekabet gücünü düşürmeme hedefine dayanmıştır. Aynı şekilde son dönemlerde petrol fiyatlarındaki düşme nedeniyle ruble ve tenge kuruna paralel olarak, önemli bir ekonomik neden olmamasına rağmen, somun dolar kurunun da düşmesine yerli üreticilerin rekabet gücünün ve Rusya'da çalışan işçi gelirlerinin azalmaması amacıyla Kırgız Cumhuriyeti Merkez Bankası tarafından özel olarak izin verildiği düşünülebilir. Bundan dolayı para ve döviz kuru politikalarının daha koordineli yürütülmesi tüm üyelerin lehine olacaktır. Ancak işbirliğinden tüm tarafların aynı oranda faydalanması temel ilke olmalıdır.

\section{Kaynakça}

- Andrienko E.V., İlyina T.G. (2017). "Valyutnoye Regulirovaniye v Stranakh EAES”. Problemy Ucheta i Finansov 28, 26-29.

- Avrasya Ekonomik Birliği resmi sitesi, http://www.eaeunion.org/

- Cote A. (1994). "Exchange Rate Volatility and Trade", Working Paper No. 95-5 (Ottawa, Ontario: Bank of Canada).

- $\quad$ Esenalieva B.B., Balandina A.F. (2017). "Vliyaniye Zolotovalyutnykh Rezervov na Valyutnuyu Politiku i Osnovnyye Ekonomicheskiye Pokazateli Kyrgyzskoy Respubliki”. Izvestiya Vuzov Kyrgyzstana 2, 66-68.)

- Gartner M. (1987). "Intervention Policy under Floating Exchange Rates: An Analysis of the Swiss Case”. Economica, p. 439-53.

- Golodova Zh.G., Ranchinskaya Yu.S., Gorokhova E.Yu. (2019) “Analiz Predposylok Soglasovaniya Aspektov Denezhno-kreditnoy Politiki v Stranakh EAES”. Digest Finance 24(2), 207-220.

- Hviding K., Nowak M. ve Ricci L. A. (2004). "Can Higher Reserves Help Reduce Exchange Rate Volatility? An Empirical Investigation”, Luiss Lab of European Economics Working Document No. 13 (Rome: Luiss Lab of European Economics).

- Kartal M.T., Kılıç Depren S. ve Depren Ö. (2018). “Türkiye’de Döviz Kurlarını Etkileyen Makroekonomik Göstergelerin Belirlenmesi: Mars Yöntemi ile Bir İnceleme”. MANAS Sosyal Araştırmalar Dergisi 7(1), ss. 209-229.

- Narayan P.K. (2005). "The Saving and Investment Nexus for China: Evidence from Cointegration Tests". Applied Economics 37(17), p. 1979-1990.

- Obstfeld M. (1983). "Exchange Rates, Inflation, and the Sterilization Problem: Germany, 1975-1981" European Economic Review March/April, p. 161-189.

- Ozturk I. (2006). “Exchange Rate Volatility and Trade: A Literature Survey”. International Journal of Applied Econometrics and Quantitative Studies 3-1, p. 85-102.

- Sandoyan E.M., Voskanyan M.A., Mnatsakanyan L.A. (2016). "Denezhno-kreditnaya i Valyutnaya Politika v Armenii: Ugrozy i Perspektivy v Kontekste Integratsii v EAES”. Vestnik RAU 1, 52-63.

- Sekmen F. \& Ravanoğlu G.A. (2017). "Faiz Haddi ve Para Arzının Döviz Kuru Üzerine Etkisi: Kazakistan Örneği”. MANAS Sosyal Araştırmalar Dergisi 6(4), ss. 333-342.

- $\quad$ Şit M. \& Karadağ H. (2019). "Döviz Kurunu Belirleyen Ekonomik Faktörler: Türkiye Ekonomisi için ARDL Sınır Testi Uygulaması”. Uluslararası İktisadi ve İdari İncelemeler Dergisi 23, ss. 151-168.

- Taylor D. (1982). "Official Intervention in the Foreign Exchange Market, or, Bet Against the Central Bank". Journal of Political Economy April, p. 356-68.

- Tunay K.B. (2008). “Türkiye’de Merkez Bankası Müdahalelerinin Döviz Kurlarının Oynaklığına Etkileri”. BDDK Bankacılık ve Finansal Piyasalar 2(2), ss. 77-111.

- Voytekhovich A.N. (2015). "Valyutnaya Integratsiya v Evraziyskom Ekonomicheskom Soyuze: Otsenka Tselesoobraznosti dlya Ekonomiki Belarusi”. Belarusian Economic Journal 4, p. 84-100. 
- Yurdakul, F. (2016). Döviz Kuru Modellemesi ve Türkiye Üzerine Bir Uygulama (Bölüm 1). Gazi Kitabevi: Ankara.

- Zaranskaya M.S. (2017). "Kharakteristika Sovremennoy Valyutnoy Politiki Respubliki Belarus"”. Aktual'nyye Nauchnyye Issledovaniya v Sovremennom Mire 9-1(29), 114-121. 


\title{
Bişkek Halkının E-Devlet Hizmetlerine Hazırlık Düzeyleri Readiness Level of Residents in Bishkek to E-Government Services
}

\author{
Asst. Prof. Dr. Azamat Maksüdünov (Kyrgyzstan-Turkey Manas University, Kyrgyzstan)
}

\begin{abstract}
Digital transformation has been increasing in all fields of human being around the globe. Within this global trend Kyrgyz Republic also declared its National Development Strategy for 2018-2040 in 2018, which outlines the contours of the country's digital transformation. In the country, 2020 is declared the year of digitization and the process has begun. Although all this transformation processes are crucial in terms of development and building transparent state, such significant changes don't occur without challenges. Along with main obstacles such as poor infrastructure, limited financial and human resources, residents' readiness to embrace e-services is also matter. In this context, the main purpose of this study is to examine residents' readiness level to e-government services. The scope of the study is limited to Bishkek, capital of Kyrgyz Republic, for several reasons. First of all, e-government services are piloted in Bishkek, and then implemented in other regions. The second reason is related to high rate of online population in Bishkek. Primary data were obtained using structured questionnaire among residents. Findings of this empirical study can provide useful insights in terms of public policy on digital transformation. Especially, the government can gain very useful insights into readiness level of consumers and their anxieties about e-government services. Deeper understanding of users' behavior can be reliable base for making decision to eliminate this problem as an obstacle for digital transformation.
\end{abstract}

\section{Giriş}

Bilgi ve iletişim çağının bir gereği olarak dünyanın dört bir yanında her alanda hızla yaşanmakta olan dijital dönüşüm süreçlerine şahitlik etmekteyiz. Bilgi ve iletişim teknolojilerinde yaşanmakta olan gelişmelerin başlangıcı 1960'lara kadar uzanmakla birlikte, digital dönüşüm konusunun ayrı bir araştırma alanı olarak son 30 yıldır gündemde olduğu ve yapılan araştırmaların özellikle 2000'li yıllardan sonra artış gösterdiği söylenebilir (Pardo ve Styrin, 2010). Digital dönüşüm başlangıçta özel sektörde yoğunlaşmakla birlikte daha sonra kamu sektöründe de hızla yerini almaya başlamıştır. Dünya genelinde hem gelişmiş, hem de gelişmekte olan devletler hızla elektronik devlet uygulamalarına, diğer bir ifadeyle e-devlete geçmektedirler.

E-devlet, devletin vatandaşlar ve diğer kurumlarla olan etkileşimlerinde bilgi ve iletişim teknolojilerinin (BİT) kullanılması olarak tanımlanmaktadır (Dewa ve Zlotnikova, 2014; Carter, vd, 2016; Kamaruddin ve Noor, 2017).

West (2005) kamu sektöründeki dijital dönüşümü (ilan panosu, kısmi hizmet sunumu, tam entegre hizmetler ve etkileşimli demokrasi) dört aşamaya ayırmaktadır. Buna göre ilk aşamada kamu kurumlarına ait web siteleri bir ilan panosundan hiç farkı yokken, her yeni aşamada web sitelerinin etkileşim ve güvenlik özellikleri geliştirilerek anlık iletişim kurulabilecek düzeylere ulaşmış durumdadır. Kamu hizmetlerinde bilgi ve iletişim teknolojilerinin kullanılması şüphesiz hem devlet açısından hem de kullanıcılar (vatandaş ve diğer kurumlar) açısından bir takım avantajlar sağlamaktadır (Akman, vd, 2005; Güler ve Döventaş, 2009; Zawaideh, 2017). Hizmet hızı ve kalitesi, mesafe, zaman ve bürokratik meselelerin ortadan kaldırılması, şeffaflık ve düşük maliyet gibi avantajlar e-devletin her iki tarafa sağladığı faydalardan sadece bazılarıdır.

Küresel ölçekte yaşanmakta olan bu tür eğilimler çerçevesinde, Kırgız Cumhuriyeti 2018 yılında ülkenin dijital dönüşümüne ilişkin esasları da içeren Ulusal Kalkınma Stratejisini (2018-2040) ilan etmiştir. Söz konusu stratejik planda öngörülen programlardan biri ülkenin dijital dönüşümünü kapsayan 'Taza Koom' (Temiz Toplam) ulusal programıdır. Bu program vatandaş, rekabetçi bir işletme, istikrarlı bir devlet ve güvenilir uluslararası ilişkiler düzeyinde açık, şeffaf ve yüksek teknolojili bir toplum yaratmak için tasarlanmıştır (Ulusal Kalkınma Stratejisi, 2018). Söz konusu plan ve programlar çerçevesinde modern bilgi ve iletişim altyapısının oluşturulması, kamu hizmetlerinin dijital ortamda sunulması gibi öncelikli hedefler belirlenmiş durumdadır. Bu çerçevede ülkede 20192020 yılları arka arkaya bölgeleri geliştirme ve dijitalleşme yılı ilan edilmiştir (KC, Cumhurbaşkanı Kararnamesi, 2019-2020). Ayrıca, kamu kurum ve kuruluşları, yerel yönetimler ve diğer kurumların (tüzel ve özel kişiler), kısacası tüm paydaşların kendi aralarında bilgi paylaşımı yapabilmeleri için 'Tündük' elektronik etkileşim merkezi oluşturulmuş ve 20 Nisan 2020 tarihi itibariyle toplam (kamu ve özel) 103 kurum eklenmiş durumdadır (Tündük, 2020). Bu anlamda, Kırgızistan bölge ülkeleri ile paralel bir şekilde yol almaktadır (Bhuiyan, 2010; Vinogradova ve Moiseeva, 2015).

E-devletin tüm potansiyel avantajlarına rağmen bir çok ülke dijital dönüşüm sürecinde bir takım zorluklarla karşı karşıya kalmaktadır. Dijital dönüşümün önünde duran zorlukların başında zayıf teknolojik altyapı, sınırlı insan ve finansal kaynaklar gibi sorunlarla birlikte kullanıcıların (vatandaş ve kurumların) e-devlet hizmetlerine hazırlık düzeyleri ve kullanma niyetleri de önemli bir sorun olarak karşımıza çıkmaktadır (Alshehri ve Drew, 2010; 
Ranaweera, 2016). Vatandaşların teknolojiye hazır olma durumları, insanların ev ve iş yaşamında hedeflere ulaşmak için yeni teknolojileri benimseme ve kullanma eğilimini ifade etmektedir (Parasuraman, 2000). Başarılı bir e-devlet dönüşümü için hükümetin altyapı, insan ve finansal kaynaklara ilişkin aldıkları önlemler tek başına yeterli değildir. Kullanıcıların yeni teknolojileri kabul düzeyi ve yeni teknolojilere hazırlık durumları kritik rol oynamaktadır (AlAwadhi ve Morris, 2009; Daştan ve Efiloğlu Kurt, 2016; Lallmahomed, vd, 2017; Mensah, 2017; Çabuk, vd, 2017) .

Bu bağlamda çalışmanın temel amacı, dijitalleşme konusunda başarı kaydetmiş veya henüz yolun başında olan farklı ülkelerin durumları incelenerek ve vatandaşlar arasında bir anket çalışması gerçekleştirilerek, henüz dijitalleşme sürecinin başlangıcında olan Kırgızistan'ın konuyla ilgili mevcut sorunlarının çözümüne yönelik öneriler geliştirmektir.

\section{Literatür}

Ülkelerin dijital yolculukları sırasında ne durumda olduklarına ilişkin CİSCO (2019) tarafından Global Dijital Hazırlık Endeksi yayınlanmaktadır. Söz konusu rapora göre, dünyada Asya Pasifik, Kuzey Amerika ve Avrupa bölgeleri ön sırada gelmekte, bu konuda en düşük performans Afrika ve Orta Doğu ülkelerine aittir. Avrasya bölgesindeki tüm ülkelerin puanları en yüksek 25 puan üzerinden ortalama 11,8 olup, orta sinıfta oldukları görülmektedir. Diğer bir ifadeyle, bu gruptaki ülkeler dijitalleşme konusunda bir takım adımlar atmış, ancak dijital hazır olma durumlarını hızlandırmak veya geliştirmek için önemli fırsatlara sahip ülkeler içerisinde yer almaktadır. Kırgızistan bu sıralamada 11,0 puanı ile ortalamanın altında kalmış, aynı göstergenin Kazakistan için 13.49, Özbekistan için 11.14, Türkiye için 12.88 ve Rusya için 13.63 olduğu görülmektedir. Ayrıca, aynı raporda ülkelerin teknolojiye hazırlık endeksleri ile teknolojik altyapı ve teknoloji kabul durumlarının arasında güçlü ve pozitif bir korelasyon $(0,96)$ olduğu belirtilmektedir. Birleşmiş Milletler (2018) tarafından yapılan E-Devlet Endeksine göre 193 Birleşmiş Milletler üyesi ülkelerin neredeyse üçte ikisi e-devlete geçiş süreçleriyle ilgili yüksek düzeyde bir performans sergiledikleri belirtilmektedir. Ayrıca, aynı çalışmada ülkelerin e-devlet sıralamaları ile gelir düzeyleri arasında pozitif bir korelasyon olduğuna da işaret edilmektedir.

Dijital dönüşüm alanında dünya çapında önde gelen ülkelerin içerisinde Singapur olduğu bilinmektedir (CİSCO, 2019). Singapur'u başarılı kılan nedenlerin başında başarılı bir e-devlet vizyonuna sahip güçlü bir liderlik gösterilmektedir. Ayrıca, Singapur bilgi ve iletişim teknolojilerinin altyapısını güçlendirmiş ve e-devlet hizmetlerinin tüm halkın erişebileceği, kolayca kullanabilecekleri duruma getirmiştir (Kee ve Wei, 2004). Ülke yönetiminin konunun önemine ve kendilerine olan inancı tam olduğunda, e-devletin tüm paydaşlarını motive edebilecek, harekete geçirebilecektir. Srivastava ve Teo (2005) e-devlet hizmetlerinin benimsenmesi ve adaptasyonu için vatandaşın güveninin çok önemli olduğuna vurgu yapmaktadır. Singapur örneğinde ele aldıkları çalışmada vatandaşın e-devlet konusunda hükümetin kabiliyetine, motivasyonuna ve bağlılığına karşı güveni ve teknolojilere karşı güveni olmak üzere iki konudaki güveninin önemli olduğu belirtilmektedir. Singapur, ilk boyuta yönelik e-devlete karşı üst yönetimin destek ve sorumluluklarını vatandaşa göstermek ve vatandaşlarından geri bildirim alarak kurumsal güven artırıcı önlemleri uygulamaya koymaktadır. Diğer taraftan, ikinci boyuta yönelik olarak ilgili bilgi ve becerilerin aktif bir şekilde sağlanması ve etkili bir yasal sistemin yürütülmesi ile başarılmaktadır. Singapur'un dijital dönüşümüne yönelik eksikliklerinin de olması doğaldır. Singapur hükümetinin e-devlet hizmetlerinin doğrudan ve dolaylı yararları hakkında kamu bilincini artırmaya yönelik daha fazla çalışma yapması, e-devlet hizmetlerini güncel, etkili ve güvenli bir şekilde uygulamaya koyması ve e-hizmetlerin benimsenmesini teşvik etmesi gerektiği belirtilmektedir (Tung ve Rieck, 2005).

Asya Pasifik bölgesinde dijital dönüşüm konusunda başarılı ülkelerden bir diğeri ise Malezya'dır. Bu ülkede kamu sektöründe dijitalleşme ile ilgili ilk ve somut adımların 1996 yıllarında atılmış olduğu ve Malezya halkının e-devlet hizmetlerini kullanma oranlarının yüksek olduğu belirtilmektedir (Kamaruddin ve Noor, 2017). Eze, vd. (2011) tarafindan Malezya'da çalışan yetişkinlerin e-devlet hizmetlerini kullanma niyetlerini belirleyen faktörlere ilişkin yapılan araştırmada da benzer sonuçlar elde edilmiştir. Ayrıca, güvenlik, internet altyapısı, güvenirlilik ve elverişlilik gibi boyutların e-devlet hizmetlerini kullanma niyeti üzerinde pozitif etkiye sahip olduğu, algılanan fayda ve algılanan kullanım kolaylığının ise etkili olmadığı tespit edilmiştir. Yine Malezya örneğinde gerçekleştirilen bir diğer çalışmada da vatandaşların e-devlet hizmetlerini kullanma niyetlerine etki eden faktörlerin başında güven faktörünün geldiği, bununla birlikte algılanan fayda, avantaj ve imajın da anlamlı etkilerinin olduğu ortaya konulmuştur (Lean, vd., 2009). Aynı bölgede dikkat çeken bir diğer ülke Çin Halk Cumhuriyetidir. Çin'de de dijital dönüşüm konusu hükümet gündeminde olup, başlangıcı 1999 yılında ilan edilen 'Hükümet Online Projesi'ne dayanmaktadır. Bu konuda Çin bilgi ve iletişim teknolojilerine yönelik altyapı, hükümet web sitelerinin geliştirilmesi, vatandaşın bilgilendirilmesi, kullanıma teşvik edilmesi gibi alanlarda önemli başarılar elde ettiği belirtilmektedir (Mensah, 2017). Ancak, bazı araştırmalarda Çin'de merkezi hükümet bazındaki başarıların yerel hükümet hizmetleri için de geçerli olmadığı, yerel düzeydeki e-devlet hizmetlerinin yer aldığı web sitelerin kullanım kolaylığı, bilgi içeriği, bilgi güncelliği gibi alanlarda geliştirilmesi gerektiği dile getirilmektedir (Zhang ve Hsieh, 2010; Mensah, 2017). 
Kuzey Amerika ve Avrupa ülkelerinde e-devlet hizmetlerinin sunulduğu web sitelerinin 'ilan panosu' aşamasını 1990-1998 yıllar arasında atlattıkları ve diğer aşamaların halen devam etmekte olduğu belirtilmektedir (Goings, 2003). Carter, vd., (2016)'nin ABD ve İngiltere'de vatandaşların e-devlet hizmetlerini kabul durumlarına ilişkin yaptıkları çalışmada, e-devlet stratejileri bakımından bu iki ülke arasında farkın olmadığı, her iki ülkede e-devlet uygulamalarının teknolojik, kültürel ve politik açıdan benzerlik gösterdiğini dile getirmektedir. Her iki ülke için, e-devlet hizmetlerinin kullanımında teknoloji kabul modelinin ve güven ile ilgili boyutların etkili olduğu sonucuna ulaşılmıştır. Ayrıca, her iki ülkenin ilgili kurumları e-devletin üstünlükleri konusunda vatandaşlarına anlatmaları önerilmektedir. ABD’de dijital hükümet uygulamalarını konu alan bir diğer çalışma Pardo ve Styrin (2010) tarafından yapılmış ve Rusya ile karşılaştırılmıştır. Bu süreç ABD'de 1990'larda başlamış iken, Rusya'da 2010'larda başlamıştır. Buna rağmen, dijitalleşme sürecinde sürecin yönetimi (merkezi olmayan/merkezi finansal model, vatandaşların hazırlık düzeyleri) farklılıklar kadar, benzerliklerin de olduğu belirtilmektedir. Benzerliklerin en önemlisi her iki ülke için e-devlet projeleri hem kamu hem de özel sektör tarafından ciddi yatırımlarla desteklenen çok önemli bir faaliyet alanını oluşturmasıdır.

Ortadoğu ve Afrika bölgesindeki ülkelerde ise dijital dönüşüm süreçlerinin başlangıcı 2000'li yıllardan sonraki döneme denk gelmekte olup: Kuveyt (AlAwadhi ve Morris, 2009) ve Ürdün'de 2000 y1lında (Zawaideh, 2017); Misırda 2001 yılında (Abdelghaffar ve Magdy, 2012); Yemen'de 2003 yılında (Al-Eryani, 2009); Tanzanya'da 2010 yılından itibaren başlamıştır (Dewa ve Zlotnikova, 2014). Kuveyt örneğinde yapılan araştırmaya göre, katılımcıların çoğunun (\%85) e-devlet hizmetlerinin yararlı olduğuna, ancak mevcut e-devlet hizmetlerinin yeterli düzeyde olmadığına inanmaktadırlar. Ayrıca, katılımcıların \%30-40’1 e-devlet hizmetleri ile ilgili güven probleminin ve teknik sorunların olduğunu ve \%90'lık büyük bir kısmı da genel olarak e-devlet projeleri ile ilgili farkındalık oluşturmaya yönelik çalışmaların yetersiz olduğunu dile getirmişlerdir (AlAwadhi ve Morris, 2009). Ürdün vatandaşlarının e-devlet hizmetlerini kullanma niyetlerini etkileyen boyutların performans beklentisi, çaba beklentisi, sosyal etki ve kolaylaştırıcı koşullar olduğu sonucuna ulaşılmıştır (Zawaideh, 2017). Mısır'da gençlerin mobil devlet hizmetlerini kullanmaya yönelik niyetleri üzerine yapılan çalışmada algılanan kullanışlılık, uyumluluk, farkındalık, sosyal etki ve yüz yüze etkileşim boyutlarının anlamlı etkiye sahip olduğu, internet deneyimi, algılanan kullanım kolaylığı, güven ve kişisel bağlantılar boyutlarının anlamlı etkiye sahip olmadığı sonucuna ulaşılmıştır (Abdelghaffar ve Magdy, 2012). Yemen hükümeti halkın e-devlete hazırlık düzeylerini arttırmaya yönelik faaliyetlerini sürdürmekte olduğu, ancak bu konuda başarılı olabilmesi için öncelikle gelir ve eğitim düzeyini arttırmaya, cinsiyet ve yerleşim yerine göre farklılıkların en aza indirmeye yönelik çalışmalara yoğunlaşması gerektiği belirtilmektedir (Al-Eryani, 2009). Dewa ve Zlotnikova (2014) tarafından Tanzanya halkının e-devlet hizmetlerine hazırlık düzeyleri araştırılmış ve halkın büyük bir kısmının henüz e-devlet hizmetlerine hazır olmadıklarını, onları endişelendiren faktörlerin başında güvenlik ile ilgili sorunların yer aldığını tespit etmişlerdir.

Avrasya bölgesindeki ülkelerde de dijital dönüşüm konusunda çalışmaların yapılmakta olduğu görülmektedir (Akman, vd, 2005; Daştan ve Efiloğlu Kurt, 2016; Çabuk, vd, 2017; Vinogradova ve Moiseeva, 2015; Bhuiyan, 2010; Ismailova, vd, 2018). Türkiye Cumhuriyeti dijital dönüşüm konusunda bölgedeki ülkeler içerisinden belki de en tecrübelisi olarak gösterilebilir. Ancak, konuyla ilgili yapılan araştırmalarda Türkiye'de de e-devlete geçiş sürecinin önünde bir takım engellerin olduğu, bu engellerin yine altyap1, liderlik, vatandaşın teknoloji okur yazarlık düzeyi ile ilgili olduğu dile getirilmektedir (Akman, vd, 2005). E-devlet hizmetlerinin kabulü ve adaptasyonu üzerinde etkili olan faktörlerin cinsiyet, eğitim gibi demografik faktörlere bağlı olarak değişim gösterdiği (Akman, vd, 2005; Çabuk, vd, 2017), ayrıca kaynakların kullanılabilirliği, algılanan fonksiyonel fayda ve algılanan hizmet yanıtı gibi faktörlerin etkili olduğu yapılan çalışmalarda görülmüştür (Daştan ve Efiloğlu Kurt, 2016). Rusya Federasyonu ve Kazakistan'da e-devlete geçiş ile ilgili çalışmaların 2000'li yıllardan sonra başladığı, 2010 yılından itibaren somut şekil almaya başladığı belirtilmektedir (Vinogradova ve Moiseeva, 2015; Bhuiyan, 2010). Kırgızistan'ın bu konudaki attığı somut adımlardan biri olarak 2018 yılında ilan etmiş olduğu Ulusal Kalkınma Stratejisi (2018-2040) gösterilebilir. Söz konusu stratejik plan ülkenin dijital dönüşümüne ilişkin esasları da içermektedir. Halkın bu tür değişimlere ve dönüşümlere hazırlık düzeyi ve kullanma niyetleri üzerine yapılan sınırlı sayıda çalışma bulunmaktadır. Vatandaşların hükümet web sitelerini kullanma niyetlerini belirlemeye yönelik bir araştırma Ismailova, vd (2018) tarafından gerçekleştirilmiştir. Araştırma sonuçlarına göre, web sitelerinin kullanım kolaylığı ve kullanışlılığı, web sitelerini kullanmanın göreceli avantajı ve katılımcıların yaşam tarzıyla uyumluluğu gibi faktörlerin hükümet web sitelerini kullanma niyeti üzerinde anlamlı etkiye sahip olduğu sonucuna ulaşılmıştır.

Vatandaşların e-devlet hizmetlerine hazırlık düzeyleri ve kullanma niyetlerine yönelik literatür incelendiğinde, aşağıdaki gibi bazı genel durumların ortaya çıktığı söylenebilir. Bunlardan birincisi, toplumun değişen ihtiyaç ve taleplerine uygun bir şekilde hizmet verebilmek için ülkelerin e-devlete geçiş çabalarının ülkelere göre farklı oluğu, ancak bu tür çabaların sonsuz bir süreç olduğudur. Başlangıçları farklı da olsa hiçbir ülkede bu süreç tamamlanmış değildir, ve hala bir takım engellerle, sorunlarla karşılaşıldığı görülmektedir. Diğer bir tespit ise, vatandaşların e-devlet hizmetlerine hazırlık düzeyleri genel olarak vatandaşın teknoloji kullanma bilgi ve becerisi, algılanan fayda ve kullanışlılık, güven gibi faktörlere bağlı olduğu görülmüştür. 


\section{Yöntem}

Araştırmanın kapsamı Kırgızistan'ın başkenti Bişkek şehri ile sınırlı tutulmuştur. Bunun nedeni ise, bilgi ve iletişim teknolojisine yönelik altyapının ve halkın hazırlık düzeyinin diğer bölgelere göre daha iyi durumda olması ve dolayısıyla e-devlet hizmetlerinin öncelikle Bişkek’te başlatılması ile ilgilidir. Ayrıca, Bişkek halkının yüksek oranda çevirim içi olması bir diğer neden olmuştur. Araştırmanın örnek kitlesini kolayda örnekleme yöntemiyle ulaşılmış 203 katılımcı oluşturmaktadır. Araştırmada birinci el veriler 20 Nisan - 10 Mayıs 2020 tarihleri arasında online anket tekniği kullanılarak elde edilmiştir. Katılımcıların e-postalarına, whatsApp, instagram, facebook gibi sosyal medya araçlarıyla gönderilmiş ve eksiksiz doldurulan yanıtlar dikkate alınmıştır. Anket formunda katılımc1larla ilgili demografik sorular, teknolojik ürün ve hizmetleri kullanma durumları ile ilgili sorular, kamu hizmetlerinin dijitalleşmesi ile ilgili sorular yer almaktadır. Katılımcıların e-devlet hizmetlerine hazırlık düzeylerini ölçmek için Daştan ve Efiloğlu Kurt’un (2016) çalışmasından yararlanılmıştır. Çalışmada 16 ifadeli dört boyutlu ölçek kullanılmıştır. İfadeler 5'li Likert ölçeğine göre hazırlanmış olup, 1-hiç katılmıyorum'dan 5tamamen katılıyorum'a kadar sıralanmaktadır. Güvenirlilik katsayılarının algılanan fonksiyonel fayda boyutu için 0,744, algılanan hizmet yanıtı boyutu için 0,802 , e-devlet adaptasyonu boyutu için 0,717 ve kaynakların kullanılabilirliği boyutu için 0,832 olduğu görülmüştür. Verilerin analizinde frekans ve yüzde dağılımları, ortalama ve standart sapma, t-testi, ANOVA, kümeleme, $\mathrm{X}^{2}$ gibi tekniklerden yararlanılmıştır.

\section{Bulgular ve Yorumlar}

Katılımcıların \%67'lik kısmının kadın, \%81'lik kısmının 35 yaş altındaki vatandaşlardan, \%65'nin bekar ve yaklaşı \% \%65'lik kısmının 30000 Somun altında gelire sahip kişilerden oluştuğu görülmektedir. Uğraş alanlarına göre dağılıma baktığımızda ise, \%50 civarında öğrenci, \%18 civarında kamu sektörü çalışanı, \%19 civarında özel sektör çalışanı ve \%15 civarında emekli, işsiz, evhanımı durumundakilerden oluşan diğer grupta yer almaktadır. Eğitim durumları açısından dağılıma baktığımızda ise, \%45 civarında lise, \%16 civarında önlisans, \%33 civarında lisans ve $\% 5$ civarında lisansüstü mezunlardan oluştuğu görülmektedir.

\begin{tabular}{|c|c|c|c|c|c|}
\hline Cinsiyet & Siklık & Yüzde & Medeni Hal & Siklık & Yüzde \\
\hline - Kadın & 136 & 67,0 & - Evli & 71 & 35,0 \\
\hline - Erkek & 67 & 33,0 & - Bekar & 132 & 65,0 \\
\hline Yaş & Siklık & Yüzde & Gelir & Siklık & Yüzde \\
\hline - 35 yaş ve altı & 165 & 81,3 & - 30000 Som ve alt1 & 117 & 64,6 \\
\hline - 36 yaş ve üstü & 38 & 18,7 & - 30001 Som ve üstü & 64 & 35,4 \\
\hline Uğraş Alanı & Siklık & Yüzde & Eğitim & Siklık & Yüzde \\
\hline - Öğrenci & 97 & 47,8 & - Lise & 92 & 45,3 \\
\hline - Kamu çalışanı & 37 & 18,2 & - Önlisans & 32 & 15,8 \\
\hline - Özel sektör çalışanı & 39 & 19,2 & - Lisans & 68 & 33,5 \\
\hline - Diğer & 30 & 14,8 & - Lisansüstü & 11 & 5,4 \\
\hline
\end{tabular}

Tablo 1. Katılımclların Demografik Bilgileri

Katılımcıların $\% 55^{\prime}$ i bilgisayar kullanım becerilerini temel düzeyde, $\% 41$ 'i profesyonel düzeyde değerlendirmekte ve geriye kalan \%4’ü ise kullanmayı bilmediklerini dile getirmişlerdir.

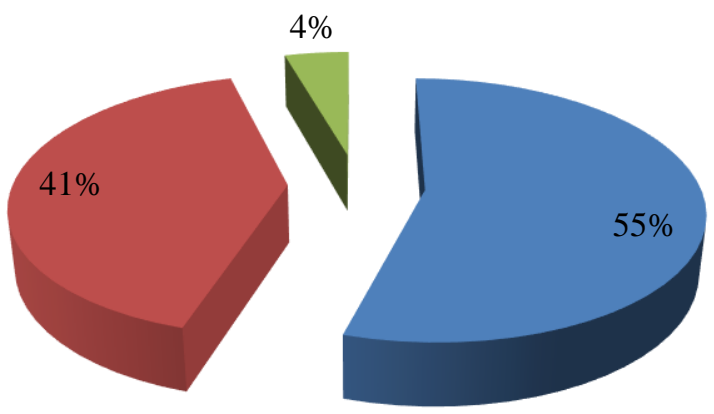

Temel $\quad$ Profesyonel Kullanmayı bilmiyor 
E-devlet hizmetlerini katılımcıların \%85'i cep telefonu, \%15'i ise bilgisayar aracılığı ile kullandıklarını dile getirmişlerdir. Uluslararası Telekomünikasyon Birliği'nin (2019) verilerine göre, Asya bölgesinde her yüz kişiye düşen bilgisayar sayısı 42 civarındayken, her yüz kişiye düşen cep telefonu sayısı 98 civarındadır. Ayrıca, evde internet erişimi olanlar \%40 civarındadır. Dolayısıyla, bu araştırmada elde edilen sonuçların gerçek durumu yansıttığı söylenebilir.

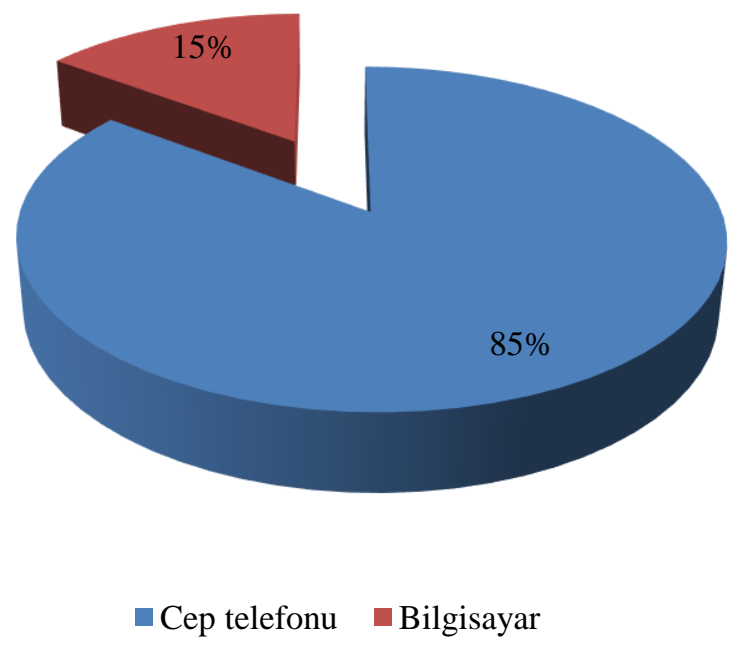

Şekil 2. Katılımcıların E-Devlet Hizmetlerine Ulaşmak Için Kullandıkları Cihazlar

Şekil 3'te görüldüğü gibi, katılımcıların internet, bilgisayar ve cep telefonu kullanım süreleri en çok 3-5 yıl arasında yoğunlaşmaktadır. Katılımcıların $\% 45^{\prime}$ i interneti, $\% 35$ 'i cep telefonunu ve $\% 37$ 'si ise bilgisayarı 3 ile 5 yıl arasında kullanmakta olduklarını dile getirmişlerdir. 9 yıldan daha uzun süredir kullananların oranı internet için $\% 18$, cep telefonu için \%24 ve bilgisayar için \%13 civarındadır. Söz konusu teknolojik ürün ve hizmetlerin Kırgızistan'da 1991 yılından sonra kullanıma açıldığını dikkate alırsak şekil 3’teki dağılım oldukça gerçekçi bir görünüm sergilemektedir.

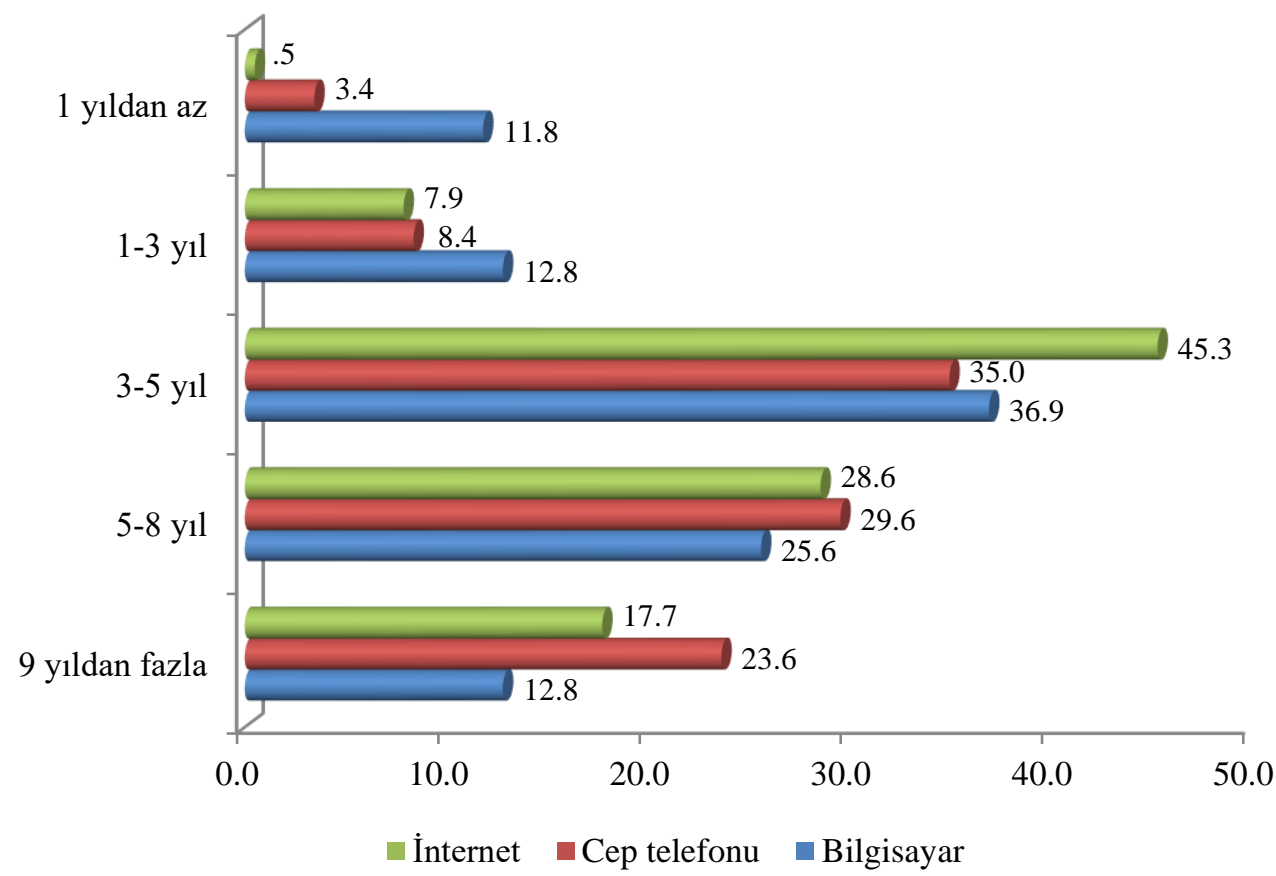

Şekil 3. Katılımclların Bilgisayar, Cep Telefonu ve Internet Kullanım Süreleri

Araştırma kapsamında katılımcıların e-devlet hizmetlerine ilişkin algılamaları dört boyutta ele alınmıştır. Bunlar sirasiyla, algilanan fonksiyonel fayda (ortalamas1 4,32 ve standart sapmas1 0,601), algilanan hizmet yanit1 (ortalamas1 3,51 ve standart sapmas1 0,932), e-devlet adaptasyonu (ortalamas1 3,99 ve standart sapmas1 0,878) ve 
kaynakların kullanabilirliği (ortalaması 4,30 ve standart sapması 0,857) boyutlarıdır. Ayrıntıları Tablo 2'de sunulan bulgulara göre, tüm boyutlarda algılamaların yüksek olduğu ve 'orta derecede katılıyorum' ifadesine denk gelen 3 'ten istatistiksel olarak $(p<0.05)$ farklı olduğu görülmüştür. Algılanan fonksiyonel fayda boyutunun en yüksek ve algılanan hizmet yanıtının en düşük değere sahip olduğu tespit edilmiştir. Bilgisayar ve internet teknolojisine sahiplik durumunu gösteren kaynakların kullanılabilirliği boyutuna ilişkin algılanan değerin de yüksek olması Şekil 1-2-3'teki bulguları da doğrulamaktadır. E-devlet hizmetlerinin kullanma durumları ve niyeti, ayrıca yakın çevresinin de kullanması için tavsiye etme durumlarını içeren e-devlet adaptasyon boyutunda da algılamaların oldukça yüksek olduğu dikkat çekmektedir. Ancak, e-devlet web sitelerinin işlevselliğini yansıtan algılanan hizmet boyutunun en düşük değere sahip olması üzerinde durulması gereken önemli bir bulgudur. Dijitalleşme sürecinin henüz başlangıcında olan ülkede elde edilen sonuçların beklenen sonuçlar olduğu söylenebilir.

\begin{tabular}{|c|c|c|c|}
\hline Boyutlar ve İfadeler & Ortal. & St. Sap. & $\mathrm{p}$ \\
\hline Algilanan fonksiyonel fayda $(A F F)$ & 4,32 &, 601 &, 000 \\
\hline E-devlet web sitelerini ihtiyacım olan her yerde kullanabilmek önemlidir & 4,70 & ,718 &, 000 \\
\hline E-devlet web siteleri işlemleri daha hızlı yerine getirmede yardımcı olur & 4,35 & ,804 & ,000 \\
\hline E-devlet web sitelerini kullanmak genel verimliliği arttırır & 4,50 & ,713 &, 000 \\
\hline E-devlet web siteleri kullanılarak işlemler daha kolay gerçekleştirilebilir & 4,25 & ,934 &, 000 \\
\hline E-devlet web siteleri daha doğru kararlar verilmesine yardımcı olur & 3,79 & 1,056 &, 000 \\
\hline Algilanan hizmet yanitı $(A H Y)$ & 3,51 & ,932 &, 000 \\
\hline E-devlet web siteleri beni değerli bir müşteri olarak hatırlar ve tanır & 3,44 & 1,146 &, 000 \\
\hline E-devlet web sitelerinin müşteri hizmetleri benim özel ihtiyaçlarımı giderir & 3,51 & 1,136 &, 000 \\
\hline $\begin{array}{l}\text { Herhangi bir sorunla karşılaştığımda E-devlet web siteleri hızlıca düzeltici } \\
\text { aksiyon alır }\end{array}$ & 3,32 & 1,185 & ,000 \\
\hline Online müşteri hizmetlerine 24 saat ulaşabilirim & 3,80 & 1,243 & ,000 \\
\hline E-devlet adaptasyonu $(E-D A)$ & 3,99 &, 878 &, 000 \\
\hline E-devlet web sitelerini bilgi edinmek ve form indirmek için kullanıyorum & 3,81 & 1,158 &, 000 \\
\hline $\begin{array}{l}\text { Bilgi edinmek ve form indirmek için gelecekte de E-devlet web sitelerini } \\
\text { kullanmak isterim }\end{array}$ & 4,17 & ,976 & ,000 \\
\hline $\begin{array}{l}\text { Bilgi edinmek ve form indirmek için E-devlet web sitelerini kullanmayı } \\
\text { akrabalarıma ve arkadaşlarıma öneririm }\end{array}$ & 4,01 & 1,156 & ,000 \\
\hline Kaynakların kullanılabilirliği (KK) & 4,30 &, 857 &, 000 \\
\hline Evde yeterli bilgisayar teknolojisine sahibim & 4,17 & 1,122 &, 000 \\
\hline İşyerimde yeterli bilgisayar teknolojisine sahibim & 4,37 & 1,004 &, 000 \\
\hline Evde her zaman internet bağlantısına sahibim & 4,34 & 1,024 &, 000 \\
\hline İşyerimde her zaman internet bağlantısına sahibim & 4,42 & 1,034 &, 000 \\
\hline
\end{tabular}

Tablo 2. Boyutların ve Ifadelerin Ortalama Değerleri ve Orta Düzeyde Katılıyorum Anlamına Gelen '3'ten Farkı

Araştırma kapsamında katılımcıların e-devlet hizmetlerine ilişkin algılamalarının demografik özelliklere göre farklılık gösterip göstermediği bağımsız örneklem t testi ve ANOVA kullanılarak incelenmiş ve sadece anlamlı farklılıkların olduğu sonuçlar Tablo 3'te sunulmuştur. Tablo incelendiğinde, algılanan fonksiyonel fayda (AFF) boyutunda sadece cinsiyete göre farlılık olduğu, diğer bir ifadeyle erkeklerin kadınlara göre daha olumlu bir algıya sahip olduğu söylenebilir. Algılanan hizmet yanıtı (AHY) boyutunda ise sadece bilgisayar kullanım becerisine göre anlamlı farklılık bulunmaktadır. Buna göre, bilgisayarı profesyonel düzeyde kullanabilirim diyenlerin algıları temel düzeyde kullanabilirim diyenlere göre daha pozitif olduğu görülmektedir. Demek ki, e-devlet hizmetlerine ilişkin sorunların sadece web sitesinin özelliklerinden değil, aynı zamanda kullanıcının da özelliklerinden etkilenmektedir. E-devlet adaptasyonu (E-DA) boyutunda ise, yine bilgisayar kullanım becerisi ve gelir seviyesine göre anlamlı farklılıkların olduğu tespit edilmiştir. Bu boyutta, temel düzeyde kullanıcıların algılarının profesyonel kullanıcılara göre ve gelir seviyesi düşük olanların yüksek olanlara göre daha olumlu olduğu görülmüştür. Bu durum algılamalarının düşük olduğu grupların (profesyonel kullanıcı ve gelir seviyesi yüksek) e-devlet hizmetlerini kullanma konusunda daha tecrübeli olmaları ile açıklanabilir. Diğer taraftan, kaynakların kullanılabilirliği (KK) boyutunda hemen hemen tüm demografik özelliklere göre anlamlı farklılıklar tespit edilmiştir. Erkeklerin kadınlara göre, evlilerin bekarlara göre, gelir seviyesi yüksek olanların düşük olanlara göre, profesyonel kullanıcıların temel düzeyde kullanıcılara göre, özel sektör çalışanlarının ve diğer grubun (işsiz, emekli, evhanımı) kamu çalışanlarına göre bu konudaki algılamalarının daha pozitif olduğu sonucuna ulaşılmıştır. Evde ve işyerinde bilgisayar ve internet imkanlarına sahip olanların daha çok yüksek gelirli, özel sektörde çalışan, evli ve bilgisayarı iyi derecede kullanan bireylerden oluşması doğal bir sonuçtur. Bu konuda kamu sektöründe çalışanların sınırlı imkanlara sahip olduğu dikkat çekmektedir. Devletin dijitalleşme sürecinde yatırım yapması gereken alanlardan biri de altyapıdır ve bu konuda öncelikle kamu görevlilerinin gerekli donanıma sahip olması önem arz etmektedir. 


\begin{tabular}{|l|c|c|c|c|c|c|}
\hline Demografik Özellikler & & AFF & AHY & E-DA & KK \\
\hline Cinsiyet & Kadın & Erkek &,- 18003 & - & - &,- 24583 \\
\hline Medeni hal & Evli & Bekar & - & - & - &, 39157 \\
\hline Gelir, Som & $\geq 30000$ & $30001 \leq$ & - & - &,- 35648 &,- 56157 \\
\hline Bilgisayar kullanımı & Temel & Profesyonel & - &, 28267 &,- 06418 &,- 26351 \\
\hline \multirow{2}{*}{ Uğraş alanı } & Kamu çalışanı & Özel sektör & - & - & - &,- 48342 \\
\cline { 2 - 7 } & Kamu çalışanı & Diğer & - & - & - &,- 40061 \\
\hline
\end{tabular}

*. Ortalamalar arasındaki fark $p \leq 0.05$ düzeyinde anlamlıdır.

\section{Tablo 3. Demografik Özelliklere Göre Algllamalardaki Farklılıklar}

Araştırma kapsamında katılımcıların e-devlet hizmetlerine yönelik algılamaları bakımından farklı pazar bölümlerine (kümelere) ayrılıp ayrılmadığı hiyerarşik olmayan kümeleme analizi ile incelenmiş ve elde edilen sonuçlar Tablo 4'te sunulmuştur. Analiz sonuçlarına göre, katılımcıların e-devlet hizmetlerine ilişkin algılamaları bakımından üç farklı kümeye (düşük, orta ve yüksek) ayrılabileceği görülmüştür. Anova testinin sonuçların gore, kümeleme analizi sonucunda elde edilen grupların bir birinden istatistiksel olarak anlamlı bir şekilde farklılık gösterdiği sonucuna ulaşılmıştır. Buna gore, en düşük düzeyde algılamaya sahip 1-kümede 22 katılımcının $(\% 10,8)$, orta düzeyde olan 2-kümede 96 katılımcının $(\% 47,2)$ ve yüksek olan 3-kümede ise 85 katılımcının $(\% 42,0)$ yer aldığ 1 görülmektedir.

\begin{tabular}{|l|c|c|c|c|c|}
\hline \multirow{2}{*}{ BOYUTLAR } & \multicolumn{3}{|c|}{ KÜMELER } & \multicolumn{2}{c|}{ ANOVA } \\
\cline { 2 - 6 } & Küme1 & Küme2 & Küme3 & F & p \\
\hline Algilanan fonksiyonel fayda (AFF) & 3,50 & 4,18 & 4,69 & 62,810 &, 000 \\
\hline Algılanan hizmet yanıtı (AHY) & 2,33 & 3,11 & 4,28 & 119,246 &, 000 \\
\hline E-devlet adaptasyonu (E-DA) & 2,44 & 3,82 & 4,60 & 128,847 &, 000 \\
\hline Kaynakların kullanılabilirliği (KK) & 2,84 & 4,28 & 4,70 & 68,612 &, 000 \\
\hline Kümedeki gözlem sayısı & 22 & 96 & 85 & & \\
\hline
\end{tabular}

Tablo 4. Kümeleme Analizi Sonuçları

Belirlenen pazar bölümlerine (kümelere) gore katılımcıların demografik özelliklerini incelemek için $\chi 2$ testi uygulanmış, sadece anlamlı farklılıkların olduğu sonuçlara Tablo 5'te yer verilmiştir. Analiz sonuçlarına göre, katılımcıların medeni hal, gelir grupları ve uğraş alanına göre pazar bölümleri arasında farklılıkların olduğu görülmüştür. Diğer taraftan, cinsiyet, yaş, eğitim düzeyi gibi özelliklere göre farklılık bulunmamıştır.

\begin{tabular}{|c|c|c|c|c|c|}
\hline Değişkenler & $\chi^{2}$ & Küme1 (\%) & Küme2 (\%) & Küme3 (\%) & Genel (\%) \\
\hline \multicolumn{6}{|l|}{ Medeni Hal } \\
\hline - Evli & \multirow{2}{*}{$6,094 *$} & 27,3 & 28,1 & 44,7 & 35,0 \\
\hline - Bekar & & 72,7 & 71,9 & 55,3 & 65,0 \\
\hline \multicolumn{6}{|l|}{ Gelir } \\
\hline - 30000 Som ve altı & \multirow{2}{*}{$6,194 *$} & 85,7 & 66,3 & 56,8 & 64,6 \\
\hline - 30001 Som ve üstü & & 14,3 & 33,7 & 43,2 & 35,4 \\
\hline \multicolumn{6}{|l|}{ Uğraş Alanı } \\
\hline - Öğrenci & \multirow{4}{*}{$16,338^{*}$} & 18,2 & 11,5 & 17,6 & 14,8 \\
\hline - Kamu çalışanı & & 68,2 & 54,2 & 35,3 & 47,8 \\
\hline - Özel sektör çalışanı & & 13,6 & 12,5 & 25,9 & 18,2 \\
\hline - Diğer & & 0,0 & 21,9 & 21,2 & 19,2 \\
\hline
\end{tabular}

\section{Tablo 5. Kümelere Göre Katılımclların Demografik Özellikleri}

Tablo incelendiğinde, e-devlet hizmetlerine yönelik algılamalarının en düşük olduğu pazar bölümü (Küme1) daha çok bekar, 30000 Somun altında gelire sahip, öğrenci ve kamu çalışanlarından oluşmaktadır. Algılamaları orta düzeyde olan pazar bölümü (Küme2) ise genellikle yine bekar, 30000 Somun altında gelire sahip, kamu çalışanı ile diğer grubu oluşturan; evhanımı, işsiz ve emeklilerden oluşmaktadır. Diğer taraftan, algılamaları yüksek düzeyde olan pazar bölümünde (Küme3) ağırlıklı olarak evli, 30000 Somun üzerinde gelire sahip, özel sektör çalışanları ile diğer grubu oluşturan; evhanımı, işsiz ve emekliler yer almaktadır.

\section{Sonuç ve Öneriler}

Araştırmaya katılan Bişkek halkının teknolojik ürün ve hizmetleri kullanma durumlarının yeterli düzeyde olduğu ve e-devlet hizmetlerine hazırlık düzeylerinin de orta derecenin üzerinde olduğu söylenebilir. Katılımcıların yeterli 
düzeyde bilgi ve iletişim teknolojilerine sahip olduğu, e-devlet hizmetlerinin faydası ve adaptasyonu konusunda oldukça yüksek algıya sahip olduğu tespit edilmiştir. Ancak, e-devlet hizmetlerinin sunulduğu web sitelerinin işlevselliği konusunda zayıflık gözlenmiştir. Elde edilen bu sonuçlar literatürde yer alan bir çok çalışma ile benzerlik göstermektedir (Kamaruddin ve Noor, 2017; Zhang ve Hsieh, 2010; Mensah, 2017; AlAwadhi ve Morris, 2009).

Katılımcıların e-devlet hizmetlerine ilişkin algılamalarının cinsiyet, medeni hal, gelir, uğraş alanı gibi demografik özelliklere göre farklılık gösterdiği ortaya konulmuştur. Halkın e-devlet hizmetlerine hazırlık durumları demografik özelliklere göre farklılık gösterebileceği yapılan diğer çalışmalarda da belirtilmektedir (Akman, vd, 2005; Çabuk, vd, 2017; Al-Eryani, 2009). Dikkat çeken önemli bulgulardan biri ise algılanan hizmet yanıtı (AHY) boyutunda bilgisayarı profesyonel düzeyde kullanabilirim diyenlerin algılarının temel düzeyde kullanabilirim diyenlere göre daha pozitif olmasıdır. Demek ki, e-devlet hizmetlerini kullanırken kullanıcının özelliği de önemli rol oynamaktadır. Dijitalleşme konusunda devlet altyapı yatırımları ile beraber halkın teknolojik okur yazarlığını geliştirmeye yönelik eğitim ve tanıtım faaliyetlerine de önem vermelidir. Bu konuda yapılan bazı çalışmalar bu sonuçları desteklemektedir (AlAwadhi ve Morris, 2009; Al-Eryani, 2009). Diğer taraftan, e-devlet adaptasyonu (E-DA) boyutunda temel düzeyde bilgisayar kullanabilenlerin profesyonel kullanıcilara göre daha olumlu görüşe sahip olması ise e-devlet hizmetlerini kullanma konusunda daha az tecrübeye sahip olmaları ile açıklanabilir. Kaynakların kullanılabilirliği (KK) boyutunda, evde ve işyerinde bilgisayar ve internet imkanlarına sahip olanların daha çok yüksek gelirli, özel sektörde çalışan, evli ve bilgisayarı iyi derecede kullanan bireylerden oluştuğu tespit edilmiştir. Kamu sektöründe çalışanların bu konuda güçlendirilmesi ve desteklenmesi önerilebilir. Dijitalleşme sürecinde kamu görevlileri e-devlet hizmetlerini kullanıcılara doğrudan aktaran, onlarla sürekli etkileşim halinde olan kimselerdir. Dolaysıyla, öncelikle kamu görevlilerinin gerekli donanıma, bilgi ve beceriye sahip olmasının sağlanması önem arz etmektedir.

Dijitalleşme sürecinde ele alınması gereken önemli konulardan birinin kullanıcılarla ilgili yapılacak çalışmalar olduğunu belirtmiştik. Kullanıcıların teknoloji kullanım becerilerinin artırılması, e-devlet hizmetlerini kullanmaya teşvik edilmesi gerekmektedir. Bu konuda, kullanıcıları homojen bir pazar olarak düşünmek kaynakların verimsiz kullanılmasına neden olacaktır. Bu çalışmada, katılımııların e-devlet hizmetlerine ilişkin algılamaları bakımından üç farklı pazar bölümüne (algılamaları en düşük, orta ve yüksek) ayrılabileceği sonucuna ulaşılmıştır. Her bir pazar bölümüne özel programlar uygulanabilir. Bu konudaki çalışmaların e-devlet hizmetleri konusunda en düşük algıya sahip grup ile başlanabilir. $\mathrm{Bu}$ gruptaki bireylerin ağırlıklı olarak düşük gelirli, bekar, öğrenci ve kamu çalışanlarından oluştuğu dikkate alınmalıdır.

Bu çalışmanın sonuçları devletin dijital dönüşüm süreçlerinde kullanıcıların davranışlarını anlamak açısından önemli ipuçlarını vermekle birlikte, bir takım sınırlılıklarının da olduğu belirtilmelidir. Çalışmada tesadüfi olmayan örnekleme yönteminin kullanılması araştırma sonuçlarının ana kitleye genellenmemesi önemli sınırlılıklardan biridir. Ayrıca, araştırmanın sadece başkent olan Bişkek şehrinde uygulanması nedeniyle araştırma sonuçlarının Kırgızistan genelini yansıtmadığı belirtilmelidir. Bir diğer önemli sınırlılık ise, çalışmada e-devlet hizmetlerine ilişkin güvenlik, uyumluluk, farkındalık, sosyal etki, yüz yüze etkileşim gibi önemli boyutların dikkate alınmamış olmasıdır. Dolayısıyla, bu konuda ileride yapılacak çalışmalar için söz konusu sınırlılıkların dikkate alınması önerilebilir. Dünya genelinde yaşanmakta olan pandemi dijitalleşme konusunu bir önceki yıla göre daha da güncel ve önemli hale getirmiştir. Bundan sonraki dönemlerde konuyla ilgili yapılması gereken faaliyetlerin yeni bir hızla devam ettirilmesi kaçınılmazdır.

\section{Kaynakça}

- Abdelghaffar ve Magdy, 2012. "The Adoption of Mobile Government Services in Developing Countries: The Case of Egypt", International Journal of Information and Communication Technology Research, 2(4), pp. 333-341.

- Akman, vd, 2005. "E-Government: A Global View and an Empirical Evaluation of Some Attributes of Citizens", Government Information Quarterly, 22, pp. 239-257.

- AlAwadhi ve Morris, 2009. "Factors Influencing the Adoption of E-government Services", Journal Of Software, 4(6), pp. 584-590.

- Al-Eryani, 2009. "E-Government Services in Yemen: Success and Failure Factors", Faculty of Science Bulletin, 22, pp. 61-74.

- Alshehri ve Drew, 2010. "Challenges of e-Government Services Adoption in Saudi Arabia from an e-Ready Citizen Perspective", in Proceedings of World Academy of Science, Engineering and Technology 2010, $p$. 1039.

- Bhuiyan, 2010. "E-Government in Kazakhstan: Challenges and Its Role to Development", Public Organization Review, 10(1), pp. 31-47.

- Birleşmiş Milletler, 2018. UN E-Government Survey, https://www.un.org/development/desa/publications/2018-un-e-government-survey.html 
- Carter, vd, 2016. "Citizen Adoption of E-Government Services: Exploring Citizen Perceptions of Online Services in the United States and United Kingdom", Information Systems Management, 33(2), pp. 124-140.

- Cisco, 2019. Global Digital Readiness Index 2019, https:/www.cisco.com/c/dam/en_us/about/csr/reports/global-digital-readiness-index.pdf

- $\quad$ Çabuk, vd, 2017. "E-Devlet Sistemine Adaptasyonun Teknoloji Kabul Modeliyle Araştırılması", Ç. Ü. Sosyal Bilimler Enstitüsü Dergisi, 26(3), ss. 140-154.

- Daştan ve Efiloğlu Kurt, 2016. "E-Devlet Adaptasyonunda Etkili Olan Faktörlerin Belirlenmesine İlişkin Ampirik Bir Araştırma: Yalova Örneği", Ege Akademik Baklş, 16(1), ss. 95-107.

- Dewa ve Zlotnikova, 2014. "Citizens' Readiness for e-Government Services in Tanzania", ACSIJ Advances in Computer Science: an International Journal, 3(4), pp. 37-45.

- $\quad$ Eze, vd., 2011. "Intention to Use E-Government Services in Malaysia: Perspective of Individual Users", in Proceedings of ICIEIS 2011, p. 512.

- Goings, 2003. "Critical Factors in the Delivery of e-Government Services: Perceptions of Technology Executives", Communications of the International Information Management Association, 3(3), pp. 1-15.

- Güler ve Döventaş, 2009. "Elektronik Devletten (E-Devlet) Mobil Devlete (M-Devlet) Geçişte Türkiye'de Yerel Yönetim Uygulamaları", Hitit Üniversitesi Sosyal Bilimler Enstitüsü Dergisi, 1(2). ss. 25-48.

- Ismailova, vd, 2018. "A Central Asian view of E-government Services Adoption: Citizens' Trust and Intention to Use E-services", Chapter in Innovative Perspectives on Public Administration in the Digital Age IGI Global 2018, pp. 212-226.

- Kamaruddin ve Noor, 2017. "From E-Government to T-Government: A Malaysian Citizens' Readiness Study", Journal of Telecommunication, Electronic and Computer Engineering, 9(2-9), pp. 15-21.

- KC Cumhurbaşkanlığ1, 2019-2020. KC Cumhurbaşkanı Kararnamesi, http://www.president.kg/

- Kee ve Wei, 2004. "Successful E-Government in Singapore: How did Singapore manage to get most of its public services deliverable online?", Communications of the ACM, 47(6), pp. 95-99.

- Kırgizistan Cumhuriyeti Milli İstatistik Komitesi, (2019). İstatistikler, http://stat.kg/kg/statistics/naselenie/

- Lallmahomed, vd, 2017. "Factors influencing the adoption of e-Government Services in Mauritius", Telematics and Informatics, doi: http://dx.doi.org/10.1016/j.tele.2017.01.003, (Accepted Manuscript).

- Lean, vd., 2009. "Factors Influencing Intention to Use E-Government Services Among Citizens in Malaysia", International Journal of Information Management, 29(6), pp. 458-475.

- Mensah, 2017. "Citizens' Readiness to Adopt and Use E-government Services in the City of Harbin, China", International Journal of Public Administration, 41(4), pp. 297-307.

- $\quad$ Parasuraman, 2000. "Technology Readiness Index (TRI): A Multiple-Item Scale to Measure Readiness to Embrace New Technologies", Journal of Service Research, 2(4), pp. 307-320.

- Pardo ve Styrin, 2010. "Digital Government Implementation: A Comparative Study in USA and Russia", in Proceedings of AMCIS 2010, p. 330.

- Ranaweera, 2016. "Perspective of Trust Towards E-Government Initiatives in Sri Lanka", Ranaweera SpringerPlus, 5(22), pp. 1-11.

- Srivastava ve Teo, 2005. "Citizen Trust Development for E-Government Adoption: Case of Singapore", in Proceedings of PACIS 2005, p. 721.

- $\quad$ Tung ve Rieck, 2005. "Adoption of Electronic Government Services among Business Organizations in Singapore", Journal of Strategic Information Systems, 14, pp. 417-440.

- 'Tündük' elektronik etkileşim merkezi, 2020. https://www.tunduk.gov.kg/

- Ulusal Kalkınma Stratejisi, 2018. Natsional'naya strategiya razvitiya Kyrgyzskoy Respubliki na 2018-2040 gody, http://www.president.kg/kg/

- Uluslararası Telekomünikasyon Birliği, 2018. Global and Regional ICT Data, https://www.itu.int/en

- Vinogradova ve Moiseeva, 2015. "Open Government and "EGovernment" in Russia", Sociology Study, 5(1), pp. 29-38.

- West, 2005. Digital Government: Technology and Public Sector Performance. Princeton University Press, New Jersey.

- Zawaideh, 2017. "Acceptance of E-Government Services Among Jordai1an Citizen", International Journal of Recent Advances in Multidisciplinary Research, 4(2), pp. 2348-2351.

- Zhang ve Hsieh, 2010. "Chinese Citizens' Opinions on E-Government Benefits, Issues and Critical Success Factors", Electronic Government, An International Journal, 7(2), pp. 137-147. 


\title{
Kurgızistan'da Yerel Yönetimlerin Vergilendirmedeki Özerkliği Autonomy of Local Governments in Taxation in Kyrgyzstan
}

\author{
Asst. Prof. Dr. Dastan Aseinov (Kyrgyz-Turkish Manas University, Kyrgyzstan)
}

\begin{abstract}
The authority for taxation might be delegated to the local governments to expand their financial autonomy through increasing their revenue. This study aims to assess the financial autonomy of local governments in Kyrgyzstan in terms of tax revenues.

The taxing power of local governments examined using local budget data for period of 2007-2017. We use variables as reflecting the level of taxing power. Variables measured as ratio of total local government tax revenue, different types of taxes revenue to the total revenue or to the total tax revenues. This study also looks at the legal framework for delegating taxation powers to local authorities.

The results show that financial autonomy of local governments in terms of taxation is low. Local governments in Kyrgyzstan largely depends on transfers from the central government budget. According to the legal framework, the tax powers of local administrations is within narrow limits. Since increasing the financial autonomy through expanding the taxing power of local governments poses problems this needs to be solved, like a narrow tax base and inefficient tax administration in the regions. Thus, it can be argued that it is too early to transfer taxation power to local governments.
\end{abstract}

\section{Giriş}

Geçiş süreci esnasında kırsal bölgede Sovyet döneminden kalan iktisadi kapasitenin yıpranmış ve yıkılmış olması önemli iktisadi ve sosyal sorunlara yol açmıştır (Abazov, 1999; Scrieciu \& Stringer, 2008; Kasenov, 2017). Günümüzde de bu ülkelerde bölgelerarası iktisadi ve sosyal farklılıkların ortadan kaldırılması, şehirleşme, iç ve dış göç sayısındaki artışlar gibi sorunlar gündeme gelmiş durumdadır. Bu sorunların çözümü yolunda yerel yönetimlerin rolü artmaktadır. Yerel yönetimlerce bu önemli görevlerinin etkin bir şekilde yürütülmesi iktisadi ve mali kaynakları gerektirmektedir. Bu tür kaynaklarının bir kısmını merkezi hükümet sağlayabilmektedir. Diğer kısmı da, mevzuat çerçevesinde kendilerine sağlanan siyasi, idari ve mali özerklik çerçevesinde yerel yönetimlerce borçlanma, vergi ve benzeri mali araçlar yardımıyla temin edilir.

Mali özerklik harcama, gelir oluşturma ve borçlanma kapsamında değerlendirilebilir. Bunlardan gelir açısından mali özerklik de esas olarak yerel yönetimlerin vergilendirmedeki özerkliği ile bağlantılıdır. Vergilendirme yetkisine sahip olan devlet, bu yetkisini uygun göreceği sınırlar ölçüsünde, yerel yönetimlere devredebilir. Yerel yönetimlerin mali özerklikleri ise, devlet tarafından kendilerine devredilen vergilendirme yetkisinin genişliği ile ölçülebilir (Çımat, 1996:62).

Çoğu ülkelerdeki uygulamalarda merkezi yönetimler mali kaynaklar yönünden yerel yönetimler karşısında önemli bir gücü elinde bulundurmakta. Bu şartlarda yerel yönetimler kaynak sıkıntısı ile karşı karşıya kalmaktadırlar (Ulusoy ve Akdemir, 2009: 260). Diğer taraftan, yerel yönetimler üzerinde merkezi otoritenin ve ulusal mali birliğin korunması ile ülkede makroekonomik istikrarın sağlanması da önemlidir. Bunun yanısıra, yerel yönetimlerin vergilendirme yetkilerinin genişletilmesi durumunda yerel yönetimlere kamu hizmetinin sunumu görevinin de aktarılması söz konusudur. Dolayısıyla, vergilendirme alanında merkezi ve yerel yönetimler arası ilişkilerin ülke ve bölgelerin özelliklerine göre optimum şekilde belirlenmesi ve sağlanması doğru görülmektedir. Fakat, söz konusu optimum paylaşım şeklinin belirlenmesi ile ilgili yazındaki bilimsel tartışmalar devam etmektedir.

Üniter devletlerin biri olan Kırgızistan'da yerel yönetimlerin merkezi yönetimle ilişkileri mali özerklik açısından önem arz etmektedir. Coğrafi ve idari olarak büyük olmayan ülke olması yerel yönetimlere tanınması gereken özerkliğin genişliği tartışılan bir konudur. 2018 ve 2019 yıllarının Kırgızistan Cumhurbaşkanı tarafından bölgeleri kalkındırma yılı olarak ilan edilmesi bu konuyu gündeme getirmiştir.

2009 yılında yeni Vergi Kanununun yürürlüğe girmesi ile yerel vergilerin sayısının 8'den 2'ye azalmıştır. Yerel yönetimler vergi tahsilatını ve denetimini geliştirerek özgelirlerini arttırabilme yetkilerinin ve bu iki verginin matrahının ve oranlarının büyük ölçüde sınırlı kalması bölgelerin gelişmesinde sorunlar yaratmaktadır. Bu tür sorunların yıllardır çözüme ulaşılmamış olması bu konunun güncelliğini göstermektedir. Yerel yönetimlerin mali özerkliğinin düzeyi gelir, harcama ve borçlanma bağlamında değerlendirilebilir. Bu çalışmada vergilendirme yetkileri açısından Kırgızistan'daki yerel yönetimlerin mali özerkliğinin değerlendirilmesi amaçlanmıştır. Bu amaç doğrultusunda vergilendirme yetkilerinin sınırlarını belirleyen hukuki çerçeve esas alınarak yerel yönetimlerin mali özerkliği analiz edilmiştir. Ayrıca, yerel yönetimlerin bütçe gelirlerinin sayısal göstergeleri incelenmiştir. Bu kapsamda bütçe istatistiki verileri kullanılarak oluşturulan bazı değişkenler yardımıyla yerel yönetimlerin vergilendirme yetkileri değerlendirilmiştir. Bu çalışma Kırgızistan'da yerel yönetimlere devredilmiş görevleri 
yerine getirebilmelerinde vergilendirme yetkilerinin ne olduğunun tespit edilmesini amaçlayan bir betimleyici araştırma olarak nitelendirilebilir.

Çalışmanın ilk kısımlarında mali özerklik ve yerel yönetimlerin vergilendirme yetkileri kavramlarının açıklanması ile birlikte önceki çalışmaların sonuçları incelenecektir. Sonraki kısmında araştırma yöntemi ve modeli açıklanacaktır. İzleyen bölümlerde yerel yönetimlerin vergilendirme yetkileri hukuki çerçeve ve istatistiki verilere temelinde ele alınacaktır.

\section{Kavramsal Cerçeve}

Yerelleşme kapsamında yerel yönetimlerin mali özerkliğinin genişliği ön plana çıkmaktadır. Harcama ve gelir yönünden yerel yönetimlerin özerkliği ölçüsü, adem-i merkeziyetçi yönetiminde verimlilik artışlarını gerçekleştirmek ve makroekonomik istikrarı desteklemek açısından çok önemlidir. Gelir açısından yerel yönetimlerin özerkliği, yerel hizmetlerin finansmanını özgelirleri ile sağlayabilecek ve gelirlerini kontrol edebilecek yetkinin genişliği ile bağlantılıdır. Daha geniş bir gelir özerkliği ise, yerel yönetimlerin en azından vergi oranlarını belirleme ve en az önemli bir vergi kaynağını belirleme yetkisine sahip olması şeklinde tanımlanabilir (Dabla-Norris, 2006:107).

Fakat, uygulamada daha çok mali bütünlük, eşitlik ve disiplinin, ve makroekonomik istikrarın sağlanması ön plana çıkarılarak yerel yönetimlerin mali özerkliği sınırlandırılmaktadır. Bunun nedeni olarak adem-i merkeziyetçiliğin olumsuz neticeleri gösterilmektedir (Bartolini vd., 2016). Prudhomme (1995)'e göre bu tür neticeler, kaynakların etkinsiz dağılımı ve kamu mallarının etkinsiz üretimine yol açması, yerel ve merkezi yönetimler yürüten maliye politikaları arasındaki çatışmalar sonucunda makro iktisadi politikaların uygulanmasını ve ülke çapında kaynakların yeniden dağıtımını daha zorlaştırması, yerel yönetimlerin idari kapasitesinin zayıf olmasidir.

Ayrıca, yerel yönetimlerin vergilendirme yetkileri mali federalizm teorisi çerçevesinde de ele alınmaktadır. İlk kez Musgrave (1959)'da önerilen ve daha sonra Tiebout (1961), Tanzi (1995), Ter-Minassian (1997), Oates (1972, 2008) ve başkaları tarafından geliştirilen bu teori gelir ve harcamaların, diğer bir ifade ile yetki ve sorumlulukların farklı düzeydeki kamu yönetimleri arasındaki dağılımını ele almaktadır.

Yönetimlerarası mali ilişkilerin ne şekilde olması gerektiği konusunda bilimsel camiada genel kabul görmüş iddianın olduğunu belirtmek zordur. Çünkü, ülke içindeki bölge, şehir ve köyler arasındaki sosyal, kültürel, siyasi ve iktisadi özellikler ve farklılıklar mali yapılarının da farklı olmasını gerektirmektedir. Yerel özellikleri daha yakından bildiği için yerel yönetimlerin yerel toplulukların refahını artırabilecek kamu mallarını sunabileceği, daha uygun olan vergilendirme ve harcama, yani maliye politikasını uygulayabileceği savunulmaktadır. Dolayısıyla, mali yerelleşme ve yönetimlerarası mali ilişkiler ülke koşulları, özellikleri ve yapısına göre düzenlenmesi önemlidir (Sertesen, 2011:2; Bartolini vd., 2016).

Dolayısıyla, federal ve üniter devletlerde yönetimlerarası mali ilişkilerin kapsamı ve içeriği farklılık gösterdiği belirtilebilir (Flowers, 1988). Yerelleştirme kapsamda yerel yönetimlere özerkliğin tanınması ile vergilendirme yetkisinin bir kısmının yerel yönetimlere tanınması da söz konusudur. Üniter devletlerde vergi türlerini, vergi oranlarını, vergi tabanını, vergi istisna ve muafiyetleri belirleme yetkileri uygulamada çoğu kez merkezi yönetimin yetki alanları içinde kalmaktadır (Groenendijk, 2011). Bundan dolayı, yerel yönetimlerin gelirlerinin büyük kısmını yönetimlerarası mali transferler veya aynı vergi tabanının yönetimler arasında paylaşılması şeklindeki mali kaynaklar oluşturmaktadır. Uygulamada yerel yönetimlerin özerkliğinin artırılması sonucunda ortaya çıkabilecek bölgeler arasında yatay eşitsizliğin azaltılması için mali transfer kullanılmaktadır. Bu şartlarda vergilendirme yetkisinin dar olmasından dolayı yerel yönetimlerin mali özerkliği sınırlı kalmaktadır.

İdari, siyasi ve mali özerkliğe sahip olan yerel yönetimler aynı zamanda vergilendirme ve hizmet sunumunda s1k1 bir rekabet ortamında bulunurlar. Bu rekabet ortamı da yerel yönetimlerin disipline edilmesi ve daha etkin faaliyet göstermesine yol açabilir (Özdemir, 2005:121; Boetti vd. 2012). Çünkü, özerklik aynı zamanda sorumluluk demektir. Dolayısıyla, vergilendirme yetkileri çerçevesinde de yerel yönetimlerin mali özerkliği, kendilerine devredilen görev ve sorumlulukların kapsam ve sınırlarına göre belirlenmesi gerekmektedir.

Yerel düzeyde kamu hizmetlerinin etkin ve kaliteli bir şekilde sunulması için yerel yönetimlerin gelir kaynaklarının kendilerinin hukuki ve siyasi kontrollerinde olmasını gerekmektedir (Brunori, 2007:2). Bundan dolayı, yerel idari bölgelerin iktisadi, sosyal, teknolojik ve tarihi şartlarına, ve yerel yönetimlerin bu şartlardaki değişimlere uyum sağlayabilmesini ve daha hızlı karar alabilmelerini sağlamak amaciyla vergilendirme yetkisi yerel yönetimlere devredilebilir (İnan ve Ekici, 2010:311).

Yerel düzeyde kamu hizmetlerinin etkin ve kaliteli bir şekilde sunulması için gelir kaynaklarının hukuki ve siyasi kontrolünün yerel yönetimlerin elinde olmasını gerektirmektedir (Brunori, 2007:2). Yerel idari bölgelerin iktisadi, sosyal, teknolojik ve tarihi şartlarına, ve yerel yönetimlerin bu şartlardaki değişimlere hızlı uyum sağlayabilmesini ve daha hızlı karar alabilmelerini sağlamak amacıyla vergilendirme yetkisi yerel yönetimlere devredilebilir (İnan ve Ekici, 2010:311). 
Vergilendirme yetkisi, vergi koyma, alma, oranlarını, matrahını belirleme konusunda devletin sahip olduğu hukuki ve fiili gücünü ifade eder. Ayrıca, kamu giderlerini karşılamak üzere ihtiyaç duyulan gelir kaynaklarının oluşturulması amacıyla gerçek ve tüzel kişiler üzerine konulan her çeşit mali yükümlülüğü hukukî cebre dayanarak belirleme yetkilerini de kapsayabilir. Devlet, bu yetkisini uygun göreceği sinırlar ölçüsünde, yerel yönetimlere devredebilir (Yüce, 2004: 929; Zengin, 2014). Bu yetkiyi devletten devralmış yerel yönetimlerin mali özerkliği, devlet tarafından kendilerine devredilen vergilendirme yetkisinin genişliği ile ölçülebilir (Çımat, 1996:62). Yerel yönetimlerin vergilendirme yetkisi, kendi sınırları içinde vergi türlerini, vergi matrahını, oranlarını, vergi indirim ve istisnaların yasal olarak merkezi yönetimden bağımsız şekilde belirleyebilmede yerel yönetimlere tanınan serbestlik derecesi olarak tanımlanabilir.

İlke olarak, "tam" yerel vergiler, aşağıdaki beş farklı şartı yerine getiren vergi olarak tanımlanabilir: (i) yerel yönetimler vergi koyma ya da koymamaya karar verebilir; (ii) Ayrıca, vergi tabanını hassas şekilde belirleyebilir; (iii) Vergi oranını belirleyebilir; (iv) Vergi yönetimini yapar (vergi tarhiyatı, vergi tahsilatı, denetimi); (v) Topladıkları tüm gelire sahip çıkarlar (Bird, 2010:6). Ancak, yerel vergilerin uygulamasında bu özelliklerin tam olarak sağlanmadığı, ve sadece bir ya da ikisine sahip olduğu görülebilir. Ayrıca, vergilerin bu özelliklere tam sahip olup olmadığını belirlemek zordur.

Yerel yönetimlere devredilen görevlerin yerine getirilmesi için merkezden gelir sağlanması, genellikle vergilerden pay verilmesi, merkezi yönetim yardımları ve bağışlar şeklinde olmuştur (Tavşancı, 2004:2). Birçok ülke uygulamasında, toplanan bazı vergi gelirlerin bir bölümü yerel yönetimlerin bütçelerine tahsil edilmektedir. Yerel idarelere ayrılacak pay oranları merkezi yönetimin takdiri ile belirlenmesi durumu yerel yönetimlerin mali özerkliğinin dar olduğunun bir göstergesidir.

\section{Literatür}

Literatür incelemesinde daha çok yerel yönetimlerin vergilendirme yetkilerini, vergilendirmedeki özerkliklerini ele alan çalışmalar üzerinde durulmuştur. Yerel yönetimlerin vergilendirme yetkileri yazında daha çok mali yerelleşme, mali özerklik ve yerel vergiler konuları çerçevesinde incelenmiştir. Bazı çalışmalarda yerel yönetimlerin vergilendirme yetkilerinin yasal düzenlemelerine kısaca değinilmiş̧ir.

İsviçre'de kantonların vergilendirmede önemli özerkliğe sahip olduğu bilinmektedir. Feld vd. (2010) tarafindan elde edilen bulgulara göre, vergilendirme yetkisinin kantonlara devredilmesi ile bütçe gelirlerinin artmıştır. Fakat, kantonlar arasında vergi rekabetinin artmasıyla bütçelerinin azaldığı görülmüştür.

Groenendijk (2011)'in çalışmasında Avrupa Birliği ülkelerinde vergilendirme ve harcama açısından yerel yönetimlerin az ölçüdeki mali özerkliğe sahip oldukları belirtilmektedir. Çalışmada dikey mali eşitsizliğe yol açan bu durumun çözümü olarak aynı tabana sahip vergilerin yönetimler arasında paylaşımı önerilmektedir.

Ulusoy ve Akdemir (2009)'in çalışmasında yerel yönetimlerin mali özerkliğinin değerlendirilmesinde yerel yönetimlerin gelir açısından özerkliği OECD ülkelerinde Türkiye ile kıyaslamalı analiz kapsamında yerel yönetimlerin vergilendirmedeki özerkliği değerlendirilmiştir. Türkiye'de yerel yönetimlerin mali özerkliği vergi gelirleri yönünden bu göstergeler kullanılarak diğer ülkelerle karşılaş̧tırmalı olarak değerlendirilmiştir (Çetinkaya ve Demirbaş, 2010).

Liberati \& Sacchi (2013) daha çok merkezi yönetimden yerel yönetimlere verilen (hibeler, yardımlar, bă̆ışlar şeklindeki mali transferlerin kamu harcamaları üzerinde pozitif bir etkiye sahip olduğunu, ve vergi özerkliğindeki arışların kamu harcamalarını azalttığını destekleyen bulgular elde etmişlerdir.

Bartolini vd. (2016) 1995-2011 dönemi 30 OECD ülkesinde mali yerelleşme ve bölgesel farklılıkları araştırmışlardır. Çalışmadaki ampirik sonuçlar yerel yönetimlerin harcamaları esas olarak yerel vergiler ile karşılandığı mali yapılarda bölgesel farklılıkların daha az olduğunu ortaya koymuştur.

Blöchliger ve Akgun (2018)'ün çalışmasında küçük OECD ülkelerinde vergilerin yerelleştirilmesi iktisadi büyüme üzerinde harcamaların yerelleştirilmesine göre daha güçlü bir etkiye sahip olduğu raporlanmıştır.

Alibegović vd. (2018)'in çalışmasında Hırvatistan'daki büyük şehirlerin mali özerkliği incelenmiştir. Elde edilen sonuçlara göre, Hırvatistan'daki büyük şehir yönetimlerinin diğer yerel yönetim birimlerine kıyasla biraz daha yüksek bir mali özerkliğe sahiptir.

Bazı durumlarda hem merkezi hem de yerel yönetimler vergilerin yerelleştirilmesinden kaçınmaktadırlar. Longobardi (2013) İtalya'daki yönetimlerarası mali ilişkilerin reformlarını araştırdığı çalışmasında merkezi yönetimimin seçmenlerin farklı mali sorumlulukları tam olarak ayırt edemeyebileceğinden; yerel yönetimler ise seçmenlere vergi ödetmemeyi tercih ettiklerinden vergilendirme yetkisinin yerelleştirilmesine karşı olduklarını öne sürmektedir.

Kırgızistan'da yerel yönetimlerin potansiyellerinin geliştirilmesi ve güçlendirilmesi alanında aktif araştırma merkezlerinin biri olan Kalkınma Politikası Enstitüsü tarafindan yapılan araştırmaların (Narusbayeva vd., 2011) önemli kısmını hukuki çerçevenin analizi oluşturmaktadır. Bu çalışmada da Kırgızistan'daki yerel yönetimlerin vergilendirme yetkilerinin sınırlarını belirleyen hukuki çerçeve incelenmiş̧ir. 


\section{Hukuki Çerçevenin Analizi}

Kırgızistan'da yerel yönetimlerin vergilendirme yetkilerini belirleyen yasal düzenlemeler: KC Anayasası (27.06.2010); Bütçe İlkelerinin Temel İlkeleri Hakkında Kanun (11.06.1998,№78), Yerel Yönetimler Hakkında Kanun (15.07.2011, №101), Yerel Eyalet İdareleri Hakkında Kanun (14.07.2011, №96), yerel yönetimlerin mali ve ekonomik temelleri Hakkında Kanun (25.09.2003, №215), Cumhurbaşkanı Kararları, Başbakanlık Kararları, Bakanlık ve diğer kamu kuruluşlarının kararları ve yönetmeliklerden oluşturmaktadır.

Yerel yönetimlerle ilgili anayasal düzenlemeler 27 Haziran 2010 tarihli KC Anayasasının sekizinci bölümünde belirlenmiştir. 111.maddesine göre, yerel yönetimler sistemini: yerel meclisler - yerel yönetim temsilci organlarını (köy meclisi, şehir meclisi, rayon meclisi), ayıl ökmötü (köy hükümeti) ve şehir belediye başkanlıkları, ve Yerel Eyalet İdareleri Hakkında Kanunun 2.maddesine göre rayonlarda yerel eyalet idareleri - yerel yürütme organlarını oluşturur. Rayonların yerel eyalet idareleri yanında oblastlar eyalet idareleri vardır. Yerel eyalet idareleri ilgili sınırlarında yürütme organının taşra birimlerinin faaliyetlerinin koordinasyonu ve bölgenin sosyo-ekonomik geliştirilmesinde yükümlüdür. Kırgızistan'da bu birimlere ait yerel bütçelerin toplam sayısı 524 olup 5 gruba ayrılmaktadır ve sayıları Tablo 1.'de sunulmuştur.

Yerel yürütme organları kendi faaliyetlerinde yerel meclislere karşı sorumludur. Merkezi yönetimden yerel yönetimlere yetkiler, onların yerine getirilmesi için gerekli maddi, mali ve diğer kaynaklarla birlikte yasal çerçeveye göre veya anlaşma ile devredilebilir. Devredilmiş görevlerin yerine getirilmesinde yerel yönetimler merkezi yönetime karşı sorumludur.

Vergilendirme yetkilerinin ölçümünde yazındaki çalışmalarda (Blöchliger ve Kim, 2016; Akai, 2013; Alibegović vd., 2018) kullanılan sinıflandırmalar mevcuttur. OECD tarafindan 1995 ve 2002 yıllarında vergi politikaları çalışmaları çerçevesinde yapılan "Eyalet ve Yerel Yönetimlerin Vergilendirme Yetkisi”" adlı çalışma kapsamında yerel yönetimlerin vergilendirme yetkilerinin kategorileri belirlenmiştir (OECD, 1999:11; Blöchliger ve Nettley 2015:4). Bu kategorilerin 2006'da yenilenmiş hali de mevcuttur. Bu kategorilerden (a) kategorisinden (e) kategorisine doğru yerel yönetimlerin vergilendirmedeki özerkliği azalmaktadır. Kırgızistan'da da yerel yönetimlerin bütçe gelirleri yerel vergiler, genel devlet vergilerinden pay şeklindeki gelirler ve merkezi yönetimin mali transferlerinden oluşmaktadır. Söz konusu sınıflandırmaya göre Kırgızistan'da yerel yönetimlerin vergilendirmedeki uygulaması ele alınırsa, "b" şıkkına dolaylı olarak toprak vergisi; "d.4" şıkkına genel devlet vergileri; toprak vergisi dışında yerel vergi olarak adlandırılan vergiler ise "e" şıkkına uygunluk sağlamaktadır.

Vergileme yetkisinin merkezi devletle yerel idareler arasındaki bölüşümüne ilişkin kurallar genellikle anayasada belirlenir. Anayasanın 13.maddesine göre, devlet bütçesi, cumhuriyet bütçesi ve yerel bütçelerden oluşur, yerel bütçeler ilgili temsilci organlar (yerel meclisler) tarafından onaylanır, KC'nde tek vergi sistemi var ve vergi koyma yetkisi KC Parlamentosuna aittir.

VK'nun 5.maddesinin, 5.bendine göre, VK'nda belirlenmiş yetkiler sınırında yerel meclisler tarafından onaylanmış yasal düzenlemelerle yerel vergiler yürürlüğe girer. Dolayısıyla yerel yönetimlerin vergi koyma yetkisi VK'da belirlenmiştir. VK'nun 31.maddesinde yerel vergiler, VK'da belirlenmiş ve yerel meclislerin yasaları ile yerel yönetimlerin sınırlarında toplanan vergi türleridir olarak tanımlanmıştır. Aynı maddenin 5.bendine göre yerel vergiler: toprak vergisi (arazi ve arsalardan alınan) ve mülkiyet vergisidir (taşınır ve taşınmaz mülkten alınan). Demek ki, VK'a göre yerel yönetimlerin söz konusu vergiler dışında yeni vergi türlerini koyma yetkisi yoktur. Yerel yönetimlerin vergilendirme yetkisi sadece KC Parlamentosu tarafından onaylanarak VK'nda belirlenmiş vergi türleri ile yetkileri sınırlandırılmıştır. Dolayısıyla, yerel yönetimi, bağımsız olarak kendi çıkarları ve sorumlulukları altında yerel sorunları çözebilmesi için yerel toplulukların Anayasa ile garanti altına alınmış hakkı ve reel imkanıdır olarak tanımlayan Anayasanın 110.maddesine alt düzeydeki kanunların aykırı geldiği ifade edilebilir.

VK'nun 47.maddesine göre, vergi daireleri yerel yönetimlere karşı tabi değildir. Vergi İdaresinde Denetleme Kurulu Üyesi Rita Karasartova'ya göre yerel yönetimler ne kadar toprak vergisi tahsil edildiğine dair bilgiyi yasal olarak Vergi Dairesinin ilgili taşra birimlerinden talep etme, alabilme hakkı yoktur (Karasartova, 2011). VK'nun 50.maddesine göre, Vergi Dairesinin ilgili taşra birimlerine yerel yönetimlerden vergilendirme ile ilgili kararları, her türlü bilgileri talep etme hakkı tanınmıştır ve birlikte 131.maddesine göre, yerel yönetimlerin komisyonlarda üyelik yapma ve vergi taşra teşkilatlarına destek göstermede görevlendirilmiştir. Sonuçta yerel yönetimlerin vergi idaresine tek taraflı bağımlılı̆̆ söz konusudur. K.C. Vergi Dairesinin Başkanı, bunun nedeni olarak yerel düzeyde vergi yönetimini yapabilecek uzmanların yetersiz olmasını bildirmiştir (Aşırov, 2011).

Vergilerin toplanmasında köy ve şehir yönetimleri, rayon yönetimlerine göre vergi idaresinin karşısında daha zayıf kalmaktadır. Çünkü, rayon idaresi bu süreci etkilemek için yeterli idari yetkiye sahiptir. Vergi idaresinin taşra birimlerinin yöneticilerinin işten alınması ve atanmasında rayon yöneticilerinin (akimlerin) onayı gerekmektedir, aynı zamanda görevden uzaklaştırılmasını gündeme çıkarabilir (Ismailov vd., 2011:8).

Yerel yönetimlerle ilgili sorunların ele alınmasında Kırgızistan 15 Ekim 1985 tarihli Avrupa Yerel Yönetimler Özerklik Şartlarına odaklanmaktadır. Avrupa'da mali özerkliğin önemi açıkça 1985 Avrupa Yerel Yönetimler Özerklik Şartında ifade edilmiştir. Şartın 9.maddesinin 3. paragrafına göre en azından yerel yönetimlerin mali 
kaynaklarının bir bölümü, tüzük sınırları içinde, oran belirleme yetkisine sahip olan yerel vergi ve harçlardan elde eder. Fakat, bu şartın Kırgızistan'da daha sağlanmadığını yasal düzenlemeler göstermektedir.

Yerel yönetimlerin temsilerine ve bütçe uzmanlarına yapılan anket ve görüşmelere katılanların \% 61,2'si vergi yönetiminin yerel yönetimlere devredilmesi ile yerel bütçe gelirlerin artacağı, $\% 15,5$ yerel düzeydeki uzmanların hazır olmadığından dolayı gelirlerin azalacağı, \%15,5 vergi yönetimine harcamaların artacağı görüşüne sahiptir (UNDP, 2013).

\section{Sayisal Analiz}

Yerel yönetimlerin gelirlerinin bileşimi, özgelirlerini oluşturmada vergi gelirleri, yerel vergi gelirleri ve genel bütçe vergilerinden yerel yönetimlere ayrılan paylar, ve onların yerel yönetimlerin gelirleri, konsolide bütçe gelirleri, GSYİH'ya oranları yerel yönetimlerin mali özerkliğinin değerlendirilmesinde kullanılan göstergelerdir.

Yasaların uygulanması sonucunda vergilendirme yetkisinin gerçekleştirilmesini yansıtan gösterge olarak yerel yönetimlerin vergi gelirlerinin ülke sınırlarında tahsil edilen toplam vergi gelirleri içindeki payı ele alınmıştır. Bununla merkezi yönetim ve yerel yönetimler arasında vergilendirme yetkisinin dağılımını değerlendirme mümkün olacaktır.

\subsection{Genel Vergilerin Paylaşım Oranları}

Yerel vergi gelirleri ve genel devlet vergilerinden paylar şeklindeki gelirler yerel yönetimlerin vergi gelirleri kapsamına alınmaktadır. Ayrılan pay oranı her sene Cumhuriyet Bütçesi Hakkındaki Kanunda KC Parlamentosu tarafından belirlenmektedir. Genel devlet vergileri, hem merkezi bütçede, hem de yerel bütçede toplanan vergi türleri, yani farklı düzeydeki yönetimler arasında paylaşılan vergilerdir. Bazı vergilerin yönetimler arasında paylaştırılması gelişmiş ve gelişmekte olan ülkelerde geniş bir uygulama türüdür (Borge, 2013; Alibegović vd., 2018).

Kırgızistan sınırlarında toplanan bu vergilerden yerel yönetimlere bırakılan pay oranları verilmiştir. Kurumların ödeyeceği gelir vergisi (stopaj), zorunlu patent esasında vergi ve satış vergilerinin Bişkek, Oş şehirlerine, il ve rayon düzeyindeki şehirlere, rayon ve köy yönetimlerine bırakılan vergi gelirinin payı gösterilmiştir. Köy bütçelerinde stopaj vergisi toplanmaz, çünkü köy sınırlarındaki mükellefler vergilerini rayon bütçelerine yatırır. Kırgızistan'da yerel bütçelerin toplam sayısı 524 olup 5 gruba ayrılmaktadır. Toprak vergisi, mülkiyet vergisi, gönüllü patent esasında vergi ve tek vergiler \%100 yerel yönetimlerin bütçesine tahsil edilir.

\subsection{Vergi Gelirleri}

Geçmiş yıllardaki yerel yönetimlerin reformları sonucunda mali özerliği sağlayacak yasal mekanizmalar daha oluşturulmadı, ve yerel yönetimlerin vergi gelirlerinin önemli kısmı yerel vergilerden değil, genel devlet vergilerinden ayrılan paylardan oluşmaktadır. 2009 yılında yeni Vergi Kanunun yürürlüğe girmesi ile yerel vergilerin sayısının azalması özgelirleri yetersiz olan yerel yönetimlerin sayısının artmasına sebep olmuştur (Ismailov vd., 2011:9). Bütçeleri daha önemli ölçüde açık veren Batken, Oş ve Calalabad illerindeki 149 köy ve şehir yöneticilerine, yani toplamın \% 75 'ine yapılan araştırma sonucunda köylerin özgelirleri toplam bütçe gelirlerinin sadece $\% 0,02-6^{\prime}$ 'lk payı oluşturduğu tespit edilmiştir. Yerel bütçelerin bu durumu yerel yönetimlerin bağımlılığını göstermekte ve gelecekte yerel yönetimlerin bağımsız olarak yerel sorunları çözebilmeleri, ilke olarak önemli ve çözümü zor olan sorunlardandır (Narusbayeva vd., 2011:57). Bunun ülke çapındaki durumu Tablo 1'de yansitılmıştır.

\begin{tabular}{|c|c|c|c|c|c|c|c|c|c|c|c|}
\hline Yıl & $\mathbf{2 0 0 7}$ & $\mathbf{2 0 0 8}$ & $\mathbf{2 0 0 9}$ & $\mathbf{2 0 1 0}$ & $\mathbf{2 0 1 1}$ & $\mathbf{2 0 1 2}$ & $\mathbf{2 0 1 3}$ & $\mathbf{2 0 1 4}$ & $\mathbf{2 0 1 5}$ & $\mathbf{2 0 1 6}$ & $\mathbf{2 0 1 7}$ \\
\hline Vergi gelirleri & 37.1 & 38.7 & 41.8 & 40.9 & 31.9 & 32.3 & 49.1 & 72.6 & 69.9 & 69.8 & 58.7 \\
\hline Vergi dıșı gelirler & 11.9 & 10.9 & 10.8 & 8.7 & 7 & 6.8 & 9.9 & 15.1 & 15 & 14 & 14.3 \\
\hline Sermaye gelirleri & 2.7 & 3.4 & 1.7 & 0.9 & 1.1 & 0.6 & 0.6 & 0.3 & 0.7 & 0.5 & 0.2 \\
\hline Merkezi yönetimden bağıșlar & 48.4 & 47 & 45.7 & 49.6 & 60 & 60.3 & 40.4 & 12.1 & 14.5 & 15.7 & 26.9 \\
\hline
\end{tabular}

Tablo 1: Kırgızistan'da Yerel Yönetimlerin Bütçe Gelirlerinin Yapısı (bileşimi), \% Kaynak: Kırgız Cumhuriyeti Milli İstatistik Komitesi web-sitesi, (erişim tarihi: 12.02.2019, http://www.stat.kg/ru/statistics/finansy/)

2007-2012 döneminde merkezi yönetimden hibeler ş̧eklindeki transferler, yerel yönetimlerin gelirlerinin en büyük kısmını oluşturmaktadır. Yazındaki çalışmalardan da görüldüğü gibi diğer ülkelerde de benzer bir durum söz konusudur (Blöchliger ve Kim, 2016). 2013'ten itibaren mali transferlerin payının azalması gelir vergisi, patent vergisi ve tek vergisinin yerel yönetimlere ayrılan payların yükseltilmesi, ve bazı vergi dışı gelirlerin yerel yönetimlere devredilmesinin sonucudur. Yerel yönetimlerin sadece 13 rayondan 54 köy yeterli özgelirlere sahiptir, dolayısıyla bütün gelirleri yerel bütçelere bırakılması durumunda da yerel yönetimlerin çoğunun bütçesi açı̆̆ının finansmanı sorunu çıkacaktır (Kurmanbekova, 2010:80). Transferlerden sonraki önemli gelir kalemi vergi gelirleridir.

Seçilmiş yıllarda yerel yönetimlerin gelirlerinin ortalama olarak \%37,9'u toplam vergi gelirlerinden oluşmuştur. Vergi gelirlerinin payının 2007-2010 yıllarda artış eğilimi gözlemlenmektedir. İzleyen iki yılda keskin bir azalmanın ardından keskin bir şekilde artış gözlemlenmiş̧ir. Bu değişimler kapsamında yerel yönetimlerin 
özgelirleri açısından mali özerkliğinin genişlediği söylenebilir. Vergi gelirlerinin payının artışının başlıca nedenleri olarak 2007 ve 2012'deki yerel yönetimlerin reformları, 2010'daki siyasi kriz etkisinden sonra istikrarın sağlanması ve vergi paylaşım oranlarındaki değişimler belirtilebilir. 2017'de de merkezi yönetimden mali transferlerin payının artması mali özerkliklerinin azalma eğiliminin başlangıç göstergesi olabilir. Bununla birlikte belirtilmesi gereken diğer bir husus, vergilendirme yetkisinin yerel yönetimlere devri gerçekleştirilmedi. Son yıllarda yerel yönetimlerin bütçe gelirlerinin önemli kısmını oluşturan vergi gelirlerinin hacimleri Tablo 2.'de sunulmuştur.

\begin{tabular}{|c|c|c|c|c|c|c|c|c|c|c|c|}
\hline YIl & $\mathbf{2 0 0 7}$ & $\mathbf{2 0 0 8}$ & $\mathbf{2 0 0 9}$ & $\mathbf{2 0 1 0}$ & $\mathbf{2 0 1 1}$ & $\mathbf{2 0 1 2}$ & $\mathbf{2 0 1 3}$ & $\mathbf{2 0 1 4}$ & $\mathbf{2 0 1 5}$ & $\mathbf{2 0 1 6}$ & $\mathbf{2 0 1 7}$ \\
\hline Toplam vergi gelirleri & 3279 & 4867 & 5842 & 6241 & 6892 & 7664 & 10428 & 11694 & 12326 & 12324 & 11905 \\
\hline Gelir ve karlara vergiler & 1298 & 2294 & 2567 & 2725 & 3143 & 3730 & 5008 & 5734 & 6175 & 6695 & 7116 \\
\hline Mülkiyet vergileri & 713 & 894 & 1386 & 1664 & 1682 & 1724 & 2065 & 2210 & 2286 & 2495 & 2625 \\
\hline Mal ve hizmetlere vergiler & 1268 & 1678 & 1889 & 1851 & 2067 & 2210 & 3355 & 3750 & 3864 & 3135 & 2164 \\
\hline
\end{tabular}

Tablo 2: Kırgızistan'da Yerel Yönetimlerin Vergi Gelirleri, (mln. som) Kaynak: Kırgız Cumhuriyeti Milli Istatistik Komitesi web-sitesi, (erişim tarihi: 12.02.2019, http://www.stat.kg/ru/statistics/finansy/)

2007 öncesi dönemde yerel yönetimlerin mali imkanları üst düzey yönetimlerin (rayon ve oblast) ve Maliye Bakanlığının taşra birimlerinin mali kontrolü altındaydı. Yerel yönetimler bütçe planlama aşamasında Maliye Bakanlığından daha çok transfer ve vergileri alma gayretindeydi. gelirleri rayon ve oblast bütçelerine aktarmada Maliye Bakanlığının taşra birimleri yetkili olan bu sistemde, yerel yönetimlerin vergi dairelerine destek göstererek gelirlerini arttırmalarına teşviki öngörülmemiştir.

Tablo 2'deki verilerden yararlanılarak yerel yönetimlerin vergi gelirlerinin vergi konusuna göre bileşimi yansıtılan Şekil 1.'deki grafik oluşturulmuştur. 2007-2017 döneminde vergi gelirlerinin ortalama olarak $\% 48,2$ 'sini kişisel gelir ve kar üzerinden alınan vergiler; \%21.5'ini motorlu taşıtlar ve gayrimenkul kıymetlerden alınan vergiler; \%30,3’ünü mal ve hizmet üzerinden alınan dolaylı vergiler oluşturmuştur.

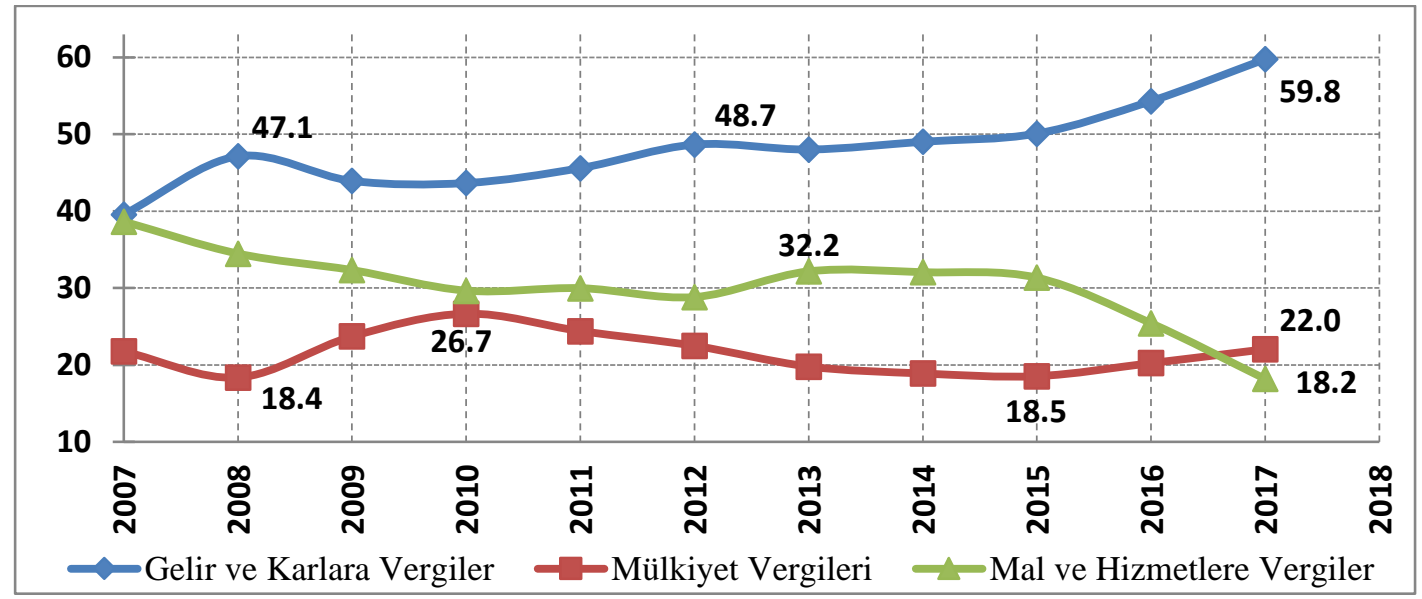

Şekil 1. Kırgızistan'da Yerel Yönetimlerin Vergi Gelirlerinin Vergi Türlerine Göre Yapısının Değişimi: 20002017 Dönemi, \% Kaynak: Kırgız Cumhuriyeti Milli Istatistik Komitesi web-sitesi, (erişim tarihi: 12.02.2019, http://www.stat.kg/ru/statistics/finansy/)

Ancak, çok ülkelerde daha istikrarlı kaynak oluşturan, ama arttırılması daha zor ve mobil olmayan matrahlı vergilerin, yani mülkiyet vergilerinin farklı kısımları yerel yönetimlere bırakılmıştır. Bu eğilimin Kırgızistan'da da geçerli olduğunu Tablo 3'ten görebiliriz. Bu durumda vergi oranlarını artırma imkanı olmayan Kırgızistan'daki yerel yönetimlerin mali kaynakları sınırlı kalmaktadır.

Tablo 3.'ün üçüncü satırındaki rakamlar ile gelir türleri itibariyle ülke çapında tahsil edilen gelirlerin hangi payı yerel yönetimlerin bütçesine tahsil edildiğini ifade etmektedir. Örneğin, 2016 yılında ülke çapında toplam kamu gelirlerin \%13,5'i; toplam vergi gelirlerin \%13,1'i; vergi dış1 gelirlerin \%9,2'si ve sermaye ile ilgili işlemlerden gelirlerin \%8,3'ü yerel yönetimlerin bütçe gelirleri olarak tahsil edilmiştir. Tablodan da tespit edilebildiği gibi bazı vergilerin \%15, \%35, \%50 ve \%100'lük kısmı yerel yönetimlere verilmiştir. Kendilerine kanuni olarak belirlenmiş olan yetkiler çerçevesinde topladıkları gelir türleridir.

Bazı vergi türlerinden yerel yönetimlere verilmiştir payların ne olduğu da bu verilerden görülmektedir. Örneğin, 2017 yılında yerel vergiler olan mülkiyet vergilerinin, bunun dışında paylaşılan vergiler olan tek vergi ve patent vergisinin \%100'ü; gelir vergisi ve satış vergisinden gelirlerin \%50'si yerel bütçelere tahsil edilmiştir. Tablodaki veriler esas alınarak 2008-2009 yıllarından sonraki dönemde bazı vergi gelirlerinin merkezi bütçeye devredildiği öne sürülebilir. Bu değişimler yeni Vergi Kanunu'nda bazı vergilerin kaldırılması, bazı genel devlet vergilerinden yerel yönetimlere ayrılan pay oranlarının azalması ile ilgilidir. 


\begin{tabular}{|c|c|c|c|c|c|c|c|c|c|c|c|c|c|c|}
\hline Yll & 2004 & 2005 & 2006 & 2007 & 2008 & 2009 & 2010 & 2011 & 2012 & 2013 & 2014 & 2015 & 2016 & 2017 \\
\hline Gelirler & 32.2 & 32.3 & 27.6 & 24.6 & 27 & 25.1 & 26.3 & 27.7 & 27.2 & 20.8 & 13.5 & 13.7 & 13.5 & 13.6 \\
\hline $\begin{array}{c}\text { Vergi } \\
\text { gelirleri }\end{array}$ & 14.9 & 14.7 & 13.8 & 12.4 & 13.6 & 16.2 & 15.9 & 13 & 12 & 14.3 & 14.2 & 14.6 & 13.1 & 11.5 \\
\hline Gelir vergisi & 35 & 35 & 35 & 29.1 & 30.8 & 34.7 & 34.7 & 34.6 & 36.3 & 50 & 50 & 50 & 50 & 50 \\
\hline $\begin{array}{c}\text { Kurumlar } \\
\text { (kar) vergisi }\end{array}$ & 35 & 35 & 35 & 29.2 & 29.6 & - & - & - & - & - & - & - & - & - \\
\hline Tek vergi & - & - & - & - & 43 & 100 & 100 & 100 & 100 & 100 & 100 & 100 & 100 & 100 \\
\hline Patent vergisi & - & - & - & - & 50.5 & 70.7 & 82.6 & 83.7 & 100 & 100 & 100 & 100 & 100 & 100 \\
\hline $\begin{array}{c}\text { Diğer gelir } \\
\text { vergileri }\end{array}$ & 34.3 & 35 & 35 & 40.7 & - & - & - & - & - & - & - & - & - & - \\
\hline $\begin{array}{l}\text { Gayrimenkul } \\
\text { vergisi }\end{array}$ & 100 & 100 & - & 100 & 100 & 100 & 100 & 100 & 100 & 100 & 100 & 100 & 100 & 100 \\
\hline $\begin{array}{l}\text { Toprak } \\
\text { vergisi } \\
\end{array}$ & 100 & 100 & 100 & 100 & 100 & 100 & 100 & 100 & 100 & 100 & 100 & 100 & 100 & 100 \\
\hline $\begin{array}{c}\text { Motorlu } \\
\text { taşitlar vergisi }\end{array}$ & 100 & 100 & 100 & 100 & 100 & 100 & 100 & 100 & 100 & 100 & 100 & 100 & 100 & 100 \\
\hline Satış vergisi & 100 & 100 & 100 & 100 & - & 44 & 50 & 50 & 42.9 & 50 & 50 & 50 & 50 & 50 \\
\hline ÖTV & 15.6 & 14.9 & 13.7 & 5.8 & 5.7 & - & - & - & - & - & - & - & - & - \\
\hline $\begin{array}{l}\text { Ülke içindeki } \\
\text { mallara ÖTV }\end{array}$ & 35 & 35 & 35 & 17.6 & 18.6 & - & - & - & - & - & - & - & - & - \\
\hline $\begin{array}{c}\begin{array}{c}\text { Vergi dıșı } \\
\text { gelirler }\end{array} \\
\end{array}$ & 22.4 & 23.3 & 21.3 & 14.6 & 16.8 & 16.7 & 12 & 9.6 & 9.3 & 10.7 & 9.1 & 7.7 & 9.2 & 9.6 \\
\hline $\begin{array}{c}\text { Sermaye } \\
\text { gelirleri }\end{array}$ & 21.3 & 99.8 & 27.6 & 80.8 & 37.2 & 92.1 & 48.8 & 60.7 & 3.6 & 7.5 & 2.2 & 5.9 & 8.3 & 15.9 \\
\hline
\end{tabular}

Tablo 3: Kırgızistan'da Yerel Yönetimlerin Gelirlerinin ve Vergi Gelirlerinin Konsolide Bütçenin Gelirleri ve Vergi Gelirleri İçindeki Payl, \% (toplam ve vergi türlerine göre) Kaynak: K.C. Milli İstatistik Komitesi, (erişim tarihi: 12.02.2019, http://www.stat.kg/ru/statistics/finansy/)

2007-2008 yıllarından önceki dönemde bazı vergi türlerinden yerel yönetimlerin bütçesine pay ayrılmıştır. İthal edilen mallardan Özel Tüketim Vergisinin \%15'inin; ülke içindeki mallara uygulanan Özel Tüketim Vergisinin \%35'inin; kurumlar vergisinin ve gelir üzerinden alınan diğer vergilerinin de \%35'inin yerel yönetimlerin bütçelerine tahsil edildiği görülebilir. 2007-2008 yıllarındaki göstergelerdeki farklılıklar geçiş süreci ve vergilendirme sürecindeki gecikmelerden kaynaklanmaktadır.

OECD ülkelerde 2009 yılındaki duruma göre vergi matrahına göre toplam vergi gelirlerinden, tüketim vergi gelirlerinin Japonya'da \%26,6 payı; mülkiyet vergi gelirlerinin \%98-100 payı artış sırasıyla Yeni Zelanda, Slovak Cumhuriyeti, Estonya, Polonya, Slovenya'da; gelir ve kardan alınan vergilerin Estonya, Finlandiya ve İsveç'te sırasıla \%60,7; \%62,6 ve 100\% payı yerel yönetimlere bırakılmıştır.

\section{Sonuç}

Kırgızistan'da yerel yönetimlerin vergilendirme yetkileri Anayasada öngörülmüşse de alt düzeydeki hukuk kaynaklarında merkezi yönetimin kararlarına bağlı kalmaktadır. Ülke çapında alındığında yerel yönetimlerin vergilendirme yetkileri açısından mali özerkliğinin düzeyi yetersizdir, ve merkezi bütçeden transferlerden büyük ölçüde bağımlı kalmaktadır. Yerel düzeyde vergilerin yönetiminde köy ve rayon düzeyindeki şehirlerin yetkileri rayon(ilçe) ve oblast(il) düzeyindeki şehirlerin yönetimine göre daha sınırlıdır. Çünkü rayon ve şehirlerin idareleri yerel düzeydeki bakanlık ve vergi dairelerinin yöneticilerinin atanması ve işten alınması konusunda yetkilere sahiptir. Kırgızistan'da yerel vergilerin sayısı ve oranlarının sınırları düzenli olarak kabul edilebilir, fakat etkinliği minimum düzeydedir. Yerel vergi sistemi etkinsizdir, çünkü daha istikrarlı ve daha kolay elde edilebilir gelir kaynağını oluşturan merkezi bütçeden transferlerin hacmi azalacağından dolayı, yerel yönetimlerin potansiyellerini kullanarak vergi gelirlerini önemli ölçüde arttırmalarına teşvik edilmemiştir.

Vergi matrahı tüm vergilerde merkezi yönetim tarafından belirlenmektedir. Sadece yerel meclislerin kararı ile bölgesel katsayı değiştirilerek toprak vergisinin matrahı dolaylı şekilde değiştirilebilir. VK'da toprak vergisinin oranının toprağın kalitesine göre en fazla 3 katına arttırma yetkisi yerel meclislere tanınmıştır. Ancak azaltma yetkisine sahip değildir. Yerel yönetimler mücbir durumlarda mükelleflere vergi nusfiyeti sağlamaya yetkilidir. Ancak iktisadi düzenleme amacıyla vergi indirimleri ve muafiyeti sağlama yetkisine sahip değildir.

Yerel yönetimlerin vergilendirme konusundaki diğer bir önemli sorun vergi yönetimiyle ilgilidir. Yerel yönetimlerin kendi sınırlarında toplanmış olan vergi gelirleri ile ilgili ayrıntılı bilgiye ulaşma ve vergi yönetiminin etkinleştirilmesinde katılma hakkı tanınmamıştır. 2007-2008 yıllarında uygulanan pilot projede yerel ve paylaşılan vergilerin yönetiminde tüm yetkilerin yerel yönetimlere devredilmesi gerçekleştirilmiştir. Bu proje sonucunda yerel yönetimlerin özgelirlerinin arttığı, ancak tüm harcamalarını finanse etmeye yetmeyeceği belirlenmiştir. Dolayısıyla gelecek reformlarda bu yetkilerin yerel yönetimlere devri söz konusudur. Hukuki çerçeveye göre yerel yönetimlerin vergilendirme yetkisi yok denilebilecek kadar dar sınırlar içinde yer almıştır. Ancak, bu yetkinin yerel yönetimlere devredilmesi daha erkendir. 
Son yıllarda paylaşılan vergi gelirlerinin payının artma, ve tam yerel vergilerin payının azalma eğilimi gözlemlenmektedir. 2009 yılında yeni Vergi Kanunun yürürlüğe girmesi ile yerel vergilerin sayısının 8'den 2'ye indirilmesi bunun nedeni olarak nitelendirilebilir. Paylaşılan vergilerden yerel yönetimlere bırakılan pay oranının son yıllarda şehirler için arttığı, ancak köy bütçeleri için azalmıştır. Sonuçta, bu açıdan köy yönetimlerinin vergi gelirlerini toplama yetkileri son yıllarda daralmıştır.

Vergilendirme yetkisinin yerel yönetimlere devredilmesinin esas amacı, yerel yönetimlerin özgelir kaynağının arttırılması ile yerel yönetimlerin mali özerkliğinin genişletilmesidir. Dolayısıyla, Kırgızistan'da 2000-2010 döneminde vergi gelirlerinin toplam gelirlerinin \% 35,2-41,8 arasında olması merkezi yönetime bağımlılığııı göstermektedir. Bölgeler arası gelişmişlik farklılıklardan dolayı vergilendirmede tam yetkilerin verilmesi yine de çoğu yerel yönetimlerin bütçelerinin açık vereceği söz konusudur. Dolayısıyla, optimum noktaya doğru vergilendirme yetkisinin yerel yönetimlere devredilmesi gerekir. Ancak, bu yolun izlenmesinde yerel düzeyde yolsuzluk, kalifiye uzmanlar ve denetimle ilgili muhtemel sorunların göz önünde tutulması gerekir.

Merkezi ve yerel yönetimlerin vergi gelirleri arasındaki paylaşıma bakıldığında 2007 yılından sonra yerel yönetimlerin vergi gelirlerinin toplam vergi gelirlerindeki payının artış eğilimi gözlemlenmektedir. Dolayısıyla, yerel yönetimlerin merkezi yönetime göre vergilendirme yetkisinin arttığı söylenebilir.

Vergilendirme yetkisinin belirlenmesinde yerel yönetimlerin gelir potansiyelinin ölçülmesinde bölgeler için sosyo-ekonomik göstergelerin geliştirilmemiş olması yerel yönetimlere mali özerkliğin tanınmasında sorunlar yaratmaktadır. Kırgızistan'da yerel yönetimlerin vergilendirme yetkilerinin dar ve sınırlandırılmış olmasının siyasi, idari, sosyal ve iktisadi nedenleri olduğu söz konusudur. Ancak, bu nedenlerin araştırılması başka bir araştırmanın amacı olabilir.

\section{Kaynakça}

- Abazov, R. (1999). Economic migration in post-Soviet Central Asia: the case of Kyrgyzstan. PostCommunist Economies, 11(2), 237-252.

- $\quad$ Akai, N. (2013), "The role of decentralization indicators in empirical research", in Kim, J., J. Lotz and H. Blöchliger (eds.), Measuring Fiscal Decentralization: Concepts and Policies, OECD Publishing, Paris

- Alibegović, D. J., Hodžić, S., \& Bečić, E. (2018). Limited Fiscal Autonomy of Croatian Large Cities. Lex Localis-Journal of Local Self-Government, 16(1).

- Aşırov, B. (2011 Prezhdevremenno peredavat' funktsii po administrirovaniyu mestnykh nalogov mestnym vlastyam, (10.04.2019, http://dpi.kg/ru/press-room/news/full/292.html)

- $\quad$ Bartolini, D., Stossberg, S., \& Blöchliger, H. (2016). Fiscal Decentralisation and Regional Disparities (No. 1330). OECD Publishing

- $\quad$ Bird, R. M. (2010). Subnational Taxation in Developing Countries: a Review of the Literature. The World Bank, Policy Research Working Paper 5450, 41 pp.

- Blöchliger, H. and O. Akgun (2018), "Fiscal decentralization and economic growth", in Kim, J. and S. Dougherty (eds.), Fiscal Decentralisation and Inclusive Growth, OECD Publishing, Paris

- Blöchliger, H., and Nettley, M. (2015). Sub-central Tax Autonomy: 2011 Update, OECD Working Papers on Fiscal Federalism, No. 20, OECD Publishing. http://dx.doi.org/10.1787/5js4t79sbshd-en

- Boetti, L., Piacenza, M., \& Turati, G. (2012). Decentralization and local governments' performance: how does fiscal autonomy affect spending efficiency?. FinanzArchiv: Public Finance Analysis, 68(3), $269-302$.

- Borge, L. (2013), "Taxonomy of grants and local taxes: The Norwegian case", in Kim, J., J. Lotz and H. Blöchliger (eds.), Measuring Fiscal Decentralisation: Concepts and Policies, OECD Publishing, Paris

- Brennan, G., \& Buchanan, J. (1979). The logic of tax limits: alternative constitutional constraints on the power to tax. National Tax Journal, 32(2), 11-22.

- Brunori, D. (2007). Local tax policy: A federalist perspective. 2nd edition, The Urban Institute.

- Çetinkaya, Ö., \& Demirbaş, T. (2010). Belediye Gelirlerinin Analizi ve Mali Özerklik Açısından Değerlendirilmesi. Maliye Araştırma Merkezi Konferansları, (53), 1-18.

- Çımat, A. (1996). Vergilendirme Yetkisi ve Bu Yetkinin Demokrasi ile İlişkisi, Mali Çözüm Dergisi, 35, 5963

- Dabla-Norris, E. (2006). The challenge of fiscal decentralisation in transition countries. Comparative Economic Studies, 48(1), 100-131.

- $\quad$ Ebel, R. D., \& Yilmaz, S. (2002). On the measurement and impact of fiscal decentralization. The World Bank.

- $\quad$ Feld, L. P., Kirchgässner, G., \& Schaltegger, C. A. (2010). Decentralized taxation and the size of government: evidence from Swiss state and local governments. Southern Economic Journal, 77(1), 27-48. 
- $\quad$ Flowers, M. R. (1988). Shared tax sources in a Leviathan model of federalism. Public Finance Quarterly, 16(1), 67-77.

- Gradval, S. Dobresova, N., İsmailova, A., Narusbayeva, U. (2011). Poslaniye praktikov politikam: chto nuzhno menyat' v sisteme MSU, chtoby uluchshit' kachestvo zhizni ?Development Policy Institute, Norwegian Institute of International Affairs, Bişkek, $20 \mathrm{~s}$.

- Groenendijk, N. (2011). Federalism, fiscal autonomy and democratic legitimacy in Europe: Towards tax sharing arrangements. L'Europe en Formation, (1), 3-19.

- İnan, M., \& Ekici, M. S. (2010). Yeni Anayasa Tasarısında Vergilendirme Yetkisi ve Yerel Yönetimler. Elektronik Sosyal Bilimler Dergisi, 9(34), 300-314.

- Karasartova, R. (2011). Nalogi za pol'zovaniye nedrami zemli dolzhny v $100 \%$ vide postupat' v gosbyudzhet, 9 Kasım 2011, (erişim tarihi: 10.12.2011, http://www.singlenews.ru/news/598529/)

- Kasenov, U. (2017). Post-Soviet modernization in Central Asia: realities and prospects. In Central Asia: Challenges of Independence (pp. 28-53). Routledge.

- Kim, J. (2018), "Fiscal decentralisation and inclusive growth: An overview", in Kim, J. and S. Dougherty (eds.), Fiscal Decentralisation and Inclusive Growth, OECD Publishing, Paris,https://doi.org/10.1787/9789264302488-3-en.

- $\quad$ Kurmanbekova, R.(2010). Finansovaya detsentralizatsiya i novyye printsipy mezhbyudzhetnykh otnosheniy v Kyrgyzskoy Respublike, Sosyal Bilimler Dergisi, Özel Sayı: 23, ss.77-82,

- Liberati, P., \& Sacchi, A. (2013). Tax decentralization and local government size. Public Choice, 157(1-2), 183-205.

- Longobardi, E. (2013), "From transfers to tax "co-occupation": The Italian reform of intergovernmental finance", in Kim, J., J. Lotz and H. Blöchliger (eds.), Measuring Fiscal Decentralisation: Concepts and Policies, OECD Publishing, Paris

- Makarenko, L. (2006). Zakonomernosti i Osobennosti Razvitiya Nalogovoy Sistemy v Perekhodnyy Period. Kırgız-Rus Slav Üniversitesi Yayınları, Bişkek, 42 s.

- Musgrave, R. A. (1959). The Theory of Public Finance. New York: McGrawHill.

- Nacar, B. (2005). Yerel Vergi Düzeni: Kuramsal Temelleri ve Türkiye Uygulaması Üzerine Bir Değerlendirme. Maliye Araştırma Merkezi Konferanslarl, (47), 157-178.

- $\quad$ Dobretsova, N., İsmailov, A., ve Narusbayeva, U. (2011). Zemlya, voda, kadry, byudzhet: vozmozhnosti i potrebnosti organov MCY, Development Policy Institute, Organization for Security and Co-operation in Europe, Bishkek, 48 s. (https://www.osce.org/ru/bishkek/75321?download=true)

- $\quad$ Oates, W. E. (1972). Fiscal federalism. NY: Harcourt Brace Jovanovich.

- Oates, W. E. (2008). On the evolution of fiscal federalism: Theory and institutions. National Tax Journal, 61(2), 313-334.

- OECD (1999), Taxing Powers of State and Local Government, OECD Tax Policy Studies, No. 1, OECD Publishing, Paris, https://doi.org/10.1787/9789264174030-en.

- Özdemir, A. R. (2005). Desentralizasyon Kamu Sektöründeki Hantallaşmayı Önler mi? Bir OECD Panel Verileri Regresyon Analizi. Dumlupınar Üniversitesi Sosyal Bilimler Dergisi, (17), 117-138

- $\quad$ Prud'Homme, R. (1995). The dangers of decentralization. The World Bank Research Observer, 10(2), 201220 .

- Scrieciu, S. Ş., \& Stringer, L. C. (2008). The transformation of post-communist societies in Central and Eastern Europe and the Former Soviet Union: an economic and ecological sustainability perspective. European Environment, 18(3), 168-185.

- Sertesen, S. (2011). Yerel Yönetim Reformu Kapsamında Yerel Yönetimlerin İdari Özerkliği Nasıl Tartışılmalı?. Politikanotu, Türkiye Ekonomi Politikaları Araştırma Vakfı

- Shadbegian, R. J. (1999). Fiscal federalism, collusion, and government size: evidence from the states. Public Finance Review, 27(3), 262-281.

- Tanzi, V. (1995). Fiscal federalism and decentralization: A review of some efficiency and macroeconomic aspects (pp. 295-316). Washington^ ${ }^{\wedge}$ D. CDC: World Bank.

- Tavşanc1, A. (2004). Türkiye'de Yerel İdarelerin Vergilendirme Yetkisi ve 1982 Anayasası. Trakya Üniversitesi Sosyal Bilimler Dergisi, 4(1).

- Ter-Minassian, M. T. (1997). Decentralization and macroeconomic management (No. 97-155). International Monetary Fund. 
- Tiebout, C. M. (1961). An economic theory of fiscal decentralization. In Public finances: Needs, sources, and utilization (pp. 79-96). Princeton University Press.

- Tortop, N. (1993). Güçlü mahalli idare anlayışının gelişmesi. Çăgdaş Yerel Yönetimler, 2(2), 3-10.

- Türkoğlu, İ. (2009). Yerel yönetimlerde mali reform arayışları: Türkiye'de belediyelerde mali özerklik ve belediye başkanlarının mali özerklik algılaması. T.C. Maliye Bakanlığı, Strateji Geliştirme Başkanlığı, Ankara, Yayın No:2009/389

- Ulusoy, A., \& Akdemir, T. (2009). Yerel yönetimler ve mali özerklik: Türkiye ve OECD ülkelerinin karşılaştırmalı analizi. Balıkesir Üniversitesi Sosyal Bilimler Enstitüsü Dergisi, 12(21), 259-287.

- UNDP (United Nations Development Programme) (2013). National Human Development Report in Kyrgyzstan 2012. Human Development as the Focus of Local Self-Government: Here and Now!, Bishkek

- Yüce, M. (2004). Kırgız Cumhuriyeti Vergi Sisteminin Genel Yapıs1 ve Değerlendirilmesi. Sosyal Siyaset Konferanslarl Dergisi, (49), 911-940

- Zengin, E., Başkurt, M., \& Es, M. (2014). Yerel yönetimler ve yerel kalkınma. Manas Sosyal Araştırmalar Dergisi, 3(2), 95-124. 


\title{
Türk Hukukunda ve Uluslararası Antlaşmalarda Hasarın İntikali Transfer of Risk of Loss in Turkish Law and International Treaties
}

\author{
Almila Özkan (Bilkent University, Turkey) \\ Ayşe Sena Aksakallı (Bilkent University, Turkey)
}

\begin{abstract}
The risk of loss refers to the value of the goods that were damaged or destroyed without responsibilities of any party. While the matter of risk of loss differs from legal systems to legal systems, it has been subject to international treaties as well. In Turkish legal system, the abrogated Code of Obligation and Turkish Code of Obligations have different features in terms of transfer of risk of loss. According to abrogated Code of Obligation, the buyer is responsible for the value of the damaged goods as soon as the parties sign the contract. In Turkish Code of Obligations, the seller bears the risk of loss until the delivery of goods or registration. Turkish Code of Obligation is compatible with civil law. And abrogated Code of Obligation is compatible with common law system. There are rules regarding transfer of risk of loss in many international treaties. By the way, it must be stated that rules of transfer of risk of loss in Vienna Convention are compatible with Turkish Code of Obligations.
\end{abstract}

\section{Giriş}

Hasar, satılan malın tarafların iradesi dışında uğradığı zarar anlamına gelmektedir. Yani, satılanın taraflardan birinin sorumlu olmadığı sebeplerden dolayı telef olması veya değerinin azalması hasarı ifade etmektedir. Hasarın intikali, hasara kimin katlanacağı konusunun belirlenmesini gerektirmektedir. Hasarın intikali konusu, hukuk sistemleri arasında farklılıklar göstermektedir.

Hasarın intikal etmesi için geçerli bir satış sözleşmesinin mevcut olması ve hasarın taraflara yükletilemeyen beklenmedik bir hal yüzünden meydana gelmesi ve hasar sözleşmenin kurulması ile malın teslimi arasındaki bir zamanda meydana gelmesi gerekmektedir.

$\mathrm{Bu}$ makalede önce Türk hukuk sisteminde hasarın anlamı belirlenecek, Türk Borçlar Kanunu hasar düzenlemelerinden hareketle tespitler yapılacaktır. Sonra Kıta Avrupa's1 ve Anglo - Sakson hukuk sistemi ile uluslar arası hukuktaki düzenlemeler ve hasar anlayışı ortaya konulacaktır.

\section{Hasar}

\subsection{Hasar ve Hasarın İntikal}

Türkçe'de hasar terimi, Almanca'da "gefahr", Fransızca'da "risque”, İngilizce'de "risk" ve Lâtince'de "periculum”a karşılık gelmektedir. Bu terimler, tehlikeyi ifade etmek için kullanılmaktadır. Bu tehlike, sözleşmenin taraflarından hangisinin ne zamandan itibaren hasara katlanmak zorunda kalacağına ilişkin bulunmaktadır. Bu tehlikeye satıcının mı alıcının mı maruz kalacağı doktrinde "hasarın intikali” (gefahrübergang), ya da "hasarın aidiyeti, hasara katlanma" (gefahrtragung) kavramılla ifade edilmektedir (Akıntürk, 1966).

Hasar, satılan malın ilgililerin yani tarafların iradesi dışında uğradığı zarar anlamına gelmektedir. Yani, satılanın taraflardan birinin sorumlu olmadığı sebeplerden dolayı telef olması veya değerinin azalmasıdır. Tarafların sorumlu olmadığı haller ise mücbir sebep ve umulmayan haller olarak belirtilebilir.

Hasarın daha iyi anlaşılabilmesi için malda öncelikle kötüleşme olmalıdır. Kötüleşme, malın telef olması veya değerinin azalmasıdır. Belirtmek gerekir ki kötüleşmeye tarafların neden olmaması gerekmektedir. Yine kötüleşmenin, sözleşmenin kurulması ve ifa arasındaki dönemde (zamanda) gerçekleşmesi önem taşımaktadır. Sözleşme kurulmadan önce bir hasar gerçekleşirse başlangıçtaki imkansızlık söz konusu olacaktır. Eğer, teslimden sonra ortaya çıkar ise bozukluk ayıplı ifa anlamını taşıyacaktır.

Hasar, sözleşmenin kurulması ile taşınırlarda zilyetliğin devri, taşınmazlarda ise tescil anına kadar geçen zamanda sözleşme konusu malın başına satıcıdan kaynaklanmayan ve umulmayan bir hal gelmesi sonucu malın tamamen veya kısmen yok olması (Eren, 2018) olarak açıklanabilir.

Hasar Yargıtay kararlarında da tanımlanmıştır. Yargıtay, hasarı ve yararı tanımlarken, sözleşmenin doğumundan sonra fakat ifasından önceki aşamada (devrede) sözleşme konusu malda meydana gelen doğal ve hukuki semereler ile malda oluşan ve "onun bozulması, kötüleşmesi, telef olması gibi sonuçlar yaratan zararlı hallerin alıcıya hangi andan itibaren geçmiş olacağının belirlenmesi (Yargıtay 13. Hukuk Dairesi, E. 1994/6197, K. 1994/7587, K.T. 15.9.1994)" değerlendirmesini yapmaktadır.

Satım sözleşmesinde hasarın intikali konusunun anlaşılması için öncelikle satış sözleşmesinin bilinmesi gerekmektedir. Satış sözleşmesi, Türk Borçlar Kanunu'nun 207. maddesinde şöyle tarif edilmiştir: "Satış sözleşmesi, satıcının, satılanın zilyetlik ve mülkiyetini alıcıya devretme, alıcının ise buna karşılık bir bedel ödeme 
borcunu üstlendiği sözleşmedir”. Bu tanımdan anlaşılacağı gibi satım sözleşmesi “iki tarafa borç yükleyen bir sözleşme" dir.

Taraflar, hem borçlu hem de alacaklı durumundadır. Gerçekten satıcı, kararlaştırılan bedeli istemek açısından alacaklı durumdadır ancak sözleşme konusu malın zilyetliğinin ve mülkiyetinin devredilmesi konusunda borçludur. Benzer şekilde, alıcı bedeli ödemesi bakımından borçlu, satılan malın zilyetlik ve mülkiyetini kazanması açısından alacaklı durumdadır.

Sözleşmenin yapılması ile satılanın mülkiyeti alıcıya geçmez, sadece tarafların hak ve borçları doğar. Satılanın mülkiyeti ancak, satıcının borcunu ifa etmesi sonunda alıcıya geçer; bu, taşınır mallarda alıcıya "teslim" (MK. m. 763), taşınmazlarda ise tapu siciline "tescil” (MK. m.705) ile geçeceği anlamına gelmektedir. Borcun ifası ile ilgili olan bu işlem tasarruf işlemi olmaktadır. Anlaşılacağı üzere, derhal ifa edilmeyen satım sözleşmelerinde, borçların doğumu ile ifaları arasında bir süre geçmektedir. Bu anlamda hasarın intikali, sözleşmenin yapılması ile tasarruf işlemi arasındaki bu zamanda ortaya çıkan bir konu (Akıntürk, 1996) olmaktadır.

Hasarın intikali, hasara kimin katlanacağının belirlenmesi bakımından, önem taşımaktadır. Örneğin, satıcı teslim borcunu yerine getirirken, alıcıdan bedeli isteyemeyecekse, böyle bir durumda "hasarın satıcıya intikali"nden söz edilecektir. Eğer alıcı, satılanı elde edememesine rağmen bedeli ödemekle yükümlü olacaksa veya önceden ödemiş olduğu bedelin kendisine iadesini artık talep edemeyecekse,bu durumda "hasarın alıcıya intikali "söz konusu olur.

Sonuç olarak, hasarın intikal etmesi için gerekli şartlar; geçerli bir satış sözleşmesinin mevcut olması ve hasarın taraflara yükletilemeyen beklenmedik bir hal yüzünden meydana gelmesi ve hasar sözleşmenin kurulması ile malın teslimi arasındaki bir zamanda meydana gelmesi (Eren, 2018) gerekmektedir.

\subsection{Türk Hukuk Sisteminde Hasarın İntikalinin Düzenlenmesi}

Hasarın intikali, Türk hukukunda 2012 öncesi ve sonrası dönemlerde farklı nitelik göstermektedir. Eski düzenlemeye göre hasar, kural olarak, sözleşme kurulduğu andan itibaren alıcıya geçmektedir .

Cins borç ile parça borç arasında bazı farklar düzenlenmiştir. Buna göre satım sözleşmesinde hasarın alıcıya geçmesi için satım sözleşmesinin yapılma anı esas alınmıştır fakat bazı yasal koşullar bulunmaktadır. Bu koşullardan birisinin bulunmaması durumunda belirtilen kural uygulanamaz. Bu koşullardan biri satılanın muayyen (belirli) olması koşuludur. BK'nun 183/II maddesi gereğince sözleşme konusu malın ayırt edilmiş olması aranmıştır (Yargıtay 13. Hukuk Dairesi,E.1994/6197, K. 1994/7587, K.T. 15.9.1994).

Eski Borçlar Kanunu'nun 183.maddesinin 2.fikrasında; cins borç parça borç ayrımını düzenleyen bu hüküm ve aynı hükmün 3.fıkrasında düzenlenmiş olan geciktirici koşula bağlı olan satış sözleşmesinde hasarın alıcıya geçmesi ile ilgili hükümler yeni Türk Borçlar Kanunu'nda düzenlenmemiştir.

Yeni Türk Borçlar Kanunu ile yapılan düzenlemeye göre parça borçları biricik olduğu ve nitelikleriyle özel belirlenmiş olduğu için, henüz ifa edilmeden borçluya yüklenemeyen sebepler dolayısıyla yok olduğu takdirde sonraki imkansızlık söz konusu olur ve borçlu borcundan kurtulur çünkü borç sona erer. TBK'nun 136. maddesine göre çeşit borçlarında da ilke olarak bu kural geçerlidir. Maddenin 1. fikrasındaki düzenlemede beklenmedik hal söz konusudur. İki tarafa borç yükleyen sözleşmelerde borcundan bu şekilde kurtulan borçlunun sebepsiz zenginleşme hükümlerine dayanarak aldığı edimi geri vermesi gerekir. Buradan anlaşılacağı gibi 136. maddenin ikinci fıkrası sonraki kusursuz imkansızlık durumlarında hasara borçlunun katlanması gerektiğini düzenlemiştir.

Hasar, "maddi edim hasarı" ve "bedel hasarı" olarak ikiye ayrılmaktadır. "Maddi edim hasarı" satılan malın sözleşme kurulmasından sonra taşınırlarda zilyetliğin devri veya taşınmazlarda tescile kadar olan sürede başına gelecek hasara rağmen satıcının ifa yükümlülüğü devam ediyorsa maddi edim hasarı satıcıya aittir. "Bedel hasarı" ise alıcının malı devralamamasına rağmen satıcıya bedeli ödemek zorunda olması durumudur. Eğer alıcı ödemeyecek idiyse bedel hasarı satıcıya aittir. Kanun'un 208. maddesinde düzenlenen hasar bedel hasarıyla ilgili olup buna göre beklenmedik olay yüzünden yok olan malın, satıcı bedel hasarına katlanacak ve alıcıdan bedeli isteyemeyecektir. Üstelik edim hasarı alıcıya ait olacak, alıcı malın ifasını satıcıdan isteyemeyecektir (Eren, 2018).

6098 sayılı Türk Borçlar Kanunu hasarın intikali konusunda değişik düzenlemeler içermektedir. Kanun’un 208. maddesinin birinci fikrasında "Kanundan, durumun gereğinden veya sözleşmede öngörülen özel koşullardan doğan ayrık haller dışında, satılanın yarar ve hasarı; taşınır satışlarında zilyetliğin devri, taşınmaz satışlarında ise tescil anına kadar satıcıya aittir." hükmü yer almaktadır.

6098 sayılı Türk Borçlar Kanunu'nun gerekçesinde ise 818 sayılı Borçlar Kanunu'nun 183. üncü maddesinin birinci fikrasında, parça borçlarında hasarın, kural olarak sözleşmenin kurulduğu anda alıcıya geçtiğinin düzenlenmiş olduğu belirtilmiş ve Türk Borçlar Kanunu'nda, hasarın, satılan malın mülkiyetinin, borçlandırıcı işlem özelliği taşıyan satış sözleşmesinin yapıldığı sırada değil, tasarruf işlemi özelliğindeki zilyetliğin devri işlemi veya tescil işleminin yapıldığı sırada alıcıya devredildiği zaman alıcıya geçtiği düzenlenmiştir.

Belirtmek gerekir ki milletlerarası satım sözleşmelerinin içerdiği kurallarda da, hasarın teslim anında alıcıya intikal etmesi gerektiği kabul edilmiştir. Bu sebeple, kanun tasarısında 818 sayılı Borçlar Kanunu'ndaki hükümden değişik olarak, satış sözleşmelerinde hasarın, taşınır mallarda zilyetliğin devri, taşınmaz mallarda ise tescil anında alıcıya geçtiği kural olarak kabul edilmesi uluslararası antlaşmalarla da uyum içindedir. 
Eski düzenlemede alıcının, henüz mülkiyet hakkı sahibi olmadığı sözleşme konusu malın hasarına katlanmak ve satış bedelini ödemek zorunda kalması, hakkaniyete uygun değildi. Bu nedenle TBK'nun 208. maddesinde hasarın satıcıya geçişini taşınırlarda, zilyetliğin devri; taşınmazlarda ise tescil anı olduğu şeklinde yapılan yeni düzenleme ile birlikte buna istisnalar getirilmiştir. İstisnalardan biri, TBK'nun 136. maddesinin 2. fikrasında "borcun ifasından önce hasara alacaklının katlanması gerektiğini düzenleyen kanun veya sözleşmeden doğan özel durumlar bu hükmün dışındadır" denilmesidir. Fakat taraflar sözleşmelerine, TBK'nun 136 ve 208. maddelerden farklı olarak hasarın hangi tarafa ait olacağına ilişkin hüküm koyabilirler (Eren, 2018). İkinci istisna ise 208. maddenin ikinci fikrası, 818 sayılı Borçlar Kanununda düzenlenmeyen sonradan eklenen bir hükümdür. Hükme göre, taşınır mal satışlarında, alıcı temerrüde düşer ve sözleşme konusu malın zilyetliğini devralmada gecikirse taşınır malın hasarı, zilyetliğin devri gerçekleşmesi gereken zamanda sanki uygun olarak devir gerçekleşmiş gibi alıcıya geçecektir. Son fikrasında ise önceki kanunda olmayan bir düzenleme vardır. Bu düzenleme üçüncü istisna olarak düzenlenmiştir. Satıcı alıcının talebi ile satılan malın sözleşmede kararlaştırılan ifa yerinden farklı bir yere gönderilmesi halinde, hasar, malın taşıyıcıya teslim edilmesi ile alıcıya intikal edecektir. Bu durumda da bazı değişik uygulamalar söz konusu olabilir. Örneğin, taşıyıcı ile satıcı arasında hizmet sözleşmesi kurulmuşsa yani taşıyıcı satıcı için çalışıyor ise hasar, sözleşmenin konusu olan malın taşıyıcıya teslim edilmesi ile geçmez, alıcıya ulaşması ile alıcıya geçer (Eren, 2018).

Eski kanun ile yeni kanun arasındaki bir diğer fark ise yeni Türk Borçlar Kanunu Tasarısı'nda, hasarın hangi ana kadar satıcıya ait olacağı düzenlenmiştir fakat 818 sayılı Borçlar Kanunu'nda, satılanın hasarının hangi anda alıcıya intikal edeceği düzenlenmiştir.

Kanun gerekçesinde, Tasarının 244. maddesinde taşınmaz satışlarıyla ilgili düzenleme vardır. Bu maddenin birinci fikrasında tescil ve teslim zamanları arasında fark olduğu takdirde uygulanacak olan düzenleme vardır. Bu TBK'nun 245. maddesini oluşturur. Buna göre, "Satılanın tescilden sonraki bir zamanda alıcı tarafından teslim alınması için sözleşmeyle bir süre belirlenmişse, onun yarar ve hasarı, alıcıya teslimle geçer.”. Örneğin, taşınmaz satışlarında tescil ile hasarın devredilmesini düzenlemek bazı durumlarda hakkaniyetli sonuçlar meydana gelmesini engelleyebilir. Eğer, taraflar aralarında tescilden sonraki bir zamanda teslimin gerçekleşeceğini karara bağlamışlarsa böyle bir durumda hasarın alacaklıya tescil değil de teslim ile geçmesi daha uygun olacaktır. Örnek olarak, bir konut satışı yapılırken tescil yapılmış olmasına rağmen satıcının kendine yeni bir ev bakması amacıyla belirli bir süre daha teslim gerçekleşmeyip konutta satıcı oturursa bu takdirde hasarın teslimle alıcıya geçmesi hakkaniyeti sağlamak açısından daha uygundur (Türk Borçlar Kanunu Tasarısı Madde Gerekçeleri).

Madde şöyle devam etmektedir; "Bu hüküm, alıcının satılanı teslim almada temerrüde düşmesi durumunda da uygulanır. Bu sözleşmenin geçerliliği, yazılı şekilde yapılmış olmasına bağlıdır.” hükümden de anlaşılacağı gibi bir şekil şartı getirilmiştir ve yapılan sözleşmenin yazılı olması aranmıştır.

\section{Mukayeseli Hukukta Hasarın İntikali}

Türk Borçlar Kanunu 1926 yılında İsviçre'den iktisap edildiği için kanunumuzdaki pek çok hüküm yabancı kanunlar ile de benzerlik göstermektedir. İsviçre kanun hazırlama sürecinde Roma Hukukundan miras kalan hükümlerden de faydalandığı için Roma hukukunda da benzer hükümler bulunmaktadır. Milletlerarası antlaşmalar hukukumuzda büyük önem ve etkiye sahip bulunmaktadır.

\subsection{Kita Avrupası Hukukunda}

Kıta Avrupası Hukuku'nda hasarın intikali satılan şeyin satıcıya geçmesi ile gerçekleşmektedir. Dolayısıyla satılanın teslimine kadar geçen süre içinde karşı edim hasarına satıcı katlanmakta, teslim ile beraber satılanın yok olması veya kötüleşmesi riski alıcıya geçmektedir (Kara, 2018). Böylece satılan şeye gelen hasar sözleşmenin geçerli olarak kurulduğu andan itibaren satılan şeyin teslimine kadar geçen sürede ise risk satıcıya aittir. "Edim hasarı satılanın teslimi ile birlikte alıcıya geçmekte ve teslimle beraber satılanın yok olma veya kötüleşme tehlikesine alıcı katlanmaktadır”. Bu kuralın altında yatan neden ise alıcının menfaatinin düşünülmesidir.

Alman Medeni Kanunu (BGB) 446 'daki ve Civil Code of France 1303'deki tanıma göre de hasarın borçlunun kontrolünde olmayan bir sebepten oluştuğu anlaşılır (Akıntürk, 1996).

BGB 243/ 2.fikraya göre, borçlunun hasara katlanmaktan kurtulması için ifa için üzerine düşen tüm sorumlulukları yerin getirdiğinin kabulü gerekmektedir.

BGB 446'ya göre hasar ve yarar sözleşme konusu malın alıcıya veya taşıyıcıya teslimi ile alıcıya geçer (Çakırca, 2007).

BGB 447'ye göre ise mesafeli satışlarda sözleşme konusu ferden tayin edilmiş malın taşıyıcıya teslimi ile hasarın artık alıcıya geçmesi kabul edilmiştir (Akıntürk, 1996). Çünkü bu gönderme işlemi alıcının menfaati için yapılmaktadır (Çakırca, 2007).

Alman Hukuku'na göre ifanın imkânsızlaşması halinde edimin bedeli alıcı tarafından ifa edilmeyecektir. Eğer, satış bedeli ifa edilmiş ise iadesi talep edilebilecektir.

BGB 281'e göre, "borçlu edasını imkânsız kılan hal sonucunda bir tazminat veya tazminat talebi elde etmişse, alacaklı bu tazminatın kendisine verilmesini veya talep hakkının devrini talep edebilir”. Yani eğer yok olan mal 
için borçluya bir tazminat ödenmişse borçlu bunu alacaklıya vermekle yükümlü bulunmaktadır. Ayrıca alıcının satılanı kabulde alacaklı temerrüdüne düşmesi durumunda karşı edim hasarı malın teslimi gerekmeksizin alıcıya geçmekte, dolayısıyla alacaklı temerrüdünden itibaren malın satıcıya atfedilemeyen sebeplerle yok olması durumunda alıcı satış, bedelini ödeme mecburiyeti altında olmaktadır. Yani alacaklı temerrüde düşmüşse eğer eşya teslim edilmemişse bile hasar riski alıcıya geçmekte ve böylece de alıcı satış bedelini ödemek zorunda bulunmaktadır.

\subsection{Anglo Sakson Hukukunda}

Anglo-Sakson Hukuk Sistemi’nde hasar, sözleşme kurulduğu andan itibaren alıcıya geçmektedir. Anglo-Sakson sistemi ile Kita Avrupası hukuk sistemini uygulayan Fransa da hasarın intikali konusunda benzerlikler bulunmaktadır.

Gerçekten, Fransız ve Anglo - sakson hukuklarında hasar, akdin inikadı anından itibaren alıcıya intikal etmekte ise de, mülkiyetin hasarla aynı anda intikali, akit prensibinin mahzurlarını ortadan kaldırmaktadır. Diğer bir deyimle, bu hukuk sistemleri, mülkiyet ve hasarı birbirinden ayırmadıkları ve her ikisini de aynı anda intikal ettirdikleri için, İsviçre/Türk hukukunda ortaya çıkan gayrı mantıkî durum, bu sistemlerde görülmez (Akıntürk, 1996).

Mülkiyetin geçmesi ile birlikte hasarın geçmesi sebebiyle hasar riski alıcıya ait olmaktadır. Böylece hasarın alıcıya geçmesi, mülkiyetin alıcıya geçmesinin doğal bir sonucu olmakta, malik haline gelen alıcı satılanın yok olması veya kötüleşmesi sebebiyle meydana gelecek zarar tehlikesine de katlanmaktadır. Fakat, alıcıya sözleşme konusu olan şey gönderilmemişse hasara satıcı katlanmaktadır.

Sale of Goods, sec20(1) ve (2) de düzenlendiği gibi, alıcıya sözleşme konusu olan şey gönderilmemişse hasara satıcı katlanmaktadır. Ayrıca Satılan, alıcıya göndermek üzere yola çıktı̆̆ı andan itibaren, satılan alıcıya teslim edilsin veya edilmesin, hasar riskini alıcı yüklenir. Ancak, teslimatta gecikmeye kusuru ile sebebiyet vermiş olan taraf, hasar riskine katlanmak zorundadır ( Çakırca, 2007) . Bu durum hem Amerika hem de İngiltere hukuk sistemlerinde geçerli olmaktadır.

Belirtildiği gibi Kara Avrupası Hukuk Sistem'inde yer alan Fransız Hukuk Sistemi de hasarın intikali konusunda Anglo-Sakson hukuk Sistemi'ne benzer bir yol izlemiştir. Fransız Hukuk Sistemi’nde hasar mülkiyetin geçmesi ile birlikte karşı tarafa geçmekte ve böylece de hasar riski alıcıya ait olmaktadır.

\subsection{Uluslararası Antlaşmalarda Hasarın İntikali}

Milletlerarası Mal Satımına İlişkin Sözleşmeler Hakkında Birleşmiş Milletler Antlaşması (Viyana Antlaşması), 1980 yılında Viyana'da yapılan Birleşmiş Milletler Konferansı'nda görüşülmüş ve kabul edilmiştir (Yelmen, 2016).

Antlaşmada yer alan hükümler emredici nitelikte olmadığından dolayı taraflarca istenildiği gibi değiştirilebilmektedir.

Viyana Antlaşmasının 6. maddesinde yer alan hükümde, "tarafların kuralların aksini kararlaştırabilmesi mümkündür” düzenlemesi bulunmaktadır. Taraflar, bu Antlaşmanın uygulanmamasını kararlaştırabilecekleri gibi, 12. maddenin 3. fikrası saklı kalmak şartıyla, hükümlerine istisna getirebilir veya hükümlerinin doğurabilec eği etkileri değiştirebilirler. Dolayısıyla taraflar, hasarın intikaliyle alakalı olarak düzenlenen hükümlerden farklı bir uygulama kararlaştırabilirler.

Viyana sözleşmesinde hasarın tanımı yapılmamasına rağmen öğretide genel olarak kabul görmüş hasar tanımı unsurları vardır: Geçerli bir sözleşme, taraflardan herhangi birine yüklenemeyen nedenlerle malın yok olması veya zarar meydana gelmesidir (Yelmen, 2016).

Viyana Antlaşması'nın 66. maddesinde bunu destekleyen nitelikte şöyle düzenlenmiştir: "Hasarın alıcıya geçmesinden sonra malların zayi olması veya zarar görmesi, alıcıyı semeni ödeme yükümlülüğünden kurtarmaz, meğerki, ziya veya zarar satıcının bir eyleminden veya eylemsizliğinden kaynaklansın”. Hasarın intikali durumu antlaşmanın dördüncü bölümünde 66 ve 70. maddeleri arasında düzenlenmiştir (Milletlerarası Mal Satımına İlişkin Sözleşmeler Hakkında Birleşmiş Milletler Antlaşması, 7 Nisan 2010 tarih ve 27545 sayılı Resmi Gazete).

Taraflardan herhangi birine yüklenemeyen sebepler derken oluşan zarar veya yokolmanın sözleşmenin taraflarından herhangi birine yüklenememesi yani herhangi birinin kusurlu davranışı sonucu meydana gelmemesidir. Eğer gelirse bu sözleşmeye aykırılık oluşturur ve antlaşmanın 70. maddesinde bu durum düzenlenmiştir. Satıcının kusurlu davranışı sonucu meydana gelmeyen hasarların bulunduğu hallere, mücbir sebep (forcemejeure) ve umulmayan hâl (frustration) örnek verilebilir. Örneğin, hasarın deprem yüzünden oluşması veya ülke genelinde düzenlenen grev nedeniyle taşınamayan malların kısmen ya da tamamen zarar görmesi durumlarında, birinci halde mücbir sebep, ikincisinde ise umulmayan hâlden bahsedilir. Üçüncü bir kişinin davranışı yüzünden mala hasar verilirse veya mal çalınırsa gene hasar söz konusu olur (Yelmen, 2016).

Satıcıya yüklenemeyen yani onun kusurlu olmadığı durumlarda hasarın intikali konusu gündeme gelir. Örneğin, satıcının sertifikasının olması gerektiği hallerde eğer satıcı sertifikasını almamış ise bu durumda satıcının sorumluğundadır, satıcı kusurludur. Bundan satıcının kurtulması için; Madde 79'a göre yeni ve öngörülemeyen 
şekilde bir ihracat veya ithalat yasağı çıkmış olabilir ancak bu gibi durumlar hasar sorunu kapsamında değerlendirilebilir.

Hasarın intikali aynı Türk hukukunda olduğu gibi bedel hasarı ve maddi edim hasarı olarak ikiye ayrılır. Maddî edim hasarı, sözleşme konusu mal zarar görmüş olmasına karşın, satıcının sözleşme konusu malı gereği gibi ifa mecburiyetinin var olup olmadığı ile ilgili bir konudur. Maddî edim hasarına satıcının katlanacağı durumlarda satıcı hala sözleşmeye uygun ifa ile yükümlüdür. Eğer, tersi şekilde maddi edim hasarına alıcının katlanması gerekiyor ise bu satıcının sözleşmeye uygun ifa mecburiyetinin sona erdiğini ifade eder. Bu durumda ödenmiş olan bedele ilişkin hasara ise alıcı katlanır (Yelmen, 2016).

Viyana Antlaşması'nda biraz farklı bir tanımlama olduğu söylenebilir. Bedel hasarı edimin zarara uğraması sonucunda satıcının sözleşmede kararlaştırılan gibi ifa etme mecburiyetinin olmaması ama alıcının kararlaştırılan bedeli ödemek zorunda kalmasıdır. Yani, bedel hasarı satıcının aslında yükümlü olduğu ifa borcundan kurtulması ve maddi edim hasarının alıcıya geçmesi demektir. Hasara satıcı katlanıyorsa yani hasar onun üzerinde ise bu kural olarak maddi edim hasarı olur ama eğer bedel hasarı varsa bu hasarın alıcının üzerinde olduğu anlamına gelir.

Viyana Antlaşması'nın 67 ve 69. maddeleri hasarın intikali konusunu düzenlemektedir. Hasarın geçiş anı üç gruba ayrılarak incelenebilir. Birincisi, malların taşınması gereken sözleşmeler bakımından yapılan ayrımdır. İkincisi, taşıma sırasında satılan mallar bakımından ve üçüncüsü ise diğer durumlar adı altında incelenir. Zaten belirtmek gerekir ki uluslararası sözleşmelerin neredeyse hepsi sözleşme konusu malın bir yerden başka bir yere taşınmasını içerir.67. maddenin 1.fikrası satıcının malların taşınmasını da kendisinin ayarlayacağı durumlar için uygulanabilirdir. "satım sözleşmesi malların taşınmasını gerektiriyorsa ve satıcı malları belirli bir yerde vermeye mecbur değilse hasar, malların, alıcıya ulaştırılması amacıyla, satım sözleşmesine uygun olarak ilk taşıyıcıya verilmesi ile alıcıya geçer. Satıcının malları belirli bir yerde taşıyıcıya vermesi gerekiyorsa malların o yerde taşıyıcıya verilmesine kadar hasar alıcıya geçmez. Satıcının malları temsil eden belgeleri alıkoyma hakkı olsa bile, bu, hasarın intikaline etki etmez.” Görüldüğü gibi hasar paylaştırılmaktadır. Malların belirli bir yerde bağımsız taşıyıcıya verilmesi ile o ana kadar satıcı hasara katlanırken artık alıcı hasara katlanır olur (Yelmen, 2016).

Hasarın, malın taşıyıcıya teslimi ile alıcıya geçmesi için sözleşme konusu malın, taşınmasının gerekli olması, bağımsız bir taşıyıcının mevcut olması, satılanın taşıyıcıya verilmesi ve satılanın somutlaştırılması gerekmektedir.

Alıcının somutlaştırmadan toplu taşımaya rıza gösterdiği hallerde hasar alıcıya, satılan malın bağımsız taşıyıcıya teslimi ile geçer. Sözleşme konusu mal somutlaştırılana kadar hasar alıcıya geçmez. Bu düzenleme Antlaşmanın m. 67/II ve m. 69/III hükmünün Türk Borçlar Kanunu ile de uyum içinde olduğunu göstermektedir. Çünkü Türk Borçlar kanununda nev'i telef olmaz ilkesi geçerlidir ve satıcı eğer imkânsızlaşan edim ferden tayin edilmediği için aynısını bulabiliyorsa edimi bulup sözleşmeye uygun ifa ile yükümlüdür.

Malların taşınması konusu incelenirken dikkat edilmesi gereken husus taşıyıcının bağımsız olup olmadığıdır. Eğer taşıyıcı bağımsız ise malların zilyetliğin taşıyıcıya geçmesi işe hasar alıcıya geçer fakat eğer taşıyıcı bağımsız değil de satıcının kendisi veya personeli ise o halde hasar malların alıcıya teslimi ile alıcıya geçer (Yelmen, 2016).

Viyana Antlaşmasında hasarın intikali zilyetliğin devri ile gerçekleşir. Bu devir de malların taşıyıcı veya alıcıya teslim edilmesi ile olur.

İkinci olarak ise taşıma halindeyken satılan mallar açısından durum incelenecektir. Viyana Antlaşması Madde 68'e göre hasar satım sözleşmesi kurulduğu anda alıcıya intikal eder. "Taşıma halindeyken satılan mallara ilişkin hasar, satım sözleşmesinin kurulduğu andan itibaren alıcıya geçer” (Milletlerarası Mal Satımına İlişkin Sözleşmeler Hakkında Birleşmiş Milletler Antlaşması, 7 Nisan 2010 tarih ve 27545 sayılı Resmi Gazete).

Üstelik istisna getirilerek hasarın alıcıya geçiş anı, koşulların haklı göstermesi şartı ile sözleşmenin kurulmasından önceye kadar gidebilmektedir. Ancak koşulların haklı göstermesi durumunda, taşıma sözleşmesine ilişskin belgeleri düzenleyen taşıyıcıya malların verilmesi anında hasar alıcı tarafından üstlenilir. Koşulların haklı göstermesi ifadesine örnek olarak alıcının geçmişe etkili sigorta yaptırması verilebilir.

Son olarak diğer durumlar bakımından hasarın intikalinin incelenmesi gerekir. Madde 69'da "Madde 67 ve 68 kapsamına girmeyen hallerde hasar, alıcının malları teslim aldığında veya malları zamanında teslim almaması halinde, malın tasarrufuna hazır bulundurulduğu ve teslim almayarak sözleşmeye aykırı bir davranışta bulunduğu andan itibaren alıcıya geçer" denerek temerrüt hali düzenlenmiştir ve maddeden de anlaşılacağı gibi genel kural hasarın, alıcıya malların kendisine teslimi ile geçtiğidir (Yelmen, 2016).

Bunlara ek olarak eğer satıcının belirli bir yerde ifa yükümlülüğü bulunuyorsa o halde hasarın alıcıya geçme anı Madde 69/2. fikraya göre teslim borcunun muaccel olduğu ve alıcının istediği malların belirtilen yerde hazır bulundurulduğundan haberdar olduğu andır.

\section{Incoterms Düzenlemelerinde}

Incoterms, farklı hukuk sistemlerinin varlığından dolayı oluşan sorunların giderilmesine ve uluslararası ticaretin gelişmesine yardımcı olan bir uluslararası hukuki metindir. Alıcı ve satıcının yükümlülüklerini ve ortaya çıkan maliyetleri ve hasarın geçiş anı ile ilgili sorunları çözmemize yaradığı için uluslararası ticarette sıklıkla başvurulan bir belgedir. Incoterms'ün kuralları bağlayıcı değildir, soft law yani esnek hukuk niteliğindedir. Fakat eğer taraflar 
aralarında yaptıkları sözleşme ile bu kurallara uyulmasını kararlaştırmış iseler o halde taraflar bu kurallarla bağlıdırlar ve kurallar bağlayıcı özellik göstermiş olur (Caner, 2012).

Uluslararası Ticaret Odası (ICC) çok uzun süredir üzerinde çalıştığı "uluslararası ticarette sıklıkla kullanılan terimler" ile ilgili yaptığı çalışmasında bazı kuralları derlemeye başlamıştır. İlk olarak 1936 yılında düzenlediği kurallar "FOB, FAS, C\&F, CIF, Ex- Ship, Ex- quay” olarak adlandırılan kurallardır (Caner, 2012).

Uluslararası satışlarda, dış ticarette satım sözleşmelerinde milletlerarası uygulamalarda yeknesaklığı sağlamak amacıyla ve ticaretin gerektirdiği hızlılık ve güven ihtiyacını karşılamak amacıyla düzenlenen bu satış kurallarında farklı satış türleri için yapılmış bulunan düzenlemeler vardır. Teslime ilişkin detayların düzenlendiği bu kurallar; fikri mülkiyet konusu olan satıma konu olmuş olan mallar örneğin bilgisayar yazılımı gibi mallar Incoterms kuralları dışında kalmaktadır (Kazma, 2011).

Incoterms'de oluşturulan bazı terimler vardır bu terimler ilk harfleri baz alınarak sınıflandııılmıştır ve bu sayede ortaya çıkan dört temel grup vardır. "E Grubu Terimler, F Grubu Terimler, C Grubu Terimler, D Grubu Terimler". Bu grupları kısaca tanımlarsak; E grubu: satıcının satıma konu olan malları kendi işyerinde alıcı için bırakmış olduklarıdır, F Grubu: satıcının sözleşme konusu malları alıcı tarafından belirlenecek olan bir taşıyıcıya teslim ettiği sözleşmelerde uygulanır, C Grubu: yüklemede satışlar için kullanılır, D Grubu: boşaltmada satışlar için kullanılır (Sevinç, 2009).

Sırası ile bu terimlerin kullanılmasının etkisini inceleyecek olursak bazı değişik düzenlemeler olduğunu görürüz.

E grubu terimler ki içerisinde yer alan tek terim EXW terimidir, bu terimde aksi belirlenmedikçe satıcı kendi iş yerinde ifa edeceğinden dolayı satıcının yükümlülüğünün en az olduğu terimdir.

F Grubunda bulunan terimler ise FCA, FAS ve FOB terimleridir. FCA terimi her türlü taşımanın kararlaştıııldığı sözleşmelerde kullanılabilirken, FAS ve FOB sadece deniz yoluyla taşımanın tercih edildiği satım sözleşmelerinde kullanılır. Bunlara yüklemede satış denmesinin nedeni ise satıcının malları teslim yerinde (limanda) ifa etmiş olmasıdır (Sevinç, 2009).

C Grubundaki terimler CFR, CIF, CPT ve CIP terimleridir. Bu terimlerin diğer terimlerden farklı olan tarafı satıcının taşıma sözleşmesi yapmak zorunda olması ve hasarın paylaşımı noktasının belirlenmesidir. Bu satışlar yüklemede satışlar için kullanılır ve teslim borcu asıl yolculuktan önce ifa edilmektedir. Alıcı satıcıya güvenmek ve taşıyıcısını seçmediği bir yolculuğun riskini üstlenmek zorunda kalmaktadır. Üstelik CIF ve CIP'te satıcı mallar için ücretini kendisinin ödediği bir sigorta yaptırmak zorundadır. CFR ve CIF sadece deniz taşımacılığına özgüdür.

D Grubu terimlerde satıcı malların taşıması yükümlülüğü ve malların uğraması olası olan hasar riskini üzerine almaktadır. Satıcı bu malların sınır ülkesi ya da ithal ülkesi içinde bir noktaya ulaştırılmasından sorumlu olduğu için boşaltmada satış biçiminde gerçekleşmektedir (Sevinç, 2009).

$\mathrm{Bu}$ terimler ile yapılacak olan sözleşmelerde hasarın geçişi ile ilgili düzenlemeler Incoterms A5 ve B5 hükümlerinde bulunmaktadır (Caner, 2012).

Hasar kavramı ile gene diğer hukuki düzenlemelerde olduğu gibi temerrüt ve sözleşmeye aykırılık halleri dışındaki sebeplerden dolayı oluşan hasar kastedilmek istenmektedir. Temerrüt ve sözleşmeye aykırılık sonucunda ortaya çıkan hasarlardan sorumluluk uygulanması gereken ulusal hukuka ya da sözleşme şartlarına tabi olacaktır.

Incoterms'te, hasarın satıcıdan alıcıya geçmesi, CISG düzenlemesine paralel olarak, malların satıcı tarafindan alıcıya tesliminin gerçekleştirilmiş olmasına bağlanmıştır. Kural olarak, satıcının teslimi gerçekleştirmesi ile hasar alıcıya geçmiş olur. Yani hasarın intikal anı da malların zilyetliğinin devri ile gerçekleşir ve hasarın intikal anından sonra artık alıcı hasara katlanmak zorunda kalır (Sevinç, 2009).

Sözleşme konusu malların mülkiyetinin alıcıya geçiş anı hasarın geçişinde göz önünde bulundurulmamıştır. Dolayısıyla, deniz taşımacılığı sırasında konşimento denilen belge ile hem mülkiyet hem de dolaylı zilyetlik karşı tarafa geçebilmektedir. Ve hasarın geçişi de mülkiyete bağlı olmadığı için konşimento denilen kıymetli evrak sahibi malları teslim noktasından alma konusunda yetkili kişidir, hasarın geçişi etkilenmez.

Hasara katlanma yükümlülüğü ile ilgili beklenmeyen hallerden kaynaklanan hasarlar bulunmaktadır. Kural olarak satıcının kendi kusurundan kaynaklanan hasarlar, hasarın alıcıya intikal anından sonra bile gene satıcının sorumluluğundadır (Sevinç, 2009).

FOB ve CIF satışlarda 2010 öncesinde malların geminin küpeştesini geçmemiş olması kaydıyla, mallardaki tüm zarara satıcının katlanacağı düzenlenmiş iken daha sonra, hasarın geçişi ancak malların gemiye doğru bir biçimde yüklenmesinden sonra gerçekleşir şeklinde düzeltilmiştir. Yani mallar gemiye yüklendiği andan itibaren, mallara ilişkin tüm masrafları, ziya ve hasar risklerini alıcı üstlenir (Caner, 2012).

Eğer alıcı geminin seçimine dair gerekli ihbarı göndermez ise veya alıcı tarafından tayin edilen gemi satıcının sözleşmeye uygun davranmasını sağlayacak şekilde zamanında gelmezse veya malları almazsa ya da ihbar edilen tarihten önce yük almayı durdurursa, malların sözleşmeye konu olan malları olduğunu belirtecek şekilde açıkça ferdileştirilmiş olmaları şartıyla alıcı kararlaştırılan tarihten veya böyle bir tarih yoksa kararlaştırılan süre içerisinde satıcı tarafından ihbar edilecek tarihten veya böyle bir ihbar yapılmamışsa; teslim için kararlaştırılan bir sürenin sona erme tarihinden itibaren mallara ilişkin tüm ziya ve hasarı üstlenir (Çakan, 2012). 
Tüm bu düzenlemelerin yanısıra eski Türk Ticaret Kanunu’nda düzenlenmiş bulunan bazı satış türleri bulunmaktaydı. FOB satış 6762 Sayılı Türk Ticaret Kanunu 1138.maddesinde düzenlenmiştir. Madde gerekçesinde de aynen ifade edildiği gibi maddenin hazırlanmasında ICC'nin uluslararası ticari teamül kuralları dikkate alınmış olup madde ICC tarafından hazırlanan 560 sayılı broşürdeki FOB satışlarla uyum içindedir (Kazma, 2010).

$\mathrm{Bu}$ satışlarda malları alıcıya gönderme borcu satıcıdadır ve gönderme masraflarına satıcı katlanacaktır. Konşimento masraflarıyla, navlun bedelini satıcı ödeyecektir (TTK.M.1138/III). FOB satışları diğer satışlardan ayıran en önemli özelliği mesafe satışı niteliğinde olmasıdır. Hasar riski bu tip satışlarda mallar geminin küpeştesini geçtiği anda alıcıya intikal eder (TTK m.1138/II). Hasar riskinin alıcıya geçmesi için alıcının da kendisine ait yükümlülükleri yerine getirmesi gereklidir. Bu yükümlülüklerin başında alıcının gemiyi zamanında limanda hazır bulundurması, taşıma sözleşmesi yapması ve bu konuda satıcıyı bilgilendirmesi gelmektedir. Bu yükümlülüğünü yerine getirmemesi alacaklının temerrüde düştüğü manasına gelecektir ki, bu durumda hasar riski malların hazır edildiği andan itibaren alıcıya geçecektir.

6762 sayılı Türk Ticaret Kanunu'na göre CIF satışlar madde 11392'da düzenlenmiştir. "Bir malın muayyen bir yere taşınması için gemiye yükletilmesi şartıyla mal değerinden ve satıcı tarafından ödenecek sigorta ücretiyle navlundan ibaret maktu bir bedel karşılığında yapılan satışa "sif” satış denir" şeklinde tanımlanmıştır. Kanunda geçtiği şekilde "SİF” satışlarda, taşıma sözleşmesi yapma, taşıma ücretini ödeme ve malların sigortalatılması masraflarına satıcının katlanması gerekir. Bu satılarda da akdin ifa yeri yükleme limanıdır. Ancak malların mülkiyetinin alıcıya geçmesi için malları temsil eden konşimentonun alıcıya ciro ve teslim edilmesi gereklidir ( TTK m.1140/IV). Bu satışlarda da hasar riski malların gemi küpeştesini geçtiği andan itibaren alıcıya geçer (TTK m.1143).

6102 Sayılı yeni Türk Ticaret Kanunu'na göre FOB ve CIF satıș ile ilgili şunları belirtmek gerekir ki 6762 sayılı TTK.'nda FOB ve CIF teslimler açıkça yer almakta iken, Tasarıda, 6762 sayılı Kanunun 25. maddesini karşılayan maddede değişiklik yapılmış ve "Sif satış ve diğer deniz aşırı satışlar" hakkındaki hükümleri saklı tutan 5 numaralı bent maddeye alınmamıştır. Tasarı, 6762 sayılı Kanunun aksine, CIF ve FOB başta olmak üzere deniz aşırı satışlara, önceki kanunda yer verilmiş olan söz konusu hükümlerin 1940'lı y1llarda geçerli olan Incoterms hükümlerinden alınmış olması nedeniyle eski olması ve sürekli bu hükümlerde değişiklik yapılmasına kanunun ayak uyduramaması nedeniyle yeni kanuna alınmamıştır. Zaten bu tür satışlarda tarafların çoğu kez Incoterms'e gönderme yapmakta veya ondan ayrılan özel düzenlemeler getirmekte oldukları da gerekçede yer almaktadır (Kazma, 2010).

01.07.2012 tarihinde yürürlüğe girmiş olan 6021 sayılı TTK'da ise denizaşırı satışlara ve FOB satışa ilişkin bir hüküm içermemektedir. Dolayısıyla hasarın küpeştenin aşılması suretiyle alıcıya geçeceğine ilişkin bir kanun hükmü söz konusu değildir. Bu bakımdan uluslararası FOB satışlarda INCOTERMS ve Viyana Satış Sözleşmesi hükümleri uygulama alanı bulacaktır ve özel hükümlerin olmadığı durumlarda Türk Kanunundaki genel hükümler gündeme gelecektir (Çakan, 2012).

Yani, Türk Borçlar Kanunu madde 208 hükmü emredici hükümler taşımadığı için yani sözleşmeler ile ondan farklı düzenlemeler yapılabildiği için "uluslararası ticarette kullanılan, Milletlerarası Ticaret Odası tarafından yayımlanan Incoterms gibi kayıtların, "CIF" ve "FOB" gibi sözleşmelerin hükümleri uygulama alanı bulabilecektir." Üstelik Yargıtay’ın Fob ile ilgili olarak vermiş olduğu bir kararında "Fob satışta nefi ve hasar, malın taşıyıcıya teslimi ile alıcıya geçmiş sayılır” cümlesi yer almaktadır (Yargıtay 19. Hukuk Dairesi E. 1996/10078, K. 1997/3268, K.T. 28.3.1997).

\section{Değerlendirme ve Sonuç}

Sonuç olarak, hasarın intikali kavramı geçmişten günümüze gelen tüm hukuk sistemlerinde tartışmalı bir konu niteliği taşımaktadır. Hasarın intikali, sözleşme kurulmasından ifa anına kadar geçen bir sürede gerçekleşen hasarın kimde bulunacağını tespit eder. Hasara alıcının katlandığı durumlar Eski Borçlar Kanunu’nda düzenlenmiştir. Ancak bu durum Yeni Türk Borçlar Kanunu ile değişerek satıcıya intikal etmiştir. Yeni düzenleme ile getirilen sistem özgün bir nitelik taşımaktadır.

Kıta Avrupa'sı Hukuk Sistemi Türk Borçlar Kanunu ile benzer nitelik göstermektedir. Anglo-Sakson Hukuk Sisteminde ise Eski Borçlar Kanunu'na benzer bir uygulama söz konusudur. Ayrıca, hasarın intikali bakımından malda bir hasar olduğunda sorumlulukların nasıl yerine getirileceği konusu önem taşımaktadır. Malların zarara uğradığı zamanlarda, eğer hasara alıcı katlanacaksa alıcı bedeli de ödemek zorundadır. Fakat, eğer sözleşme kurulduğu andan ifaya kadar geçen sürede zarara satıcı katlanıyorsa ifa bedelini alıcı ödemeyebilir.

\section{Kaynakça}

- Akıntürk, 1966. “Satım Akdinde Hasarın İntikali”, Ankara Üniversitesi Hukuk Fakültesi Yayınları, p. 7-117.

- Caner, 2012. "Incoterms 2010 (ICC Rules for the Use of Domestic and International Trade Terms)”, İstanbul Ticaret Üniversitesi Sosyal Bilimler Dergisi, 22, p. 223. 
- C Çakan, 2006. "FOB Satışlarda Tarafların Yükümlülükleri ile Hasarın Geçişi”,, Marmara Üniversitesi Sosyal Bilimler Enstitüsü, 7, p. 1-184.

- Çakırca, 2007. "Satımda Edim ve Karşı Edim Hasarının Alıcıya Geçmesi”, İstanbul Üniversitesi Yayınevi, 1, p. 177-206.

- $\quad$ Eren, 2018. Borçlar Hukuku Özel Hükümler. Yetkin Yayınevi. Ankara.

- Kara, 2018. "Public and Private International Law Bulletin” İstanbul Üniversitesi Yayınevi, 38, p. 107-145.

- Kazma, 2011. “Incoterms 2000 Incoterms 2010 Değişiklikleri ve Türk Hukuku’nda Incoterms”, Agchukuk , p. 4-14.

- Sevinç, 2009. "Uluslar arası Ticari Terimler (Incoterms)”, İstanbul Üniversitesi Sosyal Bilimler Enstitüsü, p. 1-199.

- Yelmen, 2016. “Milletlerarası Mal Satımına İlişkin Sözleşmeler Hakkında Birleşmiş Milletler Antlaşmasına Göre Hasarın İntikali”, Marmara Üniversitesi Hukuk Fakültesi Hukuk Araştırmaları Dergisi, 22, p. 29492964. 


\title{
Banka Kredi Yapılandırmalarında Kefilin Durumu Guarantor Situation in the Bank Credit Restructurings
}

\author{
Prof. Dr. Mustafa Topaloğlu (Özyeğin University, Turkey)
}

\begin{abstract}
In Turkish bank practice a great variety of bank credits are extended. Banks take or convey by mortgage such as real security or surety as personal guarantee to secure loans. In the surety regulated in the Turkish Code of Obligations in essence, very strict requirements have been arranged for the purpose of protecting the guarantor. Bank credit relations are continued over a long period of time. In this process, new contracts of surety are signed or credit restructurings are in question. Here are the changes in this relation the situation of guarantor was tried to be legally disclosed in the light of Supreme Court's decisions.
\end{abstract}

\section{Giriş}

Kredi, ticari hayatın vazgeçilmez kavramlarından biridir. Kredi ilişkisine girmeden hiçbir ticari işletme ya da şirketin faaliyetini sürdürmesi mümkün değildir. Kredi ilişkisinin merkezinde ise olağan tüketicilerden veya yatırımcılardan mevduat ve fonları toplayarak girişimcilere veren bankalar veya finans kurumları yer alır (Oğuz, 2019). Bankalar pasif işlemler sonucu topladıkları fon ve mevduatları aktif işlemle kendi yükümlülükleri altında müşterilerine tahsis ederek faiz farkına dayalı işlemleri gerçekleştirmektedirler (Kaplan, 2020).

\section{Banka Kredi Sözleşmeleri}

Banka tarafından kredi verme veya kredi tahsisi kredi açma sözleşmesiyle olmaktadır. Kredi sözleşmesi, bankanın müşterisine tahsis ettiği limitler dâhinde kredi kullandırmayı taahhüt ettiği müşterinin de kullandığı bu kredi karşılığında faiz ve/veya komisyon ödemeyi taahhüt ettiği sözleşme olarak tanımlanmaktadır (Oğuz, 2019).

Kredi açma sözleşmesinin hukuki niteliği tartışmalıdır. Hatta kendine özgü -sui generis bir sözleşme olduğu dahi ileri sürülmüştür (Kaplan, 2020). Kredi açma sözleşmesini tüketim ödüncü, satım, iş görme (vekalet), garanti ve cari hesap sözleşmesinin unsurlarını kısmen içeren kısmen de bunlardan ayrılan çerçeve niteliğinde bir sözleşme olarak nitelemek uygun olur (Oğuz, 2019).

\subsection{Banka Kredi Türleri}

Bankalar Bankacılık Düzenleme ve Denetleme Kurumundan gerekli izinleri alarak her tür ve cinste kredi verebilirler. Banka kredilerinin çok fazla tür olmasına rağmen 5411 sayılı Bankalar Kanunu sadece nakdi - gayri nakdi kredi ayrımı yapmıştır.

Nakdi kredi, kredi verenin müşterisine nakit olarak tedavüldeki bir parayı ya da değerli madeni doğrudan vermiş olduğu kredi türüdür. Nakdi krediler cari hesap, 1skonto ya da iştira şeklinde kullanılabilir (Oğuz, 2019).

Gayri nakdi krediler ise bankanın müşterisi lehine üçüncü kişilere karşı garanti vermek suretiyle nakde dönüşebilen bir taahhüt altına girmesidir.5411 sayılı Bankacılık Kanunu'nda gayri nakdi krediler de, teminat mektupları, kefaletler, aval, ciro, kabul gibi krediler şeklinde örnek kabilinden sayılmıştır (Oğuz, 2019; Kaplan, 2020). Kanaatimce çek hesabı açılması halinde de 5941 sayılı Çek Kanunu m.3 hükmünde belirtilen bankaların her çek yaprağı karşısında maktu ödeme yükümlülükleri nedeniyle gayri nakdi kredi de kullandırmış olmaktadırlar.

Konumuz bakımından önemli olan cari hesap sözleşmesi üzerinden işleyen kredilerde kredi önce cari hesaba geçer ve oradan müşteriye transfer edilir. Cari hesap usulünde, müşteri tarafından yapılan ödemeler ve banka tarafından tahakkuk ettirilen komisyon, faiz ve diğer masraflar tek tek değil toplu takas edilerek işlem kolaylığı sağlanır (Oğuz, 2019).

Bankacıllk uygulamasında, tüketim ödüncü şeklinde işleyen taksitli ticari ve tüketici kredileri ile müşterinin vade sonunda tek bir ödemede bulunduğu tek taksitli (spot) krediler de çok yaygındır (Oğuz, 2019).

\subsection{Banka Kredi Teminatları}

Bankalar hemen hemen verdikleri kredilerin tamamında ödememe ve diğer risklere karşı teminat almaktadırlar. Teminat altına alınan risk gerçekleştiğinde kanunlarda gösterilen kurallar çerçevesinde icra müdürlükleri vasıtasıyla teminatlar paraya çevrilmektedir. Bu nedenle bankalar, en az zararla karşılaşabileceği ve en kolay paraya çevirebileceği teminatları tercih etmektedirler (Kaplan, 2020).

Bankalar ayni veya şahsi teminat kabul etmektedirler. Ayni teminatları esas itibariyle taşınır ve taşınmaz rehni oluşturmaktadır. Bunların dışında, teminat için tevdi, teminat için teslim, teminat için temlik, mülkiyeti muhafaza kaydı gibi rehin benzeri ayni teminatlar da söz konusudur (Kaplan, 2020).

Şahsi teminatlar ise aşağıda ayrıntılı inceleyeceğimiz kredi kefaleti, borcu üstlenme, birlikte borçluluk, borca katılma ve banka garantisi olarak sayılabilir. Bunların dışında teminat olarak bir miktar nakit para ya da banka teminat mektubunun alındığı da görülmektedir (Kaplan, 2020). 


\section{Kefalet Sözleşmesi}

TBK m.581 uyarınca kefalet sözleşmesi, kefilin asıl borçlunun borcu ödememesi halinde borçtan şahsen sorumlu olmayı üstlendiği sözleşmedir. Kefalette üç ayrı tür ilişki bulunur. Bu ilişkiler asıl borçlu ile asıl alacaklı arasındaki asıl borç ilişkisi, kefille asıl borçlu ve asıl alacaklı arasındaki ilişkilerdir.

Esas itibariyle kefalet sözleşmesinde kefille asıl alacaklı arasındaki ilişki önem taşır. Kendisi yararına kurulan kefalet sözleşmesine asıl borçlunun rızası ve hatta bilgisi gerekmez. Kefalet sözleşmesinin kurulması aynı zamanda kefille borçlu arasında bir borç ilişkisi oluşması için yeterli değildir. Kefilin ödemiş olduğu kefalet sözleşmesinden kaynaklanan borç, asıl borçlunun borcu değil, kendisinin üstelenmiş olduğu borçtur. Kefille asıl borçlu arasındaki ilişki, kefalet sözleşmesinden ayrı olarak vekalet, vekaletsiz iş görme veya bağışlama sözleşmesinden kaynaklanabilir (Aral ve Ayranc1, 2018).

\subsection{Kredi Kefaleti}

Kefalet, ticari hayatta daha çok bankalardan kredi kullanarak ödünç para alan borçluya kefil olma şeklinde görülmektedir. Banka kefaleti denilen bu türde neredeyse tüm kredilere kefil alınmaktadır. Banka kredisi kullanan asıl borçlu ticaret şirketiyse şirketin bütün ortakları müteselsil kefil olarak kredi sözleşmelerine imzaları alınmaktadir (Kaplan, 2020).

Bu şekilde Türk bankacılık uygulamasında, anonim ve limited şirket borçlarından ortakların sadece koymayı taahhüt ettikleri borçtan dolayı sınırlı sorumlu olduklarını öngören TTK m.329 ve 602 hükümleri etkisiz bırakılmış olmaktadır. Asıl borçlu şirket borcu ödeyemezse bankalar müteselsil kefil sıfatıyla imza koyan ortaklara kolaylıkla başvurmaktadırlar. Üstelik, asıl borçlu şirket için kanunlarda öngörülen konkordato ve benzeri hukuki imkanlardan kefil ortakların yararlanması ya imkânsız ya da çok sınırlı olmaktadır. Halbuki sınırlı sorumluluk ilkesinin kabul sebebi, ticari girişimde bulunan tacirin sadece bu işe özgülediği malvarlığı ile sorumlu olması, şahsi malvarlığına başvurulamamasıdır (Topaloğlu, 2010).

\subsection{Kefaletin Şekil Şartları}

Kefaletin şekli şartları da TBK m.583 hükmünde gösterilmiştir. Buna göre, kefalet sözleşmesinin yazılı olması ve kefilin sorumlu olduğu miktar ile kefalet tarihinin kendi el yazısı ile yazılması gerekmektedir. TBK m.583 hükmünde "Kefalet sözleşmesi, yazılı şekilde yapılmadıkça ve kefilin sorumlu olacağı azami miktar ile kefalet tarihi belirtilmedikçe geçerli olmaz. Kefilin, sorumlu olduğu azami miktarl, kefalet tarihini ve müteselsil kefil olması durumunda, bu sıfatla veya bu anlama gelen herhangi bir ifadeyle yükümlülük altına girdiğini kefalet sözleşmesinde kendi el yazısıla belirtmesi şarttır." denilmektedir.

Kanunun bu hükmünden, kefalet sözleşmesinde kefilin;

- sorumlu olacağı azami miktarı,

- kefalet tarihini,

- müteselsil kefalet halinde, bu sıfatla veya bu anlama gelen herhangi bir ifadeyle yükümlülük altına girdiğini, kendi el yazısı ile yazması zorunlu tutulmaktadır.

TBK m.583/II hükmüne göre, kefil olma konusunda verilecek temsil yetkisi ve vekâletler için dahi yukarıda belirtilen şekil koşullarına uymak gerekir. Örneğin kefil olma konusunda verilecek bir vekâletnamede bile kefil olunacak miktarın kefil olunulacak tarihin ve müteselsil kefil olunacaksa bu husususun vekaletnameye açıkça yazılması şarttır (Eren, 2015).

TBK m.584'e göre evli kişilerin ancak eşlerinin yazılı izniyle kefil olabilirler. Ancak 6455 sayılı Kanunla TBKm.584'e eklenen fikra ile ticari ilişkilerde eşin rızasına önemli istisnalar getirilmiştir. Buna göre, kefil ticaret siciline kayıtlı ticari işletmenin sahibi ise veya ticaret şirketinin ortak ya da yöneticisi tarafından işletme veya şirketle ilgili olarak verilecek kefaletler, mesleki faaliyetleri ile ilgili olarak esnaf ve sanatkarlar siciline kayıtlı esnaf veya sanatkarlar tarafindan verilecek kefaletler, kamu bankaları tarafindan verilecek bazı kefaletler ile tarım kredi, tarım satış ve esnaf ve sanatkarlar kredi ve kefalet kooperatifleri ile kamu kurum ve kuruluşlarınca kooperatif ortaklarına kullandırılacak kredilerde verilecek kefaletlerde eşin rızasının alınmasına gerek yoktur (Yavuz, 2019).

Yine, nitelikli bir kefalet olan TTK m.700-702.maddelerinde düzenlenmiş bulunan bono, poliçe ve çek borçlularından birisi lehine evli kişilerin aval vermesi halinde Yargıtay İçtihatları Birleştirme Büyük Genel Kurulu'nun 20.04.2018 tarih ve E.2017/4, K.2018/5 sayılı kararına göre diğer eşin rızası aranmaz. Başka bir deyişle, söz konusu içtihadı birleştirme kararı gereği kambiyo senetlerine aval halinde TTK m.584/III hükmü uygulanmaz (Pulaşl1, 2019).

Yargıtay gayrinakdi kredi türleri olan banka teminat mektuplarının bedellerinin depo edilmesi taleplerinde müşterinin sorumluluğuna kefalet için genel kredi sözleşmesinde bu hususa ilişkin açık ve özel hükmün varlığını aramaktadır. Yoksa sadece kredilere kefil olunduğuna yönelik kefalet beyanı teminat mektup bedellerinden kefil olarak sorumlu tutulmak için yeterli değildir. Yargıtay 19.Hukuk Dairesi'nin bu konudaki 24.03.2016 tarih ve E.2015/16437, K.2016/5281 say1lı içtihadında şu ifadelere yer verilmektedir: "Dava konusu genel kredi sözleşmesinde müşterek ve müteselsil borçlu sıfatıyla sorumlu olan davalılar ..., ...ve... 'nun temyiz itirazlarına gelince, müşterek ve müteselsil borçlu olan davalılardan teminat mektubu depo bedelinin talep edilebilmesi için, 
takip dayanağl genel kredi sözleşmesinde müşterek ve müteselsil borçlular yönünden açıça hüküm bulunması gerekmektedir. Söz konusu sözleşmede böyle bir hüküm bulunmadiğl takdirde müşterek ve müteselsil borçluların teminat mektubu depo bedelinin ödenmesi ile sorumlu tutulamayacaklarının gözetilmemesi doğru görülmemiştir.”

Yüksek Yargıtay, aynı şekilde 5941 sayılı Çek Kanunu m.3 uyarınca bankaların çek yaprağı başına ödeyecekleri maktu bedellerin depo edilmesi taleplerine kefaletin geçerli olabilmesi için de bu konuda genel kredi sözleşmesinde açık ibarenin bulunması gerektiği görüşündedir: "Dava konusu genel kredi sözleşmesinde müşterek ve müteselsil borçlu sıfatıyla sorumlu olan davalılar ..., ...ve... 'nun temyiz itirazlarına gelince, müşterek ve müteselsil borçlu olan davalılardan teminat mektubu depo bedelinin talep edilebilmesi için, takip dayanağı genel kredi sözleşmesinde müşterek ve müteselsil borçlular yönünden açıça hüküm bulunması gerekmektedir. Söz konusu sözleşmede böyle bir hüküm bulunmadığ takdirde müşterek ve müteselsil borçluların teminat mektubu depo bedelinin ödenmesi ile sorumlu tutulamayacaklarının gözetilmemesi doğru görülmemiştir." (Yargıtay 19. Hukuk Dairesi, 11.04.2016 gün ve E.2016/3619, K.2016/6223).

\section{Kefalet Sözleşmesinde Değişiklik ve İlaveler}

Kefalet sözleşmesinde kefilin sorumluluğunu artıran sonradan yapılan değişikliklerin, yine yukarıda belirtilen şekil şartlarına uyulmaz ise geçerli olmayacağı TBK m.583/III hükmünde öngörülmüştür.

Ancak, TBK m.584/II uyarınca, kefalet sözleşmesinde sonradan yapılan ve kefilin sorumlu olacağı miktarın artmasına veya adi kefaletin müteselsil kefalete dönüşmesine ya da kefil yararına olan güvencelerin önemli ölçüde azalmasına sebep olmayan değişiklikler için eşin rızası aranmaz.

Kefaletin kapsamı ve kefilin sorumluluğu konusunda banka kredi sözleşmelerinden doğan itirazın iptali davalarını inceleyen Yargıtay 19. Hukuk Dairesi, özel bir takım yorum kuralları ve içtihat hukuku geliştirmiş̧tir. Yargıtay, özellikle süreç içinde birden fazla kredi sözleşmesinin imzalandığı banka kredi ilişkilerinde, kredi, hangi sözleşmeye istinaden kullanılmışsa, o sözleşmede imzası bulunan kefili sorumlu tutmaktadır. Diğer bir deyişle kefil, ancak kefaleten imzaladığı sözleşmeye dayalı kullanılan kredilerden sorumludur. Kural olarak banka kredi ilişkisi, rotatif ve cari hesap şeklinde çalışıyorsa, kredi bakiyesi zaman içinde değişiklik gösterebilir. Borçlu bankadan çektiği bu tür kredi ilişkilerinde ödeme yaparak bakiyeyi sıfırlayabilir, sonradan ayanı kredi ilişkisi içinde tekrar kredi kullanabilir. Kefilin sorumluluğu da imzaladığı genel kredi sözleşmesine bağlı olarak yürüyen kredi ilişkisi tamamen sona erinceye kadar devam eder. Zaman içinde kredi bakiyesinin değişiklik göstermesi, kredinin artması azalması hatta sıfirlanıp tekrar kullanılması kefilin sorumluluğunda değişiklik yapmaz. Ancak, daha sonra imzalanan yeni kredi sözleşmesine dayalı olarak kullanılan yeni kredilerde sonraki kredi sözleşmesinde imzası bulunmayan kefil sorumlu tutulamaz. Bunun için Yargıtay, kullanılan kredilerde krediyle sözleşmelerin referans numaralarının da araştırılmasını ve karşılaştırılmasını istemektedir. Bu titiz araştırmanın temelinde başkasının borcu için şahsen sorumluluk altına giren kefili koruma düşüncesi yatmaktadır. Yargıtay’ın bu konuda istikrar kazanmış görüşü yansıtan 19.Hukuk Dairesi'nin 17.12.2018 tarih ve E.2017/1029, K.2018/6660 say1l kararı şu şekildedir: "Mahkemece, toplanan deliller ve tüm dosya kapsamına göre, icra dosyası içeriğinden alaca $\breve{g}$ temlik eden Akbank tarafından dava dışı Doğa şirketi ile iki ayrı kredi taahhütnamesi imzalandı̆̆l, davalının 2005 tarihli sözleşmede imzasının bulunduğu ancak 2011 tarihli sözleşmede imzasının olmadı̆̆l, takibe konu kredinin 2011 tarihli kredi sözleşmesine istinaden kullandırıldĭ̆ , Yargltay yerleşik uygulamaları gereğince de sonraki tarihli başka bir kredi sözleşmesine istinaden kredi kullandırllmış ise sonraki sözleşmeden dolayı, kefilin sorumlu olmayacağından davanın reddine karar verilmiş, karar davacı vekili tarafindan bozulması istemiyle temyiz edilmiştir.

Dosyadaki yazllara kararın dayandı $\breve{l}$ delillerle gerektirici sebeplere, delillerin takdirinde bir isabetsizlik bulunmamasına göre, davacı vekilinin yerinde görülmeyen bütün temyiz itirazlarının reddiyle usul ve kanuna uygun bulunan hükmün ONANMASINA,"

\section{Banka Kredi Yapılandırmaları}

Reel sektörün yaşadığı finansal darlıklar ve kredi geri ödemelerinde yaşanan sıkıntılar nedeniyle bankalar kredi müşterilerinin kullandıkları kredileri yapılandırma yoluna gitmektedirler. Bunun için banka ile müşterisi arasında yeni bir yapılandırma kredi sözleşmesi imzalanmaktadır.

\subsection{Genel Olarak Yenileme}

TBK m.133-134.maddelerinde düzenlenen yenileme, borcu sona erdiren nedenlerden biridir. Yenilemeyle eski borç ortadan kalkar ve onun yerine yeni bir borç doğar (Oğuzman ve Öz, 2020).

Borcun yenilenmesi için alacaklı ile borcu arasında yenileme denilen bir sözleşmeye ihtiyaç vardır. Borcun yenilenmesi, karine olarak kabul edilmediğinden tarafların açık iradesinin varlığını gerektirir. TBK m.133/II hükmü, bu hususu teyit etmek için mevcut borç için kambiyo taahhüdünde bulunulmasının, bir alacak senedi veya yeni bir kefalet senedi düzenlenmesinin yenileme sayılmayacağını açıkça ifade etmektedir (Eren, 2017). 
Yenileme, eski borcun sona ermesine, buna karşılık yeni borcun doğmasına sebep olur. Yeni borç bağımsız bir borç olarak varlık kazanır. Yenilemenin faiz borçlarında gösterdiği özellik, faiz borcunun ana para borcuna dönüşmesi ile kendisine faiz yürütülmesinin mümkün hale gelmesidir (Eren, 2017).

Yenilemeyle birlikte eski borçtan doğan defiler ve rehin, kefalet gibi feri haklar da sona erer. Zira asıl borç sona erince ona bağlı feri hakların sona ermesi, asillik ferilik ilişkisinin doğal bir sonucudur (Eren, 2017).

\subsection{Banka Kredi Yapılandırmalarının Yenileme Niteliği}

Esasen kredi yapılandırma işlemi bir tür yenileme (tecdit) niteliğindedir. Zira yenilemeyle birlikte eski kredi borcu vade ve taksit miktarı gibi bütün modülleriyle birlikte sona ermektedir. İkinci ve yenilen kredi borcu bütün bu modülleriyle birlikte yeni bir borç olarak ortaya çıkmaktadır.

Bundan başka eski kredi borcuna bağlı kefalet ve ipotek gibi teminatlar da kendiliğinden sona ermektedir. Bunun için eski borca kefil olanların yenilenen kredi borcuna da ayrıca kefil olarak imza atmaları gerekir. Aksi halde önceki krediye kefillerin yapılandırılmış yeni kredi sözleşmelerinden kefil olarak sorumlu tutulmaları mümkün olmaz.

Mevcut ipotek, ipotek akit tablosu doğacak borçları da kapsaması şartıyla yenilenen kredi borcunu da temin etmeye devam eder.

Yargıtay 19. Hukuk Dairesi, kredi yapılandırmalarını ve yapılandırma için imzalanan kredi sözleşmelerini yenileme niteliğinde görmektedir. Yüksek Daire'nin bu konuda istikrar kazanmış uygulamasına göre, kredi borcunun yapılandırılması halinde, yapılandırma/kredi sözleşmesini imzalamayan önceki kredi sözleşmesinin kefilinin yenilemeyle sona eren önceki borçtan sorumluluğun kalkacağı ve imzası bulunmayan yapılandırma kredisinden sorumlu tutulamayacağı yönündedir: Yargıtay 19. Hukuk Dairesi 15.11.2018 gün ve E.2016/20198, K.2018/5840 sayılı kararında yapılandırma ve önceki sözleşmedeki kefilin hukuki durumunu belirleyen son emsal kararı şu şekildedir: "Davacı vekili, davacı banka ile dava dışı ... arasında ilk olarak 12/05/2009 tarihinde, daha sonra 02/11/2011 tarihinde genel kredi sözleşmesi imzalandı̆̆ını, davalının da müşterek müteselsil kefil sıfatıyla sözleşmeyi imzaladığını, kredi borcunun ödenmemesi üzerine, kredi alacă̆ının tahsili için başlatılan icra takibine davalının itiraz ettiğini belirterek, itirazın iptali, takibin devamı ile davalı aleyhine icra inkar tazminatına hükmedilmesini talep ve dava etmiştir.

Davalı vekili, davalının 12/05/2009 tarihli 50.000-USD bedelli sözleşmeye kefil olduğunu, ayrıca bu kredinin teminatı olarak dava dışı borçlu ...'ın gayrimenkulü üzerine ipotek tesis edildiğini, davacı banka ile dava dışı ... arasında 02/11/2011 tarihinde imzalanan ikinci sözleşmede davalının imzasının olmadığını, ikinci sözleşme ile ilk sözleşmenin ortadan kaldırıldığını, ikinci sözleşmenin imzalandı̆̆ı tarihte ilk sözleşmeden dolayı herhangi bir borcun bulunmadı̆̆ını belirterek, davanın reddine karar verilmesini istemiştir.

Mahkemece yapılan yargılama, toplanan deliller ve benimsenen bilirkişi raporlarına göre, davacı banka ile dava dışı borçlu ... arasında 12/05/2009 tarihinde imzalanan genel kredi sözleşmesinde davalının kefalet imzasının bulunduğu, bu sözleşmeye istinaden kullandırılan krediler ile ilgili ödeme yapılmaması nedeniyle davacı banka ile dava dışı asıl borçlu ... arasında 02/11/2011 tarihli yeni bir genel kredi sözleşmesi imzalandı̆̆l, bu sözleşme ile önceki kredi sözleşmesinden doğan borçların kapatılarak yeniden borç yapılandırmasına gidildiği, ikinci sözleşmede davalının imzasının bulunmadığ sözleşme ile önceki sözleşmeye istinaden kullandırllan kredilerin kapatıldı̆̆l, tecdit (yenileme) sözleşmesinin önceki borçlar yönünden borcu sona erdiren nedenlerden olduğu, tecdit sözleşmesinde davalının imzası bulunmadı̆̆ından davalının sorumlu tutulamayacă̆l gerekçesiyle davanın reddine, davacının kötüniyetli olarak takip başlattığı ispatlanamadığından davalının kötüniyet tazminatı talebinin reddine karar verilmiş, hüküm taraf vekilleri tarafindan temyiz edilmiştir.

Dosyadaki yazllara kararın dayandı̆̆ delillerle gerektirici sebeplere, delillerin takdirinde bir isabetsizlik bulunmamasına göre, taraf vekillerinin yerinde görülmeyen bütün temyiz itirazlarının reddiyle usul ve kanuna uygun bulunan hükmün ONANMASINA..."

\section{Sonuç}

Banka kredileri günlük hayatımızın vazgeçilmez bir parçasıdır. Bankalar da verdikleri kredilere sıklıkla kefil olarak şahsi teminat altına almak istemektedirler. Yargıtay, kefaletin geçerliliği açısından başkasının borcu için sorumluluk altına giren kefil lehine yorum yapma eğilimindedir.

Özellikle faiz dalgalanmaları ve ekonomik krizler bankalarla müşterileri arasında yapılandırma kredisi kullandırma yoluna gitme ihtiyacı doğurmaktadır. Kredi yapılandırmaları TBK m.133 anlamında yenileme niteliğindedir. Dolayısıyla yapılandırma ile ilk kredi borcu sona ermekte ve yapılandırılan yeni kredi borcu bağımsız bir borç olarak doğmaktadır. Bu bakımdan eski kredi borcuna bağlı olarak verilmiş bulunan kefaletler de sona erer. Bunun için kefillerin yapılandırma ile oluşan yeni kredi borcunu da kefil olarak imza koymaları gerekir. 


\section{Kaynakça}

- Aral ve Ayranc1, 2018. Borçlar Hukuku Özel Borç İlişkileri. Yetkin Yayınları, Ankara.

- Eren, 2015. Borçlar Hukuku Özel Hükümler. Yetkin Yayınları, Ankara.

- Eren, 2017. Borçlar Hukuku Genel Hükümler. Yetkin Yayınları, Ankara.

- Kaplan, 2020. Banka Sözleşmeleri Hukuku. Yetkin Yayınları, Ankara.

- Oğuz, 2019. Bankacılık Hukuku Yönünden Ticari Kredi Açma Sözleşmeleri. Seçkin Yayıncılık, Ankara.

- Oğuzman ve Öz, 2020. Borçlar Hukuku Genel Hükümler. C.II. Vedat Kitapçılık, İstanbul.

- Pulaşl1, 2019. Kıymetli Evrak Hukukunun Esasları. Adalet Yayınevi, Ankara.

- Topaloğlu, 2010. "Sermaye Şirketlerinde Tüzel Kişilik Perdesinin Kaldırılması ve Bu Konuda Ticaret Kanunu Tasarısında Getirilen Hükümler”, Prof. Dr. Firat ÖZTAN’a Armağan, Turhan Kitabevi, Ankara. p.2083.

- Yavuz, 2019. Borçlar Hukuku Dersleri (Özel Hükümler). Beta Basım Yayın, İstanbul. 


\title{
İdari Yaptırımlar, Lehe Kanun Uygulaması ve Yargıya Güven Administrative Sanction Decisions, the More Favorable Law Application and Trust on Judiciary
}

\author{
Assoc. Prof. Dr. Gürsel Özkan (Turkish State Council, Turkey)
}

\begin{abstract}
In terms of administrative sanctions, application of the more favorable law means that when the law in force the time an act was committed, and a law subsequently brought into force is different, the law which is more favorable should be applied. EHRC states that applying more stringent punishment to an offender on the grounds that more stringent punishment was in force when the time criminal offence was committed. Misdemeanors have been considered within the scope of criminal law by the Constitutional Court and the Constitutional Court accepts that the principle of the application of the more favorable law should be applied to misdemeanors. Danıştay (the Turkish Council of State) decides that "it should be taking into account in terms of administrative sanctions, when a law which is the ground of punishment is set aside or more favorable law is brought into force". Since administrative acts are reviewed during annulment cases, a law brought into force after an administrative act cannot affect the act retrospect. A law which is enters into force after an administrative act established, could set up a rule which has retrospective affect only if the rule clearly is an amnesty. After an administrative fine is imposed, applying criminal law principals to administrative law and administrative sanctions, in other words, rendering decision of annulment on the ground of the principle of the more favorable law betrays the trust on judicial bodies and law.
\end{abstract}

\section{Giriş}

Ceza sisteminin etkili olması toplumsal huzur ve düzenin korunması ve toplumsal gelecek bakımından önem taşımaktadır. Ceza adalet sisteminin yeterli etkiye sahip olmaması ise devlete saygı ve güvenin azalmasına ve bunun sonucu olarak da toplum içerisinde anarşi ve kargaşanın doğmasına neden olabilmektedir. Cezalandırmanın toplum tarafından kabul edilip, insan vicdanında onay görmesi, diğer bir deyişle, meşruiyetini kazanması, ancak âdil bir cezalandırma ile mümkün olabilir. Cezalandırma, aslında adaleti gerçekleştirme aracı olup suç bir haksızlık olarak kabul edildiğinde cezalandırma, bu haksızlığın giderilmesinin aracı olmaktadır. Bu anlamda cezayı ortaya çıkaran, cezalandırma ihtiyacıdır. İşte cezanın şiddetini belirleyen de haksızlığın şiddeti, yani adalet ihtiyacının azlığı ya da çokluğudur.

Türkiye mevcut hukuki yapıdan dolayı modern bir toplum niteliği taşımaktadır. Ancak kanunların ya da ceza usullerinin yasal olarak düzenlenmiş olması yeterli olmamakta, benimsenen kanunların uygulanması da gerekmektedir. Ceza adalet sisteminin etkinliği için öncelikle cezanın caydırıcılığının sağlanması önem taşımaktadır. Ceza adalet sistemine toplumun güven duygusunun azalmasının nedeni, yargılamaların uzun sürmesi, ceza kanunlarının sık sık değişmesi ve suç işleyenlerin hak ettikleri cezayı almadıkları ya da alsalar bile bu cezanın genel af ya da örtülü aflarla tam olarak infaz edilmediği düşüncesinin toplumda yaygın olarak yer etmiş bulunmasidir.

Bu tebliğde, hukuka aykırı eylem nedeniyle tesis edilen yaptırım-idari para cezasının iptali istemiyle açılan dava devam ederken gerek mahkeme aşaması gerekse istinaf ve temyiz sürecinin uzun sürmesi diğer bir ifadeyle yargılamanın makul sürede sonuçlandırılmaması nedeniyle işlemin tesis edilmesinden sonra idari para cezasına konu eylemin suç niteliği ile ilgili yeni bir düzenleme yapılması durumunda, idari işlemin tesis edildiği tarihteki mevzuata uygunluğu bakımından iptal davasına ilişkin idare hukuku ilkeleri yerine sonradan yapılan düzenleme esas alınarak suç ve cezalara ilişkin ceza hukuku ilkelerinin sonradan çıkan kanunun lehe hüküm olması durumu dikkate alınarak lehe hüküm nedeniyle verilen iptal kararlarının değerlendirilmesi yapılacak ve yargıya güven duygusuna olan etkisi üzerinde durulacaktır.

\section{Yaptırım Kavramı ve İdari Yaptırımlar}

\subsection{Yaptırım Kavramı}

Yaptırım, hukuk kuralının ihlaline sosyal yapı tarafından gösterilen tepki ve ihlal edene uygulanan zorlama veya cebir (Antalya, 2019), diğer bir ifadeyle hukuk kuralının kişiden belirli bir davranışta bulunmasını istemesi ve istenildiği gibi davranışta bulunulmamasının cezalandırılması anlamına gelmektedir. Yaptırım, kanunda düzenlenen davranış kuralına uygun davranmama halinde devlet zoruyla uygulanan maddi, olumsuz, zorlayıcı hukuki sonuçtur. Hukuk normundaki maddi olgular gerçekleştiğinde hukuki sonuç (yaptırım) somut olaya uygulanır. Çünkü maddi yaptırımı olmayan bir hukuk düzeninin geçerli olması ve varlığını devam ettirmesi düşünülemez (Güriz,1999). Belirtmek gerekir ki yaptırım hukuk kuralının ihlaline bir tepki (Hafızoğulları,1996) niteliği taşımaktadır. 
Devlet tarafından yaptırıma bağlanmış kurallara aykırı davranış halinde yine devlet tarafından zorla uygulanan norm olma niteliği ile birlikte yaptırım; baskı ve cezalandırma, tazmin, tatmin, önleme ve caydırma gibi birden fazla amaçları gerçekleştirmeye yönelik olabilmektedir. Bütün toplum için geçerli kurallar koyup bu kuralların emredici ve bağlayıcı olmasının sağlanabilmesi için hukuk sistemince kişilere yüklenmiş olan ödevlerin yerine getirilmediği durumda hukuk sistemince öngörülmüş olan zorlayıcı normların bulunması gerektiği kuşkusuzdur. İşte bu zorlayıcı normlar yaptırım olarak karşımıza çıkmaktadır.

Yaptırım, hukukun kişilere yüklemiş olduğu yükümlülükleri kendi istekleri ile yerine getirmemeleri halinde, yükümlülüklerini yerine getirmeleri için kamu gücü ile zorlanması ve gerektiğinde bu yükümlülüklerin zorla yerine getirtilmesinin sağlanmasıdır. Yaptırım ile hukuk sisteminin düzgün işlemesi, kuralların ihlal edilmesinin önlenmesi, hukuk kuralına aykırı davranılması halinde bu aykırılığın cezalandırılması ve aykırı davranma sonucunda ortaya çıkan zararın da giderilmesi amaçlanmaktadır. Bu da, bireysel ve toplumsal hak ve özgürlüklerin korunması ve toplumsal düzenin sürdürülmesi için zorunlu bulunmaktadır.

\subsection{Yaptırım Türleri}

Genellikle yaptırımın türü ve uygulanışı kanun koyucu tarafından düzenlenmekte, ancak özel hukuk yaptırımları ve kamu hukuku yaptırımları olarak genel bir tasnife tabi tutulmaktadır.

Özel hukuk yaptırımları; cebri icra, tazminat, hükümsüzlük olarak, kamu hukuku yaptırımları ise ceza hukuku yaptırımları, anayasa hukuku yaptırımları, uluslar arası kamu hukuku yaptırımları ve idare hukuku yaptırımları olarak belirtilebilir.

Özel hukuk yaptırımlarından cebri icra, bir borç ilişkisinde borcunu rızasıyla yerine getirmeyen borçlunun, kamu gücü aracılığıyla bu borcun ifasının zorla yerine getirilmesini sağlayan bir yaptırım çeşididir. Tazminat, bir kimsenin bir hukuk kuralına veya yaptığı sözleşmeye aykırı davranması sonucunda sebep olduğu zararı ödeme yükümüdür. Hükümsüzlük veya geçersizlik yaptırımı ise işlemdeki eksikliğin önemine göre ikiye ayrılmaktadır. Yokluk yaptırımı, bir hukuki işlemin kanunda öngörülen kurucu unsurlardan herhangi birinin eksik olması halinde o işlemin hiç yapılmamış gibi sonuç doğurmasıdır. Geçersizlik yaptırımının diğer türü ise butlan olup, bir hukuki işlemin kanunun öngördüğ̈ kurucu unsurları taşımakla birlikte kanunun emredici hükümlerine aykırılık taşıması durumunda "mutlak butlan", kanunun emredici hükümlerine uygun olmakla birlikte o işlemi oluşturan iradede bir sakatlığın bulunması durumunda ise "nispi butlan" söz konusu olmaktadır.

Kamu hukuku yaptırımları ise ceza hukuku yaptırımları, ağırlaştırılmış müebbet hapis, müebbet hapis, süreli hapis cezası ve adli para cezasıdır. Güvenlik tedbirleri, ceza hukukunda cezanın uygulanamadığı, uygulansa dahi yeni suçların işlenmesini önleyemediği, yetersiz kaldığı hallerde ceza sistemini tamamlayan hukuki himaye aracıdır. Bunlar belli hakları kullanmaktan yoksun bırakma, eşyaların müsaderesi, kazanç müsaderesi, çocuklara özgü güvenlik tedbirleri, akıl hastalarına özgü güvenlik tedbirleri, sınır dışı edilme ve tüzel kişilere özgü güvenlik tedbirleri şeklinde belirtilebilir.

Anayasa hukuku yaptırımları ise Anayasada öngörülmüş olan siyasi partilerin hazine yardımından mahrum bırakılması, siyasi partilerin kapatılması, TBMM üyelerinin yasama dokunulmazlıkları ile milletvekilliğinin düşürülmesi gibi anayasa hukuku yaptırımlarıdır.

Uluslararası kamu hukuku yaptırımları, diplomatik yaptırımlar, hukuksal yaptırımlar, ekonomik ve mali yaptırımlar, askeri yaptırımlar, manevi yaptırımlar, cezai yaptırımlar, tanımama, kınama, hukuka aykırı fiillerin duyurulması, uluslar arası örgütlere üye kabul etmeme, baskı ve vazgeçirme önlemleri, karşı önlemler ve zorlama yolları (savaş)dır.

İdari yaptırımlar ise idari cezalar olarak; idari para cezaları, disiplin cezaları, kabahat cezaları ve idari tedbirler şeklinde ayrıma tabi tutulabilir.

\section{3 İdari Yaptırımlar}

İdari yaptırımlar, idarenin kanunun açıkça yetki verdiği veya yasaklamadığı durumlarda, yargı kararına ihtiyaç olmaksızın doğrudan tesisi edeceği bir işlem ile idare hukukuna özgü usullerle verdiği cezayı (Özay, 1985) ifade etmektedir.

İdari yaptırımlar veya idare hukuku yaptırımları, sadece idari işlemin unsurlarında meydana gelmiş olan hukuka aykırılıklara bağlanan yaptırımları değil aynı zamanda özellikle teknik ve karmaşık düzenlemelerin olduğu alanlarda etkili bir cezalandırma aracı olarak kullanılan ve idare hukukuna özgü niteliğiyle diğer hukuk dallarına ait yaptırım türlerinden ayrılmış olan disiplin cezaları, lisans iptalleri, idari para cezaları gibi yaptırım türünü de kapsayan yaptırımlardır.

Devletin yürütme fonksiyonu, toplumun her gün değişen ihtiyaçlarına cevap verme, kamu ihtiyaçlarının gerektirdiği kamu hizmetlerini sunma, kamu güvenliğini ve sağlığını koruma, kamu düzenini sağlama ve sürdürme gibi günlük iş ve eylemlere ilişskin görevlerini kapsamaktadır. Bu görevleri yerine getirmek için idare, kimi zaman genel, soyut, objektif ve kişilik dışı düzenleyici işlemler yapmakta kimi zaman da bir hizmetin görülmesi için özel ve sübjektif işlemler tesis etmektedir. İdare nasıl tüzük, yönetmelik, yönerge, sirküler gibi düzenleyici işlemlerle kanunların açıklamasını yaparak bir nevi yasama yetkisine iştirak etmekte ise benzer şekilde idare, şartları 
oluştuğunda kişilere ceza tayin ve tatbiki suretiyle yargı erkine de katılmaktadır. İşte yürütme fonksiyonu olarak idarenin düzenleme yetkisini düzenleyici işlemlerle, yargı fonksiyonunun cezalandırma yetkisini de idare idari yaptırımlarla kullanmaktadır. Bu anlamda idari yaptırımlar, idarenin kendi faaliyet alanı ile ilgili aldığı kararlara, emir ve yasaklara uyulmasını sağlamak amacıyla yaptırımlara ihtiyacı bulunduğu dikkate alınırsa, idarenin kanunların yasaklamadığı ve açıkça yetki verdiği hallerde herhangi bir yargı kararına gerek olmaksızın tesis edeceği bir işlemle uygulanabilen yaptırımlardır. İdari yaptırımların temeldeki belirleyiciliği, bir idari organ veya makam tarafindan kamu gücü kullanılarak yapılan tek yanlı bir idari işlem olması ve bu işlemle yasal veya idari düzenlemelere uyulmamasının karşılığında bir "ceza" öngörülmesidir (Tan, 2004). İdare, yaptırımlar alanındaki faaliyetlerini çoğu zaman kolluk yetkisine dayanarak kullanmaktadır. İdare bu yetkiyi; adli ceza yaptırımının söz konusu olduğu konularda adli makamları devreye sokacak karar ve işlemleri yaparak, idari yaptırımı doğrudan (resen) uygulayabildiği hallerde idari yaptırımı uygulayarak, bu iki imkâna sahip olamadığı acele hallerde ise resen icra gücünü uygulayarak kullanmaktadır (Oğurlu, 1999).

İdare tarafından alınan yıkım kararları idari işlem olup yıkım kararının uygulanması- icrası da bir idari işlem niteliğindedir. İdarenin bir yıkım kararı bulunmaksızın yıkımı gerçekleştirmesi ise idari bir eylem niteliğindedir. Ayrıca vergi hukukuna ilişkin idari yaptırımlarda cezanın uygulanması özellikle mali otoritelere bırakılmış olup uyuşmazlık halında yargısal otoritelerin yetkisi kabul edilmiştir. Vergi cezalarında ceza ve tazmin özelliği birlikte yer almaktadır. Mali bir yükümlülüğe uymamak mali bir yaptırımı gerektirmektedir. Belirtmek gerekir ki vergi cezaları da, idari karakterin hâkim olduğu tipik idari yaptırımlardır.

\section{1 İdari Yaptırım Türleri}

İdari düzenin bozulmasını önlemek ve bozulan düzeni yeniden kurmak amacıyla çok çeşitli tür ve niteliklerde idari yaptırımlar öngörülmüştür. İdari yaptırımları; idari para cezaları, meslek ve sanatın tatili, ruhsat ve lisans iptalleri, imar ve belediye mevzuatında öngörülen yaptırımlar ve diğer ekonomik yasal düzenlemelerden doğan (düzenleyici ve denetleyici kurullar) yaptırımlar olarak sıralamak mümkündür. İşyerinin kapatılması, belli bir yayının durdurulması, bir eserin toplanması, ruhsat ya da ehliyetin geri alınması, araçların trafikten men edilmesi gibi yaptırımlarda bulunmaktadır.

Kabahatler Kanunu'nun 16. maddesinde idari yaptırımlar, idari para cezaları ve idari tedbirler olarak belirtilmiş devamında da idari tedbirler, mülkiyetin kamuya geçirilmesi ve ilgili kanunlarda yer alan diğer tedbirler olarak düzenlenmiştir.

\subsection{1 İdari Para Cezaları}

İdari para cezası, suç teşkil etsin veya etmesin, bir hukuk kuralını ihlal eden kişinin devlete veya kanunda belirtilen başka bir yere, bir zararın tazmini amacı taşımaksızın ödemek zorunda olduğu belirli bir miktar parayı ifade etmektedir. İdari para cezaları, hazinenin uğradığ zararı ödetme amacı güden aynı zamanda "tehdit" ve "cezalandırma" yönü de bulunan yaptırımlardır. Yargı organlarının müdahalesi olmadan doğrudan idarece kararlaştırılmakta ve uygulanmaktadır. İdarî para cezaları ile kamu düzenine aykırı davranışların önlenmesi, toplumda disiplin ve düzenin sağlanması amaçlanmaktadır.

\subsection{2 İdari Tedbirler}

Yaptırım, herkesin işlemiş olduğu fiilin sonuçlarına katlanmasını, bunu ödemesini, hukuka aykırı fiili nedeniyle maruz kalacağı yaptırımın vereceği acı ve 1stırabı çekmesini öngörürken; idari tedbirler, cezalandırma iradesi taşımazlar. İdari yaptırımın ayırt edici özelliğinin cezalandırma iradesi olmasına karşın, idari tedbirin amacı hukuka aykırı bir davranışı cezalandırmak olmayıp, ilgiliyi idari kararı uygulamaya zorlayan "zorlayıcı önlemler/tedbirler" alınmasını sağlamaktır. Ceza hukukunda yer alan güvenlik tedbirleri de idari tedbirler kapsamında bulunmaktadır. Örneğin idarenin iznine bağlı olarak yürütülen bir faaliyette, izin verilmesi için aranan şartlardan birinin kaybedilmesi veya yerine getirilmemesi üzerine iznin geri alınması idari yaptırım olarak değerlendirilmemekte, idari tedbir olarak kabul edilmektedir. Bu kapsamda çeşitli kanunlarda öngörülmüş bulunan idari yaptırım gerektiren fiiller bakımından belli bir meslek ve sanatın yerine getirilmemesi, işyerinin kapatılması, ruhsat ve ehliyetin geri alınması bir tehlike durumuna karşı genel sağlık, genel güvenlik veya genel ahlak açısından zararlı kabul edilerek tehlikenin önlenmesi veya düzenin bozulmasının önlenmesi amacı taşımakta ve uygulandıklarında idari tedbir niteliğine haiz olmaktadır. Eğer bunlar bir tehlike oluşturma şartı aranmaksızın uygulanıyor iseler bu durumda, idari tedbir değil birer idari yaptırıma dönüşürler.

Bazı idari yaptırımlar kamu güvenliği ve genel sağlığı tehlikeyi düşüren durumlara son vermek için uygulandığından, bu türden idari yaptırımlara genellikle idari tedbirlerle idari yaptırımlar arasında bir yer verilmektedir. Örneğin alkollü sürücünün sürücü belgesinin geçici bir süre için geri alınması kimi zaman idari tedbir kimi zamanda idari yaptırım olarak kabul edilmektedir (Tan, 2004). Bu hususta polis tedbirleri idare tarafından uygulanmasına rağmen idari bir yaptırım olarak kabul edilmemektedir. İdarenin resen icra yetkisi ve önleyici tedbirler alma yetkisi yaptırım kavramının dışında tutulmaktadır.

İdare tarafından verilen yıkım kararlarının tamamı idari yaptırım niteliğinde olmayıp bir kısmı idari tedbir niteliği taşımaktadır. Örneğin yıkılma tehlikesi içinde olan bir yapının yıkımı, deprem sonrası hasar görmüş binaların kullanımının can güvenliği açısından tehlikeli olması durumunda yıkımı gibi hallerde artık bir kolluk tedbiri söz konusu olmaktadır. 


\section{4 İdari Yaptırımlarda Lehe Kanun Uygulaması}

\subsection{Lehe Kanun Uygulaması}

İnsan Hakları Evrensel Beyannamesi'nde, Birleşmiş Milletler Medeni ve Siyasal Haklar Sözleşmesi'nin 15/2. maddesinde geçmişe uygulama yasağının istisnası olan lehe olan kanunun geçmişe uygulanacağı açıkça düzenlenmiş bulunmaktadır.

Türk Ceza Kanunu (TCK)'nun zaman bakımından uygulamayı düzenleyen 7. maddesi lehe kanun uygulamasının dayanağını oluşturmaktadır. Buna göre hiç kimse işlendiği zaman yürürlükte bulunan kanuna göre suç sayılmayan bir fiilden dolayı cezalandırılamaz ve hakkında güvenlik tedbiri uygulanamaz. Yine "işlendikten sonra yürürlüğe giren kanuna göre suç sayılmayan bir fiilden dolayı da kimse cezalandırılamaz" ve güvenlik tedbiri uygulanamaz. Kabahatler Kanunu'nun 5. maddesine göre bu ilke kabahatler açısından da geçerli kılınmıştır.

İdari yaptırımlar açısından da sonraki kanunun aleyhe olması halinde uygulanmaması lehe olması halinde de geriye uygulanması yaptırım kararı alınmadan önceki hallerde kabul edilmiş ancak idari yaptırım kararı alındıktan sonra "yerine getirilmesinden önce" yürürlüğe giren ilgili mevzuat açısından da ceza infaz rejiminde olduğu gibi derhal uygulanırlık ilkesi benimsenmiştir. Ayrıca lehe kanunun belirlenmesi hususunda Yargıtay, fiilin suç olmaktan çıkarılıp idari yaptırıma bağlanarak kabahate dönüştürülmesini de lehe kanun olarak kabul etmektedir.

Bir fiil ancak işlendiği tarihte yürürlükte bulunan yasanın onu suç olarak nitelendirmesi halinde cezalandırılabilir. Böylece fiil tarihinden sonra çıkarılan kanunla suç ihdas edilmesi ya da suç olarak kabul gören bir fiilin cezasının nitelik ya da nicelik olarak ağırlaştırılmasının önüne geçilmektedir. Geçmişe uygulanmazlık ilkesi gereğince hiç kimse fiilin işlendiği tarihte suç olarak kabul edilmeyen bir fiilden dolayı cezalandırılamayacağı gibi fiilin işlendiği tarihte öngörülen cezadan daha ağır bir ceza ile de aleyhe sonuç doğuracak şekilde cezalandırılması mümkün değildir.

Lehe kanunun uygulanmasının temelinde hukukun genel ilkelerinden olan "eşitlik" ilkesi yatmaktadır. Eşitlik ilkesi, lehe olan kanunun genel ve eşit bir şekilde uygulanmasını gerektirmekte, lehe kanunun geçmişe uygulanması eşitlik ilkesinin bir sonucu olmaktadır. Yine zamanaşımına ilişkin olup, aleyhe sonuç doğuran sonraki normun geçmişe uygulanmaması da gerekmektedir.

Geçmişe uygulanma yasağı ve lehe kanunun geçmişe uygulanması ilkelerinin düzenleyici işlemler açısından da kabul edilerek bu ilkelerin uygulama alanının genişletilmesi, özünde özgürlüklerin güvence altına alınması ve bu anlamda temel hak ve özgürlüklerin genişletilmesi anlamı taşımaktadır. Başta fiili suç olmaktan çıkaran kanun olmak üzere lehe olan kanunların geçmişe uygulanması temel bir insan hakkı olarak kabul edilmektedir.

Lehe olan kanunun geçmişe uygulanması açısından süreli ve geçici kanunlar ile vergi kanunları istisna oluşturmaktadır. Bu tür kanunlar açısından geçmişe yürürlük ötesi uygulama yasağı terk edilebildiği gibi lehe olan kanunun uygulamasına da istisnalar getirilebilmektedir.

Düzenleyici işlemin suçun tanımına etkisi ölçüsünde suçun kanuni tanımını etkileyeceği ve bu yöndeki etkisi dolayısıyla da tıpkı bir ceza kanunu gibi düzenleyici işlemlerinde ceza yasalarının tabi olduğu rejime tabi olması gerekmektedir.

Zaman bakımından uygulama, ceza kanunlarının hangi tarihten itibaren hüküm ifade edeceği, suç ve cezalara ilişkin normların yürürlük öncesi uygulanıp uygulanmayacağına ilişkindir (Çağlayan, 2006). Yasaların zaman bakımından uygulanmasında temel ilke yasaların birbirini takip etmesi olup fiil tarihindeki yasanın esas alınıp geçmişe uygulanmamasıdır. Aynı konuya ilişkin, aynı nitelikte iki yasa aynı anda uygulanamaz. Bir yasa yürürlük tarihinden itibaren ilişkin olduğu olaylara uygulanır ancak bazen bu uygulama yürürlük tarihinden önceki olayları kapsayabileceği gibi bazen de yürürlükten kalkmış olan önceki yasa bazı hususlarda geçerli olmaya devam eder (Akı1lıŏ̆lu,1984).

İdari yaptırımlarda derhal uygulanırlık kuralının uygulaması, esasen idari yaptırım kararı verilmiş ama henüz infazı, uygulaması gerçekleştirilmemiş ve bu aşamada söz konusu kabahatin infazına ilişkin yeni bir norm yürürlüğe girmiş ise bu durumda bu norm, kendisinin yürürlüğe girmesinden önce işlenmiş yaptırımlara da uygulanması anlamı taşımaktadır. Bu halde normun kabahate ilişkin yaptırımın infazını ağırlaştırması ya da hafifletmesi açısından bir fark bulunmamakta her halükarda yürürlüğe giren norm uygulanmaktadır (Çağlayan, 2006).

\subsection{Lehe Kanun Uygulaması ve Avrupa İnsan Hakları Mahkemesi (AİHM)}

İdari suç ve ceza ile adli suç ve ceza, cezalandırmaya yetkili organ, yaptırımın uygulanması sırasında izlenen usul, yaptırımın konusu ve ağırlığı, cezalandırmayı ortadan kaldıran nedenler açısından birbirinden ayrılmaktadır. $\mathrm{Bu}$ ayrıma rağmen AİHM içtihatlarında, idari yaptırımların da bir ceza içeriği taşıdığı ve bu nedenle idari makamların bu yaptırımları uygularken izlemiş olduğu usul ve esasları "adil yargılanma hakkına" uygunluğu açısından incelemektedir (Karabulut, 2008). Bu anlamda idare hukukunun ceza hukukundan etkilenmesi, idare hukukunun gerektiği hallerde ceza hukuku kurallarını uygulaması önem taşımaktadır.

Hukuk sistemimiz içinde kimi idari yaptırımların sulh ceza mahkemelerinde yargısal denetime tabi olmaları, kimi idari yaptırımların ise kendi özel düzenlemeleri gereği ya da Kabahatler Kanunu dışında kalan yaptırım 
olmaları nedeniyle idari yargı denetimine tabi olmaları, idari yaptırımların yargısal denetiminde iki ayrı denetleme ölçü ve ilkelerinin uygulanmasına yol açılmıştır.

Avrupa İnsan Hakları Sözleşmesi (AİHS) idari yaptırımlara ilişkin herhangi bir hüküm içermemektedir. Ancak AİHM, Sözleşmenin adil yargılanma hakkını düzenleyen 6. maddesindeki "cezai nitelikteki suçlama" kavramını şekli değil maddi ölçüte göre değerlendirmekte, bu madde kapsamında ülkelerin kendi iç hukuklarında bir yaptırımı veya yükümlendirici işlemi “cezai” nitelikte görüp görmemeleri ile bağlı olmadığını ve bu konuda kendisinin “otonom” değerlendirme yapacağını belirtmektedir. AİHM, ceza'nın mutlaka üye ülkenin bir mahkemesince verilmiş olmasının zorunlu olmadığını ve idarece verilen cezaların da belli kriterleri taşıması kaydıyla bu madde yönünden "cezai nitelikte" görülebileceğini ve böylece Sözleşmenin bu maddesinde öngörülen hukuki güvencelerin aranacağını belirtmektedir. Yine, AİHM, bir yaptırımın AİHS açısından "ceza" niteliğinde sayılması için, bir mevzuat ihlaline karşılık olarak verilmesinin gerekli olduğunu ve verilen zararın tazmini kapsamında uygulanan yaptırımların Sözleşmenin 6. maddesi kapsamında "ceza” olarak görülemeyeceğine vurgu yapmaktadır (AİHM, Bendenoun/Fransa, 24.2.1994).

AİHM, bir yaptırımın Sözleşmenin adil yargılanma hakkını düzenleyen hükümleri (6. madde ve 13. madde) açısından "cezai" nitelikte kabul edilebilmesi ve bu maddelerin sağladığı güvencelerden yararlanabilmesi için, yapacağı değerlendirmede; bir yaptırımın iç hukukta nasıl nitelendiği, ihlalin gerçek niteliği, cezanın muhatabı üzerindeki etkisi ve ağırlık derecesini dikkate alacağını açıklamıştır. Uygulamada AİHM'in idari yaptırımları Sözleşmenin 6. ve 13. maddeleri yönünden "cezai" nitelikte görüp görmemede esas olarak ihlalin niteliğine ve cezanın ağırlık derecesine bakmakta ve bu noktada en belirleyici olan faktörün, yaptırımın "caydırıcı ve bastırıcı" amaç taşıyıp taşımaması önemli olmaktadır (Ulusoy, 2013).

AİHM, hukukun üstünlüğü ilkesi gereğince hâkimin, suç oluşturan eyleme kanun koyucunun orantılı bir ceza olarak belirlediği cezayı vermesinin tutarlı olduğunu, suç işleyene sadece suç işlediği tarihte daha ağır bir ceza öngörüldüğü gerekçesi ile ağır bir ceza verilmesinin ceza hukukunun temel ilkelerine aykırı bulunduğunu, bunun aynı zamanda suçun işlendiği tarihten sonra meydana gelen bütün yasal değişiklikleri ve toplumun o suç karşısındaki yaklaşım değişikliğini görmemek anlamına geldiğini, lehte olan ceza hükmünün geriye yürümesi ilkesinin cezaların öngörülebilir olması gerekliliğinin bir uzantısı olduğunu, buna göre, eğer suçun işlendiği tarihte yürürlükte olan ceza kuralı ile kesin bir hükmün verilmesinden önce kabul edilen bir ceza kuralı farklı ise hâkimin, sanığın lehine olan ceza kuralını uygulaması gerektiğini belirtmiştir. (AİHM, Scoppola/İtalya, 17.9.2009).

\subsection{Lehe Kanun Uygulaması ve Anayasa Mahkemesi (AYM)}

Lehe kanun uygulaması için ortada ceza hukuku anlamında bir suç veya cezanın bulunması gerekmektedir. AYM kabahatin suç niteliğinde olduğu saptamasını yapmakta ve suçta ve cezada kanunilik ilkesi uyarınca lehe kanun hükmünün uygulanmasını kabul etmektedir.

“Kabahatler Kanunu’nun, karşılığında idari yaptırım uygulanmasını öngördüğü kabahatlerden bir kısmının ceza hukuku kapsamında suç niteliği taşıdığı açıktır. Suç tarihinden sonra yürürlüğe giren kanunun aynı fiili suç olmaktan çıkarması veya aynı suç için daha hafif bir ceza öngördüğü durumlarda ise diğer bir alt ilke olan lehe kanunun uygulanması ilkesi gündeme gelmektedir. Sonraki kanunun fiili suç olmaktan çıkarması veya daha hafif bir ceza öngörmesi durumunda lehe kanundan söz edilir. Aleyhe kanunun geçmişe uygulanması yasağından farklı olarak lehe kanunun uygulanması ilkesine ilişkin bir hükme Anayasa'nın 38. maddesinde açıkça yer verilmemiştir. Bununla birlikte aynı maddede suç için mutlaka fiilin işlendiği zaman yürürlükte olan kanunun öngördüğü cezanın verilmesi yönünde bir kural da bulunmamaktadır.” (AYM, E. 2019/9, K. 2019/27, K.T. 11/4/2019).

AYM'nin idari yaptırımları ceza hukuku kapsamında suç saymasının açıklaması ceza kanunu kapsamındaki fiillerin kabahat olarak idari para cezasına dönüştürülmüş olmaları gerekçesine dayandırılmıştır. "Nitekim Kabahatler Kanunu'nun İkinci Kısmında 'Çeşitli kabahatler' başlığı altında düzenlenen fiilleri, ağırlıklı olarak 765 sayılı Türk Ceza Kanunu'nun 526. ve devamı maddelerinde düzenlenmiş olan kabahatler oluşturmaktadır. Ayrıca, çeşitli yasalarda yer alan ve yaptırımı hafif hapis ya da hafif para cezası veya her ikisi olan fiiller, 5252 sayılı Türk Ceza Kanununun Yürürlük ve Uygulama Şekli Hakkında Kanun'un 7. maddesiyle idari para cezasına dönüştürülmüşlerdir. Uygulanacak yaptırımın yasa ile 'idari' para cezasına dönüştürülmesinin bu tür yaptırım uygulanacak eylemlerin gerçekte ceza hukuku alanına giren suç olma özelliklerini etkilemeyeceği açıktır” (AYM, E.2007/115, K.2009/80, K. T. 11/6/2009).

\subsection{Danıştay Kararlarında Lehe Kanun Uygulaması}

Suç teşkil eden fiilin işlenmesi ile cezanın hukuki anlamda kesinleşmesi arasındaki süreçte o suç ve/veya cezaya ilişkin olarak mevzuat değişikliği olursa ve sonraki değişiklik suçlananın lehine ise bu değişikliğin o kişiye uygulanması, aksi durumda yani aleyhine ise sonraki değişiklik değil, önceki mevzuat hükümlerinin uygulanmaya devam edilmesi Danıştay tarafından yerleşik içtihat olarak benimsenmiştir. Danıştay bu ilkenin tüm idari cezalar için uygulanmasını hukuksal bir zorunluluk olarak görmektedir.

Danıştay, “...İdari yaptırımlar bakımından ceza verilmesinin dayanağı kuralın yürürlükten kaldırılması veya lehe düzenleme yapılması yoluyla ortaya çıkan yeni hukuki durumun dikkate alınması gerektiği... (Danıştay İDDK, E. 2015/4256, K.2017/2345, K.T. 29.5. 2017)" ne karar vermekte, yine "Ceza hukuku kökenli bir ilke olan lehe olan hükmün uygulanması, işlendiği zamanın hukuki normları uyarınca suç sayılan bir fiil sonradan yürürlüğe 
giren bir düzenleme ile suç olmaktan çıkarılmış bulunuyorsa veya sonradan yürürlüğe giren düzenleme suçun işlendiği zaman mevcut olan düzenlemeye göre suçlunun lehinde ise, sonraki normun daha önce işlenmiş olan fillere uygulanmasını öngörmektedir" (Danıştay İDDK, E.2014/5191, K.2016/211, K.T. 10.2.2016) şeklinde açıklama yapmaktadır. Danıştay lehe kanun hükmü uygulamasını, değişik yönleriyle dikkate almakta ve bu konuya ilişkin ilke niteliğinde esaslar belirlemiş bulunmaktadır.

\subsubsection{Zamanaşımı Uygulaması}

İdarî yaptırımlar bakımından ceza verilmesinin dayanağı kuralın yürürlükten kaldırılması veya lehe düzenleme yapılması yoluyla ortaya çıkan yeni hukukî durumun dikkate alınması gerekmektedir. Zamanaşımına ilişsin hükümler açısından, zamanaşımı hükümlerinin sonuçları bakımından yerine getirilmesi yani zaman aşımı infaz aşaması bakımından sonuçlar doğurmaktadır. Dolayısıyla ceza verme ve cezayı infaz etme imkânını ortadan kaldıracağı ve bu durumun da maddî ceza hukukuna ilişkin olduğu dikkate alındığında, idari yaptırım kararı alınması için belirlenmiş olan sürede işlem tesis edilmemiş olmasında lehe kanun hükmünün uygulanması gerekmektedir.

Danıştay zamanaşımı uygulamasına ilişkin verdiği kararda; "Dava konusu olayda, 5015 sayılı Kanun'da öngörülen 5 ylllık zamanaşımı süresine göre lehe düzenlemeler getiren 5326 sayll Kabahatler Kanunu'nun 20. maddesinde yer alan 4 ylllık zamanaşımı süresinin uygulanacağı...dava konusu idarî para cezasının verilmesine dayanak olan davacı şirketin yeniden satış amaçlı satış yaptı̆̆ son tarihin 10.05.2006 tarihi olduğu davalı idarece sunulan savunma ekinde yer alan muavin defter kayıtlarından anlaşılmakla, davacı şirketin yeniden satış amaçlı satı̧ yaptı̆̆ son tarih olan 10.05.2006 tarihinden itibaren 4 yll geçmekle zamanaşımına uğrayacağl, zamanaşımı süresinin dolmasindan sonra alınan, davacı şirketin idarî para cezası ile cezalandırlmasına ilişskin 21.12.2010 tarihli Kurul kararında hukuka uygunluk görülmemiştir. " (Danıştay Onüçüncü Daire, E. 2011/1196, K. 2015/4806, K.T.29.12.2015; Danıştay Onüçüncü Daire, E. 2014/1952, K. 2019/2798, K.T. 30.09.2019).

\subsubsection{Yaptırım Türünün Değişmesi}

Danıştay, idari yaptırım uygulandıktan sonra yaptırıma konu eylem için belirlenmiş olan yaptırım türünde değişiklik yapılması veya yaptırıma konu eylemin suç vasfında değişiklik olması, yaptırıma tabi tutulmuş suç sayılarak cezayı gerektiren eylemi işleyen kişinin lehine sonuç doğurması değerlendirmesi yapmaktadır.

Nitekim Danıştay, “... niteliği itibarıyla düzeltme imkânı bulunan fiilleri işleyenlerin önceki kanun döneminde doğrudan idarî para cezasına muhatap oldukları hâlde, söz konusu kanun değişikliğinden sonra aynı fiilleri işleyenlerin ihlâlin ortadan kaldırlması hususunda ihtar edilmelerinin öngörülmesi, böylelikle ihtar edilen kişilerin söz konusu ihlâli ortadan kaldırarak ceza almaktan kurtulabilmelerine imkân tanınması karşısında, ihtar müessesesinin maddî hukuka etkisinin bulunduğu ve lehe kanun kapsamında belirtilen fiilleri önceki kanun döneminde işleyenler yönünden de geçmişe etkili olarak uygulanması gerektiği sonucuna ulaşılmuştır...Tüm bu hususlar bir arada değerlendirildiğinde, 5307 sayılı Kanun'da yapılan değişiklik uyarınca alınan düzenleyici Kurul kararlyla niteliği itibarıyla düzeltme imkânı olan fiiller arasinda sayılan sorumlu müdür belgesine sahip sorumlu müdür çalıştırmama fiili nedeniyle idarî para cezası verilmeden önce ihtarda bulunma şartının yerine getirilmesi ve lehe kanun niteliği taşıyan söz konusu kuralın davacıya da uygulanması zorunluluğu karşısında, lehe kanun hükmü dikkate alınarak yeniden bir karar verilmesi gerekmektedir." (Danıştay Onüçüncü Daire, E. 2014/5278, K. 2019/3928,K.T. 28.11.2019; Danıştay Onüçüncü Daire, E. 2014/1139, K. 2019/3452, K. T. 05.11.2019; Danıştay Onüçüncü Daire, E. 2013/2712, K. 2019/1557, K.T. 07/05/2019; Danıştay Onüçüncü Daire, E. 2014/1263, K. 2019/3455, K.T. 5,11,2019) gerekçesine yer vermektedir.

Yaptırım türünün değiştirilmesi normlar hiyerarşisine tabi olarak kanunilik ilkesinin gereği aynı norm ile düzenleme yapılmasını gerektirmektedir. Danıştay, kanun hükmü ile para cezasını gerektiren fiilin yönetmelik ile uyarı yaptırımı olarak hafifletilmesini hukuka aykırı bulmuştur. İdarenin düzenleyici işlemi ile kanun koyucu tarafından açıkça yaptırım olarak para cezası öngörülen fiiller hakkında, yaptırım türünün değiştirilmesi mümkün değildir. Nitekim "Bilgi Teknolojileri ve İletişim Kurumu İdari Yaptırımlar Yönetmeliği ile kanuna aykırı olarak getirilen "uyarı" müessesesinin hukukî dayanağı bulunmadı̆̆ından, 5809 sayılı Kanun hükümlerine göre idarî para cezası uygulanmasını gerektiren bir ihlâl ya da fiile, idarenin, kanunda sayılan hafifletici nedenleri gözeterek yine kanunda belirtilen alt ve üst sinır içerisinde para cezası uygulamak dışında, başka bir yaptırım uygulamak ya da hiç yaptırım uygulamamak şeklinde bir takdir yetkisi bulunmamaktadır." (Danıştay Onüçüncü Daire, E. 2018/1372, K. 2018/2140, K.T. 27.06.2018; Danıştay Onüçüncü Daire, E. 2014/5223, K. 2020/670, K.T. 27.02.2020).

\subsubsection{Para Cezası Miktarında Azalma Olması}

Bir idari işlem, yürürlüğe girdikten sonraki mevzuat değişiklikleri nedeniyle hukuka aykırı görülemez. Ancak o idari işlem için üst norm niteliğindeki sonraki bir mevzuat değişikliği o işlemi konusuz bırakabilir, yok hükmünde sayılmasına neden olabilir veya ileriye yönelik olarak artık hukuki etki ve sonuç doğurmasını engellemiş olabilir.

$\mathrm{Bu}$ durumda idareye yapılacak yeni bir başvuru ile idarenin o işlemi ileriye yönelik olarak kaldırması talep edilebilir. Bu durumda dahi o işlemin yeni mevzuat değişikliğinden geriye dönük tüm hukuki etki ve sonucu geçerli kalmaya devam edeceğinden, hak doğuran işlemler için kazanılmış hakların ve haklı beklentilerin korunması 
gerekir. Her halükarda bir idari işlemin bu nedenle kaldırılması, o idari işlemin hukuka aykırı olduğu anlamına gelmemektedir.

Yaptırıma konu idari para cezası suç sayılan fiile uygulandıktan sonra yeni düzenleme ile ceza miktarında azalma olması durumunda da Danıștay, bu durumu dikkate almaktadır.

Danıştay, “...davacı şirkete "4. madde hükümlerinin ihlâli" nedeniyle 5015 sayılı Kanun'un 19. maddesinin 2. fikrasinin (b) bendinin (3) numarall alt bendi uyarınca 280.000.-TL idari para cezasi uygulanmasindan sonra, 11/04/2013 tarihinde yürürlüğe giren değişiklikle yeniden düzenlenen 19. maddede, "4. madde hükümlerinin ihlâli" hâlinde idari para cezası verileceğine ilişkin düzenlemenin yer almadı̆̆l, isnat edilen fiil nedeniyle ancak 19. maddenin 7. fikrasl uyarınca 1.500 TL'den 70.000 TL'ye kadar idari para cezasl verilebileceği dikkate alındı ̆̆ında, dava konusu Kurul kararında ve davanın reddi yolundaki daire kararında hukuka uygunluk bulunmamaktadır." (Danıştay Onüçüncü Daire, E.2019/586, K. 2019/4081, K.T. 04.12.2019) açılamasına dayalı olarak para cezasının miktar olarak azalmasını lehe hüküm olarak değerlendirmiştir.

Yine, "3984 sayıl Kanun'un 21. maddesinin beşinci fikrasında düzenlenen yayın ilkesinin tekraren ihlal edildiği, yayın kuruluşu hakkında para cezası verilmesine ilişkin Radyo ve Televizyon Üst Kurulu kararında mevzuata aykırılık bulunmamakla birlikte daha sonra yürürlüğe giren 6112 sayılı Radyo ve Televizyonların Kuruluş ve Yayın Hizmetleri Hakkında Kanun'un para cezasını düzenleyen "İdarî Yaptırımlar" başlıklı 32. maddesindeki düzenlemenin davacı şirketin lehine olup olmadı $\breve{g l}$ hususunun tartışıldı̆̆l, ilgili yasal hükümler karşısında, idarî para cezalarında, ceza verilmesinin dayanağı kuralın yürürlükten kaldırllması veya lehe düzenleme yapılması hâlinde uyuşmazlı̆̆ın ortaya çıkan yeni hukukî durum dikkate alınarak sonuçlandırıldı̆̆g, verilmesi gereken idari para cezasının ihlalin tespit edildiğ $i$ aydan bir önceki aydaki brüt ticari iletişim gelirinin \% 1'i; miktarl: 4.927-TL ve \% 3'ü miktarl: 14.782-TL olduğu ve ceza miktarının davacının lehine olacak şekilde azaldı̆̆ için 250.000-TL'lik idari para cezasına ilişkin 08.09.2009 tarih ve 2009/49 sayılı kararın hukuka uygun

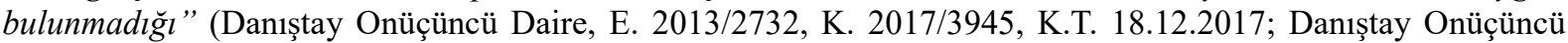
Daire, E. 2014/1599, K. 2019/3842, K.T. 26.11.2019)) gerekçesiyle para cezasının matbu olmaktan çıkarılarak nispi olarak verilmesi düzenlemesini yapılan hesaplamada eğer miktarda azalma oluyorsa bu durumu da lehe kanun olarak nitelendirmiştir.

\subsubsection{Tahsilâtı tamamlanmamış ceza miktarında azalma olması}

Danıştay, idari para cezasında kesinleşmeden ve infaz edilmeden (tahsil edilmeden) önce yeni mevzuat değişikliği ile hafifletilmişse (idari para cezası düşürülmüşse), yeni mevzuat değişikliği nedeniyle önceden verilmiş (ve yeni mevzuata aykırı hale gelmiş) cezanın iptaline gerek duymamakta; buna karşın karar gerekçesinde, cezanın tahsili aşamasında idarenin yeni mevzuatla hafifletilmiş şekliyle tahsilat yapmakla yükümlü olduğunu belirlemektedir.

İdare, dava açılıp açılmadığına bakılmaksızın tahsilâtı tamamlanmamış idarî para cezasının miktarında lehe bir değişiklik varsa bunu tespit etmekle ve uygulamakla yükümlü bulunmaktadır. Dolayısıyla tahsilat aşamasına özgü mevzuat değişikliği yapılması durumunda, idarî para cezasının iptali istemiyle açılan davalarda dikkate alınmayarak bu konuda idarenin yükümlülüğ̈̈ne vurgu yapılmaktadır. Nitekim “dağıtıcısı haricinde başka bir kaynaktan akaryakıt temin ettiğinin sabit olduğu, bu fiili nedeniyle uygulanacak idarî para cezasının miktarında lehe olan değişikliğin tahsilat aşamasında vergi dairesince dikkate alınacak olması sebebiyle davanın bu kısmının reddi yönündeki Mahkeme kararında sonucu itibarlyla hukukî isabetsizlik görülmemiştir. " (Danıştay Onüçüncü Daire, E. 2013/3148, K. 2019/4500, K.T. 19.12.2019) şeklinde değerlendirme yapılmaktadır.

\subsubsection{Fiilin suç olmaktan çıkması}

Yaptırıma konu fiilin suç olmaktan çıkarılması durumunda da Danıştay lehe kanun hükmünü uygulamaktadır. Danıştay, "5015 sayılı Kanun'un 19. maddesinde yer alan ve bayilerin akaryakıt istasyonunda kaçak akaryakıt veya sahte ulusal marker elde etmeye, satmaya ya da herhangi bir piyasa faaliyetine konu etmeye yarayacak şekilde lisansa esas teşkil eden belgelerde belirlenenlere aykırı sabit ya da seyyar tank, düzenek veya ekipmanı bulundurmama yükümlülügünü ihlâl etmeleri hâlinde, dă̆ıtıcı lisansı sahibine idarî para cezası verilmesini öngören kanun hükmü, 7164 sayılı Kanun'un 32. maddesiyle değiştirildiğinden ve maddenin yeni hâlinde anılan düzenlemeye yer verilmediğinden, davacı şirkete değişiklikten önceki fiilinden dolayı verilen cezanın iptal edilmesi gerektiği açıktır." (Danıştay Onüçüncü Daire, E. 2019/2817, K. 2019/2730, K.T. 26.09.2019) gerekçesiyle lehe kanun hükmünü uygulayarak iptal kararı vermektedir.

\subsubsection{Yasaklama yaptırımının dayanağı kuralda lehe değişiklik yapılmış olması}

Yaptırıma esas alınan fiilin suç olma niteliğinde değişiklik yapılması durumunda, Danıştay lehe kanun değerlendirmesi yapmaktadır. Nitekim “6359 sayılı Kanun'la yapılan düzenleme ile, haklarında kamu davası açılmasına karar verilmesi nedeniyle, yargllama sonuna kadar Kanun kapsamında yer alan kamu kurum ve kuruluşlarının ihalelerine katılamayacak durumda olanların, 4734 sayıl Kanun'un 11. maddesinin 1. fikrasının (a) bendi kapsamı dışına çıkartılmış olması karşısında, "idarî yaptırım" niteliğinde olan ihalelere katılmaktan yasaklama kararının dayană̆ kuralda lehe düzenleme yapılması yoluyla ortaya çıkan yeni hukuki durumun dikkate alınması gerekmektedir (Danıştay Onüçüncü Daire, E. 2013/722, K. 2017/25, K.T. 04.01.2017), "Sermaye Piyasasında Bă̆ımsız Denetim Standartları Hakkında Tebliğ'in "Bă̆ımsız denetim faaliyetinde bulunma yetkisinin iptali" başlıklı 30. maddesinin 2. fikrasında, söz konusu eylem nedeniyle sermaye piyasasında bağımsız 
denetim yapmanın yasaklanması herhangi bir süreye bağlanmamış iken, anılan fikranın değişmesi sonucu 2 yıldan az olmamak kaydı ile süreli veya süresiz olarak yasaklama getirilebileceği düzenlenmiş olup, bu düzenleme sorumluluğun niteliğine göre ilgililerin lehine olabilecek hükümler içerdiğinden, söz konusu değişiklik kapsamında davalı idarece, davacının sorumluluğunun içeriği dikkate alınarak sermaye piyasasında bă̆ımsız denetim yapmasının süreli veya süresiz olarak yasaklanması hususu değerlendirildikten sonra bir işlem tesis edilmesi gerekmektedir." (Danıştay Onüçüncü Dairesi, E. 2012/922, K. 2018/3535, K.T. 03.12.2018) şeklinde kararlar verilmektedir.

\subsubsection{Anayasa Mahkemesince Kanun Hükmünün İptal Edilmesi}

Yaptırım uygulanmasının dayanağı olan kanun hükmünün Anayasa Mahkemesince iptal edilmesi durumunu da Danıştay iptal hükmü uyarınca lehe hüküm olarak değerlendirmektedir. Nitekim “Anayasa Mahkemesi'nce 5015 sayılı Kanun'un 19. maddesinin ikinci fikrasının (a) bendinin "Aşağıdaki hâllerde sorumlulara altı yüz bin Türk Lirası idarî para cezası verilir." bölümünün, Kanun'un 7. maddesinin dördüncü fikrasinın üçüncü cümlesinde yer alan "...bayi, sözleşme yaptığ yeni dă̆ıtıcının ürünlerini pazarladığı anlaşılacak şekilde faaliyetine devam eder..." ibaresi yönünden Anayasa'nın 2. maddesine aykırı bulunarak iptal edildiği görüldüğünden, Anayasa Mahkemesi'nce verilen iptal hükmünün hukukî sonuçlarl gözetilerek Mahkemece yeniden bir karar verilmesi gerekmektedir." (Danıştay Onüçüncü Daire, E.2015/4966, K.2017/3272, K.T. 23.11.2017) şeklinde karar vermiştir.

Danıştay, lehe kanun hükmünün uygulanması amacıyla verilecek iptal kararının başka yaptırım uygulanmasına engel olmayacağını benimsemektedir. Fiilin işlendiği tarih itibariyle yürürlükte bulunan mevzuat ile daha sonra yürürlüğe giren mevzuat hükümleri farklı ise yaptırım uygulanacak olan kişilerin lehine olan mevzuat hükmünün dikkate alınması gerektiği lehe kanun ilkesi uyarınca zorunlu bulunmaktadır. Ancak lehe hükmün uygulanması amacıyla verilecek bir iptal kararının başka yaptırımların uygulanmasına engel olmaması gerekmektedir. Bu kapsamda Danıştay, "Olayda, davacının üzerine atılı fiili işlediği, soruşturma dosyasında mevcut bilgi ve belgelerin değerlendirilmesi neticesinde sabittir. Bu bakımdan, yeni oluşan hukuki durum dikkate alınarak, İdare Mahkemesince davacının eylemine uyan Kanunun ve ilgili Yönetmeliğin eski halinde düzenlenen fiilin, Kanun ve ilgili Yönetmeliğin yeni halinde düzenlenip düzenlenmediği ve/veya söz konusu fiil için daha hafif bir ceza öngörülüp öngörülmediğinin araştırılarak, eski ve yeni mevzuat hükümlerinden davacı lehine olanın uygulanması sureti ile yeniden bir karar verilmesi gerekmektedir.” (Danıştay Sekizinci Daire, E.2016/8928, K. 2020/609, K.T. 06.02.2020) şeklinde karar vermektedir.

\subsubsection{Mükerrer Ceza Verilememesi (İnfaz Edilme Durumu)}

İdarî yaptırım kararının dayanağı kuralın yürürlükten kaldırılması veya lehe düzenleme yapılması hâlinde, eğer idari yaptırım kararı uygulanmış ise sonradan yapılan lehe düzenlemenin uygulanması durumunda aynı eylemin iki kere cezalandırılması sonucu doğacağından lehe kanun uyarınca uyuşmazlığın ortaya çıkan yeni hukukî durum dikkate alınarak sonuçlandırılması yoluna gidilmemektedir. Suç teşkil eden fiilin işlenmesi ile cezanın hukuki anlamda kesinleşmesi arasındaki süreçte o suç ve/veya cezaya ilişkin olarak mevzuat değişikliği olursa ve sonraki değişiklik suçlananın lehine ise bu değişikliğin o kişiye uygulanması gerekmektedir. Ancak uygulama için cezanın uygulanıp tükenmemiş olması yani infaz edilmemiş bulunması gerekir.

Danıştay, “...dü̧̈ünceyi açıklama ve yayma hürriyetini sınırlayan program yayınını durdurma yaptırımının, para cezası yaptırımı ile kıyaslandı̆̆ında davacı şirketin aleyhine olduğunun Kanun koyucu tarafından yeni yürürlüğe giren Kanun'da da kabul edilmesi karşısında, dava konusu Kurul kararında hukuka uygunluk bulunmadığı, ... davacı şirket hakkında lehe kural olan idarî para cezasının uygulanabilmesi için hakkında tesis edilen program yayınını durdurma cezasının infaz edilmemiş olması gerektiği, yayın durdurma kararı uygulanmışsa davacıya mükerrer ceza verilemeyeceğinden para cezasının fiilen uygulanamayacă̆ ”" (Danıştay Onüçüncü Daire, E.2019/3255, K. 2020/664,27.02.2020) değerlendirmesini yapmaktadır.

Yine, "infazı tamamlanan, geri alınması mümkün olmayan ve iptal edilmesi hâlinde davacının lehine herhangi bir sonuç doğurmayacak olan program durdurma cezasının iptali istemiyle açılan davada tüm bu hususlar göz önünde bulundurularak davanın reddine karar verilmesi gerekirken, dava konusu işlemin iptali yolunda verilen temyiz konu İdare Mahkemesi kararında hukukî isabet bulunmamaktadır." (Danıştay Onüçüncü Daire, E. 2014/5170, K. 2019/3843, K.T. 26.11.2019; Danıştay Onüçüncü Daire, E. 2014/4456, K. 2014/4278, K.T. 15.12.2014) şeklinde dava açılmasından sonra dava açan kişinin daha kötü duruma düşürülmemesi yolunda, idari para cezası verilmesi gerekli olduğu durumda daha ağır olan yayın durdurma cezası uygulanıp infaz edildiği dikkate alınarak karar verilmektedir

\subsubsection{Aleyhe Düzenleme Durumu}

Mevzuat değişikliği aleyhe ise sonraki değişiklik değil, önceki mevzuat hükümlerinin uygulanmaya devam edilmesi gerekmektedir. Çünkü işlemin tesis edilmesine esas alınan mevzuat yaptırımın muhatabı açısından daha lehe sonuç doğurmaktadır.

Aleyhe düzenleme yasağı konusunda Danıştay, "davacının fiilinin karşılı̆̆ı olarak uygulanacak yaptırımın sonraki düzenlemeyle adli para cezasına dönüşü̈rülmesi ve bu durumun davacının aleyhine olması karşında, davacının lehine olan dava konusu idari para cezasında hukuka aykırılık, davanın reddi yolundaki temyize konu Mahkeme kararında ise sonucu itibarlyla hukukî isabetsizlik bulunmamaktadır." (Danıştay Onüçüncü Dairesi, 
E.2012/1711, K. 2018/4404, K.T. 26.12.2018), “davacı şirkete verilen para cezasinın yeni Yönetmelikte belirtilen sinır olan net satışların yüzbinde ǚç olarak tespit edilmişs olması karşısında, yeni Yönetmelikte yer verilen kuralın lehe hüküm olduğundan söz edilmesi hukuken mümkün olmayıp, bu gerekçeyle dava konusu işlemin iptali yolunda verilen İdare Mahkemesi kararında hukuki isabet görülmemiştir." (Danıştay IDDK, E. 2016/1138, K. 2018/1597, K.T. 09.04.2018) şeklinde karar vermektedir.

\section{5 İdari Yaptırımlarda Lehe Kanun Değerlendirmesi ve Yargıya Güven Sorunu}

İdari işlemlerde en temel kurallardan biri, idari işlemlerin tesis edildikleri tarihteki mevzuata uygun olmalarıdır.

İdari işlemlerin tesis edildikleri tarihten sonra yürürlüğe giren mevzuatın bu işlemlerin hukuka uygunluğunda dikkate alınmaması gerekmektedir. Mevzuat değişikliğinin idari işlemin ileriye yönelik olarak kaldırılmasına sebep oluşturabileceği değerlendirilebilir. Bu durumda mevzuat değişikliği işlemi hukuka aykırı kılmamakta, işlemin mahkemece iptaline veya idarece geri alınmasına sebep olmamaktadır. Çünkü hukuk devleti ilkesine göre bir işlemin hukuka aykırı olabilmesi için işlemin tesis edildiği anda yürürlükte bulunan hukuk kurallarına uygun olmaması gerekmektedir. Mevzuat değişikliği nedeniyle ilgililerin başvuruda bulunarak işlemin değiştirilmesi, kaldırılması veya geri alınması yönünde talepte bulunması ve idarenin yeni bir işlem tesis etmesi halinde yeni mevzuatın uygulanarak işlemin değiştirilmesinin idarenin takdir yetkisi kapsamında olduğu bilinmektedir.

Başka idarelerce ve hatta aynı idare tarafından yapılan sonraki mevzuat değişikliği idarenin her zaman öngörebileceği bir durum olarak değerlendirilemeyeceğinden yapıldığ tarihteki mevzuata uygun olarak tesis edilen ancak işlem yapıldıktan sonraki mevzuat değişikliği nedeniyle yeni mevzuata aykırı hale gelen işlem nedeniyle idarenin hukuka aykırı davrandığını kabul etmek hukuken mümkün değildir. İdari işlemin tesisinden sonra yürürlüğe giren mevzuat hükmüyle, açıkça belirtmek suretiyle geçmişe yönelik olarak ancak af niteliğinde düzenleme yapılması mümkündür. Ancak idare hukuku ilkeleri böyle olmasına karşın ceza hukukuna özgü ilkeler lehe hüküm uygulamasını, gerek teorik değerlendirmeler yoluyla gerekse başta AİHM ve AYM olmak üzere Danıştay içtihatlarıyla gerekli kılmıştır. İptal davası bakımından yargısal denetim işlemin tesis edildiği tarihte yürürlükte bulunan mevzuata uygunluğu bakımından yapılırken, ceza hukukunun lehe kanun uygulaması önce AİHM kararları ile sonra da Anayasa Mahkemesi tarafindan verilen kararlar üzerine idari yaptırımların yargısal denetiminde uygulama alanına geçmiştir. Danıştay idari para cezalarının yargısal denetiminde ceza hukukunun lehe kanun uygulamasinı esas almaktadır.

Belirtmek gerekir ki lehe kanun ilkesi idari para cezaları dışındaki idari yaptırımlara (idari tedbirler) uygulanma zorunluluğu bulunmamaktadır. İdari tedbirler için idari işlemlere dair genel uygulama olan, tedbirin öngörüldüğü idari işlemin tesis edildiği tarihteki mevzuat hükümleri uygulanmakta, muhatabının lehine bile olsa idari tedbirler sonraki mevzuat değişikliklerinden etkilenmemektedir. Çünkü yükümlendirici de olsa idari tedbirler "cezai" nitelikte olmadıklarından idari işlemlerin genel hukuki rejimine tabi bulunmaktadırlar (Ulusoy, 2013).

Suç olmaktan çıkarma ile toplumsal düzeni derinden sarsmayan hafif suçlar ve diğer yandan, toplumsal düzenin korunabilmesi (özellikle ekonomik düzen) açısından çabuk ve pratik şekilde verilmesi gereken cezalar yargı erkinden idareye transfer edilmektedir. Suç olmaktan çıkarma eğilimi çerçevesinde suç fiillerini idari yaptırıma dönüştüren kanunlar ceza kanunlarının yürürlüğü gibi sonuç doğurmaktadır. Bu kanunlarla fiil suç olmaktan çıkarılmakta ancak aynı zamanda idari yaptırıma dönüşmektedir. Bu halde fiil her ne kadar ceza hukuku anlamında suç olmasa da hukuk düzenince hukuka uygun kabul edilmemektedir.

Suç olmaktan çıkarma eğiliminin, ceza yargılaması işlevini kolaylaştıran, mahkemelerin iş yükünü azaltan olumlu etkileri olmakla birlikte, cezaların caydırıcılığı açısından ağır ihlallerin önlenebilmesi için hafif ihlallerinde suç olarak kabulü gerektiği, suç olmaktan çıkarılan fiillerin daha sık işlenir hale gelmesi, bu eğilimin zamanla ceza sistemine olan saygıyı azaltacağı, suç durumundan çıkarmanın sınırı ve ölçüsünün tam bir belirsizlik yaratması sonucu doğmaktadır (Bayraktar, 1984).

İdari para cezası verilip ilgilisine tebliğ edilerek kesinleşmesinden sonra ceza hukuku ilkelerinin idare hukuku alanına ve idari yaptırımlara uygulanmasına ilişkin 5326 sayılı Kabahatler Kanunu hükmü, hukuka güvenin sarsılması sonucunu doğurmaktadır.

$\mathrm{Bu}$ durumun bir örnek ile açıklanması uygun olacaktır. Aynı hukuk kuralının ihlal edilmesi ve yaptırıma tabi tutularak aynı idari para cezasının uygulandığı komşu iki ticaret erbabının varlığını düşünelim. Bunlardan birisi hukuk kuralının ihlali nedeniyle eyleminin karşılığı olarak uygulanan para cezasını ödemesine karşın, diğerinin bu işleme karşı iptal davası açtığını varsayalım. Dava açan kişinin önce idare mahkemesi sonra Danıştay'daki temyiz süreci devam ederken para cezasına konu eylemin suç olmaktan çıarılması veya daha hafif para cezası verilmesine ilişkin düzenleyici işlem tesis edildiğini ve Danıştay'ın mahkemenin ret kararını "lehe kanun uygulaması" gerekçesiyle bozduğu sonuçta da bu cezanın iptal edilmek suretiyle davacının eyleminin karşıllı̆̆ para cezasını ödemekten kurtulduğu durumun sonucunu değerlendirelim. Dava açtı̆̆ için para cezasını lehe kanun uygulaması nedeniyle ödemekten kurtulan tacirin komşusu olan idari para cezasını hukuk kuralını ihlal ettiğini bildiği için ceza miktarını ödeyen kişinin, devlete ve yargıya olan güven duygusunun ne denli zarar gördüğünün/göreceğinin değerlendirmesi büyük önem taşımaktadır. Hatta para cezasına karşı açılan davanın reddedilerek derecattan geçmek suretiyle kesinleştiğini ve para cezasının ödenmek zorunda kalındığı ancak aynı dönemde aynı nitelikteki 
eylemin aynı tür yaptırımla cezalandırılmasına rağmen yargı sürecinin uzaması nedeniyle yargılamadan kaynaklanan gecikmeden dolayı başka birinin açtığı davada "lehe kanun" uygulamasından dolayı verilen iptal kararı örneğinde durum daha da vahim olacaktır.

\section{Sonuç ve Öneriler}

Toplumsal düzenin korunması ve sürdürülmesi için öngörülmüş olan hukuk kurallarının uygulanması sırasında ve bu kuralların ihlal edilmesi halinde birey devletle karşı karşıya gelmekte ve özellikle de idari yaptırımlar en çok başvurulan bir çözüm yolu olmaktadır.

Türkiye'de ceza adaletine ilişkin sorunların başında, ceza adaletine yön veren etkenlerin toplumsal yapıyla doğrudan bağlantılı olmaması gelmektedir. Toplumsal yapının göz ardı edilmesi ceza uygulamalarında başarısızlığa neden olmuş, başarısızlıkların ortaya çıkması da ceza uygulamaları üzerinde sürekli değişiklik yapmayı gerektirmiştir. Bunun sonucunda, ceza adalet politikalarının amaçları ile toplumsal ve kurumsal beklentiler arasında uçurum oluşmuştur.

Suç olmaktan çıkarma eğiliminin etkisi ile yapılan düzenlemelerle idari yaptırım alanının genişlediği ve bu eğilimin artarak devam ettiği dikkate alındığında, ceza hukuku alanına ait olan suç tiplerinin bu alandan idare hukuku alanına aktarılmasının, idarenin üstün yetki ve ayrıcalıklarla donatılmışlı̆̆ının sonucu olarak, idari işlemin tek yanlı olarak yürütülebilmesi ve bu yürütmenin kanuna uygunluk karinesinden yararlanıyor olmasından doğan özel önemi bulunmaktadır.

İdari yaptırımlar alanının genişletilmesi ve bağımsız idari otoritelerin denetleyici özellikleriyle ortaya çıkan ve ciddi sonuçlara neden olan idari yaptırım uygulamaları bu alandaki temel ilke ve kuralları daha dikkat çekici hale getirmiştir. İdari yaptırımlar her ne kadar bir idari işlemle ortaya konmakta ise de özünde bir yaptırımı içermesi nedeniyle özgürlükleri sınırlandırıcı bir yönü bulunmaktadır. Bu durum temel hak ve özgürlükler açısından daha güvenceli esas ve usullere tabi bir işlemle idari yaptırım uygulanmasını zorunlu kılmaktadır.

İdari yaptırımlarda lehe kanun uygulamasının dayanağı, "işlendikten sonra yürürlüğe giren kanuna göre suç sayılmayan bir fiilden dolayı kimsenin cezalandırılamayacağı" na ilişkin ceza hukukunun temel ilkesi ve Kabahatler Kanunu'nun 5. maddesi ile 5237 sayll Türk Ceza Kanunu'nun 7. maddesi hükmüdür.

Yukarıda verilen örnek dikkate alındığında, yargıya güven duygusunu aşındırdığı ve iptal davası inceleme ilkelerine ve idari işlem teorisine uygun olmadığı açıklanan lehe kanun uygulamasının idari yargıda ortaya çıkardığı olumsuz sonuçların giderilmesi büyük önem taşımaktadır.

Lehe kanun uygulamasında, idari para cezalarının ilgilisine tebliği edildikten sonra işleme karşı dava açılmaması halinde işlemin kesinleşmesi gerçekleşeceğinden sonradan yapılacak mevzuat değişikliği veya Anayasa Mahkemesince verilecek iptal kararı üzerine idareye yeni hukuki durum nedeniyle yeni başvuru yapılması gerekmektedir. Bu durumda yargı yerlerince lehe hüküm değerlendirmesi söz konusu olmamaktadır.

Öncelikle lehe kanun uygulamasının kesinleşerek tahsilatı gerçekleşmiş olan idari para cezaları bakımından etkisinin olmadığı, yargılamanın uzun sürmesi nedeniyle lehe kanun hükmünü yargı yerlerinin uygulamak zorunda kaldığı gözden uzak tutulmamalıdır. Dolayısıyla yargılamanın makul sürede tamamlanmasına yönelik olarak “ idari para cezalarının öncelikli işler kapsamına alınması ve ivedilikle yargılamanın bitirilmesine" ilişsin 2577 sayılı İdari Yargılama Usulü Kanunu'na hüküm sevkedilmesi uygun bir çözüm yolu olacaktır. Nitekim 2577 sayılı Kanun'un ivedi yargılama usulüne ilişkin 20/(A) maddesi ve Millî Eğitim Bakanlığı ile Ölçme, Seçme ve Yerleştirme Merkezi tarafından yapılan merkezî ve ortak sınavlar, bu sınavlara ilişkin iş ve işlemler ile sınav sonuçları hakkında açılan davalara ilişkin yargılama usulünde uygulanan 20/(B) maddesi hükümleri bu konuda yapılacak düzenlemeye örnek niteliği taşımaktadır.

Ayrıca idari para cezalarının iptali istemiyle açılmış olan dava devam ederken lehe kanun durumunun oluşması halinde işlemin kesinleşmesinin gecikeceği dikkate alınarak, yasama organınca genel kanun olarak "Kabahatler Kanunu' na lehe kanun hükmü nedeniyle gerekli uygulamanın yapılması konusunda idareye görev ve yetki verilmesine" ilişkin hüküm konulması da gerekmektedir. Bu durum lehe hüküm uygulamasına konu düzenlemenin yasama organınca değil de düzenleyici işlem ile yapılması halinde, idareye lehe hüküm uyarınca kesinleşmemiş idari para cezalarına yönelik yeni hukuki duruma uygun işlem yapma zorunluluğu getirecektir. Dolayısıyla yargı yerlerince lehe hüküm nedeniyle bozma ve iptal kararı verilmesine ihtiyaç kalmayacaktır.

\section{Kaynakça}

- Akıllığlu, T, (1984). "Yasaların Zaman Bakımından Uygulanmasına İlişkin Bazı Sorunlar”, Amme İdaresi Dergisi, 17, p. 36.

- Antalya, O. G, (2019). Hukuk Teorisi. Seçkin Hukuk Yayınları, Ankara, p.107

- Bayraktar, K, (1984). “Ceza Hukukunda Suç Olmaktan Çıkarma Akımı”, IÜHFM, 50, p.206.

- Çağlayan, R, (2006). İdari Yaptırımlar Hukuku (Kabahatler kanunu yorumu). Yetkin Yayınları. Ankara, p. 78

- Güriz, A, (1999). Hukuk Başlangıcı. Siyasal Kitabevi. Ankara, p.68 
- Hafızoğulları, Z, (1996). Ceza Normu: Normatif bir yapı olarak ceza hukuku düzeni. US-A Yayıncılık, Ankara, p. 217

- Karabulut, M, (2008). İdari Yaptırımların Hukuki Rejimi. Turhan Kitabevi. Ankara, p. 62

- Oğurlu, Y, (1999). “İdari Yaptırımlara Genel Bir Bakış ve İdari Yaptırım- Ceza Yaptırımı Ayrımı”, Hukuk Fakültesi Dergisi, III, p. 150.

- Özay, İ, (1985). İdari Yaptırımlar, İÜ Yayını, p. 35. Tan, “İdari Yaptırımlar ve Avrupa İnsan Hakları Sözleşmesindeki Güvenceler”, Hukuk Kurultay, Ankara Barosu Yayınları/ İnsan Hakları2, p. 99.

- Ulusoy, A, (2013). İdari Yaptırımlar. XII Levha Yayıncılık. İstanbul, p. 41 


\title{
Formation of Integrated Structures in Industrial Manufacturing Enterprises and their Regional Analysis
}

\author{
Ph.D. Candidate Tural Suleymanli (Odlar Yurdu University, Azerbaijan)
}

\begin{abstract}
In modern conditions, it becomes necessary to select and justify the methods and techniques of inter-regional economic integration during the formation of a new economy. At the stage of aggravation of the competitive environment, regional economic integration is the main factor in the development of regions. They significantly differ from those known in foreign practice by their substantive nature, focus on increasing the efficiency of such important sectors of the economy as industry and agriculture, achievements in close cooperation, strengthening integrated, integrated production relations, and the exchange of modern ICTs. At the same time, they contribute to the formation of positive and negative effects in the regional economy.
\end{abstract}

\section{Introduction}

An important direction of the state economic policy of the Republic of Azerbaijan is the development of industry, increasing the competitiveness of industrial enterprises in the domestic and foreign markets.

The effective orientation of the state to stimulate industrial development to a certain extent is determined by the adequacy of the measures implemented at the level of industrial enterprises and measures to increase the efficiency of their activities. Without a set of measures of industrial development at the macro and micro levels, the solution of the tasks of accelerating the pace of economic growth, ensuring production and technological independence, and increasing the competitiveness of domestic industrial production seems almost impossible. Therefore, the theoretical and applied task is the development of tools to improve the efficiency of industrial development management (Abramov R.A., 2016).

\section{Methodology}

Domestic experience indicates that a significant potential for increasing the effectiveness of managerial mechanisms for the development of industry is associated with a comprehensive consideration of the trends in the integration of production structures. The opportunities for productive application in the management of the opportunities that these tendencies provide provides are due to the fact that at the present stage of competition among manufacturers, objectively necessary is the activation of opportunities to increase business stability. Significant reserves in this area can be mobilized on the basis of the development of integration processes in the domestic industry that provide a significant synergistic effect in the regional context. It should be borne in mind that integration processes are closely related to the development of regions.

Existing problems cannot be solved without the necessary scientific and analytical justifications, which makes it important to conduct a special study of this problem related to the possibilities and directions of using integration tools in the regions in order to increase the organizational, economic and industrial-technical level of industrial enterprises.

Integration processes in industry are carried out on the basis of asset control and are characterized by a number of signs: economic; organizational; legal.

Domestic experience shows that in modern conditions in the industrial sector, integration transformations are not traditional vertical or horizontal, but more often mixed, integrating industrial structures simultaneously on several grounds with a variety of areas of interaction between participants. Integrated industrial structures have their positives and negatives, the main ones on the following approaches. 


\begin{tabular}{|l|l|}
\hline \multicolumn{1}{|c|}{ Positives } & \multicolumn{1}{|c|}{ Negatives } \\
\hline Direct impact on selected sectors of the economy & $\begin{array}{l}\text { The complexity of the management structure and the } \\
\text { increase in AHR }\end{array}$ \\
\hline Resource pooling & $\begin{array}{l}\text { Reduced flexibility and responsiveness to the } \\
\text { environment }\end{array}$ \\
\hline Synergistic effect of close interaction & $\begin{array}{l}\text { The difficulty of coordinating intra-integration } \\
\text { interactions }\end{array}$ \\
\hline $\begin{array}{l}\text { The effect of the concentration of capital and } \\
\text { production }\end{array}$ & Decrease in innovation activity \\
\hline $\begin{array}{l}\text { Cost reduction, primarily transactional and inter- } \\
\text { technological. } \\
\text { Diversification of production and increased } \\
\text { competitiveness of the integrated industrial structure. }\end{array}$ & $\begin{array}{l}\text { Decrease in effect due to incompetent production and } \\
\text { pommercial activities of individual integration } \\
\text { participants }\end{array}$ \\
\hline $\begin{array}{l}\text { Sales growth due to lower product prices } \\
\text { Systematic supply of raw materials through a single } \\
\text { technological chain }\end{array}$ & $\begin{array}{l}\text { Increased costs in the process of integration } \\
\text { transactions } \\
\text { process }\end{array}$ \\
\hline $\begin{array}{l}\text { Expansion of technical and technological capabilities } \\
\text { of manufacturing enterprises }\end{array}$ & \begin{tabular}{l} 
Increased tax burden due to legal process \\
\hline $\begin{array}{l}\text { Improving product quality through standardization of } \\
\text { business processes }\end{array}$
\end{tabular} $\begin{array}{l}\text { Increase in the number and intensity of interaction } \\
\text { between integration participants }\end{array}$ \\
\hline $\begin{array}{l}\text { Continuity of existence, which is not associated with } \\
\text { the transfer of assets between owners }\end{array}$ & $\begin{array}{l}\text { Decreased independence in decision-making by } \\
\text { participants in the integration process }\end{array}$ \\
\hline
\end{tabular}

Table 1. The Positives and Negatives of Integrated Industrial Structures

\begin{tabular}{|c|c|}
\hline Sphere & Integration Efficiency Growth Factors \\
\hline \multirow{2}{*}{ Accommodation } & Territorial proximity \\
\hline & Local Resource Locations \\
\hline \multirow{4}{*}{ Production } & Getting economies of scale \\
\hline & $\begin{array}{l}\text { Strengthening the tightness of the interaction between the stages of the } \\
\text { production process, R\&D and the distribution process }\end{array}$ \\
\hline & Improving the structure of fixed assets and inventories \\
\hline & Production Services \\
\hline \multirow{2}{*}{ Innovation } & Building MTB, intensification of the exchange of NTD \\
\hline & Modernization of the technological system and the pace of technology updates \\
\hline \multirow{4}{*}{ Management } & Increase Information Space \\
\hline & ICT development of regional distributed management \\
\hline & Increased sustainability through diversification of the income base \\
\hline & $\begin{array}{l}\text { Development of intercompany relations and the adoption of joint management } \\
\text { decisions }\end{array}$ \\
\hline \multirow{4}{*}{$\begin{array}{l}\text { Marketing } \\
\text { position }\end{array}$} & Identification of target market segments \\
\hline & Optimization of costs associated with market research and product promotion \\
\hline & Increasing competitiveness in the regional market \\
\hline & Risk Management Reduction \\
\hline \multirow{3}{*}{ Investments } & Reducing investment risks and increasing investment attractiveness \\
\hline & Growth in investment attraction \\
\hline & Increase return and reduce return on investment \\
\hline \multirow[t]{2}{*}{ Relationship with the state } & $\begin{array}{l}\text { Formation of new forms of partnership between the state and business in the } \\
\text { development of industry }\end{array}$ \\
\hline & Enhanced participation in the implementation of industrial and cluster policies \\
\hline
\end{tabular}

Table 2. Factors for Industrial Integration

As practice shows, the modern development of industry is characterized not only by the spread of various types of integration, but also by simultaneous disintegration processes. Gradually, with the development of technological capabilities and the diffusion of innovations in industry, they are not only trying to implement integration strategies aimed at economies of scale, but also "niche" strategies that satisfy seasonal, temporary or other needs.

In modern conditions, the main form of integrated structures is a large association of enterprises engaged in joint activities on the basis of voluntary centralization of the functions of scientific, technical and industrial development, investment, financial, foreign economic and other activities, self-supporting services for enterprises. 
Included in these enterprises, producing individual goods located in different regions, retain commercial, industrial and legal independence (Anshin V.M., 2017).

The formation of large associations was an objective process for the survival of industrial enterprises in the conditions of the economic crisis, their desire to improve economic and financial indicators, stop the decline in production, and restore destroyed economic and cooperative ties. With their formation, additional opportunities appeared for the development of manufacturers, strengthening their positions in both external and domestic markets.

The methodological principles for creating integrated structures are: voluntary entry and freedom of exit of enterprises from the integrated structure; unlimited number of participants in an integrated structure; the ability to combine resources with a different number of participants in the integrated structure for investing in progressive projects for the development of production; creation of conditions for the formation of various integrated structures.

The main goal of the formation of integrated structures are:

- $\quad$ expand investment attractiveness due to the possibility of attracting investments on more favorable terms, as well as the concentration of own investment resources and their direction in the development and restructuring of production (Akberdina V.V, 2009).

- $\quad$ reduce costs per unit of production by expanding the scale of production and increasing the price competitiveness of goods.

- $\quad$ increase competitiveness through diversification of production, which allows the flexible use of resources in the environment.

- combine financial, material and labor resources with a view to their effective use.

- $\quad$ expand technical re-equipment and modernization of production through the consolidation of financial resources.

Despite the obvious positive results in industrial and commercial activities from the formation of integrated structures, a number of problems, in particular in relation to the specific conditions of problem regions, require a quick response. In order to identify and take into account industry and regional characteristics, there is a problem of continuous diagnosis of ongoing integration processes.

In our opinion, the unsolved problems of the formation of the effective functioning of integrated structures in industry include: the lack of a comprehensive state policy in the field of integration processes for the formation of integrated structures; low share of small industrial enterprises involved in the integration process; low technical level of production of most industrial enterprises; low volume of export of industrial products; poor investment and innovation in many industrial manufacturing enterprises.

The formation of scientific integrated structures in solving the problem of the optimal combination of the value of acquired assets with their production potential will create an effective integrated structure, the market value of assets of which will be significantly higher than the similar value of its constituent enterprises. Each enterprise gains economic interest in the effective activities of all market entities that are part of the joint venture.

Their functioning on the basis of industry sub-sectors will have a number of the following advantages:

- $\quad$ reduction of costs for trade, marketing and other services.

- $\quad$ introduction of the advantages of diversification of production, a single credit and financial policy.

- $\quad$ increased efficiency in the use of financial, investment and other resources.

- adoption of more effective management decisions in connection with the emergence of new opportunities caused by the pooling of resources included in the integrated structures.

- $\quad$ the emergence of opportunities in achieving goals that are difficult to achieve for a single enterprise.

- use of modern technology.

- $\quad$ direction in the necessary volumes of capital investments for the reorganization of enterprises.

- $\quad$ the formation of new foreign economic relations and others.

Integration of resources in the basic areas will allow pursuing an investment policy at a qualitatively different level, providing loans with the necessary guarantees and other financial instruments, which in turn will make it possible to re-equip the complex and produce competitive products that are not inferior to world analogues.

A positive feature of the functioning of integrated industry structures is that their activities practically exclude intermediary enterprises that essentially do not create real added value.

Foreign practice of integration in small business confirms that the merger of capital, even small enterprises, is rightly considered the least expensive way to expand industrial production and increase markets.

The formation of interregional integrated structures created the conditions for the revival of industrial enterprises, and allowed to obtain the following positive results:

- $\quad$ find favorable conditions and conditions for technical re-equipment, the development of new technologies and advanced forms of organization of production. 
- $\quad$ ensure the financial stability of enterprises.

- $\quad$ create a favorable climate for domestic and foreign investment.

- $\quad$ increase the production of competitive products in enterprises.

\section{Results}

The role of the state in regulating integration processes is growing, since it is able to create favorable conditions for integration, take actions to form integrated structures in cases where it is possible and expedient. Close interweaving in the integrated structures of private and state forms of ownership will allow the state to more effectively solve the problems of forming the republican budget and its use in the most priority areas, taking into account the country's social, economic, scientific and technical interests. Moreover, the size of the centralized resources of the state must constantly exceed the capabilities of integrated structures (Akberdina V.V, 2009).

The main measures to regulate integration processes in industry, taking into account the priorities of economic development, can be considered:

- $\quad$ the formation of the necessary conditions for the creation of corporate structures and the realization of their economic potential on the basis of improving the system of state regulation.

- $\quad$ direct participation in the development of integration processes through the use of state-owned property and shares of privatized enterprises.

- $\quad$ assistance in the formation of private enterprises that meet the interests of the development of the country's economy.

- determination of the strategic interests of the state and private business on the basis of mutual obligations, guarantees for their implementation.

The mechanism of interaction between government and integrated industrial enterprises should include:

- conclusion of a long-term strategic agreement defining the ways and time frames for the achievement of the goals by the concerns.

- the signing of special investment agreements providing for the obligations of the parties, in the case of the concern's implementation of large investment projects that solve large-scale tasks of industrial development.

- providing guarantees of the republic for attracting foreign investment and product purchases within the framework of the state order, allocation of funds from the budget for development, etc.

Next, we identify the main prerequisites for the formation of integrated structures in the industry of the Republic of Azerbaijan. It should be emphasized that in recent years certain positive and negative changes have occurred in this area. So, for example, for 2011-2016. in Baku, the number of industrial enterprises decreased from 1215 to 1153; respectively, in the Aran economic region - from 336 to 329; Nakhichevan Autonomous Republic - from 135 to 135 .

An increase in the number of industrial enterprises is observed in the following economic regions: Absheron from 215 to 236; Ganja-Kazakh - from 270 to 288; Sheki-Zakatalsky - from 107 to 141; Lankaran - from 84 to 95 ; Guba-Khachmaz - from 76 to 95; Verkhne-Karabakh - from 28 to 38; Nagorno-Shirvan - from 40 to 44.

\begin{tabular}{|l|c|c|c|c|c|c|}
\hline & 2011 & 2012 & 2013 & 2014 & 2015 & 2016 \\
\hline Baku city (with settlements) & 1215 & 1219 & 1249 & 1225 & 1170 & 1153 \\
\hline Absheron economic region & 215 & 213 & 218 & 235 & 253 & 236 \\
\hline Ganja-Gazakh economic region & 270 & 269 & 264 & 271 & 297 & 288 \\
\hline Sheki-Zagatala economic region & 107 & 113 & 113 & 116 & 132 & 141 \\
\hline Lankaran economic region & 84 & 75 & 76 & 77 & 90 & 95 \\
\hline Guba-Khachmaz economic region & 76 & 79 & 75 & 79 & 91 & 95 \\
\hline Aran economic region & 336 & 339 & 323 & 321 & 329 & 329 \\
\hline Upper Karabakh economic region & 28 & 29 & 30 & 31 & 37 & 38 \\
\hline Mountainous Shirvan economic region & 40 & 40 & 40 & 39 & 44 & 44 \\
\hline Nakhchivan Autonomous Republic & 135 & 135 & 135 & 135 & 132 & 134 \\
\hline
\end{tabular}

Table 3. Number of Enterprises Operating in the Regions

Except in Baku from 2011 to 2016. in all economic regions of the country there is an increase in industrial production. So, in the Ganja-Kazakh economic region, this indicator increased from 263.6 million manats to 615.7 million manats; Absheron - from 475.9 to 977.3; Sheki-Zakatalsky - from 75.7 to 193.2; Lankaran - from 65.9 to 102.0; Guba-Khachmaz - from 89.3 to 94.3; Aransky - from 797.1 to 1145.6; Upper Karabakh - from 11.6 to 29.3; Nagorno-Shirvan - from 9.7 to 19.6; Nakhchivan Autonomous Republic - from 680.9 to 942.9 (Bendikov M.A, 2002).

In the city of Baku for the study period, there is a decrease in industrial production from $31,782.8$ million manat to 27432.4 million manat. 
It should also be noted that according to 2016, the index indicators of industrial production compared with the previous year are very high, and in the economic regions of the republic it ranges from $102.2 \%$ to $135.7 \%$.

\begin{tabular}{|l|r|r|r|r|r|r|r|}
\hline & 2011 & 2012 & 2013 & 2014 & 2015 & 2016 & $\begin{array}{l}\text { Indices for 2016, } \\
\text { compared to the } \\
\text { previous year, } \%\end{array}$ \\
\hline $\begin{array}{l}\text { Baku city (with } \\
\text { settlements) }\end{array}$ & 31782850 & 30876683 & 30225126 & 28178874 & 22408874 & 27432370 & 98,5 \\
\hline $\begin{array}{l}\text { Absheron } \\
\text { economic region }\end{array}$ & 475918 & 512819 & 501009 & 543829 & 614994 & 977296 & 115,9 \\
\hline $\begin{array}{l}\text { Ganja-Gazakh } \\
\text { economic region }\end{array}$ & 263569 & 332819 & 304754 & 329262 & 413521 & 615676 & 119,3 \\
\hline $\begin{array}{l}\text { Sheki-Zagatala } \\
\text { economic region }\end{array}$ & 75686 & 75735 & 74835 & 87246 & 109025 & 193190 & 135,9 \\
\hline $\begin{array}{l}\text { Lankaran economic } \\
\text { region }\end{array}$ & 65920 & 65844 & 65170 & 70995 & 74709 & 101997 & 132,7 \\
\hline $\begin{array}{l}\text { Guba-Khachmaz } \\
\text { economic region }\end{array}$ & 89284 & 77136 & 81720 & 77683 & 77689 & 94265 & 107,2 \\
\hline $\begin{array}{l}\text { Aran economic } \\
\text { region }\end{array}$ & 791090 & 821524 & 858935 & 963014 & 881897 & 1145653 & 106,2 \\
\hline $\begin{array}{l}\text { Upper Karabakh } \\
\text { economic region }\end{array}$ & 11640 & 14529 & 18112 & 23913 & 24169 & 29346 & 112,5 \\
\hline $\begin{array}{l}\text { Mountainous } \\
\text { Shirvan economic } \\
\text { region }\end{array}$ & 9733 & 13234 & 15039 & 18672 & 17140 & 19631 & 102,3 \\
\hline $\begin{array}{l}\text { Nakhchivan } \\
\text { Autonomous } \\
\text { Republic }\end{array}$ & 680921 & 799492 & 862871 & 891486 & 916818 & 942945 & 101,7 \\
\hline
\end{tabular}

Table 4. Cost and Indices of Industrial Products (works, services) by Regions, in Actual Prices (thousand manats)

If we take a longer period $(2010=100)$, then the indices of industrial production are even higher (see Table No. 2.11): Absheronsky - 188.1\%; Ganja-Kazakh - 243.4\%; Sheki Zakatalsky - 211.1\%; Lenko ransky - 224.8\%; Khachmaz Bay - 117\%; Aransky - 111.1\%; Upper Karabakh - 179.4\%; Nagorno-Shirvan - 220.9\%; Nakhchivan AR - 270.1\%.

From this we can conclude that the accelerated pace of development of industrial production in the economic regions of the country can be the main basis for the introduction of integrated structures in order to increase their effective activity (Bedakova M.S., 2016).

\begin{tabular}{|l|c|c|c|c|c|}
\hline & 2012 & 2013 & 2014 & 2015 & 2016 \\
\hline Baku city (with settlements) & 89,4 & 90,9 & 89,7 & 92,2 & 90,4 \\
\hline Absheron economic region & 144,8 & 143,5 & 155,3 & 162,3 & 188,1 \\
\hline Ganja-Gazakh economic region & 154,6 & 158,8 & 173,9 & 204,0 & 243,4 \\
\hline Sheki-Zagatala economic region & 117,7 & 117,7 & 139,9 & 155,3 & 211,1 \\
\hline Lankaran economic region & 204,7 & 179,9 & 176,1 & 169,4 & 224,8 \\
\hline Guba-Khachmaz economic region & 111,0 & 116,9 & 107,0 & 109,1 & 117,0 \\
\hline Aran economic region & 109,3 & 110,8 & 119,3 & 104,6 & 111,1 \\
\hline Upper Karabakh economic region & 124,4 & 138,7 & 148,4 & 159,5 & 179,4 \\
\hline Mountainous Shirvan economic region & 176,5 & 195,6 & 236,7 & 215,9 & 220,9 \\
\hline Nakhchivan Autonomous Republic & 238,9 & 254,0 & 260,4 & 265,6 & 270,1 \\
\hline
\end{tabular}

Table 5. Industrial Production Indices by Regions, in Constant Prices, $2010=100$, in percent.

\section{Conclusions}

The development of the non-oil sector, whose share is growing from year to year, can be considered a positive trend in the production of industrial products in the republic. So, for 2011-2016. this indicator in the economic regions increased: Baku - from 81.4\% to 81.7\%; Absheron - from 57.6\% to 61.4\%; Ganja-Kazakh - from $49.0 \%$ to $59.8 \%$; Sheki-Zakatalsky - from $62.5 \%$ to $83.0 \%$; Lenko ransky - from $59.8 \%$ to $67.4 \%$; Guba-Khachmaz from $43.0 \%$ to $44.7 \%$; Upper Karabakh - from 8.5\% to 24.6\%; Nagorno-Shirvan - from 23.4\% to 40.2\%; Nakhchivan AR - from 91.8 to 95.6\%. The exception is the Aran Economic Region (Bautin V.M., 2017). 


\begin{tabular}{|l|c|c|c|c|c|c|}
\hline & 2011 & 2012 & 2013 & 2014 & 2015 & 2016 \\
\hline Baku city (with settlements) & 81,4 & 80,5 & 81,9 & 79,9 & 77,4 & 81,7 \\
\hline Absheron economic region & 37,6 & 52,4 & 44,2 & 40,4 & 48,6 & 61,4 \\
\hline Ganja-Gazakh economic region & 49,0 & 66,0 & 59,0 & 54,2 & 57,5 & 59,8 \\
\hline Sheki-Zagatala economic region & 62,5 & 58,5 & 61,0 & 67,5 & 74,1 & 83,0 \\
\hline Lankaran economic region & 59,8 & 58,6 & 59,9 & 58,7 & 60,6 & 67,4 \\
\hline Guba-Khachmaz economic region & 43.0 & 35.4 & 45.0 & 31.9 & 34.2 & 44.7 \\
\hline Aran economic region & 62,5 & 60,3 & 60,9 & 55,5 & 45,7 & 58,4 \\
\hline Upper Karabakh economic region & 8,5 & 13,9 & 14,6 & 11,3 & 12,4 & 24,6 \\
\hline Mountainous Shirvan economic region & 23,4 & 40,8 & 46,6 & 51,2 & 44,2 & 40,2 \\
\hline Nakhchivan Autonomous Republic & 91,8 & 92,6 & 92,6 & 92,6 & 95,4 & 95,6 \\
\hline
\end{tabular}

Table 6. The Share of the Private Sector in the Volume of Industrial Output by Region, in percent

Naturally, labor resources occupy a significant place in the formation of integrated structures in industrial enterprises. Only for 2011-2016. the growth of workers in industrial enterprises of the republic by region was as follows: Baku - from 92311 to 94722; Absheron - from 17982 to 19754; Ganja-Kazakh - from 13117 to 12363 (decrease); Sheki-Zakatalsky - from 4556 to 5312; Lenko ransky - from 3913 to 5978; Guba-Khachmaz - from 4287 to 4254 (decrease); Aransky - from 22412 to 23008; Upper Karabakh - from 1440 to 1720; Nagorno-Shirvan - from 1721 to 2249; Nakhchivan Autonomous Republic - from 14454 to 16525.

\begin{tabular}{|l|c|c|c|c|c|c|}
\hline & 2011 & 2012 & 2013 & 2014 & 2015 & 2016 \\
\hline Baku city (with settlements) & 92311 & 96420 & 102338 & 102571 & 97521 & 94722 \\
\hline Absheron economic region & 17982 & 17241 & 20899 & 21985 & 21834 & 19754 \\
\hline Ganja-Gazakh economic region & 13117 & 12505 & 15035 & 13359 & 11642 & 12363 \\
\hline Sheki-Zagatala economic region & 4556 & 4992 & 5348 & 5345 & 4255 & 5312 \\
\hline Lankaran economic region & 3913 & 4363 & 5560 & 5827 & 5537 & 5978 \\
\hline Guba-Khachmaz economic region & 4287 & 4810 & 4999 & 4875 & 3967 & 4254 \\
\hline Aran economic region & 22412 & 22267 & 24085 & 23922 & 21315 & 23008 \\
\hline Upper Karabakh economic region & 1440 & 1303 & 1485 & 1597 & 1447 & 1720 \\
\hline Mountainous Shirvan economic region & 1721 & 1826 & 1955 & 2054 & 2002 & 2249 \\
\hline Nakhchivan Autonomous Republic & 14454 & 15095 & 15385 & 15551 & 17404 & 16525 \\
\hline
\end{tabular}

Table 7. Number of Employees in Industrial Enterprises by Regions, people

Thus, the analysis of industrial enterprises in the regions of the republic showed that at present there is a need to form integrated structures in industrial enterprises of manufacturers.

\section{References}

- Abramov R.A. Interregional cooperation in the integration processes of the union state // Spatial Economics. № 4, 2016, p. 153-173.

- Anshin V.M. The project approach to the implementation of the concept of sustainable development in the company. M.: INFRA-M. 2017, -266p.

- Akberdina V.V. Innovative - technological potential of the region: issues of assessment and dynamics // Regional Economics. - 2009, - №23 (116), p.41.

- Bautin V.M. The mechanism for the development of integration processes in the region.// Vestnik. №2, 2017.

- Bedakova M.S. Management of integration and disintegration processes of industrial enterprises and complexes. 2016, - 24 p.

- Bendikov M.A., Frolov I.E. The trend and role of integration processes in industry. // Management in Russia and abroad. 2002, №4, p. 3-22. 


\title{
The Process of Developing an Integrated Model of Catering Services Efficiency
}

\author{
Ph.D. Candidate İlhama İskandarova (Odlar Yurdu University, Azerbaijan)
}

\begin{abstract}
The rapid socio-economic development of the Republic of Azerbaijan is conditioned by many factors, including the sphere of services in various sectors of the economy, including the catering market.

In recent years, the catering market in the country has expanded significantly. During 2000-2015 alone, the catering turnover in the country increased from 18.4 million manat to 1111.2 million manat.

Such a pace of development of catering services has not been observed in any other sector of the economy. The growing role of the catering market in the country fully justifies the fact that the welfare of the country's workers has significantly increased, which is an important element in the integrated assessment of the development of society. To solve many complex problems of the catering market, we need a scientific basis based on modern research methods, including complex marketing research.

In addition, in order to solve a large number of such complex problems, it is necessary to pay special attention to regulatory issues, reducing the level of production costs, rapid development of market infrastructure, raising the level of service culture. Ultimately, this will ensure that tactics and strategies improve the performance of market services in line with market conditions. We believe that a scientific approach to complex marketing research will help solve many problems in the catering market.
\end{abstract}

\section{Introduction}

The final stage of complex marketing research should be the process of developing an integrated model of marketing effectiveness.

To this end, it is necessary to develop a concept for evaluating marketing activities. It represents an integrated model that describes the effectiveness of marketing in a firm as a constant dynamic process. The model expresses the process of the sequence of efficiency, built on the principle of cause-and-effect relationships, that is, each step that comes before is the basis for the next step.

We believe that the final stage of complex marketing research should be the process of developing an integrated model of marketing effectiveness.

\section{Methodology}

For this purpose, it is necessary to develop a concept for evaluating marketing activities. This represents an integrated model that describes the effectiveness of marketing in a firm as a constant dynamic process (Arsenyeva E.V., Nosova G.V., 2015).

The model expresses the process of the sequence of efficiency, built on the principle of cause-and-effect relationships, that is, each step that comes before is the basis for the next step.

The peculiarity of the development of an integrated model for assessing the effectiveness of catering services marketing is that it is necessary to reflect the specifics of efficiency in the field of catering services. We believe that this model can be described as follows in the example of the expansion of the restaurant "Fontan" (Alekseev A.N., 2014). 


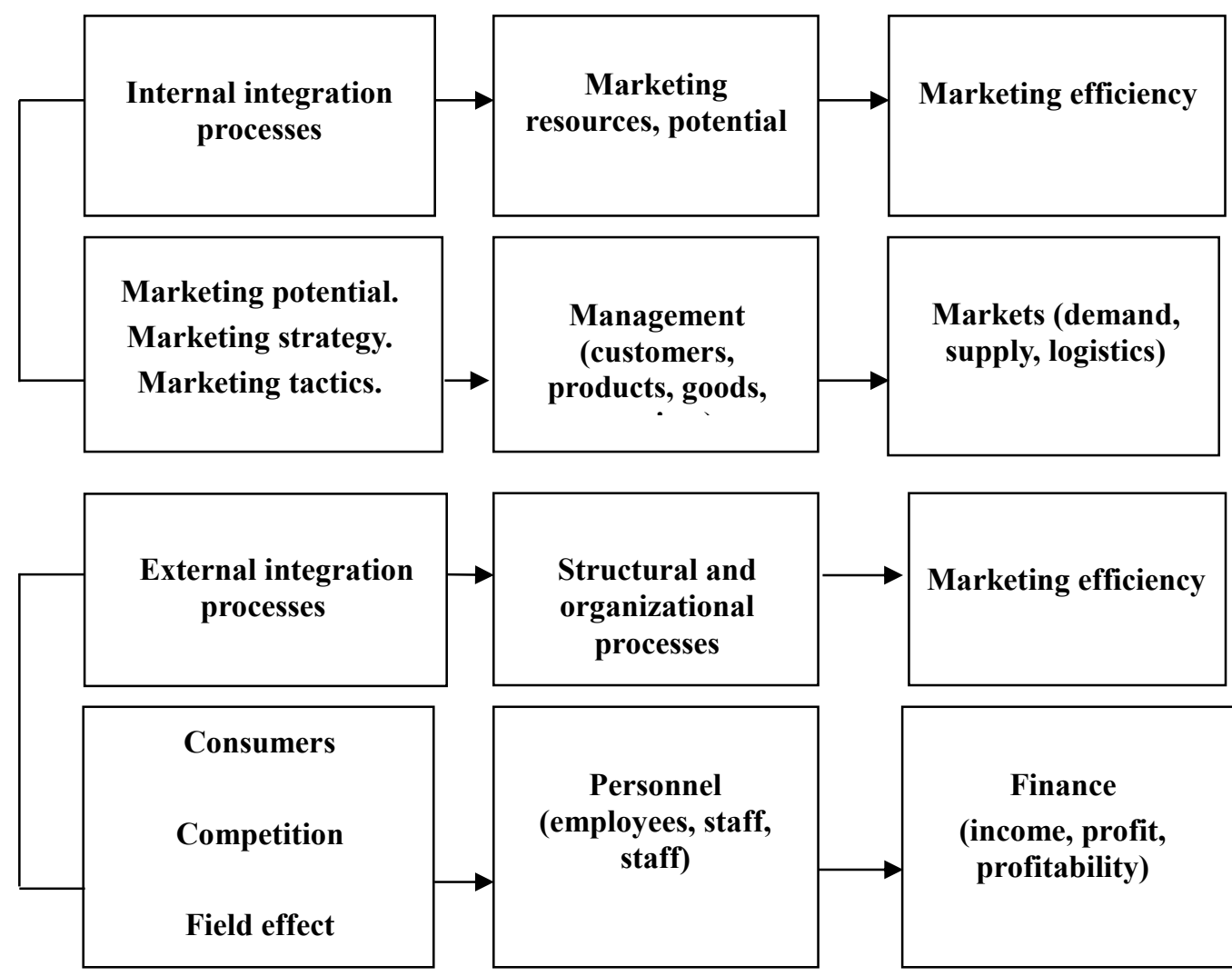

Figure 1. Integrated Model for Evaluating the Effectiveness of Service Marketing in the Restaurant

As can be seen, the proposed integrated model for assessing the effectiveness of catering services marketing in the RN Fontan restaurant consists of two blocks (Gashimov G.I., 2015).

1. Internal integrated processes, including marketing potential, marketing strategy, marketing tactics. The subblocks of this model are marketing resources (management - customers, products, goods, services) and marketing efficiency (market - raw materials, supply, logistics).

2. Externally integrated processes, including customers, competitiveness, industry impact. The sub-blocks of this model are structural and organizational processes (personnel - employees, employees, personnel) and marketing efficiency (finance - income, profit, profitability) (Kotler F., 2016).

The proposed integrated model of efficiency shows that there is a connection between the sphere of marketing and the sphere of service delivery, and managers in both spheres should try to understand the goals of the other party.

At the same time, marketers need to understand that the majority of contacts are related to the interaction between the customer and the staff, which highlights the importance of human resource management, especially in service areas with a high level of contacts.

The final practical result of the marketing function of the provision of services in the field of market relations, and ultimately the operation of the whole system, is the fulfillment of a specific goal determined by the needs of the consumer. Our research has shown that the specific model of activity and work of a particular enterprise as a result of market relations is the result of the introduction of a certain generalized logistics model of the market. All this allows us to characterize the interaction of the main elements of the service marketing system and reveal their regularities.

When integrating all the subsystems that determine customer satisfaction activities into the model, it should be noted that only a certain balance of all interrelated elements allows the catering company to operate optimally in the services market. The operation of such a system, by its very nature, does not require the administration of a traditional administrative command. The system is self-regulating, its operation depends primarily on the balance of demand and consumption of services. Conceptually, the integration of the catering enterprise into the system of market relations means the replacement of the management system of the enterprise with the original system of self-regulatory marketing activities to meet the target needs of the customer for a particular service.

The interaction of all the components of the characteristics of this activity in the market system is a reflection of certain complex relationships inherent in the market of services. 


\section{Results}

The developed model is, by its nature, universal for market structures, which allows it to be used not only in the context of services, but also in other areas of production and commercial activities related to marketing relations. At the present stage:

- search and describe the relevant relationships of the elements used in the services marketing system;

- identify and substantiate the functional dependence of the elements of the service marketing model, logically describe these dependencies using modern methods;

- it is important to build and develop situational models of systematic and integrated levels.

Thus, in general, the considered functional elements can be divided into two groups.

The first group includes elements that characterize the subjects (consumers and producers) and objects of the marketing system: external environmental factor, product image, standard, economic group, consumer group, professional group, purchasing power, purchasing power, wages, product value, service status, labor evaluation, unit of goods, unit of labor, efficiency.

The second group includes the elements (need, demand, supply, welfare, bargaining, training, demand, activity, satisfaction) that characterize the certain situation and movement of the subjects of the system against the background of market relations.

Thus, the integrated model of service marketing expresses the logical regularity-universal connection of the elements and concepts that characterize human activity aimed at meeting the needs and requirements through exchange.

\section{Conclusions}

The integrated model of service marketing efficiency in modern conditions solves systemic strategic issues consisting of four stages.

Strategy I - "capturing depth in the market", can be used when the market and its consumers are known. It is not difficult to identify the segments. In this case, a selective approach involving the selection of one or more wellknown segments is appropriate. This strategy is applied when a new phase of the standard format already exists in the market, and you have to base your "depth" on your own concept.

Strategy II - focuses on the largest number of possible segments, selected on the basis of careful analysis of the firm's resources and customer segments.

Strategy III - refers to the specialization of the catering company. This approach is close to the first strategy, the only difference being that the proposal is not very specific. For example, the restaurant "Fontan" attracts the attention of a certain segment of customers with its appropriate environment, along with which everyone can get acquainted with a new type of fast food company.

Strategy IV - Differentiation of proposals is aimed at extensive expansion of activities and is justified when it is very difficult to identify segments. Using this strategy, it is necessary to determine the approximate boundaries of the segments, try to offer the maximum number of services and opportunities for such customers in your restaurant.

Finally, the most profitable concept for a catering company to ensure a competitive position in the market is to have any quality (kitchen, service, environment, interior) that is of great importance in the field. Having one of these qualities means working effectively. The competitive position of the restaurant on various criteria:

- on the basis of what customers prefer (restaurant for customers of fast food);

- based on traditions;

- for national cuisine;

- can be provided based on the popularity of the restaurant concept.

\section{References}

- Arsenyeva E.V., Nosova G.V. Marketing research. Moskow ,.MSU.2015, -441p.

- Alekseev A.N. Marketing services market research. Moscow, 2014,- 230 p.

- Gashimov G.I. Commercial activities in the service sector. Baku.AzDIU. 2015,-308p.

- Kotler.F. The basics of marketing. Moskow, 2016, - 752 c. 


\title{
Methods of Segmentation and Positioning in the Product Market with Access to a New Foreign Market
}

\author{
Ph.D. Candidate Rana Mikailova (UNEC- Azerbaijan State University of Economics, \\ Azerbaijan)
}

\begin{abstract}
Entering a new foreign market has always remained an urgent problem. The interrelation of the internal and external commodity market is an important condition for the successful development of the economy of any country. Foreign experience shows that various strategic approaches are used for this purpose. The basic basis of the strategic approach is the systematic coverage of the product market, which includes undifferentiated marketing, differentiated marketing and concentrated marketing. Below we will consider in more detail the above strategic approaches to coverage of the product market. In particular, it is considered when an enterprise refuses features and explores the entire market from the position of a single approach. Differentiated marketing tactics are not about identifying a single need, but a general one. These include the formation of a product and a marketing program that will be useful to a significant number of consumers. A distinctive feature of differentiated marketing is that the company operates in a number of market segments and forms a distinctive offer for them. This approach is based on offering different products to the market in order to increase sales and penetrate deeper into the development of product market segments. Finally, concentrated marketing provides an opportunity for businesses to discover an additional opportunity that is more attractive from a resource constraint perspective. It is manifested by the concentration of efforts on a small share of a large commodity market.
\end{abstract}

\section{Introduction}

Marketing research methods make it possible to study in more detail the issues of segmentation in the product market. First of all, let us define the category of segmentation, which, in our opinion, is the differentiation of the product market into groups of consumers that have relatively similar content for a deeper study of their maneuverability in choosing target segments of the product market.

At the same time, the segmentation of the commodity market is determined by the grouping of buyers in the consumer market into various subsystems, within which buyers have approximately equal demands, which are satisfied by an integrated marketing system. There are no standard methods for segmenting the market. The researcher of the commodity market should choose different variants of segmentation based on variable parameters, one or several at once, in order to develop a more rational study of the market structure.

\section{Methodology}

Along with the segmentation of the product market in marketing research, an important role is assigned to the issues of positioning, which is a set of measures that contribute to the formation of individual opinions among buyers about certain products. The components of product positioning on the market are:

- selection of the positioning component, taking into account the usefulness of the product for the buyer, which is the reason for purchasing it in a particular enterprise;

- positioning takes place for the selected target segment, because for individual sites the most significant components of positioning will naturally be individual (Velichko V.V., 2018);

- positioning involves the approach of an adversary who is displaying goods for a given target segment

Positioning principles should also be defined, which can be categorized into the following system:

- phasing of the chosen position, functioning without changes for a relatively long period. At the same time, a number of position components may change, but not the position itself as a whole;

- information availability of the position of the enterprise in relation to the consumer, its simplicity and availability;

- the components of the trade should consistently and realistically reflect the chosen position of the firm.

Marketing research on product positioning contributes to the determination of the key advantage of the product, which in practice is called the positioning attribute.

Selecting clients for positioning begins with identifying segment potential and benefits. Metrics are grouped according to the interests that they hope to get from the product. 


\begin{tabular}{|l|l|}
\hline Groups & Classification of approaches \\
\hline Zones & Territorial approach \\
\hline Regions & Major world economic zones \\
\hline Cities & $\begin{array}{l}\text { With a population from 5 thousand people to more than 1 } \\
\text { million people }\end{array}$ \\
\hline Population density & Cities, towns, countryside \\
\hline \multicolumn{1}{|c|}{ Social approach } \\
\hline Social level & $(-) ;(-;+) ;(+)$ \\
\hline Life style & Traditional, luxurious \\
\hline \multicolumn{2}{|c|}{ Behavioral approach } \\
\hline Making a purchase & A special case \\
\hline Seeking benefits & Quality, service, economy \\
\hline Intensity of purchases & Low, moderate and active buyers \\
\hline Directional level & Medium, strong, absolute \\
\hline Consumer readiness level for product perception & Informed, interested \\
\hline Product attitude & Positive, negative \\
\hline
\end{tabular}

Table 1. Selection of Variables Used to Segment the Product Market.

\section{Results}

Quality-based positioning marketing research is generating increased interest from product use. The buyer gets the impression that past experience on the price they paid is critical. The product is rated very worthwhile if it exceeds such expectations. The challenge is that every positive experience creates an expectation of better quality in the long run.

Marketing research of product positioning on the market consists of a number of successive phases:

a) identify a set of competitive products serving the target market;

b) compose a set of defining elements covering the product market in which the positions are distributed;

c) collection of information, study a sample of consumers and potential buyers of the perception of a particular product by the relevant attributes;

d) identify the condition of the goods on the commodity market;

e) identify a relatively preferred set of defining attributes for customers;

f) investigate the correspondence between the preferences of market segments and the present position of the product;

j) draw conclusions about positioning and develop proposals for the further formation of a marketing strategy.

It should be noted that the use of segmentation and positioning methods in the domestic product market contributes to a successful entry into a new foreign market.

Marketing research of product market segmentation and product positioning make it possible to decide on entering the foreign market.

The phases of the methodology for selecting a foreign market and modeling the economic indicators of exports are built as follows:

A. Assessment of the capacity of the commodity market, within the boundaries of which the organization of the sale of goods is supposed.

B. Diagnostics of the structure of the target product market.

C. Assessment of barriers to entry and exit within product markets.

The capacity of the consumer market, as noted, is the volume of sales of a certain product in a given market of the country during a certain period of time. Many marketers, when characterizing the market capacity, are guided by its potential level and define it as "the potential volume of sales of goods on the market."

Assessment of the dynamics of market capacity as a whole and of individual types of goods is the main one for diagnosing one's capabilities in the product market, developing a strategy and marketing policy. World experience shows that firms should have monthly data on the capacity of the consumer market and the share of firms in it, which makes it possible to quickly respond to changes in the commodity market. However, there is no uniform approach to such studies. When calculating the capacity of the commodity market as an economic category, two approaches should be noted: assessment of the satisfied demand; assessment of potential demand.

For non-food products, the potential capacity can be calculated by the capacity used by firms. In a word, the potential market capacity should be understood in the future as a situation when all commodity producers will fully utilize their production capacities.

It is also necessary to diagnose the production of goods within the regional boundaries of the market. 
Market diagnostics is not limited to the proposed ways and can be supplemented by a study of market demand, price data, an assessment of the balance of supply and demand in the market. The result of marketing research: identification of promising directions for selling goods.

The main factors in diagnosing the market structure are indicators of market concentration, which is discussed in detail in the previous sections of the work.

Further, in order to make a rational decision by firms to export goods to the foreign market, it is proposed to consider the barriers to doing business in these countries

As noted earlier, market segmentation is expressed as an activity to classify potential buyers, goods produced and sold by the firm in accordance with the qualitative specifics of demand. In addition, market segmentation is possible based on criteria not related to indicators. Segmentation by product type is a way of dividing the market by functional and ICT components of the product manufacturers.

The next step is the process of modeling the indicators of the export of goods. The essence of modeling comes down to comparing the options for the volume of admission and the price of goods, as well as prices and tariffs for energy resources. The ratio of these parameters is considered rational, which will allow achieving the highest income of the export product.

At the beginning of the simulation, the main parameters for the export product are set: the volume of output and the corresponding costs (Virina M.E., 2017).

Taking into account the relationship of income with costs and results, commercial and economic calculations make it possible to determine the influence of decisions made on changes in volumes, prices and material costs on the income of a given product.

The modeling of export indicators for a product should be the result of export assessments of the real situation by the personnel of the marketing department, economists and financiers of the exporting firms.

Let us consider the practical side of this methodology using the example of export-import operations in the Republic of Azerbaijan.

Diagnostics of the market environment for foreign trade will be carried out by calculating the real capacity of the market for export and import goods in the republic. For this, we will use data on exports "Table 1", imports "Table 2". and the volume of production of industrial and food products.

\begin{tabular}{|c|c|c|c|c|c|c|c|c|c|c|}
\hline & \multicolumn{10}{|c|}{ Export, mln USD } \\
\hline & 2013 & $\%$ & 2014 & $\%$ & 2015 & $\%$ & 2016 & $\%$ & 2017 & $\%$ \\
\hline Total & 23975,1 & 100 & 21828,6 & 100 & 12729,1 & 100 & 15457,1 & 100 & 13811,6 & 100 \\
\hline Food products & 647,8 & 2,7 & 648,2 & 3,0 & 625,1 & 4,9 & 478,2 & 3,6 & 601,4 & 4,4 \\
\hline $\begin{array}{l}\text { Drinks and } \\
\text { tobacco }\end{array}$ & 41,7 & 0,2 & 44,6 & 0,2 & 35,2 & 0,3 & 37,6 & 0,2 & 37,2 & 0,3 \\
\hline $\begin{array}{l}\text { Unproductive } \\
\text { resources }\end{array}$ & 47,0 & 0,2 & 33,9 & 0,2 & 25,7 & 0,2 & 45,2 & 0,3 & 79,0 & 0,6 \\
\hline Mineral fuel & 22229,8 & 92,7 & 30177,2 & 92,4 & 11187,1 & 87,9 & 12270,1 & 91,2 & 12358,7 & 89,5 \\
\hline $\begin{array}{l}\text { Chemical } \\
\text { goods }\end{array}$ & 175,4 & 0,7 & 231,1 & 1,1 & 190,2 & 1,5 & 159,2 & 1,1 & 178,7 & 1,3 \\
\hline $\begin{array}{l}\text { Prom. } \\
\text { products }\end{array}$ & 265,0 & 1,1 & 200,9 & 0,9 & 179,8 & 1,4 & 273,7 & 2,0 & 323,4 & 2,3 \\
\hline $\begin{array}{l}\text { Cars and } \\
\text { transport }\end{array}$ & 149,3 & 0,6 & 190,1 & 0,9 & 88,9 & 0,7 & 15,7 & 0,1 & 19,3 & 0,1 \\
\hline Others & 72,9 & 0,3 & 76,9 & 0,3 & 82,8 & 0,7 & 76,8 & 0,6 & 139,4 & 1,0 \\
\hline
\end{tabular}

Table 2. Diagnostics and Analysis of the Structure of Export of Goods of the Republic of Azerbaijan

Analysis of import flows in trade shows that such commodity groups as mineral fuels (89.5\%); food products (4.4\%); chemical products $(1.3 \%)$, and the rest of the goods make up a negligible share, i.e. less than $1 \%$.

Export dynamics show that there is a positive trend for certain goods. For example, for 2013-2017. for food products, the share of exports increased from $2.7 \%$ to $4.4 \%$, for industrial goods - from $11 \%$ to $2.3 \%$. However, the dominant position is still occupied by energy resources. Their share decreased from $92.7 \%$ to $89.5 \%$ ( Zagidulina G.M., 2015).

At the same time, the diagnostics and analysis of imports shows that foreign goods are actively imported in the republic. For food products for 2013-2017 their share increased from $9.9 \%$ to $14.36 \%$, mineral fuels - from $1.3 \%$ to $4.3 \%$, chemical products - from $8.7 \%$ to $11.8 \%$, finished products - from $8.7 \%$ up to $9.8 \%$. 


\begin{tabular}{|c|c|c|c|c|c|c|c|c|c|c|}
\hline & \multicolumn{10}{|c|}{ Imports, mln USD } \\
\hline & 2013 & $\%$ & 2014 & $\%$ & 2015 & $\%$ & 2016 & $\%$ & 2017 & $\%$ \\
\hline Total & 10712,5 & 100 & 9187,7 & 100 & 9216,7 & 100 & 8489,1 & 100 & 8782,0 & 100 \\
\hline Food products & 1062,0 & 9,9 & 982,3 & 10,7 & 910,5 & 9,9 & 1189,7 & 14,0 & 1232,4 & 14,6 \\
\hline $\begin{array}{l}\text { Drinks and } \\
\text { tobacco }\end{array}$ & 400,2 & 3,7 & 469,3 & 5,1 & 360,0 & 3,9 & 210,0 & 2,5 & 231,8 & 2,6 \\
\hline $\begin{array}{l}\text { Unproductive } \\
\text { resources }\end{array}$ & 324,0 & 3,0 & 146,3 & 1,6 & 212,0 & 2,30 & 187,4 & 2,2 & 231,1 & 2,6 \\
\hline Mineral fuel & 141,6 & 1,3 & 297,0 & 3,2 & 150,1 & 1,6 & 282,6 & 3,3 & 178,8 & 4,3 \\
\hline $\begin{array}{l}\text { Chemical } \\
\text { goods }\end{array}$ & 934,0 & 8,7 & 875,0 & 9,5 & 838,3 & 9,1 & 895,5 & 10,5 & 1040,0 & 11,8 \\
\hline Prom. products & 1933,7 & 18,1 & 1778,5 & 19,4 & 2362,3 & 25,6 & 1864,2 & 22,0 & 1684,5 & 19,2 \\
\hline $\begin{array}{l}\text { Cars and } \\
\text { transport }\end{array}$ & 4173,3 & 39,0 & 3454,8 & 37,6 & 3677,5 & 39,0 & 2805,3 & 33,0 & 2979,8 & 33,4 \\
\hline Finished goods & 749,1 & 7,0 & 692,0 & 7,5 & 631,9 & 6,9 & 909,8 & 10,7 & 859,8 & 9,8 \\
\hline Others & 923,5 & 8,7 & 419,2 & 4,6 & 3022,4 & 0,0 & 1678,2 & 0,3 & 155,1 & 0,3 \\
\hline
\end{tabular}

Table 3. Diagnostics and Analysis of the Structure of Imports of the Azerbaijan Republic.

In a word, the layout of import-export goods in the republic is not entirely positive, which requires the development of the non-oil sector of the economy.

Nevertheless, the Republic of Azerbaijan is applying an import substitution policy using the possibilities of domestic production.

Diagnostics of the data obtained shows that for 2013-2017. the real market for food products increased from 2.7 million manats to 3.1 million manats.

\begin{tabular}{|l|r|r|r|r|r|}
\hline & $\mathbf{2 0 1 3}$ & $\mathbf{2 0 1 4}$ & $\mathbf{2 0 1 5}$ & $\mathbf{2 0 1 6}$ & $\mathbf{2 0 1 7}$ \\
\hline Food products & 2286,4 & 2422,0 & 2307,6 & 2964,7 & 2999,8 \\
\hline Drinks and tobacco & 231,7 & 244,8 & 224,9 & 265,4 & 302,6 \\
\hline Prom. products & 1441,8 & 1463,5 & 1375,3 & 1582,2 & 2280,8 \\
\hline Chemical goods & 200,3 & 247,2 & 353,2 & 374,2 & 513,9 \\
\hline Machinery and equipment & 262,7 & 360,9 & 304,4 & 300,0 & 280,6 \\
\hline Finished goods & 147,1 & 137,0 & 119,1 & 197,1 & 304,3 \\
\hline Total & 7244,9 & 8060,6 & 7880,4 & 8899,5 & 9723,5 \\
\hline
\end{tabular}

Table 4. The Volume of Production of the Manufacturing Industry in the Republic (million manat)

\begin{tabular}{|l|r|r|r|r|r|}
\hline & \multicolumn{1}{|c|}{$\mathbf{2 0 1 3}$} & $\mathbf{2 0 1 4}$ & \multicolumn{1}{c|}{$\mathbf{2 0 1 5}$} & \multicolumn{1}{|c|}{$\mathbf{2 0 1 6}$} & $\mathbf{2 0 1 7}$ \\
\hline Food products & 2700,6 & 2756,1 & 2593,0 & 3676,2 & 3630,8 \\
\hline Drinks and tobacco & 580,2 & 669,5 & 569,6 & 387,8 & 497,2 \\
\hline Prom. products & 3110,1 & 3023,1 & 3555,8 & 3172,7 & 3641,9 \\
\hline Chemical goods & 958,9 & 891,1 & 1001,3 & 1110,5 & 1375,2 \\
\hline Machinery and equipment & 4272,5 & 3728,5 & 3773,3 & 3002,0 & 3200,4 \\
\hline Finished goods & 746,9 & 638,9 & 661,5 & 1091,2 & 1144,8 \\
\hline
\end{tabular}

Table 5. The Real Capacity of the Commodity Market of the Republic of Azerbaijan for 2013-2017 (million manat)

According to "Table 5", the real capacity of the commodity market decreased in terms of beverages and tobacco from 580.2 million manats to 497.2 million manats, industrial goods increased from 3.1 billion manats to 3.6 billion manats, chemical products - from 958.8 million manats to 1375.2 million manats, etc. In a word, for 20132017. the volume of the capacity of the commodity market as a whole has increased (Vasilyeva O.E., 2011).

\section{Conclusions}

Research for 2013-2017 in the area of the structure of export of goods of the republic, they showed that very negative processes are observed in this area, because about $90 \%$ of exports are mineral resources and fuel, and only a small part falls on products of the commodity market;

- diagnostics and analysis of the structure of imports in the republic indicate that during the study period there is a slight decrease in the main commodity groups (with the exception of food products, chemical goods, finished goods), which indicates a partial activation of the commodity market in the country;

- calculations of the real volume of the commodity market capacity (according to the manufacturing industry data without indicators of production of energy resources and combustible minerals) in the republic increased over 2013-2017. insignificantly (food products - from 2.7 billion manats to 3.6 billion manats; beverages - from 0.6 to 
0.5 ; industrial goods - from 3.1 to 3.6 ; chemical products - from 1.0 up to 1.4 ; machinery and equipment - from 4.5 to 3.2 ; finished products - from 0.7 to 1.1 ).

\section{References}

- Lazerev N.V. Organization of innovation in construction companies. M .: buildinginformizdat. 2017.-130p.

- Strategic Road Map for the development of construction in the Republic of Azerbaijan (16.XII 2016).

- Vasilyeva O.E. Formation and economic evaluation of service support for industrial enterprise products: theory and methodology. Auto Doc. Chelyabinsk: SUSU. 2011.

- Velichko V.V. Risk management of construction projects. M: Telecom 2018-212 p.

- Virina M.E. Fundamentals of the economics of construction. M .: Academy. 2017.- 235 p.

- Zagidulina G.M. Construction Economics. M .: INFRA-M. 2015, -360 p. 


\title{
Cryptocurrencies, Blockchain Technology and Sustainability
}

\author{
Dr. Burcu Sakız (Istanbul Aydın University, Turkey) \\ Prof. Dr. E. Ayşen Hiç Gencer (Beykent University, Turkey)
}

\begin{abstract}
Satoshi Nakamoto is the name used by the presumed pseudonymous person or persons believed to be the inventor of cryptocurrency Bitcoin, came up with the concept of blockchain as a core component of it when published a white paper on "BitCoin: A peer to peer electronic cash system" in 2008, blockchain technology made its public debut. Bitcoin is generally considered the first decentralized cryptocurrency and since the release of it, over 6,000 altcoins have been created. Cryptocurrencies use decentralized control as opposed to well-known, traditional centralized digital currency and also central banking systems. The decentralized control of each cryptocurrency works through distributed ledger technology, typically a blockchain. Blockchain is a system that in which a record of transactions made in cryptocurrencies are maintained across several computers/servers that are linked in a peer-to-peer network. Blockchain based applications provides many opportunities to create a more sustainable world. This paper contribute to the discussion on future avenues for sustainability especially in terms of cryptocurrencies and blockchain based platforms and services.
\end{abstract}

\section{Introduction}

The global economy is not all sunshine and rainbows. Throughout the world, there are alarming warning signs that consumers and especially some countries are being overburdened with debt. In the financial crisis of 2008, the available alternative assets were gold, silver, and real estate but it is strange that bitcoin was born out of the financial crisis. Bitcoin offers an alternative to fiat currency. Bitcoin is not controlled by any person or any government, capital controls cannot be imposed, and it can be freely used across borders. 2008 Financial crisis has revealed the inadequacies of some of big institutions which were believed too big to fail, and has energized a loose coalition of entrepreneurs and information technology companies and startup companies try to reform and reinvent the current financial system (Olleros \& Zhegu, 2016).

Virtual currencies namely cryptocurrencies are online payment systems that are not issued or backed by central governments like fiat money are one of the hottest topics in financial world. They are transferable digital assets, secured by cryptography. Almost all of them have been created by private individuals, academics, organizations or firms. Cryptocurrencies are digital alternatives to traditional paper monies. Bitcoin has emerged as the most successful cryptographic currency in history. Current cryptocurrencies, starting with Bitcoin in 2009, build a decentralized blockchain based transaction ledger, maintained through proof of work that also generate a monetary supply. Such decentralization structure has benefits, such as independence from national political control, but also significant limitations in terms of scalability and computational cost (Danezis, Meiklejohn, 2015).

The blockchain, the ledger technology that underlies Bitcoin, has huge implications for many industries. Blockchain consist of distributed database of records, or public ledger of all transactions or digital events that have been executed and shared among participating parties. Each transaction in the public ledger is verified via consensus of a majority of the participants in the network. Once entered, information can not be deleted, only insert operation is permitted. Blockchain architecture is similar to a distributed ledger that is consensually kept, saved, updated, protected, validated and can not deleted by any party involved in all the transactions within a public, hybrid or private network (Risius, Shoprere, 2017).

Blockchain technology has paved the way for disrupting different business industries over the world. It is known as one of the most significant technical innovations in digitalization of asset ownership. One of the important points is, the most impactful blockchain applications require tight collaboration between developers, incumbents, innovators, and regulators, adding complexity and delaying implementation (Wef, 2016). The decentralized nature of the blockchain makes cryptocurrencies theoretically immune to the old ways of government control and also it eliminates need for mediation (Rosic, 2016). Additionally, it is kind a financial tool that plays an important role in the sustainable development of the global economy. That's why this paper focuses on the emerging landscape for blockchain technology in terms of sustainability.

\section{Rise of Cryptocurrencies}

Cryptocurrencies, predominantly spearheaded by the Bitcoin, are unique instruments in the investing and finance world. It's obvious that cryptocurrencies are an important and rising element in today's digital economy. All digital currencies and Bitcoin are based on the idea of a distributed ledger trust mechanism called the "blockchain", a way of keeping track of trusted transactions in a decentralized way (Wef, 2015). Virtual assets such as Bitcoin are powerful financial tools which can transfer wealth immutably. Starting with Bitcoin, the blockchain technology has developed beyond a global payments system and started to also impact other areas, i.e access to finance, supply chain management, digital identities, smart contracts, health care, land registries or aid, through decentralized 
applications. Unlike traditional banks, blockchain uses a distributed network of volunteer users (miners) from around the world to produce, record, monitor, and verify Bitcoin.

Cryptocurrency is an umbrella term used for all digital mediums of exchange that implement a cryptographic framework and security features. They have become the new business opportunities for investors across the globe. Cryptos are protected by technology that makes it impossible to expand the money supply by more than a predetermined algorithmic rate that is already known to the public. The cryptocurrency phenomenon traces its roots back to 1998. Nick Szabo has been involved in the crypto sector since the 90s, pioneering, among other ideas, the notion of "smart contracts" as well as designing BitGold. He proposed a system for a financial system that combines different elements of cryptography and mining to accomplish decentralization. These elements include timestamped blocks (information) that are stored in a title registry and are generated using "proof of work" strings. In 2008, an individual (or a group) published a paper under the name of Satoshi Nakamoto entitled "Bitcoin: A Peer-To-Peer Electronic Cash System" and this became the birth of cryptocurrency systems. It wasn't until 2009 that developer Satoshi Nakamoto implemented the first blockchain. Bitcoin uses blockchain technology on a peer-to-peer network as a de-centralized ledger for all transactions (Url-1, 2019).

Cryptocurrency properties are listed below (Rosic, 2016).

- Irreversible: Transactions can not be reversed after confirmation.

- Pseudonymous: Neither transactions nor accounts are connected to real-world identities.

- Fast and Global: Transactions are propagated almost instantly in the network and are confirmed in a couple of minutes.

- Secure: A public key cryptography system keeps cryptocurrency funds. Only the owner of the private key can send cryptocurrency.

- Permissionless: There is no gatekeeper. It's just a software that everybody can download for free.

- Controlled Supply: All cryptocurrencies control the supply of the token by a schedule written in the code. Most cryptocurrencies limit the supply of the tokens. In Bitcoin, the supply decreases in time and will reach its final number sometime around the year 2140 .

- No debt but bearer: Cryptocurrencies don't represent debts, they just represent themselves.

Version 0.1 of the cryptocurrency Bitcoin is released and includes a generation system intended to create 21 million bitcoins through 2040 (Zimmermani, 2016). The name of unknown inventor of Bitcoin is Satoshi Nakamoto. According to him, strict peer-to-peer version of electronic cash can allow online payments to be sent directly from one person to another without mediation that eliminates transactions going through a financial institution. The cost of mediation increases transaction costs high. Bitcoin does not have a mediation mechanism. Blockchain is one of a kind decentralized technology and distributed decentralized ledger that implements bitcoin architecture. Blockchain technology presents an innovative way of conducting all manner of transactions over the Internet. Introducing the blockchain environment will actually enhance the economics. Blockchain architecture enables all the transaction are recorded right from the manufacturer to the buyer.

In 2002, a Turkish academician Mr. Emin Gün Sirer in US at Cornell University implemented a peer-to-peer system protocol called "Karma". It was a digital currency for peer-to-peer distributed systems. So, Satoshi is not the first one who held peer to peer system distributed concept and virtual currency. Starting in 2002, Emin Gün Sirer and his two students aim was to build one global currency, with no inherent monetary value, which could be used to download digital things by creating the first distributed mint based proof of work. The main problem in decentralization is getting consensus and difficulty of cooperation between different parties. They described three important characteristics that a system needs to have facilitating peer-to-peer networks (Mahler, 2018):

- Distribution: It must be completely distributed with no centralized functionality or trust;

- Replication: Account data needs to be replicated to insure against loss and tampering;

- Coordination: Coordination among the different replicas must be kept to a minimum. 


\section{The History of Cryptocurrency}

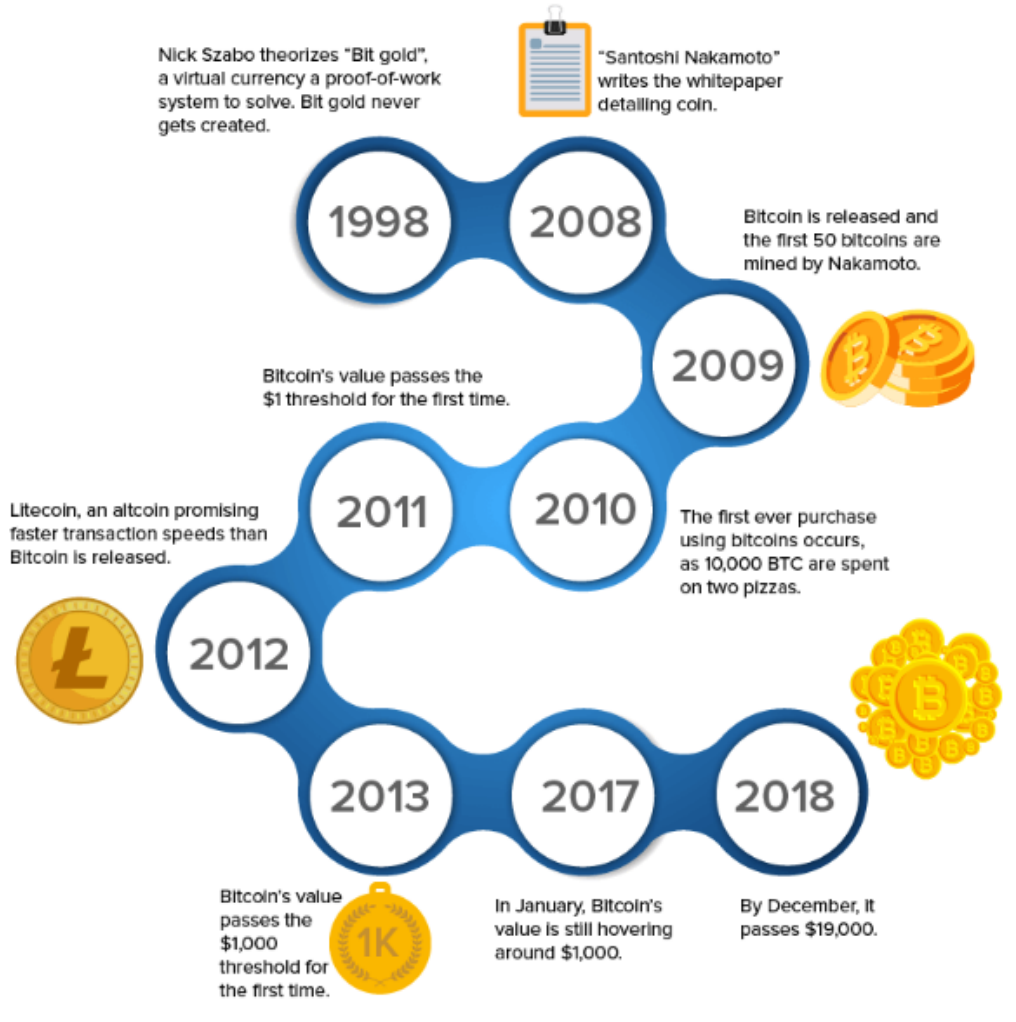

Figure 1. The History of Cryptocurrency Technology Source: (Url-2, 2018)

Actually even known as 2009 is the year that Blockchain concept revealed, Blockchain was invented in 1991. It's history back to early 1990's by two researchers: Stuart Haber and W. Scott Stornetta who are co-inventors of the blockchain technology. Several aspects of the Bitcoin blockchain architecture are based on Stornetta's work. Haber and Stornetta worked on a cryptographically secured chain of blocks whereby nobody can tamper with timestamps of documents. Afterwards they upgraded block chain system to incorporate with Merkle trees that enhanced efficiency and performance thereby enabling the collection of more documents on a single block in 1992 (Url-3, 2019).

There are a lot of digital moneys developed since 2008. Cryptocurrencies have attained much attention from the financial and tech sectors and academics. According to coinmarketcap web site, total market capitulation is more than $\$ 247$ billion. This is the list of most popular ones among 5403 coins are shown in Table 1:

\begin{tabular}{|l|l|l|}
\hline Name & Symbol & Market Cap \\
\hline Bitcoin & BTC & $\$ 160,451,968,735$ \\
\hline Ethereum & ETH & $\$ 24,027,240,150$ \\
\hline XRP & XRP & $\$ 9,972,159,875$ \\
\hline Tether & USDT & $\$ 6,412,543,756$ \\
\hline Bitcoin Cash & BCH & $\$ 4,727,872,384$ \\
\hline Bitcoin SV & BSV & $\$ 3,842,732,871$ \\
\hline Litecoin & LTC & $\$ 3,161,201,935$ \\
\hline EOS & EOS & $\$ 2,764,461,241$ \\
\hline Binance Coin & BNB & $\$ 2,064,696,186$ \\
\hline Tezos & XTZ & $\$ 2,064,696,186$ \\
\hline
\end{tabular}

Table 1 : Top 10 Cryptocurrencies by Market Cap Source: (Url-4,2020)

Cryptocurrencies are challenging the traditional pillars of the financial system by seeking to provide a secure, fast, and frictionless means to store, spend, and move value. By the end of the decade, most tech startups will have a crypto component, just like most tech startup companies use increasingly the internet and take the advantage of artificial intelligence, machine learning and deep learning technologies today. Also more than a decade cryptocurrencies, bitcoin and blockchain has attracted extensive attentions from both industry and academia. By 
shifting cryptocurrency from being primarily about trading and speculation to being about real world utility, the 2020s will see a huge increase in the number of people using cryptocurrency.

\section{Development of Blockchain}

Ever since January of 2009, blockchain technology has still been growing and evolving. It is widely accepted that the computational architecture of blockchain technology which is a distributed ledger technology creates a wide range of potential uses. A blockchain is a decentralized digital ledger that saves transactions on thousands of computers around the globe. In 2015, World Economic Forum Report states that around 10 percent of GDP by 2027 will be stored on blockchain and similar technologies (Wef, 2015). There is a wide spectrum of blockchain applications ranging from cryptocurrency, financial services, risk management, internet of things to healthcare, identity, insurance, real estate, supply chain, contracts, public, government and social services. The economic, political, health care, humanitarian, intellectual property and legal system benefits of blockchain start to make it clear that it is a potentially disruptive technology. Blockchain revolution can broke down into 3 categories shown in Table 3 (Swan, 2015).

\begin{tabular}{|l|l|}
\hline Year & Blockchain Revolution Explanation \\
\hline $\begin{array}{l}\text { Blockchain } \\
1.0\end{array}$ & Currency (deployment of cryptocurrencies in application related to cash, i.e currency transfer, \\
\hline $\begin{array}{l}\text { Blockchain } \\
2.0\end{array}$ & Conittance, digital payments) \\
\hline $\begin{array}{l}\text { Blockchain } \\
3.0\end{array}$ & Applications (beyond currency, finance and markets- especially for government, healthcare, \\
\hline
\end{tabular}

Table 2: Blockchain Revolution Summary Source: (Swan, 2015)

Also Swan (2015) lists 7 technical properties, challenges and limitations for the adaption of blockchain technology:

- Throughput: The potential throughput of issues in the Bitcoin network is currently maximized to 7 transactions per second. When the frequency of transactions in blockchain increases to similar levels, the throughput of the blockchain network needs to be improved.

- Latency: To create sufficient security for a bitcoin transaction block, it takes currently roughly 10 minutes to complete one transaction. To achieve effective security mechanism, more time has to be spent on a block, because it has to outweigh the cost of double spending attacks.

- Size and Bandwidth: There is a limitation in the number of transactions that can be handled (on average 500 transaction in one block). If the blockchain needs to control more transactions, the size and bandwidth issues have to be solved.

- Security: The current blockchain has a possibility of a $51 \%$ attack . If this occurs, a single entity would have full control of the majority of the network's mining hash-rate and would be able to manipulate blockchain. To solve this issue, more research on security is necessary.

- Versioning, hard forks, multiple chains: A small chain that consists of a small number of nodes has a higher possibility of a $51 \%$ attack. Another issue emerges when chains are split for administrative or versioning purposes.

- Usability: The Bitcoin API is difficult to use. There is a need to develop a more developer and use friendly API for Blockchain.

- Wasted resources: Unfortunately bitcoin mining wastes huge amounts of energy. The waste in bitcoin mining is caused by the "Proof-of-Work (PoW)" effort. There are some alternatives in industry fields, such as "Proof-of-Stake (PoS)". With PoW, the probability of mining a block depends on the work done by the miner. However with PoS, the resource that is compared is the amount of Bitcoin a miner holds. The issue with wasted resources needs to be solved to have more efficient mining in Blockchain (Swan, 2015).

Blockchain technology differs from most existing information systems designs by including four key characteristics; decentralization, security, auditability and smart execution (Steiner and Baker 2015). In blockchain, an agent creates a new transaction. New transaction is broadcast to the network for verification and auditing by all parties in the system. Once the majority of nodes in the chain approve this transaction according to prespecified approved rules, this new transaction is added to the chain as a new block. A record of that transaction is saved in several distributed nodes for security. Meanwhile, the smart contract, as a critical feature of blockchain technology allows the performance of credible transactions without third parties' involvement (Saberi et al, 2018). 


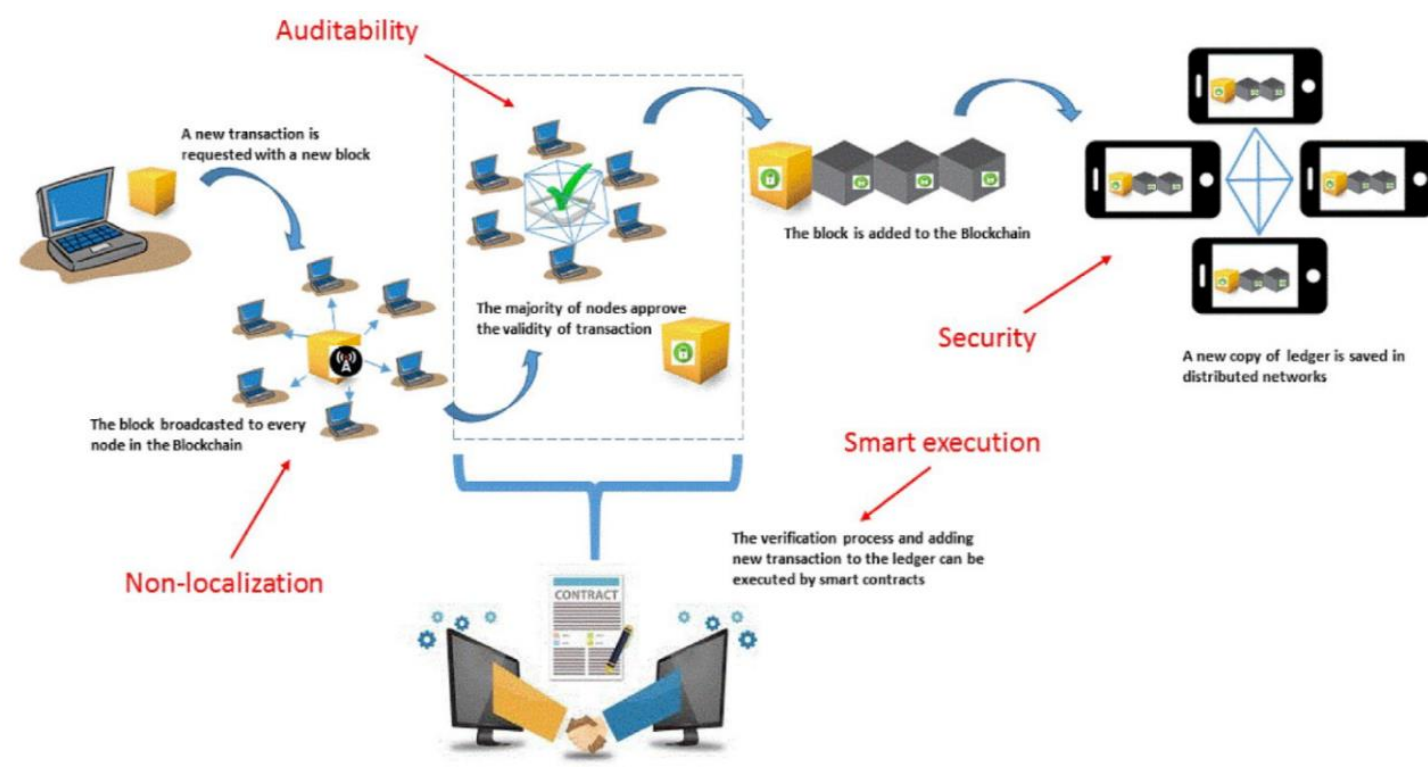

Figure 2. Steps in Blockchain Information and Transactions. Source: (Saberi et al, 2018)

Blockchain's distributed, decentralized system should turn out to be a more robust, trusted and reliable solution than is usually provided by a centralized authority to its stakeholders (Collomb, Sok, 2016). Blockchain technology is not limited to processing cryptocurrency transactions. Besides finance, from a supply chain perspective, such visibility will help ensure efficient transactions, while promoting food safety, efficient recalls, the elimination of counterfeits, and the assurance of ethical trading partners (Leblanc, 2019). Sustainability has been defined by the triple-bottom-line concept that includes a balance of environmental, social, and business dimensions when managing the supply chain (Seuring et al. 2008).

According to a research by $\mathrm{PwC}$, it is listed that most effected sectors by blockchain's distributed ledger technology in 2018 (PwC, 2018).

\begin{tabular}{|l|c|}
\hline \multicolumn{1}{|c|}{ Industry } & Blockchain Involvement \\
\hline Financial Services & $46 \%$ \\
\hline Industrial products and manufacturing & $12 \%$ \\
\hline Energy and Utilities & $12 \%$ \\
\hline Healthcare & $11 \%$ \\
\hline Government & $8 \%$ \\
\hline Retail and Consumer & $4 \%$ \\
\hline Entertainment and Media & $1 \%$ \\
\hline
\end{tabular}

Table 3. Industries Seen as Leaders in Blockchain, Source: (PwC, 2018.)

\section{Blockchain and Sustainability}

Even if there are a lot of advantages of disruptive new blockchain technology, there are some issues such as energy consumption of Bitcoin mining need to be solved. In 2018, Bitcoin miners and other cryptocurrencies could require up to 140 terawatt-hours of electricity, about 0.6 percent of the global total which is more than expected power demand from electric vehicles in 2025 (Tomesco, Loh, 2018). Governance is another issue for Blockchain. Even if a blockchain can be permissionless, the core developers are making daily decisions on behalf of the other blockchain users. That's why it is appropriate to understand that Bitcoin is actually decentralized (Gervais et al., 2014). Under the perspective of its being a driver of social change, bitcoins and related blockchain technologies might overcome the problems highlighted by numerous detractors.

Bitcoin has inherent scalability limit that tradeoff between throughput and latency (Eyal, et al., Sirer \& van Renesse., 2016). Despite criticisms about illegal uses and social consequences, it is attracting the interest of the scientific community. Blockchain protocols face a significant scalability barrier and sustainability issues. Because of inefficiencies and protocol based problems, developers continue to implement new crypto coins and protocols such as Avalanche. For example, Emin Gün Sirer and his team developed 3 protocols called Snowflake, Snowball and Avalanche recently. They combine the best of Bitcoin's consensus with the best of classical. These are fast, efficient and less energy consuming ones compared to Bitcoin. They aim to solve non-sustainable proof-of-work mining problems of Bitcoin. Bitcoin itself is technically very hard and has some issues. It's incredibly limited in its scale and its performance and when the network is congested, throughput and latency will increase. With these new systems called autonomous blockchains, where two party can engage in secure communications and secure 
data sharing without recourse to a public blockchain — without having to make any of the information public and without a private blockchain, either, without having to designate third-parties to hold their data (Casado et al., 2018).

Blockchain technology is not limited to cryptocurrencies transactions. There is a pilot project planned and initiated in Turkey, İzmir. Solar Bankers, an USA renewable energy company, wants to apply an energy efficient form of blockchain technology and elaborate solutions for off-grid electricity networks with the aim of helping developing countries expand rural electrification. Solar Bankers' de-centralized ledger system may enable individuals to trade energy amongst themselves without a utility company. Their system uses the highly scalable and efficient blockchain platform to create a virtual currency system for effective, high performance and secure electricity trading. The model is currently being tested in a pilot project in Izmir, Turkey and tested by Turkish company named Enerclever (Jost, 2018). The new system could allow remote areas in developing countries to better participate in the global economy in a sustainable way.

It is seen that, there are obvious efforts has been made by some companies such as IBM to prevent timeconsuming activities. Last year in 2019, IBM developed a blockchain based supply chain verification network, named "Trust Your Supplier". IBM said that Trust Your Supplier is "designed to eliminate manual time-consuming processes and help reducing the risk of frauds and errors, creating frictionless connectivity across supply chains and designed to improve supplier qualification, validation, onboarding and life cycle information management." (Chitkara, 2019). Also there are promising outcomes of blockchain applications i.e sustainability, decreased environmental impact and better assurance of human rights and fair work practices. For human rights and fair work case, product history clear reports may help product buyers to be confident that goods being purchased are coming only from sources that have been recognized, trusted. Additionally, there has been a proliferation of internet of things and artificial intelligence applications that can automate big data collection and processing for use in blockchain platforms (Wef, 2018).

\section{Conclusion}

Blockchain, which is the base for a distributed and public ledger of the transactions, could foster new and challenging opportunities. Not only for cryptocurrencies, but also sharing the framework of medical data, energy generation and distribution in micro grids at the citizen level, may benefit from blockchain based transactions. The security of the blockchain depends on an algorithm which is compute intensive for bitcoin mining, that prevents double spending of bitcoins and tampering with confirmed transactions. Hence, more research is required to evaluate the adoption of blockchain technology for different business purposes. The important thing is that blockchain can be programmed to record not only financial transactions, but anything of value.

Blockchain technology has been hailed as the next disruptive leap forward in data sciences. Most legal scholarship related to the topic has mentioned its applications on finance, but it could revolutionize business supply chains. Especially, solutions implemented blockchains are expected to improve the reliability of data related to supply chains and to help businesses eliminate waste and harms to people and the environment. Moreover, experts trying to build new protocols, applications and more efficient cryptocurrencies especially in terms of processing power, electricity and energy consumption. Understanding the full implications of blockchain technology in the supply chain will require transdisciplinary efforts. System related issues of blockchain requires more focus in future research and effective technical solutions to address the scalability issues need to be more studied. The opportunities that blockchain offers need to be developed and governed wisely, with upfront and continual management of unintended consequences and downside risks. It is obvious that there is a substantial amount of work in this area for future research direction.

\section{References}

- Casado Vara R., Prieto J., De La Prieta F., Corchado J. M., 2018. "How blockchain improves the supply chain: case study alimentary supply chain", Procedia Computer Science Volume 134, Pages 393-398

- Chitkara, H., 2019. "IBM has introduced a blockchain-based supply chain verification network", https://www.businessinsider.com/ibm-cuts-costs-with-new-blockchain-network-20198?utm_source $=$ twitter\&utm_medium $=$ referral\&utm_content=topbar\&utm_term $=$ desktop\&referrer $=$ twitter

- Collomb A., Sok K. (2016). "Blockchain / Distributed Ledger Technology (DLT) What Impact On Financial Sector? ", Digiworld Economic Journal, No:103, third quarter, 93.

- Danezis G., Meiklejohn S., 2015. "Centrally Banked Cryptocurrencies", Cornell University Computer Science Cryptography and Security, https://arxiv.org/abs/1505.06895

- $\quad$ Eyal, I., Gencer, A. E., Sirer, E. G \& van Renesse, Robbert, 2016. "Bitcoin-NG: A Scalable Blockchain Protoco". Proceedings of the 13th USENIX Symposium on Networked Systems Design and Implementation (NSDI '16), 45-59. 
- $\quad$ Gervais, A., Karame, O. G., Capkun, S., \& Capkun, V. , 2014. "Is Bitcoin a Decentralized Currency? ", IEEE S\&P Magazine.

- Jost, A., 2018. "Renewable Energy Company Solar Bankers Uses Blockchain for Solutions in Sustainable Development", https://www.prnewswire.com/news-releases/renewable-energy-company-solar-bankers-usesblockchain-for-solutions-in-sustainable-development-680338483.html

- $\quad$ Leblanc, R., 2019. "How Blockchain Will Transform Supply Chain Sustainability", https://www.thebalancesmb.com/blockchain-and-supply-chain-sustainability-4129740

- $\quad$ Mahler, T. A., 2018. "It's Karma", https://medium.com/blockwhat/03-it-s-karma-484fdc2d8657

- Olleros, F. X. \& Zhegu, M. (Ed.), 2016. "Research Handbook on Digital Transformations”, Edward Elgar Publishing.

- $\quad$ PwC, 2018. "Blockchain is here. What is your next move?", https://www.pwc.com/gx/en/issues/blockchain/blockchain-in-business.html

- $\quad$ Risius M., Shoprere K., 2017. "A Blockchain Research Framework: What We (don't) Know, Where We Go from Here, and How We Will Get There", Business \& Information Systems Engineering, 59(6), 385-409.

- $\quad$ Rosic, A., 2016. "What is Cryptocurrency? [Everything You Need To Know!].", https://blockgeeks.com/guides/what-is-cryptocurrency/

- $\quad$ Saberi S., Kouhizadeh M., Sarkis J., 2018. "Blockchain technology and its relationships to sustainable supply chain management", International Journal Of Production Research, Volume 57- Issue 7.

- $\quad$ Seuring, S., J. Sarkis, M. Müller, and P. Rao., 2008. "Sustainability and Supply Chain Management - An Introduction to the Special Issue.", Journal of Cleaner Production 16 (15): 1545-1551.

- Steiner, J., and J. Baker., 2015. "Blockchain: The Solution for Transparency in Product Supply Chains.", https://www.provenance.org/whitepaper.

- Swan M., 2015. Blockchain: Blueprint For New Economy, O'reilly Media Inc.

- $\quad$ Tomesco, F., \& Loh, T., 2018. "Bitcoin Could End Up Using More Power Than Electric Cars", https://www.bloomberg.com/news/articles/2018-01-10/bitcoin-outshines-electric-cars-as-driver-of-globalpower-use

- Url-1, https://www.worldcryptoindex.com/blockchain/, Alıntı Tarihi: 05.04.2020

- Url-2, https://101blockchains.com/history-of-blockchain-timeline/\#prettyPhoto, Alıntı Tarihi: 03.04.2019

- Url-3, https://appinventiv.com/blog/cryptocurrencies-market-trends/, Alıntı Tarihi: 20.04.2020

- Url-4, https://www.coinbase.com/, Alınt1 Tarihi: 29.04.2020

- World Economic Forum (Wef), 2015. "Deep Shift Technology Tipping Points and Societal Impact.", http://www3.weforum.org/docs/WEF_GAC15_Technological_Tipping_Points_report_2015.pdf\#page=24

- World Economic Forum (Wef), 2016. "The Future Of Financial Infrastructure An ambitious Look At How Blockchain Can Reshape Financial Services" https://www.weforum.org/reports/the-future-of-financialinfrastructure-an-ambitious-look-at-how-blockchain-can-reshape-financial-services

- World Economic Forum (Wef), 2018. "Building Block (chains) For A Better Planet"

- Zimmermani 2016. The Evolution of Fintech, The New York Times, https://www.nytimes.com/2016/04/07/business/dealbook/the-evolution-of-fintech.html. 


\title{
Footprint of Inexhaustible Energy Usage and Financial Development on Carbon Outrush of Eurasian Countries
}

\author{
Ph.D. Candidate Daberechi Chikezie Ekwueme (Eastern Mediterranean University, TR of \\ Northern Cyprus)
}

\begin{abstract}
Climate change has a menacing influence on the life and health of human beings; and environmental hallmarks for the future cohort. Carbon outrush has been attributed as the fundamental cause of global warming and change in the climate. In the retardation of carbon effusion, reciprocation between financial development and the utilization of clean energy have been revealed by empirical literature to perform a vital function. Thus, this study analyzed the footprint of inexhaustible (clean) energy usage and financial development on $\mathrm{CO}_{2}$ outrush of 10 Eurasian countries utilizing the PMG-ARDL (Pooled Mean Autoregressive distributive lag model) from 1990 to 2017. Yearly Panel data was collected from the 2019 version of the World Development Indicator of the World Bank. The output of the analysis revealed that clean energy has a negative substantial footprint on the $\mathrm{CO}_{2}$ outrush while financial development has a positive substantial footprint on carbon outrush in the Eurasian countries under study. This output implies that the hallmark of the Eurasian countries' environment has greatly improved by utilizing clean energy and this has enhanced economic buoyancy. Therefore, we recommended that governments and policymakers in Eurasian countries in addition to enhancing the utilization of clean etymology of energy by firms and individual households should expedite the establishment of financial policies and funding that are ecofriendly.
\end{abstract}

\section{Introduction}

Climate change has a menacing influence on the life and health of human beings; and the environmental hallmark for future cohort, carbon outrush has been attributed as the fundamental cause of global warming. In the retardation of carbon effusion, reciprocation between financial development and the utilization of clean energy have been revealed by empirical literature to perform a vital function.

An enlarging unanimity has materialized among environmental, energy, and scientific investigators concerning the menacing influence of global heating and variation in climate on the life and health of human beings; and the environmental hallmark for a future cohort over the previous few decagons (Zhang et.al, 2017). Enormous policymakers and scientific investigators have accentuated the notability of curtailing effusions from (GHG) greenhouse gas which has been attributed as the fundamental cause of global heating to eschew catastrophe in the environment globally. For example, according to Owusu \& Amsumadu Sarkodie, (2016) and Carbon Footprint, (2018), the thought of moderating the emission of carbon dioxide which has a greater percentage of the anthropogenic greenhouse gas amounting to about $81 \%$ has become the priority of the developed economies of the world.

This is further established by the White House (2016) that stated GHGs (Emissions of greenhouse gases) have been spotted to compose a higher proportion of the prime mover of climatic change and spotlighted that urgent attention geared towards abating effusion of carbon is a prerequisite to avert impending national security and growth in the economy in the remote future.

Thus, according to Charfeddine and Kahia (2019), concerning mitigation of effusions from GHG if no measures are taken, then these outcomes explicitly suggest that the average temperature globally will escalate to $2^{\circ} \mathrm{C}$ and if this escalating temperature threshold degree has transcended the influence on the life of humans and the ecosystem following the numerous environmental experts and environmental organizations stipulations will be very intense and will greatly upset all facets of life.

Transcending the threshold degree of $2^{\circ} \mathrm{C}$ will amount to the melting of the Arctic, reduction of freshwater and crops, intense hurricanes, wildfires escalation, super droughts, mass extinctions, and the swift increase in seas levels according to the current statement on Climate and Health by the Medical Society Consortium. Li and $\mathrm{Wu}$ (2017) further buttressed that it will also result in an escalation of health problems, water pollution, and mitigation in the quality of food and air.

Enormous studies in the literature of environment experimentally discovered that the alteration in the climate is primarily ascribed to the expeditious escalation in the greenhouse gas effusions from nitrous oxide, methane gas, and carbon dioxide (Belaid and Youssef 2017, Ozokcu and Ozdemir, 2017, Ekwueme and Zoaka, 2020). Numerous additional studies have stated that the majority of the endeavors (for instance the United Nations Framework Conventions on Climate Change and the Kyoto protocol) are not adequate to tackle the challenges posed by alteration in climate (Charfeddine and Kahia (2019). Consequently, ratification of ultra-modern economic policies, laws, and regulations has been suggested by numerous scholars and researchers as a tool that will enhance the quality of the ecosystem (Cardenas et al., 2016 and Zhang and Wang 2017). 
Nevertheless, a handful of more studies have revealed that reduction in the growth of the economy can emanate from enhancing the standard of the environment through the policies of conservation of energy (Destek and Aslan 2017 and Chen et al., 2016). Therefore, those involved in policymaking are faced with the primary obstacle of maintaining an equilibrium between having sustainable economic growth and mitigation of environmental deterioration objectives (Kahia et al. 2017 and Charfeddine et al., 2016). Policymakers thus are confronted to construct constant and low-priced energy origins accessible simultaneously with mitigating effusions from GHG.

Various vital policy alternatives have been proposed from the pragmatic standpoint to provide a superior blueprint environmentally that can mitigate the accelerating rate of carbon effusions. Three postulations from the viewpoint of economic, energy, and environment are of major curiosity and they are clean energy advancement, financial sector advancement, and the scrutinizations of the links between clean energy usage and financial enlargement (development) on economic growth and $\mathrm{CO}_{2}$ outrush. The first postulation comprised of advancing the origin of clean energy and consequently mitigating substantially carbon effusions and other forms of pollutants. Enormous empirical researches have proved that the advancement of the financial sector by promoting the advancement of technology in the energy sector can perform an essential function in carbon effusions mitigation. Further, concerning the third postulation, empirical research has provided evidence of linkages between usage of clean energy, and financial development and mitigation of effusions from carbon (Abbas and Riaz, 2016 and Charfeddine and Kahia 2019). Charfeddine and Kahia 2019 revealed that the credit markets and commercial banking can perform a vital function of invigorating and advancing the inexhaustible energy sector. This is further buttressed by Kim and Park (2016) who revealed that the reliance of clean sections (sectors) on funding from the capital market has resulted in a spontaneous unequal escalation in nations with advanced financial markets.

Thus, this study attempts to investigate the footprint of inexhaustible (clean) energy usage and financial development on the $\mathrm{CO}_{2}$ outrush of 12 Eurasian countries utilizing the PMG-ARDL (Pooled Mean Autoregressive distributive lag model) from 1990 to 2017. Prior research from the standpoint of literature has explored the footprint of clean energy and financial development on carbon outrush adopted univariate category of model employing either panel data or time-series data approach. Additionally, only a handful of research has examined these variables together in one equation. In Eurasian countries, there is no empirical literature to the best of our knowledge that has examined the footprint of clean energy usage and financial development on $\mathrm{CO}_{2}$ outrush in a multivariate panel taking into account both variables (clean energy and financial development) exclusively in one regression. This study, therefore, filled the above-identified gap by employing the multivariate PMG-ARDL (Pooled Mean Autoregressive distributive lag model) mode to scrutinize the footprint of inexhaustible (clean) energy usage and financial development on $\mathrm{CO}_{2}$ outrush.

This research will enhance the literature of environment and energy in the Eurasian countries concerning the footprint of inexhaustible (clean) energy usage and financial development on $\mathrm{CO}_{2}$ outrush. The Eurasian countries were sampled because the majority of the countries are vastly energy exhaustive, possess a large capacity of financial resources, and exhibit an enormous ability to produce energy from clean sources like wind and solar.

Finally, the study provides many policy implications geared towards enhancing the footprints of clean energy and financial development on the outrush of $\mathrm{CO}_{2}$. The contributions from the research will help the policymakers to know the connection between these variables and the vital function it performs in the sustainable development of the countries, and the need to establish policies, procedures, and strong institutions that will facilitate the transition to clean energy sources.

The study's remaining parts are structured as follows: Section 2 comprises of literature review; data and methodology are contained in section 3; section 4 comprises of outcomes (results) and the methodology; deductions (conclusions) and the policy inferences (implications) of the study are found in section 5.

\section{Literature Review}

Prior literature as regards the footprint of financial development and clean energy usage was reviewed in this part of the study. For the prior two decagons, there had been an energetic discourse regarding the swift advancement of clean energy usage and its influence on the outrush of $\mathrm{CO}_{2}$ ( Shabbaz et al. 2017, Al-Mulali et al., 2015, Moutinho and Robaina 2016, Kahia et al., 2017, and Kahia et al 2016). It is a well-known fact from the viewpoint of climate alteration that the utilization of clean energy has a positive footprint on the quality of the environment by mitigating the rate of outrushing from greenhouse gas in the air (Boluk and Mert. 2014 and Bhattacharya et al. 2016, Bekun et al 2019).

Additionally, investing in sources that produce clean energy according to the 2018 report of OECD have been observed to be slighter carbon exhaustive, unlike unclean energy. Therefore, nations will evolve an international green and clean ecosystem scheme and enhance the standard of the environment by adopting sources that generate clean energy.

Nevertheless, from the viewpoint of the economic, evolvement of clean energy origins presents numerous energy and economic advantages (Dai et al., 2016 and Spiegel-Feld et al., 2016). According to Mu et al., (2018) and Ortega-Izquierdo et al. (2016), the economic advantages of adopting clean energy sources are providing solutions 
to numerous problems like unemployment, the outflow of foreign currency, energy mix portfolio diversification, and energy security to mention but a few, this is because, in comparison to the unclean energy sector, the clean energy sector uses more labor. Reliance of oil-importing nations on foreign oil will be mitigated by investment in clean energy, on the other hand, it will promote diversification of economy and shift of technology together with maintenance of earnings from the export of hydrocarbon for oil-exporting nations (Kahia et al., 2017 and Kahia et al., 2016).

Broadly, the outcomes from the empirical literature are conflicting and appear to rely on the techniques of econometrics adopted, type of data (panel or time series data), the duration of the study, and the economic features of the sampled countries.

Numerous studies discovered two-way causal linkages between clean energy and outrush of carbon, For example, Al-Mulali et al. (2015) examined this for the Caribbean and Latin America nations; Moutinho and Robaina (2016) examined this for twenty European countries; Apergis and Payne (2015) examined this for seven Central American nations; while Charfeddine and Kahia (2019) examined this for countries in the MENA region . On the other hand, the uni-directional causal link between clean energy, economic growth, and carbon outrush was supported by some empirical literature for example (Sardorsky, 2009 examined this for G7 countries).

Furthermore, clean energy usage was found to have a positive influence on the standard of the environment and enhances sustainable growth in the economy by some studies such as Bhattacharya et al. (2016) who examined this for eighty-five developing and developed nations using the system GMM and FMOLS model; Ito (2017) who examined this for forty-five developing nations using the GMM and Pooled Mean Group techniques; and Boluk and Mert (2014) who examined this for sixteen EU nations adopting the panel fixed-effect model. Contrarily, only a handful of studies discovered that a negative impact of clean energy usage on economic growth, for example, Silva et al. (2012) found this for Spain, Denmark, and Portugal.

Sinha and Shabbaz (2018) scrutinized the hypothesis of EKC for emissions of carbon dioxide in India from 1971 to 2015 utilizing the ARDL technique and revealed that the hypothesis exists for India with an inverted U-shape, also they discovered renewable energy usage and trade mitigates effusions of carbon in both the long-run and short-run, although it is effect is more in the long-run.

Dong et al (2018) examining the hypothesis of EKC against carbon effusions in China from 1965 to 2016 affirms that the hypothesis exists for China concerning effusions of carbon. Further, they discovered that in both the shortrun and long-run that natural gas and renewable energy reduces the effusion of carbon dioxide, nevertheless, in the remote future (long-run) the ability of natural gas to mitigate carbon effusions will be weakened but that of renewables will be constantly progressing in terms of reduction in carbon emissions.

Regarding the influence of financial development on the outrush of carbon, there is a solid concurrence theoretically, among scholars concerning the vital function performed by financial development in the stimulation of growth in the economy (Charfeddine and Kahia (2019). Presently, there is no wavering that developing the financial sector is a requisite pile for growth in the economy since it provides optimal allocation of capital, the amassment of capital via mobilization and fusing of savings, and enhancing the needed information for investment activities. By promoting the advancement of technology in the energy supply sector, the financial sector according to Kim and Park (2016), performs an essential function in monitoring effusions from energy. This proves that the development of the financial sector which reveals the actual financial resource available for manufacturing activities and financing mechanism for investments by stock markets and banks can perform an essential function in the strive against degradation of the environment through mitigation of carbon outrush (Charfeddine et al. 2018).

According to Hayat et al. (2018), development of the financial sector can normally start with R\&D (research and development) programs, allure FDI (foreign direct investment), and consequently, accelerate economic activities to affect the environmental standard through investments in green-related projects. Also, Charfeddine (2017) stated that an efficiently advanced financial sector can enhance the energy sector efficiency by impeding the energy outrush spread, mitigating the cost of borrowing, and promoting green investment activities.

Ekwueme and Zoaka (2020) employing fully modified ordinary least square in the study on the links between financial development, energy usage, openness in trade, growth economically, and C02 effusions in the MENA region revealed that financial development had a negative inference on the effusions of carbon, thus it enhances the quality of the environment.

Furthermore, financial development was discovered by Dogan and Seker (2016) to result in substantial mitigation in effusions of carbon in twenty-three (23) countries that use renewable energy.

Nevertheless, the development of the financial sector can degrade the quality of the environment by accelerating production activities, resulting in a rise in the rate of pollution and environmental deterioration (Nassani et al 2017). Nassani et al (2017) found that for countries in BRICS the emission of Nitrous oxide accelerates with financial development. Similarly, in Malaysia, carbon effusions from the gas and transport sector were discovered by Maji et al. (2017) to be enhanced by financial development, while financial development mitigates effusions from the construction and manufacturing sectors. 
Also, Kwakwa et al. (2018) examined the linkages between natural resources extraction and financial development within the framework of the hypothesis of EKC in Tunisia from1971 - 2016 and discovered that total effusion from carbon is enhanced by financial development.

Thus, there is no agreement among investigators empirically concerning the influence of financial development on carbon outrush. However, theoretically, there is a harmony that financial development and clean energy have a positive influence on economic growth and the standard of the environment, nevertheless prior empirical research finds it difficult to arrive at this agreement. Therefore, we employed the PMG-ARDL (Pooled Mean Autoregressive distributive lag model) econometric approach to contribute to this literature.

\section{Research Methodology}

\subsection{Description of Data}

Yearly Panel data was collected from the 2019 version of the World Development Indicator of the World Bank from 1990 to 2017 for 10 Eurasian countries; Armenia, Moldova, Azerbaijan, Russia Federation, Belarus, Tajikistan, Georgia, Ukraine, Kyrgyzstan, and Kazakhstan. The panel model was used because nations diverge in disparate facets and to control for heterogeneity differences. Table 1 below summarizes the variables employed in this study, their symbols, their predicted sign on $\mathrm{CO}_{2}$ outrush, and their proxies. To reduce heteroscedasticity and non-normality, the entire variables were expressed in natural logarithm form.

\begin{tabular}{lll}
\hline Symbols & Variables & Proxy \\
\hline GDPT $(+)$ & Economic growth & constant 2010 US \$) Gross domestic product \\
TRDE & Trade openness & \{percentage of GDP \} sum of imports and exports \\
RENR(-) & Renewable energy use & $\%$ of total final energy use \\
FD $(+)$ & Financial development & (\% of GDP) Domestic credit to privates \\
CO2E & Carbon outrush & Metric per tons per capital \\
\hline
\end{tabular}

Table 1: List of Variables Used and Their Proxy

\subsection{Specification of Model.}

The footprint of clean energy, economic growth, financial development, and trade openness on $\mathrm{CO}_{2}$ outrush was modeled on the EKC hypothesis theoretically, and empirically by extending the model utilized by to Charfeddine and Kahia (2019) and Nguyen and Kakinaka, (2019). Nevertheless, our model is unique as it included financial development variables in one regression equation in contrast to the above-mentioned works. Therefore, our model is stated below:

Co $2 E i_{t}=\alpha+\partial X i_{t}+\varepsilon i_{t}$

Where $\mathrm{CO} 2 \mathrm{E}$ denotes carbon outrush and is the dependent variable, $\mathrm{i}$ denotes sampled nations, $\mathrm{t}$ denotes years (time), and X represents the regressors (namely: clean energy usage, financial development, economic growth, and openness in trade). Eis the country-specific impact that cannot be observed.

\subsection{Econometric Techniques}

Many econometrics techniques were utilized in establishing the linkages between financial stability, $\mathrm{CO}_{2}$ outrush, and monetary policy. Firstly, the stationarity of the data was determined using the IPS $2003 \mathrm{of} I \mathrm{~m}$, Pesaran and Shin, LLC (Levin-Lin-Chu, 2002), PP (Philips-Perron) by Philip and Xiao (1998), and the Augmented DickeyFuller (F-ADF) unit root test. Secondly, Kao residual Cointegration test was carried out to ascertain if the variables are related in the long run. Then, the PMG-ARDL (Pooled Mean Autoregressive distributive lag model) will be estimated to assess the dynamic association between the various variables employed in the study. The traditional estimation models of Autoregressive distributive lag model (ARDL) is incapacitated to check for intolerance (bias) associated with the correlation between the white noise term and the mean differenced explanatory variable particularly in panel data exhibiting individual influences (effects), therefore, the ARDL model was combined with PMG estimator by Pesaran et al. (1999) to offer a solution to the problem. The Pooled Mean Autoregressive distributive lag model employed by Sarkodie and Strezov (2018) was applied in this study.

\section{Results and Discussions}

The outcomes of the analysis are presented and discussed in this section. 


\subsection{Descriptive Statistics}

\begin{tabular}{lllcll}
\hline Statistics & LNCO2EM & LNFD & LNRENR & LNGDPT & LNTRDE \\
\hline Mean & 1.02 & 2.69 & 1.91 & 23.83 & 4.50 \\
Median & 1.26 & 2.74 & 1.71 & 23.22 & 4.51 \\
Maximum & 2.75 & 4.50 & 4.16 & 28.15 & 5.16 \\
Minimum & -1.22 & 0.15 & -0.50 & 21.55 & 3.82 \\
Standard deviation & 1.08 & 0.89 & 1.28 & 1.70 & 0.30 \\
\hline
\end{tabular}

Table 2: Summary of Descriptive Statistics
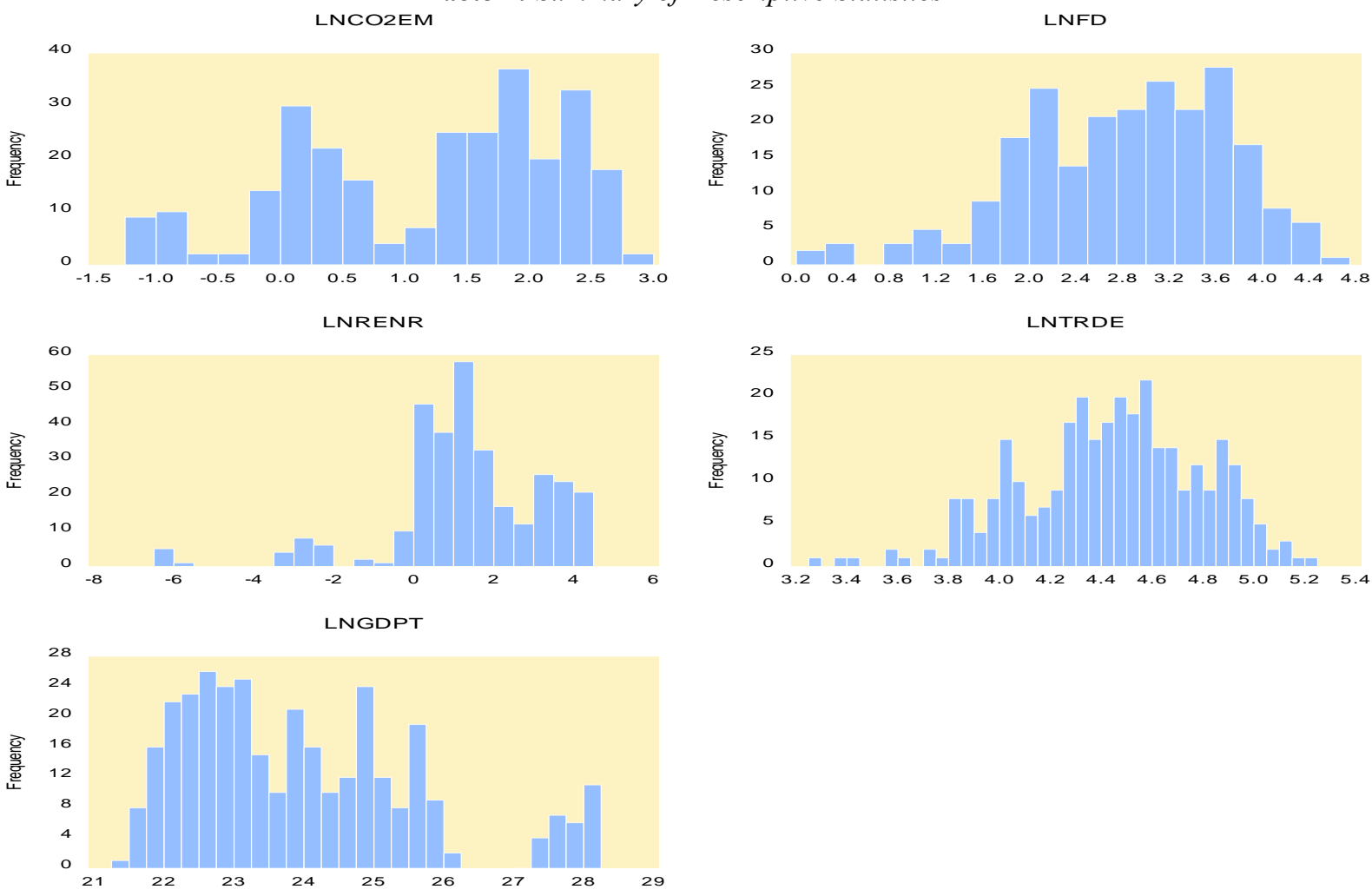

Fig. 1 Movement Pattern of Financial Development (FD), Renewable Energy Use (RENR), Economic Growth (GDPT), TRDE (trade openness), and CO2EM (carbon emissions

\begin{tabular}{|c|c|c|c|c|c|}
\hline Correlation & LNCO2EM & LNFD & LNRENR & LNTRD & LNGDPT \\
\hline LNCO2EM & 1.0000 & & & & \\
\hline T_Statistic & $\ldots \ldots$ & & & & \\
\hline Prob_V. & $\ldots \ldots$ & & & & \\
\hline LNFD'- & 0.3657 & 1.0000 & & & \\
\hline T_Statistic & 5.5719 & $\ldots \ldots$ & & & \\
\hline Prob_V. & $0.0000 *$ & $\ldots \ldots$ & & & \\
\hline LNRĒER & -0.5815 & -0.2133 & 1.0000 & & \\
\hline T_Statistic & -10.1339 & -3.096 & $\ldots \ldots$ & & \\
\hline$\overline{P r o b \_V}$. & $0.0000 *$ & $0.0022 *$ & $\ldots \ldots$ & & \\
\hline LNTR̄DE & -0.2765 & -0.0721 & 0.0920 & 1.0000 & \\
\hline T_Statistic & -4.0805 & -1.0258 & 1.3102 & $\ldots \ldots$ & \\
\hline Prob_V. & $0.0001 *$ & 0.3062 & 0.1916 & $\ldots \ldots$ & \\
\hline LNGDיPT & 0.5555 & 0.3124 & -0.2235 & -0.4243 & 1.0000 \\
\hline$T$ Statistic & 9.4641 & 4.6632 & -3.2518 & -6.6445 & $\ldots \ldots$ \\
\hline Prob_V. & $0.0000 *$ & $0.0000^{*}$ & $0.0013 *$ & 0.0000 & $\ldots \ldots$ \\
\hline
\end{tabular}

* "represents statistical rejection at $0.05 \%$ significance level

Table 3: Results of the Correlation Coefficient Matrix

Table 1 is the presentation of the descriptive statistics of LNCO2EM (carbon outrush), LNFD (financial development), LNRENR (clean energy use), LNGDPT (economic growth), and LNTRDE (Trade). The mean of LNFD is very small in comparison to other developing and developed economies. The fluctuations in the level of financial development are shown by the maximum and minimum values of 2.75 and -1.22 respectively. This means that the financial development of Eurasian countries was relatively low in comparison to other regions in the world. The clean energy use (LNRENR) mean of 1.91 is also relatively small and the variability in the level of the clean 
energy use (LNRENR) is exhibited by the maximum value and the minimum value of 4.16 and -0.50 respectively. The mean, maximum, and minimum values of the LNGDPT, LNCO2EM, and LNTRDE suggest a small variation over time.

The correlation matrix output in Table 3 displays the associations among the series which is in accordant with the laid down theories of economics. For instance, financial development and GDP is anticipated to have a positive correlation with the outrush of carbon. While clean energy use is anticipated to have a negative relationship with carbon outrush.

\subsection{Unit Root Test}

Employing LLC, IPS, PP (Philips-Perron), and the Augmented Dickey-Fuller (F-ADF) unit root test the study determined the stationarity of the variables under study. The Schwarz Information Criterion (SIC) was observed utilizing the lag length.

\begin{tabular}{|c|c|c|c|c|c|}
\hline Methods & LNCO2EM & LNFD & LNRENR & LNGDPT & LNTRDE \\
\hline \multicolumn{6}{|l|}{ LLC_t-stat* } \\
\hline Level & $-7.7390 *$ & -0.1219 & $-9.0684 *$ & 0.8561 & $-3.3259 *$ \\
\hline First difference & & $-8.3212 *$ & & $-4.6200 * \%$ & \\
\hline \multicolumn{6}{|l|}{ IPS-W-stat } \\
\hline Level & $-5.4688 *$ & -0.1 .2625 & $-5.4457 *$ & 3.4511 & $-4.7570 *$ \\
\hline First difference & & $-10.1115^{*}$ & & $-4.1684 *$ & \\
\hline \multicolumn{6}{|c|}{ ADF-Fisher Chi-sq. } \\
\hline Level & $85.3662 *$ & 39.8993 & $82.3469 *$ & 12.6183 & $80.2526^{*}$ \\
\hline First difference & & $122.345^{*}$ & & $56.5351 *$ & \\
\hline \multicolumn{6}{|l|}{ PP-Fisher Chi-sq. } \\
\hline Level & $63.8433 *$ & 44.0866 & $60.175^{*}$ & 6.9829 & $54.4658 *$ \\
\hline First difference & & $136.669 *$ & & $47.1629 *$ & \\
\hline
\end{tabular}

Notes: * implies the rejection of null hypothesis at $0.05 \%$ level of significance. For the entire test probabilities calculated asymptotic normality is assumed. The numbers are the t.statistic of the individual test.

\section{Table 4: Results of Panel Unit Root Test}

The outcome of Table 4 above reveals that at level three series (LNCO2EM, LNRENR, and LNTRDE are stationary, while two series (LNFD and LNGDPT) are stationary at the first difference at $0.05 \%$ significance level in all the tests. Therefore, based on the results we deduced that LNCO2EM, LNRENR, and LNTRDE are I (0) series, while LNFD and LNGDPT are I (1) series, as they become stationary at first difference. Hence, we moved to Kao residual cointegration test.

\subsection{The outcome of Kao Residual Cointegration Test}

\begin{tabular}{lll}
\hline ADF & t. Statistics & Prob.value \\
\hline & -4.0421 & $0.0000^{*}$ \\
\hline Residual variance & 0.0126 & \\
HHAC variance & 0.0127 & \\
\hline
\end{tabular}

Table 5: Results of Kao Residual Cointegration Test

The hypothesis of no cointegration among the series was rejected at $0.05 \%$ significance level by the Kao residual cointegration in Table 5 above, thus we concluded that the entire variables under study are related in the long-run.

\subsection{The outcome of PMG-ARDL (Pooled Mean Autoregressive Distributive Lag Model)}

Having determined that the series are not integrated of the same order, we proceeded to estimate the PMGARDL to ascertain the enormity of the cointegration is displayed in Table 6. 


\begin{tabular}{lcccc}
\hline Variables & coefficient & Std.Error & t-statistics & Prob.value \\
\hline \multicolumn{5}{c}{ Long Run Equation } \\
\hline LNFD & 0.0914 & 0.0116 & 7.8390 & $0.0000^{*}$ \\
LNRENR & -0.4329 & 0.0202 & -21.3526 & $0.0000^{*}$ \\
LNTRDE & 0.2534 & 0.0703 & 3.6033 & $0.0005^{*}$ \\
LNGDPT & 0.3814 & 0.0250 & 15.2415 & $0.0000^{*}$ \\
\hline \multicolumn{5}{c}{ Short Run Equation } \\
\hline ECT(-1) & -0.6003 & 0.1230 & -4.8769 & $0.0000^{*}$ \\
LNFD & 0.0395 & 0.0440 & 0.8967 & 0.3723 \\
LNRENR & -0.1090 & 0.1734 & -0.6285 & 0.5313 \\
LNGDPT & 0.1769 & 0.4098 & 0.4316 & 0.6670 \\
LNTRDE & -0.0513 & 0.1435 & -1.5148 & 0.7212 \\
\hline
\end{tabular}

Note $* *$ and $*$ means statistically significant at $0.10 \%$ and $0.05 \%$ respectively. Akaike info criterion is the model selection method which suggested lag 2 and the most parsimonious.

Table 6: Outcome of PMG-ARDL (2, 2, 2, 2, 2)

The outcome in Table 6 reveals that a significant positive correlation between LNFD (financial development), LNTRDE (openness in trade), LNGDPT (economic growth), and $\mathrm{CO}_{2}$ outrush in the long-run in the sampled Eurasian countries. This suggests that a $1 \%$ increase in the development of the financial sector, trade openness, and economic activities will amount to $0.09 \%, 0.25 \%$, and $0.38 \%$ increase in $\mathrm{CO}_{2}$ outrush respectively. This is accordant with the scale influence (effect); therefore this research supports a positive correlation between growth in the economy and deterioration of the environment (Alola and Alola, 2018 and Ito, 2017). This discovery is an indicator of policymakers and environmental managers in these countries on the urgency to mitigate $\mathrm{CO}_{2}$ outrush. Concerning clean or inexhaustible energy usage, a significant negative correlation was discovered between LNRENR (clean energy use) and $\mathrm{CO}_{2}$ outrush in the long-run, this suggests that a $1 \%$ increase in clean energy use will amount to a $0.43 \%$ reduction in $\mathrm{CO}_{2}$ outrush in the sampled Eurasian countries. This outcome is accordant with Charfeddine and Kahia (2019) and Nguyen and Kakinaka, (2019), and it is interesting to environmental and energy economists. This outcome is creditable and could be attributable to the fact that the majority of the Eurasian nations are endorsers of the Kyoto protocol agreement aimed at mitigating $\mathrm{CO} 2$ outrush.

Furthermore, the outcome reveals a robust computation with a speed of convergence of $6 \%$ by the contribution of other regressors towards the path of equilibrium. Nevertheless, in the short-run, there was a negative correlation between clean energy usage, openness in trade, and $\mathrm{CO}_{2}$ outrush, though it is not statistically significant. Also, an insignificant [positive relationship was found between economic growth and $\mathrm{CO} 2$ outrush in the sampled Eurasian countries. This result is accordant with Bekun et al, (2019) who discovered a positive insignificant positive correlation between growth in the economy and $\mathrm{CO}_{2}$ outrush in $16 \mathrm{EU}$ countries in the short-run.

The diagnostic test of confidence ellipse displayed in Fig. 2 below reveals that the points of stability are within the center of the ellipse, this suggests that a significant confidence level is exhibited in the model.

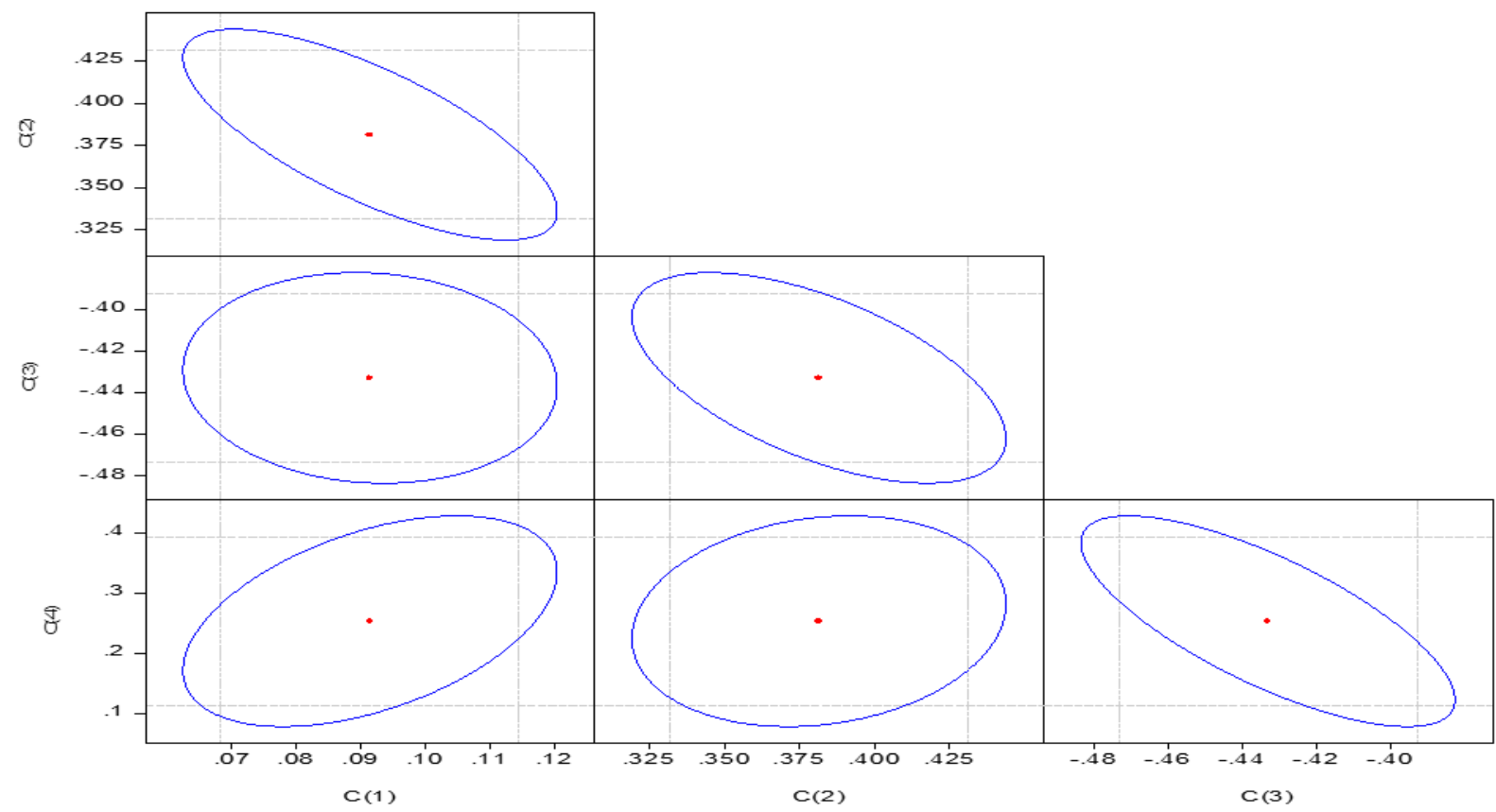

Fig 2: Coefficient Diagnostic Test with Confidence Interval 


\section{Conclusion}

Climate change has a menacing influence on the life and health of human beings; and environmental hallmarks for the future cohort. Carbon outrush has been attributed as the fundamental cause of global warming and change in the climate. In the retardation of carbon effusion, reciprocation between financial development and the utilization of clean energy have been revealed by empirical literature to perform a vital function. Thus, this study analyzed the footprint of inexhaustible (clean) energy usage and financial development on $\mathrm{CO}_{2}$ outrush of 10 Eurasian countries utilizing the PMG-ARDL (Pooled Mean Autoregressive distributive lag model) from 1990 to 2017.

The outcome of the analysis revealed a significant negative correlation between LNRENR (clean energy use) and $\mathrm{CO}_{2}$ outrush in the long-run, this suggests that the quality of the environment in Eurasian countries can be enhanced in the long-run by utilization of clean energy sources. This output implies that the hallmark of the Eurasian countries' environment has greatly improved by utilizing clean energy. This result can be attributed to the dedication of the countries in the Eurasian region to mitigating carbon outrush and promoting the utilization of clean etymology (origins) of energy by firms and individual households and the majority of the sampled countries are endorsers of the Kyoto protocol.

However, the results further reveal a significant positive correlation between LNFD (financial development), LNTRDE (openness in trade), LNGDPT (economic growth), and $\mathrm{CO}_{2}$ outrush in the long-run. This suggests that governments and policymakers of Eurasian countries should promote formulation and implementation of financial reforms aimed at encouraging $\mathrm{R} \& \mathrm{D}$ (research and development) for inventive mechanizations concerning clean energy such as solid waste, solar, hydro, biogas, and biomass. This will mitigate $\mathrm{CO}_{2}$ outrush and enhance a sustainable environment.

\section{References}

- Abbasi, F., \& Riaz, K. (2016). CO2 emissions and financial development in an emerging economy: an augmented VAR approach. Energy Policy, 90, 102-114.

- Al-Mulali, U., Saboori, B., \& Ozturk, I. (2015). Investigating the environmental Kuznets curve hypothesis in Vietnam. Energy Policy, 76, 123-131.

- $\quad$ Alola, A. A., \& Alola, U. V. (2018). Agricultural land usage and tourism impact on renewable energy consumption among Coastline Mediterranean Countries. Energy \& Environment, 29(8), 1438-1454.

- $\quad$ Apergis, N., Bowden, N., \& Payne, J. E. (2015). Downstream integration of natural gas prices across the US states Evidence from deregulation regime shifts. Energy Economics, 49, 82-92.

- $\quad$ Bekun, F. V., Alola, A. A., \& Sarkodie, S. A. (2019). Toward a sustainable environment: Nexus between $\mathrm{CO} 2$ emissions, resources rent, renewable and nonrenewable energy in 16-EU countries. Science of the Total Environment, 657, 1023-1029.

- $\quad$ Belaid, F., \& Youssef, M. (2017). Environmental degradation, renewable, and non-renewable electricity consumption, and economic growth: Assessing the evidence from Algeria. Energy Policy, 102, 277-287.

- Bhattacharya, M., Paramati, S. R., Ozturk, I., \& Bhattacharya, S. (2016). The effect of renewable energy consumption on economic growth: Evidence from top 38 countries. Applied Energy, 162, 733-741.

- Bölük, G., \& Mert, M. (2014). Fossil \& renewable energy consumption, GHGs (greenhouse gases) and economic growth: Evidence from a panel of EU (European Union) countries. Energy, 74, 439-446.

- Carbon Footprint, (2018). Climate change. Retrieved from. https://www.carbonfootprint.com/warming.html.

- Cardenas, L. M., Franco, C. J., \& Dyner, I. (2016). Assessing emissions-mitigation energy policy under integrated supply and demand analysis: the Colombian case. Journal of Cleaner Production, 112, 37593773 .

- Charfeddine, L. (2017). The impact of energy consumption and economic development on Ecological Footprint and CO2 emissions: Evidence from a Markov Switching Equilibrium Correction Model. Energy Economics, 65, 355-374.

- Charfeddine, L., \& Kahia, M. (2019). Impact of renewable energy consumption and financial development on $\mathrm{CO} 2$ emissions and economic growth in the MENA region: A panel vector autoregressive (PVAR) analysis. Renewable energy, 139, 198-213.

- Charfeddine, L., \& Khediri, K. B. (2016). Financial development and environmental quality in UAE: Cointegration with structural breaks. Renewable and Sustainable Energy Reviews, 55, 1322-1335.

- Charfeddine, L., Al-Malk, A. Y., \& Al Korbi, K. (2018). Is it possible to improve environmental quality without reducing economic growth: Evidence from the Qatar economy. Renewable and Sustainable Energy Reviews, 82, 25-39. 
- Chen, P. Y., Chen, S. T., Hsu, C. S., \& Chen, C. C. (2016). Modeling the global relationships among economic growth, energy consumption, and $\mathrm{CO} 2$ emissions. Renewable and Sustainable Energy Reviews, 65, 420-431.

- $\quad$ Dai, H., Xie, X., Xie, Y., Liu, J., \& Masui, T. (2016). Green growth: The economic impacts of large-scale renewable energy development in China. Applied energy, 162, 435-449.

- Destek, M. A., \& Aslan, A. (2017). Renewable and non-renewable energy consumption and economic growth in emerging economies: Evidence from bootstrap panel causality. Renewable Energy, 111, 757-763. Dong K., Sun R., \& Li H., et al. (2018) Does natural gas consumption mitigate CO2 emissions: Testing the environmental Kuznets curve hypothesis for 14 Asia-Pacific countries. Renew Sust Energy Rev 94: 419-429.

- $\quad$ Ekwueme, D. C., \& Zoaka, J. D. (2020). Effusions of carbon dioxide in MENA countries: inference of financial development, trade receptivity, and energy utilization. Environmental Science and Pollution Research, 1-12.

- Hayat, F., Pirzada, M. D. S., \& Khan, A. A. (2018). The validation of Granger causality through formulation and use of finance-growth-energy indexes. Renewable and Sustainable Energy Reviews, 81, 1859-1867.

- Im, K. S., Pesaran, M. H., \& Shin, Y. (2003). Testing for unit roots in heterogeneous panels. Journal of econometrics, 115(1), 53-74.

- Ito, K. (2017). CO2 emissions, renewable, and non-renewable energy consumption, and economic growth: Evidence from panel data for developing countries. International Economics, 151, 1-6.

- Kahia, M., Aïssa, M. S. B., \& Charfeddine, L. (2016). Impact of renewable and non-renewable energy consumption on economic growth: New evidence from the MENA Net Oil Exporting Countries (NOECs). Energy, 116, 102-115.

- Kahia, M., Aïssa, M. S. B., \& Lanouar, C. (2017). Renewable and non-renewable energy use-economic growth nexus: The case of MENA Net Oil Importing Countries. Renewable and Sustainable Energy Reviews, 71, 127-140.

- $\quad$ Kim, J., \& Park, K. (2016). Financial development and deployment of renewable energy technologies. Energy Economics, 59, 238-250.

- Kwakwa, A.P., Alhassan, H., \& Aboagye, S. (2018). Environmental Kuznets curve hypothesis in financial development and natural resource extraction context: evidence from Tunisia.

- Levin, A., Lin, C. F., \& Chu, C. S. J. (2002). Unit root tests in panel data: asymptotic and finite-sample properties. Journal of econometrics, 108(1), 1-24.

- $\quad$ Li, B., \& Wu, S. (2017). Effects of local and civil environmental regulation on green total factor productivity in China: A spatial Durbin econometric analysis. Journal of Cleaner Production, 153, 342-353.

- $\quad$ Maji I. K., Habibullah M. S., \& Saari M. Y. (2017) Financial development and sectoral CO2 emissions in Malaysia. Environ Sci Pollut Res 24: 7160-7176.

- Moutinho, V., \& Robaina, M. (2016). Is the share of renewable energy sources determining the CO2 kWh and income relation in electricity generation?. Renewable and Sustainable Energy Reviews, 65, 902-914.

- Mu, Y., Wang, C., \& Cai, W. (2018). The economic impact of China's INDC: Distinguishing the roles of renewable energy quota and the carbon market. Renewable and Sustainable Energy Reviews, 81, 2955-2966.

- Nassani A, A., Aldakhil A. M., \& Abro M. M. Q., et al. (2017) Environmental Kuznets curve among BRICS countries: spot lightening finance, transport, energy, and growth factors. J Clean Prod 154: 474-487

- $\quad$ Nguyen, K. H., \& Kakinaka, M. (2019). Renewable energy consumption, carbon emissions, and development stages: Some evidence from panel cointegration analysis. Renewable Energy, 132, 1049-1057.

- Ortega-Izquierdo, M., \& del Río, P. (2016). Benefits and costs of renewable electricity in Europe. Renewable and Sustainable Energy Reviews, 61, 372-383.

- Owusu, P., Asumadu, S.S., (2016). A review of renewable energy sources, sustainability issues, and climate change mitigation. Adv. Hum. Perform. Cogn. Eng. Res. 3, 1167990. https://doi.org/10.1080/23311916.2016.1167990

- $\quad$ Özokcu, S., \& Özdemir, Ö. (2017). Economic growth, energy, and environmental Kuznets curve. Renewable and Sustainable Energy Reviews, 72, 639-647.

- $\quad$ Pesaran, M. H., Shin, Y., \& Smith, R. P. (1999). Pooled mean group estimation of dynamic heterogeneous panels. Journal of the American Statistical Association, 94(446), 621-634.

- $\quad$ Phillips, P. C., \& Xiao, Z. (1998). A primer on unit root testing. Journal of Economic Surveys, 12(5), 423470 . 
- Sadorsky, P. (2009). Renewable energy consumption and income in emerging economies. Energy Policy, 37(10), 4021-4028.

- $\quad$ Sarkodie, S. A., \& Strezov, V. (2018). Empirical study of the environmental Kuznets curve and environmental sustainability curve hypothesis for Australia, China, Ghana, and USA. Journal of cleaner production, 201, 98-110.

- $\quad$ Shahbaz, M., Van Hoang, T. H., Mahalik, M. K., \& Roubaud, D. (2017). Energy consumption, financial development, and economic growth in India: New evidence from the nonlinear and asymmetric analysis. Energy Economics, 63, 199-212.

- Silva, S., Soares, I., \& Pinho, C. (2012). The impact of renewable energy sources on economic growth and CO2 emissions-a SVAR approach. European Research Studies, 15, 133.

- Sinha A., \& Shahbaz M. (2018) Estimation of Environmental Kuznets Curve for CO2 emission: Role of renewable energy generation in India. Renew Energy 119: 703-711.

- $\quad$ Spiegel-Feld, D., Rudyk, B., \& Philippidis, G. (2016). Allocating the economic benefits of renewable energy between stakeholders on Small Island Developing States (SIDS): Arguments for a balanced approach. Energy Policy, 98, 744-748.

- World Bank, (2019).World development indicators. Retrieved from. http://data.worldbank.org/country.

- Zhang, B., Wang, B., \& Wang, Z. (2017). Role of renewable energy and non-renewable energy consumption on EKC: evidence from Pakistan. Journal of Cleaner Production, 156, 855-864.

- Zhang, X., \& Wang, Y. (2017). How to reduce household carbon emissions: A review of experience and policy design considerations. Energy Policy, 102, 116-124. 


\title{
How Do the Volume and Maturity of Debt Relate to Investment Efficiency? The Case of Asia
}

\author{
Ehsan Poursoleiman (Urmia University, Iran) \\ Dr. Gholamreza Mansourfar (Urmia University, Iran) \\ Assoc. Prof. Dr. Sazali Abidin (Lincoln University, New Zealand)
}

\begin{abstract}
This study aims to investigate the impact of debt volume and maturity on investment efficiency. It also analyzes the role of debt maturity in the association between debt volume and investment efficiency. The sample consists of 8,741 firm-year observations from 1,301 Asian corporations, covering the period 2007-2017. Financial leverage is employed as a proxy for debt volume as well as short-term debt for debt maturity. The findings reveal that debt volume and short-term debt are inversely related to investment efficiency. It also shows that the negative relationship between financial leverage and investment efficiency is weaker (closer to zero) for firms with higher use of short-term debt than those with lower use of short-term debt. This paper tries out agency and information asymmetry theories and provides practical implications regarding the optimal capital structure for firms headquartered in Asia.
\end{abstract}

\section{Introduction}

In perfect markets where the tax on revenue and agency problems do not exist, all corporates investments result in improving firms' value. Whereas, in imperfect markets, information asymmetry and agency problems make firms invest inefficiently which in turn may lead to the decease of firms' financial performance. Acceptance of lucrative projects and rejection of poor projects lead to efficient investments. Conversely, embracing loss-making activities and rejecting favorable opportunities cause over-investment and under-investment problems, respectively. Managers' private incentives, such as the effort aversion and the desire for a quiet life intensify underinvestment problems (Bertrand \& Mullainathan, 2003), and managers' motivations for building an empire and their inconsiderations increase the risk of over-investment problems (Blanchard, Lopez-de-Silanes, \& Shleifer, 1994; Aggarwal \& Samwick, 2006). Beside, managerial entrenchment (Shleifer \& Vishny, 1989) and over-selfconfidence (Heaton, 2002) adversely influence investment efficiency. All these inclinations originate from agency conflicts and high costs of monitoring (Jensen, 1986; Richardson, 2006); therefore, the gap between managers and stakeholders push the firms toward investment inefficiency (Jensen \& Meckling, 1976). Thus, the only possible way to keep firms away from the inefficient investment is to eliminate this gap and conflict. Financial leverage (debt volume) could tighten the gap between managers and outsiders, and as a result, can mitigate agency costs (Poursoleiman, Mansourfar, \& Abidin, 2020). It imposes strict controls over managers' decisions and their incentives for building empire by increasing the number of contract renewals and imposing strict requirements such as keeping a definite return on asset ratio (Lang, Ofek, \& Stulz, 1996; Khan, Kaleem, Nazir, \& Khan, 2012). Thus, debt could enhance investment efficiency through mitigating over-investment problems.

Financing constraints make firms unable to channel all the available funds into projects, which may drive firms into under-investment problems (Myers \& Majluf, 1984). Increasing in risk puts significant barriers on firms access to financial resources and consequently raises financing costs. In grave conditions, the risk could impede firms from financing and as a consequence, lead them to financial distress point (Biddle, Hilary, \& Verdi, 2009). Incidentally, it is the debt that increases the risk (Tsai \& Gu, 2007; Hsu \& Jang, 2008; Koh, Lee, \& Boo, 2009). In other words, an increase in debt level is associated with an increase in firms' risk, so financial leverage (debt level) could have a considerable detrimental effect on investment efficiency through the risk channel.

Theoretically, financial leverage has both positive and negative impacts on investment efficiency. It could enhance investment efficiency by imposing strict controls over managers and on the other hand it could exacerbate investment efficiency by increasing the risk and costs of financing. Therefore, a question is being raised here which this paper intends to address: What is the experimental effect of financial leverage on investment efficiency?

Moreover, financial leverage is made up of short-term and long-term debt. Short-term debt brings liquidity risk which can block a significant amount of financial resources; therefore, short-term debt can increase investment inefficiency through blocking available funds. In addition, short-term debt as a sub-scenario of financing could mitigate agency conflicts between the two sides more efficiently than long-term debt because of its shorter durations of contracts (González, 2017; Poursoleiman et al., 2020). Therefore, short-term debt can also increase investment efficiency by tightening the gap between the two sides (Childs, Mauer, \& Ott, 2005; Gomariz \& Ballesta, 2014). As a result, financial leverage and short-term debt affect investment efficiency through the similar channels. They both restrict the accessibility to financial resources and also mitigate information asymmetry or agency conflict. Therefore, these two factors are expected to have an analogous correlation with investment efficiency dimensions - they decrease investment efficiency through decreasing financial resources and increase 
investment efficiency through mitigating agency conflicts. As a result, if financial leverage has an inverse association with investment efficiency, short-term debt also should establish such relationship with investment efficiency. Therefore, we aim to investigate this claim in the present study.

The remainder of the paper is organized as follows: In section 2, the existing literature on the role of debt level and maturity on investment efficiency is reviewed and the research hypotheses are developed. In section 3, the research design, models, evaluation of variables and the sample are introduced. In section 4, the results are presented and finally, in section 5 the main conclusions of this paper are presented.

\section{Literature Review and Hypothesis Development}

Investment efficiency is accomplished through appropriate injection of financial resources into operating activities. Investment and non-investment per se do not necessarily lead to investment efficiency, only investing in profitable projects in terms of net present value, as well as not investing in poor projects, lead to investment efficiency. According to finance theories, three factors exert considerable influences on investment efficiency: (1) financing constraints and costs, (2) agency problems, which refer to the conflict of interest between managers and stockholders, and (3) information asymmetry. The disagreement between managers and stockholders generates agency problems and information asymmetry. Also, the risk of high debt brings financing constraints and difficulties.

Flynn (2017) concluded that an increase in financial leverage is associated with a decrease in future external financing. Incidentally, in imperfect markets, financing precedes investment and firms finance in order to supply funds for investing in projects; therefore, financial leverage decreases future investment through the financing and risk channel (Bao, 2010; Flynn, 2017; Barbiero, Brutscher, Kolev, Popov, \& Wolski, 2018; Danso, Lartey, Fosu, Owusu-Agyei, \& Uddin, 2019). Bao (2010) predicted that decreasing in investments makes firms unable to employ and pursue growth and profitable opportunities, so a negative relationship between financial leverage and investment leads to investment inefficiency. Therefore, financial leverage decreases investment efficiency by increasing financing costs. Moreover, when debt level in capital structure is high, managers struggle to keep a great deal of money on hand and avoid investing these amounts in projects lest they might be unable to repay the debts at maturity (Jensen, 1986). Therefore, financial leverage could make managers lose their incentives to invest in positive projects in terms of net present value. So, financial leverage decreases investment efficiency by blocking financial resources and increasing financing costs.

In accordance with Myers (1977), in external debt financing, if the investment profit is not sufficient to be fairly distributed among creditors, debtors will receive more than stockholders because of the priority they possess. As a result, the incentive of managers-stockholders coalition to invest in positive projects will decrease. Surprisingly, leveraged firms will have fewer growth opportunities because of rejecting positive projects (Noravesh \& Yazdani, 2010). Therefore, increasing in financial leverage is probably associated with decreasing in investment efficiency. It can be concluded that financial leverage is inversely related to investment efficiency.

In debt financing, managers block a great deal of funds due to the fearing of inability to reimburse the debt's principal and interests at maturity. Incidentally, short-term debt, as an option of borrowing, imposes higher liquidity risks to firms, which makes managers more conscious and aware of maturity dates (Zhaoguo, Weifeng, \& Jing, 2008). Therefore, short-term debt seems to cause under-investment problems, and as a result, it is expected to increase investment inefficiency.

To sum up, the mentioned experimental and theoretical studies suggest that financial leverage and short-term debt have a meaningful effect on investment efficiency. Financial leverage exacerbates investment efficiency by increasing financing constraints and decreasing the accessibility of financial resources, and also short-term debt blocks managers' free cash flow, which can intensify under-investment problems and as a result decreases investment efficiency. Therefore, short-term debt is expected to cause financial leverage to have an inverse effect on investment efficiency through decreasing or blocking financial resources. Thus, the negative effect of financial leverage on investment efficiency through decreasing cash flow is mainly due to the presence of short-term debt. Moreover, these two factors are expected to have an inverse relationship with investment efficiency and it also expected that the coefficient between financial leverage and investment efficiency is higher than the coefficient between short-term debt and investment efficiency. Thus, the first hypothesis of this study is as follows:

H1: Financial leverage and short-term debt exacerbate investment efficiency.

Information asymmetry theory can also demonstrate how financial leverage and short-term debt are related to investment efficiency. Information asymmetry significantly affects agency conflicts and costs, which both have meaningful effects on investment efficiency. Previous empirical studies, such as Verdi (2006), Biddle and Hilary (2006), Biddle et al. (2009), Chen et al. (2011), Morellec and Schürhoff (2011), Zhai \& Wang (2016) and Li, He, and Xiao (2019), predicted that an increase in information asymmetry is associated with a decrease in investment efficiency. Incidentally, financial leverage and short-term debt play a decisive role in decreasing information asymmetry (Flannery, 1986; Ortiz-Molina \& Penas, 2008; Barbiero et al., 2018). Therefore, financial leverage 
could affect investment efficiency through the channel of information asymmetry. In this paper, this channel will be studied from the viewpoints of timing, pecking order and signaling theories.

From the perspective of timing theory of Modigliani and Miller (1958), firms finance through borrowing in order to repurchase stocks when the stock price is below the actual value and issue new stocks when the stock price is above the actual value. According to market participants, in this process, debt financing and equity financing have occurred because of false pricing. Stockholders, therefore, infer that in the case of debt financing, the actual value exceeds the market value, and conversely in the case of equity financing, the market value surpasses the actual value. Therefore, financing activities reports positive and negative news to the market, which can mitigate information asymmetry and disclose firms' internal news about managers' incentives. Following timing theory, signaling theory of Ross (1977) claims that financial leverage mitigates information asymmetry because it is a criterion of management performance and could mitigate management's misbehavior. Pecking order theory of Myers (1984) presumes that information asymmetry and its consequences - adverse selection and moral hazard - create hierarchies. According to this theory, managers prefer to finance through resources that get the least affects from asymmetric information. Therefore, accumulated profit and reserves as internal financing resources bring the least costs to firms, and equity financing as an external financing scenario generate the most costs $(\mathrm{He}$, Lepone, \& Leung, 2013). Furthermore, the maintenance of current stockholders and avoidance of equity financing sent positive signals to the capital market, and debt financing indicate that the firm has an appropriate future financial position. Thus, debt financing (financial leverage) could significantly decrease information asymmetry through signaling (Andres, Cumming, Karabiber, \& Schweizer, 2014).

According to agency and information asymmetry theories, financial leverage and short-term debt mitigates information asymmetry. Moreover, short-term debt can alleviate agency conflicts more efficiently than long-term debt because of its shorter maturity (González, 2017). Childs et al. (2005) and Gomariz \& Ballesta (2014) claimed that short-term debt can mitigate over-investment problems. As a result, the negative relation between financial leverage and investment efficiency is expected to be weaker (closer to zero) for firms with higher use of shortterm debt than those with lower rate of short-term debt. The following hypothesis is developed to test this expectation:

H2: The impact of financial leverage on investment efficiency is less negative for firms with higher use of shortterm debt.

\section{Research Design}

\subsection{Model Specification}

Model 1 and 2 have been used to analyze $\mathrm{H} 1$ and $\mathrm{H} 2$, respectively. These models were employed by Gomariz and Ballesta (2014) and Benlemlih and Bitar (2018) and have been developed from Biddle et al. (2009) and Chen et al. (2011) studies.

$$
\begin{gathered}
\text { Efficiency }_{i t}=\beta_{0}+\beta_{1} \text { Lev }_{i t}+\beta_{2} \text { STDebt }_{i t}+\beta_{3} i t+\beta_{4} \text { Cash }_{i t}+\beta_{5} M T B_{i t} \\
+\beta_{6} \text { LnAge }_{i t}+\beta_{7} \text { Tang }_{i t}+\beta_{8} \text { ROA }_{i t}+\beta_{9} H P_{i t}+\varepsilon_{i t}
\end{gathered}
$$

where Efficiency represents investment efficiency, Lev represents financial leverage, STDebt is short-term debt ratio, Size is the size of firm, Cash represents cash, MTB is the market to book value of assets, LnAge is the age of firm, Tang represents tangible assets, $R O A$ is the return to assets ratio, and $H P$ is a dummy for financing constraints.

Also, in order to minimize the concern that financial leverage and short-term debt may link to each other; two separate regressions were estimated based on Model 1: (1) regression of investment efficiency on financial leverage and control variables (2) regression of investment efficiency on short-term debt and control variables.

(2)

$$
\begin{aligned}
& \text { Efficiency }_{i t}=\beta_{0}+\beta_{1} \text { Lev }_{i t}+\beta_{2} \text { STDebt }_{i t}+\beta_{3} \text { Lev } \times \text { DumSTDebt }_{i t}+\beta_{4} i t \\
& +\beta_{5} \text { Cash }_{i t}+\beta_{6} \text { MTB } B_{i t}+\beta_{7} \text { LnAge }_{i t}+\beta_{8} \text { Tang }_{i t}+\beta_{9} R O A_{i t}+\beta_{10} H P_{i t}+\varepsilon_{i t}
\end{aligned}
$$

As shown in the literature review, short-term debt could reduce information asymmetry more efficiently than long-term debt; incidentally, it was shown that information asymmetry could have a considerable impact on investment efficiency. Therefore, it is expected that in $\mathrm{H} 2$, the inverse relation between financial leverage and investment efficiency is less negative (closer to zero) for firms with higher use of short-term debt. As a result, similar to Gomariz and Ballesta (2014), in this study, an interaction effect has been considered between financial leverage and a dummy variable for the proxy of short-term debt (DumSTDebt), which takes 1 if the ratio of shortterm debt to total debt is above the median and otherwise, it takes 0 . Thus, Lev $\times$ DumSTDebt represents an interaction effect. In Model 2, $\beta \_1$ indicates the impact of financial leverage on investment efficiency for firms with lower use of short-term debt; $\beta \_1+\beta \_3$ represents the effect of financial leverage on investment efficiency for firms with higher level of short-term debt than the median. 


\subsection{Variable Measures}

\section{Dependent variable: investment efficiency}

Previous studies suggested employing the growth opportunities model for measuring investment efficiency. The concept of this model is that growth opportunities should explain firms' capital investments; therefore, any failure in explanation and deviation indicates the occurrence of inefficient investment. Therefore, Model 3, designed by Biddle et al. (2009), was utilized to measure investment efficiency.

(3)

$$
\text { Investment }_{i t}=\beta_{0}+\beta_{1} \text { SaleGrowt }_{i t-1}+\varepsilon_{i t}
$$

where Investment is the change in tangible and intangible assets from the last year $(t-1)$ to the current year $(t)$ divided by total assets and SaleGrowth is the rate of change in sales from $t-2$ to $t-1$.

Positive errors in Model 3 indicate that investment exceeds growth opportunities, so the value of such error is the value of over-investment. On the other hand, negative errors in this model indicate that investment could not follow growth opportunities; in other words, managers did not invest enough in projects, so the digit of negative error is the value of under-investment. Absolute values of both positive and negative errors measure investment inefficiency. Therefore, to determine investment efficiency, the absolute values were multiplied by -1 .

\section{Independent variable: financial leverage}

The ratio of total debt to total assets is used in order to measure debt level or financial leverage.

\section{Independent and moderator variable: short-term debt}

The ratio of short-term debt to total debt is used to measure the level of short-term debt.

\section{Control variables}

Based on previous literature and theories, some control variables were used as follows: Size = natural logarithm of total assets; Cash $=\neg$ cash divided by total assets; LnAge $=$ natural logarithm of firm age; MTB $=$ market to book value of assets; Tang $=$ ratio of tangible assets to total assets; ROA = return on assets; $\mathrm{HP}=$ takes 1 if HP index is above the median and 0 otherwise. HP index was measured by Hadlock and Pierce (2010) and defined as: $-7.373 \times$ (natural logarithm of total assets $)+0.043 \times$ (natural logarithm of total assets) $2-0.04$ (the age of firm)

\subsection{Sample}

The sample includes firms from the Asia continent during 2007-2017. There are in sum 8,741 observations. Data were obtained from the Thomson Reuters database. Moreover, in order to mitigate the influence of outliers, all variables were winsorised at $2 \%$ and $98 \%$ levels. Table 1 shows the sample distribution by country.

\begin{tabular}{|l|c|c|}
\hline Country & No. Firms & Percentage \\
\hline China & 170 & $13.07 \%$ \\
\hline Hong Kong & 124 & $9.53 \%$ \\
\hline India & 105 & $8.07 \%$ \\
\hline Indonesia & 39 & $3.00 \%$ \\
\hline Japan & 425 & $32.67 \%$ \\
\hline Malaysia & 53 & $4.07 \%$ \\
\hline Philippines & 26 & $2.00 \%$ \\
\hline Singapore & 43 & $3.31 \%$ \\
\hline South Korea & 118 & $9.07 \%$ \\
\hline Taiwan & 133 & $10.22 \%$ \\
\hline Thailand & 39 & $3.00 \%$ \\
\hline Turkey & 26 & $2.00 \%$ \\
\hline Total & 1301 & $100 \%$ \\
\hline
\end{tabular}

Table 1. Sample Distribution by Country

\section{Results}

\subsection{Descriptive Statistics}

Table 2 provides descriptive statistics for the variables. The mean of financial leverage (Lev) is 0.361 which indicates that the firms use less debt compared to equity; in other words, the ratio of debt to total assets is less than the ratio of equity to total assets. The mean of short-term debt ratio (STDebt) is 0.497 , indicating that on average, the firms use equal amounts of short-term debt and long-term debt. 


\begin{tabular}{|l|c|c|c|c|c|c|}
\hline Variable & Mean & Median & Maximum & Minimum & Std. Dev. & Obs. \\
\hline Investment & 0.030 & 0.014 & 0.259 & -0.096 & 0.065 & 8741 \\
\hline Efficiency & -0.036 & -0.023 & 0.000 & -0.280 & 0.040 & 8741 \\
\hline Lev & 0.361 & 0.349 & 0.728 & 0.079 & 0.153 & 8741 \\
\hline STDebt & 0.497 & 0.517 & 0.978 & 0.000 & 0.301 & 8741 \\
\hline Size & 19.147 & 19.191 & 24.931 & 14.145 & 2.327 & 8741 \\
\hline Cash & 0.106 & 0.076 & 0.467 & 0.002 & 0.101 & 8741 \\
\hline MTB & 2.313 & 1.630 & 10.551 & 0.430 & 2.064 & 8741 \\
\hline LnAge & 2.796 & 2.970 & 3.762 & 0.112 & 0.805 & 8741 \\
\hline Tang & 0.328 & 0.300 & 0.822 & 0.004 & 0.203 & 8741 \\
\hline Roa & 0.076 & 0.062 & 0.287 & -0.056 & 0.068 & 8741 \\
\hline HP & 0.587 & 1.000 & 1.000 & 0.000 & 0.492 & 8741 \\
\hline SaleGrowth & 0.127 & 0.083 & 1.055 & -0.311 & 0.236 & 8741 \\
\hline
\end{tabular}

Investment is the change in tangible and intangible assets from $t-1$ to $t$ scaled by total assets; Efficiency is the absolute value of residuals of investment model of Biddle et al. (2009) multiplied by -1 ; Lev is the ratio of total debt to total assets; STDebt is the ratio of short-term debt over total debt; Size is the natural logarithm of total assets; Cash is the ratio of cash to total assets; MTB is the market to book value of assets; LnAge is the natural logarithm of firm age; Tang is the proportion of tangible assets over total assets; $R O A$ is the return on assets ratio; $H P$ takes 1 if HP index is above the median and 0 otherwise. HP index was measured by Hadlock and Pierce (2010) and is calculated as: $-0.737 \times$ (the natural logarithm of total assets $)+0.043 \times(\text { the natural logarithm of total assets })^{2}-0.04 \times($ firm age); and SaleGrowth is the rate of change in sales from $t-2$ to $t-1$.

\section{Table 2. Descriptive Statistics}

Table 3 presents the Pearson and Spearman correlation matrices for the variables. Correlations between variables are not high, therefore, collinearity is not likely to be a problem in this study.

\begin{tabular}{|c|c|c|c|c|c|c|c|c|c|}
\hline Pearson Spearm & Lev & STDebt & Size & Cash & MTB & LnAge & Tang & Roa & HP \\
\hline Lev & 1 & $0.061 * * *$ & $0.074 * * *$ & $-0.112 * *$ & $0.037 * * *$ & $-0.1 * * *$ & $0.053 * * *$ & $-0.251 * *$ & 0.009 \\
\hline STDebt & $0.046 * * *$ & 1 & $0.143 * * *$ & $-0.202 * *$ & $-0.2 * * *$ & $0.1 * * *$ & $0.22 * * *$ & $-0.233 * *$ & $-0.032 * *$ \\
\hline Size & $0.072 * * *$ & $0.155^{* * * *}$ & 1 & $-0.116^{* *}$ & $-0.261 * *$ & $0.377 * * *$ & $0.137 * * *$ & $-0.147 * *$ & -0.015 \\
\hline Cash & $-0.135 * *$ & $-0.273 * *$ & $-0.185^{* * *}$ & 1 & $0.047 * * *$ & $-0.032 * *$ & $-0.365 * *$ & $0.094 * * *$ & $0.047 * * *$ \\
\hline MTB & $0.112 * * *$ & $-0.192 * *$ & $-0.266 * *$ & $0.119 * * *$ & 1 & $-0.29 * * *$ & $-0.067 * *$ & $0.563 * * *$ & $0.178 * * *$ \\
\hline LnAge & $-0.097 * *$ & $0.09 * * *$ & $0.304 * * *$ & $-0.116 * *$ & $-0.223 * *$ & 1 & 0.01 & $-0.202 * *$ & $-0.142 * *$ \\
\hline Tang & $0.072 * * *$ & $0.197 * * *$ & $0.139 * * *$ & $-0.358 * *$ & $-0.078 * *$ & -0.012 & 1 & $-0.058 * *$ & $-0.096 * *$ \\
\hline Roa & $-0.224 * *$ & $-0.262 * *$ & $-0.138 * *$ & $0.165 * * *$ & $0.569 * * *$ & $-0.176^{* *}$ & $-0.081 * *$ & 1 & $0.2 * * *$ \\
\hline HP & 0.011 & $-0.032 * *$ & -0.001 & $0.051 * * *$ & 0.136 *** & $-0.145 * *$ & $-0.095 * *$ & $0.191 * * *$ & 1 \\
\hline
\end{tabular}

Table 3. Correlation Matrix

\subsection{Regression Results}

Table 4 reports the results of the regression estimation of models 1 and 2 on analyzing $\mathrm{H} 1$ and $\mathrm{H} 2$. $F$-statistics of the models are significant at $1 \%$. As far as Durbin Watson statistics are in an acceptable range, the outcomes of the table are reliable.

In Eq. 1, the coefficient between financial leverage and investment efficiency is $-0.0259(p<0.01)$, indicating that financial leverage exacerbates investment efficiency. Furthermore, the coefficient of short-term debt with investment efficiency is $-0.0084(p<0.01)$; therefore, it can be concluded that short-term debt decreases investment efficiency, so H1 is supported. In Eq. 2 financial leverage has a coefficient of $-0.0223(p<0.05)$ and in Eq. 3 short-term debt has a coefficient of $-0.0068(p<0.01)$. Therefore, financial leverage and short-term debt in equations where the concern that these two variables may link to each other does not exist, are negatively related to investment efficiency, thus $\mathrm{H} 1$ is reconfirmed.

In Eq. $4, \beta_{1}$ is $-0.0281(p<0.01)$, representing the coefficient between financial leverage and investment efficiency for firms with lower use of short-term debt. $\beta_{1}+\beta_{3}$ is -0.0224 , showing the coefficient between financial leverage and investment efficiency for firms with higher use of short-term debt. Therefore, financial leverage is less negatively related to investment efficiency for firms with higher use of short-term debt than those with lowlevel short-term debt $\left(\beta_{1}<\beta_{1}+\beta_{3}=-0.0281-0.0224\right)$. In short, short-term debt could alleviate the negative association between financial leverage and investment efficiency; as a result, $\mathrm{H} 2$ is supported. 


\begin{tabular}{|c|c|c|c|c|}
\hline Variable & Equation 1 & Equation 2 & Equation 3 & Equation 4 \\
\hline \multirow[t]{2}{*}{ Lev } & $-0.0259 * *$ & $-0.0223 * *$ & & $-0.0281 * * *$ \\
\hline & $(-2.3172)$ & $(-1.9637)$ & & $(-2.6039)$ \\
\hline \multirow[t]{2}{*}{ STDebt } & $-0.0084 * * *$ & & $-0.0068 * * *$ & $-0.0107 * * *$ \\
\hline & $(-5.0376)$ & & $(-3.5853)$ & $(-7.0902)$ \\
\hline \multirow[t]{2}{*}{ Lev $\times$ DumSTDebt } & & & & $0.0057^{*}$ \\
\hline & & & & $(1.7639)$ \\
\hline \multirow[t]{2}{*}{ Size } & $-0.005 * *$ & 0.0011 & 0.0018 & $-0.005 * *$ \\
\hline & $(-2.3259)$ & $(0.1883)$ & $(0.3021)$ & $(-2.3081)$ \\
\hline \multirow[t]{2}{*}{ Cash } & 0.0124 & 0.0137 & 0.0131 & 0.0122 \\
\hline & $(1.4187)$ & $(1.5046)$ & $(1.407)$ & $(1.38)$ \\
\hline \multirow[t]{2}{*}{ MTB } & -0.0002 & -0.0006 & $-0.0008 *$ & -0.0001 \\
\hline & $(-0.9502)$ & $(-1.1225)$ & $(-1.6923)$ & $(-0.9073)$ \\
\hline \multirow[t]{2}{*}{ LnAge } & $0.0066 * * *$ & $0.007 * * *$ & $0.0065 * * *$ & $0.0065 * * *$ \\
\hline & $(2.9961)$ & $(3.5728)$ & $(3.2541)$ & $(2.9625)$ \\
\hline \multirow[t]{2}{*}{ Tang } & -0.0026 & -0.0027 & -0.0038 & -0.0025 \\
\hline & $(-0.2049)$ & $(-0.2116)$ & $(-0.2834)$ & $(-0.1958)$ \\
\hline \multirow[t]{2}{*}{ Roa } & $0.0891 * * *$ & $0.0894 * * *$ & $0.091 * * *$ & $0.0897 * * *$ \\
\hline & $(5.9455)$ & $(6.8947)$ & $(5.9754)$ & $(5.9529)$ \\
\hline \multirow[t]{2}{*}{$\mathrm{HP}$} & -0.0022 & -0.0089 & -0.01 & -0.0022 \\
\hline & $(-1.1796)$ & $(-1.2309)$ & $(-1.4241)$ & $(-1.1709)$ \\
\hline \multirow[t]{2}{*}{ Intercept } & 0.0492 & -0.0679 & -0.0825 & 0.05 \\
\hline & $(1.2221)$ & $(-0.6284)$ & $(-0.779)$ & $(1.2297)$ \\
\hline Cross-section dummies & Yes & Yes & Yes & Yes \\
\hline Year dummies & Yes & Yes & Yes & Yes \\
\hline$R^{2}$ & 0.3496 & 0.3484 & 0.3480 & 0.3497 \\
\hline$F$ & $3.7140 * * *$ & $3.6951 * * *$ & $3.6885 * * *$ & $3.7131 * * *$ \\
\hline$\overline{D W}$ & 2.19513 & 2.197514 & 2.201084 & 2.19509 \\
\hline Obs. & 8741 & 8741 & 8741 & 8741 \\
\hline
\end{tabular}

*** Significance at $1 \%$ level.

** Significance at $5 \%$ level.

* Significance at $10 \%$ level.

T-statistics in brackets.

See Table 2 for variables definitions.

Table 4. Regression of Investment Efficiency on Financial Leverage, Short-Term Debt and Control Variables

\section{Conclusion}

This study is carried out to analyze the association between financial leverage and investment efficiency as well as the role of short-term debt in this relationship. Previous literature suggested that financial leverage increases firms' risks, cost of financing, and financing constraints and lowers free cash flow; as a result, we predicted that debt volume may be inversely related to investment efficiency. Besides, there are two sub-scenarios in debt financing - short-term and long-term debt. We believed that the main reason for the negative impact of financial leverage on investment efficiency is due to the presence of short-term debt; the reason stems from the default and maturity risk which are imposed upon firms by short-term debt. Thus, the first hypothesis predicted that financial leverage and short-term debt both are inversely related to investment efficiency. This hypothesis was supported.

Agency theory argues that debt volume can mitigate information asymmetry between the two sides by increasing the number of contracts between managers and creditors. Additionally, short-term debt could lessen this conflict more efficiently than long-term debt since short-term debt has shorter maturity and can increase the number of contract renewals more frequently than long-term debt. Therefore, it was predicted in the second hypothesis that the inverse relationship between financial leverage and investment efficiency is more for firms with lower use of short-term debt than for firms with higher use of short-term debt. This hypothesis was confirmed.

These findings recommend corporations domiciled in Asian countries to reduce debt volume due to the inverse relationship between financial leverage and investment efficiency. Furthermore, in case of being unable to minimize debt amounts, they are recommended to replace long-term debt with short-term debt.

\section{References}

- Aggarwal, R. K., \& Samwick, A. A. (2006). Empire-builders and shirkers: Investment, firm performance, and managerial incentives. Journal of Corporate Finance, 12(3), p. 489-515.

https://doi.org/10.1016/j.jcorpfin.2006.01.001 
- $\quad$ Andres, C., Cumming, D., Karabiber, T., \& Schweizer, D. (2014). Do markets anticipate capital structure decisions?-Feedback effects in equity liquidity. Journal of Corporate Finance, 27, p. 133-156. https://doi.org/10.1016/j.jcorpfin.2014.02.006

- Bao, H. (2010). A study on leverage and firm investment: Chinese evidence. Master of Science Thesis, Royal Institute of Technology, (June). Retrieved from https://www.kth.se/polopoly_fs/1.169309!/Menu/general/column-content/attachment/Huijie Bao.pdf

- $\quad$ Barbiero, F., Brutscher, P.-B., Kolev, A., Popov, A., \& Wolski, M. (2018). Misallocation of investment in Europe: The role of debt overhang and credit market distress. In Finance and Investment: The European Case, Oxford University Press, 57-63. https://doi.org/10.1093/oso/9780198815815.003.0003

- Benlemlih, M., \& Bitar, M. (2018). Corporate Social Responsibility and Investment Efficiency. Journal of Business Ethics, 148(3), p. 647-671. https://doi.org/10.1007/s10551-016-3020-2

- Bertrand, M., \& Mullainathan, S. (2003). Enjoying the quiet life? Corporate governance and managerial preferences. Journal of Political Economy, 111(5), p. 1043-1075. https://doi.org/10.1086/376950

- Biddle, G. C., \& Hilary, G. (2006). Accounting quality and firm-level capital investment. Accounting Review, 81, p. 963-982. https://doi.org/10.2308/accr.2006.81.5.963

- $\quad$ Biddle, G. C., Hilary, G., \& Verdi, R. S. (2009). How does financial reporting quality relate to investment efficiency? Journal of Accounting and Economics, 48(2-3), 112-131. https://doi.org/10.1016/j.jacceco.2009.09.001

- Blanchard, O. J., Lopez-de-Silanes, F., \& Shleifer, A. (1994). What do firms do with cash windfalls? Journal of Financial Economics, 36(3), p. 337-360. https://doi.org/10.1016/0304-405X(94)90009-4

- Chen, F., Hope, O. K., Li, Q., \& Wang, X. (2011). Financial reporting quality and investment efficiency of private firms in emerging markets. Accounting Review, 86(4), p. 1255-1288. https://doi.org/10.2308/accr10040

- Childs, P. D., Mauer, D. C., \& Ott, S. H. (2005). Interactions of corporate financing and investment decisions: The effects of agency conflicts. Journal of Financial Economics, 76(3), p. 667-690. https://doi.org/10.1016/j.jfineco.2004.06.012

- Danso, A., Lartey, T., Fosu, S., Owusu-Agyei, S., \& Uddin, M. (2019). Leverage and firm investment: the role of information asymmetry and growth. International Journal of Accounting \& Information Management, 27(1), p. 56-73. https://doi.org/10.1108/IJAIM-10-2017-0127

- Flannery, M. J. (1986). Asymmetric information and risky debt maturity choice. The Journal of Finance, 41(1), p. 19-37. https://doi.org/10.1111/j.1540-6261.1986.tb04489.x

- Flynn, S. (2017). Debt Structure and Future Financing and Investment. Doctoral dissertation, Arizona State University. https://repository.asu.edu/items/44024

- Gomariz, M. F. C., \& Ballesta, J. P. S. (2014). Financial reporting quality, debt maturity and investment efficiency. Journal of Banking \& Finance, 40, p. 494-506. https://doi.org/https://doi.org/10.1016/j.jbankfin.2013.07.013

- González, V. M. (2017). Firm and country determinants of debt maturity: New international evidence. International Finance, 20(3), p. 256-270. https://doi.org/10.1111/infi.12116

- Hadlock, C. J., \& Pierce, J. R. (2010). New evidence on measuring financial constraints: Moving beyond the KZ index. Review of Financial Studies, 23(5), p. 1909-1940. https://doi.org/10.1093/rfs/hhq009

- He, W. P., Lepone, A., \& Leung, H. (2013). Information asymmetry and the cost of equity capital. International Review of Economics \& Finance, 27, p. 611-620. https://doi.org/10.1016/j.iref.2013.03.001

- Heaton, J. B. (2002). Managerial optimism and corporate finance. Financial Management, 31(2), p. $33-45$. https://www.jstor.org/stable/3666221

- Hsu, L.-T., \& Jang, S. (2008). The determinant of the hospitality industry’s unsystematic risk: A comparison between hotel and restaurant firms. International Journal of Hospitality \& Tourism Administration, 9(2), p. 105-127. https://doi.org/10.1080/15256480801907877

- Jensen, M. C. (1986). Agency costs of free cash flow, corporate finance, and takeovers. American Economic Review, 76(2), p. 323-329. https://www.jstor.org/stable/1818789

- Jensen, M., \& Meckling, W. (1976). Theory of the firm: Managerial behaviour, agency costs and ownership. Strategic Management Journal, 3(4), p. 305-360. https://doi.org/10.1016/0304-405X(76)90026-X

- $\quad$ Khan, A., Kaleem, A., Nazir, M. S., \& Khan, K. (2012). Voluntarily contribution and Agency cost of Free Cash Flow: Evidence from Manufacturing sector of Pakistan. J. Basic. Appl. Sci. Res, 2(7), p. 6882-6888. https://lahore.comsats.edu.pk/Papers/Abstracts/146-8588087133582664558.pdf 
- $\quad$ Koh, Y., Lee, S., \& Boo, S. (2009). Does franchising help restaurant firm value? International Journal of Hospitality Management, 28(2), p. 289-296. https://doi.org/10.1016/j.ijhm.2008.10.001

- $\quad$ Lang, L., Ofek, E., \& Stulz, R. M. (1996). Leverage, investment, and firm growth. Journal of Financial Economics, 40(1), p. 3-29. https://doi.org/10.1016/0304-405X(95)00842-3

- $\quad$ Li, Y., He, J., \& Xiao, M. (2019). Risk disclosure in annual reports and corporate investment efficiency. International Review of Economics \& Finance, 63, p. 138-151. https://doi.org/10.1016/j.iref.2018.08.021

- Modigliani, F., \& Miller, M. H. (1958). The cost of capital, corporation finance and the theory of investment. The American Economic Review, 49(4), p. 655-669. https://www.jstor.org/stable/1812919

- Morellec, E., \& Schürhoff, N. (2011). Corporate investment and financing under asymmetric information. Journal of Financial Economics, 99(2), p. 262-288. https://doi.org/10.1016/j.jfineco.2010.09.003

- Myers, S. C. (1977). Determinants of corporate borrowing. Journal of Financial Economics, 5(2), p. 147175. https://doi.org/10.1016/0304-405X(77)90015-0

- $\quad$ Myers, S. C. (1984). Finance theory and financial strategy. Interfaces, 14(1), p. 126-137. https://doi.org/10.1287/inte.14.1.126

- $\quad$ Myers, S. C., \& Majluf, N. S. (1984). Corporate financing and investment decisions when firms have information that investors do not have. Journal of Financial Economics, 13(2), p. 187-221. https://doi.org/10.1016/0304-405X(84)90023-0

- Noravesh, I., \& Yazdani, S. (2010). The Impact of Leverage on Firm Investments in Tehran Stock Exchange (TSE). Journal of Financial Accounting Research, 2(2), p. 35-48. Retrieved from http://far.ui.ac.ir/article_16876.html

- $\quad$ Ortiz-Molina, H., \& Penas, M. F. (2008). Lending to small businesses: The role of loan maturity in addressing information problems. Small Business Economics, 30(4), p. 361-383. https://doi.org/10.1007/s11187-007-9053-2

- Poursoleiman, E., Mansourfar, G., \& Abidin, S. (2020). Financial leverage, debt maturity, future financing constraints, and future investment. International Journal of Islamic and Middle Eastern Finance and Management. https://doi.org/10.1108/IMEFM-10-2019-0430

- Richardson, S. (2006). Over-investment of free cash flow. Review of Accounting Studies, 11(2-3), p. 159189. https://doi.org/10.1007/s11142-006-9012-1

- $\quad$ Ross, S. A. (1977). The determination of financial structure: the incentive-signalling approach. The Bell Journal of Economics, 8(1), p. 23-40. https://www.jstor.org/stable/3003485

- $\quad$ Shleifer, A., \& Vishny, R. W. (1989). Management entrenchment: The case of manager-specific investments. Journal of Financial Economics, 25(1), p. 123-139. https://doi.org/10.1016/0304-405X(89)90099-8

- Tsai, H., \& Gu, Z. (2007). Institutional ownership and firm performance: empirical evidence from US-based publicly traded restaurant firms. Journal of Hospitality \& Tourism Research, 31(1), p. 19-38. https://doi.org/10.1177\%2F1096348006296056

- Verdi, R. S. (2006). Financial reporting quality and investment efficiency. http://dx.doi.org/10.2139/ssrn.930922

- Zeitun, R., \& Haq, M. M. (2015). Debt maturity, financial crisis and corporate performance in GCC countries: a dynamic-GMM approach. Afro-Asian Journal of Finance and Accounting, 5(3), p. 231-247. https://doi.org/10.1504/AAJFA.2015.070291

- Zhai, J., \& Wang, Y. (2016). Accounting information quality, governance efficiency and capital investment choice. China Journal of Accounting Research, 9(4), p. 251-266. https://doi.org/10.1016/j.cjar.2016.08.001

- Zhaoguo, Z., Weifeng, H., \& Jing, C. (2008). Firm leverage and the private benefits of control in Chinese firms. Afro-Asian Journal of Finance and Accounting, 1(1), p. 6-16. https://doi.org/10.1504/AAJFA.2008.016887 


\title{
Медицинский Туризм в Кыргызской Республике: Возможности и Перспективы
}

\section{Medical Tourism in the Kyrgyz Republic: Opportunities and Prospective}

\author{
Prof. Dr. Anara Kamalova (Kyrgyz National University, Kyrgyzstan)
}

\begin{abstract}
Tourism world development shows that in recent years medical tourism has been developing rapidly. Tourists trip to other countries not only for rest and have a good time, but also to be treated. In the Kyrgyz Republic, medical tourism has gained popularity relatively recently. Mainly developing external medical tourism. However, Kyrgyzstan has great potential for the development of domestic medical tourism, which is currently receiving not enough attention, and as a result is very poorly developed. This paper tries to discuss the issues of medical tourism successful development in the Kyrgyz Republic, identifies problems and gives recommendations for its further development, since this kind of tourism has significant potential for development. Moreover, this area is one of the ways to increase the overall tourism level in the country's GDP.
\end{abstract}

\section{1 Введение}

Как всем известно, медицинский туризм - это совмещение отдыха за рубежом с высококвалифицированным медицинским обслуживанием. Медицинский туризм включает в себя также оздоровительный и диагностический туризм. Исходя из этого, медицинский туризм может преследовать разные цели: профилактика, оздоровление, лечение. Оздоровительный туризм подразумевает путешествие с целью оздоровления, укрепления своего здоровья и улучшения внешнего вида. Диагностический туризм направлен на обследование своего организма с целью установления правильного диагноза. И, собственно, основной целью медицинского туризма является лечение. В структуре медицинского туризма преобладает оздоровительный туризм, в том числе СПА-туризм (это многочисленные процедуры, связанные с минеральной, пресной или морской водой) - на его долю приходится $41 \%$ рынка медицинского туризма.

\section{2 Современное Состояние Развития Медицинского Туризма}

В настоящее время медицинский туризм относится к быстрорастущей сфере международного туристического бизнеса. Этот вид туризма получил такое широкое распространение в основном по следующим причинам:

- получение качественной и высококвалифицированной медицинской помощи;

- открытые международные границы;

- доступность и быстрое развитие логистики туризма;

- неравенство стран в вопросах стоимости и качества медицинского обслуживания;

- наличие современных медицинских технологий.

Анализируя развитие медицинского туризма в современных условиях, мы видим, что мировой рынок медицинского туризма сегодня оценивается экспертами в более 15 млрд долларов.

Медицинский туризм имеет тенденцию регионального развития. Медицинский туризм благоприятно развивается в странах Европы и Северной Америки - США, Германия, Япония, Франция и Австрия. Доля этих стран составляет 63\% мирового рынка медицинского туризма. Между тем такие страны как Индия, Сингапур, Мексика, Таиланд, Бразилия, Израиль, Турция, Южная Корея являются лидерами по приему медицинских туристов из стран Европы и Северной Америки. По данным Global Spa \& Wellness Summit, к 2017 году 50\% рынка медицинского туризма приходилось на страны Азии, Латинской Америки и Ближнего Востока. В этих странах помимо низких цен и качественного лечения пациентов привлекает также высокий уровень развития индустрии туризма в стране. Медицинский туризм имеет тенденцию регионального развития. В арабских странах популярными сетями являются клиники Дубай и Иордании.

Согласно исследованиям международной консалтинговой компании «McKinsey and Company» основными побудительными мотивами медицинского туризма являются: 


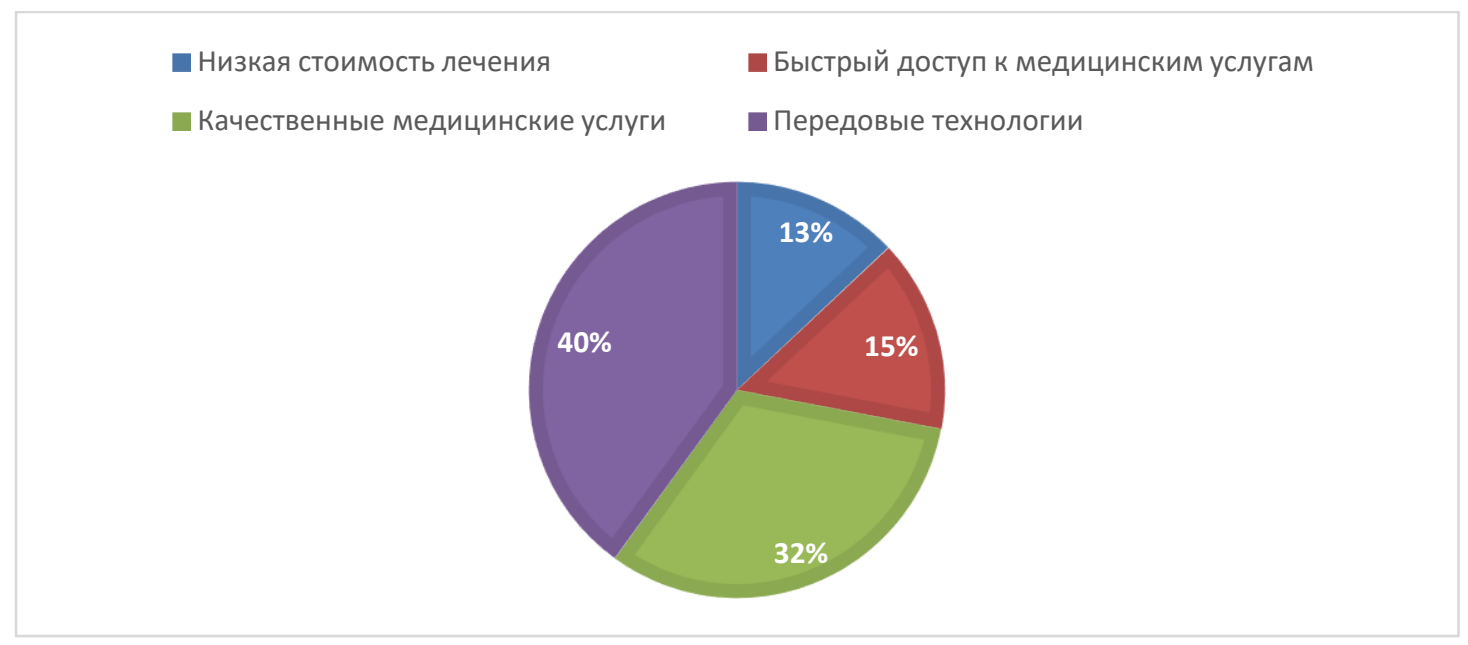

Диаграмма 1. Основные Мотивы Лечения Граждан Кыргызстана За Рубежом

Большинство кыргызстанцев в последнее время всё чаще стали отправляться на лечение за границу в основном за получением более точного диагноза и шанса на выздоровление. Жители нашей республики ездят лечится в такие страны как Германия, Израиль, которые лидируют по развитию медицинского туризма. Однако это гораздо реже, чем жители других стран. Основная причина этого является высокая цена оказываемых медицинских услуг в этих странах, например, в Германию рядовые жители Кыргызстана отправляются в основном по благотворительной линии.

Среди Азиатских стран, куда кыргызстанцы ездят на пересадку органов, лидируют Индия, Турция, Китай и Пакистан. В Индии качественно и относительно недорого делают пересадку печени. Если в Турции такая операция стоит от $\$ 85$ тыс., то в Индии - от $\$ 50$ тыс. Дешевле обходится и пересадка почки - от $\$ 18$ тыс. В Турции на аналогичную операцию вместе с реабилитацией пациент затрачивает $\$ 35$ тыс. Те, у кого нет родственного донора, на пересадку едут в Пакистан или Китай. Пациенты с пороками сердца, которых не смогли прооперировать врачи Кыргызстана, попадают в Россию.

\section{3 Возможности Кыргызской Республики в Развитии Медицинского Туризма}

Если рассмотреть состояние развития медицинского туризма в Кыргызстане, то оно находится на фазе внедрения. В настоящее время в республике отмечается тенденция роста посещения нашей страны иностранными гражданами. Так если в 2010 году Кыргызстане отдыхали 314,1 тыс. иностранных туристов, то в 2018 году эта цифра выросла почти 4 раза.

Согласно статистическим данным Кыргызской Республики, в 2018 году численность иностранных граждан, пересекших границу Кыргызской Республики, составила 4,7 млн. человек. Основной поток иностранных туристов прибыл из соседнего Казахстана (52\%), России (14\%) и с самым низким показателем из Индии (0,6\%), из них 1.4 млн. составили отдыхающие. Если анализировать число туристов, приехавших в Кыргызскую Республику из стран дальнего зарубежья, то они занимают небольшую долю: туристы из Турции - $1,2 \%$, Германии и США - $1 \%$. К сожалению, пока нет точных данных относительно их приезда с целью оздоровления.

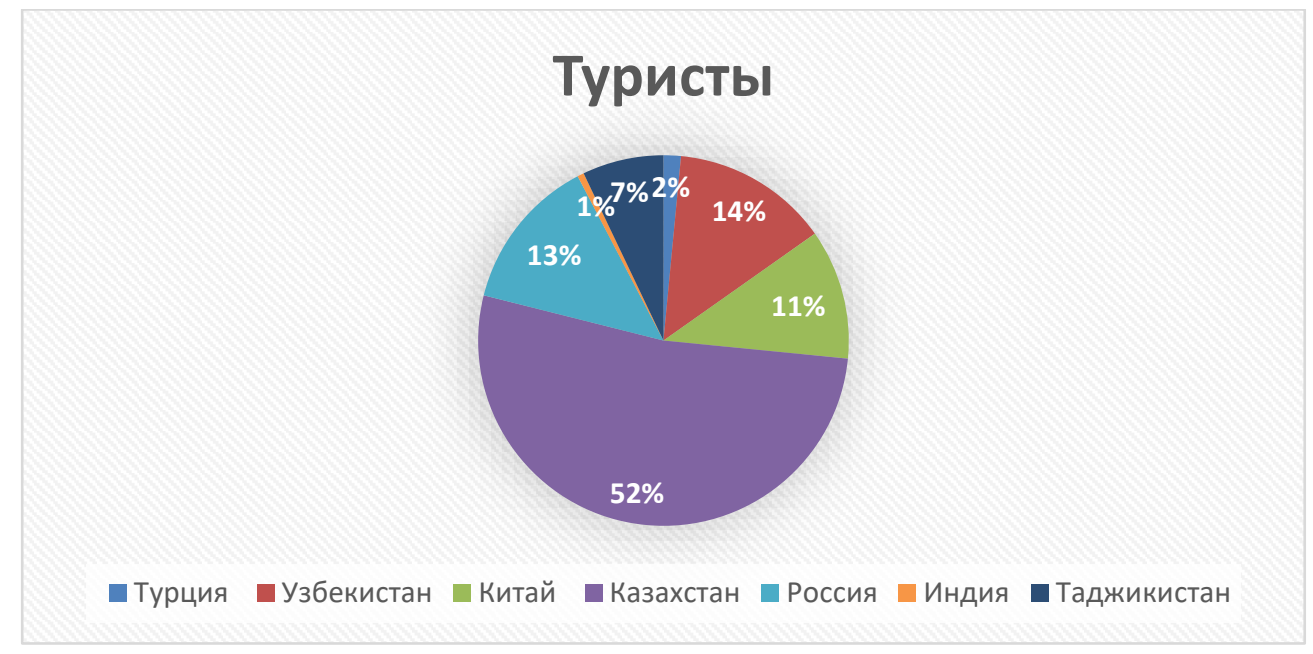

Диаграмма 2. Доля Туристов, Посетивших Кыргызстан Из Стран ВШП В 2018 
Наличие естественных природных объектов Кыргызстана (горы, ущелья, озера, пещеры и др.) дают нам реальную возможность развивать медицинский оздоровительный туризм. Наша страна славится как край курортных и туристических достопримечательностей, включая самый широкий спектр предлагаемых услуг: отдых в спортивно-оздоровительных лагерях, санаториях, пансионатах, горнолыжных курортах, походы по горно-туристическим маршрутам, охота и т.д.

Основной туристический поток приходится на озеро Иссык-Куль, которое имеет богатые минеральные источники и природные богатства для развития медицинского туризма.

В настоящее время Кыргызстан располагает уникальными природными ресурсами, представляющими интерес для развития медицинского туризма как перспективной отрасли экономики, где можно предоставлять услуги по лечению болезней сердечно-сосудистой и опорно-двигательной системы, органов дыхания, костно-мышечной системы, мочевыводящей системы, гинекологических заболеваний, желудочно-кишечного тракта, печени и желчевыводящих путей и многих других заболеваний.

Природное богатство Кыргызской Республики позволяет создавать заповедники и национальные природные парки, что дает еще большую возможность для привлечения иностранных туристов, нуждающихся в оздоровлении своего здоровья (психоневрологических, опорно-двигательных, сердечных, органов дыхания и т.д.). В Таблице 1 приведены данные о развитии заповедников, природных парков, учреждений санаторно-курортного лечения в республике за 2014-2018 годы.

\begin{tabular}{|l|l|l|c|c|}
\hline & \multirow{2}{*}{2014} & \multicolumn{2}{|c|}{2018} & \multirow{2}{*}{2018 в \% к 2014} \\
\cline { 3 - 4 } & & Количество & Удельный вес, \% & \multirow{2}{*}{$\begin{array}{l}\text { Предприятия туризма и учреждения } \\
\text { отдыха }\end{array}$} \\
\hline Санаторно-курортные учреждения & 943 & 967 & 88,8 & 111,1 \\
\hline Природные парки и заповедники & 19 & 100 & 9,2 & 115,8 \\
\hline ВСЕГО & $\mathbf{9 5 2}$ & $\mathbf{1 0 8 9}$ & $\mathbf{1 0 0}$ & $\mathbf{1 1 3 , 9}$ \\
\hline
\end{tabular}

Таблица 1. Анализ Развитие Объектов Туризма И Отдыха В Кыргызской Республике На Конеи Года Источник: Туризм В Кыргызстане 2014-2018 Гг. Стат.Сборник - Бишкек, 2019.

Как видно из таблицы, число заповедников в 2018 году, по сравнению с 2014 годом, возросло на 15,8\%, за этот же период число предприятий туризма и учреждения отдыха увеличилось на $14,7 \%$, а число санаторно-курортных учреждений на $11,1 \%$.

На сегодняшний день медицинская туристическая инфраструктура представлена различными объектами туризма и отдыха. Рассмотрим динамику развития санаториев и учреждений отдыха по стране за 2014 2018 годы.

\begin{tabular}{|l|l|l|l|l|l|l|}
\hline & 2014 & 2015 & 2016 & 2017 & 2018 & $\begin{array}{l}2018 \text { в \% или } \\
\text { р. к 2014 }\end{array}$ \\
\hline Санатории & 13 & 13 & 15 & 15 & 13 & 100 \\
\hline Детские санатории & 5 & 5 & 4 & 5 & 6 & 120 \\
\hline Санатории-профилактории & 10 & 10 & 12 & 11 & 10 & 100 \\
\hline Спортивно-оздоровительные лагеря & 4 & 5 & 8 & 10 & 9 & в 2,25 p. \\
\hline Пансионат с лечением & 2 & 3 & 5 & 5 & 5 & в 2,5 p. \\
\hline Детские оздоровительные комплексы & 26 & 29 & 27 & 22 & 24 & 92,3 \\
\hline ВСЕГО & $\mathbf{6 0}$ & $\mathbf{6 5}$ & $\mathbf{7 1}$ & $\mathbf{6 8}$ & $\mathbf{6 7}$ & $\mathbf{1 1 1 , 7}$ \\
\hline
\end{tabular}

Таблица 2. Динамика Развития Оздоровительно-Санаторных Учреждений Кыргызской Республики На Конеи Года Источник: Туризм В Кыргызстане 2014-2018 Гг. Стат.Сборник - Бишкек, 2019.

Данные таблицы показывают, что основное место в этих объектах занимают детские оздоровительные комплексы - 50 единиц или 43\%. Положительная тенденция наблюдается в появлении пансионатов с лечением и увеличение числа спортивно-оздоровительных лагерей, отрицательное явление - уменьшение числа детских оздоровительных комплексов (в 2018 г. по сравнению с 2014 г. уменьшилось на 7.7\%).

Наиболее важными показателями являются результаты маркетингового исследования мнений иностранных туристов по поводу цели приезда в Кыргызстан. 34\% туристов приезжают с целью встречи с друзьями и родственниками, которые в основном тоже являются потенциальными клиентами оздоровительных учреждений, а 29\% этих туристов являются уже реальными клиентами, так как они прямо указывают цель приезда «курортно-оздоровительная». 


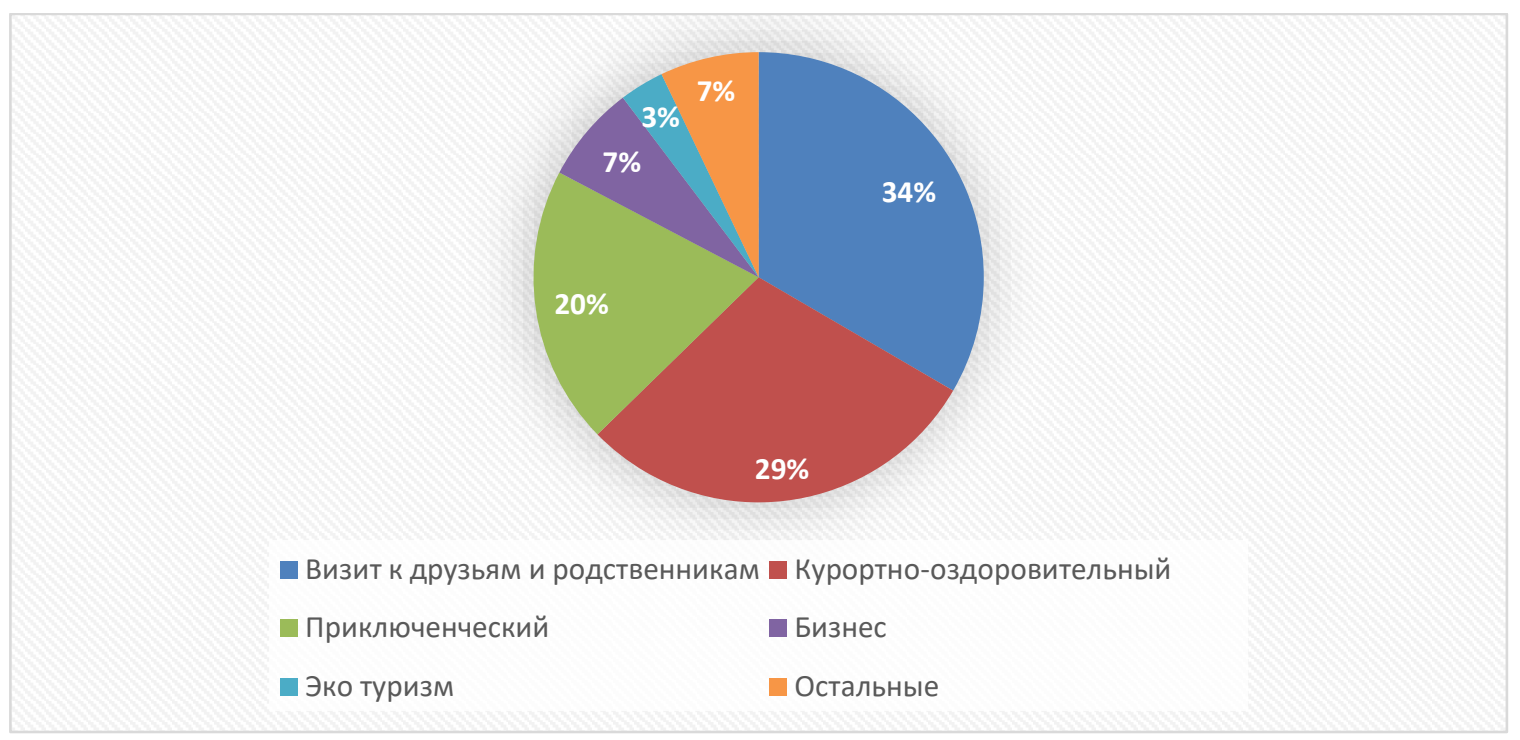

Диаграмма 3. Доля Туристов, Посетивиих Кыргызстан Из Стран ВШП В 2018

Результаты выше сделанного анализа доказывают возможности перспективного развития медицинского туризма в республике по направлению профилактики и оздоровления, тем самым создавая возможности дальнейшего развития медицинского туризма в стране.

Вместе с такими позитивными сторонами есть много недостатков для успешного развития медицинского туризма в Кыргызстане. Оставляет желать лучшего развитие медицинской отрасли республики. По всем показателям кыргызская медицина отстает от зарубежного по многим параметрам. Сюда можно отнести состояние технической оснащенности клиник, малочисленный состав высококвалифицированных кадров, устаревшее состояние объектов медицины, курортно-оздоровительных учреждений, недоразвитость логистики медицинского туризма, плохое состояние автомобильных дорог, авиаперевозок и т.д.

В Кыргызстане с созданием современных медицинских клиник и развитием в стране кардиохирургической и нейрохирургической помощи потребность в зарубежном лечении значительно уменьшилась, а для иностранцев появилась возможность получать медицинские услуги в Кыргызстане по международным стандартам. Отрадно то, что создаются медицинские центры совместно с турецкими, китайскими, корейскими бизнесменами в области медицины. Создание ассоциации медицинского туризма, которая открылась в 2018 году, на наш взгляд, будет способствовать дальнейшему развитию этой отрасли.

\section{4 Перспективы Развития Медицинского Туризма в Кыргызской Республике}

Для дальнейшего и устойчивого развития медицинского туризма в Кыргызской Республике, на наш взгляд, необходимо:

- разработать концепцию развития медицинского туризма в Кыргызской Республике на будущий период;

- привлекать инвестиции для рынка медицинского туризма;

- создать маркетинговые лаборатории по привлечению клиентов, грамотного продвижения медицинских услуг;

- внедрять на международный рынок узнаваемый отечественный бренд медицинских услуг, ориентированный на медицинский туризм;

- улучшить инфраструктуру и разработку продуктов медицинского туризма;

- улучшить качество оказываемых услуг и гостеприимства в медицинских учреждениях;

- предоставлять персоналу возможность изучения иностранных языков;

- ввести учебные планы по направлению «Менеджмент», «Маркетинг», «Управление бизнесом» дисциплины «Медицинский туризм».

По нашему мнению, перспективы развития медицинского туризма огромная, необходимо только создать условия для его развития.

\section{Литература}

- Стратегия развития страны до 2020 г.

- Соколов А.С., Манько Н.П., Гуляев В.Г. Теоретико-методологические аспекты медицинского туризма. 2017. 
- Сегизбаев А., Курманова С., Турсынбекова Ж., 2012. "Вопросы развития медицинского туризма в Астане". Клиническая медииина Казахстана, 2, стр. 37-39.

- $\quad$ РГП НА ПХВ «Республиканский Центр Развития Здравоохранения», 2019. Концепция развития медицинского туризма в Республике Казахстан. Нур-Султан.

- Национальный статистический комитет Кыргызской Республики, 2016. Национальный статистический сборник «Туризм Кыргызстана». Бишкек

- Марченко О.Г., 2013. "Мировой медицинский туризм смещается в страны АТР. Аналитический обзор". Современные проблемы науки и образования, 6.

- Концепция развития туристической отрасли в КР до 2020 г.

- Камалова А., Максудинов А, 2016. Маркетинг услуг. Бишкек.

- Калмыков Н.Н, 2017. Аналитическая записка «О состоянии и развитии медицинского туризма в PФ». M.

- World Tourism Organization, 2018. UNWTO Tourism Highlights, 2018 Edition. UNWTO, Madrid, DOI: https://doi.org/10.18111/9789284419876 


\title{
Диагностика Финансирования Системы Здравоохранения в Кыргызской Республике и ее Модернизация Diagnostics of Financing the System of Public Health in the Kyrgyzstan Republic and its Modernization
}

\author{
Prof. Dr. Damira Japarova (Kyrgyzstan-Turkey Manas University, Kyrgyzstan)
}

\begin{abstract}
Despite the multi-channel resources, the financial sources of state health programs do not cover the needs of their implementation in the Kyrgyz Republic. The residual principle of health financing keeps unchanged and the amount of financing does not match the real health needs. The variety of problems in financing, the ambiguity of their positive practical solutions and controversy of theoretical aspects makes the research topic particularly relevant. No funds are allocated for prevention, and this type of medical service remains formally, just on paper. The main drawback of compulsory health insurance is the lack of forms for the insured patient to participate in the economic system of insurance relations. In this connection, it is relevant to develop a mechanism for attracting additional sources of financing. To increase the interest of commercial structure to this structure, it is proposed to introduce personalized accounting of compulsory medical insurance.

Informal payments in medicine shouldn't be considered as a "bribe", since this type of payment for medical services acts as an addition to the market price in the absence of an adequate regulatory mechanism by the state, and it is impossible to cancel such a mechanism. The only way to formalize them is legalization. Revenues from paid services should be the source of the own fund of health organizations and used primarily to increase the salaries of medical workers.
\end{abstract}

\section{1 Введение}

Обеспечение качественными и доступными медицинскими услугами является задачей любого государства. В Кыргызской Республике финансовые источники государственных программ не покрывают потребности их реализации, что является главной проблемой модернизации системы здравоохранения. Система Единого плательщика в КР имеет несколько источников финансирования: государственный бюджет, обязательное медицинское страхование (далее - OMC), сооплата и платные услуги. Несмотря на многоканальность источников ресурсов, объем финансирования не соответствуют реальным потребностям здравоохранения.

В Кыргызской Республике (далее - КР) сохраняется остаточный принцип финансирования здравоохранения. Поиск потенциальных источников ресурсов для здравоохранения и определение путей эффективного их распределения и использования требуют совершенствования финансирования государственных организаций здравоохранения. В связи с этим является актуальной разработка механизма привлечения дополнительных источников финансирования и результативного их использования.

\section{2 Финансовые Источники Единого Плательщика}

Здравоохранение КР финансируется из следующих основных источников: республиканский бюджет, средства Фонда ОМС и местного бюджета города Бишкек, а также сооплаты пациентов. ФОМС объединяет все основные источники финансов здравоохранения и распределяет финансовые ресурсы между организациями здравоохранения по территориям КР [Табл.1.].

Анализ источников средств Единого плательщика показывает, что за 10 лет произошел значительный рост финансовых ресурсов. В Кыргызской Республике (далее - КР) сохраняется остаточный принцип финансирования здравоохранения.

Госрасходы на здравоохранение составляют лишь 10\% расходов бюджета и около 3\% ВВП. Основную долю из общих расходов организаций здравоохранения составляют расходы на оплату труда - 63,2\%, расходы на приобретение лекарственных средств - 11,0\%, приобретение продуктов питания - 3,7\%. В 2019 году расходы стационаров на обеспечение медикаментами 1 больного в день составили в среднем - 168,90 сомов, на питание в стационаре - 75,89 сом. [Отчет ФОМС за 2019 г.] 


\begin{tabular}{|l|r|r|r|r|r|r|r|r|}
\hline $\begin{array}{l}\text { Основные } \\
\text { источники }\end{array}$ & 2009 & 2011 & 2013 & 2015 & 2016 & 2018 & 2019 & $\begin{array}{r}2019 \text { г. в } \\
\% \text { к 2009 }\end{array}$ \\
\hline $\begin{array}{l}\text { Республиканский } \\
\text { бюджет }\end{array}$ & 4008,3 & 6056,7 & 8481 & 8551,9 & 9081,8 & 10466,7 & 11129,2 & 277,7 \\
\hline ФОМС & 765,4 & 1062,2 & 1390 & 1855,7 & 1916,0 & 2328,4 & 2388,3 & 304,2 \\
\hline Частные & 333,8 & 434,5 & 660,3 & 924,1 & 1328,5 & 1784,3 & 2213 & 662,9 \\
\hline Всего & 5107,5 & 7553,4 & 10532 & 115590,9 & 12326,5 & 4579,4 & 15720,5 & 307,8 \\
\hline
\end{tabular}

таблица 1 Динамика Изменения Общих Расходов Здравоохранения Кыргызской Республики (млн сом.). Источник: Рассчитана по Данным МЗ КР за 2009-2019годы.

Заработная плата работников стационаров составила в среднем для врачей 12918 сомов, заработная плата работников организаций первичной медико-санитарной помощи составила в среднем для врачей 14777 сом. При этом средняя заработная плата семейного врача составила 25188 сомов, из которых 14153 сом доплачиваются по показателям деятельности, что составляет 128,3\% от заработной платы семейного врача, установленного государством по общей тарифной сетке. Отсюда следует, что несмотря на многоканальность источников ресурсов, объем финансирования не соответствуют реальным потребностям здравоохранения.

\section{3 Финансовое Обеспечение Здравоохранения в Рамках Обязательного Медицинского Страхования}

Система государственного финансирования здравоохранения, наряду с бюджетом, имеет и такой источник финансового обеспечения, как Фонд обязательного медицинского страхования - ФОМС. Он представляет систему Единого плательщика. Для формирования данного фонда работодатели отчисляют определенный процент из фонда заработной платы своих работников. Полученные таким образом средства идут на оплату гарантированного пакета медицинских услуг, предоставляемых государственной системой здравоохранения. И бюджетное финансирование, и система ОМС противопоставлены частной форме финансирования. Если частная форма предусматривает оплату предоставляемых медицинских услуг в зависимости от их объема, где важным фактором становится платежеспособность пациента, то система ОМС исключает данный фактор. Здесь здоровые люди вносят определенные суммы в общий страховой фонд, который управляется специальным страховым институтом или страховой компанией, затем получают возможность лечиться за счет собранных средств.ФОМС при Правительстве Кыргызской Республики собирает, накапливает и распределяет поступающие бюджетные средства и страховые отчисления, представляя систему Единого плательщика. Предоставляется возможность финансирования регионов в равных долях [Отчеты ФОМС КР, 2010]. Для того чтобы определить, нужна страховая система или нет, обратимся к причинам ее возникновения. Как было отмечено в первой главе, непредсказуемость болезни ведет к затруднению планирования расходов семьи на здравоохранение. Человек вынужден учитывать риск заболевания и связанные с ним затраты. Чтобы избежать больших единовременных расходов в ситуации неопределенности, люди используют различные формы страхования.

Рассматриваемая нами система ОМС имеет распространение как в масштабе мира, так и СНГ, представляя собой способ социальной защиты граждан в сфере здравоохранения. Она привлекательна для стран, благодаря таким функциям, как: осуществление независимой экспертизы качества оказываемых услуг здравоохранения, накопление внебюджетных средств на медицинское обслуживание за счет взносов работодателя; гарантированная оплата предоставленных медицинских услуг из фонда средств, вносимых страховщиком.

Реализация системы ОМС в Кыргызской Республике задумывалась в виде модели страхования, но истинно таковой ее назвать нельзя. Поскольку она выполняет лишь функцию перераспределения собираемых налоговыми органами и органами Социального фонда налогов и страховых взносов. Средства ОМС с момента создания системы обязательного медицинского страхования поступают в Социальный фонд и затем направляются в ФОМС. Замечено, что в национальной системе ОМС нет экономических форм и механизмов, которые позволяют включить пациента, потребляющего медицинские услуги, в отношения по поводу страхования. Обязательный взнос на ОМС представляет некую разновидность обязательного государственного налога и государственной формы финансирования системы здравоохранения.

Изучение экономического содержания системы ОМС в Кыргызстане вскрывает, что в ней не присутствуют понятия страхового случая и риска. В осуществлении финансовых компенсаций задействован количественный фактор. Включаются такие показатели, как стоимостная характеристика отдельной услуги, амбулаторное посещение и койко-дни. Таким образом, мы еще раз убеждаемся, что застрахованный пациент не входит в отношения страхования. Из числа опрошенных пациентов стационарного лечения $63 \%$ ответили, что не знают о бесплатных медицинских услугах по программе государственных гарантий и обязательного медицинского страхования, более того, они входит в 
параллельные внесистемные отношения с медицинскими работниками, как неофициальная плата за лечение. 28,6\% пациентов, или почти каждый третий из опрошенных пациентов стационарного лечения отметил, что оплатил лечение неофициально. Из них 27,4\% неофициальную плату осуществляют практически всегда, а 43\% отметили, что иногда покупают лекарства за свой счет [Джапарова, проект КТУ «Манас» 2014]. И самое главное - мы не видим прямой мотивации, которая позволила бы потребителя медицинской услуги выделить в системе отношений с теми, кто предоставляет эти услуги, как главный приоритет во взаимоотношениях.

Рассмотрим удельный вес средств ОМС в Кыргызской Республике. Если проследить динамику доходов Единого плательщика, поступающих от ОМС, то удельный вес средств ОМС (Табл. 2. ) в общих расходах здравоохранения снизился на 1,1\% и в 2016 г. составил всего 13,9\% доходов Единого плательщика. Причина низкого удельного веса страховых поступлений состоит в следующем. Работодатель бюджетной сферы представлен в системе обязательного медицинского страхования в республике как главный плательщик. Он вносит значительную долю взносов в фонд ОМС, но при этом у него невысокие и фиксированные доходы, так как основные плательщики это работники бюджетной сферы, имеющие фиксированные доходы. Это значит, что реальные источники ОМС крайне ограничены.

Кроме того, В Кыргызстане существует норма страховых взносов, вступившая в силу в 1997 г. и с тех пор не пересматривавшаяся. Она составляет 2\%. Этот процент рассчитывается от фонда заработной платы работодателя. Работодатель ежемесячно от всех видов доходов делает отчисления в Фонд обязательного медицинского страхования в соответствии с этой нормой. В странах СНГ и дальнего зарубежья, как видно из Табл. 2. действующие тарифы значительно выше.

\begin{tabular}{|l|c|c|}
\hline \multirow{2}{*}{ Страна } & \multicolumn{2}{|c|}{$\begin{array}{c}\text { Отчисления в фонд обязательного медицинского страхования } \\
\text { (\%) }\end{array}$} \\
\cline { 2 - 3 } & от работодателя & от физического лица \\
\hline Кыргызстан & 2 & - \\
\hline Россия & 5,1 & - \\
\hline Грузия & 3.0 & 3,5 \\
\hline Молдова & 3,5 & 7,45 \\
\hline Германия & 7,45 & - \\
\hline
\end{tabular}

Таблица 2. - Действующие Тарифы ОМС в Странах СНГ, Дальнего Зарубежья и в Кыргызской Республике. Источник: Государственное Медицинское Страхование в Германии.

В сборнике социальных законов Германии есть данные, согласно которым на поддержание, восстановление и улучшение своего здоровья средний налогоплательщик тратит 14,3\% заработной платы, работодатель затрачивает немногим меньше половины указанной суммы. Эти данные могут варьировать от 12 до 15\%. Всё зависит от больничной кассы. И как свидетельствуют экономические исследования, сумма взносов будет только увеличиваться. За 10-12 лет она приблизится к 25\%. Объясняется это вполне объективными причинами, связанными с естественным старением людей и ростом затрат на медицинское обслуживание [Ананко, А. Государственное медицинское страхование в Германии. 2018г.].

Государственное медицинское страхование в Германии имеет свои особенности. Сумма взноса застрахованного лица зависит исключительно от его дохода, при этом не важно, каков размер взноса, внесенного в кассу, то есть, если лицо застраховано, то объем услуг ему будет предоставлен в том объеме, в каком это предусмотрено договором, эти же услуги будут предоставлены и членам его семьи, автоматически они также являются застрахованными. Но есть условие, чтобы доход не был выше установленной границы.

Положительным моментом является наличие равных возможностей в пользовании медицинскими услугами, так как не являются ограничителями ни возраст, ни физическое и психическое состояние, ни финансовые условия [Ананко, А. Государственное медицинское страхование в Германии 2018г.].

Есть еще одна особенность государственной системы страхования Германии. Основывается она на принципе самоуправления государственных больничных касс. То есть в управлении участвуют и сотрудники медучреждения, и врачи, и сами пациенты - все звенья одной цепочки. Поскольку больничные кассы представлены как органы самоуправления, то и в выборах может участвовать каждый застрахованный человек. Выборы организуются раз в несколько лет. Мы видим много положительных моментов, характеризующих принципы, на которых основывается система медицинского страхования Германии. Привлекает она и широким спектром предоставляемых на правах гарантии услуг здравоохранения. В отличие от германской системы, американская, швейцарская, голландская в большей степени ориентирована на платежеспособность пользователей медицинских услуг. 


\begin{tabular}{|c|c|c|c|c|c|c|c|c|}
\hline \multirow[b]{2}{*}{$\begin{array}{l}\text { Категории } \\
\text { граждан }\end{array}$} & \multicolumn{2}{|c|}{2012} & \multicolumn{2}{|c|}{2013} & \multicolumn{2}{|c|}{2015} & \multicolumn{2}{|c|}{2019} \\
\hline & 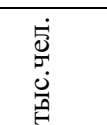 & $\%$ & $\begin{array}{l}\dot{5} \\
\stackrel{0}{\sigma} \\
0 \\
0 \\
\end{array}$ & $\%$ & 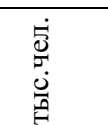 & $\%$ & $\begin{array}{l}\dot{5} \\
\stackrel{5}{5} \\
0 \\
0 \\
0\end{array}$ & $\%$ \\
\hline Работающие & 1146,3 & 27,7 & 806,6 & 20,1 & 782,2 & 19,2 & 946,8 & 15,4 \\
\hline Пенсионеры & 521,1 & 12,6 & 533,0 & 13,1 & 522,7 & 13 & 557,1 & 9,1 \\
\hline Дети до 16 лет & 1779,6 & 43,0 & 1768,8 & 44,0 & 1872,1 & 45,6 & 2102,7 & 34,3 \\
\hline $\begin{array}{l}\text { Дети от } 16 \text { до } 18 \\
\text { лет (школь-ники) }\end{array}$ & 216,3 & 5,2 & 208,8 & 5,2 & 201,7 & 4,9 & 199,2 & 3,2 \\
\hline Фермеры & 389,4 & 9,4 & 606,3 & 15,1 & 583,5 & 14,2 & 766,6 & 12,5 \\
\hline $\begin{array}{l}\text { Лица, } \\
\text { получающие соц. } \\
\text { пособия }\end{array}$ & 77,5 & 1,9 & 83,4 & 2,1 & 87,2 & 2,1 & 67,3 & 1,1 \\
\hline $\begin{array}{l}\text { Лица, само- } \\
\text { стоятельно } \\
\text { приобретшие } \\
\text { полис ОМС }\end{array}$ & 4,9 & 0,2 & 8,7 & 0,2 & 38,5 & 0,9 & 8,5 & 0,1 \\
\hline $\begin{array}{l}\text { Беженцы, за } \\
\text { которых } \\
\text { поступают } \\
\text { средства из УВКБ } \\
\text { ООН }\end{array}$ & 0,2 & 0,0003 & 0,1 & 0,003 & 0,2 & 0,01 & 0,2 & 0,01 \\
\hline Военнослужащие & 2,6 & 0,06 & 2,5 & 0,06 & 2,5 & 0,06 & 4,3 & 0,1 \\
\hline Всего & & & 4018,2 & 100 & 4105,2 & 100 & 6138,9 & 100 \\
\hline
\end{tabular}

Таблица 3. - Динамика и Структура Застрахованных Граждан по Республике за 2012-2015 г2. Источник: Данные ФОМС за 2009-2019 г2.

Обратимся к кыргызской системе страхования. Хотя основная часть населения Кыргызстана (98\%) застрахована, на вопрос «Получаете ли бесплатно медикаменты за счет дополнительного пакета обязательного медицинского страхования?» из 375 опрошенных пациентов 66,4\% ответили «нет» [Джапарова, проект КТУ «Манас» 2014]. Это значит, что Программа государственных гарантий застрахованных граждан Кыргызстана не достигает цели. Главная причина состоит в ограниченности финансовых ресурсов. Как видно из Табл. 3, структура застрахованных граждан претерпела существенные изменения: уменьшилась доля работающих граждан с 27,7 в 2009 г. до 15,4\% в 2019 г., от которых поступала значительная часть страховых отчислений работодателей. Это связано с тем, что работодатели не заинтересованы в том, чтобы вносить взносы по обязательному медицинскому страхованию, отмечается явное их желание сделать эти платежи как можно меньше, так как конкретному плательщику неизвестно, как используются его деньги. По данным Табл. 3 видно, что основную часть участников страхования составляют потребители средств ОМС. В структуре граждан, пользующихся средствами ОМС, наибольшую долю составляют дети в возрасте до 16 лет - 34,3 \%, пенсионеры - 9,1\% и фермеры - 12,5\%.

Часть населения, работающего в коммерческих структурах и имеющего более высокие доходы, системой страхования здоровья почти не охвачена.Незначительные финансовые средства удается собрать с фермеров и частных предпринимателей. Кроме того, основная часть населения Кыргызстана, то есть порядка 70\% населения, проживающего в сельской местности в связи с отсутствием основного места работы, не принимает участия в оплате средств обязательного медицинского страхования.

Однако в связи с низкой доходностью они подвержены риску заболевания больше, чем городское население.Есть большая недоработка, связанная с отсутствием страховки у такой категории граждан страны, как находящиеся на военной службе, не имеющие работы, к ним примыкают также учащиеся НПУЗ, студенты и другие [Калиев, М. Т. С. Мейманалиев. Обязательное медицинское страхование в КР. 2016.] В связи с этим необходимо учесть реальную ситуацию и предусмотреть источники лечения безработных граждан страны.

Обратим внимание еще на один фактор, характеризуемый как дополнительный источник поступления финансовых средств. Это иностранные граждане. Именно те иностранные граждане, которые длительно проживают на территории Кыргызской Республики, но не имеют медицинского страхования своего здоровья, являются потенциальным ресурсом для финансирования ОМС.В последние годы практикуется реализация полисов иностранным гражданам. Однако полисы не гарантируют качественные услуги, в связи с чем количество иностранных граждан, использующих их, крайне ограничено.

Итак, доходы по медицинскому страхованию в силу указанных причин незначительны и требуют изменения принципов страхования. Необходимо преобразование действующей бюджетно-страховой системы финансирования здравоохранения в систему финансирования, основанную на страховом принципе. Должна быть прозрачность счетов страхования. 
В ФОМСе нет накопительной системы, и, если тот или иной человек перестает работать, он автоматически выбывает из числа застрахованных. Накопительная система заинтересовала бы людей страховать здоровье.

Для того чтобы охватить коммерческую структуру, необходимо, чтобы представители этой сферы сами были заинтересованы в этом. Необходимо персонифицировать учет средств обязательного медицинского страхования. Есть потребность построить нормальную, гибкую, дифференцированную, с учетом сферы деятельности, возраста и других критериев, систему страхования с прозрачными и доступными для застрахованного человека счетами.

Сегодня, в связи со значительным ростом цен на товары и услуги, объем средств, направляемых на здравоохранение из средств государственного бюджета и обязательного медицинского страхования, не обеспечивает покрытие первоочередных расходов организаций здравоохранения на предоставление качественных медицинских услуг. Недостаток финансирования системы здравоохранения в Кыргызстане не позволяет в полной мере развивать передовые медицинские технологии. Значительная часть медицинского оборудования в организациях здравоохранения морально и физически устарела, административные здания организаций здравоохранения требуют капитального ремонта.

\section{4 Анализ Внебюджетных Форм Финансирования Здравоохранения}

Статистика свидетельствует, что львиная доля средств, которые государство предоставляет сфере здравоохранения, идет на помощь льготникам. Это большой показатель - 94\%, остальных средств явно не хватает для обеспечения лечения и профилактики заболеваний граждан, которые вынуждены сами (и граждане, и работодатель) финансировать оказываемые услуги. Таким образом, декларируется одно, а в реальности мы наблюдаем иные экономические условия. Для того, чтобы получить медицинскую помощь, необходимо нести все больше и больше расходов, поскольку они беспрерывно растут.

Базовая программа ОМС покрывает лишь 57\% минимальных потребностей социальных категорий населения, которые нуждаются в бесплатном лечении. И для решения проблем со здоровьем, чтобы выжить они должны самостоятельно оплачивать медицинские услуги. Как показывает практика, этот процесс стихийный и бессистемный. Нет продуманной и объективно обусловленной стратегической программы замены бесплатных услуг на платные. Поэтому встретить что-то подобное в официальных или законодательных материалах не приходится. Несмотря на это, она реально существует.

Связь видится в существовании старых прейскурантов. Датируемые еще 2008 г., некоторые расценки ниже себестоимости затрат на препаратные процедуры. Например, это касается рентгена и развернутого анализа крови. Так в городе Таласе рентген работает только для стационара и стоит 50 сом. Цены на анализы не покрывают затраты. Технология старая, томографии нет. Ультразвук стоит 25 сом, обследование желчного пузыря и печени - 38 сом, прокол гайморовой пазухи - 64 сом, вскрытие паратонзилярного абсцесса - 47 сом. А в частной клинике только общий анализ крови стоит 160-300 сом [Джапарова, проект КТУ «Манас» 2014].

Исследование методом анкетирования показало, что пациент, обративший в лечебное заведение по поводу хирургической операции, зачастую вносит, кроме сооплаты, дополнительные средства. Среди опрошенных по этому поводу высказалось 26,9\% пациентов. Этим можно объяснить, почему многие высказываются за легализацию дополнительно вносимых средств. Из обследованных за легальную оплату медицинской помощи высказалось 70,2\% . На вопрос пациентам поликлиники: «Считаете ли нужным платить медицинским работникам за качество лечения?»-36,4\% ответили «да». При этом 67,8\% пациентов поликлиник абсолютно не знают о перечне 24 бесплатных медицинских услуг по Программе государственных гарантий. И 41,2\% пациентов считают, что гарантировать качественное лечение можно только путем оплаты медицинских услуг. В настоящее время одни и те же медицинские работники и на одном и том же оборудовании оказывают и платные, и бесплатные услуги. В этих условиях не обойтись без нарушений и теневых доходов в системе здравоохранения.

Из числа опрошенных пациентов 58\% считают, что качественное лечение можно получить только путем оплаты лечения, и 28,6\% опрошенных пациентов оплачивают медицинские услуги в руки врачам. При этом удельный вес поступлений от частных выплат, как сооплата и официальная плата за медицинские услуги, поступающие в доходы Единого плательщика, составляет лишь 10,8,\%. Это значит, что реальная оплата за услуги имеет неофициальную форму [Джапарова, проект КТУ «Манас» 2014]. Высказывая свою позицию в этом вопросе, отметим, что не считаем взяткой платежи, которые попадают в руки врача по неформальным каналам. В системе финансирования здравоохранения не разработан регулирующий механизм. Мы не можем отменить неофициальные платежи, которые в этих условиях дополняют рыночную цену. И это никем не регулируется. Значит, правы те, кто требует легализовать эти дополнительные платежи. Тем самым они будут на виду, и их можно будет регулировать.

Специальные средства, или поступления от платных услуг, должны стать источником собственного фонда поликлиники или больницы, используемого в первую очередь для повышения доходов работников, 
предоставляющих медицинские услуги. А пока эти средства, как дополнительный взнос за оказанную медицинскую услугу (это может быть плата за медицинские препараты, презенты доктору и его помощникам, денежные средства за операционное вмешательство) поступают, минуя кассу.

Есть еще одна уловка врачебного персонала - это долевое участие в приобретении препаратов через определенную аптеку или совершении лабораторных исследований. Врач имеет договорные отношения с аптекой и лабораторией, благодаря которым, он получает свою долю от проданного лекарства и выполненного анализа. Нередки случаи, когда те или иные лабораторные исследования не были нужны. Вывод однозначен - наши пациенты несколько раз платят за услугу, при этом он не получает никакой гарантии в том, что проведенное лечение обеспечит ему выздоровление.

Несмотря на рост государственного финансирования в последние годы,

доля платных услуг в медицинской помощи увеличивается. Стихийный процесс замены расходов из госбюджета на медицинские услуги частными имеет место быть, как и низкое качество бесплатных услуг. При этом в убытке оказывается все больше тех, кто представляет уязвимые слои населения. Социальные последствия такого явления - рост неравенства в получении качественной медицинской помощи.

Платные медицинские услуги осуществляются в виде официальных и неофициальных выплат пациентов за оказанные услуги (например, стоматологические и др.). Специальные средства - это поступления от платных услуг медицинского и немедицинского содержания. К последним относятся средства, поступающие в виде платы за аренду того объекта, который медицинское учреждение имеет на своем балансе. Некоторые пациенты нуждаются в палате, которая отличается уровнем комфортности. В подобных палатах он значительно выше, и пациент оплачивает его.

Специальные средства пополняют бюджет медицинской организации напрямую, минуя участие государства. Назовем те формы личных расходов, которые существуют в системе здравоохранения Кыргызской Республики и имеют медицинскую направленность. Это: приобретение лекарств напрямую, оказание платных услуг по полной стоимости, неформальные платежи за оказание услуг. Благодаря платным услугам медицинское учреждение имеет возможность внедрять новые технологии лечения, смягчается дефицит бюджета, что важно в условиях перехода к рыночным отношениям. Но есть и минусы. Отсутствует управляющая функция. Отношения по поводу оплаты медицинских услуг складываются стихийно. Не обновляется прейскурант, не определяется объем оказываемых услуг. Кадры государственного здравоохранения и оборудование, принадлежащее государству, используются для оказания платных услуг. Эта тенденция выражена и влечет за собой использование государственных палат для лечения платных пациентов.

Последствия проявляются в неэффективном использовании ресурсов здравоохранения, сверхлимитных расходах коммунальных услуг. В этих условиях трудно говорить об оптимизации помощи, оказываемой в стационарах. Возникает противоречие. С повышением объемов услуг, оказываемых на платной основе на душу населения, растет продолжительность пребывания пациента в больнице, а с ней и коечный фонд. Что происходит: больничный ресурс распределяется на много случаев госпитализации, что влияет на стоимость одного случая - она становится ниже.

\begin{tabular}{|l|c|c|c|c|c|c|c|c|c|c|}
\hline Терри-тории & 2009 & 2010 & 2011 & 2012 & 2013 & 2014 & 2015 & 2016 & 2016 к 2009 в \% \\
\hline г. Бишкек & 32,1 & 33,8 & 42,0 & 63,8 & 95,8 & 287,6 & 244,0 & 254,4 & 7,9 \\
\hline \multicolumn{8}{|c|}{ Области } \\
\hline Чуйская & 10,1 & 13,1 & 16,2 & 19,6 & 26,0 & 33,7 & 49,0 & 66,7 & 6,6 \\
\hline Ошская & 15,3 & 28,3 & 39,0 & 51,5 & 56,5 & 62,4 & 101,4 & 119,0 & 7,8 \\
\hline Баткенская & 2,0 & 3,2 & 5,8 & 6,5 & 8,5 & 21,2 & 17,6 & 29,4 & 14,7 \\
\hline $\begin{array}{l}\text { Джалал- } \\
\text { Абадская }\end{array}$ & 5,6 & 7,7 & 9,2 & 10,9 & 16,6 & 30,8 & 50,0 & 87,0 & 15,5 \\
\hline $\begin{array}{l}\text { Иссык- } \\
\text { Кульская }\end{array}$ & 5,5 & 6,4 & 7,8 & 10,3 & 14,8 & 19,7 & 47,5 & 31,2 & 5,7 \\
\hline Нарынская & 1,3 & 1,6 & 2,3 & 3,4 & 4,0 & 7,6 & 15,9 & 19,2 & 14,8 \\
\hline Таласская & 0,6 & 0,9 & 1,0 & 2,0 & 3,2 & 3,8 & 6,7 & 23,5 & 39,2 \\
\hline Всего & 73,0 & 95,0 & 123,3 & 168,0 & 225,4 & 466,8 & 532,1 & 630,4 & 8,6 \\
\hline
\end{tabular}

Таблица 4. Поступление специальных средств в систему здравоохранения Кыргызской Республики в разрезе территорий за 2009-2016 г2. (млн. сом.) Источник: данные Министерства здравоохранения КР за 2009-2016 г2.

Одновременно ниже становится уровень, характеризующий качество предоставления медицинских услуг пациенту. Платные услуги обусловливают и появление лишних мощностей у лечебного учреждения, на которые расходуются средства, а это влечет за собой неэффективное их использование. По логике, появившиеся лишние мощности должны быть закрыты. И здесь неважно, какой у них источник финансирования.Специальные средства, поступающие в учреждения здравоохранения за оказанные дополнительные услуги гражданам за оплату, возросли в целом по республике за 8 лет в 8,6 раза (Табл. 4.). 
Однако их доля в бюджете здравоохранения не превышает 6\%. Это значит, что значительная часть платы за услуги приобретает форму «неформальных платежей».

Поступление по регионам неравномерное. Наиболее высокий рост наблюдается в Таласской (в 39,5 раза), Баткенской (14,7 раза) и Ошской (7,8 раза) областях (Табл. 2.12). В г. Бишкеке, Чуйской и Иссык-Кульской областях темпы роста поступлений спецсредств примерно одинаковые. Это можно объяснить тем, что ввиду отсутствия технологии лечения и диагностики в регионах, больные вынуждены ехать в столицу или в областные центры и производить оплату медицинских услуг. Рассмотрим направления расходования спецсредств по поставщикам медицинских услуг по статьям затрат. Средства, направляемые на финансирование первичной медико-санитарной помощи, выросли в 3,4 раза, а на стационары - в 8,2 раза. За 2008-2016 гг. рост финансирования за счет специальных средств основных статей расходов, как расходов на медикаменты, составляет всего $23 \%$ и питание - 7,4\%. Причем большая часть средств направлена на увеличение заработной платы медперсонала, оплату коммунальных услуг и прочие расходы. Таким образом, больные люди, которые нуждаются в государственной поддержке, доплачивают заработную плату врачей, при этом незначительная доля их средств используется для лечения и питания в стационарах. Как было отмечено выше, существующие тарифы устарели и не охватывают все виды медицинских услуг, которые реально оплачиваются неформально. В расходах статья «Другие расходы» занимает значительную долю, однако нам не удалось получить расшифровку содержания данной статьи расходов.

\section{5 Сооплата}

Важным источником дополнительного финансирования учреждений здравоохранения являются средства граждан, уплачиваемые ими в виде сооплаты за лечение в стационарах. Сооплата - участие граждан в оплате стоимости получаемых ими медицинских услуг, оказываемых организациями здравоохранения, работающими в системе Единого плательщика, на амбулаторном и стационарном уровне, сверх объема финансирования ПГГ. Средства, полученные организациями здравоохранения в порядке сооплаты населения, не подлежат налогообложению и изъятию в государственный бюджет.

Сооплата на стационарном уровне вносится за хирургические и терапевтические услуги, согласно размерам, установленным Программой государственных гарантий [О Программе государственных гарантий по обеспечению граждан медико-санитарной помощью. 2015г.]. Сооплата на амбулаторном уровне вносится за лабораторные и диагностические исследования (за исключением базовых лабораторных и диагностических исследований, предоставляемых по Программе государственных гарантий бесплатно), проводимые в центрах семейной медицины, центрах общеврачебной практики амбулаторно-диагностических отделениях стационаров широкого профиля, консультационнодиагностических отделениях стационаров третичного уровня.

Сооплата - это единовременная выплата. Она демонстрирует участие потребителя в оплате каждой полученной медицинской услуги и рассматривается как дополнительный источник финансирования для поставщиков медицинских услуг разных уровней. В большинстве стран сооплата вводится с той целью, чтобы ограничить чрезмерные потребности пациентов, получающих медицинскую помощь, которая оплачивается из страховых средств.

Известны три типа схемы такой оплаты в зависимости от договоренности финансовых сторон. Это может быть 1) удержание, 2) сострахование (устанавливается некоторая пропорция в стоимости медпомощи, принятой за единицу, и эту пропорцию за каждую единицу выплачивает застрахованный), 3) соучастие (услуги оплачиваются в зависимости от категории населения). Соплатежи довольно распространены в странах Запада, где общественное здравоохранение находится на высоком уровне, и каждая из них использует свой вариант. Имеется в виду сумма соплатежей. Она может быть или чисто символической, как, например, в Швеции, или довольно высокой, как, например, во Франции. В Российской Федерации, также как и в Кыргызской Республике имеет место так называемый «натуральный соплатеж». Это означает, что пациенты сами покупают лекарства, питание, в больничные палаты приносят свое постельное белье и посуду. Однако законодательно это не закреплено [Положение о сооплате за медицинские услуги 2007г.]. В некоторых странах, и их немало, наряду с работодателем, застрахованные вносят некоторую часть взносов. Таким образом, соплатежи входят в систему обязательного медицинского страхования.

Возьмем пример Швеции, в которой основную нагрузку по финансированию медицинских расходов берет на себя государство, тем не менее население также участвует в этом процессе, на его долю приходится 10\%. Если рассматривать более подробно расходы населения на поддержание своего здоровья, то они следующие: посещение врача - 100-300 шведских крон, нахождение в больнице в течение одного дня - около 80 шведских крон. Есть льготы для молодежи, не достигшей 20 лет. Они могут пользоваться услугами стоматолога бесплатно. Взрослое население получает компенсацию. Затратив первоначально 700 крон, дальнейшее лечение пациент получает со скидкой 35-70\%. Процент устанавливается в зависимости от того, какова его общая стоимость. Есть лимит на сумму покупки лекарств. Он достигает 100 долл. США в год. На эту сумму пациенты тратят собственные средства. Дальнейшие расходы (в зависимости от их 
величины) осуществляются по дотационной системе [Колосницкая М.Г. Шейман И.М. «Экономика здравоохранения» 2018.].

Такой тип оплаты, как удержание предполагает выплату некоторой суммы наличными деньгами до начала действия механизма страхования и предоставления медицинской помощи. Например, пациент уплачивает первые 50 долл. наличными в счет покрытия расходов на лечение в больнице или 200 долл. в счет покрытия расходов на амбулаторно-поликлинические услуги за год.

Второй тип оплаты - соучастие в оплате услуг - это единовременная выплата, она предусматривается за каждую услугу, которую получает пациент. Например, 5 долл. за выписанный рецепт.

Третий тип оплаты - сострахование - предусматривает оплату определенного процента от общей суммы самим пациентом. Например, пациент оплачивает $20 \%$ от стоимости лечения.

Сооплата рассматривается как дополнительный источник финансирования для поставщиков разных уровней. В схемы сооплаты входят медикаменты, оптика, в некоторых странах введены определенные ставки за посещения врача или пребывание в больнице.

Сооплата по категориям населения.

Уровень сооплаты зависит и от категорий населения. Это делается с целью защиты малоимущих, или тех, кто страдает тяжелыми хроническими заболеваниями. Размер сооплаты должен быть приближен к реальным затратам на каждого отдельного пациента, иначе он не будет знать, за что вносится сооплата.

В Кыргызской Респубике внесенные в соответствии с сооплатой средства поступают в систему Единого плательщика. В соответствии с этим они накапливаются в едином фонде. Далее, они распределяются в зависимости от того, как много пролеченных случаев отмечено в отчетах больничных учреждений. Данные берутся за прошедший год.

Отмечается незначительный удельный вес сооплаты и спецсредств [Табл.5].

Это объсняется тем, что согласно Программе госгарантий список, людей, попадающих в список льготников, расширился. Кроме того, произошли незначительные изменения в сооплате за лечение с 2002 г. Так, если в 2013 г. 1,3 млн. человек, или 24,8\% всего населения республики приобрели льготы на бесплатное получение медицинской помощи по ПГГ, то в 2016 г. - 1,075 человек, или 18,7\% населения страны. Из них 17,2\% граждане, имеющие льготы по социальному статусу. Размер сооплаты, вносимой пациентами при госпитализации, остался на прежнем уровне. Так, пенсионеры до 70 лет, лица, награжденные медалью.

\begin{tabular}{|l|r|r|r|r|r|r|}
\hline $\begin{array}{l}\text { Источники } \\
\text { финансирования }\end{array}$ & \multicolumn{1}{|c|}{2014} & \multicolumn{1}{c|}{2015} & \multicolumn{1}{c|}{2016 г. } & \multicolumn{1}{c|}{2018} & \multicolumn{1}{c|}{2019} & 2019 г. в \% к 2014 г. \\
\hline Республиканский бюджет & 7,092 & 7,915 & 9,082 & 10466,7 & 11129,2 & 1567 \\
\hline Средства ОМС & 1,843 & 1,641 & $1,916.0$ & 2328,4 & 2388,3 & 1327 \\
\hline Средства сооплаты & 434.9 & 393.2 & 480.6 & 550,3 & 551,7 & 127 \\
\hline Специальные средства & 466.8 & 560.6 & 847.9 & 744,5 & 543,6 & 117 \\
\hline Местный бюджет г.Бишкек & $1,075.1$ & 575.3 & & & & 1398 \\
\hline Итого & 10,911 & 11,086 & 12,326 & 14579 & 15234,6 & $\overline{1}$ \\
\hline
\end{tabular}

Таблица 5. - Динамика Источников Финансирования Консолидированного Бюджета Системь Единого Плательщика за 2014-2019 г2. (млн. сом.) Источник: Данные ФОМС за 2013-2016 г2

«Ветеран труда», лица, получающие социальное пособие вносят минимальный размер сооплаты. Это 330 сом. при госпитализации в терапевтическое отделение, 430 сом. при госпитализации для проведения хирургических вмешательств. Застрахованная категория (дети старше 5 лет, работающие, фермеры и члены фермерских хозяйств, лица, имеющие полис ОМС) вносят средний уровень сооплаты. Это 840 сом./1090 сом. (через дробь указаны терапия/хирургия) в городских, районных, областных больницах, в республиканских организациях и национальных центрах - 1160 сом./1510 сом. Остальные граждане вносят максимальный уровень сооплаты. Это 2650 сом./3440 сом. в городских и районных стационарах, 2980 сом./3870 сом. в республиканских организациях и национальных центрах [150]. Есть разные мнения по поводу сооплаты, точнее ее размера. Одно мнение, и оно преобладает, сводится к тому, что размер остается неизменным с 2002 г. А это часть стоимости медуслуг, в то же время стоимость других услуг и продуктов за этот период возросла. Следовательно, стоимость этой части медуслуг также должна возрасти. У сооплаты есть существенный недостаток, связанный с тем, что пациенту приходится несколько раз нести расходы не за разные, а одну и ту же услугу. При этом ему никто не гарантирует, что он полностью выздоровит.

Многие руководители медицины считают, что сооплату с пациентов брать не нужно, так как больные сами за свой счет покупают лекарства, и в этой связи много претензий и возмущений. Кроме того, сам принцип установления объема сооплаты является необоснованным. В Кыргызстане в 2003 г. ПРООН провел опрос среди жителей Иссык-Кульской области о расходах семьи на медицину в течение года. И эти 
затраты - в среднем 1200 сом. - были заложены в основу сооплаты, что не имеет ничего общего с затратами на конкретного пациента, тем более на конкретный вид болезни.

«Объем сооплаты определяется исходя из потребности здравоохранения в финансовых ресурсах» - так формулируется в «Положении о порядке сооплаты населением медикаментов» [Положение о сооплате за медицинские услуги. 2015]. Отсюда трудно установить критерии размера сооплаты для отдельного пациента и тем более учесть реальные затраты на его лечение. Сооплата в 2016 г. составляла лишь 4\% доходов Единого плательщика. Изъян действующей методики заключается в том, что пациент на самом деле не имеет государственной поддержки. В реальности одни пациенты покрывают расходы других пациентов. В этом случае справедливее больному самому оплачивать часть расходов на медицинскую помощь. На наш взгляд, следует убрать фиксированные соплатежи на медицинские услуги и практиковать дифференцированную сооплату, которая будет касаться лекарственных препаратов, стоимость которых пациент будет оплачивать не полностью, а частично. Эта практика широко распространена в Турции и на нее стоит обратить внимание. Опыт других стран также свидетельствует о тенденции, связанной с повышенной ответственностью потребителя в финансировании своего лечения. То есть имеется в виду форма сооплаты.

> Необходимо пересмотреть объем финансирования из республиканского бюджета для лечения граждан, достигших пенсионного возраста, детей, не достигших 16 лет, граждан, живущих на социальные пособия.

$>$ Чтобы было соответствие государственных гарантий их реальному финансированию, необходимо конкретизировать виды бесплатной медицинской помощи в рамках госгарантий и платных медицинских услуг.

$>$ Для того чтобы охватить коммерческую структуру, необходимо, чтобы представители этой сферы сами были в этом заинтересованы. Необходимо персонифицировать учет средств обязательного медицинского страхования.

$>$ Необходимо создать систему страхования иностранных граждан как потенциальный источник финансирования медицины.

$>$ Есть потребность определить источники лечения безработных граждан страны. Необходимо построить гибкую, дифференцированную с учетом сферы деятельности, возраста и других критериев систему страхования с прозрачными и доступными для застрахованного человека счетами.

$>$ Не следует считать взяткой платежи, которые попадают в руки врача по неформальным каналам. В системе финансирования здравоохранения не разработан регулирующий механизм. Мы не можем отменить неофициальные платежи, которые в этих условиях дополняют рыночную цену. И это никем не регулируется. Значит, правы те, кто требует легализовать эти дополнительные платежи. Тем самым они будут на виду, и их можно будет регулировать.

$>$ Специальные средства, или поступления от платных услуг должны стать источником собственного фонда поликлиники или больницы, используемого в первую очередь для повышения заработной платы медицинских работников.

$>$ Размер сооплаты должен быть дифференцированным и приближен к реальным затратам на каждого отдельного пациента, иначе он не будет знать, за что вносится сооплата.

$>$ Следует убрать фиксированные соплатежи на медицинские услуги и практиковать дифференцированную сооплату, которая будет касаться лекарственных препаратов, стоимость которых пациент будет оплачивать не полностью, а частично. Эта практика широко распространена в Турции.

\section{Литература}

- Ананко, А. 2018. Государственное медицинское страхование в Германии. Исторические корни и принцип- Medicus Amicus, http://medicusamicus.com/index.php? action=7x994-9egx1.

- $\quad$ В Кыргызстане предлагают повысить отчисления на обязательное медстрахование за счет доходов работника с 2 до 3\% 2014. - Бишкек, http://www.akipress.org/zdorovie/news:17203/.

- Данные Министерства здравоохранения КР за 2009-2016 гг

- Данные ФОМС КР за 2009-2019гг.

- Джапарова, Д. 2018.Система оплаты труда в государственном секторе здравоохранения. Джапарова, Т. Ю. Джолдошова // Сибирская Академия финансового дела. -. - №3. - С. 19-23.

- Джапарова, Д. 2016.Экономика здравоохранения Кыргызстана в период трансформации. Германия: LAP LAMBERT Academic published,

- Джапарова, Д. Экономический анализ системы здравоохранения в КР [Текст]: проект КТУ «Манас» № 2013.SOB.08 / Д. Джапарова.- Бишкек, 2014. 
- Калиев, М. Т. С. Мейманалиев. Обязательное медицинское страхование в Кыргызской Республике (20 лет опыта). 2016/ Бишкек,.

- Колосницкая М.Г. Шейман И.М. Шишкин С.В. 2018. «Экономика здравоохранения».

- $\quad$ О Программе государственных гарантий по обеспечению граждан медико-санитарной помощью. Постановление Правительства Кыргызской Республики от 20.11. 2015. http://cbd.minjust.gov.kg/act/view/ru-ru/98210. - Загл. с экрана.

- Отчет ФОМС за 2009- 2019 гг.

- Положение о сооплате за медицинские услуги, предоставляемые организациями здравоохранения, работающими в системе Единого плательщика. Постановление Правительства КР от 24 августа 2007 года № 363. http://cbd.minjust.gov.kg/act/view/ru-ru/58604?cl=ru-ru.

- $\quad$ Положениео порядке сооплаты населением медикаментов, питания и отдельных видов медицинских услуг, оказываемых государственными лечебными учреждениями. 2018. https://online.zakon.kz/document/?doc_id=30260447\#pos=1;-70 


\title{
Проблемы Эффективной Трансформации и Перспективы Развития Аграрного Сектора Кыргызстана в ЕАЭС Problems of Effective Transformation and Prospects for the Development of the Agricultural Sector of Kyrgyzstan in the EAEU
}

\author{
Prof. Dr. Dzhumabek Dzhailov (Ministry of Agriculture, Kyrgyzstan)
}

\begin{abstract}
The article discusses the main directions and effectiveness of the transformation of the agricultural sector of Kyrgyzstan in the EAEU. The problems and possible risks of the development of the agricultural sector in the conditions of Eurasian integration are identified. It was revealed that the ongoing reforms within the EAEU do not fully contribute to increasing the competitiveness of the agricultural sector of Kyrgyzstan. It is justified that the predominant development of small-scale production, the underdeveloped processing, agricultural services and logistics negatively affect the development of the industry and increase its export potential. A comparative assessment of the forms and volumes of state support for the agricultural sector in the EAEU countries is presented.
\end{abstract}

\section{1 Введение}

Кыргызская Республика среди государств участников ЕАЭС отличается выраженной аграрной направленностью национальной экономики. Формирование единого агропродовольственного рынка на евразийском экономическом пространстве положительно сказалось на успешной трансформации аграрного сектора. Сельскохозяйственный сектор адекватно реагирует на потребности и конъюнктуру продовольственного рынка ЕАЭС. За период функционирования в рамках ЕАЭС растет экспорт отечественной сельскохозяйственной продукции и продовольствия. Создаются крупные региональные логистические центры по формированию соответствующих объёмов и стандартов агроэкспортной продукции. Возрождаются сельскохозяйственные отрасли, которые решают вопросы импортозамещения продовольствия, а также интенсивно развиваются отрасли экспортной направленности.

Указанные положительные сдвиги в трансформации аграрного сектора Кыргызстана также стали возможными благодаря поддержки со стороны Евразийской Комиссии и основных партнеров по ЕАЭС. В частности, со стороны Российской Федерации, оказывается существенная финансовая помощь по эффективной трансформации отдельных отраслей национальной экономики в евразийское экономическое пространство. По линии Кыргызско-российского инвестиционного фонда Российская Федерация выделила 500,0 млн.долл.США для льготного кредитования отраслей реального сектора экономики Кыргызстана. Существенная часть кредитов направляется на строительство или модернизацию предприятий агроперерабатывающей промышленности (пищевой и легкой промышленности), а также развитие промышленного садоводства и плодоводства в республике. На грантовые средства Российской Федерации во всех регионах Кыргызстана созданы современные фито-санитарные и ветеринарные лаборатории, а также модернизирована ветеринарная служба республики, что является фактором динамичного развития ведущей отрасли- животноводства.

Вместе следует указать, что дальнейшее развитие сельского хозяйства и ее эффективная трансформация в евразийское экономическое пространство сдерживается рядом нерешенных хронических проблем. Усугубляется мелкокрестьянская и мелкотоварная структура аграрного производства с сопутствующей ей технико-технологической отсталостью, не развивается вертикальная и горизонтальная сельскохозяйственная кооперация, что негативно отражается на устойчивом и конкурентоспособном развитии отрасли. Мелкотоварный характер аграрного производства, универсальная специализация хозяйствующих субъектов в результате деконцентрации производства ограничивает возможности эффективной системы государственного регулирования и поддержки приоритетных отраслей сельскохозяйственного производства. В этой связи актуальными становятся выявление проблем и обоснование мер по эффективной трансформации и росту конкурентоспособности аграрного сектора в контексте усугубления евразийской интеграции.

\section{2 Анализ и Результаты}

Сельское хозяйство является одним из приоритетных и жизненно важных отраслей экономики Кыргызстана. Несмотря на то, что в последние годы удельный вес отрасли в ВВП республики сокращается с 14,1 \% в 2015г. до 11.7 \% в 2018г., отрасль практически во всех регионах страны остается по прежнему 
ведущей отраслью региональных экономики $(30,0-40,0 \%$ РВП) и в ней занята четвертая часть трудоспособного населения страны (см.табл.1).

\begin{tabular}{|l|l|l|l|l|}
\hline & 2015 & 2016 & 2017 & 2018 \\
\hline Доля с/х-ва в ВВП, в \% & 14,1 & 13,2 & 12.9 & 11,7 \\
\hline Вал.прод.с-ва, млн.сом, в том числе : & 196936 & 197413 & 207378 & 198706 \\
-растениеводства & 97532 & 97803 & 108219 & 100366 \\
-животноводства & 94710 & 94817 & 94203 & 98340 \\
\hline Кол-во субъектов с/х-ва, ед & 401350 & 415433 & 428730 & 440316 \\
\hline Численность занятых. тыс.чел. & 689,3 & 633,3 & 541,4 & 482,7 \\
\hline Индексы физ. обьема прод.с/х-ва, в \% к & & & & \\
предыд.году & 106,2 & 103,1 & 102,2 & 102,7 \\
\hline Пр-во прод. с/х-ва, тыс.сом: & & & & \\
- на 100 га с/угодий; & 1853,6 & 1856,8 & 1956,9 & 1987.0 \\
-на одного работника & 273,0 & 311,4 & 382,0 & 410,8 \\
\hline Кред. ресурсы-всег, млр.сом: & 20407,0 & 29076,0 & 26290,0 & - \\
в т. ч., льгот. кред. & 9980,0 & 13245,0 & 14564,0 & - \\
доля льгот. кредитов ,\% & 48,9 & 45,5 & 55,3 & - \\
\hline
\end{tabular}

Таблица 1. Основные показатели развития сельского хозяйства Кыргызской Республики за 2013 -2018г2. Источник: Данные Нацстаткомитета КР

Вступлением Кыргызстана в ЕАЭС были связаны ожидания существенных изменений в устойчивом и конкурентоспособном развитии отрасли. Надо отметить, что подобные ожидания оправдались лишь частично. В целом развитие отрасли характеризируется неустойчивостью, что выражается в низких темпах роста объёмов производства валовой продукции сельского хозяйства, а также неэффективным использованием земельных ресурсов.

Тем не менее, вследствие положительной реакции развития отрасли на конъюнктуру евразийского продовольственного рынка в производстве сельскохозяйственной продукции произошло сушественное переформатирование внутриотраслевой ее структуры (см.табл.2). За последние четыре года практически на одном уровне стабилизируется производство зерновых (1700,0 тыс.тонн), картофеля (1400,0 тыс.тонн), овощи (1000.0 тыс.тонн). Стабилизация производства зерновых объективно обусловлена необходимостью преодоления перекоса в структуре посевных площадей сельскохозяйственных культур, связанных монопольным положением зернового клина, сложившегося в последние годы.

\begin{tabular}{|l|l|l|l|l|}
\hline & 2015 & 2016 & 2017 & 2018 \\
\hline Зерно & 1723,1 & 1728,1 & 1681,8 & 1741,5 \\
\hline Хлопок -сырец & 44,1 & 52,1 & 65,3 & 74,7 \\
\hline Табак & 1,3 & 0,5 & 1,5 & 1.8 \\
\hline Сахарная свекла & 183.2 & 705,2 & 712,3 & 773,0 \\
\hline Картофель & 1416,4 & 1388,0 & 1416,0 & 1446,6 \\
\hline Овощи & 1052,1 & 1069,3 & 1086,7 & 1094,9 \\
\hline Плоды и ягоды & 209,2 & 239,3 & 240,6 & 250,1 \\
\hline Виноград & 5,7 & 8,6 & 8,6 & 8,8 \\
\hline Мясо ( в уб. весе) & 208,3 & 212,4 & 216,5 & 221,1 \\
\hline Молоко сырое & 1481,1 & 1524,6 & 1556,2 & 1589,7 \\
\hline Яйца, млн.шт & 432,9 & 469,7 & 510,7 & 533,2 \\
\hline Сахар-песок & 24,1 & 66,8 & 101,2 & 122,5 \\
\hline Растительное масло & 13,8 & 11,5 & 11,2 & 11.6 \\
\hline Мясо, субпродукты, & 13,7 & 15,6 & 17,1 & 18,6 \\
\hline Переработанное молоко & 37,3 & 37,2 & 39,7 & 41,2 \\
\hline
\end{tabular}

Таблица 2. Производство важнейших видов сельскохозяйственной продукции и продовольствия в Кыргызской Республике за 2015-2018г2., тыс. тонн Источник: Данные Нацстаткомитета КР.

В то же время совершенно необоснованна ситуация с производством картофеля и овощей, которые до этого развивались наиболее динамично и являлись одним из существенных статей экспорта продукции. В первую очередь такое положение в основном обусловлено снижением их экспорта в страны ЕАЭС- Россию и, особенно, в Казахстан ввиду присутствия элементов недобросовестной конкуренции со стороны наших основных торговых партнеров по ЕАЭС. Также следует отметить, что Казахстан в последние годы добился существенного увеличения производства картофеля и овощей.

В этой связи, чтобы и дальше развивать производство, в частности картофеля, следует уже искать альтернативные каналы ее сбыта, в третьи страны. В производстве овощей необходимо менять структуру 
производства, переходит на более трудоемкие и доходные культуры, в частности, чеснок, болгарский перец.

В качестве положительного тренда изменения внутриотраслевой структуры сельскохозяйственного производства, также следует отметить резкое оживление производства технических культур- сахарной свеклы, хлопка-сырца и табака. Впервые в условиях суверенитета Кыргызстан добился самообеспечения сахаром за счет резкого увеличения производства сахарной свеклы и ее переработки. Производство сахарной свеклы составила в 2018 году 773. 0 тыс .тонн, что в 4, 2 раза выше, чем было в 2015 г. За этот период в республике производство сахара -песка увеличилась с 22,4 до 122,5 тыс.тонн., т.е..5.0 раза. Впервые в условиях суверенитета Кыргызстан осуществил экспорт сахара в соседний Казахстан в объёме более 19,0 тыс. тонн. Нельзя также не отметить то обстоятельство, что рост производства сахарной свеклы в 2018 году в основном обеспечен на основе роста ее урожайности, по уровню которого мы догнали Белоруссию (474 ц/га).

И в перспективе в Кыргызстане имеются реальные условия для дальнейшего наращивания производства и переработки сахарной свеклы, учитывая существующий спрос как со стороны ближайших партнеров по ЕАЭС, так и стороны соседних стран ЦА (Узбекистан, Таджикистан). Успехи в развитии свеклосахарного производства также стали результатом совершенствования кооперационно-интеграционных отношений в отрасли, а также системы управления отраслью, когда предприятия пищевой промышленности перешли в подчинение непосредственно в Министерство сельского хозяйства. пищевой промышленности и мелиорации КР. Успехи в развитии отрасли и изменения в системе управления свеклосахарным производством в республике создают реальные предпосылки для создания в Чуйской области крупнейшего в Центральной Азии свеклосахарного кластера.

Особенно важное значение для развития сельского хозяйства Юга Республики имеет рост производства хлопка -сырца и табака, как наиболее доходных культур. Рост производства хлопка сырца с 44,1 до 74,7 тыс.тонн (или в 1, 7 раза) привел к значительному росту экспорта хлопкового волокна на 233,0\% ( с 16,1 до 37,6 тыс.тонн). В перспективе следует добиться глубокой переработки хлопка-сырца на основе развития предприятий текстильной и легкой промышленности и формирования на этой основе крупного регионального текстильного кластера на юге страны.

В этой связи, надо также решить вопрос ведомственной подчиненности предприятий легкой промышленности, которые в своей производственной деятельности в основном используют импортные хлопчатобумажные ткани КНР, Турции. Переподчинение этой отрасли МСХ предоставит возможности развития отечественной сырьевой базы легкой и текстильной промышленности за счет осуществления глубокой переработки хлопка-сырца. В этой связи назрела необходимость строительства на юге страны текстильного комбината. В противном случае, увеличение импорта текстильных изделии из хлопчатобумажной ткани из соседнего Узбекистана негативно скажется в первую очередь на развитие хлопководства. А это чревата дальнейшим обострением социальных проблем в трудоизбыточных регионах юга страны, ростом сельской безработицы и миграции.

Кыргызстан имеет в рамках ЕАЭС возможности наращивания производства плодов, ягод и винограда. За период 2015 -2018гг. производство плодов и ягод в республики увеличилось в 1,2 раза и винограда - в 1,5 раза. Кыргызстан в перспективе, с учетом больших потребностей евразийского рынка, имеет существенный потенциал для дальнейшего роста производства объёмов производства плодов, ягод и винограда, практически в каждом регионе. Особенно благоприятны условия для развития интенсивного садоводства и виноградарства в южных областях страны. В связи с тем, что возрождение и интенсивное развитие указанных отраслей связано с высокой капиталоемкостью производства, государство должно ее всячески поддерживать и стимулировать. В качестве направлений существенной поддержки развития садоводства, плодоводства и виноградарства, следует активно использовать возможности по субсидированию затрат фермеров, связанных с приобретение высокоурожайных сортов указанных культур из Турции, стран Европы. Также немаловажное значение имеет возрождение перерабатывающей промышленности по производству соков, вин. Все это способствует превращению Кыргызстана в крупного производителя и поставщика на евразийский рынок продукции садоводства и виноградарства в свежем и переработанном виде.

Вступление Кыргызстана в ЕАЭС в целом положительно отразилось на развитии животноводства, особенно, производства мясной продукции, объёмы которой достигли в 2018 г. 221,0 тыс. тонн., что на 6,3 \% больше чем в 2015 г. Объёмы переработки мяса выросли до 18,6 тыс. тонн, хотя удельный вес переработки мяса остается низким (8,4\%). Естественно это сказывается на снижении экспорта мясной продукции с21,1 до 20, 4 тыс.тонн. В то же время, на внутреннем рынке мясной продукции объём импортного мяса, несмотря на ее снижение, превышает 34,1 тыс.тонн. Справедливости ради следует отметить, что подавляющая часть этого мяса поставляют партнеры по ЕАЭС.

Кыргызстан в ЕАЭС обладает существенным потенциалом для развития животноводства, особенно, мясного направления. Для дальнейшего развития данной отрасли, необходимо в первоочередном порядке 
решить следующие задачи: для начала построить в регионах республики современные мясокомбинаты, которые на основе долгосрочных контрактов с фермерскими хозяйствами, будут способствовать значительному росту ее сырьевой базы- поголовью и продуктивности скота и овец; развивать межфермерскую кооперацию по откорму скота и овец и с этой целью целесообразно в районах создавать откормочные комплексы на средства Кыргызско-российского инвестиционного фонда; с целью стимулирования передачи молодняка КРС фермерами на откорм следует предусмотреть субсидирование затрат фермеров для приобретения элитных высокопродуктивных пород скота; передать в пользование откормочным комплексам государственные земли Фонда перераспределения сельскохозяйственных угодий для организации кормовой базы; привлекать для строительства и организации деятельности откормочных комплексов также инвесторов из стран ЕАЭС. Развитие животноводства в ближайшей перспективе в указанных направлениях приведут к организации в каждом регионе страны мясных кластеров.

Сбалансированно развивается в республике молочный рынок, полностью обеспечивающей потребности населения страны в молочных продуктах, а также экспорт молочной продукции на евразийском рынке. Эффективному развитию молочной отрасли и рынка молочной продукции способствует развитая ее сырьевая база и перерабатывающая промышленность, которое практически функционирует на кластерных принципах. Вследствие этого молочное скотоводство в республике является одним из важнейших экспортоориентированных отраслей АПК. Более 13,0\% произведенного в республике сырого молока перерабатывается, 5,0\% экспортируется. Оптимизация взаимной торговли молочной продукцией в рамках ЕАЭС, также способствует росту импорта молочной продукции в республику, удельный вес которого в потреблении молочной продукции не превышает 3,0\%.

Несмотря на то, что в последние годы в республике начинает возрождаться птицеводство, это отрасль не обеспечивает потребности республики в мясе птице. Почти весь объем импортируемого в республику мяса является мясом птицы из Российской Федерации, Казахстана, Украины. Тем не менее, развитие птицеводства способствовало росту производства яиц, что привело к увеличению ее потребления и сокращению ее импорта в общем потреблении до $1,5 \%$.

Несмотря на отмеченные выше тенденции развития сельского хозяйства, она по-прежнему развивается на экстенсивной основе, остается низкой урожайность основных видов сельскохозяйственных культур, продуктивность скота. Рост производства продукции в основном, за исключением сахарной свеклы, осуществляется за счет расширения посевных площадей или роста поголовья скота, овец и птицы. Необходимо в корне менять подходы к организации и совершенствованию селекционно-племенной и семеноводческой работы, создавать современные инновационные станции и центры.

Последствием экстенсивного характера развития отрасли является низкая производительность сельскохозяйственного труда. Ее уровень в 4,0-3,5 раза ниже, чем в Республике Беларусь и РФ. Низкая производительность труда отражается на высокой себестоимости произведенной продукции. Практически по основным видам сельскохозяйственной продукции она выше, чем в остальных странах ЕАЭС, что также отражается на низком уровне конкурентоспособности сельскохозяйственной продукции.

Неустойчивое развитие отрасли, нерешенные проблемы по эффективной трансформации отрасли в евразийское экономическое пространство также оказывают свое неоднозначное влияние на развитие экспорта и экспортного потенциала отрасли и импортозамещения продовольствия (см.табл.3).

\begin{tabular}{|l|l|l|l|l|}
\hline Наименование продукции & \multicolumn{2}{|c|}{ Экспорт } & \multicolumn{2}{c|}{ Импорт. } \\
\hline & $2015 г$. & $2018 г$. & $2015 г$. & $2018 \Gamma$. \\
\hline Мясо и мясопродукты & - & - & 47,3 & 33,4 \\
\hline Молоко и молочные продукты & 48,6 & 18,7 & 10,1 & 5,4 \\
\hline Овощи & 310,4 & 62,2 & 26,3 & 35,6 \\
\hline Фрукты & 36,4 & 29,0 & 79,7 & 104,0 \\
\hline Хлопковое волокно & 16,1 & 37,6 & - & - \\
\hline Зерновые и пшеница & - & - & 401,3 & 209,6 \\
\hline Зернобобовые(фасоль) & 69.6 & 75,1 & - & 46,2 \\
\hline Сахар & - & 19,3 & 70,9 & 41,6 \\
\hline Растительное масло & - & - & 58,7 & \\
\hline
\end{tabular}

Таблица 3. Динамика экспорта и импорта продовольствия в Кыргызскую Республику, тыс.тонн.

$$
\text { Источник: Данные Наџбанка КР }
$$

Существенным сдвигом в развитии экспортного потенциала отрасли является рост экспорта сахара-песка и хлопкового волокна. Кыргызстан, в результате указанных выше реализации трансформационных сдвигов, сумел значительно уменьшить импортозависимость по потреблению сахара-песка и достичь увеличения ее экспорта. Также значительно увеличены объёмы экспорта хлопкового-волокна и фасоли. Сокращается импорт зерновых (пшеницы) и растительного масла, хотя остается по потреблению этих 
продуктов достаточно высокая импортозависимость. Несмотря на сокращение импорта мяса (в основном мяса птицы), доля импортного мяса, также достаточна высока на внутреннем рынке.

Ряд обстоятельств, связанных со сложностями трансформационного периода, преимущественного развития мелкого производства, неразвитости сфер переработки, сельскохозяйственных услуг и логистики негативно сказались на существенном снижении объёмов экспорта продукции традиционно экпортоориентированных отраслей аграрного сектора- прежде всего молока и молочной продукции, а также овощей. При положительном решении вопросов, связанных с продвижением данных видов продукции в Казахстан, Российскую Федерацию, объёмы их экспорта должны не только восстановится, но и значительно увеличиться.

Наряду с указанными выше факторами это и приводит к падению объёмов экспорта сельскохозяйственной продукции. Если в 2015 году доля сельскохозяйственной продукции в общем экспорте отечественной продукции составляла 8,1\%, то в 2018 г.- 7,2 \%. Справедливости ради следует отметить, что также снизилась доля импортного продовольствия в общем импорте продукции- с 3,1 до 2,5 \%. Это свидетельствует, с одной стороны, об усилении ориентации развития сельского хозяйства на удовлетворение внутреннего потребительского спроса на продовольствие, а с другой- о снижение конкурентоспособности отрасли на внешних рынках, в том числе, и на рынках ЕАЭС.

В условиях функционирования национальной экономики в рамках ЕАЭС, организация эффективного финансово-кредитного обслуживания и в целом функционирования кредитной системы, играют исключительно важную роль в эффективной трансформации аграрного сектора в евразийский агропродовольственный рынок. Опыт отдельных стран ЕАЭС, добившихся высоких результатов в развитии конкурентоспособного сельского хозяйства, свидетельствует о важности развития разветвленной и эффективной рыночной системы кредитной и государственной поддержки отрасли. В этой связи, от эффективности функционирования рыночной кредитной системы зависят формирование в стране не только высокоэффективного и конкурентоспособного на евразийском рынке сельского хозяйства, развитие ее агроэкспортного потенциала, но и темпы экономического развития страны в целом.

Доля кредитных ресурсов, выделяемых для кредитования сельскохозяйственного производства, в общем объеме кредитных ресурсов страны растет, и составляет $26,0 \%$, т.е. почти каждая четвертая часть кредитных ресурсов направляется на поддержку сельского хозяйства. Несмотря на некоторое снижение относительного показателя, общий объем кредитных ресурсов для сельского хозяйства в абсолютном выражении вырос с 2015 по 2017гг., в 1,3 раза. В 2015 году доля банковских кредитов, выданных сельскому хозяйству в общем объеме выданных кредитов 18,5\%, в 2016г. - 25,7\%, и 2017 году доля сельских кредитов от общего объема банковских кредитов составила 18,1\%. Также растет доля выданных льготных кредитов сельскому хозяйству (Табл.1).

В развитых странах нормативы потребности кредитными ресурсами составляют 70,0\%. В рамках ЕАЭС сельское хозяйство Кыргызстана является отраслью с самой низкой государственной поддержкой [1]. Самый высокий уровень государственной поддержки отрасли отмечается в Республике Беларусь, где удельный вес всех выделяемых на поддержку отрасли государственных средств (субсидий, дотаций, субвенций) в ВВП сельского хозяйства составляет $18,8 \%$, а в расчете на 1 га пашни - 250 долл. США. Эти показатели составляют в Российской Федерации - соответственно 8,0\% и 60 долл. США, Республике Казахстан - 4,1\% и 18 долл. США, а в Кыргызстане - 0,3\% и 7 долл. США.

Практика динамичного развития в Кыргызстане свеклосахарного производства свидетельствует о эффективности кредитной поддержки отрасли. Так на льготные кредиты Кыргызско-Российского инвестиционного фонда полностью обновлены производственные мощности сахарного завода ОАО «Кошой», что дало возможность мощности по переработке свекла-сырца в республике совместно с действующим сахарным комбинатом ОАО «Каинды-Кант» до 950 тыс. тонн. Для обеспечения потребности в сырье, сахарные заводы активно используют кредитование свеклосеющих крестьянских хозяйств под сдачу урожая. В частности, свеклоперерабатывающие предприятия взяли на себя обязательства по обеспечению хозяйств элитными семенами и оказании помощи на условиях лизинга в проведении уборки и транспортировке сахарной свеклы.

Цель интеграции в аграрном секторе стран ЕАЭС является не только развитие внутреннего продовольственного рынка, но и создание условий для превращения стран ЕАЭС в крупного экспортера агропродовольственной продукции на глобальных рынках. Это стимулирует необходимость перехода от политики согласования развития отрасли к проведению единой сельскохозяйственной политики, где также необходимо предусмотреть меры по унификации для всех стран ЕАЭС мер по государственные поддержки отрасли.

Функционирование АПК, в рамках ЕАЭС, в контексте выработки и проведения единой агропромышленной политики предъявляет особые требованию к формам и методам государственной поддержки отрасли и в, частности, ее кредитной поддержки. Постепенно с расширением и углублением 
формата евразийской интеграции, работа в данном направлении будет унифицирована применительно к особенностям развития сельского хозяйства каждого государства, члена ЕАЭС.

В условиях глубокой интеграции аграрной экономики в евразийское экономическое пространство направлениями кредитной политики и поддержки отраслей национального АПК являются: пересмотр стратегических направлений кредитования аграрного сектора, переход от узкоотраслевого производственного подхода к программному (кластерному), включающий весь технологический цикл производства конечной продукции АПК; снижение процентных ставок кредитования до приемлемого уровня на основе развития конкуренции в сфере банковского и небанковского кредитования АПК и проведения протекционистской работы в отношении АПК денежно-кредитной политики НБ КР; концентрация кредитных ресурсов и их целенаправленное использование для кредитной поддержки программ и проектов, имеющих стратегическое значение для развития отрасли.

Развивающаяся на евразийском агропродовольственном рынке конкуренция, усиливает требования к поставкам качественной стандартизированной и объемной агропродукции. В этой связи, в республике необходимо предпринять дополнительные меры по развитию крупно товарного сельскохозяйственного производства на основе стимулирования и поддержки, в том числе и кредитной, развития сельскохозяйственной кооперации. Развитие горизонтальной и, особенно, вертикальной кооперации в АПК, будет способствовать как развитию крупно товарного производства, так и налаживанию тесных взаимовыгодных экономических связей в системе АПК. Развитие процессов консолидации аграрного сектора благоприятствуют развитию интеграции АПК на национальном уровне и в рамках ЕАЭС.

В условиях мелкокрестьянской структуры производства подобный опыт кредитной поддержки следует шире распространять и в других отраслях, в производстве овощей и картофеля, фруктов и др., функции по кредитной поддержке хозяйств могут выполнять создаваемые логистические центры. Несмотря на существенный рост объема банковского кредитования сельского хозяйства, в настоящее время, удельный вес кредитных ресурсов в отношении общего объема валовой продукции сельского хозяйства (рассчитываемый как отношение объема банковских кредитов к валовой продукции сельского хозяйства КР) составляет только 10,0\%.

Проблемой эффективной трансформации сельского хозяйства в рамках единого агропродовольственного рынка по-прежнему остается усугубляющаяся мелкокрестьянская и низкотоварная структура аграрного производства. Численность крестьянских хозяйств в республике достигла 440,0 тыс . ед., что больше чем во всех других странах ЕАЭС. Более 98,4 \% продукции отрасли производится крестьянскими хозяйствами и ЛПХ. Сокращается численность организованных форм хозяйствующих субъектов ( СПК, ККХ, АО), доля которых в производстве продукции мизерная - 1,6 \%.

Эта самая гипертрофированная структура хозяйствования в сельском хозяйстве из всех стран ЕАЭС. Она же является обьективной причиной, ограничивающей возможности эффективного государственного регулирования и государственной поддержки агросектора. В этой связи по-прежнему актуальной остается стимулирование развития крупных сельскохозяйственных предприятий на основе кооперирования фермерских хозяйств, что и обозначено в Национальной стратегии развития Кыргызской Республики на 2018-2040 годы [2, с.57].

В целом, указанные тенденции развития сельского хозяйства напрямую влияют на обеспечение продовольственной безопасности в стране. В рамках ЕАЭС Кыргызстан, как и другие страны ЕАЭС (за исключением Армении), преодолел пороговые значения продовольственной безопасности. Кыргызстан за исключением потребности в пшенице, фруктам, растительном масле, по основным продуктам питания достиг самообесечения [3]. Но надо при этом учесть, что по уровню фактического потребления основных видов продовольствия (за исключением картофеля и овощей), мы значительно отстаем от всех партнеров по ЕАЭС. Поэтому исключительно важно добиться наряду с обеспечением физической доступностью продовольствия, ее экономической доступности, что связано с низкими доходами населения, которые в свою очередь, обусловлены тенденциями в развитии национальной экономики в целом, и в частности, сельского хозяйства.

\section{3 Выводы}

-с целью эффективной трансформации аграрного сектора в ЕАЭС, обеспечения роста агроэкспортного потенциала отрасли и повышения конкурентных преимуществ отрасли необходимо проводить целенаправленную работу по совершенствованию специализации сельскохозяйственного производства и формирование этой основе региональных агрокластеров;

- с расширением и углублением формата евразийской интеграции необходима в рамках перехода к единой сельскохозяйственной политики разработка мер по унификации для всех стран ЕАЭС мер по государственные поддержки отрасли; 
-в целях обеспечения динамичного развития аграрного сектора Кыргызстана в ЕАЭС необходимо предпринять дополнительные меры по развитию крупно товарного сельскохозяйственного производства на основе стимулирования и поддержки развития сельскохозяйственной кооперации;

-стимулировать развитие сферы переработки сельскохозяйственной продукции и агрологистики, что будет также способствовать эффективной трансформации агропродовольственного сектора страны в ЕАЭС;

-не допускать в соответствии с регламентами Евразийской экономической комиссии периодически повторяющихся проявления недобросовестной конкуренции, введение эмбарго на поставки отечественной сельскохозяйственной продукции со стороны отдельных партнеров по ЕАЭС.

\section{Литература}

- Джаилов Д.С, Мардалиева Л.А, Кожомкулова В.К. Развитие и конкурентоспособность аграрного сектора Кыргызской Республики в условиях экономической интеграции // Вестн. Кырг. нац. аграр. ун-та им. К.И. Скрябина. - 2017. - № 4 (45). - С. 24-33.

- Национальная стратегии развития Кыргызской Республики на 2018-2040 годы. Б, 2018.-150 c./www.president.kg

- Агропромышленный комплекс. Статистика Евразийского экономического союза: статистический сборник; Евразийская экономическая комиссия. - Москва: 2018. - 159 с.

- Национальные счета Кыргызской Республики.-Б.:Нацстатком Кыргызской Республики, 2018.-210с /http://www.stat.kg/ru/

- Кыргыстан в цифрах: статсборник.-Б.; Нацстаткомитет Кыргызкой Республики , 2017.-355c. /http://www.stat.kg/ru/

- Сельское хозяйство Кыргызской Респубики:2013-2107.-Б.; Нацстаткомитет Кыргызкой Республики , 2018.-90c. /http://www.stat.kg/ru/

- Платежный баланс Кыргызской Республики. Б.: Национальный банк ЕР, 2018.-155c. https://www.nbkr.kg/DOC/21062019/000000000052537.pdf 


\title{
Евразия Экономикалык Биримдигине Мүчө Өлкөлөрдө Тышкы Карыздын Туруктуулугу
}

\section{External Debt Sustainability in the Eurasian Economic Union Countries}

\author{
Asst. Prof. Dr. Junus Ganiev (Kyrgyz-Turkish Manas University, Kyrgyzstan) \\ Asst. Prof. Dr. Damira Baigonushova (Kyrgyz-Turkish Manas University, Kyrgyzstan)
}

\begin{abstract}
After the global financial crisis, there have been serious increases in state debt of most countries. In addition, the debts for economic development are constantly increasing in the Eurasian Economic Union countries. As a result, the sustainability problem of government debt arises. In some countries, such as Kyrgyzstan, a significant portion of government debt is taken from a single country. This situation increases the risk even more. The aim of the study is to analyze the sustainability of state debts comparatively in the countries of the Eurasian Economic Union. To this end, the current state of government and total external debt were analyzed in light of various sustainability rates. The ratio of government debt and debt service to variables such as Gross Domestic Product and export was determined and compared. ADF and PP unit root tests and quarterly data for the period 2008-2019 was used to determine the stability of external debt. According to the empirical results, it is showed that the external debt is unsustainable in EAEU countries. Therefore, they need to implement rational policies on external debt management, in both the public and private sectors.
\end{abstract}

\section{1 Киришуу}

Глобалдык финансылык кризистен соң көпчүлүк өлкөлөрдүн мамлекеттик карызы бир топко жогорулады. Евразия экономикалык биримдигине мүчө өлкөлөрдө ошол эле учурда экономикалык өнүгүҮ максатында алынган карыздар да тынымсыз өсүүдө. Мындан улам мамлекеттик карыздын туруктуулугу (sustainability), башкача айтканда, аны эч көйгөйсүз тейлөө маселеси келип чыгууда. ЭВФнун аныктамасы боюнча, карыздын туруктуулугу деп карызкор (карыз алган тарап) өзүнүн карыздарын, келечекте киреше жана чыгашалар балансын абдан чоң өзгөртүүгө мажбур болбостон, тейлей алат деп күтүлгөн учур аталат (IMF, 2002: 4). Башка бир аныктама боюнча, бир өлкөнүн тышкы карызы, эгер анын келечектеги күтүлгөн кирешелеринин учурдагы наркы анын тышкы карызынын азыркы наркына барабар болсо «туруктуу» деп айтылат (Mohammadi et al., 2007: 2442). Демек, тышкы карыздын туруктуулугу алынган карыздардын туура багытта колдонулуп, экономикалык өнүгүүгө алып келген жана натыйжада өлкө андан алган кирешелери менен карызды жана анын пайыздарын эч көйгөйсүз төлөй алган учурду түшүндүрөт. Карыз туура эмес колдонулса, аны тейлөөдө маселелер жаралат. Кыргызстан сыяктуу кээ бир өлкөлөрдө мамлекеттик карыздардын маанилүү бөлүгү бир өлкөдөн алынууда. Бул тобокелчиликти ансайын өстүрүүдө.

Бирок тышкы карыздын көптөгөн пайдалары бар. Сырттан алынган карыз башында өлкөнүн ресурстарына кошумча булак болот. Бул капитал запасын өстүрүп, инвестицияларды жана натыйжада экономикалык өсүү ылдамдыгын жогорулатат. Инвестициялардын өсүшү өндүрүш чыгымдарын төмөндөтүп, өндүрүмдүүлүктү өстүрөт, бул калктын бакубаттык деңгээлин көтөрүп, өнүгүүгө шарт түзөт. Ошондой эле, мамлекеттер тышкы карызга жаңы жумуш орундарын түзүү, төлөмдөр теңдемин сактоо, баа туруктуулугун камсыз кылуу, кирешенин кайрадан бөлүнүшүн жөнгө салуу, аймактарды бирдей өнүктүрүү сыяктуу максаттарда кайрылышы мүмкүн (Evgin, 2000: 2). Албетте, мында карыздарды туура багытта пайдалануу маселеси биринчи кезекте турат. Антпесе карыздын тейлөөгө байланыштуу тобокелчиликтер пайда болбошу үчүн мамлекеттер тышкы карызды чектөөгө мажбур болушу мүмкүн. Бир көз-караш боюнча (Bal, 1998: 35-37), бир өлкөдө тышкы карыздын чыгымы пайдасынан жогору болуп, тышкы карызды төлөө кыйынчылыгы туулганда тышкы карызга чектөө коюлушу зарыл. Же болбосо, мамлекет тарабынан алына турган ар бир тышкы карыздын чыгымы жана пайдасы абдан кылдат эсептелиши шарт. ЕАЭБ өлкөлөрүндө да бул тема актуалдуу маселелердин бири жана көптөгөн эмгектер тарабынан анализ кылынган. Атап айтканда, Логин (2009), Буценко (2020), Семенов (2000), Моисеев (2000), Смирнов (2001), Караталов (2007), Асанова\&Шатманов (2007), Мансурходжаев (2010) ж.б. авторлор ЕАЭБге мүчө өлкөлөрдө тышкы карыздын абалы жана натыйжалары тууралуу анализ жасашкан. Бирок беш мүчө өлкөнү бири-бирине салыштырмалуу анализ жасаган эмгектер көп кездешпейт.

Ошондуктан бул эмгектин максаты ЕАЭБ өлкөлөрүндө мамлекеттик карыздын туруктуулугун салыштырмалуу анализдөө болуп эсептелет. Бул максатта алгач мамлекеттик карыздардын учурдагы абалы бир канча туруктуулук көрсөткүчтөрүнүн негизинде бааланат. Тагыраак айтканда, мамлекеттик карыздын жана карызды тейлөөнүн ички дүң продукт, экспорт, эл аралык резервдер сыяктуу чоңдуктарга болгон 
катышы аныкталып салыштырылат. Андан соң бирдик тамыр тести сыяктуу эконометрикалык ыкмалар колдонулат. Аягында жыйынтык чыгарылып, сунуштар берилет.

\section{2 Мамлекеттик Тышкы Карыз Көрсөткүчтөру}

Өлкөлөр тышкы карызды оптималдуу пайдаланып, тышкы карыз экономикага оор жүк алып келбеши үчүн, белгилүү кыска жана узун мөөнөт критерийлерин карап анализ жүргүзүшү зарыл. Тышкы карызды тейлөө кубаттуулугун өлчөөдө кыска мөөнөттө төмөнкүдөй критерийлер каралат (Орuş, 2002: 188-189):

- Тышкы карыздын көлөмү/ИДП;

- Тышкы карыздын көлөмү/экспорт;

- Тышкы карызды тейлөө/ИДП;

- Тышкы карызды тейлөө/экспорт;

- Эл аралык резервдер/Тышкы карыздын көлөмү.

Ошондуктан алгач ЕАЭБ мүчөлөрүнүн мамлекеттик тышкы карыздарынын жана карызды тейлөө көлөмдөрүнүн ички дүң продукт, экспорт, эл аралык резервдер сыяктуу чоңдуктарга болгон катыштарын карайлы. Бул көрсөткүчтөр кыска мөөнөттө өлкөнүн карызды тейлөө кубаттуулугун чагылдырат деп эсептелет.

\begin{tabular}{|c|c|c|c|c|c|c|c|}
\hline \multicolumn{2}{|l|}{ Көрсөткүчтөр } & 2014 & 2015 & 2016 & 2017 & 2018 & 2019 \\
\hline \multirow{5}{*}{$\begin{array}{l}\text { Жалпы тышкы } \\
\text { карыз/ИдП }\end{array}$} & Армения & 73.56 & 84.51 & 94.38 & 91.30 & 87.78 & 89.46 \\
\hline & Беларусь & 50.96 & 69.16 & 79.02 & 72.83 & 65.53 & 64.50 \\
\hline & Казахстан & 70.96 & 82.98 & 118.96 & 100.25 & 88.53 & 86.98 \\
\hline & Кыргызстан & 99.00 & 115.33 & 116.24 & 105.52 & 98.40 & 98.56 \\
\hline & Россия & 28.82 & 37.85 & 39.99 & 32.91 & 27.20 & 28.87 \\
\hline \multirow{5}{*}{$\begin{array}{l}\text { Жалпы тышкы } \\
\text { карыз/экспорт }\end{array}$} & Армения & 257.37 & 284.37 & 284.31 & 244.10 & 232.19 & 231.30 \\
\hline & Беларусь & 92.27 & 116.45 & 125.12 & 108.85 & 92.95 & 97.18 \\
\hline & Казахстан & 182.53 & 299.99 & 392.85 & 310.78 & 236.46 & 239.04 \\
\hline & Кыргызстан & 218.57 & 311.56 & 323.43 & 308.16 & 311.64 & - \\
\hline & Россия & 106.64 & 131.92 & 153.98 & 126.17 & 89.59 & 101.94 \\
\hline \multirow{5}{*}{$\begin{array}{l}\text { Мамлекеттик } \\
\text { карызды } \\
\text { тейлөө/ИДП }\end{array}$} & Армения & 3.40 & 6.05 & 5.16 & 5.53 & 5.44 & 8.31 \\
\hline & Беларусь & 0.74 & 0.84 & 0.90 & 0.78 & 0.70 & 0.58 \\
\hline & Казахстан & 1.58 & 1.59 & 1.98 & 1.63 & 1.77 & 2.04 \\
\hline & Кыргызстан & $\ldots$ & $\ldots$ & $\ldots$ & 3.89 & 4.17 & 1.56 \\
\hline & Россия & 3.42 & 4.86 & 3.39 & 5.27 & 3.53 & 2.94 \\
\hline \multirow{5}{*}{$\begin{array}{l}\text { Мамлекеттик } \\
\text { карызды } \\
\text { тейлөө/экспорт }\end{array}$} & Армения & 11.90 & 20.36 & 15.54 & 14.77 & 14.38 & 21.48 \\
\hline & Беларусь & 1.34 & 1.42 & 1.42 & 1.16 & 0.99 & 0.87 \\
\hline & Казахстан & 4.07 & 5.75 & 6.56 & 5.07 & 4.72 & 5.60 \\
\hline & Кыргызстан & $\ldots$ & $\ldots$ & $\ldots$ & 11.36 & 13.21 & $\ldots$ \\
\hline & Россия & 12.66 & 16.95 & 13.06 & 20.21 & 11.64 & 10.37 \\
\hline \multirow{5}{*}{$\begin{array}{l}\text { Эл } \quad \text { аралык } \\
\text { резервдер/Жалпы } \\
\text { тышкы карыз }\end{array}$} & Армения & 17.44 & 19.91 & 22.15 & 21.99 & 20.70 & 23.28 \\
\hline & Беларусь & 12.64 & 10.91 & 13.13 & 18.36 & 18.22 & 23.05 \\
\hline & Казахстан & 18.59 & 18.22 & 18.19 & 18.54 & 19.48 & 18.47 \\
\hline & Кыргызстан & 25.08 & 21.84 & 23.78 & 25.68 & 25.42 & 28.07 \\
\hline & Россия & 64.25 & 71.05 & 73.81 & 83.51 & 102.97 & 112.95 \\
\hline
\end{tabular}

Таблица 1. ЕАЭБ Өлкөлөрүндө Тышкы Карыз Көрсөткүчтөру (Кыска Мөөнөт) Булак: Евразия Экономикалык Комиссиясынын Расмий Маалыматтарынын Негизинде Авторлор Тарабынан Эсептелди.

Тышкы карыздын көлөмүнүн ички дүң продуктка катышы көп колдонулган бир критерий. Тышкы карыз көлөмүнүн ИДПдан ылдамыраак өсүшү бул катышты жогорулатат. Дүйнөлүк Банктын жана Эл аралык валюта фондунун критерийлери боюнча, тышкы карыздын ИДПга катышы 50\%дан ашса, өлкө сырттан карыз алуунун чегине жетти деп эсептелет (Evgin, 2000: 10). Мамлекеттик тышкы карыз жагынан караганыбызда, анализ кылынган периоддо бир гана Кыргызстан 2015-2017-жылдары бул чектен ашкан. Армениянын абалы да бул чекке жакын болсо, калган үч өлкөдө дээрлик бул критерий боюнча эч кандай маселе жок экени байкалган. Ал эми жеке сектор да кошо, бүт өлкөнүн жалпы тышкы карызы каралганда, Россиядан башка бардык өлкөлөрдө бул катыштын аталган критерийден ашып кеткени, ал тургай, Армения, Кыргызстан жана Казахстанда 100 пайыздын тегерегинде болгону көрүнүп турат.

Тышкы карыздын экспортко катышы товар-кызмат экспортунан келген кирешелер менен алынган карыздын канчалык бөлүгүнүн төлөнө алаарын көрсөтөт. Бул катыштын жогорулашы өлкөнүн тышкы карыздан көз-каранды абалга келгенин чагылдырат. Дүйнөлүк Банк менен ЭВФнун критерийлери боюнча, мунун 275\%дан ашышы өлкөнүн тышкы карыздын чегине келгенин түшүндүрөт (World Bank, 1990: 24). 
Мамлекеттик тышкы карыздын экспортко катышын караганыбызда, эч бир өлкөдө бул катыштын белгиленген критерийден ашпагандыгы аныкталган. Жалпы тышкы карыздын экспортко катышы каралганда, Россия менен Беларусь өлкөсүнүн экспорт көлөмүнүн жетиштүү деңгээлде болуп жатканын жана бул критерий жагынан эч кандай кыйынчылык жок экенин көрүүгө болот. Калган үч өлкөдө бул катыштын эл аралык уюмдар тарабынан белгиленген чектен ашып кеткени байкалууда.

Тышкы карызды тейлөөнүн ИДПга катышы өлкөнүн жергиликтүү булактарынан алган кирешеси менен тышкы карыздын негизги бөлүгүн жана пайыздарын төлөө жөндөмдүүлүгүн чагылдырат. Бул критерий боюнча, тышкы карыз жүгүн чектөө үчүн бул катыш ИДПнын өсүү ылдамдыгынан төмөн болушу шарт (Glasberg and Ward, 1993). Жалпы тышкы карызды тейлөө боюнча статистикалык маалыматтар табылбагандыктан, бул жана кийинки критерийде анын ордуна мамлекеттик карызды тейлөө статистикалары колдонулган. 3,5-4,0\%ды бир чек катары алганыбызда, Армения, Кыргызстан жана Россияда кээ бир периоддордо бул катыштын мындан ашып кеткени көрүнүп турат.

Тышкы карызды тейлөөнүн экспортко катышы бир өлкөдө товар-кызмат экспортунан келген кирешелердин канчалык бөлүгүнүн тышкы карызды тейлөө төлөмдөрүнө коротулганын көрсөтөт. Дүйнөлүк Банк менен ЭВФнун критерийлери боюнча, бул катыш 30\%дан ашса, өлкө сырттан карыз алууга чектөө коюшу зарыл (Evgin, 2000: 10). Анализ кылынган периоддо ЕАЭБ өлкөлөрүнүн эч биринде мамлекеттик карызды тейлөөнүн экспортко катышы бул критерийден ашкан эмес.

Эл аралык төлөмдөрдө кабыл алынган бардык активдер эл аралык резерв деп аталат. Жыл өткөн сайын эл аралык резевдердин тышкы карызга катышы төмөндөп баратса, анда сырттан карыз алууну чектөө зарыл. Бул катыштын төмөн болушу карызды тейлөөдө жана валюта рыногунун туруктуулугун камсыз кылууда маселелерди пайда кылышы ыктымал. ЕАЭБ өлкөлөрүнүн дээрлик баарында акыркы жылдары бул чоңдуктун жай болсо да өсүп жатканын байкоого болот. Армения, Беларусь, Казахстан жана Кыргызстанда бул катыш орточо 20-30\%ды түзүүдө. Мында Россиянын эл аралык резервдерди арттырууга өзгөчө көңүл буруп жатканын жана бул катыштын алты жылда эки эсеге жакын өскөнүн белгилөөгө болот. Учурда Россиянын эл аралык резервдери, жеке сектор да кошо, өлкөнүн бардык тышкы карызынын көлөмүнөн дээрлик $13 \%$ га жогору.

\begin{tabular}{|c|c|c|c|c|c|c|c|}
\hline \multicolumn{2}{|l|}{ Көрсөткүчтөр } & 2014 & 2015 & 2016 & 2017 & 2018 & 2019 \\
\hline \multirow{5}{*}{$\begin{array}{l}\text { Ички инвести- } \\
\text { циялар/ИДП }\end{array}$} & Армения & 20.00 & 20.70 & 17.50 & 17.60 & 16.83 & $\ldots$ \\
\hline & Беларусь & 33.00 & 29.60 & 26.40 & 26.60 & 26.52 & $\ldots$ \\
\hline & Казахстан & 21.80 & 23.50 & 23.30 & 22.27 & 21.74 & $\ldots$ \\
\hline & Кыргызстан & 32.50 & 31.80 & 31.79 & 31.50 & 31.48 & $\ldots$ \\
\hline & Россия & 21.29 & 20.48 & 21.88 & 21.98 & 20.57 & $\ldots$ \\
\hline \multirow{5}{*}{ Экспорт/ИДП } & Армения & 28.58 & 29.72 & 33.20 & 37.40 & 37.81 & 38.68 \\
\hline & Беларусь & 55.23 & 59.39 & 63.15 & 66.91 & 70.50 & 66.37 \\
\hline & Казахстан & 38.87 & 27.66 & 30.28 & 32.26 & 37.44 & 36.39 \\
\hline & Кыргызстан & 45.30 & 37.02 & 35.94 & 34.24 & 31.58 & \\
\hline & Россия & 27.03 & 28.69 & 25.97 & 26.09 & 30.36 & 28.32 \\
\hline \multirow{5}{*}{ Импорт/ИДП } & Армения & 47.26 & 41.87 & 42.83 & 49.65 & 53.46 & 53.13 \\
\hline & Беларусь & 55.80 & 59.15 & 63.17 & 66.72 & 68.95 & 66.84 \\
\hline & Казахстан & 25.43 & 23.92 & 26.28 & 24.37 & 25.78 & 27.81 \\
\hline & Кыргызстан & 87.31 & 73.38 & 70.28 & 66.38 & 67.27 & $\ldots$ \\
\hline & Россия & 20.61 & 20.57 & 20.79 & 20.78 & 20.53 & 20.78 \\
\hline
\end{tabular}

Таблица 2. ЕАЭБ Өлкөлөрүндө Мамлекеттик Тышкы Карыз Көрсөткүчтөрү (Узун Мөөнөт) Булак:

Евразия Экономикалык Комиссиясынын Расмий Маалыматтарынын Негизинде Авторлор Тарабынан Эсептелди.

Ал эми узун мөөнөттө өлкөнүн тышкы карыз жүгүн жана чыгымын анализдөө үчүн көбүнчө ички сактоолордун, ички инвестициялардын, экспорттун жана импорттун ички дүң продуктка катышы сыяктуу көрсөткүчтөр каралат. Ички сактоолор менен инвестициялардын ИДПга катышынын жогорулашы өлкөнүн узун мөөнөттө тышкы карызды төлөө кубаттуулугунун өскөнүн көрсөтөт. Бир өлкөдө сактоолор өскөн сайын тышкы капиталга жана тышкы ресурстарга муктаждык азайат. Бул критерий боюнча, сактоолордун ИДПга катышы инвестициялардын ИДПга катышына барабар же андан чоң болсо, анда тышкы карызга муктаждык болбошу шарт (Opuş, 2002: 190). Башкача айтканда, өлкөнүн ички ресурстары жетиштүү, болгону толук пайдаланылбай жатат деген мааниге келет. Экономикадагы бош ресурстарды инвестицияга багыттоо боюнча натыйжалуу иш-чаралар жүргүзүлүшү зарыл. Тилекке каршы, ЕАЭБ өлкөлөрүндө сактоолордун көлөмү боюнча статистикалык маалыматтар табылбаганына байланыштуу, бул эки катышты бири-бирине салыштыруу мүмкүнчүлүгү болгон жок. Бир гана ички инвестициялардын ИДПга катышы анализ кылынды. Армения, Казахстан, Россияда бул чоңдук 20\%дын тегерегинде болсо, Кыргызстан менен Беларусь өлкөсүндө 25-30\% болууда. 
Узун мөөнөттө тышкы карыздарды кыйынчылыксыз кайтарып, карыз айлампасына кабылбоо үчүн, экспорттун ИДПга катышы импорт менен тышкы карыздын ИДПга катышынан ылдамыраак өсүшү шарт. Экспорттун өсүшү импортко жана тышкы карызды төлөөгө керектүү валютаны камсыз кылат. Антпесе, кайрадан карыз издөө муктаждыгы жаралат (Eroğlu, 1997: 148-150). Бул критерий боюнча караганда Кыргызстан менен Армениянын эң көйгөйлүү өлкөлөр экенин көрүүгө болот. Бул эки өлкөдө хроникалык тышкы соода дефицити маселеси бар. Беларусь өлкөсүндө дээрлик тышкы соода балансы орун алса, Казахстан менен Россияда профицит уланууда. Демек, Кыргызстан, Армения жана Беларусь өлкөлөрү тышкы карызды тейлөөдө жаңы карыз алуу, чет өлкөлүк кыска же узун мөөнөттүү капиталды тартуу же мигранттардын акча которууларынан пайдалануу сыяктуу жолдорду колдонууга мажбур болушууда.

\section{3 Мамлекеттик Тышкы Карыздын Туруктуулугу}

Тышкы карыздын туруктуулугун аныктоо үчүн кээ бир эмпирикалык эмгектерде бирдик тамыр тести колдонулууда. Trehan \& Walsh (1991) тышкы карыздын туруктуулугу үчүн тышкы карыздын ИДПга катышынын туруктуулугун талап кылган бир ыкманы сунушташкан. Бул ыкмага таянган көптөгөн эмпирикалык изилдөөлөр бар. Алсак, Yilanci \& Özcan (2007) Түркия экономикасында тышкы карыздын туруктуулугун изилдөө үчүн тышкы карыздын ИДПга катышы тууралуу кварталдык маалыматтарды жана бирдик тамыр тестти колдонуп, Түркиянын тышкы карызынын туруктуу эместигин аныктаган. Takeuchi (2010) АКШда тышкы карыздын ИДПга катышын кварталдык маалыматтардын негизинде, бирдик тамыр тестти колдонуу аркылуу изилдеп, тышкы карыз туруктуу эмес деген жыйынтыкка келген. Lau et al. (2013) панель бирдик тамыр тестин жана жылдык маалыматтарды колдонуп Азия өлкөлөрүн изилдеген жана Азия өлкөлөрүндө тышкы карыздын туруктуу экенин тапкан. Schoder et. al. (2013) кварталдык маалыматтарды жана панель бирдик тестин колдонуп, евро аймакка кирген өлкөлөрдө тышкы карыздын туруктуу эместигин аныктаган. Cuestas et al. (2015) кварталдык маалыматтарды жана бөлчөк интеграция ыкмаларын пайдаланып, Европа өлкөлөрүндө тышкы карыз туруктуу деген жыйынтыкка келишкен. Goktas \& Hepsag (2015) бирдик тамыр тестин жана кварталдык маалыматтарды колдонуп, Түркияда тышкы карыз туруктуу эмес деген тыянак чыгарышкан.

Ушул эмгектердин негизинде ЕАЭБ мүчөлөрүндө тышкы карыздын туруктуулугу изилденди. Анализде ЕАЭБ өлкөлөрүнүн мамлекеттик тышкы карызынын ИДПга катышы (debt) жана жалпы тышкы карызынын ИДПга катышы (tdebt) эсептелип, ар бири өз-өзүнчө каралды. Евразиялык экономикалык биримдиктин расмий сайтынан (www.eaeunion.org) алынган 2008-2019-жылдарга тиешелүү кварталдык маалыматтар (n = 48) пайдаланылды.

\begin{tabular}{|l|c|c|c|}
\hline Өзгөрмөлөр & Бош коэффициент & Тренд & Экөө тең \\
\hline debt_ar & $-2.76(2018 \mathrm{Q} 1)$ & - & - \\
\hline debt_be & $-3.96(2015 \mathrm{Q} 1)$ & $-3.27(2017 \mathrm{Q} 4)$ & $-4.34(2015 \mathrm{Q} 3)$ \\
\hline debt_kg & $-3.37(2014 \mathrm{Q} 4)$ & $-2.55(2017 \mathrm{Q} 2)$ & $-3.83(2015 \mathrm{Q} 2)$ \\
\hline debt_kz & $-5.23^{*}(2015 \mathrm{Q} 3)$ & $-2.43(2017 \mathrm{Q} 3)$ & $-7.28^{* *}(2015 \mathrm{Q} 3)$ \\
\hline debt_ru & $-4.66(2010 \mathrm{Q} 3)$ & $-4.88^{* *}(2011 \mathrm{Q} 4)$ & $-5.00(2012 \mathrm{Q} 3)$ \\
\hline tdebt_ar & $-2.86(2017 \mathrm{Q} 1)$ & - & $-3.33(2010 \mathrm{Q} 2)$ \\
\hline tdebt_be & $-2.67(2017 \mathrm{Q} 4)$ & $-2.61(2017 \mathrm{Q} 3)$ & $-4.19(2015 \mathrm{Q} 1)$ \\
\hline tdebt_kg & $-3.31(2014 \mathrm{Q} 2)$ & $-2.65(2016 \mathrm{Q} 2)$ & $-4.02(2015 \mathrm{Q} 2)$ \\
\hline tdebt_kz & $-4.71(2015 \mathrm{Q} 4)$ & $-3.08(2011 \mathrm{Q} 1)$ & $-5.14 *(2015 \mathrm{Q} 4)$ \\
\hline tdebt_ru & $-2.77(2013 \mathrm{Q} 1)$ & $-2.52(2016 \mathrm{Q} 2)$ & $-3.84(2014 \mathrm{Q} 4)$ \\
\hline
\end{tabular}

ЭскертүY: **, * кезеги менен 1\% жана 5\% маанилүҮлүк деңгээлдерин көрсөтөт

Таблица 3. Зивот-Эндрюс Структуралык ӨзгөрүY Тести. Булак: EViews 9 Программасында Авторлор Тарабынан Эсептелди.

Алгач структуралык өзгөрүүнү текшерүҮ үчүн Зивот-Эндрюс структуралык өзгөрүү тести жасалып, анын жыйынтыктары Таблица 3тө берилди. Анын жыйынтыгы боюнча, кээ бир өзгөрмөлөрдө гана статистикалык жактан маанилүү структуралык өзгөрүү болгону аныкталды. Атап айтканда, Казахстандын мамлекеттик тышкы карызынын ИДПга катышында 2015-жылдын үчүнчү кварталында, Россиянын мамлекеттик тышкы карызынын ИДПга катышында 2011-жылдын төртүнчү кварталында жана Казахстандын жалпы тышкы карызынын ИДПга катышында 2015-жылдын төртүнчү кварталында статистикалык жактан маанилүү структуралык өзгөрүү болгон.

Андан соң, Кеңейтилген Дики-Фуллер жана Филлипс-Перрон бирдик тамыр тесттерин колдонуу менен бул катыштардын туруктуулугу (stationarity) текшерилди. Таблицадан көрүнүп тургандай, Армениянын жалпы тышкы карызы гана бош коэффициент кошулган теңдемеде туруктуу, калган теңдемелерде туруктуу эмес. Калган катыштардын баарын эки тест тең туруктуу эмес деп көрсөтүүдө. Демек ЕАЭБ өлкөлөрүндө мамлекеттик тышкы карыз да, жалпы тышкы карыз да туруктуу эмес. 


\begin{tabular}{|l|c|c|c|c|c|c|}
\hline \multirow{2}{*}{ Өзгөрмөлөр } & \multicolumn{2}{|c|}{ Кеңейтилген Дики-Фуллер тести (ADF) } & \multicolumn{2}{|c|}{ Филлипс-Перрон тести (РР) } \\
\cline { 2 - 7 } & $\begin{array}{c}\text { Бош } \\
\text { коэффициент }\end{array}$ & $\begin{array}{c}\text { Тренд жана } \\
\text { бош } \\
\text { коэффициент }\end{array}$ & Эч бири & $\begin{array}{c}\text { Бош } \\
\text { коэффициент }\end{array}$ & $\begin{array}{c}\text { Тренд жана } \\
\text { бошффициент }\end{array}$ & Эч бири \\
\hline debt_ar & -2.37 & -2.53 & 0.98 & -2.48 & -2.51 & 0.98 \\
\hline debt_be & -2.41 & -1.65 & 1.21 & -2.26 & -1.92 & 0.74 \\
\hline debt_kg & -2.48 & -2.38 & 0.12 & -1.98 & -1.82 & 0.06 \\
\hline debt_kz & -1.43 & -2.18 & -0.17 & -1.13 & -1.94 & 0.12 \\
\hline debt_ru & -0.41 & -2.96 & 1.06 & 0.23 & -2.49 & 2.51 \\
\hline tdebt_ar & $-2.98^{*}$ & -2.28 & 1.53 & $-4.65 * *$ & -2.29 & 1.33 \\
\hline tdebt_be & -2.42 & -2.89 & 0.10 & -2.08 & -1.62 & 0.59 \\
\hline tdebt_kg & -2.46 & -2.41 & 0.07 & -2.33 & -2.14 & 0.27 \\
\hline tdebt_kz & -1.56 & -1.56 & -0.16 & -1.75 & -1.80 & -0.19 \\
\hline tdebt_ru & -1.96 & -1.78 & -0.19 & -1.97 & -1.78 & -0.17 \\
\hline
\end{tabular}

ЭскертүY: **, * кезеги менен 1\% жана 5\% маанилҮүлүк деңгээлдерин көрсөтөт.

таблица 4. ЕАЭБ Өлкөлөрүндө Жалпы Тышкы Карыздын Жана Мамлекеттик Тышкы Карыздын Туруктуулугу Булак: EViews 9 Программасында Авторлор Тарабынан Эсептелди.

Бул абалды графиктик анализдер да тастыктап турат. График 1де ЕАЭБ өлкөлөрүндө мамлекеттик тышкы карыздын ИДПга катыштары чагылдырылган. Горизонталдуу окто «Т» чоңдугу убакытты көрсөтүп, 2008жылдан 2019-жылга чейинки кварталдарды (жалпысынан 12х4=48 квартал) түшүндүрөт.

Кээ бир жылдары төмөндөөлөр байкалганы менен, жалпысынан беш өлкөдө тең бул чоңдуктун туруксуз экени жана барган сайын өсүп баратканы байкалууда. Бул чоңдук боюнча өзгөчө Кыргызстанда акыркы жылдары маанилүү төмөндөө байкалса, Россияда тынымсыз жогорулоо орун алууда.
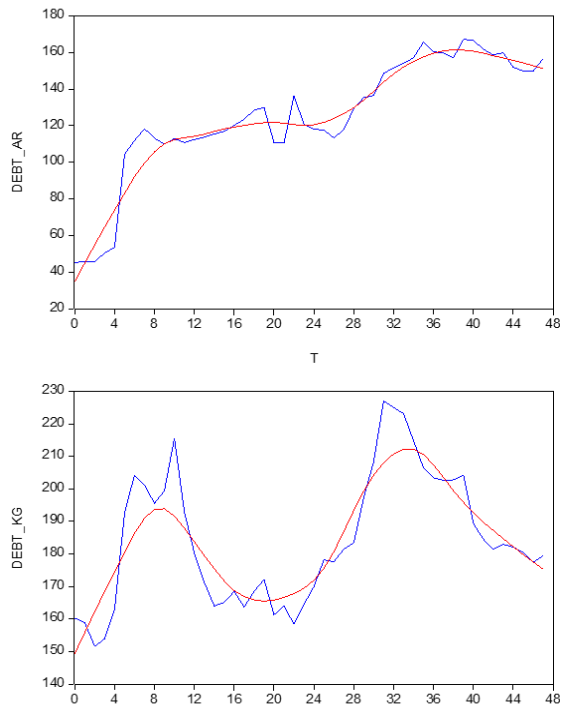
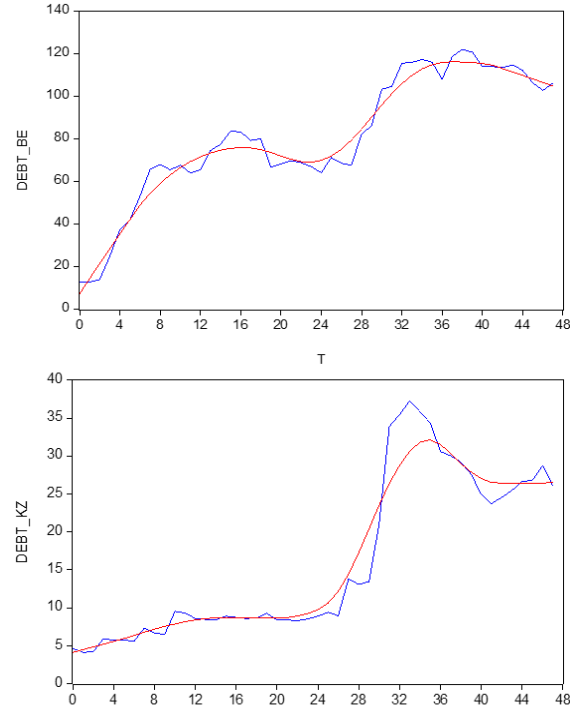

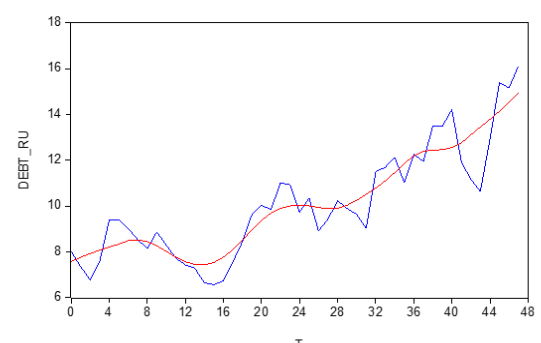

График 1. ЕАЭБ Өлкөлөрүндө Мамлекеттик Тышкы Карыздын Динамикасы

Армения менен Беларусь өлкөлөрүндө дээрлик окшош абал көрүнүп турат. Казахстанда Зивот-Эндрюс структуралык өзгөрүҮ тести да көрсөткөндөй, 2015-жылдын аягына жакын кескин жогорулоо болуп, андан соң абал бир аз турукташкан. 

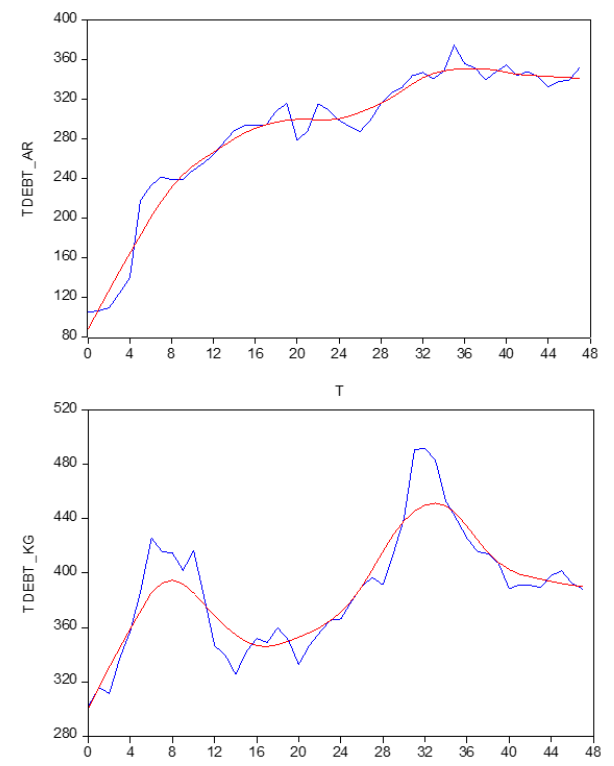
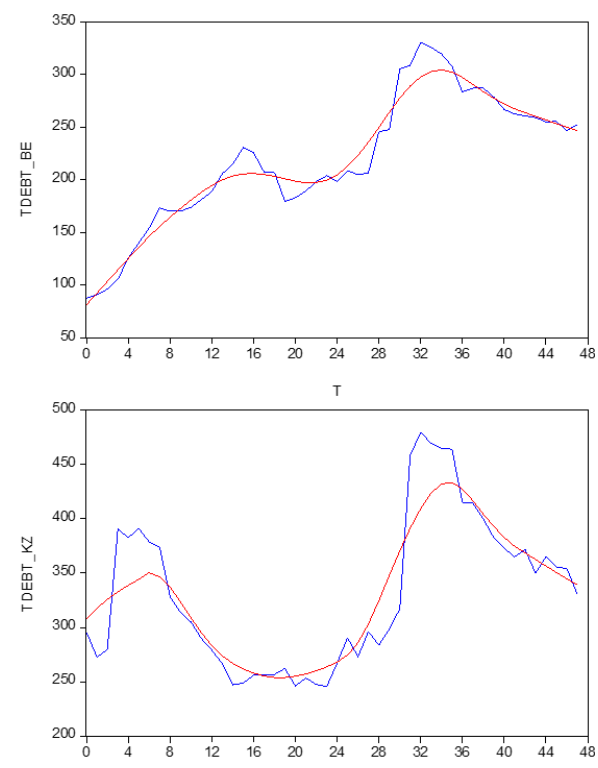

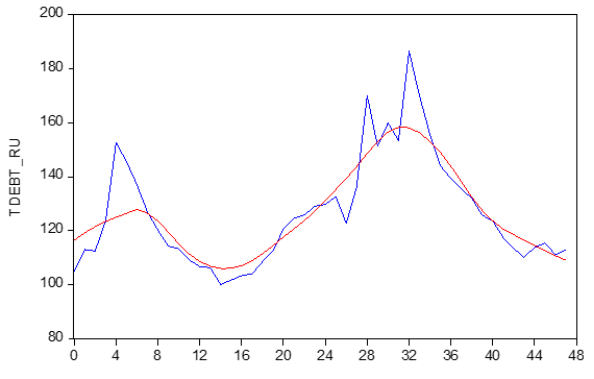

График 2. ЕАЭБ ӨлкөлөрҮндө Жалпы Тышкы Карыздын Динамикасы

График 2де ЕАЭБ өлкөлөрүндө жалпы тышкы карыздын динамикасы чагылдырылган. Арменияда бул көрсөткүчтүн акыркы жылдары тездик менен өсүп жатканын көрүүгө болот. Калган төрт өлкөдө 20152016-жылдары бир топ жогорулоо орун алып, андан төмөндөө байкалууда.

Бирок он жылдан бир аз көбүрөөк мөөнөт гана анализ кылынганына карабастан, ушул мөөнөттө деле бир топ жогорулоо-төмөндөөлөр орун алып, жалпысынан туруксуздук болуп жатканы көрүнүп турат. Демек графиктик анализ да эконометрикалык анализдин жыйынтыктарына шайкеш келүүдө.

\section{4 Корутунду Жана Сунуштар}

Бул эмгекте ЕАЭБ өлкөлөрүндө тышкы карыздын абалы жана туруктуулугу кыска жана узун мөөнөттөгү критерийлердин жана бирдик тамыр тесттеринин негизинде анализ кылынды.

Кыска мөөнөттөгү критерийлердин арасынан көп колдонулган тышкы карыздын ИДПга катышы көрсөткүчү боюнча, Россиядан башка бардык өлкөлөрдө бул чоңдуктун эл аралык уюмдар тарабынан белгиленген критерийден ашып кеткени, ал тургай, Армения, Кыргызстан жана Казахстанда 100 пайыздын тегерегинде болгону аныкталды. Тышкы карыздын экспортко катышы каралганда, Россия менен Беларусь өлкөлөрүндө бул критерий жагынан эч кандай кыйынчылык жок экени, калган үч өлкөдө бул катыштын эл аралык уюмдар тарабынан белгиленген чектен ашып кеткени белгилүү болду. Тышкы карызды тейлөөнүн экспортко катышы көрсөткүчү боюнча, анализ кылынган периоддо ЕАЭБ өлкөлөрүнүн эч бири белгиленген критерийден ашкан эмес. Эл аралык резевдердин тышкы карызга катышы каралганда, ЕАЭБ өлкөлөрүнүн дээрлик баарында акыркы жылдары бул чоңдуктун жай болсо да өсүп жатканы аныкталды. Армения, Беларусь, Казахстан жана Кыргызстанда бул катыш орточо 20-30\%ды түзсө, Россияда 64\%дан $113 \%$ га жогорулаган.

Узун мөөнөттө тышкы карыздарды кыйынчылыксыз кайтарып, карыз айлампасына кабылбоо үчүн, экспорттун ИДПга катышы импорт менен тышкы карыздын ИДПга катышынан ылдамыраак өсүшү шарт. Бул критерий боюнча караганда Кыргызстан менен Армениянын эң көйгөйлүү өлкөлөр экенин көрүүгө болот. Бул эки өлкөдө хроникалык тышкы соода дефицити маселеси бар. Беларусь өлкөсүндө дээрлик тышкы соода балансы орун алса, Казахстан менен Россияда профицит уланууда. Демек, Кыргызстан, Армения жана Беларусь өлкөлөрү тышкы карызды тейлөөдө жаңы карыз алуу, чет өлкөлүк кыска же узун 
мөөнөттүҮ капиталды тартуу же мигранттардын акча которууларынан пайдалануу сыяктуу жолдорду колдонууга мажбур болушууда.

Тышкы карыздын туруктуулугун, башкача айтканда, өлкөнүн келечекте тышкы карызды төлөөдө кыйынчылыктарга туш болуп-болбошун аныктоо максатында көптөгөн эмпирикалык эмгектерде ар кандай бирдик тамыр тесттери колдонулууда. Ошол эмгектердин негизинде ЕАЭБ мүчөлөрүндө тышкы карыздын туруктуулугу изилденди. Анализде ЕАЭБ өлкөлөрүнүн мамлекеттик тышкы карызынын ИДПга катышы (debt) жана жалпы тышкы карызынын ИДПга катышы (tdebt) эсептелип, ар бири өз-өзүнчө каралды. Кеңейтилген Дики-Фуллер жана Филлипс-Перрон бирдик тамыр тесттерин колдонуу менен бул катыштардын туруктуулугу (stationarity) текшерилди. Анын жыйынтыгында Армениянын жалпы тышкы карызы гана бош коэффициент кошулган теңдемеде туруктуу, калган теңдемелерде туруктуу эмес деп табылды. Калган чоңдуктардын баары туруктуу эмес деп аныкталды. Демек ЕАЭБ өлкөлөрүндө мамлекеттик тышкы карыз да, жалпы тышкы карыз да туруктуу эмес. Графиктик анализ да эконометрикалык анализдин жыйынтыктарын тастыктады. Жалпысынан ЕАЭБ өлкөлөрүндө мамлекеттик тышкы карыз да, жалпы тышкы карыз да туруксуз деп айтууга болот. Демек ЕАЭБ мүчөлөрү сырттан карыз алууда анын чыгымын жана пайдасын кылдат анализдөөгө тийиш. Ошондой эле, жеке тармактын тышкы карызы кескин жогорулабашы үчүн ички ресурстарды мүмкүн болушунча толук пайдалануу багытында иш-чараларды жүргүзүүсү зарыл. Интеграция алкагында бүт тарапка пайдалуу кызматташтыкты арттырып, биргелешкен өнүктүрүү фонддорун мындан да кеңейтүү керек. Өзгөчө саясий, экономикалык туруксуздуктар күчөгөн азыркы убакта бардык мүмкүнчүлүктөрдү бириктирип, сыртка болгон көзкарандылыкты мүмкүн болушунча азайтуу шарт.

\section{Литература}

- Bal H. (1998). “Gelişme Sürecinde Dış Finansman Kullanımı ve Türkiye”, Hazine Müsteşarlığı Araştırma ve İnceleme Dizisi 16, Ankara, 126s.

- Cuestas J.C., Gil-Alana L.A. \& Regis P.J. (2015). "The Sustainability of European External Debt: What have We Learned?”. Review of International Economics 23, pp. 445-468. http://dx.doi.org/10.1111/roie.12175

- Eroğlu Ö. (1997). "Does Foreign Aid Work on Economic Development of Developing Countries". Süleyman Demirel Üniversitesi İIBF Dergisi 2, pp.135-150.

- Evgin T. (1994). “90’lı Yıllarda Bütçe ve Bütçe Açı̆̆ının Finansmanı”. Ekonomik Yaklaşım 5(13), ss. 35151 .

- Evgin T. (2000). "Dünden Bugüne Borçlarımız", Undersecretariat of the Treasury, Ankara, Turkey, Mimeo, $64 \mathrm{~s}$.

- Glasberg D. S. \& Ward K. B. (1993). "Foreign Debt and Economic Growth in the World System”. Social Science Quarterly 74, pp.703-720.

- Goktas O. \& Hepsag A. (2015). "The Analysis of External Debt Sustainability by Periodic Unit Root Test with Structural Break: The Case of Turkey". Research in Applied Economics 7(4), pp. 1-15. http://dx.doi.org/10.5296/rae.v7i4.8123

- IMF, (2002). “Assessing sustainability. Policy Department and Review Department”. Washington, USA.

- Lau E., Baharumshah A.Z. \& Soon S. (2013). "The Behavior of External Debt in Asian Countries: Evidence Based on Panel Unit Root Tests”. Journal of Business Economics and Management 14, pp. 377-394. http://dx.doi.org/10.3846/16111699.2012.720589

- Mohammadi H., Cak M. \& Cak D. (2007). "Capital Mobility and Foreign Debt Sustainability: Some Evidence from Turkey”. Applied Economics 39, 2441-2449. http://dx.doi.org/10.1080/00036840600707274

- Schoder C., Proaño C.R. \& Semmler W. (2013). "Are the Current Account Imbalances Between EMU Countries Sustainable? Evidence from Parametric and Non-Parametric Tests”. Journal of Applied Econometrics 28, pp. 1179-1204. http://dx.doi.org/10.1002/jae.2291

- Takeuchi F. (2010). "US External Debt Sustainability Revisited: Bayesian Analysis of Extended Markov Switching Unit Root Test”. Japan and the World Economy 22, pp. 98-106. http://dx.doi.org/10.1016/j.japwor.2009.12.001

- Trehan, B., \& Walsh, C.E. (1991). "Testing Intertemporal Budget Constraints: Theory and Applications to U.S. Federal Budget and Current Account Deficits". Journal of Money, Credit and Banking 23(2), pp. 206223. http://dx.doi.org/10.2307/1992777

- World Bank, (1990). “A Strategy for Managing Debt, Borrowing and Transfer Under Macroeconomic Adjustment: Turkey”, Washington D.C.

- Yilanci V., \& Özcan B. (2007). "External Debt Sustainability of Turkey: A Nonlinear Approach”. International Research Journal of Finance and Economics 20, pp. 91-98. 
- $\quad$ Асанова А.А. \& Шатманов И.С. (2007). «Внешний долг Кыргызской Республики и его влияние на экономическую безопасность». Вестник КРСУ 7(11), с. 22-26. (Asanova A.A. \& Shatmanov I.S. (2007). «Vneshniy dolg Kyrgyzskoy Respubliki i yego vliyaniye na ekonomicheskuyu bezopasnost'». Vestnik KRSU 7(11), s. 22-26).

- Буценко И.Н. (2020). «Внешний долг государственного сектора как составляющая совокупного внешнего долга Российской Федерации». Финансовая архитектоника и перспективы развития глобальной финансовой системы (Сборник материалов VIII Научно-практической конференции), c.29-31. (Butsenko I.N. (2020). «Vneshniy dolg gosudarstvennogo sektora kak sostavlyayushchaya sovokupnogo vneshnego dolga Rossiyskoy Federatsii». Finansovaya arkhitektonika i perspektivy razvitiya global'noy finansovoy sistemy (Sbornik materialov VIII Nauchno-prakticheskoy konferentsii), s.29-31).

- Караталов О.К. (2007). «Влияние производственно-экономических показателей и внешнего долга на экономическую безопасность Кыргызстана». Вестник КРСУ 7(11), с. 13-21. (Karatalov O.K. (2007). «Vliyaniye proizvodstvenno-ekonomicheskikh pokazateley i vneshnego dolga na ekonomicheskuyu bezopasnost' Kyrgyzstana». Vestnik KRSU 7(11), s. 13-21).

- Логин И.В. (2009). «Пороговые значения для внешних долгов государства к проблеме управления государственным внешним долгом». Российское предпринимательство 9(2), с.10-14. (Login I.V. (2009). «Porogovyye znacheniya dlya vneshnikh dolgov gosudarstva k probleme upravleniya gosudarstvennym vneshnim dolgom». Rossiyskoye predprinimatel'stvo 9(2), s.10-14).

- Мансурходжаев Э.С. (2010). «Проблемы образования и регулирования внешнего долга Кыргызской Республики». Вестник КРСУ 10(1), с. 152-156. (Mansurkhodzhayev E.S. (2010). «Problemy obrazovaniya i regulirovaniya vneshnego dolga Kyrgyzskoy Respubliki». Vestnik KRSU 10(1), s. 152-156).

- Моисеев А.К. (2000). «Внешний долг России - состояние и проблемы платежеспособности». Проблемы прогнозирования 4, с. 99-107. (Moiseyev A.K. (2000). «Vneshniy dolg Rossii - sostoyaniye i problemy platezhesposobnosti». Problemy prognozirovaniya 4, s. 99-107).

- Семенов В.Л. (2000). «Внешний долг: Россия и опыт Латинской Америки». Россия и современный мир 1(26), с. 43-47. (Semenov V.L. (2000). «Vneshniy dolg: Rossiya i opyt Latinskoy Ameriki». Rossiya i sovremennyy mir 1(26), s. 43-47).

- Смирнов О.В. (2001). «Внешний долг России и проблемы его урегулирования». Вестник финансовой академии 4(20), с. 98-110. (Smirnov O.V. (2001). «Vneshniy dolg Rossii i problemy yego uregulirovaniya». Vestnik finansovoy akademii 4(20), s. 98-110). 


\title{
Потенциал Развития Торгово-Экономического Сотрудничества Кыргызстана в Условиях Углубления Интеграции
}

\section{Potential of Development of Trade and Economic Cooperation of Kyrgyzstan under Conditions of Deepening Integration}

\author{
Asst. Prof. Dr. Asel Dzhailova (State Service for Regulation and Supervision of the Financial \\ Market, Kyrgyzstan) \\ Prof. Dr. Arzybek Kozhoshev (State Service for Regulation and Supervision of the Financial \\ Market, Kyrgyzstan)
}

\begin{abstract}
The main directions of trade and economic cooperation of Kyrgyzstan at the present stage are considered. Structural changes in trade and economic cooperation of Kyrgyzstan are identified in the context of deepening integration processes. The assessment of foreign economic activity of Kyrgyzstan is presented. The factors of unbalanced development of the foreign trade turnover of Kyrgyzstan, as well as a decrease in the volume of attracting foreign investment, are highlighted. The positive shifts in the foreign trade of Kyrgyzstan within the framework of the EAEU and the efficiency of the use of investments of the main economic partners are determined. The directions of the effective use of potential and prospects for improving trade and economic cooperation of Kyrgyzstan within the EAEU and the implementation of the Silk Road integration model are substantiated. Particularly highlighted are the opportunities for the dynamic development of foreign economic cooperation of Kyrgyzstan with the countries of Central Asia for the joint use of the economic potential of the region.
\end{abstract}

\section{1 Введение}

Современный мир характеризируется развитием и углублением двух противоположных тенденций: глобализации и регионализации мирохозяйственного развития. Глобализация мирохозяйственной системы сопровоеждается усилением торгово-экономических отношений, стандартизации и взаимозависимостью экономического развития, широким развитием глобальных систем коммуникации и цифровизации мировой экономики.

В то же время, глобализация стирает особенности развития национальных экономик, приводит к размыванию национальной идентичности и самобытности развития государств. Обостряются проблемы несбалансированного развития мировой экономики, одностороннего конкурентного преимущества и недобросовестной конкуренции, неэквивалентного товарного обмена, бедности и миграции. Следствием глобализации являются периодически возникающие глобальные экономические кризисы, сопровождающиеся существенными геополитическими и социально- экономическими изменениями. В условиях перманентно развивающейся череды финансовых, экономических и социальных кризисов слабеют фундаментальные основа глобализации- неолиберальная модель развития экономики и т. д..

Под воздействием и в противовес глобализации активно развиваются процессы региональной экономической интеграции. Практически в каждом географическом континенте мира возникли и успешно функционируют более 90 региональных экономических интеграционных формирований [1]. Причем, в отличии от процессов глобализации, практика развития региональных интеграционных формирований (нp, ЕС) способствует более сбалансированному экономическому развитию государств-участников интеграционного формирования, что достигается проведением единой экономической политики, формированием и сбалансированным функционированием национальных и наднациональных органов управления и институтов.

Развал СССР и становление на постсоветском пространстве независимых суверенных государств сопровождался развитием не только политического суверенитета, но и развитием широкомасштабных дезинтеграционных процессов. Рыночные реформы, либерализация торговли способствовало тому, что внешнеэкономическая деятельность суверенных государств в основном стала ориентироваться на развитые страны Запада, Азии, Востока. В целом коренной перелом в экономической и внешнеэкономической политике бывших союзных республик стал основным фактором сильного спада объёмов и темпов роста ВВП в начальные и последующие годы реформ.

Дезинтеграция экономических отношений сильно ударила по социально-экономическому развитию всех без исключения бывших союзных государств. Несоразмерность и дисбаланс в проведении экономических реформ, политический антураж и эгоизм лидеров суверенных государств также в немалой степени способствовал дальнейшему усугублению дезинтеграционных процессов на постсоветском пространстве. 
В то же время, укрепление суверенитета бывших союзных государств, рост конкуренции на мировых рынках, развитие социальной напряженности в отдельных странах выступили факторами, способствующими формированию и развитию интеграционных отношений на постсоветском пространстве исключительно на новой рыночной основе. Причем, на ранних стадиях возможности региональной экономической интеграции ограничивались странами постсоветского пространства (договора о создание Содружества Независимых Государств). Впоследствии на постсоветском пространстве была реализована идея евразийской интеграции, что привело к созданию в 2015 г. Евразийского Экономического Союза (ЕАЭС) [2]. Впервые на крупнейшей материковой территории мира в единое экономическое пространство объединились пять независимых суверенных государств- Армения, Кыргызская Республика, Республика Беларусь, Республика Казахстан и Российская Федерация.

Параллельно евразийской интеграции страны СНГ активно включаются в процесс реализации китайской стратегии Экономического пояса Шелкового пути (ЭПШП). Страны Центральной Азии (Таджикистан, Узбекистан, Казахстан, Кыргызстан), выступили с проектами сопряжения планов национального развития с ЭПШП» [3]. Для Кыргызстана этот проект важен с точки зрения развития транспортно-логистического потенциала, выхода на емкий потребительский рынок КНР с экологической продукцией АПК, эффективного использования гидроэнергетического потенциала, а также в качестве важнейшего источника трансферта передовых технологий и крупных инвестиций в экономику страны. Развертываются исследования крупного регионального проекта «Большая Евразия», которая подразумевает создание сети зон свободной торговли, межблоковых торгово-экономических партнерств и сопряжение региональных интеграционных процессов на всем евразийском материке [4]. В последние годы вновь активизировались усилия по углублению интеграционных процессов в странах Центральной Азии. Активное участие Кыргызстана в указанных интеграционных формированиях будет способствовать динамичному социально экономическому развитию в контексте совершенствования торгово-экономического сотрудничества.

\section{2 Основная Часть}

Функционирование экономики Кыргызской Республики в условиях углубления интеграционных процессов характеризируется в целом положительными изменениями макроэкономических показателей, обеспечению сбалансированности национальной экономики, совершенствованию торгово-экономического и инвестиционного сотрудничества. Экономика Кыргызстана эффективно трансформируется в евразийское экономическое пространство, развивает инвестиционное сотрудничество в рамках реализации интеграционной модели Возрождения Щелкового пути, налаживает взаимовыгодное торговоэкономическое сотрудничество со странами Центральной Азии.

В качестве важнейших результатов интеграционного эффекта для развития экономики Кыргызстана в ЕАЭС за последние четыре года следует отнести:

-обеспечение макроэкономической стабильности и устойчивых темпов роста национальной экономики; сравнительно высокие темпы роста ВВП среди стран ЕАЭС;

-низкий уровень инфляции;

-опережающий рост промышленного производства, особенно, легкой и пищевой промышленности; рост экспорта продукции в страны ЕАЭС и сокращение разрыва между экспортом и импортом продукции;

-положительные тренды в изменении внутриотраслевой структуры важнейшей отрасли национальной экономики-сельского хозяйства, возрождение и динамичное развитие традиционных ее отраслей;

-стабильный рост доходов населения и денежных переводов в республику [6].

Важно отметить, что среди государств-участниц ЕАЭС экономика Кыргызстана показывает сравнительно высокие темпы роста ВВП. Рост ВВП страны в 2018 году по сравнению с 2015 годом составил $17,0 \%$, продукции промышленности $-38.2 \%$, сельского хозяйства-3,4 \%, строительства- $62,1 \%$, инвестиции в основной капитал выросли на 13,2\%. За период 2015-2018 гг. темпы роста ВВП республики были соответственно на 6,$0 ; 4,4 ; 2,8$ и 1,0 пункта выше среднего ее значения по ЕАЭС.

Сравнительно высокие темпы роста ВВП Кыргызской Республики по сравнению со среднеевразийскими, в основном обеспечены за счет восстановления и эффективного использования потенциала отраслей промышленности республики, а также развития отраслей АПК республики. За указанный период удалось достичь достаточно высоких темпов объёмов наращивания производства в легкой и пищевой промышленности, а также на предприятиях горнодобывающей отрасли. Это является следствием проводимой эффективной инвестиционной политики по линии Кыргызско-Российского инвестиционного фонда. В результате за указанный период модернизированы и начали функционировать ряд крупных предприятий пищевой промышленности, а также введены в действие новые предприятия легкой промышленности.

Вместе с тем, Кыргызстан по основным макроэкономическим показателям находится на последнем месте в ЕАЭС (табл.1). В Кыргызстане, по сравнению со средними данными по ЕАЭС на порядок ниже производится ВВП на душу населения, самой низкой являются доходы населения. По сравнению с 
Россией, являющейся самой развитой в экономическом отношении страной ЕАЭС, эти показатели соответственно ниже в 8,5 и 2,9 раза. Также среди стран ЕАЭС самым высоким также является государственный долг Кыргызстана.

\begin{tabular}{|l|r|r|r|r|r|}
\hline \multicolumn{1}{|c|}{ Показатели } & Армения & Беларусь & Казахстан & Кыргызстан & Россия \\
\hline Числ. нас, млн.чел. & 2,9 & 9,5 & 18,4 & 6,4 & 146,8 \\
Стоим.ВВП, млр.долл. & 12,4 & 53,9 & 172,9 & 8,1 & 1661,0 \\
ВВП на душу нас, в долл & 4188 & 6283 & 9462 & 1332 & 11312 \\
Прод.пром,млр.долл & 3,5 & 53,9 & 79,9 & 3,6 & 1104,6 \\
Прод. с/х ,млр.долл. & 1,8 & 9,3 & 12,8 & 3,0 & 81,9 \\
Госдолг,вмлр.ед.нац.вал. & 3340 & 45,4 & 1537 & 311 & 10360 \\
Отн. госдолга к ВВП,в \% & 54,6 & 35,6 & 20,2 & 48,0 & 10,0 \\
Ср.мес.зарплата, долл & 358 & 470 & 471 & 236 & 695 \\
\hline
\end{tabular}

Таблица 1:Основные макроэкономические показатели стран ЕАЭС в 2018г Источник: Данные ЕЭК, Нацстаткома и Нацбанка КР

Это является следствием неэффективности проводимых экономических реформ в стране, предшествующих до вступления страны в ЕАЭС, обусловливающих крупные диспропорции в структуре национальной экономики. По-прежнему в экономике страны значительную роль играет сельское хозяйство и сектор услуг, в то же время слаба развита индустриальная база национальной экономики. В Кыргызстане только в последние годы объёмы производства промышленной продукции превысили значения предреформенного уровня. В то же время сложившаяся индустриально-инновационная структура национальных экономик Российской Федерации, Республики Казахстан и Беларусь, где на долю промышленности приходится почти третья часть экономик, в целом обеспечивает высокие их макроэкономические показатели и сравнительно высокую конкурентоспособность национальной экономики. Что касается самого сельского хозяйства страны, экстенсивный характер ее развития, не способствует ее динамичному и эффективному развитию. Об этом свидетельствует то важное обстоятельство, что объёмы производства сельскохозяйственной продукции еще не достигли предреформенного уровня, что сказывается на проблемах продовольственного самообеспечения населения страны.

Одним из успешных и традиционных направлений углубления интеграционного процесса в ЕАЭС, является развитие торгово-экономического сотрудничества между государствами-участниками. Причем, расширяются не только объёмы взаимной торговли, но и происходит существенное совершенствование структуры внутреннего рынка. Нивелируются таможенные, технические барьеры расширения внутренней торговли между странами - участниками интеграционного формирования. Вводятся стандарты на потребительские и производственные товары и услуги, соответствующие мировым ее аналогам, что позитивно отражается на модернизации производственной базы национальных экономик.

Растет внешнеторговый оборот Кыргызстана и меняется ее структура в пользу усиления торговосотрудничество со странами ЕАЭС (табл.2). В 2018году внешнеторговый оборот страны составил 5602,5 млн долл. США и по сравнению с 2016 года увеличился на 10,9 \%. В то же время со странами ЕАЭС он сложился в объеме 2179,2 млн долл. США и увеличился на 14,3\%. Причем доля стран ЕАЭС в общем объеме товарооборота республики выросла до 38,9 \%, в том числе экспорт составляет 33,9 \% и импорт $40.8 \%$ и в целом страны ЕАЭС занимают первые места как во внешнеторговом обороте, так и экспорте продукции из Кыргызстана, так и в импорте продукцию в Кыргызстан.

\begin{tabular}{|l|l|l|l|l|}
\hline & Россия & Казахстан & Беларусь & Армения \\
\hline $\mathbf{2 0 1 5}$ & 166,8 & 210,7 & 5,6 & 0,2 \\
\hline экспорт & 1460,2 & 553,2 & 51,4 & 0,3 \\
\hline импорт & \multicolumn{5}{|l|}{} \\
\hline $\mathbf{2 0 1 8}$ & 247,2 & 7,0 & 0,1 \\
\hline экспорт & 314,1 & 34,1 & 0,6 \\
\hline импорт & 1239,9 & 502,0 &
\end{tabular}

Таблица 2-Динамика внешней торговли Кыргызстана со странами ЕАЭС, в 2015-2018 годы, млн. долл. США Источник: Данные ЕЭК, Наџстаткома и Нацбанка КР

Наибольшую долю в 2018 году во взаимной торговле Кыргызской Республики со странами ЕАЭС занимала Российская Федерация - 66,26\% и Казахстан -31,95\%. Совершенно неразвиты торговоэкономические связи Кыргызстана с Белоруссией $(1,75 \%)$ и Арменией $(0,03 \%)$. Также наибольшую долю в экспорте во взаимной торговле Кыргызской Республики занимает Россия - 55,25\%, значительна доля и Казахстана -43,49\%, при этом на Республику Беларусь приходится - 1,22 и Армению -0,02\%. В импорте 
превалирует также доля Российской Федерации (69,78\%) и Республики Казахстан (28,26\%), на Беларусь приходится 1,92\% и Армению -0,03\% всего импорта [9].

В качестве положительной тенденции развития торгово-экономического сотрудничества Кыргызстана со странами ЕАЭС следует особо отметить значительный рост экспорта отечественной продукции и снижения импорта. Экспорт продукции Кыргызстана вырос в Российскую Федерацию в 1,9 раза, в Казахстан - на 23.5 \% и в Беларусь - на 25.0 \%. Рост экспорта отечественной продукции на рынки ЕАЭС сопровождается соответствующим снижением объёмов импорта, что свидетельствует о тенденциях растущей сбалансированности структуры внешней торговли Кыргызстана со странами ЕАЭС.

В целом положительная динамика развития торгово-экономического сотрудничества Кыргызстана в рамках ЕАЭС свидетельствует о положительном влияние интеграционных процессов. Несмотря на, то что со стороны отдельных партнеров по ЕАЭС, периодически создаются преграды для расширения торговоэкономического сотрудничества, евразийская интеграция способствует ее углублению, что является одним из важных условий дальнейшего развития единого евразийского экономического пространства.

Однако, евразийская интеграция также наглядно высветила сохранение негативных тенденций в экономическом развитии Кыргызстана, ограничивающего рост потенциала взаимовыгодного торговоэкономического и инвестиционного сотрудничества. К таким факторам относятся сохранение зависимости экспорториентированных отраслей промышленности от поставок импортного сырья. Практически вся легкая промышленность Кыргызстана, продукция которой востребована на евразийском рынке, работает на импорте тканей и технологического оборудования из КНР или Турции. Такая зависимость от поставок импортного сырья, для производства которой в республике имеются все необходимые базовые условия (развитая овцеводство, хлопководство), негативно сказывается на конкурентоспособности и устойчивом развитии данной важнейшей национальной отрасли.

Евразийская интеграция также, несмотря на определенный рост экспорта агропродукции (молочной продукции, овощей, фруктов), вывила хронические недостатки развития агропромышленного производства в республике. Прежде всего сохранение преимущественно мелкокрестьянской структуры аграрного производства, что сказывается на возможности формирования соответствующих объёмов и стандартов сельскохозяйственной продукции, экспортируемой на рынки ЕАЭС. Несмотря на то, что отечественная агропродукция по своим качественным параметрам соответствует всем необходимым стандартам, из-за выше указанных проблем экспортный потенциал отрасли используется неэффективно.

В этом отношении актуальными становятся формирование развитие в регионах республики крупных региональных агропромышленных кластеров по производству экспортоориентированной продукции АПК. На основе развития региональных агрокластеров (по производству и переработке мясной и молочной продукции, овощей и фруктов, хлопка, сахарной свеклы) можно значительно повысить экспортный потенциал отраслей АПК. Реализация указанных направлений развития агропромышленного производства республики также положительно скажется на привлечение инвестиций в АПК из стран основных партеров ЕАЭС.

Кыргызстану важно и дальше углублять торгово-экономическое сотрудничество в рамках евразийского интеграционного формирования, что будет способствовать в дальнейшем совершенствованию углубленной специализации производства в республике с учетом необходимости более эффективного использования сравнительных преимуществ страны и потребностей евразийского рынка. Углубление специализации, развитие тесных кооперационно-интеграционных связей хозяйствующих субъектов ЕАЭС, несомненно придаст импульс динамичному развитию евразийского экономического союза, повысить экспортный потенциал национальных экономики и в целом конкурентоспособность продукции стран ЕАЭС не только в формате интеграционного формирования, но и за ее пределами.

С целью эффективной трансформации и конкурентоспособного экономического развития Кыргызстана в ЕАЭС следует активизировать привлечение инвестиций и кредитных ресурсов из фондов ЕАЭС для создания совместных предприятий в приоритетных отраслях - в сфере гидроэнергетики, горнодобывающей промышленности, агропромышленного комплекса и т.д. Необходимо создать благоприятные условия для привлечения в республику банковского капитала из стран ЕАЭС, для повышения экспортного потенциала страны на основе прямого договора с регионами России, создавать крупные региональные торгово-логистические центры.

В то же время по-прежнему усугубляется отрицательное сальдо внешнеторгового оборота Кыргызстана с третьими странами, среди которых основным партнером Кыргызстана является КНР. КНР занимает второе место во внешнеторговом обороте Кыргызстана, после Российской Федерации и первое место по притоку иностранных инвестиций в республику.

Для обеспечения сбалансированного торгово-экономического баланса с КНР Кыргызстану следует активно и с выгодой использовать преимущества

Экономического сотрудничества по линии «ЭПШП» КНР. КНР представляет интерес для Кыргызстана не только с точки зрения как крупного инвестора, но и как крупного потребителя экологически чистой 
продукции сельского хозяйства. В это отношении следует активно развивать взаимовыгодное сотрудничество в области налаживания в республике крупных агротехнопарков по развитию органического земледелия. Необходимо на законодательном уровне решить вопросы для использования в этих целях государственных земель Фонда перераспределения сельскохозяйственных угодий. Создание на этих землях совместных агропредприятий с привлечением передовых агротехнологий из КНР положительно отразится на увеличение объёмов производства и экспорта соответствующей продукции в КНР.

В дальнейшем следует в рамках реализации стратегии возрождения Щелкового пути, ориентироваться с экспорта готовой продукции из КНР на экспорт технологического оборудования. В рамках сопряжения Кыргызской Республики для реализации стратегии «ЭПШП» КНР следует активно развивать сотрудничество в сфере создания китайских промышленных предприятий для производства экспортоориентированной на рынки ЕАЭС продукции, создавать крупные региональные логистические центры, технопарки и зоны свободной торговли. Весьма перспективны развитие туризма и туристической отрасли в Кыргызкой Республике и эффективная трансформация ее в туристический пояс «ЭПШП».

В последние годы географические и культурно-гуманитарные признаки близости способствуют развитию торгово-экономическое сотрудничества Кыргызстана со странами ЦА. Растет взаимный товарооборота Кыргызстана со странами ЦА. За период 2015-2018 гг. в общем внешнеторговом обороте Кыргызстана удельный вес товарооборота со странами ЦА вырос с 17,9\% до 19,0 \%. Вырос приток инвестиций -с 1,3 до3,6 \%, хотя объём инвестиций остается незначительным. Однако следует признать, недостаточность экономического сотрудничества Кыргызстана со странами ЦА.

Учитывая, что в последние годы в странах ЦА наметились тенденция роста объёмов торговли, инвестиций, меняется политический климат, представляется возможным сдвинуть с мертвой точки развитие интеграционных процессов внутри центрально-азиатских стран (ЦА)-между Республикой Казахстан, Республикой Узбекистан, Кыргызской Республикой, Республикой Таджикистан и Туркменистаном и придать им более устойчивый и целенаправленный характер.

Следует расширять целенаправленную работу по преодоления существующего дисбаланса в торговле, для чего активизировать торгово-экономическое сотрудничество со странами ЦА, особенно, с Узбекистаном, в рамках заключения межправительственных соглашений.

Экономическая интеграция стран ЦА должна преследовать цели более эффективного использования природно-экономического и трудового потенциала региона. Приоритетными направлениями взаимовыгодного экономического сотрудничества должны стать комплексное освоение природных ресурсов, рациональное использование быстрорастущих трудовых ресурсов, совместное использование гидроэнергетического потенциала, создание разветвленной транспортной и энергетической системы, создание крупных региональных финансово-промышленных групп, развитие потенциала сельских, горных и пустынных территорий и т.д.

\section{3 Выводы}

- развитие торгово-экономического сотрудничества Кыргызстана в рамках ЕАЭС, несмотря на некоторые положительные сдвиги, требует внесения существенных корректив в части обеспечения сбалансированности внешнеторгового оборота республики в интеграционном формировании. В этих условиях важнейшими компонентами ее достижения становятся дальнейшее наращивание экспорта и оптимизация импортозамещения в рамках ЕАЭС;

- в целях обеспечения сбалансированного торгово-экономического баланса с КНР Кыргызстану следует активно и с выгодой использовать преимущества экономического сотрудничества в рамках реализации китайской стратегии Возрождения Щелкового пути, развивать сотрудничество в организации совместного производства и экспорта продукции органического земледелия из Кыргызстана в КНР и в дальнейшем ориентироваться с экспорта готовой продукции из КНР на экспорт технологического оборудования;

- в целях развития экономической интеграции с соседними странами Центральной Азии на начальном этапе следует расширять целенаправленную работу по преодоления существующего дисбаланса в торговле, для чего активизировать торгово-экономическое сотрудничество с Узбекистаном, Таджикистаном и Туркменией в рамках заключения взаимовыгодных межправительственных соглашений. В последующем развитие взаимовыгодного торгово-экономического сотрудничества должна стать основой для более углубленной экономической интеграции стран Центральной Азии.

\section{Литература}

- Владимир Путин: Большая Евразия - это цивилизационный проект.- http://www.stoletie.ru/na

- Евразийский Экономический Союз в цифрах: краткий статсборник.- Москва, ЕЭК, 2019. - 199 с. 
- Евразийский экономический союз-Санкт-Петербург: ЦИИ ЕАБР, 2017.- 296с

- Кыргызская Республика в Евразийском экономическом союзе: первые результаты.-Москва, 2018.-88с.

- Кыргызстан в цифрах: статсборник.-Бишкек, Нацстатком , 2019.-361с

- Платежный баланс Кыргызской Республики, 2018.- Бишкек, Нацбанк КР , 2019.-https://www.nbkr.kg

- Региональные организации: типы и логика развития.-СПб: ЦИИ ЕАБР,2016.- 86 с

- С.К Песцов. Большая Евразия: что скрывает фасад вдохновляюшей идеи. - https:/cyberleninka.ru/

- Ц Центрально-Азиатский Союз.- https://ru.wikipedia.org/wiki 


\title{
Развитие Торговых Отношений Кыргызской Республики с Турцией
}

\section{Development of Trade Relations of the Kyrgyz Republic with Turkey}

\author{
Assoc. Prof. Dr. Khicheza Fynchina (Kyrgyz-Russian Slavic University, Kyrgyzstan)
}

\begin{abstract}
The progressive development of the economy of each country in the context of globalization is to a large extent determined by its foreign trade activities. Individual entrepreneurship of the Kyrgyz Republic was the locomotive for the development of trade cooperation with many countries of the far abroad, among which Turkey is one of the leaders. Sources of research: statistical data. The main methods of cognition: analysis, synthesis, logical sequence. Key findings: The participation of the Kyrgyz Republic in the Eurasian Economic Union (EAEU) contributed to the revival of trade relations of the Kyrgyzstan with the EAEU members and other countries. The structure of foreign trade has improved: leading export growth compared to import growth. The pace of development of foreign trade relations shows that the participation of Kyrgyzstan in the EAEU is not a deterrent to its integration into the world trade community. The production orientation of imports from Turkey and China showed the basis for restoring the production potential of the light industry of Kyrgyzstan. An analysis of official data on foreign trade of Kyrgyzstan and mirror statistics of key partner countries revealed the problem of the presence of inaccuracy in the statistics of foreign trade of Kyrgyzstan and possible budget losses. The principles of building a new relationship between a man and society under the influence of the Covid-19 pandemic will be based on the rationalization of consumption and production. This will be the basis for the restoration and development of foreign trade of the Kyrgyz Republic.
\end{abstract}

\section{1 Введение}

Торговые отношения Кыргызской Республики со странами СНГ исторические. Их развитие с отдельными его членами, прежде всего соседними странами, в условиях Евразийского экономического союза (ЕАЭС) считается закономерным. В то же время, являясь участником ВТО с конца 1998 г., Кыргызская Республика имеет вполне определенный интерес по развитию торговых отношений со всеми странами мирового сообщества на взаимовыгодных условиях и на основе сложившихся логистических связей в понимании управления материальными потоками в сфере обращения.

Внешняя торговля сыграла ключевую роль в развитии предпринимательской деятельности (прежде всего индивидуального предпринимательства) в Кыргызской Республике в годы становления рыночной экономики. Она явилась фактором создания базы для появления среднего класса, обеспечив самозанятость огромной массе оставшейся не у дел людей в годы развала плановой экономики, удовлетворения потребностей населения необходимыми товарами, качественного насыщения внутреннего рынка товарами на основе конкуренции. Отсюда и налаживание внешнеторговых отношений со странами, с которыми традиционно не имели развитых торговых связей, вне каких либо экономических сообществ, таких как Китай, Турция, ОАЭ, Индия и других.

\section{2 Первые Итоги ЕАЭС и Роль Индивидуального Предпринимательства в Развитии Внешней Торговли КР}

Вступлению Кыргызстана в Евразийский экономический союз (ЕАЭС) в 2015 г. прогнозировалось положительное влияние на развитие внешней торговли и другие сферы внешнеэкономического сотрудничества. Это обосновывалось в первую очередь на отмене таможенных пошлин внутри экономического сообщества. Также строились обоснованные прогнозы по ухудшению торговых связей со странами вне ЕАЭС, с которыми укрепились торговые отношения Кыргызской Республики с первых перестроечных дней на рыночную экономику. Каковы реальное положение дел и тенденции развития?

Влияние ЕАЭС на развитие экономики, в том числе и индивидуального предпринимательства (ИП), неоднозначно. При любом раскладе влияние ИП на развитие экономики будет ощутимо вследствие большого вклада этого сегмента предпринимательской деятельности в экономическое развитие Кыргызстана и высокой корреляционной связи валовой добавленной стоимости ИП и ВВП (до 0,995 nо данным за период с 2000 г.). Так, доля валовой добавленной стоимости (ВДС) ИП в 2014 г. и объём этого показателя рекордно выросли, составив около 84 млрд. сом. или $21 \%$ к ВВП республики. Создание ЕАЭС в 2015 г. несколько снизило эту долю (Кыргызстан стал участником сообщества позже на полгода, в связи с этим были потери объема товарооборота из-за тарифной политики ЕАЭС). Но уже к 2017 г. этот показатель восстановился до уровня в $21,2 \%$. 
Анализ показателей взаимного товарооборота Кыргызстана с государствами ЕАЭС характеризует преодоление этапа адаптации Кыргызской Республики к требованиям ЕАЭС (Диаграммы 1 и 2).

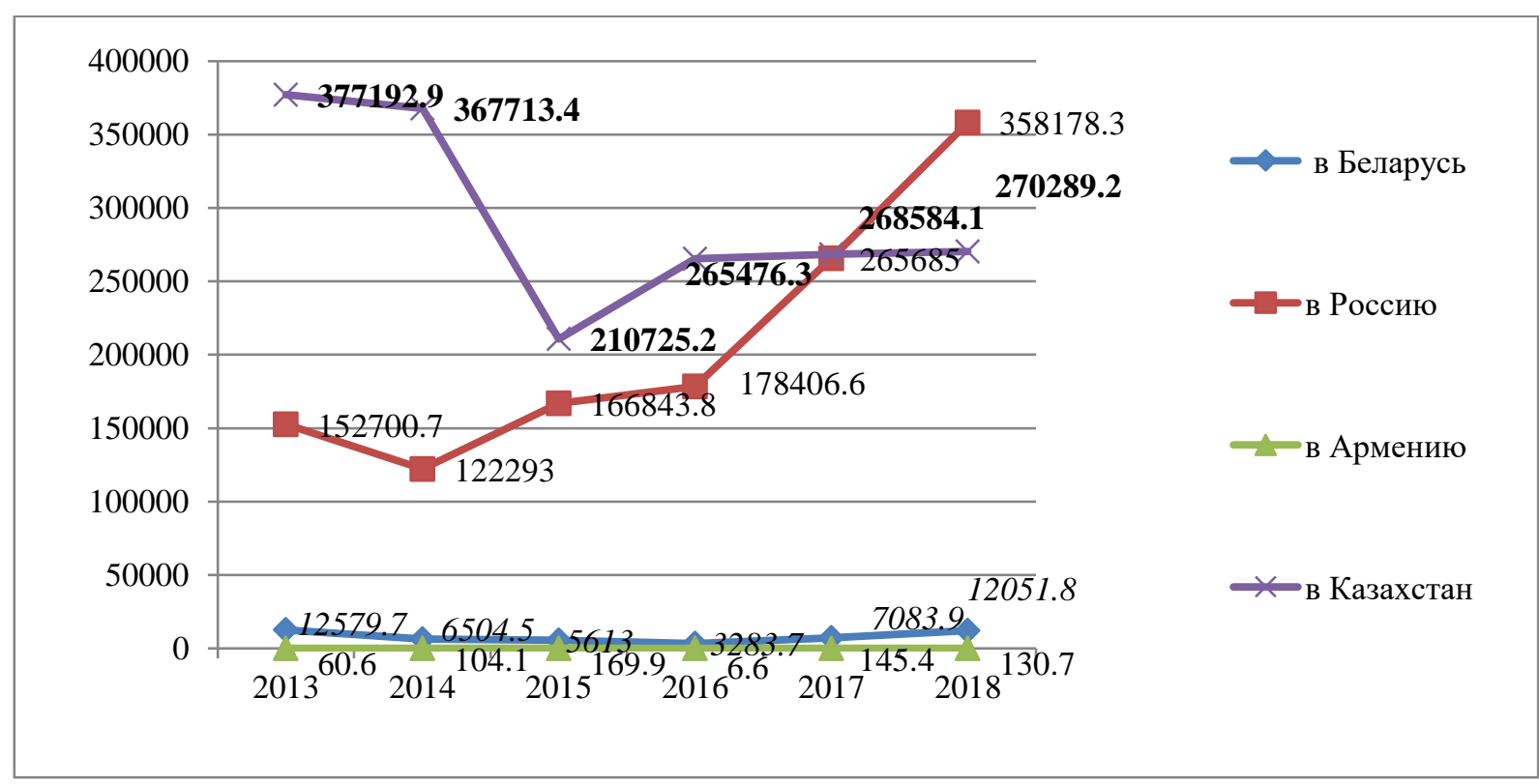

Диаграмма 1. Экспорт товаров КР в страны участников ЕАЭС, тыс. долл. США. Источник: на основе данных Национального статистического комитета (НСК) КР (Внешняя торговля КР 2018).

Так, если в первый год участия Кыргызской Республики в ЕАЭС отмечено снижение экспортноимпортных поставок КР с другими участниками экономического сообщества (кроме экспорта в РФ), то к 2018 г. поставки практически со всеми странами-участниками имеют динамику роста, за исключением импорта из Беларуси на фоне его пикового уровня в 2017 г. (47 190,3 тыс. долл. против 108 651,3 тыс. долл.) и Армении, взаимный товарооборот с которой весьма скромен и на диаграмме практически не просматривается. Торговые отношения КР с Арменией в рамках ЕАЭС только налаживаются и находятся на стадии исследования имеющегося в двух странах потенциала для развития взаимной торговли.

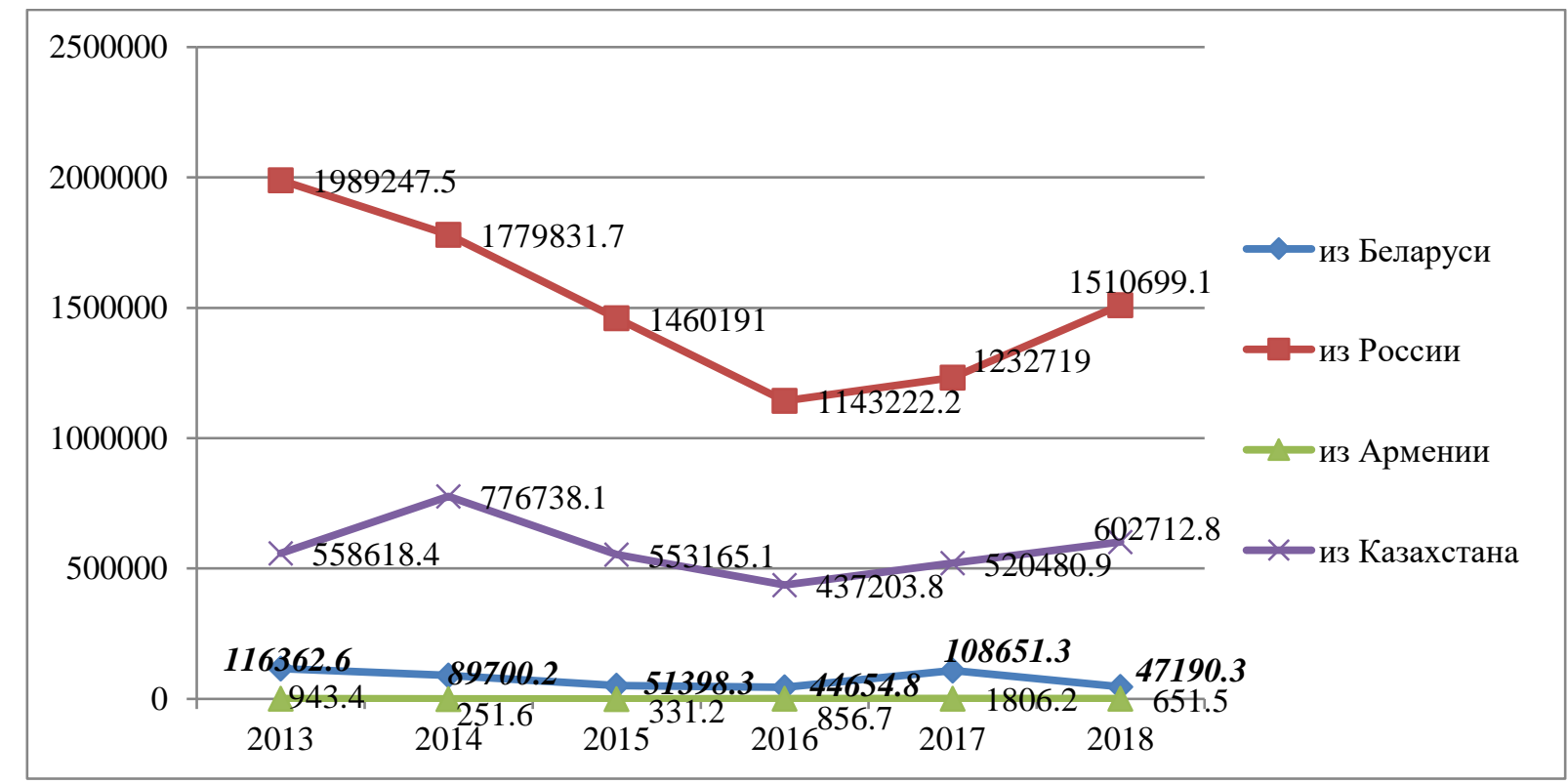

Диаграмма 2. Импорт товаров КР из стран участников ЕАЭС, тыс. долл. США. Источник: Внешняя торговля КР.

Примечательно, что складывающаяся после вступления в экономический союз структура товарооборота с основными внешнеэкономическими партнерами улучшилась для КР. Наблюдается опережающий рост экспортных операций из Кыргызской Республики (кроме Казахстана в 2017 г., когда оказало влияние политический фактор). Например, если в 2014 г. импортные поставки из РФ превышали экспортные в 14,6 раз, то в 2018 г. только 4,2 раз, по Беларуси: 13,8 против 3,9. Если такое соотношение имеет рост, то небольшой (например, по Казахстану: 2,1 против 2,2). 
Начало экономическому сотрудничеству КР со странами дальнего зарубежья (вне постсоциалистического пространства) было положено индивидуальными предпринимателями с переходом к рыночной экономике. Они освоили так называемый «челночный бизнес» при содействии различных коммерческих организаций (совместных или иностранных) по туристической линии. Среди многих видов деятельности хозяйствующих субъектов с участием турецкого капитала с первых лет торгового сотрудничества более 150 субъектов экономики были заняты в сфере туризма и торговли. Их деятельность была основана на том, что Кыргызская Республика с начала перестроечного периода явилась страной с высокой готовностью потребления товаров широкого спроса. Большая часть импорта из Турции, Китая и других стран составляла товары первой необходимости, такие как одежда, обувь, ткани, кофе, чай, кондитерские изделия.

По ИП в последние годы наблюдаются более высокие темпы развития экспортных торговых отношений с партнерами по ЕАЭС (кроме Армении, с которой, как отмечалось, имеются слабо налаженные экономические связи, в том числе и в секторе ИП), чем вне этого экономического сообщества.

Турция наряду с Китаем (здесь и далее для сравнения) находится в числе лидеров по взаимному обороту индивидуальных предпринимателей после стран-участников ЕАЭС и СНГ, занимая пятое место в рейтинге 2018 г. (четвертое - Китай), в рейтинге 2014 г. - первое место за счет большой доли в экспортных поставках (третье место - Китай). Значимость этих стран для ИП в течение последнего десятилетия значительно колебалась как в экспортных операциях, так и в импортных поставках (Табл. 1).

\begin{tabular}{|l|c|c|c|c|c|c|c|c|c|}
\hline & 2006 & 2009 & 2012 & 2014 & 2015 & 2016 & 2017 & 2018 \\
\hline - Доля экспорта, осуществляемого ИП (\% к общему объему экспорта ИП КР): \\
\hline в Турцию, \% & 16,1 & 11,1 & 5,0 & 36,9 & 4,2 & 1,6 & 1,1 & 2,1 \\
\hline в Китай, \% & 5,5 & 2,0 & 1,2 & 8,4 & 0,7 & 0,5 & 1,0 & 2,1 \\
\hline Доля импорта, осуществляемого ИП (\% к общему объему импорта ИП КР): \\
\hline из Турции, \%
\end{tabular}

Таблица 1. Показатели деятельности индивидуальных предпринимателей во внешней торговли по Туричии и Китаю. Источник: на основе данных НСК КР (Малое и среднее предпринимательство в КР 2006, 2013, 2018).

Анализ показывает снижение удельных показателей импорта по индивидуальным предпринимателям, прежде всего, по причине оживления взаимной торговли Кыргызской Республики и участниками ЕАЭС. Более заметно их снижение по импорту товаров из Китая, нежели по Турции.

Адаптация к новым условиям предпринимательства определила предпочтения участников внешней торговли. Итоги 2018 года показывают рост вклада индивидуального предпринимательства Кыргызской Республики во внешней торговле с Турцией и Китаем. Изменилась в целом структура взаимной торговли. Изменения не основаны на льготах тарифной политики ЕАЭС, поскольку лидерами в рейтинге оказались не обязательно страны ЕАЭС. Место в ранжировании по объему импортных поставок ИП распределилось в 2018 г. следующим образом: РФ (1 место), Китай (2), Узбекистан (3), Казахстан (4), Турция (5). Следует заметить, доля импорта из Китая не превысила уровень, например, 2012 или 2015 гг. В то же время, импорт из Турции сложился выше уровня 2012 г. на 6 процентных пунктов. Или: если объем поставок ИП из Китая возрос в 2018 году по сравнению с 2006 г. на 1,2 раза $(70123,9 / 58383,2)$, то из Турции - на 13,1 раза $(55009,3 / 4186,3)$.

Наращивание прежних объемов импорта ИП КР из Турции и Китая может показывать, что не в полной мере оправдались ожидания экспертов по комплексному восстановлению производственного потенциала страны в результате вступления в ЕАЭС. Адаптация предпринимателей КР к условиям таможенной политики евразийского экономического сообщества прошла с определением внешнеторговых партнеров вне данного сообщества, в частности, Турцией и Китаем. Эти страны под влиянием многих внутренних и внешних (в рамках ВТО) факторов способны осваивать производство постоянно обновляющегося и все более технически сложного ассортимента продукции и экспортировать их во внешний рынок.

\section{3 Значение Взаимной Торговли во Внешнеторговой Деятельности КР и Турции}

Одно из лидирующих мест во внешней торговле среди партнеров внешнеэкономической деятельности КР занимают Турция, с которой КР наладила торговые отношения одной из первых стран вне СНГ. Торговоэкономические отношения между Кыргызстаном и Турцией основаны на установлении дипломатических отношений между Республикой Кыргызстан и Турецкой Республикой в декабре 1991 г. и Соглашении об экономическом и торговом сотрудничестве между Республикой Кыргызстан и Турецкой Республикой.

Анализ данных за многолетний период внешнеторговых связей показывает интенсивное развитие торговых отношений между Кыргызской Республикой и Турцией (Табл. 2). 


\begin{tabular}{|l|c|c|c|r|r|}
\hline & 1996 & 1998 & 2000 & 2003 & 2006 \\
\hline Общчй оборот & & & & & \\
\hline Экспорт & 5252,1 & 7370,6 & 7178,3 & 11002,5 & 27225,6 \\
\hline Импорт & 47594,7 & 37384 & 26760,6 & 25988,9 & 39466,6 \\
\hline Баланс взаимного оборота & $-42342,6$ & $-30013,4$ & $-19581,7$ & $-14986,4$ & -12241 \\
\hline & 2009 & 2012 & 2015 & 2017 & 2018 \\
\hline Общчий оборот & 109456,2 & 225795,2 & 251495,8 & 356133,6 & \\
\hline Экспорт & 36654,3 & 50178,1 & 85203,7 & 131204,1 & 104272,5 \\
\hline Импорт & 72801,9 & 175617,1 & 166292,1 & 224929,5 & 290232,2 \\
\hline Баланс взаимного оборота & $-36147,6$ & $-125439,0$ & $-81088,4$ & $-93725,4$ & $-185959,7$ \\
\hline
\end{tabular}

Таблица 2. Внешнеторговый оборот КР и Турциии в период с 1996 по 2018 г2., тыс. долл. Источник: Внешняя торговля КР 2013, 2018.

Как видно, данные таблицы показывают интенсивное развитие внешнеторговых отношений между двумя странами. Заметное влияние на развитие оказал кризис 1998 года, который в первый же год сократил общий товарооборот на $38 \%$ в основном за счет снижения импортных поставок из Турции ИП. Докризисный уровень товарооборота был достигнут только к 2005 г. При этом все годы торгового сотрудничества между двумя странами характеризуются хроническим отрицательным сальдо взаимного оборота, который в силу определенных условий является признаком развития внешней торговли и в целом экономики КР. Показатель этого признака неблагоприятного развития национальной экономики КР с Турцией в последние годы имел определенную тенденцию к уменьшению, что может быть вызвано именно влиянием участия в ЕАЭС. Однако в 2018 г. он вновь имеет значительное отрицательное сальдо, превысив баланс предшествующего года почти вдвое.

Во внешней торговле КР со странами вне ЕАЭС Турция достойно соперничает с Китаем. Данные таблицы 3 показывают динамику показателей внешней торговли за большой период, что дает возможность оценить роль торговых отношений КР с Турцией, влияние на ее изменение деятельности ЕАЭС.

\begin{tabular}{|c|c|c|c|c|c|c|c|c|c|c|c|c|}
\hline & 2007 & 2008 & 2009 & 2010 & 2011 & 2012 & 2013 & 2014 & 2015 & 2016 & 2017 & 2018 \\
\hline $\begin{array}{l}\text { Доля экспорта КР в Турцию, } \\
\text { \% к общему экспорту КР }\end{array}$ & 3,3 & 2,8 & 2,5 & 2,5 & 2,8 & 3,0 & 4,3 & 4,6 & 5,7 & 5,7 & 7,4 & 5,7 \\
\hline ранжирование & $\ldots$ & 8 & 8 & 8 & 6 & 6 & 5 & 6 & 4 & 5 & 6 & 5 \\
\hline 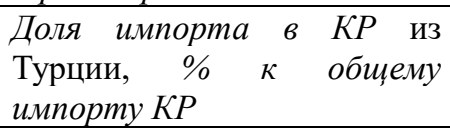 & 1,8 & 2,2 & 2,4 & 2,6 & 2,7 & 3,1 & 3,4 & 5,4 & 4,0 & 4,8 & 5,0 & 5,5 \\
\hline ранжирование & $\ldots$ & 9 & 9 & 8 & 8 & 7 & 7,0 & 4,0 & 4,0 & 4,0 & 4,0 & 4 \\
\hline
\end{tabular}

Таблица 3. Место Турцฺии во внешней торговле КР. Источник: Внешняя торговля КР 2008, $2013,2018$.

В перечне основных импортных и экспортных операций Кыргызской Республики Турция традиционно находится рядом с КНР, лидером мирового экспорта, и в последние годы сдвинулась вперед на несколько позиций. Так, Турция в 2018 г. занимала 4 место в рейтинге по импорту и 5 место по экспорту, поднявшись по сравнению с 2008 годом, соответственно, с 9-го и 8-го местов. Одним из аргументов вступления Кыргызстана в ЕАЭС было оживление инвестиционной деятельности в сферу производства на основе ресурсов извне. Открытие совместных производств дает возможность увеличить экспорт из КР (Савин, 2014). В этом плане сдвиги очевидны, так как с 2014 по 2017 гг. импортная квота КР сократилась на 17,8 п. п., а экспортная квота - только на 2,1 п. п., составив 23,3\% в 2017 г.

Как видно, участие Кыргызской Республики в ЕАЭС не является сдерживающим фактором для развития внешнеторговых связей и интеграции ее в мировое торговое сообщество.

При всей развитости экономики Турции сальдо торгового баланса остается отрицательным. Однако по статистическим данным внешней торговли Турции можно установить снижение разрыва между импортными и экспортными поставками. Так, если в 2018 г. отрицательное сальдо торгового баланса Турции составило 55126,5 млн. долл., то в 2019 г. - 31222,6 млн. долл. На этом фоне заметно для экономики Турецкой Республики определенное позитивное влияние внешней торговли с КР, с которой у Турции складывается положительное сальдо торгового баланса (Табл. 4).

Более того, отмечен его рост именно с периода функционирования ЕАЭС в связи с увеличением импорта из Турции товаров, связанных с производственной деятельностью, в частности, используемых в качестве сырьевого материала для легкой промышленности. Очевидно, что значимость внешнеторгового оборота Турции с КР несравнимо выше для КР, чем для внешней торговли Турции. Однако представляется важным определить тенденции в развитии взаимовыгодного сотрудничества двух стран. Так, экспортные поставки Турции в КР имеют тенденцию роста и составили в 2019 г. 0,25\% всего экспорта Турции в объеме 171480,8 млн. долл., увеличившись за год на 0,3 процентных пункта (п. п.). Вместе с тем доля импорта товаров из 
КР в общем импорте Турции (202703,4 млн. долл.) незначительна и относительно быстро снижается (на 0,4 п. п. за последние два года).

\begin{tabular}{|l|c|c|c|c|c|c|c|}
\hline & 2013 & 2014 & 2015 & 2016 & 2017 & 2018 & 2019 \\
\hline Общий оборот, млн. долл. & & & & & & & \\
\hline Экспорт в КР, млн. долл. & 388,3 & 421,4 & 294,7 & 308,9 & 343,6 & 377,1 & 430,5 \\
\hline Доля КР в общем экспорте, проичент & 0,26 & 0,27 & 0,2 & 0,22 & 0,22 & 0,22 & 0,25 \\
\hline Импорт из КР, млн. долл. & 37 & 65,6 & 76,9 & 101,1 & 143,8 & 47,3 & 43,3 \\
\hline Доля КР в общчем импорте, процент & 0,02 & 0,03 & 0,04 & 0,05 & 0,06 & 0,02 & 0,02 \\
\hline Баланс взаимного оборота & 351,3 & 355,8 & 217,8 & 207,8 & 199,8 & 329,8 & 387,2 \\
\hline
\end{tabular}

Таблица 4. Внешнеторговый оборот Туриии с КР за 2008-2017 г2. Источник: на основе данных Статистического института Tурияии (Turkish Statistical Institute. 16.03.2020).

\section{4 Анализ Товарной Структуры во Внешней Торговле КР с Турцией и Китаем}

Качественный аспект развития внешнеторговых отношений в целом характеризует показатель платежного баланса. По Кыргызской Республике он отрицательный как с Турцией, так и в отношениях с Китаем. И в настоящее время доля экспорта КР в Турцию самая большая из стран вне СНГ - 5,7\%, Китай на 2 месте $-3,3 \%$.

Проведем анализ товарной структуры для выявления тенденций развития экономики стран-партнеров внешнеторговой деятельности КР.

Из всего экспорта из Кыргызской Республики в Турцию 2008 г. в сумме 44852,5 тыс. долл. выделены три позиции: овощи свежие или охлажденные $(39,2 \%)$, орехи (около $12,6 \%)$ и хлопковое волокно $(10,9 \%)$. В 2017 г. структура товаров перераспределилась и доли этих товарных групп сократились, составив соответственно: 13\%, 2\% и 9\%. В 2018 г. товарная структура экспорта КР в Турцию заметно изменилась, определив ведущее место нефтепродуктам - 32,2\% (бункерное топливо); сельхозпродуктам - 20,4\% (в основном, бобовым) и хлопковому волокну $-11,9 \%$.

Импорт товаров в Кыргызскую Республику из Турции достаточно длительное время сохраняет в основном потребительскую направленность. Преобладающими товарными позициями импорта остаются машины и оборудование, химические товары, одежда и обувь. Структурный анализ импорта из Турции и Китая выявляет, что ожидания экспертов по комплексному восстановлению производственного потенциала КР в результате вступления в ЕАЭС в определенной мере оправдываются в сфере легкой промышленности. Известно, что она осуществляет производство своей продукции в основном на завозных сырьевом и комплектующем (компонентном) материалах. С 2014 г. доля текстиля и текстильных изделий в общем турецком импорте в КР выросла в 3 раза (Диаграмма 3).

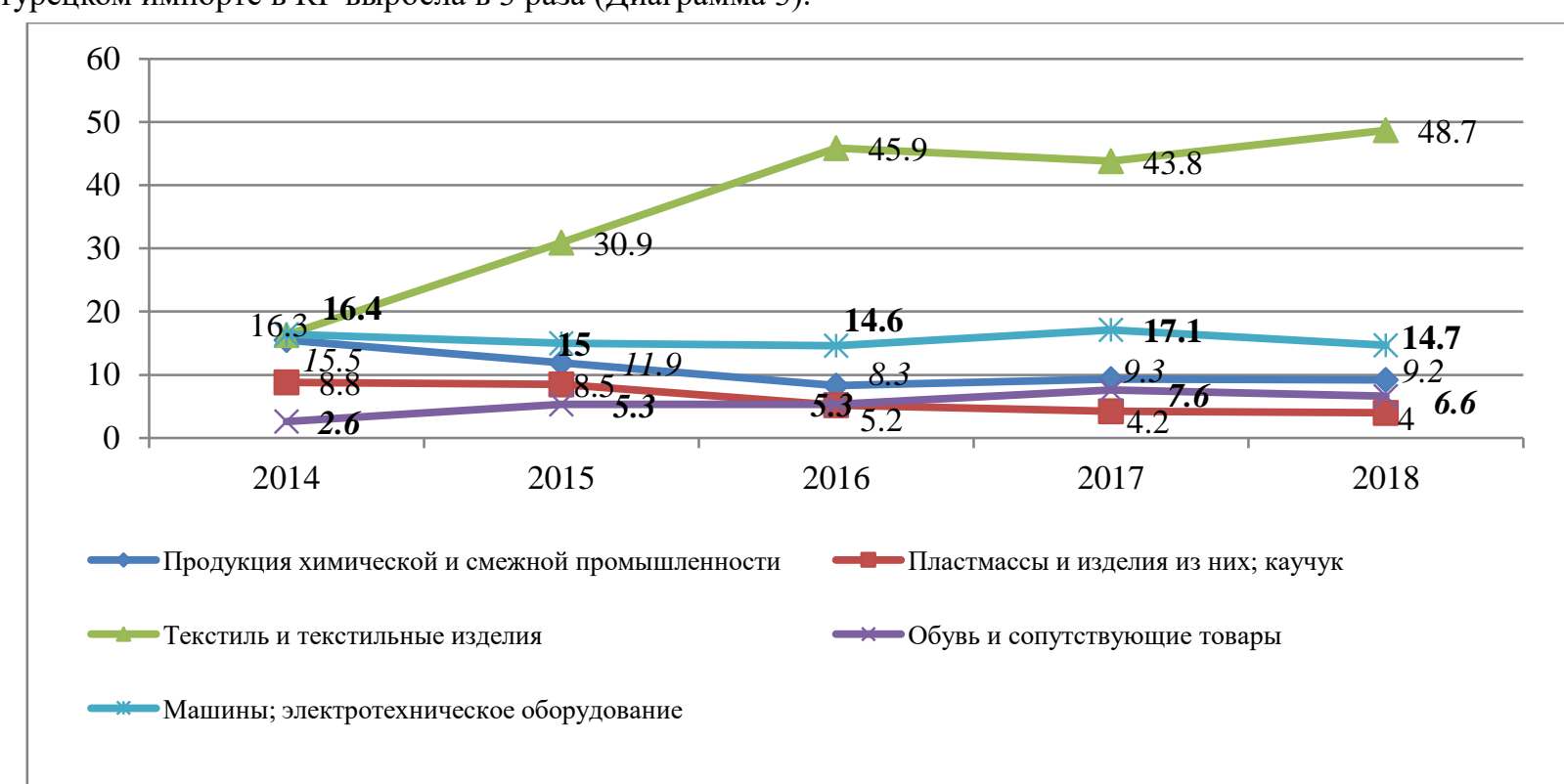

Диаграмма 3. Структура импорта КР из Туричи (по разделам ТН ВЭД ЕАЭС). Источник: Внешняя торговля КР 2018.

Анализ импорт товаров из Турции в 2018 г., кроме отображенных на диаграмме, выделяет также фармацевтическую продукцию (3,5\%); экстракты красильные, краски и лаки $(2,2 \%)$; полимерные материалы, пластмассы и изделия из них $(3,8 \%)$; трикотажное полотно машинного или ручного вязания $(7,4 \%)$ и др. 
Рост китайского импорта товаров в КР в целом умеренный. Однако здесь более выражена производственная направленность импорта: преобладающими импортными статьями являются не только обувь и одежда, но и машины и оборудование, химические товары и др. Следует отметить высокий темп роста импорта как в целом, так и по отдельным товарным группам. Так, например, рост трикотажного полотна машинного или ручного вязания в 2018 г. составил 143 раза по сравнению с 2014 г. и в 8 раз по сравнению с 2017 г. В сложившейся структуре большую долю занимают химические товары, электрические машины и оборудование, что может положительно влиять на развитие производства в КР.

Каким будет развитие внешнеторговой деятельности Кыргызской Республики после пандемии по коронавирусу Covid-19? Несомненно, влияние ее будет реально ощутимым для экономики Кыргызстана, до сих пор функционирующей в условиях отсутствия какой-либо индустриализации и даже без аграрного товарного производства, так как, по сути, сельское хозяйство это мелкое фермерство в домашних хозяйствах. Как подчеркивалось выше, в развитии экономики КР большое влияние оказывает индивидуальное предпринимательство. В годы становления рыночной экономики именно предпринимательство в сфере внешней торговли положило начало социально-экономическому развитию Кыргызстана. В условиях пандемии остановилось функционирование малого бизнеса, ориентированного на торговлю импортируемыми непродовольственными товарами. Следовательно, невосполнимый урон будет нанесен в первую очередь ИП и всей цепочке связанных с ним звеньев экономики. В том числе налаженной в условиях ЕАЭС системе швейной промышленности, ориентированной на экспорт в силу малого внутреннего рынка.

Мир после пандемии, несомненно, будет другим. Общество должно пересмотреть человеческие ценности, как материальные, так и духовные. В первую очередь, это затрагивает принципов общественного рационального (не бездумного) потребления, основанном на рационализации производства, максимально щадящем экологию, и присущей ей международном разделении труда. Следовательно, будет основание не только для восстановления, но и развития внешней торговли в КР.

\section{5 Инвестиционная Политика Внешнеэкономической Деятельности КР: Китайский и Турецкий Аспект}

Открытость экономики - один из признаков развитости внешней торговли. К количественным показателям открытости экономики относятся экспортная и импортная квоты. За период с 2008 года в КР произошло снижение этих показателей: экспортной квоты с 36,1\% до 23,3\% в 2017 году, импортной квоты, соответственно, с 79,2\% до 59,4\%, которые, однако, характеризуют приемлемую степень открытости экономики. Снижение вызвано влиянием не только объективных факторов (снижение общей инвестиционной активности), но и субъективных. К ним, в частности, можно отнести снижение инвестиционной привлекательности КР вследствие имевших место определенных фактов правовой незащищенности иностанных инвесторов.

Один из критериев открытости экономики предполагает организацию хозяйственной деятельности на основе различных форм предпринимательства, в том числе совместного и иностранного предпринимательства. На смену государственной и кооперативной форм торговли плановой экономики пришла многоукладная торговая система с индивидуальной, частной и акционерной формами собственности. Особую роль в таком развитии в сфере внешней торговли сыграли индивидуальные предприниматели, освоившие «челночный» бизнес. Они стояли у истоков современной внешней торговли КР и явились стартовой площадкой для перехода на более высокий уровень предпринимательской деятельности (уровень малого, среднего, крупного бизнеса) и совместного предпринимательства.

Анализ сотрудничества в сфере инвестиций позволяет не только определить векторы инвестиционной политики, но и перспективы развития торговых отношений между КР и другими странами. За период 20142018гг. Турции и Китай наряду со странами ЕАЭС и СНГ продолжали оставаться основными торговыми партнерами предприятий с иностранными инвестициями (Диаграмма 4). 


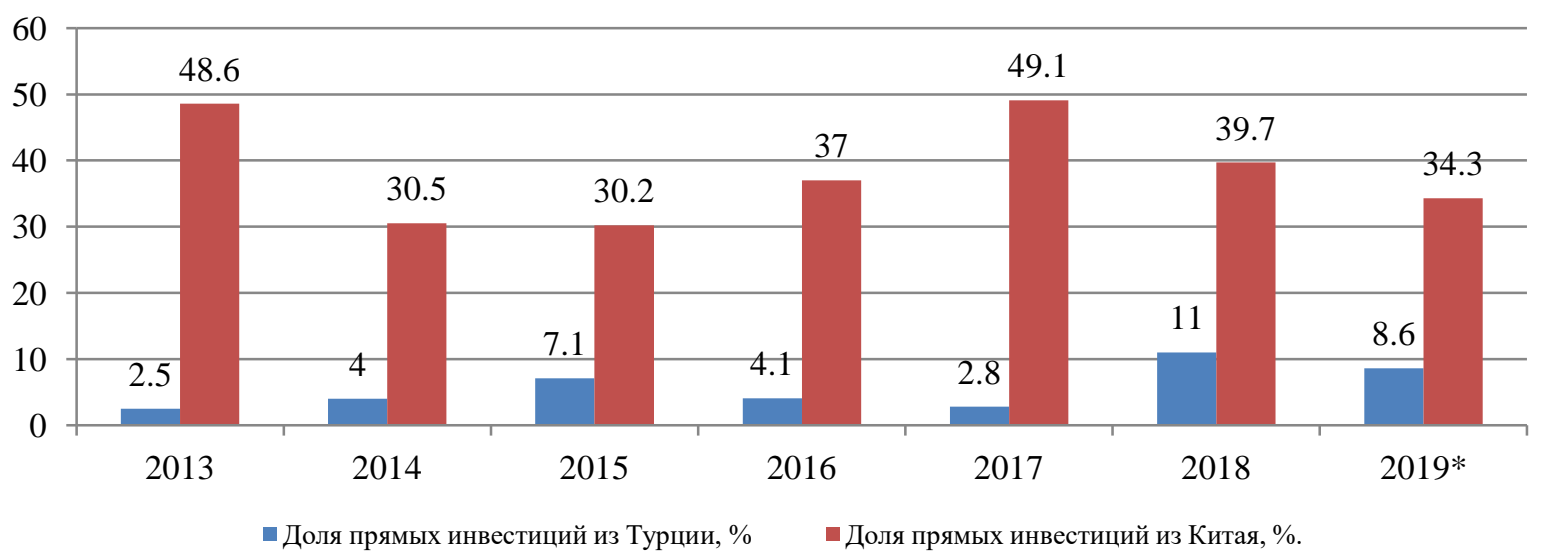

Диаграмма 4. Структура прямых инвестиций в КР из Китая и Туричи. Источник: на основе данных НСК КР. *Примечание: данные 2019 г. предварительные.

Сравнительный анализ показателей динамики прямых инвестиций из Китая и Турции позволяет выявить тенденцию роста инвестиционной деятельности турецких предпринимателей. Как видно, инвестиционный вклад Китая несопоставимо выше турецкого. Однако заметен и тренд в инвестиционной деятельности рост доли турецких прямых инвестиций в 2018 году по сравнению с 2014 г. почти в 3 раза. При общем снижении прямых иностранных инвестиций по КР в 2018 по сравнению с 2013 г. на 11,7\% их рост из Турции составил 3,9 раза, в то время как по Китаю наблюдается снижение прямых инвестиций на $18 \%$ (HCK, 2018).

Предприятия с иностранными инвестициями вносят определенный вклад в качественном развитии внешней торговли КР. Удельные показатели внешнеторговых показателей, осуществляемых предприятиями с иностранным капиталом за период с 2014 г., по экспорту повысились - с 23,3\% до 26,8\% от общего экспорта по КР (доля экспорта предприятий с турецким капиталом составляет 16,1\%, с китайским - 6,5\%), по импорту снизились с 38,5\% до 31,8\% (доля импорта предприятий с турецким капиталом составляет $2,6 \%$, с китайским - 30,2\%). Эти данные говорят о том, что продукции предприятий с турецким капиталом конкурентоспособны и ориентированы на внешний рынок.

Важной составляющей достижения целей интенсивного развития экономики КР является привлечение турецких инвестиций, прежде всего в текстильную, легкую промышленность (подготовка и прядение хлопковых волокон, производство обуви ковров и ковровых изделий, мебели); пищевую (производство хлеба и мучных кондитерских изделий недлительного хранения, макаронных изделий, какао, шоколада и кондитерских изделий из сахара); химическую промышленность и производство строительных и отделочных материалов (производство красок, эмалей и лаков на основе полимеров, изделий из бетона для использования в строительстве, кирпича, черепицы и прочих строительных изделий); в строительство (объектов жилого, нежилого и другого гражданского назначения); в сельское хозяйство (разведение крупного рогатого скота молочного направления, сельскохозяйственной птицы, переработка и консервирование фруктов и овощей.), сферу услуг (деятельность грузового автомобильного транспорта), торговлю (оптовая и розничная, массовое питание); туризм и др. (сортировка и переработка отходов для получения вторичного сырья).

В КР в 2018 г. численность предприятий с участием капитала из Китая выросла по сравнению с 2014 г. на 143,9\% и составила 639 единиц, 70\% из которых - с полным участием китайского капитала. Предприятий с участием турецкого капитала 405 единиц, что по сравнению с 2014 г. меньше на 3\%, но доля предприятий с полным участием турецкого капитала больше - 72,1\%.

Многолетний пример успешной предпринимательской деятельности турецких инвесторов в КР показывают такие участники реального сектора в КР, как ЗАО «Кока-Кола Бишкек Боттлерс» (производство безалкогольных напитков), действующий с 1995; ЗАО «Бета Кыргызстан Интернэшнл» (производство и переработка чая и кофе, 1996); ОcОО «Yildizlar» (производство ковров и ковровых изделий, 1996); Закрытое акционерное общество «Акун» (производство муки из зерновых, 1997); ЗАО «Бета Иншаат Ятырымжылык» (розничная торговля, 1997); ОсОО «Яшар» (производство муки из зерновых, 1997); ОcОО «Челеби Пластик Сан А.Ш.» (Производство пластмассовых изделий, 1997); Турецкая фирма «Plasform Ambalaj Sanayi ve Ticaret A.S.» (Производство пластмассовых изделий, 1998); ОсОО «Паритет» (Производство какао, шоколада и кондитерских изделий, 1998); ОсОО «Пак Кыргызстан» (Производство дрожжей, 1998); OcOO «Winterlux» (Производство промышленного холодильного и вентиляционного оборудования, 1998); OcOO «Lion» (Розничная торговля, 2004) и др. 


\section{6 Проблемы Сопоставимости Статистики Внешней Торговли}

При обработке статистических данных по теме исследования возникла необходимость сравнительной оценки значимости взаимной внешней торговли для КР и стран-партнеров. Следует отметить, что для обеспечения сопоставимости данных статистики разных стран существует Система национальных счетов (CHC), как совокупность согласованных форм и рекомендаций для ведения расчетов и упорядочивания макроэкономических показателей. Кроме того имеется Руководство по Статистике международной торговли товарами, разработанное ООН. На практике, однако, имеются различия в официальной информации по внешней торговле разных стран. Как отмечают исследователи, это может быть обосновано: 1) нерезультативностью существующих статистических методологий; 2) неточностью и недостоверностью учета товаров статистическими органами; 3) наличием нелегального ввоза и вывоза товаров. Эти причины в меньшей или большей степени носят субъективный характер. Поэтому размеры отклонения зависят от постановки дела в государственном управлении.

Сравним показатели внешней торговли КР по данным Национального статистического комитета (HCK) Кыргызской Республики и Статистического института Турции (Таблица 5).

\begin{tabular}{|c|c|c|c|c|c|c|}
\hline & 2007 & 2008 & 2009 & 2010 & 2011 & 2012 \\
\hline $\begin{array}{l}\text { Импорт из Турции (статистические данные } \\
\text { КР) }\end{array}$ & 50919 & 91111 & 72802 & 84700 & 117090 & 175617 \\
\hline $\begin{array}{l}\text { Экспорт в КР (статистические данные } \\
\text { Турции по специальной торговой системе) }\end{array}$ & 181311 & 191351 & 140002 & 129202 & 180241 & 234947 \\
\hline Отклонение & -136291 & -100240 & -67200 & -44502 & -168532 & -59330 \\
\hline $\begin{array}{l}\text { Отнотение импорта по статистическим } \\
\text { данным Туричии к официальнымм по КР }\end{array}$ & 3,6 & 2,1 & 1,9 & 1,5 & 1,5 & 1,4 \\
\hline & 2013 & 2014 & 2015 & 2016 & 2017 & 2018 \\
\hline $\begin{array}{l}\text { Импорт из Турции (статистические данные } \\
\text { КР) }\end{array}$ & 204730 & 307968 & 166292 & 191102 & 224930 & 290232 \\
\hline $\begin{array}{l}\text { Экспорт в КР (статистические данные } \\
\text { Турции по специальной торговой системе) }\end{array}$ & 388336 & 421431 & 294702 & 308933 & 343600 & 377073 \\
\hline Отклонение & -183606 & -113463 & -128410 & -117831 & -118670 & -86841 \\
\hline $\begin{array}{l}\text { Отноомение импорта по статистическим } \\
\text { даннымм Турции к официальным по КР }\end{array}$ & 1,9 & & 1,8 & 1,6 & 1,5 & 1,3 \\
\hline
\end{tabular}

Таблица 5. Анализ показателей по импорту в КР из Турции, тысс. долл. Источник: на основе данных НСК КР (Внешняя торговля КР 2007, 2019) и Статистического института Туричи.

Как видно, отклонение показателей по импорту в соответствии со статистикой Кыргызской Республики и его зеркального показателя (экспорта из Турции в Кыргызстан по статистике Турции) огромное. Пик его за исследуемый период, как отмечено выше, пришелся на 2007 г., когда отклонение зеркальных показателей турецкого импорта превысил официальный статистический по КР в 3,6 раза. Если в 2013 г. турецкий импорт в КР по статистике Турции больше его официального показателя в 1,9 раз, в 2018 г. он несколько снизился (до 1,3 раз). Именно эта неравномерность в отклонениях за весь исследуемый период в первую очередь исключает влияние методологического характера выявленных больших расхождений по импорту в статистике внешней торговли КР от зеркальных показателей стран-партнеров.

Выше отмечалось, что во внешнеторговых операциях Кыргызской Республики Турция в течение длительного периода находится рядом с КНР. Во внешней торговле Кыргызстана в последние годы Китай занимает 1 место по импорту, Турция - 4. И если анализировать аналогичные показатели по Китаю, выявится, что отклонение официальных показателей импорта товаров из Китая от зеркальных по статистическим данным Китая (соответственно, экспорт) более значительное по сравнению с импортом из Турции. Официальные показатели по импорту из Китая отличаются от зеркальных от 1,9 до 3,7 раз в период 2013-2018 гг. Разброс, как видно, большой. При этом как по Турции, так и по Китаю сохраняется тенденция уменьшения расхождения. Представляется, это результат борьбы с коррупцией в налоговых и таможенных органах, которая проводится в последние годы в КР, как резонанс на исследование проблемы достоверности статистики внешней торговли КР. Выявление государственными контролирующими органами коррупционных схем вывода из госбюджета НДС в 2017-2018 гг. способствовало возврату в бюджет огромных потерь (Фынчина, 2019).

Для обеспечения определенной объективности проанализируем показатели официальных данных взаимной внешней торговли между Турцией и Грузией, считающейся страной с наименьшим уровнем коррупции (Таблица 6). 


\begin{tabular}{|c|c|c|c|c|c|c|}
\hline & 2013 & 2014 & 2015 & 2016 & 2017 & 2018 \\
\hline Импорт из Туричии (НСС Грузии) & 1410197 & 1728816 & 1327478 & 1353585 & 1373739 & 1473173 \\
\hline $\begin{array}{l}\text { Экспорт в } \\
\text { Турции) }\end{array}$ & 1245917 & 1443790 & 1108740 & 1176634 & 1208645 & 1315101 \\
\hline $\begin{array}{l}\text { Отночение импорта туреццких } \\
\text { товаров в Грузию к зеркальной по } \\
\text { Туричии }\end{array}$ & 1,13 & 1,2 & 1,2 & 1,15 & 1,14 & 1,12 \\
\hline Сумма расхождения & 164280 & 285026 & 218738 & 176951 & 165094 & 158072 \\
\hline То же в процентах к импорту Грузии & 11,6 & 16,5 & 16,5 & 13,1 & 12,0 & 10,7 \\
\hline
\end{tabular}

Таблица 6. Динамика импорта туреиких товаров в Грузию, тыс. долл. Источник: на основе данных НСС Грузии и Статистического института Туричии.

В случае с импортом турецких товаров в Грузию отмечается расхождение с положительным значением. То есть по статистическим данным Турции в Грузию экспортировано товаров меньше, чем импортировано по статистическим данным Грузии или наоборот. В течение анализируемого периода: превышение данных по турецкому импорту товаров в Грузию составляет в пределах 10-16 процентов к импорту Грузии товаров из Турции. Такое линейное в целом и сравнительно незначительное отклонение на фоне данных по КР можно обосновать использованием разных методологических подходов к ведению статистики внешней торговли в Грузии и Турции.

Такая равномерность официальных показателей внешней торговли Турции с зеркальными данными НСС Грузии (Национальная статистическая служба Грузии, 10.03.2020) может быть демонстрацией отсутствия коррупции в деятельности соответствующих служб, контролирующих внешнюю торговлю двух стран. Особенно если рассмотреть данную проблему, оперируя международными критериями. Прежде всего, исходя из рейтинга стран по Индексу восприятия коррупции, как основного результата исследований Международной неправительственной организациии «Transparency International». В 2019 году он был составлен для измерения коррупции в государственном секторе в 180 странах с присвоением баллов от нуля (очень коррумпированный) до 100 (очень чистый). В этом рейтинге 2019 года Кыргызстан занимает 126 место с 30 баллами, улучшив соответствующий показатель 2015 года (28 баллов). Относительно КР лучше ситуация с коррупцией в Турции - 91 место (39 баллов против 42 баллов, ухудшение); в Китае - 80 место (41 балл против 37 баллов); в Грузии - 44 место (56 баллов против 52 баллов). (Corruption perceptions index, 2019).

Представляется, эти рейтинговые показатели места страны в полной мере соответствуют данным, полученным в результате анализа показателей зеркальной статистики внешней торговли КР с Турцией и Китаем.

Заметим, что проблему таких расхождений в объемах поставок в КР со странами-партнерами поднимали и ранее. Например, исследование достоверности статистики внешней торговли КР определило уровень положительного расхождения с Турцией за период с 2008 по 2012 гг. в размере 64,7\% к импорту (352142 тыс. долл.), с Китаем - 564\% (Зеркальная таможенная статистика КР, 2014). Однозначно, наличие высокого уровня расхождений между официальной информацией и зеркальной статистикой является следствием коррупционного фона в таможенном деле Кыргызской Республики, приводящим к большим потерям государственного бюджета, составившим за исследуемый пятилетний период с 2008 по 2012 гг. 15,5 млрд. сом. Один из выводов исследования - это: содержание высокой степени недостоверности в таможенной статистике Кыргызстана.

\section{7 Заключение}

Кыргызская Республика проводит в сфере внешнеэкономической политики стратегию эффективного интегрирования в мировую экономику. Внешняя торговля является основным факторов для достижения целей интеграции, развития экономики и обеспечения ее стабилизации страны.

На основе проведенного исследования можно сделать выводы и определить тенденции развития:

- В целом участие КР в ЕАЭС привело к 2018 г. к оживлению торговых отношений, которое показывает динамику роста практически со всеми странами-участниками экономического сообеесва. Положительной тенденцией развития является улучшение структуры товарооборота КР с основными внешнеэкономическими партнерами - опережающий рост экспортных операций из КР по сравнению с ростом импорта.

- Высокие темпы развития внешнеторговых связей с Турцией и Китаем показывают, что участие Кыргызской Республики в ЕАЭС является параллельным направлением развития внешней торговли наряду с участием в ВТО и не является сдерживающим фактором для развития внешнеторговых связей и интеграции в мировое торговое сообщество. В том числе и по индивидуальным предпринимателям, 
по которым наблюдаются более высокие темпы развития экспортных торговых отношений с партнерами по ЕАЭС, чем вне этого экономического сообщества.

- Структурный анализ импорта из Турции и Китая показал, что определенные ожидания экспертов по комплексному восстановлению производственного потенциала страны в результате вступления в ЕАЭС оправдываются в сфере легкой промышленности, что вытекает из более выраженной производственной направленности импорта.

- Анализ официальных данных внешней торговли Кыргызской Республики и зеркальной статистики стран-партнеров выявил проблему наличия недостоверности в информации по внешней торговле КР и возможные потери бюджета. Выявленные различия в официальной информации КР по внешней торговле и зеркальной по Турции составили значительные неравномерные размеры долей отклонений в общем объеме экспортных/импортных торговых операций. Рассмотрение вопроса на фоне значений оценки КР в международном рейтинге индекса восприятия коррупции и на основе выводов по исследованиям независимых экспертов позволяет определить наличие в таможенном деле КР значительной коррупционной составляющей в проблеме расхождений официальной статистики внешней торговли КР от зеркальной стран-партнеров.

- Кризис вследствие пандемии по коронавирусу будет реально ощутимым для развивающейся экономики Кыргызстана. Однако принципы построения новых взаимоотношений человека и общества будут базироваться на рационализации потребления и производства, что станет основанием для восстановления и развития внешней торговли Кыргызской Республики.

Таким образом, можно заключить, что ЕАЭС способствует развитию экономики КР в рамках международного экономического взаимодействия на постсоветском пространстве. Параллельное сотрудничество во внешнеэкономической деятельности - это Юго-восточное направление, в котором лидерами являются Китай и Турция. ЕАЭС и Всемирная торговая организация (ВТО) по сути являются партнерскими организациями, ставящими целью либерализацию международной торговли и развитие внешнеэкономической деятельности КР. Учитывая уровень развития и структуру экономики Кыргызстана, можно утверждать, что развитие внешней торговли способно быстро и эффективно сгладить негативные социально-экономические последствия современного кризиса экономики, вызванного пандемией вирусной инфекции.

\section{Литература}

- Государственное статистическое управление Китая. Foreign Trade and Economic Cooperation, http://www.stats.gov.cn/tjsj/ndsj/2013/indexeh.htm (http://www.stats.gov.cn/tjsj/ndsj/2014/indexeh.htm http://www.stats.gov.cn/tjsj/ndsj/2018/indexeh.htm), http://english.customs.gov.cn/Statics/38407e5f-81c34c22-95a8-36a1515c9be7.html), 2020.

- Зеркальная таможенная статистика Кыргызской Республики 2008-2012. (Аналитическое исследование) - Бишкек: 2014, 82 с. (http://precedent.kg/wpcontent/uploads/2017/08/Mirror_customs_statistics_2014_Final_20.pdf)

- Национальная статистическая служба Грузии. https://www.geostat.ge/ka, 2020.

- $\quad$ Савин B.E. Развитие торговых отношений Кыргызстана и Китая // Вестник Бишкекского гуманитарного университета им. К. Карасаева. - 2014. - № 3.

- Статистические сборники НСК КР «Внешняя торговля КР» НСК КР, 1996-2017; «Малое и среднее предпринимательство в КР», 2006-2018.

- Статистический институт Турции, 2020. Foreign Trade Statistics, http://www.turkstat.gov.tr/PreTablo.do?alt_id=1046, 2020.

- Фынчина X.A. Налоговый контроль как инструмент обеспечения налоговой безопасности Кыргызской Республики / Х.А. Фынчина // Вестник КРСУ. 2019. Т. 19. № 7. С. 64.

- $\quad$ Transparency International. Corruption perceptions index 2019. https://www.transparency.org/cpi2019?/news/feature/cpi-2019. 


\title{
Анализ Инновационного Потенциала в Управлении Здравоохранением Азербайджана
}

\section{Analysis of Innovative Potential in Healthcare Management of the Republic of Azerbaijan}

\author{
Prof. Dr. Farhad Rahmanov (Azerbaijan State Economy University, Azerbaijan) \\ Assoc. Prof. Dr. Elchin Suleymanov (Baku Engineering University, Azerbaijan)
}

\begin{abstract}
In the paper we have studied the progress and results of reforms in the healthcare system of Azerbaijan, the role of national programs for the modernization of various health sectors in strengthening public health in context of the problems facing the Azerbaijani economy. A notable progress is being made in the transformation of the delivery system medical care for the population over the years of reform. Particular attention is paid to the issues of medical science, improving the system of training medical personnel, increasing the reliability of medical data, and the introduction of information and communication technologies in the health sector. There is a need to develop and implement a model of the medical information system for medical institutions as a key element in the development of priority national health programs. The paper pays attention to the improvement of the organization, management, and financial support of the medical care system. In this regard, it is noted that it is necessary to apply the most effective ways of organizing medical care and using the available resource potential based on the introduction of innovative management technologies.
\end{abstract}

\section{1 Введение}

Усиление социальной ориентации экономического развития, происходящее на современном этапе, обусловливает необходимость совершенствования управления отраслями социального сектора Азербайджана. В связи с этим большое теоретическое и практическое значение приобретают проблемы повышения эффективности отраслей, оказывающих населению разного рода услуги социальнокультурного, материально-бытового и др. характера, и в их числе здравоохранения. Целью статьи является исследование трансформации сферы здравоохранения Азербайджана и разработка рекомендаций по повышению инновационного потенциала в управлении здравоохранением республики. При проведении исследования использованы такие методы, как сравнительный анализ, методы оценки, статистические данные.

Научная гипотеза состоит в обосновании положения, что ключевой проблемой, затрудняющей формирование адекватной сегодняшним вызовам системы здравоохранения республики, является низкая восприимчивость современного менеджмента в здравоохранении к социальным и управленческим инновациям. Проведенное исследование показало, что сложное переплетение факторов, содействующих и препятствующих внедрению инноваций в здравоохранение республики, формирует темпы внедрения инновационных решений в организационно-экономическом механизме управления учреждений сферы здравоохранения. Как показал анализ, переход здравоохранения на современную инновационную модель роста осуществляется медленными темпами, в частности, сохраняется непозволительно низкий уровень инновационной активности в управлении этой сферой. В то же время, сфера охраны здоровья в Азербайджане, так же как и вся социальная сфера, остро нуждается в широком использовании инноваций в хозяйственном механизме, в управлении и технологическом развитии. Необходимо расширение инновационного поля в отрасль, чья деятельность непосредственно формирует качество жизни граждан республики.

Учитывая особенности сферы здравоохранения, где решающую роль играет человеческий фактор, следует содействовать всемерному распространению инновационных технологий, позволяющих снизить затраты учреждений, разгрузить органы управления сферой от второстепенных задач и направить, тем самым, их внимание на решение стратегических проблем. Отмечается, что устранение основных проблем инновационного управления в здравоохранении под углом зрения развития медицинской науки, образования, стандартизации, информатизации и т.п. требует существенных ресурсных и временных затрат.

Анализ, проведенный в работе, дал возможность выделить ряд направлений, в об-ласти дальнейшего развития рыночных отношений в отрасли, совершенствования законо-дательной базы, развития институциональной инфраструктуры, системы стандартов ока-зания медицинской помощи, а также развития страховых принципов финансирования и обучения управленческих кадров, особенно важных для выработки государственной поли-тики в области инновационного развития здравоохранения. Исследование иннова-ционного потенциала управления сферы здравоохранения Азербайджана и 
выдвинутые предложения по его совершенствованию смогут способствовать эффективному решению задач социального развития, повышению человеческого капитала страны.

Обосновывается вывод о том, что укрепление инновационного потенциала управления является в современных условиях важнейшим направлением повышения результативности здравоохранения, дающим возможность существенно повысить эффективность использования ресурсов в этой сфере.

В период социально-экономических реформ, благодаря значительному увеличению государственного финансирования здравоохранения (в 14,5 раза), в этой сфере был реализован ряд масштабных государственных программ: национальные программы модернизации различных секторов здравоохранения; развития кадрового потенциала в общественном здравоохранении; программа «Электронный Азербайджан» и др., которые позволили увеличить обеспечение медицинских учреждений республики современным оборудованием, увеличить объемы лекарственной, профилактической и высокотехнологичной медицинской помощи населению Азербайджана. В то же время наблюдались положительные изменения в состоянии здоровья населения: снизились показатели смертности, стабилизировались показатели заболеваемости ( см. Табл 1).

\begin{tabular}{|l|c|c|c|c|c|c|}
\hline \multicolumn{1}{|c|}{$\begin{array}{c}\text { Характеристика } \\
\text { Здоровья }\end{array}$} & $\mathbf{1 9 9 0}$ & $\mathbf{1 9 9 5}$ & $\mathbf{2 0 0 0}$ & $\mathbf{2 0 0 5}$ & $\mathbf{2 0 1 0}$ & $\mathbf{2 0 1 8}$ \\
\hline Коэффициент смертности & 9,1 & 6,7 & 5,9 & 6 & 6,5 & 6,8 \\
\hline $\begin{array}{l}\text { Все причины смерти (на 100 тыс.чел.), } \\
\text { в том числе: }\end{array}$ & 606 & 672 & 589 & 606 & 599,7 & 583,6 \\
$\quad$-от болезней системы кровообращения & 293,8 & 340,6 & 330,5 & 348,0 & 364,4 & 385,6 \\
-от новообразований & 68,1 & 62,9 & 64,1 & 77,6 & 74,3 & 65,1 \\
\hline Продолжительность жизни мужчин & 67,0 & 65,2 & 68,6 & 69,5 & 70,9 & 73,1 \\
\hline Продолжительность жизни женщин & 74,8 & 72,9 & 75,1 & 75,2 & 76,2 & 78,2 \\
\hline Коэффициент младенческой смертности & 23,0 & 23,3 & 12,8 & 12,8 & 11,2 & 10,6 \\
\hline Коэффициент материнской смертности & 17 & 53 & 44 & 34 & 15,7 & 14,0 \\
\hline Заболеваемость на 1000 человек & 245 & 212 & 171 & 177 & 180 & 183 \\
\hline
\end{tabular}

Таблица 1. Динамика Здоровья Населения Азербайджана Источник: Energy Статистические Показатели Азербайджана в 2018 г.,

В период ускоренного экономического роста системе здравоохранения удалось обеспечить динамику сокращения показателей смертности от отдельных причин; сохранена доступность бесплатной медицинской помощи для населения; реализован комплекс мероприятий по реструктуризации системы оказания медицинской помощи и повышению ее эффективности; увеличена заработная плата медицинским работникам.

Конкретно продвижение в реформировании системы оказания медицинской помощи обеспечено по следующим направлениям:

- расширение мероприятий по профилактике заболеваний, расширение масштабов и повышение эффективности диспансеризации населения.

- $\quad$ реорганизация сети больниц в сторону их укрупнения и сокращения маломощных и неэффективных подразделений.

- развитие стационарозамещающей медицинской помощи.

- формирование трехуровневой системы оказания медицинской помощи, соз-дание в регионах Азербайджана межрайонных центров, в которых концентрируются диаг-ностические и кадровые ресурсы специализированной помощи в муниципальных образованиях.

- $\quad$ развитие сектора высокотехнологичной медицинской помощи, расширение объемов этой помощи, в том числе в региональных медицинских учреждениях.

- совершенствование системы подготовки медицинских кадров (Арас О., Сулейманов Э.2016).

Вместе с тем, многие важные вопросы совершенствования организации, управления и финансового обеспечения системы оказания медицинской помощи пока еще остаются нерешенными.В выступлениях руководства страны, в научных публикациях подчеркивается несоответствие между требованиями современного периода развития Азербайджана и возможностями его сферы здравоохранения. Проблемы развития системы здравоохранения, затрагивающие жизненные интересы граждан, обнаруживаются практически во всех его структурах - низкий уровень управления, недостаточное финансирование, дефицит квалифицированных медицинских кадров и т.п.

В принятых за последние годы программных документах: Концепции развития «Азербайджан-2020: взгляд в будущее», «Стратегической дорожной карте по развитию национальной экономики и ее основных секторов» и др.(World Bank, 2010.) отмечается: чтобы улучшить ситуацию с состоянием здоровья граждан, необходимо обеспечить качественный прорыв в системе здравоохранения. Отечественной сфере 
здравоохранения нужны инновационные разработки в сфере профилактики, диагностики и лечения заболеваний, эффективная система управления, подготовки медицинских кадров и квалифицированных специалистов, способных решать задачи инновационного развития.

Низкая восприимчивость современного менеджмента в здравоохранении к социальным и управленческим инновациям является, на наш взгляд, одной из основных проблем, затрудняющих формирование адекватной сегодняшним вызовам сбалансированной социально-экономической системы. Задача выхода на уровень развитых стран по показателям благосостояния диктует новые требования к системе управления здравоохранением, использование и внедрение инновационных управленческих технологий (Зарецкая, 2011).

В связи с этим возникает целый комплекс научных и практических проблем, объединяемых одной концепцией: Азербайджану необходимо добиться, чтобы при тех ресурсах, которые республика может выделить на развитие сферы здравоохранения, был получен максимально возможный эффект в плане повышения качества жизни граждан, улучшения показателей здоровья населения республики. Такая задача неразрешима при технологиях, устоявшихся с советских времен, и в силу этого инновационный вектор развития для этой сферы важен не менее, чем для отраслей материального производства. При этом инновации необходимы не только в рамках самого производства медицинских услуг (инновационные программы медицинского образования, высокотехнологичная медицинская помощь, и т.п.), но и, прежде всего, в сфере управления здравоохранительным комплексом, что может дать значительно больший социально-экономический эффект.

Однако в данном направлении существует определенный дефицит научных разработок: если частные направления инновационного развития социальной сферы уже рассматривались в отдельных публикациях , то в республиканской литературе практически еще не было попыток комплексного рассмотрения инновационного процесса в управлении сферой здравоохранения. В настоящей статье проведен анализ инновационного потенциала в управлении здравоохранением в современном Азербайджане и определены пути его совершенствования в перспективе.

\section{2 Анализ Состояния Научного Потенциала Здравоохранения Азербайджана}

Инновационная модель развития здравоохранения республики предусматривает тесное взаимодействие системы здравоохранения и медицинской науки, применения современных методов управления, планирование научных медицинских исследований в зависимости от потребностей здравоохранения, активное внедрение научных результатов в медицинскую практику, а также целенаправленную подготовку специалистов, способных обеспечить внедрение научных достижений.

На наш взгляд, проблема инноваций на современном этапе развития азербайджанского здравоохранения является ключевой. Передовые инновационные технологии в области управления здравоохранением могли бы способствовать качественному прорыву в системе здравоохранения и совершенствованию доступности медицинской помощи.

Как известно, инновационный потенциал объединяет в себе характеристики всех видов ресурсов, непосредственно участвующих в реализации инновационного процесса, совокупность технологических, коммерческих, управленческих компетенций для генерации, распространения и использования нововведений(Арас,Сулейманов.2016). Он характеризует возможность дальнейшего развития инновационных процессов, создания новых продуктов, а также диффузии инноваций в другие области хозяйственной деятельности.

В настоящий момент в Азербайджане есть элементы инновационного потенциала, в т.ч. компоненты, необходимые для развития инновационных технологий в здравоохранении: научная база и кадры с большим потенциалом, инвесторы, а также компании, импортирующие зарубежные инновационные разработки.

Единство науки, образования и практики должно обеспечить отечественное здравоохранение не только принципиально новыми способами диагностики и лечения самых различных заболеваний, но и современными методами управления в здравоохранении.

Научный потенциал медицины служит отправной точкой в осуществлении начальных стадий инновационного процесса, являясь одной из наиболее важных составляющих инновационного потенциала. Уровень развития медицинской науки определяет перспективы совершенствования всей системы здравоохранения. Вместе с тем, настоящее состояние медицинской науки в республике характеризуется размытостью приоритетов, невысоким инновационным потенциалом, фрагментарностью государственного регулирования, слабой связью с государственными заказчиками и системой внедрения научных результатов в практическое здравоохранение. 
В настоящее время в Азербайджане функционирует 11 специализированных НИИ и центров, в т.ч. кардиологии, травматологии, онкологии, профилактической медицины, хирургии и др. На эти медицинские учреждения приходится около $1 \%$ бюджета республиканского здравоохранения (см. Табл. 2).

\begin{tabular}{|c|c|c|c|}
\hline & 2005 & 2010 & 2018 \\
\hline Поликлиники и амбулатории & $19,7 \%$ & $16,7 \%$ & $15,9 \%$ \\
\hline Больницы & $66,5 \%$ & $55,3 \%$ & $56,0 \%$ \\
\hline Прочие услуги в области охраны здоровья & $2 \%$ & $2,0 \%$ & $2,1 \%$ \\
\hline $\begin{array}{l}\text { Научно-исследовательская деятельность } \\
\text { в сфере здравоохранения }\end{array}$ & $0,8 \%$ & $0,8 \%$ & $0,9 \%$ \\
\hline $\begin{array}{l}\text { Прочие услуги, связанные со здравоохранением (включая } \\
\text { государственные программы по охране здоровья) }\end{array}$ & $5,2 \%$ & $25,1 \%$ & $26,0 \%$ \\
\hline
\end{tabular}

Таблица 2. Структура Госуд. Бюджета Здравоохранения в 2005-2018 2.2. (в \%) Источник: Министерство Финансов Азербайджанской Республики, 2018.

В то же время, необходимо отметить несовершенство механизмов внедрения полученных этими учреждениями медицины результатов в процесс разработки политики развития здравоохранения, совершенствования медицинских технологий.

Одной из целей проводимых в системе здравоохранения республики реформ является развитие азербайджанского здравоохранения до стандартов развитых стран. С этой точки зрения одной из важных и значимых задач становится в определенной форме адаптация используемых в нашей республике врачебных специальностей принятым в развитых странах реестру специальностей и учебным программам (Бородин,2014).

В этой связи Министерство здравоохранения подготовило усовершенствованный список используемых в учреждениях здравоохранения республики врачебных специальностей. Этот список охватывает 40 специальностей, и в соответствии с ними получила свое утверждение должностная номенклатура специалистов, работающих в лечебных учреждениях (Шейман, Шевский ,2015).

Анализ показывает, что, несмотря на рост инвестиций в здравоохранение, Азербайджан заметно отстаёт от развитых стран по объёмам финансирования и показателям, определяющим уровень развития медицинской науки. В развитых странах, инвестиции в «науки о человеке» составляют не менее $30 \%$ от общих затрат на фундаментальные исследования (Госович и другие, 2006)

Развитие здравоохранения неразрывно связано с государственными инициативами и мероприятиями по стимулированию и внедрению инноваций по основным направлениям его реализации. Непрерывный поступательный процесс обновления медицинских технологий требует формирования и адекватного финансового обеспечения национальных целевых научных программ по приоритетным направлениям развития здравоохранения (см. табл.3).

Дальнейшее развитие современных научных исследований в области здравоохранения возможно лишь при условии комплексного подхода, основанного на привлечении разработок фундаментальных медикобиологических, естественных и точных наук, а также новых технологических решений(Шейман.

Одним из главных направлений развития системы здравоохранения республики является внедрение новых медицинских технологий, в первую очередь, диагностического оборудования, а также лекарственных средств. В рамках государственных программ создана сеть региональных диагностических и перинатальных центров. Это позволяет оказывать экстренную медицинскую помощь с использованием высоких технологий не только в столице, но и в регионах республики. 


\begin{tabular}{|c|c|c|c|}
\hline \multirow{2}{*}{ НАЗВАНИЕ ПРОГРАММЫ } & \multicolumn{3}{|c|}{$\begin{array}{l}\text { Бюджетныеинвестиции } \\
\text { (млн. манат) }\end{array}$} \\
\hline & 2005 & 2008 & 2018 \\
\hline Программа по хронической почечной недостаточности & 13,0 & 14,4 & 20,0 \\
\hline Программаподиабету & 12,0 & 13,8 & 17,3 \\
\hline Программа по гемофилии и талассемии & 9,1 & 9,2 & 11,1 \\
\hline $\begin{array}{l}\text { Программа по обеспечению онкологических больных } \\
\text { основными противоопухолевыми препаратами }\end{array}$ & - & 5,0 & 10,2 \\
\hline Программаиммунизации & 1,9 & 1,1 & 5,1 \\
\hline Программа охраны здоровья матери и ребенка & 4,8 & 5,2 & 5,2 \\
\hline Программа по обеспечению донорской кровью & 0,7 & 0,8 & 3,0 \\
\hline Программа «ЭлектронныйАзербайджан» & - & 2,1 & - \\
\hline $\begin{array}{l}\text { Расходы, связанные с введением обязательного медицинского } \\
\text { страхования }\end{array}$ & - & 4,0 & 50,2 \\
\hline $\begin{array}{l}\text { Программа развития кадрового потенциала в общественном } \\
\text { здравоохранении }\end{array}$ & - & 1,4 & 0,1 \\
\hline $\begin{array}{l}\text { Расходы, связанные с введением «электронных карт здоровья» } \\
\text { и «карт медосмотра» }\end{array}$ & 0,4 & 1,6 & - \\
\hline Программа профилактики и борьбы с ВИЧ/СПИД & - & - & 1,98 \\
\hline $\begin{array}{l}\text { Общие расходы на реализацию государственных программ в } \\
\text { области здравоохранения }\end{array}$ & 42,2 & 58,6 & 124,2 \\
\hline
\end{tabular}

Таблица 3. Государственные Программы в Области Здравоохранения, 2005-2018 г2. Источник: Министерство финансов Азербайджанской Республики, 2018.

Закупки медицинского оборудования, приборов и аппаратов для медицинских учреждений системы Министерства здравоохранения производятся централизованно. Этим занимается созданный при этом министерстве в 2005 г. Центр инноваций и снабжения. Все государственные учреждения здравоохранения ежегодно подают в Министерство здравоохранения свои заявки, где они анализируются и утверждаются. После утверждения Министерством здравоохранения, Центр инноваций и снабжения объявляет открытый тендер на закупки. Процесс закупок в частном секторе и в ведомственных учреждениях здравоохранения Министерством здравоохранения не регулируется и производится на основании решений собственников учреждений. Дорогостоящее медицинское оборудование - такое как компьютерные томографы и ЯМР (ядерно-магнитный резонанс) -томографы - в государственной системе здравоохранения используется в меньшей степени.

В настоящее время многие направления современной медицины требуют серьёзной технологической оснащенности. В то же время, применение современных технологий в отечественных учреждениях здравоохранения сдерживается, в т.ч., из-за отсутствия эффективных механизмов допуска этих технологий на рынок.

Создаваемые отечественными фармацевтическими предприятиями и медицинскими вузами разработки востребованы незначительно. Это связано, прежде всего, с недостаточным финансированием здравоохранения и законодательной незащищённостью отечественных разработок. Вопросы поддержания необходимого состояния медицинских изделий и использования средств госбюджета и внебюджетных источников, направляемых на их производство, закупку, должную эксплуатацию и утилизацию, не решаются в достаточной мере.

Дальнейшее развитие данной ситуации приводит, в частности, к закупкам дорогостоящего иностранного оборудования, внедрению отечественных разработок через иностранные фирмы и, как следствие, повышению затратности отечественного здравоохранения.

Анализ научно - инновационного потенциала здравоохранения республики показал, что по многим параметрам наблюдается прогресс. В то же время, в организации инновационной деятельности научной сферы присутствует ряд проблем, среди которых наиболее важными являются проблема недостаточного финансирования, необходимость формирования четкой позиции и выстраивания приоритетов поддержки научного потенциала, осознания роли медицинской науки в реализации инновационных процессов, в обеспечении долгосрочного воспроизведения инновационного типа развития здравоохранения.

\section{3 Информационно-Коммуникационная Составляющая Иннова-Ционного Потенциала Отечественного Здравоохранения}

Информационное обеспечение здравоохранения, достигшее в последнее время нового качественного уровня, расширяет возможности эффективного управления, поскольку предоставляет в распоряжение 
менеджеров, финансистов, руководителей медицинских учреждений всех уровней современные методы обработки и анализа информации, необходимой для принятия управленческих решений, обеспечения инновационной деятельности.

В Азербайджане разработка и реализация программ информатизации здравоохранения ведется с 1992 г. К настоящему времени в стране созданы элементы информационно-коммуникационной инфраструктуры для нужд медицины, положено начало применению и распространению современных ИКТ в сфере здравоохранения. В республике созданы медицинские информационно-аналитические центры, автоматизированные информационные системы страховых медицинских организаций.

Однако поскольку на районном уровне финансированием медицинских учреждений занимаются местные органы власти, а регулированием их деятельности - Минздрав, то такое разделение функций оказывает негативное влияние на потоки информации о деятельности поставщиков медицинских услуг на местах. Минздрав не получает своевременной и достаточно подробной информации от органов местного уровня, так как системы отчетности не компьютеризированы и требуют усовершенствования. Несмотря на все попытки улучшений, единой информационной системы здравоохранения, с помощью которой можно было бы проводить сбор, отчетность и анализ данных о деятельности медицинских учреждений, предоставляемых услугах и качестве медицинской помощи, пока нет. Из-за фрагментарности этой системы не происходит и обмена потенциально полезной информацией между различными структурами системы здравоохранения. Еще одним фактором, ограничивающим возможности Минздрава в области мониторинга качества медицинской помощи и состояния здоровья населения, является степень достоверности медицинских данных.

Как видим, разработанные информационные системы, как правило, носят узконаправленный характер, ориентированный на обеспечение частных функций и задач. Отсутствие единого подхода при их развитии в процессе эксплуатации приводит к возникновению определенных проблем. В результате существующие информационные системы представляют собой комплекс разрозненных автоматизированных рабочих мест, а не единую информационную среду.

Уровень оснащения системы здравоохранения современными информационно-коммуникационными технологиями крайне неоднороден, и в основном ограничивается использованием нескольких компьютеров в качестве автономных автоматизированных рабочих мест.

Некоторые учреждения внедряют системы, позволяющие вести учет контингента больных, проводить анализ деятельности и составление регламентных отчетов. В целом же в учреждениях системы здравоохранения не формируется единого информационного пространства, поэтому электронный обмен данными между ними затруднен.

Единственный вид программного обеспечения, установленный практически повсеместно в учреждениях здравоохранения, это разработанные программы учета реестров оказанных услуг, а также компоненты информационных систем обеспечения льготными лекарственными средствами.

Таким образом, существующий уровень информатизации системы здравоохранения пока не позволяет оперативно решать вопросы планирования и управления отраслью.

В целях решения проблем сбора и качества данных в информационной системе в целом Минздрав активно занимается разработкой Концепции создания Интегрированной информационной системы здравоохранения. С введением новых механизмов оплаты услуг поставщиков появится возможность коренным образом улучшить и информационную систему здравоохранения.

В 2005 г. Президентом Азербайджанской Республики И. Алиевым был подписан Указ «Об утверждении Государственной программы развития связи и информационных технологий в Азербайджанской Республике на 2005-2008 гг. (Электронный Азербайджан) ». В этой программе был поставлен целый ряд масштабных целей - от улучшения доступа населения к Интернету до формирования «электронного правительства». План мероприятий по реализации этой программы включал также задачи, касающиеся сферы здравоохранения:

- создание национального центра мониторинга здоровья населения и ряда электронных медицинских регистров.

- создание системы «электронных карт здоровья» граждан.

- разработка и внедрение модели медико-информационной системы для медицинских учреждений.

В 2006 г. Кабинет министров утвердил «Правила внедрения системы электронных карт здоровья». Для внедрения этой системы Минздравом была начата реализация проекта «Электронные карты здоровья», финансирование которого было организовано в соответствии со специальной государственной программой. В рамках этой программы Минздравом был создан отдельный Информационный центр, который действует как главный информационный банк данных для системы электронных карт здоровья. Планируется, что в перспективе все больницы, поликлиники, амбулатории, аптеки и другие учреждения здравоохранения будут оснащены необходимым оборудованием, позволяющим считывать информацию, 
содержащуюся в электронных картах здоровья, а также вводить в эти карты новые данные. Минздрав начал выдачу считывающих устройств в конце 2007 г. Электронная карта здоровья позволяет вводить, сохранять и изменять информацию, в том числе сведения о личности гражданина, о состоянии его здоровья, а также данные о страховании.

Внедрение электронных карт здоровья было начато с детского населения - сначала ими были обеспечены все новорожденные, затем взрослое население, и постепенно охват этой системой станет всеобщим. Внедрение системы электронных карт здоровья в полном объеме позволит создать различные электронные медицинские регистры для иммунизации, дородового наблюдения и т. д. Кроме того, это может стать основой для создания медицинской информационной системы для учреждений первичного звена. Существенно упростится обмен информацией между медицинскими учреждениями.

В будущем Система электронных карт здоровья станет неотъемлемым элементом системы обязательного медицинского страхования, поскольку в электронную карту здоровья предполагается введение данных о страховании ее владельца.

В настоящее время разработка системы электронных карт здоровья только началась, поэтому давать оценку ее эффективности и прогрессу, достигнутому в области реализации задач сектора здравоохранения, поставленных в Государственной программе развития связи и информационных технологий, еще рано.

В республике также идет работа по внедрению инновационных медицинских разра-боток, включающих: организационные и лечебно диагностические технологии, лекарст-венные препараты, медицинские изделия, в том числе медицинское оборудование».

Систематический подход к оценке качества медицинских услуг как в государственных, так и в частных медицинских учреждениях пока отсутствует, и никаких механизмов мониторинга безопасности пациентов нет. В то же время, в целях повышения качества медицинской помощи населению в республике предпринимаются согласованные усилия по добровольному внедрению национальных клинических руководств. В настоящее время единственным официальным подходом к разработке национальных клинических руководств являются принципы доказательной медицины. К 2018 г. было разработано уже 30 клинических руководств по ведению конкретных заболеваний, 27 из которых было утверждено Минздравом. Эти руководства касаются ведения заболеваний, в большинстве случаев предотвратимых мерами первичной медицинской помощи, а также заболеваний, оказывающих наиболее серьезное воздействие на состояние здоровья населения.

В настоящее время идет процесс обучения медицинских работников применению этих клинических руководств на практике; кроме того, предпринимаются усилия по пересмотру учебных планов последипломной подготовки медицинских кадров в целях приведения их в соответствие содержанию данных руководств и принципам доказательной медицины.

Анализ показал, что специальных органов, занимающихся оценкой медицинских технологий (в том числе лекарственных средств, медицинских приборов и аппаратов, процедур и систем организации и поддержки оказания медицинской помощи), проводимых в целях содействия принятию стратегических решений,, в азербайджанской системе здравоохранения пока нет, и на процесс принятия этих решений проводимые оце-нки влияния не оказывают. Однако разработаны национальные клинические протоколы, составленные с учетом обеспечения клинической и экономической эффективности.

Задача повышения достоверности медицинских данных была признана ключевой при разработке приоритетных национальных программ в области здравоохранения (к которым, в частности, относятся программы по охране материнства и детства). В этой связи Министерствј здравоохранения предпринимает последовательные усилия по улучшению качества демографической статистики и данных о смертности.

На наш взгляд, задачи по исправлению этой ситуации, наряду с рядом других планируемых мероприятий, должны найти свое отражение в Концепции создания Национальной интегрированной информационной системы здравоохранения, которая находится в стадии разработки.

Помимо прочих проектов реформ в качестве инструмента повышения качества оказания медицинской помощи населению в здравоохранении республики планируется ввести процедуру обязательной сертификации врачей.

Обеспечением соблюдения норм и стандартов безопасности и вопросами инфекционного контроля занимается система органов санэпиднадзора, которые имеют право проводить проверку санитарногигиенического состояния медицинских учреждений и в случае необходимости закрывать их на дезинфекцию. Кроме того, за несоблюдение соответствующих норм и стандартов они могут также наложить на медицинское учреждение штраф. С 2009 г. в стране разрабатывались нормативы оптимальной численности медицинских учреждений и медицинских работников на душу населения. 


\section{4 Заключение}

В результате проведенного в работе исследования проблем повышения инновационного потенциала системы здравоохранения республики, автором были сделаны следующие выводы:

1. Необходимым условием выхода отечественного здравоохранения на уровень развитых стран по показателям медицинской помощи является ускоренная диффузия в эту сферу инновационных управленческих технологий. Как показал проведенный в статье анализ, в период социальноэкономических реформ в целях развития инновационной деятельности в здравоохранении Азербайджана была проведена определенная работа, т.к. это является одной из стратегических задач государственной политики. Повысились доступность и качество первичной медико-санитарной помощи на ос-нове укрепления участковой службы по всей территории страны, улучшены показатели снижения смертности от отдельных причин, реализован комплекс мероприятий по рест-руктуризации системы оказания медицинской помощи и повышению ее эффективности, проведена подготовительная работа по внедрению в 2020г. в республике системы ОМС. Вместе с тем, в Азербайджане, осуществляющем переход на современную инновационную модель экономического роста, ликвидация структурных диспропорций в здравоохранении идет медленно, сохраняется непозволительно низкий уровень инновационной активности в здравоохранении.

2. Устранение основных проблем инновационного управления в здравоохранении под углом зрения развития медицинской науки, образования, стандартизации, информатизации и т.п. требует существенных ресурсных и временных затрат. Недостаточное финансирование тормозит реализацию эффективных инновационных проектов, снижая тем самым общий уровень инновационной активности в здравоохранении. Что касается возможности частного инвестирования в инновационные технологии, то оно сдерживается, с одной стороны, недостаточным информационным обеспечением, а с другой отсутствием чётких государственных гарантий. Кроме того, пока еще не налажены тесные, постоянные и продуктивные контакты между медицинской наукой и бизнесом.

3. Приоритетными направлениями развития системы здравоохранения под углом зрения повышения инновационного потенциала должны выступать:

- развитие рыночных отношений в этой сфере, активное содействие конкуренции в оказании медицинской помощи.

- совершенствование законодательной базы, регулирующей все аспекты инновационной деятельности в развитии технологий управления в здравоохранении.

- развитие институциональной инфраструктуры в области инновационных технологий управления.

- развитие системы стандартов оказания медицинской помощи при заболеваниях, оптимизация размеров финансирования с затратами, необходимыми для выполнения этих стандартов.

- $\quad$ развитие страховых принципов финансирования здравоохранения. Несмотря на то, что правовая база для организации сбора взносов на обязательное медицинское страхование была создана еще в 1999 г. Законом о медицинском страховании, пока что система ОМС, как элемент основных реформ финансирования здравоохранения в республике, не введена.

- введение новых инструментов легального софинансирования оказания медицинской помощи государством и отдельными группами населения (например, соплатежей для обеспеченных пациентов за виды медицинской помощи, основанные на инновационных медицинских технологиях, не входящих в существующие государственные гарантии.

- обучение управленческих кадров основам разработки и применения новейших технологий управления в сфере здравоохранения.

4. Новые цели, связанные со стимулированием и инфраструктурной поддержкой развития новых управленческих технологий, науки и инноваций в здравоохранении, не реализуются в полной мере. Их законодательное и нормативное обеспечение несовершенно, к тому же запаздывает или откладывается на неопределённое время. Нужны существенные преобразования в организации оказания медицинской помощи, реализация инноваций в механизмах ее финансирования и прочие оптимизационные мероприятия, соответствующие как новой экономической ситуации, так и долговременным задачам развития этой сферы. Поэтому следующим шагом в совершенствовании сферы здравоохранения должно стать освоение и распространение передовых технологий в области управления, способных решать задачи инновационного развития здравоохранения, и, в конечном итоге, содействовать повышению его эффективности.

\section{Литература}

- «Стратегическая дорожная карта по развитию национальной экономики и ее отдельных секторов». 2016г. 
- European health for all database (HFA-DB). World Health Organization Regional Office for Europe.Updated: December 2018.http://data.euro.who.int/hfadb

- OECD Health Data: Health care resources, http://stats.oecd.org/viewhtml.aspx?datasetcode=HEALTH_REAC\&lang=en\#

- $\quad$ OECD Health Statistics. 2018.

- $\quad$ Seifert B., Svab I., Madis T., Kersnik J., Windak A., Steflova A., Byma S. Perspectives of family medicine in Central and Eastern Europe // Family Practice. 2008. V. 25. P. 113-118

- World Bank, 2010. Net migration statistics, http://data.worldbank.org/indicator/SM.POP.NETM

- Арас О., Сулейманов Э., Экономика Азербайджана. Изд-во « Восток- Запад, Баку, 2016, 412c.

- Бородин В.А. Организация и управление инновационной деятельностью. Барнаул: Изд-во АлтГТУ, 2014. - 134 c.

- $\quad$ Госович О.М., А.В.Иванов, О.В.Родин, С.А.Смирнов, А.В.Тихомиров. Пути адаптации учреждений здравоохранения к новым реалиям. //Главный врач: хозяйство и право. 2006. - № 1. - С.20-32.

- Государственная Программа социально-экономического развития регионов Азербайджанской Республики на 2014-2018гг. Баку, «НУРЛАР», 2014, 184c.

- Зарецкая, С.Л. Социальные проблемы здравоохранения в странах Запада. - М.: ЮНИОН РАН, 2011. $158 \mathrm{c}$.

- Зоидзе А., Мехтиев Ф. Предложения по Программе Финансирования Здравоохранения в Азербайджане. USAID, IMC, Abt, CIF, 2006, 35 c.

- Известия НАНА. Наука и инновации, 2011, Центр науки и инноваций НАНА. Баку, «Наука», 2011.

- Концепция развития «Азербайджан-2020: взгляд в будущее», Баку, 2012, 40 с.

- Сбережение народа /под ред. Н.М. Римашевской; Ин-т соц. Экон. проблем народонаселения РАН.М.: Наука, 2007.-326 с.

- Статистические показатели Азербайджана в 2018 г., Баку: «Сяда», 2016, 808 с.

- Человеческое развитие: количественное измерение и процессы в мировой системе. МЭиМО, 2010, №7, c.102-114.

- Шейман И.М., Шевский В.И. Кадровая политика в здравоохранении: сравнительный анализ российской и международной практики //Вопросы государственного и муниципального управления. 2015. № 1. С. 143-167. 


\title{
Azerbaycan'da Kamu Hizmet Kalitesinin Artırılmasında E-Devlet Innovativ Teknoloji Kullanımının Gelişimi
}

\section{Development of E-State and Innovative Technology in Improving Public Service Quality in Azerbaijan}

\author{
Prof. Dr. Farhad Rahmanov (Azerbaijan State Economy University, Azerbaijan) \\ Assoc. Prof. Dr. Elchin Suleymanov (Baku Engineering University, Azerbaijan) \\ Khayala Ibrahimova (UNEC- Azerbaijan State University of Economics, Azerbaijan)
}

\begin{abstract}
The rapid development of the Internet technologies and the continuous increase in the usage area, increase the service quality and speed by utilizing the internet technologies in some of the public services provided. Most of the public services are now provided as electron in developed countries. The concept of state management through innovation methods, the importance of e-government structure in increasing the speed of the state provided by the state is increasing every day, Azerbaijan is also one of the fastest developing countries as it is an internet infrastructure and its population is highly effective on the internet and other innovative technologies. Particularly, some of the oil revenues coming to the country are spent on modernization of modern technologies. The aim of this study is to examine the effects of innovation and e-government applications in the field of public administration in Azerbaijan over the last decade and its impact on public service quality. Developments in recent years in terms of increasing the quality of public service in Azerbaijan, ASAN service, E Signature, ASAN Signature, Electronic tax system and other innovations in the field of public service have constituted the subject of the research and at the end of the study proposals have been made to increase the efficiency of the system.
\end{abstract}

\section{Giriş}

Uluslararası Avrasya Ekonomileri Konferansı için bildiri yazmak için şu anda okuduğunuz taslak kullanılmak Son çeyrek asırda dünyada internetin yaygınlaşması ve smart teknolojilerinin hızlı bir şekilde herkesin kullanımına dahil olması verilen kamu hizmetlerinde ve vatandaşlarla olan devlet-vatandaş ilişkilerinde bu teknolojilerden geniş kullanılmasını zaruri ediyor. Devletlerin yönetim yapısı ile beraber takdim ettikleri hizmet anlayışı ve hizmet kullanım alanı sürekli değişmekte, verilen kamusal hizmetlerde internet teknolojilerinden yararlanarak hizmet kalitesinin artırılması amaçlanmaktadır. Dünyada her gün devlet-vatandaş ilişkilerinin yapısı değişmekte, vatandaşların bürokrasi ve zaman kaybı problem her gün daha da azalmaktadır. Aynı zamanda bu teknoloji kullanımı ekonomik olarak da mühim avantaj kazanmaktadır. Bilişim teknolojilerinin hızlı değişimi ve İnternet'in hızla yaygınlaşmaya başlamasının getirdiği kolaylıklar hantal devlet yapısının değişmesine yönelik bir ihtiyacı ortaya çıkarmıştır. Bu ihtiyaç kamu hizmetinin eski hantal yapısını değiştirip, vatandaşa elektronik imkânların kullanılarak daha hızlı hizmetlerin verildiği e-devlet kavramının ortaya çıkmasına neden olmuştur. Özellikle ABD, Kanada, Nedherland, Japonya ve Güney Kore gibi ekonomik olarak güçlü ülkeler bu alanda lider devletlerdendir. Avrupa'yı dünyadaki en dinamik ve rekabet gücü yüksek pazar haline getirmek gibi iddialı bir amacı olan bu girişim, aday ülkelerde de benzer bir plan uygulanması yoluna gitmiştir. Hatta program sadece aday ülkelerle sınırlı kalmamış Avrupa Konseyine üye ülkelerde bu programın kapsamına alınmış bulunmaktadır. Bu program çerçevesinde Avrupa Birliğine komşu ülkelerde e-devlet projeleri desteklenmekte ve bu projelere önemli miktarlarda krediler verilmektedir. Bu program çerçevesinde Avrupa coğrafyasında: Bilgi Toplumunun temellerinin oluşturulması; Daha ucuz, hızlı ve güvenli internet sağlanması; İnsana yatırım; İnternet kullanımının arttırılması amaçlanmaktadır.

Kanada, ABD, Singapur ve Kore gibi ülkelerin deneyimleri, e-devlet binasında iki model bulunduğunu gösterdi - Batı (Kanada, ABD) ve Doğu (Singapur, Kore) modeli. Bu modellerin karşılaştırmalı analizine dayanarak, tüm ülkeler için tek tip bir model olmadığı sonucuna varılabilir.

Elektronik devlete geçmek, diğer gelişmekte olan ülkeler gibi Azerbaycan için de çok önem arzetmektedir. Bu sisteme geçiş hukuki ve teknik altyapı ve sistemi yaygın kullanabilecek personelin eğitilmesini gerekmektedir. Bu alanda mesafe kat etmek için Azerbaycan internet altyapı yatırımlarına önem verilmeli, kamu kuruluşlarının bu konuya duyarlılığı arttırılmalıdır. E-devlet uygulamaları başarılı olursa, hem kamunun kendi içindeki işlemlerde, hem de kamu ile vatandaş arasındaki işlemlerde kolaylık sağlayacağından dolayı, bugüne kadar aksayan veya hatalara sebep olan sorunlarından ortadan kalkmasına yardımcı olacaktır. Aynı zamanda son yıllar e-devlet uygulamasının yaygınlaşması Azerbaycan ve benzeri post-Sovyet ülkeleri için bürokratik engeller ve yolsuzluklardan kurtulma reçetesidir. 


\section{E-Devlet Uygulaması ve Onun Yapısı ile İlgili Bilimsel Çalışmalar}

Abramson ve Mins (2001) ve Muir ve Oppenheim (2002), Howard (2001). hükümet, kamu (sivil ve ticari) ve çalışanlar arasındaki "e-devlet" tanımını elektronik iletişim (bilgi alışverişi ve bilgi alışverişi) olarak tanımlamıştır. E-devlet kavramının kuramsal temeli, yukarıda bahsedilen "bilgi toplumu" teorisidir. E-devlet olgusunun kavramsal temelleri, bilim adamları C.Bellamy, J.Taylor, J.Fountaun ve A.Antiroikkoum'un çalışmalarına yansıtılmıştır. Geleneksel ve yeni e-devlet, birbirinin çapı ile karakterize edilir: Geleneksel hükümet karmaşıktır, e-devlet yapısı ve süreçleri nedeniyle nispeten basittir; Geleneksel hükümet "iktidarın dikey gücünü güçlendirmek" potansiyeline sahiptir ve e-devlet özerklik ve çeviklik gibi alternatif özelliklere sahiptir; Geleneksel hükümet hizmetinin ölçümü rakamlar ve yapılan işlerin isimleri içermektedir: bu ya da bu amaç için ne kadar para harcanmış, ne kadar para toplanmıştır. E-devlet hizmet raporu, sonuçlara ve ölçülebilir kullanım kalitesine göre tahmin edilmektedir. E-devlet, açık bir sosyal sistem gibi geleneksel iç süreçlere değil, yeni koşullardaki dış etkenlere ve tüketicilere yöneliktir. Bu noktada etik konular dikkate alınmaktadır. E-devlet, aşağıdaki hedefleri bir konsept olarak ileri sürmektedir: Yönetim alanının etkinliğini arttırmak; Vatandaşların yaşam kalitesini iyileştirmek (sosyal hizmetleri ve sağlık sistemlerini geliştirmek, eğitim kapasitesini artırmak, çevreyi geliştirmek ve güvenliği artırmak).

Devlet ve vatandaşlar arasındaki karşılıklı ilişkilerin etkinliğini artırmak için devlet portalı- devlet kurumlarının web kaynaklarını bütünleştiren, devletin elektronik hizmetlerini gerçekleştiren ve transaks iletişiminde yüksek güvenlik sağlayan bir bilgi sistemi. Başka bir deyişle, portal vatandaşlara hizmet eden sanal bir devlet kurumudur. Singapur eyalet portalı www.ecitizen.gov.sgbuna'nın bir örneği olabilir. Portalın içeriği şöyledir - işletmenin çalışma şekli ve fonksiyonunu belirleyen temel normatif belgeler, üst kuruluşların belgeleri, yahut onlara referanslar, işletmenin konumu, çalışma tablosu ve gerekli durumlarda görevlileri hakkında tam bilgi, işletmenin kendi işlevine uygun yayımladığı güncel materyaller, işletmenin işindeki yenilikler, konu ilgili haberler, fiziksel veya tüzel kişiler için ipuçlarını arama, tipik problemlerini çözmek için bölümler. E-devlet işleyişinin başlıca avantajları: İnternet'e "24/7" modunda (haftada 7 gün 24 saat) erişirken e-hizmetler mevcuttur; Geliştirilmiş ön büro ve arka ofisi portala entegre ederek, devlet kurumu vatandaşlar hakkında daha kaliteli bilgi edinir ve toplar ve kamu ihtiyaçları veya mevcut hizmetler ile daha sonraki e-hizmetleri sağlar; Azaltılmış hükümet harcamaları. Elektronik hizmetlerin maliyeti, birçok devlet memurunun maliyetinden önemli ölçüde daha düşüktür. Ancak yetkililerin yeni bir yöntem üzerinde çalışmaları ve BT araçlarını nasıl kullanacaklarını öğrenmeleri gerekiyor; Kanada'da aparılmış bir araştırmaya göre basit bir vatandaşlık işlemi evvelce posta ulaşım ve kırtasiyecilik masrafları olan 35-40 dolardan sistem sayesinde bir dolardan da aşağı düşmüştür ve bu ülke ekonomisi için büyük katkıdır. Government to Citizens (G2C-Hükümetten vatandaşa) sistemine bilgilerin topluma ulaştırılması, sözleşmelere izin verilmesi, çeşitli raporların ve formların alınması, doğum, ölüm, vatandaşlık durumu işlemlerinin düzenlenmesi, gelir vergisinin ödenmesi, eğitim, sağlık, tıbbi bilgiler, kütüphaneler ve bu gibi diğer temel hizmetler dahildir. O zaman, devlet bütçesi paradan tasarruf edecek ve vatandaşlar zaman kazandıracak.

\section{E-Devlette Küresel ve Bölgesel Eğilimler}

Birleşmiş Milletler 'in 2001 yılında e-devletin durumunu belirleme amaçlı girişiminin başlamasından bu yana 17 yıldan bu yana e-devletin kullanımı hızla artmaktadır. 2018 Anketi, daha yüksek düzeydeki e-devlet kalkınmasına yönelik kalıcı bir küresel eğilimin altını çizmektedir.BM son anketinde 40 ülke e-devlet uygulamasında “Çok Yüksek", 0.89'dan 1.00'a kadar puan almışlardı ki 2003'te sadece 10 ülkeye ve 2016'da 29'a ülke bu kategoride idi. 2014'ten bu yana, tüm 193 Üye Devlet bazı çevrimiçi varlığın şekli. Ortalama dünya EGDI, alt bileşenlerin endekslerinin sürekli olarak iyileşmesi nedeniyle 2014 yılında 0,47'den 2018'de 0,55'e yükselmiştir (https://publicadministration.un.org/egovkb/en-us/Reports/UN-E-Government-Survey-2018). Bu, küresel olarak, e-devlet ve kamu hizmetlerinin çevrimiçi iyileştirilmesinde sürekli bir ilerleme olduğunu göstermektedir. Ancak, bazı ülkelerde elde edilen bazı kalkınma kazançları ve büyük yatırımlara rağmen, e-devlet ve dijital bölünmeler devam ediyor. Düşük EGDI grubundaki on dört ülke Afrika'dır ve en az gelişmiş ülkeler tarafından sahiplenilmiştir. E-devlet Gelişim Endeksi (EGDI) 2018 E-devlet Gelişim Endeksi'dir (EGDI). İlk 10 ülke İngiltere, İsveç, Finlandiya, Singapur, Yeni Zelanda, Fransa ve Japonya'dır. Ankete göre, 2018'deki en yaygın kullanılan üç çevrimiçi hizmet, yeni işlerin ödenmesi ve kayıt altına alınmasıdır. E-postalar, özet akışı güncellemeleri, mobil uygulamalar ve SMS yoluyla hizmetlerin sunulması, özellikle sağlı ve eğitim sektörlerinde küresel olarak iki katına çıkmıştır. Etkili e-devlet sonuçları için kamu güvenini oluşturmak, SDG'lerin gerçekleştirilmesine yönelik temel bir adımdır (https://sustainabledevelopment.un.org/?menu=1300). Bu, kamu hizmetlerinin kalitesine bağlı olacaktır. Etkili hizmet sunumu için, e-devlet uygulamaları ihtiyaçların karşılanması için tasarlanmalı ve en önemlisi, her düzeyde güvenilir plan ve projelerin uygulanması için tasarlanmalıdır. Yerel otoritelerin sürdürülebilir kalkınmadaki rolü, en savunmasız duruma ulaşmak için daha da önemli olacaktır. Bu nedenle, yenilikçi katılım mekanizmaları ile tüm topluluklarla yerel olarak çalışmak şarttır. Vatandaşların etkili, adaletli ve vatandaş merkezli hizmetlere yönelik beklentileri, yüksek derecede bağlılık ve dezavantajlı bir artış. Mobil cihazlar, erişim bölmesinin köprülenmesinde yardımcı oluyor. Sabit ve mobil geniş bant fiyatları düşmekte, bu da BİT'leri daha erişilebilir ve uygun maliyetli hale getirmektedir. Bununla birlikte, gelişmiş ve gelişmekte olan 
ülkeler arasında büyük tutarsızlıklar vardır. Mobil abonelikler gelişmiş ülkelerde her 100 kişiye 127.3 'e yaklaşırken, gelişmekte olan ülkelerin sayısı 98,7' dir. Dünya çapında mobil cihazların hızla artan kullanımı, edevletin bir alt kümesidir. Mobil hizmetler ve akıllı telefonlar, hükümetlerin en fakir ve en savunmasız olanlara daha iyi ulaşmalarına izin veriyor.

E-devlet karşısında, aşağıdaki görevler vardır: İnsanlar için daha elverişli bir iş ortamı yaratmak. Özellikle kırsal ve uzak topluluklarda verimlilik ve ekonomik büyümeyi destekleyen bir araçtır. İKT-nin hükümette kullanılması ve e-hükümet altyapısının oluşturulması sırayla karşılıklı ilişkileri düzenlemeye ve hükümetle iş arasındaki ortak çıkarları artırmakla elverişli iş ortamın oluşmasına yardımcı olur. Bu hedefin uygulanması büyük ölçüde ülkeye, endüstriyel potansiyeline ve küresel rekabet gücüne bağlıdır. Örneğin, e-satınalma yerel işletmeler için yeni pazarlar açabilir ve bu da Hükümetin satın alma sürecini ortaya çıkarması için daha rekabetçi ve adil bir hale getirir. Alıcılar ağda, canlı sıralarda değil. Bu hizmet, kamu mallarının ve hizmetlerinin, bir devlet temsilcisinin doğrudan müdahalesiyle vatandaşlara daha verimli bir şekilde ulaştırılmasını sağlar. Yönetimde iyi yönetişimin ve halkın katılımının iyileştirilmesi. Yönetimi (yönetim) ve işlemlerde BİT katılımı hükümette şeffaflığı ve sorumluluğu artırmakla beraber, hem de vatandaşlara hükümetin politikalarında ve karar alma süreçlerinde yer sağlar. Devlet kurumlarının verimliliğini ve etkinliğini arttırmak. BT uygulaması dəftərxanadakı süreç ve prosedürleri hızlandırır ve hizmetleri hayli kolaylaştırıyor, çalışanların verimliliğini artırır ve aynı zamanda, devlete ait gelirlerin tasarruf edilmesine olanak sağlar. E-devlet size daha fazla yardımcı olabilir: Devlet görevlilerinin verimliliğini artırmaya, bazı kontrollerden ve kağıt yönetiminden can kurtarmaya, yönetimin devlet tarafından planlanması imkanlarını artırmaya, ticaret kurumları ve vatandaşların lisanslar elde etmek için başvurular sayısının fazla olmasına ve gelirlerin artmasına; Hükümet ilk aşamada çok bölmeli iletme platformları (hem geleneksel, hem de e-hükümet) teklif ettiğinden fiyatlar artmaya meyilli olsa da, sahibkarları uzun süre fiyatların orta düzeyde tutarak ikna etmeye; Devlet operasyonlarını yöneterek kağıt kullanımının azaltılması için gereksiz işlemlerin BİT yoluyla azaltılması. Dezavantajlı topluluklarda kalitenin arttırılması. İKT, hükümetin ilgisiz gruplara ve derneklere dikkat çekmesini sağlar. Bu, pratikte, onlara politik süreçlere katılma hakkı, en çok ihtiyaç duydukları mal ve hizmetlerin sunulması anlamına gelir. Sonuç olarak, e-yönetimin amacı toplumun üç toplum, vatandaşlar ve iş alanı arasında karşılıklı ilişkilerini arttırarak, ülkedeki siyasi, sosyal ve ekonomik gelişmeyi hızlandırmak.

Kısacası, e-yönetimin tüm amaç ve görevleri modern devletin başlıca görevi çerçevesindedir: "Modern devletin başlıca görevi, birincisi, nüfusa sosyal refah ihsan etmek, sosyal ve ekonomik gelişmeye katkıda bulunmak, ekonomik verimlilik dikkati artırmak, ikincisi ise, sosyal adalet ilkesine uyularak nüfus arasında gelir dağılımında yüksek bir eşitlik düzeyi yaratıyor. "Devlet Bilgi İşlem Sistemleri "devlet kurumları internette temel düzeyde yer almaktadır ve devlet kurumları web sitesi üzerinden çalışmalarıyla ilgili bilgi vermektedir. Her bakanlık ve kuruluş, İnternet'teki "kartvizitler" hakkında bilgi sayfaları hazırlarlar - faaliyetlerinin misyonları ve yönlendirmeleri. İlgili teknolojik ve politik bilgiye erişimi olan çoğu hükümet yetkilisi, e-devleti hükümetin çevrimiçi olarak oluşturduğu portallar olarak görüyor. Bu aşama, devlet kurumlarından vatandaşlara - topluma tek taraflı bir bilgi akışıyla karakterizedir. Devlet yetkilileri ve vatandaşların temsilcileri arasında "geri bildirim etkileşimli etkileşim" arasında ikili bir etkileşim var. Hükümet yetkilileri ve vatandaşlar arasındaki etkileşim, eposta, diğer elektronik (ön büro) ve e-posta veritabanları (arka ofis) yardımıyla daha üst düzeydedir. Vatandaşlar vergi beyannamelerini ve diğer belgeleri elektronik formda doldurabilir, e-posta ve bilgi alabilirler. Bu aşamada, devlet, vatandaşların işbirliği ve ihtiyaç ve ihtiyaçlarını öğrenmek için BT'nin bir iletişim aracı olarak görmektedir. $\mathrm{Bu}$ aşamada, esas olarak modernleşme sorunları var. "İşlem" gerçek bir etkileşimdir - kamu görevlileri ile vatandaşlar arasındaki karşılıklı ilişkiler gerçek zamanlıdır. Teknolojik bir temel ve yüksek nitelikli personel eğitimi sağlar. Devletin işlemi yürütmek için bir porta ihtiyacı var. Bu portalın yardımıyla vatandaşlar otosertifikasyona başlayabilir ve elektronik servisleri kullanabilirler. Çoğu durumda, çeşitli devlet kurumları işlem hizmetlerinin sağlanmasında yer alır. Tek tip standartlara dayalı bir "elektronik hükümet altyapısı" oluşturulmasıyla, "E-devlet", niteliksel olarak daha yüksek bir seviyeye geçmektedir. Bu aşamada vatandaşlar, kamu kuruluşlarının kalkınma stratejisinin gelişimine katılabilirler. Dördüncü aşamada, devlet portalı hem işletmeler hem de vatandaşlar için tüm hizmetler için tek bir erişim noktasıdır ve dijital eşitsizliği ortadan kaldırmak için pratik önlemler alınır. Dijital eşitsizlik daha sonraki aşamalarda sosyal eşitsizliğe gider. Bu aşamada, e-devletin en yüksek verimlilik düzeyine ulaştığına dikkat edilmelidir.

\section{Azerbaycan'da E-Devlet Uygulamasına Geçilmesi Süreci}

Azerbaycan'da "Elektronik Hükümet" in kurulması, uluslararası tecrübeye ve Azerbaycan Cumhuriyeti Cumhurbaşkanı'nın "Azerbaycan'da 2010-2012 (Elektronik Azerbaycan) için İletişim ve Bilgi Teknolojilerinin Geliştirilmesine Yönelik Devlet Programının Onaylanması", "Elektronik Hükümet Hizmetlerinde" 23 Mayıs 2011 tarihli Kanun Hükmünde Kararname ve diğer kanuni hukuki düzenlemeler için bazı önlemler üzerinde yasal bir çerçeve oluşturulmuştur. Azerbaycan Cumhuriyeti Devlet Başkanı Devlet Hizmet ve Sosyal İnovasyonları için Devlet Ajansı, bu alandaki çalışmaların koordinatörü olarak "Elektronik Hükümet” in oluşumu konusunda diğer devlet kurumlarıyla yakın işbirliği içinde olup, ilgili altyapının kurulması ile ilgili faaliyetler yürütmektedir. Elektronik imzaların kullanımı için Ulusal Belgelendirme Hizmet Merkezi kurulmuştur. Devlet bilgi sistemleri 
arasında bilgi alışverişi için bir altyapı kurulmuştur. "Elektronik Hükümet" portalı hazırlanmış ve işletmeye alınmıştır. Bütün devlet kurumları, vatandaşlara bunları kullanarak e-hizmetler sunabilmektedir. Bu program çerçevesinde Azerbaycan'da da kısa sürede e-devlet uygulamasına geçilmesi zorunlu hale gelmektedir. Zira Avrupa kurumları ile entegrasyon Azerbaycan yönetiminin temel politikalarından birini oluşturmaktadır. Bu nedenle Azerbaycan'da kısmi olarak örneklerine rastlanılan yeni devletçiliğin modern uygulaması organize olarak tek bir çatı altında toplanılmalı ve yönetimde karşılaşılan kırtasiyecilik, aşırı bürokrasi, rüşvet ve adam kayırmacılık gibi yönetim hastalıkların önlenmesi sağlanmalıdır. Azerbaycan Cumhuriyetinde E-devlet Politika ve Stratejilerine Genel Bakış Azerbaycan Cumhuriyetinde devlet yapılanması, güçlü ekonominin oluşturulması, toplumun demokratikleşmesi, halkın refahının yükseltilmesi ve insan gelişiminin sağlanması yönlerinde çok yönlü faaliyet gerçekleştirilir. Mevcut durum itibariyle Azerbaycan ekonomisinin lokomotifi olarak petrol ve gaz sektörleri görülmekte ve buradan elde edilen gelirlerle ekonomik büyüme gerçekleştirilmektedir. Azerbaycan'da petrol ve gaz rezervlerinin sınırlı olması itibariyle bu kalkınmanın uzun vadeli gerçekleştirilemeyeceği bilinmektedir. Bu çerçevede belirlenen devlet programında öncelikli sektör ICT olarak öngörülmüş ve bu sektöre yapılacak yerli ve yabancı yatırımlar sayesinde önümüzdeki 10-15 yıl içinde Azerbaycan'da bilişim sektöründen elde edilecek gelirlerin petrolden elde edilen gelirlerle rekabet edebileceği ifade edilmiştir. Belirtilen konularda edevletin özel bir yeri vardır ve alanın gelişim seviyesi öne sürülen amaçlara ulaşmaya etkileyen faktörlerdendir. Çeşitli ülkelerde, özellikle gelişmiş ülkelerde bu amaçla bilgi toplumunun ve bilgilere dayalı ekonominin geliştirmek çaba gösterilir ve bu faaliyet BM Binyıl Zirvesi'nde belirlenen gelişme amaçları ile tam uzlaşır. Azerbaycan Cumhuriyetinde de bu alanda amaçlı faaliyet yapılıyor ve bilişim teknolojileri alanı ülkenin gelişme önceliklerine dahil edilmiştir. Modern küreselleşmede, bilgi toplumuna geçiş, kamu yönetiminin oluşmasını gerektirir - elektronik bir hükümetin kurulması. E-devlet, BİT firsatlarına ve sivil toplum değerlerine dayanan kamu yönetiminin verimliliğini artırmakta, tüketicilere doğrudan çeşitli hizmetler sunmakta ve vatandaşlara devlet kurumlarının faaliyetleri hakkında düzenli bilgi sağlamaktadır.

Bu yaklaşımlardan biri, ülkede 2005 yılında "Elektronik Azerbaycan" Devlet Programının kabul edilmesidir. "E-Azerbaycan" Devlet Programı kapsamında "E-devlet" kurulması amaciyla 2005-2008 ve 2010-2012 Eylem Planı'nın geliştirilmesi bu alandaki gerçek adımlardan biridir. E-devletin kurulması ve geliştirilmesi karmaşık bir süreç olarak hatırı sayılır bir zaman gerektirir. Aynı zamanda Azerbaycan'da 2013 yılı "Bilişim Teknolojileri Yı1ı" olarak belirlenmesi, bu alandaki önemli görevlerin uygulanmasını önemli ölçüde hızlandırmıştır. Son on yılda, bilgi ve iletişim teknolojileri (BİT), günlük hayatımızın çeşitli alanlarında önemli bir rol oynamıştır. Bu alanlar, turizmden sağlığa, bankacılık, ticaret, iş iletişimi, sosyal iletişim ve bireysel ve devlet kurumları arasındaki ilişkilere kadar uzanan alanları içermektedir. E-Servisler, bilgisayar tabanlı bir araç ile gerekli çalışmaları basitleştirmeyi ve gerçekleştirmeyi amaçlamaktadır. Ülke vatandaşları en son teknolojiye sahip, dijital ve 24 saat elektronik hizmetlere ihtiyaç duymaktadır. E-hizmetlerin geliştirilmesi ve geliştirilmesi için, ülkeler vatandaşların ihtiyaçlarını karşılayan bilgi sistemlerinin gelişimini uygulamalıdır. Kronolma'ya göre e-hizmetlerin temel amacı, bir iletişim formu olarak IT sistemleri oluşturulabildiği gibi, ülke vatandaşları ile devlet organları arasındaki bağlantıların oluşturulmasıdır. İLETİŞiM Kriterleri, elektronik hizmetlerle desteklenen üç tür kalitesini birleştirebilir: Etkileşim kalitesi - Kullanıcı ile elektronik hizmet arasında karşılıklı iletişim mevcuttur. İletişim kalitesi - iki kullanıcı arasındaki iletişim (kamu otoritesi ve kullanıcı). Kalitenin amacı - amaç kalitesi, kamu otoritesi ile kullanıcı arasındaki hedeflere ulaşmaktır.

“Azerbaycan Cumhuriyetinde iletişim ve bilişim teknolojilerinin gelişimi üzere 2005-2008 yılları için Devlet Programı'na (E-Azerbaycan) uygun olarak Azerbaycan'da 'elektronik hükümet (e-government)'in uygulaması devlet organlarının vatandaşlara ve kurumlara sunduğu hizmetlerin kalitesinin iyileştirilmesi ve teslim olunma sürelerinin azaltılmasına, devlet aparatının çalışmasının etkin ve optimal olmasına hizmet etmeye odaklıdır. Dünya tecrübesinin tahlilini dikkate alarak 'elektronik hükümet'in oluşturulması uzun vadeli perspektife sahiptir ve üç aşamadan oluşan olmakla hayata geçirilecek. Birinci aşama "Elektronik hükümet" altyapısının oluşturulmasıdır. Bu aşama kapsamında "Elektronik hükümet” portalı ve banka sistemi ile karşılıklı ilişki için “ücret şlüzü”, ulusal tanımlama sistemi, devlet organlarının tek ağ altyapısı gibi temel bileşenlerin oluşturulması, merkezi ve yerel icra organlarının idareler arası ve standart bilgi sistemlerinin oluşturulması ve geliştirilmesi, Birinci aşama "Elektronik hükümet" altyapısının oluşturulmasıdır. Bu aşama kapsamında "Elektronik hükümet" portalı ve banka sistemi ile karşılıklı ilişki için “ücret şlüzü”, ulusal tanımlama sistemi, devlet organlarının tek ağ altyapısı gibi temel bileşenlerin oluşturulması, merkezi ve yerel icra organlarının idareler arası ve standart bilgi sistemlerinin oluşturulması ve geliştirilmesi, 3 www.e-qanun.gov.az, 2013 onların ortak çalışmalarının sağlanması, ayrıca elektronik hizmetlere çıkışın sağlanması öngörülüyor. Bu aşamada, ayrıca bilgi ve interaktif hizmet planlanıyor. İkinci aşamada "Elektronik hükümet"-in vatandaşların ve devlet organlarının faaliyetlerinin tüm alanlarını kapsayan çeşitli hizmetlerin gelişmesi, ayrıca idari süreçlerin tam kapsamlı yeniden yapılanması öngörülüyor. Üçüncü aşama, devlet organları ve kurumlarının faaliyetlerinin yeni ortama transformasyonu, e-sağlık, e-eğitim, e-kültür, e-demokrasi vb. gibi projelerin hayata geçirilmesi de dahil olmak üzere bilgi toplumuna geçişin şekillendirilmesi ve gelişmesini öngörüyor. Bu Programın hayata geçirilmesinin birinci aşamasının sona ermesinin sonuçlarına göre "Elektronik hükümet"in oluşturulması ve olanaklarından etkin kullanımı için aşağıdaki temel önlemlerin uygulanması öngörülüyor: 
-“Elektronik hükümet”in ve onun kullanıcılarının faaliyetlerini tanzim eden hukuki esasların şekillendirilmesi ve geliştirilmesi. -Toplumda bilgi elde etme imkânı ve BT'den kullanma alışkanlıklarının düzeyi açısından eşitsizliğin giderilmesi için gerekli önlemlerin uygulanması, Geniş nüfus kitlelerinin "Elektronik hükümet" hizmetlerine çıkışın sağlanması ve nüfusun "Elektronik hükümet"-in olanaklarını kullanıma alınması; Devlet yönetim organlarında ve teşkilatlarında, yerel yönetim organlarında bilgi ve iletişim teknolojilerinin geniş uygulanması ve geliştirilmesi; Devlet yönetiminin tüm düzeylerinde idari $\neg$ prosedürlerin standartlaştırılması ve resmileştirilmesi, ayrıca devlet organlarının bilgilendirilmesi, birim yönetim politikasının geliştirilmesi ve uygulanması. Devlet görevlilerinin bilgi ve iletişim teknolojileri alanında bilgilerinin düzenli artırılması mekanizmasının hazırlanması ve uygulanması; Bilgi ve iletişim teknolojilerinin geliştirilmesi Azerbaycan Cumhuriyetinin devlet politikasının temel öncelik yönlerinden biridir. 2003 yılında onaylanmış "Azerbaycan Cumhuriyetinin gelişmesi için bilgi ve iletişim teknolojileri (BİT) üzerine Milli Strateji (2003-2012 yılları)" yakın 10 yıl içinde yapılacak işlerin genel çizgisini belirlemiştir. Azerbaycan Cumhuriyeti Güney Kafkasya'da bu alan için Milli Strateji kabul etmiş tek ülkedir. alanında devlet programının hazırlanmasını önemli konu olarak ileri sürmüş ve "Azerbaycan Cumhuriyetinde iletişim ve bilişim teknolojilerinin gelișimi üzere (2005 - 2008 yılları) Devlet Programı” hazırlanmış ve onaylanmıştır. 2005 yılının Temmuz ayından itibaren BM Kalkınma Programı ile birlikte "Milli E-Yönetim şebekesi girişimi" (Azdatacom) projesi hayata geçirilmeye başlanmıştır. Bu projenin uygulanması sonucunda devlet yapılarının BİT kullanarak olanakları daha da artacaktır. Ülkedeki bakanlık ve hükümet organlarının 30 faizden çoğunun resmi Web siteleri (Internet-rezervleri) mevcuttur. 2000 yılından devlet yapıları gov.az alanında ücretsiz kullanırlar. Hükümet organlarına ait Web sitelerinde genellikle örgütün misyonu, yapısı ve görevleri hakkında bilgiler yerleştirildi. Bazı sitelerde ise artık bazı hizmetler ve onlardan istifade kuralları, tarifeler hakkında yaptığı bilgiler, çeşitli belgelerin örnekleri kullanıcılara sunulmaktadır. Devlet Gümrük Komitesinin bilgi sistemi online şekilde veri ağı vasitasıyla merkezle bölgelerde bulunan kurumlar arasında faaliyet gösteriyor. Bu da Azerbaycan'da E-yönetim alanında geniş ağ sisteminin ilk pratik örneğidir. Devlet Sosyal Müdafaa Fonu Dünya Bankası ile birlikte üç yönde - burslar, sosyal yardım ve iş piyasasında İslam Kalkınma Örgütü (İKÖ)'nün geniş kullanımını sağlamak için ortak iş yapıyorlar. Artık sonuç olarak başkentte ve birçok bölgelerde burslar kart sistemi ile ödenir. Vergiler Bakanlığında da Geniş Alan Ağ sistemi oluşturulur. Artık bakanlığın Web sitesinde vatandaşlar verdikleri sorulara hızlı cevap alabiliyorlar. Standartlaşma, Metroloji ve Patentler Devlet Ajansı çalışmalarını uluslararası düzeyde kabul edilmiş BİT standartlarına göre kurmaya başlamıştır. Ödeme sistemi alanında da elektronikleşme gerçekleştirilir. Öyle ki, artık gerçek zaman şeklinde Bankalar arası Milli Hesap Sistemi faaliyet gösteriyor. İletişim ve Bilgi Teknolojileri Bakanlığı ülkenin BİT sektöründe yapılan çalışmalar üzere elektronik şeffaflık ilkesini hayata geçirmeye, iletişim ve bilgi teknolojileri alanında yerli ve yabancı kullanıcıları dünya standartları seviyesinde bilgi kaynakları ile sağlamaya olanak veren Bilgi Partalı hazırlamış, İngiliz ve Rus dillerine tercüme olunarak abonelerin ve sivil toplumun kullanımına sunulmuştur. BİT alanında devlet programının hazırlanmasını önemli konu olarak ileri sürmüş ve "Azerbaycan Cumhuriyetinde iletişim ve bilişim teknolojilerinin gelişimi üzere (2005 - 2008 yılları) Devlet Programı" hazırlanmış ve onaylanmıştır. 2005 yılının Temmuz ayından itibaren BM Kalkınma Programı ile birlikte "Milli EYönetim şebekesi girişimi” (Azdatacom) projesi hayata geçirilmeye başlanmıştır. Bu projenin uygulanması sonucunda devlet yapılarının BİT kullanarak olanakları daha da artacaktır. Ülkedeki bakanlık ve hükümet organlarının 30 faizden çoğunun resmi Web siteleri (Internet-rezervleri) mevcuttur. 2000 yılından devlet yapıları gov.az alanında ücretsiz kullanırlar. Hükümet organlarına ait Web sitelerinde genellikle örgütün misyonu, yapısı ve görevleri hakkında bilgiler yerleştirildi. Bazı sitelerde ise artık bazı hizmetler ve onlardan istifade kuralları, tarifeler hakkında yaptığı bilgiler, çeşitli belgelerin örnekleri kullanıcılara sunulmaktadır. Devlet Gümrük Komitesinin bilgi sistemi online şekilde veri ağı vasıtasıyla merkezle bölgelerde bulunan kurumlar arasında faaliyet gösteriyor. Bu da Azerbaycan'da E-yönetim alanında geniş ağ sisteminin ilk pratik örneğidir. Devlet Sosyal Müdafaa Fonu Dünya Bankası ile birlikte üç yönde - burslar, sosyal yardım ve iş piyasasında İslam Kalkınma Örgütü (İKÖ)'nün geniş kullanımını sağlamak için ortak iş yapıyorlar. Artık sonuç olarak başkentte ve birçok bölgelerde burslar kart sistemi ile ödenir. Vergiler Bakanlığında da Geniş Alan Ağ sistemi oluşturulur. Artık bakanlığın Web sitesinde vatandaşlar verdikleri sorulara hızlı cevap alabiliyorlar. Standartlaşma, Metroloji ve Patentler Devlet Ajansı çalışmalarını uluslararası düzeyde kabul edilmiş BİT standartlarına göre kurmaya başlamıştır. Ödeme sistemi alanında da elektronikleşme gerçekleştirilir. Öyle ki, artık gerçek zaman şeklinde Bankalar arası Milli Hesap Sistemi faaliyet gösteriyor. İletişim ve Bilgi Teknolojileri Bakanlığı ülkenin BİT sektöründe yapılan çalışmalar üzere elektronik şeffaflık ilkesini hayata geçirmeye, iletişim ve bilgi teknolojileri alanında yerli ve yabancı kullanıcıları dünya standartları seviyesinde bilgi kaynakları ile sağlamaya olanak veren Bilgi Partalı hazırlamış, İngiliz ve Rus dillerine tercüme olunarak abonelerin ve sivil toplumun kullanımına sunulmuştur. 2000 y1lından itibaren ise toplumda giden demokratik süreçlerin temel göstergesi olan seçim sürecinin şeffaf bir şekilde yapılması için seçimler Otomatik Bilgi Sistemi vasıtasıyla aparılıyor. Bu sistemin en önemli fonksiyonlarından biri bölgelerdeki seçim daireleri ile Merkez Seçim Komisyonu arasında hızlı bilgi alışverişini sağlamaktır. 2004 yılından Azerbaycan Cumhuriyetinin bütün vatandaşları, ayrıca ülkede sürekli yaşayan Yabancılar ve vatandaşlığı olmayan kişiler hakkında bilgileri yansıtan devlet bilgi bankası - Devlet Registri oluşturulmaya başlanmıştır. "Azerbaycan Cumhuriyetinde bilgi ve iletişim teknolojilerinin gelişmesi için (2003-2012) Milli stratejinin hayata geçirilmesi doğrultusunda ve "Bilgi edinme hakkında" Azerbaycan 
Cumhuriyeti kanununu uygulanması ile ilgili devlet organlarının otomatik karşılıklı bilgi ilişkisinin sağlanması amacıyla tek elektronik belge alışverişi sisteminin uygulaması bazında devlet organlarının bilgi altyapısının oluşturulması hayata geçirilir. Bu amaçla: "Fiziksel kişiler”, "Yasal kişiler", "Adres registri”, "Gayrimenkul varlık registri"; Elektronik belge hacmi, elektronik arşivler bilgi sistemleri; "E-devlet"in öğeleri olan standart bilgi sistemleri (bütünleşmiş bilgi sistemi, vergi ödeyenler ve vergi tutma nesneleri reyestri, otomasyon gümrük bilgi sistemi vb.) kuruldu. Devlet yönetiminin bilgilendirilmesi alanında belli sorunlar mevcuttur: -E-hükümet stratejisinin olmaması; Devlet yönetiminin bilgilendirilmesinde kurumsal mekanizmanın olmamas1; Devlet organları arasında karşılıklı ilişkini sağlayan ağ altyapısının olmaması; Bilgilendirme alanında normatif-hukuki bazın $\neg$ mükemmel olmaması; İdareler arası bilgi sistemlerinin oluşturulmasında işlev ve sorumlulukların bölüştürülmesinin yönetmeliğin olmaması; Birçok devlet organlarında bilgi teknolojileri alanında devlet görevlilerinin ihtisas seviyesinin yeterince olmamas1;

Şu anda ülkede bilgi toplumunun oluşturulmasında ve gelişmesinde temel engellerden biri de toplumda bilgi eşitsizliğinin mevcut olmasıdır. Azerbaycan'da e-devlete Geçerken Atılması Gereken Öncelikli Adımlar Öncelikle Azerbaycanlı yetkililerin, Avrupalı devletlerin de yaptığı gibi, e-devlet hedefini gerçekleştirmek için uygulamaya başlangıç yılını belirlemesi gereklidir. Bu hedef e-devlet için gerekli çalışmaların belirli bir kararlıkla gerçekleştirilmesi için teşvik olacaktır. Çalışmaların aksamadan yürütülebilmesi için gerekli hukuksal düzenlemelerin yapılması şarttı. Bu teknolojik alt yapı tasarımları ile desteklenmeli ve uygulamaya hızlı bir şekilde geçilmelidir. Ancak en önemli problem e-devletin finansmanıdır. Finansman için klasik bütçe hazırlama usullerinin dışına çıkılmalı ve yeni modeller oluşturulmalıdır. Aynı zamanda insan faktörünün de eğitilmesi gerekmektedir6 . Toplumun düşünülen ve planlanan sistemlere uyumu ve sistemi kullanması için gerekli eğitim sağlanmalı değişim yönetimi gerçekleştirilmelidir. Bunun için de hizmet altyapısını oluşturulması gereklidir. Kullanıcıların en verimli ve etkili bir şekilde hizmet alabileceği teknolojiler belirlenmeli ve gerekli alt yapı oluşturulmalıdır. E-devlete geçişin bir başka aşaması hizmet mekanizmasının oluşturulmasıdır. Servis mekanizmasını oluşturmak, sistem bileşenlerinin bir arada çalışma prensiplerini belirlemeyi gerektirir. Bilgiye ulaşma, saklama, paylaşma prensipleri servis mekanizması tarafından belirlenir. E-devlette tüm birimler arasında etkin bir veri paylaşım sistemi oluşturulmalı ve içerik meydana getirilmelidir. Bu gerçekleştirilirken dikkate alınması gereken önemli husus, güvenlik ve gizliliğin temin edilmesidir. E-devlet hizmetleri, kullanıcılarının bilgilerini güvenli bir ortamda saklamalı ve kullanıcılar gizlilik prensiplerinin uygulandı̆̆ından emin olmalıdırlar. Yine e-devlet'e geçişte performans değerlendirmesi yapabilmek için kritik başarı faktörlerinin belirlenmesi gerekmektedir. En önemli önceliklerden biri, bütün kamu kurumlarının tek bir koordinasyon merkezinden yönetilmesi ve tek bir Devlet portalının oluşturulmasıdır.

BM Ekonomik ve Sosyal İşler Dairesi, her yıl e-devlet Geliştirme Endeksi'ni yayınlamaktadır.

E-devlet geliştirme endeksini hesaplarken, aşağıdaki üç temel gösterge kullanılır:

1. Çevrimiçi servis endeksi;

2. Telekomünikasyon altyapısı endeksi;

3. İnsan sermayesi endeksi.

$\mathrm{Bu}$ anket sonucuna göre Azerbaycan son yıllarda post Sovyet ülkeleri arasında konumunu en fazla iyileştiren ülkelerdendir.

\begin{tabular}{|l|l|c|c|c|}
\hline No & Ülke ismi & $\begin{array}{c}\text { E-government survey } \\
\mathbf{2 0 1 2}\end{array}$ & $\begin{array}{c}\text { E-government survey } \\
\mathbf{2 0 1 4}\end{array}$ & $\begin{array}{c}\text { E-government survey } \\
\mathbf{2 0 1 6}\end{array}$ \\
\hline 1 & Kazakistan & 38 & 28 & 33 \\
\hline 2 & Rusya & 27 & 27 & 35 \\
\hline 3 & Belarus & 61 & 55 & 49 \\
\hline $\mathbf{4}$ & Azerbaycan & $\mathbf{9 6}$ & $\mathbf{6 8}$ & $\mathbf{5 6}$ \\
\hline 5 & Gürcistan & 72 & 56 & 61 \\
\hline 6 & Ukrayna & 68 & 87 & 62 \\
\hline 7 & Moldova & 69 & 66 & 80 \\
\hline 8 & Özbekistan & 91 & 100 & 87 \\
\hline 9 & Ermenistan & 94 & 61 & 97 \\
\hline 10 & Kirgizistan & 99 & 101 & 140 \\
\hline 11 & Türkmenistan & 146 & 128 & 139 \\
\hline 12 & Tacikistan & 122 & 129 & 6 \\
\hline
\end{tabular}

Tablo 1. Dünya Post-Sovyet Ülkelerinin Electron Hükümet Katılım Endeksinde Azerbaycan'ın Konumu Kaynak: https://publicadministration.un.org/egovkb/en-us/Reports/UN-E-Government-Survey verileri kullanılarak yazarlar tarafindan oluşturulmuştur

BM raporundaki ikinci önemli endeks "Elektronik Katılım Endeksi" (E-Participation). Azerbaycan bu endeks açısından dünya genelinde konumunu 30 basamak iyileştirerek 77'den 47. sıraya yükselmiştir. Birleşik Krallık, dünya e-Katılım Endeksi arasında liderdir. İkinci yer iki ülke Japonya ve Avustralya arasında paylaşılıyor. Önceki raporda ilk olan Güney Kore dördüncü sırada konumlanmaktadır. 


\begin{tabular}{|l|l|c|c|c|}
\hline No & Ülke ismi & $\begin{array}{c}\text { E-government survey } \\
\mathbf{2 0 1 6}\end{array}$ & $\begin{array}{c}\text { E-government survey } \\
\mathbf{2 0 1 4}\end{array}$ & Fark \\
\hline 1 & Rusya & 32 & 30 & -2 \\
\hline 1 & Ukrayna & 32 & 77 & +45 \\
\hline 2 & Azerbaycan & 47 & 77 & +30 \\
\hline 2 & Özbekistan & 47 & 71 & +24 \\
\hline 3 & Moldova & 50 & 40 & -10 \\
\hline 4 & Kirgizistan & 67 & 81 & -45 \\
\hline 4 & Kazakistan & 67 & 22 & -21 \\
\hline 5 & Belarus & 76 & 55 & -27 \\
\hline 5 & Gürcistan & 76 & 49 & -25 \\
\hline 6 & Ermenistan & 84 & 59 & -21 \\
\hline 7 & Tacikistan & 149 & 158 & +9 \\
\hline 8 & Türkmenistan & 179 & 158 & -214 \\
\hline
\end{tabular}

Tablo 2. Post-Sovyet Ülkelerinin Elektron Katılım Endeksinde Azerbaycan'ın Konumu Kaynak: https://publicadministration.un.org/egovkb/en-us/Reports/UN-E-Government-Survey verileri kullanılarak yazarlar tarafindan oluşturulmuştur

Tüm dünyada nüfusun geniş kitlesinin bilgi kaynakları kullanımının sağlanmasına Devlet ilgi göstermeye başlamıştır. Gelişmiş birçok ülkede gerçekleştirilen elektronik hükümet programlarında "e-citizen” (elektronik vatandaş), G2C (kamudan vatandaşa), gibi uluslararası terimleri kabul edilmiştir. G2C - vatandaşlarla karşılıklı ilişkiyi düzenleme sistemidir. Bu terim ABD, İngiltere, Moldova, Beyaz Rusya ve Kazakistan'ın bilgilendirme üzere kabul ettikleri programlarda kullanılır. "E-citizen” ilk alandır ki, vatandaşlara geniş spektrumlu entegre edilmiş devlet bilgi ve hizmetlerinden yararlanma imkânı yaratıyor. Elektronik vatandaş sadece vatandaşlara hükümetin elektronik hizmeti demek değildir, bu hizmetlerden yararlanmak için vatandaşın elektronik vatandaşa dönüşümüdür, yani bilgi toplumunun oluşumu ortamında her bir vatandaşın bilgisayar bilgileri artmalıdır. Dijital teknolojiler, bio-teknolojiler, iletişim ağının gelişmesi, ticaretin genişlemesi bunların hepsi kimliğin gelişmesi için büyük firsatlar sunuyor. Nüfusun geniş kitlesinin bilgi kaynaklarını kullanımını sağlamak için birçok ülkelerin hükümeti ve uluslararası kurumlar teknik altyapını genişler, devlet hizmetlerini ve kontrollerini otomatikleştirir ve elektronik belge hacmini uygular, vatandaşlarla karşılıklı etkileşimli sistem yaratır.

Tüm dünyada nüfusun geniş kitlesinin bilgi kaynakları kullanımının sağlanmasına Devlet ilgi göstermeye başlamıştır. Gelişmiş birçok ülkede gerçekleştirilen elektronik hükümet programlarında "e-citizen” (elektronik vatandaş), G2C (kamudan vatandaşa), gibi uluslararası terimleri kabul edilmiştir. G2C - vatandaşlarla karşılıklı ilişkiyi düzenleme sistemidir. Bu terim ABD, İngiltere, Moldova, Beyaz Rusya ve Kazakistan'ın bilgilendirme üzere kabul ettikleri programlarda kullanılır. "E-citizen” ilk alandır ki, vatandaşlara geniş spektrumlu entegre edilmiş devlet bilgi ve hizmetlerinden yararlanma imkânı yaratıyor. Elektronik vatandaş sadece vatandaşlara hükümetin elektronik hizmeti demek değildir, bu hizmetlerden yararlanmak için vatandaşın elektronik vatandaşa dönüşümüdür, yani bilgi toplumunun oluşumu ortamında her bir vatandaşın bilgisayar bilgileri artmalıdır. Dijital teknolojiler, bio-teknolojiler, iletişim ağının gelişmesi, ticaretin geniş̧lemesi bunların hepsi kimliğin gelişmesi için büyük firsatlar sunuyor. Nüfusun geniş kitlesinin bilgi kaynaklarını kullanımını sağlamak için birçok ülkelerin hükümeti ve uluslararası kurumlar teknik altyapını genişler, devlet hizmetlerini ve kontrollerini otomatikleştirir ve elektronik belge hacmini uygular, vatandaşlarla karşılıklı etkileşimli sistem yaratır.

Nüfusun bilgisayar bilgilerinin giderilmesi sorununu nasıl çözüm etmeli, toplu öğretimi ve herhangi eğitimi metotlarını düzenlemek amacı ile 2002 tarihinden Avrupa birliği ECDL uluslararası fonu tarafından e-citizen uluslararası Sertifikasyon programı onaylanmıştır. Bilgisayar ve internetten başlangıç düzeyde bilgiye sahip olmayan insanlar için öngörülen e-citizen sertifikasyonu yaş, eğitim, sosyal grup farkı koymadan tüm vatandaşlar için, dahil, işsizler, sınırlı imkânlı kişiler, göçmenler, özgürlüğünden yoksun bırakılan kişiler, emekliler için belirlenmiştir. Sertifika programının temel amacı vatandaşlara bilgi toplumunun tüm çeşitliliği ile tanışmak imkânı yaratmaktır. Artık Elektronik vatandaş pilot proje olarak Birleşik Krallıkta, Finlandiya, Norveç, Hırvatistan, Almanya, Fransa, İsviçre, İtalya, Avustralya, Romanya, Yunanistan, Macaristan, Rusya'da başarıyla yerine getirilir. Bilgi toplumunun oluşumu yönünde Azerbaycan'da da bir takım reformlar gerçekleştirilmektedir.

Devlet organlarının resmi sitelerine göz attığımızda görürüz ki, devlet organının uygun yapısı kullanıcıdan yüksek düzeyde beceri ve özel bilgi gerektirir. Burada temel sorun vatandaşların bilgisayar bilgisi ve internete erişim imkânlarının olmamasıdır. Maalesef, nüfusun geniş kitlesi bu hizmetten de yararlana bilmiyor. Devlet yapıları ile karşılıklı ilişkiyi kolaylaştırmak, uzak bölgelerin sakinlerine İnternet üzerinden eğitim almaya ve bilgi seviyelerini yoklamaya olanak yaratmak, devlet memurlarının ihtisasını yükseltmek, vatandaşlara bilgi toplumunun tüm çeşitliliği ile tanışmak imkânı yaratmak, bilgisayar kültürünün kabul edilmesine toplumun hazırlanması, her bir vatandaşa online iletişimden kullanım imkânı vermek amacıyla e-citizen programının kabul edilmesi her vatandaşın bilgi teknolojileri üzere bilgi düzeyini belirleyen mobil test merkezinin oluşturulması bugün önemli konulardan en önemlisi. Şu anda tüm bunlar dünyanın gelişmiş ülkelerinde bir güncel sorun olarak 
dikkat merkezindedir. Nüfusun bilgisayar bilgilerinin giderilmesi sorununu çözümü, toplum öğretimi ve eğitimi metotlarını düzenlemek amacı ile 2002 tarihinden Avrupa Birliği ECDL uluslararası fonu tarafindan e-citizen uluslararası Sertifikasyon programı onaylanmıştır. Bilgisayar ve internetten başlangıç düzeyde bilgiye sahip olmayan insanlar için öngörülen e-citizen sertifikasyonu yaş, eğitim, sosyal grup farkı koymadan tüm vatandaşlar için, dahil, işsizler, sınırlı imkânlı kişiler, göçmenler, özgürlüğünden yoksun bırakılan kişiler, emekliler için belirlenmiştir. Sertifika programının temel amacı vatandaşlara bilgi toplumunun tüm çeşitliliği ile tanışmak imkânı yaratmaktır. Artık Elektronik vatandaş pilot proje olarak Birleşik Krallıkta, Finlandiya, Norveç, Hırvatistan, Almanya, Fransa, İsviçre, İtalya, Avustralya, Romanya, Yunanistan, Macaristan, Rusya'da başarıyla yerine getirilir. Bilgi toplumunun oluşumu yönünde Azerbaycan'da da bir takım reformlar gerçekleştirilmektedir. Bilgi toplumunun kurulmasına ve devletimizin genel gelişmesine hizmet eden "Azerbaycan Cumhuriyetinde İletişim ve Bilişim Teknolojilerinin Gelişimi Üzere 2005-2008 Yılları İçin Devlet Programı” (“Elektronik Azerbaycan”), "Elektronik İmza ve Elektronik Belge Hakkında", "Elektronik Ticaret", "Telekomünikasyon Hakkında", "Bilgi Edinmek Hakkında" yasalar kabul edilmiştir. Uluslararası iktisadi forum uzmanları tarafından yapılan "The Global Information Technology Report 2006-2007” adlı araştırmaların sonucu gösteriyor ki, 2007 yılının başında BİT sektörünün gelişim durumu üzere Danimarka, İsviçre ve Singapur ön sıralarda gidiyor. Dünyanın 122 ülkesinin BİT gelişme seviyesi üzere sıralamada Azerbaycan'ın Rusya'dan sonra 71-inci yerde olduğu gösterilmiştir.9 Azerbaycan Cumhuriyeti 2007 yılı için bilgi toplumuna hazırlık endeksine bakalım: ABD'de her bir kişiye 1 bilgisayar düştüğü halde, Rusya'da 3 kişiye 1 bilgisayar, Azerbaycan'da ise 33 kişiye 1 bilgisayar düşüyor. İnternet kullanıcılarının sayısına göre ABD’de 160 milyon, Rusya-16 milyon, Azerbaycan-400 bin göstericiye sahiptir. Şu anda ülkemizde bilgi toplumuna hazırlık aşamasında bu göstergelerin artırılması güncel mesele olarak dikkat merkezindedir. İletişim ve Bilgi Teknolojiler Bakanlığı “İT’nin gelişmesi adına insan kaynakları" fonu "Halk bilgisayarı" projesi hayata geçirecek. Yakın iki yılda her 100 kişiye düşen bilgisayarların sayısının yaklaşık 25'e ulaştırılması hedeflenmektedir.10 Artık modern yaşamın nabzını tutmak, işsizliği gidermek ve nüfusun istihdamını tanzim etmek için yeni bilgi teknolojilerine ulaşabilmek hayatımızın temel görevlerinden birine çevrilmiştir. Bilgi teknolojilerine ulaşabilmek yaş ve ihtisas farkı olmadan herkese aittir. Azerbaycan'da e-citizen sertifikasyon programının uygulanmasını, mobil test merkezlerinin oluşturulmasına ihtiyaç var. Bu programın hayata geçirilmesi uluslararası bilgi toplumuna dahil olmaya, bilgi teknolojilerinin hayatımızın ayrılmaz bir parçası haline gelmesine, elektronik duraklamanın giderilmesine yardımcı olacaktır. Yabancı deneyimlere dayanarak neredeyse bugün Azerbaycan'da e-citizen (elektronik vatandaş) devlet programı kabul edilmesi ve e-citizen portalının oluşturulması devlet kurumları ile vatandaşlar arasında karşılıklı ilişkiyi sağlayabilir. E-devletin önemli uygulamalarını oluşturan "Elektronik belgelerin devlet tarafından kabul edilmesi ve bu belgelerde kimlik kanıtlanması", "Sanal kurum kimliğinin tanımlanması", "Kişisel bilgilerin mahremiyetinin sağlanması", "Elektronik imzanın kabulü”, “İnternet ortamında işlenen suçlara ilişkin düzenlemelerin yapılması”, "Tüketicinin korunması", "Sözleşme hukuku ve Devlet ihale mevzuatının düzenlenmesi”, "Kurumlar arası bilgi paylaşımında kural ve standartların ortaya çıkartılması", "Girişimciliğin desteklenmesi", "Genel devlet politikasının ve stratejisinin oluşturulması", "Kaynak israfının önlenmesi” gibi konuların hukuki açıdan netleştirilmesi, bu konularla ilgili yürürlükte olan hukuki düzenlemelerin uyumlulaştırılması zorunludur. İkinci grup problemleri "Teknik Sorunlar" başlığı altında toplamak mümkündür. Bu tür problemler "Ülke geneline dağılacak hizmete ulaşım için yeterli altyapının olmaması", "İlk yatırım maliyetinin yüksekliğgi”, "Gizliliğinin ve güvenliğin sağlanması", "Bilgi paylaşımında belirli standartların oluşturulması", "İletişim altyapısının yetersizliğgi”, "AR-GE çalışmalarının desteklenmesi" olarak ifade etmek mümkündür. Üçüncü grup problemleri ise "İdari Sorunlar" oluşturmaktadır. Bu grupta yer alan problemler e-devlet'e geçişin karşısındaki en zor ve tehlikeli problemlerdir. Çünkü alışkanlıklar, yönetim hastalıklarından kaynaklanan beklentiler, yeni uygulamanın devlet bütçesine getireceği maliyet e-devletin hayata geçmesinin karşısındaki en tehlikeli sorunlardır. Bunun yanısıra kalifiye personel ihtiyacı, bilgi işlem merkezlerinin aktif çalışması ihtiyacı, Koordinasyon kurulunun oluşturulması ihtiyacı, kullanıcının giderlerinin düşürülme zorunluluğu, sisteme güvenin sağlanma zorunluluğu, devlet hizmetlerinde bir standardın belirlenme ve bedelinin maliyetini karşılamaya yetmemesi gibi sorunlar da eklendiğinde gelişme döneminde olan devletlerde bu tür bir uygulamaya geçiş caydırıcı olmakta ve genellikle de hükümetler geçişi mümkün olduğu kadar ertelemeyi tercih etmektedirler. Kabul etmek gerekir ki, e-devlet olumlu neticeler vermesine karşın özellikle kuruluş aşamasında önemli bir maliyete sahiptir. Azerbaycan'da yönetimde yaşanan problemlerin düzeltilmesi, vatandaşların devletle olan ilişkilerinin yeniden tanımlanması, "Elektronik Hükümet" - modern bilgi teknolojilerinin kullanımı ile devlet kurumları tarafından Azerbaycan Cumhuriyeti topraklarında yaşayan tüm vatandaşlara, gerçek ve tüzel kişilere, yabancı vatandaşlara ve vatandaşlığı olmayan kişilere bilgi ve e-hizmetlerin gösterilmesini sağlıyor. Yaratılan firsatların temel amacı, devlet memurları ve vatandaşlar arasındaki sosyal hizmetlerin "mesafesini" azaltmak ve bu ilişkileri basitleştirmek ve şeffaflaştırmaktır. E-hizmetlerin kamu makamları tarafından yaygın olarak uygulanması, sayılarının ve kalitesinin artırılması ve vatandaşların hizmetlerle ilgili memnuniyetlerinin artırılması bu hedefe ulaşmanın aracıdır. Uluslararası deneyime göre, "tek duraklı alışveriş" ilkesi ve devlet otoriteleri tarafından sağlanan elektronik hizmetler ile düzenlenen "E-devlet" portalı, devlet organlarıyla vatandaşların temaslarını daha iyi organize etmek için uygulanmaktadır. Azerbaycan'da "Elektronik Hükümet" in oluşturulması uluslararası tecrübeye göre ve Azerbaycan Cumhurbaşkanının "Azerbaycan Cumhuriyetinde iletişim ve bilgi teknolojilerinin gelişimi üzere 
2010-2012 yılları için Devlet Programı (Elektron Azerbaycan)" onay kararı, "Devlet kurumlarının elektronik hizmetler göstermesinin teşkili alanında 23 Mayıs 2011 tarihli Kanun Hükmünde Kararname ve diğer kanuni hukuki düzenlemeler için bazı önlemler üzerinde yasal bir çerçeve oluşturulmuştur. Azerbaycan Cumhuriyeti Cumhurbaşkanlığına bağlı Vatandaşlara Hizmet ve Sosyal Yenilikler üzere Devlet bu alanda yapılan çalışmaların koordinatörü olarak "Elektronik Hükümet" in oluşumu üzere diğer devlet kurumları ile yoğun faaliyet ve ilgili altyapının oluşturulması üzere faaliyet gerçekleştirmektedir. Elektronik imzaların kullanımı için Ulusal Belgelendirme Hizmet Merkezi oluşturulmuş, devlet bilgi sistemleri arasında bilgi alışverişi için bir altyapı kurulmuş ve "Elektronik Hükümet" portalı hazırlanmış ve işletmeye alınmıştır. Bütün devlet kurumları, vatandaşlara bunları kullanarak e-hizmetler sunabilmektedir.

"Elektronik Hükümet" in İlkeleri:

$\checkmark$ Azerbaycan Cumhuriyeti'nin mevcut mevzuatına uygunluk;

$\checkmark$ Kamu politikasının, bilişim, devlet ve ulusal çıkarların korunması alanında uygulanması;

$\checkmark$ Kullanıcılara, sağlanan bilgilerin eksiksizliği, doğruluğu, alaka düzeyi, güvenliği ve güvenliğine basit ve zamanında erişebilmelerini sağlamak;

$\checkmark$ Devlet kurumları arasında sorumlulukların ve sorumlulukların dağılımı,,

"Elektronik Hükümet" in Önemi:

$\checkmark$ Kamu yönetiminde modern teknolojilerin tanıtımını genişleterek ve bunlara erişimlerini kolaylaştırarak yürütülen faaliyetlerin seviyesini arttırmak;

$\checkmark$ Devlet kurumlarının ve yerel öz yönetişim organlarının verimliliğinin artırılması ve sağlanan elektronik hizmetlerin kalitesinin artırılması;

$\checkmark$ Devlet kurumları tarafindan kullanıcılara sunulan e-hizmetlerin optimizasyonunu ve uygulanmasını basitleştirin;

$\checkmark$ Elektronik hizmetlerle kullanıcılara gerçekliğin, eksiksizliğin, güvenilirliğin ve kullanıcılara ücretsiz erişimin sağlanması;

$\checkmark$ Kullanıcının isteğine göre bilgi aramak ve almak için harcanan sürenin azami süresi;

$\checkmark$ Kullanıcının coğrafi konumu ne olursa olsun, ülke genelinde sağlanan elektronik hizmetleri kullanabilme.

"Elektronik Hükümet", ülke vatandaşlarına sanal alanı, modern teknolojilerin yeteneklerini ve kamu kurumlarındaki yüksek bilgi düzeyini kullanarak yeni bir hizmet kalitesi sunmaya hizmet ediyor.

Bilgisayar teknolojisi dünyasında, bilgi güvenliği giderek daha önemli hale geldi. Bilgi değişimi sırasında aktarılan bilgilerin korunması çok önemli bir konudur. Devlet kurumları ile çeşitli faaliyetlerde bulunurken, güvenli ağlar gittikçe popüler hale gelmektedir ve böylece vatandaşlar üçüncü şahıslara ait kişisel bilgileri ele geçirmemektedir. Buna ek olarak, elektronik operasyonlar sırasında bir vatandaşın belirlenmesi de güvenlik kadar önemlidir. Belirtilen tüm elektronik imza gereklilikleridir. Elektronik imza düşüncesi 20. yüzyılın 70-80 yıllarında meydana gelen ve esas mahiyeti bilgileri hazırlayan kişinin gerçekliğinin kontrol ve 3. tarafa (yargı, internet market vb.) Bu bilgiyi yaratan özel belli etmesine olanak yaratmaktır. Halihazırda elektronik imza kullanan ülkeler diğerlerinden daha gelişmiş olarak değerlendiriliyor ve bu ülkelerin gelişimi daha da dinamiktir (http://www.eimza.az).

Bugün, e-devletin temel özelliklerinden biri olarak kabul edilen elektronik imza, Azerbaycan'da da başarıyla uygulanmaktadır. Elektronik İmza ve Elektronik Belge Yasası'nın kabulünden sonra Ulaştırma, Haberleşme ve Bilgi Teknolojileri Bakanlı̆̆ı'nın "elektronik imzayı" merkezi yürütme organı olarak yürütmesi talimatı verildi. Eylül 2011'de kurulduğundan beri, Merkez, nüfusun çeşitli katmanlarına, yani sıradan vatandaşlara, tüzel kişiliklere ve girişimcilik faaliyetinde bulunan kişilere ve devlet memurlarına hizmet vermektedir. E-imza hizmetlerini etkin bir şekilde sağlamak için, Bakü merkezlerinin ana merkez ve şubeleri ile ülke bölgelerindeki postanelerde Kayıt Merkezleri oluşturulmuştur. Vatandaşlara elektronik imza hizmetlerinin etkin bir şekilde düzenlenmesi ve soruların yanıtlanması amacıyla Merkezin uzmanları www.e-imza.az sitesini hazırlamıștır. Site aracılığıyla, vatandaşlar e-imza, çeşitli talimatlar ve sertifikaları hakkında Merkez'in faaliyetleri ile ilgili daha fazla bilgi edinebilirler. Bugün, cumhuriyetimizde elektronik imza sisteminin kurulması ve devlet kurumlarında elektronik hizmetlerin sağlanması, ülkemizin dünya bilgi sistemi ve Avrupa'ya entegrasyonunu daha da hizlandıracaktır.

Bir diğer seçenek GSM operatörleri tarafından sunulan "ASAN İmza" (Mobil Kimlik) tüm mevcut e-hizmetlerin kullanılmasını mümkün kılan alternatif imkândır. "Kolay İmza" geliştirilmiş mobil e-imza hizmetinin, çeşitli kamu ve özel kuruluşlar tarafından sağlanan ülke genelinde 650 'den fazla elektronik hizmet tarafindan kullanılmakta olduğu belirtilmelidir. "Kolay İmza" ile (Mobil Kimlik), vergi, gümrük, finans, eğitim ve diğer birçok alanda çeşitli hizmetleri kullanmak mümkündür. Böylece, elektronik vergi beyannamelerinin getirilmesi, malların gümrük beyannamelerinin beyanı ve ulaşım araçları, istihdam bildirimlerinin elektronik olarak kaydedilmesi, yükseköğretim kurumlarına kabul edilmenin online kaydı "Asan İmza" ile internet ve mobil bankacılık gibi işler yapılmakta ve mobil imza hizmeti "Asan İmza" halihazırda kamu ve özel kuruluşların telefon ve çağrı merkezlerine entegre edilmiştir. Easy Signature" (Mobil Kimlik), Azerbaycan'da Made in Azerbaijan markasıyla 
çeşitli uluslararası konferans ve sergilerde düzenli olarak sunulmaktadır. "Asan İmza" teknolojisinin avantajı, akıllı kart okuyucularını okumak için ilave donanım ve yazılıma gerek olmamasıdır. SIM kart tabanlı bir cep telefonunun kullanılabilirliği, kimlik doğrulama ve dijital imza tuşları ile hizmetin kullanımı için yeterlidir (www.asanimza.az). Mobil imza sistemlerinde kullanılan "Asan İmza" kimlik doğrulama ve elektronik imza sertifikaları, Azerbaycan Cumhuriyeti Vergi Dairesi Vergileri Bakanlığı tarafından sağlanmaktadır. ASXM, vatandaşlık, kamu ve yerel özerk yönetişim organlarına, girişimcilik faaliyetinde bulunan tüzel kişiler ve bireylere tam sertifikalar sunma hakkına sahiptir. Daha fazla bilgi için lütfen www.asxm.gov.az adresini ziyaret ediniz.

Mobil kimliğiniz "Mobil Sinyal" teknolojisi, vatandaşların çevrimiçi e-hizmetlere kaydolmalarına ve cep telefonlarını elektronik imza olarak kullanarak belgeleri imzalamalarına izin veriyor. "Kolay İmza" (Mobil Kimlik), Azerbaycan Cumhuriyeti yasalarına göre, kişinin imzasıyla yasal olarak geçerlidir.

Azerbaycan Cumhuriyeti Cumhurbaşkanlığı Devlet Hizmet ve Sosyal İnovasyonları Devlet Dairesi Başkanlığı görevini üstlenerek 13 Temmuz 2012 tarihinde Azerbaycan Cumhuriyeti Cumhurbaşkanlığg Kararı ile ASAN hizmet merkezleri kurulmuştur.

- “ASAN servisi” merkezleri, devlet organları tarafından sunulan hizmetleri tek ve koordineli bir şekilde sağlayan kuruluşlardır.

- “ASAN xidmət” merkezleri, devlet memurlarının faaliyetlerinde vatandaşların vatandaşlık memnuniyetini sağlamak için yeni bir yaklaşım yaratmaya, ülkedeki niteliksel olarak yeni bir memur-vatandaş ilişkileri düzeyine geçişe hizmet etmektedir.

- Merkezler, işlevsellik, şeffaflık, nezaket, sorumluluk ve esneklik prensipleri üzerine kurulmuştur.

"AVIS" ve "AVIS - 2" - Azerbaycan Cumhuriyeti Vergi Bakanlığı için Vergi Bilgi Sistemi Otomatik Vergi Bilgi Sistemi

Azerbaycan Cumhuriyeti'nde vergi sisteminde her seviyesinde bilgi akışı, Azerbaycan Cumhuriyeti Vergi Dairesi'nin Otomatik Vergi Bilgi Sistemi (AVIS) aracılığıyla kurumsal ağ sistemi üzerinden gerçekleştirilmektedir. AVIS 2006'dan beri faaliyete geçti. AVIS'in temel amacı, bütçenin vergi kısmının tam ve zamanında ödenmesini sağlamak ve esnek ve verimli vergi yönetiminin uygulanması için etkin bilgi desteği sağlamaktır. Bu sistem, yerel vergi idarelerinin kurum faaliyetlerini doğrudan vergi mükellefleri ile ilişkilerini elektronik ortama getirme, diğer devlet kurumlarıyla internet bazlı entegre olma ve çeşitli ekonomik analizler ve tahminler yapma yeteneğini kazanmaktır. Sistem, tüm Vergiler Bakanlığı verilerini tek bir birleşik bilgi alanında depolamasına ve işlemesine izin verir. Sistemin başlıca avantajlarından biri, diğer bilgi sistemleri (Hazine, Devlet İstatistik Komitesi, Devlet Gümrük Komitesi, Devlet Sosyal Güvenlik Fonu, bankalar) ile bilgi alışverişi yapabilmektir. 1 Mart 2010 tarihinde itibaren vatandaşların ve mükelleflerin vergi organlarına "İnternet vergi idaresi" üzerinden online başvuru yapması imkanı yaratılmış, bu amaçla her bir kullanıcı için kişisel elektronik panel ayrılmıştır. Kişisel elektronik hesap, vergi mükellefleri ile vergi makamları arasındaki elektronik belge alışverişinin etkinliğini arttırmakta ve geleneksel bir şekilde, kağıt belgeleri göndermeye kıyasla zaman ve kaynak kayıplarını önler. 05.04.2010 tarihinden kişisel elektronik kutusu olan vergi Dairesi (Kullanıcı kodu / şifre / Şifre almış kişiler) gönderilecek belgeler (resmi mektupları, bildirişler, uyarılar, bilgiler vb.) imzalandıktan hemen sonra otomatik olarak tüm mükelleflerin sistemdeki kişisel elektronik adresine gönderilir. Vergi organından gönderilen herhangi dokümanın sadece kağıt taşıyıcısı gönderilmesi gereken durumlar hariç diğer durumlarda kişisel elektronik kutusu olan kişilerle yazışmalar elektronik ortamda yapılmaktadır. "Otomatik Vergi Bilgi Sistemi" in esas amacı bütçenin gelir kısmının tam ve zamanında oluşturulması, esnek ve verimli vergi inzibatçılığının uygulanması için etkili bilgi desteğinin sağlanması; · Vergiler Bakanlığı'nın bütün yapılarında birleştirilmiş bilgi ve verilerin oluşturulması ve sürdürülmesi; · Yerel vergi makamlarının fonksiyonlarının otomasyonu; · Devlet kurumlarıyla entegrasyonun uygulanması ve onlarla bilgi alışverişi.

Sistemde aşağıdaki alt modüller aktifti.

"Sekreterye" - Aboneler gelen ve giden mesajları, raporları vb. İçerir. Kayıt, yönetimdeki mektubun gözetimi, performansin kontrolü (yanıt verme), vb.

"Vergi Mükellefinin Kaydı" - Alt sistem vergi mükellefinin ilk kaydından vergi iadesine kadar otomatik alımını sağlar.

"Vergi beyannamelerinin kabulü ve kameralı kontrol" - Bu altsistem aracılığıyla bildiri ve raporların kabulü, mükelleflerin kameralı (Vergi idaresince) kontrol, analoji olarak vergilerin hesaplanması, tüm rapor formlarında yansımış göstergelerin mümkün karşılıklı ilişkisinin kontrol ve sair önemli işlevler yerine getirilir.

"Vergi gelirlerinin muhasebesi" - Bu altsistemin girişinde resmi formatlı banka dekontları kabul edilir, sistemin çalışması sonucu ise gelirleri vergi mükelleflerinin şahsi hesap sisteminden kullanıma yöneliktir.

"Vergi mükelleflerinin şahsi hesap sayfası" - Bu altsistem kameralı ve belgesel denetimler sonucunda gelirler ve mali yaptırımlar üzere bütçeye ödenilmeli tutarların otomatik işlenmesi, emeklilik ödeme tutarlarının otomatik hesaplanması, vergi mükelleflerinin eksik ve fazla ödemelerinin karşılıklı olarak görme imkanları mevcuttur. 
"Vergi fatura" - Altsistemi hesap faturaların muhasebe ve hesap faturalar üzere yapılmış əvəzləşmələrin doğruluğu kontrol sağlar.

"İdari para cezaları" - Altsistemi vergi organlarının görevlileri tarafından uygulanan idari para cezası tutarlarının belirlenmesi, bu tutarların eklenmesi ve çeşitli raporların alınması ve sair fonksiyonların yerine getirilmesini sağlar.

"Vergi borçlarının iptal edilmesi için gerçekleştirilen etkinliklerin sonuçlarının muhasebesi" - altsistem üzerinden beyanname sunmayan ve bütçeye borcu olan mükelleflerin listelerinin hazırlanması, İcraat faturaları açılması, bildirimlerin basılması, serencamların konulması, mülkiyet listeye alınması, yargı ilgisi üzere çalışmaların yapılması, mahkeme kararlarının geliştirilmesi ve borçsuzluğun giderilmesi.

"Vergi incelemelerinin sonuçları için muhasebe" - Alt sistem, operasyonel vergi incelemelerinin sonuçlarının uygun bir kaydını sağlar.

"Seyyar vergi yoklamalarının belirlenmesi üzere kararın kabulü ve denetimlerin sonuçlarının muhasebesi" Seyyar vergi yoklamasının yapılması, vergi mükellefi belirlenmesi, denetimlerin atanması, sonuçların kaydı ve kişisel hesap vərəqələrinə tam veri aktarımı.

"Vergi organlarının ve çalışanlarının etkinliğinin değerlendirilmesi" - altsistem tam ve dolgun denetimler sonucunda iç etkinliğin değerlendirilmesini uygular.

"Mükellefiyet" - Bu altsistemde vergi ödeyicisinin mükellefiyet, özel rejim bilgi dilekçesi, sertifika ve özel moddaki anlaşmaların bilgileri yığılır.

"Vergi Mükellefi Hizmeti” - abonelik hizmetlerinin sonuçlarının vergi mükelleflerine kaydedilmesinin otomasyonu için tasarlanmıştır.

"İnternetin sağladığı hizmetler" - Tüm hizmetler diğer devlet kurumlarıyla entegrasyon sonucunda İnternet üzerinden sağlanmaktadır.

"Elektronik başvuru" - "Banka açılması amacıyla sertifika-kopyalanması alınması için" ve "Mükellef katma değer vergisinin amaçları için tescil alınması hakkında" dilekçelerin vergi organına İnternet Vergi İdaresi sitesi aracılığıyla elektronik olarak sunulması.

"Personel" - tüm personel faaliyetlerinin planlanması ve uygulanması için tasarlanmış bir alt sistemdir.

"Finansal ekonomi" - Bu alt sistemdeki tüm finansal faaliyetlerin eksiksiz otomasyonu.

"Muhasebe" - Azerbaycan Cumhuriyeti mevzuatına dayanarak otomasyonun yapılması

Bu sistemde kullanılan teknolojiler esasen Oracle, HP, Cisco, Java programlaması ağırlıklıdır.

\section{Sonuç ve Öneriler}

Son yıllarda Azerbaycan'da bilgi toplumu ve e-devlet alanında elde edilen tecrübe ve sonuçlar, öncelikle genelleme, sistemizasyon, derinlemesine araştırma ve analiz gerektirir. Böylece, İnternet ağı yıldan y1la genişlemektedir ve eğitim, sağlık, bilim, endüstri ve hizmetlerde BT'nin uygulama alanı giderek artmaktadır. Azerbaycan'da ulusal BİT altyapısının kurulmasına özel önem verilmektedir. Ülke halihazırda IT ve iletişim, ürün ve hizmet pazarını kurmuş ve başarıyla faaliyet göstermiştir. Kamu hayatının her alanında bilgisayar sayısı giderek artıyor. Üretim, tarım, ekonomi, kamu yönetimi, bankacılık sektörü ve diğer alanların bilgilendirilmesi sürekli genişlemektedir. E-devlet stratejisinde uygulanan bir sonraki projelerin uygulanmasında bilimsel analizler sonucunda geliştirilen öneriler dikkate alınacaktır. Yapılan araştırmalarda ülke çapında Bilgi ve İletişim Teknolojilerinin uygulanmasının dinamik olarak ekonomik faydalar sağladığını göstermiştir. Bu, BİT sektörünün her yıl GSYİH içindeki payında önemli bir artışla kanıtlanmıştır. Sosyo-ekonomik kalkınmanın modern dünyasında, bilgi önemli bir stratejik kaynak haline gelmiștir. Küreselleșme faktörü ve bilgi toplumunun kurulması, modern İKT'nin zamanın gereklerini yerine getirmesini gerektirir. Modernleşme çağının modern çağında, "yeni bir ekonominin" ortaya çıkışı, insan potansiyelinin gelişmesi ve devlet ile toplum arasındaki karşılıklı ilişkilerin yeniden kurulması. Yeni bir kamu yönetimi biçimi olan e-devlet, bu sorunları ele almak için modern BİT'ler kullanılarak oluşturulmuştur. Yapısal bakış açısından, bileşenleri ve bölümleri analiz edilmiştir. Edevlet binasında lider ülkelerin büyük deneyimlerinin incelenmesi, e-devlet oluşumunun adım adım ve uzun vadeli bir süreç olduğunu göstermiştir. BM raporundaki ikinci anahtar endeks "Elektronik Katılım Endeksi" (E-Katılım). Azerbaycan bu endeks açısından dünya genelinde 77 'den 47. sıraya yükseldi. Her ülke kendi politik-ekonomik sistemi, ulusal-ahlaki değerleri ve yerel gerçekliği ile kendi modelini yaratmalıdır. Kuşkusuz, ulusal e-devlet kurmanın küresel deneyimi de kullanılmalıdır. E-devlet binası, teknik, sosyal, politik, psikolojik, finansal ve kurumsal gerekliliklerin yerine getirilmesini gerektirir. Güçlü BİT altyapısı ve istikrarlı finansman, başarılı eyönetişimin en önemli koşulları arasındadır. Azerbaycan'da bulunan e-hizmetlerin, taşınabilirliklerinin ve kullanım düzeylerinin, devlet kurumları tarafından sağlanan e-hizmetlerin hala düşük olduğu not edilmelidir. Bu nedenle, devlet kurumları tarafindan sunulan hizmetlerin çoğunluğunu kolaylaştırmak için daha fazla önlem alınmalıdır. Ayrıca, kamu makamları tarafından sunulan tüm hizmetlerin elektronikleştirilmesi tavsiye edilebilir. Elektronik hizmetlerle ilgili portalların tasarımıyla ilgili olarak, bu endüstrinin geliştirildiği ülkelerin 
deneyimlerine dayanarak hizmetleri vatandaşlara ve iş adamlarına ayırmak daha iyi olacaktır. Ayrıca, kullanıcı ihtiyaçlarının ve kullanıcı memnuniyetinin sistematik olarak izlenmesi de yapılmalıdır.

\section{Kaynakça}

- Abramson, M. A., \& Means, G. (2001). E-government. Rowman \& Littlefield.Muir ve Oppenheim (2002),

- Asia-Pacific Telecommunity, "APT report on e-government implementation in Asia-Pacific developing countries and its challenges and obstacles", Bangkok, 2012.

- Carter, L., \& Bélanger, F. (2005). The utilization of e-government services: citizen trust, innovation and acceptance factors. Information systems journal, 15(1), 5-25.

- European Journal of ePractice, "Best practices in eGovernment: on a knife-edge between success and failure", February 2008.

- Howard, M. (2001). E-government across the globe: how will'e'change government. e-Government, 90, 80.

- http://www.asan.gov.az/az

- https://publicadministration.un.org/egovkb/en-us/Reports/UN-E-Government-Survey-2018

- https://publicadministration.un.org/egovkb/en-us/Reports/UN-E-Government-Survey-2018)

- https://sustainabledevelopment.un.org/?menu=1300)

- https://www.e-gov.az/

- International Conference on Innovation, Management and Service, "Conceptual approach to e-government, targets and barriers" (2011) IACSIT Press, Singapore.

- Krugman, 1980. "Scale Economies, Product Differentiation, and the Pattern of Trade", American Economic Review, 70, p. 950.

- Krugman, 2007. The Consience of a Liberal. W.W. Norton, New York.

- Krugman, 2010. "The New Economic Geography, Now Middle-Aged", in Proceedings of AAG 2010 Meeting, p. 348.

- "Measuring and Evaluating E-Government in Arab Countries". High Level Seminar on Measurement and Evaluation of E-Government - held in Dubai on 12 March 2007. Dubai School of Government and the OECD.

- Moon, M. J. (2002). The evolution of e-government among municipalities: rhetoric or reality?. Public administration review, 62(4), 424-433.

- "National Strategies and Policies for Digital Identity Management in OECD Countries", OECD (2011),

- UN, “E-Government survey”, 2009-2017.

- UNESCO, "E-Government in developing countries: Lessons learned from Republic of Korea", 2006. 


\title{
Azerbaycan'ın Uluslararası Ticaret İlişkileri Integration Processes of the Republic of Azerbaijan to the World Economy
}

\author{
Assoc. Prof. Dr. Ramin İsmayilov (Odlar Yurdu University, Azerbaijan)
}

\begin{abstract}
The article deals with the economic development characteristics of the Republic of Azerbaijan, the natural resources and production of Azerbaijan. After the independence, the policy of the new market economy followed by the Azerbaijani state and government and plans of how the developed countries will integrate their economic practice will be examined. With the new investments in the country and the introduction of the products to be produced in the world markets, the steps and plans to strengthen the economic relations with the world will be discussed. The role of Azerbaijan in the world economy, its foreign-economic relations with other states and continents were analyzed extensively. Proposals have been made to further develop and upgrade existing economic relations.
\end{abstract}

\section{Giriş}

Herhangi bir devlet için dış ticaretin önemini değerlendirmek gerçekten zordur. Amerikalı iktisatçı J.Sachs`ın dediği gibi "ülkenin ekonomik başarısı onu direkt diş ticaret gelişimi ile ilişkilidir”. Şimdiye Kadar dünya ekonomisi ile ilişkisi olmayan devlette sağlam, rekabete dayanıklı ve gelişmiş toplum oluşturmak mümkün olmamıştır. İleriki tarihlerde olduğu gibi şimdiki dönemde de uluslararası ekonomik işbirliği bütün dünya ekonomisinin gelişiminin önemli temel taşıdır.

Büyük coğrafi keşifler, sanayinin inkılapları, ilim ve teknolojinin gelişimi, bazen meydana gelen ekonomik krizler ve belli olmayan ekonomik durum dünya ekonomisinin gelişimine önemli derecede etki ederek, coğrafi ve emtia yapısını da değiştirmektedir. Bu sebepten de bu alanın daha derinden ve geniş şekilde araştırılmasına ve öğrenilmesine gerek duyulmaktadır.

Makalenin amac1, Azerbaycan Cumhuriyetinin dünya ticaret sistemindeki yerini ve öneminin ne ölçüde olduğunu belirlemek, dış ticarette önemli ortak devletleri ortaya çıkarak hangi alanda ithal ihraç ticareti yapıldığını ve gelecek perspektifte hangi alanda ve hangi devletlerle ticaret yapılması gerektiğini ortaya çıkarmak için analiz yapmak ve istikametleri belirlemektir. Bundan ilave Azerbaycan`ın ihraç potansiyelinin artırılması için ihraç çeşitlendirilmesi için tekliflerin hazırlanması önemli yer tutmaktadır.

\section{Azerbaycan'ın İthal ve İhraç Potansiyeli (Devletler ve Üretim Alanlarına Göre)}

Azerbaycan ekonomisi yabancı yatırımcılar için açık olmakla birlikte her türlü ekonomik alanda faaliyet göstermektedir. Statistik bilgilere göre 2018 yılında Azerbaycan`ın dış ticaret hacmi Gayri Safi Milli Hasılanın \%43.3-nü oluşturmaktaydı. 2000 yılında ise Azerbaycan`ın dış ticaret hacmi GSMH-nın \%54.7, 2005-te \%64.8 ve 2016-da ise \%57.2-ni oluşturmaktaydı. Yukarıdaki rakamlar Azerbaycan`ın dış ticaret ilişkilerinin ne kadar önemli olduğunu göstermektedir. Ülkemizin diğer devletlerle hem siyasi hem de ekonomik alanda sıkı işbirliği yaparak uluslararası ekonomik ilişkilerini aktif hale getirmesi dış ticaretin gelişimi açısından çok önemli olmuştur.

2018 yılı itibarı ile Azerbaycan Cumhuriyeti dünyanın 164 ülkesiyle ithalat, 116 devleti ile de ihracat yapmıştır. $\mathrm{Bu}$ dönemde ithalat ve ihracat ekonomik ilişkileri sayesinde yeteri kadar verimli işler yapılmış ve dünya ticaret alanında Azerbaycan, ekonomik anlamda itibarını ciddi anlamda güçlendirmiştir.

Siyasi bağımsızlık elde edildikten sonra Azerbaycan ekonomisinin gelişimi için öncelikli ve en önemli şey dış ticaret ilişkilerinin güçlendirilmesi ve geliştirilmesi olmuştur. Bu politikanın en önemli taraflarından birisi dünya ekonomisi ile entegrasyon aşamasıydı.

1994 yılında Azerbaycan, dünya ekonomik sistemine entegre olabilmek için büyük bir başarı göstermiştir. Şöyle ki, 20 eylül 1994 tarihi, bağımsız Azerbaycan tarihine altın harflerle yazılmıştır ve bu tarih asırlar boyu insanların akıllarında kalacak ve sonraki kuşaklara geçecektir. Bu tarihte dünyanın bir çok şirketleriyle "Azeri-ÇıraqGüneşli" petrol rezervlerinin birlikte aranması ve çıkarılması için "Asrın anlaşması" kontraktı imzalandı. Azerbaycan `n dünya için önemli olan petrol stratejisi, dönemin devlet başkanı Haydar Aliyevin büyük çalışmaları sonucunda meydana gelmiştir.

“Asrın anlaşması”nda dünyanın 8 ülkesinin (Azerbaycan, ABD, İngiltere, Rusya Federasyonu, Türkiye, Norveç, Japonya, ve Birleşik Arap Amirlikleri) 13 büyük petrol şirketi (Amoco, BP, Mc Dermott, Unocal, SOCAR, Lukoil, Statoil, Exxon, TPAO, Pennzoil, İtochu, Ramco, Delta) katılmıştır. Bununla da "Yeni petrol stratejisi" ve doktrinin başarılı şekilde hayata geçirilmesi aşaması başlamıştır. 
İlk hesaplamalara göre çıkarılacak petrol rezervi 511 milyon ton olmuş, daha sonraki değerlendirmelerin sonucunda ise bu rezervler 730 milyon tona çıkarılmıştır ve bununla ilgili işlerin yapıla bilmesi için talep olunan sermayenin miktarı 11.5 milyar dolar olarak kabul edilmiştir. Anlaşmaya göre, toplam gelirlerin \%80-i Azerbaycan`ın, \%20-si ise yatırımcı şirketlerindir.

Azerbaycan kendi bağımsızlığını kazandıktan sonra kendi dış ekonomi politikasını güçlendirmekle birlikte aynı zamanda uluslararası maliye kredisi desteği almış ve ekonomik örgütlerle işbirliği yaparak ilişkilerini pekiştirmeye başlamıştır. Bu gün Azerbaycan Cumhuriyeti dünya ekonomisinin gelişiminde önemli rol oynayan 33 uluslararası örgütün üyesidir.

Azerbaycan ekonomisinin gelişiminde dünyanın önde gelen bankası "Dünya Bankası"nın da katkısı büyük olmuştur. Şöyle ki, Dünya bankası Azerbaycan`a 51 proje için 3.6 milyar dolar kredi ayırmıştır. Bundan ilave 2014 yılında Dünya bankası 2015 ilk yarı yılını kapsayacak şekilde yeni işbirliği stratejisini onaylamıştır. Şimdiye kadar Dünya bankası Azerbaycan hükümeti ile stejinin önemli konularını kapsayacak şekilde ve farklı istikametlerde sürekli karşılıklı tavsiyelerde bulunmaktadır.

Dünya bankasının Azerbaycan'da hayata geçirdiği projeler, trafik yolları alt yapısının gelişimi, köy işleri ve su arzı, halkın sosyal dayanıklılığı, mülkiyet haklarının kayıt altına alınması, mahkeme sisteminin gelişimi gibi alanları kapsamaktaydı. Bankanın Azerbaycan Cumhuriyeti ile imzaladığı kredi miktarı 4 milyar dolardan fazladır.

Bu gün Azerbaycan dünyanın 140-dan fazla devleti ile karşılıklı ve verimli ekonomik işbirliği yapmaktadır. Azerbaycan'ın mevcut ekonomik potansiyeli, doğal kaynak rezervleri, doğal ortamı, uygun ekonomisi ve coğrafi durumu dünya devletleriyle verimli işbirliğinin gelişimine zemin oluşturmaktadır.

Azerbaycan Cumhuriyeti Bağımsız Devletler Topluluğu (BDT)'na üye olan ülkelerle dış ticaret ilişkilerini hayata geçirmekte ve bu ilişkiler her yıl genişlenmektedir. 2010 yılında bu devletlerle ithal hacmi 2051,1 milyon dolar, ihraç ise 1983,9 milyon dolar, cari açık 67,2 milyon dolarken, 2018- yılında bu rakamlar ithal 2862,1 milyon dolar, ihraç 1138,2 milyon dolar olmuştur. 8 yılda ticaret hacminde ithal 39, 5\% oranında artmış, ihraç ise 57, 4\% oranında azalmıştır. Azerbaycan neredeyse bütün BDT devletleriyle yaptığı ticaret ilişkilerinde sürekli ticaret açığı vermiştir. En fazla ticaret açığını Rusya Federasyonu ile yaşamaktadır, 2010 yılında -371,4 milyon dolar, 2018-de ise 1.2 milyar dolar hacminde ticaret açığı olmuştur. Bu sıralamada Ukrayna ve Kazakistan da listeye öncülük etmekteler. Böylelikle Azerbaycan Cumhuriyeti nin dış ticaret hacmi 1 numaralı tabloda gösterilmiştir.

\begin{tabular}{|l|c|r|r|r|}
\hline Yıllar & Toplam Ticaret Hacmi & \multicolumn{1}{c|}{ İthal } & \multicolumn{1}{c|}{ İhraç } & \multicolumn{1}{c|}{ Ticaret Açı̆̆ } \\
\hline $\mathbf{2 0 0 9}$ & 20824,5 & 6123,1 & 14701,4 & 8578,3 \\
\hline $\mathbf{2 0 1 0}$ & 33160,7 & 6600,6 & 26560,1 & 10959,5 \\
\hline $\mathbf{2 0 1 1}$ & 44161,7 & 9756,0 & 34405,7 & 24649,7 \\
\hline $\mathbf{2 0 1 2}$ & 43813,5 & 9652,9 & 34160,6 & 24507,7 \\
\hline $\mathbf{2 0 1 3}$ & 43554,1 & 10712,5 & 32841,6 & 22129,1 \\
\hline $\mathbf{2 0 1 4}$ & 39467,5 & 9187,7 & 30219,8 & 21032,1 \\
\hline $\mathbf{2 0 1 5}$ & 25809,0 & 9216,7 & 16592,3 & 7375,6 \\
\hline $\mathbf{2 0 1 6}$ & 21596,6 & 8489,1 & 13107,5 & 4618,4 \\
\hline $\mathbf{2 0 1 8}$ & 31755,9 & 11465,0 & 20290,9 & 88215,9 \\
\hline
\end{tabular}

Tablo 1. Azerbaycan'ın Toplam Dış Ticaret Hacmi (milyon \$) Kaynak: Azerbaycan Devlet Statistik Komitesi, s631.

Grafikten belli olduğu üzere 2009-2018 tarihlerinde Azerbaycan diş ticaret hacmi artmış ve ticaret açı̆̆ oluşmamış aksine ticaret açığını kapatarak artıya geçmiştir. Buna rağmen 2012-2016 yıllarında ticaret hacmi aşağ düşmüştür ki, bunun da en önemli nedeni dünyadaki ekonomik krizin meydana gelmesi olmuştur.

Azerbaycan`ın dış ticaret hacminin büyük bölümünü Ekonomik İşbirliği ve Kalkınma Teşkilatı'na üye devletlerden ibaret gelişmiş ülkelerle gerçekleştirmektedir. Böyle ki, 2018-de diş ticaret hacminde ithalatın \%50.2ni, ihracatın ise \%65, 7-si bu örgüte üye devletlerle gerçekleştirilmiştir.

Azerbaycan ihracatında önemli ortak devletlerin listesi Tablo 2-de gösterilmiştir. Gözüktüğü üzere ihracatta ilk sırada her zaman İtalya bulunmakta, böylelikle ihracatın ortalama olarak \%30-nu kapsamaktadır. İhraç hacminin \%28, 7-ni, yani 5812, 4 milyar dolarını ham petrol oluşturmaktadır. İhracatın geri kalan kısmını 107, 3 milyon dolar hacminde dizel yakıtı, 60,9 milyon dolar hacminde ise doğal gaz oluşturmaktadır. Böylelikle ihracatın önemli bölümüne ham petrol ve petrol ürünlerinden oluşmaktadır. 


\begin{tabular}{|l|l|l|l|l|l|l|l|l|l|}
\hline & Ülke & $\mathbf{2 0 1 0}$ & $\mathbf{2 0 1 1}$ & $\mathbf{2 0 1 2}$ & $\mathbf{2 0 1 3}$ & $\mathbf{2 0 1 4}$ & $\mathbf{2 0 1 5}$ & $\mathbf{2 0 1 6}$ & $\mathbf{2 0 1 8}$ \\
\hline $\mathbf{1}$ & İtalya & 3.3 & 35.2 & 23.2 & 25 & 22 & 19.7 & 17.1 & 30.2 \\
\hline $\mathbf{2}$ & Türkiye & 0.8 & 1.7 & 2.5 & 2.2 & 2.3 & 2.7 & 12.4 & 9.4 \\
\hline $\mathbf{3}$ & Tayvan & 1.4 & 1.7 & 2.7 & 1.9 & 2 & 8.7 & 8.7 & 3.7 \\
\hline $\mathbf{4}$ & İsrail & 8,2 & 3,1 & 7 & 5,3 & 8,1 & 7 & 7,3 & 6,7 \\
\hline $\mathbf{5}$ & Almanya & & 2 & 4 & 5,7 & 8,8 & 10,7 & 6,7 & 4 \\
\hline $\mathbf{6}$ & Fransa & 8,7 & 15,2 & 7,4 & 4,7 & 7 & 7,6 & 5,4 & 2,3 \\
\hline $\mathbf{7}$ & Hindistan & 1,4 & 1,4 & 7,9 & 4,6 & 3,6 & 2,4 & 4,8 & 4,2 \\
\hline $\mathbf{8}$ & Rusya Fed & 3,6 & 4,5 & 40 & 4,5 & 2,9 & 15,6 & 4,5 & 3,4 \\
\hline $\mathbf{9}$ & Gürcistan & 1,9 & 2 & 2,4 & 2,2 & 2,5 & 3,2 & 3,8 & 2,5 \\
\hline $\mathbf{1 0}$ & Çin & 1,6 & 0,2 & 0,8 & 0,4 & 0,3 & 2,3 & 3 & 0,6 \\
\hline $\mathbf{1 1}$ & Portekiz & 1,6 & 1,8 & 1 & 2,2 & 2,5 & 3,2 & 2,8 & 2,7 \\
\hline $\mathbf{1 2}$ & Endonezya & 3,7 & 3,4 & 7,4 & 11,6 & 9,2 & 4,2 & 0,8 & 3,1 \\
\hline $\mathbf{1 3}$ & ABD & 7,6 & 6,8 & 6,7 & 4,1 & 3,4 & 3 & 0,9 & 1,7 \\
\hline $\mathbf{1 4}$ & Hirvatistan & 3,7 & 1,3 & 1,4 & 0,9 & 1,4 & 1,6 & 2,6 & 1,3 \\
\hline $\mathbf{1 5}$ & Tayland & 0,9 & - & 1,4 & 6,9 & 3,8 & 2,3 & 1,1 & 0,7 \\
\hline $\mathbf{1 6}$ & Yunanistan & 1,5 & 0,8 & 3,5 & 3,4 & 1,2 & & 5,7 & 0,8 \\
\hline $\mathbf{1 7}$ & İngiltere & 2,4 & 2,5 & 1,4 & 2 & 0,6 & 0,1 & 0,6 & 1,3 \\
\hline
\end{tabular}

Tablo 2. 2010-2018 Tarihlerinde Azerbaycan `ın İhracında Önde Gelen 17 Devletin Ağırlıkl Orantısı (\%) Kaynakça: Azerbaycan Devlet Statistik Komitesi, s 641.

Azerbaycan yabancı ülkelere ham petrol, petrol ürünleri ve ekipman, pamuk lifi, tütün, alkollü içecekler (şarap), buz dolabı ve klimalar, işlenmemiş metal ve kimya ürünleri göndermektedir, karşılığında ise gida ürünleri (yağ, un, şeker, tahıl, meyveler, iplik, bez, ayakkabı, gübre ve ev eşyaları) almakta. 2019 yılından itibaren Azerbaycan yeni istismara vermiş olduğu Karbamit gübre fabrikasıyla üretiminin 25\%-ni yerli piyasaya, 75\%-ni ise yurt dişına satmayı hedeflemektedir. Bu da onu göstermektedir ki, bundan sonra gübre alanında ithalat tamamen durdurulmuş ve bu alanda ihracata yönlendirilerek ihraç hacmi artırılması hedeflenmektedir. Azerbaycan gelecekte hammadde yerine daha çok hazır sanayi ürünleri ihraç etmeği planlamaktadır. Yukarıda da belirtildiği üzere Azerbaycan devleti dünyanın bütün kıtalarını kapsayacak şekilde bir çok ülke ile karşılıklı verimli işbirliği ile ithal-ihraç potansiyelini arttırmaktadir.

Genellikle 2009-2016 tarihleri süresince Azerbaycan ihracatının ortalama olarak \%93.5-ni, 2018-de ise \%88.3nü petrol bazlı ürünlerden oluşmaktadır. Azerbaycan`ın ürün ihracatı Tablo 3-te ayrıntılı şekilde gösterilmiştir.

\begin{tabular}{|l|r|r|r|r|r|r|r|r|r|r|}
\hline & $\mathbf{2 0 0 5}$ & $\mathbf{2 0 0 9}$ & $\mathbf{2 0 1 0}$ & $\mathbf{2 0 1 1}$ & $\mathbf{2 0 1 2}$ & $\mathbf{2 0 1 3}$ & $\mathbf{2 0 1 4}$ & $\mathbf{2 0 1 5}$ & $\mathbf{2 0 1 6}$ & $\mathbf{2 0 1 8}$ \\
\hline $\begin{array}{l}\text { Gıda ürünleri ve tarım } \\
\text { ürünleri (hammadde) }\end{array}$ & 5.05 & 4.6 & 4.5 & 2.6 & 3.4 & 3.6 & 2.8 & 2.4 & 5.7 & 3.5 \\
\hline $\begin{array}{l}\text { Doğal kaynak suları ve } \\
\text { petrol ve petrol ürünleri }\end{array}$ & 84.63 & 92.8 & 94.2 & 94.5 & 93.1 & 92.8 & 94.2 & 86.6 & 87.4 & 88.3 \\
\hline Kimya sanayisi ürünleri & 3.03 & 0.2 & 0.22 & 0.4 & 0.7 & 0.2 & 0.2 & 0.7 & 0.6 & 0.4 \\
\hline $\begin{array}{l}\text { Ucuz metaller ve onlardan } \\
\text { hazırlanmış ürünler }\end{array}$ & 2.35 & 0.8 & 0.6 & 0.8 & 0.9 & 0.7 & 0.5 & 1.2 & 2.4 & 1.2 \\
\hline $\begin{array}{l}\text { Otomobiller, } \\
\text { mekanizmalar, araçlar }\end{array}$ & 1.91 & 1.4 & 0.2 & 0.2 & 0.4 & 0.6 & 0.2 & 0.5 & 1.1 & 0.4 \\
\hline Diğer ürünler & 3.03 & 0.2 & 0.28 & 1.5 & 1.5 & 2.1 & 2.1 & 8.6 & 2.8 & 6.2 \\
\hline
\end{tabular}

Tablo 3. Azerbaycan ın İhraç Ettiği Ürünlerin Çeşitleri Oranla (\%) Kaynakça: Azerbaycan Devlet Statistik Komitesi, s 643.

Yukarıdaki tabloda gözüktüğü gibi 2005-2018 yıllarında toplam ihracatın tahminen \%3.74-nü gıda ürünleri ve tarım ürünlerinin hammaddeleri oluşturmaktadır. Bu ürünler arasında patates, taze sebze, meyve, bitkisel yağlar, şeker ve benzeri ürünler bulunmaktadır. 2016-da Azerbaycan`dan diğer devletlere 113.2 milyon dolar hacminde yani yaklaşık 124.5 bin ton taze sebze, 243.4 milyon değerinde yani 214.3 bin ton taze meyve, 10.2 milyon dolar değerinde bitkisel yağlar ve gıda ürünleri ihraç etmiştir. 2018-de ise 202.8 milyon dolar değerinde yani 233.3 bin ton sebze meyve, 325.6 milyon dolar değerinde yaklaşı 319.2 bin ton taze meyve , 9.4 milyon dolar değerinde ise 10.8 bin ton bitkisel yağlar ve gıda ürünleri ihraç edilmiştir. Önemli olan konulardan bir diğeri ise son dönemlerde Azerbaycan `dan 24.97 milyon dolar değerinde yani 44.1 bin ton şeker ihraç etmiştir. 
İhracat potansiyeline ve ihraç ürünlerini irdelediğimiz zaman ihracatın tek taraflı olarak büyük çoğunlukla ham petrol ve petrol ürünlerinden oluştuğunu görmekteyiz. Umuyoruz ki, Azerbaycan ihracat çeşitliliğini artırmalı ve ihracat alanında köklü değişikliklerin edilmesine büyük ihtiyaç vardır. 1990 tarihine kadar Azerbaycan SSCB `ye bağlı devletlerin çoğuna üzüm, üzüm şarabı, konyak ihraç etmiş ve Azerbaycan`ın güney doğu bölgesini (Lenkeran, Astara ve diğer iller) Moskova ve Piter şehirlerinin sebze tedarik merkezi adlandırmaktaydılar.

Azerbaycan`ın petrol dışındaki ürünlerin üretimini artırmak ve geliştirmekle ihraç alanında büyük potansiyele sahiptir. 2019-da GSMH-da petrol dışı ürünlerin hacmi \%37.5 oluşturmaktaydı. Aslına baktığımız zaman 2005-te bu rakam \%25.7, 2010-da \%41.3, 2013-te \%56.6 oranında olmuştur. Genel olarak baktığımızda Azerbaycan ekonomisinin çeşitlenme hızı giderek artmaktadır.

Petrol dışı alanın ihraç potansiyelinin artırılması için ilk önce ekonomik faaliyetini BDT’nun piyasasına istikametlenmelidir. Nedeni, uzun bir süre bu devletlerin pazarların sürekli ürün tedarik etmesi ve aynı zamanda gümrük anlaşması ile sadece KDV ile mal alınıp satılması ve diğer vergilerden muaf olmasıdır. Buna rağmen BDT ile Azerbaycan arasında ithal-ihraç hacmi giderek aşağı düşmektedir. Şöyle ki, 2011-de BDT ile ihracatın \%11-ni oluşturduğu halde, 2012-de bu ihracat hacmi 2.2 defa azalarak \%5-e kadar gerilemiştir. 2013-te bu rakam biraz artarak \% 6-ya çıkmıştır ancak, 2018-de yeniden \%5.7-e gerilemiştir.

BDT ile ithalattaki Azerbaycan`ın payı \%25 - \%27 arasında değişmektedir. Petrol dışı alanda insan emeğinin verimliliğinin ve tarım alanında gelişimin artması önemli rol oynamaktadır. Sadece şunu söylemek yeterlidir ki, Azerbaycan da 1083.1 dekar alanda buğdaydan elde edilen ürünün değeri aynı alanda Danimarka da 10 milyon ton civarında ürün elde etmesine rağmen, ülkemizde ise 3.3 milyon ton üretilmiştir. Toprakların verimliliğinin artırılması istikametinde önemli adımlar atılmalıdır. Özelleşmeden dolayı insanlara ödeme karşılığı olmadan verilmiş toprakların veya sonradan alınmış toprakların bir kısmı işlenmemekte ve hiçbir ürün yetiştirilmemektedir. Küçük işletmeler modern tarım teknolojisini alma imkanına sahip olamamasından dolayı eskimiş teknoloji ile mahsullerini işlemekte ve toplarken de verimliliğin yeteri kadar olmamasına sebebiyet yaratmaktadır. Bu da üretimin artmasına engel teşkil etmekte ve verimlilik aşağı düşmektedir. Tarım alanında şirketleşmeye gidilmeli, firma bazında üretim artırılmalıdır. Doğal ortama bağlı olarak üretim potansiyeli yüksek olan alanlarda uzmanlaşmaya dikkat edilmeli, devlete satılan tarım ürünlerine özel imtiyazlar sağlanmalıdır. Bu gibi bir çok köylü ve tarım kooperatifleri için özel imtiyazların sağlanması ülkemizde iç talebin karşılanmasına ve ihraç potansiyelinin artmasına sebebiyet verecektir. Azerbaycan dünyanın 100-den fazla ülkesinden ürün ithal etmektedir. İthalatta önemli yeri tutan devletlerin sıralaması 5 numaralı tabloda gösterilmiştir. Gözüktüğü üzere sürekli ilk sıralarda Rusya Federasyonu ve Türkiye Cumhuriyeti tutmaktadır. 2010-2018 yıllarında Azerbaycan`a Rusya 'dan toplam ithalin ortalama olarak \%16, Türkiye'den ise \%13.75 oranında olmuştur.

\begin{tabular}{|l|r|r|r|r|r|r|r|r|r|}
\hline & $\mathbf{2 0 0 9}$ & $\mathbf{2 0 1 0}$ & $\mathbf{2 0 1 1}$ & $\mathbf{2 0 1 2}$ & $\mathbf{2 0 1 3}$ & $\mathbf{2 0 1 4}$ & $\mathbf{2 0 1 5}$ & $\mathbf{2 0 1 6}$ & $\mathbf{2 0 1 8}$ \\
\hline $\begin{array}{l}\text { Gıda ürünleri ve tarım } \\
\text { ürünleri }\end{array}$ & 19.6 & 18.3 & 14.2 & 14.9 & 14.6 & 16.9 & 14.9 & 18.4 & 14.8 \\
\hline $\begin{array}{l}\text { Doğal kaynak suları ve petrol } \\
\text { ve petrol ürünleri }\end{array}$ & 2.8 & 3.1 & 2.4 & 3.1 & 3.3 & 4.9 & 5.2 & 3,8 & 6.7 \\
\hline Kimya sanayisi ürünleri & 6.6 & 6.6 & 6.4 & 6.8 & 7 & 7.8 & 7.6 & 8.3 & 8.5 \\
\hline $\begin{array}{l}\text { Ucuz metaller ve onlardan } \\
\text { hazırlanmış ürünler }\end{array}$ & 10.8 & 14 & 6.4 & 15.2 & 12.1 & 13.6 & 20.3 & 15.4 & 12.3 \\
\hline $\begin{array}{l}\text { Otomobiller, mekanizmalar, } \\
\text { araçlar, elektronik eşyalar }\end{array}$ & 50.5 & 40.9 & 48.4 & 41.8 & 39.1 & 36.9 & 34.4 & 33 & 29.7 \\
\hline Diğer ürünler & 9.7 & 17.1 & 22.2 & 18.2 & 23.9 & 19.9 & 17.6 & 21.1 & 28 \\
\hline
\end{tabular}

Tablo 4. Azerbaycan'ın İthal Ettiği Ürünleri Yıllara Oranla (\%) Kaynakça: Azerbaycan Devlet Statistik Komitesi, s 643.

Azerbaycan 4 numaralı tabloda gösterildiği üzere diğer ülkelerden makinalar, ev elektronik eşyaları, araçlar (2009-2018 tarihlerinde toplam ihracın \%39.4-nü oluşturmaktayd1), gıda ürünleri ve tarım hammaddeleri (\%18.3) ihraç etmektedir. 2018-de Azerbaycan ithalatının \%50.2-si yani 5760.0 milyon doları Ekonomik İşbirliği ve Kalkınma Teşkilatı`na üye 34 devletle yapılmıştır. 


\begin{tabular}{|l|l|c|c|c|c|c|c|c|c|}
\hline & Ülke & $\mathbf{2 0 1 0}$ & $\mathbf{2 0 1 1}$ & $\mathbf{2 0 1 2}$ & $\mathbf{2 0 1 3}$ & $\mathbf{2 0 1 4}$ & $\mathbf{2 0 1 5}$ & $\mathbf{2 0 1 6}$ & $\mathbf{2 0 1 8}$ \\
\hline $\mathbf{1}$ & Rusya Federasyonu & 17.3 & 16.8 & 14.3 & 14.1 & 14.3 & 15.6 & 19.2 & 16.4 \\
\hline $\mathbf{2}$ & Türkiye & 11.7 & 13.4 & 15.8 & 13.7 & 14.0 & 12.7 & 13.8 & 13.8 \\
\hline $\mathbf{3}$ & Almanya & 9.2 & 8.7 & 8.1 & 7.7 & 7.7 & 7.5 & 4.7 & 5.8 \\
\hline $\mathbf{4}$ & Çin & 8.9 & 6.4 & 6.5 & 5.3 & 7.6 & 5.6 & 8.2 & 10.4 \\
\hline $\mathbf{5}$ & Ukrayna & 7.1 & 5.7 & 5.6 & 5.5 & 4.6 & 3.4 & 3.4 & 4.1 \\
\hline $\mathbf{6}$ & İngiltere & 4.6 & 5.0 & 5.1 & 12.5 & 10.6 & 6.0 & 5.8 & 2.3 \\
\hline $\mathbf{7}$ & Kazakistan & 4.4 & 2.2 & 3.5 & 2.9 & 2.4 & - & 1.1 & 1.5 \\
\hline $\mathbf{8}$ & ABD & 3.1 & 6.5 & 7.4 & 3.5 & 6.1 & 9.2 & 5.5 & 4.6 \\
\hline $\mathbf{9}$ & Brezilya & 2.4 & 1.8 & 1.9 & 3.5 & 2.6 & - & 2.4 & 1.5 \\
\hline $\mathbf{1 0}$ & Güney Kore & 2.4 & 2.1 & 2.5 & 2.1 & 3.0 & - & 0.8 & 2.0 \\
\hline $\mathbf{1 1}$ & Japonya & 2.2 & 1.8 & 2.5 & 2.7 & 2.6 & 6.1 & 3.3 & 3.3 \\
\hline $\mathbf{1 2}$ & Fransa & 2.1 & 6.2 & 1.9 & 4.0 & 1.7 & 2.3 & 1.8 & 1.6 \\
\hline $\mathbf{1 3}$ & İtalya & 1.8 & 2.6 & 2.7 & 2.3 & 3.0 & 6.4 & 3.9 & 3.0 \\
\hline $\mathbf{1 4}$ & İran & 1.8 & 1.7 & 1.8 & 1.9 & 1.6 & 1.5 & 1.9 & 3.6 \\
\hline $\mathbf{1 5}$ & Hollanda & 0.7 & 1.2 & 1.6 & 1.7 & 2.1 & 2 & 0.9 & 0.9 \\
\hline
\end{tabular}

Tablo 5. 2010-2018 Tarihlerinde Azerbaycan`ın İthalatında Önde Gelen 15 Devletin Ağırlıklı Orantısı (\%)(\%) Kaynakça: Azerbaycan Devlet Statistik Komitesi, s 640.

2018-de dış ticaret hacminin \% 63.7-si ihraç, geri kalan kısmı yani \%36.1-i ise ithalat hacmini oluşturmaktaydı. 2015-de ülkenin ihraç pensiyalinin büyük bölümünü Avrupa Birliği devletleri oluştursa da 2018-de bu oran değişerek "Diğer devletler” grubuna geçmiştir. BDT ise diş ticaret hacminde çok aşağı seviyelerde kalmakta devam etmektedir.

Aşağıda 6 numaralı tabloda dış ticaret ilişkilerindeki önemli devletlerin oranlara göre grupları gösterilmektedir. Toplam ticaret hacminin \%23.2-ni Türkiye, \%19.8-ni Rusya, \%13.2-ni İtalyan, \%9.8-ni Almanya, \%11-ni Çin oluşturmaktaydı. İlk beş sıradaki devletler 2018-de toplam ticaret hacminin \% 77-ni oluşturmaktaydı.

\begin{tabular}{|c|c|c|c|c|}
\hline Ülkeler (grup halinde) & İhraç & $\begin{array}{c}\text { İhracatın oranı } \\
(\%)\end{array}$ & Ithal & $\begin{array}{c}\text { İthalatın oranı } \\
(\%)\end{array}$ \\
\hline Bağımsız Devletler Toplulukları & 1138.2 & 5.6 & 2862.1 & 25.0 \\
\hline Avrupa Birliği devletleri & 10579.0 & 52.2 & 2328.7 & 25.0 \\
\hline Diğer devletler & 8573.7 & 42.2 & 6274.2 & 54.7 \\
\hline Toplam & 20290.9 & 100.0 & 11465.0 & 100.0 \\
\hline
\end{tabular}

Tablo 6. 2018-de Azerbaycan'ın Dış Ticaret Toplam Hacmi ve Faiz Oranı (milyon \$)

7-ci tabloda dış ticarette ürünlerin ithal edildiği ülkeler ve bu ülkelerden edilmiş ithal hacmi gösterilmiştir. İthal olunan ürünlerin hacminin \%16.4-nü Rusya, \%10.4-nü Türkiye, \%13.85-ni Almanya’nın, \%4.6-nı ise İngiltere ve diğer devletler oluşturmaktadır.

\begin{tabular}{|l|r|}
\hline Devletler & Dolar Bazında Rakam \\
\hline Rusya & 1885.1 \\
\hline Türkiye & 1576.9 \\
\hline Çin & 1196.7 \\
\hline İngiltere & 263.7 \\
\hline ABD & 527.2 \\
\hline Almanya & 659.9 \\
\hline İtalya & 340.0 \\
\hline Japonya & 383.9 \\
\hline Norveç & 104.7 \\
\hline Diğer ülkeler & 4526.9 \\
\hline
\end{tabular}

Tablo 7. 2018-de Azerbaycan `a İthal Edilen Ürünlerin Hacmine Göre Ülkelere Dă̆llımı (\$)

Sonuç itibarı ile Azerbaycan dış ticaret ilişkilerinde her ne kadar büyük oranda başarı kaydetmiş olsa da, bu başarının büyük bölümü doğal kaynaklar, ham petrol ve petrol ürünlerinden oluşmaktadır. Diğer alanlarda 
yapılması gereken daha çok işlerin olduğu gözükmektedir. Hükümet tarafından 2016 yılından itibaren Strateji Yol Haritası hazırlayarak uygulamaya konulmuştur. Bu uygulama ile devletin bütün alanlarında yıllara ve dönemlere göre planlı şekilde gerekli alanları geliştirmek ve mevcut potansiyelleri kullanarak ekonomik ve sosyo dinamik alanda gelişmelerin kaydedilmesini planlanmaktadır.

\section{Sonuç}

Sonuç itibari ile, Azerbaycan `ın diş ticaret hacmi 2005-2018 yılları analiz edilmiş ve araştırılmıştır. Araştırma sonucuna göre, Azerbaycan`ın dış ticaret ilişkileriyle birlikte diğer alanların da gelişimi için siyasi ve ticari işbirliklerin gelişimin ne kadar önemli olduğu ortaya çıkmıştır. Diğer devletlerle sıkı iş birliğini pekiştirmiş ve uluslararası ekonomik ilişkilerin önemli faktörlerinden birine dönüşmüştür. Sadece şunu söylemek yeterlidir ki, Azerbaycan `n dış ticaret hacminin \%50.2-ni ithalat, \%65.7-ni ise ihracat oluşturmaktadır. Şunu da belirtmekte fayda vardır ki, dış ticaretin büyük bir bölümü ekonomik kalkınma örgütüne üye devletlerle yapılmıştır. Azerbaycan ekonomisinin çeşitlenme temposu giderek yükselmektedir. Petrol dişı alanlarda ise gelişmeler de gözükmektedir. Petrol dışı alanlarda ihraç potansiyelini artırmak için yıllarca hem siyasi hem de ortak ekonomik alanında işbirliği yaptığı Bağımsız Devletler Topluluğu ile ilişkilerini yeniden gözden geçirmeli ve bu alanda ciddi işbirliği yapılmalıdır. Eski ticaret hacmini her yıl biraz daha artırmaya çalışmalıdır.

Tarım ve köy işleri alanında verimliliğin artırılmalı, verimli topraklarlar maksimum kullanılmalı, aşamalı tarıma geçilmelidir. Bunlarla birlikte modern tarım teknolojileri kullanılmalı ve verimlilik giderek artırılmalıdır. Devletlerle karşılıklı ekonomik işbirliği yaparak, tedarik zinciri planları yapılmalı her sene planlı şekilde iç pazarla birlikte ihraç potansiyeli de artırılmalıdır.

Köy işlerinde büyük ölçekli kooperatifleşmeye geçilmeli ve köylülerin ürettiği ürünleri daha kaliteli ve piyasa değerinde fiyatlara alınarak dış pazarlara çıkarılmalıdır. Özellikle son dönemde sulama alt yapısı alanında büyük ölçekli yatırımlar yaparak daha çok verim alınması istikametinde işler yapılmalıdır.

\section{Kaynakça}

- Azerbaycan`ın Statistiği, 2019. Azerbaycan Devlet Statistik Komitesi, Bakü 2019.

- A.H. Alekberov, Uluslararası Ekonomik İlişkiler, Çaşığlu, Bakü, 2010.

- BMT`nın Genel Sekreterliği, Uluslararası Ticaret ve Geliştirme 74. Oturum Raporu, 25 Haziran2019.

- $\quad$ S.V. Fomişin, Uluslararası Ekonomik İlişkiler, Feniks, Rostov, 2006. 


\title{
Müəssisələrin Menecmentində Aparılan İslahatlar Sistemində Marketinqin Effektivliyinin və Səmərəliliyinin Qiymətləndirilməsi Evaluation of the Effectiveness and Efficiency of Marketing in the
System of Reforms in the Management of Enterprises
}

\author{
Ph.D. Candidate Cinara Kocarieva (Odlar Yurdu University, Azerbaijan)
}

\begin{abstract}
Marketing productivity models provide a common conceptual framework for future research. These models also define a common conceptual framework for the creation of instrumental models for marketing productivity management. At the same time, it is necessary to further study the most important relationship of marketing results with financial indicators and indicators of performance evaluation of the enterprise as a whole. The development of these models is associated with the creation of more complex systems that reflect the relationship of indicators at the level of management. Marketing productivity models form the conceptual framework for the transition to a more realistic level. This is the level of management of marketing efficiency, ie the area of creating models of management of marketing results. Following the logic of productivity (marketing actions - marketing results financial results - business results), as well as the need to consider it in two dimensions, we can move on to the creation of operational models of marketing efficiency.
\end{abstract}

\section{Giriș}

Marketinqin effektivliyi və səmərəliliyi problemləri bu gün üçün xeyli əhəmiyyətli problemlər olaraq qalmaqdadır.

Marketinqin effektivliyi və səmərəliliyi üzrə nəzəri və empirik tədqiqatlarda.

a) müəssisənin effektivliyinin və səmərəliliyinin qiymətləndirilməsinə, müəs-sisə nəzəriyyəsinə, bazar dəyəri nəzəriyyəsinə, təşkilati davranış nəzəriyyəsinə nəzəri yanaşmaların inkişafi;

b) müəssisənin mənfəətliliyinin və ya dəyərinin marketinq amillərinin qeyd olunması daxil olmaqla, marketinqin effektivliyinin və səmərəliliyinin formalaşdı-rılması modellərinin və onun qiymətləndirilməsi göstəricilərinin axtarılması;

c) müəssisənin dəyər amili kimi, marketinq aktivlərinin öyrənilməsi;

d) marketinq kompleksi çərçivəsində tədbirlərin səmərəliliyi sahəsində tədqi-qat;

e) tərəfdaşlıq münasibətlərinin marketinqi nəzəriyyəsinin inkişafı və marke-tinqin effektivliyinin qiymətləndirilməsinə yeni yanaşmaların meydana çıxması kimi qısaca ifadə edilmiş bir neçə əsas istiqaməti qeyd etmək olar (Karsev, 2016).

Yuxarıda göstərilənlər marketinq göstəricilərinin çərçivələrini yaratmaq imkanı verir. Lakin onların biznesin səmərəliliyinin qiymətləndirilməsinin korpo-rativ sisteminə inteqrasiyası problemləri aşağıdakılardan ibarətdir (Kitova, 2012).

1. Marketinq funksiyalarının effektivliyinin qiymətləndirilməsindən ötrü istifa-də olunan göstəricilər müəssisənin maliyyə nəticələri ilə bağlı deyildir.

2. Tətbiq olunan göstəricilər yalnız funksional prosesləri əks etdirir.

3. Göstəricilərin əksəriyyəti qısamüddətli perioda yönəlmişdir və müştərilər hesabına dəyər artımını, habelə bu artıma səbəb olan investisiyaları əks etdirmir.

4. Strateji nəticələri olan investisiyaların və ya nəticələri qeyri-maddi olan investisiyaların səmərəliliyinin qiymətləndirilməsinin adekvat göstəriciləri yoxdur.

5. Bir sıra dəyişənlərə (məsələn, yenilikçilik səviyyəsi, işlək kapitala tələbat) marketinq qərarlarının təsiri nəzərə alınmır.

6. Strateji və əməliyyat səviyyələri arasında inteqrasiya yoxdur.

7. İdarə olunması çətin olan, bir-biri ilə uzlaşmayan böyük sayda göstəricilər mövcuddur.

İdarəetmə və maliyyə metodikalarının, o cümlədən, göstəricilərin tarazlaş-dırılmış sisteminin bazasında menecmentin və digər metodikaların zəif tətbiq edilməsini qeyd etmək olar (Korotkov, 2016).

Bir sıra praktik problemlər də mövcuddur.

Birinci problem marketinq fəaliyyətinin bütün uzunmüddətli effektlərinin qiymətləndirilməsinin mürəkkəbliyi ilə bağlidır

İkinci problem marketinq fəaliyyətinin özü ilə şərtlənən nəticələrin ayrılıqda qeyd olunmasının mürəkkəbliyi ilə bağlıdır. Marketinq nəticələri tədqiqatlar və təkmilləşdirmələr, istehsal prosesi və s. daxil olmaqla digər funksiyalarda və proseslərdə qismən əks olunur (Kuzmina, 2018).

Üçüncü problem ondan ibarətdir ki, bir çox marketinq göstəriciləri maliyyə ölçülərinə malik deyillər. 
Gələcək tədqiqatların predmeti bu problemlərin həlli ilə bağlıdır. Lakin həm səmərəlilik amillərinin, həm də nəticələrin özlərinin sistemsizliyi səbəbindən, universal nəzəriyyənin yaradılması və marketinqin səmərəliliyinin formalaşdırılması modellərinin qurulması kifayət qədər mürəkkəb məsələlərdir. Hər bir konseptual model müəssisənin və bazarın spesifik xüsusiyyətlərinin nəzərə alınmasının kontekstualizasiyasına da aid olur.

Məhsuldarlıqda giriş və çıxış elementləri arasında əlaqələr, habelə trans-formasiya prosesi nəzərdən keçirilir, bu proses vasitəsi ilə girişlər və çıxışlar əlaqələnir. Məhsuldarlığın diaqnostikasının marketinq modellərinin spesifikası ondan ibarətdir ki, girişlər qismində təkcə mövcud resurslar deyil, həm də firmanın aktivləri (onların böyük hisəsi qeyri-maddi xarakter daşıyır) nəzərdən keçirilə bilər (Kozina, 2016).

Məhsuldarlığa əsaslanan yanaşmalar bu və ya digər amillərin konkret nəticələrin əldə olunmasındakı roluna diqqəti cəlb edir.

Məhsuldarlıq ümumi halda iki ölçünün: qənaətcilliyin, daxili effektivliyin və xarici effektivliyin dialektikasında nəzərdən keçirilir, müxtəlif müəssisələrin mü-qayisə olunması yolu ilə müəyyən olunur.

\section{Marketinqin Effektivliyinin və Səmərəliliyinin Qiymətləndirilməsi}

Marketinqin məhsuldarlıq modelləri gələcək tədqiqatlar üçün ümumi konseptual bazanı müəyyən edir. Bu modellər, habelə marketinqin məhsuldarlığının idarə olunmasının instrumental modellərinin yaradılması üçün ümumi konseptual bazanı müəyyənləşdirir. Eyni zamanda, marketinq nəticələrinin maliyyə göstəriciləri ilə və bütövlükdə müəssisənin fəaliyyətinin nəticələrinin qiymətləndirilməsi göstəriciləri ilə ən mühüm əlaqələrinin sonrakı tədqiqatı zəruridir. Bu modellərin inkişafı, menecmentin səviyyələri üzrə göstəricilərin əlaqələrini əks etdirən daha mürəkkəb sistemlərin yaradılması ilə bağlıdır (Lipsis, 2016).

Marketinqin məhsuldarlığının modelləri daha real səviyyəyə keçid üçün konseptual bazanı formalaşdırır. Bu isə marketinqin səmərəliliyinin menecmenti səviyyəsidir, yəni marketinq nəticələrinin menecmenti modellərinin yaradılması sahəsidir. Məhsuldarlı̆̆ın məntiqinə (marketinq hərəkətləri - marketinqin nəticələri - maliyyə nəticələri - biznesin nəticələri) əməl edərək, habelə onun iki ölçüdə nəzərdən keçirilməsi zərurətini əsas götürərək, marketinqin səmərəliliyinin əməliyyat modellərinin yaradılmasına keçmək ola (Kireenko, 2015).

Normativ səmərəlilikdən asılı olaraq, marketinqin səmərəliliyinin qiymətlən-dirilməsi sistemi nəzərdən keçirilən yanaşmalar arasında bu məntiqi daha dəqiq əks etdirir və kontekstual modellə təqdim olunur. I - marketinq fəaliyyəti prosesini başa düşməyə imkan verən universal əsası ifadə edir. II - konkret müəssisələrin və konkret şəraitin kontekstinə tətbiq olunur. Normaiv model marketinq fəaliyyətini proses kimi ifadə edir, burada:

I. müəssisənin üstünlüyünün mənbələri;

II. müəssisənin reallaşdırılan strategiyasını əks etdirən mövqe üstünlükləri;

III. bazarda fəaliyyətin yekunları;

IV. müəssisənin maliyyə fəaliyyətinin nəticələri olmaqla, dörd fazanı qeyd etmək olar.

Nəhayət, müəssisənin menecmentində aparılan islahatlar sistemində marketin-qin qiymətləndirilməsinin inteqrasiya olunmuş modelinin fraqmentlərinin nəzərdən keçirilməsi çox əhəmiyyətlidir "Cədvəl 1". 


\begin{tabular}{|c|c|c|c|c|}
\hline $\begin{array}{l}\text { Bölmənin } \\
\text { strukturu }\end{array}$ & Ad & Vəzifələr & Biznes-proses & TGS-nin elementləri \\
\hline \multirow{10}{*}{ 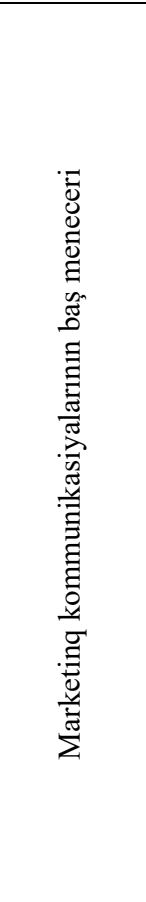 } & $\begin{array}{l}\text { Etibarlılıq, dəqiqlik, keyfiyyət, } \\
\text { motivasiyalılıq parametrlərinin qəbul } \\
\text { edilməsi }\end{array}$ & $\begin{array}{l}\text { Müştərilərin } \\
\text { məmnunluq } \\
\text { səviyyəsinin } \\
\text { artması }\end{array}$ & $\begin{array}{l}\text { Brendin } \\
\text { menecmenti }\end{array}$ & $\begin{array}{l}\text { Müştərilərin } \\
\text { komponentləri }\end{array}$ \\
\hline & Xidmətlərin ierarxiyas 1 & \multirow[t]{3}{*}{ İstehlakın artımı } & $\begin{array}{l}\text { Təklifin } \\
\text { menecmenti }\end{array}$ & \multirow{9}{*}{$\begin{array}{l}\text { Daxili biznes- } \\
\text { proseslərin } \\
\text { komponentləri }\end{array}$} \\
\hline & $\begin{array}{l}\text { Yeni abonent niyyəti ilə reklama və } \\
\text { marketinqə çəkilən xərclər }\end{array}$ & & \multirow{2}{*}{$\begin{array}{l}\text { Kreativ } \\
\text { konsepsiyanın } \\
\text { formalaşdırılması } \\
\text { və reklam } \\
\text { materiallarının } \\
\text { istehsalı }\end{array}$} & \\
\hline & Reklam təsirinin xüsusi çəkisi & & & \\
\hline & $\begin{array}{l}\text { Reklamın qavranılmas1 və düzgün } \\
\text { identifikasiya olunması }\end{array}$ & \multirow{6}{*}{$\begin{array}{l}\text { İnnovasiyalar və } \\
\text { keyfiyyət } \\
\text { sahəsində lider } \\
\text { imicinin } \\
\text { yaradılması }\end{array}$} & \multirow[t]{6}{*}{$\begin{array}{l}\text { Brendin } \\
\text { menecmenti }\end{array}$} & \\
\hline & $\begin{array}{l}\text { İnnovasiyalar və keyfiyyət sahəsində } \\
\text { lider imicinin yaradılmasına yönəldilmiş } \\
\text { tədbirlərin sayı }\end{array}$ & & & \\
\hline & PR-tədbirlərin effektivliyi & & & \\
\hline & Operator haqqında məlumatlı1ıq dərəcəsi & & & \\
\hline & Brendin qavranılması & & & \\
\hline & $\begin{array}{l}\text { Operatora münasibətdə reklamın } \\
\text { təsirinin qiymətləndirilməsi }\end{array}$ & & & \\
\hline$\Xi$ & Reklamın cəld yerləşdirilməsi & $\begin{array}{l}\text { İnnovasiyalar və } \\
\text { keyfiyyət } \\
\text { sahəsində lider }\end{array}$ & $\begin{array}{l}\text { Reklamın kütləvi } \\
\text { informasiya } \\
\text { vasitələrinə }\end{array}$ & $\begin{array}{l}\text { Daxili biznes- } \\
\text { proseslərin } \\
\text { komponentləri }\end{array}$ \\
\hline 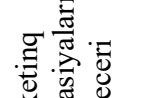 & Reklamın cəld yayılması & $\begin{array}{l}\text { imicinin } \\
\text { yaradılmas1 }\end{array}$ & $\begin{array}{l}\text { yönəldilməsi və } \\
\text { monitorinq }\end{array}$ & \\
\hline 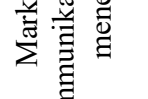 & $\begin{array}{l}\text { Reklam mallarının çatdırılmasının } \\
\text { operativliyi }\end{array}$ & & & \\
\hline 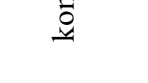 & $\begin{array}{l}\text { Daxili informasiya materiallarının } \\
\text { verilməsinin operativliyi }\end{array}$ & & & \\
\hline
\end{tabular}

Cadval 1. Müəssisənin Menecmentində Aparlan İslahatlar Sistemində Marketinqin Qiymətlandirilməsinin Inteqrasiya Olunmuş Modelinin Fraqmenti

Bundan ötrü qeyri-istehsal sferasının müəssisələrində auditoriyanın daha yaxşı məlumatlandırılması nəticəsində alıcıların (istifadəçilərin) sayının artmasına dair məlumatlar üzrə marketinqin səmərəliliyinin konkret hesabatlarına keçək "Cədvəl 2".

\begin{tabular}{|l|c|c|c|}
\hline Müəssisələr & $\begin{array}{c}\text { Alıcıların sayının artması } \\
(\Delta \mathbf{Q A})\end{array}$ & $\begin{array}{c}\text { Auditoriyanın ümumi } \\
\text { sayı } \\
(\mathbf{Q P q a})\end{array}$ & $\begin{array}{c}\text { İnformasiyalı } \\
\text { müştərilərin sayı } \\
(\mathbf{Q P i a})\end{array}$ \\
\hline 1) ticarət & 5053 & 66155 & 61102 \\
\hline 2) ödənişli xidmətlər & Statistik məlumatlar yoxdur & $-/ /-$ & $-/ /-$ \\
\hline 3) ictimai iaşə & 1650 & 17295 & 15645 \\
\hline 4) turizm & 29 & 272 & 243 \\
\hline 5) nəqliyyat & Statistik məlumatlar yoxdur & $-/ /-$ & $-/ /-$ \\
\hline
\end{tabular}

Codval 2. Auditoriyanın Daha Yaxşı Molumatlandırılması Naticəsində Alıcıların (İstifadəçilorin) Sayındakı Artımının Müayyan Edilmasi

Aşağıdakı nəticələri əldə etmişik:

1) $\Delta \mathrm{QA}_{\text {tic }}=66155-61102=5053$;

2) $\Delta \mathrm{QA}_{\mathrm{öd}}=$ ? (statistik məlumatlar yoxdur);

3) $\Delta \mathrm{QA}_{\mathrm{ic}}=17295-15645=1650$;

4) $\Delta \mathrm{QA}_{\text {tur }}=272-243=29$;

5) $\Delta \mathrm{QA}_{\text {nəq }}=$ ? (statistik məlumatlar yoxdur). 
Göründüyü kimi, qeyri-istehsal sferasının müəssisələrində alıcıların (istifadə-çilərin) sayındakı artım müvafiq qaydada ticarət üzrə - 5053 nəfər; ictimai iaşə üzrə - 1650 nəfər; turizm üzrə - 29 nəfər təşkil etmişdir.

İndi isə alıcı auditoriyasının genişləndirilməsi üzrə tədbirlərin aparılması nəticəsində alıcıların (istifadəçilərin) sayındakı artımın müəyyənləşdirilməsindən ötrü hesablamalar aparaq "Cədvəl 3" Hesablamalar aşağıdakı nəticələri vermişdir.

\begin{tabular}{|l|c|c|c|}
\hline \multicolumn{1}{|c|}{ Müəssisələr } & $\begin{array}{c}\text { Alıcıların sayındakı artım } \\
(\Delta \mathbf{Q A i})\end{array}$ & $\begin{array}{c}\text { Reklam müraciətinin } \\
\text { translyasiya olunduğu } \\
\text { auditoriyanın sayı } \\
(\mathbf{Q A q a})\end{array}$ & $\begin{array}{c}\text { Reklam kampaniyasının } \\
\text { gedişində yeni cəlb } \\
\text { edilmiş müştərilərin sayı } \\
\text { (QAar) }\end{array}$ \\
\hline 1) ticarət & 2257 & 60371 & 58114 \\
\hline 2) ödənişli xidmətlər & statistik məlumatlar yoxdur & $-/ /-$ & $-/ /-$ \\
\hline 3) ictimai iaşə & 1422 & 15293 & 13871 \\
\hline 4) turizm & 26 & 259 & 233 \\
\hline 5) nəqliyyat & statistik məlumatlar yoxdur & $-/ /-$ & $-/ /-$ \\
\hline
\end{tabular}

Codval 3. Alıcı Auditoriyasının Genişlandirilmasi Üzra Tadbirlorin Aparılması Naticasində Alıcıların (İstifadəçilorin) Sayındakı Artımın Müəyyənloşdirilməsi

1) $\Delta \mathrm{QAi}_{\text {tic }}=60371-58114=2257$;

2) $\Delta \mathrm{QAi}_{\mathrm{öd}}=$ ? (statistik məlumatlar yoxdur);

3) $\triangle \mathrm{QAi}_{\text {ic }}=1529-13871=1422$;

4) $\Delta \mathrm{QAi}_{\text {tur }}=259-233=26$;

5) $\Delta \mathrm{QAi}_{\text {nəq }}=$ ? (statistik molumatlar yoxdur).

Yekunda, internet-texnologiyalar vasitəsilə auditoriya ilə qarşılıqlı əlaqənin aktivləşdirilməsi nəticəsində

Son illərdə müəssisələrin menecmentində aparılan islahatlar sistemində marketinqin effektivliyinin və səmərəliliyinin qiymətləndirilməsindən ötrü, müəssisədə menecmentin islahatlarına dair praktik proqramdan fəal şəkildə istifadə olunur .

Müəssisədə menecmentin islahatlarına dair praktik proqram, bir çox xarici müəssisələrin praktikasından götürülmüş müxtəlif nümunələrin təhlilinin və ümumiləşdirliməsinin nəticəsi olaraq meydana gəlmişdir. Belə nümunələrin sırasına "20 açar" sistemi aiddir.

Həmin proqramın unikallığı, aşağıdakı ardıcıllıqla yerləşdirilmiş 20 elementin qarşılıqlı əlaqələrinin nəzərdən keçirilməsindən ibarətdir

Dərəcənin müəyyənləşdirilməsi.

I. Şaquli idarəetmə sisteminin təşkilinin optimallaşdırılması.

II. Kompleks iş. Komanda işi.

III. Yarımçıq məhsulun ehtiyatlarının azalması.

IV. Cold yenidən təchiz etmə texnologiyası.

V. İstehsal əməliyyatlarının təkmilləşdirilməsi.

VI. Daimi nəzarət olmadan istehsal.

VII. Yanaşı təşkilati-texnoloji sahələr arasında aralıq toplayıcılar.

VIII. Avadanlığın texniki servisi.

IX. Oməyin və istirahətin reqlamenti.

X. Keyfiyyətin tominatı sistemi.

XII. İstehsal sisteminin effektivliyinin yüksəldilməsində təchizatçılara yardım.

XI. Yol xəritəsinin köməyi ilə xərclərin azaldılması.

XII. Oməkdaşların öz işlərini daim yaxşılaşdırmağa cəlb edilməsi.

XIII. İxtisasların birləşdirilməsi.

XIV. İstehsal-texnoloji proseslərin menecmenti.

XV. Omək məhsuldarlığının yüksəldilməsinin menecmenti.

XVI. İKT.

XVII. Enerjiyə qənaət.

XVIII. Müasir və yeni texnologiyalar.

Konkret əsas istiqamət üzrə işin əhəmiyyəti müəssisədə cari işlərin müəyyənləşdirildiyi strategiyalardan asılıdır. İstehsal sisteminin təkmilləşdirilmə-sinə müvafiq olaraq, əsas istiqamətlərdən hər birinin mənası dərindən dərk olunur.

"20 açar" proqramı məhsulun keyfiyyətinin idarə olunması sahəsində ən yaxşı xarici və yerli təcrübəni uğurla özündə birləşdirir. Bu proqram məhsuldarlığı və keyfiyyəti yüksəltməyə imkan verən yaxşı məlum olan bütün yanaşmaları və metodikaları özündə cəmləşdirir. 
"20 açar" proqramının müsbət cəhətləri:

- ümumi korporativ məqsədə xidmət edən bütün bölmələrin məqsədləri;

- müəssisənin fəaliyyətinin təkmilləşdirilməsi və effektivliyinin yüksəldilməsi üzrə proqramın reallaşdırılmasına müxtəlif səviyyəli əməkdaşların cəlb edilməsi;

- proqramın müddəalarının əməkdaşlar üçün etibarlılığı və əlverişliliyi;

- hər bir işçi üçün aydın olan sxemlərin və qrafiklərin köməyi ilə müəssisənin fəaliyyətinin təkmilləşdirilməsinin müxtəlif səviyyələrinin göstərilməsi;

- tərtib edilən sənədlərin minimal sayı;

- təşəbbüskar təkliflərin, menecmentin imkanlarının meydana çıxması və təş-viqi;

- müəssisənin işçi heyəti tərəfindən proqramın həyata keçirilməsinə qeyri-rəs-mi yanaşma;

- nəticənin ölçülməsi üçün etalon qiymətləndirmənin tətbiq edilməsi;

- daxili və xarici bençmarkinqin aparılması üçün istənilən bölmənin öz-özünü qiymətləndirməsinin nəticəsinin tətbiq edilməsi imkan1;

- hər bir bölmədə tacrübə toplanması və ötürülməsi mərkəzlərinin yaradıl-ması;

- proqramın sənədlərinin dərin metodik tədqiqatı hesabına qarşıya qoyulmuş məqsədlərə daha tez nail olunması;

- müəssisənin təkmilləşdirilməsi üzrə menecmentin xüsusi sisteminin müəy-yən edilməsi üçün əsas olan kompleks biliklər bazasının yaradılmasıdır (Lamben, 2007).

“20 açar” proqramının tətbiqi və tədqiq edilməsi sahəsində təcrübə ilə bir çox müəssisələrdə aşağıdakı müsbət nəticələr qeydə alınmışdır.

1. Oməkdaşların peşəkar vərdişləri inkişaf etmişdir.

2. Kollektivin mənəvi ruhu yüksəlmişdir.

3. İşçilər arasındakı ünsiyyət yüksək səviyyəyə çatmış, onlar biznes-məqsədləri və bu məqsədlərə təsir edən amilləri daha yaxşı dərk etmişlər.

4. Xərclər azalmışdır.

5. Məhsuldarlıq yüksəlmişdir.

6. Zay məhsul buraxılışı azalmışdır.

7. İstehsal ehtiyatları azalmışdır.

İstehsal sferasında realizə olunmuş məhsulun tam dəyişdirilməsi əsasında müəssisənin menecmentindəki dəyişikliklər sistemində marketinq fəaliyyətinin faktiki effektivliyinin qiymətləndirilməsi üzrə əldə etdiyimiz hesabat məlumatları bunu təsdiq edir "Cədvəl 4". Alınmış nəticələr aşağıda göstərilmişdir.

\begin{tabular}{|l|c|c|c|}
\hline Müəssisələr & $\begin{array}{c}\text { Realizə olunmuş } \\
\text { məhsulun həcminin tam } \\
\text { dəyişməsi }(\boldsymbol{\Delta Q p )}\end{array}$ & $\begin{array}{c}\text { Məhsulun bazarda təklifi } \\
\text { hesabına dəyişikliklər } \\
(\mathbf{\Delta m u ̈ ə s . Q p )}\end{array}$ & $\begin{array}{c}\text { Satış şəraitinin } \\
\text { dəyişməsi hesabına } \\
\text { dəyişikliklər }(\boldsymbol{\Delta} \text { şər.Qp) }\end{array}$ \\
\hline 1) Hasilat sənayesi & 26022 & 21192 & 4830 \\
\hline 2) Emal sənayesi & 9918 & 8899 & 1019 \\
\hline 3) Energetika sektoru & 30295 & 25438 & 4857 \\
\hline 4) Kənd təsərrüfatı & 488,3 & 449,2 & 39,1 \\
\hline 5) Tikinti & 8001,2 & 7660,4 & 340,8 \\
\hline
\end{tabular}

Codval 4. Realiza Olunmuş Məhsulun Tam Doyişdirilməsi Osasında Müəssisənin Menecmentindəki Dəyişikliklar Sisteminda Marketinq Faaliyyatinin Faktiki Effektivliyinin Qiymatlandirilmasi (Mln. Manatla)

1) $\Delta \mathrm{Qp}-\mathrm{h}=21192+4830=26022$

2) $\Delta \mathrm{Qp}$-em $=8899+1019=9918$

3) $\Delta Q p$-en $=25438+4857=30295$

4) $\Delta \mathrm{Qp}-\mathrm{k} / \mathrm{t}=449,2+39,1=488,3$

5) $\Delta \mathrm{Qp}-\mathrm{t}=7660,4+340,8=8001,2$.

\begin{tabular}{|l|l|l|l|l|}
\hline \multicolumn{1}{|c|}{ Müəssisələr } & $\begin{array}{c}\text { Satış sisteminin } \\
\text { effektivliyinin } \\
\text { inteqral göstəricisi } \\
\text { (Jn) }\end{array}$ & $\begin{array}{c}\text { Satışın i-ci } \\
\text { kanalının j-ci } \\
\text { göstəricisinin } \\
\text { qiyməti (Q) }\end{array}$ & $\begin{array}{c}\text { j-ci göstəricinin } \\
\text { balla qiyməti } \\
\text { (Bq) }\end{array}$ & $\begin{array}{c}\text { j-ci göstəricinin } \\
\text { əmsalının çəkisi } \\
\text { (Әç) }\end{array}$ \\
\hline 1) Hasilat sənayesi & 11146,1 & 4830 & 3,0 & 1,3 \\
\hline 2) Emal sənayesi & 2241,3 & 1019 & 2,0 & 1,1 \\
\hline 3) Energetika sektoru & 18942,3 & 4857 & 3,0 & 1,3 \\
\hline 4) Kənd təsərrüfatı & 126,7 & 39,1 & 2,7 & 1,2 \\
\hline 5) Tikinti & 862,2 & 340,8 & 2,3 & 1,1 \\
\hline
\end{tabular}

Codval 5. Inteqral Göstarici Osasında Qeyri-İstehsal Sferası Müəssisalərinin Marketinq Faaliyyətinin Ümumi Qiymatlandirilmasi (Mln. Manatla) 
Sonra isə inteqral göstəricinin əsasında qeyri-istehsal sferasının müəssisələ-rinin marketinq fəaliyyətinin ümumi qiymətləndirilməsini aparmışıq “Cədvəl 5”. Bu, aşağıdakı nəticələri vermişdir:

1) $\mathrm{Jnh}=4830 \cdot 5,0 \cdot 1,3=11146,1$

2) Jnem $=1019 \cdot 4,0 \cdot 1,1=2241,8$

3) Jnen $=4857 \cdot 5,0 \cdot 1,3=18942,3$

4) $\mathrm{Jnk} / \mathrm{t}=39,1 \cdot 3,7 \cdot 1,2=126,7$

5) $\mathrm{Jnt}=340,8 \cdot 3,3 \cdot 1,1=862,2$.

Nəhayət, yekunda qeyri-istehsal sferasının müəssisələrinin menecmentindəki islahatlar sistemində marketinq təşəbbüslərinin effektivliyinin inteqrasiya olunmuş göstəricilərini müəyyən etmişik. Bu, aşağıdakı nəticələri vermişdir "Codvəl 6".

\begin{tabular}{|c|c|c|c|c|c|c|c|c|}
\hline $\begin{array}{l}\text { İqtisadiyyatın ayrı- } \\
\text { ayrı sahələrinin } \\
\text { müəssisələrinin adları }\end{array}$ & 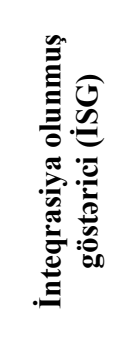 & 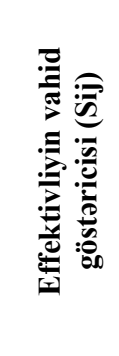 & 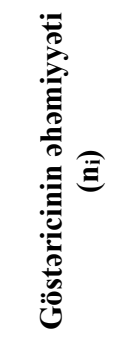 & 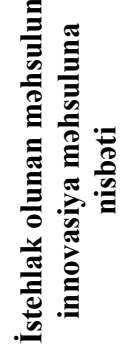 & 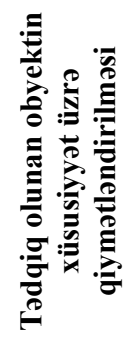 & 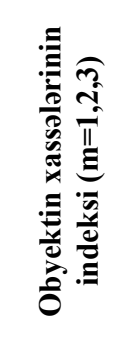 & 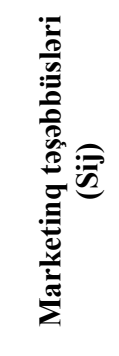 & 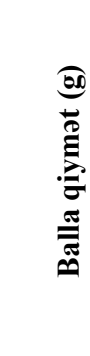 \\
\hline 1) Hasilat sənayesi & 6279 & 4830 & 1,3 & 0,016 & 1,3 & 0,016 & 150,0 & 3,0 \\
\hline 2) Emal sonayesi & 1120,9 & 1019 & 1,1 & 0,089 & 1,1 & 0,089 & 20,4 & 2,0 \\
\hline 3) Energetika sektoru & 6314,1 & 4857 & 1,3 & 0,015 & 1,3 & 0,015 & 157,9 & 3,0 \\
\hline 4) Kənd təsərrüfatı & 46,9 & 39,1 & 1,2 & 2,132 & 1,2 & 2,132 & 1,05 & 2,7 \\
\hline 5) Tikinti & 374,9 & 3408,8 & 1,1 & 0,267 & 1,1 & 0,267 & 7,82 & 2,3 \\
\hline
\end{tabular}

Cadval 6. Mü̈ssisalarin Menecmentindəki Islahatlar Sistemində Marketinq Taşabbüslarinin Effektivliyinin Inteqrasiya Olunmuş Göstaricilarinin Müəyyən Edilmasi (Bax: Metodika 1.3), Mln. Manatla

A. İnteqrasiya olunmuş göstərici (İSG):

1. İSG $\mathrm{h}=4830 \cdot 1,3=6279$

2. İSG em $=1013 \cdot 1,1=1120,9$

3. İSG en $=4857 \cdot 1,3=6314,1$

4. İSG $\mathrm{k} / \mathrm{t}=39,1 \cdot 1,2=46,9$

5. İSG $\mathrm{t}=348,8 \cdot 1,1=374,9$.

B. İnnovasiya prosesinə nisbət əmsalı (Jk):

1. $J_{n h}=\frac{1}{6279} \cdot 100=0,016$

2. $J_{\text {nem }}=\frac{1}{1120,9} \cdot 100=0,089$

3. $J_{\text {nen }}=\frac{1}{6314,1} \cdot 100=0,015$

4. $J_{n k / t}=\frac{1}{46,9} \cdot 100=2,132$

5. $J_{n t}=\frac{1}{374,9} \cdot 100=0,267$.

C. Marketinq təşəbbüslərinin effektivliyi (Sij):

1. $S_{i . s . h}=\frac{1}{1,3 \cdot 0,016} \cdot 3,0=\frac{1}{0,02} \cdot 3,0=150,0$

2. $S_{\text {i.s.em }}=\frac{1}{1,1 \cdot 0,089} \cdot 2,0=\frac{1}{0,098} \cdot 2,0=20,4$

3. $S_{\text {i.s.en }}=\frac{1}{1,3 \cdot 0,015} \cdot 3,0=\frac{1}{0,019} \cdot 3,0=157,9$

4. $S_{\text {i.s.k } / t}=\frac{1}{1,2 \cdot 2,132} \cdot 2,7=\frac{1}{2,558} \cdot 2,7=1,05$

5. $S_{\text {i.s.t }}=\frac{1}{1,1 \cdot 0,267} \cdot 2,3=\frac{1}{0,294} \cdot 2,3=7,82$.

Beləliklə, yuxarıda göstərilən hesabat məlumatları əsasında əldə olunmuş nəticələr onu təsdiq edir ki, marketinq təşəbbüslərinin effektivliyi müəssisənin menecmentini kifayət qədər yüksək səviyyədə dəyişməyə qadirdir. 


\section{Xülasə}

Müəssisənin istehsal-kommersiya fəaliyyəti prosesində yeni şəraitə, sahənin məhdudiyyətlərinə, tələbin dinamikasına, rəqiblərin innovasiya aktivliyi amillərinə, hazırlanan hüquqi aktlara və standartlara uyğunlaşmaq zərurəti qarşıya çıxır. Vəziyyətdən asılı olaraq, bu amillər inkişafın həm məhdudlaşdırıcı, həm də stimullaşdırıcı amilləri kimi meydana çıxır. Müasir şəraitdə malların və xidmətlərin istehsalı prosesi mürəkkəbləşmişdir, müştərilərin məhsulun keyfiyyətinə və xidmət səviyyəsinə tələbləri artmışdır. Yeni malların bazara çıxarılışı vaxtı azalır, bu da müəssisənin inkişafının idarə olunması metodologiyasının və texnologiyasının təkmilləşdirilməsini tələb edir. Beləliklə, effektiv inkişafın təmin olunması, müəssisənin bazarın tələb etdiyi malları istehsal etmək, onları müştərilər üçün münasib olan, amma eyni zamanda xərclərin ödənilməsini və gəlirin əldə edilməsini təmin edən qiymətlərlə satmaq imkanları ilə bağlıdır. Bu səbəbdən, müəssisələrin effektiv inkişafının idarə olunması problem-lərinin təkcə rəqabət qabiliyyətliliyinin yüksəldilməsi problemləri ilə deyil, həm də müasir marketinq sisteminin yaradılması problemləri ilə inteqrasiya olunmuş şəkildə nəzərdən keçirilməsi son dərəcə aktuallaşır. Ön plana istehsal məsələləri deyil, satış məsələlərinin keçdiyi zamanda müəssisələrin marketinq idarəetməsinin tətbiqi ilə əlaqədar olaraq, müasir marketinq sisteminin yaradılması problemləri getdikcə daha böyük zərurətə çevrilir.

\section{Odəbiyyat}

- $\quad$ Karsev A.P., O.A. Shevchenko. Marketing research and situational analysis. Libersi: Yurait. 2016, - 323 p.

- Kireenko N.V., Marketing in the management system of small and medium enterprises. Minsk: Misasta.2015,$211 \mathrm{p}$.

- $\quad$ Kitova O.V. Marketing performance management: methodology and design modeling. M .: INFRA-M. 2012, -328 p.

- $\quad$ Korotkov A.V. Marketing research. M .: Yurayt. 2016, - 595 p.

- Kozina E.V. The practical program of revolutionary transformations "20 keys" - A modern approach to the modernization of enterprises // Science of Science. 8, №2, 2016, p. 1-14.

- Kuzmina E.E., G.R Suzdalyova. Marketing. Liberians: Yurayt.,2018, - 383 p.

- Lamben J.J. Market oriented management. Per. from English SPb .: Peter. 2007, - 800 p.

- $\quad$ Lipsis I.V., Oiner O.K. Marketing management. M .: Yurayt.,2016, - 376 p. 


\title{
Problems of Innovative Management Strategies in Manufacturing
}

\author{
Ph.D. Candidate Elvin Balakishiev (Odlar Yurdu University, Azerbaijan)
}

\begin{abstract}
The solution of economic problems is closely related to social problems, therefore, investment policy should be understood as a key direction of socio-economic policy of the state, which is able to achieve its goals through the management of financial instruments at all hierarchical levels. Attracting investments at the regional level should be based on the principles of equality and proportionality, able to address various planned issues, ensure the stability of economic development in individual economic regions and territories, and ensure optimal state regulation of investment processes. This is primarily due to the fact that large investment projects affect one sector of the economy or another. Therefore, there is a need to develop a unified investment policy that addresses both sectoral and regional issues. It is necessary to find the optimal direction in the sphere of interaction of spheres and regions, as well as in their regular interaction. For this reason, the solution of theoretical, methodological and methodological issues in the field of improving the regional management of investment activities, the development of new sectoral investment projects in interaction with the regions and their effective practical application are of particular relevance and importance.
\end{abstract}

\section{Introduction}

Many factors must be taken into account when developing the concept of regional investment management, including:

- investment attractiveness;

- assessment of the level of investment concentration;

- the totality of goals and interests of the parties on regional investment management can be noted (Karimov T., 2017).

It is the systematic consideration of the above elements that should form the conceptual framework for regional investment management. Let's give a brief description of these elements and factors:

- investment attractiveness takes into account regional socio-economic development factors, which can significantly affect the amount of investment involved in both qualitative and quantitative relations;

- the level of investment concentration allows to determine the degree of similarity of the economic region as a whole;

- the totality of goals and interests of the parties on regional investment management allows to achieve the maximum effect, taking into account both external and internal factors of regional management.

As can be seen, only the combination of the above-mentioned elements and factors is able to increase the efficiency of the regional investment management system in the country by addressing many integration issues.

Therefore, the basic concept of regional investment management is to establish the functions of management, structure and methods of regulation of investment management mechanism in the regional management system (depending on the content, direction and relationship of investment attractiveness factors).

In order to implement the concept and objectives, it is necessary to address the issue of synthesis of the regional investment management mechanism as an important subsystem of the regional management system. In accordance with the methodology of systematic analysis, the principles of formation of the mechanism (by rationally organizing their practical application) are taken as the main provisions of the theory of management in the synthesis.

In our opinion, more general approaches to the creation of the concept of regional governance were developed by Professor AA Alabugin. He believes that the development of the regional economic system should be based on the scientific principles of management. Among them are the following.

\section{Methodology}

I. Principles based on the law of synergy in the self-organizing procedures of the components of macroeconomic and microeconomic systems, with the recognition of the following sub-principles:

- process management in the general system of regional management, management of regional investments;

- management of investment activity potential within the other regions;

- management of strategic changes in the regional investment management system.

II. The principles underlying the system's self-protection law are defined by the fact that the system provides the following components for the sustainable development of regional investment management:

- regional management of investment potential, provided that stakeholders follow the rules;

- taking into account risk and uncertainty factors in the formation of regional investment management; 
- selection of investment models and projects, taking into account the factors of stakeholders;

- selection of key parameters and indicators of regional management systems in the field of investment activity;

- development of qualitative and quantitative methods of research;

- ensures consideration of urgency and cost recovery factors in the regional investment management system.

The laws of evolution in the regional management of investment activities include the principles of taking into account the periodicity and periodicity of changes in the system of regional investment management.

The concept of regional investment management should be based on the interaction of regional authorities, municipalities and business structures, including:

- accounting for investments in key facilities;

- regulation of sources of investment financing, allocation of money from the budget, replacement of resources by private investors;

- creation of rational organizational structures and development of economic methods of investment process management;

- identification of new investment projects of special importance, profitable in terms of cost recovery, job creation, etc. can be noted.

Systematization of research, the main complexities of the implementation of regional investment policy and the attraction of regional investments:

- relatively weak attractiveness of the investment climate of many regions due to the deviations and structural disproportions in different regions (Trachuk A., 2008);

- weak completeness, weak normative-legal base, insufficient application of state incentives for investment development of the regions during the development of the state regional policy;

- weak impact of the local budgeting system on the economic development of the regions;

- minimum efficiency and productivity of support for regional investment activities at the expense of centralized resources, delay and resistance to decentralization of the budget process, weak level of budget discipline;

- allowed to note the contradictions of investment competition between the regions.

At the present stage, the problem of creating investment resources at both the macro and micro levels is important for regional investment policy. Necessary regional investments in the process of interaction of regional, local authorities and business structures, funds from various sources:

- personal financial resources and funds - internal reserves of the investor: income, depreciation, savings, collection of corporate income;

- extra-budgetary funds;

- state budget funds;

- funds of local budgets;

- can be invested at the expense of investors.

The main issue for the formation of the necessary volume of investment in modern conditions (for the actual use of forms and mechanisms of concentration of investment resources) is the interaction of regional, local authorities and business structures.

The investment policy of regional development includes the definition of state and regional priorities, as well as changes in the organizational and structural direction of the R\&D system, the creation of modern country structures in the scientific and technical direction.

These areas include measures to select and attract investment. The next element of regional investment policy is the choice of regional investment priorities, which emphasizes the creation of priority and targeted investment projects in various sectors of the economy. The system of targeted investment projects creates the necessary conditions and opportunities for the development of the region in more effective directions.

An important issue in the implementation of regional investment policy on the basis of interaction between regional, local authorities and business structures is the need to identify coordinated areas, financial, investment and credit activities in the region.

In the complex case, regional investments include a number of important issues:

- formation of market-oriented economies, rational application of their potential, on the basis of reproduction of municipal resources;

- systematic solution of issues arising from the need to reduce both sectoral and intersectoral risks in favor of the region and the state as a whole;

- improving ICT in all areas of commercial activity in order to achieve the competitiveness of goods and services of commercial structures of the region (Isayev S.Z. ,2011);

- have the ability to address issues of regional development.

The main task of regional investment policy is the sustainable development of the region on the basis of optimal use of investment resources. To do this, it is necessary not only to concentrate investment resources, but also to increase the economic and social efficiency of their application in various sectors of the economy. 
The revival of investment activity at the regional level depends to a large extent on the development characteristics of financial markets, where the bank lending market and the stock market differ. Effective financial markets provide the public sector with access to long-term resources, which allows for capital investment.

Therefore, regional investment policy should be developed on the basis of the development and implementation of investment projects grouped in the system of investment programs, organized on the basis of priority areas of regional development.

The development of the concept of regional investment management cannot be realized on its own without government intervention. Public administration of the investment process, by its very nature, defines a special form of regulation aimed at increasing socio-economic efficiency. The solution of economic problems is closely related to social problems, therefore, investment policy should be understood as the main direction of socioeconomic policy of the state, which is able to achieve its goals through the management of financial instruments at all hierarchical levels (Mannakov A.,2006).

\section{Results}

The current concept of regional investment policy includes a comprehensive purposeful, scientifically based activities of the authorities on the rational use of investment resources for sustainable socio-economic development and improving the living standards of the population of the region.

The following are the main methods and ways of state regulation of investment activities.

\begin{tabular}{|l|l|}
\hline Direct purpose methods. & Direct purpose methods. \\
\hline Regional development programs; & Methods of taxation and its stimulation; \\
Regional funds and budgets; & Tax rates; \\
Public investment; direct destination standards & Debt (loan) rates; \\
and norms; & Export promotion: on loans; \\
Licensing; & Provision of direct export credits; \\
Territorial controlling stake; & Export credit insurance; \\
District property and local property; & State guarantee for loans; \\
Stimulation of demand and price regulation; & Investment tax credit; \\
State funding of R\&D; & District bonds and local bonds; \\
& Payments for the use of district and local resources; \\
& Guarantees and concessions to credit companies in the area. \\
\hline
\end{tabular}

Table 1. The Main Methods and Ways of State and Regional Regulation of Investment Activities.

Thus, important elements of regional investment policy:

- adoption of the legislation of the country regulating the investment policy;

- assistance to investors through certain concessions of financial and non-financial nature;

- establishment of organizational structures to assist investments;

- preparation of investment projects at the expense of the state;

- providing services to investors in the field of customs privileges;

- providing guarantees to banks for the allocation of funds for the preparation of investment projects.

An important mechanism of investment policy in the regions in modern conditions is the legal framework.

Currently, the legislative framework for the management of these activities has shifted to the regional level, which is due to the strengthening of the role of the regions in the economic and legal spheres, the acute demand for investment resources in the regions.

Therefore, the assessment of the effectiveness of the region's investment policy can be determined by the degree of competition in the market in which investments are attracted, as well as the rating of the regions.

Today, economic growth is determined by the ability of the state to effectively manage the investment process. First of all, the reasons for the low growth rates of the economy are: incomplete structural and institutional reforms in the real sector, its low competitiveness, lack of fixed assets, structural deformations of socio-economic development of the regions, unequal distribution of wages and social explosion; and other causes need to be addressed.

As investment policy is an important tool for influencing both the country's economy and commercial activity, effective investment policy in the current situation is based on the following key concepts:

- achievement of concentration of investment resources in strategic directions of investment programs;

- identification of ways of state regulation of business in order to concentrate investment potential and implement the mutual interests of firms and territories in the formation of investment policy;

- should be based on the development of rationalization of legal support of investment activity (Mannakov A.,2006). 
The state's investment policy must be guided by a rational purpose in accordance with the adopted concept and the principles of the state investment strategy. When financial resources are limited, investment policy should be a clear reflection of economic modernization policy.

Modern trends in the management of the country's economy are determined by the fact that the state strengthens its economic and investment functions in connection with the adjustment (adjustment) of market instruments and mechanisms on a qualitatively new basis.

At the national level, the state's investment policy means a system of targeted measures aimed at modernizing investment activities, economic growth and production efficiency, solving social and other problems.

At the national level, the state's investment policy consists of comprehensive goals and programs to ensure a successful level and structure of capital investment in various sectors of the economy, strengthening the investment activity of all subjects of reproduction. In short, this is the activity of the state, aimed at finding sources of investment and identifying effective areas of their application (Isayev S.Z. ,2011).

The state's investment policy must be able to intensify investment activities at the level of both regions and firms, and ensure the integrity of the investment space in all regions of the country. Its main provisions are:

- expediency of investment;

- directions towards effective investment in order to obtain income and efficiency (limited by the objectives of a specific project, the duration of its implementation and the resources involved for its implementation);

- national significance, representing only the interests of society as a whole, which does not provide for the implementation of one or another national ideology and the concentration of corporate, group and personal interests of the parties;

- development and use of normative-legal bases of the right of pledge;

- achievement of structural balance, including optimal structural balance in the regional economy;

- determination of certain limit rates of development and current situation.

The economic literature suggests that public investment policy is divided into classification groups such as sectoral, regional and corporate investment policy. These are closely related to each other, but the leading one is the republic's investment policy, because it creates conditions for investment activity in all hierarchies and helps to intensify this activity.

Regional investment policy means the development of a set of priorities at the territorial level, the concentration of investment resources and the identification of the most effective areas of their application in the interests of the population of the region and individual investors (Boyko I.V., 2000).

Peculiarities of investment policy at the regional level:

- implementation of economic and social policy in a certain area;

- volume of existing production potential;

- provision with energy and raw material resources;

- location;

- condition of the environment;

- the attractiveness of the region for foreign investment, etc.

Its main tasks, including the methods and techniques of applying regional investment policy in the regions, may not coincide, because at the same time the state has common goals of regional investment policy, which include:

- increase the volume and increase the efficiency of investments through the creation of new organizational structures;

- strategic direction of individual regions and the country as a whole;

- the creation of a favorable investment climate in the region can be considered as a prerequisite for economic growth.

The main tactical tasks of the investment policy of the regions:

- structural reform of the country's regions;

- ensuring the freedom and economic security of the regions;

- improving the location of productive forces in the region and strengthening the industrial base, development of export-oriented industries;

- identification of priority investment projects in accordance with the interests of regional investment policy.

Stakeholders involved in the investment process are those who accept the investment, domestic investors, foreign investors and those who manage the activity.

In addition, there is a corporate investment policy. It is a system of measures to ensure the efficient investment of personal, borrowed and other funds, commercial activities in order to ensure the financial stability of the firm in the future (Andreycikov A.V. ,2004). 


\begin{tabular}{|l|l|l|l|}
\hline \multicolumn{1}{|c|}{ Current } & \multicolumn{1}{c|}{ Tactics } & \multicolumn{1}{c|}{ Strategies } \\
\hline Money- credit & $\begin{array}{l}\text { Balancing receivables } \\
\text { and payables }\end{array}$ & $\begin{array}{l}\text { Growth at the expense of } \\
\text { taxes }\end{array}$ & $\begin{array}{l}\text { Decreased demand for } \\
\text { transfers }\end{array}$ \\
\hline Economy & $\begin{array}{l}\text { Increase in the entity's } \\
\text { income }\end{array}$ & $\begin{array}{l}\text { Decrease in the level of } \\
\text { prices in the region }\end{array}$ & $\begin{array}{l}\text { Increasing investment } \\
\text { attractiveness }\end{array}$ \\
\hline Social & $\begin{array}{l}\text { Wage growth of the } \\
\text { population }\end{array}$ & Rising living standards & $\begin{array}{l}\text { Improving the quality of } \\
\text { life }\end{array}$ \\
\hline
\end{tabular}

Table 2. Benefits from the Application of Investment Potential.

The return on investment comes in direct, current, tactical and strategic forms.

Only the sum of all types of use of investment potential can form the conceptual basis of regional investment management ( Trachuk A., 2008).

Therefore, the concept of regional investment management should be closely linked to state, sectoral and corporate investment policy.

The concept of regional investment management should include mechanisms for shaping investment processes in the region.

Periodic changes in the goals and criteria of investments for the subjects of the investment process occur due to changes in their current and long-term needs. These needs are of a different nature and are classified as strategic and current needs.

The strategic needs of the subjects arise from the long-term interests of the development of the economic system and are located in that system. Strategic needs for stability of interests can be easily adjusted, as they overlap in many respects with the same logic of long-term components of the economic system that affect the subjects of the investment process. The regulation of the balance of interests is also facilitated by the fact that in the strategic plan, in the first place, there are indicators of investment efficiency assessment for each of the subjects, which do not lead to conflict between them.

The current needs of entities arise from short-term interests, which leads to a stricter procedure for managing investment processes.

It should be noted that investment process management is an important type of business and:

- due to specific features;

- due to the need to take into account the unusual strategies of stakeholders;

- characterized by the need to take into account the economic interests of stakeholders.

This specific feature of the investment process is the basis for the development of specific methods of managing these processes. In modern conditions, working methods of investment management need to be improved. It consists of several phases.

In the I phase, investment potential is emerging. Investment potential is assessed taking into account the stakeholders of the investment process, taking into account the needs and proposals of economic entities at the micro, meso and macro levels.

In Phase II, favorable conditions are created for the use of investment potential on time.

In phase III, the efficiency of the used potential is assessed for all subjects of investment potential.

The efficiency category of the use of investment potential is based primarily on the possibility of obtaining the estimated return.

\section{Conclusions}

We noted that the investment process in the region is the purposeful use and activation of the investment potential of the economic system of the region in order to obtain socio-economic benefits in terms of achieving the results required for all entities. The investment process, in turn, involves the sequencing of a number of activities that need to be managed. It is proposed to balance the interests of the subjects of the regional investment process as a criterion for managing the investment process. Balancing interests means being able to choose an effective option for the development of the investment process that meets the interests of all actors at a certain stage. The main purpose of the balance of interests will be an investment system that can set complex goals and criteria for the selection of stakeholders at each stage of the process.

\section{References}

- Andreycikov A.V. Strategic management in innovative organizations. M .: INFRAM, 2004,-556p.

- Boyko I.V. Fundamentals of innovative development and the new economy. SPb .: ITMO University, 2000,$198 \mathrm{p}$. 
- İsayev S.Z. Legal regulation of investment activity. Baku. 2011, -188 p.

- Karimov T. Regional features of the formation of investment potential in Azerbaijan. // TURAN-SAM, 9/2017

- Mannakov A. The system of innovation management in the organization. Problems of theory and practice of management.,2006-126p.

- Mannakov A. The system of innovation management in the organization. Problems of theory and practice of management.,2006-126p.

- Trachuk A. Innovative company strategy. Problems of management theories and practices.2008,-99p. 


\title{
Diagnostics of Hotel Business: Features and Specifics
}

\author{
Ph.D. Candidate Ilkin Gahramanov (Odlar Yurdu University, Azerbaijan)
}

\begin{abstract}
In all countries of the world, the market of tourism services and hotel business is expanding every year, including in the Republic of Azerbaijan. This was facilitated by a number of serious measures adopted by the leadership of the country, among which are: the law on tourism (1999); UN programmatic development to increase the competitiveness of the tourism sector (2009); development of industrial tourism in accordance with the strategic plan of the Road Map (2016), etc.

Currently, the tourism services market acts as one of the important connecting links along the entire chain of market processes, including almost all sectors of the economy. In addition, thanks to the expansion of the tourism market, many social problems are being addressed.

In recent years, new areas of tourism services and the hotel industry have appeared, among which investmentinnovative can be distinguished; financial credit and many others.

All this contributed to the fact that the tourism market and hotel business of the country began to solve not only domestic, but a number of international problems.
\end{abstract}

\section{Introduction}

A distinctive feature of the diagnosis of hospitality enterprises from tourism enterprises is that they are somewhat limited in the spatial system and are mostly fixed in nature. If tourism enterprises carry out their main function outside their system (departures, travel, etc.), then hotel enterprises carry out their activities within the enterprise (services, services, etc.), i.e. directly in hotels.

For these reasons, it is proposed to diagnose hospitality enterprises in the following sequence:

- the main indicators of hotels and hotel-type enterprises;

- the number of persons accommodated in hotels and hotel-type enterprises;

- the average monthly number of employees of hotels and hotel-type enterprises;

- distribution of hotels and hotel-type enterprises by ownership;

- income and expenses of hotels and hotel-type enterprises in general and by ownership.

In addition, it is separately recommended to conduct an analysis of catering facilities (as part of hotels or outside) in the following sequence:

- main indicators of catering enterprises;

- the volume of food supply;

- food turnover indices.

The following is a specific analysis of the activities of enterprises of hotel guests in the above mentioned areas.

Diagnostics of the main indicators of hotels and hotel-type enterprises in the republic showed a number of positive developments in this area. So, in 2011-2016 their number increased from 508 to 548, the one-time volume of seats - from 31979 to 40042, and the number of rooms - from 14815 to 20330 (Antones V.Q., 2017).

A significant increase is observed in the number of person-days spent for the night from 1504312 to 2125266 (including foreign citizens - from 673811 to 1406264), and in number - from 510162 to 1122068 (including foreign citizens - from 257987 to 776784 ).

For the purpose of recreation and entertainment, the number of persons accommodated increased sharply 172797 to 565738 (including foreign citizens - from 48647 to 367067 ); business trips - from 185094 to 258299 (including foreign citizens - from 124264 to 188652 ).

At the same time, a decrease in accommodated persons in hotels, stay for treatment and other tourist purposes.

Qualitative shifts are observed in the expansion of the hotel industry. In particular, during the study period they increased - from 2746.9 thousand square meters to 3642.3 thousand square meters, of which the living area - from 442.3 to 553.0 .

\section{Methodology}

The number of employees in hotels and hotel-type enterprises has also increased from 6198 to 9838 ; incomes of enterprises - from 114.7 million manat to 240.1 million manat; expenses - from 88.7 million manat to 204.8 million manat. 


\begin{tabular}{|c|c|c|c|c|c|c|c|}
\hline & 2011 & 2012 & 2013 & 2014 & 2015 & 2016 & $\begin{array}{c}2016 / 201 \\
1 \%\end{array}$ \\
\hline $\begin{array}{l}\text { Number of hotels and hotel-type } \\
\text { enterprises, unit }\end{array}$ & 508 & 514 & 530 & 535 & 536 & 548 & 107,9 \\
\hline Disposable capacity, space & 31979 & 32834 & 33951 & 35652 & 37278 & 40042 & 125,3 \\
\hline Number of numbers, revelation & 14815 & 15898 & 16559 & 17363 & 17953 & 20330 & 137,2 \\
\hline Number of nights, man-night & 1504312 & 1640863 & 1674065 & 1687457 & 1644056 & 2125266 & 141,3 \\
\hline Total number of placed people, people & 510162 & 624924 & 666348 & 672345 & 838145 & 1122068 & $2,2 \mathrm{~d}$ \\
\hline for relaxation, entertainment & 172797 & 225646 & 226464 & 237506 & 256285 & 565738 & $3,3 \mathrm{~d}$ \\
\hline for business purposes & 185094 & 247304 & 232796 & 206234 & 275896 & 258299 & 140,0 \\
\hline for the purpose of treatment & 27533 & 15145 & 45060 & 70981 & 68896 & 11450 & 41,0 \\
\hline for other tourism purposes & 40242 & 32863 & 42617 & 35922 & 37282 & 33814 & 84,1 \\
\hline for other purposes & 84496 & 103966 & 119411 & 121702 & 199786 & 252767 & $3,0 \mathrm{~d}$ \\
\hline $\begin{array}{l}\text { Total area owned and (or) used by } \\
\text { enterprises, thousand sq.m. }\end{array}$ & 2746,9 & 3020,6 & 3073,3 & 3563,1 & 3463,5 & 3642,3 & 132,6 \\
\hline $\begin{array}{l}\text { Living space from the common area. } \\
1000 \text { sq.m. }\end{array}$ & 442,3 & 518,2 & 526,5 & 516,0 & 507,8 & 553,0 & 125,1 \\
\hline Number of employees. People & 6198 & 7321 & 8259 & 9009 & 8364 & 9838 & 158,7 \\
\hline $\begin{array}{l}\text { Income earned by enterprises, thousand } \\
\text { manat }\end{array}$ & 114686,1 & 153980,9 & 171255,9 & 181047,3 & 183055,1 & 240112,7 & $2,1 \mathrm{~d}$ \\
\hline $\begin{array}{l}\text { Costs of production of goods and } \\
\text { services, thousand manats }\end{array}$ & 88680,4 & 110684,0 & 1454683 & 147068,1 & 171730,8 & 204852.3 & $2,3 \mathrm{~d}$ \\
\hline $\begin{array}{l}\text { Taxes paid to the budget, thousand } \\
\text { manats }\end{array}$ & 27966,5 & 18058,8 & 29951,3 & 28201,5 & 28098,5 & 38525,7 & $1,4 \mathrm{~d}$ \\
\hline
\end{tabular}

Table 1. Key Indicators of Hotels and Hotel-type Enterprises Source: (Antones V.Q.,2017)

\section{Results}

A more detailed analysis of accommodated persons in hotels and hotel-type enterprises. As you can see, in 20112016 there is a decrease in the placed man-days in the public sector from 130657 to 112523 , an increase in the private sector from 1148717 to 1817012 . As for the number of people placed, they have increased in both the public and private sectors: from 20158 up to 41932; from 349416 to 976801 (Agaeva A.N., Vasilchenko T.Z, 2011).

\begin{tabular}{|c|c|c|c|c|c|c|c|}
\hline & 2011 & 2012 & 2013 & 2014 & 2015 & 2016 & $\begin{array}{c}2016 / 2011 \\
\%\end{array}$ \\
\hline Number of nights, man-night & 1504312 & 1640863 & 1674065 & 687457 & 1644056 & 2125266 & 141,2 \\
\hline \multicolumn{8}{|l|}{$\begin{array}{l}\text { including by types of ownership of } \\
\text { hotels and hotel-type enterprises: }\end{array}$} \\
\hline state & 130657 & 67793 & 72366 & 61177 & 108672 & 112523 & 85,5 \\
\hline special & 1148717 & 1237678 & 1246669 & 1392938 & 1321601 & 1817012 & 158,1 \\
\hline foreign & 160943 & 165613 & 204687 & 88828 & 108701 & 86400 & 53,4 \\
\hline joint & 63995 & 169779 & 150343 & 144514 & 105082 & 109331 & $1,7 \mathrm{~d}$ \\
\hline $\begin{array}{l}\text { Number of placed people, total, } \\
\text { people }\end{array}$ & 510162 & 624924 & 666348 & 672345 & 838145 & 1122068 & $2,2 \mathrm{~d}$ \\
\hline \multicolumn{8}{|l|}{$\begin{array}{l}\text { including by types of ownership of } \\
\text { hotels and hotel-type enterprises: }\end{array}$} \\
\hline state & 20158 & 16513 & 18172 & 14398 & 31688 & 41932 & $2,1 \mathrm{~d}$ \\
\hline special & 349416 & 401355 & 468163 & 550626 & 679053 & 976801 & $2,8 \mathrm{~d}$ \\
\hline foreign & 85964 & 134173 & 111129 & 31555 & 60730 & 40104 & 46,5 \\
\hline joint & 54624 & 72883 & 68884 & 75766 & 66674 & 63231 & \\
\hline
\end{tabular}

Table 2. Number of Overnight Stays and Accommodation in Hotels and Hotel-type Establishments, Persons Source: (Agaeva A.N.,2011)

The growth is also observed in the number of employees in hotels and hotel-type enterprises, both in the public and private sectors: from 507 to 888 ; from 4737 to 7911 . 


\begin{tabular}{|c|c|c|c|c|c|c|c|}
\hline & 2011 & 2012 & 2013 & 2014 & 2015 & 2016 & $\begin{array}{c}2016 / 2011 \\
\%\end{array}$ \\
\hline $\begin{array}{l}\text { Average annual number of } \\
\text { employees - total }\end{array}$ & 6198 & 7321 & 8259 & 9009 & 8364 & 9838 & 158,7 \\
\hline \multicolumn{8}{|l|}{$\begin{array}{l}\text { including by types of ownership of } \\
\text { hotels and hotel-type enterprises: }\end{array}$} \\
\hline state & 507 & 240 & 232 & 525 & 367 & 888 & $1,7 \mathrm{~d}$ \\
\hline special & 4737 & 5982 & 6826 & 7366 & 6894 & 7911 & $1,7 \mathrm{~d}$ \\
\hline foreign & 716 & 791 & 730 & 634 & 609 & 552 & 77,1 \\
\hline joint & 238 & 308 & 471 & 484 & 494 & 487 & $2,0 \mathrm{~d}$ \\
\hline $\begin{array}{l}\text { The number of employees serving } \\
\text { tourists out of the total number of } \\
\text { employees }\end{array}$ & 3616 & 4723 & 5526 & 5793 & 5670 & 5670 & 156,8 \\
\hline
\end{tabular}

Table 3. Average Annual List of Employees in Hotels and Hotel-type Enterprises, People Source: (Artomova E.N., Kozlova V.A.,2005)

The distribution of the area of hotels and hotel-type enterprises by ownership forms shows that for 2011-2016 for all forms of ownership, their areas increased and accordingly amounted to (thousand square meters): total from 2746.9 to 3642.3 ; state - from 154.5 to 242.6 ; private - from 2494.9 to 3294.6 ; foreign - from 52 to 60.1 ; joint practically did not change.

It should be noted that a significant part of the total area of hotels and hotel-type enterprises falls on the living space.

\begin{tabular}{|c|c|c|c|c|c|c|c|}
\hline & 2011 & 2012 & 2013 & 2014 & 2015 & 2016 & $\begin{array}{c}2016 / 2011 \\
\% \\
\end{array}$ \\
\hline & \multicolumn{7}{|c|}{ Total } \\
\hline Total area of enterprises & 2746,9 & 3020,6 & 3073,3 & 563,1 & 2433,9 & 3642,3 & 132,5 \\
\hline \multicolumn{8}{|l|}{ From here: } \\
\hline leased area & 19,5 & 16,3 & 21,4 & 21,4 & 49,5 & 64,2 & $3,4 \mathrm{~d}$ \\
\hline residential area & 442,3 & 518,2 & 526,5 & 522,0 & 452,4 & 558,9 & 126,4 \\
\hline leased area & 39,5 & 65,4 & 70,1 & 86,1 & 102,6 & 80,9 & $2,1 \mathrm{~d}$ \\
\hline & \multicolumn{7}{|c|}{ State } \\
\hline Total area of enterprises & 154,5 & 131,8 & 133,1 & 133,0 & 169,5 & 242,6 & 157,8 \\
\hline \multicolumn{8}{|l|}{ From here: } \\
\hline leased area & 1,7 & 1,5 & 1,5 & 1,4 & 4,3 & 2,2 & 129,4 \\
\hline residential area & 48,9 & 40,7 & 32,6 & 40,2 & 36,0 & 49,5 & 101,2 \\
\hline leased area & 0,1 & 0,1 & 0,1 & - & 2,8 & 0,8 & - \\
\hline & \multicolumn{7}{|c|}{ Special } \\
\hline Total area of enterprises & 2494,9 & 2771,9 & 2832,7 & 3320,3 & 2154,4 & 3294,6 & 132,1 \\
\hline \multicolumn{8}{|l|}{ From here: } \\
\hline leased area & 13,6 & 10,9 & 17,2 & 17,4 & 41,4 & 58,2 & $4,1 \mathrm{~d}$ \\
\hline residential area & 347,4 & 423,0 & 438,9 & 426,2 & 363,9 & 460,1 & 132,6 \\
\hline leased area & 30,3 & 42,4 & 43,9 & 56,9 & 76,9 & 74,5 & $2,4 \mathrm{~d}$ \\
\hline & \multicolumn{7}{|c|}{ Fore1gn } \\
\hline Total area of enterprises & 52,4 & 72,0 & 59,3 & 59,8 & 65,0 & 60,1 & 114,7 \\
\hline \multicolumn{8}{|l|}{ From here: } \\
\hline leased area & 4,0 & 1,4 & 0,1 & - & - & - & - \\
\hline residential area & 30,0 & 36,7 & 34,0 & 34,6 & 33,8 & 30,7 & 1,02 \\
\hline leased area & 9,1 & 17,9 & 17,9 & 19,2 & 17,9 & 0,6 & 6,6 \\
\hline & \multicolumn{7}{|c|}{ Joint } \\
\hline Total area of enterprises & 45,2 & 45,0 & 48,2 & 50,0 & 45,0 & 45,0 & 99,5 \\
\hline \multicolumn{8}{|l|}{ From here: } \\
\hline leased area & 0,2 & 2,4 & 2,6 & 2,6 & 3,8 & 3,8 & $1,9 \mathrm{~d}$ \\
\hline residential area & 16,0 & 17,8 & 21,0 & 21,0 & 18,6 & 18,6 & 116,2 \\
\hline leased area & - & 5,0 & 8,2 & 10,0 & 5,0 & 5,0 & 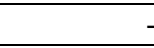 \\
\hline
\end{tabular}

Table 4. Distribution of the Total Area Owned and (or) Used by Hotels and Hotel-type Enterprises by Types of Property, thousand sq. m. Source: (Almosov S.M.,2011).

In 2011-2016, the income structure for all items increased, including income from the sale of rooms, from the sale of food and medical and recreational activities (as a whole from 114.8 million manat to 240.1 million manat). There is also an increase in expenses for all items, including expenses for materials and equipment; salary of employees; energy, fuel and water; depreciation of fixed assets; rent; for repairs, etc. (as a whole from 88.7 million manat to 204.8 million manat) (Artomova E.N., Kozlova V.A. 2005). 
The food market in the republic for 2011-2016 expanded more than 2 times, so the supply turnover increased from 565.5 million manats to 1215.4 million manats, including in the public sector - from 13.1 million manats to 15.6 million manats, and in non-state - from 552.4 million mana to 1199.8 million manat. The number of individual entrepreneurs engaged in this field has significantly increased from 9146 to 17295 . The qualitative changes in the food system include the increase in seats in catering enterprises from 307.4 thousand to 660.2 thousand.

\begin{tabular}{|c|c|c|c|c|c|c|c|}
\hline & 2011 & 2012 & 2013 & 2014 & 2015 & 2016 & $\begin{array}{c}2016 / 201 \\
1 \% \\
\end{array}$ \\
\hline Catering turnover, million manat & 565,5 & 680,0 & 800,1 & 956,0 & 1111,2 & 1215,4 & $2,1 \mathrm{~d}$ \\
\hline \multicolumn{8}{|l|}{ From here: } \\
\hline state & 13,1 & 12,0 & 13,8 & 14,8 & 15,2 & 15,6 & 119,1 \\
\hline non-state & 552,4 & 668,0 & 786,3 & 941,2 & 1096,0 & 1199,8 & $2,2 \mathrm{~d}$ \\
\hline $\begin{array}{l}\text { Index of physical volume of food } \\
\text { turnover, as a percentage of the } \\
\text { previous year }\end{array}$ & 122,6 & 118,8 & 116,0 & 118,2 & 114,0 & 100,1 & \\
\hline state & 113,0 & 102,3 & 113,8 & 105,7 & 101,2 & 93,6 & - \\
\hline non-state & 122,8 & 119,2 & 116,1 & 118,4 & 114,2 & 100,2 & - \\
\hline $\begin{array}{l}\text { Index of physical volume of food } \\
\text { turnover, as a percentage of the } \\
\text { previous year }\end{array}$ & 9146 & 9502 & 11043 & 13874 & 15645 & 17295 & $1,9 \mathrm{~d}$ \\
\hline \multicolumn{8}{|l|}{ From here: } \\
\hline state & 37 & 30 & 30 & 23 & 12 & 19 & 51,3 \\
\hline non-state & 9109 & 9472 & 11013 & 13851 & 15633 & 17276 & $1,9 \mathrm{~d}$ \\
\hline $\begin{array}{l}\text { Index of physical volume of food } \\
\text { turnover, as a percentage of the } \\
\text { previous year }\end{array}$ & 307,4 & 326,9 & 378,9 & 504,5 & 575,7 & 660,2 & $3,2 \mathrm{~d}$ \\
\hline
\end{tabular}

Table 5. The Main Indicators of Catering Source: (Abdulov A.V.,2011).

If we analyze the supply turnover for a longer time (1995-2016), then it increased from 11.0 million manats to 1215.4 million manats, i.e. 110.4 times, and for 1 person - from 1.4 manats to 126.1 manats.

\begin{tabular}{|c|c|c|c|}
\hline Years & $\begin{array}{c}\text { Catering turnover, } \\
\text { million manat }\end{array}$ & $\begin{array}{c}\text { Physical volume indices of catering turnover, as } \\
\text { a percentage of the previous year }\end{array}$ & $\begin{array}{c}\text { Catering turnover per } \\
\text { capita, manat }\end{array}$ \\
\hline 1995 & 11,0 & 76,0 & 1,4 \\
\hline 2000 & 18,4 & 106,7 & 2,3 \\
\hline 2005 & 74,0 & 126,1 & 8,9 \\
\hline 2010 & 417,8 & 116,3 & 46,7 \\
\hline 2011 & 565,5 & 122,6 & 62,5 \\
\hline 2012 & 680,0 & 118,8 & 74,1 \\
\hline 2013 & 800,1 & 116,0 & 86,1 \\
\hline 2014 & 956,0 & 118,2 & 101,5 \\
\hline 2015 & 111,2 & 114,0 & 116,6 \\
\hline 2016 & 1215,4 & 100,1 & 126,1 \\
\hline
\end{tabular}

Table 6. Catering Turnover and Physical Volume Indices Source: (Bezrutcenko Y.V.,2016).

A more visual representation of the success of the food market is indicated by index indicators of food turnover.

\begin{tabular}{|c|c|c|c|c|c|c|c|c|}
\hline & 2009 & 2010 & 2011 & 2012 & 2013 & 2014 & 2015 & 2016 \\
\hline $1995=100$ & 1301,1 & 1513,1 & 1855,1 & 2203,9 & 2556,5 & 3021,8 & 3444,8 & 3448,3 \\
\hline $2000=100$ & 822,8 & 956,9 & 1173,2 & 1393,8 & 1616,8 & 1911,1 & 2178,6 & 2180,8 \\
\hline $2005=100$ & 275,0 & 319,9 & 392,2 & 465,9 & 540,4 & 638,8 & 728,2 & 728,9 \\
\hline $2010=100$ & & 100,0 & 122,6 & 145,6 & 168,9 & 199,6 & 227,6 & 227,8 \\
\hline $2011=100$ & & & 100,0 & 118,8 & 137,8 & 162,9 & 185,7 & 185,9 \\
\hline $2012=100$ & & & & 100,0 & 116,0 & 137,1 & 156,3 & 156.5 \\
\hline $2013=100$ & & & & & 100,0 & 118,2 & 134,7 & 134,9 \\
\hline $2014=100$ & & & & & & 100,0 & 114,0 & 114,1 \\
\hline $2015=100$ & & & & & & & 100,0 & 100,1 \\
\hline $2016=100$ & & & & & & & & 100,0 \\
\hline
\end{tabular}

Table 7. Physical Volume Indices of Catering Turnover, in percent Source: (Bezrutcenko Y.V.,2016)

Thus, the diagnostics of hotels and hotel-type enterprises in the republic showed that these enterprises are the main component of the tourism market and are closely linked with tourism enterprises. The results of the study showed a number of positive and negative aspects in the activities of hotels and hotel-type enterprises (Almosov S.M., 2011). 
The positive aspects include the following: for the period from 2011 to 2016 . the number of hotels and hoteltype enterprises increased by $7.9 \%$, their one-time capacity - by $25.3 \%$, the number of rooms - by $37.2 \%$, and the number of person-days by $41.3 \%$; during the study period, the number of persons accommodated increased 2.2 times, including vacationers - 3.3 times, business trips - 1.4 times, used total area - 1.3 times (including living area - 1.25 times), the number of employees - 1.6 times, profit - 2.1 times, expenses -2.3 times, taxes to the budget 1.4 times; a positive point can be considered an increase in the total and living space of hotels and hotel-type enterprises for all types of ownership - total (32.5\%), state $(57.8 \%)$, private $(32.1 \%)$, foreign $(14.47 \%)$, joint - no change (Abdulov A.V. 2015).

Considering the fact that hotels and hotel-type enterprises are directly related to food, very positive shifts are observed in this area as well, including: during the study period, the food turnover in the republic increased 2.1 times; the number of individual entrepreneurs engaged in catering - 1.9 times; the number of seats in catering facilities increased 3.2 times; index indicators of food enterprises are stably positive (Bezrutcenko Y.V., 2016).

The disadvantages of the activities of hotels and hotel-type enterprises are: during the study period, there is a decrease in the number of foreign citizens accommodated in hotels (53.4\%); poor work of hotels and hotel-type enterprises in joint directed activities; low flow of visitors to hotels arriving for treatment (41.0\%), etc.

\section{Conclusion}

Research on the problems of increasing the efficiency of the tourism market and the hotel industry in modern conditions yielded the following results:

1. Currently, research on the tourism market and the hotel industry is becoming an important area for the development of the non-oil sector of the country. The interconnection of enterprises of the tourism market and the hotel industry contributes to the expansion of trade, therefore, increase profits and incomes, and improve the living standards of the population.

Despite the development of the tourism market and hotel business in the republic, there are still many unresolved theoretical and practical problems.

The issues related to integration and integrated processes in the enterprises of the tourism market and the hotel industry remain slightly changed. This requires clarification of the categorical apparatus and identification of fundamental trends in the development of this sphere.

2. Under the influence of integration and integrated processes, the market of tourist and hotel services undergoes a significant transformation: the national market of tourist services is being formed, the relationship between tourism industry enterprises and the hotel industry is being strengthened and complicated, the volume of cross-border movement of goods and services in the industry is increasing, the international division of labor is deepening, and more actively apply modern information and telecommunication technologies. Modern travel companies are increasingly focused on international standards of activity, the formation of international information and communication systems, modern organizational forms of integration and partnerships in the form of multinational companies and integrated network associations.

3. Studies have shown that the main component of the tourism market, a tourism product has a number of specifics, the main production resource is economic systems, the production and consumption process is multifaceted, characterized by its variability in quality and inability to store, which is why, in order to expand the market It requires the involvement of various sectors of the economy, including the hotel business, the formation of the relevant infrastructure in the regions.

The versatility of tourism products leaves its mark on various forms of integration processes and cooperation between tourism and hotel companies. Many integration and partner associations are created on a territorial-sectoral basis, in particular in the tour operator business, international associations of transport carriers, international hotel chains in the hotel business, international restaurant chains in the restaurant.

At the same time, the need for cooperation in the activity of these relations, the desire to expand the market and establish stable control over the market space, contributes to the emergence of intersectoral integration and partnerships under a single management system. The integration processes are based on the association of brands, the creation or purchase of new companies outside the home country. This is possible on the basis of the development of general rules and standards that ensure the maintenance of the corporate level of services by consumers, and the widespread use of advanced ITCs.

4. A promising direction for expanding the tourism market and hotel industry is the regionalization process, which is able to study the tourist specification of a particular region, to develop and implement national innovative projects for its application. The formation of the scientific provisions of tourist zoning helps to identify potential resources and other prerequisites for expanding the tourism market in developed areas; to 
find new tourist areas; to reveal their tourist orientation, to use the advanced world experience in tourism development.

5. At this stage, certain scientific prerequisites have been formulated, basic organizational and economic concepts and methods have been developed for improving the public administration system for the development of the tourism industry in the context of overcoming the global economic crisis and increasing competition in the global tourism services markets. In developed countries, there is a transition from a model of centralization of regulation to decentralization of customization. At the same time, the goals of state regulation of tourism include: the integrated development of a sanatorium complex and infrastructure elements; preservation of cultural and historical values; creation of conditions for improving the quality of tourism and hotel services.

6. The studies showed that the conceptual model of integration of the regional tourism industry and the hotel industry is expressed in the diversity of multi-vector integration processes and legal impact. In the formation of this model, it is advisable to use an integrated approach that includes the following subsystems: market integration, based on the flows of resources and income in the system of the tourist market and the hotel industry, market integration, based on the identification of the main actors in the tourism market and the hotel industry; highlighting the objects of formation of a regional tourist product in the context of hotel services.

In the process of implementing the author's approach, the following scientific results were obtained:

- identified and calculated parameters of the effectiveness of the main components of tourism enterprises and hotels, which include the following: a general calculation of the effectiveness of the main parameters of tourism enterprises and hotels; determination of suppliers reliability indicators in tourism enterprises and hotels; determination of indicators of the availability of human resources in tourism enterprises and hotels; determination of the uniqueness of the product and services in tourism enterprises and hotels; determination of the indicator of the potential of the product and services in tourism enterprises and hotels; determination of consumer loyalty indicator in tourism enterprises and hotels; determination of the indicator of accessibility of contracts with clients in tourism enterprises and hotels.

- identified and calculated integrated and integration indicators of tourism enterprises and hotels in the following direction: a mathematical integrated assessment of the readiness of the external environment adopted for the implementation of innovations in tourism enterprises and hotels; determined the values of increasing indicators for each level of external factors on the activities of the integrated structure of tourism enterprises and hotels; the values of decreasing indicators were determined for each level of external factors acting on the activity of the integrated structure of tourism enterprises and hotels; the correlation of the influence of environmental factors on tourism enterprises and hotels is given; An integral indicator of the effectiveness of marketing activity in tourism enterprises and hotels has been determined.

- developed a block diagram of the formation of a regional strategic alliance in the tourism market and the hotel business; given a block diagram of the types of regional integration and integrated associations in the tourism market and hotel business; developed a block diagram of factors affecting the development of event marketing in the tourism market and the hotel business; a model has been developed for integrating the regional tourism industry into the hotel services system, which includes the subsystem: streaming, the interaction of objects and regulators.

\section{References}

- Antones V.Q. Marketing strategy for the development of industrial tourism. Autocan. Donetsk: LSU. 2017, $30 \mathrm{p}$.

- Agaeva A.N., Vasilchenko T.Z. Comparative characteristics of marketing research methods // Bulletin of BUPK, No. 1, 2011.

- Artomova E.N., Kozlova V.A. The basics of hospitality and tourism. Eagle: GTU. 2005, - 104 p.

- Almosov S.M. Hotel business. M., Laboratory book. 2011.- 94 p.

- Abdulov A.V. The use of information technology in the hotel industry. // Collection. Omsk: OMIS. 2015, p. 45-46.

- Bezrutcenko Y.V. Marketing in social and cultural services and tourism. M .: Dashkov and K. 2016, - 232 p. 


\title{
Determination of Correct Lighting Based on Fuzzy Logic Model to Reduce Electricity in the Workplace
}

\author{
Ph.D. Candidate Rahib Imamguluyev (Odlar Yurdu University, Azerbaijan)
}

\begin{abstract}
Today, awareness of electrical systems is almost one of our main needs. Reducing our energy consumption by ensuring energy efficiency in such a widely used system provides savings that will affect the economy and the life of energy sources, both economically and in terms of energy efficiency. The difference between electricity generation and the amount of electricity required in the last few years has been a cause for concern. In recent years, due to the increase in electricity prices, the steering committees of various organizations have begun to consider various ways to reduce electricity prices, and in this regard, attention should be paid to the basic lighting system. By applying healing methods or using new technologies without reducing production and switching to more efficient use of energy. Improving energy efficiency is more economical than investing in new energy sources. Energy saving in lighting is to provide good lighting conditions without compromising the quality of light. It is possible to achieve the same level of lighting with energy consumption, as good lighting will be provided by more efficient lighting elements. With efficient lighting, there will be less electricity consumption and eye health will be protected. This article discusses the application of a lighting system based on a fuzzy logic model to reduce electricity costs in offices.
\end{abstract}

\section{Introduction}

Lighting is an essential necessity in our daily lives and the most common type of energy used in lighting today is electrical energy. Efficiency is the ratio of the received light energy to the electricity consumed in the lighting systems operating with electrical energy.

Providing energy efficiency in lighting goes through small details. For example, incandescent lamps that we use in daily life use large amounts of electrical energy to convert most of this energy to heat energy, thereby emitting unnecessary energy by emitting heat. By replacing these lamps with fluorescent or LED lamps (Ağan, Y.,.2005) with less energy loss, we reduce energy consumption and provide efficiency in lighting energy.

In addition, savings in lighting systems can be achieved with energy management. Lighting systems can be provided by creating technology control systems based on GPRS, GSM or SCADA. In this way, energy savings can be achieved by eliminating dead time in lighting times.

Energy saving in lighting can be achieved by using high efficiency light sources instead of low efficiency light sources and by taking some simple measures. The important thing here is to show the necessary attention to the subject. Some of these measures can be listed as follows:

1. High efficient ones should be preferred when purchasing a lamp. Lamp selections should be made based on the highest lumen / watt ratio (efficiency factor).

2. Unused areas should not be illuminated.

3. Daylight should be used as much as possible.

4. Lighting fixtures should be periodically maintained. Dirty and dusty fixtures absorb some of the light and cause inefficient lighting.

5. Lamp light output should be used efficiently. Whether the lamp light output reaches the surfaces to be illuminated at the maximum rate is one of the most important factors affecting the efficiency of the lighting system.

6. Controlling lighting through timers, photocells or proximity sensors is important for energy savings.

7. Wall, ceiling and decoration materials should be selected as light as possible.

8. In sections where more light is needed, using a single high power lamp instead of many low power lamps provides more efficient lighting.

9. Care should be taken to use small powerful bulbs in stair lighting.

10. Decorative lamps send light in undesirable directions. Light-colored, transparent shade lampshades transmit light better.

11. Lamps should be turned off when leaving the room.

12. Table lamp should be used while working.

13. Fluorescent bulbs should be used instead of halogen and normal bulbs to prevent energy loss. Thus, $40 \%$ energy savings can be achieved.

14. The use of compact fluorescent lamps instead of incandescent lamps saves up to $80 \%$ energy (Çolak, N., 2003).

15. In road lighting, if high pressure sodium vapor lamps are used instead of high pressure mercury vapor lamps, approximately $60 \%$ savings are achieved at the same level of illumination. 
16. In garden and environmental lighting, if low pressure sodium vapor lamps are preferred instead of high pressure mercury vapor lamps, approximately $70 \%$ energy savings can be achieved at the same level of brightness (Daylighting Control, 2020).

\subsection{New Energy Economy}

With the transformation of energy, there is also an evolution in the energy economy.

Green economy is defined as the economy that aims to reduce environmental risks and ecological scarcity and aims at sustainable development without harming the environment. In the report published by the United Nations Environment Program (UNEP) in 2011, the concept of green economy is defined as "Policies aimed at reducing environmental risks and improving ecological wealth significantly by ensuring the welfare and social equality of humanity".

Looking at it, many environmental activists see capitalism as an enemy. While the debates are endless, we must admit that the economy and society are actually intertwined in today's capitalist world. In this period when society is slowly reorganizing and adopting environmental reforms, we cannot think of the economy as a natural consequence behind it. Ideas such as the 'green economy' are also proof that these two factors are actually parallel.

Energy economy, on the other hand, refers to the study of the supply and use of energy. This also includes the impact of energy consumption.

Many companies claim to have a green energy plan today. Actually this has almost become a trend. However, we can say that technology is not progressing or catching up with the trend. For the dream of a green economy to be possible, there must be some important developments in technology.

According to the US Energy Information Administration, World Energy Consumption in 2013 was $5.67 \times 1020$ joules. Hydrocarbons are responsible for providing more than $80 \%$ of energy worldwide. However, solar and wind energy constitute only $2 \%$ of global energy.

For a full transition to renewable energy, we need a 90 -fold increase in production over the next two decades. In this table, Canada, USA and Saudi Arabia, which are among the leading countries in the world, have the highest per capita energy demand today.

The new energy economy will have three levels of impact. These; Individuals, companies and governments. Looking at it, these three factors have a large direct impact on our lives. As we move towards this new economy, we must prepare ourselves for the changes that will arise from all three.

It has long been known that energy consumption is linked to economic growth. Since 2018, the demand for energy is actually due to climate change. The number of extremely hot or extremely cold days has increased, resulting in dependence on air conditioning. Therefore, we can say that climate change directly drives the economy.

New reforms in energy will regulate national economies for many countries with high solar and wind potential in the long run. Especially the end of fossil fuel use is very close; Conscious actions towards clean technology will benefit the country and its citizens environmentally. For this reason, the new energy economy is one of our main factors that we need to focus on.

Nowadays, we can think of startups as new superpowers. For this reason, we should head towards green energy together with these entrepreneurs. Because most of the interest of investors in green energy comes from these companies. We hope this trend continues and is supported.

The batteries produced annually by Tesla Gigafactory can now store three minutes of the annual electricity demand of the US. Storage of energy that can be provided by a 300-pound barrel requires 20,000 kilos of Tesla batteries. However, the interest shown by companies such as Tesla has led many investors and entrepreneurs to consider capitalist energy companies. This change has led to the emergence of many innovative energy solutions such as energy storage facilities and artificial intelligence powered microgrids. The journey to the green economy is still long. As individuals begin to embrace green energy, it is inevitable for companies to eventually follow the same path (Zahide Kaplan, 2020).

\section{Lighting Control Systems}

From an economic point of view, the increase in the types and number of fixtures used in lighting systems has made lighting control very difficult. Lighting control systems are used to facilitate the control of lighting devices and to make the most efficient use of lighting (Uyanik, M., Saribas, N., 2005).

The intended use of lighting control systems can be grouped under four main headings.

1. Efficiency

2. Energy Saving

3. Aesthetics

4. Flexibility

The most important benefit of lighting control is energy saving. Lighting control can save $30 \%$ in energy consumption and $10 \%$ in operating costs. A comfortable working environment is created with a correctly selected 
and implemented lighting control system. In addition, efficiency of the employees will increase with an appropriate lighting control (IEA Task 21, 2020).

In areas such as meeting rooms, design offices, textile workshops, factories, lighting control is very important for the highest level of work efficiency. With a well-programmed lighting automation system, it is possible to provide the highest level of work efficiency with the most suitable light level according to the working hours, the location of daylight and the nature of the work performed in such work areas. Lighting automation systems, sudden lighting programs according to the function by making changes in a very short time, it also eliminates the loss of time due to lighting adjustments.

Thanks to the dimmer units used in lighting automation systems, it is possible to save energy and extend the lifetime of the light sources as the lighting is reduced.

Light sensors to make maximum use of daylight, motion detectors to prevent energy consumption in areas where no one is available, astrological time clocks are integrated into the lighting automation system in order to be able to economically program environmental lighting to regulate lighting control according to working hours and environmental lighting. can be saved. In addition, energy savings can be achieved by automatically activating different lighting programs for times when electricity is expensive or inexpensive (Zhang, L., Yu, Y., Ma, H., Zhang, Y., Cao, P., 2018).

In places where there are no regular working hours and the lamps are left open when not in use, significant energy savings are achieved by controlling the lighting with motion sensors. With this method; Energy savings reaching $20 \%$ in open offices, $60 \%$ in personal offices, $70 \%$ in toilets, $40 \%$ in warehouses, $50 \%$ in classrooms and $65 \%$ in toilets in hotel rooms can be achieved (Cziker, A., Chindris, M., Miron, A., 2007).

A well-designed and daylighting lighting system saves $30 \%$ of lighting energy during the bright hours of the day. However, with the application of the saving methods mentioned below, this rate can reach $70 \%$.

- Application of time clock to the system and use of lighting only when necessary with access control systems.

- Use of motion detectors in areas with low personnel density.

- System dimmers working in harmony with daylight with the use of light level sensors.

- The light control system, when energy use reaches peak values, shuts down or diminishes insignificant areas (Lighting Controls Association, 2020).

\section{Calculation of Office Lighting}

\subsection{Lighting Account}

Various data and calculations are used for correct lighting. (Cao, C., Zhu, X, 2018) The tables given to you here are in the form of sampling. With these data, you can make more specific applications. Illumination calculations and factors of a place are explained step by step below (Cziker, A., Chindris, M., Miron, A.,2007).

\subsection{Reflection Coefficients of Important Substances}

In the table below, the reflection coefficients of some materials according to their color status are given. You can use these coefficients in the calculation.

\begin{tabular}{|l|c|l|c|}
\hline Material & $\boldsymbol{\%}$ & Wall Paints & $\%$ \\
\hline Dark & $0,10-0,20$ & Oak Light Color & $0,25-0,35$ \\
\hline Brown & $0,60-0,70$ & Chipboard Cream Color & $0,50-0,60$ \\
\hline Light yellow & $0,45-0,55$ & Plaster & 0,90 \\
\hline Light green & $0,30-0,50$ & Anodized Aluminum & 0,85 \\
\hline Light red & $0,35-0,45$ & Concrete & $0,10-0,50$ \\
\hline Sky blue & $0,70-0,90$ & Glass-Silver-Moon & $0,85-0,90$ \\
\hline White & $0,45-0,55$ & Granite & $0,20-0,25$ \\
\hline Pink & $0,40-0,60$ & White Marble & $0,60-0,65$ \\
\hline Light grey & $0,20-0,30$ & Lime whitewash & $0,40-0,45$ \\
\hline
\end{tabular}

Table 1. Reflection Coefficients of Some Materials and Wall Colors 


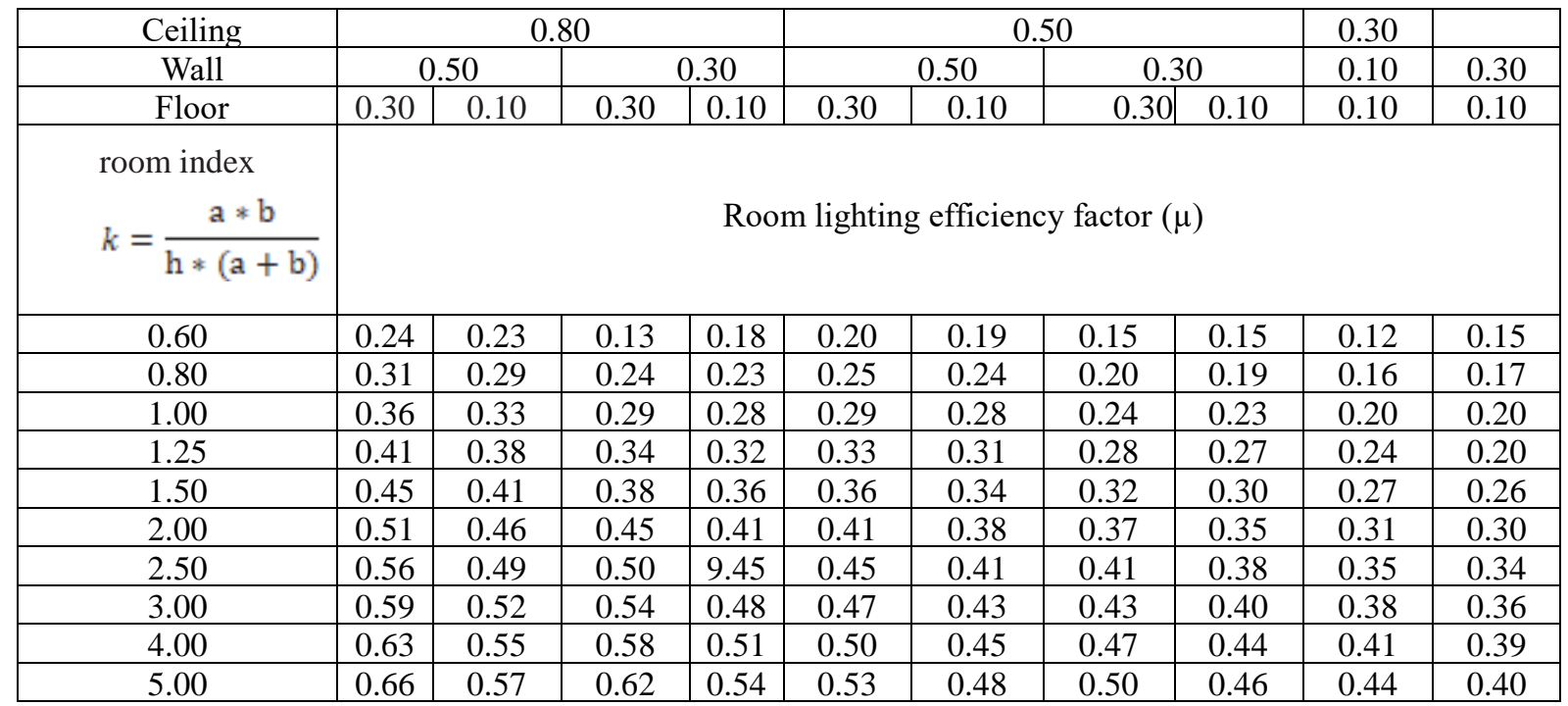

Table 2. Room Lighting Efficiency According to $k$ Values $\mu$

\subsection{Lighting Account Formulas}

$\mathrm{k}=$ room index

$\mathrm{a}=$ short edge length of the room

$\mathrm{b}=$ long edge of the room

$\mathrm{H}=$ height between armature and working surface

$$
k=\frac{a * b}{H *(a+b)}
$$

Using these values, the room index $\mathrm{k}$ value is calculated. When each luminaire is installed in place, the lamp is usually 20 to $60 \mathrm{~cm}$ below the ceiling. B type luminaires do not have a distance, but for example for chandeliers, rod length can be taken as $60 \mathrm{~cm}$. The working plane is generally considered to be $70-80 \mathrm{~cm}$ from the table length. In the sitting plane, 50 - $60 \mathrm{~cm}$ can be considered (Görgülü, S., Ekren, N., 2013).

\section{Practical Application of Fuzzy Technologies}

When both input and output are used with membership functions, conventional expressions between them are drawn up in this form: If (input UF x), then (output UF y). For example, "if the color is too dark, then the cost of success is very low". In the general approach, the model can have more than one input parameter and must be combined with the AND, OR, NO .T (Zadeh, Lotfi A., 1994). The parameters and rules are unstable, they can be changed under different conditions, which increases the model's usability. In the fuzzy process, each rule is evaluated to determine the output, and in the end the Fuzzy Inference System is the average of all outputs "Figure 4." In this way, each design work is done with a quantity that indicates that it is ultimately successful in terms of time and quality. This value is in the range [0 100] "Figure 3." When the process is complete, a list is created and can be used for visualization. It is possible to implement the model based on the values given in "Table 2".

The MATLAB program has developed a logical system with 3-inputs "Figure 1." 1 output "Figure 2." type and a fuzzy logic with 18 conditional constraints.

Input settings:

1) "Ceiling"

2) "Wall "

3) "Floor"

The output parameter is one: Value. 


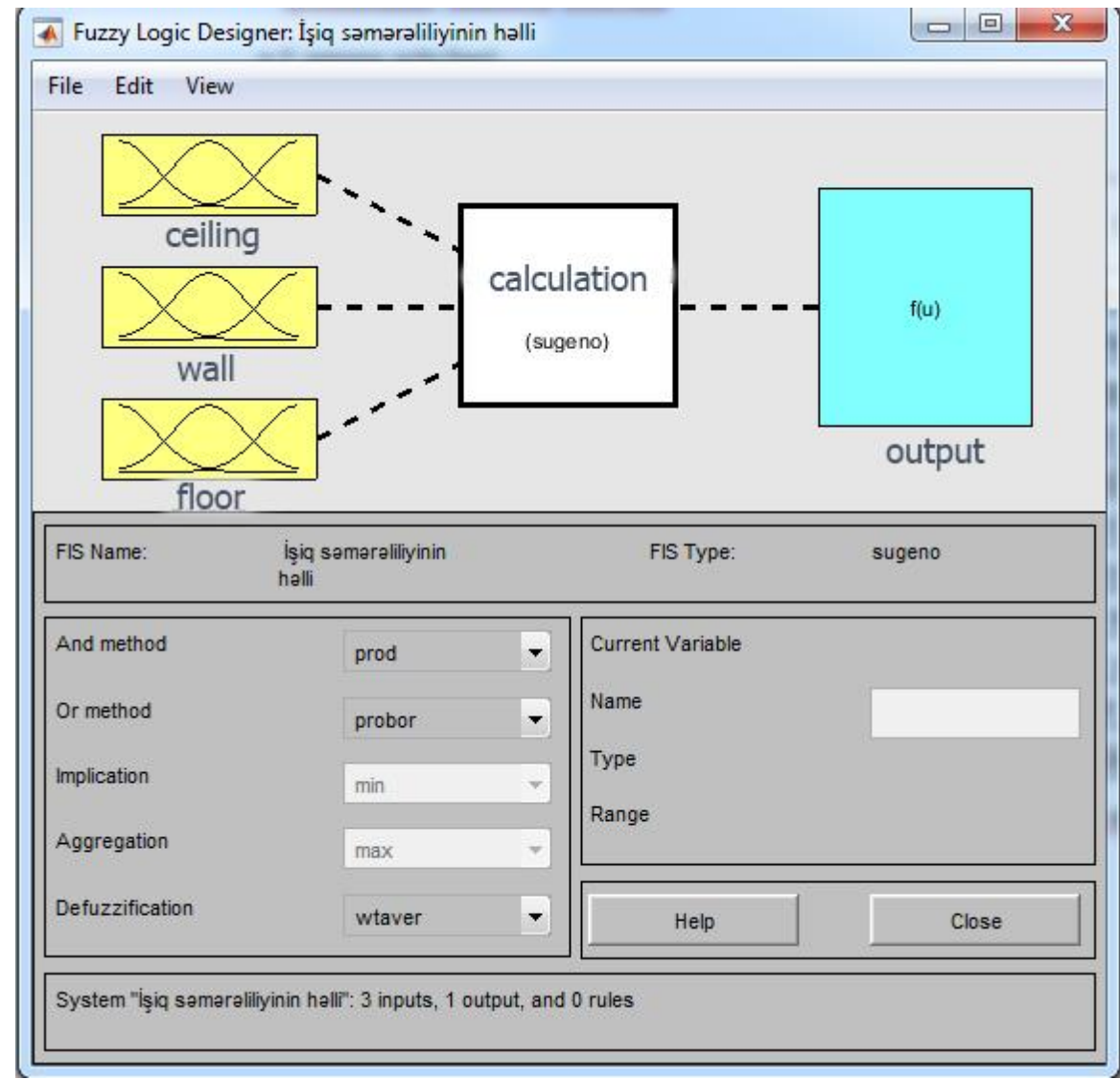

Figure 1. Input FIS-Editor Window

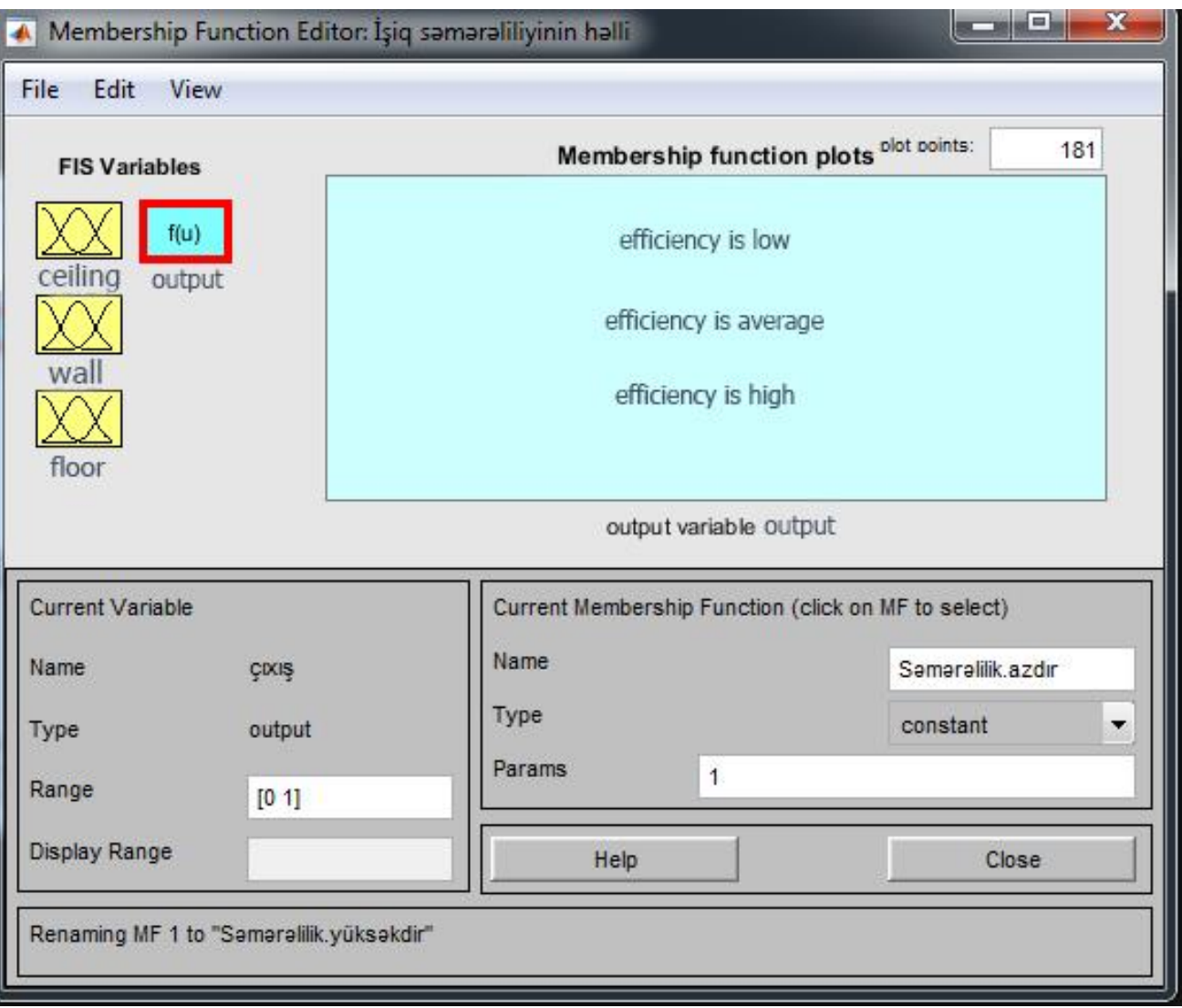

Figure 2. Output FIS-Editor Window 


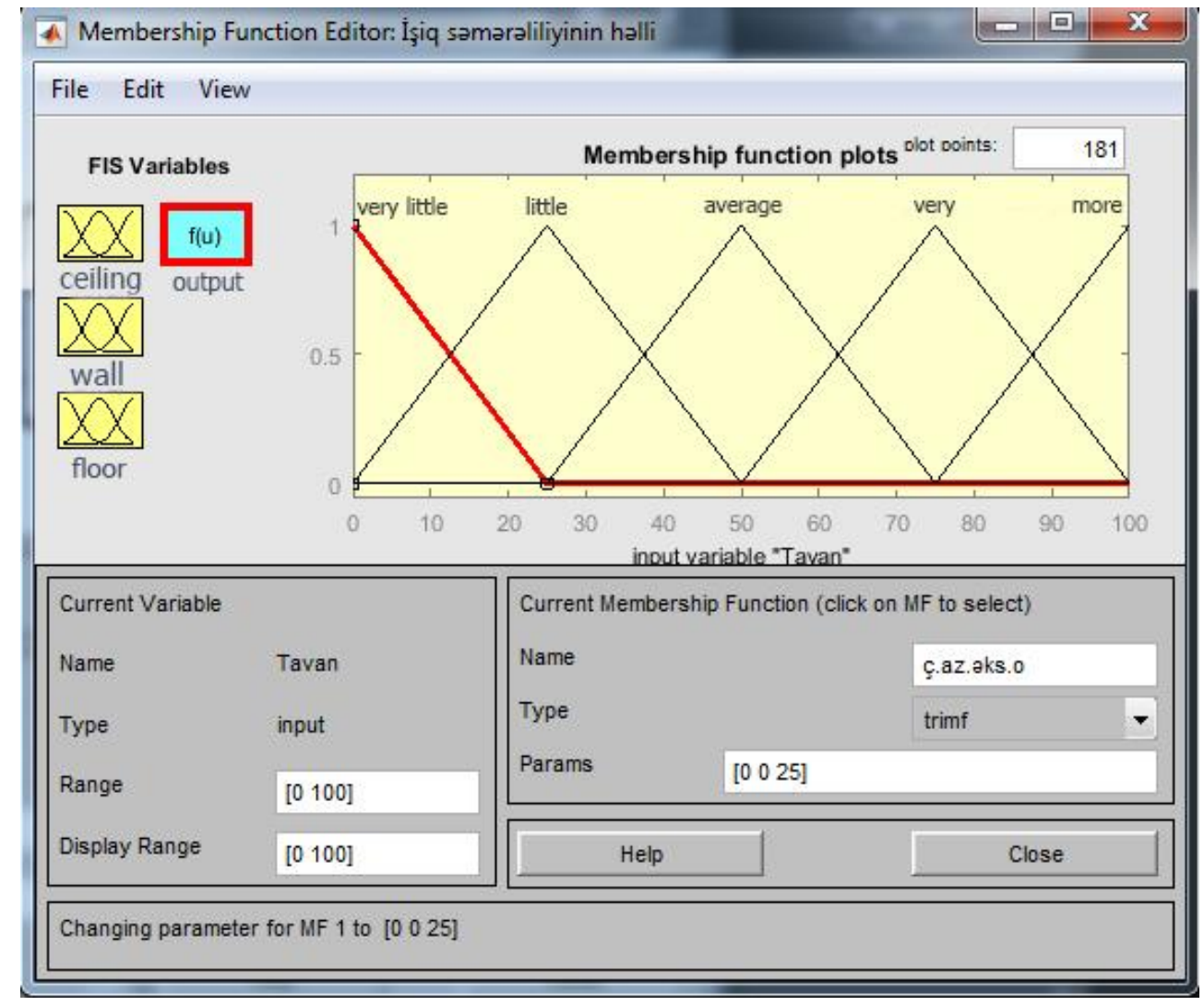

Figure 3. For the Application of Criteria Fuzzy Member Functions Edit Window

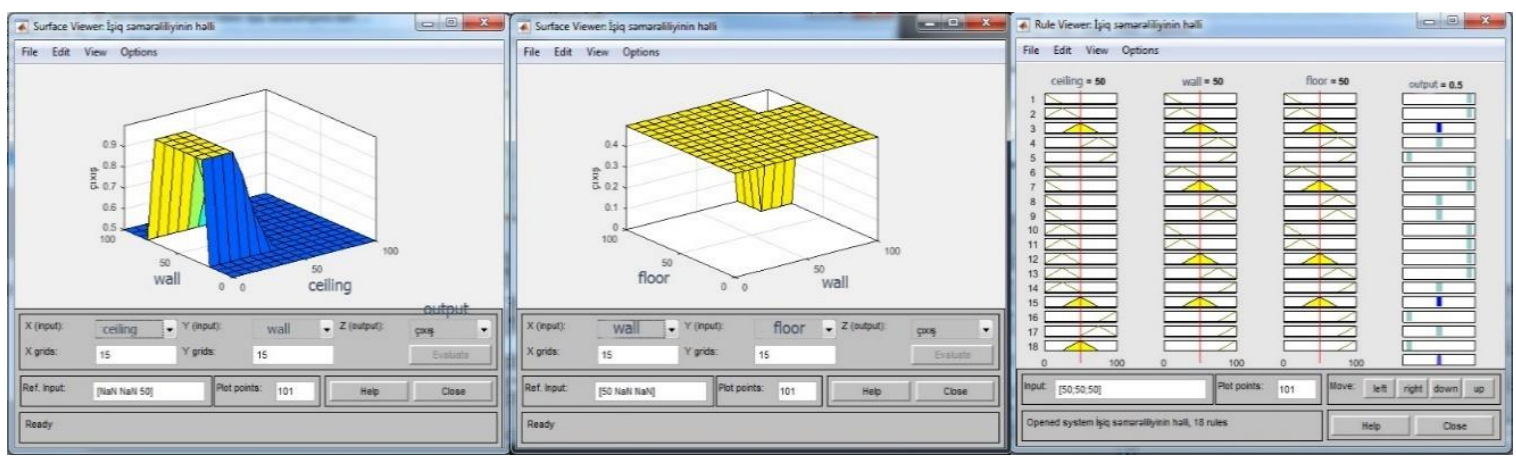

Figure 4. The Window of Fuzzy Rules

\section{Conclusion}

The application and innovation of energy efficient methods is a challenge for everyone. By reducing light scattering, higher levels of light production can be achieved without an increase in energy levels. Particular attention should be paid to energy saving with a clever combination of daylight and artificial light. When choosing lamp types, it should be noted that the efficiency factor has the highest efficiency classification and thus increases the level of high energy distribution with low energy levels. Developments in LED lighting technology need to be closely followed. Thus, it is recommended that all light reflection rates of colors be calculated based on a fuzzy logic model.

\section{References}

- $\quad$ Ağan, Y., LED Teknolojisi İle Aydınlatma Sanatı, İnşaat Dünyası Dergisi, Ekim 2005.

- Cao, C., Zhu, X.: Energy Management using Optimal Fuzzy Logic Control in Wireless Sensor Network. International Journal of Online and Biomedical Engineering 14(9), 35-52 (2018).

- Çolak, N., Hareket Sensörleri ile Aydınlatmanın Kontrolü, 3e Electrotech Dergisi, Sayı 105, Şubat 2003

- Cziker, A., Chindris, M., Miron, A.: Fuzzy Controller for Indoor Lighting System with Daylighting Contribution. In: ELECO'2007 5th International Conference on Electrical and Electronics Engineering. Turkey, (2007). 
- Cziker, A., Chindris, M., Miron, A: Implementation of Fuzzy Logic in Daylighting Control. In: 11th International Conference on Intelligent Engineering Systems, pp. 195-200. INES, (2007).

- Daylighting Control, Design and Application Guide, https://www.legrand.us//media/brands/wattstopper/resources/application-guide/ws-appguide-daylightingcontrol.ashx, last accessed 2020/04/30.

- Görgülü, S., Ekren, N.: Energy Saving in Lighting System with Fuzzy Logic Controller Which Uses LightPipe and Dimmable Ballast. Energy and Buildings 61, 172-176 (2013).

- IEA Task 21, Application Guide for Daylight Responsive Lighting Control, https://www.ieashc.org/Data/Sites/1/publications/8-8-1\%20Application\%20Guide.pdf, last accessed 2020/04/30.

- Lighting Controls Association, Introduction to Lighting Automation, http://lightingcontrolsassociation.org/2005/02/14/introduction-to-lighting-automation-for-the-home/, last accessed 2020/04/30.

- $\quad$ Rea, M.S.: IESNA Lighting Handbook. 9th edn. Illuminating Engineering (2000).

- Türk Mühendis ve Mimar Odaları Birliği, Enerjinin Etkin ve Verimli Kullanılmasının Ana Hatları, Şubat 2005 , s. 21-22.

- Uyanık, M., Sarıbaş, N., Aydınlatmada Enerji Verimliliği - Balast İlişkisi, 3e Electrotech Dergisi, Sayı 129, Şubat 2005.

- Zadeh, Lotfi A.,: Fuzzy Logic, Neural Networks, and Soft Computing, Communications of the ACM(37), 7784(1994).

- Zahide Kaplan: Yeni Enerji Ekonomisi Hakkında Bilmeniz Gereken Her Şey, elektrikport.com (2020).

- Zhang, L., Yu, Y., Ma, H., Zhang, Y., Cao, P.: Design of Photovoltaic Power Supply MPPT Circuit for WSN Node Based on Current Observation. International Journal of Online Engineering 14(7), 45-61 (2018). 


\section{Author Index}

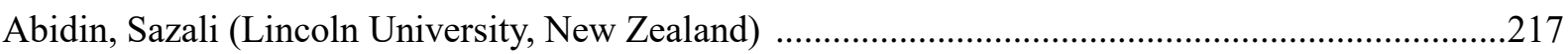

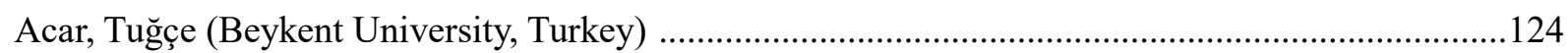

Aksakall1, Ayşe Sena (Bilkent University, Turkey) .............................................................................162

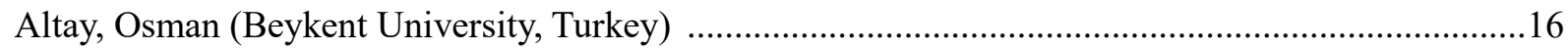

Aseinov, Dastan (Kyrgyz-Turkish Manas University, Kyrgyzstan) ...................................................152

Avcil, Seniha (Memorial Şişli Hospital, Turkey) ..............................................................................76

Baigonushova, Damira (Kyrgyz-Turkish Manas University, Kyrgyzstan) ...............................136, 247

Bal, Hakan (Beykent University, Turkey) …….........................................................................23

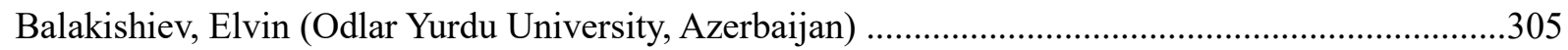

Balc1lar, Mehmet (Eastern Mediterranean University, TR of Northern Cyprus) .....................................1

Bozkurt, Gözde (Beykent University, Turkey) …………….........................................................115

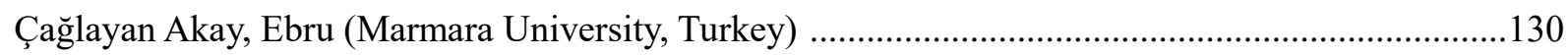

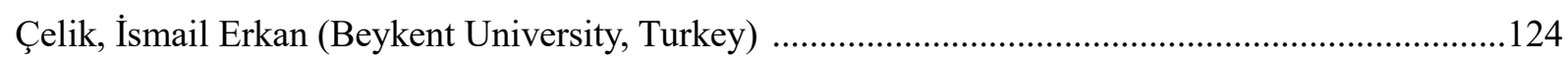

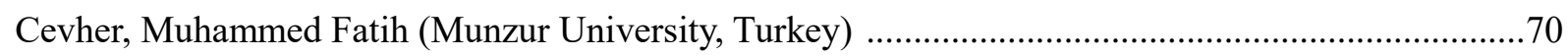

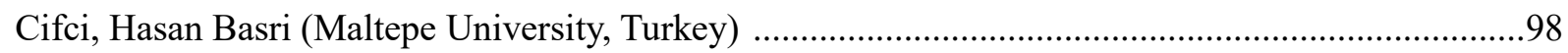

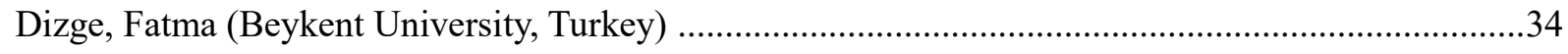

Dzhailov, Dzhumabek (Ministry of Agriculture, Kyrgyzstan) ........................................................240

Dzhailova, Asel (State Service for Regulation and Supervision of the Financial Market, Kyrgyzstan)

255

Ekwueme, Daberechi Chikezie (Eastern Mediterranean University, TR of Northern Cyprus) ..........207

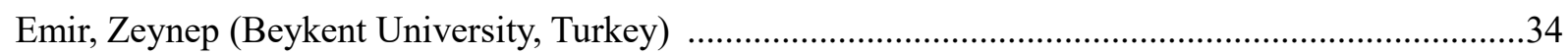

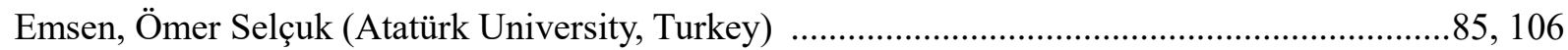

Fynchina, Khicheza (Kyrgyz-Russian Slavic University, Kyrgyzstan) ............................................261

Gahramanov, Ilkin (Odlar Yurdu University, Azerbaijan) ...................................................................311

Ganiev, Junus (Kyrgyz-Turkish Manas University, Kyrgyzstan) ...........................................136, 247

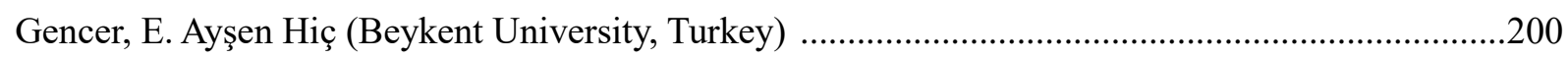

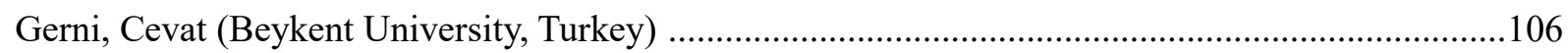

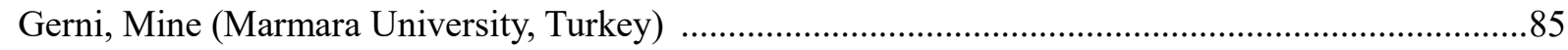

Hotar, Nükhet (Dokuz Eylül University, Turkey) …………...............................................................

Ibrahimova, Khayala (UNEC- Azerbaijan State University of Economics, Azerbaijan) ....................280

Imamguluyev, Rahib (Odlar Yurdu University, Azerbaijan) .............................................................. 317

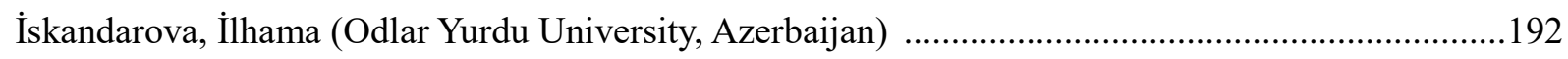

İsmayilov, Ramin (Odlar Yurdu University, Azerbaijan) ..................................................................292

Japarova, Damira (Kyrgyz-Turkish Manas University, Kyrgyzstan) ................................................230

Kamalova, Anara (Kyrgyz National University, Kyrgyzstan) ........................................................225

Kocarieva, Cinara (Odlar Yurdu University, Azerbaijan) .................................................................298 
Kolçak, Menşure (Atatürk University, Turkey)

Kozhoshev, Arzybek (State Service for Regulation and Supervision of the Financial Market,

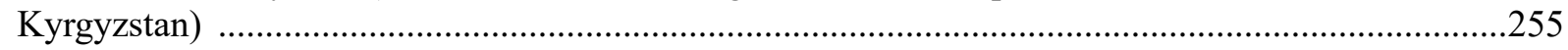

Maksüdünov, Azamat (Kyrgyz-Turkish Manas University, Kyrgyzstan) .........................................143

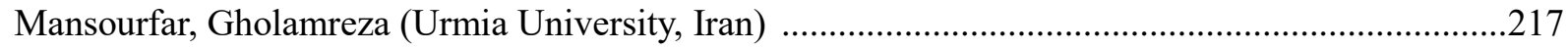

Mikailova, Rana (UNEC- Azerbaijan State University of Economics, Azerbaijan) ............................195

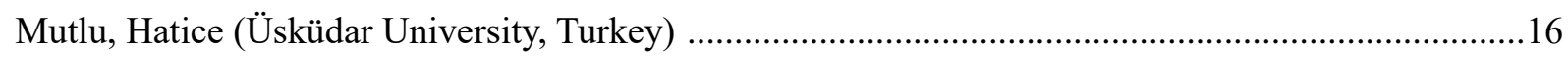

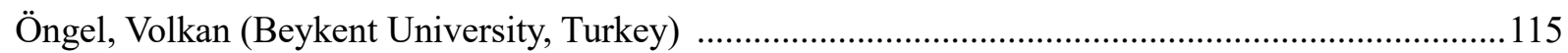

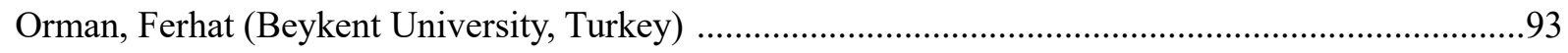

Oskonbaeva, Zamira (Kyrgyz-Turkish Manas University, Kyrgyzstan) ............................................130

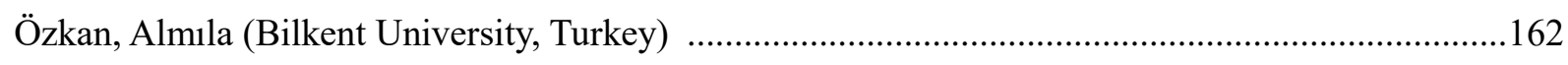

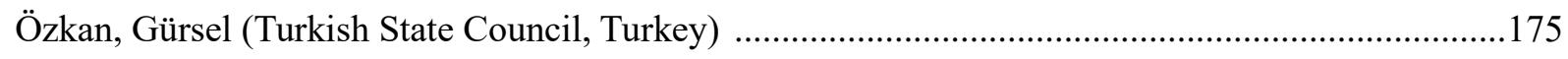

Pirimbaev, Jusup (Kyrgyz-Turkish Manas University, Kyrgyzstan) ...............................................136

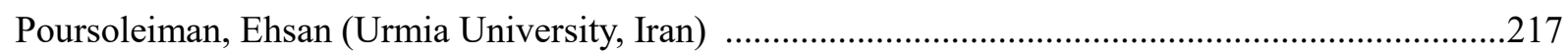

Rahmanov, Farhad (Azerbaijan State Economy University, Azerbaijan) ……..........................271, 280

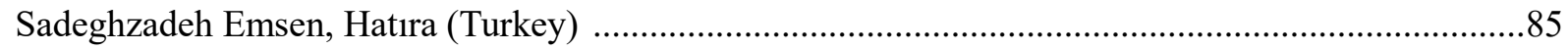

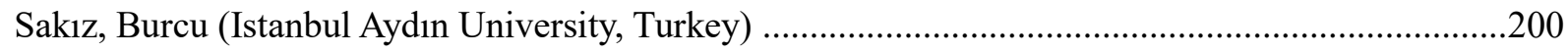

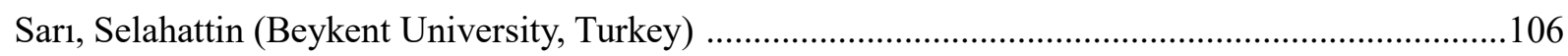

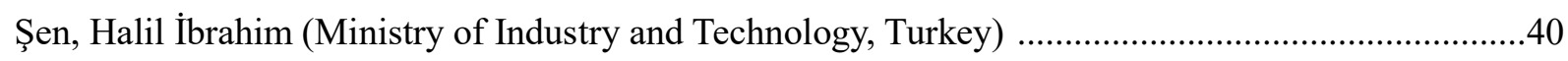

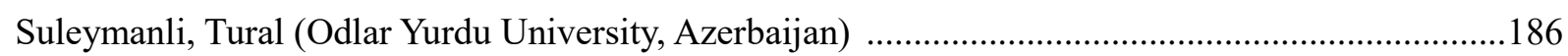

Suleymanov, Elchin (Baku Engineering University, Azerbaijan) ...........................................271, 280

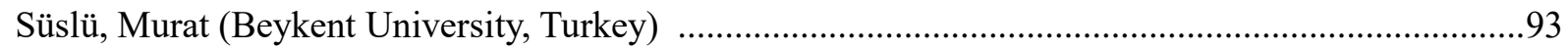

Taşkın, Erdoğan (Beykent University, Turkey) ..............................................................................70

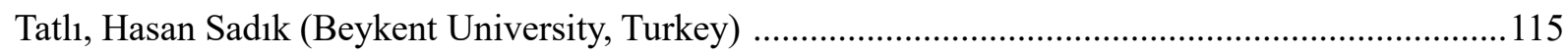

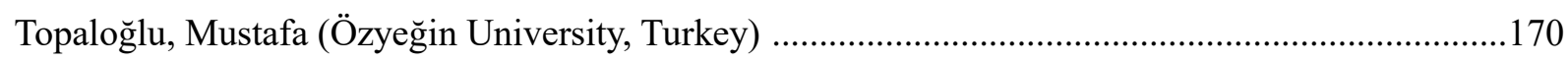

Tufaner, Mustafa Batuhan (Beykent University, Turkey) …........................................................29, 34

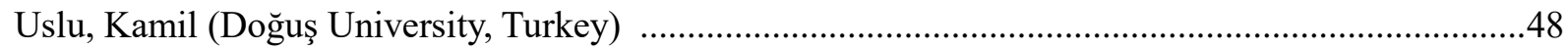

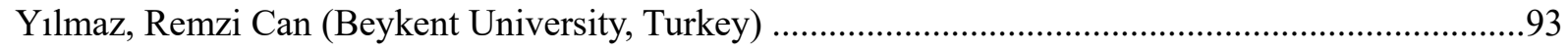

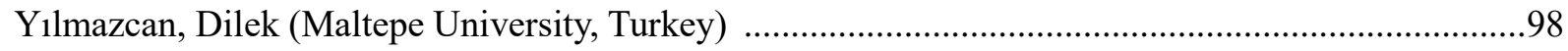

Yurttançıkmaz, Ziya Çağlar (Atatürk University, Turkey) ........................................................85, 106 
